

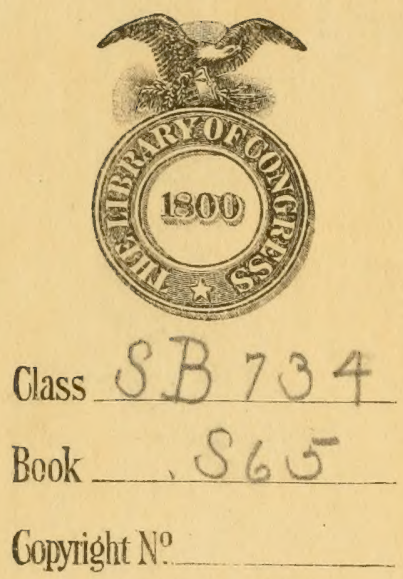

COPYRIGHT DEPOSIT. 








\title{
AN INTRODUCTION TO
}

\section{BACTERIAL DISEASES OF PLANTS}

\author{
BY \\ ERWIN F. SMITH \\ In Charge of Laboratory of Plant Pathology, \\ Bureau of Plant Industry,
}

United States Department of Agriculture, Washington, D. C.

Member of the National Academy of Sciences and of the American Academy of Arts and Sciences; Fellow of the American Philosophical Society; Ex-President: Society for Plant Morphology and Physiology (I90I), Society of American Bacteriologists (I906), Botanical Society of America (1910), American Phytopathological Society (Igr 7 ), etc.

Ecrire l'histoire d'une science nouvelle, c'est se vouer à d'éternels recommencements.-Madame Duclaux.

\section{PHILADELPHIA AND LONDON \\ W. B. SAUNDERS COMPANY \\ 1920}




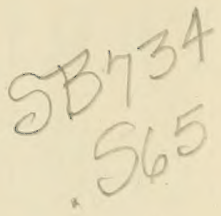

Copyright, 1920, by W. B. Saunders Company

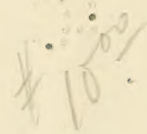

PRINTED IN AMERICA

NOV -91920

(2) 4604016 
To the memory of Charles F. Wheeler and Volney M. Spalding: modest American men of science, strong idealists and splendid teachers.

Wheeler was born in New York; studied in Mexico Academy and the University of Michigan; served in the Civil War; was 20 years in a Michigan country drugstore, which he made a center of fine intelligence; was instructor in botany in the Michigan Agricultural College for 12 years; and, finally, for $S$ years research worker in the United States Department of Agriculture.

Spalding was born in New York; pursued high school and academic studies in Ann Arbor, Nichigan; was teacher of botany in the Lniversity of Michigan for 28 years, broken only by studies in Germany under Detmer, Pfeffer and Brefeld; was investigator for 6 years in the Carnegie Desert Laboratory at Tucson, Arizona; and, finally, endured a long period of forced inaction in Southern California, retaining, however, his clear mind and his seientific interests to the end.

Wheeler studied critically the flora of a State, Spalding changed the type of botanical teaching in our secondary schools. Each was my friend for nearly 40 years. The first showed me how to study flowering plants, opened my eyes to the wonders of wood and field and was my companion in a thousand delightful rambles. From him I had also my first lessons in French. The second taught me how to study the parasitic fungus and where to find its literature, of ten reading it with me when it was in foreign tongues. Each was devoted to the microscope and to the laboratory method. Each served his generation faithfully and now sleeps with his fathers.

They reached a multitude of students whose gratitude remains, and so, in the lovely words of Simonides, they lie

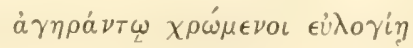





\section{PREFACE}

THE manuscript of this book was completed for publication in 1915 and, in general, that year may be taken as the date of the outlook, but here and there, where it seemed most necessary, it has been revised down to the end of 1919 .

Those who seek for completeness in these pages will not find it. The book is in no senes a monograph, but only, as its title indicates, an introduction to the subject.

While the book has been made primarily for laboratory use under the guidance of a competent teacher, who will add to it or subtract from it as he desires, it is believed that many persons not students may find in it various things of interest, and partly with this wider public in view it has been illustrated very fully.

This book is the result of 35 years of reading and 25 years of diligent laboratory and field investigation. More than most books, it is the product of experiment. There is scarcely a line or a statement in it that has not required more than one experiment. It is also largely the product of a single laboratory, that is to say, 8 of the 14 organisms here selected for special study were named by the writer (one with a colleague), two were worked out by others in his laboratory (Bacillus carotovorus and Bacterium maculicolum), and of the remaining four, all of Appel's statements have been verified with additions under Bacillus phytophthorus, many additions have been made to Pammel's statements under Bacterium campestre, the entire body of description has been worked up for Bacterium mori, and some additions have been made to Bacillus amylovorus. Moreover, all but 35 of the 650 illustrations are from this laboratory.

A majority of the photographs in the book were made by James F. Brewer and the remainder by the writer. Frequently we worked together. In case of particularly good 
photographs involving special technic I have sometimes mentioned the maker and the method used, since every student should learn to make his own photographs and photomicrographs if he wishes to excel. Nearly all the photomicrographs were made on the lit.tle upright stand (Fig. 55) because I wished to demonstrate to the student that excellent results can be obtained with very simple apparatus if one is only willing to take pains.

The book was written at the earnest request of teachers and by their judgment it will stand or fall. It is the first treatise of its kind in the world and, therefore, I trust, that evidences of crudity will be excused. Not being a teacher, I have been in doubt many times how best to present the difficult subject.

I shall be glad to receive criticisms and suggestions looking toward a second edition and also notes, photographs, cultures, fresh and dry specimens and separates of papers from all parts of the world, that I may be able to continue my monographic studies.

Washington, D. C.,

ERIIN F. SMITH. August, 1920 


\title{
CONTENTS
}

\author{
PART I
}

\section{A CONSPECTUS OF BACTERIAL DISEASES OF PLANTS}

Distributiov Among Flowerivg Plants - ot

Period of Greatest Sosceptibility. . . . . . . . . . . . . 8

What Governs Infection . . . . . . . . . . . . . . . . 12

How Infection Occurs . . . . . . . . . . . . . 15

Time Between Infection and Appearance of the Disease. . . . . 16

Recovery from DISEASE. . . . . . . . . . . . . . . . 17

Agents of Transmission. . . . . . . . . . . . . . . 19

Extra-vegetal Habitat of the Parasites. . . . . . . . . . 34

Morphology and Cultural Characters of the Parasites. . . . . . 35

action of the Parasite on the Plant . . . . . . . . . . . 41

Reaction of the Plant-Color-changes, Blights, Decars, Distortions,

Overgrowths. . . . . . . . . . . . . 48

Prevalence and Geographical Distribution . . . . . . . 51

Methods of Control. . . . . . . . . . . . . 68

\section{PART II}

\section{METHODS OF RESEARCH}

Reference Books. . . . . . . . . . . . 76

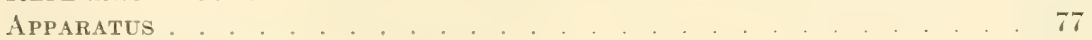

For Preparation of Culture Media . . . . . . . . . 77

For Isolation and Care of Cultures. . . . . . . . . . . . . . 80

For Preparation and Study of Sections . . . . . . . . . . 81

For the Hot House and Inoculation Experiments. . . . . . . . . . . sti

For the Photographic Room. . . . . . . . . . . . . . 89

Uses of Culture Media _.. . . . . . . . . . . . . 99

Preparation of Culture-Media . . . . . . . . . . . . . 100

Technic of lsolatica. 107

Care of Cultures 109

Study of Cultures . . . . 110

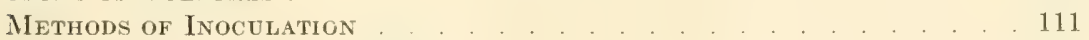

Time and Place of Inoculation . . . . . . . . . . . 112

Care of Inoculated and Control Plants. . . . . . . . . . . . . 113

Preparation of Sétions . . . . . . . . . . . . . . . . 114 
Stainjag Methods . . . . . . . . . . . . . . . . . . 116

Care of Spectmens . . . . . . . . . . . . . . . . . . . . . 119

Preparation of Illustrations. . . . . . . . . . . . . . . . 120

Photographs . . . . . . . . . . . . . . 120

Photomirographs . . . . . . . . . . . . . . . . . 12:3

Lumière Plites . . . . . . . . . . . . . . . . 126

Planats. . . . . . . . . . . . . . . . . . . . . . . . . . 26

Drawings. . . . . . . . . . . . . . . . . 126

Paintings . . . . . . . . . . . . . . . . . . . . . . . . . . . . . . .

Card Catalogues and Systems of Filing. . . . . . . . . . . . . 130

PART III

SYNOPSIS OF SELECTED DISEASES

I. The C'vertrit Whit $\ldots \ldots$

Trpe . . . . . . . . . 1322

Caune-Bacillus truche iphilus EFs. . . . 132

Technic . . . . . . . . . . . . . . . . .

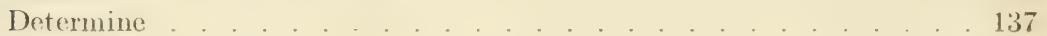

For the Organism . . . . . . . . . . . . 137

Morphology . . . . . . . . . . . . 137

Cultural characters. . . . . . . . . . . . 138

Response to Non-nutritional Environment . . . . . . 139

For the Direase? . . . . . . . . . . . . . . . . .

Sign . . . . . . . . . . . . . . . .

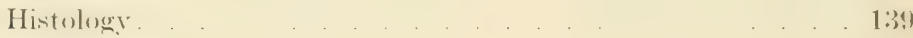

Variability . . . . . . . . . . . . 141

Tran-mision $\ldots 141$

Literature . . . . . . . . . . . . . 145

1I. Black Rot of Cruclfers. . . . . . . . . . . . . 145

Туре. . . . . . . . . . . . . . . . . . . . . . . .

Cause-Bacterium campestre (Pammel) EFS. . . . . . . . . . . 147

Technic. . . . . . . . . . . . . 149

Determine . . . . . . . . . . . . 154

For the Organism . . . . . . . . . . . . 154

Morphology . . . . . . . . . . . . 154

Cultural Characters . . . . . . . . . . 155

Response to Non-nutritional Environment . . . . . . . 155

For the Disease . . . . . . . . . . . . . . .

Signs . . . . . . . . . . . . 156

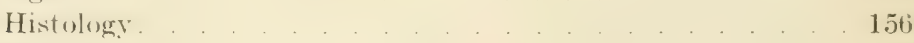

Variability _ . . . . . 157

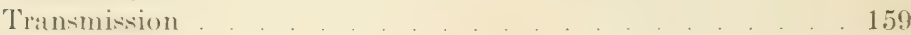

Means of P'revention. . _ . . . . . . . . . . . . . . . .

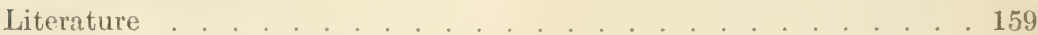

III. Stemart's Disease of Matze. . . . . . . . . . 160

Type . . . . . . . . . . . . . . . . . . 
Cause-Aplanobacter stewarti (EFS.) MeCulloch. . . . . 161

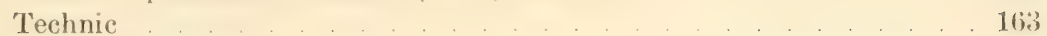

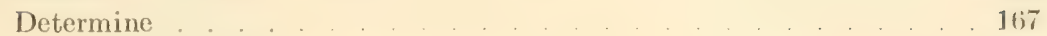

For the organism _. . . . . . . . . . . . . . . . . . .

Morphology . . . . . . . . . 167

Cultural Characters . . . . . . . . . 16s

Response to Non-nutritional Environment . . . . . . . 16s

For the Disease . . . . . . . . . . . . . . . .

Signs. . . . . 169

Histology _ . . . . . . . 170

Variability . . 172

Transmission ......... 17t

Means of Prevention. _. . . . 17ti

Literature. . . . . . . . 176

IV. The Brown Rot of Solanaceae 177

Type . . . . . . . 177

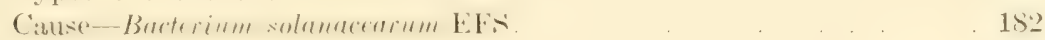

Technic. . . . . 165

Determine . . . . . . . . . . . . .

For the Organism . . . . . . . . . . . . . . . . .

Morphology . . . . . 18?

Cultural Characters _............ 19:3

Response to Non-nutritional Environment _. . 19.5

For the Disease. 19.5

Signs. 19.5

Histologr. . . . . 196 19

Variability . . 19s

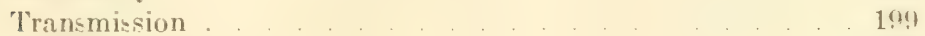

Literature . . . . . 200

V. Bacterial Canker of Tomate. . . 20?

Type . . . . . 202

Cause-Aplanobacter michiganense EFS . . 20.5

Technic. . . . 207

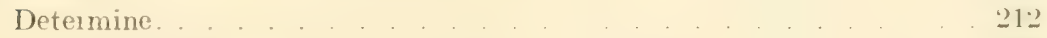

For the Organism _ . . . . . 2 . 2 . 212

Mor phology . 212

Cultural Characters .............. 21:3

Response to Non-nutritional Environment . . . 214

For the Disease . . . . . 21.5

Signs. . . . . 215

Histology . 215

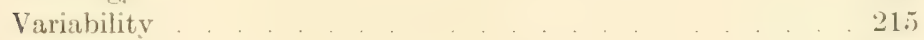

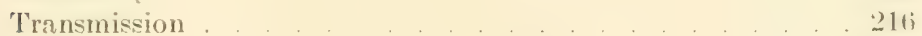

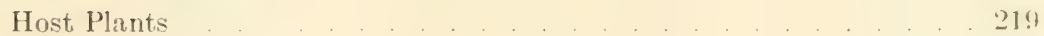

Literature. . . . . . . . . . 2 222

VI. Jones' Soft Rot of Carrot, Etc. . . . . . . . . . . . . . 223

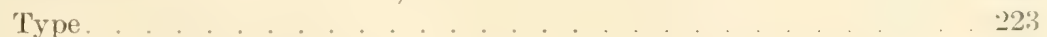

Cause-Bacillus carotovorns L. R. Jones . . . . . . . . . 230

Technic. . . . . . . . . . . . . . . . . 41 
PAGE

Determine . . . . . . . . . . . . . . 243

For the organism . . . . . . . . . . . . . . . . . 243

Morphology. . . . . . . . . . . . . . . . . . 243

Cultural Characters . . . . . . . . . . . . . . 246

Response to Non-nutritional Environment . . . . . . . . . 249

For the Disease . . . . . . . . . . . . . . . . . . . . . . . 251

Signs. . . . . . . . . . . . . . . . . . 251

Histology . . . . . . . . . . . . . . . . . 251

Valiability . . . . . . . . . . . . . . . . 251

Transmission . . . . . . . . . . . . . . . . . 252

Literature. . . . . . . . . . . . . . . . . . . . 252

V11. Bacterial Black Rot of the Potato . . . . . . . . . . . 253

Tyре. . . . . . . . . . . . . . . . . . . . 253

Cause-Bacillus phytophthorus Otto Appel . . . . . . . . . . . . . . 257

Technic. . . . . . . . . . . . . 263

Determine . . . . . . . . . . . . . . . . 268

For the Organism . . . . . . . . . . . . . . . . 268

Morphology. . . . . . . . . . . . . . . . . . . . . 268

Cultural Characters . . . . . . . . . . . . . . . 269

Response to Non-nutrituonal Environment . . . . . . . . . 272

For the Disease . . . . . . . . . . . . . . . . . . 274

Signs. . . . . . . . . . . . . . . . . . 2 274

Histology . . . . . . . . . . . . . . . . . . . . 274

Variability . . . . . . . . . . . . . . . . 277

Transmission . . . . . . . . . . . . . 278

Literature. . . . . . . . . . . . . . . . . 278

VIII. The Bean Blight. . . . . . . . . . . . . . . . . . . . 280

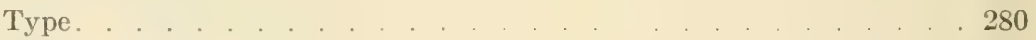

Cause-Bacterium phaseoli EFS . . . . . . . . . . . . . . . . . . 285

Technic . . . . . . . . . . . . . . . . . . 287

Determine . . . . . . . . . . . . . . . . . . . . 291

For the Organism . . . . . . . . . . . . . . . . . . 291

Morphology. . . . . . . . . . . . . . . . . . . 291

Cultural Characters . . . . . . . . . . . . . . . 291

Response to Non-nutritional Environment _. . . . . . . . . 293

For the Disease . . . . . . . . . . . . . . . . . 294

Signs. . . . . . . . . . . . . . . . . 294

Histology. . . . . . . . . . . . . . . . . 294

Variability . . . . . . . . . . . . . . . . . . 295

Transmission . . . . . . . . . . . . . . . . 295

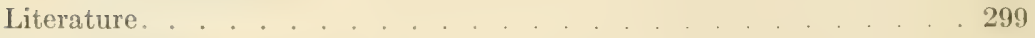

1X. MeCulloch's Cauliflower Spot. . . . . . . . . . . . . . . . . 300

Type. . . . . . . . . . . . . . . . . . . . . . 300

Cause-Bucterium maculicolum Iucia McCulloch. . . . . . . . . . . 304

Technic. . . . . . . . . . . . . . . . . . 310

Determine . . . . . . . . . . . . . . . . . . 311

For the Organism . . . . . . . . . . . . . . . . . . 311

Morphology. . . . . . . . . . . . . . . . . . 311

Cultural Characters . . . . . . . . . . . . . . . 312 
Response to Non-nutritional Environment P:A

For the Disease . . . . . . . . . . . . . . . . . . . . . .

Signs . . . . . . . . . . . . 312

Histology . . . . . . . . . . . . . 313

Variability . . . . . . . . . . . . . . 313

Transmission . . . . . . . . . . . . . . 313

Literature. . . . . . . . . . . . . . . 313

X. The Angular Leaf Spot of Cotton. . . . . . . . . . . 31 . .

Type. . . . . . . . . . . . . 314

Cause-Bacterium malvacearum EFS . . . . . . . . . . . . . . . 321

Technic . . . . . . . . . . . . . . 330

Determine . . . . . . . . . . . . . . 333

For the Organism . . . . . . . . . . . . . . . . 333

Morphology . . . . . . . . . . . . . . 333

Cultural Characters . . . . . . . . . . 333

Response to Non-nutritional Environment . . . . . . . . 335

For the Disease . . . . . . . . . . . . . . . . . . . . . . . 335

Signs . . . . . . . . . . . . . . . . . . . .

Histology . . . . . . . . . . . . . . . . . . . . . . . .

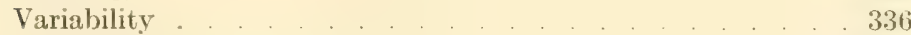

Transmission . . . . . . . . . . . . . . . . . . .

Literature. . . . . . . . . . . . . . . . . . . . . . . . . .

XI. The Mulberry Blight . . . . . . . . . . . . . . . 340

Type. . . . . . . . . . . . . . 310

Cause-Bacterium mori Boyer and Lambert emend. EFS . . . . . . . 342

Technic. . . . . . . . . . . . . . . . . . . . . .

Determine . . . . . . . . . . . . . . . . . . . . . 354

For the Organism . . . . . . . . . . . . . . 354

Mot phology. . . . . . . . . . . . 35t

Cultural Characters . . . . . . . . . . . 354

Response to Non-nutritional Environment . . . . . . . 355

For the Disease . . . . . . . . . . . . . . . . . . . . . . . . . 350

Signs . . . . . . . . . . . . . . . 356

Histology . . . . . . . . . . . . 357

Variability _ . . . . . . . . . . . . . 358

Transmission . . . . . . . . . . . . . . . . . . . . . . 358

Literature. . . . . . . . . . . . . . . . . . . . . . . . .

XII. Fire-blight of Apple, Pear, Quince, Etc. . . . . . . . . . 359

Tyре. . . . . . . . . . . . . . . . . 359

Cause-Bacillus amylovorus (T. J. Burrill) Trevisan . . . . . . . . 367

Technic . . . . . . . . . . . . . . . . . . . . . . 374

Determine . . . . . . . . . . . . . . 380

For the Organism . . . . . . . . . . . . 380

Morphology. . . . . . . . . . . 380

Cultural Characters .......... . . . . 380

Response to Non-nutritional Environment . . . . . . . 380

For the Disease . . . . . . . . . . . . . . . . 380

Signs . . . . . . . . . 3so

Histology. . . . . . . . . . . . . . 381 
PAGE

Variability . . . . . . . . . . . . . . . . 383

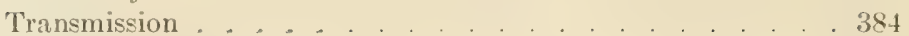

Eradieation of the Disease . . . . . . . . . . . . . . . . 385

Literature. . . . . . . . . . . . . . . . . . . . 387

XIII. The Olive Tubercle . . . . . . . . . . . . . . . . . . . . . . 389

Tyре. . . . . . . . . . . . . . . . . . . . . . . 389

Cause-Bacterium sarastanoi EFS . . . . . . . . . . . . . . . . . 391

Technic. . . . . . . . . . . . . . . . . . . . . . . . . . . . . . 401

Determine . . . . . . . . . . . . . . . . . . . 40

For the Organism . . . . . . . . . . . . . . . . . . 406

Morphology . . . . . . . . . . . . . . . 406

Cultural Characters . . . . . . . . . . . . . . . . 407

Response to Non-nutritional Enviromment . . . . . . . 409

For the Disease . . . . . . . . . . . . . . . . . . 409

Signs. . . . . . . . . . . . . . . . . . 409

Histology . . . . . . . . . . . . . . . . . 409

Variability . . . . . . . . . . . . . . . 410

Transmission . . . . . . . . . . . . . 410

Literature. . . . . . . . . . . . . . . . . . 411

XIV. The Crown Gall. . . . . . . . . . . . . . . . . 413

Type. . . . . . . . . . . . . . . 413

Cause-Bacterium tumefaciens Smith and Townsend . . . . . . . . . 421

Technic. . . . . . . . . . . . . . . . . 4 . . . . . . . . . . . . 452

Determine . . . . . . . . . . . . . . . . 451

For the Organism . . . . . . . . . . . . . . . 451

Morphology . . . . . . . . . . . . . 4 451

Cultural Characters . . . . . . . . . . . . 151

Response to Non-nutritional Enviromment . . . . . . . . . 457

For the Disease . . . . . . . . . . . . . . . . . 459

Signs. . . . . . . . . . . . . . 459

Histology. . . . . . . . . . . . . . 460

Variability . . . . . . . . . . . . . . . . . 468

Transmission . . . . . . . . . . . . . . . 469

Literature. . . . . . . . . . . . . . . . . . . . . . . . . 41

PART IV

MISCELLANEOUS

I. Notes on Some Adeitional Diseases. . . . . . . . . . 473

II. Suggestion of Subjects for Special Study _ . . . . . . . . . 474

1II. Production of Tumors in the Absence of Parasites . . . . . . . 477

IV. Speculations on the Chemical and Physical Stimuli Underlying

T'UMOR-ForMATION . . . . . . . . . . . . . . . . . . . . . . . . . . .

V. On The Production of Teratosis in the Absence of Tumors and

of Parasites . . . . . . . . . . . . . . . . . . . . . . . . . 


\section{PART V}

\section{GENERAL OBSERVATIONS}

\begin{tabular}{|c|c|}
\hline \\
\hline n Seerng Things. . & \\
\hline On Experimentation . . . . . . . . & \\
\hline On Beginning Work Thoughteessly. & \\
\hline On Interpretation of Phenomena . . . . . . . . . . & \\
\hline N Repetition of Experinients-Other People's, One's Own & \\
\hline 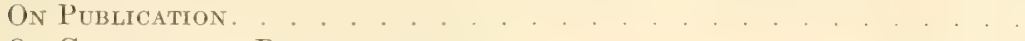 & \\
\hline On Clearness in Presentation . . . . & \\
\hline N Completeness of Presentation. . . . . . . . . . & \\
\hline N Brevity of Statement-When Brevity is not Desirable. & \\
\hline N the Ethics of Research. . . . . . . . . . . . . & \\
\hline Keeping One's Own Counsel. & \\
\hline v'TeAMI WORK. . . . . . . & \\
\hline Sharing Credits. . . . . . . . . . . . . . . . . & \\
\hline $\begin{array}{l}\text { Attending Meetings and Keeping Up Menibership in Societifs, and } \\
\text { on being Generaldy Public-Spirited and Helpfol in Science. }\end{array}$ & \\
\hline 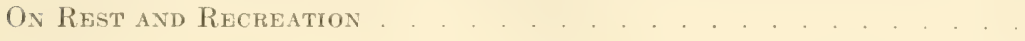 & \\
\hline $\mathrm{DEX} \ldots \ldots$ & \\
\hline
\end{tabular}





\section{LIST OF ILLUSTRATIONS}

Frontispiece: Prof. Thomas J. Burrill diseoverer of the first bacterial disease of plants (pear blight). Photograph in 1884 (at 45), handwriting in 1915 (at 76).

1. Savastano, Cavara, Wakker, Arthur, and Waite. Photographs of early workers on bacterial diseases of plants. All except of Savastano are of the period when they made their first investigations.

2. Mango fruit-cluster attacked by Doidge's bacterial spot disease.

3. Bacterial leaf-spot of mango from South Africa. 1/2 nat. size........

4. Coconut bud-rot of the West Indies........................ . .

5. Cross-section of a banana fruit-stalk attacked by Rorer's disease ..... 11

6. Angular leaf-spot of cucumber due to Bacterium lachrymans Smith and Bryan.

7. Cucumber stem showing white film and cracks due to Bacterium luchrymans. . . . . . . . . . . . . . . . . . . . . . . . . 11

S. Gelatin stab culture of Bacterium lachrymans.............. 15

9. Small gelatin colony of Bacterium lachrymans for marginal appearance. 15

10, 11. Recovery of tomatoes from an attack of Bacterium solanacearum EFS 18

12. Head of wheat showing bacterial black chaff disease (Kansas, 1915)... 19

13. Agar poured plate colony of black chaff bacterium (Bacterium translucens var. undulosum Smith, Jones and Reddy). No. 273, Nebraska. 20

14. Stalk- and glume-striping in black chaff of wheat. No. 268, Kansas... 222

15. Bacterial exudate from glumes in black chaff of wheat. A natural infection on Montana spring wheat.

16. Black chaff of wheat, showing a pure culture glume-infection done with No. 20 .

17. Black chaff of wheat, showing ordinary appearance of the yellow colonies on agar plates. No. 20, McKinney, Texas............... 26

18. Black chaff of wheat, showing internal markings of surface colonies on agar. Vo. 662 from Monticello, Illinois . . . . . . . . . . . 27

19. Same as fig. 18 but No. 678 from El Reno, Oklahoma............ 2.s

20. Black chaff of wheat: gelatin colonies of Bact.translucens var. undulosum, showing dry liquefaction pit: No. 252 from Republic, Missouri....

21. Black chaff of wheat, showing thin, secondary margin of two gelatin colonies. Medium magnification.

22. A, B. Black chaff of wheat. Same series as fig. 21 but older and more highly magnified .......................... 32

23. Blade of a cucumber leaf attacked by angular leaf-spot showing teardrop ooze of Bacterium lachrymans Smith and Bryan .......... 37

24. Gelatin colonies of Bacterium lachrymans.................

25. Colony markings of Bacterium lachrymans on: (A) gelatin and (B) agar. 39 
26. A. Crystals formed by Bacterium lachrymans.

B. Ditto by Bacterium solanacearum............................... 40

27. Ardisia leaf showing swollen serratures occupied by bacteria ....... 41

28. Bacterial eavity in leaf-tooth of Ardisia . . . . . . . . . . . . . 41

29. Like figure 28 , but showing the water-pore . . . . . . . . . . . . 42

30. A. Leaf of Pavetta angustifolia from Java showing knots. B. Same without knots

31. Cross section of fig. $30 \mathrm{~A}$ in vicinity of a nodule . . . . . . . . . 43

32. Bacterial cavities in leaf-knot on Pavetta angustifolia . . . . . . . . . . 43

33. Detail from another nodule in same series as figure $32 \ldots \ldots \ldots \ldots \ldots 4$

34. Bacterial masses from nodule on leaf of Pavetta angustifolia......... 45

35. A. O'Gara's disease in head of western wheat grass. B. The same showing a knee-shaped bending of the culm. C. D. Hutchinson's East Indian (Punjah) wheat disease.

36. Shoots developing from the middle of a healthy tomato leaf ....... 50

37. Schizomycete of Japanese basket-willow disease-Agar plate colony showing internal structure when viewed by oblique light . . . . . . . .

38. Kernels of wheat (No. 271A, Kansas, 1917) attacked and shriveled

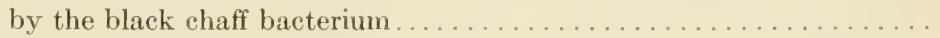

39. Head of wheat from Kansas (No. 478) showing the basal glume rot due to Bacterium atrofaciens. McCulloch............... 57

40. Glumes and kernels of wheat attacked by the basal glume rot...... 58

41. Citrus canker on grape fruit leaves [due to Bacterium citri (Hasse) Jehle]. Fully developed.

42. Citrus canker on grape fruit leaf. Early stage. . . . . . . . . . 60

13. Citrus canker on stems. . . . . . . . . . . . . . . . . . . 61

44. Section through a young bactcrial canker on a grape fruit leaf ...... 62

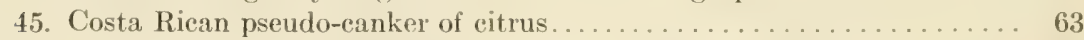

46. Costa Rican pseudo-canker of citrus. A detail from figure $45 \ldots \ldots \ldots 4$

47. Scab on Florida citrus leaf due to Cladosporium citri . . . . . . . . . 65

4R. Bacterial citrus eanker enlarged to show the translucent horder surrounding old leaf-scabs

49. Celery rot, due to Bacillus a piovorus Wormald ...............

50. A. Kernels of wheat developing Bacterium translucens var. undulosum on nutrient agar. $B$. The same freed from the black chaff bacteria by formaldehyd.

51. Braun's new seed-wheat treatment, less harmful to the grain than

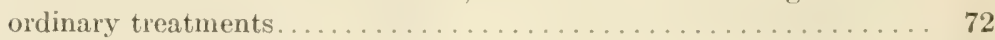

52. Electric centrifuge . . . . . . . . . . . . . . . . . . . 79

53. Freezing microtome . . . . . . . . . . . . . . . 82

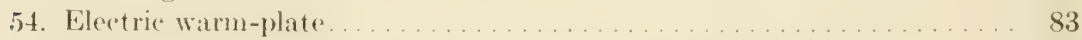

55. Zeiss photomierographic stand and small upright eamera ........ 85

56. The Rutter kettle and other apparatus of the sterilizing chamber. . . . 87

57. Simple home-made device for steaming infected soil . . . . . . . . . 88

58. The Crandall Model View Camera, $3 \frac{1}{4}$ by $41 / 4$ inches. . . . . . . . . . 91

59. Camera stand recommended by the writer . . . . . . . . . . . . 93

60. Horizontal view of figure $59 \ldots \ldots \ldots \ldots \ldots \ldots \ldots \ldots \ldots \ldots$

61. Diagram of photographic room and dark room used by the writer.... 96

62. Cucumber plant wilted by Bacillus tracheiphilus EFS . . . . . . . . 133 
63. Squash plant wilted by Bacillus tracheiphilus............... 133

64. Muskmelon plant wilted by Bacillus tracheiphilus............... 133

65. Bacterially infected cucumber leaf gnawed by beetles. The infection preceded the gnawing

66. Sound leaf locally infected by the gnawing of infected insects. The infection followed the gnawing. . . . . . . . . . . . . . . . 134

67. Plant infected throughout as a result of insect gnawings like those

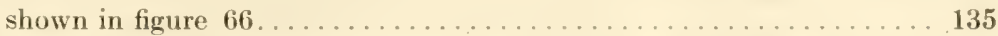

68. Flagellate rods of Bacillus tracheiphilus: $a, b, \times 2000 ; c, \times 1000 \ldots \ldots .136$

69. Enlarged colony of Bacillus tracheiphilus viewed by oblique transmitted light . . . . . . . . . . . . . . . . . . . . . . . . . . 136

70. Like fig. 69 but less magnification: internal colony markings of Bacillus tracheiphilus on an agar-poured plate, visible by oblique transmitted light. Smooth on surface and homogeneous by direct transmitted light . . . . . . . . . . . . . . . . . . . . . . . . 138

71. Agar buried and surface colonies of Bacillus tracheiphilus by reflected light. . . . . . . . . . . . . . . . . . . . . . . . . . . . 140

72. Leaf-stalk of an infected squash in cross-section.............. 141

73. Infected cucumber stem in cross-section. . . . . . . . . . . . . . 142

74. $A$, Inner bundle of figure 73 enlarged; $B$, outer bundle of figure 73 enlarged . . . . . . . . . . . . . . . . . . . . . . . . . . . 142

75. Infected cucumber stem in longitudinal section. Bundle destroyed... 143

76. Infected cucumber stem in longitudinal section showing empty and occluded spiral vessels........................ 143

77. Bacillus tracheiphilus highly magnified. From an infected cucumber vessel . . . . . . . . . . . . . . . . . . . . . . . . . . . . . . 143

78. Cross-section of segment of a bacterially invaded pitted vessel. From a cucumber.

79. Field of cabbage in Wisconsin destroyed by black rot due to Bacterium campestre (Panmel) EFs. ......................... 145

80. Early stages of water-pore infection in cabbage. Natural size...... 146

81. Vertical section through an infected water-pore on cabbage .......... 146

\$2. Section parallel to surface of a cabbage leaf-tooth showing oceluded and empty water-pore................................. 147

83. Upper stoma (water-pore) of the preceding enlarged, showing the rodshaped (bacterial) mass blocking the stoma............... 147

84. Inoculated cabbage leaf showing black-veined marginal spots due to water-pore infection. ........................... 148

85. Middle of a cabbage leaf showing black-vein disease due to stem inoculation. . . . . . . . . . . . . . . . . . . . . . . . . . 148

86. $A, B$. Cabbage leaf-stalks in cross-section showing black bundles, due to Bacterium campestre .............................. 149

87. Black bundles in fleshy part of kohlrabi, due to Bacterium campestre... 149

88. A, B. Flagellate rods of Bacterium campestre............... 150

89. A, B. Colonies of Bacterium campestre on agar. $\times 10 \ldots \ldots \ldots \ldots \ldots 150$

90. Buried and surface colonies of Bacterium campestre by direct transmitted light . . . . . . . . . . . . . . . . . . . . . . . . . 151

91. Agar colonies of Bacterium campestre by oblique transmitted light..... 152

92. Cultures of Bacterium campestre and Bacterium phaseoli in Dunham's solution.......................................... 153 
93. Tyrosin crystals in milk fermented by Bacterium campestre......... 153

94. Cross-section of a small cuvity in a cauliflower stem, due to Bacterium

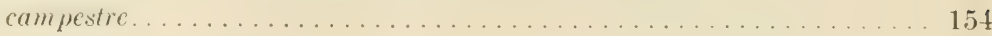

95. Cauliflower bundle in longitudinal section showing disorganization due to Bacterium campestre........................ 154

96. Turnip root in cross-section showing a bundle attacked by Bacterium campestre.

97. Beginning of a bacterial cavity in a turnip root $\ldots \ldots \ldots \ldots \ldots \ldots \ldots$

98. Single cell of turnip root showing Bacterium campestre, occupying the intercellular spaces. . . . . . . . . . . . . . . . . . . . 158

99. Longitudinal section showing a vessel and cells of a turnip root occupied by Bacterium campestre......................... 158

100. Large sweet-corn plant destroyed in the field by Aplanobacter stewarti

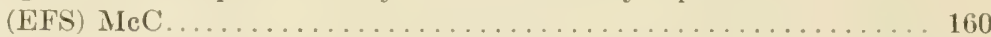

101. Flint field-corn, showing white top due to A planobacter stewarti...... 162

102. A planobacter stewarti oozing from cut bundles (cross-section) of a sweet-

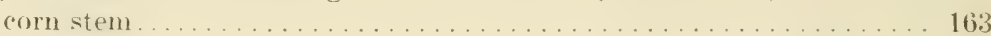

103. Aplanobacter stewarti oozing into water from vascular bundle of a sweet-corn stem-longitudinal section. . . . . . . . . . . . 163

104. Corn plant from Chula Vista, California, showing dwarfing, white top and suckering due to A planobacter stewarti .............. 164

105. Yellow spots on inner husk of sweet corn due to A planobacter stewarti. . 164

106. Cross-section of corn-husk from an inoculated plant showing bacterial masses in the tissues. . . . . . . . . . . . . . . . . . . . 165

107. Stewart's disease of sweet corn, a detail of figure $106 \ldots \ldots \ldots \ldots$

108. Infected small bundle at extreme base of a corn kernel. Cross-section.. 167

109. Cross-section of a larger bundle at the same level as figure $108 \ldots \ldots \ldots 168$

110. Longitudinal section showing infected vessels, etc., in periphery of a corn kernel, at the level of the radicle. . . . . . . . . . . . . . . . 169

111. Infected vessels in periphery of sweet-corn kernel at the level of figure 110. It shows A planobacter stewarti forming a small cavity . . . . . . 169

112. Inoculated young sweet-corn plant attacked by A planobacter stewarti... 170

113. Sweet-corn plant inoculated when young, and diseased when old ..... 171

114. A, B. Two types of surface colony in A planobacter stewarti........ 172

115. Agar plate showing buried colonies of Aplanobacter stewarti and one coming to the surface. Also erystals.................. 173

116. Longitudinal section of two infected corn stems showing brown node and yellow striping . . . . . . . . . . . . . . . . . . 174

117. Appearance under the microscope of cross-section of empty and infected (stained) hundles in a maize stem.

118. Single disorganized bundle of an infected maize stem, enlarged. Bacterial mass stained deep red. . . . . . . . . . . . . . . . . . 175

119. Potato attacked by Bacterium solanacearum EFS. From a field near Washington, D. C......................... 177

120. Early Rose potato inoculated with Bacterium solanacearum. Late stage . . . . . . . . . . . . . . . . . . . . . . . .

121. Inoculated young tomato. Early stage. Leaves of inoculated shoot reflexed . . . . . . . . . . . . . . . . . . . . 179

122. A later stage of figure 121, showing incipient roots on inoculated stem. . 179 
123. Tobacco leaf attacked by Bacterium solanacearum.............. 180

124. Inoculated young tobacco plant attacked by Bacterium solanacearum... 181

125. Dwarf nasturtium attacked by Bacterium solanacearum........... 182

126. A. Common garden balsam attacked by Bacterium solanacearum. $B$. stem of same enlatged. . . . . . . . . . . . . 18.3

127. Dwarfing of Ricinus due to Bacterium soianacearum.............. 184

128. A, B. Sunflowers destroyed by Bacterium solanacearum........... 185

129. Cross-section of a mature potato tuber showing vascular invasion by Bacterium solanactarum........................... 186;

130. Petiole of Tropaeolum majus (nasturtium) attacked by Bacterium solanacearum. Inoculation on stem at $X \ldots \ldots \ldots \ldots \ldots \ldots \ldots . \ldots \ldots$

131. Dwarfing of Helianthus annuus due to Bacterium solanacearum. Checks at right and left . . . . . . . . . . . . . . . . . . . . . 189

132. Appearance of Bacterium solanacearum on agar poured plates........ 190

133. Fluid character of colonies of Bacterium solanacearum on agar plates. . . 191

134. Flagellate rods of Bacterium solanacearum: $a$, East Indian origin; $b$, American origin. . . . . . . . . . . . . . . . . . . . . . . . . 192

135. Stabs of Bacterium solanacearum in nutrient +10 gelatin......... 192

136. Cross-section of a young potato tuber showing removal of starch from the areas infected by Bacterium solanacearum............... 193

137. Infected potato stem in longitudinal section. Early stage. Bacterium solanacearum confined to a single vessel.................. 194

138. Beginning of a bacterial cavity (around a vessel) in stem of a potato plant inoculated on a leaflet with Bacterium solanacearum......... 196

139. Empty and bacterially occluded vessel in a potato plant. Result of a stem inoculation.................................. 197

140. Bacteria from same series as figure 139, highly magnified.......... 198

141. Tomato stem in cross-section, showing origin and structure of two incipient roots-result of an inoculation................. 199

142. Tyloses in vessels of a potato stem attacked by Bacterium solanaccarum. Bacteria at $X$.

143. Tomato plant attacked by A planobacter michiganense EFS, as result of needle-prick inoculation. . . . . . . . . . . . . . . . . . . . . . 203

144. Tomato plants inoculated one month with a pure culture of Aplanobacter michiganense. Massachusetts organism. 1915, colony A. Check plants in background. .

145. Stems of tomato plants showing only a slight tendency to form roots when inoculated (over 3 months) with A planobacter michiganense... 205

146. Tomato leaf showing irregular withering of leaflets due to A planobacter michiganense. Inoculated in the stem .................. 206

147. Tomato stem in cross-section showing an incipient root destroyed from within (the black part) by A planobacter michiganense.......... 207

148. $A, B$. Tomato stem in cross-section showing large cavities in the phloem as a result of inoculating A planobacter michiganense...........208

149. Longitudinal section of a tomato stem attacked by A planobacter michiganense in the sieve-tube region...................... 209

150. Cross-section of a small group of sieve-tubes in a tomato stem showing sieve-plates, and disintegration of the phloem by A planobacter michigrumerise... 
151. 1, 2. Green tomato fruits attacked by A planobacter michiganense. From

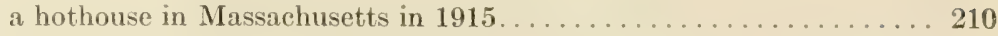

152. Same series as figure 150, showing loss of green color and swelling of stems before rupture. (See figure 153 for later stage.) . . . . . . . . 211

153. Crack on a tomato stem due to Aplanobacter michiganense which was inoculated farther down. . . . . . . . . . . . . . . . . . . 211

15f. Green tomato fruit oozing A planobacter michiganense as result of a stem inoculation.

155. Tomato plant infected with A planobacter michiganense through broken roots

156. Stomatal leaf-infection due to A planobacter michiganense ......... 213

157. Longitudinal section of a tomato leaf showing bundle disorganization due to A planobacter michiganense. . . . . . . . . . . . . . . . 214

158. Detail of a leaf-bundle infection in a tomato sprayed with Aplanobacter

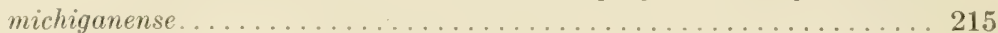

159. Rods of Aplanobacter michiganense highly magnified ............ 216

160. A planobacter michiganense induced to grow in acid agar by presence of

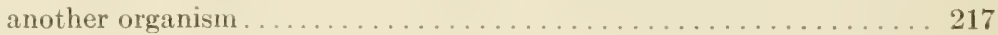

161. The new Massachusetts potato disease (net-necrosis) by reflected light. . . . . . . . . . . . . . . . . . . . . . . .

162. Cross-section of stem-end and eye-end of a diseased potato tuber (netnecrosis) from Massachusetts........................ 220

163. Thin section of a third tuber photographed by transmitted light ..... 221

164. Raw carrot destroyed by Bacillus carotovorus L. R. Jones. Check-half sound

165. Like right half of figure 164, but after it was accidentally dropped . . . 226

166. Separation of cells of carrot due to Bacillus carotovorus . . . . . . . . . 225

167. A. Bacillus carotovorus streaked on flabby vs. turgid carrot-3d day;

$B$. Ditto, 6th day. In each case one check is omitted . . . . . . . 227

168. Raw potato tuber attacked by Bacillus carotovorus. . . . . . . . . . . 228

169. Potato shoot attacked by Bacillus carotovorus................ 228

170. Green cucumber rotted by Bacillus carotovorus. Check-half sound.... 229

171. Calla lily rot due (?) to Bacillus carotovorus. . . . . . . . . . . . . . . 230

172. Enlarged eross-section of figure 171 at base . . . . . . . . . . . . 231

173. A detail of figure 172 highly magnified, showing bacterial disorganization of the cell-wall . . . . . . . . . . . . . . . . . . . . 232

174. Cork layer formed by a potato tuber under a rot spot due to Bacillus carotovorus. . . . . . . . . . . . . . . . . . . . . . 233

175. Cross-section of a potato stem attacked by Bacillus carotovorus...... 233

176. Flagellate rods of Bacillus carotovorus. . . . . . . . . . . . . . . . 234

177. Agar-poured plate colonies of Bacillus carotovorus (?). Stock culture $3 a$ (long in my laboratory) . . . . . . . . . . . . . . . . . . 235

178. Do. Jones' original stock of Bacillus carotovorus. $3 a$ (received from

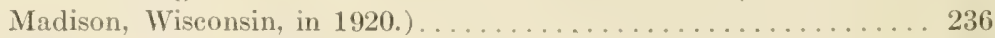

179. Gas from Bacillus carotovorus in potato juice . . . . . . . . . . . 237

180. Bacillus carotovorus on gelatin-magnified surface colony 24 hours old, showing fimbriate margin. . . . . . . . . . . . . . . . 239

181. Bacillus carotovorus on gelatin-fimbriate margin of a surface colony 3 days old-liquefied at left $\ldots \ldots \ldots \ldots \ldots \ldots \ldots \ldots \ldots$ 
182. Bacillus carotovorus in gelatin-buried colonies 24 hours old, showing root-like outyrowths.

183. A, Bacillus carotovorus and B, Bacillus apiovorus in gelatin stabs...... 241

184. Behavior of soft rot bacteria in peptone beef bouillon with ten per cent ethyl alcohol................................ 242

185. Rot of celery due to Bacillus apiovorus Wormald............... 244

186. Resistance of potato shoots to Bacillus apiovorus............... 245

187. $A, B, C$. Three photomicrographs of flagella of Bacillus aroidece Towns-

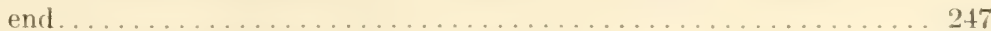

188. Bacillus aroideae after 8 days on raw carrot................ 248

189. A, B. Gas in milk produced by Bacillus aroideae -all $\mathrm{CO}_{2} \ldots \ldots \ldots \ldots .250$

190. Curling of potato leaflets when stem is attacked by Bacillus phytophthorus Appel. . . . . . . . . . . . . . . . . . . . . . . . 258

191. Potato stems attacked by basal stem rot due to Bacillus phytophthorus48 hours. . . . . . . . . . . . . . . . . . . . . . . . . . . 254

192. Same as figure 191 but after another 48 hours............... 254

193. Inoculated potato plant destroyed by Bacillus phytophthorus -7 days.. 255

194. Potato shoot attacked by Bacillus phytophthorus-43 hours.......... 256

195. Shoots of White McCormick potato inoculated with Bacillus phytophthorus in 1915. Control plants in the background........... 258

196. Same as figure 195 , but two days later................... 259

197. Woody base of figure 193 two days later. Sound mother tuber at

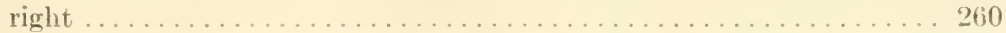

198. Bacillus phytophthorus: same as figure 195, but the inoculations are on older, more resistant sheots

199. Same as in figure 195, but 19 days later-new shoots growing up from the undestroyed base ............................. 262

200. Enlarged cross-section of figure 193, well above the inoculated part.

Bacteria in at resed . . . . . . . . . . . . . . . . . . . . . . . 26ti3

201. Bacillus phytophthorus attacking the cut surface of a raw potato ...... 264

202. Lenticel infection in a potato tuber due to Bacillus melanogenes P. and M. 265

203. Very early stage of decay in potato tuber under a sound skin-lenticel

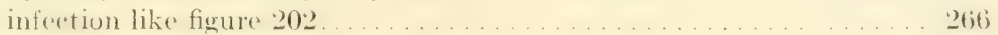

204. Flagellate rods of Bacillus phytophthorus................... 267

205. a. Gelatin colonies of Bacillus carotovorus with (b) those of Bacillus phytophthorus for comparison. Natural size................. 269

206. Gelatin plate cultures of Bacillus phytophthorus from a South Carolina

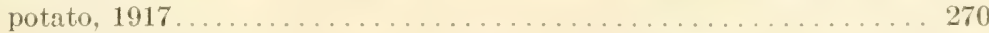

207. Bacillus phytophthorus on gelatin-a surface colony magnified to show the

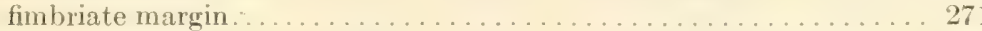

205. Bacillus phytophthorus in gelatin-2 buried colonies, magnified ...... 271

209. Bacillus phytophthorus. - Small buried colony in gelatin 5 days at $16^{\circ} \mathrm{C}$., showing lenticulate coronal colonies in the gelatin............ 272

210. Effect of ethyl alcohol on Bacilus phytophthorus and Bacillus carotovorus in peptone bouillon. . . . . . . . . . . . . . . . . . . . . . 273

211. Inoculations showing virulence of Bacillus phytophthorus (Appel I) after 13 years on culture media

212. Gelatin plate culture of Bacillus carotovorus. B. Cross-section of Tropaeolum stem attacked by Bacterium solanacearum............ 
213. Portion of an immature bean leaflet showing an early stage of infection with Bacterium phaseoli EFS. . . . . . . . . . . . . . . 280

214. Pure-culture spray inoculation of Bacterium phaseoli on an immature bean leaflet.

215. Bean leaflet attacked by Bacterium phaseoli. From a garden in Washington, 1908.

216. Spots on a bean leaflet due to a pure culture stomatal infection of 1914 . Chlorophyll persisting around the spots............... 283

217. Distortions of bean leaves due to infection of the young veins by Bacterium phaseoli.................................. 284

218. Portion of a bean pod enlarged to show earliest visible stage of stomatal infection. 8th day............................... 285

219. Pure culture pod inoculation of bean blight (Bacterium phaseoli). A single spot enlarged............................ 286

220. Bean pod sprayed 14 days with Bacterium phaseoli and showing spots. 1914. Natural size.............................. 287

221. Base of bean pod attacked by Bacterium phaseoli. From Idaho, 1914.. 288

222. Same series as figure 218 , but some days later............. 288

223. Cross-section of a sprayed bean leaf prior to collapse-a stomatal infection. . . . . . . . . . . . . . . . . . . . . . . . 289

224. A portion of figure 223 more highly magnified - two stomata visible... 290

225. Cross-section of a sprayed bean pod (stomatal infection) showing epidermis pushed up by the bacteria..................... 291

226. Cavities in outer tissues of a bean pod due to Bacterium phaseoli. Needle-

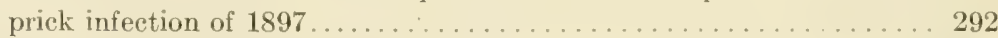

227. Flagellate rods of Bacterium phaseoli...................... 294

228. Effect of sunlight on Bacterium phaseoli................... 295

229. Buried and surface agar colonies of Bacterium phaseoli.......... 296

230. Agar poured plate colonies of Bacterium phaseoli showing internal markings by direct transmitted light-surface smooth.......... 298

$230^{*}$. Agar poured plate of Bact. phaseoli showing ringed colonies... . . . . 299

231. Cauliflower leaves spotted by Bacterium maculicolum McCulloch..... 301

232. Cauliflower heads attacked by Bacterium maculicolum. . . . . . . . . . . 302

233. Agar poured plate of Bucterium maculicolum from a Sanford, Florida, cauliflower................................... 303

234. Cross-section of an inoculated infected cauliflower head . . . . . . . . 305

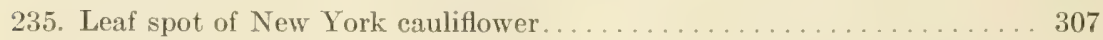

236. Surface and buried colonies of Bacterium maculicolum from the New York cauliflower (figure 235) ... . . . . . . . . . . . . . . . . 309

237. Flagellate rods of Bacterium maculicolum.................. 313

238. A natural infection of Bacterium malvacearum EFS on cotton leaves. From South Carolina, 1903... . . . . . . . . . . . . . . . 314

239. Bacterium malvacearum on cotton-a natural infection of leaves and

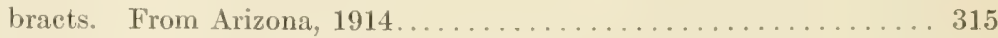

240. Inoculated cotton leaves. Stomatal infections. Veins diseased. Bac-

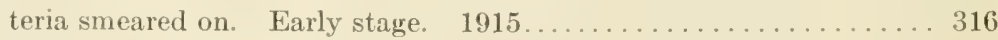

241. Results obtained in 1915 by inoculating cotton leaves in various ways with pure cultures of Bacterium malvaceanum............... 318

242. Inoculated cotton leaves. Stomatal infection due to Bacterium malvacearum. Time, 6 weeks. Bacterial suspension sprayed on. 1915. 319 
243. Cross-section (under a stoma) of an angular leaf spot of cotton in an early stage of infection, i.e., before collapse and shrinking of the spot .

244. Cotton leaf inoculated from a "windowed" colony of Bacterium malvacearum. Time, 53 days.......

245. Green cotton bolls accidentally attacked by Bacterium malvacearum. Hothouse. 1904.

246. Middle stage of bacterial boll spot of cotton due to Bacterium malracearum-lint involved a little

247. Cotton stems attacked by Bacterium malvacearum- "black arm" of cotton

24. Flagellate rods of Bacterium malvacearum

249. Agar-poured plates showing development of Bacterium malvacearum five days after exposure of one-half to bright sunlight for 2 minutes. C'ontrast with figure 228 .

250. Effect of freezing on Bacterium malvacearum................ 325

251. Young (3-day) agar-plate colonies from one of the spots shown in figure 240. Plating of March 20, enlarged ............... 329

25.). Agar colonies of Bacterium malvacearum to show fugitive mottling.

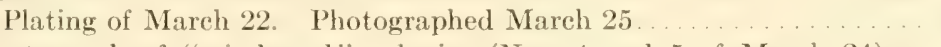

253. Photograph of "windowed" colonies (Nos. 4 and 5 of March 24) as they appeared on March 26 when filled in. See figure $256 \ldots \ldots \ldots .33: 2$

254. Third day agar plate of Bacterium malvacearum showing "windowed" and feebly mottled surface colonies.................... 3332

255. Accidental inoculations of Bacterium malvacearum on cotton bolls.

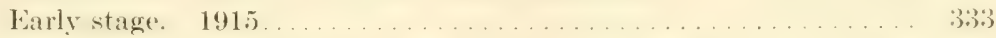

256. Mottled colonies of Bacterium malvacearum on agar plate (for later appearance see figure 253). Also three buried colonies.......... 334

257. Spatulate, finger-like down-growths of Bacterium malvacearum in softened gelatine

25.5. Streak cultures of Bacterium malvacearum and Bacterium phaseoli on Löftler's solidified blood serum.

259. Milk culture of Bacterium malvacearum.

260. Tyrosin crystals from old litmus milk culture of Bacterium malvaccarum 338

261. Section of diseased cotton leaf extruding bacteria through a stoma in the upper epidermis. From the field.

262. American mulberry shoot inoculated with Bacterium mori Boyer and Lambert emend. EFS. Leaves spotted and distorted ............. 341

263. Distortion of South African mulberry leaves due to Bacterium mori... . 342

264. Inoculated shoots of mulberry showing sunken stripes and extrusion of bacteria in cirri from lenticels

26.5. South African mulberry twigs killed by Bacterium mori.......... 344

266). French Morus nigra attacked by Bacterium mori. . . . . . . . . . . . 345

267. French Morus alba attacked by Bacterium mori............... 3416

26s. Cross-section of stem-tissues of milberry showing inner bark destroyed by Bacterium mori as the result of a natural infection. Arkansas,

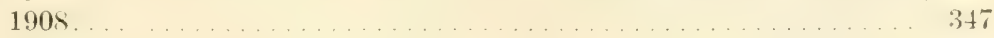

269. $a$, Same as figure 268 but enlarged; $b$, cavity in a stem resulting from an inoculation. 
270. Leaves and stems of mulberry from Georgia attacked by Bacterium

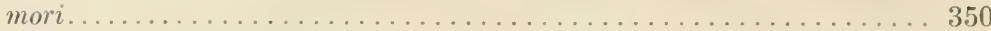

271. South African mulberry disease due to Bacterium mori. Section of a leaf showing a bacterial pocket.

272. A. Flagella of the South African mulberry parasite. $B$. The South African mulberry organism in the tissucs................ 353

273. Flagellate rods of Bacterium mori from the United States.......... 355

274. $a, b$. Appearance of agar poured plate colonies of Bacterium mori with

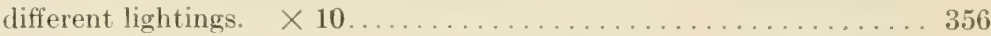

275. A single surface colony of Bacterium mori further enlarged by oblique light to show internal markings . . . . . . . . . . . . . . . 357

276. Healthy and blighted branch of a Maryland pear tree. A detail..... 360

277. Branch of an apple tree, showing flowers, fruits and shoots blighted by Bacillus amylovorus (Burrill) Trevisan .................. 361

278. Pear tree showing recently blighted limbs. At $X$, dead blight of the

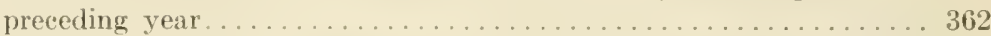

279. Pear blight on apricot in Washington, D. C.................. 363

280. Blighting pear leaves collected in Washington, D. C. May, 1915 ..... 364

281. Shoot of Clapp's Favorite pear inoculated 5 days with a pure culture of Bucillus amylovorus.

282. Apple blight canker (Waite's hold-over blight). Spring condition--

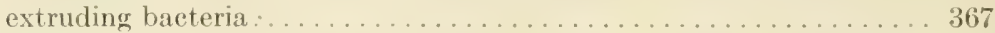

283. A detail above figure 282 enlarged six times to show bacterial ooze

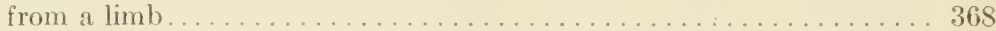

284. Inoculated green pear fruit rotted by Bacillus amylovorus. It shows stomatal ooze in many places........................ 369

285. Blighting pear petiole. A detail from figure 280 showing the copious hacterial ooze from many stomata.

286. Cavities in a pear shoot due to Bacillus amylovorus. Only the cortical

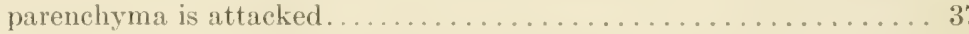

287. A detail from figure 286 showing the bacteria. Inoculation of 1915 on a young shoot of Clapp's Favorite. Time, 5 days........... 372

288. Rods of Bacillus amylovorus as ordinarily seen in disintegrating tissues of pear fruit (fig. 284) . . . . . . . . . . . . . . . . . . . . . 373

289. Texas pear orchard destroyed by blight.................. 375

290. A, B. Pear trees in Maryland orchard, showing recovery from blight due to tree-surgery . . . . . . . . . . . . . . . . . . . . 376

291. Flagellate rods of Bacillus amylovorus................... 377

292. Surface and buried colonies of Bacillus amylovorus from agar-poured plates: $A, 1905 ; B, 1915 \ldots \ldots \ldots \ldots \ldots \ldots \ldots \ldots \ldots \ldots \ldots$

293. $A, B$. Surface and buried colonies of Bacillus amylovorus on agar plates photographed by transmitted light; $A$, direct light; $B$, oblique light. 379

294. Buried and surface gelatin colonies of Bacillus amylovorus after 3 days

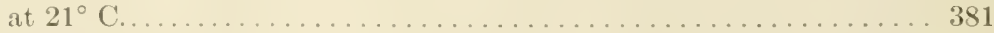

295. Action of Bacillus amylovorus on milk in the closed end of a fermentation

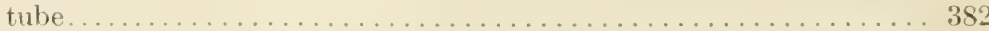

296. Inoculated browned blighting pear shoot, showing beads of bacterial ooze. Variety "Blight-proof" ...................... 383

296*. Pyrus ussuriensis Maxim., a species resistant to fire-blight....... 388 
297. Tumor-bearing olive branches from Genoa, Italy . . . . . . . . . . . . 390

295. Olive tubercles due to Bacterium savastanoi EFS-pure culture inoculations of 1903. Washington, D. ('. .

299. Olive branch showing dwarfing and death of terminal (inoculated) shoot and new surface infections below................... 391

300. Toung olive tree showing result of inoculating Bacterium savastanoi (at $\mathrm{X}$ )

301. A detail from figure 300 , about $3 / 4$ natural size . . . . . . . . . . . 393

302 . Cross-section of a young cheesy olive tubercle, slightly magnified . . . . 393

303. Like figure 302 but more highly magnified . . . . . . . . . . . . . . 395

304. Channel of infection $(\mathrm{X}$ ) in an olive petiole. Low power.......... 396;

305. A detail from figure 304 at $X$, showing the bacteria. Highly magnified 397

306. Cross-section of an olive twig at the level of a small tuberele which is composed chiefly of bark-cell proliferations............... 394

307. Section of small tubercle on under surface of an olive leaf . . . . . . 399

30s. Luigi Savastano. Photograph made in Naples at time he was studying olive tubrele (1s97 to 1899$)$.

309. Flagellate rods of Bucterium savastanoi

310. Agar surface and buried colonies of Bacterium savastanoi......... 40.2

311. Surface colony of Bacterium savastanoi on gelatin 37 days. Year 1908. Enlargerl.

312. Gelatin surface and buried colonies of Bacterium sacastanoi. Year 1910. Enlatrorel

313. Ringed surface colony of Bacterium savasianoi on +10 peptone beef gelatin with 1 per eent dextrose. Enlarged ................ 407

31. Agar-poured plate of Bacterium savastanoi, 1,2 insolated (on ice) 30 mimutes with killing effert

315. Inoculated crown gall on hov due to Bacterium tumefaciens Smith and Townsend

316. Dwarfing effect of crown-gall on sugar-beet-inoculated 37 days.

317. 1. Crown gall on hop-Washington State. 2. Crown gall on roseNew Jersey. 3. Crown gall on apple limb-North Carolina. 4. Grafted crown gall on a pear seedling-Washington, D. C . . . . . . . .

31s. 1. Inoculated crown gall on yellow Paris daisy -1 month $1 a$. Inoculated crown gall on yellow Paris daisy: one infected needle-prick; sterile pricks above. 2. Inoculated erown gall on peach-time, 5 months. 2a. Ditto, time 18 days, 1907. 3. Inoculated crown gall on apple stem. 4. Inoculated erown gall on grape. Time, 44 days ............. 416

319. 1. Inoculated crown gall on radish. 2. Paris daisy showing primary (inoculated) stem-tumor (at $X$ ); and 3 secondary (leaf) tumors73 days. 3. Crown gall on Paris daisy, time 10 months. A new tumor developed below the sloughed old one. Stem dead. 4. Secondary crown gall on sunflower due to proliferation from a tumorstrand, primary tumor in the disk. 1915 5. Crown gall on Paris daisy. Section of stem between tumors showing a large tumorstrand. 6. Crown gall on Paris daisy. Section of stem between tumors showing 3 tumor-strands; also secondary tumors growing out of the leaf stubs.............................. 41

320. Crown gall on sugar beet-inoculated 3 months. Tissues sound...... 420 
321. Inoculated erown gall on sugar beets, showing necrosis........... 422

322. Natural crown gall on willow limbs - from South Africa.......... 423

323. Tumor-strand in eross-section (in daisy stem near pith)-magnified.

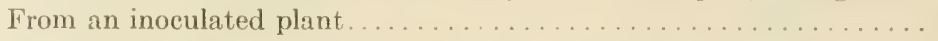

324. 1. Radial longitudinal section of leaf-trace of Paris daisy, showing the normal anatomy, pitted vessels at right; spirals at left. 2 . Radial longitudinal section of leaf-trace of inoculated Paris daisy, showing the interpolation of a tumor-strand-magnified. 3. Tumor strand in cross-section (stem of an inoculated Paris daisy), showing large cells with big nuclei. 4. Cross-section of stem of an inoculated Paris daisy with tumor-strand showing immature tracheids, developing therefrom . . . . . . . . . . . . . . . . . . . . . . .

325. Crown gall tumor-strand in cortex of an inoculated Pelargonium . . . . 427

326. Like figure 327 , sub 4, but tumor full-grown and ruptured to surface of daisy leaf. Stem structure very distinct. . . . . . . . . . . . . 428

327. 1. Very early stage of crown gall on inoculated daisy stem. 2. Longitudinal section of unruptured small secondary tumor in petiole of an inoculated daisy. 3. Part of sub 2 enlarged. 4. Cross-section showing stem structure of secondary tumor in a daisy leaf-the tumor was still developing . . . . . . . . . . . . . . . . . . . . . . 429

32S. Lignin out of place in crown gall, i.e., deposited on walls of 3 large parenchyma cells. . . . . . . . . . . . . . . . . . . . . 430

329. Vascularized crown gall in bark parenchyma of Paris daisy induced by shalluw needle-prick inoculations. . . . . . . . . . . . . . 431

330. Inoculated crown gall on white Paris daisy-showing a killed branch. Time, 7 months. . . . . . . . . . . . . . . . . . . . . .

331. Nucleated cells of erown gall of daisy with bodies formerly identified as the bacteria in place. Gold chloride impregnation. . . . . . . . 433

332. $a, b$. Crown gall on the daisy showing mitochondrial (?) rods formerly identified as Bacterium tumefaciens within the cells. One rod branched 434

333. Inoculated crown-gall teratoma on cauliflower, enlarged. Also side view natural size . . . . . . . . . . . . . . . . . . . . . 43

334. Inoculated crown-gall teratoma on Ricinus communis (castor vil plant). Plant badly dwarfed. Normal stem of same age at right . . . . . . 436

335. Tobacco crown gall bearing flower buds as result of a pure culture inoculation of Bacterium tumefaciens.................... 437

336. A, B. Inoculated leafy crown galls on tobacco internodes. . . . . . . . 439

337. Natural crown-gall witch-broom on Dianthus caryophyllus (the car-

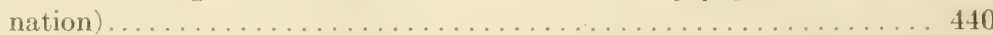

33.8. Inoculated crown-gall teratoma on hothouse geranium (Pelargonium) . 442

339. A, B. Sections of an internodal tobaceo teratoma . . . . . . . . . . 443

340. A, B. Inoculated tobacco crown-gall teratomas showing development of shoots from leaves. . . . . . . . . . . . . . . . . . . . . 444

341. Crown-gall tumors and malformation on inoculated tobacco produced with the carnation isolation of Bacterium tumefaciens (fig. 337) . . . . 447

342. Delayed crown-gall teratoma on inoculated orange stem . . . . . . . 448

343. Inoculated, slow-growing, hard, crown-gall teratoma on mango..... 450

344. A. An embryomatous portion of the mango tumor (fig. 343) enlarged. $B$. Crown gall in center of an inoculated young orange fruit ...... 452 
346. Like figure 345 but from another part of the same locule and further enlarged. Normal tissue at right. Disoriented tumor cells at left. 455

347. Inoculated crown-gall teratoma on sugar beet . . . . . . . . . . 456

348. Inoculated crown gall on top of garden balsam showing roots developing from the tumor (hairy root.)

349. Flagellate rods of Bacterium tumefaciens. Organism from hop..... . . 459

350. a, b. Y-shaped bodies of Bacterium tumefaciens from a culture treated with acetic acid

351. Agar surface and buried colonies of Bacterium tumefaciens isolated from the Rose (colons P)

352. Agar surface and buried colonies of Bacterium tumefaciens isolated from the Hop.

353. Inoculated crown gall of Paris daisy showing structure of the tumor (spindle cells) ............................. 464

354. Structure of tumor tissue in crown gall on Paris daisy. Another part of figure 353 (round tumor cells) . . . . . . . . . . . . . . 465

355. Margin of inoculated crown gall in sunflower pith showing both erushing and invasion. Cells of tumor tissue disoriented............. 467

356. Crown gall in gland of inoculated Ricinus communis. Epidermis involved and dividing.

357. Chestnut wood injected with lithium carbonate showing ingrowths (tyloses) in ressels

355, 359. Cross-section and longitudinal section of tyloses in vessels of chestnut wood. Enlarged . . . . . . . . . . . . . . . . . . 479, 480

360. Chestnut bark showing islands of wood (at 6 ) due to injection of lithium carbonate - a general view . . . . . . . . . . . . . . . . . 481

361,362 . Island of wood in chestnut bark. Enlarged . . . . . . . . 482, 484

363. Cabbage pith showing effect of injecting sodium bicarbonate....... 485

364 Tumors in Ricinus stem produced by vapor of monobasic ammonium

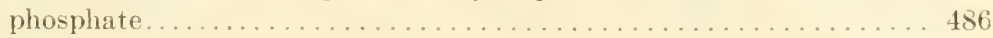

365. 'Tumors on cauliflower leaf produced by dilute vapor of ammonia watler.

366. Acetic acid tumors on under surface of a cauliflower leaf. $1916 \ldots \ldots 48$

367. Same as figure 366 but produced in $1918 \ldots \ldots \ldots \ldots \ldots \ldots \ldots \ldots$

$368,369,370,371$. Cross-sections of three acetic acid cauliflower tumors at different levels.................... 491, 492, 493, 494

372. Longitudinal section of an acetic acid cauliflower tumor . . . . . . . 495

373. 1-3. Formaldehyde tumors on cauliflower. 4. Section of the same... . 497

$374,375,376$. Formic acid tumors on cauliflower leaves........ 498, 499, 500

377. Structure of formic acid tumors on cauliflower leaves. . . . . . . . . . 501

378. Photographs showing slight sub-epidermal injury preceding acetic acid

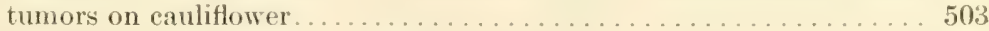

379. Harvey's frost tumors on a cabbage leaf . . . . . . . . . . . . . . 504

380. 1, 2. Structure of Harvey's frost tumors on cabbage leaves ........ 505

351. Mottling of cauliflower leaf after exposure to vapor of ammonia waterit precedes tumor formation. ..................... 506

382. A, B. Wolf's sand blast intumescences on cabbage leaves......... 507

383. Cross-section of Vermont tomato leaf showing oedema...........50s 
384. Atkinson's experimental intumescences on tomato............. . 509

3\$5. A. Lenticel proliferations (semi-asphy'xiation tumors) on Ficus clastica (rubber tree). B. Vertical section of the same, enlarged ......... 512

386. 1, 2. Lenticel proliferations (semi-asphyxiation tumors) on Morus alba (white mulberry). 3, 4. Untreated parts of same branch......... 514

387. Vertical section of one of proliferating lenticel tumors shown in figure 386516

38. A, B. Proliferated (semi-asphyxiated) and normal lenticel of Olea europex (common olive) ......................... 517

389. $A, B$. Proliferated (semi-asphyxiated) and normal lenticel in Begonia.. 518

390. $A, B, C$. Tumors which formed accidentally on the sterile cut surfaces under the cork layer of a raw block of a potato tuber in a sealed tube 520

391. Structure of the tumor at $X$ on figure $390 \ldots \ldots \ldots \ldots \ldots \ldots \ldots \ldots \ldots$

392. Block of pared sterile raw potato with small tumors experimentally

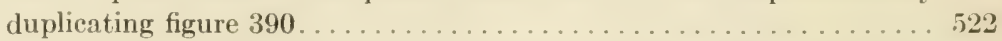

393. Tumors on top and bottom of a block of pared sterile raw potato growing in a sealed tube. Cork layer ruptured ................... 523

394 Blocks of raw potato showing development of callous tissue and small tumors in sealed tubes at room temperature. . . . . . . . . . . . . 524

394*. Well developed intumescences on silver spotted begonia due to painting with petrolatum in 1920

395. Tumors on pared sterile surface of Early Rose potato tuber grown in a sealed tube on wet cotton. .

396. Sterile cut surface of Early Rose potato tuber, showing a continuous series of tumors arising from the cambium and others not originating in the cambium.

397. Irish Cobbler potato showing tumors bursting through the normal skin of the tuber. Grown in a sealed tube on wet cotton.............528

398. Irish Cobbler from same series as figure 397. Tumors rupturing widely. 529

399. General view of figures 397 and 398 showing method of treatment.... 530

400. Intumescences (hyperplasias) developing under stomata on potato shoots in saturated air at high temperatures in bright light........ 532

401. Like figure 400 but the basal intumescences fused and widely ruptured forming a collar................................. 533

402. Shoot of White MeCormick potato grown in a sealed tube in the dark in saturated air at room temperatures-base covered with intumescences, tip dying. . . . . . . . . . . . . . . . . . . . 534

403. Sprouts shown in figure 399 , enlarged $\times 5$. Intumescences numerous. 535

404. A, B. Same series as figure 403, but inturnescences further ruptured... 536

405. Front and back view of a stunted swollen potato shoot exposed at $28^{\circ}$ to $35^{\circ} \mathrm{C}$. and covered with intumescences. From a pared sterile block in one of the sealed tubes: Effect of moist confined air, increased $\mathrm{CO}_{2}$ and decreased oxygen............................ 537

406. Pared sterile blocks of Early Ohio potato in sealed tubes in the dark at $23^{\circ}-25^{\circ} \mathrm{C}$, bearing shoots covered with intumescences ruptured and unruptured. Tips of roots and shoots asphyxiated..........538

407. Hyperplasia under a stoma on a potato shoot (fig. 406). Medium

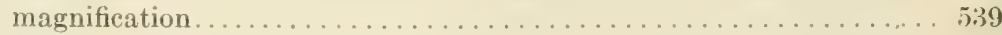

408. Stages of growth in a tumor (teratoma) which developed from the surface of a pared sterile block of potato in a sealed tube at room temperature. Shoots covered with small hyperplasias......... 540 
409. Small intumescences on potato stems abundantly supplied with water but top destroyed by Bacillus phytophthorus............... 542

410. Same as figure 409 , but further enlarged and from the other side of the stem.

411. Intumescences (hyperplasias) on potato shoots which are dwarfed for lack of water-tissues full of sugar, starch, acids and oxydizing enzymes, base of shoots tumefied ................... 54

412. Vertical section through intumescences under stomata on a potato shoot (see figure 411). Tissue gorged with starch..............547

413. Surface view of hyperplasias on potato shoots from figure 411. Stoma central and wide open over each one

414. A. B. Structure of a very young nematode tumor with the young worms in place. Shows both hypertrophy (giant cells) and hyperplasia.

415. Structure of a polythalamous gall on Rosa rubiginosa (the sweetbriar) leaves of an unusual type, i.e., somewhat resembling the calyx lobes. 552

416. Magnified section of a part of fig. $415 B$ with two attached leaves...... 554

417. Monothalamous cynipid gall from an oak tree (Quercus prinus ?): leaves of an unusual type, i.e, resembling those of the willow-leaved oak

418. A. B. Enlarged views of the oak gall with some of the linear leaves removed

419. Stained section of the center of fig. $418 \mathrm{~B}$ magnified 25 times....... 559

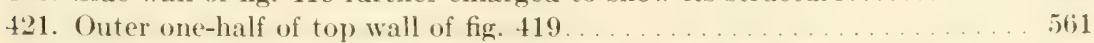

422. Tangential section of the oak gall passing through the middle part of the wall-small cells of the hyperplasia in the middle, larger ones at either side, i.e., nearer the surface and farther from the larval excretions.

423. Tangential section of the wall of the oak gall showing, in the middle, the deep staining hypertrophied inner nutritive layer.

424. A. B. C. Cells of the hypertrophied inner layer, some containing more than one nucleus. Highly magnified.

425. Ordinary appearance of Beyonia phyllomaniaca .............. 576

426. Non-proliferous and proliferous shoots of Begonia phyllomaniaca..... 577

427. Enlarged central part of a dwarfed proliferous leaf showing that the proliferations are not restricted to the main veins............ $5 \pi$ s

428. A, B. Structure of leaf buds of Begonia phyllomaniaca; C. Plant grown from an adventive shoot on a leaf blade; $D$. Enlarged view of stemlenticels and glands.

429. A, B. Proliferation on shoot and leaf stalk of Plant No. 1, first series, front and back view; $C$. Proliferation and beginning cork formation on a branch of the same.

430, 431. Dwarfed proliferous leaf of No. 1, first series, and next four leaves above it

432. Plant No. 6, first series, showing proliferous leaves and internodes with non-proliferous ones above and below . . . . . . . . . . . . . 586

433. Plant No. 6, first series, showing proliferous upper face of leaf blade $Z$ and nearly smooth face of $Z^{1}$ next below it ............... 588

434. (1) Lower (free) and (2) middle (leafy) internodes of No. 6, first series; 
(3) Branch of No. 1, first series showing cork formation in stimulated part . . . . . . . . . . . . . . . . . . . . . . . . . . . . 5.9

4:35. Plant No. 8, first series, showing old and new proliferations on the main axis. . . . . . . . . . . . . . . . . . . . . . . . . . 591

436. A. Plant No. 8, first series, third branch, showing proliferous and non-proliferous internodes; $B$. Plant No. 9, first series, whole of main axis with two stimulated proliferous internodes; $C$. Shoot arising from a trichome.

437. Plant No. 3, second series, main axis, showing dwarfing of proliferous leaf (M), adventive shoots on middle internodes, cork formation ( $\mathrm{Ck}$ ), ete.

438. Plant No. 9, second series, petiole and upper face of leaf $M$, blade proliferations mostly from the midribs . . . . . . . . . . . . . . .

439. A. Plant No. 9, first series, part of an internode enlarged with cork at $C$ : $B$, Plant No. 9, second series, petiole enlarged. Both very proliferous

440. A. Plant No. 10, second series, main axis, contrasting, especially, big proliferous and non-proliferous leaves; $B$. Cross-section of a petioletrichome showing a bud arising from it . . . . . . . . . . . . . . 602

141. Plant No. 10, second series: middle back part (center) of proliferous leaf blade $J$ of fig. 440 , enlarged. . . . . . . . . . . . . . . . 604

412. Plant No. 10, second series, middle leaf, from a branch showing effect of vicinity of midribs on number and size of the adventive shoots..... 605

443. Plant No. 15, second series, main axis, upper face of leaf-blade $L$ and its 'petiole, full of adventive shoots . . . . . . . . . . . . . . . . 60

441. 1, 2. Plant No. 18, second series, main axis, upper and lower part of the proliferous internode, enlarged..................... 60 s

115. Plant No. 1, third series of dried cuttings. $C k$, cork; $T$ ' , topmost small leaf when cutting was made; $X$, fallen leaf; $Y$, proliferous leaf: St, stipules. Proliferous leaf $Y$ is dwarfed.

446. Plant No. 1, sixth series of cuttings, third, fourth and fifth leaves from the top. Stimulated proliferous leaf not dwarfed................

147. Parts of leaves enlarged showing leafy shoots originating from the edge

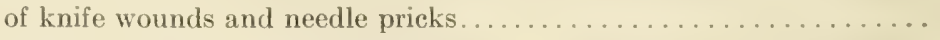

44S. A. Shoots arising from knife-slit in lower surface of a midrib; $B$, effect of dwarfing on limitation of production of shoots from edges of wounds;

$C$, two abnormal fused leaves from an adventitious shoot..........

449. 1, 2. Petioles developing adventive shoots from trichomes. 3. Stimulated internodes which have developed adventitious shoots and cork formation. (Pl. No. 6, first series.) 4. Same as 1 and 2. 5. Midribtrichomes developing shoots . . . . . . . . . . . . . . . 616

450. A, B, C. Further evidence of the development of shoots from petiole hairs

451. A. Cross-section of a leaf and, $B$, cross-section of an internode, showing superficial origin of the adventive shoots.

152. Abnormal leaves from adventive shoots: also stem-glands $(x, y)$ giving rise to shoots. . . . . . . . . . . . . . . . . . . . . . . .

453. Like $451 \mathrm{~A}$ but an earlier stage of shoot-development from the epidermal region $(x, y)$ 


\title{
BACTERIAL DISEASES OF PLANTS
}

\author{
PART I
}

\section{A CONSPECTUS OF BACTERIAL DISEASES OF PLANTS}

All our knowledge of these diseases has come within a generation. It began forty years ago with the announcement of the bacterial origin of pear blight by Professor T. J. Burrill of the University of Illinois (Nee Frontispiece), who has but recently passed away. ${ }^{1}$ During the first half of this period progress was very slow and doubt universal, especially in Europe. In the early study of these diseases a few men were far in adrance of their generation, as always happens when a new science unfolds. Photographs of the leading workers of that period, all of whom are still living, are shown in Fig. 1. All were made at that time with exception of Savastano's which reached me too late and is shown separately as Fig. 308.

It is now twenty-four years since I ventured the statement, ${ }^{2}$ that "there are in all probability as many bacterial diseases of plants as of animals." This statement was received with much skepticism, not to mention active opposition, but time has more than borne out my statement, and there is now no one left to dispute it. To-day I will venture another and broader generalization, to wit: It appears likely that eventually bacterial diseases will be found in every family of plants, from lowest to highest. This prediction is based on the fact that although the field is still a very new one, with no workers in most parts of the world, such diseases have been reported

\footnotetext{
${ }^{1}$ Born in Massachusetts, April 25, 1839; deceased in Illinois, April 14, 1916.
}

${ }^{2}$ Am. Nat., vol. 30, p. 627. 1896. 


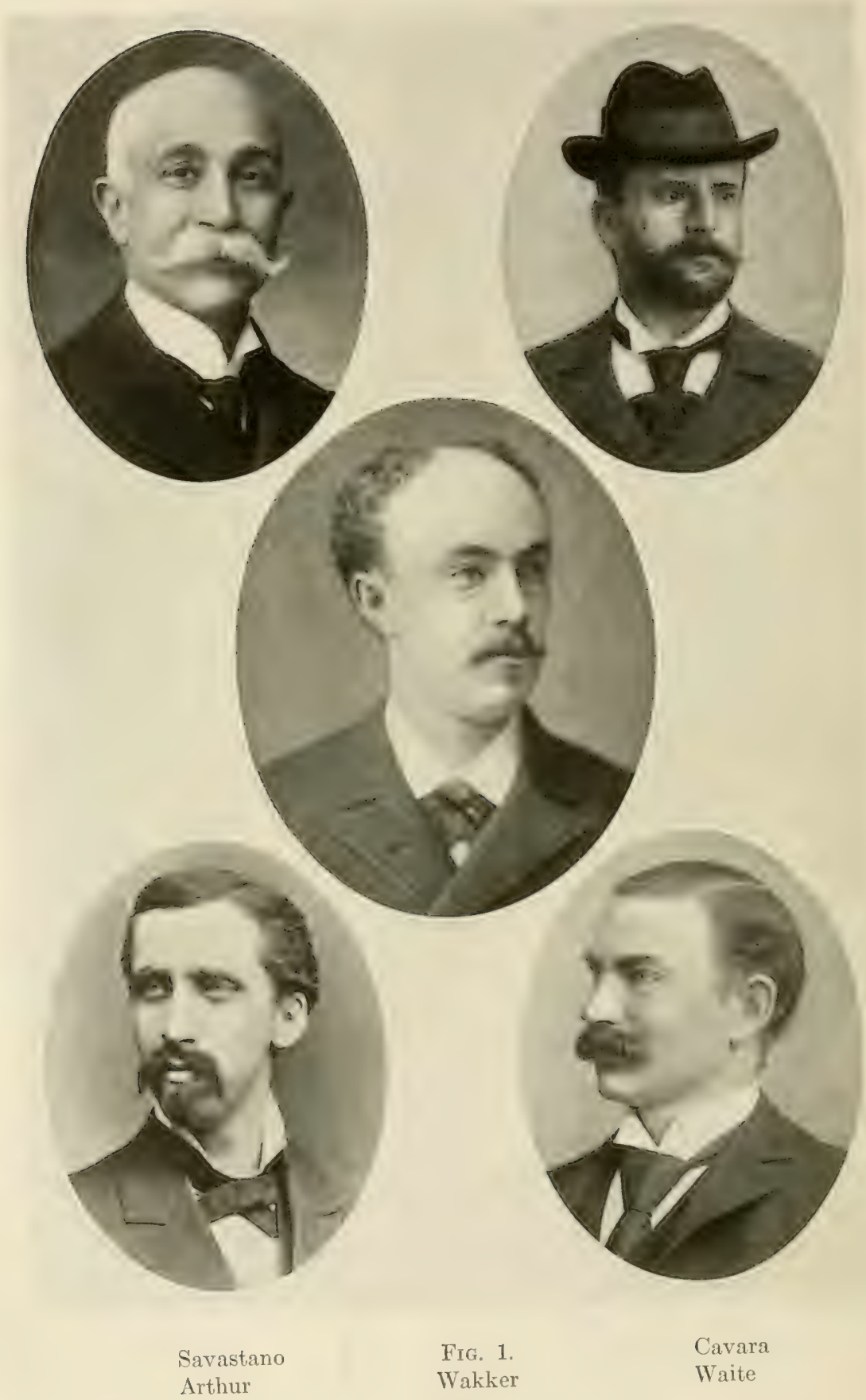




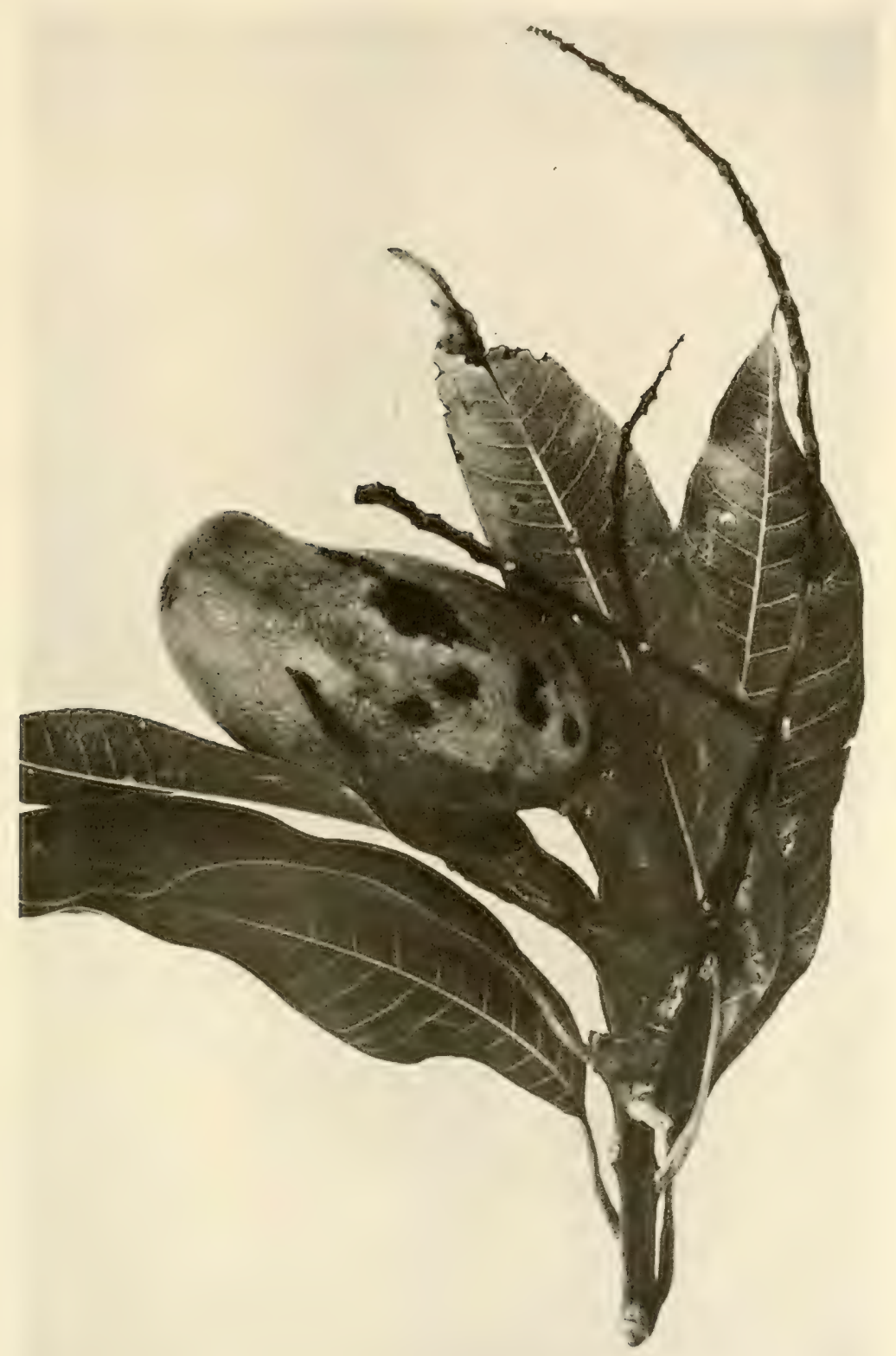

FIG. 2.-Fruit, fruit-stalk, and leaves of mango attacked by the South African bacterial disease. (After Ethel M. Doidge.) 
from every continent, and are already known to occur in plants of one hundred and fifty genera distributed through more than fifty families.

\section{DISTRIBUTION}

Following Engler's arrangement, I will list these families that you may see how wide is the distribution of bacterial diseases in plants and how utterly wrong were those who said that there were no such diseases, and also those who conceded a little but said that they were very rare and restricted to the soft underground parts of a few bulbous and tuberous plants, and generally preceded by fungi (German writers and their followers). In this list, I have included only the flowering plants, but some of the cryptogams are also subject to bacterial attack. The number following the family name indicates the number of bacterial diseases known within the limits of the family. The total of the figures, however, will not give the number of bacterial parasites, because some of the diseases overlap.

\section{TABLE I}

SHOWING THE FAMILIES OF FLOWERING PLANTS ARRANGED SERIALLY FROM LOWEST TO HIGHEST. THOSE CONTAINING GENERA SUBJECT TO BACTERIAL DISEASES ARE UNDERSCORED, AND WHEN SEVERAL DISEASES HAVE BEEN RECOGNIZED THEIR NUMBER IS ALSO GIVEN *
1. Cycadaceae
17. Gramineae $\mathbf{1 4}$
34. Juncaceae
2. Ginkgoaceae
18. Cyperaceae
3. Taxaceae
4. Pinaceae 2
19. Phoenicaceae
19. Palmae
5. Gnetaceae
20. Cyclanthaceae
6. Typhaceae
7. Pandanaceae
21. Araceae
22. Lemnaceae
8. Sparganiaceae
23. Flagellariaceae
9. Potamogetonaceae
24. Baloskionaceae
10. Naiadaceae
24. Restionacene
25. Centrolepidaceae
26. Mayacaceae
27. Xyridaceae
28. Eriocaulaceae
29. Rapateaceae
30. Bromeliacea
31. Commelinaceae
32. Pontederiaceae
33. Philydraceae
35. Stemonaceae
36. Melanthiaceae
37. Liliaceae 3
38 .Convallariaceae
39. Smilacaceae
36.
37.
38.
Liliaceae
39.
40. Haemodoraceae
41. Amaryllidaceae
42. Velloziaceae
43. Taccaceae
44. Dioscoreaceae
45. Iridaceae
46. Musaceae
47. Zingiberaceae
16. Triuridaceae
17. Poaceae
48. Cannaceae

(a) 
49. Marantaceae

50. Burmanniaceae

51. Orchidaceae 7 (?)

5). Casuarinaceae

53. Saururaceae

54. Piperaceae

5.). Chloranthaceae

56. Salicaceae 2

57. Myricaceae

5.. Balanopsidaceae

59. Leitneriaceae

60. Juglandaceae 2

61. Betulaceae

62. Fagaceae 2

63.). Ulmaceae

6.t. Moraceae

65. Urticacene 5

66i. Proteaceae

67. Loranthaceae

65. Myzodendraceae

69. Santalaceae

70. Grubbiaceae

71. Opiliaceae

72. Olacaceae

73. Balanophoraceae

74. Aristolochiaceae

75. Rafflesiacere

76. Hydnoraceae

77. Polygonaceae 2

78. Chenopodiacese 5

79. Amaranthaceae

so. Nyctaginacene

81. Batidaceae

s2. Theligonaceae

82. Cynocrambaceae

83. Phytolaccaceae

84. Aizoacene

85. Portulacaceae

86. Basellaceae

si. Silenaceae

s7. Caryophyllaceae 2

sis. Nymphaeaceae

89. Ceratophyllaceae

90. Trochodendraceae

91. Ranunculaceae

92. Lardizabalaceae

93. Berberidaceae

94. Menispermaceae
TABLE I--(Continued)

95. Magnoliaceae

96. Calycanthaceae

97. Lactoridaceae

98. Annonaceae

99. Myristicaceae

100. Gomortegaceae

101. Monimiaceae

102. Lauraceae

103. Hernandiaceae

104. Papaveraceae 2 (?)

105. Brassicaceae

105. Cruciferae 5

106. Tovariaceae

107. Capparidaceae

108. Resedaceae

109. Moringaceae

110. Sarraceniaceae

111. Nepenthaceae

112. Droseraceae

113. Podostemonaceae

114. Hydrostachyaceae

115. Crassulaceae

116. Penthoraceae

115. Crassulacere

116.

117. Cephalotaceae

118. Saxifragaceae

119. Hydrangeaceae

120. Escalloniaceae

121. Grossulariaceae 2

11 s.

119.

120. Sarifiagaceat

121.

122. Pittosporaceae

123. Brunelliaceae

124. Cunoniaceae

125. Myrothamnaceae

126. Bruniaceae

127. Hamamelidaceae

128. Platanaceae

129. Crossosomataceae

130. Rosaceae

131. Malaceae

132. Amygdalaceae

130.

131. Rosaceae 7

132.
13:3. Connaraceae

134. Mimosaceae

133. Caesalpiniaceae

136. Krameriaceae

137. Fabaceae

134.

135. Lequminosae 7

137.

138. Geraniaceae 2

139. Oxalidaceae

140. Tropaeolaceae 3

141. Linaceae

142. Humiriaceae

143. Erythroxylaceae

14. Zygophyllaceae

145. Cneoraceae

14ti. Rutrcege 4

147. Simaroubaceae

14s. Balsameaceae

14s. Burseraceae

149. Meliaceae

150. Malpighiaceae

151. Trigoniaceae

152. Vochyaceae

152. Vochysiaceae

15:3. Tremandraceae

154. Polygalaceae

15.5. Dichapetalaceae

156. Euphorbiaceae 2

157. Callitrichaceae

15s. Buxaceae

159. Coriariareae

160. Empetraceae

161. Limnanthaceae

162. Anacardiaceae

16:3. Cyrillaceae

164. Pentaphylacaceae

16.5. Corynocarpaceae

166. Aquifoliacere

167. Celastraceae

16. Hippocrateaceae

169. Stackhousiaceae

170. Staphyleaceae

171. Ieacinaceae

172. Aceraceae

173. Aesculaceae 
173. Hippocastanaceae

174. Sapindaceae

175. Sabiaceae

176. Bersamaceae

176. Melianthaceae

177. Impatientaceae

177. Balsaminaceae 2

178. Rhamnaceae

179. Vitaceae 4

1s0. Elaeocarpaceae

181. Schizolaenaceae

181. Chlaenaceae

182. Gonystylaceae

18:3. Tiliaceae

18t. Malvaceae 3

155. Tripiochitonaceae

1S6. Bombacaceae

187. Sterculiaceae

1s. Scytopetalaceae

189. Dilleniaceae

190. Eucryphiaceae

191. Ochnaceae

192. Caryocaraceae

193. Marcgraviaceae

19.. Quiinaceae

195. Theaceae

196. Hypericaceae

197. Clusiaceae

196. $197 . \quad$ Guttiferae

14ฬ. Dipterocarpaceae

19!). Elatinaceae

200. Frankeniaceae

201. Tamaricaceae

2()2. Fouquieviaceae

203. Cistaceae

204. Bixaceae

205. Cochlospermaceae

206. Koeberliniaceae

207 . Canellacene

20s. Violaceae

209. Flacourtiaceae

210. Stachyuraceae

211. Turneraceae

212. Malesherbiaceae

213. Passifloraceae

214. Achariaceae

215. Papayaceae

215. Caricaceae

216. Loasaceae

217. Datiscaceae
TABLE I.-(Continued)

218. Begoniaceae 2

219. Ancistrocladaceae

220. Cactaceae

221. Geissolomaceae

222. Penaeacea

223. Oliniaceae

224. Thymelaeaceae

225. Elaeagnaceae

226. Lythraceae

227. Blattiaceae

227. Sonneratiaceae

228. Crypteroniaceae

229. Punicaceae

230. Lecythidaceae

231. Rhizophoraceae

232. Combretaceae

233. Myrtaceae

234. Melastomataceae

235. Onagraceae

236. Trapaceae

236. Hydrocaryaceae

237 . Haloragidaceae

237. Halorrhagidaceae

238. Cynomoriaceae

239. Araliaceae 2

240. Apiaceae

240. Umbelliferae 4

241. Cornaceae

242. Clethraceae

243. Pyrolaceae

244. Monotropaceae

243.

244. \}Prolaceae

245. Lennoaceae

246. Ericaceae

247. Vacciniaceae

246.

247.

Ericaceae

248. Epacridaceae

249. Diapensiaceae

250. Theophrastaceae

251. Myrsinaceae

252. Primulaceae

253. Plumbaginaceae

254. Sapotaceae

255. Diospyraceae

255. Ebenaceae

256. Styracaceac

257. Symplocaceae

258. Oleaceae 3
259. Salvadoraceae

260. Loganiaceae

261. Gentianaceae

26.). Menyanthaceae

261.

262.

263. Apocynaceae

264. Asclepiadaceae

265. Convolvulaceae

266. Cuscutaceae

265. Convolvulaceae

267. Polemoniaceae

268. Hydrophyllaceae

269. Boraginaceae

270. Verbenaceae

271. Menthaceae

271. Labiatae

272. Nolanaceae

27.3. Solanaceae 10

274. Scrophulariaceae

275. Bignoniaceae

276. Pedaliaceae

277 . Martyniaceae

278 . Orobanchaceae

279. Gesneriaceae

2 so. Columelliaceae

2S1. Pinguiculaceae

281. Lentibulariaceae

252. Globulariaceae

283. Acanthaceae

2S4. Myoporaceae

28.5. Phrymaceae

286. Plantaginaceae

287. Rubiaceae

2ss. Caprifoliaceae

2S9. Adoxaceae

290. Valerianaceae

291. Dipsacaceae

292. Cucurbitaceae 3

293. Campanulaceae

294. Goodeniaceae

295. Candolleaceae

296. Calyceraceae

297. Cichoriaceae

298. Ambrosiaceae

299. Asteraceae

297.

295. Compositae 6 
The widest gaps, it will be observed, are between Cruciferae and Rosaceae and between Hypericaceae and Begoniaceae, but these I believe represent nothing more than lack of knowledge. ${ }^{1}$

I give below - a list of genera within the limits of which one or more species are now said to be subject to attack. Many of these genera contain plants of great economic importance. Where I have some personal knowledge of the subject $I$ have italicized the genus name, and in what follows the reader will naturally expect me to draw illustrations principally from the diseases most familiar to me.

TABLE II

SHOWING GENERA OF FLOWERING PLANTS SUBJECT TO DISEASES OF BACTEIRIA ORIGIN

\begin{tabular}{|c|c|c|c|}
\hline Macrozamia & Dendrobium & Delphinium & Trifolium \\
\hline Pinus & Cattleya & Papaver & Medicago \\
\hline Hordeum & Oncidium & Brassica & Arachis \\
\hline Dactylis & Odontoglossum & Raphanus & Acacia \\
\hline Bromus & Cypripedium & Cheiranthus & Prosopis \\
\hline Zea & Phalaenopsis & Matthiola & Erythrina \\
\hline Setaria & Vanilla & Ribes & Geranium \\
\hline Andropogon & Salix & Amelanchier & Erodium \\
\hline Avena & Populus & Sorbus & Pelargonium \\
\hline Saccharum & Juglans & Eryobotrya & T'ropaeolum \\
\hline Secale & Castanea & Pyrus & Chaetospermum \\
\hline Triticum & Corylus & Cydonia & Fortunella \\
\hline Phleum & Morus & Prunus & Citrus \\
\hline Poa & Pouzolzia & Rubus & Lansium \\
\hline Agropyron & Protea & Cratogus & Cedrela \\
\hline Cocos & Cannabis & Fragaria & Manihot \\
\hline Oreodoxa & Acalypha & $\operatorname{Ros} a$ & Hevea(?) \\
\hline Richardia & Humulus & Heteromeles & Ricinus \\
\hline Amorphophallus & Ficus & Dotichos & Euphorbia \\
\hline Hyacinthus & Hippocratea & Lathyrus & Mangifera \\
\hline Allium & Rheum & Indigofera & Euonymus \\
\hline Lilium & Polygonum & Kraunhia (?) & Impatiens \\
\hline Iris & Atriplex & Lupinus & Vitis \\
\hline Ixia & Spinacia & Mucuna & Gossypium \\
\hline Gladivlus & Beta & Phascolus & Malva \\
\hline Musa & Amaranthus & Cicer & Sterculia \\
\hline Zingiber & Dianthus & Vigna & Elodea \\
\hline Canna & Nelumbium & Pisum & Begonia \\
\hline
\end{tabular}

${ }^{1}$ Since this was written two bacterial disenses have been reported on ${ }^{1}$ ibes and I have inoculated crown gall into Resedaceae and Crassulaceae. 
TABLE II.-(Continued)

$\begin{array}{llll}\text { Opuntia } & \text { Diospyros } & \text { Nicotiana } & \text { Ambrosia } \\ \text { Eucalyptus } & \text { Ligustrum } & \text { Physalis } & \text { Crepis (?) } \\ \text { Oenothera } & \text { Syringa } & \text { Petunia } & \text { Ageratum } \\ \text { Aralia } & \text { Olea } & \text { Datura } & \text { Chrysanthemum } \\ \text { Hedera } & \text { Fraxinus } & \text { Calceolaria } & \text { Lactuca } \\ \text { Daucus } & \text { Strychnos } & \text { Sesamum } & \text { Blumea } \\ \text { Pastinaca } & \text { Nerium } & \text { Pavetta } & \text { Spilanthes } \\ \text { Levisticum } & \text { Symphytum } & \text { Psycotria } & \text { Pluchea } \\ \text { Apium } & \text { Tectona } & \text { Benincasa } & \text { Synedrella } \\ \text { Arbutus } & \text { Verbena } & \text { Cucumis } & \text { Calendula } \\ \text { Vaccinium } & \text { Coleus } & \text { Cucurbita } & \text { Tragopogon } \\ \text { Ardisia } & \text { Salvia } & \text { Citrullus } & \text { Bellis } \\ \text { Crispardisia } & \text { Capsicum } & \text { Sicyos } & \text { Helianthus } \\ \text { Amblyanthus } & \text { Solanum } & \text { Echinocystis } & \text { Aster } \\ \text { Amblyanthopsis } & \text { Lycopersicum } & \text { Eclipta } & \end{array}$

PERIOD OF GREATEST SUSCEPTIBILITY

In certain diseases the brief seedling stage of the plant is the one most subject to attack, e.g., Stewart's disease of maize due to Aplanobacter stewarti, and brown rot of tomato and tobacco due to Bacterium solanacearum, but many bacterial diseases of older plants are also rather strictly time-limited. In both groups it is a question of abundant immature tissue. To the latter class belong the numerous leaf-spots, fruit-spots, and blights, e.g., black spot on the plum and peach, due to Bacterium pruni, the fire-blight of the pear, apple, quince, etc., due to Bacillus amylororus and the blight of the mango due to Bacillus mangiferce (Figs. 2, 3,). In such cases, so far at least as they occur in temperate climates, the disease appears in the spring and the greater part of it occurs during a brief period in the early summer, in which growth of roots, leaves and shoots is proceeding rapidiy and there are many young and succulent parts. The cause of the disease may and often does remain on the plant over winter in a latent or semi-latent condition (walnut blight, pear blight, plum canker, etc.), but the active period is limited to three months, more or less, of actively growing weather in which developing tissues, subject to infection, are abundant. With the end of rapid growth and the hardening of the 
tissues in late summer and autumn, the disease ischecked and disappears, or remains as a slow canker to appear again on other parts the following spring. It is a very instructive experiment to see, for example, inoculations of Bacillus amylovorus on ripen-

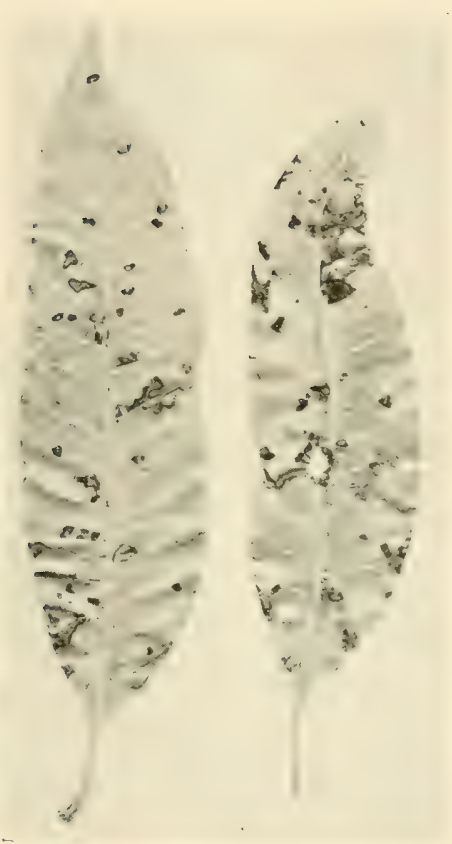

FIG. 3.-MIango leaves showing bacterial spots. Specimens received from South Africa. (Courtesy of Miss Doidge.)

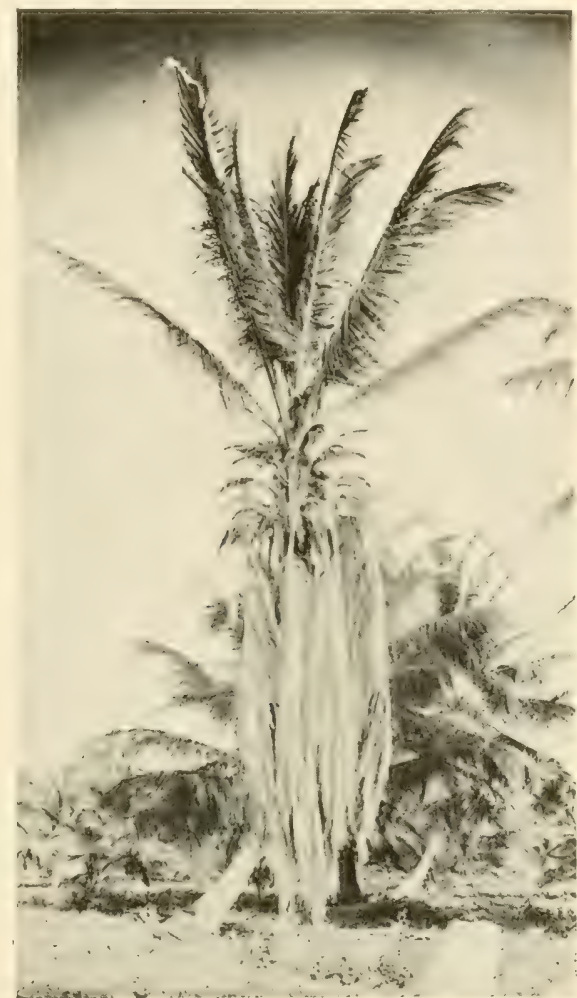

FIG, 4.-West Indian coconut budrot. The reflexed persistent dead fronds are typical. (After John R. Johnston.)

ing fruits and shoots of the pear wholly fail toward the end of summer, which were eminently successful on the same trees at its beginning. The difference in this case is not due to lessened virulence on the part of the organism, but to changes in the host-plant, making it non-susceptible. Similar changes 
leading to non-susceptibility occur in the Japanese plum subject to Bacterium pruni; the young fruits are very susceptible, the maturing fruits cannot be infected. In the destructive coconut bud-rot of the West Indies (Fig. 4) only the young "swords" and the undeveloped, sheathed, terminal bud are attacked by the bacteria.

Other parasites, on the contrary, are able to attack, disintegrate and destroy matured tissues, such as the pith of cabbage stems, turnip roots, the ripened tubers of the potato, the well-developed roots of sugar beets and of carrots, the bulbs of onions and hyacinths, full-grown melon and cucumber fruits.

In both of these types the action of the parasite is expended chiefly on the parenchyma. Although in some cases (the plum disease, Appel's potato rot) there is more or less bacterial inrasion of the local ressels, vascular occupation is not a special characteristic.

In the typical vascular diseases the case is reversed. Here parenchyma is also destroyed, more or less, but the most conspicuous and destructive action is on the vascular bundles, the hadrome ressels of which are occupied for long distances, to the death, or great detriment, of the whole plant. In maize attacked by A planobacter stewarti, it is not unusual, indeed one might rather say it is customary, to find the ressels of the stem filled with the bacteria continuously for a distance of 3 to 6 feet from the point of infection, i.e., from the surface of the earth to the top of the full-grown plant. In cucurbits attacked by Bacillus tracheiphilus, in bananas attacked by Bacillus musae (Fig. 5) and in sugar-cane attacked by Bacterium vascularum the same thing occurs, and many of the ressels are filled solid with the bacterial slime to a distance of 8 or 10 feet from the place of infection. In such cases infection has taken place, generally, near the base of the plant which continues to grow for some weeks or months.

Transitions, of course, occur. For example, Aplanobacter stewarti, is confined much more strictly to the vascular bundles of the maize stem than is Bacterium solanacearum to those of the tomato, potato, or tobacco stem, although it also is a vascular parasite; that is, following infection of the ressels we do not 


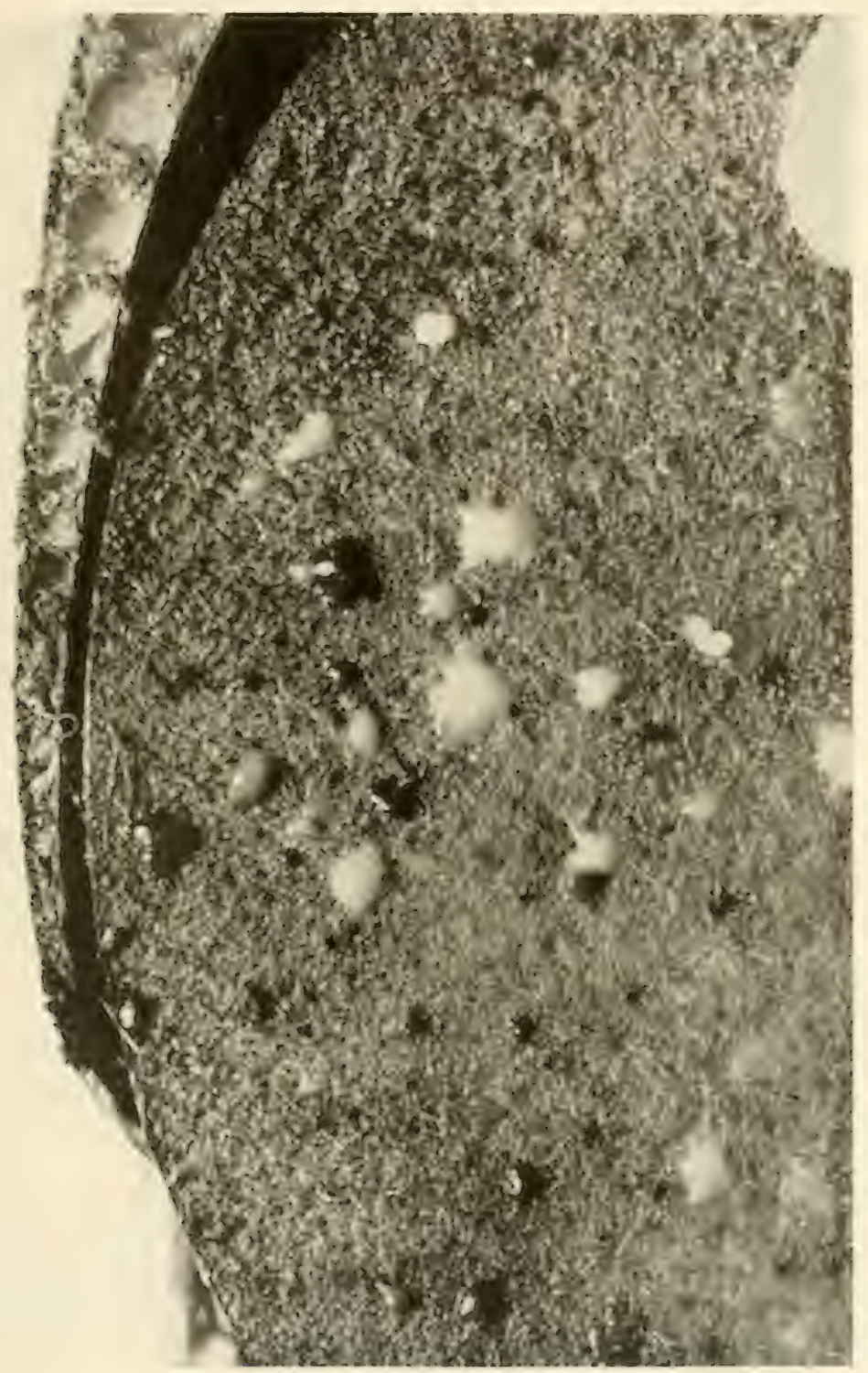

EIG. 5. - Cross-section of a banana fruit-stalk from Trinidad showing drops of the slime of Bacillus musa Rorer oozing from the vascular bundles, some of which together with the drops are stained brown. $\times 3$.

Photo. by James F. Brewer. 
find in the maize stems that extensive breaking down of the pith and bark into vast cavities which is so common, for example, in tobacco and tomato stems.

\section{WHAT GOVERNS INFECTION}

Within the plant we may suppose, from certain indications, that abundant juiciness is one of the factors governing the infection of immature tissues. To this may be added an abundant supply of well-adapted food and, in some cases, probably the absence of inhibiting substances, which may appear later. Is parts approach maturity, the intercellular air-spaces become much larger and the water content becomes relatively less. Along with this, acids, sugars, proteids, amino-acids, etc, are consumed and converted into substances less well adapted to the needs of the meristem-parasites, if not wholly inimical. In young shoots of potato and tomato, or of pear and apple, as contrasted with old ones, or in the roots of carrots as compared with the leaves, or in juicy carrots as compared with flabby ones, or in rapidly growing cabbages as compared with slow-growing ones, we know that there is an excess of water, and this alone appears to be sufficient to explain the difference in behavior of their respective parasites in old versus young parts. When, however, we come to ripening fruits, such as the pear and the plum, it would seem that they are still juicy enough to favor the growth of almost any bacterium; we are forced, therefore, to the hypothesis of chemical changes within the fruits to account for the failure of inoculations, and this throws some doubt on the preceding hypothesis. As a rule (there are striking exceptions), parasitic micro-organisms are rather sensitive to changes in their environment, e.g., to drying, exhaustion of foodsupplies, multiplication of their own by-products, conversion of an easily assimilable substance into one less assimilable or actually harmful, appearance of esters, new acids, etc. But why speculate! Nuch additional experimenting must be undertaken before we shall have precise and full data. We are still largely in the observational stage and experiments are needed. ${ }^{1}$

\footnotetext{
${ }^{1}$ In the above connection the following list of fruit acids may be of some use:
} 
The parasites of ripened tissues do not require so much water, are able to convert starch into sugar, or have a special liking for some other element of the plant tissue.

Externally, a number of factors favor infection. One of these is excessive shade, either of clouds or of foliage, and another is high temperature. When these two factors are accompanied by excessive rainfall, high winds, wet earth, and heavy dews, the conditions are ideal for the rapid dissemination and the destructive prevalence of a variety of bacterial diseases of cultivated plants. The bean blight due to Bacterium phaseoli, the angular leaf spot of cucumber due to Bacterium lachrymans (Figs. 6 to 9), the black spot and canker of the plum due to Bacterium pruni, and the lark-spur disease due to Bacterium delphinii, are all favored by heavy dews and by shade. In hot, wet weather in midsummer, pear blight due to Bacillus amylovorus often bursts out like a conflagration and sweeps over whole orchards. In warm, moist autumns bacterial diseases of the potato may destroy almost or quite the entire crop over extensive districts.

Fruit

Apple. ...

Banana

Cantaloupe

Cherry.

Cranberry............

Currant.....

Gooseberry

Peach.

Pear.

Persimmon............

Plum .

Pomegranate.

Quince

Raspberry (red) .........

Watermelon
Acids found

Malic only.

Probably malic only.

Malic none-probably all citric.

Malic only.

Citric probably predominates-malic also present.

Citric probably predominates-malic sometimes present.

Malic and eitric.

Probatbly malic only.

Malic only in some varieties; citric probably predominates in others with small amounts of malic.

Probably malic only.

Malic only.

Probably all citric - no malic or tartaric.

Mialie only-no citrie.

Probably citric only-malic, if present, in traces only.

Malic, no eitric.

Jour. Amer. Med. Assoc., vol. lxix, No. 17, Oct. 27, 1917, p. 1433.

Bigelow, W. D., and Dunbar, P. B.: The acid content of fruits, Jour. Industrial and Engineering Chem., 1917 (9, 762). 


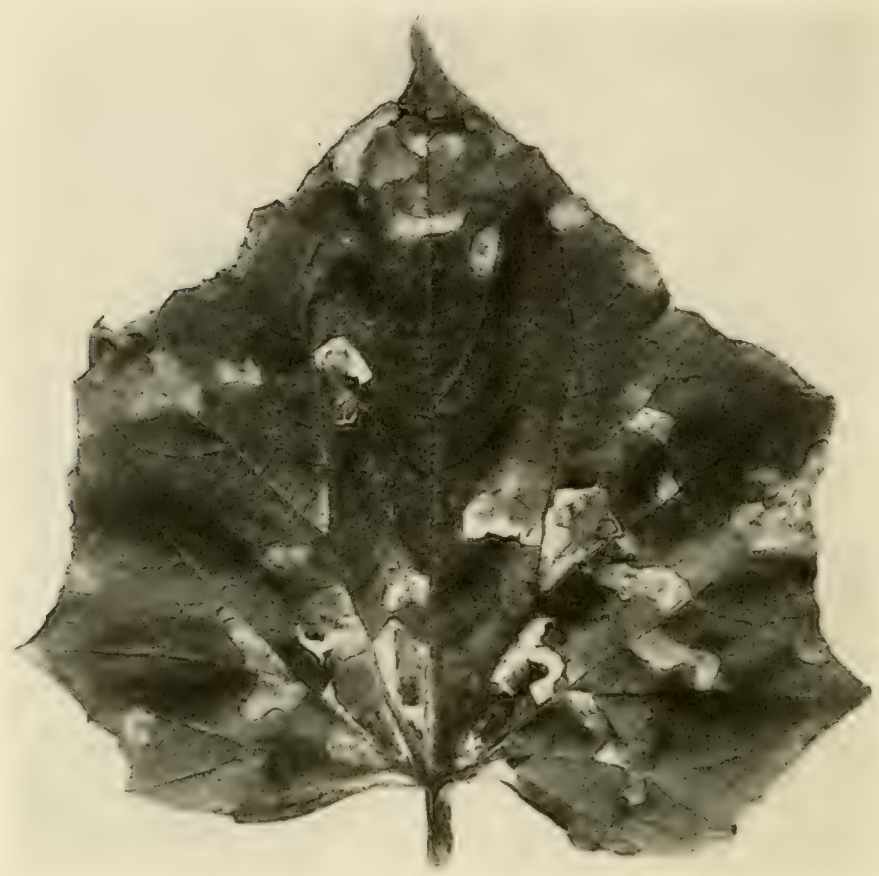

Fig. 6.-Angular leaf-spot on cucumber due to stomatal infections produced by spraying-on Bacterium lachrymans Smith and Bryan. It shows breaking of tissue around old spots. Time, 12 days.

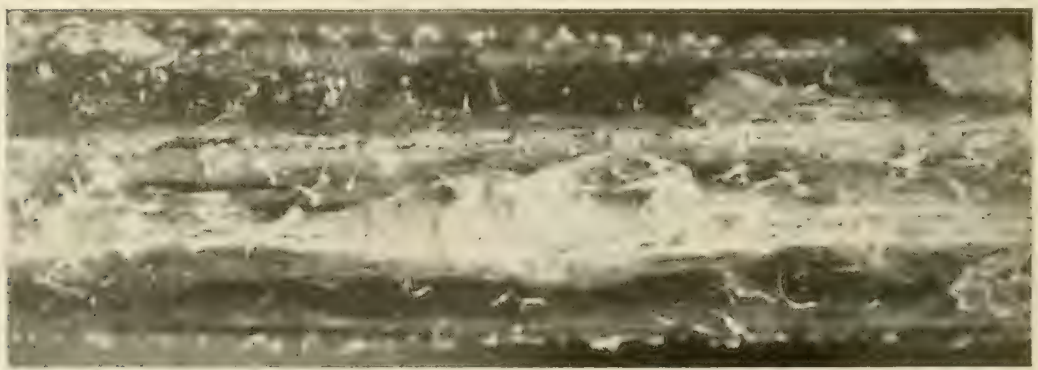

Fig. 7.-Cucumber stem showing white bacterial film and eracks due to Bacterium lachrymans. Inoculated by spraying May 6, 1915. Photographed May 20. $\times 14$. 


\section{HOW INFECTION OCCURS}

As I have already described elsewhere how infection occurs, ${ }^{1}$ I will dwell on it here only for a moment, offering a few examples.

The commonest way of infection is probably through wounds. In Italy, the olive tubercle due to Bacterium savastanoi has been observed to begin very often in wounds made by hail-

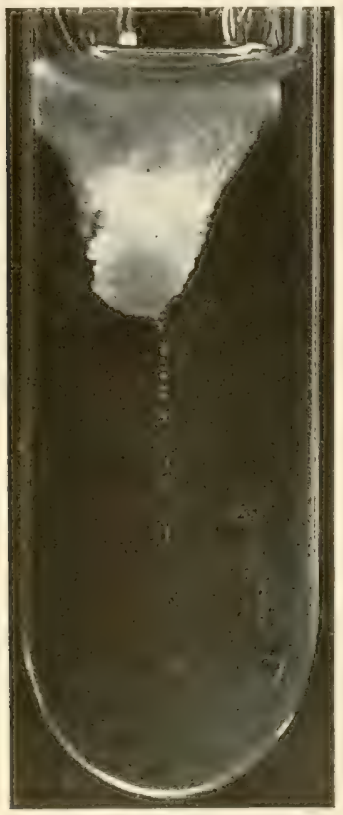

FIG, S.

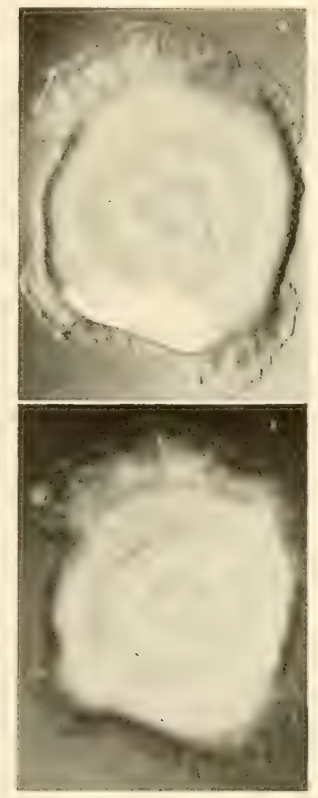

FIG, 9.

FIG. S.-A beef peptone gelatin $(+10)$ stab culture of Bacterium lachrymans after 12 days at $20^{\circ} \mathrm{C}$. In the unliquefied part the colonies along the needle track are very small showing that it is aërobic.

FIG. 9.-Two different illuminations of a small gelatin colony of Bacterium lachrymans to show the characteristic margin. $\times 14$.

stones. In South Africa, crown gall is said to be disseminated in the same way. In this country and also in Sumatra, Bacterium solanacearum enters the plant more often than otherwise through broken roots. A tomato or tobacco plant with

${ }^{1}$ Smith, Erwin F.: "Bacteria in relation to plant diseases," Carnegie Inst. Washington, Publ. 27, Vol. 2, pp. 51-64, 1911. 
unbroken roots will thrive in a soil deadly to one that has been root-pruned. I have myself observed this. We may suppose that substances attractive to the particular bacteria diffuse into the soil from the broken roots, following which they enter the plant. Resistant plants may be supposed to diffuse indifferent or repellant substances. All infections must be chemotactic.

More interesting perhaps are those diseases which begin in natural openings, i.e., in places where the protective covering of the plant gives place to special organs such as nectaries, waterpores, and stomata.

All the pome fruits subject to fire-blight are liable to blossom infection. The bacteria multiply first in the nectaries of the flower and pass down into the stem by way of the ovary and pedicel. Blossom blight of the pear is a very conspicuous and common form of the disease, as everybody knows. Thousands of blighted blossom-clusters may be seen in any large orchard subject to this disease. Blossom-blight arises from "hold-over" blight (see Figs. 282 and 283), the visiting insects acting as carriers.

In the black rot of the cabbage due to Bacterium campestre, the majority of the infections begin in the water-pores. These are grouped on the margins of the leaf at the tips of the serratures. From this point the bacteria burrow into the vascular system of the leaf and so pass downward into the stem and upward into other leaves.

In the black spot of the plum, due to Bacterium pruni almost or quite all of the leaf and fruit infections are stomatal. A large proportion of them are also stomatal in the leaf-spot of cotton due to Bacterium malvacearum, the leaf-stripe of sorghum and broom-corn due to Bacterium andropogoni, the leaf-spot of carnations due Bacterium woodsii, and other leaf-spots. ${ }^{1}$

\section{TIME BETWEEN INFECTION AND APPEARANCE OF THE DISEASE}

As in animal diseases, the period of latency may be very short or surprisingly long. Some time must be allowed the

1 The writer first called attention to stomatal infections in 1897 , having demonstrated their existence experimentally. See "Bacteria in Relation to Plant Diseases," Vol. 2, pp. 39, 56, 57; Pls. ${ }_{-3}^{3}$, 4, and Figs. 11, 12, 15, 16, 17. 
parasitic organism to multiply inside the plant before it does damage serious enough to be recognized externally as a disease. This is the so-called "period of incubation," during which the parasite is growing and its enzymes and toxins are becoming active. The microscope shows it to be present in the tissues, but the latter have yielded only a little in the immediate vicinity of the bacterial focus. This time is short or long depending on whether the parasite or the host has the first advantage. If the host is growing rapidly it may either entirely outstrip the parasite, or be only so much the more subject to it. All depends on whether the parasite finds the initial conditions entirely suited to its needs, or by means of its secretions and excretions can quickly make them so, and consequently can from the start make a rapid growth, or must first slowly overcome obstacles of various sorts, such as inhibiting acids and resistant tissues. The plant may show signs of infection within as short a time as one or two days after inoculation (various soft rots), or it may be as long a time as one to two months before they appear (Cobb's disease of sugar-cane, Stewart's disease of sweet-corn). In the latter, infection generally occurs in the seedling stage and the maize plant may be three months old and six feet tall before it finally succumbs. Of course, as in case of bacterial animal diseases, the greater the volume of infectious material, the shorter the time. I have seen many instances of that law. In general, the period of latency may be said to vary from one to three weeks (yellow disease of hyacinth, black rot of cabbage, black spot of plum, cucurbit wilt, pear blight, angular leaf-spot of cotton, sorghum leaf-stripe, etc.). The longest period of latency I have observed was two years. This was in crown gall on orange (see Fig. 342).

\section{RECOVERY FROM DISEASE}

Mention has already been made of the self-limited spot diseases and blights. As the actively growing season draws to a close such diseases cease their activity.

Also in some plants well developed signs of vascular disease may be suppressed (squash, maize, sugar-cane, etc.), or 


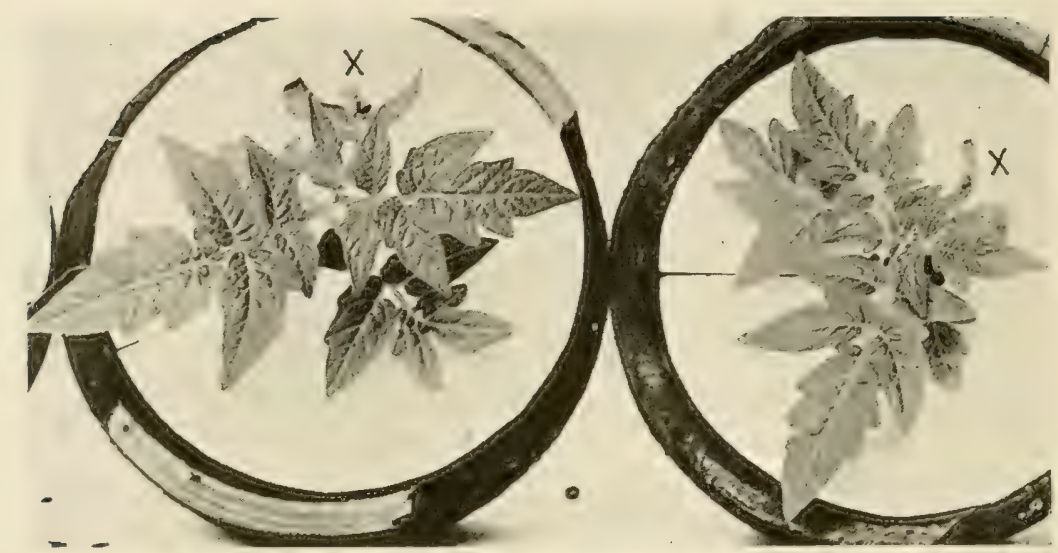

FIG. 10.-Two young tomato plants of a sensitive variety inoculated and wilting on leaf marked $X$, as a result of needle-pricks introducing the Sumatran strain of Bacterium solanacearum which had been exceedingly virulent but was"now losing its power to infect. These plants recovered and are shown in Fig. 11.

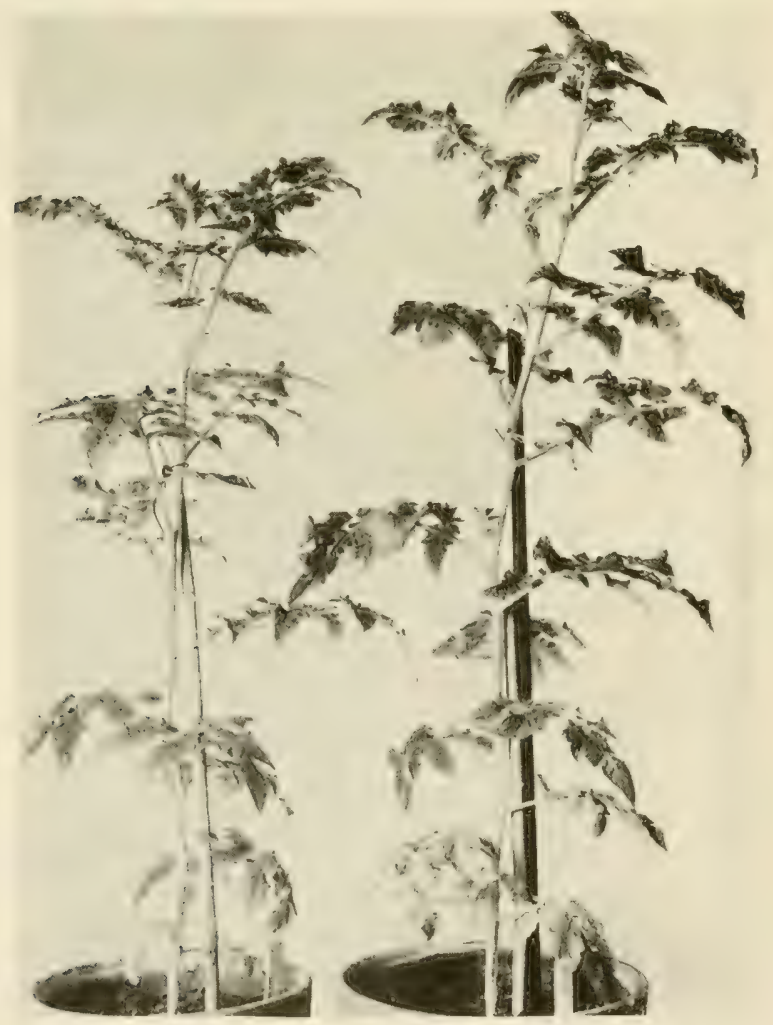

FIG. 11. - Same as Fig. 10, but after 21/2 months. Plants recovered. The only part of the stem to develop incipient roots was the base near the inoculated leaf. Plants 2 feet 6 inches and 2 feet 11 inches high. Leaves not reflexed. 
remain in abeyance for a longer or shorter period, according to the varying fortunes of the host and the capabilities of the parasite. The tomato plants inoculated with Bacterium solanacearum (Medan III) and photographed for Volume III of "Bacteria in Relation to Plant Diseases," (Plate $45 \mathrm{D}$ ), entirely outgrew the disease (Figs. 10 and 11), as did also certain sugarcanes (series vi) inoculated with Bacterium vascularum. ${ }^{1}$ Also, I have seen tomato plants recover only to develop a second and fatal attack of the vascular brown rot three months after the first attack, during which period they had made an extensive healthylooking growth. ${ }^{2}$

Recovery from disease may depend on loss of virulence on the part of the parasite. This loss often occurs when bacteria are grown for some time on culture-media, and it occurs also in nature, but its cause is obscure; possibly it is due to oxidations. Practically nothing is yet known about acquired immunity on the part of the host plant.

\section{AGENTS OF TRANSMISSION}

These may be organic or inorganic. In many cases the plant itself harbors the parasite indefinitely, carrying it over from year to year on some portion of its growth (Pear blight, citrus canker, crown gall, etc.).

Seeds, tubers, bulbs, grafts, or the whole plant may be responsible for the appearance of the disease the following year in the old localities, and through the

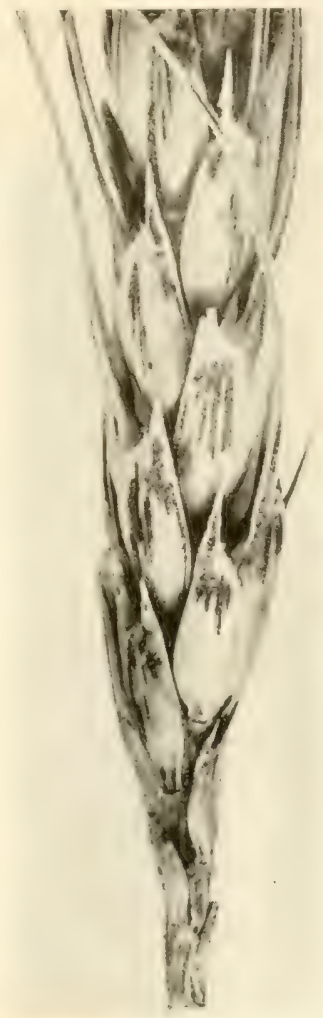

F I G. 12.-Bacterial black chaff disease of wheat. Kansas, end of June, 1915 . Black stripes on glumes and rachis. Kernels shriveled and also bacterially invaded. $\times 21 \%$. agency of seedsmen, nurserymen, or whoever disseminates plants, for outbreaks in regions hitherto exempt.

'Smith, Erwin F.: "Bacteria in relation" to plant diseases," Carnegie Inst. Washington, Publ. 27, Vol. 3, p. 33, 1914.

${ }^{2}$ Ibid., p. 179. 
There is good reason to believe that the black rot of cabbage and Stewart's disease of sweet corn have been disseminated broadcast in the United States in recent years by ignorant and unscrupulous seedsmen. Both diseases are transmitted to seedling plants from the seed. The bacterial black chaff of wheat (Figs. 12 to 22) which is widely prevalent in Kansas, Iowa and

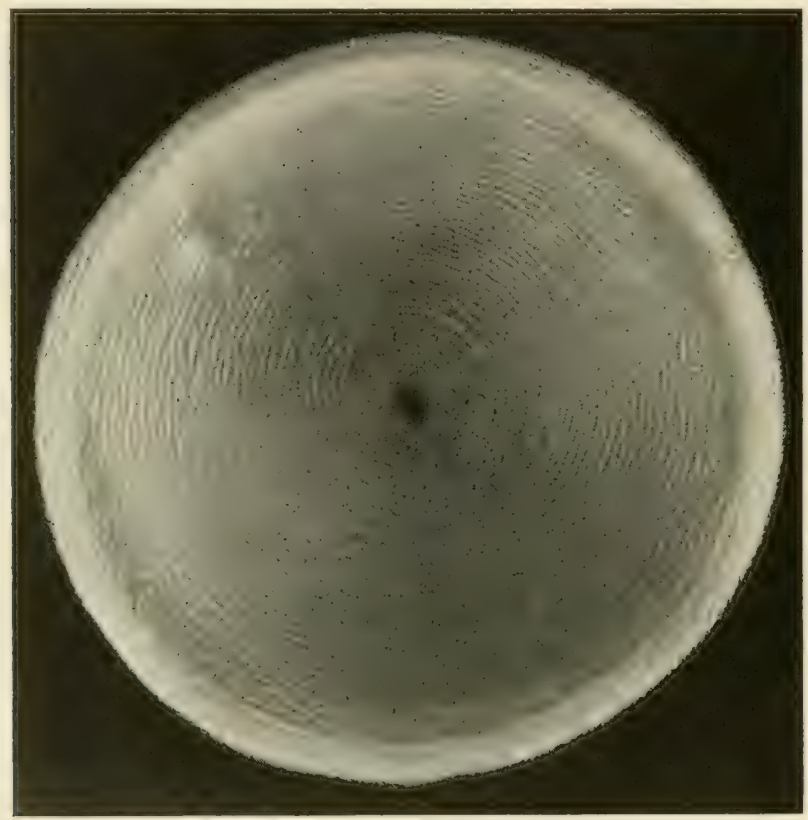

FIG. 13.-A single yellow surface colony of Bacterium translucens var. undulosum Smith, Jones and Reddy, the schizomycete causing black chaff of wheat. A glume isolation on +15 beef-peptone agar from No. 273, Dubois, Nebraska. Photographed by oblique, transmitted light to show internal wave-like markings, surface perfectly smooth. Plate poured July 9, 1917. Photo July 30, Temp. $25^{\circ}-32^{\circ} \mathrm{C} . \times 10$.

other Western States is a seed-borne infection, and so is the very similar barley disease described by Jones, Johnson and Reddy. The yellow disease of hyacinths is carried in the bulb. Potato tubers from diseased fields may infect healthy fields. Apple grafts have transmitted crown-gall. Slightly infected trunks and limbs of trees (hold-over pear blight, walnut blight, canker of the plum) may infect shoots, leaves, blossoms, or fruits 
the following season. The soil around the infected plant may serve, it is believed, for years as a source of infection to other species (crown gall), or to other individuals of the same kind (various leaf-spots). Occasionally, however, a parasite seems to die out of certain soils (Bacterium solanacearum, Bacillus tracheiphilus). The pear blight organism probably dies as quickly in soils as it does in a majority of the blighted branches. Pear blight or cucurbit wilt by soil-infection is not known.

Among extraneous agents, wind and water have been suspected. I have never seen any clear indications of purely windborne infection, not even when contiguity seemed to invite it, but water and, of course, in driving rains, the wind, also, often carries parasites and furnishes conditions favorable to infection (citrus canker, angular leaf-spot of cotton, and bacterial canker of the tomato due to Aplanobacter michiganense). Horne has shown that the olive tubercle in California may be transmitted from the surface of diseased branches to sound branches by rain or dew (see Fig. 300). Honing, in the tobacco fields of Sumatra, has traced infection several times to the watering of plants from infected wells, and has cultivated the parasite from the water. I have discovered experimentally that to obtain in abundance several sorts of bacterial leaf-spots, e.g., those occurring on bean, cotton, peach, plum, carnation, larkspur, sorghum, geranium, etc., the leaves must be kept moist to the same extent they would be in case of prolonged dews or frequent light showers. In nature such conditions are necessary to enable the bacteria to penetrate the stomata and begin to grow. In case of water-pores, however, the plant itself furnishes the water necessary for infection, if the nights are cool enough, i.e., if the air remains near enough to saturation to prevent for some hours the evaporation of the excreted water from the leaf-serratures. Every plant with functioning water-pores a waits its appropriate bacterial parasite. The genus Impatiens is a good example. I have looked for one on it in vain but I am sure it must occur.

Man and the domestic animals, especially through the agency of the dung-heap, infallible repository of all sorts of disearded refuse, undoubtedly help to spread certain bacterial diseases of plants (potato rots, black rot of cabbage, etc.). 


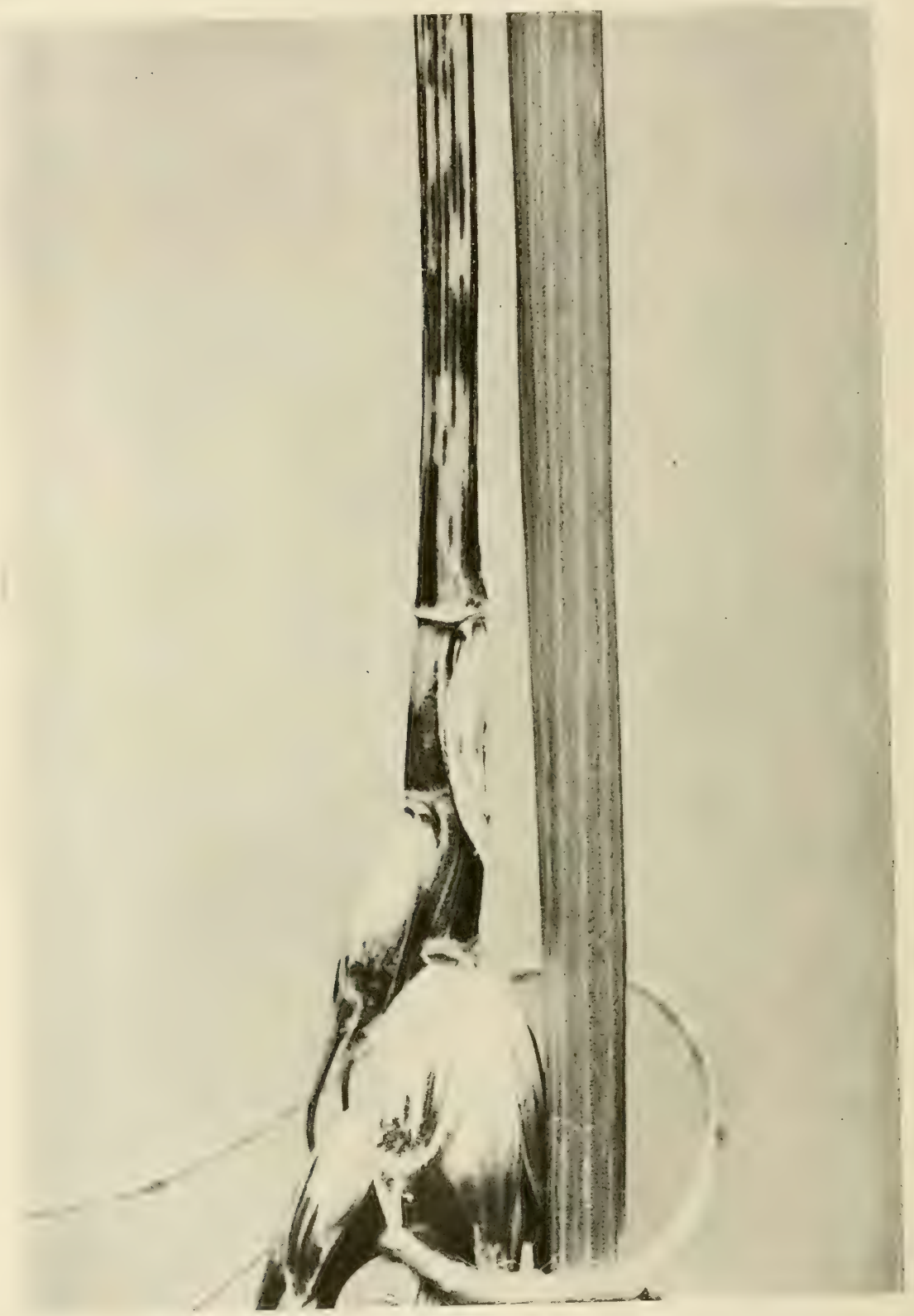

Fig, 14-Bacterial black chaff of wheat. Stalk bent double to show diseased (black-striped) upper part and sound (pale green) middle part. Wheat No. 268, collected June 28, 1917, on the Rhodes farm at Manhattan, Kansas. Photographed July 3, 1917, by James F. Brewer, using a W. and W. panchromatic plate and a yellow color screen. 


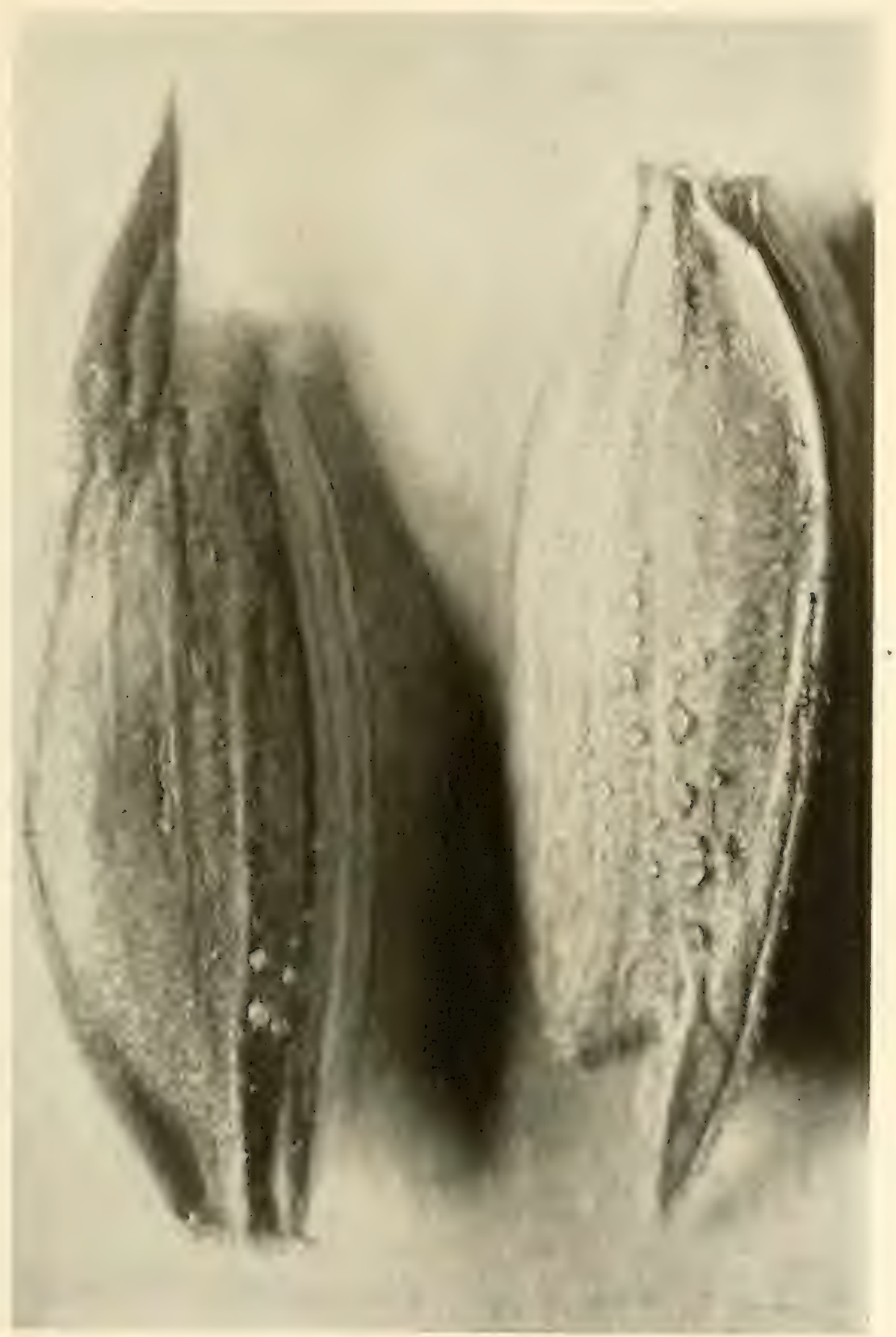

FIG. 15.-Montana spring wheat. Crop of 1917. Coll. Nu. 318. Diseased glumes showing bacterial exudate of the black chaff organism, Bacterium translucens var. undulosum S., J. and R. $\times 15$. 


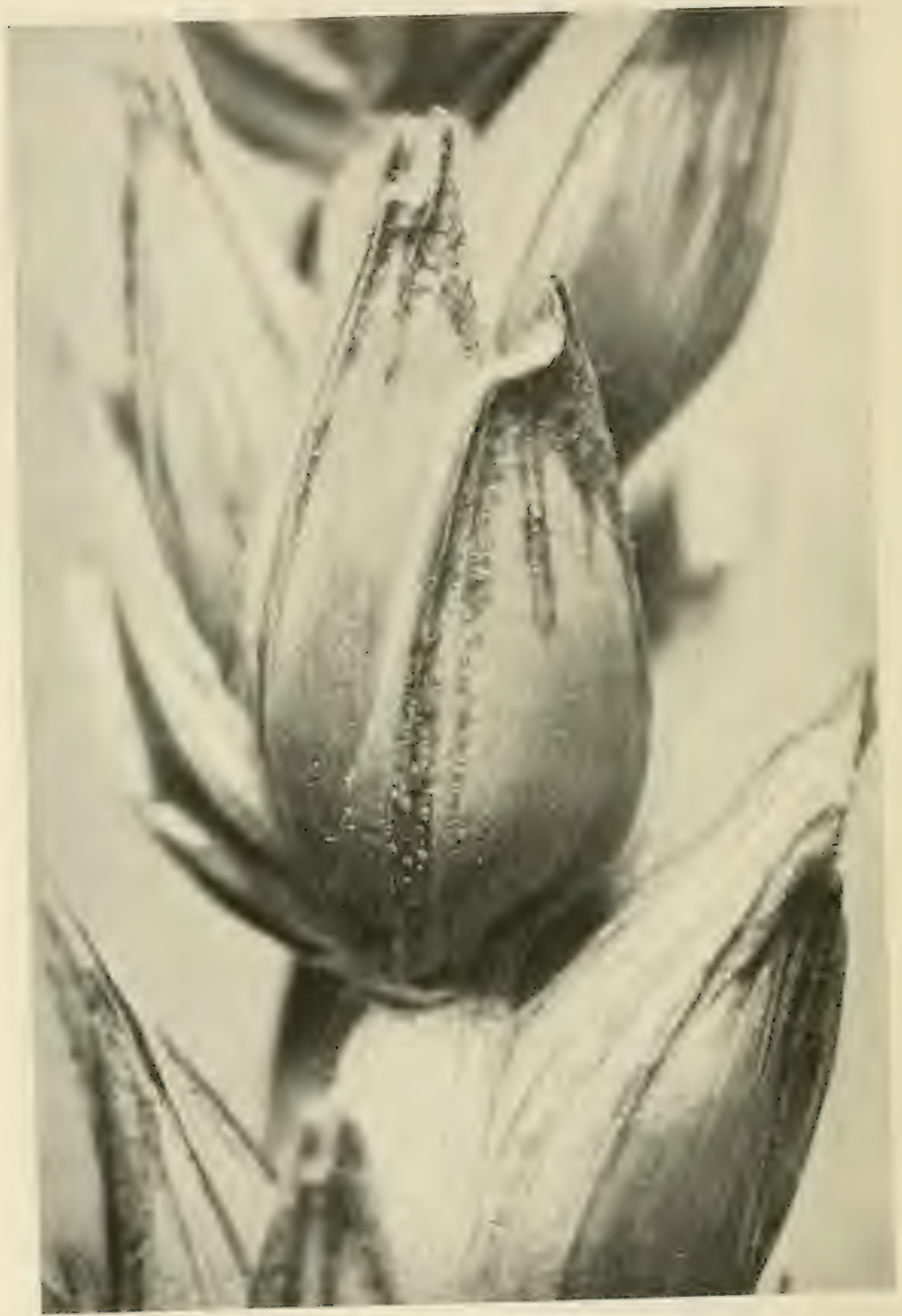

FIG. 16.-Black chaff of wheat. A glume infection done by Lucia McCulloch in the summer of 1917 with No. 20, from MeKinney, Texas. Inoculated June 21 from a pure culture. Photographed July 9 . The tiny beads are bacterial masses oozing from stomata. $\times 13$. 
Birds probably transmit some of these diseases on their feet or in other ways. In connection with the bud-rot of the coconut palm in the West Indies, I suspect the turkey-buzzard, but the evidence is not complete. Long since, Merton B. Waite obtained (once in Florida, once in Maryland) the strongest kind of circumstantial evidence going to show that pear blight may be spread by birds.

Respecting insects, molluses, and worms, the evidence is complete. They often serve to carry these diseases. I have summarized our knowledge in another place $^{1}$ and will here content myself with a brief statement calling renewed attention to the subject.

We had very good evidence of the transmission of one bacterial disease of plants (pear blight) by insects long before the animal pathologists awoke to the importance of the subject, ${ }^{2}$ but it cannot be said that they have ever paid much attention to it, although it antedates by two years the work by Theobald Smith and Kilborne showing that Texas fever is transmitted by the cattle tick (Ixodes bovis Ry.). That discovery also belongs to the credit of the Inited States Department of Agriculture, and the two together may be said to have laid broad and deep the foundations of this most important branch of modern pathology. Waite isolated the pear blight organism, grew it in pure cultures and proved its infectious nature by inoculations. With such proved cultures he sprayed clusters of pear flowers in places where the disease did not occur and obtained blossom-blight, and later saw this give rise to the blight of the supporting branch, found the organism multiplying in the nectar, and re-isolated it from the blighting blossoms. On some trees he restricted the disease to the sprayed flowers by covering them with mosquito netting to keep away bees and other nectar-sipping insects. On other trees where the flowers were not covered he saw bees visit them, sip from the inoculated blossoms and afterwards visit blossoms on unsprayed parts of the tree, which then blighted.

'Smith, Erwin F.: "Bacteria in relation to plant diseases," Carnegie Inst. Washington, Publ. 27, Vol. 2, p. 40, 1911.

2 Waite, Merton B.: Results from recent investigations in pear blight, Bot. Gaz. 16, 259; Am. Assoc. Adv. Sci., Proc., 40, 315, 1891. 


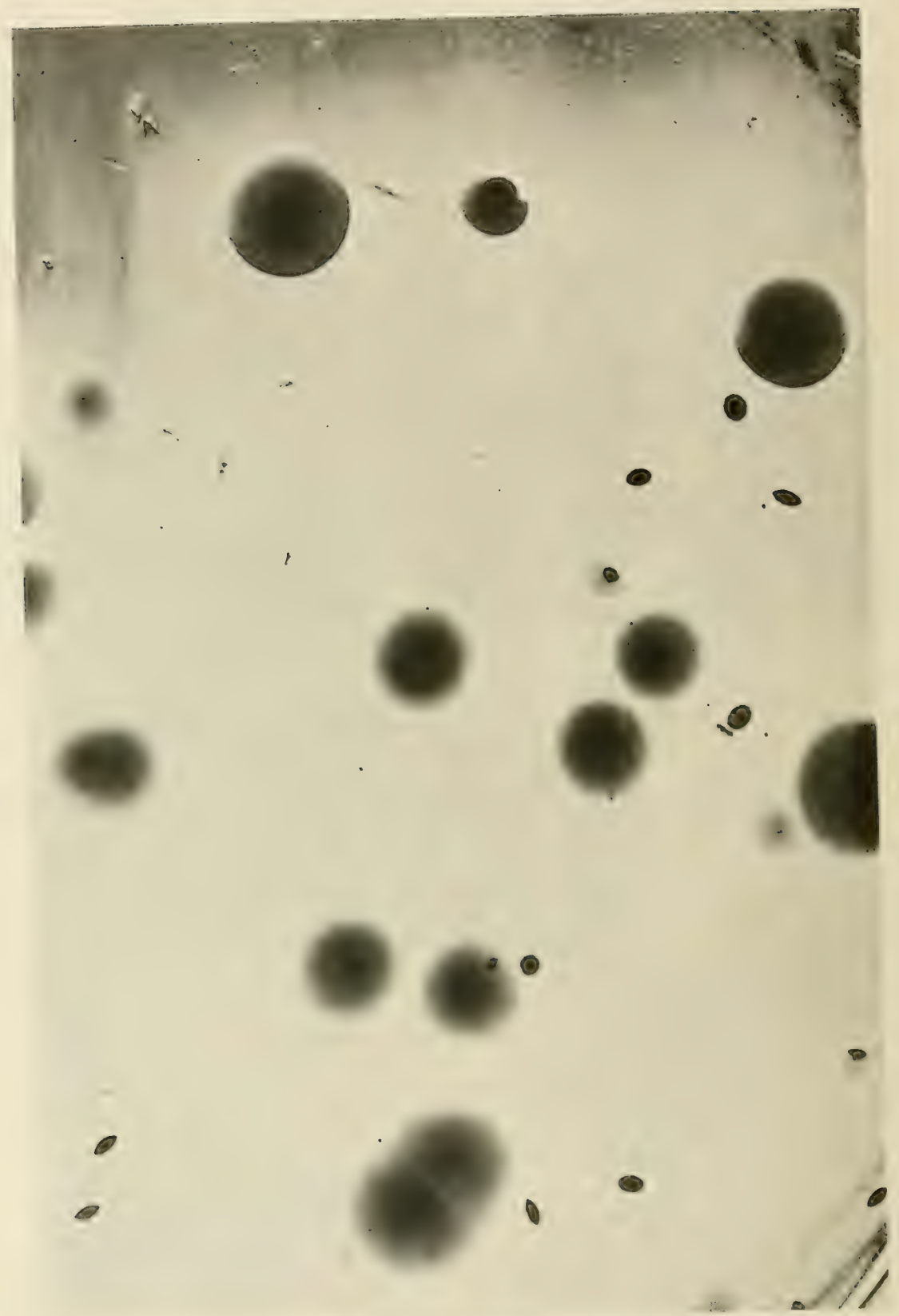

FIG, 17.-Black chaff of wheat. Agar plate poured (June 2, 1917) from a leaf

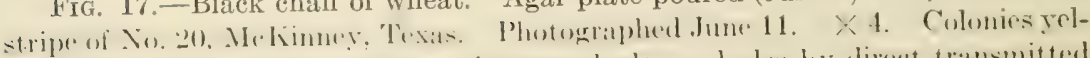

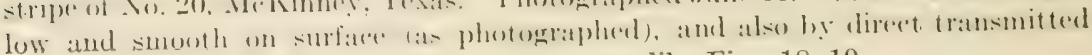
light; but by oblique transmitted light they are like Figs. 18, 19. 

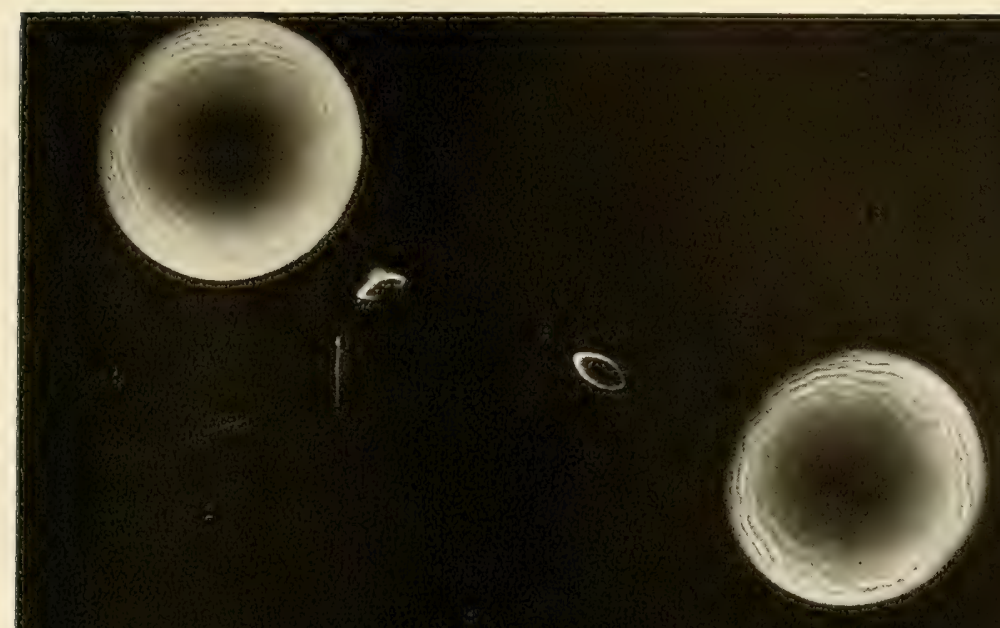

C
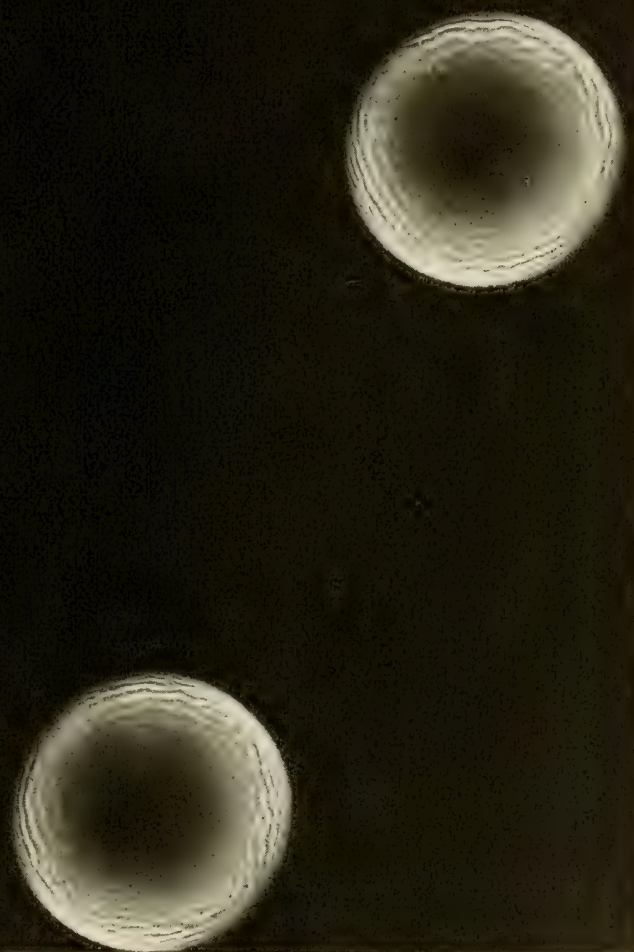

FIG. 18.-Bacterium translucens var. undulosum Smith, Jones and Reddy, from black chaff of wheat. No. 662, Monticello, Illinois. Surface and buried yellow colonies on +15 beef-peptone agar-poured plate. A pure-culture glume isolation of June 21, 1918. Photographed July 1 by oblique light to show internal markings-surface smooth. $\times 10$. 


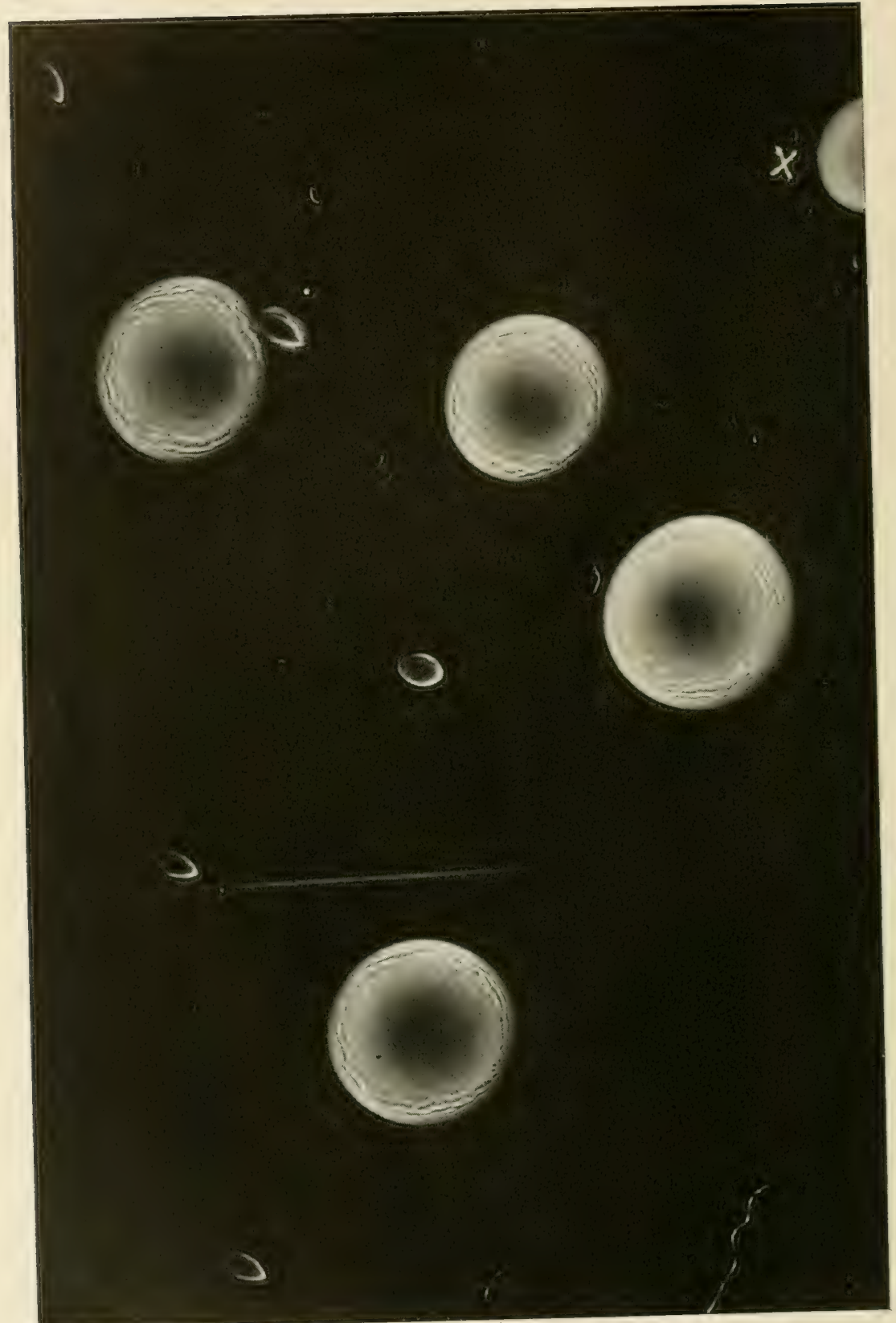

FIG. 19.-Bacterium translucens var. undulosum S., J. R. from black chaff of wheat. No. 678, El Reno, Oklahoma. Surface and buried yellow colonies on +15 beef-peptone agar plate. Plated June 24, 1918 (from a glume). Photographed July 2, by oblique light; surface smooth. At $x$ an intruding colony. $\times 10$. 


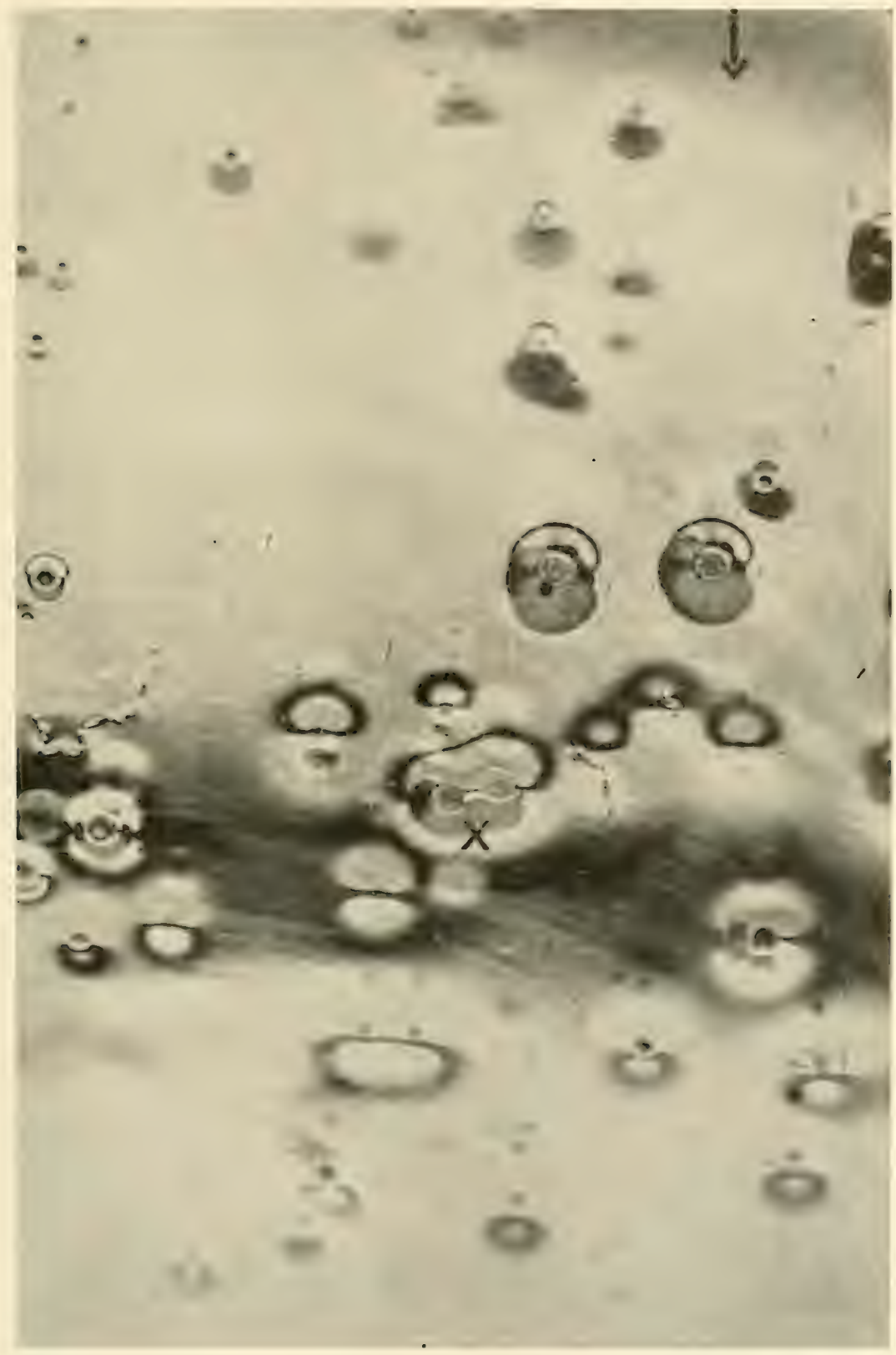

FIG. 20.-Bacterium translucens var. undulosum S., J. R. from black chaff of wheat. No. 252, Republic, Missouri. Beef-peptone gelatin-poured plate $(+9)$ from colony 52. Photographed by oblique light (from direction of the arrow) to show the small dry liquefaction pits. For the two at $x$, enlarged, see Fig. 21. 
Finally he captured bees that had visited such infected blossoms, excised their mouth parts, and from these, on agar-poured plates, obtained Bacillus amylovorus, with colonies of which he again produced the disease. These experiments were done in several widely separated localities with identical results. I saw them and they made a great impression on me.

The writer has since proved several diseases to be transmitted by insects, notably the wilt of cucurbits, and here the transmission is not purely accidental, but there appears to be an adaptation, the striped beetle (Diabrotica vittata) chiefly responsible for the spread of the disease being fonder of the diseased parts of the plant than of the healthy parts. This acquired taste, for it must be that, works great harm to melons, squashes, and cucumbers. Whether the organism winters over in the beetles, as I suspect, remains to be determined. Certainly the disease appears in bitten places on the leaves very soon after the spring advent of the beetles, i.e., before they have had opportunity to become infected from newly wilted cucurbits:

In the summer of 1915, Mr. Frederick V. Rand, assistant pathologist in my laboratory, undertook, at my suggestion, two series of experiments on Long Island, N. Y., to determine the truth or error of this hypothesis. His results, which have afforded a striking confirmation of my views, may be summarized in brief as follows:

In two cucumber fields where 75 per cent of the plants contracted the bacterial wilt disease in 1914 and where, up to September 1, 800 plants or about one in four contracted it in 1915 (later cases no doubt occurred but no further record was attempted owing to the appearance of the downy mildew), 180 plants kept inside of 50 large insect cages distributed at uniform distances through the two fields remained entirely free from the disease, except in two cages. In one of these two cages Diabrotica viltata was purposely introduced when the plants were only 2 to 3 inches high, and before there was any of the disease on the check plants. In this cage all of the plants contracted the disease which first appeared in bitten places on the leaves. In the other cage, a single beetle of that species penetrated accidentally later in the season (when the disease was quite prevalent outside on the checks) and gnawed and infected a single plant before it was discovered and removed, the other, unbitten, plants in the cage remaining healthy. The beetles were collected in one of the two experimental fields, remote from other plantations, at a time when the check plants were small and all still free from the disease. It is believed, therefore, that they hibernated in the vicinity and that their last source of infection was diseased plants of the preceding year, i.e., that they carried the wilt organism over winter in their bodies. That not all hibernated beetles transmit the disease is shown by the fact that some were liberated at the same time in three other cages but the plants remained healthy, and by the additional 

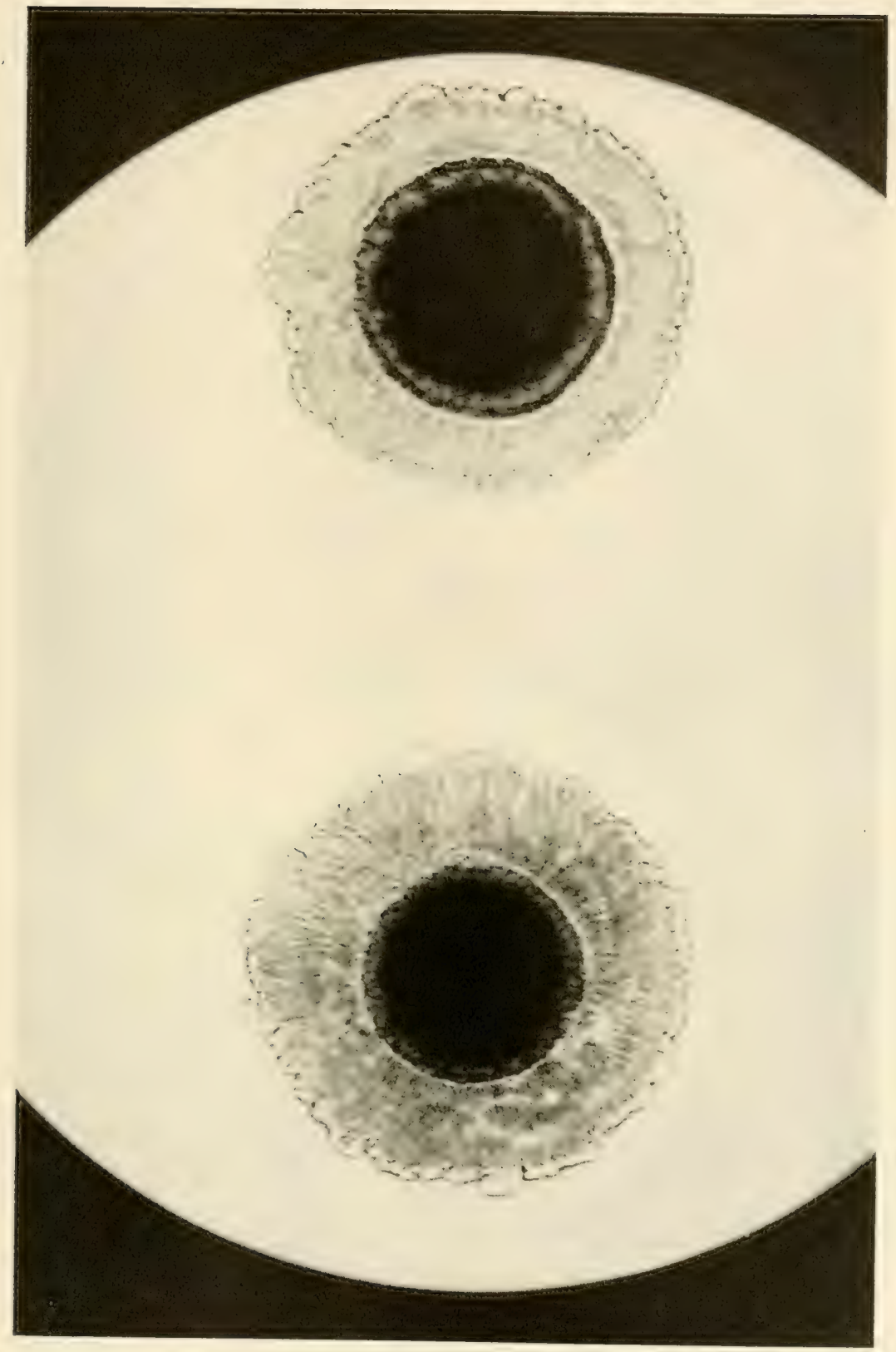

FIG. 21.-Black chaff of wheat. Two small surface colonies on +9 beef peptone gelatin. Enlarged $\times 85$ to show thin pale fringe in the dry pit of liquefaction. Plate poured January 30, photographed February 9, 1918. 


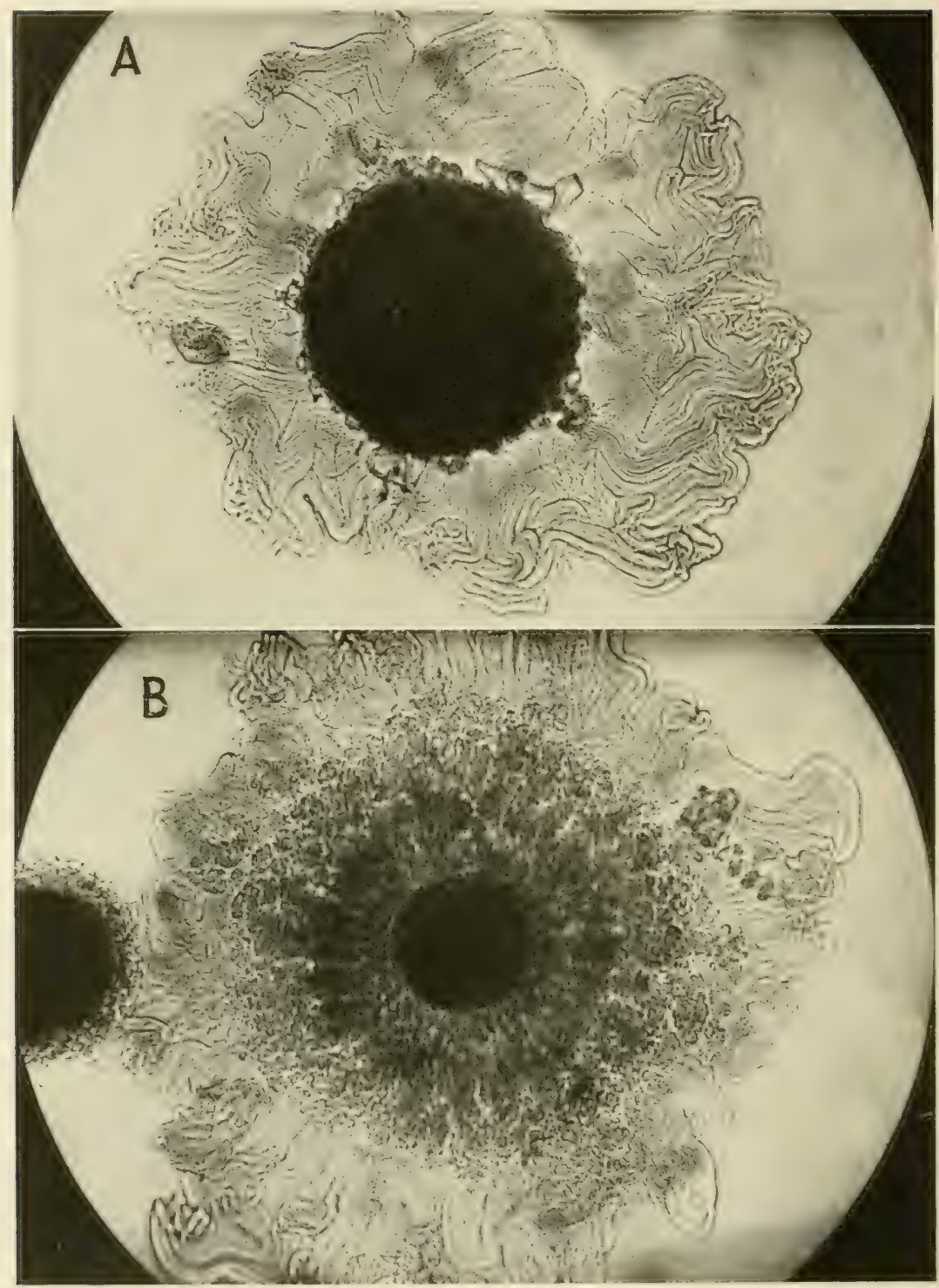

FIg. 22.-Colonies of Bacterium iranshucens var. undulosum S., J. R., the cause of black chaff of wheat. Same as Fig. 21 but three days later. At the upper right side of the lower colony, lifted above the surface of the gelatin, is a bacterial tendril which has made 6 turns. $\quad \times 85$ 
fact that on the checks the disease first appeared on a few only of the many bitten plants, and from these few was subsequently spread to many others by the beetles, the disease appearing everywhere first, in bitten leaves, a few days after they were gnawed by the beetles. From these experiments we may conclude:

1. Striking confirmation of my statements respecting summer distribution of this disease by Diabrotica viltata.

2. Freedom of plants from disease when protected from this beetle by wire screens, although presumably growing in infected soil.

3. Inability of aphides and flea beetles to cause the disease, since they entered the cages to some extent but did not act as carriers.

4. Evidence that the disease is not air-borne or water-borne.

5. Proof that the disease is not transmitted by way of the soil-at least not in the absence of insects.

6. Strong circumstantial evidence that Bacillus tracheiphilus winters over in "bacillus carriers," i.e., in certain beetles which function as the spring distributors of the disease. ${ }^{1}$

In 1897 I observed and proved experimentally that molluses sometimes transmit brown rot of the cabbage, and in 1913 I saw indications in southern France which learl me to think that snails are responsible for the spread of the oleander tubercle, i.e., I saw them eating both sound and tubercular leaves, and found young tubercles developing in the eroded margins.

Parasitic nematodes break the root-tissues and open the way for the entrance of Bacterium solanacearum into tobaceo and tomato, as was first observed by Hunger in Java and later by myself in the United States. One of the serious problems of plant pathology is how to control the nematode, Heterodern mdicicola, not only because of its wide distribution on a great variety of cultivated plants and the direct injury it works but also on account of the often very much greater injury it causes through the introduction into the roots of the plant of bacterial and fungous parasites. The man who shall discover an effective field remedy will deserve a monument more enduring than bronze. Parts of our Southern States in particular are overrun by this parasite. In the hothouse, of course, it may be controlled by steaming the soil, and in other ways.

Much remains to be done before we shall know to what extent fungous parasites function as carriers of parasitic bacteria. H. Marshall Ward sought to explain the presence of

${ }^{1}$ In most beetles, as shown by Rand's further studies (which will appear in Phytopathology) the ingested bacilli are promptly destroyed: in a few, they persist for a long time and are voided in the feces, which are then infectious. 
bacteria in diseased plants by supposing that they must enter the plant through the lumen of fungous hyphae. In this he was wrong, certainly, if it be stated as a general proposition, since many bacteria are able to attack and do attack, unassisted, but it appears to be clear that in some cases the two types of parasites work together, the fungus invading first, and the bacterium following hard after and often doing the major part of the damage, as in potatoes attacked by Phytophthora infestans. The reverse of this also occurs, the bacterium entering first and the fungus following, as in crown gall followed by Fusarium.

Parasitic bacteria are soon followed by saprophytic bacteria, which complete the destruction of the tissues, and, if the disease is somewhat advanced, cultures from the tissues may yield only the latter (potato rots, lettuce rots, etc.). Also, as in animals, one bacterial disease may follow another and the second be more destructive than the first, e.g., fire-blight on the apple following crown gall.

\section{EXTRA-VEGETAL HABITAT OF THE PARASITES}

Here is perhaps the place to say a few words about the nonparasitic life of the attacking bacteria.

All are able to grow saprophytically, i.e., on culture media of one sort or another, and probably all live or may live for a time in the soil. Very few, howerer, have been cultivated from it. The vast mixture of organisms present in a good earth rather discourages search. In some of the unsuccessful attempts failure may have been due to having undertaken isolations at not exactly the right time, or in not just the right place, or on not just the proper medium, but more often probably to the swamping tendency of rapidly growing saprophytes. How long a parasite is able to maintain its virulent life in a soil must depend largely on the kind of competitors it finds. I have used the term virulent, because it is conceivable that an organism might remain alive in a soil long after losing all power to infect plants, just as we know it can in culture media. Bacterium solanacearum causing brown rot of Solanaceae and of many other plants, Bacillus phytophthorus causing basal stem- 
rot and tuber-rot of the potato and Bacterium tumefaciens, causing crown gall, sometimes certainly live in the soil, and the soundest plants when set in such soils, especially if wounded, are liable to contract the disease, if they belong to susceptible species. The root-nodule organism of Leguminosae, which I have not considered here, also lives in many soils, as every one knows.

MORPHOLOGY AND CULTURAL CHARACTERS OF THE PARASITES

Nost of the plant bacteria are small or medium sized rodshaped organisms. They have rounded ends and are of rariable length but are seldom more than $1 \mu$ in diameter and sometimes less than $0.5 \mu$. Very few parasitic coccus forms are known; in fact, none are very well established, but animal diseases due to cocci occur and presumably there are such plant diseases. Some of these bacteria are Gram positive, others are not; few, if any, are acid fast. All takes stains, especially the basic anilin dyes, but not all stain with the same dye equally well. Most of the species are motile by means of flagella-polar or peritrichiate; a few are non-motile, genus Aplanobacter." Some develop conspicuous capsules, others do not. Few, if any, produce endospores. Under special conditions long filaments and chains are frequent. Under abnormal conditions many become club-shaped, y-shaped, or otherwise branched. Löhnis believes (Jour. Agr. Research, Vol. 6, July 31, 1916, p. 675) that all bacteria have an amorphous stage, but such is not my belief. Grown pure on. culture media in mass, they are either yellow, pure white, or brownish or greenish from the liberation of soluble pigments. Red or purple plant parasites are not known. We formerly supposed that there were no green fluorescent species capable of parasitism, but now several are known: e.g., the organism causing the lilac blight of Holland (Bacterium syringae [C.J.J. van Hall] EFS), with pure cultures of which the witer was the first to obtain typical infections, at Amsterdam in 1906 (garden of the Willy Commelin Scholten Labolatory, courtesy of Johanna Westerdijk) and afterwards in

'Smith, Erwin F.: "Bacteria in relation to plant diseases." Carnegie Inst. Washington, Publ. 27, Vol. 1, p. 171, 1905; Ibid. 27, Vol. 3, pp: 155, 161, 1914. 
the United States: Bacterium lachrymans, the organism causing the angular leaf-spot of cucumber (Figs. 6 to 9 and 23 to 26); Bacterium aplatum Brown and Jamieson, causing leaf-spots on Tropaeolum and on beet; and some of the lettuce spot organisms (Bacterium viridilividum Brown, Bacterium marginale Brown).

Some species produce gas (chiefly $\mathrm{CO}_{2}$ and $\mathrm{H}$ ), liquefy gelatin, consume asparagin, destroy starch, and reduce nitrates; others do not. Their fondness for sugars and alcohols is quite variable. Some are extremely sensitive to sunlight and dry air (Bacillus carotovorus, Bacillus tracheiphilus, Bacterium solanacearum, Bacterium malvacearum); others are remarkably resistant, remaining alive and infectious on dry seeds for a year (Bacterium campestre, Aplanobacter stewarti, A planobacter rathayi, Bacterium translucens). Some are strictly aërobic, others can grow in the absence of air, if proper foods are available. Some are very sensitive to acids, alkalies and sodium chlorid, others are not. Some have wide ranges of growth from $0^{\circ} \mathrm{C}$. upwards. Some will not grow at or near $0^{\circ} \mathrm{C}$, others will grow at or above $38^{\circ} \mathrm{C}$. Very few, however, will grow at blood temperature, certain ones even in plants or on culture media are killed by hot summer temperatures, and none are known definitely to be animal parasites, unless we except Bacterium tumefaciens. My own animal experiments with this organism have been limited largely to efforts to produce tumors in fish and salamanders. Many of the trout died early of what appeared to be septicaemia and from the dorsal aorta of one of these fish the crown-gall organism was re-isolated in pure culture on agar poured plates and with subcultures from one of the colonics crown galls were induced on sugar beets. Other trout have yielded, both in the abdominal wall and in the eye-socket, what I regard as small tumors but no metastases have been observed. According to Friedmann, Bendix, Hassel and Magnus, Bacterium tumefaciens causes a purulent meningitis in man and also an ulceration of the intestinal mucosa (Zeits. f. Hygiene u. Infektionskr., April 23, 1915), but Jensen of Copenhagen has contradicted this, having shown that Friedmann's supposed pure culture was contaminated, and Friedmann himself now admits that he was in error. 


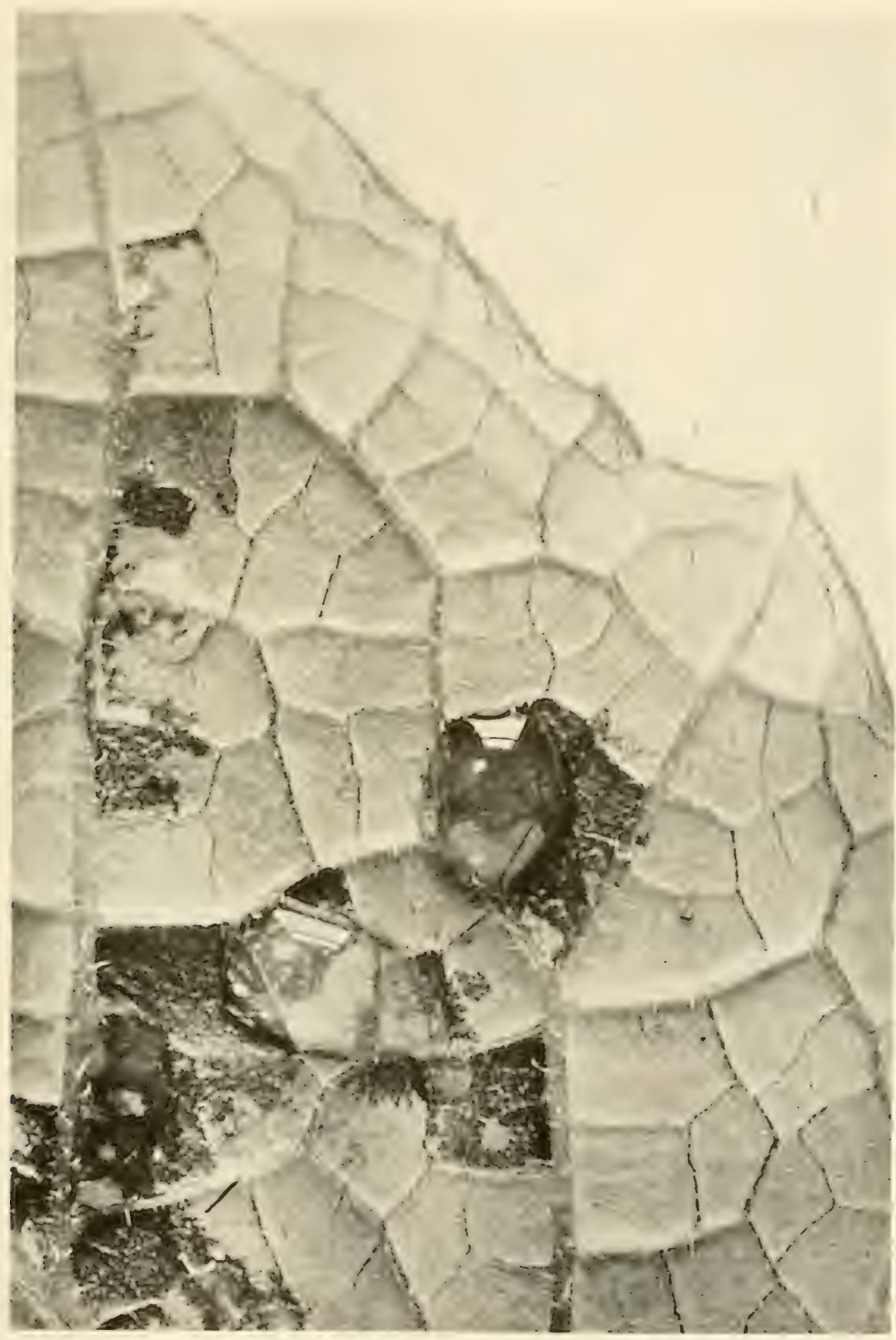

FIG. 23.-Angular leaf-spot of cucumber. Under-surface of an inoculated leaf showing the "tear-drop" exudate of Bacterium lachrymans Sm. and Bry. Planar enlargement by James F. Brewer. Inoculated May 6, 1915. Photographed May $12 . \times 4$ circa. 


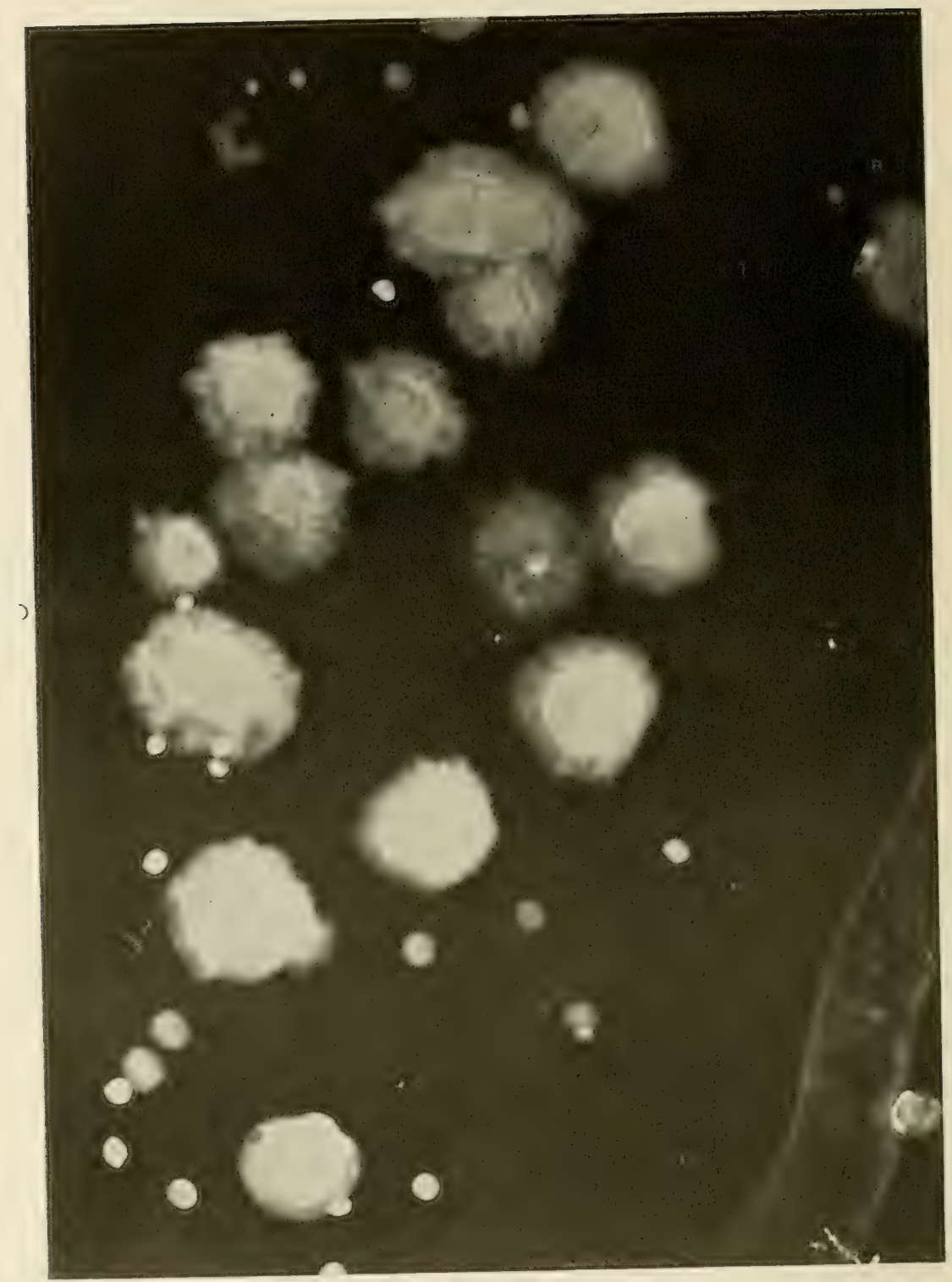

FIG. 24.-Buried and surface colonies of Bacterium lachrymans Sm. and Bry. on a rather thickly sown +10 peptone-beef-gelatin plate: the cause of angular leaf-spot of cucumber. Poured May 12, 1915. Photographed May $17 . \times 10$. 


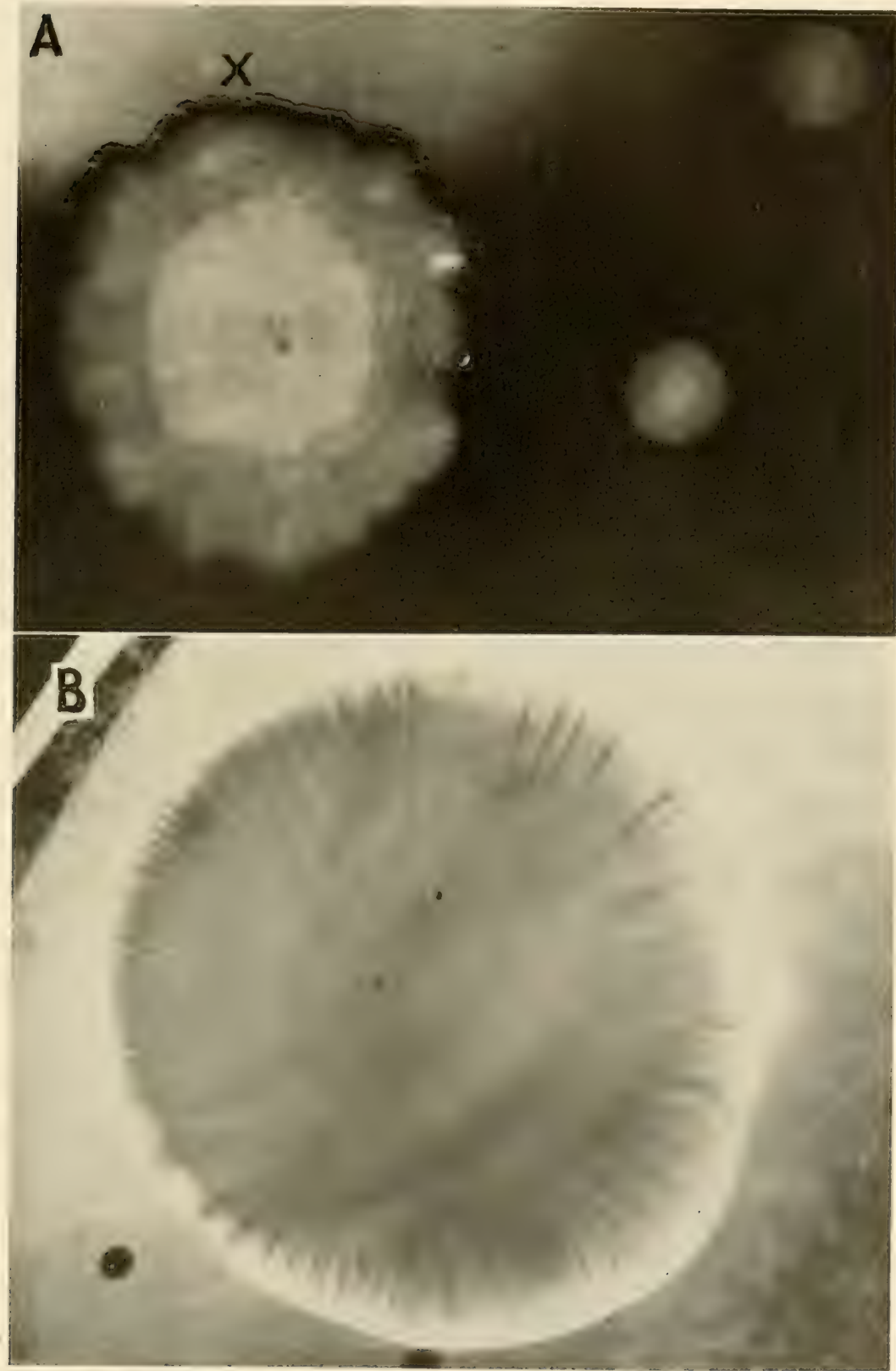

FIG. 25. - Surface and buried colonies of Bacterium lachrymans Sm. and Bry., on thin-sown plates: $A$. Peptone-beef gelatin $(+10)$. Plate poured May 12 1915. Photographed May 19 with oblique lighting to show the peculiar margin at $x . \quad \times 14 . \quad B$. Peptone-beef agar $(+15)$. Photographed by direct transmitted light to show the internal structure of the smooth white surface colonies. Plate poured August 6, 1916. Photographed August $9 . \times 14$. 


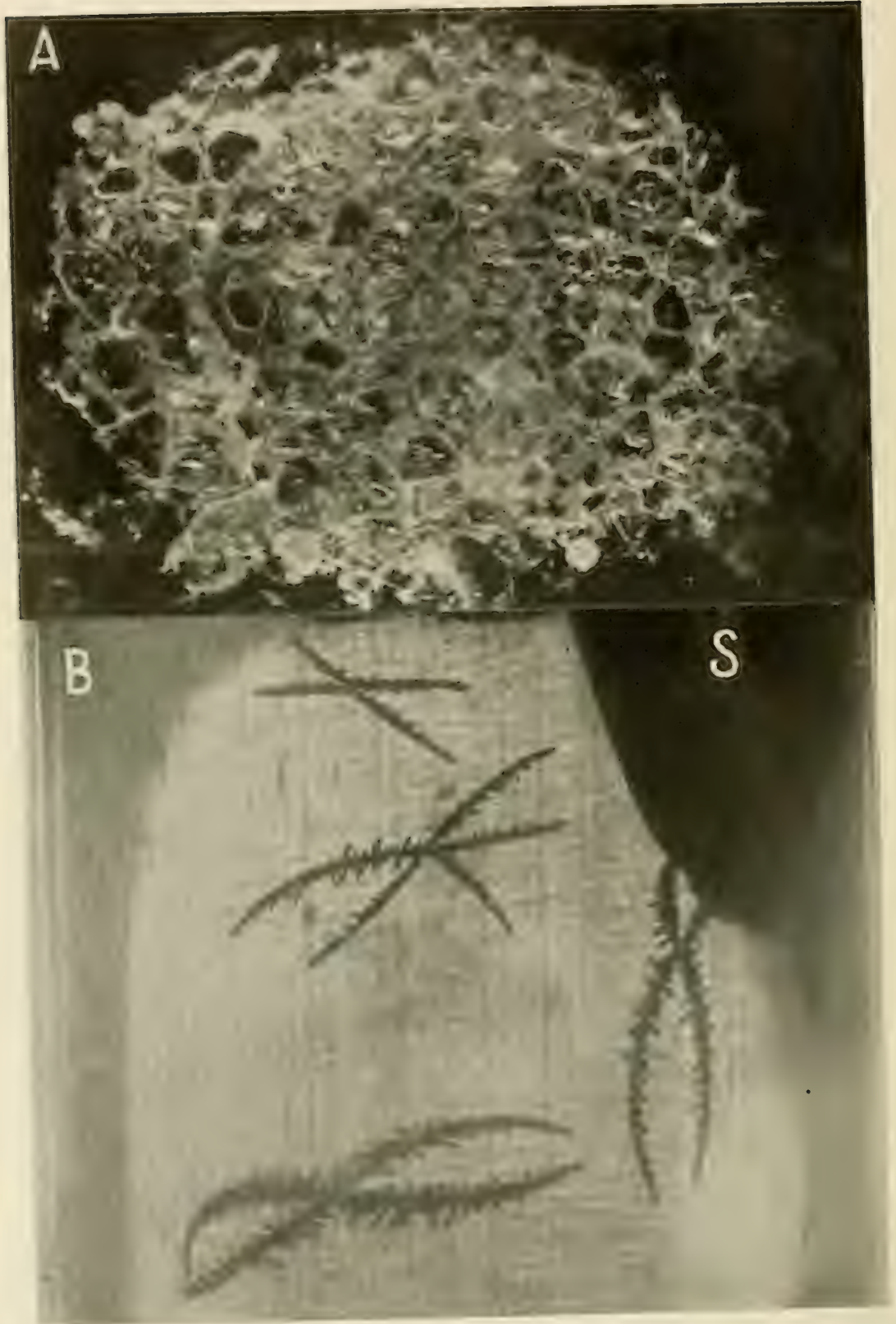

FIG. 26. - A, Film of Bacterium lachrymans floating on Cohn's solution and full of crystals. Inoculated November 23. Photographed November 28, 1914. $\times 13$. B. Bottom of an agar slant culture of Bacterium solanacearum from Tropaeolum, showing crystals formed in the agar. Slant at $S$. Photographed September 23, 1914. $\times 7$. 


\section{ACTION OF THE PARASITE ON THE PLANT}

In some cases it is hard to draw the line between parasitism and symbiosis or mutualism. Probably we shall find more and more of these transition states; undoubtedly there are many. I have included Ardisia in my list of genera and have excluded the genera of legumes subject only to root-nodules. But a nodule on the root of a legume, so far as the local condition is

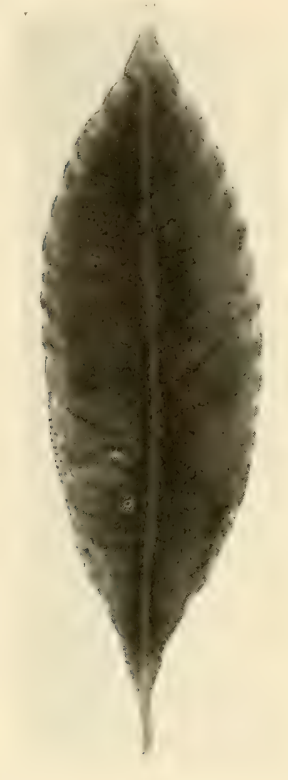

FIG. 27.

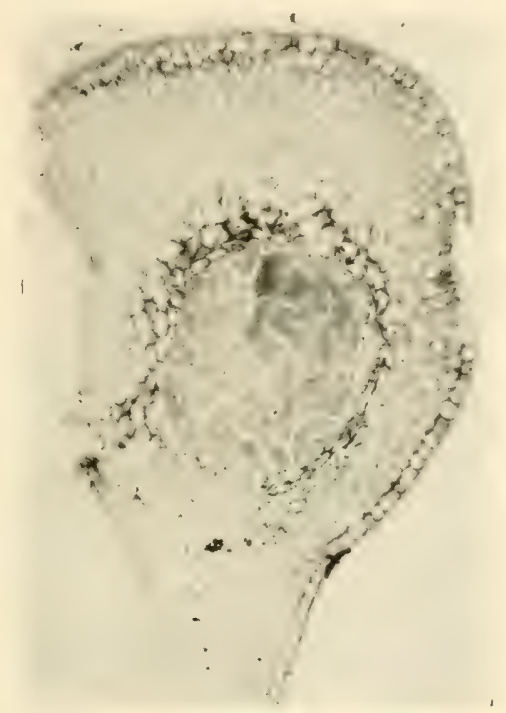

FIG. 28.

FiG. 27.-Ardisia leaf showing swollen, white, bacterially invaded leaf-teeth. $1 / 2$ nat. size.

FIG. 28.-Bacterial cavity in leaf-tooth of Ardisia crispa.

concerned, is a disease as much as a leaf-spot, and, if Nobbe and Hiltner's statements are to be credited the general effect of the root-nodule organism on the plant may be excessive and injurious and not to be distinguished from a disease. ${ }^{1}$

In the tropical East Indian Ardisia, which is one of the strangest cases of mutualism known to me, and on which Miehe

1 Smith, Erwin F.: "Bacteria in relation to plant diseases," Carnegie Inst. Washington, Publ. 27, Vol. 2, 1911, p. 131, last paragraph. 
has done a beautiful piece of work, we have perhaps something akin to what occurs in the root-nodules of legumes. This is a common hothouse plant, grown for its ornamental red berries and thick evergreen foliage (Fig. 27). Here the bacterial injury is local and internal. The bacteria are most abundant in the leaf-teeth where they form pockets or cavities (Fig. 28) and multi-

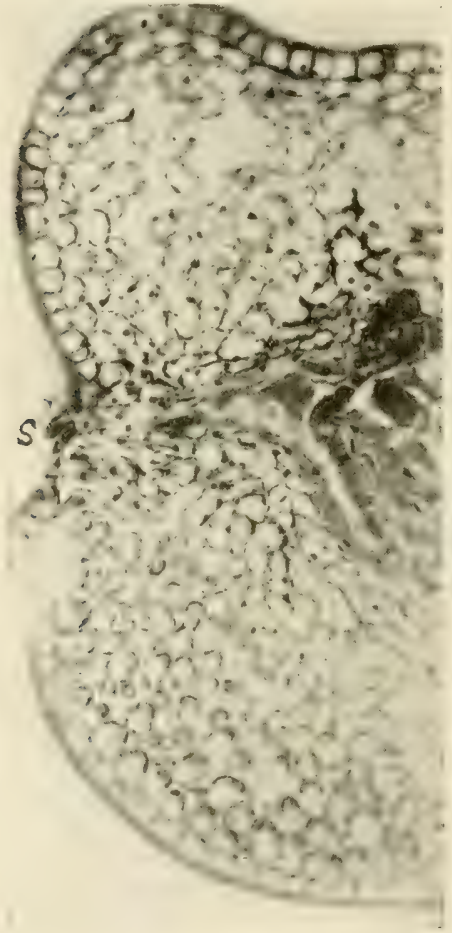

Fic. 29. - Section of leaftooth of Ardisia, showing a waterpore $(S)$ connecting with the hacterial cavity.

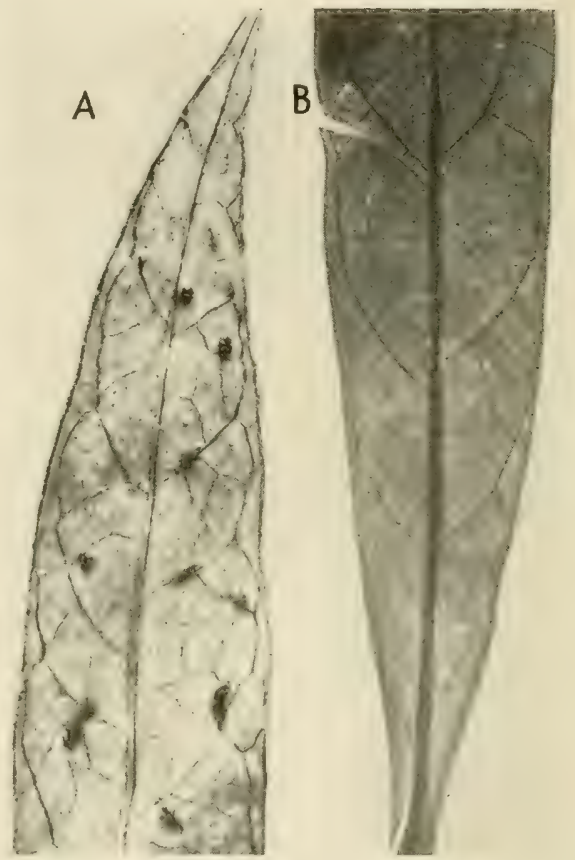

Fig. 30.-A. B. Photographs of two leaves of Pavetta angustifolia from Java. One showing bacterial leaf knots; the other free. Reduced. (Courtesy of Johanna Westerdiji.)

ply enough to make the leaf-serratures appear blanched or yellowish and slightly swollen, but never enough to kill them, or cause the leaves to become yellow and fall. There are no superficial indications of disease, except that the leaf serratures gradually enlarge slightly, lose chlorophyll and become white. In smaller numbers the bacteria occur in other parts of the plant, including the inner parts of the seed from which they are trans- 
mitted to the seedling, whose leaf-serratures, infected probably through their water-pores (Fig. 29), in turn become the chief focus of the bacterial multiplication. Apparently the bacteria are always present, and we do not know what would happen to

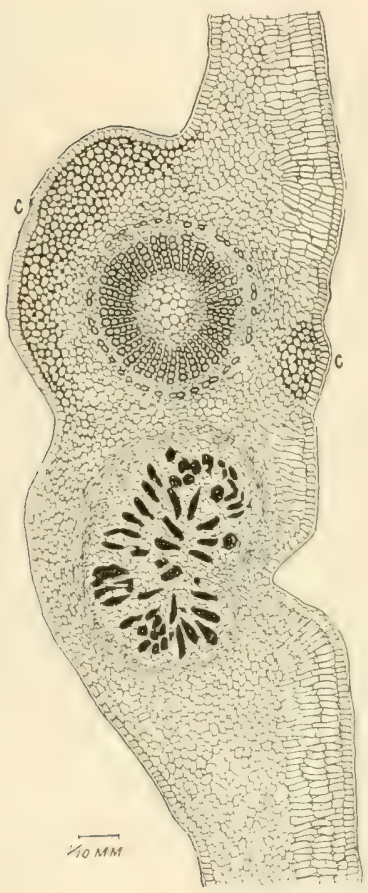

FIG. 31.

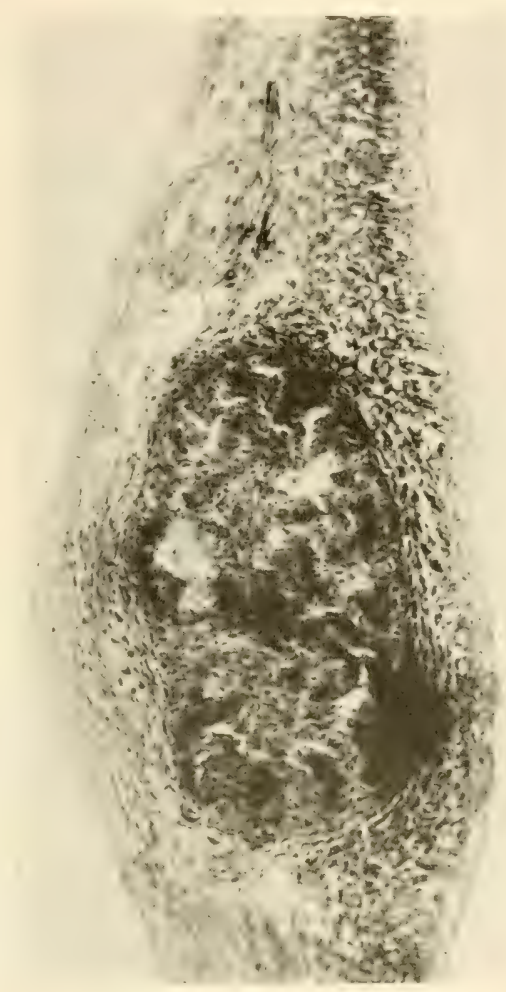

FIG. 32.

Frg. 31.-Cross-section of leaf of Pavetta angustifolia showing a reinlet and : small bacterial nodule. The veinlet has a closed cylinder of xylem. The bacterial pockets in the roung nodule are drawn in solid black. At c.c. are masses of collenchyma. It looks as if the organisms entered from the upper surface very early through the palisade tissue. Drawn November 21, 1914, from an unstained section lying in water.

Fig. 32. - Structure of one of the leafknots shown in Fig. 30.4. Stained with anilin blue.

Ardisia plants grown without them, nor do we know how to obtain such plants (1915). It would be an interesting experiment to see if they could be produced without the bacteria and to watch their behavior. 
Ardisia plants, so far as I have been able to observe, grow very slowly. Query: Are they dwarfed by the presence of the bacteria, or on the contrary if deprived of them would they be unable to grow at all? I set one of my assistants at work on the problem, asking her to heat Ardisia seeds in water at temperatures between the killing point of the seeds and that of the bacteria (which is somewhat lower). The seeds heated for the

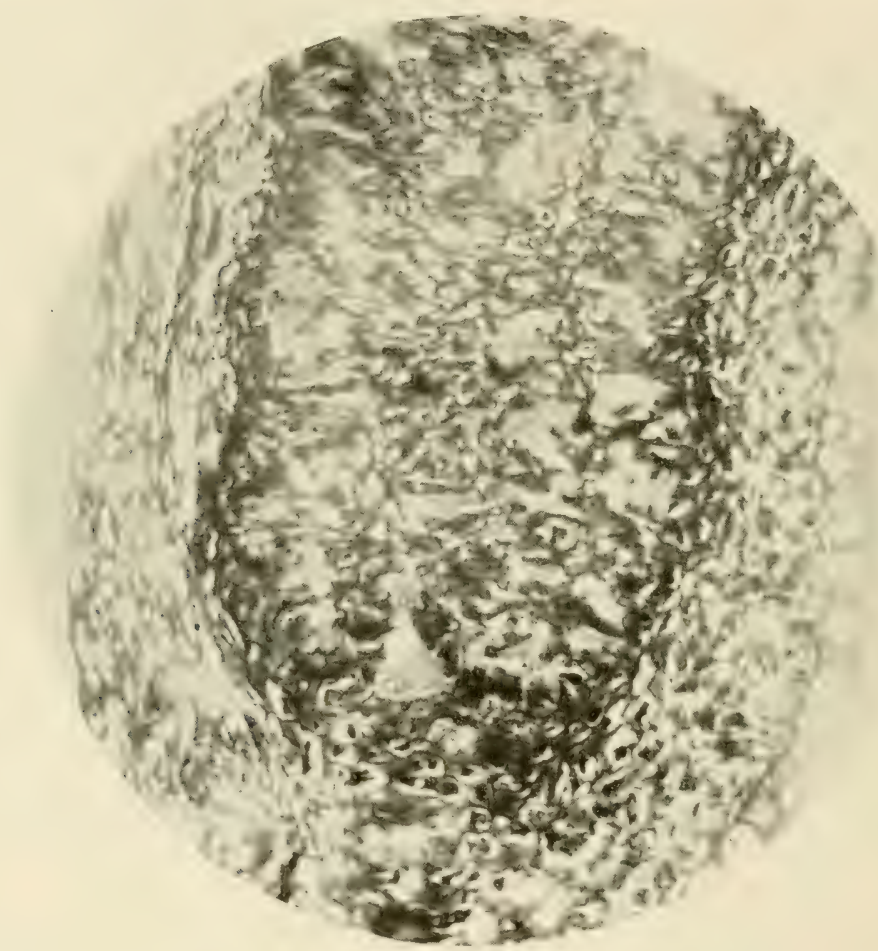

FIG. 33.-Part of another leaf-nodule of Pavetta angustifolia (Fig. 30A) more highly magnified, showing many small cavities.

right time at the proper temperature were not killed but germinated and grew, although with extreme slowness as compared with those growing from untreated seed, so that even after a year they had scarcely a leaf to show but only a swollen bud and some roots. Sections from the leaf-teeth of such plants showed them to be free from bacteria, and this makes it seem probable that Ardisia plants actually require the bacteria. A 
repetition of this experiment gave the same results-good growth of checks and astonishingly slow growth of plants from the heated seed.

We are now (1918) growing Ardisia plants from surfacesterile seeds in flasks of glowed sand in nitrogen-free media. ${ }^{1}$

The bacterial nodules on the leaves of the East Indian Pavettas (first described by Zimmermann) are apparently of a similar nature, but here the bacterial foci are scattered over the surface of the leaf, often, however, with astonishing regularity (Figs. 30 to 34 ).

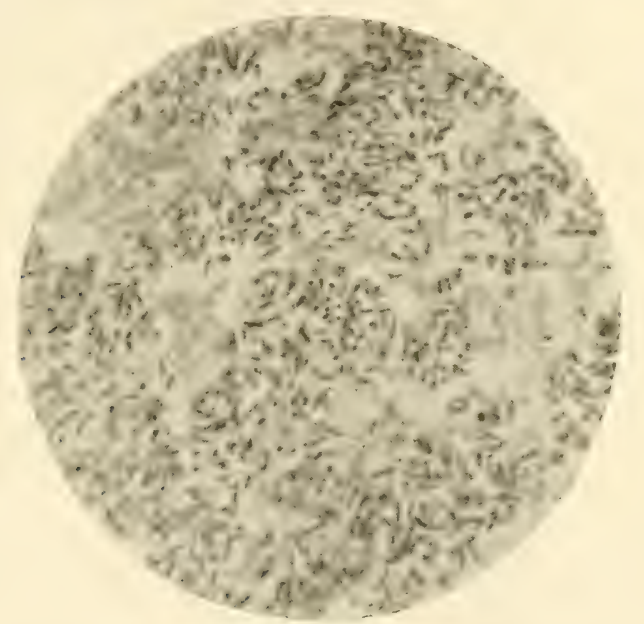

Fig. 34.-Bacteria from a nodule on leaf of Pavetta angustifolia. $\times 1000$ Stained with anilin blue.

The action of such organisms as I have just mentioned differs probably from the behavior of active parasites in that they liberate much weaker toxins and enzymes, can attack only very actively growing parts, and also give off compensating nitrogenous substances. Not yet proved for Ardisia (1915) but proved apparently for the Pavettas by Dr. F. C. von Faber whose paper is in Jahrb. f. wiss. Bot., 1914, Bd. 54, p. 243.2

${ }^{1}$ Dee., 1919. These plants have remained alive for 18 months, but the foliage is paler and the plants have made less growth than checks in ordinary soil. The experiment is not conclusive because at the end Dr. Jodidi found a trace of nitrogen in the sand $(0.5 \mathrm{mg}$. per kilo).

${ }^{2}$ Since this was written Miehe claims to have proved it for Ardisia, but owing to the war I have not been able to obtain his paper, which is in Ber. d.d. Bot. Ges., xxxiv Bd., 1916, pp. 576-580. 
The active parasites produce toxins freely, poisoning the tissues, and enzymes converting starches into sugars, complex sugars into simpler ones, and so on, for their nutrition. They also neutralize and consume plant acids, and feed upon amino bodies and other nitrogenous elements of the host. Is a result of their growth, many of them liberate both acids and alkalis, to the detriment of the plant. The solvent action of their products on the pectin compounds of the middle lamellae separates cells and leads to the production of cavities in the cortex, pith, phloem and xylem. There is also, or may be, a mechanical splitting, tearing or crushing due to the enormous multiplication of the bacteria within confined spaces. The whole intercellular mechanism of soft plants may be honeycombed and flooded in this way, and if the cavities are near the surface the tissues may be lifted up or the bacteria may be forced to the surface through lenticels or stomata in the form of tiny beads or threads (pear, plum, bean, maize, sugar-cane, cotton, mulberry, etc.), or by a splitting process. The splitting in plum fruits and peach fruits, due to the black spot, results, however, from local death of the attacked tissue with continued growth of the surrounding uninjured parts. I now doubt if any of these plant parasites consume true cellulose.

A majority of the forms known to cause plant diseases are extra-cellular parasites occupying chiefly the vessels and intercellular spaces, causing vascular diseases, soft rots, spot diseases, etc.; but intra-cellular parasites also occur, e.g., Bacterium leguminosarum ${ }^{1}$ causing root-nodules on legumes, and Bacterium tumefaciens causing crown gall. The former multiplies within the cell myriadfold, prevents its division, destroys its contents including the nucleus, and enormously stretches the cell wall so that the cell becomes much larger than its normal fellow cells and is packed full of the bacteria. The latter does not multiply abundantly in the cell, does not enlarge it greatly, does not injure its viability, and would be a harmless messmate were it not for the fact that it exerts a stimulating reffect on the nucleus. (om $)$ elling the cell to divide again and again.

This is a polar flagellate organism-usually it is $1-3$ flagellate. 
CONSPECTUS: ACTION ON THE PLANT

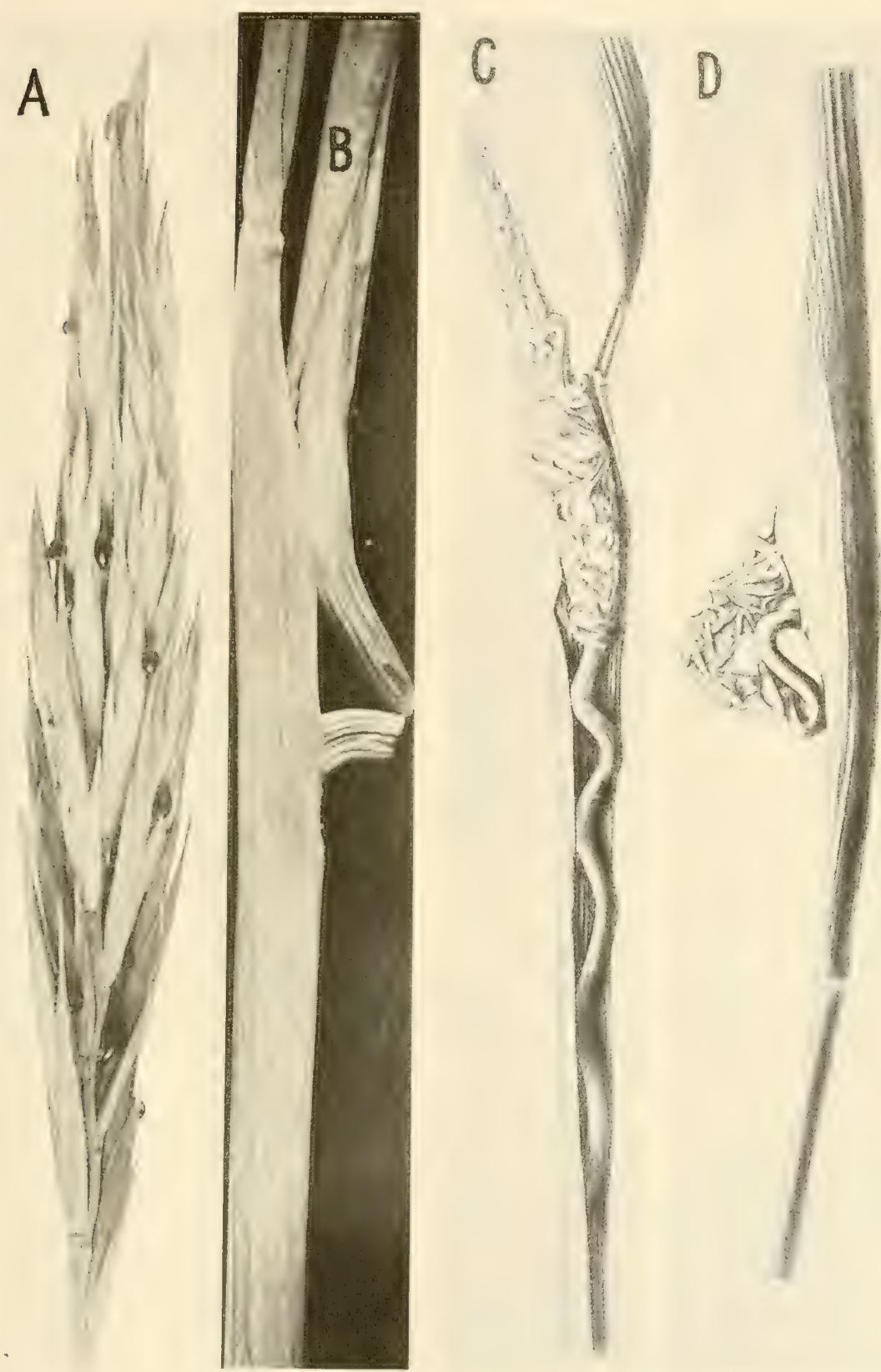

FIG. 35.-A. O'Gara's A planobacter agropyri on Agropuron smithii (the western wheat grass). Utah, photographed from dried material collected by P. J. 
In 1911 from Maryland carnations ${ }^{1}$ and again in 1913 from Danish orchard grass ${ }^{2}$ the writer called attention to a new type of bacterial disease in which the principal growth of the parasite is on the surface of the plant, that is between closely appressed organs. Since then O'Gara has described a similar disease from wheat-grass in $\mathrm{Utah}^{3}$ and Hutchinson from wheat in India ${ }^{4}$ See Fig. 35.

\section{THE REACTION OF THE PLANT}

We now come to the reaction of the plant. What response does it make to this rude invasion? Twenty years ago we might have said, "With rare exceptions, the plant is passive or nearly so," but that would have been a superficial observation. In every disease we must suppose that the plant makes some effort to throw off the intruder, although of ten its forces are paralyzed and overcome very early in the progress of the disease.

One of the most conspicuous results is lessened growth In some of my plants recovering from brown rot due to Bacterium solanacearum, ${ }^{5}$ a month after external signs of the disease had disappeared the check plants were twice the size of the inoculated ones, and there was still a very decided dif-

1 Smith, Erwin F.: "Bacteria in relation to plant diseases," Carnegie Inst. of Washington, Publ. 27, Vol. 2, Fig. 4, Oct. 30, 1911.

${ }^{2}$ Smith, Erwin F.: A new type of bacterial disease, Science, n.s., Vol. 38. p. 926, Dec. 26, 1913. For a fuller account with figures see "Bacteria in relation to plant diseases," Carnegie Inst. of Washington, No. 27, Vol. 3, pp. 155-160.

${ }^{3}$ O'Gara, P. J.: A bacterial disease of western wheat-grass, Agropyron Smithii, Phytopathology, Vol. 6, No. 4, August, 1916, p. 341.

${ }^{4}$ Hutchinson, C. M.: A bacterial disease of wheat in the Punjab. Memoirs of the Department of Agriculture in India, Agr. Research Inst., Pusa, October, 1917, Bacteriological Series, Vol. 1, No. 7.

${ }^{5}$ Smith, Erwin F.: "Bacteria in relation to plant diseases," Carnegie Inst. Washington, Publ. 27, Vol. 3, 1914, Plate 45-D.

O'Gara in 1916. The slime dries brownish yellow and masses of it may be seen adhering to various parts of the spike; $B$. The same showing a knee-shaped culm bending; $C, D$. Hutchinson's wheat disease of the Punjab (India) said to be due to a polar flagellate schizomycete (Pseudomonas tritici Hutch.). All the spikelets are stuck together or overgrown with a mass of lemon yellow slime. In $D$ there is bending of the culm. (After Hutchinson.) 
ference after more than two months. See also Fig. 169 where the development of the potato shoot inoculated with Bacillus carotovorus has lagged behind its twin shoot. Even more striking retardation results were obtained by the writer and Mr. Godfrey (summer of 1918) on Ricinus communis and on Helianthus anmuus, using the same organism (Figs. 127, 131). On potato plants attacked early by Bacterium solanacearum the tubers remain small. On maize attacked by Aplanobacter stewarti the ears are imperfect. Olive shoots inoculated and infected by Bacterium savastanoi are always dwarfed (Figs. 299 and 300), and frequently the crown-gall dwarfings are very conspicuous. The dwarfings of melon and squash plants attacked by Bacillus tracheiphilus are also conspicuous. Uninoculated sugar-cane stems soon surpass in height and vigor those successfully inoculated with Bacterium vascularum. I do not know how to explain this checked growth unless it be due to the paralyzing effect of absorbed toxins.

Changes in color are also conspicuous. The attacked parts may become greener than normal, or fade to yellow, red, brown or black. In tomato fruits there is often a retarded ripening on the attacked side, with persistence of the chlorophyll. In certain leaf-spots also the leaf green persists in the vicinity of the spot while the rest of the leaf becomes yellow (beanblight). Crown galls on daisy are greenish. On the contrary the teratoid parts of crown galls on tobacco and on cauliflower are often blanched. The male inflorescence of maize attacked by A planobacter stewarti ripens prematurely and becomes white (Fig. 101).

Distortions of various kinds appear (leaves of bean, lilac, larkspur, hyacinth, mulberry, Persian walnut, ete.). The leaves of tomato plants attacked by Bacterium solanacearum are bent downward; so are the fronds of the coconut palm when attacked by the bacterial bud-rot (Fig. 4). The leaves of potatoes attacked by Bacillus phytophthorus are sometimes bent upward and almost always the leaflets are rolled upward, from the edges. Knee-shaped. curvatures of the culms appear on Dactylis attacked by A planobacter rathayi, in the buds of the sugar-cane attacked by Cobb's disease, on Agropyron attacked 
by O'Gara's disease (Fig. 35B), and on wheat attacked by Hutchinson's disease (Fig. 35D).

Organs may be developed in excessive number or out of place, as roots or leafy shoots in crown gall, witch-brooms on Pinus, and incipient roots on the stems of tomato, tobacco, chrysanthemum, nasturtium, etc. Hunger found a bud on a tomato leaflet which he attributed to the stimulus of Bacterium solanacearum but this may have been natural (see Fig. 36) and an old paper by Duchartre ${ }^{1}$ who first discovered adventitious buds on the leaves of the tomato.

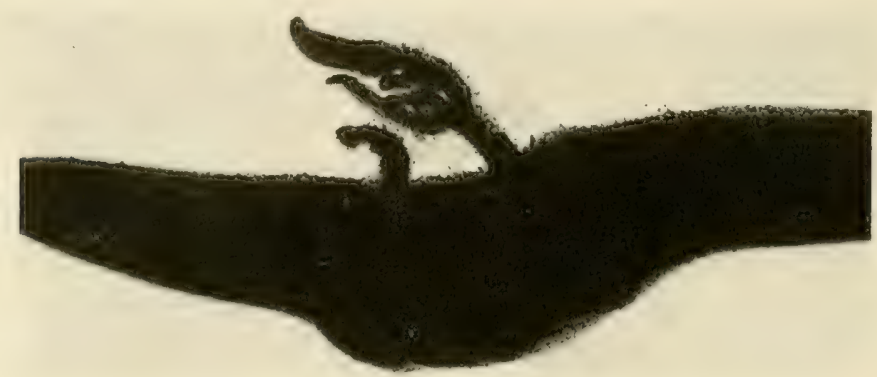

Fig. 36. - Cross-section of middle part of a tomato leaf in the region of the midrib showing leafy shoots originating from the sulcus. Variety Livingston's Dwarf Aristocrat. I have rooted and grown these foliar shoots into mature fruit-bearing plants. Photographed June 23, 1916. $\times 4$.

In various diseases the plant removes starch from the vicinity of the bacterial focus which it endeavors to wall off by the formation of a cork-barrier, and in this effort it is sometimes successful, if the parasite is growing slowly (Figs. 136, 174). In. other cases (hyperplasias) starch is stored in the diseased parts.

The most conspicuous response of the plant, however, is in the form of pathological overgrowths-cankers, tubercles, and tumors. Some of these are very striking, e.g., those on the ash, olive, citrus, beet $\left(\right.$ Bact. beticolum $\left.{ }^{2}\right)$, pine, oleander, and on a multitude of plants attacked by crown gall. In some of these

${ }_{1}^{1}$ Duchartre, P.: Sur des feuilles ramifères de Tomates, Ann. d. Sei. Nat. 3 Sér. Bot., Tome 19, Paris, 1853, pp. 241-251, Plate 14.

"See "Tuberculosis of Beets" in "Crown Gall of Plants: Its Cause and Remedy." Bull. 213, U. S. Dept. Agr., Bu. Pl. Ind., Washington, D. C., 1911, pp. 194-195, and plate XXXIV. 
growths, which are hyperplasias, there is a great multiplication and simplification of the parencinyma and a great reduction of the vascular system, but in crown galls produced in the torus of the sunflower (which is a very vascular tissue) there is an excessive number of vessels. There are also various other phenomena, chemical and physical, nearly related to what takes place in certain insect galls, that is, increase of sugars, starches, enzymes, acids; and structural simplifications and reversions to more primitive forms. What I mean by reversions may be seen by consulting my figures illustrating insect galls. In crown gall, cell-division under compulsion proceeds at such an abnormally rapid rate that the cells are forced to divide while still immature, and in this way masses of small-celled, unripe (anaplastic) tissue arise (Figs. 353, 354) and these develop tumor-strands (Figs. 319 and 323 to 325 ) in which secondary tumors form - phenomena suggestive of what occurs in malignant animal tumors (Consult text of No. XIV and various plates and figures and, especially, read Jensen's recent (1918) Danish paper referred to under Literature of No. XIV).

\section{PREVALENCE AND GEOGRAPHICAL DISTRIBUTION}

Economically considered, bacterial diseases of plants may be classed as major or minor. Most of the leaf-spots would fall into the latter class. Various soft rots, blights and vascular diseases, being wide-spread and destructive to plants of great economic importance, may be classed as major diseases. Cankers and tumors. would fall midway in such a grouping. Occasionally a minor disease, e.g., lettuce rot, celery rot, ${ }^{1}$ under condition farorable to the parasite may assume great importance. This is especially true of leaf-diseases which attack the fruit, e.g., the black spot of plum and peach due to Bacterium pruni, the bean-blight due to Bacterium phaseoli, the angular leaf-spot of cotton due to Bacterium malvacearum, the African mango disease due to Bacillus mangiferae, the black chaff disease of wheat

${ }_{1}$ "The loss from this disease in the field where I gathered the specimens was 150 crates out of every 700 erates packed." (Dr. J. Rosenbaum, Hastings, Fla. Letter of April 4, 1916.) 
due to Bacterium translucens var. undulosum (see Figs. 12, 14, 38) and citrus canker due to Bacterium citri.

It will be of interest to mention a few of these diseases with particular reference to their distribution and prevalence.

Dutch East Indies.-The tobaceo disease of Sumatra and Java is probably the most destructive, if the Sereh of sugarcane is not bacterial. Each of these diseases has caused enormous losses. Each threatens or has threatened an industry. The tobacco disease occurs also in the West Indies, in the United States, and probably also in South Africa. If Janse's root disease of Erythrina, the coffee shade tree of Java, is also bacterial, as he supposed, then there is another great bacterial plague in that region, for hundreds of thousands of trees have died, and another species has been substituted as a shade tree. The brown bast disease of rubber trees (Hevea brasiliensis), which is a tumor disease of the bast of suspected bacterial origin, is widespread and has attracted much attention in recent years. There is also a bacterial disease of peanuts.

West Indies.-Here the most destructive disease is the bacterial bud-rot of the coconut palm, which occurs all around the Caribbean, and threatens the entire destruction of a profitable industry in Cuba. There is also the bacterial disease of bananas and plantains, but the most wide-spread and destructive $M u s a$ disease of the Western Hemisphere is the Panama disease, due to Fusarium cubense EFS. ${ }^{1}$

Australia.-Cobb's disease of sugar-cane has probably attracted more attention in Australia than any other bacterial trouble, although bacterial rots of the potato are also very destructive. The cane disease in both Queensland and New South Wales has in many cases destroyed the output of whole plantations and greatly discouraged planters. This disease occurs also in Fiji, and probably in South America. Aceording to C. F. Hill, the citrus canker occurs in the Northern Territory of Australia (Bull. N. T., Austr., 18, 1918).

${ }^{1}$ On this subject see papers by Elmer W. Brandes as follows: (1) Ann. Rep., Porto Rico Agr. Exp. Sta. for 1916, pp. 29-31; (2) Distribution of Fusarium cubense EFS, the cause of Banana wilt, 20th Report Mich. Acad. of Sciences, 1918, pp. 271-275; and (3) Banana wilt, Phytopathology, Sept., 1919, pp. 339389,14 plates and 5 text figures. 
Japan.--The tobacco wilt, which has destroyed many fields, is probably the worst Japanese disease. This is believed by Honing and by the writer to be identical with the tobacco wilt of Sumatra and of the United States. 'The citrus canker occurs and several other interesting bacterial blights have been reported from Japan, including one on the basket willow (Fig. 37).

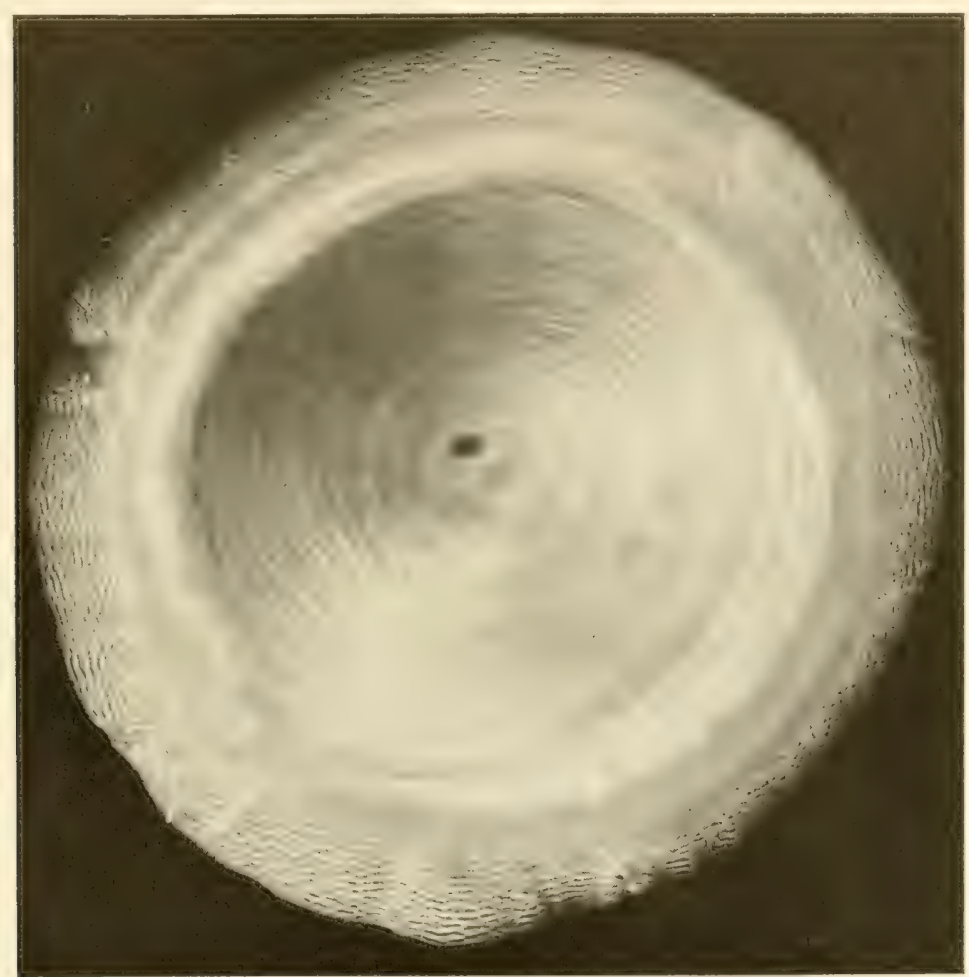

Fig. 37.--Agar poured plate colony of the schizomycete causing the Japanese basket-willow disease. Photographed by oblique transmitted light to show internal structure. $\times 10$.

China.-In the interior of China there is a destructive wilt disease of tobacco (Frank N. Meyer), but its nature is unknown. A Fusarium cultivated from it in my laboratory did not cause the wilt when I inoculated it copiously into the soil near broken roots of young tobaccos nor yet when I introduced it into deep wounds made in the stems of young vigorous plants at the surface of the earth. 
The Phitippines.-In Luzon, citrus canker, a bud-rot of coconut, brown rot of potatoes and egg plants, a leaf spot of tobacco, bean blight, a bacterial rot of bananas and Musa textilis, and some other diseases occur. Most of the islands are pathologically unexplored. According to Reinking (The Philippine Journal of Science, Vol. XIV, Jan., 1919, pp. 131-151) the coconut budrot of the Philippines is due to Phytophthora faberi Maubl., Bacillus coli and a schizomycete resembling $B$. coli isolated from the rotting palm bud may aggravate the rot but cannot initiate it except under very favorable conditions of moisture and previous injury.

India.-The brown rot of Solanacex is common and destructive. (itrus canker is common especially in the Punjab (Hutchinson, in a letter to the writer). There is also a bacterial disease of the opium poppy. Most of Asia is a terra incognita.

South Africa.-The mango disease in recent years has greatly reduced the exports. Potato and tomato wilts are common. There is a serious tobacco disease, probably bacterial. Crown gall is common and injurious on shade and orchard trees. Angular leaf-spot of cotton is prevalent. Other bacterial diseases occur, including several on citrus. Nothing is known about the greater part of Africa.

South America.-There is a serious disease of sugar-cane in Brazil and another in Argentina, both of which I believe are of bacterial origin and identical with Cobb's disease, but this remains to be proved. Bondar has reported a destructive manihot disease. The bud-rot of the coconut occurs in the north. The banana disease of Guiana, however, is due to Fusarium cubense. Most of South America, like Asia, is unexplored.

United States and Canada.-Potato rots of which we have several distinct forms, probably cause the greatest losses, one year with another. Following these I should think pear and apple blight. Perhaps the latter should be placed first, for the destruction of an acre of potatoes would scarcely equal the value of a single fine pear tree, and thousands are destroyed every year. In California, which was formerly free from pear blight, the losses in the last twenty years have been enormous, amounting to about one-third of all the full-grown orchards and to a money- 
loss estimated at $\$ 10,000,000$ for the five years preceding the efforts for its restriction begun in 1905 by the United States Department of Agriculture. This is a very conservative estimate considering the number of trees destroyed. In the San Joaquin Valley in California, "in the short space of three years, from 1900 to 1904," according to O'Gara, "almost half a million pear trees were lost by blight. Practically no attempt was made to check the disease and one of the greatest industries of the San Joaquin Valley vanished like a dream." Very serious losses from this disease are experienced every year in the East, or were until growers became generally familiar with methods of control. In certain seasons bacterial diseases of barley and oats injure these crops to a considerable extent.

In our southern states the wilt disease of tobacco and the tomato, due to Bacterium solanacearum, has made it impossible to grow these crops on many fields. In the northern United States the cucurbit wilt is wide-spread and destructive, but cucurbits are, of course, a minor crop. Blight of beans due to Bacterium phaseoli is another common and troublesome disease. In certain seasons and on some varieties the angular leaf-spot injures cotton very seriously (see Part III, No. X).

The wide prevalence and destructive nature of the bacterial black chaff of wheat in the United States west of the Mississippi River in 1915, and since, adds another to our serious bacterial diseases. This blights the leaves, shortens the head and shrivels the kernels (Fig. 38). In the study of this disease in my laboratory during the last three years we have discovered a second bacterial disease of wheat previously confused with the "black chaff," the basal glume rot (Figs. 39, 40), due to Bacterium atrofaciens McCulloch, a green fluorescent organism which cause: a black rot at the base of the kernel.

The walnut blight has done much damage in California and recently it has been reported from New Jersey (Cook) and from other parts of the Eastern United States (McMurran, Bull. 611, U. S. Dept., Agric). This disease occurs also in Chili, South Africa (Miss Doidge: Letter to the Author), New Zealand and Tasmania.

The bacterial disease of alfalfa has been serious in parts 


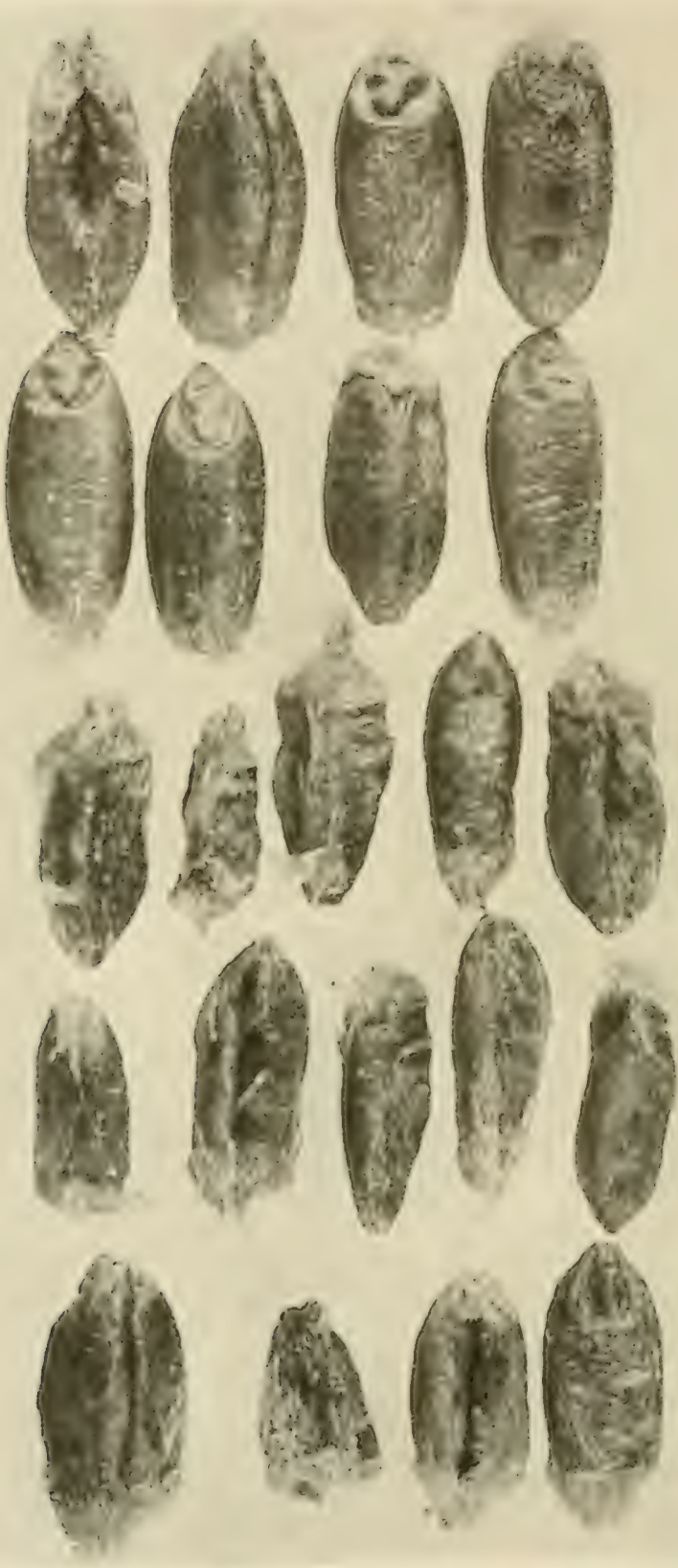

Fig. 38.- Kernels of Russian winter wheat attacked and shriveled by the black chaff organism, Bacterium iranslucens var. undulosum, S., J. R., Coll. No. 271 A, Kansas, 1917. All kernels from one head and all but 8 shriveled. Bacterial films can be seen on the shriveled kernels, especially those of the middle row. 


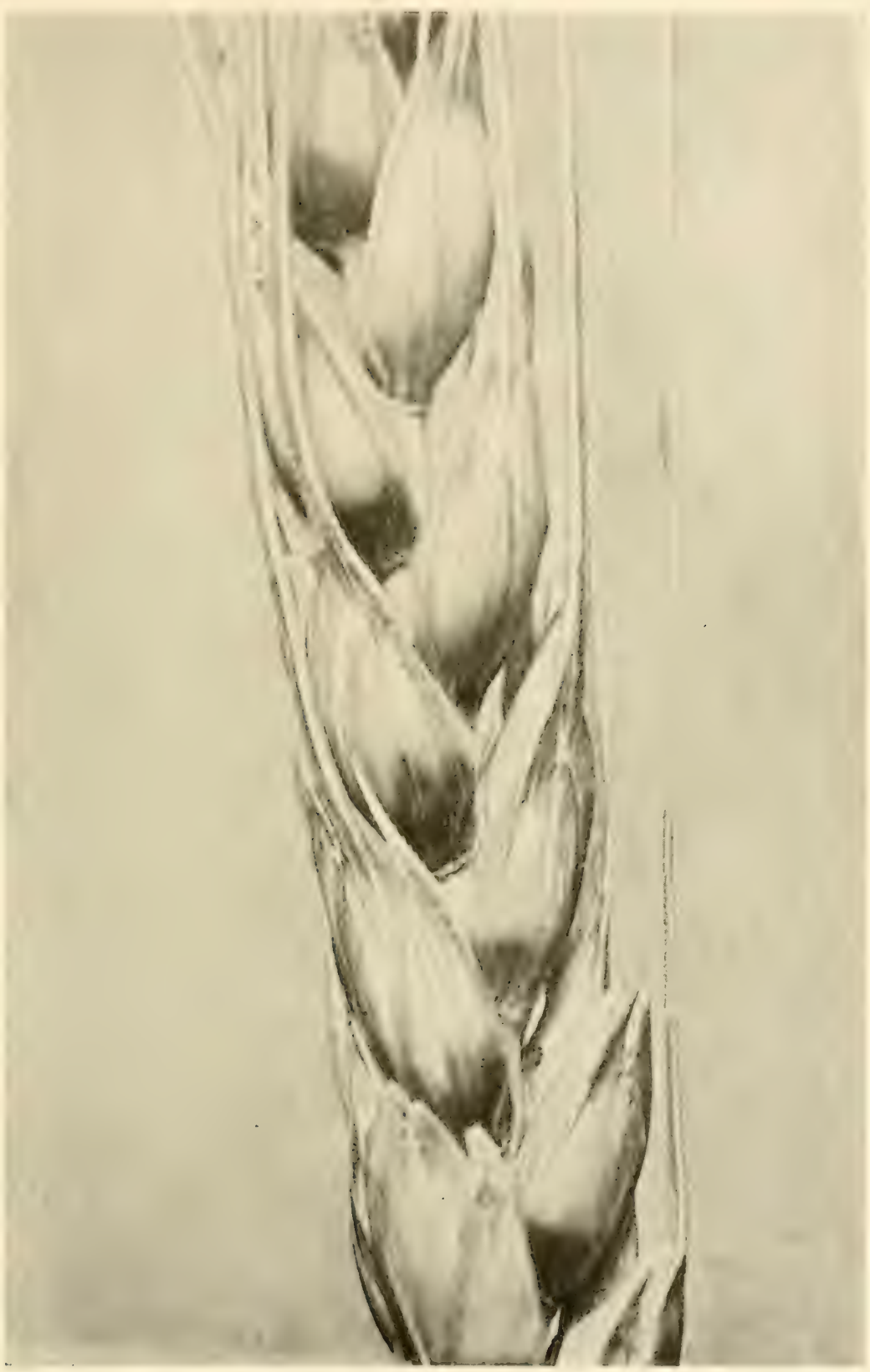

FIG. 39.-Head of wheat from Kansas crop of 1917, Coll. No. 478, showing basal glume rot, a new disease, due to Bacterium atrofaciens McCulloch, a white organism causing a green fluorescence in media. 

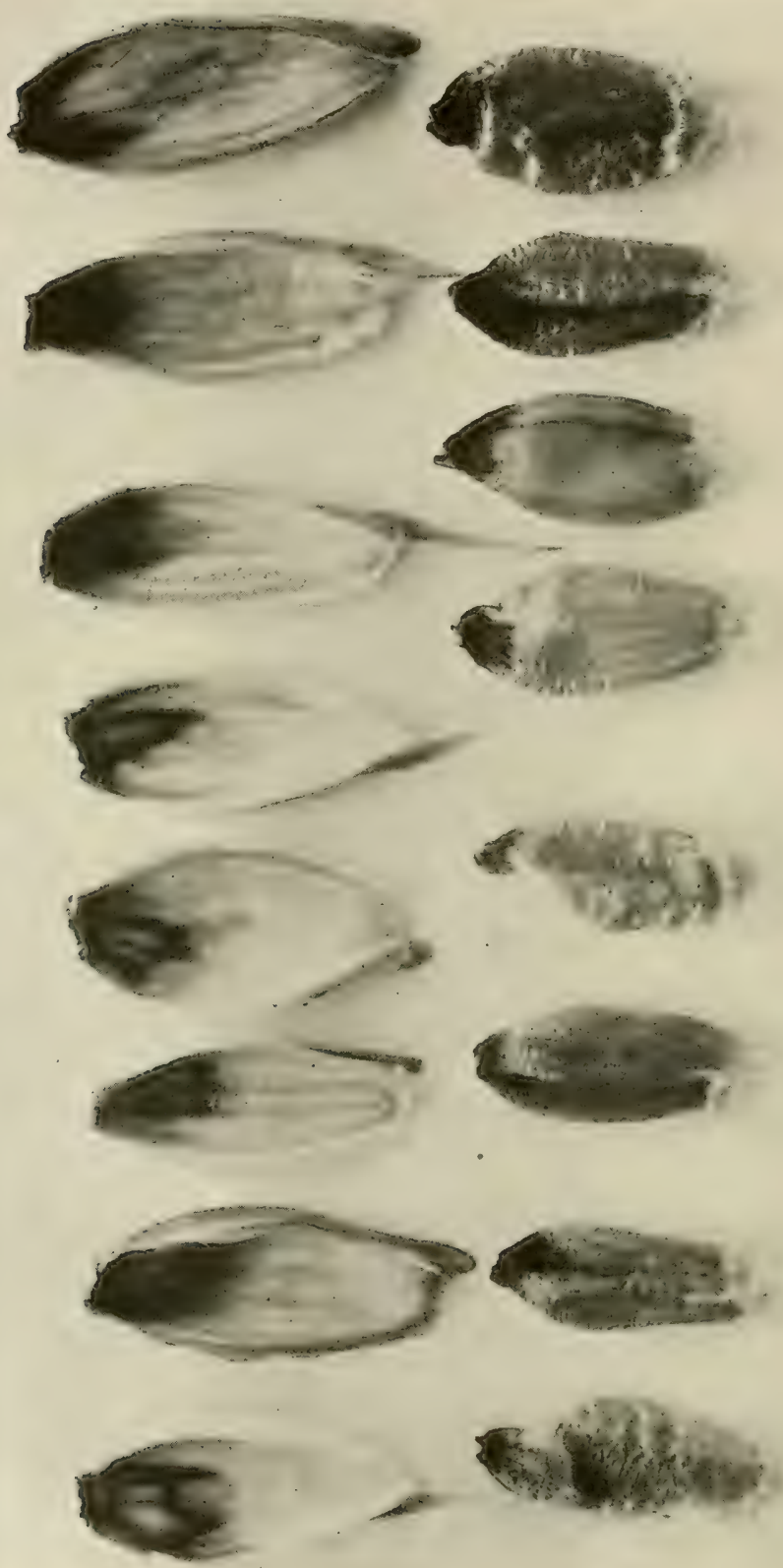

FIg. 40.-Glumes and kernels of wheat blackened by Bacterium atrofaciens McCulloch, the cause of the basal glume rot, crop of 1917, Coll. No. 285 (New York) and No. 399 (Canada). 

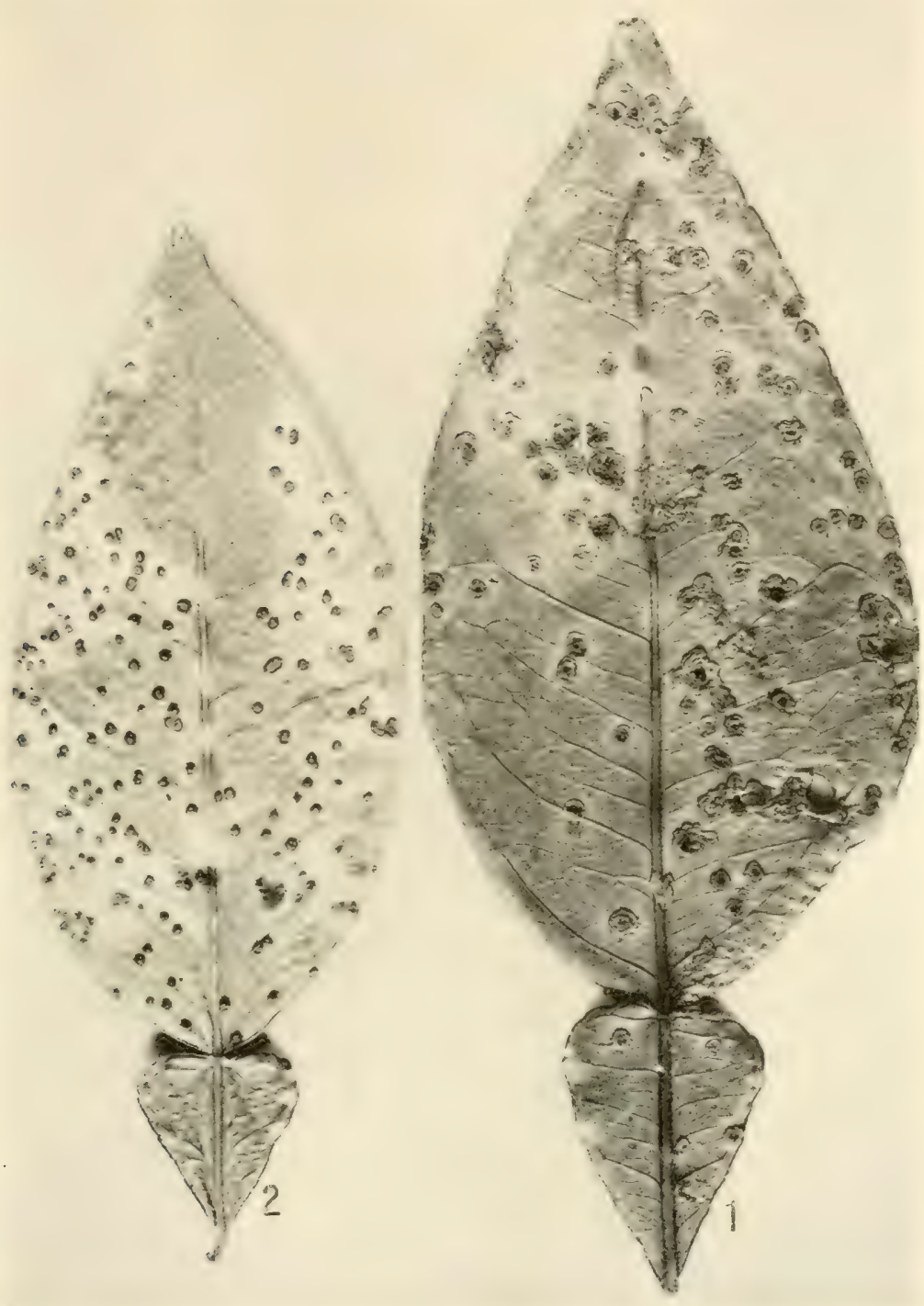

FIG. 41.-Bacterial canker on leaves of grape-fruit from Florida: (1) A natural infection, 1914; (2) an inoculation of 1914. Both leaves were deposited in the Pathological Collections, B. P. I., U. S. Department of Agriculture, in June, 1914, by H. E. Stevens of Florida. No. 2, designated as a "pure-culture inoculation," was supposed by Stevens to have been caused by his fungus (Phoma or Phyllocticta) which is present, but is not the parasite. 


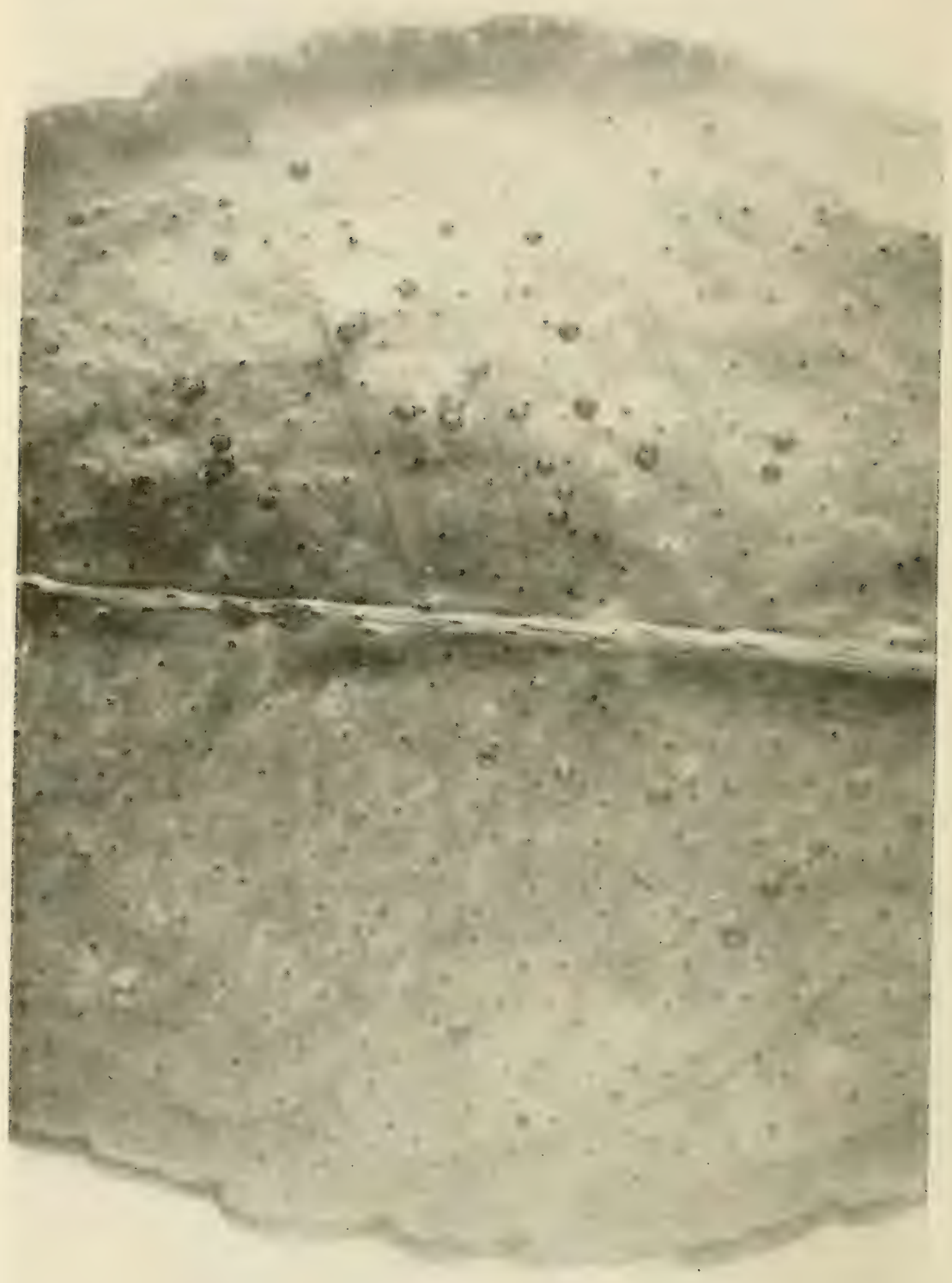

FIG. 42.-Citrus canker on leaf of seedling grape-fruit. Inoculated by the writer with Bacterium citri (Hasse) Jehle, isolated from a grape-fruit leaf received from Mississippi in 1915. Time, 16 days. Cankers not yet ruptured. $\times 5$. 
of the West, but I have not heard of its occurrence in the East. It is most injurious early in the season, i.e., on the first cutting. Alfalfa is now, according to Piper ${ }^{1}$ the third most important forage crop in the United States, only timothy and red clover exceeding it. There is a physiological "white spot" on alfalfa (O'Gara) not to be confused with Sackett's disease.

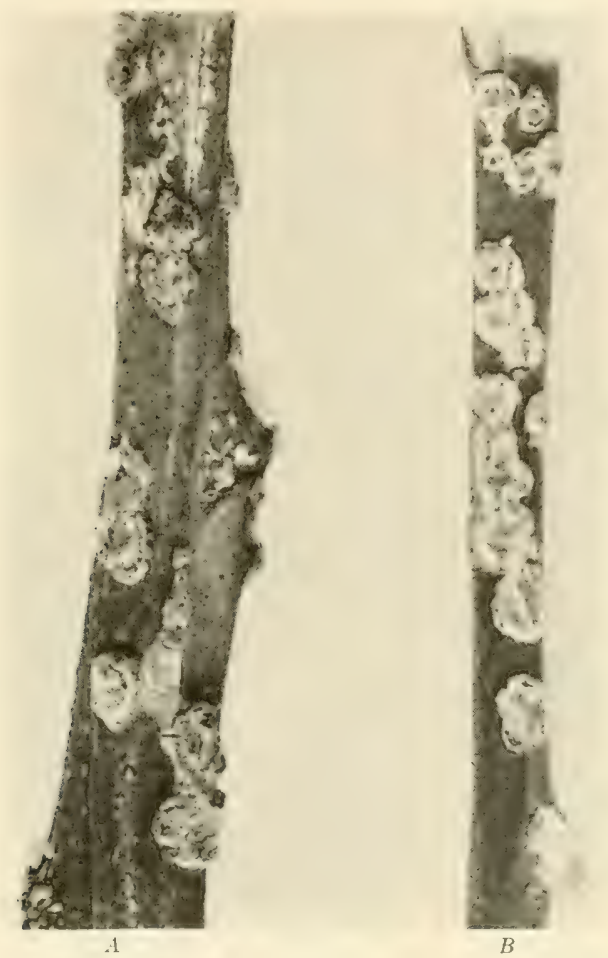

FIG, 43,-Citrus canker due to Bacterium citri (Hasse) Jehle: A, on Citrus decumana (grape fruit); $B$, on Citrus trifoliata. Disease introduced into America recently from Eastern Asia.

Recently in Florida the citrus canker (see Figs. 41 to 44) has caused orange growers a great scare and strenuous efforts are on foot to suppress it. During the last four years, under pressure from the citrous States, the General Government of the United States has made five appropriations for this purpose 1914.

1 Piper, Chas. V.: Forage plants and their culture, N. Y., The Macmillan Co., 
as follows: Apecial, January, 1915, \$35,000; special, February, $1916, \$ 300,000$; general, in Department of Agriculture appropriation bills, $1916-17, \$ 250,000 ; 1917-18$, $\$ 430,000 ; 1918-$ $1919, \$ 250,000 .^{1}$ This disease oceurs also in Japan, China and the Philippines (Water T. Swingle) and was certainly introduced into the United States on imported citrus plants. It

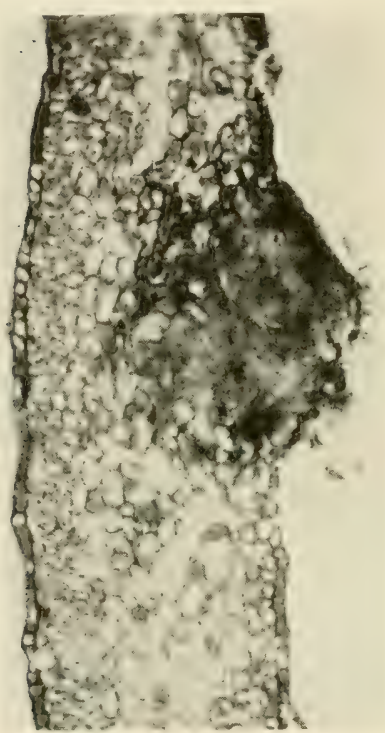

Fig. 44.-Cross-section of grape-fruit leaf showing a young canker inoculated by the writer in 1915 . Time, 16 days. See Fig. 42. now occurs (or did occur in 1916) in every Gulf State. It should not be confused with the somewhat similar looking Costa Rican pseudo-canker (Figs. 45, 46) which is of non-bacterial origin, nor with the verrucosities due to Cladosporium citri (Fig. 47). The true bacterial canker is usually surrounded by a narrow water-soaked area best seen by holding the leaf up to the light (Fig. 48) and is swarming with bacteria, whereas the pseudocanker shows no such border and contains at most only some fungous threads well corked out.

Holland and Denmark.-In Holland the yellow disease of hyacinths will eventually put an end to hyacinthgrowing for export if means cannot be had for its control, since the land suited to hyacinths is limited in amount. Black rot of cabbage occurs in Holland and Denmark, and is common now also in many parts of the United States. It was probably imported into the United States from Denmark on cabbage seed. some years in nurseries about Amsterdam the lilac blight has been troublesome. In Denmark Rathay's disease is said to be rather troublesome on orchard grass grown for seed.

${ }^{1}$ On April 30, 1918, in the Florida Plant Commissioner's Office, Department of Citrus Canker Eradication, 183 persons were employed, including a divisional inspector, district inspectors, assistant district inspectors, foremen and inspectors. During the year 1918 over $2,000,000$ grove trees were inspected and six times as many nursery trees. 


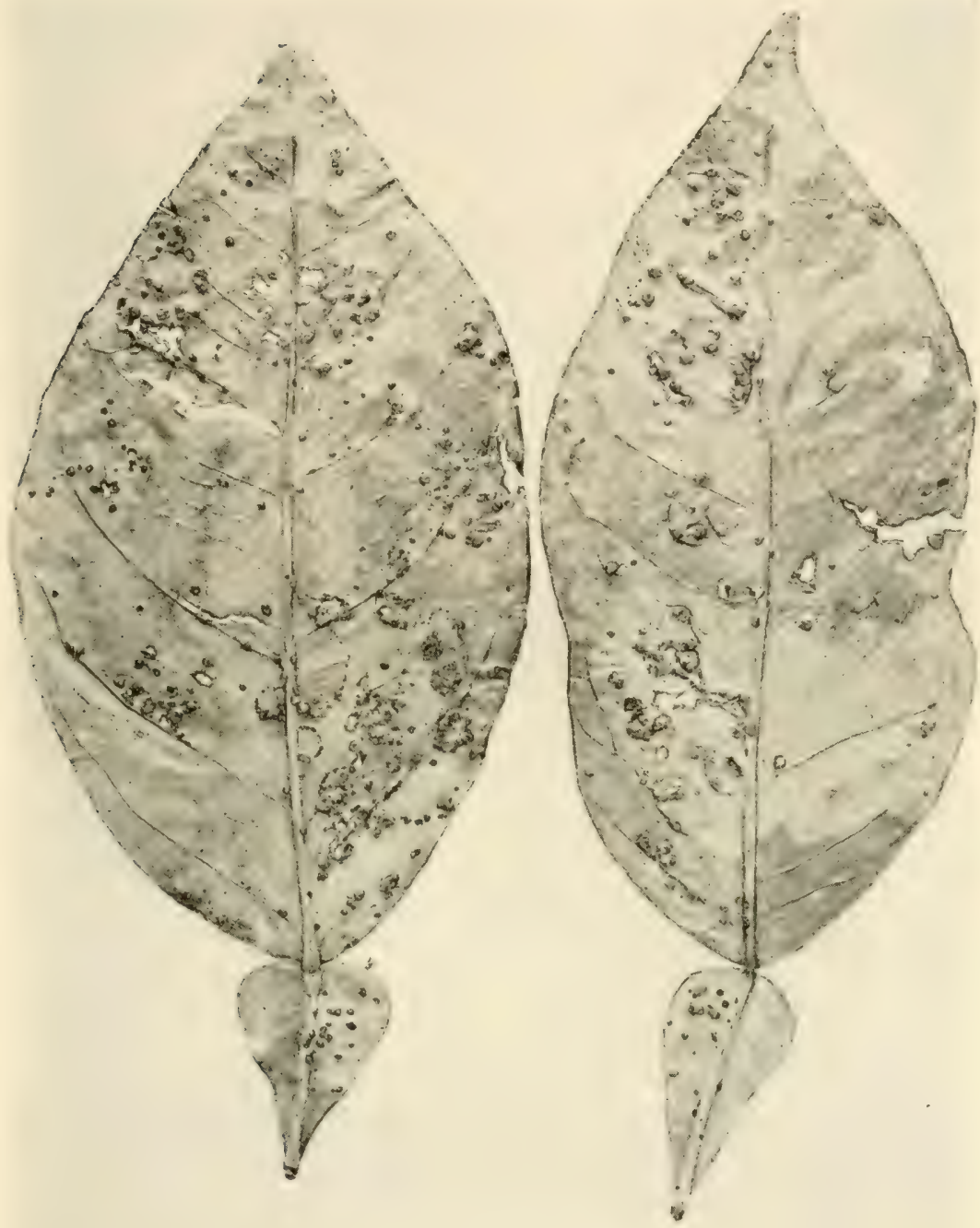

PIG. 45.-Pseudo-canker on Citrus aurantium, probably scab due to cladosporium citri. Some mycelium is present but no spores. The cankers have healed, being cut off from the rest of the leaf by a cork layer. Costa Rica, 1913. 
Sandwich Islands. - There is a serious banana disease but its cause is not known (1915). It attacks the Chinese banana. There is a serious potato disease and a bad shade tree disease, both of unknown origin. The mosaic of sugar-cane occurs.

Great Britain and Germany.--Until recently in these countries not much critical study was given to bacteria as a cause of plant

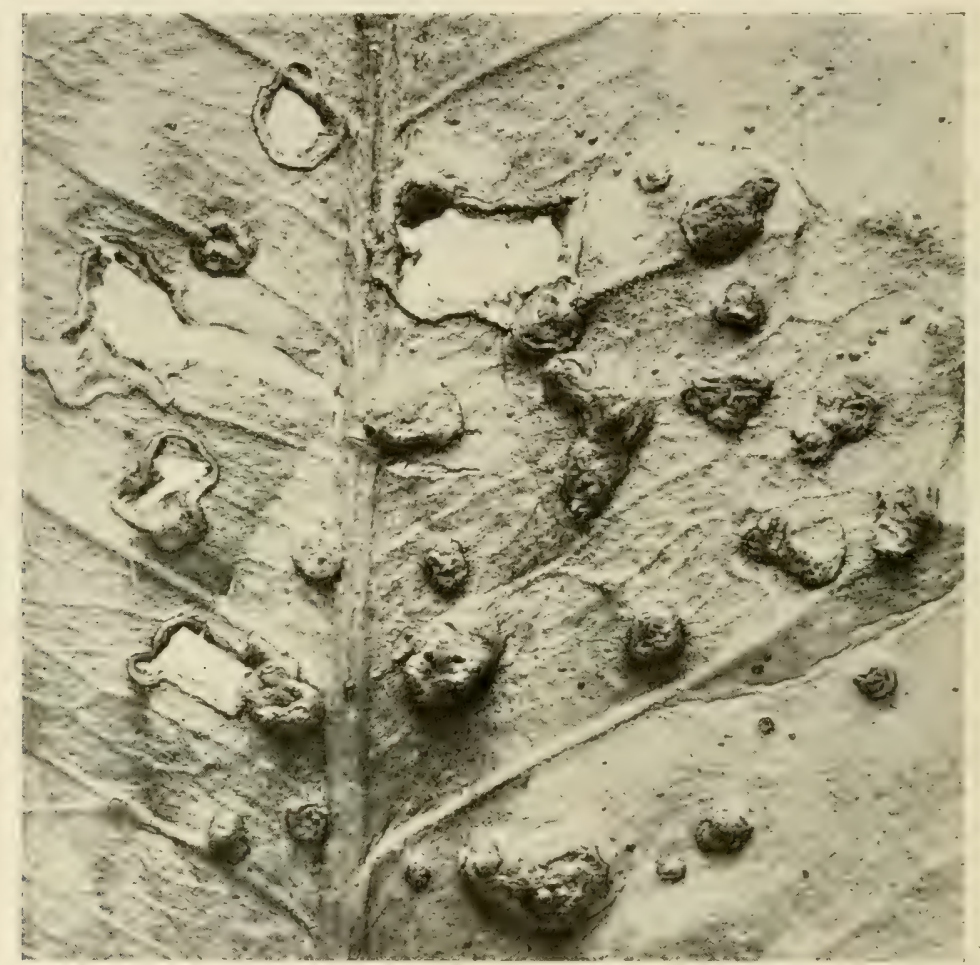

F1G. 46.-Costa Rican peudo-canker of citrus. A detail from Fig. 45, further enlarged to show absence of any translucent border such as that shown in Fig. 48. Photographed by transmitted light. $\times 6$.

diseases, but now good students are at work. Potato rots are probably the most destructive bacterial diseases. Appel has described one and Spieckermann another. The bacterial potato rot Pethybridge and Murphy described from Ireland ${ }^{1}$ is like the German "black leg." Wormald has described a rot of celery which is common also in the United States (Fig. 49).

${ }^{1}$ Proc. R. Irish Acad., vol. xxix, Sect. B, No. 1, 1911. 


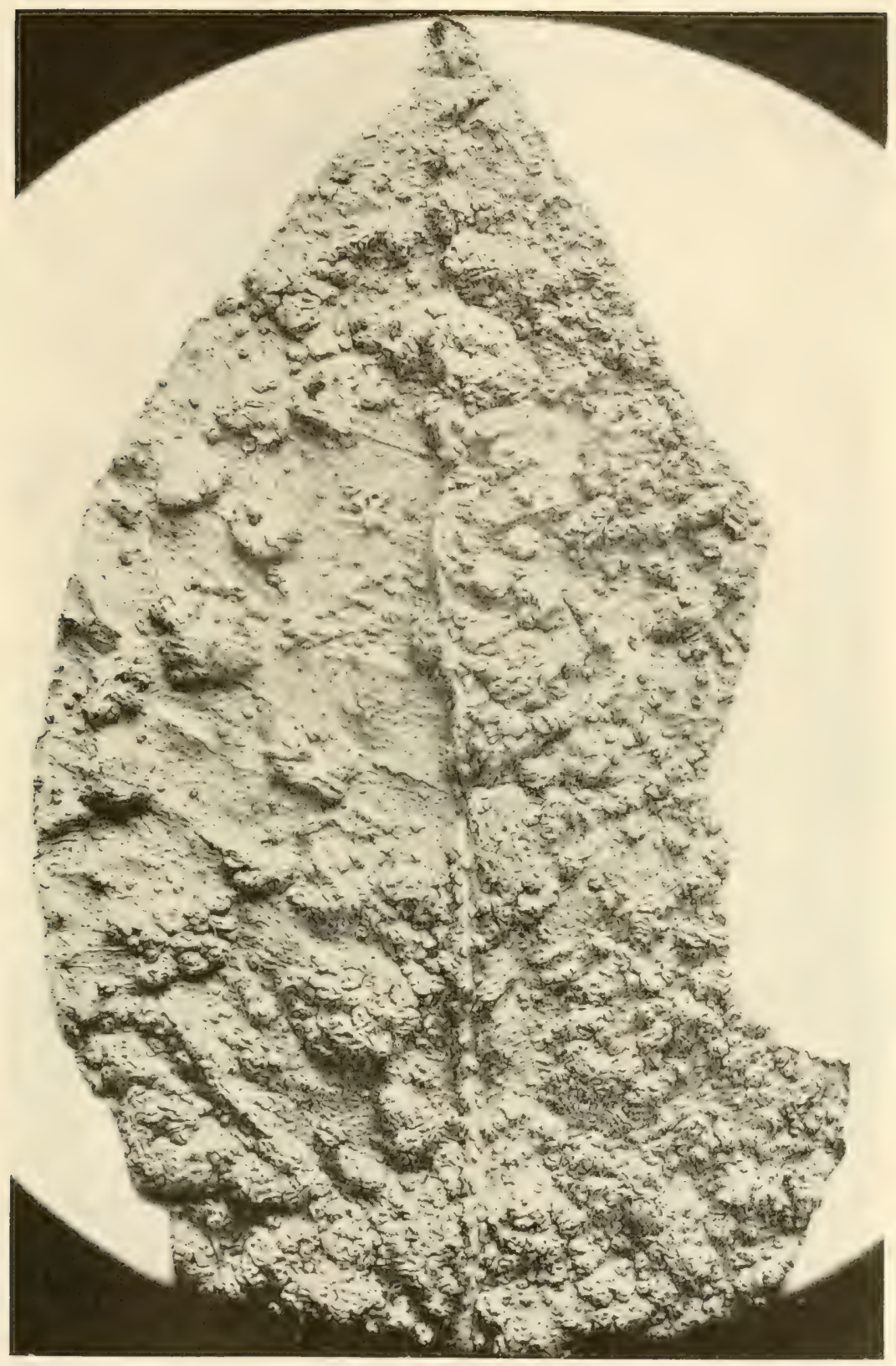

FIG. 47.-Verrucosities on an orange leaf from Florida, due to the fungus Cladosporium citri. Photo by Brewer, but on a Seed's plate which shows no distinction between the pale green of the leaf and the dull yellow of the scabs. See page 121. 
Potter has written on a rot of swedes and Paine on a rot of mushrooms and a leaf-spot of Protea.

France and Italy.-Potato diseases are common and at times very destructive. Olive tubercle, common also in California, and all around the Mediterranean, is prevalent in spots. Vine diseases, especially Maladie d'Oleran and crown gall, do considerable damage. Pear blight seems to be absent in France, but has been reported from several places in Italy. Mulberry blight occurs. The destructive Italian rice disease,

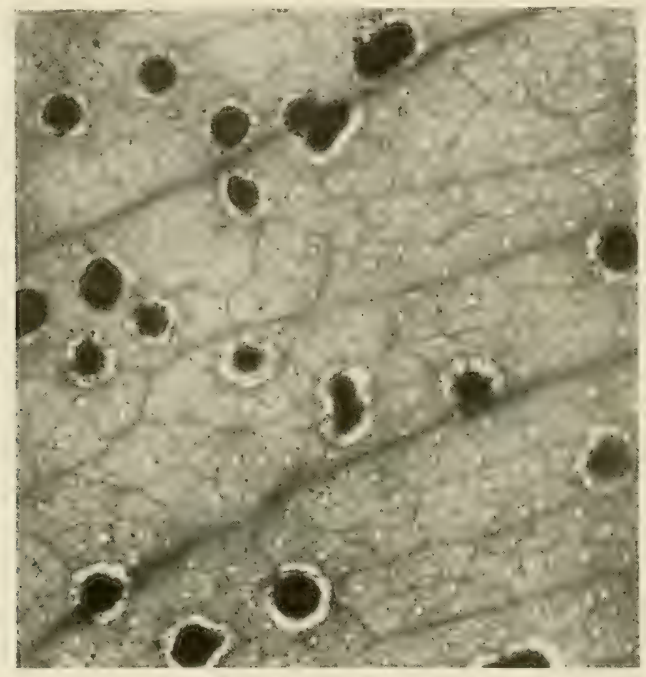

FiG. 48. - Bacterial citrus canker enlarged and photographed by transmitted light to show translucent border. $\times 6$. The tiny white specks are oil glands.

brusone, is not due to bacteria as reported, but to a fungus (Piricularia). Not much exact work has been done on bacterial diseases of plants either in France or Italy.

Spain and Porlugal.-These countries are a terra incognita. Russia.-A few years previous to the late war there was a great awakening in Russia. A plant pathological journal was founded and numerous discoveries were reported. From this journal and other sources it is evident that many bacterial diseases of plants occur. I think, for example, that our black chaff of wheat is an importation from Russia. At least it should be 


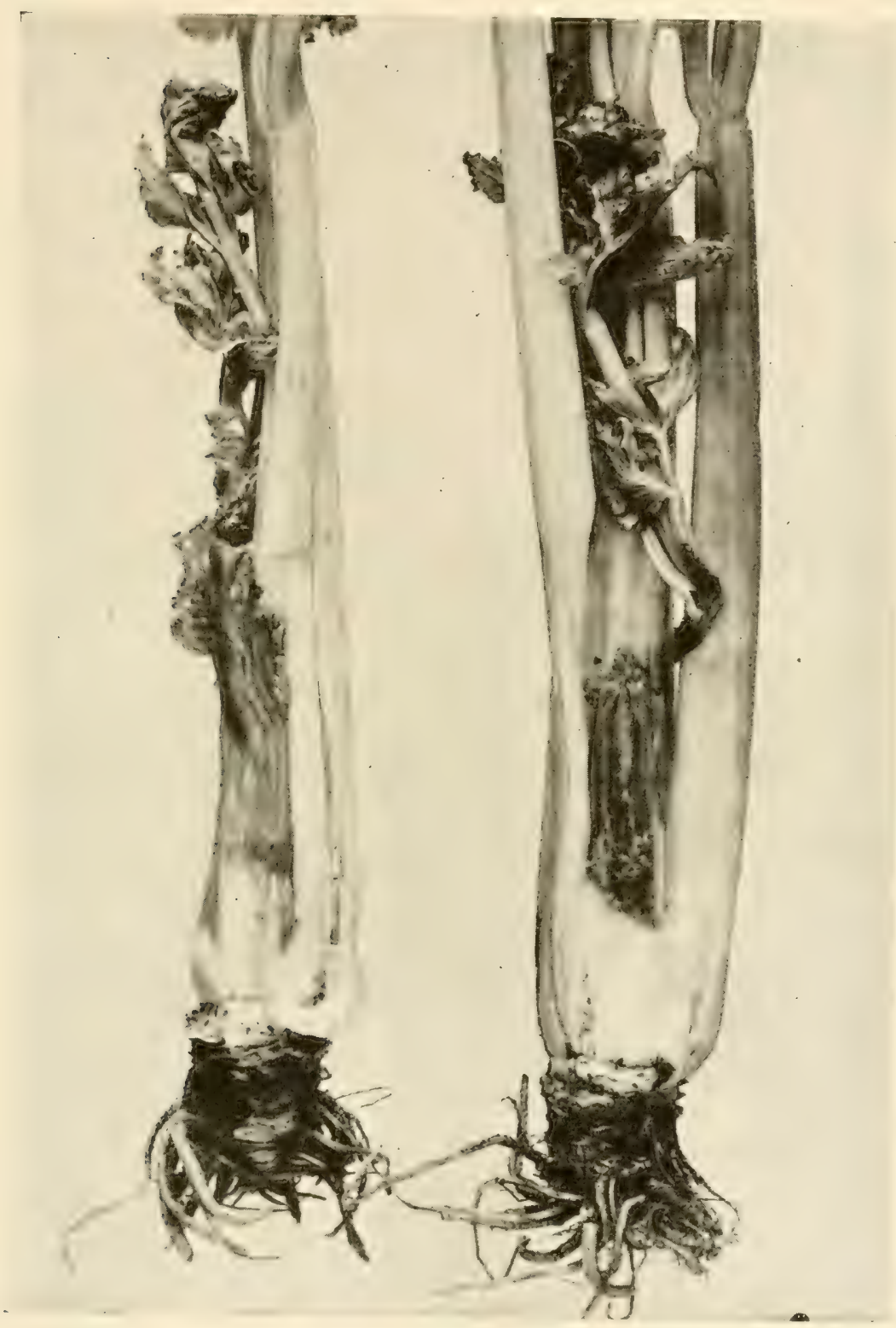

FIG. 49.-Celery plants 24 hours after needle pricks introducing Wormald's celery-rot organism (Bacillus apiovorus). Photographed July 22, 1914. Natural size. 
searched for in that country. It was not observed in the wheat region. West of the Mississippi River until after numerous importations of Russian wheats.

\section{METHODS OF CONTROL}

In conclusion, some words on prophylaxis will be in order. Until recently almost nothing was known. Unfortunately so far as regards most of these diseases, methods of control must. still be worked out. But with rapidly increasing knowledge of the biological peculiarities of the parasites causing these diseases, and of the ways in which they are disseminated, light begins to dawn, so that before many years have passed we may confidently expect the more intelligent part of the public to be applying sound rules for the control of these diseasesrules based on the individual peculiarities of the parasites and carefully worked out experimentally by the plant pathologist. In the United States within a generation every large crop establishment will have its plant pathologist. The little that we now know may be summarized as follows:

Waite has shown that pear blight winters over in exceptional trees on trunk and limbs in the form of patches which ooze living bacteria the following spring (see Figs. 282, 283) and are visited by bees and other insects, and that if these "hold-over" spots are cut out thoroughly over regions several miles in diameter (wide as a bee flies), the disease does not appear on the blossoms and shoots the following spring, except as it is introduced into the margins of this area from remoter uncontrolled districts. He has tried this method of control very successfully, both in Georgia and California. Sometimes only one tree in many carries over the disease, but such is not always the case, as Sackett has shown, and the success of this method involves the inspection of every pome tree in a district, with complete eradication of every case of the hold-over blight, and this in great fruit regions requires a small army of trained inspectors. During the blighting period in late spring and early summer, if one would save his orchard, the trees must be cut over for removal of diseased material as often as every week, and in the worst weather oftener. Furthermore, some 
of the stone fruits, e.g., apricots and plums, and various wild plants of the Family Rosacer, must be inspected because these also are subject to the blight.

The introduction of diseases transmitted by way of seeds, bulbs, and tubers may be avoided by obtaining these from plants not subject to the disease. As this freedom cannot always be known, bulbs and tubers should be inspected critically before planting, and firm-coated seeds should be soaked for 15 minutes in 1:1000 mercuric chlorid water; thin coated seeds susceptible to mercuric chlorid, e.g., wheat, in 1:1000 copper sulphate solution (20 minutes) followed for a moment by milk of lime; or exposed to formaldehyd (40 per cent. formalin 1 part, water 400 parts, for 10 minutes and then held moist for some hours). In case of five plants (cabbage, maize, wheat, barley and oats) we know positively that the diseases are transmitted on the seed and this is probably true for several otherspeas, beans, soy beans, cucumber (angular leaf spot ${ }^{1}$ ), sorghum, orchard grass. All shrivelled seeds should be screened out before planting. Dry beans will endure at least 10 minutes exposure to $1: 1000$ mercuric chlorid water and germinate freely. I have not tried longer exposures. The germination of wheat is injured even by 10 minutes exposure to 1:1000 mercuric chlorid water and very seriously by 1/200 formalin water, and also by heavy doses of copper sulphate such as have been recommended for the elimination of smuts. A. G. Johnson has recently recommended hot dry air for the destruction of fungous and bacterial parasites on various grains, but tried on wheat for black chaff I found that either it seriously injured germination or failed to destroy all of the bacteria. It may serve admirably, however, for plot experiments where the aim is simply to procure sound grain for subsequent field sowings, since here a loss even of one-third of the seed grain is of no consequence in comparison with the end in view. Formaldehyd (formalin), if properly used, destroys all of the black chaff organisms on the surface of wheat kernels (Fig. 50) but kills some of the

\footnotetext{
2"I saw remarkably virulent development of Bacterium lachrymans this summer [in Wisconsin] introduced on seed and spreading rapidly" (L. R. Jones, 1919: Letter to the author).
} 


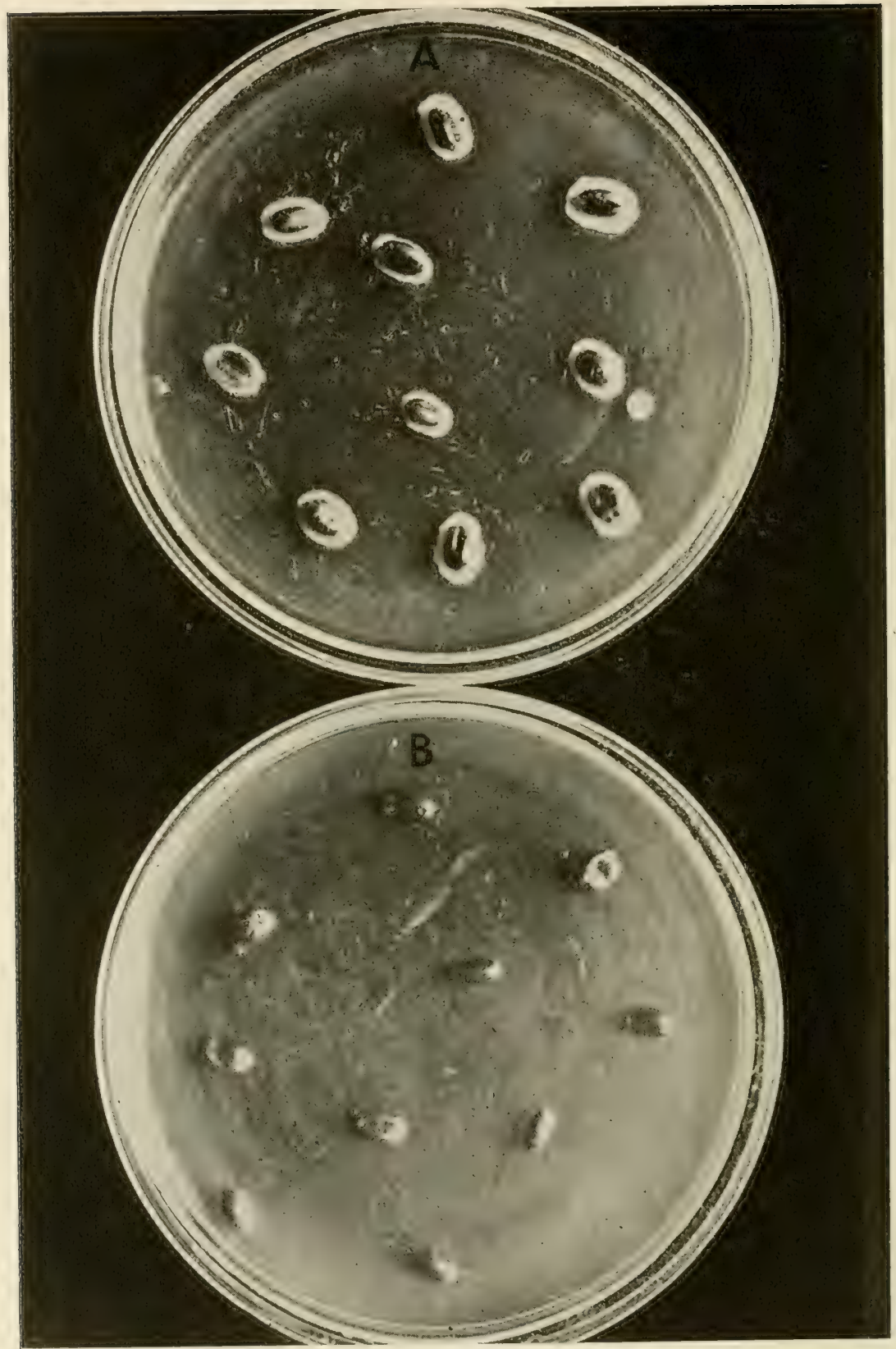

Fig. 50.-Bacterium translucens var. undulosum, the cause of black chaff of wheat (Isolation No. 286, Island Park, Iowa) showing killing effect of 10-minute exposure to 1,400 formalin water: (See next page.) 
kernels and retards germination of the rest. The whole subject of germicidal treatment needs careful revision.

Since the above was written Harry Braun of my laboratory has discovered (1919) that injury to seed-wheat, which is considerable when formalin solutions or copper sulphate solutions are used, is eliminated by soaking the seed in water for 10 minutes and then keeping it moist for 6 hours before treating it. This allows it to absorb sufficient water to become resistant, since most of the injury is caused by the formaldehyd that is carried into the grain along with the imbibition water. It is then soaked in one part of formalin to 400 parts of water for 10 minutes, drained, and covered for six hours to get effective action of the remaining aldehyd vapor on all the parasites, whereupon it is dried and planted. His work, repeated many times on different varieties of wheat and to some extent also on other grains, shows nearly as full germination and quite as good growth in the treated plots as in the control plots. In fact, growth from the treated seeds is stimulated a little (Fig. 51).

In studying pear blight Reimer found (1918) that 1 part of formalin in 9 parts of water is very effective for destroying the Bacillus amylovorus both on tools and in the tree wounds. $\mathrm{He}$ also found $1 / 500$ cyanide of mercury in water destroyed the pear blight organism in tree wounds effectively (with some slight injury to the wound) while Bordeaux paste or $1 / 500$ mercuric chlorid water often failed. His $1 / 1000$ cyanid of mercury water was not always effective, and he still has formalin treatment and the proper dose of cyanid under consideration (see Part III, No. XII). The cyanides, it should be remembered, are deadly poisons to man and the domestic animais.

A. Check. Each kernel is surrounded by a pure culture of the yellow slime.

$B$. Treated seeds. All are free from bacteria. The seeds were first haked to kill surface saprophytes, then soaked in a thick bouillon suspension of the blackchaff organism made from a young agar eulture. Dried a day or two, exposed to the formalin and then planted on the nutrient agar.

Nine active isolations of the black-chaff organism were tested in this series. Of the 894 formalin treated seeds only 13 showed any growth of the black-chaff organism after 8 days on the nutrient agar. Of the 528 check seeds all but 5 developed colonies of the black-chaff bacterium. Photographed December 4, 1918 . 

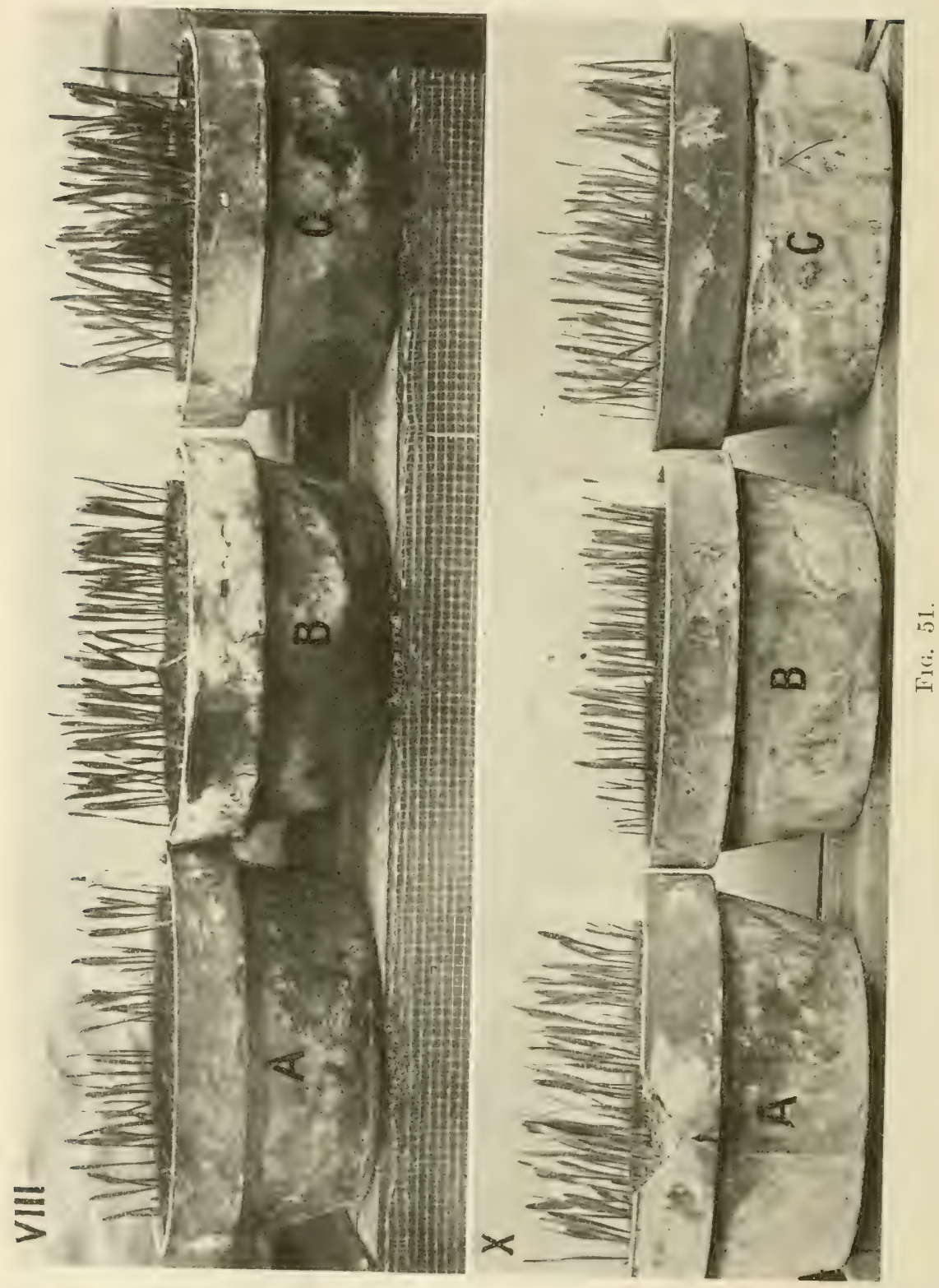
The seed bed in case of tobacco, tomato, cabbage, and transplanted plants generally, should be made on steam-heated or fire-heated soil, or on new earth which one has good reason to think free from the parasite in question.

In the greenhouse, nematode-infested soils should be aroided or steamed or drenched with formalin water (one pint of formalin to 40 gallons of water).

Cuttings of carnations, chrysanthemums, roses, peaches, plums, apples, quinces, sugar-cane, etc., used for slips, buds, or grafts should be from sound plants. By following this practice, recommended by Cobb, the more intelligent sugar-cane planters in New South Wales, it is said, have overcome the disease due to Bacterium vascularum.

Commercial growers of hothouse roses in Maryland, New Jersey, New England and Canada have been much troubled in recent years by crown gall. To avoid this disease in houses great care should be exercised in the selection of soil and of cuttings. A knife used on diseased roses must not be used again on sound plants until disinfected. When a soil has become infected it may be steamed under weighted sheet-iron pans for an hour at 65 pounds pressure, by use of the autoclave (Fig. 56), by the steam-chamber (Fig. 57), or by means of a steam-drag

FIG. 51.-Braun's imbibition experiments with seed wheat to prevent injury when subsequently treated with germicides. Formalin in distilled water (1/400) was used but the same results have been obtained with copper sulphate in water $(1: 80)$ and with formalin water $(1 / 320)$. In each pot 100 seeds were used:

VIII. Fulcaster wheat, planted March 8, 1918: photographed March 14.

$A$. Soaked in formalin-water for 10 minutes (the usual method), then covered for 6 hours to get penetrating effect of the formalin vapor. Pot shows much retardation and killing. Germination 68 per cent.

B. Check. Germination 85 per cent.

$C$. Seeds presoaked, then treated with formalin as in $A$. By "presoaking" is meant that the seeds were plunged into water for 10 minutes, then removed and covered for 6 hours to keep moist. Germination 81 per cent. Plants show stimulation.

X. Poole wheat, planted March 20, 1919; photographed March 26.

A. Seeds presoaked $(10$ minutes in water) then covered 6 hours to keep moist. Treated 10 minutes in formalin-water, removed and covered for 6 hours. Then planted. Pot shows stimulation and 86 per cent. germination.

$B$. Check; 95 per cent. germination.

$C$. Duplicate of $A$. Shows stimulation and 89 per cent. germination. 
which resembles a land-drag but is made of steam pipes, the teeth as well as the frame-work being hollow. The teeth are pointed and perforated with small holes so that when they are driven into the ground and live steam turned on it escapes and permeates the entire soil. I have seen the soil of lettuce houses in New England freed from parasites in this way. (Made by Geo. M. D. Sargent, Belmont, Mass.)

On badly infested fields, whatever the disease, a careful rotation should be practised and low places should be drained.

Certain diseases may be held in check by germicidal sprays. Newton B. Pierce reduced the number of infections in walnut blight in California 50 per cent by this method, using Bordeaux mixture. Scott and Rorer combated leaf-spot of the peach in this way using self-boiled lime sulphur, the sprayed trees retaining their leares, the unsprayed ones becoming defoliated. G. Bellini in Italy has recommended Bordeaux mixture and used it successfully on olive trees, following hail-storms, to keep out the olive tubercle.

When, as in case of the cucurbit wilt due to Bacillus trachciphilus, diseases are transmitted by insects, destruction of the latter must receive prompt attention. Trap crops may be used.

Great care should be taken to keep the manure heap free from infection. Diseased rubbish should be burned or buried deeply. It must not be thrown into a water-supply or fed to stock or dumped into the barnyard. Diseased potatoes and other crops should be cooked before feeding to animals.

One of my fancies is that plant pathologists will eventually discover competing saprophytes which when sown on infected soils will overcome and render harmless certain of the bacterial parasites present in them. We have some evidence that nature does this, and man working toward a definite end should be able to improve on nature.

Wet fields should be drained and, in general, every effort should be made to put the crop under good growing conditions, i.e., to give it a proper soil, good food, the right climate and the right amount of soil moisture. A wise rotation should also be practised. Rotation is the keynote of successful agri- 
culture. The man who grows one crop year after year on the same soillinvites disaster.

It has seen found that some cultivated varieties are less subject to disease than others (pear, apple, plum, rose, maize, beans, soy beans, potato, tomato, sugar-cane, banana, cabbage, etc.), and there are also individual variations within the variety. These phenomena lead us to hope that by selection, or hybridization, valuable resistant strains may be originated. Meanwhile the resistant sorts when they are of any value commercially should be substituted for sensitive sorts in localities much subject to the disease. Unfortunately some of the resistant sorts have other less desirable qualities. A vast amount of experimental work must be done in this field before we shall have substantial results, and at least a generation or two will be required to learn even the boundaries of the field. But the problem offered is so enticing, and has such immediately practical bearings on the food-supply of the world, that in the near future we may suppose many pathologists will devote themselves to it, and that long before the whole field is worked over, many useful results will be fortheoming. The labor involved is enormous and exacting to discouragement at times, the results come so slowly, so much must be done to be certain of so little, all because the organisms dealt with are very small- how small, we seldom realize! If the inhabitants of the United States or of Great Britain were reduced to the size of the smaller bacteria the entire population could occupy the surface of a silver dollar or of an English penny-and that too without crowding! O'Ciara's happy characterization of the Fire-blight organism, "under the microscope, when magnified 1,000 diameters, its appearance is that of a hyphen "-," applies equally well to nearly or quite all of the forms described in this book. 


\section{PART II \\ METHODS OF RESEARCH}

A few pages on the technics of plant bacteriology will be of service to the student. These are not designed to do away with the need of reference books. Therefore, at the beginning, the student is advised to read as much as he has time in the following standard works, and to consult them daily as problems arise. The list is by no means exhaustive and does not include all the good book', but is more than sufficient probably for the beginner.

A FEW OF THE MORE RECENT REFERENCE BOOKS

LeE: The Microtomists' Vade-mecum. 7th ed. Philadelphia, P. Blakiston's Son \& Co., 1913.

Gage: The Microscope. 12th ed. Comstock Pub. Co., Ithaca, N. Y., 1917.

Mallory and Wright: Pathological Technique, IV. B. Saunders Company, Philadelphia and London.

Jordan: A Text Book of General Bacteriology. W. B. Saunders Company, Philadelphia and London.

Erre: Bacteriological Technique. W. B. Saunders Company, Philadelphia and London.

Muir and Rrtchie: Manual of Bacteriology. The Macmillan Co., New York and London.

Hewlett: Manual of Bacteriology. Clinical and Applied. 5th ed. J. and A. Churchill, London, 1914.

STiтT: Practical Bacteriology, Blood Work and Animal Parasitology, incluting Bacteriological Keys, Zoological Tables and Explanatory Clinical Notes. 5th ed. P. Blakiston's Son \& Co., Philadelphia, 1918.

Аввотт: The Principles of Bacteriology. A practical manual for students and physicians. 9th ed. Lea and Febiger, Philadelphia and New York, 1915. 
Park, Williams and Krumwiede: Pathogenic Microörganisms. A practical manual for students, physicians and health officers. 6th ed. Lea and Febiger, New York and Philadelphia, 1917.

Kendalu: Bacteriology. General, Pathological and Intestinal. Lea and Febiger, Philadelphia and New York.

Microbiology: A text-book of microörganisms general and applied. By Charles E. Marshall and many others. Second edition revised and enlarged with 186 illustrations. Published by P. Blakiston's Son \& Co., Philadelphia, 1917.

Laboratory Methods of the United States Army. Compiled by the Division of Infectious Diseases and Laboratories, Office of the Surgeon-General, War Department, Washington, D. C. Medical War Manual No.6, pp. 256. Lea and Febiger, Philadelphia and New York. A marvel of compactness and accuracy. It weighs only 4 ounces and is a veritable Vade-mecum.

Ridgway, Robert: Color Standards and Color Nomenclature. Washington, D. C., 1912. Published by the author. I have referred to this book as " $\mathrm{R}_{2}$ " and to its predecessor, "A Nomenclature of Colors for Naturalists" (Little, Brown and Co., Boston, 1886), as " $\mathrm{R}_{1}$."

\section{APPARATUS}

Only some hints which may prove useful are here included.

\section{For Preparation of Culture Media}

Culture media can be made, in default of better appliances, with some neutral litmus paper, a glass graduate, a pair of scales, some cork-stoppered flasks or bottles, a pen-knife, a kitchen stove and a tea-kettle, but certain other and more convenient kinds of apparatus are desirable. I shall mention only some of the leading articles.

Receptacles.-Test tubes, beakers, pipettes, graduates, Erlemmeyer flasks, and Petri dishes are the most commonly used glassware. Resistant (insoluble) Jena glass or its equivalent, American Pyrex glass, is always desirable and is absolutely necessary for some purposes. 
Cotton and Gauze.-The best surgeon's roll-cotton is not too good for plugging test tubes and flasks. Surgeon's gauze in bolts should be on hand for coarse filtering and various other uses.

Balances.- There must be coarse pan-balances for ordinary weighings, and fine balances for the more delicate operations, these latter usually under lock and key, especially where careless persons are wandering about. The Becker chemical balance, and the Kny-scheerer analytical balance (Aartorius model) are very good.

Dry Ovens.-The best dry oven I know is Lautenschläger's. This gives in all parts a very uniform temperature, and requires a minimum of watching.

Steamers.-The Boston Board of Health steamer, made by the Arnold Steam Sterilizer Company, Rochester, New York, is recommended.

Autoclaves.-I use two kinds: an upright autoclave made in Paris by P. Lequex, known as the Chamberland-Wiesnegg (depth 17 inches, diameter 13 inches), and a larger horizontal apparatus made by the Kny-Scheerer Company, New York, N. Y. The latter has a capacity of twelve 2-liter flasks, the depth being 28 inches, and the inside diameter 20 inches. By adjusting a valve, air is pumped out of the inner chamber and by another turn steam is allowed to enter whereupon the two pressure gauges should register alike. The steam may be generated by gas flames or may be taken directly from the enginehouse boiler. I prefer gas, which is more easily controlled.

Centrifuges.- Nilk and other fluids frequently require centrifuging, and for this purpose a centrifuge holding at least half a liter is necessary. This may be propelled either by steam or by electricity. I formerly used a very good electric centrifuge made by Lautenschlïger but the gearing required so much space that I have abandoned it for a much more compact and equally serviceable machine made by the International Instrument Company, ('ambridge, Mass, using electricity as the motive force (Fig. 52). Our instrument is so compact that it occupies only some waste space behind a door. It is bolted to a thick block of concrete (18 by 26 by 30 inches) resting on the floor. It is 
their Type B, Size 2, Amperes 2.15, volts 220. It is 22 inches high, the steel shell that encloses the whirling part having a depth of 13 inches and an inside diameter of about 23 inches. There are 8 carriers (two larger than the others), the total capacity being about $1100 \mathrm{cc}$, and the number of revolutions per minute 3000 when accurately leveled, properly loaded and running at full speed. The levelling and equal loading are very important.

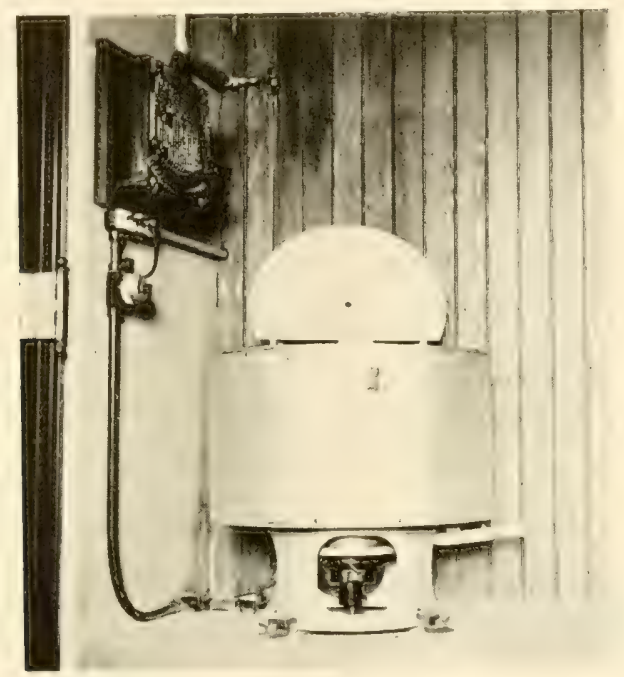

PIG. 52.-Electric centrifuge made by the International Instrument Company, Cambridge, Mass.

Filters.- The Berkefeld and Chamberland filters are often necessary and in connection one must have some kind of device for supplying compressed or exhaust air. In vol. I of "Bacteria in Relation to Plant Diseases," I figured (Plate 10) a rery good steam pump for furnishing compressed air and a high vacuum. Having moved into another building we no longer use this particular pump but obtain our exhaust and pressure from the main engine room of the Department of Agriculture. Where such steam pumps are not available small mercury pumps may be used. Very perfect ones are now for sale, of which the Gaede, the May-Nelson, and the Geryk are those commonly in use. Of the three the Gaede is said to be the best. For removing the 
last traces of air quickly from rather large spaces the Langmuir Condensation High-vacuum mercury pump is highly recommended. This requires a rather large opening and the initial vacuum must be made by means of another pump. Very recently "A New Cenco High Vacuum Pump" has been advertised as accomplishing quickly the removal of air from considerable spaces, down to $0.001 \mathrm{~mm}$. without the aid of an accessory pump (Science, n.s., Oct. 3, 1919, page x). Its dimensions are: length 32 in., width 11 in., height 18 in. Strong claims are also made for "The Gramercy Rotary High Vacuum Pump" (Science 1. s., Dec. 26, 1919 (Cover).

Titration Apparatus. - See Sutton's "Volumetric Analysis."

Blood Serum and Starch Media Oven.-See the Text books.

Miscellaneous.-Grinders, shakers, meat-presses, knives, forceps, shears, graduates, beakers, ring-stands, Bunsen burners, cork-borers, glass tubing, copper wire and many other small articles add to the convenience of the laboratory which should be supplied with gas, electricity, hot and cold water, and ice, all in abundance.

\section{For Isolation and Care of Cultures}

Tools.-For isolation of bacteria from plant tissues very simple derices are all that is required, viz., steel needles in bone or wooden handles, small forceps, spatulas, platinum-iridium needles and loops, small knives, scissors, pipettes, glass-tubing, rubber-tubing, sterile Petri dishes, test tubes and flasks, a gas burner or alcohol lamp, sterile water or bouillon for diluting, and suitable culture media. To these may be added large resistant glass bottles for holding distilled water and stock solutions of the standard germicides-especially mercuric chlorid and carbolic acid.

Culture Chambers. - Isolations may be made in clean open rooms if air currents are excluded, but it is safer to work under a small hood or in a special culture chamber from which the indifferent and the unclean are carefully excluded. In the Department of Agriculture we use a special standard culture chamber made in sections in Baltimore by Ruse and Co., at a cost singly of $\$ 130$ (pre-war price). These are well lighted, of convenient 
size and leave little to be desired. They are of polished oak (about 10 feet high and with an internal diameter of approximately 4 by 4 feet). Specifications and blueprint drawings may be had from the Bureau of Plant Industry, United States Department of Agriculture.

The equipment of the transfer room, which should have a large window and a broad work-shelf on the side facing the best light and several shelves at the right, consists of a cut-off gasburner, needles, loops, forceps, litmus paper, and various, movable racks, tubes and dishes. There should be also a shallow drawer under the work shelf for rubber bands, pencils for writing on glass, ete.

Sub-cultures are placed for study at various temperatures. These require closed cupboards for room temperatures, ice boxes for temperatures from $15^{\circ} \mathrm{C}$. to $0^{\circ} \mathrm{C}$, electric or gas thermostats for temperatures from $30^{\circ} \mathrm{C}$. upward, and specially devised ammonia apparatus for temperatures below $0^{\circ} \mathrm{C}$.

Thermostats.-Our thermostats are of various patterns. Large sizes are preferable. The best one we have is an old instrument covered with felt, made many years ago by Rohrbeck in Berlin. All our thermo-regulators are the French metal-bar regulator commonly known as the Roux. These require less attention than those containing mercury or other fluids.

Besides ordinary ice boxes we make large use of Paul Altmann's ten-compartment ice thermostat, and during a part of our year can keep the temperature in the lowest compartment at $0.5^{\circ} \mathrm{C}$, but not during the summer.

Our stock cultures are carried in ordinary kitchen refrigerators, but shelves in a specially cooled room would be much better. Refrigerators that have the ice compartment over the storage chamber are certain to leak into the latter sooner or later and to spoil cultures.

For thermal bath see "Bacteria in Relation to Plant Diseases," Vol. I, Fig. 63.

\section{For Preparation and Study of Sections}

A paraffin embedding oven, microtomes, stains, staining dishes, flawless slides and covers, good Canada balsam and 
good microscopes are the principal equipment required for the preparation and study of permanent sections.

Microtomes.-Zoologists generally, especially those who have studied in Europe, seem to prefer the Jung or the Reichert sliding microtome for section cutting. The writer has used both, having first learned to cut sections on the Jung, but for many years we have used almost exclusively a rotary Dutch machine made at Delft and known as the Reinhold-Ciltay. Dr. Charles E. Bessey was, I believe, the first person in this country to use

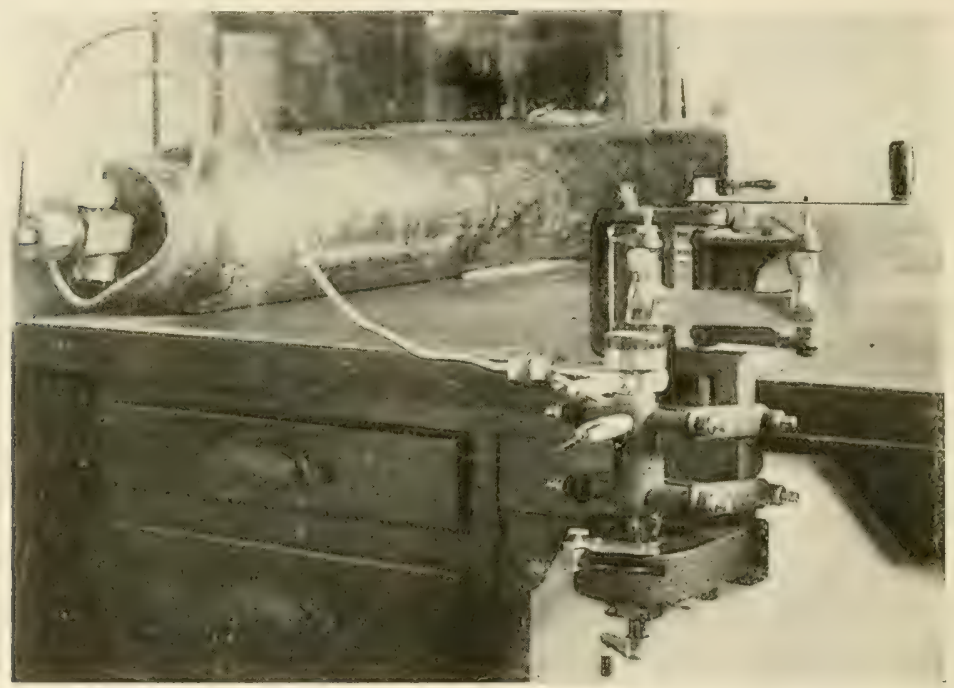

FIG. 53.-Freezing microtome made by the Spencer Lens Co., Buffalo, N. Y., with cylinder of compressed carbon dioxide.

this machine and his high praise of it induced the writer to order one for the Laboratory of Plant Pathology. All that was said by Dr. Bessey in praise of this instrument has been more than borne out by our experience with it. The machine we first bought (for figures of it see "Bacteria in Relation to Plant Diseases," Vol. I, 1905, pl. 13 and Fig. 119) is still in use and nothing has ever been spent on it for repairs. In recent years, with increase of our work, one microtome proved insufficient, and we purchased a second machine of the same make. This microtome is better, I think, than that similar and more recently 
constructed microtome known as the Minot Rotary, which we also have, and use occasionally. For some purposes, such as making large sections with a long slant stroke, we have also used the large Ninot Precision. Nicrotome, which is a very good instrument but too cumbrous for our ordinary work. Another excellent instrument which we use is the Spencer Rotary Microtome No. 820. Our freezing microtome also is one made by the Spencer Lens Co., of Buffalo, N. Y. (Fig. 53).

The style of razors recommended for use with the Reinhold-Giltay microtome are figured in "Bacteria in Relation to Plant Diseases," Vol. I. p. 123.

Paraffin Oven.-Any small water-jacketed oven with a safe, selfregulated, constant flame which can be set very low will serve for keeping at the proper temperature $\left(59^{\circ}\right.$ to $60^{\circ} \mathrm{C}$.) the paraffin used in embedding. For figure of a small paraffin oven in use see "Bacteria in Relation to Plant Diseases," Vol. I, p. 11s. This is sufficient for private use, but where several persons must be accommodated at

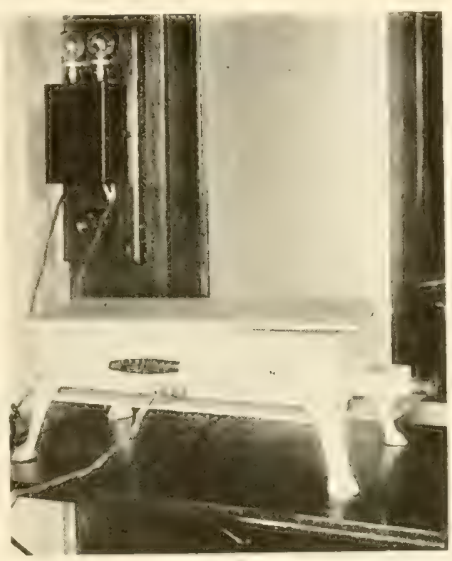

Fig. 54.-Electrie warm plate used for straightening out paraffin sections. Made by IV. C. II reatens. Gimb.H.. Manan a M.. (iemany. No. t.o. (i. $220 \mathrm{~V}$. the same time the large compartment oven devised by Professor Frank R. Lillie is recommended.

Section Straightener. -For straightening out sections on the slides we used formerly the low flame of an alcohol lamp under an asbestos board, but more recently we have substituted an electric constant temperature apparatus made by W. C. Heraeus, G. m. b. H., Hanau a/M., Germany (Fig. 54). With a little watching this warm-plate gives a temperature just sufficient for straightening the sections without melting them. Previously for the same purpose we tried a little electric oven made by The Thermo-electric Instrument Co., Newark, N. J. (Freas' Electric Incubator, Serial 111, voltage 220 , wattage $15.0 ; 7^{\prime \prime} \times 7^{\prime \prime} \times$ 
$10^{\prime \prime}$; cost $\$ 57$ ) but without success, since the temperature proved too variable.

Stains and Staining Jars.-A full set of Grübler's stains are very desirable. Few persons know how to use any great number of them, but for those few who do they should be available. It is best to buy them in unbroken packages. We use the Coplin staining jar (figured in "Bacteria in Relation to Plant. Diseases," Vol. I, p. 121). There is nothing better than this.

Mounting Media.-This varies, of course, with the nature of the sections. I have not fallen in love with glycerine or glycerine jelly mounts, but as made by some persons they appear to be quite permanent. We employ mostly Canada balsam or Dammar balsam. It should be purchased only from makers of the highest reputation, e.g., Grübler, with special reference to freedom from traces of acids which, if present, will infallibly bleach and ruin the best stained slides in course of time. I formerly made my own balsam, of good quality, by purchasing the best grade of crude balsam and driving off all volatile products in an oven kept for some days at the proper temperature, after which the brittle unburned residue was dissolved in xylol to the proper consistency. I was forced to do this by inability to find at that time any fit balsam on the market.

Microscopes.-When properly stained, mounted and dry, the sections are ready for study. For this purpose only the best microscopes are recommended. At least the objectives, eyepieces, and the substage apparatus should be of the very best workmanship, owing to the small size of the objects sought and the need of studying them in a clear light with very sharp definition. The fine adjustmeni also should have a very slow movement.

The writer now uses only the Carl Zeiss instruments and specially recommends his photomicrographic stand, but the one shown in Fig. 55 rather than the newer pattern which is very inconvenient to carry, having only two separate awkward finger holes in place of the convenient large opening on the old pattern. It is also less well finished, e.g., in the two which we have, the vernier plate at the right projects above the stage and catches the end of the slide, making it very inconvenient to use with 
slides bearing serial sections. These two were made, however, since the great German war began, and this may be an incident of it. The new pattern differs slightly also in other particulars but so far as I can see is not better than the old, if as good.

Objectives and Eyepieces.- There is nothing better for initial magnification than the Zeiss apochromatic objectives, especially the superb $16-\mathrm{mm}$. and 8-mm. dry lenses (each of which will give a clear image with a No. 12 eyepiece) and the $3-\mathrm{mm} .1 .30 \mathrm{~N}$. a. and 2-mm. $1.30 \mathrm{~N}$. a. homogeneous immersion objectives, both of which have a fairly long working distance, especially the $3-\mathrm{mm}$.

If one has the $8-\mathrm{mm}$. apochromatic objective and a No. 12 compensating ocular, it is seldom necessary to use the adjustable-collar Zeiss 4-mm. dry objective. We have several of them but they cloud easily and, according to my experience, seldom give sharp images for any great length of time. It is, I think, the least useful of all the Zeiss objectives. If higher powers than the $16-\mathrm{mm}$. or 8$\mathrm{mm}$. are necessary, the student should learn to use the oil immersion objectives. We have also a Zeiss 2-mm. $1.40 \mathrm{~N}$. a. and a Zeiss $1.5-\mathrm{mm}$., but I seldom use them. For use with these apochromatic objectives several compensating eyepieces are furnished, the most necessary

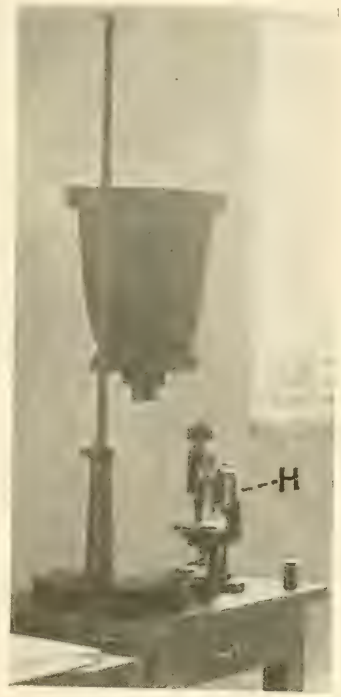

FIG. 55.-Zeiss Photomicrographic stand and small upright camera. Nearly all the photomicrographs in this book were made with this microscope and camera. of which are the Nos. 4, 8, and 12. For research I generally use the No. 8 or 12 eyepiece, the No. 18 is not necessary, and for photomicrographic work the No. 4, in place of the special eyepieces provided by Zeiss.

Cheaper microscopes, but very good ones, are also made by the Leitz Company, and by the Spencer Lens Company of Buffalo, N. Y. 
These are the three sorts of microscopes I feel specially disposed to recommend.

Hand Lens.-- I good hand lens, that is, one with a flat field free from chromatic aberration and having a long working distance, is absolutely essential. It should magnify about 6 times. Hand lenses having a higher magnification $(X 10$ or $\times 15)$ are sometimes very convenient, but are of less general use because, owing to their short focus, they will not reach to the center of an agar-stab culture or through the top of a Petri dish. The writer uses a Zeiss $\times 6$ Aplanat which leaves little to be desired.

\section{For Hothouse and Inoculation Experiments}

A large autoclave is necessary very frequently for sterilizing pots, soil, discarded infectious plants, and other things used about the hothouse. It should be large enough to take in a small table, a big inoculation eage, or several 200-lb. sacks of soil at the same time. The steam should be from the enginehouse pipes. The apparatus we use is the Merrel and Soule No. 3, made by the Sprague Canning Machinery Company, Hoopeston, Illinois, and sold at $\$ 45$ (pre-war price). Its depth is 60 inches and its diameter 45 inches. It is serviceable but inconvenient. A larger and more convenient horizontal (canners') autoclave, having a depth of 100 inches and an internal diameter of 44 inches (Fig. 56) is marle by the same firm and is called "R K 1. The Rutter Kettle." It is not a very perfect autoclave but by attaching to it a small pump to remove the air it may be used successfully with steam or may be filled with hydrocyanic acid or other insecticidal gases. The Office of Seed and Plant Introduction of the United States Department of Agriculture has devised several inexpensive convenient pieces of apparatus for destroying the nematodes and fungi in greenhouse soil by means of steam heat without puddling the earth.

FIG. 56.-Sterilization room of Office of Seed and Plant Introduction, United States Department of Agriculture, Washington, D. C. The Rutter Steam Kettle in the center. At the extreme left is the pump for removing air from the autoclave or gas, if used as an insecticidal chamber. (Courtesy of Dr. B. T. Galloway.) 


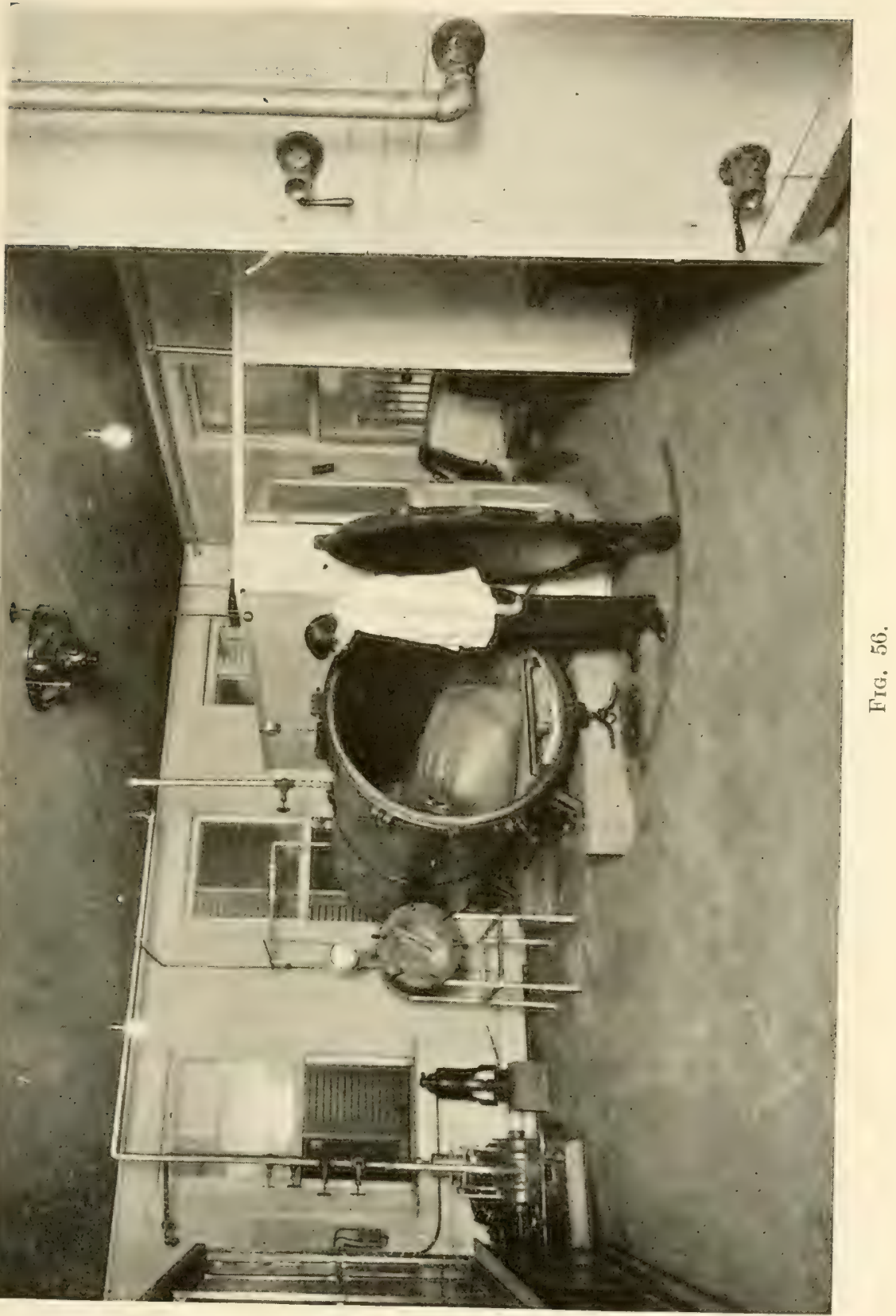




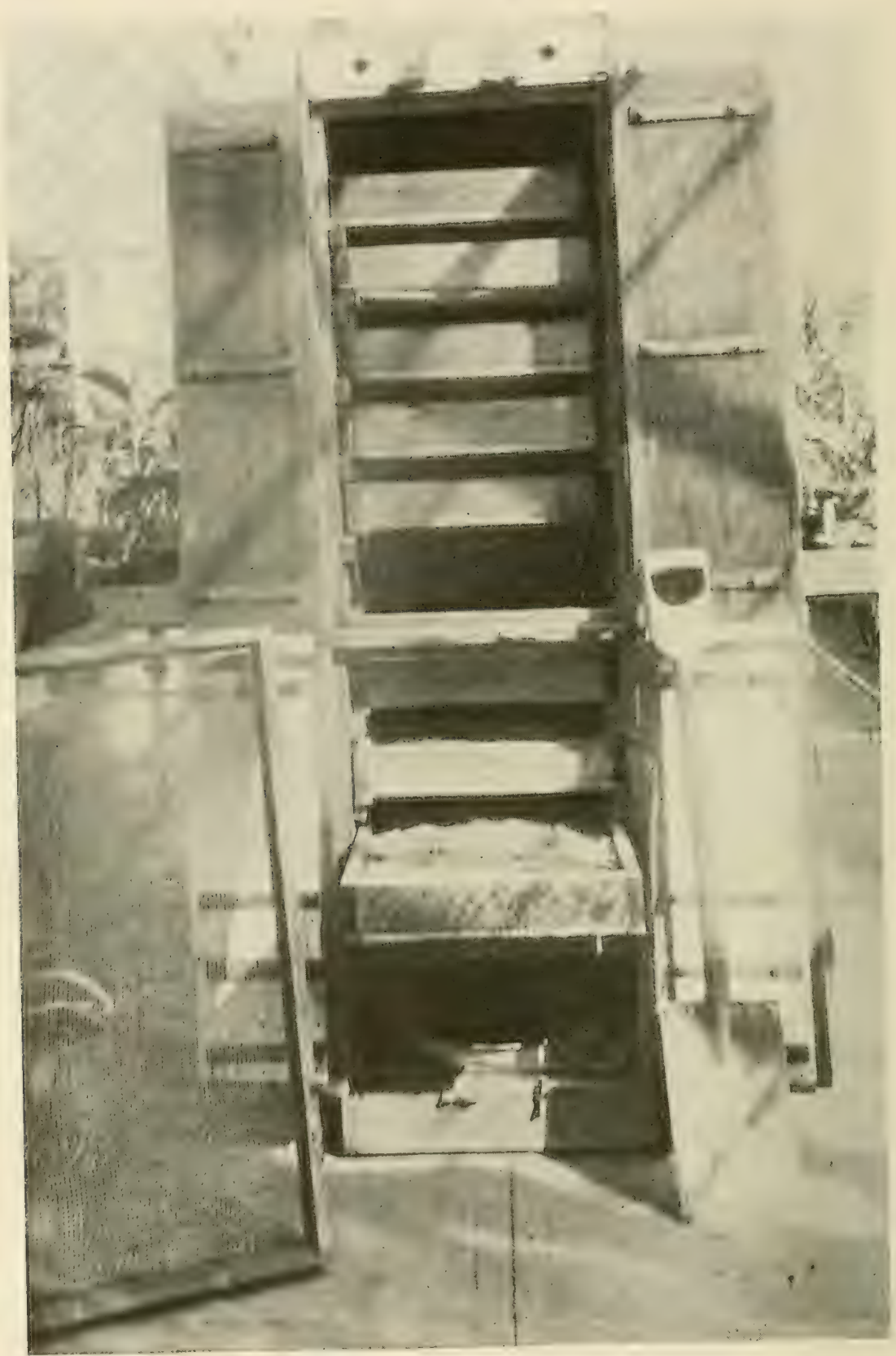

Frg. 57.-Home-made device for steaming infected soil. It is a steam-chamber holding 12 drawers having wire-mesh bottoms. These slide in and out on rollers. 
One simple piece, a sort of tall deep cupboard, which any carpenter can make and which takes up very little room, will sterilize 6 bushels of soil in an hour (Fig. 57). This earth is held in half-bushel lots resting on sacking in shallow drawers having wire-mesh bottoms. The steam enters at the bottom (back) and the air flows out at the top (front) through openings which are closed by a slide when steam begins to escape. The cupboard is 3 inches deeper than the length of the drawers and every other one of these is shoved back so that the steam (15 pounds pressure) readily passes under and over each drawer. The later are 18 inches wide, 30 inches long and 3 inches deep.

The other pieces of hothouse apparatus required are very simple.

In addition to knives, labels, steel needles, hypodermic syringes (rarely necessary) and atomizing devices (a cologne sprayer will do), I need mention only alcohol lamps, eages with walls of glass (inoculation cages) and cages with walls of wiregauze (insect cages). These may be made of such size as will suit the best convenience of the experimenter. One whole side should be used as an opening (double door), and for the insect cages an additional small opening is very desirable. The bottom of each is, of course, open, resting on the earth, or on a bench or platform of some sort.

\section{For the Photographic Room}

If possible, the photographic room should have north, south, and overhead light, or at least south light and overhead north light in order that advantage may be taken of direct sunlight for heliostats, etc., and overhead light for a variety of indoor photographic lightings. For these reasons it is best located on a top floor. Our own rooms being on a middle floor we have had to make shift with south light only, taking it from

and are shorter than the depth of the chamber by a few inches allowing every other one to be shoved back or pulled forward so that steam, which enters at the back, at the bottom, may circulate freely around each one. The soil is placed on coarse sacking and each drawer holds a half bushel. Air is displaced through the two holes at the top and these are closed by slides when steam begins to appear. Photograph from Dr. B. T. Galloway. 
two big windows. One window is hardly sufficient for such a room if several persons are to use it, since it is often necessary to make natural size pictures and photomicrographs or lantern slides at the same time. For photomicrographs I use southwest light in the morning and southeast light in the afternoon, protecting the camera from the direct light of the sun, the south window therefore must not be too close to either wall.

The principal pieces of apparatus in our room are the camera stands, two or three small tables and wall-cases, and the sink and washing boxes. It can be entered without passing through the anti-chamber of the dark room. This is important.

Cameras and Lenses. - Whatever results are worth the time spent on them are also worth recording, therefore, from the beginning the student who hopes to become a naturalist should be taught to use the camera as freely as the microscope. If he learns to do this early he will have a great advantage over such as neglect it. The essentials are a light-tight bellows and a lens that will give a correct and sharp image, to which has been fitted a shutter allowing for measured long and short exposures. Shutters, however, are not absolutely essential and the size of the camera is also of minor importance, if the image is sharp enough to enlarge, as it will be, provided the lens is good, and the focus for the photograph is correct. If, however, the lens is poor or the focus is nearly out, the picture will not stand enlargement. The writer with Zeiss lenses has made pictures sharp enough to stand $a \times 10$ enlargement. The camera for natural size work should have a bellows long enough to give a magnification of two diameters, i.e., it should be 3 times the equivalent focus of the lens. I have seen nothing better than the Folmer and Schwing (Eastman Kodak Company) 612 by 81,2 slightly modified Collins and Brown camera figured in Vol. I of "Bacteria in Relation to Plant Diseases" (pp. 134 and 145). For a light, traveling camera provided with a tripod, the East man Company Century Grand ( 4 by 5 ) leaves little to be desired. This is much less bulky than the Folmer and Schwing 5 by 7 Reversible-back Graphic, which, however, is extremely compact and durable, and in weight stands about midway between the two already mentioned. The lenses for such cameras should be the best on the market, and should be provided with the Volute 
shutter. I prefer the Zeiss double-protar lenses, Series VIIa. These are made and sold by Bausch and Lomb, Rochester, N. Y., under the name of Convertible Anastigmatic Lenses, Series VIIa. Very recently (1919) Mr. E. L. Crandall of the United

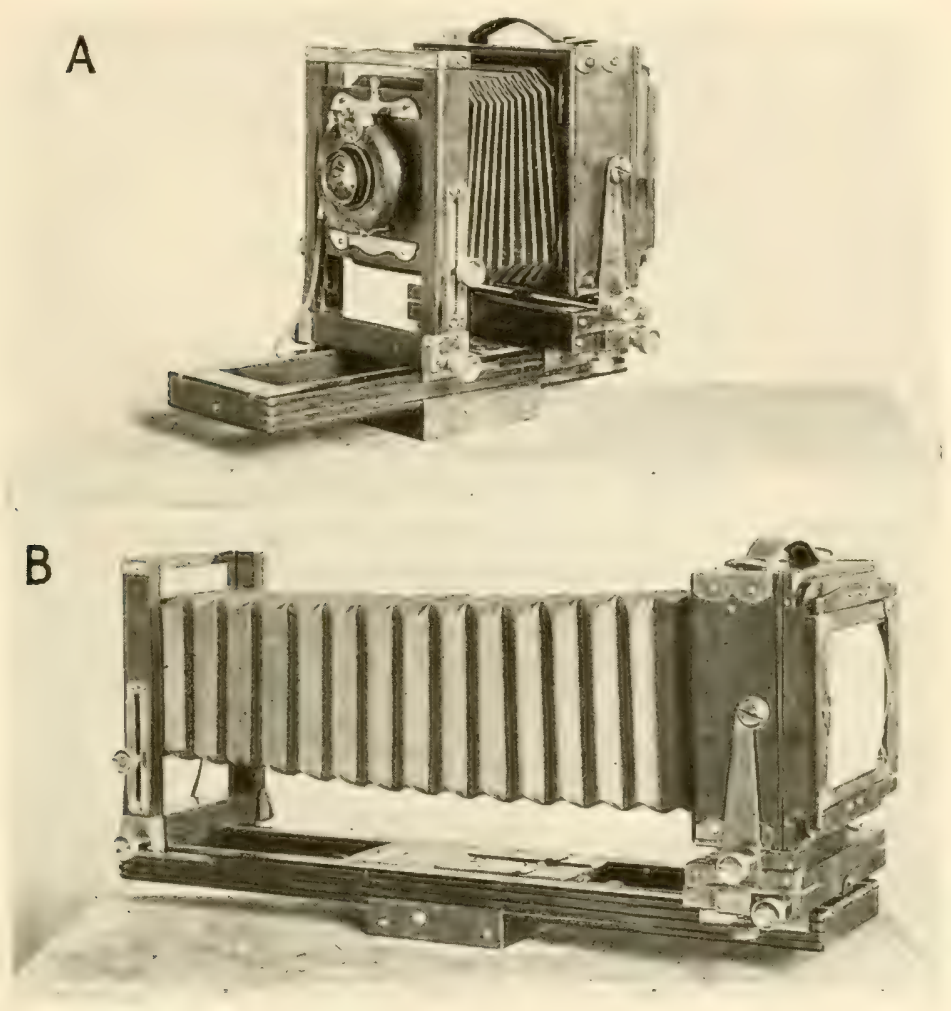

FIG. 58. - The Crandall model view camera which can also be used for small objects natural size or $\times 2$. Bellows extension 18 inches, weight $5 \frac{1}{2}$ pounds without tripod. Well made. This takes a B. and L. Zeiss Double Protar VIIa lens having a focus of about 5 inches. Front combination focus about 8 inches, rear combination focus about 12 inches. Made by the Folmer and Schwing Division of the Eastman Kodak Co., Rochester, N. Y. It carries a film, dry plate or Lumère plate $3 \frac{1}{4}$ by $4 \frac{1}{4}$ inches.

States Department of Agriculture, has designed an excellent, moderate priced small camera for field work that can also be used for small objects natural size or twice enlarged (Fig. 58). This also is made by the Eastman Kodak Co. 
The Zeiss Planar lenses, Series Ia, may have a word here. They are fully described in the Zeiss catalogues and I have figured Nos. 1 to 5 (those best adapted to photomicrographic work) in "Bacteria in Relation to Plant Diseases," Vol. I, p. 132, together with the special substage condensers to be used with them. These lenses have a focus varying from $20 \mathrm{~mm}$. to 100 $\mathrm{mm}$. and yield, when stopped-down, images ranging from 1 to 5 inches in diameter. They may be used either on the microscope or on the ordinary camera. They are very rapid lenses working with a minimum of light. They yield very sharp images, but have not much depth of focus. As stated in the catalogue "Focusing must be done with the most scrupulous care." I generally use a hand lens, focusing on a clear-glass image, and stop-down as much as possible to get all the depth of focus possible. In selecting a focus with the stop wide open it is well to remember that the increased depth of sharpness to be obtained later by stopping-down will be mostly away from the observer rather than toward him.

Camera Stands.-For many purposes a simple tripod, or a home-made device such as that figured in "Bacteria in Relation to Plant Diseases," Vol. I, p. 133, is sufficient, but for use with planars and generally for best results in lighting, we now use a universal position stand, i.e., the stand made by Folmer and schwing (Eastman's catalogue of photographic apparatus and materials, p. 50) with important modifications by James F. Brewer, as shown in Figs. 59-60. These improvements consist of (1) a device at the bottom of the stand for rotation; (2) castors for translocation; (3) a swing device under the backboard for raising or lowering the camera as a whole and locking it in the position desired; (4) an object carrier movable not only backward and forward but also to either side and away from the central axis of the stand; (5) a carrier behind the preceding for the background; $(6)$ a screw device for shortening or lengthening the distance of the camera as a whole from the object; (7) a test-tube rack attached to the front part of the object carrier and sliding up and down. In this carrier are a series of inch holes through which are thrust the tubes to be photographed, the same being held in place by a lining of perforated 


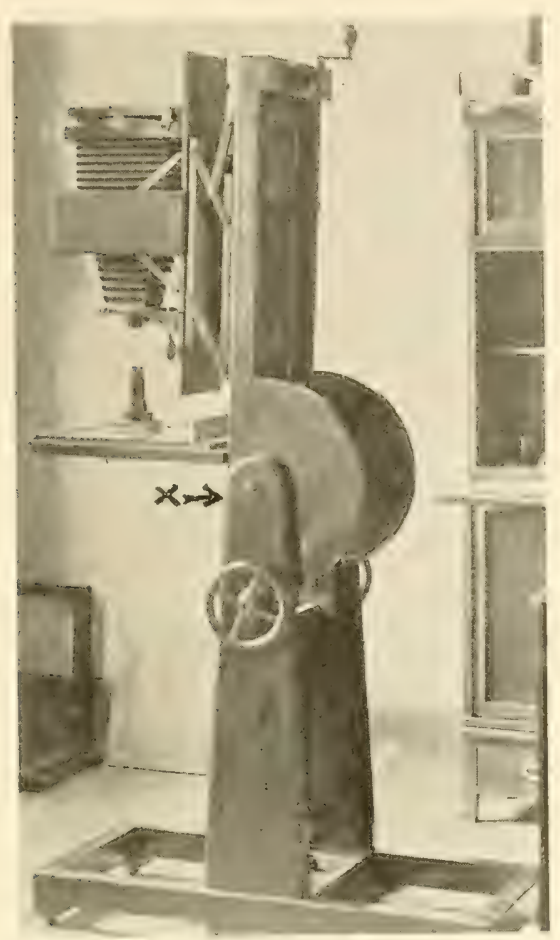

Frg. 59.-Camera stand used by the Laboratory of Plant Pathology. Made by Folmer and Schwing Division, Eastman Kodak Co., Rochester, N. Y.

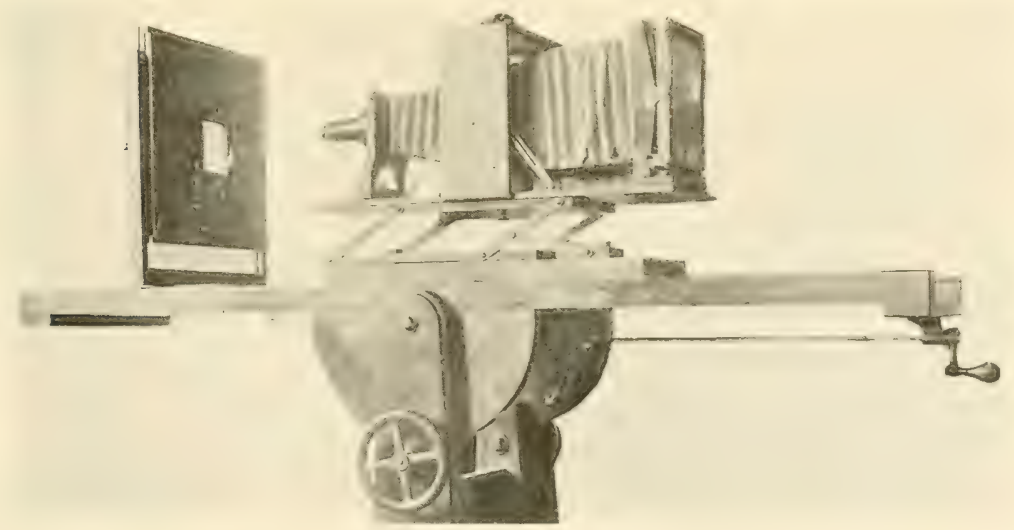

FIG. 60.-Horizontal arrangement of Fig. 59. 
rubber, the holes in which are smaller than any test tube but are slit in four places $90^{\circ}$ apart so as to receive and hold tubes of any size. For very large tubes a second carrier is provided. With these additions the apparatus is most convenient since it can be rotated toward any part of the compass, tilted and locked at any angle from vertical to horizontal, lengthened or shortened as required, and the rarious parts shifterl so that the object to be photographed can be centered on the ground glass with a minimum of labor. Two additional changes would make it nearly perfect-(1) a cut in the top of the framework at a given point $(\mathrm{x})$ so that the object carrier might be removed (lifted out bodily) without sliding it all the way to the end of the frame-work, where the background carrier is often in place and must now also be removed to let it out; (2) the object carrier can be moved to the right or left any distance desired, but only 3 inches away from the central axis of the stand, whereas sometimes it is desirable to move it farther, that is, 4,5 , or 6 inches. This could be accomplished very easily by lengthening the stop groove in the brass strap on the under surface of the frame.

Photomicrographic Work.- Nearly all of the photonicrographs used in this book were made on the small Zeiss upright camera (Fig. 55). (For more details see "Bacteria in Relation to Plant Diseases," Vol. I, and various text-books.) Dr. L. B. Wilson of the Mayo Laboratories, Rochester, Minn., has devised and described a very convenient upright stand. For an illustration of this photomicrographic camera see the 1917 catalogue of the Spencer Lens Co., Buffalo, N. Y., p. 120.

Light Filters.-For the large horizontal photomicrographic camera I have generally used the green, fluid, ray-filter known as the Zettnow filter, but for planars the dry Wratten filters made by the Eastman Kodak Company, Rochester, N. Y., are very useful. (Catalogue and explanations for use will be furnished by the Eastman Company on application.)

Dry Plates and Developers.-All these have been greatly improved in recent years. The essentials in dry plates and films are to have some giving strong contrasts and others correct color values. It is sometimes impossible to tell in advance 
whether an ordinary plate or an orthochromatic plate will give best results, colors having much the same appeal to the eye sometimes behaving differently on the dry plate. The writer uses Seed's rapid, gilt-edge (non-isochromatic) plates for some purposes and for others Cramer's instantaneous and slow isochromatic plates, also Hammer's non-halation (double coated) orthochromatic plates, and for exact color values Wratten and Wainwright's Process Panchromatic plates, these last being very sensitive even to dull red light.

Any one of half a dozen developers may be used. It is good to stick to one until you have mastered it. We use at present Citol which has the advantage of great simplicity, the only preliminary to its use being its dilution with 20 parts of distilled water, more or less, according as the plate is under or over exposed. For contrasts in photomicrography I use a hydrochinon developer.

Washing Devices. - Two washing tanks made by Burke and James, (Jackson Blvd. and Desplaines St., Chicago, Ill.), have proved very useful. The one for negatives takes any size without readjustment, and jets currents of water over the negatives from two directions, thus insuring a very thorough circulation and removal of the fixative in a minimum time. The one for washing prints also has an ingenious device for keeping the water in circulation and the prints separated and moving about. They should be made of tinned copper, but unless specially so ordered they are made of galvanized sheet iron which soon rusts out.

The Developing or Dark-room.- The dark-room should be impervious to light. If it is set up in part of a larger room after the construction of the building, the walls may be of inch pine boards, matched, and should be covered inside with heavy carton (composition) board which must be painted a dead (lusterless) black.

By preference, the entrance should be through a labyrinth (a reversed and flattened letter $\mathrm{S}$, or if one thinks of the walls rather than of the pasiage way, then two linked letter U's ᄅ) opening outward into the darker part of an ante-room. Doors are inconvenient, and if they open directly into the dark-room 
from a light room they must be kept locked while development is going on. Often this is very inconvenient to others, but it is the only safe way.

Our own dark-room (Fig. 61) occupies the northwest corner of a well-lighted large south room which is used for general photographic purposes. It measures, inside, approximately 9 feet north and south by 15 feet east and west, and is divided into

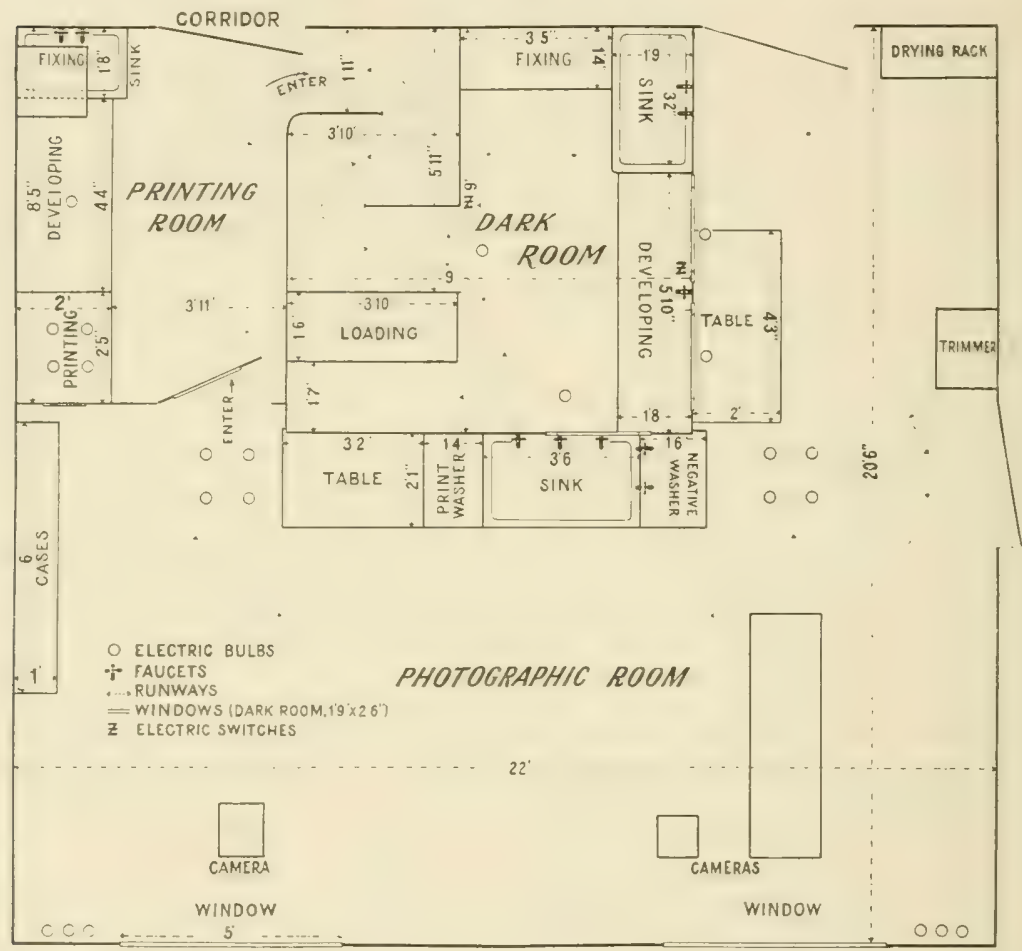

FiG. 61.-Diagram of photographic room, printing room and dark-room used by the writer.

two parts: (1) an ante-room on the west side, used for making prints: (2) the dark-room proper, used only for the derelopment of negatives. The ante-room is long and narrow with a sink at the northwest corner (behind the corridor door), the remainder of the west wall space being occupied by a printing and developing table. The printing is done by means of a battery of large size, fixed tungsten lights, in the southwest corner. The 
dereloping is done under a red bulb drop light near the sink. There is a door at either end both opening inward): one gives entrance from the bright photographic room. the other from the rather dark central corridor of the building. Both should be hinged on the side nearest to the dereloping table. The size of this ante-room is 5 feet 8 inches by 9 feet.

The dark-room proper takes the remainder of the space $(9$ feet 4 inches by 9 feet), but one corner of it is occupied by the labyrinth so that the actual working space is considerably reduced. The labyrinth ( 2 feet ride) begins in the northeast corner of the ante-room next the door opening into the dark corridor. As an additional precaution against the accidental entrance of light, this corridor door is provided with a push lock to be used whenerer necessary. On the right-hand side, as one enters the dark-roon proper, behind the suuth wall of the labrrinth. is a narrow space occupied its whole length on one side (the north side) by the loading shelf. On the east $\pi$ all, facing the observer as he enters the dark-room. is the develuping shelf. At his left against the north (corridor) wall is the fixing shelf and in the angle between the two shelres is the deep sink (36 inches long by 20 inches wide). The dark-room consists. therefore, of two rectangles, the larger 5 by 9 feet occupied on the outer cast side by the long dereloping shelf and the sink just referred to; and at one end (the north) by the shorter fixing shelf, and at the other (south) end opening into the smaller rectangle 3 feet 10 inches long by 3 feet wide which is vecupied. as already stated, by the loading shelf. This abuts against the labyrinth wall, and above and below it are other shelves for the storage of boxes of dry plates and plate holders. There are also shelres under the developing thelf for extra tray and under and above the fixing shelf.

Two persons can develop in this dark-room without interference and the loading shelf is also long enough to allow two persons to use it at the same time. There is, howerer. no waste. space and everything is within conrenient reach. A step or two brings you to any part of the room.

The subdued light by means of which exposures must be dereloped may be sunlight or electric light, passed through a 
series of screens, i.e., ground glass, orange glass or orange paper and red glass. An opaque screen also should be provided and all the screens should be counter-weighted to slide up and down easily inside a window frame. There should be at least two of these windows. Our room has three. Two are over the developing shelf and a third is in the south wall between the developing shelf and the loading shelf.

The developing shelf should face the source of light at a convenient height rather than receive its light from one side.

The washing sink ( 1 foot deep) should be close to the developing shelf to avoid waste of time and on the other side of it should be a roomy fixing shelf. By "roomy" I mean large enough for several trays.

The loading and fixing shelves and the developing table are each 36 inches high. The loading and fixing shelves are 18 and 16 inches wide. The dereloping table is 20 inches wide and the surface of this table consists of two removable frames of slat-work. Under it is a shallow lead-lined sink sloping to the left and emptying into the deep sink. The window-ledges are $81 / 2$ inches above the top of this table.

There should be plenty of storage shelves in the dark-room (under the fixing shelf and the developing shelf, and over them also) for trays, bottles, beakers, graduates, etc.

The loading shelf should be in the darkest part of the room, i.e., as far away from the red lights as possible and behind the door or labyrinth, so that there shall be a minimum of danger from fogging when boxes of dry plates are opened. I open boxes of dry plates, always, with the opaque screen drawn low over the red light, especially if they are orthochromatic plates. The washing and printing are best done in adjoining rooms (see Fig. 61). Dark-rooms, like kitchens, are most convenient if ererything is handy; they should not, therefore, be very large, and consequently some sort of ventilation becomes necessary, especially if they are much used. In the top of our own room I have inserted a hood in the bottom of which is placed an electric fan which can be furned on at will and which rapidly pumps the foul air out of the room, the fresh outside air flowing in through 
the labyrinth. This cost only a small sum and has proved very satisfactory.

The electric bulbs for the red lights are outside but may be turned on or off without leaving the dark-room, by means of a double push button at $Z$ (Fig. 61).

\section{USES OF CULTURE-MEDTA}

Culture-media are needed every day in the routine work of the laboratory and are required for several distinct purposes: (1) for the isolation of organisms from mixtures or directly from diseased tissues; (2) for the long-continued growth of organisms without loss of virulence; (3) for differential descriptive purposes; (4) for cultures adapted to chemical analysis.

For the first purpose we must study the nature and needs of the rarious parasites, and when they differ from the common sorts must cater to them, devising media exactly suited to their requirements, or at least better adapted to the needs of the parasite than to those of the accompanying saprophytes. This frequently requires considerable study, as to range of toleration of acids, alkalies, salts, N.-compounds, sugars, alcohols, etc., but standard media should be tried first. For first isolations I always try +15 peptone-beef-agar poured plates. If this fails, then +7 beef-peptone agar may be tried, and other media, such as steamed potato and special agars, e.g., dextrose potato agar or whey agar.

The second kind of media varies a great deal with the organism and can be discovered only after prolonged study of the parasite on a variety of substrata. Some observations on such media will be found under the various diseases described in Part III.

The third sort need not be, and in fact cannot be, media of universal value. They are good only for the particular purpose in mind, and the future will see a large increase in their number. What we seek here are media that will bring out not necessarily good growth, or any growth at all, for that matter, but differences in behavior when a variety of bacteria are tested in it, that is, changes in gross appearance, morphology, pigmentation, precipitates, pellicles, crystals, weak vs. dense clouding, medium 
reactions (acid, neutral, alkaline), using neutral litmus and phenolphthalein, ete. - and here a medium generally neglected by bacteriologists may be just the one needed. The student should not regard the chart sanctioned by the Society of American Bacteriologists as in any sense a finality - there are no last words in science, at least not in bacteriology — and he must be always on the lookout for simple and effective means of differentiation. Often, when the colonies of two organisms look exactly alike on + 15 peptone-beef agar, we try potato agar, prune agar, stringbean agar, starch agar, whey agar, or some kind of gelatin medium, and find a difference. In this connection see Fig. 184.

For the fourth purpose, to avoid complications, one would naturally select, first of all, well-aërated, simple synthetic media.

Carefully considered (tested) formulae for the preparation of various culture-media will be found in "Bacteria in Relation to Plant Diseases," Vol. I. For Meyer's mineral solution consult Ibid., Vol. III, p. 250.

\section{PREPARATION OF CULTURE-MEDIA}

It is impossible to pursue the study of bacterial diseases of plants without the use of at least some forms of culture media, and the student should know how to prepare with his own hands all necessary substrata. It is a useful training of the hands and of the judgment even for those who are not to use it later in research.

Culture-media may be divided into two classes: (1) complex organic substances and (2) simple synthetic preparations. The first, though they are harder to prepare, are still used more generally than the second, and are in the main better adapted to the growth of parasitic micro-organisms than are the more exact media compounded out of simple chemical substances. The latter, however, may be expected event ually to take the place largely of the more or less variable animal and plant compounds now in general use. At the same time the writer would like to register an objection against the discontinuing of any of the cultural substances now in use until such time as we have wellrecognized suitable substitutes. At present we need all of them, 
especially for the study of parasites. Before proceeding to a discussion of these cultural substances, the student should read quite carefullythat part of the preceding chapter on Apparatus, and also what he can find on the making of culture media in other text books.

In the preparation of culture-media one must be governed by the substances and the apparatus at hand. The simplest substances to prepare are cylinders and slices of potato, carrot, and other vegetables, and these are still of great use in the study of diseases of plants, and not to be discarded for purely synthetic media. These vegetable substances may be used either cooked or raw. If cooked, they are best kept in cottonplugged test tubes in the form of slant cylinders, standing with the bottom immersed in a small quantity of water or free on wet cotton. If raw, they may be cut into the form of cubes or slabs and placed in deep Petri dishes. We will first discuss the proper preparation of such media. A great variety of cooked vegetable substances can be used, both for study of pure subcultures of the various micro-organisms, and in default of gelatin or agar for their isolation from the diseased plants. We will, therefore, first consider the proper preparation of these substances.

Steam-sterilized Solid Vegetable Substances. - Felect sound carrot roots, potato tubers, turnips roots, and similar vegetables, wash thoroughly under the tap with hand-rubbing or brushscrubbing to free from dirt, and with a clean knife pare away the outer surface, being careful to contaminate the inner portions as little as possible by contact with the outer surface of the parings or with soiled hands. The remainder may now be thrown into beakers of sterile water and rinsed, after which cylinders may be punched out with a nickel-plated cork borer of the proper size, slanted with a sharp knife and, after a preliminary rinsing, dropped by means of sterile forceps into clean test tubes after which the necessary amount of water should be added and the tubes plugged with clean cotton. The cylinders should be smaller than the bore of the test tube so that there may be room for the water, otherwise they soon dry out and are not then suited for the growth of many organisms. 
There should be enough water added so that the culture will remain moist for a number of weeks but not enough so that the slant surface is covered. For isolation purposes, by means of parallel strokes, the slant should be long and the amount of water such that it will in no case flood over the slant surface. Merely for the study of the organism on a particular medium this is not so necessary. When the tubes have been filled and plugged they must be steamed on 3 consecutive days, for 15 minutes each time. In default of a steamer they may be stood upright in a tea-kettle and boiled. Formerly we had much trouble in this laboratory in sterilizing potatoes and similar substances derived from roots, i.e., after three steamings the cultures would often develop a wrinkled white or gray white bacterial growth. This growth came from spore-bearing bacteria lodged on the surface of the potato tuber and introduced into our tubes through defective technic in their preparation, i.e., we were not careful enough in paring and handling the potatoes and other vegetables used, the surface of which almost always contains resistant spore-bearing bacteria. We are now very particular in the preparation of these media not to contaminate either the pared portions or the cylinders punched from the same. For that reason we rarely handle them with our fingers in the last stages, but with forceps, and before putting them into the tubes we give them a final rinsing in beakers of distilled water, and now generally we autoclave such media. To avoid erroneous conclusions it is well to let the sterilized medium remain on the shelf some days before using it, that the unkilled spores of fungi and bacteria may germinate, and always, of course, each tube should be critically inspected before it is inoculated. In some laboratories it is difficult to keep media sterile because Penicilliums and other common fungi have been allowed to fruit freely in the rooms until the whole laboratory has become an unclean place. Such laboratories are a disgrace to the profession. The first thing is to have a general cleaning up, and then to stay clean. In 1917 we had much trouble for some weeks from a spore-bearing, very heat-resistant and acidresistant white schizonycete introduced from the Middle West on dirty culture dishes. 
Preparation of Raw Vegetable Substances.-Select, as before, sound tubers and roots, etc., wash thoroughly with hand-rubbing or brush-scrubbing. Instead of paring, plunge them one minute into alcohol (to drive air out of the crevices), and then 30 to 40 minutes in 1:1000 mercuric chlorid water, then remove, dry with a sterile cloth, or with sterile filter paper, and cut on a sterile surface into suitable slabs with a cold sterile knife; one of large size such as is used in kitchens is suitable. As soon as cut, the slices are removed without touching the cut surface and placed in sterile deep culture dishes in pairs, one of which may be inoculated and the other held as a check. If this work is done in clean still air, with sterile instruments, and if the cut surface is never touched with the hands or with contaminating instruments, there will be little opportunity for intruding organisms to obtain a foothold. Undoubtedly some bacteria on the roots are not killed even by the long soaking in mercuric chloride water but their surface layers are so impregnated with the poison that they seldom derelop or give any trouble in the dishes. The amount of poison dragged across the cut surface in making the slices is wholly negligible, if the roots are dry when cut.

Fluid Vegetable Substances. - The juices of regetables diluted with water are also useful as culture-media. They may be used in 10-ce. portions in test tubes, or filled into suitable fermentation tubes, or used in flasks. These are generally steam-heated a short time on 3 consecutive days before using. The same care should be used in the preliminary surface preparation of regetables, the juice of which is to be used for culturemedia as has been recommended already for the preparation of steam-sterilized potato cylinders, etc. This juice is obtained either by cooking or by crushing or grinding and presisure. It is very easy to sterilize such media if they have not been contaminated by carelessness in the initial stages of the preparation. These fluids must be filtered before they are tubed, first through two folds of cheesecloth or surgeon's gauze and afterward through filter paper. Substances containing starch filter with difficulty after they have been boiled. Therefore, if juices are to be extracted from starchy vegetables by heat 
in advance of filtration it is desirable that such heating should not be carried to the boiling point. We extract potato juice from thin slices of the tubers by heating for an hour in double their weight of water at a temperature not higher than $60^{\circ} \mathrm{C}$., in order that we may be able to filter the fluid without difficulty. Fluids extracted from vegetables by grinding and pressure are usually not very well adapted in their concentrated form to the growth of bacteria and must, therefore, be diluted with a considerable volume of water before they are steam sterilized (1:4, 1:10 may be taken as standard dilutions, but I also try them full strength). Such juices may be sterilized cold, if desired, by passing them through a Chamberland filter free from cracks.

Animal Substances.-Cow's milk is one of the easiest and most satisfactory of animal substances for use, provided it can be obtained in a fresh condition and is properly sterilized. I use it both with and without cream, especially without. For separating the cream we use a centrifuge. Small quantities may, however, be prepared nearly cream-free by filtration through coarse filter paper but this is a slow process. Overheating changes the nature of milk somewhat and should be avoided. We generally use it in 10-ce. portions in sterile test tubes, cotton-plugged, which portions are steamed on 4 consecutive days, each time for a short period only. Often three times heating is enough, but occasionally the fourth heating is required to render the milk free from resistant bacteria, and therefore we have adopted the four heatings, as a routine practice. These steamings may be for 15 minutes on the first day, $10 \mathrm{~min}-$ utes on the second and third days, and 5 minutes on the fourth day. This destroys all aërobes, but some anaërobes may remain. Milk should not only be used in the manner described but should also be used in the form of litmus milk, only enough sensitive blue litmus being added to render the fluid a lilac or lavender blue. If the curd is precipitated in the steaming, then something is wrong either with the litmus or with the milk. Usually it means that such milk is old and full of organisms and their by-products. Methylene blue may also be added to milk (6 cc. of 1 per cent. methylene blue in distilled water to each 200 cc. of milk) for study of the reducing activities of organ- 
isms. It is best not to autoclave milk or any substance containing sugars. We do, however, autoclave most other substances, heating them seldom higher than $110^{\circ} \mathrm{C}$. or longer than 15 or 20 minutes.

Next to milk, beef bouillon is one of the most commonly used substances in the bacteriological laboratory. It may be used alone but is generally fortified by the addition of 1 per cent peptone to which sugar is also sometimes added. A number of peptones are on the market and they vary so much in quality and in their nutrient value for organisms, that it is best, except for special experiments, to make use of only one, namely, that now commonly recommended in bacteriological laboratories, and known as Witte's peptonum siccum (Fee the observation under Olive Tubercle Organism, No. XIII, concerning the inhibiting action of Merck's peptone from flesh). Beef bouillon is much better, in my judgment, if made from flesh of beef than from meat extracts. In my experience meat extracts often contain salt and bacteria which are hard to sterilize in the steamer, whereas a good grade of fresh meat seldom gives any trouble. For further notes on preparation of this medium and many other media consult "Bacteria in Relation to Plant Diseases," Vol. I.

Blood Serum.-Löffler's solidified blood serum is another substance much used by the bacteriologist, but as it is rather difficult of preparation, for those who do not have access to the apparatus and the animals of an animal pathological laboratory, it is recommended to purchase from time to time in the open market the small amount the plant pathologist needs. We buy ours from Parke, Davis and Company, Detroit, Michigan.

Gelatin and Agar Media.-The bacteriologist makes very extensive use of gelatin and agar culture media in the form of Petri-dish poured plates for isolation of his organisms. The basis is peptonized beef bouillon to which agar is generally added in 1 per cent or gelatin in 10 per cent quantities to obtain the proper solidity. Of course, other substances may be employed, if desired, instead of beef juice, such as simple peptone-water or peptone-water reinforced with 1 or 2 per cent cane-sugar, grape-sugar, milk-sugar, etc. On the whole, agar is more useful for isolation purposes than gelatin, especially in very warm 
climates. The student, therefore, must learn how to prepare it. For details of preparation of both agar and gelatin, consult "Bacteria in Relation to Plant Diseases," Vol. I, pp. 29 to 36. Our Standard agar is +15 and our Standard gelatin +10 on Fuller's scale, or 1.5 per cent and 1 per cent respectively, if reckoned on 100-ce. portions. It is better to keep to Fuller's scale since we make up media in liters not in $100 \mathrm{cc}$. portions.

We still use Nelson's photographic shredded gelatin for our gelatin culture media and for our agar media a powdered agar made by Kahlbaum in Berlin, and have no trouble in filtering either one or in obtaining a uniform and clear product. Difficulties of agar filtration may usually be traced to the fact that the medium has not been cooked sufficiently. The work must then be done over. It is a lazy bacteriologist who is content with a clouded culture medium, either fluid or solid.

Peptone-water Media.--For the study of the behavior of organisms in contact with various sugars and alcohols we use distilled or river water to which has been added 1 or 2 per cent Witte's peptone and the desired amount of the carbon food, seldom more than 2 per cent. It is steamed, filtered, filled into fermentation tubes and sterilized discontinuously as in the case of other substances. Comparison should be made using other peptones, Merck's, Difco, etc.

Excess of acidity or alkalinity of medium should be corrected by determining the actual acidity or alkalinity by titration, using phenolphthalein and $\mathrm{N} / 20$ sodium hydrate or $\mathrm{N} / 20$ hydrochloric acid, as the case may be, and then adding calculated quantities of a much stronger acid or alkali and re-titrating. The latter must not be neglected. Without titration it is impossible to have any two batches of media alike, but when it is regularly employed there is great uniformity in the product of the laboratory, and in the results obtained. Our method is to put 50 ce. of boiling distilled water in a white capsule with 1.2 cc. of the phenolphthalein solution and 5 cc. of the substance to be tested and run in barely enough alkali to give a trace of pink color which is the neutral point. Do not re-boil, nor make the solution red. The slightest pink that can be seen is the place to stop. Synthetic Media.-Certain synthetic media have great use in the bacteriological laboratory because micro-organisms be- 
have toward such media in quite different manners. Cohn's solution, Uschinsky's solution, Fermi's solution and Meyer's solution are examples of such media; for the preparation of these and others consult "Bacteria in Relation to Plant Diseases," Vol. I and the various text books.

Pure Chemicals.-The best quality of everything, without regard to expense, should be the rule. Especially in the preparation of synthetic media and in fermentation studies must absolute purity of the chemicals be assured. Pure sugars and alcohols, in particular, are difficult to obtain, and expensive. Rare sugars are now to be had in this country from Digestive Ferments Co., Detroit, Mich., and the Special Chemicals Co., Highland Park, Chicago, Ill.

\section{TECHNIC OF ISOLATION}

I have said so much on this subject under the different diseases in Part III, that not much need be said here, particularly if the student reads carefully what is said on this subject in the various text books recommended for his perusal on page 76 .

Fire.-This is a very certain method for disposing of troublesome bacteria and is often resorted to by the bacteriologist. "Flambez vos vases, flambez vos vases!" cried Pasteur on a memorable occasion. With the same end in view, flame, or burn lightly with a hot spatula, the surface from beneath which you wish to take material for a transfer. A little experience will be more useful to you than many words. You should aim to scorch the surface without cooking the interior. It is best, however, to err on the side of underheating.

Autoclave all discarded culture dishes before the glassware is handed over to the servant to be washed.

Germicides.-Certain chemicals, in another way, bring about the same result as fire. Often, however, I use these substances so that they act only as antiseptics. How long they may be allowed to act and how strong they may be used, depends on the nature of the germicide, and on the character of the tissues exposed to it. We use about the laboratory commonly only two germicides, 1:1000 mercuric chlorid water, and 5 
per cent carbolic acid water, the former more than the latter. Surfaces covered with a thick cork layer, e.g., potato tubers, stand exposure to $1: 1000$ mercuric chlorid well (30 minutes); thin green parts, such as pieces of leaves, should be exposed to it only for a minute or two. Infected tools which cannot be flamed may be dipped into the carbolic acid water. Carbolic acid should not be used on the hands. Discarded culture-tubes, flasks, dishes, etc., which are not autoclaved should be treated with the chromic acid cleaning mixture before washing. Rubber gloves should be used in handling this mixture. Infected hands may be washed in the mercuric chlorid water. The student should remember that germicides are poisons, and should govern himself accordingly. They must not be left where children or animals can get them. Hands accidentally wetted with the chromic acid mixture should be washed immediately and thoroughly.

Still Air.-I regard clean still air as very important. For this reason I never make transfers in the open room, but always under a hood or in a special transfer chamber, such as I have described, and I do not advise its ventilation by means of an air current.

Clean Hands.- These are still more important. The average individual infects everything he touches, and also, as a rule, touches every thing within his reach. Hence the great prevalence of contagious diseases! Apparently it is a necessary part of the psychology of a great many persons to become satisfactorily acquainted with an object only through the sense of touch. Deprived of touch such persons are almost as blind as the sightless. Until the student has learned to consider his hands, even when "clean," as never really clean but always as contaminated, he has scarcely made a beginning in bacteriology. Your hands should be kept out of media and also out of your mouth.

To these preliminary remarks need be added only what is said under the special diseases, and some general cautions. The culture-room should be wiped up frequently with clean water. Generally, one's coat should be removed and his shoes cleaned before entering it. Fragments covered with spores of molds should never be taken into this chamber, nor should 
any vegetable fragments be left there to mold later on. Select for isolation experiments the most recently diseased parts of the freshest material available. Further, because saprophytes often supplant parasites very speedily in diseased tissues and because even in the absence of these there may have been wholesale death of the parasite owing to the acids or other by-products it has liberated, thick sowings and other special devices are often necessary in order to isolate the cause of the disease.

\section{CARE OF CULTURES}

Room Temperatures.--When first made, the plates naturally must remain for a short time on a level shelf in the culture room, but as soon as solidified they must be removed to a suitable safe place for incubation, viz., to a clean dry cupboard, free from insects and protected from the light, at least from direct sunlight, or bright reflected light. If the laboratory is a clean one there should be little trouble from the larger vermin such as rats, mice, flies or cockroaches, but minute animals such as mites and small ants often live in the walls of buildings, beyond reach, and may sometimes cause much annoyance in clean places. We have been troubled with both of these pests and now, as a routine practice, keep our plates and other cultures on shelves supported on cork legs resting in glass dishes containing mercuric chlorid dissolved in water, but after the water has evaporated more need not be added since the crystals uniformly distributed over the bottom of the plate are a sufficient barrier. The shelf, of course, should not anywhere touch the walls of the cupboard. This has proved quite effective. The pest of ants may be done away with by finding and destroying the nest, which is sometimes a long distance away. A good plan is to drive deep holes into the ground by means of a crow bar and fill these with kerosene. Record the temperature daily.

Thermostats. These are usually only for temporary use and the temperatures are to be shifted as needed, or rather some days in advance of the need, since often they are hard to regulate. We use the Roux metal-bar thermo-regulators. 
Ice Boxes.- Stock cultures must be kept at low temperatures. They live much longer when cool and thus the labor of transfer, which is always considerable in any laboratory dealing with many organisms, is minimized.

Our stock cultures are kept in ordinary refrigerators such as housewives use. This corresponds probably to the practice of many other laboratories but it is not the best way, since occasionally through carelessness on the part of the ice man or of servants the outlet becomes stopped up or the floor supporting the ice becomes cracked and water drips down on some of the cultures, destroying them or at least contaminating them so that they must be plated out. A better way would be to keep stock cultures in a thick-walled roomy vault constantly supplied with cooled air.

Ice Thermostats. - We make frequent use of the Paul Altman derice containing ten small compartments. This, when the upper large chamber is filled morning and night with cracked ice, gives temperatures ranging, except during about four months of our year (June to September), from $0.5^{\circ} \mathrm{C}$. to $20^{\circ} \mathrm{C}$. These temperatures are not absolutely constant under our room conditions, but would be nearly so in a room having itself a fairly constant air temperature. By looking frequently and adding more ice if the temperature is observed to be rising, we are enabled to make much use of it in determining lowest temperature at which seeds will germinate, microorganisms grow, etc. It is not, however, a perfect instrument.

\section{S'TUDY OF CULTURES}

All the various plant pathogenic bacteria should be grown on a great variety of media for discovering special characteristics, useful in identification, and also to determine the media best suited to their growth and longerity. These cultures should be examined frequently with the hand lens in a variety of lights, and often under the compound microscope, and should not be discarded for several weeks. Of course, checks should be held. To what I have said in other places, I would add here that colonies on agar and gelatin plates should be photographed in 
various lightings, enlarged ten times (that being recommended as a convenient standard magnification). This is so useful for purposes of comparison (Figs. 25, 114, 230, 254) that I have made it a routine practice in my laboratory for several years. In particular, oblique transmitted light will of ten reveal an inner colony-structure (Figs. 13, 37, 69, 275) not visible on the surface or by direct transmitted light.

\section{METHODS OF INOCULATION}

Needle Punctures. - I have made much greatcr use of the needle than of any other instrument in making inoculations. Its wounds are slight. It carries into the plant a minimum quantity of the organism to be tested and inoculations made in this way conform more nearly to natural methods of infection than do those produced by instruments making coarse wounds and introducing excessive numbers of bacteria. I am always suspicious of results that can be obtained only by drenching and swamping tissues with foreign organisms.

Syringes. - Those injection syringes are to be preferred which are simple in construction, easily separable into a few parts for cleaning, and not liable to spirt out fluids around the piston. The piston and barrel should be of glass, the latter, of course, graduated, at least to tenths of cubic centimeters. They are seldom necessary in plant pathological work.

Infection Cages. - Cages 2 feet deep by 2 feet high by 3 feet wide are most convenient. They should have a strong sash frame open at the bottom but set on all sides (including the top) with window glass, and the whole front should consist of two swing doors closing against each other in the center and closing at the botton on a 2-inch baseboard. Such cages will hold eight 8-inch pots. Each time before use they should be autoclaved. In absence of conveniences for this they should be wiped inside with mercuric chlorid water a day in advance of use. Plants on which bacterial suspensions have been sprayed may be exposed to moist air in such cages 48 hours without harm.

Soil Inoculations. - The earth may be sprayed or drenched with water suspensions of the bacterial cultures, or infected by burying in it recently diseased plants. At the same time 
the roots of some of the plants should be broken. In many instances it is necessary to break them in order to obtain infections (see Part III, Nos. IV and V).

Checks should be held in the same soil, or if not, and especially if the experiments are to be few, the earth should be autoclaved in advance and the plants watered with sterile (autoclaved) water.

Infection by Means of Insects.-The common way is to confine the plants in insect cages (like the infection cages but with fine wire netting substituted for glass) into which the insects are introduced after they have been allowed to feed upon recently diseased leares, stems, ete. Night-feeding insects should be infected and liberated at night, being removed next morning or earlier, especially if voracious. In case of trees, the insects may be confined to special branches by means of fine mosquito netting or surgeon's gauze. Lnder ground, the insects may be confined to the roots of special plants by wire netting.

\section{TIME AND PLACE OF INOCULATION}

In studying a particular disease, the student will, of course, seek to inoculate those parts of the plant which naturally develop the disease - roots, tubers, stems, leaves, flowers or fruits, as the case may be. He must remember, however, as he examines the plant, that the infection he has under observation took place some days, weeks, or months ago when the diseased part was in an earlier stage of growth and in making inoculations must govern himself accordingly.

In many instances, inoculations on very young, turgid, rapidly growing stems, leaves and fruits offer best prospect of success. Always some of the inoculations, whether by needle puncture or by spraying, should be on such incompletely developed organs (see Part III, Nos. IV, VII, XII, and XIV).

Full-grown leaves, stems and fruits are resistant to many diseases (bean, No. VIII, pear, No. XII, and olive, No. XIII). On the other hand in case of soft rots of roots (carrot) and tubers (potato) the full-grown organs are quite susceptible provided they have not become flabby (Fig. 167). Certain cankers may also be inoculated through a wide range of months. 
Every plant has its own peculiar demands for soil, water, light and heat. Some plants endure crowding and poor earth much better than others, but all prosper best when their needs are respected. The student should treat his plants with some consideration. He should water them regularly and sufficiently but not excessively; should keep them free from plant lice, red spiders, mealy-bug, white-fly and other pests and to this end should carefully aroid introducing infected plants into clean houses; should not over-crowd them, should be quick to see when they require shifting to larger pots; and especially should not try to grow plants requiring a cool temperature in warm houses, or vice versa. The last is like trying to ride two horses going different ways. He cannot learn how to care for plants without being much with them, nor without this expert knowledge will he ever be more than a bungler in plant pathology. It is not enough to trust that "the gardener will attend to all this," nor is it right to feel that this part of the labor is rather beneath the attention of an aspiring man of science. Nothing is too small or too menial to receive painstaking and minute attention if you wish to achieve a worthy success. Remember then that your plants should be looked after every day as to soil, air, light, heat, water, space to grow in, and freedom from insects, nematodes and fungous parasites.

Mildewed or fungus spotted plants and all that are dwarfed by nematodes or defective in any way should be thrown away as soon as discovered and good ones substituted. Have others coming on, for this purpose. Do a little thinking in advance of actual needs! Neglected plants often become stunted or "pot bound," to use the gardeners' expression, and are then worthless.

Seedlings often perish from damping-off fungi, especially if they are over-watered or the soil is poor. Plants require the same amount of water on scarcely any two days, and the student must learn as speedily as possible when to give and when to withhold water. On sunny and windy days they require a great deal, on still, cloudy days very little water or none what- 
ever. Seedlings and cuttings require only a minimum quantity, but that they must have. A single excessive watering of seedlings, or cuttings, may destroy your experiment.

Plants seldom do well if transferred in full leaf to very different conditions as to light, heat and moisture, e.g., from the hothouse to the laboratory or to the garden or vice versa.

For hothouse experiments great care should be taken to select good soil, i.e., that free from nematodes, ants, and parasitic soil fungi, such as Rhizoctonia or Fusarium. Often a whole year's work is lost by reason of nematode-infested or fungusinfested soil. If you have any reason to suspect the soil, it must be steamed or baked, or drenched with formalin-water before it is used. Bordeaux mixture sprayed upon the earth will sometimes stop the activities of a damping-off fungus.

Ants may be kept off benches by having runways all around them and their upright metal supports capped at about 2 feet from the ground by metal cups containing oil in which stand the short legs of the bench. Feed ants sweetened tartar emetic.

\section{PREPARATION OF SECTIONS}

Free-hand Sections.-Good free-hand sections are very useful in the preliminary examination. They can be made only by one who has enough gumption to sharpen a razor as often as it becomes dull, which is about every day. It is worth while even in a busy semester to learn how to do this. Sometimes a good-natured barber will show you how. The Torrey razor is excellent for section cutting but it is no longer on the market.

Turgid tissues cut better than flabby ones, which latter sometimes recover turgor if thrown into water. The material to be cut should be held in a cleft of elder pith, never between corks, which dull razors. After a little experience very thin sections can be made of many things; these are usually more or less wedge-shaped, but if they are thin enough to see through that is all that is required, since one seldom mounts for permanent preservation anything but microtome sections.

Microtome Sections.-Read what is said under Apparatus about microtomes. There are several methods of making 
sections on the microtome. The tissues to be sliced may be frozen and cut on a special machine, and this is the quickest way and the best way for preliminary studies, but it is of no value for permanent sections of tissues containing bacteria, since they diffuse out too readily, or they may be embedded in celloidin or paraffin and cut on the ordinary microtome, which is the best way for permanent mounts. I will limit my account to paraffin, describing the way it is done in our laboratory.

First the tissues are fixed. We select for this purpose, clean, perfectly fresh, characteristic bits which should not be large. Various fixing agents are used; we often use Carnoy's fixative ( $1 / 4$ glacial acetic acid, $3 / 4$ absolute alcohol). They will fix better in many cases if the air is pumped out of them as soon as they are put into the fixative. I make this an invariable rule. After 24 hours in this solution (12 hours is enough in some cases) the pieces are shifted into 90 or 95 per cent aleohol, the next day into a second alcohol, and finally from absolute alcohol into mixtures of alcohol and xylol, then into pure xylol, a second pure xylol, to remove all traces of the alcohol, then into xylol-paraffin, then paraffin plus xylol, and finally into pure melted paraffin, from which after some hours they are transferred to another melted paraffin in which they are embedded. There is some choice in the melting point of paraffin to be used for the final embedding depending on the climate. In Washington we use during the summer Cirübler's paraffin melting at $56^{\circ}$ to $58^{\circ} \mathrm{C}$, and during the winter that melting at $52^{\circ} \mathrm{C}$. The embedded pieces are trimmed and stuck to one end of a small rectangular white pine block by means of a hot needle and a little melted paraffin. The number of the specimen, corresponding to an account in a record book, is written on one or more sides of the pine block with a lead pencil. The wooden block is now clamped into the microtome. If the material is soft, ribbon sections are cut; if hard, slant-stroke sections are cut. If the knife is dull, or if the tissue is gritty or contains crystals, or is imperfectly embedded, the sections will be torn and worthless, or nearly so. Occasionally when the tissues are full of calcium oxalate crystals we have to be content with torn sections, but ordinarily the tissue should be reembedded and a sharper knife 
selected. Of course, in the preliminary selection of material for microtome sections, the greatest care should be exercised to avoid that which is sandy or gritty. Dull knives and too soft paraffin also tend to give sections which are crowded together endwise and this is undesirable. Always, thin, machinemade sections are more or less wrinkled, and the folds must be straightened out with gentle heat before the sections are glued to the slides; i.e., while they are floating on the water. This may be done, slide by slide over a low flame, or more conveniently on a metal table (Fig. 54) warmed slightly by means of an electric current, after which the slides bearing the sections are set on end to drain and dry. There are various ways of sticking sections to slides. We now commonly use prepared egg-albumen, a little of which is rubbed over the surface of the slide with a clean finger before water is pipetted on to the slide to receive the paraffin sections.

After two or three days, i.e., when the slides are thoroughly dry they are ready for staining, and it is best that they should be stained and covered soon, so that they will not accumulate dust. In no case, if the material is good, should the stained sections be left uncovered.

\section{STAINING METHODS}

Bacteria in the Plant.-The paraffin of the properly dried sections is melted away by very gentle heat, just enough to render it fluid and no more, or they may be put into the xylol unwarmed, if one is not in a hurry, and this is the better way, whereupon the slides are put immediately into xylol, and often into a second xylol, to complete the removal of the paraffin. They are then graded through pure ethyl alcohols (95 per cent, usually 2 jars) to remove the xylol, graded from this pure alcohol into water, or alcohol and water to receive the stain. After this they are graded back into absolute alcohol to remove the water, and from this into pure xylol to remove every trace of alcohol. From pure (water-free) xylol they are mounted in Canada balsam or dammar balsam. The least water in the xylol will give a cloudy slide. 
The proper degree of stain for sections should be determined by inspection under the microscope during the process of staining. The slides must be shaken or jarred as little as possible during these transfers, and, after staining, the shifting through the graded alcohols must be swift, so that the stain shall not be all removed. In my sections I prefer a good strong stain.

Many of the slides put up in this laboratory and formerly very good are now nearly or quite worthless because they have faded. This has been due partly to use of aniline dyes which are fugitive even to diffused light, but more often I think to overwashing or to the presence of unsuspected traces of acid in the Canada balsam. If you would avoid much future disappointment use the utmost care in the selection of balsam for mounting purposes and do not overwash. Valuable sections which have faded may be restored by dissolving off the cover-glass in xylol and restaining. No invariable or general rule can be laid down for staining bacteria in situ since plants and parasites both vary in their reaction toward stains. Fome bacteria also diffuse out of the sections vexatiously. Under the various heads in Part III, special stains are mentioned when such have been found particularly useful.

Gram's stain varied by the substitution of amylic alcohol for ethyl alcohol (generally referred to later as amyl Gram) has been found to give a clean sharp picture of the bacteria in a number of tissues, e.g., olive tubercle, angular leaf-spot of cotton, pear blight.

Carbol fuchsin may also be mentioned here as a widely applicable permanent bacterial stain. Its chief objection is a tendency to over-stain the tissues of certain plants, e.g., those of the mulberry.

Two other very good stains are iron-haematoxylin and Flemming's triple stain. Nigrosin (soluble in water) also sometimes gives good results.

Long since (1894) the writer resorted to methyl violet, preceded by a bath in tannin water to reduce the excessive stain of the host tissues in stems of eucumber attacked by Bacillus tracheiphilus, and the bacterial masses in the vessels still hold their massive blue stain on a pale background (1915) but the 
bacteria have held the stain less than some substance between them. Where only tissue differences are to be brought out, methyl green followed by acid fuchsin (see Part III, No. XIV) leaves little to be desired, at least in certain plants, e.g., crown gall on the Paris daisy, sunflower or house geranium, where the parenchymatic tissues become red or pink, and the lignified tissues blue.

Staining Bacteria from Cultures. - I variety of stains are useful for staining smears and streaks from dilutions of pure cultures e.g., methylene blue, Gentian violet, basic fuchsin, carbol fuchsin, amyl Gram. It is important to start with clean slides or covers, to dilute the culture so that the bacteria shall not be crowded, and so to stain and wash that the bacteria shall be sharply and deeply colored on a clean clear background. A momentary bath in alcohol following the stain is sometimes serviceable, or in acid alcohol if the organism is an acid fast. organism, or in iodine followed by ethyl alcohol if it stains by Gram's method.

Flagella Staining.--This is more troublesome than either of the preceding and will tax to the uttermost the ingenuity and capacity of the average student. Some never learn to do it, most are able to accomplish it with perseverance. A very few become experts and obtain beautiful preparations with comparative ease. To succeed, the culture must be suitable. One seldom obtains good preparations from cultures that are not actively motile. Some species are much more obdurate than others. Attempts should be made as a rule only from very young agar-streak cultures (6-24 hours) and not then unless an inspection of the organism on the margin of a hanging drop shows it to be actively motile. Sometimes better success may be had by transfers from bouillon to agar than from agar to agar, or by flooding a roung agar culture with 15-20 ce. of distilled water and then taking motile organisms from the top part of the fluid.

The slides or covers used must be absolutely clean and of good quality. The mordanting fluid should be fresh. The bacterial film should be evenly spread and the individual bacteria widely separated but not too widely. The covers may be lightly flamed before staining but this is not always necessary. Very 
important is the right length of exposure to the mordant and then the right length of exposure to the stain Only some such very general directions can be giren because a method that will succeed with one organism often ails entirely with another The student should consu't the various text books and then go ahead. We have had excellent results on a variety of organisms using half a dozen different staining methods.

Special Stains.-For method of staining spores and capsules consult the various text books. The opposition to the use of morphological differences for classifying bacteria has come largely, I believe, from persons who are not naturalists and who have had indifferent success in staining bacteria.

\section{CARE OF SPECIMENS}

In many institutions there exists a discreditable lack of thoroughness in the preservation of interesting specimens, and those persons who throw away good pathological material are usually the very ones who have described it badly to begin with, so that between an imperfect description and entire absence of the materials on which the description was founded, the systematist can only guess what was the real state of the case. Sometimes when a laboratory changes heads the collections of the first man are destroyed by the second. I have known one shocking case of this kind. The student should remember that whatever is worth describing is also worth preserving. The collections of a pathological laboratory, if well made, become of greater and greater importance as time passes. They should include the following groups of material.

Herbarium Specimens. - These are to be fastened on sheets of stiff white paper of the standard herbarium size, and properly labeled, one sheet being devoted to each parasite, but the more specimens of it the better, especially if they are from different localities.

Coarse Dried Material.-Limbs, trunks, and other material too cumbrous for the herbarium sheets should be properly ticketed and stored in tight boxes or in glass cases. This material and the herbarium sheets must be examined frequently 
for insect depredations and treated for the same like other herbarium material.

Alcoholic Material.--Quantities of this should be preserved for two purposes: $a$, class use; $b$, permanent records and exhibition purposes. The former must be fixed in Carnoy's fluid or some other suitable fixative before transfer to the alcohol. Flat (parallel-walled) jars may be used for the exhibition collection, which may be set off by a background of milk-white glass placed inside the jars, though this is not absolutely necessary. Any alcoholic collection must be examined once a year and leaking jars refilled and resealed.

Pathological material may be preserved, with the green color of leaves and stems retained, by boiling the specimens for about 5 minutes, more or less ( 1 to 10 minutes) in 80 parts of distilled water to which has been added 20 parts of glacial acetic acid saturated with copper acetate. The treated specimens should be rinsed in water and placed permanently in water containing 5 per cent formalin, or in localities not subject to freezing they may be kept in sulphurous acid water (Gino Pollaci's method).

Microscopic Preparations.--These may be laid in flat trays or in grooved wooden boxes. The writer uses the common Pillsbury boxes which hold each 25 slides. These slides have a gummed label on one or both ends bearing the block number and other necessary data, i.e., object, date, kind of stain, etc. These should be kept in the dark. The slide boxes in my laboratory are filed either under the name of the parasite or serially.

\section{PREPARATION OF ILLUSTRATIONS}

Photographs.-The general excellence of photographic apparatus in recent years, and the slight cost of plates and films, render this method of making records extremely serviceable. The student who is planning a career in science should determine from the start to be master of all the common methods of photography. In every locality, nearly, there is some one who can teach him the rudiments, and even if not, good journals and books on the subject are now numerous and inexpensive. There is, therefore, no excuse for neglect of this interesting and im- 
portant aid to research. How important it is, will be evident at once if we reflect that photography enables us to fix the thousand and one fleeting phenomena of nature in a permanent record with which to refresh our memory and from which to draw, in a way quite beyond the power of former generations, convincing illustrations for papers, books, and lectures Not infrequently the study of a good negative reveals details overlooked on the object itself. This is most important, of course, in astronomy, but it also has its uses in pathology.

Remember that one good picture is better than half a dozen pages of text in hammering home your argument and that if you fail to convince your readers and hearers, then your work is in vain. Therefore, do not spare good illustrations.

The following fragmentary observations are drawn from our own procedure and may be of service in smoothing the way for the beginner.

Good lenses, light-proof bellows, and suitable dry plates are essential to the making of good photographs. The student should read what is said on this subject under Apparatus.

Pathological subjects usually show strong contrasts and to get similar contrasts on the negative often taxes the skill of the expert. It took the writer and James F. Brewer two days to get the result shown in Fig. 281.

Development should be carried on in the dark as much as possible. When light is allowed to reach the developing plate it should be only of a minimum brightness (very dull red) and for only very brief periods, especially during early stages of development, and at all stages of development in case of plates corrected for the red end of the spectrum

For ordinary work and for certain color contrasts such as white and black or red and blue, Seed's rapid No. 30 Gilt Edge dry plates may be used. These are not sensitive to red light, therefore contrasting reds, yellows and greens wil come out dark on the prints and often be disappointingly alike, while the overexposed blue and violet parts will be pale or white on the prints. Consequently, for many subjects where color contrasts are desired, Cramer's Iso medium or Iso slow plates may be used. Better still for this purpose are Wratten and Wain- 
wright's Panchromatic plates, which give nearly perfect color values, and for this reason are so sensitive to red light that they should be developed from start to finish in the dark, recommendations to the contrary notwithstanding. Even with the best plates it is sometimes impossible to get the contrast of nature unless color screens are used. See Fig. 281. Here a bluish black stripe on a pale green ground, perfectly distinct to the naked eye, defied all attempts at photographing until the exposure was made through a yellow screen. See also Fig. 239 of cotton leaves and bracts and Fig. 47.

As a developer, rodinol (sometimes called cytol), which is ready for use on dilution with water, leaves little to be desired. Many developers are poisonous and iritating to the skin. The hands, therefore, should be kept out of them as much as possible and always washed immediately after they have been dipped into the tray.

Prints for filing, or for use of the photo-engraver should be on paper that does not curl. Films or papers that curl are a source of endless vexation. We now employ two styles of Eastman's Velox paper, viz., Apecial Glossy Velox paper for hard (contrasty) negatives and Regular Glossy Velox paper for soft negatives. In printing, dense negatives may be exposed to daylight for a few seconds (10 to 20 , at some distance from the window), but thin negatives must be exposed to a weaker light.

Reproductions from photographs are usually made on copper by the half-tone process. Half-tones illustrative of pathological appearances (details) should be made with a screen not coarser than 150 meshes to the inch, and in many subjects important features will be lost if the screen is not finer, i.e., 175 meshes to the inch. On good paper, with a good pressman (and this is all important), there is no difficulty in getting a clear impression from a well-made half-tone having 175 meshes per inch, only the paper must be suitable, must be backed up properly and printed carefully with just the proper amount of good ink. Many of the smudges passing for illustrations in current publications are a disgrace both to the scientific man and to the printer. I provide against loss of important small details through unavoidable defects in the half-tone, by enlargements to twice 
natural size with the ordinary lenses and an extra long bellows, or by means of planar enlargements. These latter enable one to show distinctly even the minutest color changes, or form changes, on leaves, stems, fruits, or other organs.

Frequently when a very good photograph has been furnished the engraver, he ruins the plate he has made from it by overetching. In such cases he should be compelled to make another. But the best half-tone ever made can be ruined by a second rate pressman. For an example of a good plate ruined by a slovenly pressman see "Bacteria in Relation to Plant Diseases," Vol. I, page 178, and for a properly printed half-tone from the same negative, see Fig. 67 in this book.

Enlargement to twice natural size requires the ground glass (focusing plate) to be from the lens a distance equal to three times the equivalent focus of the lens, i.e., the enlargement of an object to twice natural size, using a lens of $9^{1} .2$ inch focal length, requires the placing of the object $14^{1} / 4$ inches in front of the lens and the bellows extended to about 28 inches.

Photomicrographs. - Sucess with the large horizontal photomicrographic apparatus formerly much used by the writer depends on keeping a few things constantly in mind: (1) the source of light must be reasonably constant; (2) the rays of light must pass in a straight line from the luminary to the ground glass, i.e., every piece of the apparatus must be centered; (3) a ray filter should be used; (4) if the bellows is elongated to twice its former length the exposure must be quadrupled, and vice versa; (5) if high power lenses are substituted for low power ones the exposure must be lengthened (one comes after a time to judge very correctly of the exposure by the amount of light on the ground glass, but the beginner will save much time and rexation by using an exposure shutter, and in its absence by drawing the ordinary slide ${ }^{1} 4$, then ${ }^{1} 2,3,4$, and finally entirely, and judging by development with a normal developer which of the various exposures, or between or beyond which, will give the best results); (6) the time required for unstained and thin-stained slides is very much less than that for those heavily stained, and in exposing thick or dark-stained slides the time must be long enough 
to allow the light to penetrate the thickest parts; ( 7 ) no specific rules can be given as to length of exposure. It varies enormously with the subject, objective, eye-piece, bellows length, size of diaphragm, sensitiveness of dry plate, kind of screen and source of light, and if sunshine is used, state of the sky, latitude, time of day and time of year. In Washington, using planar lenses with short bellows length and bright sun light, it is generally only fractions of a second (sometimes as short as 1/100 second). With high powers, long bellows, small stop and dark subjects it is often five minutes or more. Sometimes it is very much longer if the source of light is feeble. Using the light of the open sky, Cramer's Iso slow plates, and a densely stained slide, I have sometimes exposed the plate for an hour, but this, of course, is exceptional, although under such conditions 10 to 20 or even 30 minute exposures are common for magnifications of $\times 1000$. Toward sunset the actinic effect of the light falls off very rapidly and the exposure must be correspondingly lengthened, 30 minutes to an hour being not unusual.

If the object is a small one in the center of an otherwise well-lighted field, the exposure should be much shorter, naturally, than when there are deeply stained objects in many parts of the field.

The beginner will do well to confine himself to the simple upright camera. If he avoids direct sunlight, focusing on the diffuse light of the sky, he will have more leeway in his exposures and will not require a shutter. The exposures with such an apparatus are very much lengthened, even on clear days, as compared with are light or heliostat light, but this is no serious difficulty. With such an apparatus, using Cramer's Iso-chromatic slow plates, a Zeiss 2-mm. apochromatic oil-immersion lens, a No. 4 compensating ocular, and a magnification of $\times 1000$, the time of exposure here in Washington on a clear summer day between $9 \mathrm{a} . \mathrm{m}$. and $3 \mathrm{p} . \mathrm{m}$. varies, with the nature of the section, and the stop, from one minute to 20 minutes or more; with all else the same, but using a Zeiss $16-\mathrm{mm}$. apochromatic objective, the time varies usually from five seconds to 10 minutes according to the subject and the stop. A little experience will enable the painstaking student to obtain good pictures, especially 
with low powers. The field must be flat, must be uniformly lighted, and the proper focus must be obtained, which focus is not exactly that of the eyepiece, but must be secured by use of a hand lens on the ground glass, or preferably on clear glass substituted for the ground glass. I first focus with the eyepiece, then attach the bellows and focus on the ground glass under a thick dark cloth (two folds), at which time I judge of the uniformity of lighting and center my object, then I substitute the plain glass for the ground glass and re-focus, using a hand lens. Last of all, I stop-down, always considerably, and make the exposure. In all this I am considering only apochromatic objectives. With some of the older Zeiss achromatic objectives I found it impossible to get a focus upon the ground glass that would photograph. In this case I determined experimentally by a series of photographs made at slightly different levels the amount of the error and thereafter obtained a sharp focus on the ground glass, turned it out the required amount, and then made my exposure.

Photomicrographs require a longer development than ordinary photographs since in the latter we aim at a pleasing gradation of tints whereas we usually have in the stained slides sharp contrasts and wish to retain these contrasts on the negative. We use hydroquinon developer (double the amount of hydroquinon of Cramer's formula with the metol left out) and I develop until the image is well through on the back. This occurs in a fully exposed plate in seven minutes, in a slightly underexposed one in 15 to 25 minutes. ' If I wish very marked contrasts such as deeply stained bacteria on a white background (Fig. 187 for example) I under-expose so that the image comes up in five to seven minutes rather than in two minutes, and I develop a long time (30 or 40 minutes), with a hydrochinon contrast developer, so as to have a very dense background.

The plates are fixed in the green (chrome alum) acid fixing bath where they should remain at least 20 minutes, and much longer will not hurt them. We prepare the bath, only when we are ready to use it, from standard stock solutions which keep indefinitely separate, adding to four tumblers of the filtered saturated water solution of sodium hyposulphite (water 128 
oz., hypo. 32 oz.), slowly stirring in. with a glass rod one tumbler of the green fluid (water $32 \mathrm{oz}$, dry sodium sulphite $3 \mathrm{oz}$, c.p. sulphuric acid $1 / 2$ oz., powdered chrome alum 2 oz., dissolved in the order named).

Lumière Plates. - Consult a booklet on "Color Photography Writh Autochrom Plates." R. J. Fitzsimons, 75 Fifth Arenue, New York, Agents for Lumière Jougla Products.

Planars.--The use of planar lenses has greatly simplified the work of the pathologist. By means of magnifications ranging from $\times 5$ to $\times 25$ they enable him to show every detail of a surface not too irregular, and the whole of sections much too large for the ordinary microscope. I make most use of magnifications ranging from $\times 5$ to $\times 15$ and prize these lenses very highly. Their only defect, if such it be, is that the field must be quite flat, if the image is to be uniformly sharp. There is, however, a little penetration and to make the most of this we usually focus with the diaphragm wide open and then stop down as much as possible. The final focusing should be on clear glass, using a hand lens magnifying about $\times 6$. What can be done with such lenses is shown in some of the illustrations in this book. Figure 72 was one of the hardest to make because the section is thin and now shows scarcely any stain except in the bacterial masses, and because it was made on the upright camera without a color screen.

Drawings.-At one time the pendulum of scientific sentiment swung away from drawings toward photographs, because it was said the drawing represents only the ideas of the artist whereas the photograph camnot lie, but now it has come back again, since it has been recognized that the latter statement is not strictly true (Fig. 210b,c), and that the former objection lies chiefly against artists who are not naturalists.

For many purposes, a good drawing is better than a good photograph, but there is no reason why the scientific man should not use both. I have heard many students say: "I can never learn to draw," but with few exceptions such is not the case. Every student should be encouraged to use pen and pencil every day to illustrate what he sees. The more he does it under proper guidance the more he will see. Certainly he has not 
seen an object to much profit if he cannot make at least a sketch of it, and this, however rude, is better than nothing, and helps just that much toward his intellectual development, which, after all, is the end of most of his studies.

Drawings may be made with lead pencil, pen and ink, or the brush.

Pencil drawings well made, are very attractive, and if there is not a question of expense they may be used to illustrate scientific papers by means of lithography, but this process is much more expensive than line engraving (zinc process) or half-tone plates, and is now seldom used by publishers except. for expensive works. Drawings designed to illustrate books and papers should, therefore, be marke, as a rule, with India ink. by use of pen or brush. The latter, known as wash-drawings, can only be half-toned. The former are generally reproduced by the zinc process. Zinc cuts are less expensive than the copper half-tones, print well, and are very attractive if well made. To get good results the ink must be black and non-soluble in water, the lines or dots must be distinct in all parts and must be properly spaced, so that when the drawing is reduced, none of them will fade out in places, owing to insufficient or pale ink, or run together into blotches because not properly spaced. The student should have a clear idea in adrance of where he intends to introduce his lights and shades so as to produce an attractive picture, and how any part will appear when it is reduced one-half or two-thirds. For this reason he should examine his drawing from time to time under a reducing glass, and when it is done not allow it to be reduced more than it will stand. I recall seeing many years ago a hundred beautiful pen-and-ink drawings made by one scientific man for the use of another. They were drawn and marked to be reduced, according to my recollection. just one-half and would have stood that amount of reduction perfectly, but for reasons of economy they were reduced twice the proper amount with disagreeable blotchy results, satisfact ory neither to the artist nor to the author. Whenever in doubt the finished drawing should be photographed at the proposed reduction. This is a sure way of deciding how much reduction any drawing will stand. I finished drawing represents 
much labor and should be carefully protected (covered) until engraved.

Very much can be done by line work alone, but the finest results, especially where details are important, can be achieved only by making the drawing partly or wholly of large and small dots (stipple), placed close together and wide apart as the shading or other features require. As such drawing is rather hard on the eyes it should generally be done under a drawing glass magnifying two or three times, and always should be drawn larger than the desired reproduction so that small inequalities in the hand work may disappear or blend into a general smooth whole when it is reduced one-half or two-thirds. Great care must be taken to lay the ink on properly so that the reduction shall look uniform and attractive. Such drawings may be made direct from the microscope or inked over a pencil sketch, or may be laid over a pale silver print on salted paper, or a blueprint, or a print on bromid paper, the remaining photographic details of which are then bleached out in a bath (the importance of the water-insoluble India ink is now apparent) after which the sheet is dried and retouched here and there, as necessary, to fill in places which were overlooked.

The bleaching baths are as follows:

1. To bleach silver-salted paper: use a weak solution of mercuric chlorid in alcohol (poison).

2. To bleach blueprints: use a dilute solution of potassium carbonate and potassium hydrate after which the print should be flowed with dilute hydrochloric acid and washed.

3. To bleach bromide prints:

a. Use Thiocarbamide............ 120 grains.

Nitric acid................ 2 fluid drams.

Water................... 10 ounces.

Wash and dry. Safe but slow.

or $b$. Use a saturated solution of iodine in

alcohol.....................

Saturated solution of potassium cyanide in water............ 3 drams.

By adding water the action becomes slower. Note.-This solution is very poisonous. 
For ordinary pen-and-ink or wash-drawings we generally use Reynolds' English Bristol board and Higgins' water-proof India ink.

The first essential of a good drawing, and the sine qua non, is fidelity, but one may have kept that and yet the drawing may be unattractive, i.e., all black or all pale. Generally I prefer to indicate certain tissues by shading them and I select these arbitrarily in such a way as to give to the drawing a varied and pleasing effect. This is gratis!

When letters or figures are introduced into photographs or drawings the intended reduction should always be taken into account, i.e., the letters and figures must be large enough so that they may not be lost or obscured when reduced, since much time is sometimes wasted in trying to read an author's references. For the same reason, when drawings numbered serially are cut apart and rearranged on a plate, as sometimes happens in an effort to economize space, they should be renumbered serially from left to right and top to bottom. This is laborious to the author, but the labor involved is as nothing compared to the burden the neglect of it throws upon a thousand readers, particularly if the figures are numerous and the lettering indistinct.

Paintings.--Water-color drawings are often indispensable, since neither photographs nor ordinary pen or pencil drawings can convey color effects satisfactorily. A faint pencil outline is usually sketched in and then the proper colors are flowed over the surface with a swift sure touch. The technic is very different from that of painting in oil, which may be worked over and over, since in a water-color the right pigments must be laid on swiftly once for all, the drawing admitting afterward only of a minimum amount of correction. It is nevertheless greatly to be preferred to oil, because it gives a smoother surface and brighter colors. Not many students will be able to make their own water-color drawings. When such are necessary some one can usually be found to do it. Since such persons are usually untrained, scientifically, in my own case I have always found it necessary to superintend the process, suggesting now and then the colors to be sought for and the details to be emphasized. In this way I have succeeded quite well with various artists 
having none of the naturalist's outlook, and unable in my judgment to do it alone. The trouble generally is that the artist sees color rather than structure and strives for general effects by omission of details, whereas the scientific man desires his colors to be laid on carefully over definite structures. This is not a criticism of the artist as such, but only of the artist turned naturalist. The ends aimed at are different and each man is right in his own field.

To see examples of the various kinds of drawings and what I mean by the above remarks, the student may consult "Bacteria in Relation to Plant Diseases," Vol. I, Figs. 1 (drawn from a photomicrograph), 2 and 3 (drawn directly from the microscope), 4 (drawn from a photomicrograph and reduced), 39, 63, 64, and 86 (good line drawings), 132 (rough but effective line drawing).

Ibid., Vol. II, Figs. 4 (drawn unstained), 12, 15, 16, 17 (drawn from stained sections directly from the microscope), 69 (drawn directly from the microscope), 80 (a good wash-drawing reduced too much, compare with photomicrograph of same subject in this book. Fig. 72), 102 (inked over an enlargement from a photomicrograph), 118 (inked over a photomicrograph and then much reduced), 137 (drawn directly from the microscope).

Ibid., Vol. III, Figs. 7 (drawn from a stained slide), 16 (drawn from a broken negative), 19, 20, and 21 (drawn large from stained slides and much reduced-contrast 20 and 21 for different methods of shading), 72 and 75 (drawn directly from stained slides), 84 (drawn from the slide and much reduced), 86 (drawn from a photomicrograph), 105 (wash-drawing much reduced), 108 (drawn from the slide but slightly diagrammatic).

\section{CARD CATALOGUES AND SYSTEMS OF FILING}

Every successful student of the natural sciences must of necessity read widely and, since memory in civilized man is an uncertain way of retaining knowledge, records of some sort are absolutely necessary. Loose sheets or a pocket notebook serve the ordinary man, but as knowledge widens, as many subjects come under observation, and as scientific materials accumulate, orderly catalogues and systems of filing become indispensable. 
Standard library cards are recommended for the literature catalogues. These should be of good size so as to admit of a short summary of contents, if thought desirable. They may be typewritten or else written in black ink and in a handwriting plain as print. For various other catalogues smaller cards are sufficient. We keep an index of negatives, of paraffinembedded material, of culture media, of stock cultures, etc. Our stained sections are filed in Pillsbury boxes, standing on end in deep drawers. The paraffin block number is written on the end of each box, and sections of all the hosts attacked by a parasite are filed together under the name of that parasite.

Our negatives are placed in strong paper negative bags and filed in deep drawers. They are arranged alphabetically according to the species name of the parasites, with lettered guide boards separating the photographs relating to the different parasites, and the photographs of each subject are numbered serially on the face of the envelopes in red ink.

Each negative bag has all necessary data written on it, but this is not enough since various persons handle these negatives and it is extremely easy to get the negative covers misplaced, so that often after years have elapsed one is in great uncertainty as to which belongs to which. I make it an invariable rule, therefore, to write all necessary data on the margin of the negative itself, earefully selecting a place where the writing will not interfere with the printing. In fact, I consider a negative without such a record on it as worthless, no matter how good it is in all other respects, because it is like a natural history specimen whose locality has been lost.

Negatives should never be filed without covers since if they are on glass they are certain to become scratched or broken. It gives me the shivers to see the way in which some scientific men treat negatives. 


\section{SYNOPSIS OF SELECTED DISEASES}

\section{THE CUCURBIT WILT}

Type.-This is a wide-spread, typically vascular, woundinfection, wilt disease (Figs. 62, 63, 64), transmited by insect. (Figs. $65,66,67$ ). The plants wilt suddenly without any visible cause, and on cross-sections of stems of such plants there is a viscid, white bacterial ooze from the vascular bundles (xylem part). The disease is first visible on the leaves locally in the form of dull green, rapidly extending, flabby patches. Later all the leaves wilt and shrivel. It is not known outside of Cucurbitaceae and some members of this family are not subject. It is believed to be non-tropical in its distribution. Its range toward the equator is unknown. Rand has recently discovered it in the United States as far south as Florida. It occurs in Europe, South Africa, and Japan. In hothouses the disease occurs not infrequently in the winter season, often destructively, and here again insects are the carriers.

Cause.--It is due to Bacillus tracheiphilus EFS. ${ }^{1}$ This is a

${ }^{1}$ Note. - The generic names in this book are used by me in the following way:

Bacillus: A rod-shaped schizomycete, motile by means of peritrichiate flagella.

Bacterium: A rod-shaped schizomycete, motile either by means of one polar flagellum or several such flagella.

A planobacter: A rod-shaped, non-flagellate, non-motile schizomycete.

For a discussion of the principles involved in this nomenclature, see "Nomenclature and Classifications" in "Bacteria in Relation to Plant Diseases," Vol. I.

The peptone referred to in this book is Witte's Peptonum siccum. The agar is Kahlbaum's Pulverized Agar Flour. The gelatine is Nelson's Shredded Photographic Gelatine, No. 1. All titrations referred to were made with N/20 $\mathrm{NaOH}$, or $\mathrm{N} / 20 \mathrm{HCl}$, using phenolphthalein as indicator, unless otherwise specified, the merest trace of the pink color being taken as the zero point. Bouillon means 1 per cent peptone-bouillon unless otherwise indicated. Milk means the fresh cream-free product. As already stated in Part II, the color changes in most cases have been compared with Ridgeway's Color Scale $\left(R_{1}\right.$ or $R_{2}$ ). Sometimes, however, there is no color in Ridgeway's system that fits, and in such cases I have used common terms. 


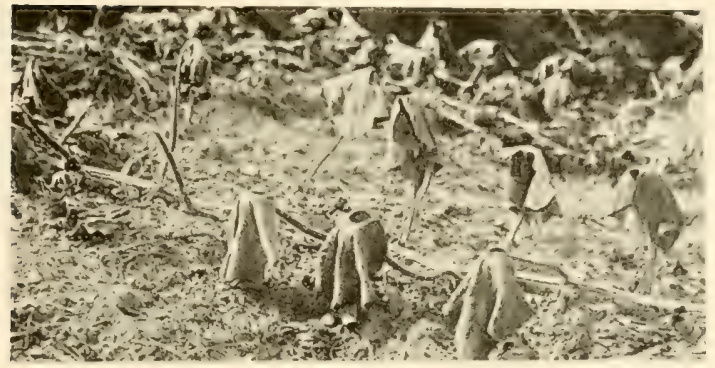

Frg. 62.-Cucumber wilt due to Bacillus tracheiphilus. A natural infection. Photographed by the writer in 1893 .

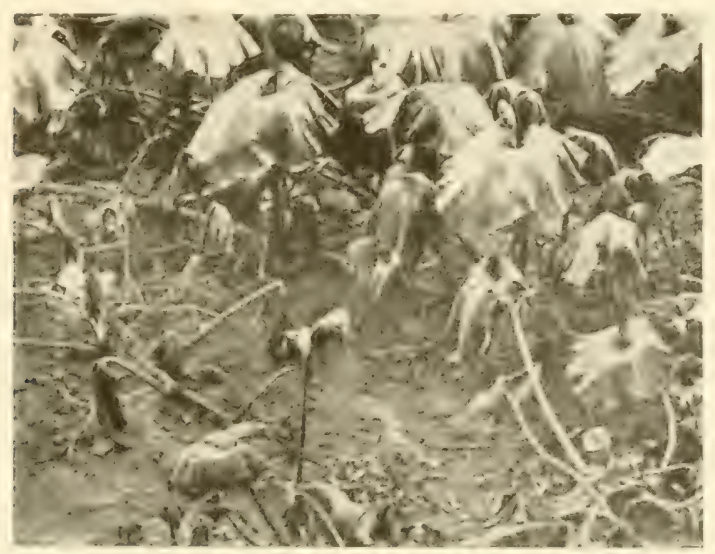

FIG. 63.-Squash wilt due to Bacillus tracheiphilus. A natural infection. (After Clinton.)

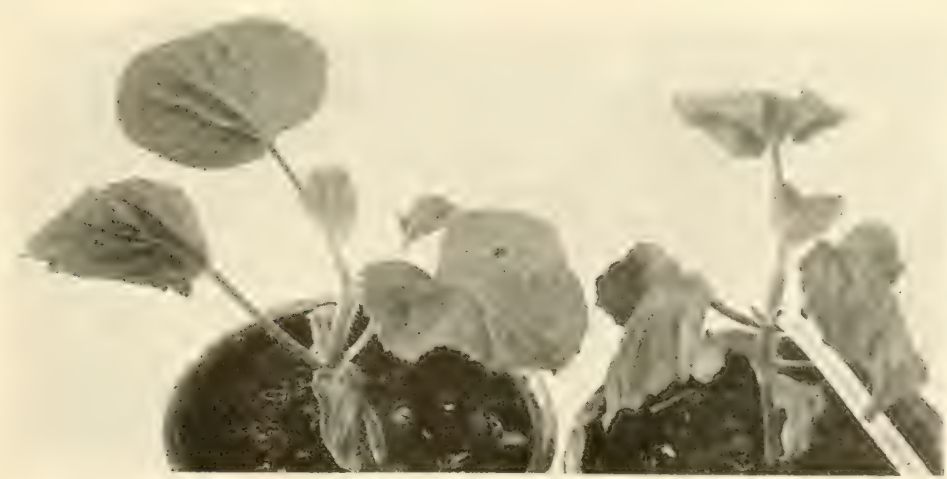

FIG. 64.-Muskmelon wilt due to Bacillus tracheiphilus. Result of a pure culture inoculation made April 15, 1896. 


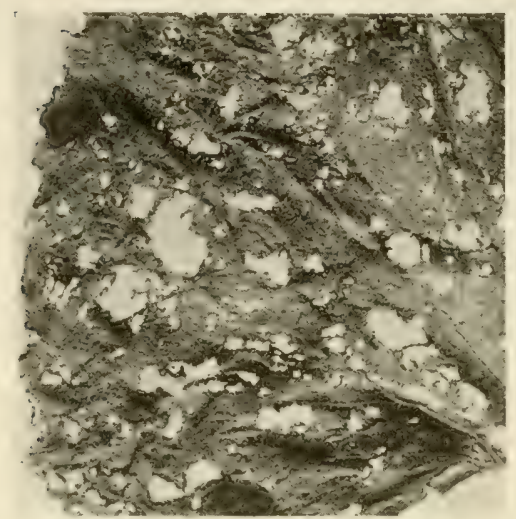

Fig. 65.-Portion of a cucumber leaf wilted by Bacillus tracheiphilus (which was abundant in many of the smaller veins) and then greedily gnawed by the striper cucumber beetle (Diabrotica vittata). Such beetles are then infectious to other plants.

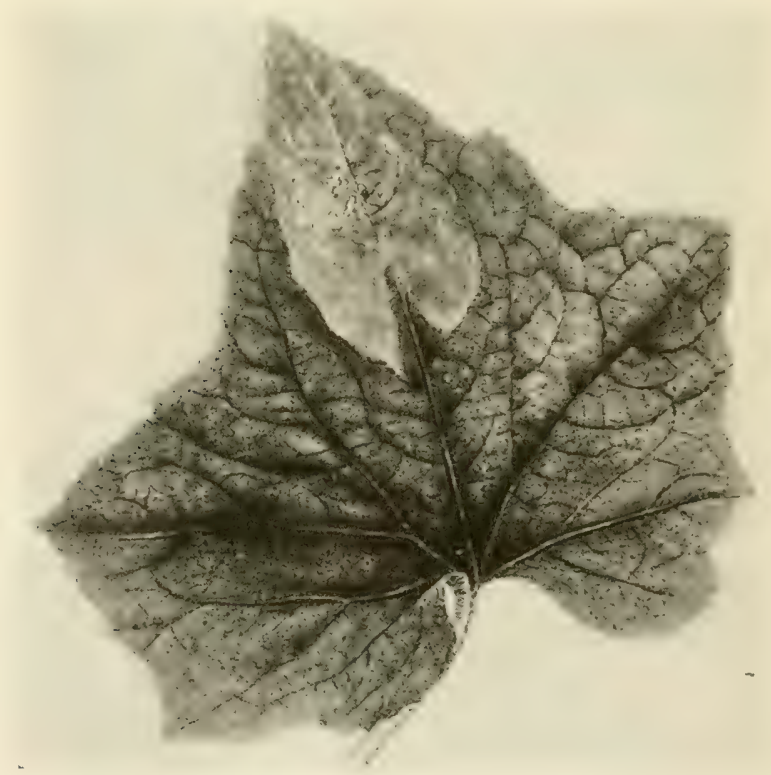

Fig. 66.-A healthy cucumber leaf slightly gnawed by an infected striped beetle and developing the bacterial wilt around the bitten places. From a field near Washington, 1893. 
viscid, capsulate, motile, white, non-sporiferous, slow-growing, nonliquefying, non-milk-curdling, nonnitrate-reducing, non-gas-forming, aërobic and facultative anaërobic (acid-producing), rod-shaped, peritrichiate schizomycete (Fig. 68), forming on the surface of agarpoured plates, internally reticulated (Figs. 69, 70), small, circular smooth, wet-shining (Fig. 71), colonies. It is easily killed by heat, by dry air and by weak acids. It must be transferred very frequently on culture-media. It may be kept alive longest in milk or in sugared peptone water over calcium carbonate. It does not lose virulence quickly. There are at least two strains, to one of which (f. cucumis EFS.) the squash is immune.

Technic.-If the organism to be used in the inoculations must be isolated from old stems, wash the stem thoroughly in clean tap water, select a middle part, roll around quickly two or three times in a

Frg. 67.-Secondary (general) bacterial wilt of a cucumber vine as the result of bites of the striped beetle (Diabrotica vitiata) after it had fed on a bacterial culture. These bites, few in number, were on the lower leaves and resembled those shown in Fig. 66. The infectious material was obtained hy the beetles from leaves of other cucumbers where

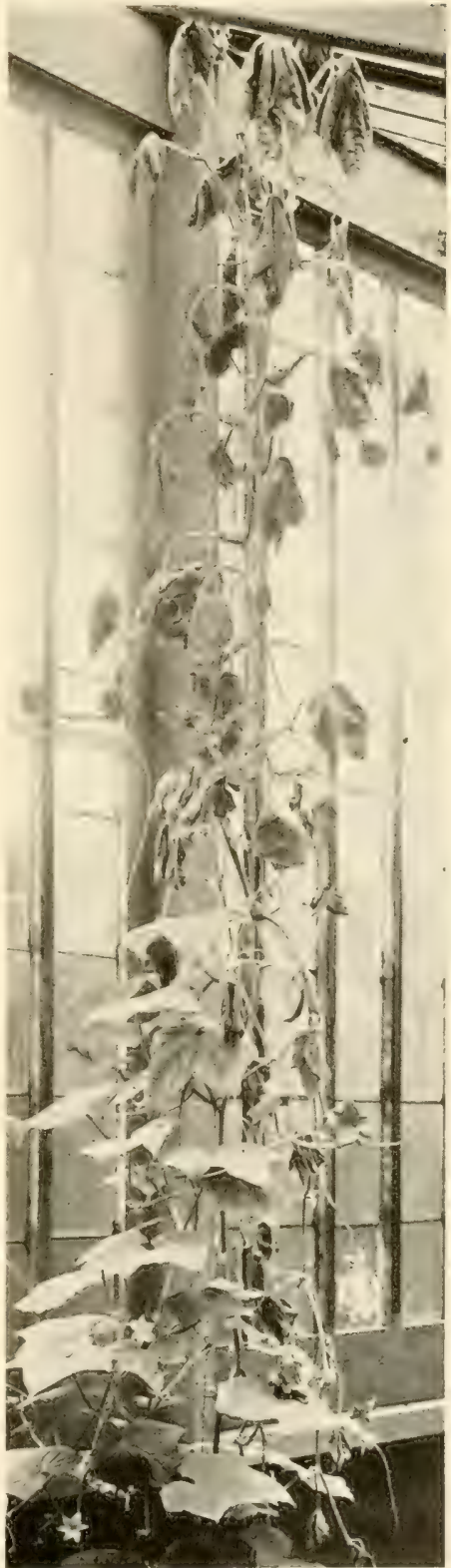

I had placed it a few hours before in making some needle-prick inoculations. Beetle-bites both on $\mathrm{my}$ inoculated leaves and on those of this plant were discovered next morning and the disease was predicted. It developed around the bitten places in the usual time and progressed just as on the pricked plants. 
Bunsen flame, or slowly in the flame of an alcohol lamp, so as to singe the surface without cooking the interior. Place the flamed part on a sterile surface (a strip of glass or a clean board passed repeatedly through the Bunsen flame, or the inside of a baked Petri dish) and cut crosswise with a red-hot knife. If you have any doubt as to the sterility of the cut surface, i.e., if you have accidentally touched it with your

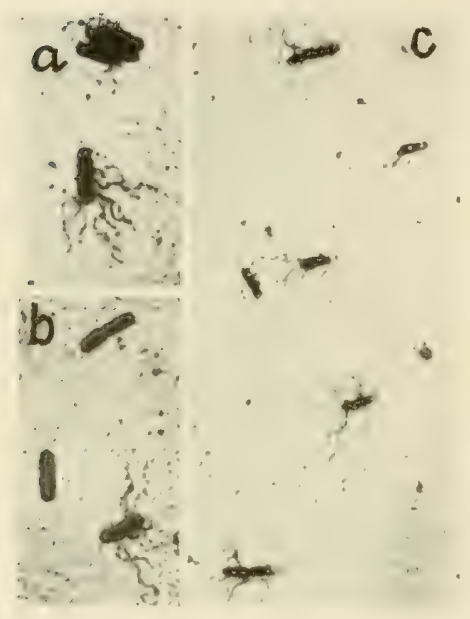

Fic. 68 .

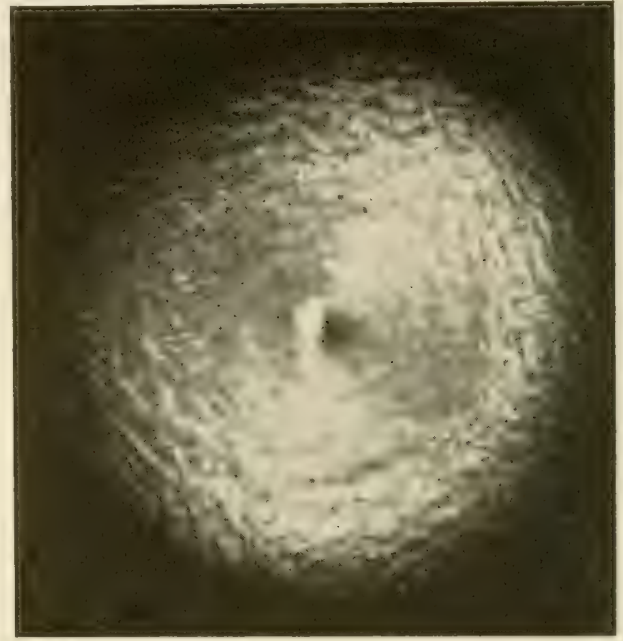

FIG. 69.

FIG. 68.-Flagellate rods of Bacillus tracheiphilus stained by van Ermengem's silver nitrate method: $a, b$, stained and photographed by the writer in 1904 . The original negatives are $\times 1000$, but the picture here shown has been marde $\times 2000$ to bring out the flagella more distinctly; $c$, stained by Mary Katherine Bryan, in 1915 , and photographed by the writer. $\times 1000$.

FIG. 69.-Agar poured plate smooth surface colony of Bacillus tracheiphilus enlarged 25 times and photographed by transmitted oblique light to show internal markings; 5th day, 1919.

fingers or have dropped it, press the hising hot knife firmly once or twice for a moment or two on the cut end of the stem. Surface organisms are thus excluded. Then squeeze the stem, forcing bacteria from the unheated part to the cut surface for your cultures.

The slime of this organism within the vessels of the stem is usually so viscid that plate cultures made from it frequently miscarry. Along with this method, therefore, try a second, i.e., 
at the time the plates are poured inoculate a tube of bouillon or of peptone water by squeezing into it a drop of the viscid fluid, let it stand 18 to 24 hours, and then pour from it a seeond set of plates, inoculating them rery sparingly from the original tube, if it is well clouded, and rather copiously if it is clear. Inoculate also from dilutions of the same. Save all tubes, or at least the dilutions until results are known. The diseased stems must also be retained until results are known, unless others are easily procurable. They may be kept in the ice box.

For inoculation purposes use cucumber, muskmelon, squash. These should be planted in a warm place 2 months before they will be needed, should be potted off early, and shifted to larger pots frequently to keep them growing rapidly. Watermelons may be inoculated for contrast. These cucurbits require houses having a day temperature varying from $65^{\circ}$ to $75^{\circ} \mathrm{F}$., and a night temperature about $15^{\circ} \mathrm{F}$. lower. Avoid chilling the plants as then they are very subject to mildew. If any mildewed plants appear they should be removed from the house immediately.

Inoculate by needle-pricks (10 to 20 to make sure, but on some a lesser number for comparison), using young (2- to (i-day) agar-streak, potato, peptone, or bouillon cultures. Prick the blades of well-developed vigorous leaves. Make check pricks on other leaves of the same plant, or upon the same leaf on the opposite side. In both cases group the pricks. Examine the inoculated leaves frequently from the second day on. Do not over-water so as to complicate by root-rot. Do not tear the leaves in making inoculations.

\section{Determine}

For the organism. Morphology.-In various media: size in microns, form, aggregation of elements if any, i.e., chains, filaments, preudozoögloeae, ete., motility on margin of hanging drop (using a high-power dry lens or an oil immersion lens, with a long working distance); absence of spores (heat, spore stains); mresence and distribution of flagella (van Ermengem's stain); stain one of the viscid, cobwebby threads on a clean slide using carbol fuchsin and study under a high magnification. Try capsule stains, Gram's stain. Do involution forms occur? 
Cultural Characters.-Growth on thin-sown agar-poured plates - internal structure of surface colonies; growth in gelatin plates; stabs and streaks on agar; do. gelatin. Appearance on steamed potato: this should be wet-glistening, and almost exactly the color of the white surface of the potato. A non-para-
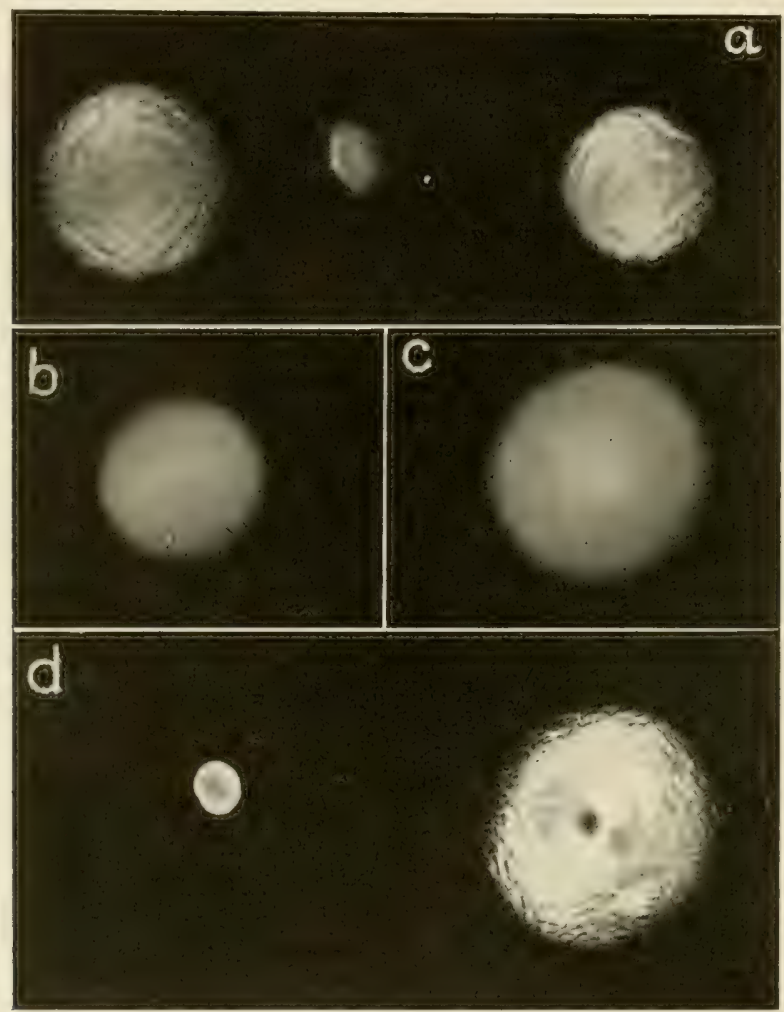

FIG. 70.-Internal markings of agar surface colonies of Bacillus tracheiphilus: $a$, Isolated from a wilting plant bitten by a striped beetle (1915); b, $c$, Rand's No. 230 ehecked up by the writer on cucumber (1918); d, Rand's No. 183 plated in 1919, also checked up on cucumber. All photographed by oblique transmitted light. $\times 10$.

sitic coccus follower answering to this description on steamed potato may be distinguished by the fact that it reddens litmus milk. Behavior in bouillon; nitrate bouillon; Cohn's solution; Uschinsky's solution; milk; litmus milk; peptone water in fermentation tubes with dextrose, with saccharose, with lactose. Can 
you determine the kind of acid produced from cane-sugar? Use large flask cultures containing peptone water cane-sugar and calcium carbonate. Be certain that they contain only this one organism i.e., plate out just before undertaking isolation of the acid, and test on young cucumber plants. Study the viscidity in cultures: compare it with that of Bacterium leguminosarum.

Non-nutritional Environment.-Effect of heat, of sunlight, of dry air (killed quickly), of chloroform in bouillon, of weak acids, of salted bouillons? Can you get any growth in bouillon at $9^{\circ} \mathrm{C}$, or at $37^{\circ} \mathrm{C}$.? How many months will the organism live dry on cucumber seeds?

For the Disease. Signs.-Contrast cucumbers and squashes. Observe period of incubation; time between local appearance of disease on inoculated leaf and general infection of the plant. What are the most conspicuous external indications of this disease? Can you produce it on watermelons? on gourds? Write a description of it.

Histology.- - How many centimeters in advance of external signs on the inoculated leaf can the bacteria be traced down the petiole? Begin before the wilt has attacked the whole leafblade. With a hot knife sever the petioles where they join the stem. Twenty or more plants will be necessary for this experiment, which is best performed as soon as a few square centimeters of the leaf show the characteristic wilt. After removal of the inoculated leaf. what per cent of the plants remain free from the disease? In tracing the organism from the leafblade into the stem, determine what tissues are occupied. Are cavities formed? Is cellulose destroyed? Is the wilt due to lack of water-supply or to toxic action? Are the bacteria in the leaf-blade confined to the vessels or do they invade the leaf-parenchyma? Do you think they swim through the ressels or only grow through them? What are your reasons?

Make cross- and longitudinal sections of the infected stems. If time permits, fix, stain and mount. Which vessels of the stem are first occupied? Why? What tissues of the stem other than vessels are occupied and destroyed?

Can you demonstrate the organism in the phloem? In the interfascicular parenchyma? Consult Figs. 72 to 78 . 


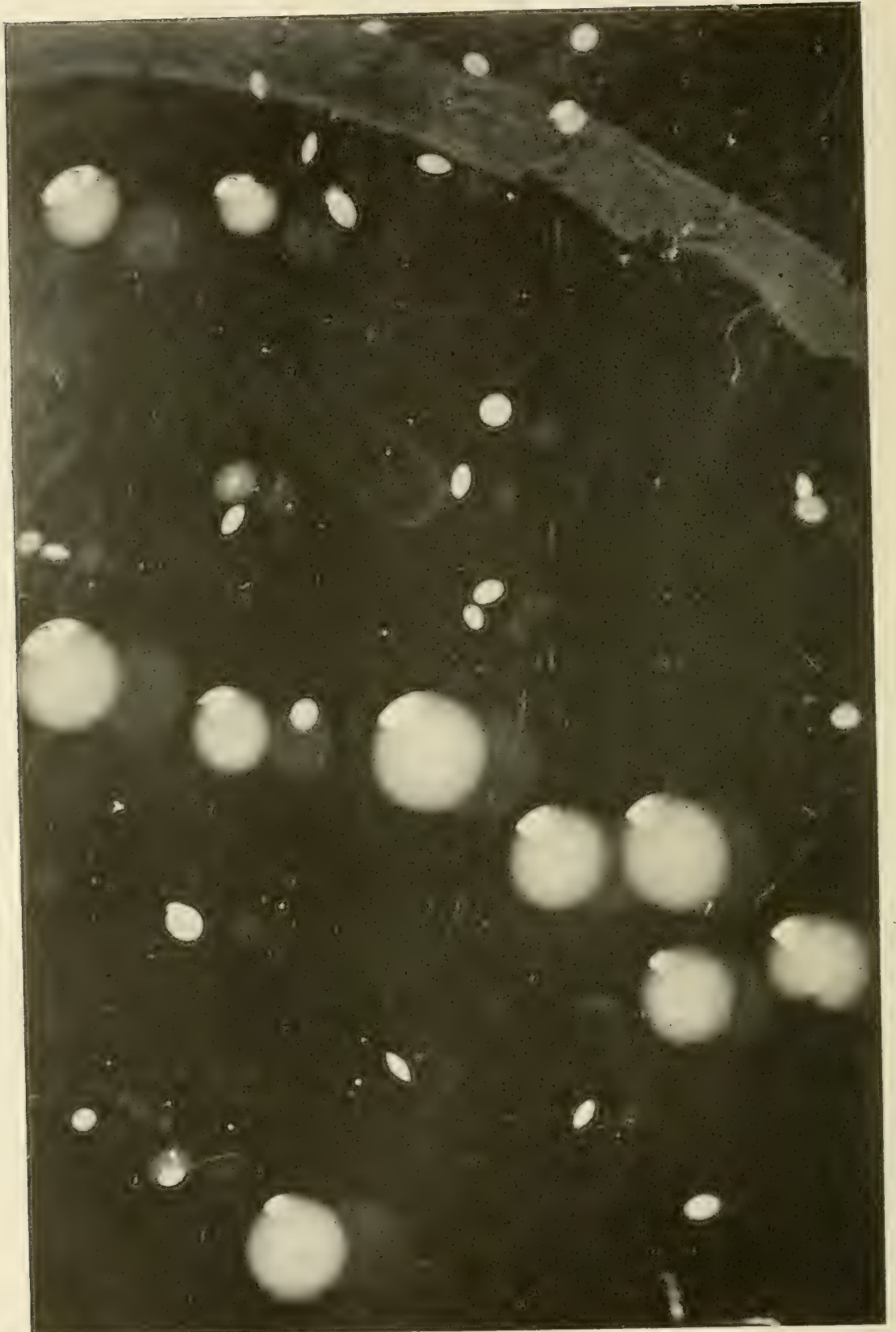

FIG. 71.-Surface and buried colonies of Bacillus tracheiphilus (R. 183) in a +15 agar poured $\neq$ plate. Surface wet-shining and smooth. Photographed by reflected light. The white spots are high-lights on a perfectly curved surface. $\times 10$. 
Does it ever come to the surface as an ooze on attacked plants. Contrast with pear blight (No. XII, Figs. 282 to 285). Make permanent slides. Stain with Ziehl's carbol fuchsin. Try at least two other stains.

Variability.-How long does an attacked plant live?

Have you seen any indications of immunity on the part of inoculated plants? of recovery? of slow development of the disease? Study this especially in squashes.

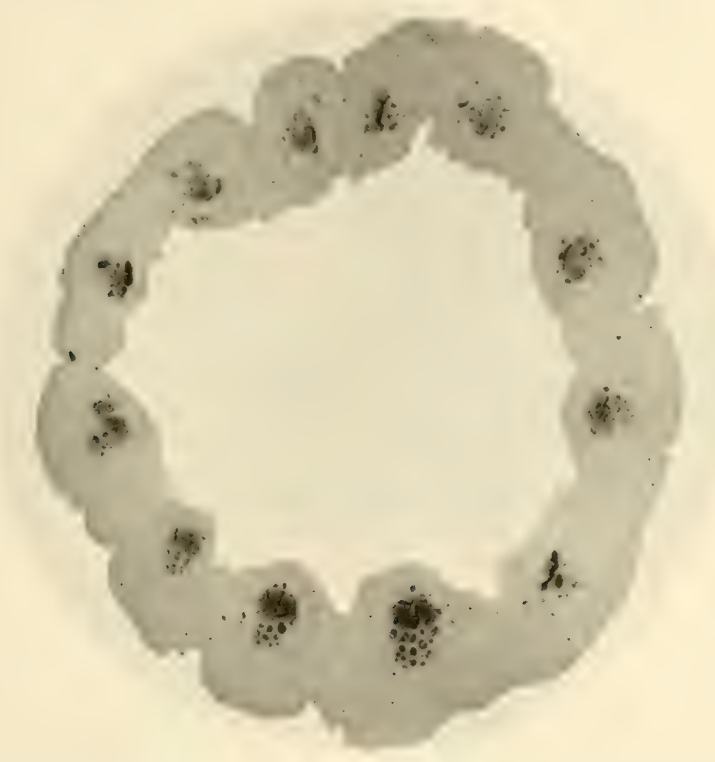

FIG. 72.-Cross-section of a squash petiole from one of my inoculated plants. Every bundle is oceupied by the bacteria which are stained. They are also to some extent in the parenchyma around the bundles. From a planar enlargement by the writer.

What effect, if any, does heavy vs. light watering have upon the progress of the disease? Why are not all susceptible cucurbits destroyed by this organism?

Transmission.-If time, season, and location permit, attempt transmission of the disease by insects. Try Diabrotica vitatta or Diabrotica 12-punctata collected from healthy plants. Starve 24 to 36 hours, feed on freshly wilting leaves for a short time only (early evening), then liberate (over-night, or a less time if they have bitten the plants freely) in insect cages con- 


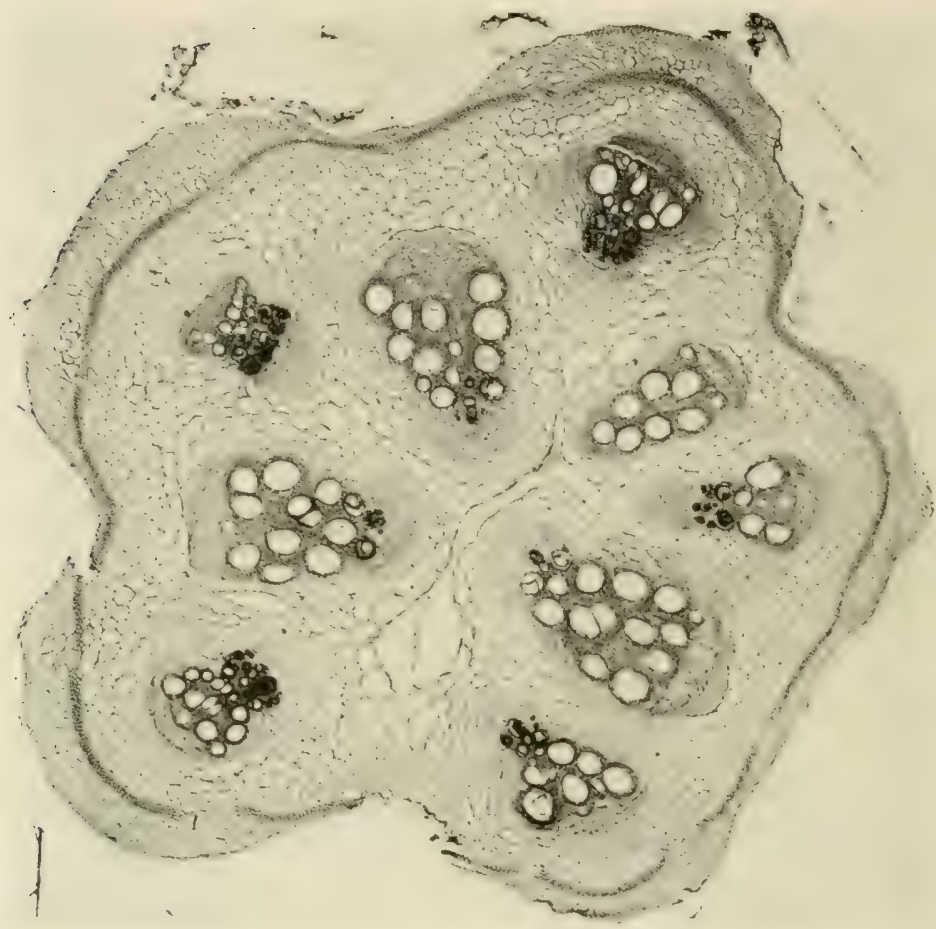

FIG. 73.--Cross-section of a cucumber stem (natural infection) showing the spiral vessels occupied in each bundle by an enormous mass of deeply stained Bacillus tracheiphilus, 1894.
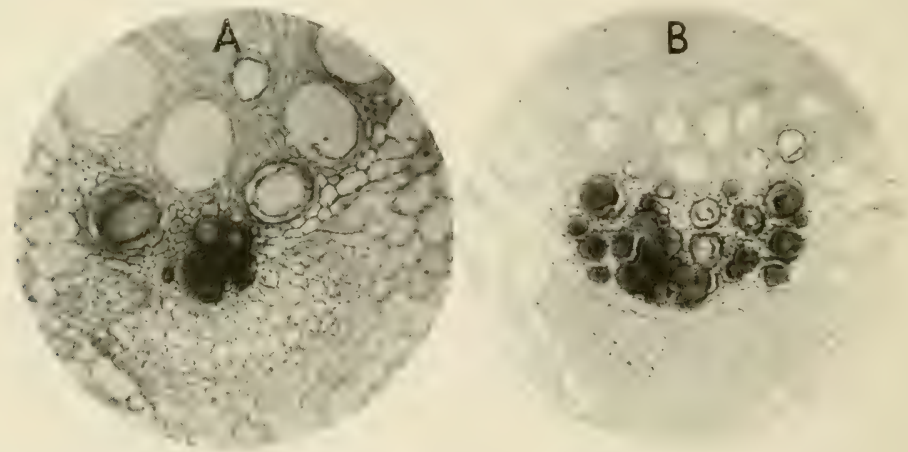

Fic. 74-Cross-section of a cucumber stem showing location of Bacillus tracheiphilus:

A. Enlarged view of an inner bundle from Fig. 73 , showing the bacterial mass confined to the spiral vessels with the exception of two neighboring pitted vessels. Around the spirals the bacteria have disintegrated the primary vessel parenchyma, forming a small cavity.

B. An outer bundle of Fig. 73. The occluded spiral vessels are surrounded by bacterial cavities; most of the pitted vessels are empty. Photomicrographed by the writer in 1894 . 


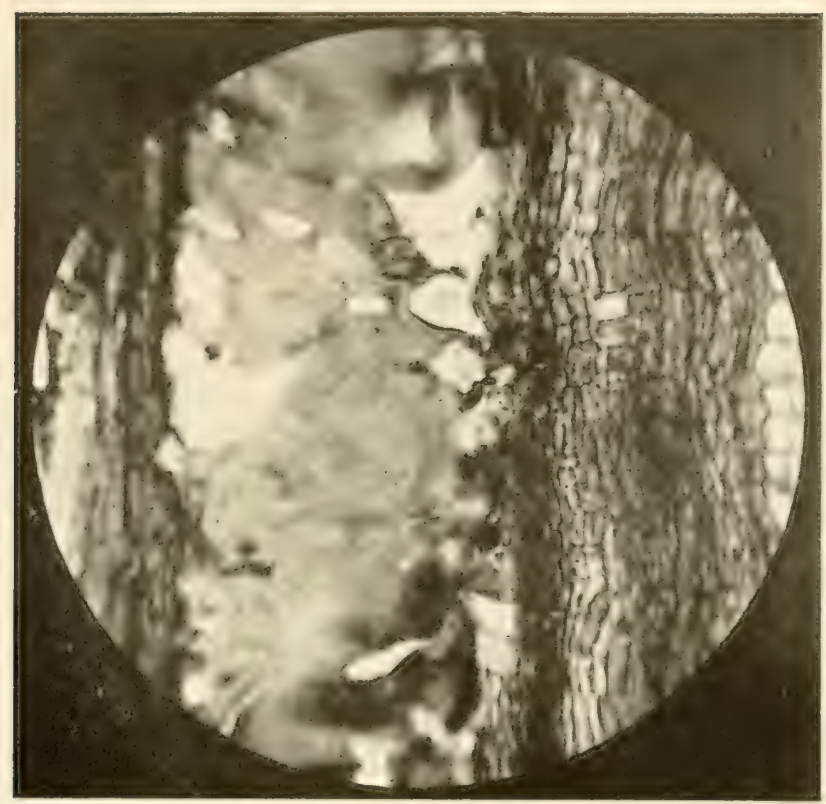

FIG. 75.-Longitudinal section of a cucumber stem, showing complete invasion and destruction of the inner part of a bundle by Bacillus tracheiphilus. Photomicrograph by the writer in 1894 .

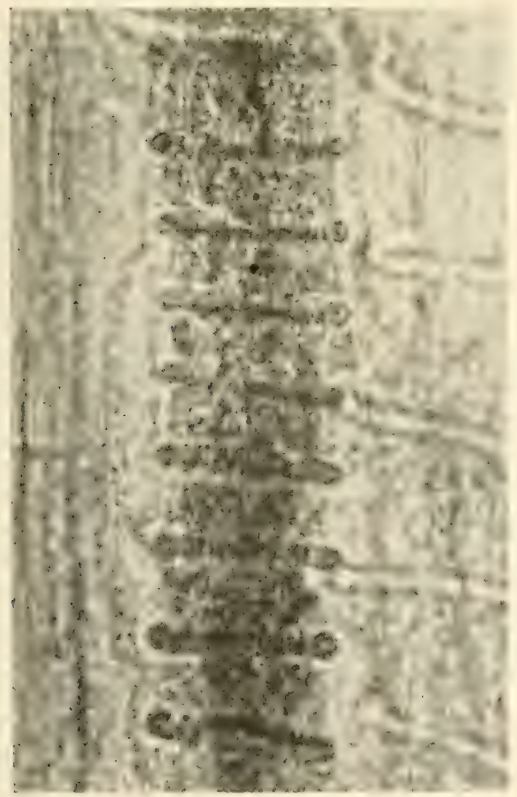

Fici。 76.

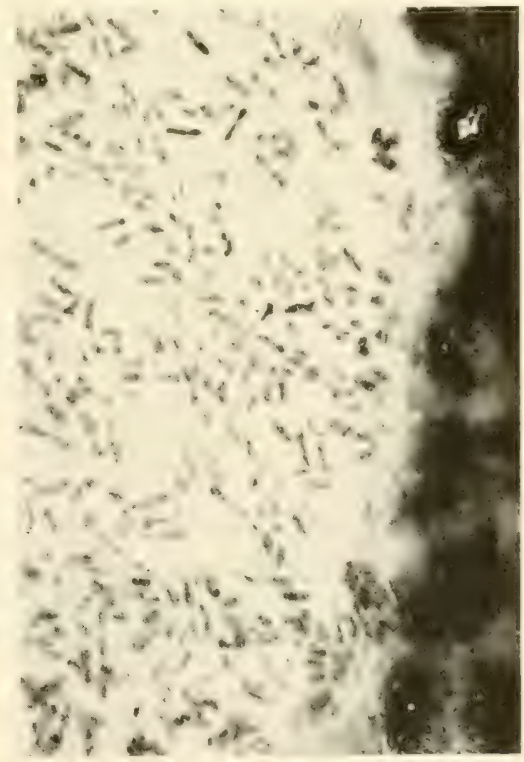

Firi, 7 .

FIG. 76.-Longitudinal section of a cucumber stem exposing two spiral vessels: one occupied by Bacillus tracheiphilus; the other empty. For details of the bacteria see a thinner section such as Fig. 77 or 78 .

Fig. 77.-Detail of Bacillus tracheiphilus from a cucumber vessel: Carbol fuchsin stain. 
taining thrifty cucumber plants bearing each about 6 or 8 leaves. Remove next morning. Repot the plants and watch closely. The squash bug, Coreus tristis, also may be tried (but only on well-grown plants because of the great injury done by this bug to small plants). Mr. F. V. Rand believes from his experiments that the squash bug does not carry the disease. For details on insect transmission see Part I, p. 30).

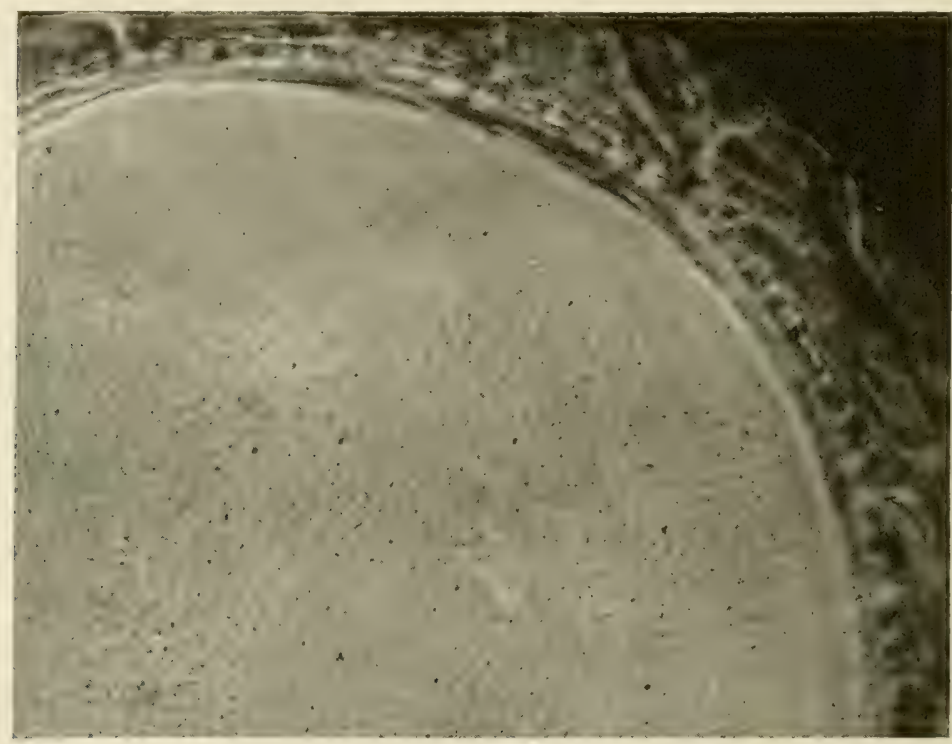

FIG. 78.-Cross-section of a cucumber stem such as Fig. 73 showing the individual bacteria in a small pitted vessel. This was photographed by the writer in 1894 from an unstained glycerin mount using a Welsbach light and an old Zeiss non-apochromatic objective the photographic focus of which was not the same as the eye focus. The duration of the exposure was about an hour and for this picture the negative was enlarged.

Where does the organism winter-over, i.e., in the soil? in hibernating beetles? or on, or in seeds? From its appearance on leaves in early summer first in places gnawed by Diabrotica, I have long believed that it winters over in the bodies of the cucumber beetles. (Nee recent observations and experiments by Frederick V. Rand, of my laboratory, in Journal of Agricultural Research, Vol. V, November 8, 1915, p. 257; Vol. VI, June 12, 1916, p. 417; Dept. Agr. Bulletin No. 828 (Professional Paper) 1920 and Phytopathology, Vol. 10, No. 4.) 
Can you obtain the disease by soil infection. (a) through wounded roots; $(b)$ through unwounded roots? Contrast with No. IV.

\section{LITERATURE}

For literature, etc., consult: Wilt of Cucurbits in "Bacteria in Relation to Plant Diseases," Vol. II, pp. 209-299, Carnegie Institution of Washington, 1911, and Ibid., Vol. I (1905) Plates 3 and 23, and Figs. 8, 9, 13, 14, 21, 47, 48, 68, 69. Also papers by Rand, Rand and Enlows and Rand and Cash.

The first paper on the subject was read by the writer in August, 1893, at a meeting of the American Association for the advancement of Science (Bot. Gaz., Sept., 1893). This was my first contribution to the literature of bacterial diseases of plants. The name Bacillus tracheiphilus was first published in 1895 in Centralb. f. Bakt. u. Par., II Abt., I Bd., 1895, p. 364.

\section{THE BLACK ROT OF CRUCIFERS}

Type.-This is a common vascular disease of cabbage, cauliflower, kohlrabi, kale, rape, turnips, and mustard. Often whole fields are destroyed (Fig. 79). Dr. F. C. von Faber also found

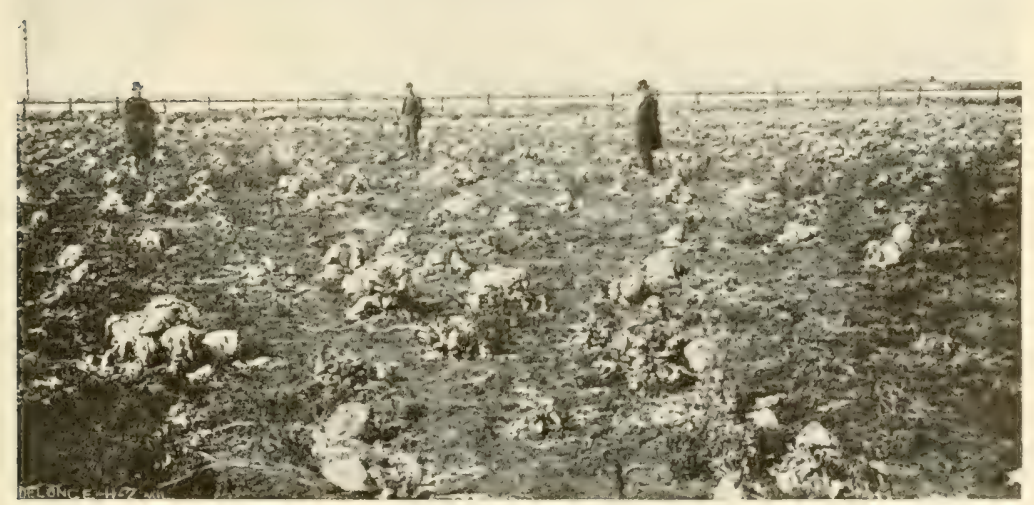

Frg. 79.-Cabbage field in Wisconsin, showing all of the plants attacked and destroyed by Bacterium campestre. Not a head was harvested. (After Russell.) 
it in Germany on winter stock (Matthiola incana). Recently Miss Nellie A. Brown, of my laboratory, has found it to be the cause of a serious disease of the highly prized Chinese cabbage (Brassica petsai L. H. Bailey) grown in the United States. There is no reason, however, to suspect that the disease was imported from China since it is everywhere in the United states. The writer did not succeed in inoculating this disease into beans. Infection occurs chiefly through the water-pores

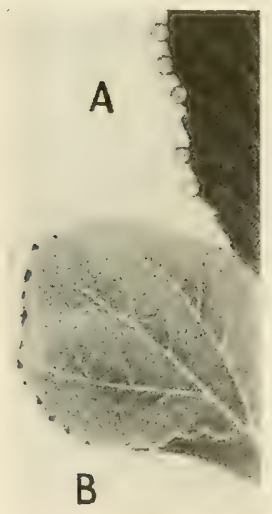

FI(i. $\$$ So

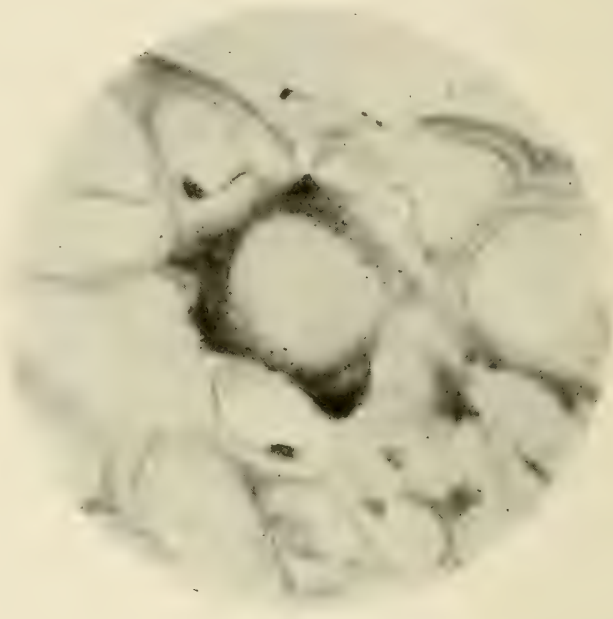

Fig. 81 .

FIG. 80.-Early stages of water-pore infection on inoculated cabbage leaves: $A$, extrusion of fluid from the water-pores leading to infection; $B$, appearance of a leaf margin about 3 weeks after water-pore infections.

Fig. 81.-Vertical section through water-pore region of a cabbage leaf showing bacteria under a stoma.

on the leaf serratures (Figs. 80 to 84 ), but may occur also through wounds (Fig. 85). Sometimes the leaves wilt, but wilting is less conspicuous than in the cucurbit wilt (No. I). In the attacked leaf parts there is a conspicuous brown venation (Figs. 84, 85) often in a yellow parenchyma. The stem bundles are also browned (Figs. 86, 87). It is not a soft rot, the attacked leaves becoming dry and leathery rather than wetrotten, unless soft-rot parasites are also present. The black 
rotoccurs almost all over Europe and North America, and probably in many other parts of the world. It is said to be common in Japan (Gentaro Yamada) and to occur in the Philippines (Reinking). It was first reported from Europe in 1900 by an American (H. A. Harding).

Cause.- This disease is due to Bac'erium campestre (Pammel) EFS. The organism is a moderately growing, non-viscid, noncapsulate, yellow, non-sporiferous, nitrate-reducing, slowly

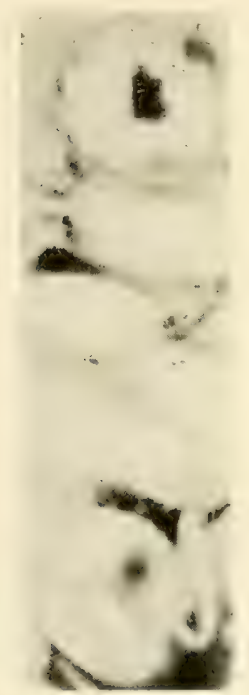

FIG. 82 .

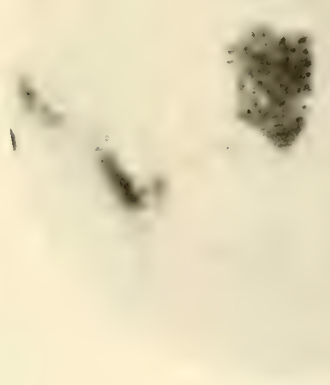

Fis. 83.

Fig. 82.- Section of a cabbage leaf-tooth parallel to the surface, showing two water-pores; one empty, the other blocked by bacteria.

FIG. 83.--Upper stoma of Fig. 82, enlarged to show more distinctly the rods of Bacterium campestre blocking its mouth.

liquefying, non-gas-forming, casein-precipitating (by a lab ferment), aërobic, rod-shaped, or slightly curved or club-shaped schizomycete, motile by means of a polar flagellum (Fig. 88), and forming on the surface of agar-poured plates small circular or slightly irregular, wet-shining colonies (Figs. 89 to 91) which are pale at first but become distinctly yellow (not orange). Filamentous chains occur in sugar-rich media. It resists drying 12 months or more under farorable conditions (Compare with Bacillus tracheiphilus, No. I, and Bacillus carotovorus, No. VI, which from bouillon cultures scarcely resist drying 
that number of minutes), and it does not lose its virulence readily. Probably it is often carried on some of the seeds from diseased plants, and whole fields may become infected in this way, directly or indirectly. ${ }^{1}$ Once present in a field, cabbage insects greatly favor its distribution, especially by gnawing

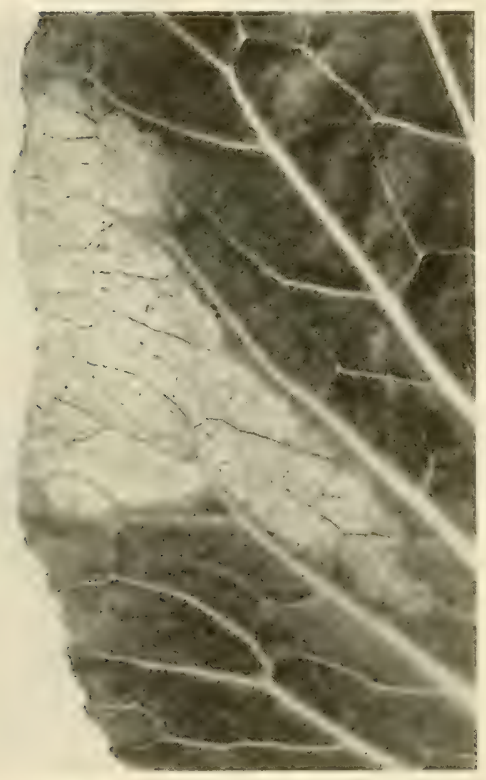

FIG. 84 .

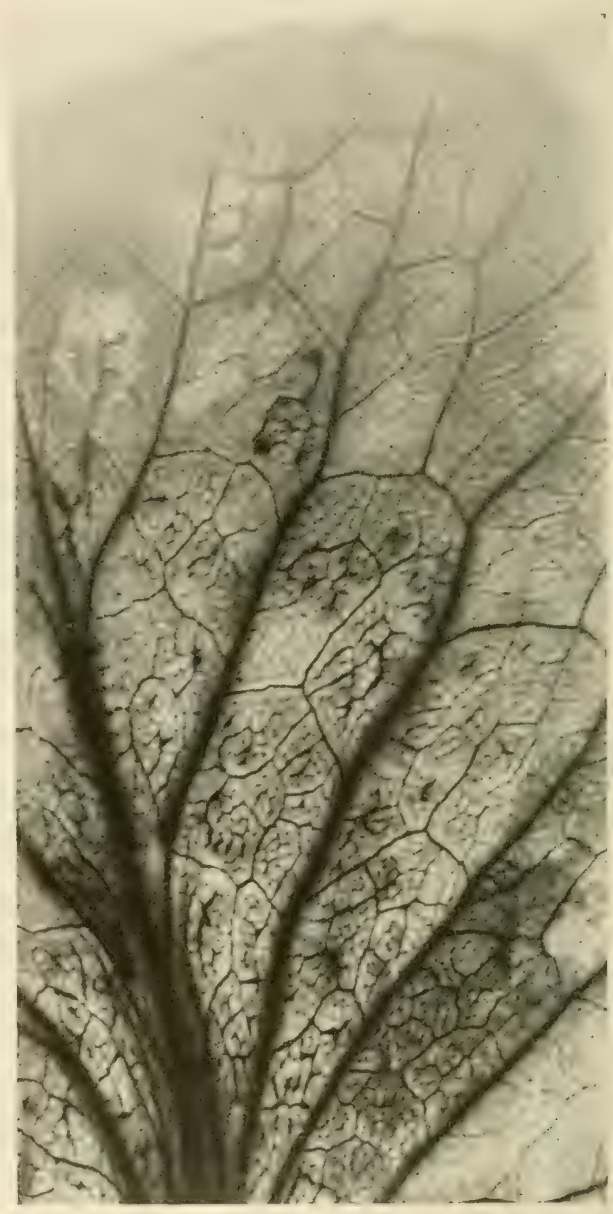

FIG. 85.

FIG. 84.-Water-pore infections on a cabbage leaf, 2 months along. Pureculture inoculation by the writer. Bacterial movement downward in the vessels.

FIG. 85. - Central part of a cabbage leaf showing brown venation due to Bacterium campestre. The inoculation was on a leaf lower down. Bacterial movement downward in vessels of the inoculated leaf, then upward, first in vessels of the stem and afterward in those of this leaf. District of Columbia, 1897.

into diseased leaves and then crawling over healthy ones.

${ }^{1}$ Geo. K. K. Link has reported to me verbally a case observed by him in Southern Florida on new land in the spring of 1919 where 60 per cent of 100 acres of cabbages was destroyed by this disease, the total shipments amounting to only 40 car-loads. 
Technic.-The organism is easily isolated on agar-poured plates inoculated from suitable material, e.g., cabbage petioles. There are no special difficulties except that sometimes heavy sowings are necessary when the organism has been in the tissues a long time. If difficulties are eneountered, the second method described under No. I may be tried. The bacteria grow readily on all ordinary culture-media; steamed potato is a good substratum.

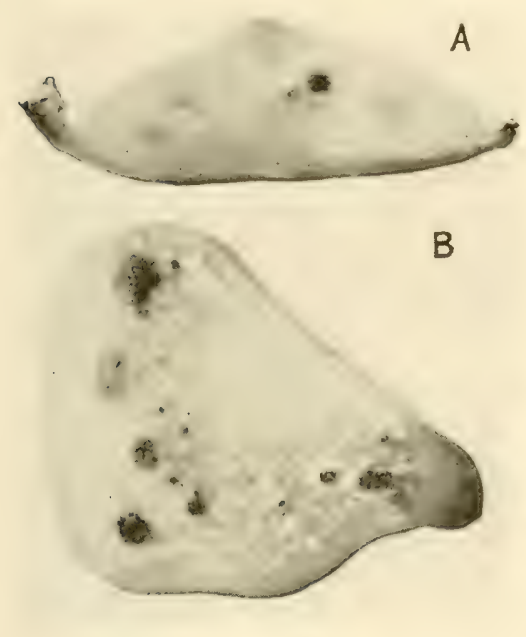

FIG. 86 .

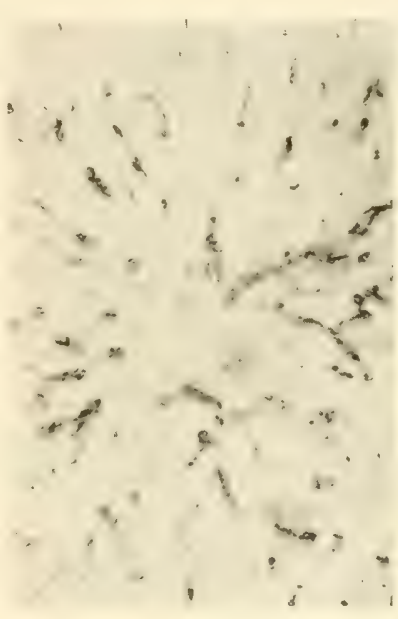

FIG. 87.

Fig. 86. - A. Cross-section of a cabbage petiole, showing only two infected and blackened bundles, and correspondingly only a small area in the center of the blade of the leaf was diseased.

$B$. Cross-section of a cabbage petiole showing every bundle blackened by Bacterium campestre, and correspondingly all of the leaf-blade was diseased. Same series of inoculations as $A, 1915$.

Fig. 87. - Section of the fleshy part of a kohlrabi showing black bundles due to Bacterium campestre. Collected by the writer in Florida in 1904.

For inoculation purposes use young plants of cabbage, turnip or cauliflower. The same hothouse cultural directions apply as for cucumbers, etc., under No. I.

For contrast the resistant Houser cabbage may be used. Several hundred plants should be provided, and they must be kept free from insects and molluses. The seed should be sown at least six weeks before the plants are needed. 
Inoculate by needle-pricks on the under surface of the fleshy petiole, some petioles on one side only, some on both sides and

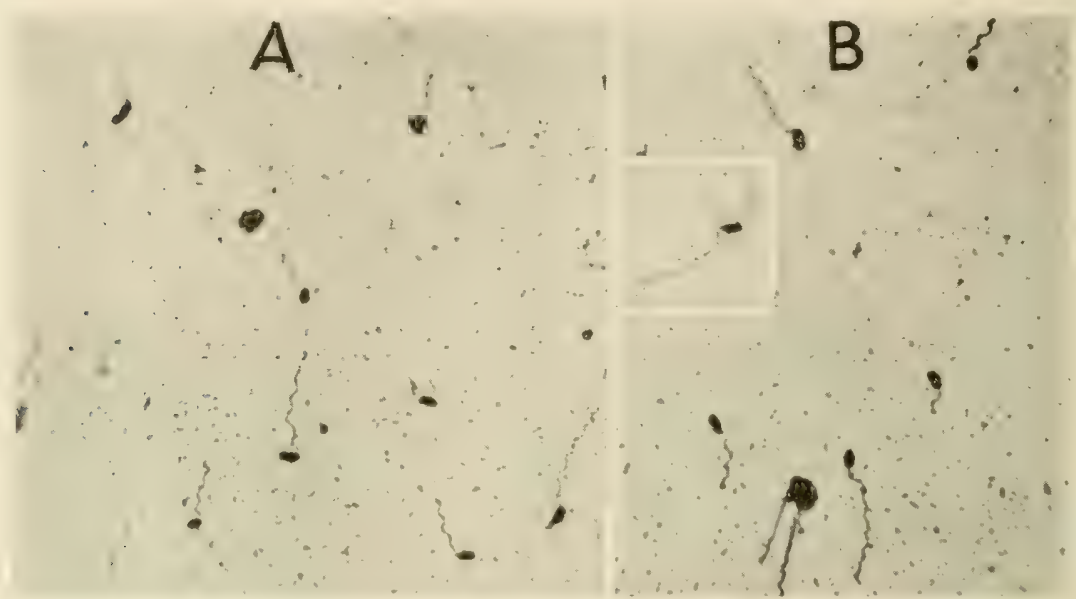

FIG. 88. - A, B. Flagella of Bacterium campestre. Stained by van Ermengem's silver nitrate method. $\times 1000$.

A
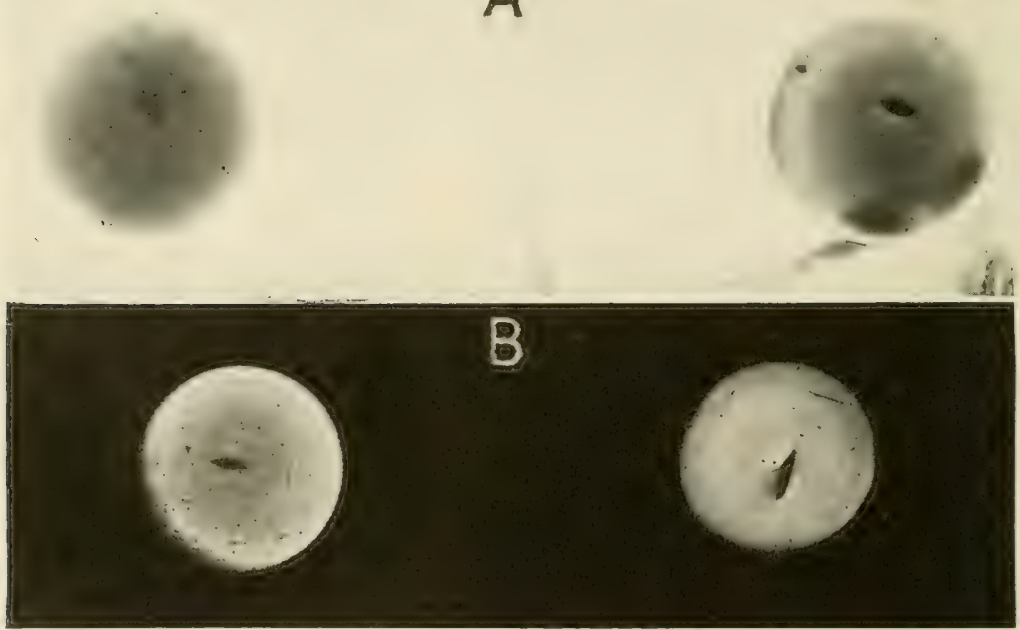

FIG. 89.-A, Surface colonies of Bacterium campestre on nutrient agar. Plated from 4 D.C. rape. Time, 6 days. Photo Feb. 6, 1919. $\times 10 . \quad B$, The same by oblique transmitted light.

in the middle, setting the needle deep enough to enter the bundles. Other plants should be inoculated in the upper soft stem 


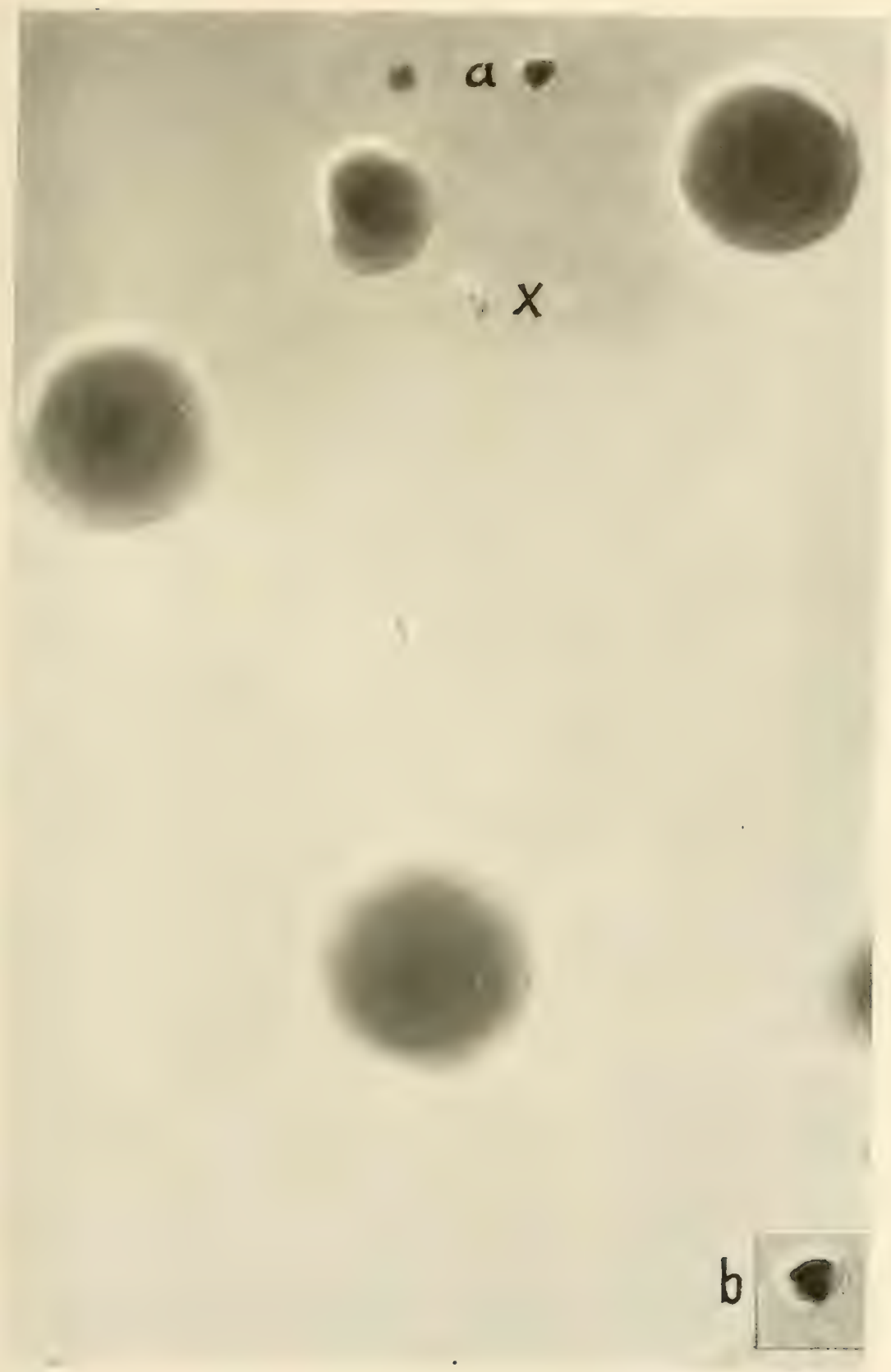

FIG. 90.- Surface and buried colonies of Bacterium campestre (New York isolation of 1908) at end of 10 days in +14 beef peptone agar. Crystal at $x$. Colonies coming to the surface at $a, b$. Photographed February 11, 1919, by direct transmitted light. $\times 10$. Tested on Crucifers Feb. 9, 1919. 


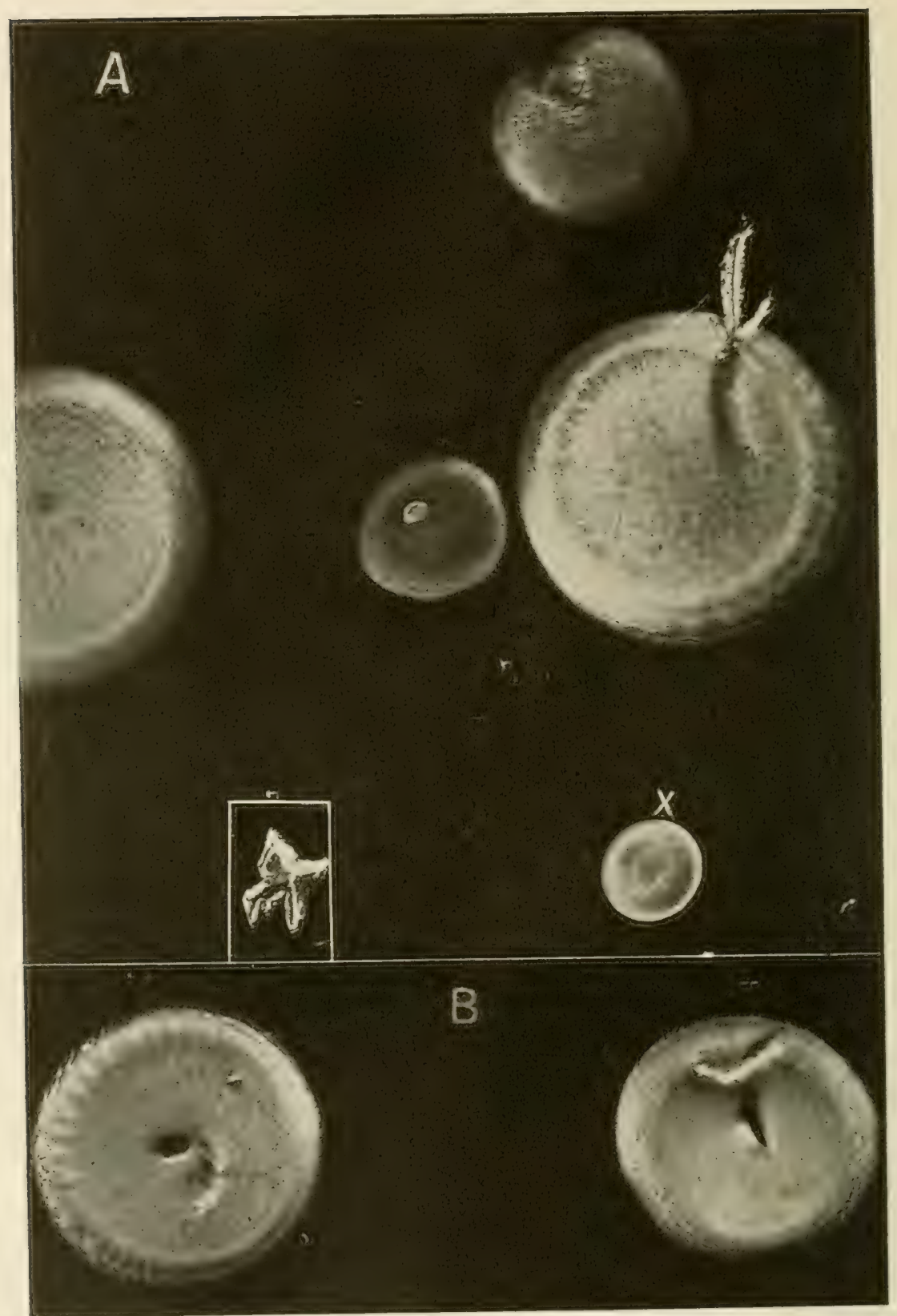

FIg. 91.-A, B. Surface and buried colonies of Bacterium campestre (isolated from D. C. rape) at end of 13 days on +14 beef-peptone agar plates. Four crystals are present, 3 in colonies. $X$ is a buried colony coming to the surface. Photographed by transmitted oblique light February 13, 1919. $\times 10$. 
immediately under the origin of a leaf; still others in the parenchyma of the leaf-blade-some at the apex, others on one side midway down. Select leaves several removes from the lowest,

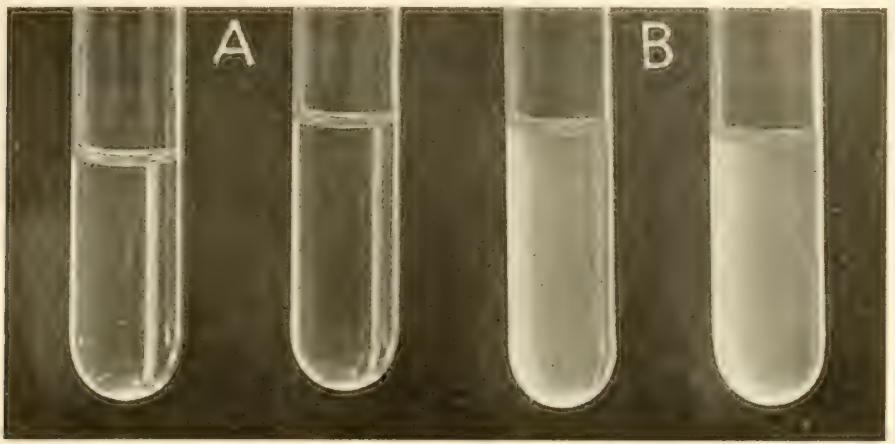

Fig. 92,-Cultures of Bacterium campestre (B), and Bacterium phaseoli (A) in Dunham's solution at end of 4 days.

otherwise the leaf may be unjointed and thrown off before stem-infection has occurred.

The plants should be well watered and growing freely for best results, which should begin to be visible in 10 days, more or less, from the time the punctures are made.

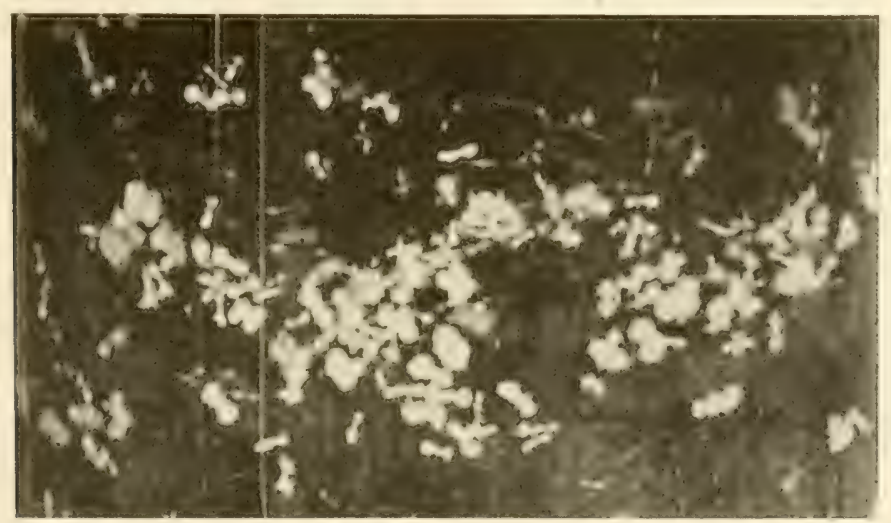

Fik. 93.- Sheaf-like tyrosin erystals in a 2-months 12-day old litmus-milk culture of Bacterium campestre. $\times 6$.

For water-pore infections confine young plants in an infection cage in a cool place and spray freely with a water suspension from a 48-hour agar or potato-streak culture. Keep the plants 
in the cages in moist air for 30 hours and water freely. Examine the plants morning, noon and evening, and if the leaves look dry atomize sterile water on them and flood the soil around the

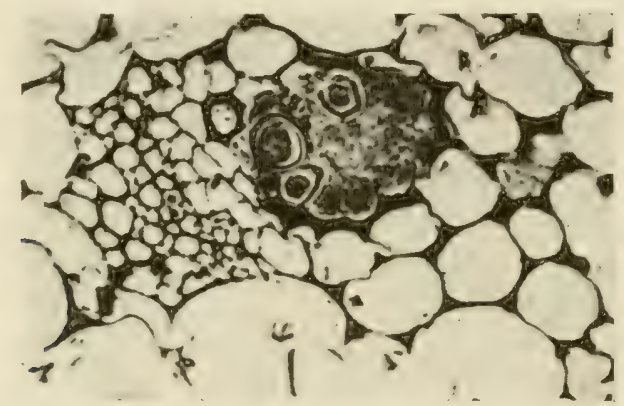

FIG. 94--Cross-section of a cauliflower stem showing a cavity in a small bundle occupied by Bacterium campestre.

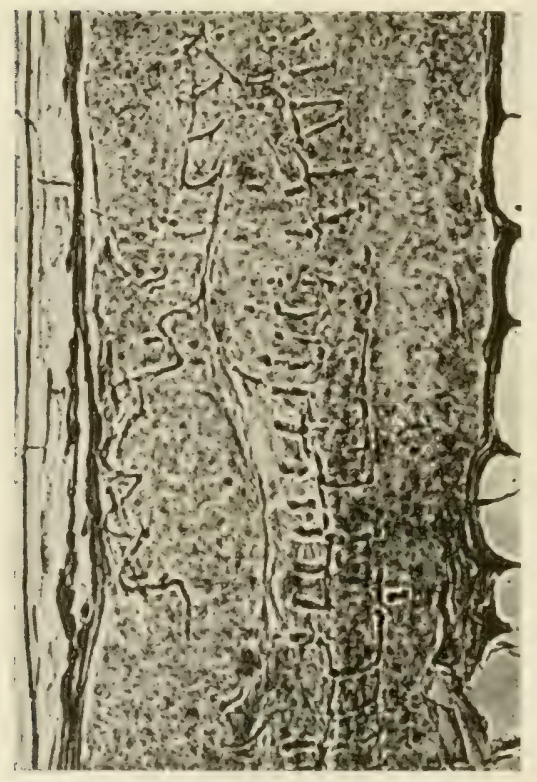

FIG. 95.-Longitudinal section of a cauliflower bundle, similar to Fig. 94 , showing entire disorganization due to Bacterium campestre. cages. Examine the leaf serratures at least once every 3 days until signs appear.

Try soil infections through broken roots: $a$, on very young plants; $b$, on plants having stems $1 / 4$ to $1 / 2$ inch in diameter. What do you conclude?

\section{Determine}

For the ORGANISM. Morphology.-Size in microns, form (straight rods, curved rods, clubshaped rods), aggregation of elements, i.e., chains, filaments, etc., motility on margin of hanging drop, absence of endospores, presence and distribution of flagella (Löffler's stain). Is there ever more than one flagellum? Try Gram's stain. Look for involution forms. Use various media. 'Try cultures of different ages. 
Cultural Characters.-Thin-sown agar plates (Figs. 89 to 91), streaks and stabs; gelatin, ditto. Beharior on steamed potatocylinders standing in water (eontrast with No. III). Why is the growth on potato so prolonged? Test for reducing sugars. Growth in Dunham's solution contrasting with Bacterium phaseoli (Fig. 92). Behavior in bouillon, nitrate bouillon, Cohn's solution, Uschinsky's solution, milk, lavender-colored litmus milk (Fig. 93), peptone water in fermentation tubes with all the common sugars and alcohols. Can you find any that will

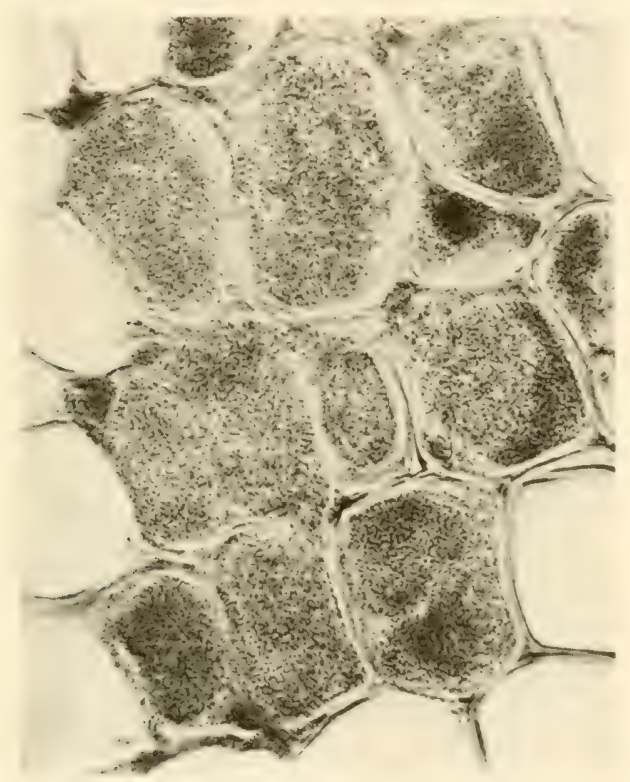

Fig. 96.-Cross-section of the root of an inoculated turnip showing Bacterium campestre occupying a small bundle. Cell walls swollen. $\times$ about 600 .

induce it to grow in the closed end of a properly constructed fermentation tube? "What is the nature of the yellow pigment"? Try extraction with solvents - alcohols, ethers, chloroform, benzine, benzole, carbon bisulphide, etc.

Non-nutritional Environment.-Can you obtain growth in bouillon at $9^{\circ} \mathrm{C}$. and at $37^{\circ} \mathrm{C}$.? Determine maximum temperature for growth, and minimum; resistance to dry air (on cover slips, or silk threads, and on baked turnip or cabbage seed); effect of chloroform in bouillon (contrast with No. III); killing 
power of sunlight (in thin-sown agar plates); effect of weak acids and alkalis; of salted bouillons (contrast with Nos. I and III). Vitality on culture-media.

For the DISEASE. Signs.-Determine time between inoculation ( $a$, by needle pricks - $b$, through the water-pores) and first local signs of the disease. In case of plants inoculated on the leaf-blade, how long before signs appear in other leaves?

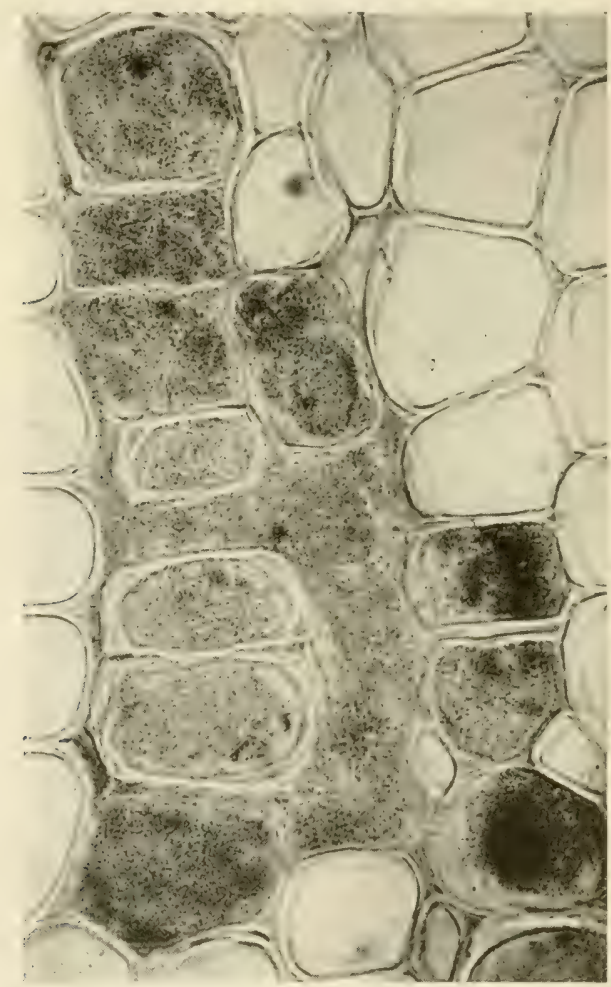

FIG. 97.-Like Fig. 96, but shows beginning of a cavity. $\times 500$.

Contrast inoculations on plants growing rapidly and slowly. In case of inoculations on the petiole, how long before signs appear in its blade? After the infection (blackening) of the water-pore region, how long before the veins of the leaf begin. to show the dark stain? Describe the disease.

Histology.-Determine by sections the occupation of the substomatic region in the infected leaf-teeth. Can you trace 
the organisms from the water-pore region into the veins of the leaf? Try microtome sections. Make preparations showing the bacteria in the vessels of the leaf-blade. How soon after water-pore infection can they be detecter in the reins of the leaf"? Have you observed them forming cavities in the leaf-parenchyma around the bundles? Why do they not produce a soft rot of the leaf? Does the organism ever enter the leaf through ordinary stomata? Why not? How many centimeters in advance of the brown stain can you trace the bacterial invasion downward in the leaf". Have you seen any indication that special areas of leaf venation anastomose with spec:al leaf-traces of the petiole?

Observe in stems of cabbage an increase of chlorophyll around the diseased bundles. What causes it? (Compare with leaf spots of No. VIII and with tumors of No. XIV on Paris daisy).

Where is the brown stain located? Can you reproduce it in culture-media? What is its nature? Is it a humus compound?

Stain sections of infected leaf and stem, using nigrosin, basic fuchsin, or iron hematoxylin. Make permanent preparations.

Do the infected vessels contain masses of granules independent of the bacteria? What are these? Are they Löhnis' granules? Cut the vessels longitudinally.

What is the action of the organism on the tissues? Is there a toxic action distinct from a solvent one? Is the cellwall destroyed? What then becomes of it? Consult Figs. 94 to 99.

Can you find the organism in the roots of cabbage or cauliflower? Is it commonly a root-infection? Does the organism commonly ooze to the surface of attacked plants? (Compare with Nos. VIII, X, XI, XII and XIII.)

Variability.-How long does the attacked plant live? Compare early and late infections; inoculations on slow-growing pot-bound dwarfed plants with those on rapid-growing plants. Study the functioning of water-pores as related to infection. 


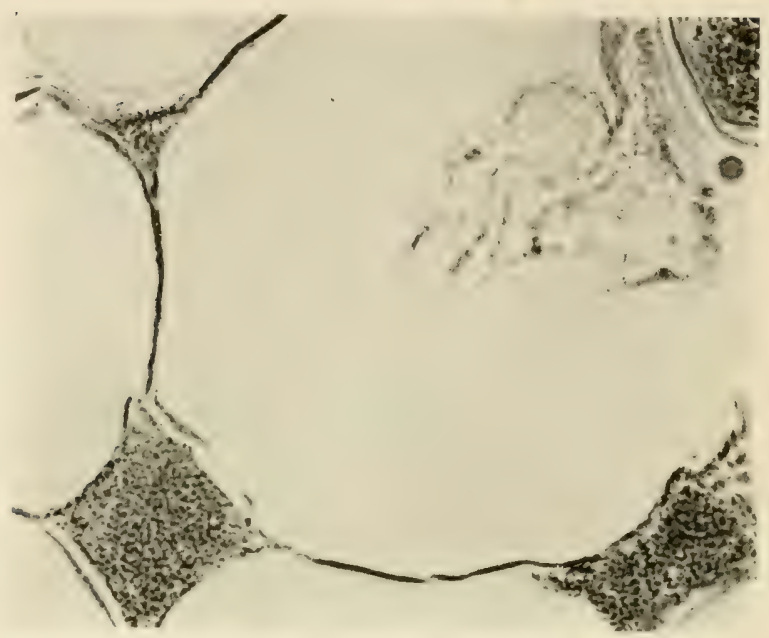

FIG. 98.-Cross-section of a turnip root showing a parenchyma cell with Bacterium campestre filling the intercellular spaces. $\times 1000$ circa.

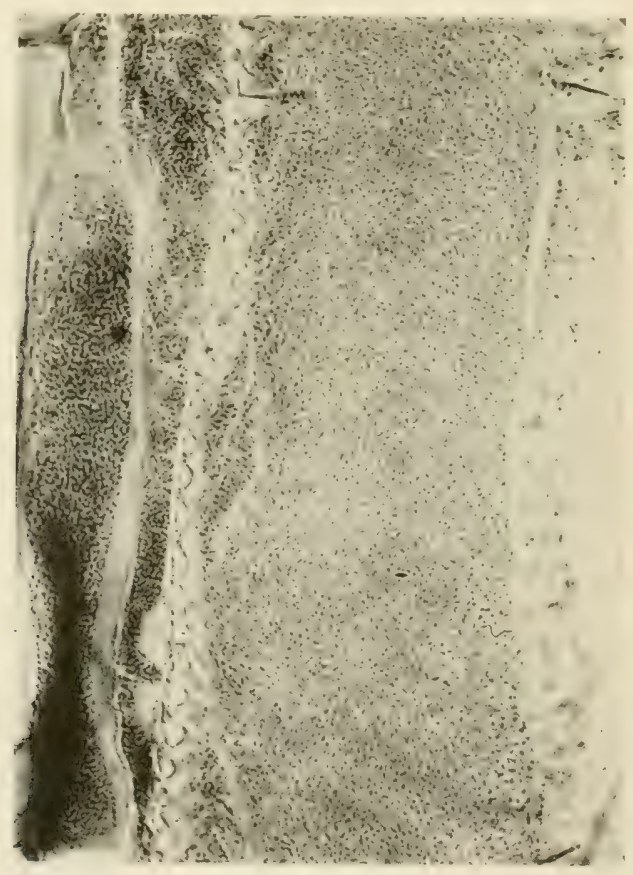

FIG. 99.-Longitudinal section of root of an inoculated turnip showing Bacterium campestre occupying a vessel and cells at the left. $\times$ circa 800 . The inoculation was made on the leaves by needle pricks. 
Transmission.-Greenhouse slugs may be used, feeding them first on infected leaves and then on sound plants. Also larvae of the cabbage butterfly. Can the disease be spread by aphides? If opportunity exists, collect seeds from diseased plants and try to isolate the organism from them (rather difficult) and to get infected seedlings from them. Why should a seedsman collect and disseminate seeds from st ock he knows to be diseased?

The writer has seen a serious outbreak of the disease on parts of a cabbage field that received as a manure the diseased refuse from a storehouse in which brown-rotted cabbage had been wintered over (see No. VII). He has seen an entire crop ruined and the organism introduced into the soil of a field previously free from it by setting it out with plants from an infected seed bed. (See U. S. Dept. of Agr., Farmers' Bull. No. 68.)

\section{MEANS OF PREVENTION}

Use of seed derived from healthy plants. Seed beds on land free from the disease. Care in transplanting that roots shall be wounded as little as possible.

\section{LI'TERA'TURE}

For literature, etc., consult: Black rot of Cruciferous Plants in "Bacteria in Relation to Plant Diseases." Vol II, pp. 300-334, Carnegie Institution of Washington, 1911. See also Ibid., Vol. I, Figs. 4, 5, 6, 7, 18, 19, 76, 77, 78, 79, 87, 115, 116, 117.

The first important paper on the subject was published in 1893 by Prof. L. H. Pammel (Bot. Gaz., Jan., 1893). The organism was first named Bacillus campestris by Pammel in 1895 in Bull. No. 27, Iowa Agr. Col. Exp. Station, pp. 130-134.

The last paper is by Walker and Tisdale: Observations on seed Transmission of the (abbage Black Rot Organism. Phytopathology, Vol. 10, No. 3, March, 1920, pp. 175-177.

These authors have proved introduction of the disease into Wisconsin on seed imported from north Europe. They have also established that the disease can be reduced to negligible proportions by soaking the seed for 30 minutes in 1-1000 mereuric chlorid water. 


\section{STEWART'S DISEASE OF MAIZE}

Type.-This is a vascular disease confined principally to sweet corns, especially those rich in sugar and ripening early, but it has been seen by the writer upon several varieties of field corn. The foliage shrivels gradually, the lower leaves usually, first (Fig. 100); the male inflorescence develops pre-

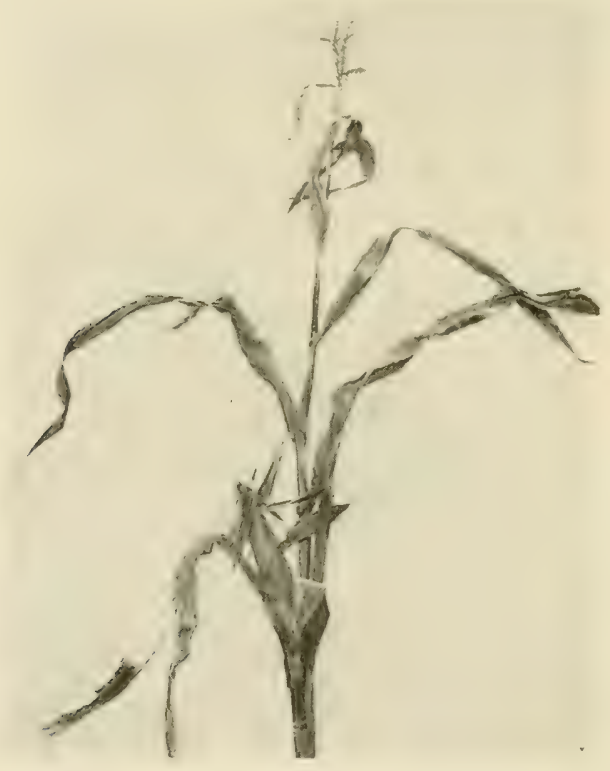

Fig. 100.-Large sweet-corn plant destroyed by Aplanobacter stewarti. A natural infection. Bundles of the stem occupied by the yellow slime. District of. Columbia, 1903.

maturely and is white (Fig. 101); and on cross-section or longitudinal-section of the stem a yellow slime oozes from the vascular bundles (Figs. 102 and 10:3); stooling also sometimes occurs (Fig. 104). Infection takes place principally in the seedling stage through stomata and is greatly farored by actively functioning water-pores situated on the young leaf-tips. The 
organism is extremely abundant in the vessels and is much inclined to come to the surface of the husks through stomata (Figs. 105, 106, and 107); thus flooding the kernels, but it may occur also inside the kernels, particularly at their junction with the cob (Figs. 108 to 111). Some of the infected plants are destroyed in the seedling stage (Fig. 112), but many of them reach a height of several feet before showing secondary signs (Fig. 113). It is a typical example of a seed-borne infection. Nothing is known as to the occurrence of this disease outside of the United States. Miss Doidge has not seen it in South Africa. The exact distribution of the disease in the United States is unknown but it oceurs from New York and Maryland to California.

Cause.-It is due to Aplanobacter stewarti (EFS) McC. This is a non-motile, non-flagellate, non-sporiferous, inadhesive, or moderately viscid, yellow, slow-growing, non-liquefying, non-milk-curding, non-nit rate-reducing, non-gas forming, nonstarch-consuming, chloroform-tolerant, sodium chlorid-tolerant, aërobic, rod-shaped schizomycete, growing on the surface of agar-poured plates in the form of small, flat, circular or nearly circular pale colonies which become yellow with age. ${ }^{1}$ It reddens lavender-colored litmus milk slightly and does not grow in Cohn's solution. Its growth on steamed potato is thin and soon at an end (contrast with Nos. II, VIII, or X). Why is this? In Dunham's solution containing methylene blue the bacterial precipitate should be blue.

Its minimum temperature in +15 peptone beef bouillon is above $9^{\circ} \mathrm{C}$. At this temperature there was no clouding in 14 days. The checks at room temperature clouded heavily the second day and formed a pellicle the third day. It is not sensitive to dry air, and like No. II retains its vitality and its virulence for a long time. It is rather tolerant of weak organic acids. On the kernels the majority of the bacteria are destroyed by exposure for 15 minutes to $1: 1000$ mercuric chlorid water:

2. Sometimes the surface colonies on agar have depressed centers (Fig. 114B). No mention was made of these in Volume III of my monograph because I was not then certain that they belonged in the life-cycle of this organism, but recently Lucia McCulloch, of my laboratory, has proved them to be infectious. She has also proved my former statements respecting the motility of this organism to be incorrect (see Phytopathology, August, 1918, p. 440). 

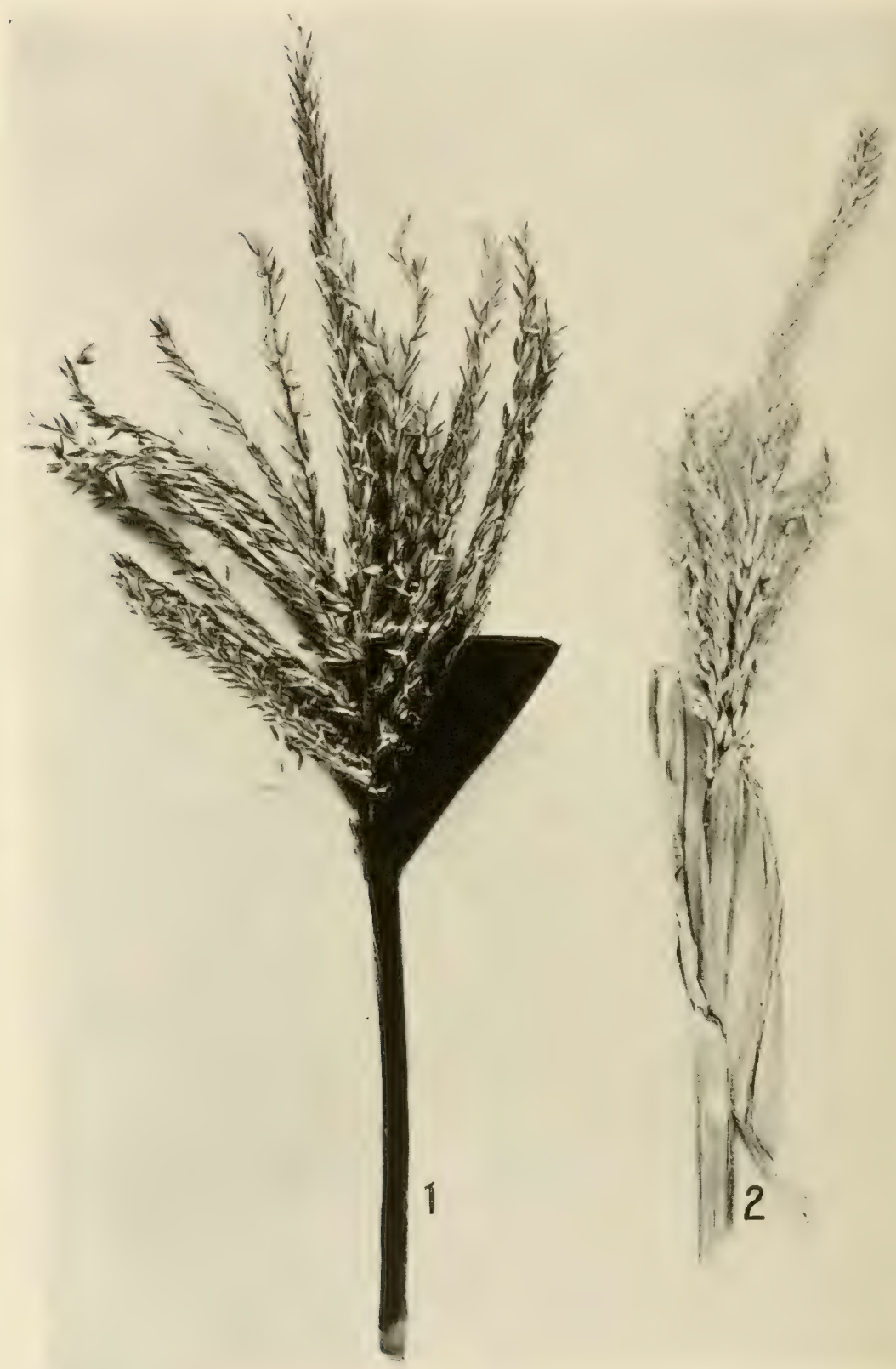

Fig 101-Blue Squaw flint corn from a field on Arlington Farm, July 16, 1015 (an early sort): No. 1, slightly diseased; No. 2, badly diseased, showing white top (prematurely dead male inflorescence) and dry pale leaves, due to Aplanohacter stewarti. Photo by James F. Brewer. 
first plunge the seeds momentarily into alcohol, rinse them very lightly and dry quickly or plant at once. Why this last airection? Why also first into alcohol? It fills the infected rascular bundles with a yellow slime which oozes on crosssection (unless the plants have been frosted). Why not then?

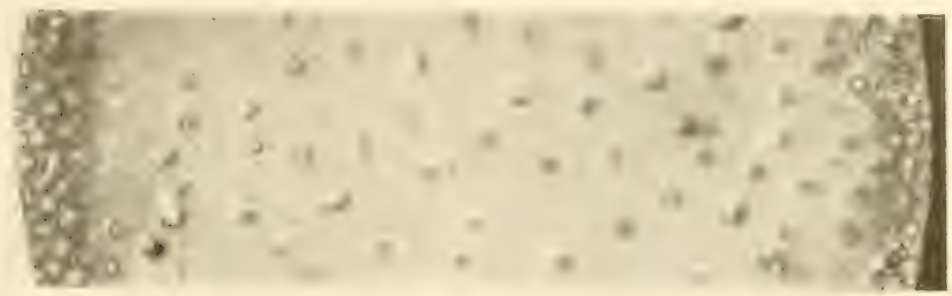

FIG. 102.-Cross-section of a diseased sweet-corn stalk showing Aplanobacter stewarti oozing from the bundles. Planar enlargement.

Technic.-Isolations may be made from externally sound upper internodes of the maize stem, by the first method described under No. I. Often pure cultures may be obtained directly from the cut stem by streaks on steamed potato or

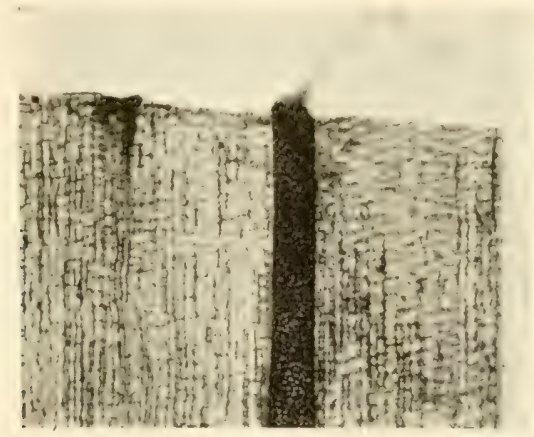

FIG. 103.-Water mount of a sweet-corn stem in longitudinal scetion showing A planobacter stewarti oozing from a vascular bundle like smoke from a chimney. (After F. C. Stewart.)

nutrient agar if the surface sterilization has been thorough, but if so made, subsequently they should be plated out. It is more difficult to isolate from the interior of kernels. Such kernels should be soaked in 1:1000 mercuric chlorid water for 30 to 60 seconds, to inhibit, rather than to kill, surface 
organisms. The bases may now be removed, crushed in a sterile mortar and allowed to soak in bouillon for some hours before plates are poured. Some of the latter should be sown heavily. Keep the tubes and pour a second set of plates next day; pour

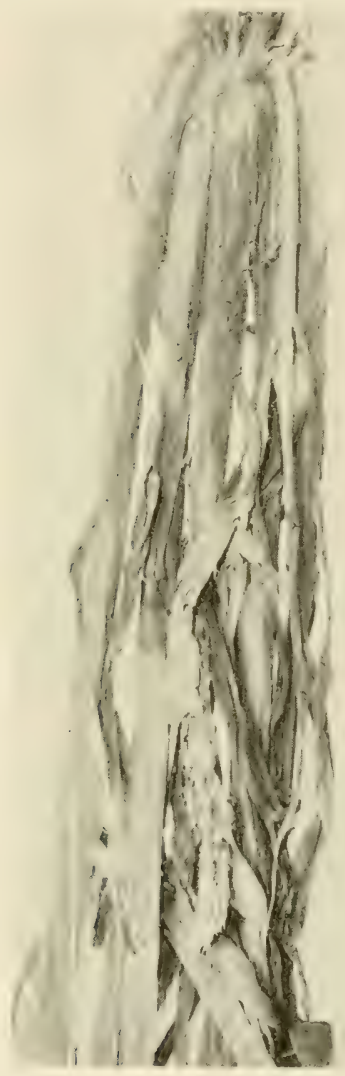

FIG. 104 .

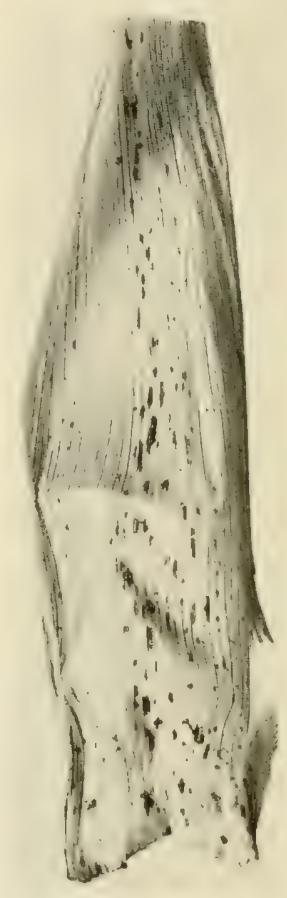

FIG. 105.

FIG. 104.-Corn plant showing very pronounced dwarfing, premature development of male inflorescence and stooling due to A planobacter stewarti. Vessels full of the yellow slime. From Chula Vista, California, in 1915.

FIG. 105. - Spots on inner husk of a sweet-corn ear as a result of bacterial cavities due to Aplanobacter stewarti. Plant from infected seed. Spots bright yellow.

also from dilutions of the same, if clouding has developed. There are various non-parasitic, motile, yellow schizomycetes on the surface of corn kernels, and only those non-motile forms which behave properly in the agar, gelatin, nitrate bouillon, litmus 
milk, Uschinsky's solution and Cohn's solution need be tried further.

For inoculation purposes select first of all seedling plants and inoculate from young potato or agar streaks on the leaftips when the plants are 2 to 3 inches high and show only 2 or 3 unfolding leaves. The inoculations may be made by spraying or by touching the leaf-tip with an infected platinum needle. After inoculation the young plants may be placed

Fig. 106-Corn husk in cross-section showing vessels and intercellular spaces of the parenchyma (dark areas) filled with Aplanobacter stewarti. Stoma oozing bacteria at $X$. See Fig. 107 .

either in cages or under the greenhouse bench. The essential is damp earth and a moist shaded place where the water-pores at the leaf-tips will function freely. Examine from time to time to make sure that drops of water remain on the leaf-tips. If necesiary, wet down the greenhouse thoroughly so as to saturate the air. After 30 hours set on the bench and withhold water for a day, if the soil look- wet. Change the plants frequently to larger pots and transplant into the garden at the end of June (May in the South) when the plants are about 15 inches tall, and make 


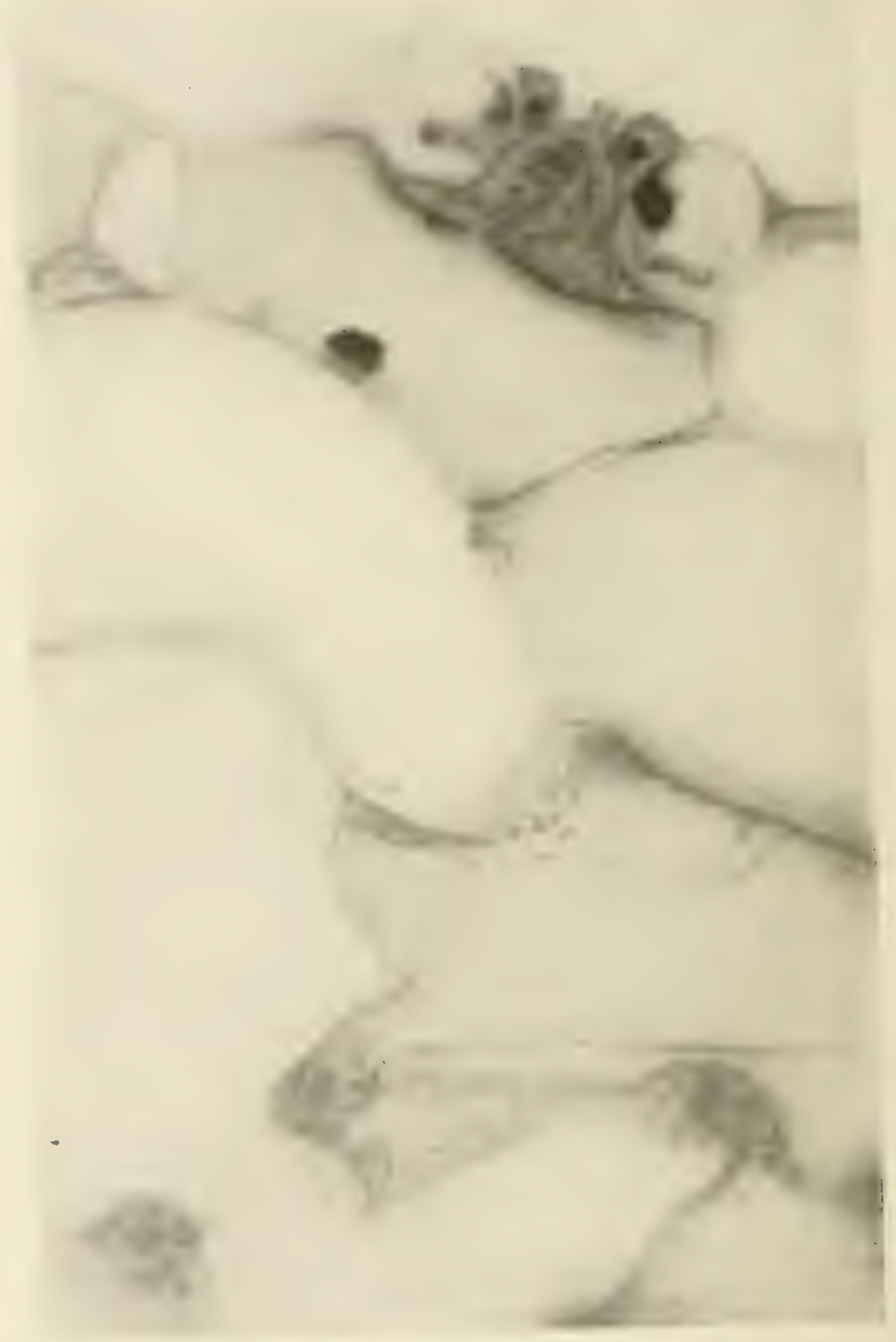

FIG. 107. - A detail from Fig. $106 \mathrm{X}$ showing A planobacter stewarti separating cells of the corn husk and filling the substomatic chamber. Photomicrograph by the writer. 
the final examinations in September before frost supervenes. One or more of the following sensitive varieties may be used: Black Mexican, Golden Bantam, Crosby's Early, Cosmopolitan, Pocahontas. Along with these, white and yellow field corns should be inoculated for comparison, taking pains to secure the names of the latter. 'The seedlings should be ready for inoculation about $S$ days after planting, which, in the North, should be toward the end of May, if the seedlings are to be transplanted into the open field.

Uninoculated check-plants should be held. These should be grown at some distance from the inoculated plants (preferably

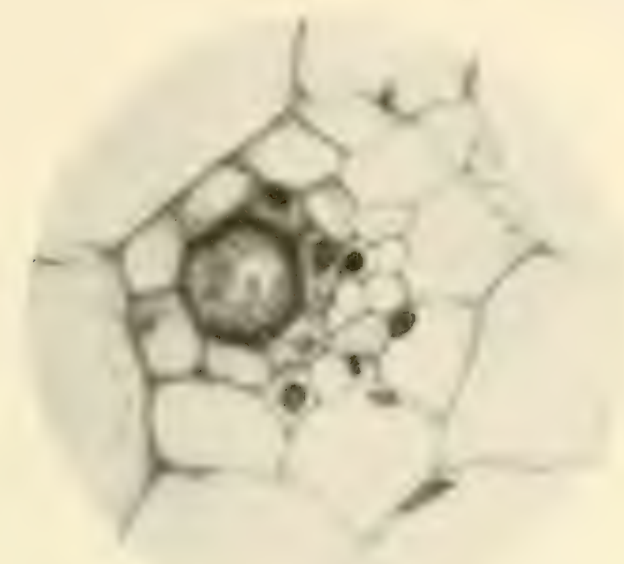

Fici, 108, - Cross-section of a small hundle at the extreme base of a kernel of sweet corn showing f planobacter stevarti in the single ressel.

in an adjoining house) and should be transplanted to the other side of the garden. Eren then, some cases may be expected unless the seed corn is beyond suspicion, and the house free from insects.

\section{Determine}

For the organisur. Morphology.-Size in microns, form (Ziehl's carbol fuchsin or amyl Gram may be used for staining), aggregation of elements, motility (hanging drop), question as to occurrence of flagella (hanging drop and van Ermengem's silver-nitrate stain; in case of the hanging-drop method, boil the 
culture and reëxamine), absence of endospores (heat, stains), presence or absence of capsule, occurrence of involution forms, reaction to Gram's stain (diaphragm wide open).

Cultural Characters.-On agar (Figs. 114, 115), on gelatin, on steamed potato, in bouillon, nitrate bouillon, Cohn's solution, Uschinsky's solution, lavender-blue litmus milk. Fermentation tubes in peptone water with various puresugars and alcohols.

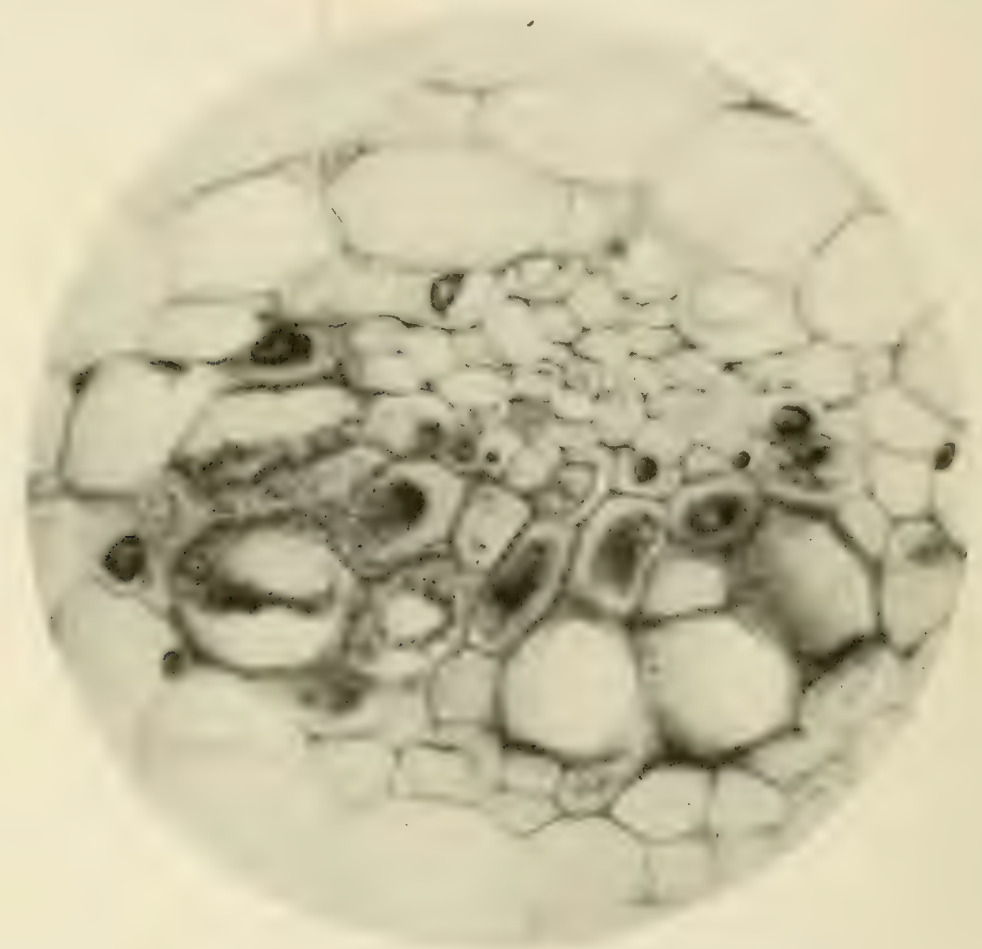

FIG. 109.-A larger bundle at the same level as Fig. 108, showing Aplanobacter stewarti occupying many of the vessels.

Growth in acid plant juices, e.g., green tomato juice full strength and diluted with an equal volume of water titrate with phenolphthalein and $>20$ sodium hydrate to determine the acidity). Compare with No. II or No. VIII.

Non-nutritional Environment.-What is the optimum temperature for growth? the maximum? the minimum? Can you get any clouding of +15 peptone beef bouillon at $9^{\circ} \mathrm{C}$.? 
Contrast with No. IX. Effect of sunlight? of dry air? of freezing? of weak acids? of weak sodium hydrate? of chloro-

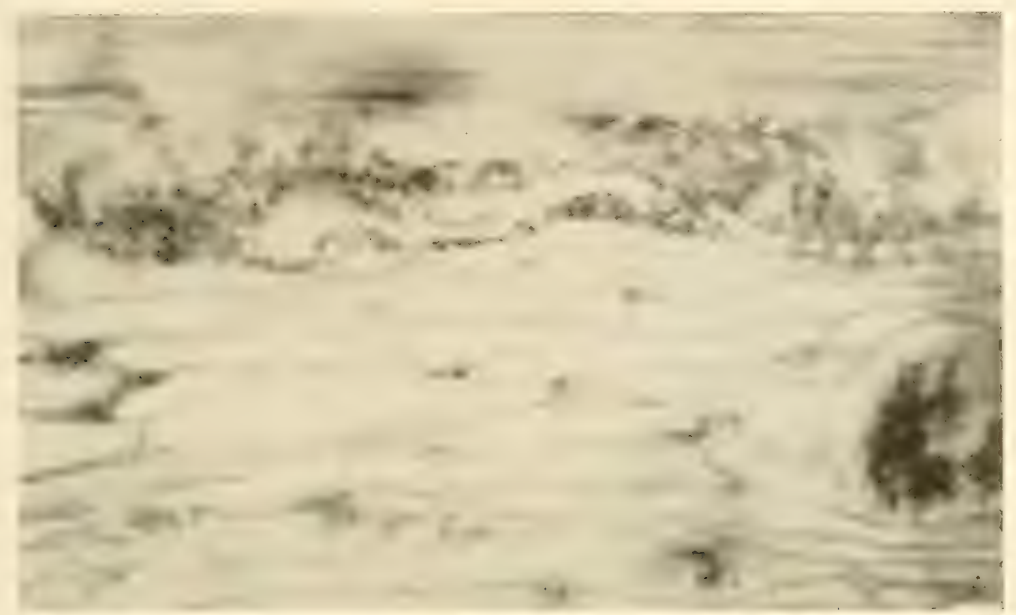

FIG. 110-Longitudinal section of outer layers at base of a sweet-corn kernel (level of the radicle) showing presence of Aplanobacter stewarti between cell-walls and in the vessels.

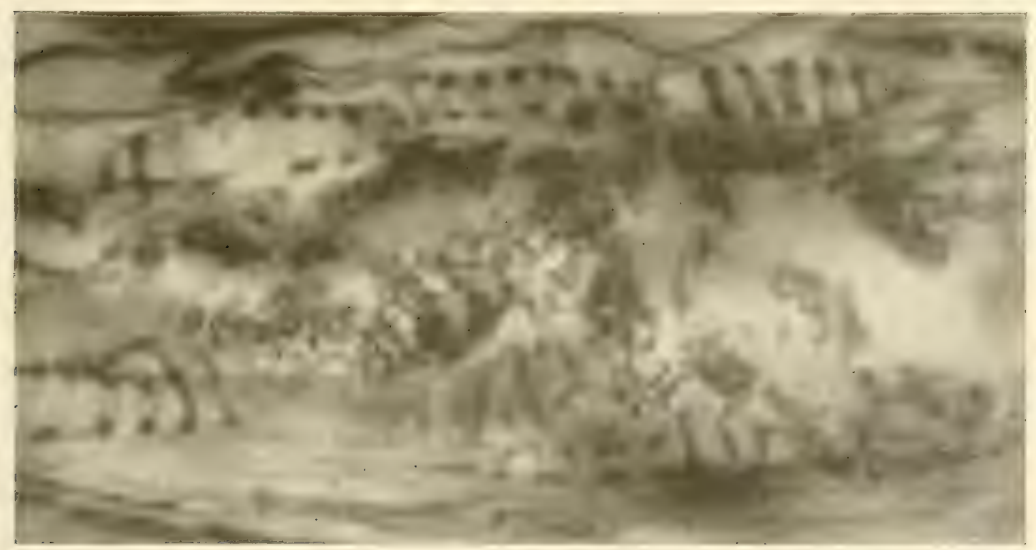

FIG. 111.-A planobacter stewarti forming a cavity in the periphery of a sweetcorn kernel. Same section and same level as Fig. 110.

form in bouillon? Maximum toleration of sodium chlorid in bouillon? (Begin with 5 per cent. Contrast with No. I.)

For the disease. Signs.-How soon does the disease appear in the inoculated leaves? How many days between the 
local appearance of the disease on the leaf-tips and signs of general infection in the plant? On well-grown plants the earliest signs are flagging and shriveling of the lower leaves, and "white top," i.e., the premature development and drying-out of the male inflorescence. This is conspicuous at a distance (Fig. 101). Watch for these signs and try to correlate them with the presence of bacteria in the vascular system of stem and leaf.

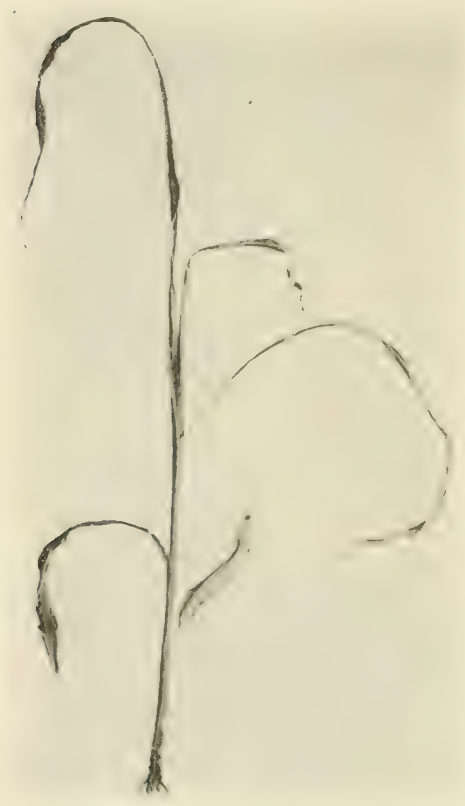

FIG. 112.- Young sweet-com plant inoculated on tips of the leaves in the seedling stage and promptly destroyed by Aplanobueter stemati. Distriet of ('olumbi:1, 1902.2. Time. 10) datys.

Can you find any macroscopic evidence of the presence of the disease on the inside (surface) of the leaf-sheaths? or in the ear, especially on the husks? Contrast with Nos. I and II.

Look for dwarfing effects. Is the plant as tall as its fellows? Are the ears well filled? Are the roots generally sound? Do the leaves become yellow before they dry out? Does the plant rot? or break over" Describe the disease.

Histology.-Select, section and stain (in Ziehl's carbol fuchsin) a number of leaf-tips, some days after inoculation ( 4 to 7 days). Can you find distinct evidences of infection? Have the bacteria entered through ordinary stomata, or through the water-pores?

Cut and stain cross- and longitudinal sections of infected stems. What vascular tissues are most subject to attack? Does the organism attack the phloem? Do cavities occur uniformly". In maturing plants how far can you trace the vascular infection? In the vessels of the stem is the general movement of the bacteria upward or downward? What is your reason for this belief"? In large leaves beginning to wilt or shrivel is there simply occlusion of the stembundles which supply these leaves, or are the bacteria also. 
present in the leaves themselves? Are such large leaves ever infected first at the apex? Make cross-sections: a at the tip; $b$ near their junction with the stem: and $c$ in the middle of the leaf. Try several leaves. Have you seen any evidence of wound-infection? If diseased ears are available, study carefully by means of sections at different levels the upward and outward morement of the bacteria in the pedicle, cob and husks. Try to demonstrate vascular infection in the base of the kernel.

Observe yellow pockets in the pith and in the husks. Make sections and determine the contents of these yellow spots. Draw what you have seen.

Have you observed any brown stain in the stems? Is it local or general". Where does it first begin? Is this stain a host reaction? Does the organism cause a brown stain in any culture medium? Compare with No. II and No. X.

What impresses you most about this disease? Do you think there are any toxins liberated? What are your reasons? How many bacteria would you estimate to be present in an infected well-grown plant when

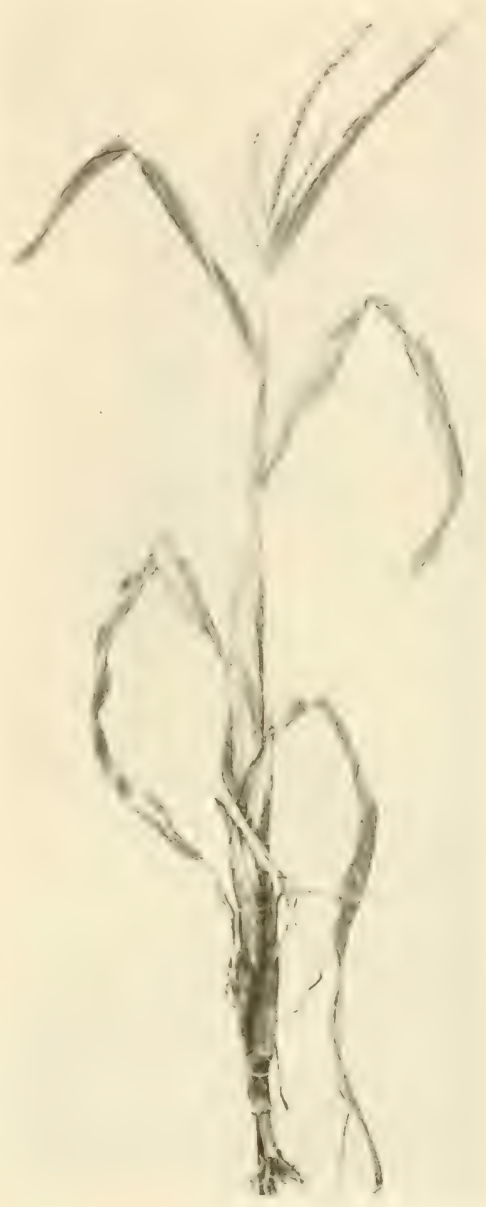

FIG. 113.- Sweet-corn plant destroyed by Aplanobacter stewarti as a result of an inoculation on the leaftips in the seedling stage. Plant dwarfed and vessels full of the yellow slime. Time, more than 60 days. District of Columbia. 1902. the leaves are beginning to shrivel? What proportion of the vascular bundles are occupied? Is there anything correspond- 
ing to this vascular invasion in the animal world? Consult Figs. 116 to 118 .

Variability.-How long does an attacked plant live? In what varieties of field corn have you found the disease, or been able to cause it by inoculations? Try many varieties, if you

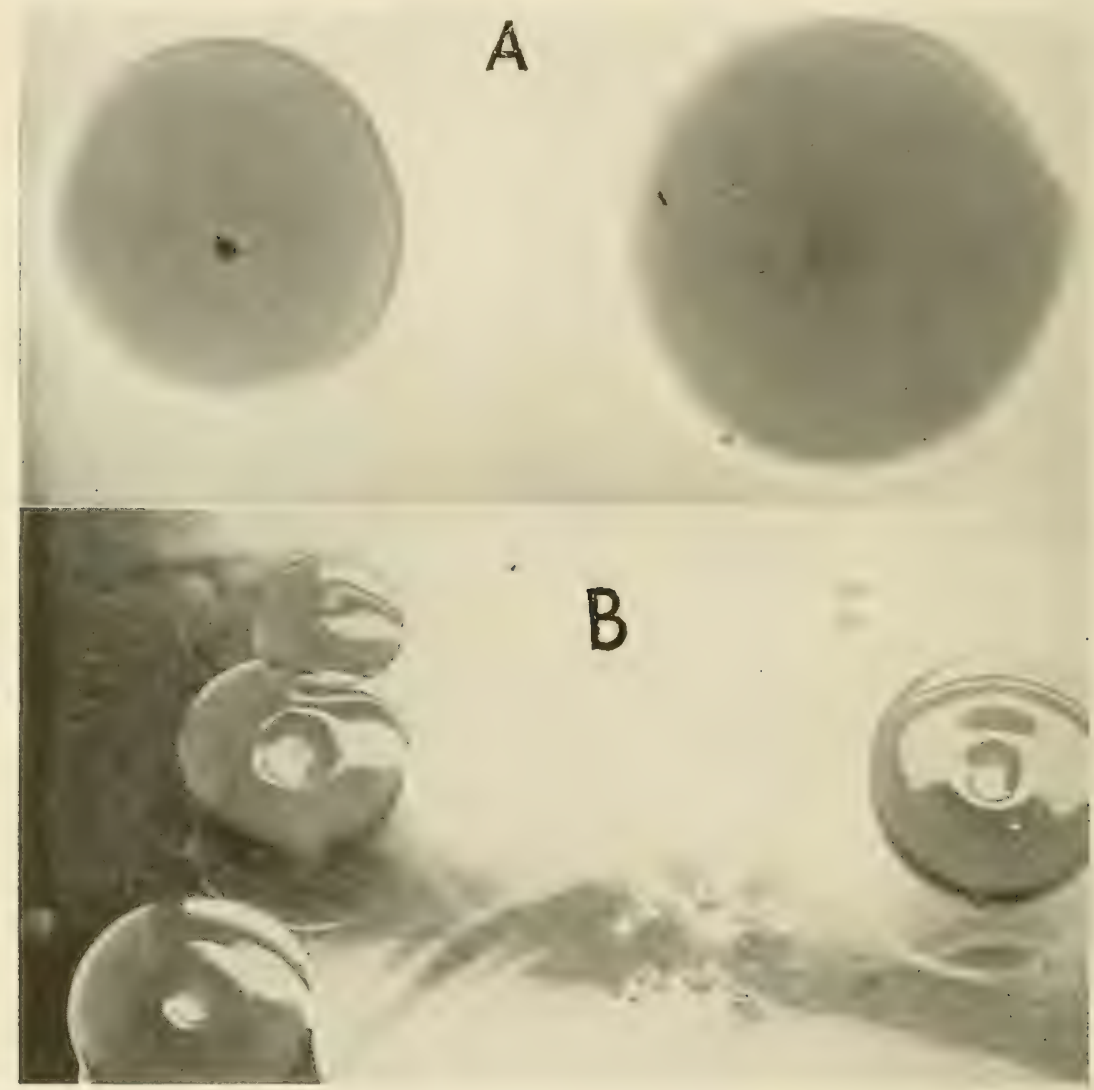

FIG. 114.-A, Agar poured plate surface colonies of A planobacter stewarti, $B$, Type showing pitted centers. $\times 10$.

have opportunity, and make records. There is much to be learned about the occurrence of this disease in field corns. What occurs when, by needle-pricks, you inoculate sweet-corn plants 2 or 3 feet high on the upper leaf-blades rather than on the leaf-tips in the seedling stage". What does this teach you".

Can you check the progress of the disease by allowing in- 


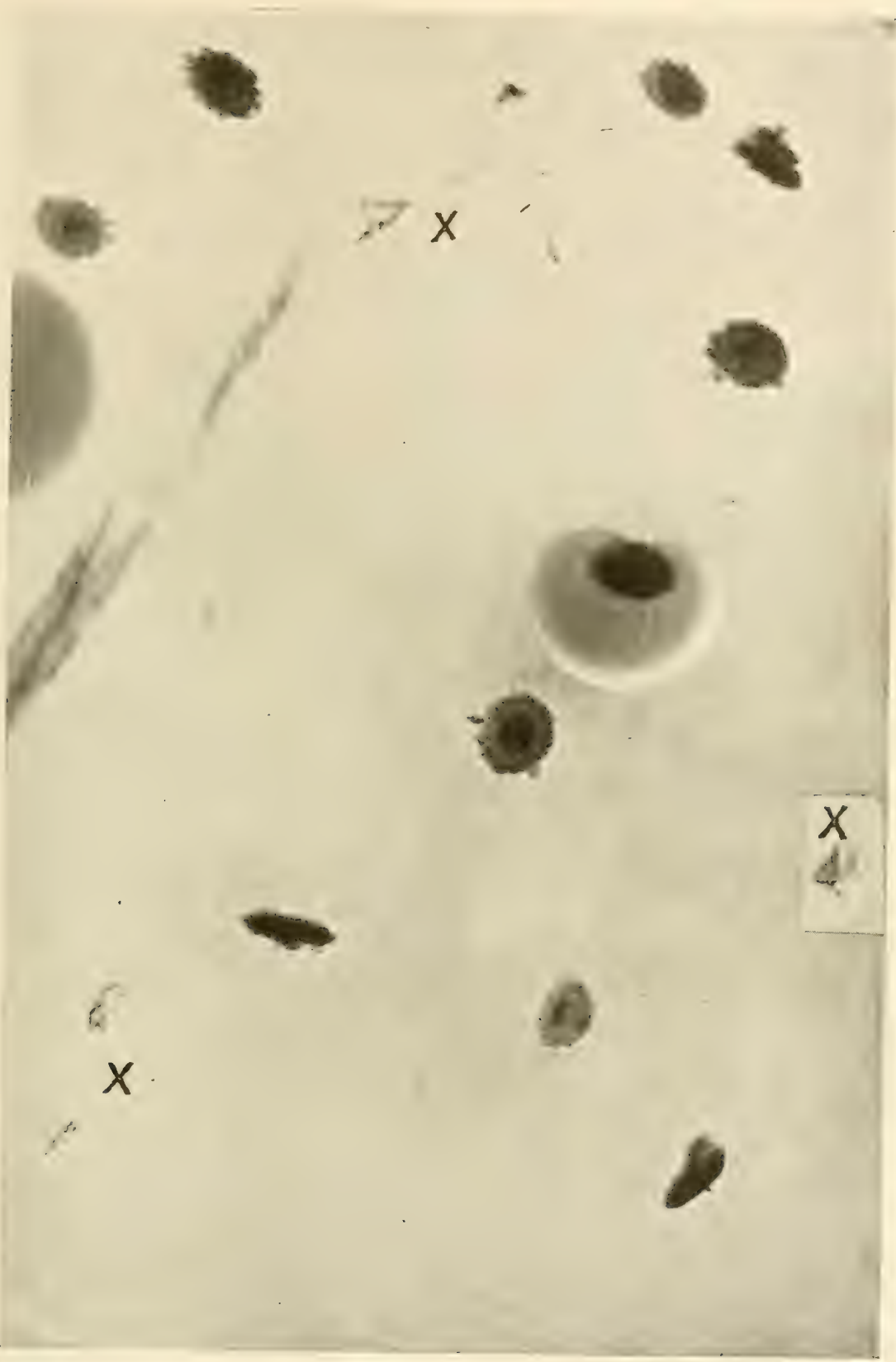

FIG. 115.--Typical buried colonies of Aplanobacter stewarti (Rand's No. 408) in +14 beef peptone agar plate, one coming to the surface. At $x, x, x$, crystals. Plate 8 days old at about $23^{\circ} \mathrm{C} . \quad \times 10$. 
oculated plants to become potbound? Can you cause general infection by stem inoculations of half-grown plants? Inoculate in the middle of internodes and also close under nodes. Does nodal inoculation make any difference, i.e., hasten infection?

If you have opportunity, examine infected fields and make lists of susceptible and resistant sweet corns. Make extensive

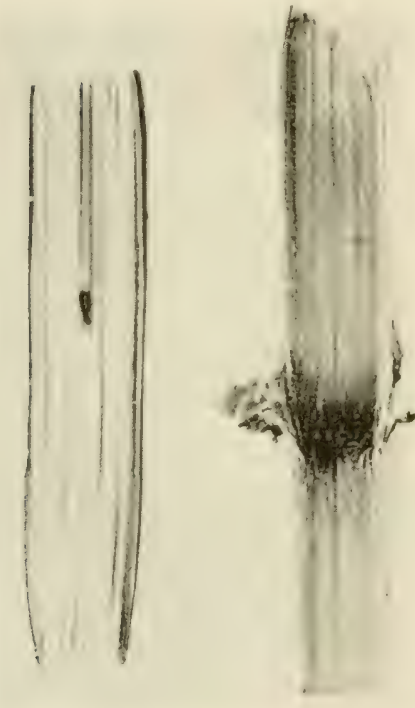

FIG. 116 .

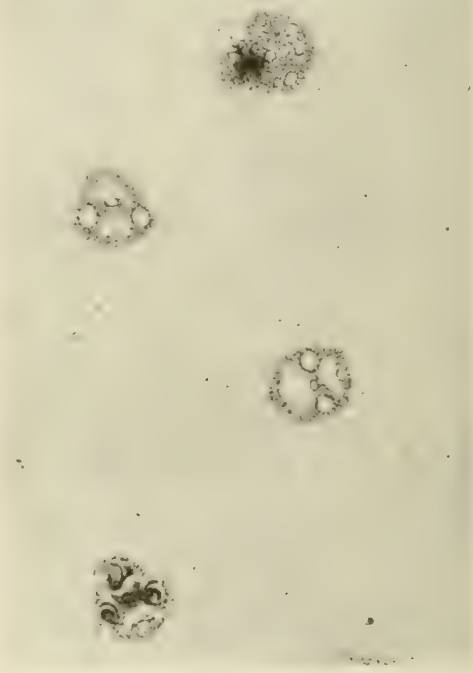

FIG. 117 .

FiG. 116.--Longitudinal section of two sweet-corn stems showing a brown node and yellow stripes in the internodes, and a bacterial cavity in the middle of the left-hand stem. This cavity was bright yellow. Sections from plants inoculated in the seedling stage.

Fig. 117.- Stained section of such a stem as Fig. 102 enlarged showing two bundles occupied by Aplanobacter stewarti and two free.

counts and express your data in per cents. Reëxamine your fields some weeks later for additional cases.

Remember: none of the diseases described in this book are known thoroughly and you may have opportunity to add to the sum of our knowledge.

Transmission.-This is commonly by way of seed corn. Very likely also by way of soil previously infected. Read what 
is said upon this subject in "Bacteria in Relation to Plant Diseases," Vol. III, pp. 114-127, and if you can find gardens or fields in which this disease has appeared for the first time, procure seeds of the infected varieties from the same seedsman and of the same origin, and repeat the experiment, trying also (as mentioned under Technic) to find the organism in some of the

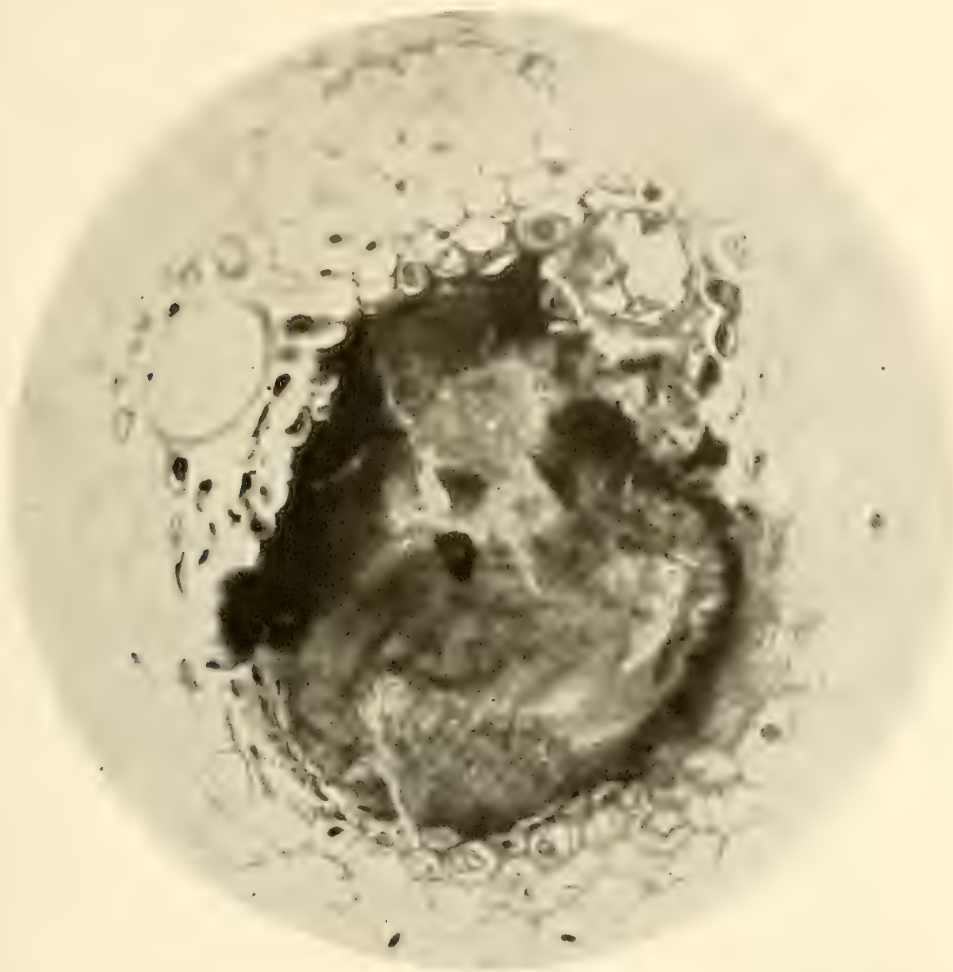

Fig. 11s-Single infected and disorganized bundle of sweet-com stem much enlarged, showing the bacterial mass of A planobacter stewarti dark because it was stained red with earbol fuchsin.

kernels (the vessels toward the base) by means of stained sections and by the agar-poured-plate method. Tell the seedsman the result.

The disease occurs in the United States every year in many localities where sweet corns are grown for market and the organism may therefore be supposed to winter over in the soil, but in places where it appears for the first time it may be assumed 
to have been brought on infected seed. No one has yet isolated it from the soil, nor do we know that it persists in soils.

MEANS OF PREVENTION

This disease is disseminated almost exclusively by the seedtrade. When growers of seed-corn have learned to recognize it and refuse to market corn from fields in which it has been prevalent, the disease will almost entirely disappear. Meanwhile, seed-corn may be rendered nearly free from the organism by plunging it for a moment into alcohol and then for 15 minutes into 1:1000 mercuric chlorid water, whereupon it may be rinsed in water (for a moment only) and then spread out to dry, or planted at once.

\section{LITERATURE}

Read Stewart's Bulletin No. 130, Geneva, N. Y. Experiment Station, which is the first paper.

Consult Stewart's Disease of Sweet corn (Maize) in "Bacteria in Relation to Plant Diseases," Vol. III, pp. 89-147; also Ibid., Vol. I, Figs. 1, 73, 74, 75; and Vol. II, Fig. 14 and Plate 17. The organism was first named by the writer Pseudomonas stewarti in 1898 in. Proc. Am. Asso. Adv. Sci., Vol. XLVII, pp. $422-426$. 


\section{THE BROWN ROT OF SOLANACEAE}

Type.- This is a destructive parenchymo-vascular wilt disease of wide distribution on a great variety of plants (Figs. 119 to 128 .

It was first described by the writer from the potato, tomato and eggplant in 1896 and subsequently from tobaceo(190) , but

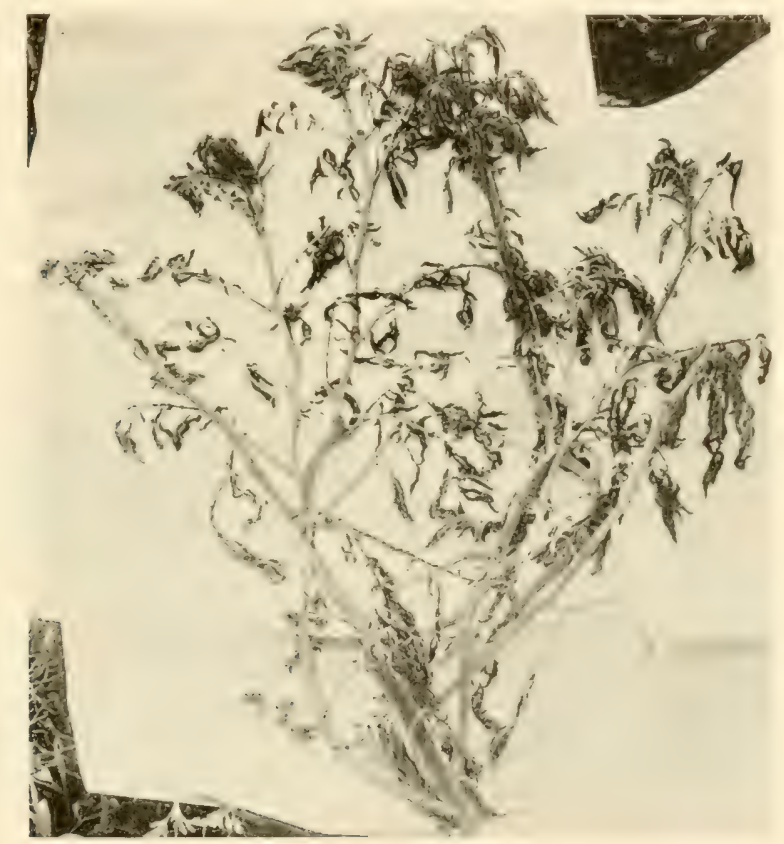

FIG. 119.-Potato attacked by Bacterium solanaceamm. From a field near Washington, D. C.

it occurs also in Physalis and red peppers, and outside of the solanaceae in species of L'rticaceae, Leguminosae, Verbenaceae and Compositae (Honing). Fulton and Winston found it on peanuts in North Carolina (1913). It has been inoculated successfully into Sesamum (Honing), and it also attacks the nasturtium (Mary Katherine Bryan, Jour. Agric. Res., Vol. IV, pp. 
451-458, 1915). Stanford and Wolf have found it attacking several weeds in North Carolina (Eclipta alba, Ambrosia artemisiaefolia) and have successfully inoculated it into a variety of plants including Impatiens balsamina. In 1918 fields of Ricinus communis (castor oil plant) were attacked by it and seriously injured in Georgia and Florida (Smith and Godfrey, l.c.) In our

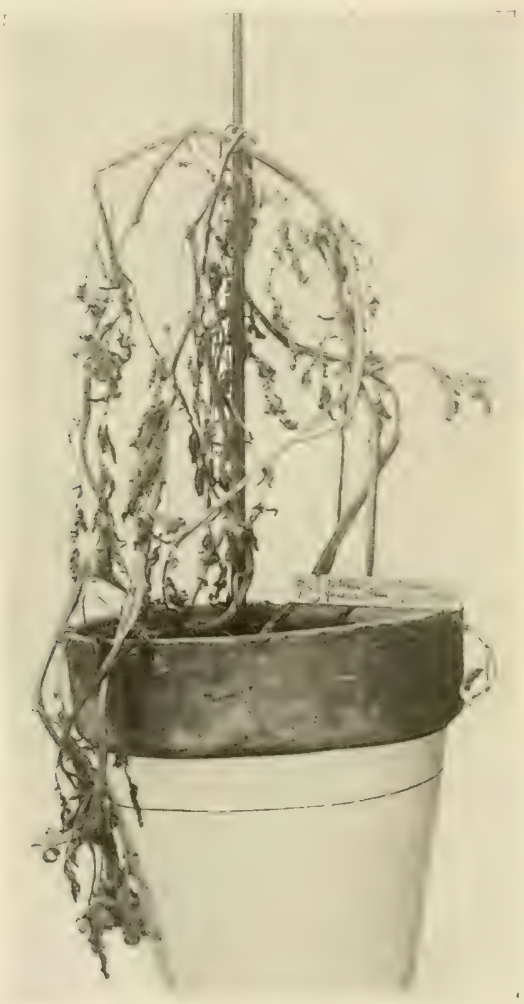

FIG. 120, - Early Rose potato inoculated by needle-pricks on the stem with a culture of Bacterium solanacearum. Time, 37 days. Wilt developed slowly, 1905.

hothouse tests we found it able to attack I'anilla planifolia, Hetianthus annuus and young cotton plants. In 1919 it was found in Florida on beans (Smith and MeCulloch, $l$. c.) and was successfully inoculated into beans and peas.

On tomatoes the leaves are bent downward (Fig. 121, left) and the stems develop numerous incipient roots (Fig. 122, left). To a lesser extent these roots appear on tobaccolstems. They 
occur also on nasturtium stems. On tobacco, longitudinal black sunken stripes appear on the softer stems and large, irregular brown spots on the leaves, especially on the basal "ears" of the leaf. The tobacco leaves also frequently show brown veins. Compare with the Black Rot of Crucifers (No. II).

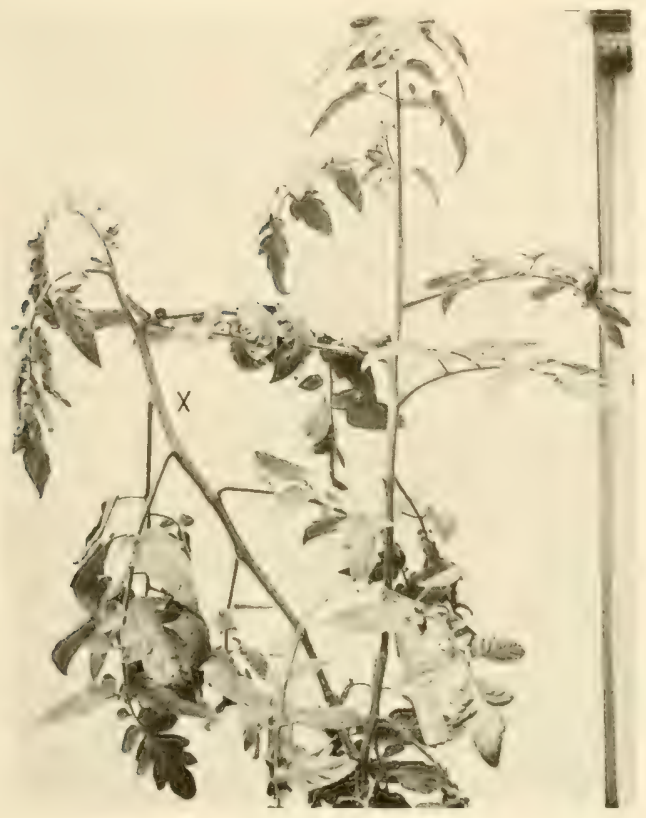

Fir. 121.
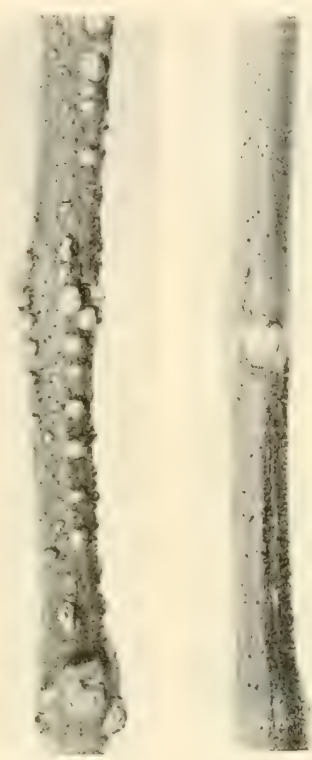

Fig. 122 .

Fig. 121. - Young tomato plant: left-hand shoot inoculated at $X$ by needlepricks introducing Bacterium solanacearum; right shoot pricked with a sterile needle. Photographed at end of 5 days. Terminal leaves of inoculated shoot, wilting and lower leaves reflexed. The inoculated stem begins to show incipient roots while the other is free (see Fig. 122).

Frg. 122.-Part of left and right branch of Fig. 121 after 12 days. The branch showing the incipient roots was inoculated on the two nodes immediately above the part here shown. The smooth branch was pricked with a sterile needle in the internodes here shown.

On all of the host plants, the foliage wilts more or less, often completely, the occluded vessels are usually stained brown or black, and there is often an extensive destruction of pith and bark, so that in tomato and tobacco the stem may be honeycombed for long distances with bacterial cavities. Sometimes 
the alkaline slime oozes to the surface but often the surface is sound. On potato, narrow dark stripes corresponding to the infected bundles often show through leaves and stems. On the leaves of the potato, infection may be lateral, running out on one side of the petiole and in particular reins of the leaflets as a black stain: compare with Fire Blight of the Pear (No. XII). The tubers are also subject to infection, principally in the vascu-

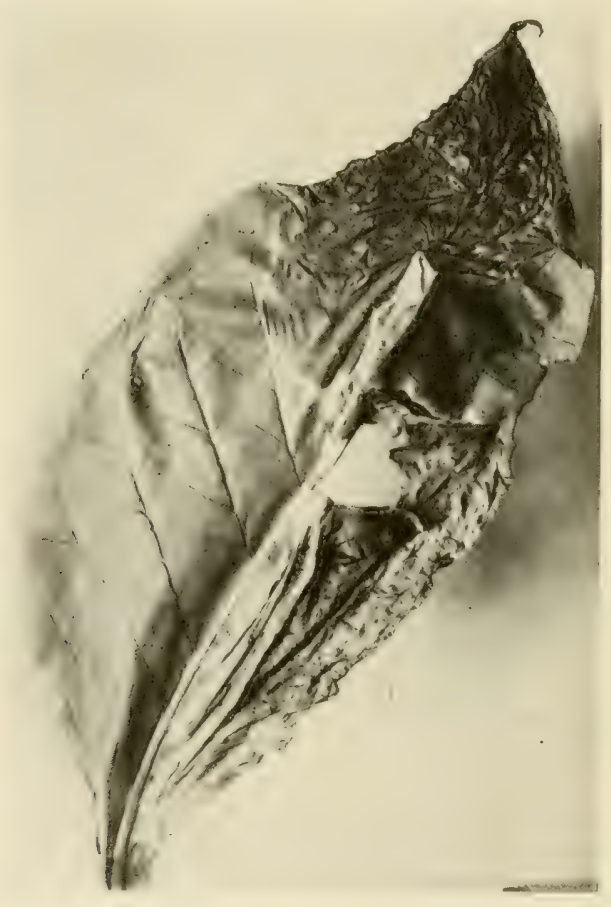

FIG. 123.-Tobacco leaf wilted by Bacterium solanacearum. Results of a stem inoculation made by the writer in 1906 .

lar region and usually by way of the stem, through the ressels of the rhizome; cavities are formed and these rupture to the surface. On cross-section of tubers in early stages there is, especially at the stem end, a ring of brown stain and a gray bacterial ooze limited to the outer (vascular) part of the tuber (Fig. 129). This stain often gives to portions of the surface of the tuber a dusky hue even when the skin is unbroken and the outer tissues are sound. Stems of attacked Helianthus, Tro- 
paeolum and Impatiens also have a livid color (see Fig. 126B) and ooze bacteria through rifts and stomata or on cross-section (Figs. 130 and 212B).

It is commonly a wound-infection disease, but infection may also occur through stomata. More often than not the bacteria enter the plant underground, through broken or punctured roots. It is easy to obtain the disease experimentally on Datura. Tro-

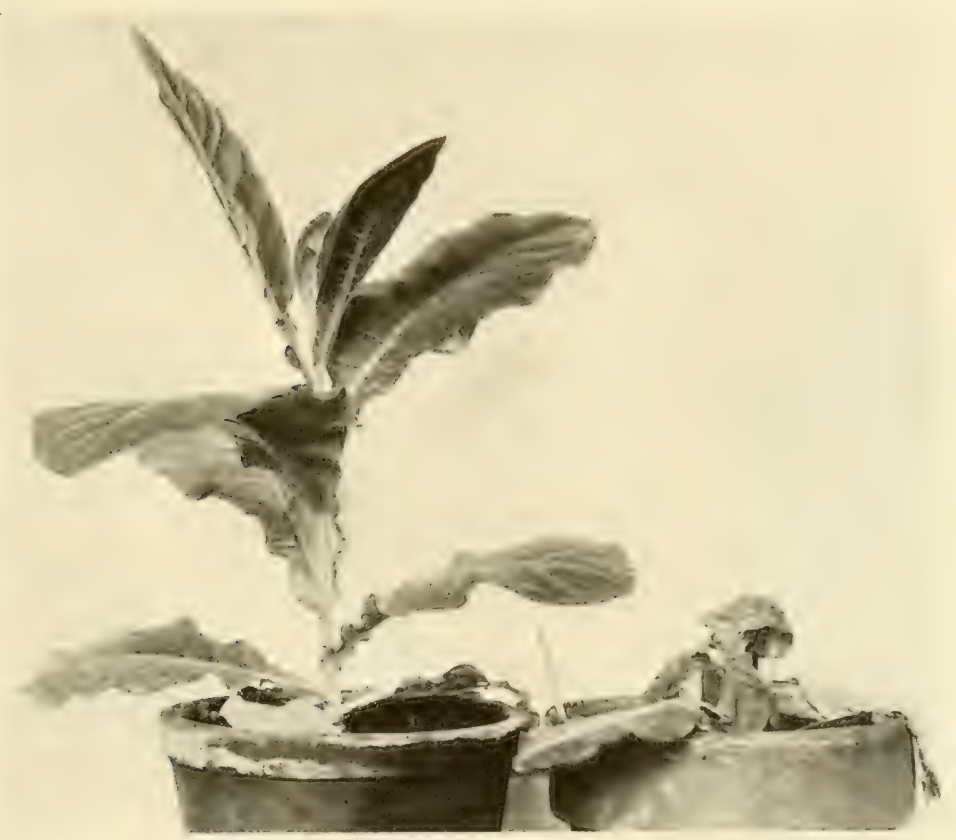

FIG. 124.-Young tobacco plant inoculated with Bacterium solanacearum by needle-pricks and photographed at the end of 17 days. The bundles of stem and leaves were browned and swarming with the bacteria. The plant showed marked dwarfing before it wilted. Inoculated May 1, 1915, with "Creedmore" of lessened virulence. Plated in 1914 from North Carolina tobacco. Photographed May 17. Check plant at left.

paeolum, and Ricinus by means of broken roots. The disease is very apt to occur in carelessly transplanted seedlings or in plants whose root-system is attacked by parasitic nematodes (Heterodera radicicola), or is gnawed by insects.

It is a disease in which there is often a conspicuous dwarfing of attacked parts (Figs. $121 \mathrm{X}, 127$ and 131). Young soft tissues are more subject to the disease than those containing less water. 


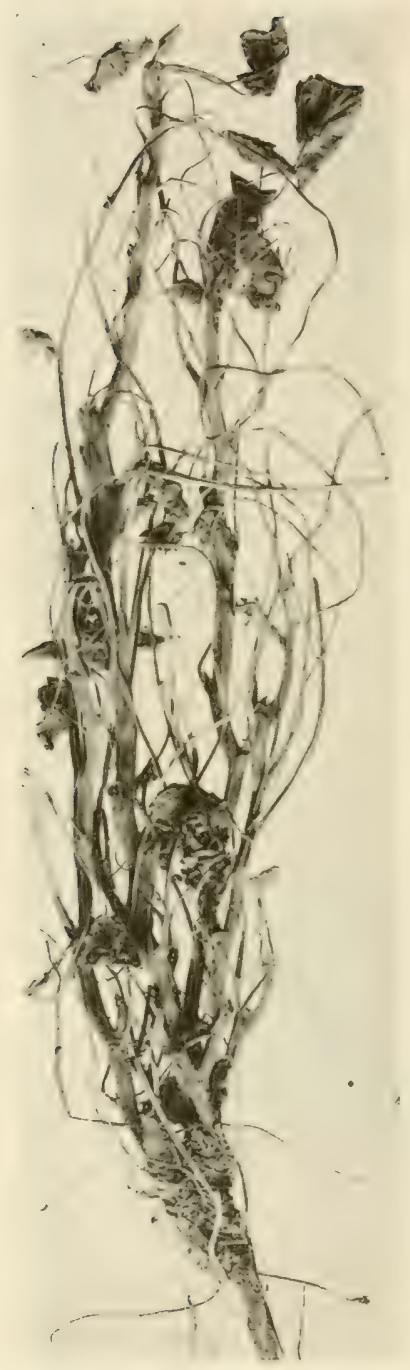

FIG. 125.-Dwarf nasturtium plant wilted by Bacterium solanacearum. From a garden in Baltimore in 1914. (See paper by M. Katherine Bryan in Journal of Agricultural Research, August, 1919, p. 451.)

It prevails under the equator and in the North and South Temperate Zones, but its northern and southern distribution are unknown. It seems to thrive best in the Eastern United States on washed river sands. In the Old World it is believed to occur from Japan and the Philippines to New Zealand and westward through Java, Sumatra and India to South Africa and Italy (?). In the United States it occurs from Maryland and New Jersey south to Florida, Cuba and Porto Rico, but its northward and westward distribution in this country are unknown. It has not been reported from South America but undoubtedly it occurs there. Probably its range is that of the plants subject to it.

Cause.-This disease is due to $\mathrm{Bac}$ terium solanacearum EFS. This is a non-viscid, motile, polar flagellate, white (bluish, brownish, opalescent), nonsporiferous, slow-growing, non-liquefying (or very slowly liquefying?), nonstarch-destroying, aërobic, milk-clearing (non-curdling) nitrate-reducing, nongas-forming, rod-shaped schizomycete, forming on the surface of agar-poured plates small circular, or rather nearly circular (Fig. 132) smooth, wet-shining, opalescent colonies (white by reflected light, pale brownish by direct transmitted light, bluish or pink-opalescent by oblique lighting). Although white at first by reflected light, the surface colonies become brown through the formation of a dark colored, water-soluble 


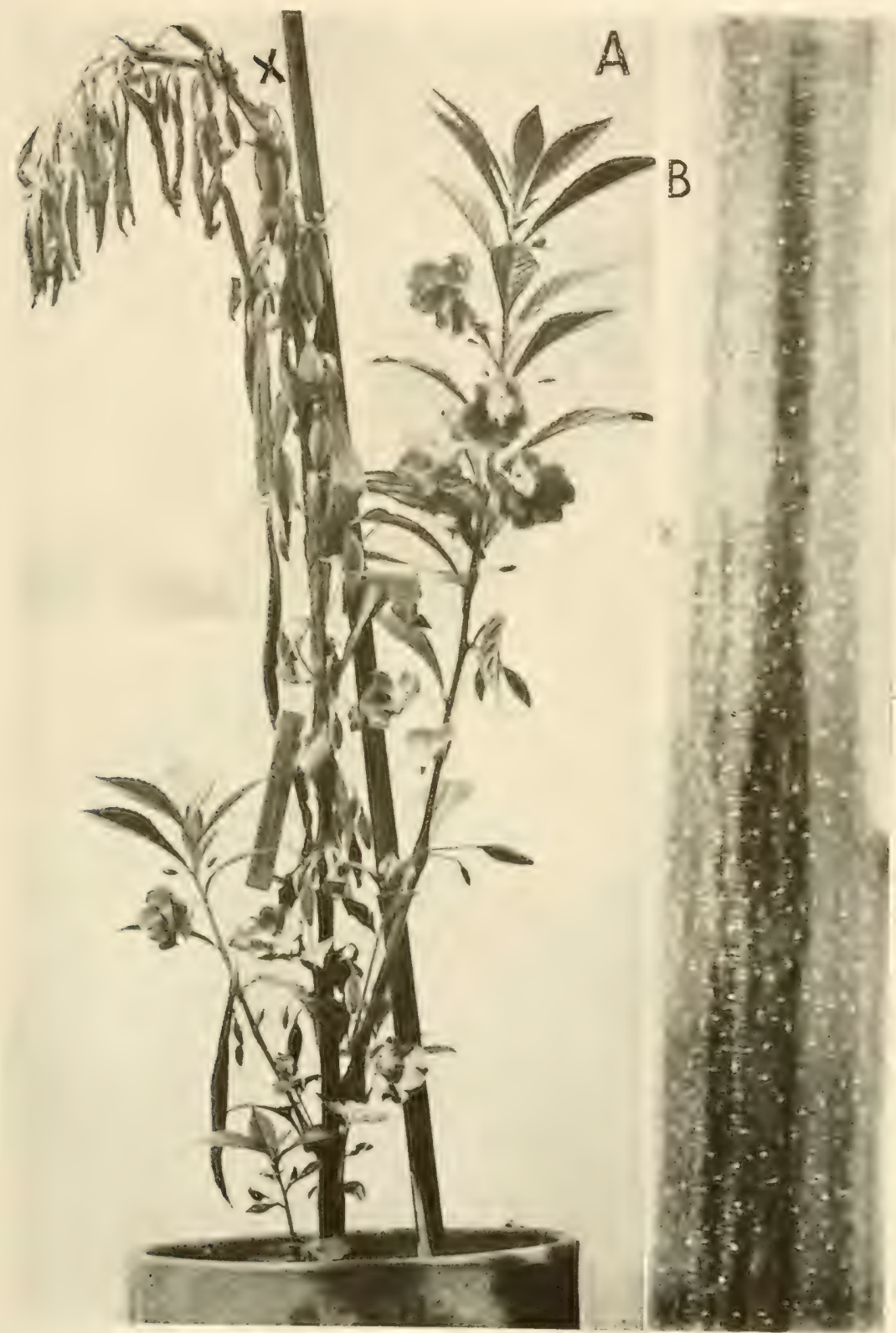

FIG. 126.-A. Bacterium solanacearum on red-flowered Impatiens balsamina. Left-hand shoot inoculated July 2, 1918. An internal brown stain extended down the stem a foot or more beyond the needle pricks which were at $X$. Height of plant 24 inches (to top of curve of wilted stem). Lower side-shoots still healthy. Photographed July 30, 1918, 1/4 natural size.

$B$. Stem of garden balsam from same series as $A$, but enlarged to show vascular black stripe visible through the unbroken translucent cortex. Plant inoculated 20 days and about 4 inches above part here shown. $\times 4$. 


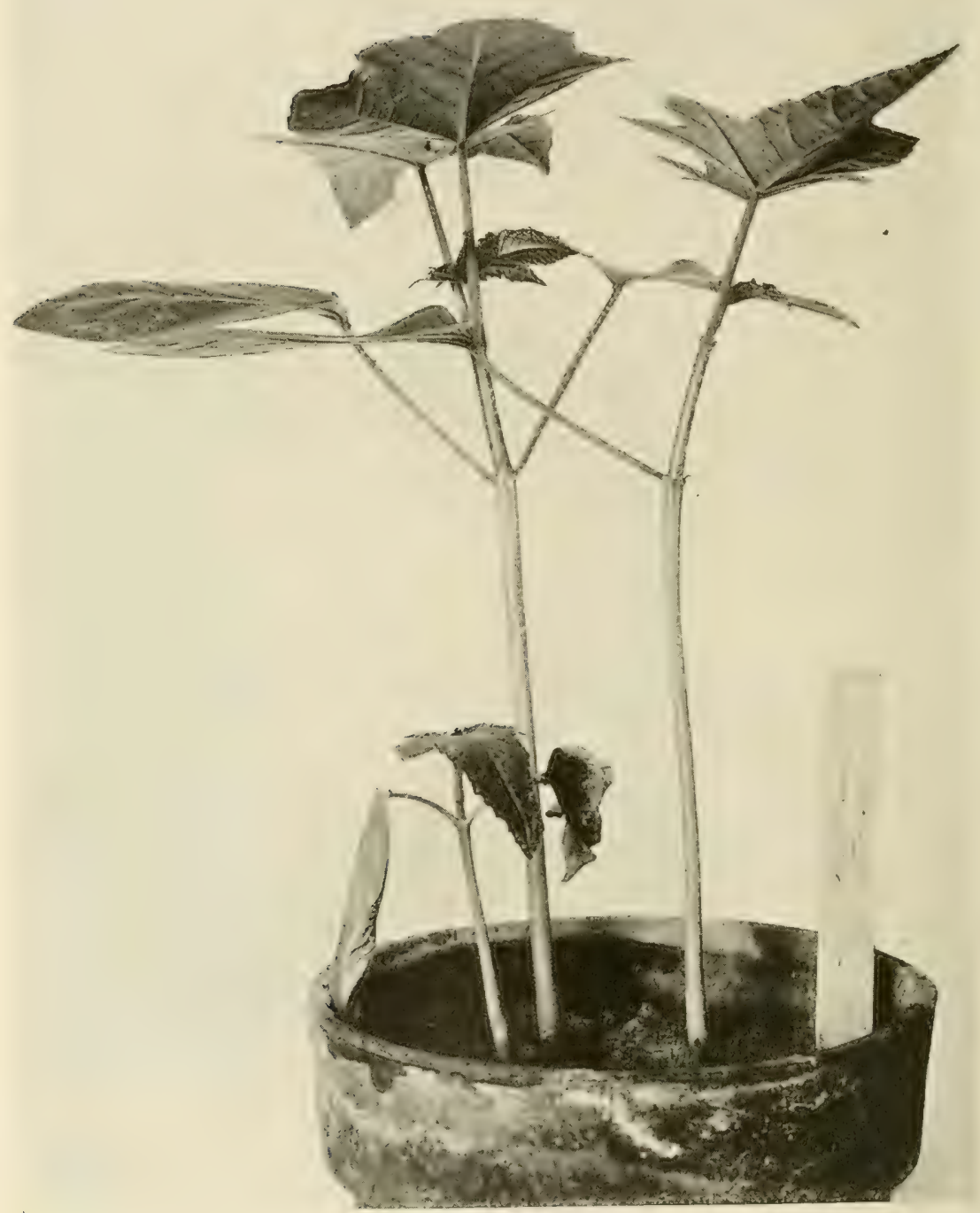

FIG. 127.-Ricinus communis showing profound dwarfing due to Bacterium solanacearum. The left-hand plant was inoculated at the base of the hypocotyl during germination by three delicate needle pricks. Checks at right. Photographed July 15, 1918. Time 19 days. Experiments of Smith and Godfrey. 


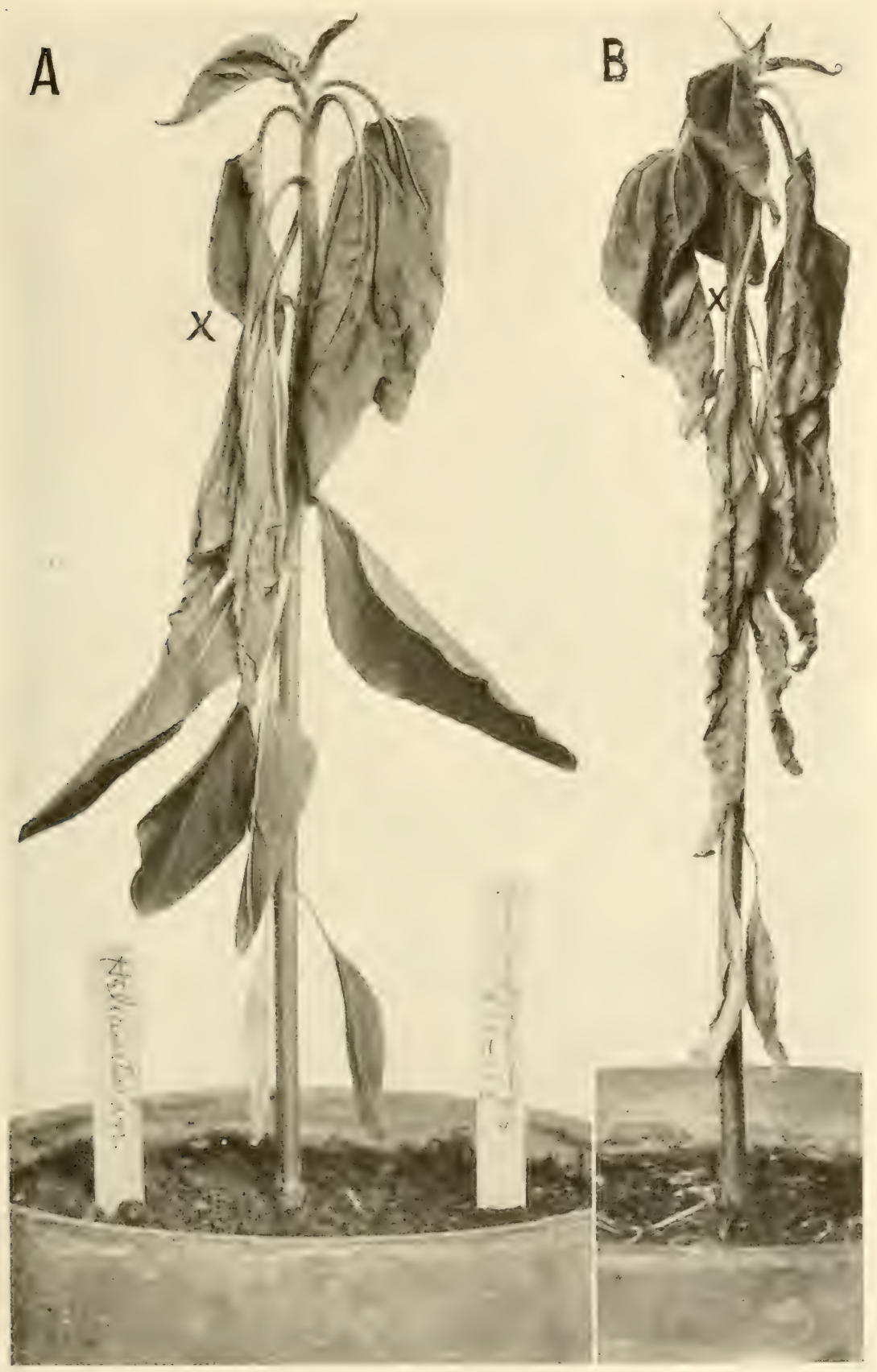

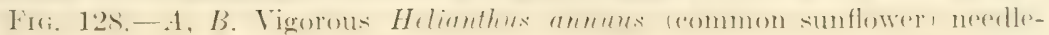
pricked in the stem at $X$ with Bacterium solanacearum plated from inoculated dis- 
pigment especially when Witte's peptone is used. On agar plates the young surface colonies are rather watery and will often flow if the plates are tilted to a vertical or semi-vertical position (Fig. 133). On gelatin plates the colonies are small and not characteristic. On steamed potato cylinders the bacterial slime is white at first, becoming gradually dark brown or black. It does not grow readily on raw potato (contrast with No. VII). Some of its most striking characters are: irregularly roundish, small,

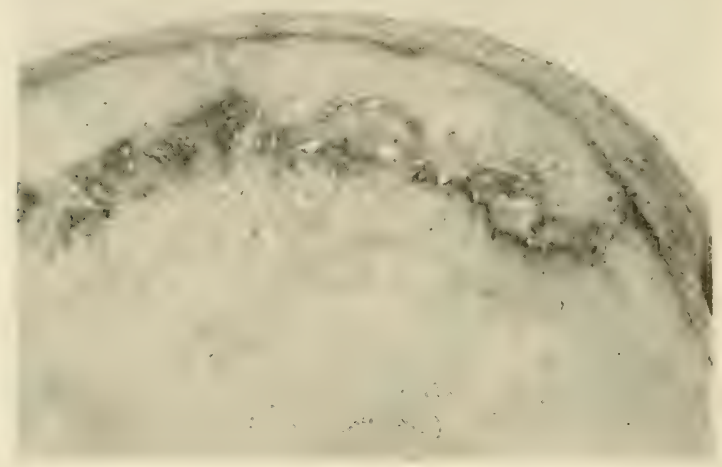

FIg. 129.-Cross-section of a mature Florida potato attacked by Bacierium solanacearum showing brown stain and gray ooze in the vascular region. A natural infection by way of the rhizome. 3 ?

opalescent suface colonies on agar-poured plates, sensitiveness to dry air, bipolar staining, aërobism, liberation of brown stain in tissues of its hosts, dark stain on steamed potato and agar, slow clearing of milk without precipitation of the casein, bluing of cream-free litmus milk, non-liquefaction of gelatin (at least during the first few weeks), reduction of nitrates and failure to grow in Cohn's solution.

It loses virulence rather quickly, dies out early on various

eased vanilla, which was inoculated from tomato, which was inoculated from diseased Georgia Ricinus. Sub-cultures from single colonies on agar-poured plates were used in each case. Six plants (of which these were 1 and 2) were inoculated and all becaine diseased and badly dwarfed. See Fig. 131. Bacteria were abundant in the xylem vessels of the stem and also in the root 2 inches below the crown (12 inches below the needle pricks) in both plants. There was a brown stain in the vascular system. Time, 10 days. Plants inoculated July 12, 1918. Photographed July 22 . 1/2 natural size. 


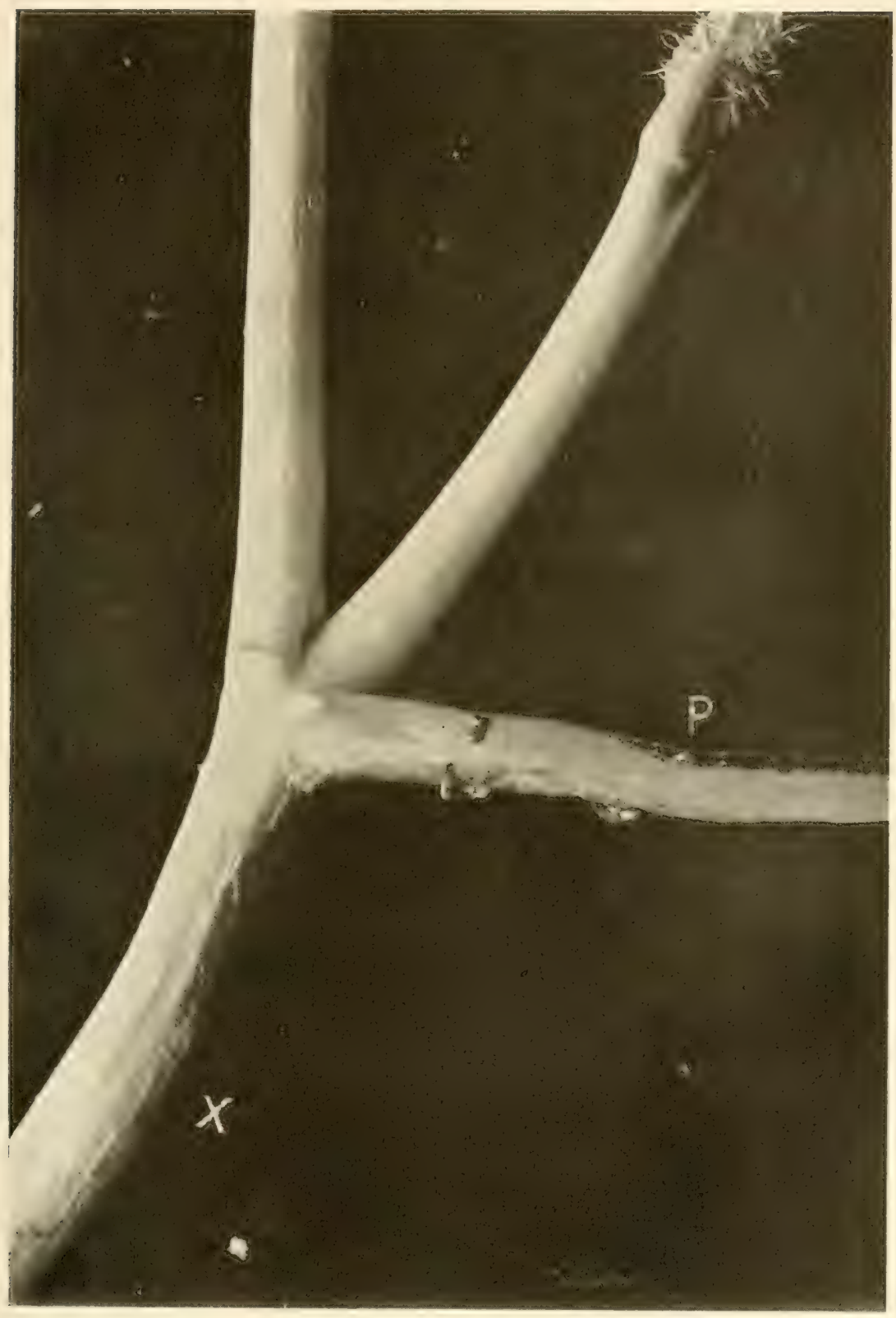

FIG. 130.-Livid color and bacterial ooze on a petiole $(p)$ of Tropocolum majus (common garden nasturtium). Inoculated by needle pricks June 26, 1918, on the hypocotyl under the petiole with Bacterium solanacearum plated from an inoculated wilting tomato plant. Photographed July $1 . \times 5$. 
media, and there are at least two strains: one of which splits fats (cream, etc.) with the formation of an acid (var. asiaticum EFS). The flagella are rather hard to stain (Fig. 134). It keeps best in milk, or litmus milk.

Technic.-Because in the host plants the parasite is promptly followed by saprophytes which often supplant it, cultures are best marle at some distance from the ground and out of parts recently diseased. It is a rather difficult organism for the beginner to isolate, owing to the fact that while it grows readily on agar-poured plates, the colonies during the first week resemble those of various saprophytes, so that only after some days can they be picked out easily by the beginner, i.e., when the brown stain has developed, but then they are apt to have lost a portion of their virulence, or may be dead. The best way is to make transfers early from a whole series of numbered colonies that look hopeful, watch the plates for opalescence in surface colonies, and later discard all sub-cultures except those from colonies which have browned properly. The organism may be kept in agar, milk, sugared peptone water, etc., but transfers should be made as often as once every 2 or 3 weeks, and the tubes should be kept in a cool box. It is a good plan also to pass the organism frequently through susceptible plants that it may retain its virulence.

For inoculation purposes select young rapidly growing shoots of nasturtium, tomato, potato, tobacco, balsam or sunflower. Inoculate by needle-pricks in various ways, i.e., on leaf-blades, petioles and soft stems, and, for contrast, into hard stems and well-developed leaves. Also drench a soil with cultures (young agar-streak suspensions in water), and plant in it tomatoes or Daturas with broken roots. Those which have stood in the seed-bed rather too long and are large may be used for this purpose. But if one has access to material from the field, diseased tobaceostems, or tomato stems may be used instead of cultures for infecting the soil, or along with cultures as an additional experiment, the diseased plants being buried in the soil a few days before the tomatoes or Daturas are transplanted.

For successful inoculation the plants should not be too old, 
and must continue to grow rapidly for at least sereral weeks. Only disappointment. will result from inoculations on old slowgrowing, woody plants, or with cultures which have been in the laboratory for a considerable period. The best results may

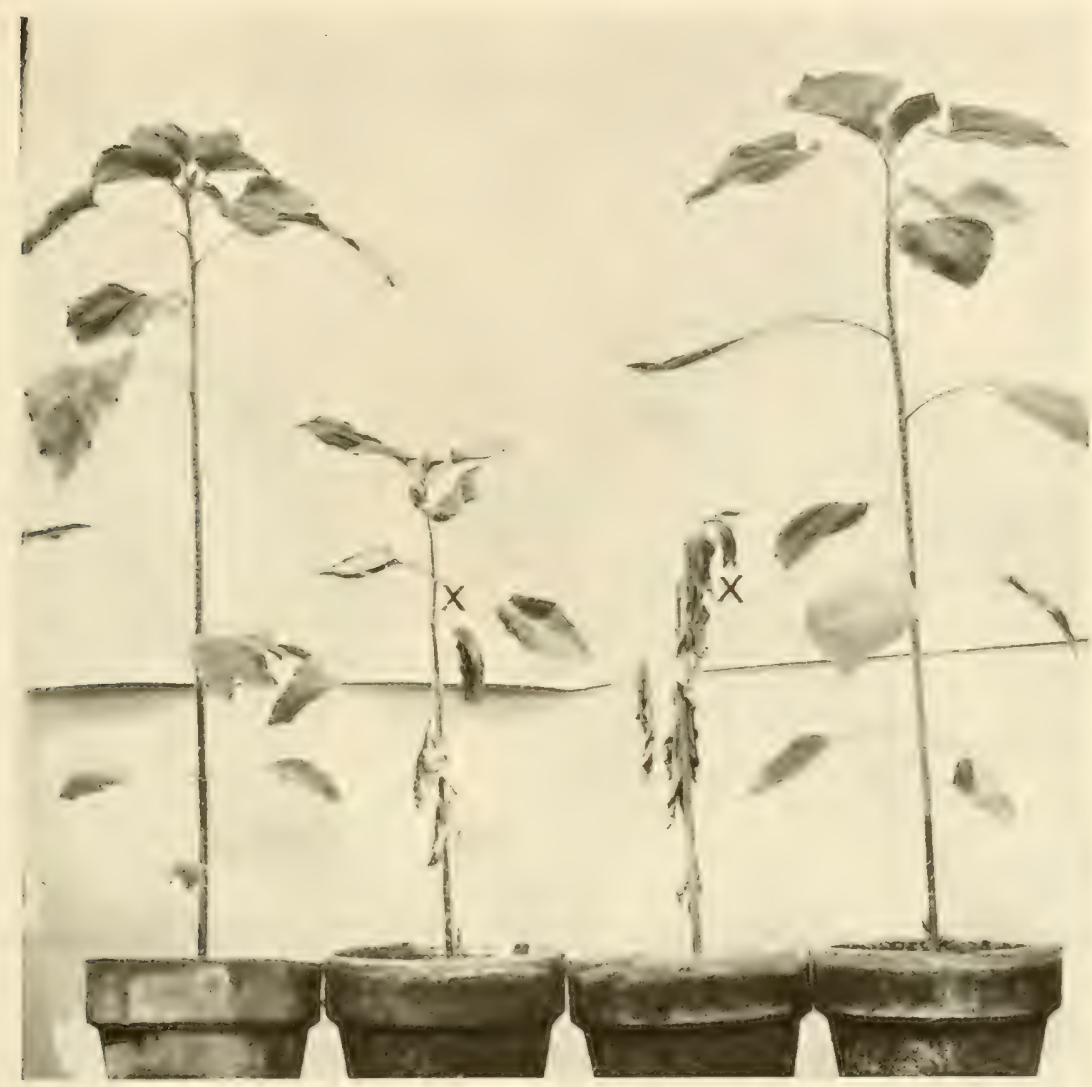

FIg. 131,-Common sunflowers (Nos, 3 and 4) inoculated with Bacterium solanacearum by needle pricks on July 12, 1918, at $X$ (on the stem) and badly dwarfed and wilting. The controls at either side were 33 inches high. Photographed July 30, 1918, about 1/8 natural size. Experiments of Smith and Godfrey.

be expected from cultures isolated the same summer they are used.

\section{Determine}

1. For the organisir. Morphology.-Size in microns (stain with methyl violet or Ziehl's carbol fuchsin), form, aggregation 


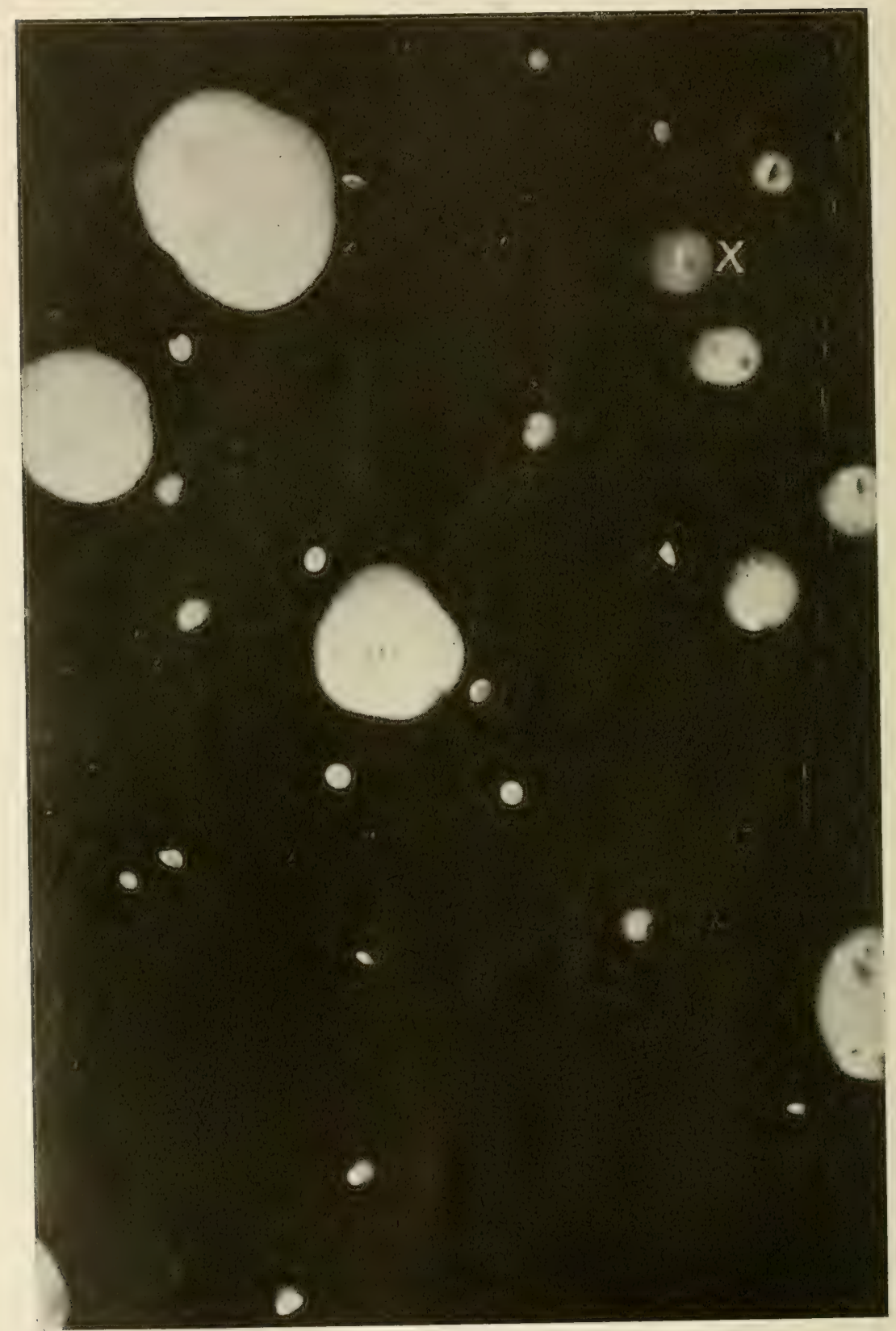

Fig. 132.- Surface and buried colonies of Bacterium solanacearum (Ricinus wilt) plated a second time from inoculated tomato. Agar plate poured July 6, 1918. Photographed July 10, with oblique light. Shows characteristic irregularity of surface colonies. At $X$ is a white concentric striate intruding colony $\times 10$. 


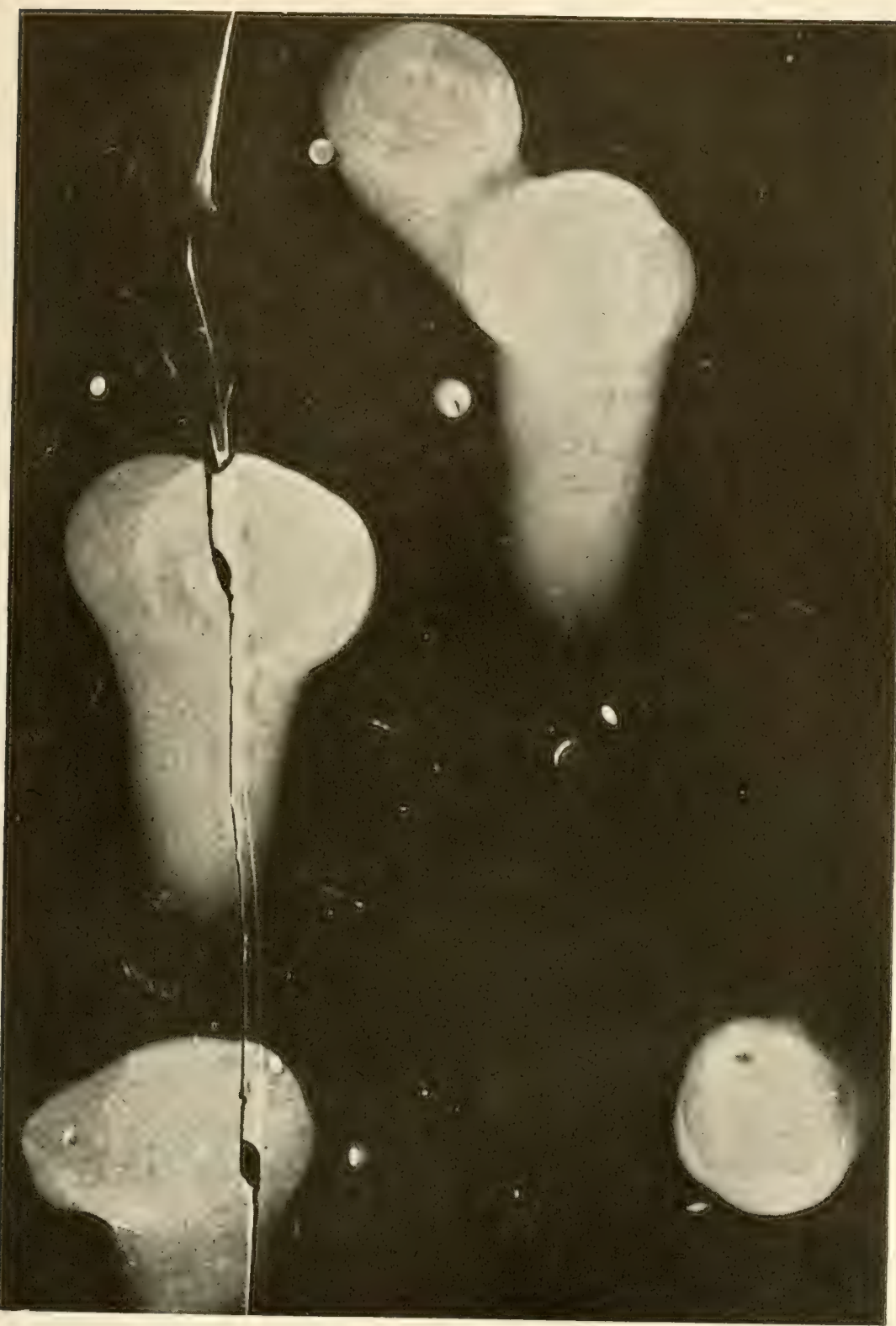

FIG. 133.-Surface and buried colonies of Bacterium solanacearum. Agar poured plate of July 13, 1918. Photographed July 17, 1918. $\times 8$. Four of the five surface colonies flowed when the plate was clamped vertically to photograph. From a broken negative. 
of elements, chains, filaments, pseudozoogloeae, motility on margin of a hanging drop (best seen by flooding a young agarstreak culture with sterile water and taking a drop from the

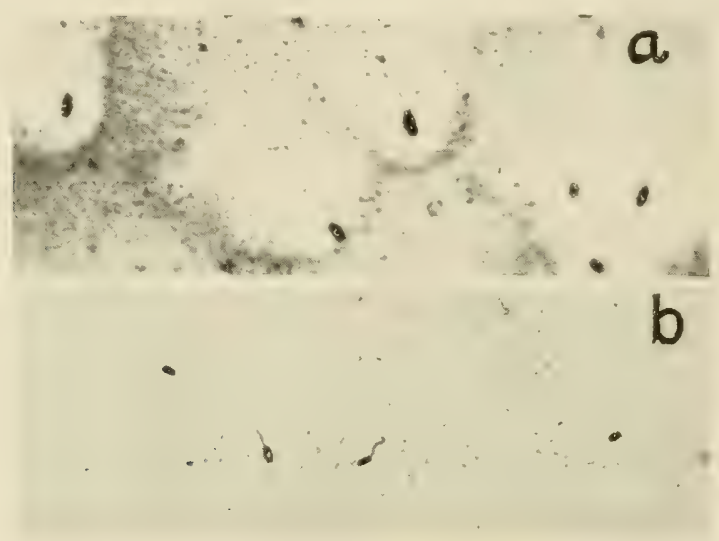

FIG. 134-Flagellate rods of Bacterium solanacearum: a, Medan III from Sumatra (Courtesy of J. A. Honing). b, North American organism (from North Carolina). Each $\times 1000$.

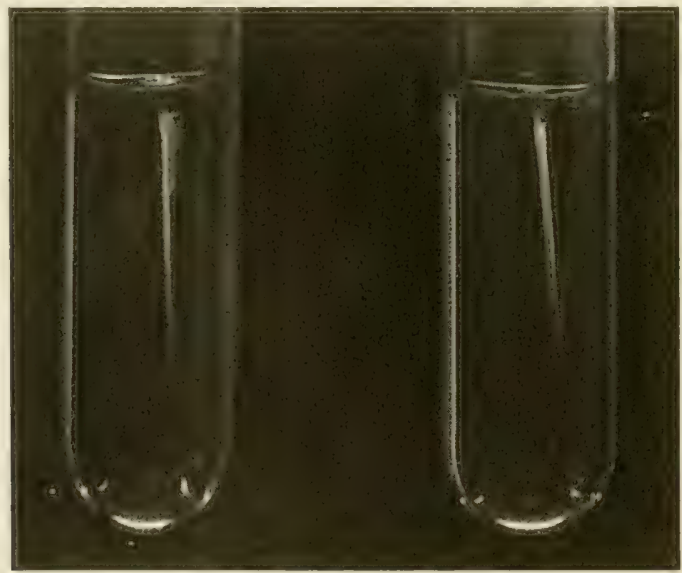

FIG. 135. - Stab cultures of Bacterium solanacearum after 5 days at $20^{\circ} \mathrm{C}$. in +10 nutrient beef peptone gelatin. Organism isolated from Baltimore Tropaeolum. No liquefaction.

top of the water after an hour or two), presence and distribution of flagella which are hard to demonstrate (try ran Ermengem's silver-nitrate method, Löwit's method, Pitfield's stain, etc.), 
absence of endospores (heat, spore stains), bipolar staining (using methylene blue), Gram's stain, acid-fast stain. Presence or absence of involution forms.

Cultural Characters.-Behavior in nutrient agar (shape of surface colonies, color in various lightings) and in gelatin (thinsown plates); streaks and stabs in agar and in gelatin (Fig. 135); growth and color on steamed potato (keep several weeks); behavior in bouillon; nitrate bouillon; Cohn's solution; Lschin-

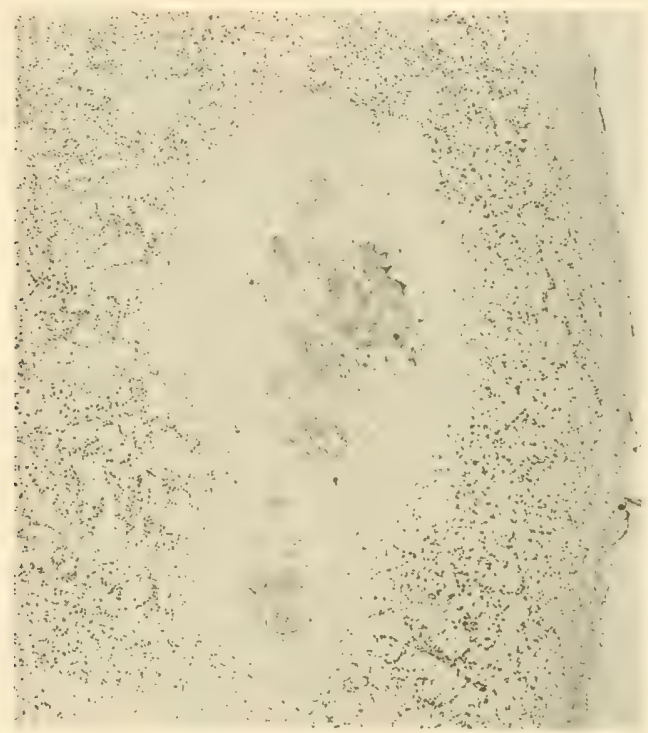

FIG. 136.-Cross-section of young Virginia potato tuber showing that starch has been removed from the vascular region occupied by Bacterium solanacearum. This was done by the potato plant, not by the schizomycete. Surface unruptured. Tuber invaded through the vascular system of the rhizome. No fungi present.

sky's solution; milk, which should be kept 10 weeks (how soon can you see your pencil, or read coarse print behind a tube of such milk?). Watch carefully to be sure that the clearing is not due to precipitation of the casein. When the milk has cleared to your satisfaction add some drops of strong hydrochloric acid. How do you explain the result? Behavior in lavender-colored, cream-free litmus milk (which should become and remain blue; watch closely to be sure that no acid is formed). Now add ammonia water, drop by drop, very gradually to check tubes of 
plain milk with shaking and compare the reaction with old milk cultures of Bacterium solanacearum. Then neutralize, and somewhat more, with hydrochloric acid and observe the second result. In view also of the bluing of litmus milk what do you conclude as to the probable cause of the slow clearing of the milk cultures? Distil old milk cultures and test steam for presence of ammonia. Test in peptone water in properly made fermentation tubes with various sugars and alcohols (compare with No. XII). Can you

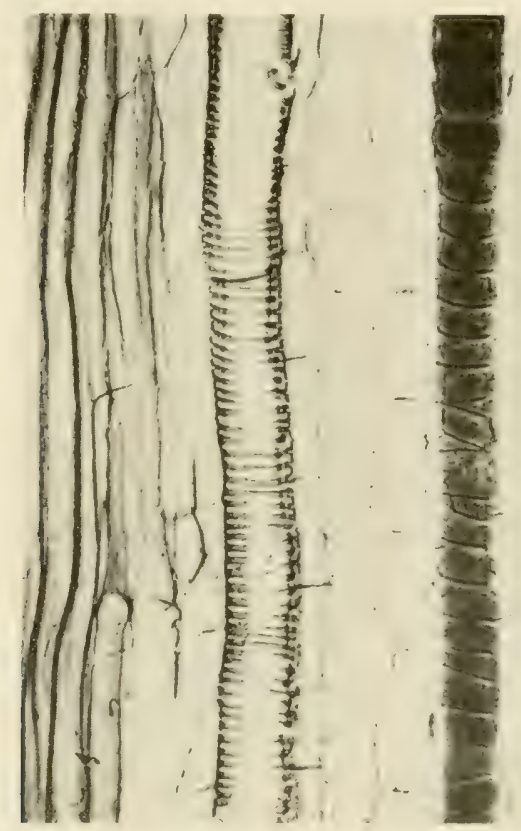

FIG. 137.-Longitudinal section through an inoculated potato stem showing the red stained dense mass of Bacterium solanacearum restricted to a single spiral vessel. $\times 170$ circa.

obtain growth in the closed end with any carbon food". (Read what is raid in "Bacteria in Relation to Plant Diseases." Vol. I, pp. 53-54, respecting good and bad fermentation tubes). If you have time study the nitrogen nutrition of the organism. Can it use asparagin? Salts of ammonia? Try Meyer's mineral solution: $a$, with ammonium citrate; $b$, with ammonium lactate. It should grow abundantly in $a$, and not at all in $b$. C'an you find the cream-splitting form? The writer knows it only from Sumatra. 
Non-nutritional Environment.-Effect of heat, of sunlight, of dry air (easily killed), of weak acids, of chloroform in bouillon, of salted bouillons?

What is the maximum temperature for growth? the minimum temperature? the optimum? What is the effect of freezing? Why does the organism so readily lose virulence (power to infect)? Can you discover any way to restore lost virulence? Any convenient way to hasten its loss?

There is reason to think that it sometimes dies out of soils or is converted into an ordinary saprophyte (my own observations and those of Coleman in Mysore). If so, we ought to be able to bring this about at will, thus disinfecting fields on which certain crops cannot now be grown profitably on account of its presence. Honing has found a soil-organism which is harmful to it. Can you find any organism which, when sown broadeast on a field, will destroy the parasite without injuring the host? Cultural studies may eventually suggest the proper treatment.

For the DISEASE. Signs.-Period of incubation. Time required to infect the whole plant. Relative effect of few $v s$. many punctures; of root $v s$. stem inoculations; of stem $v s$. leaf inoculations; of inoculations on young vs. old plants. The very susceptible tomato, Livingston's Dwarf Aristocrat, may be used for this purpose, inoculating first when 3 inches high and again when 2 feet high. On inoculated tomatoes how soon do the leaves begin to bend downward? Where first, and how soon, do the root-anlage appear on inoculated tomato shoots? Where do they naturally appear later on uninoculated plants? Can such root-anlage be made to develop further? Bind on wet sphagnum or bury a portion of the stem without separating it from the plant and examine from time to time. Have you found any plant in which the disease occurs without the brown stain? Are part of the signs due to a toxin? Inoculate seedling Ricinus by needle-pricks at top of hypocotyl as the plant emerges from the soil and compare subsequent growth with that of control plants: there is a conspicuous dwarfing due to such inoculations (Fig. 127). Consult also Fig. 131 and try Helianthus annuus. Read what Hutchinson says about 
toxins. You will find an abstract in "Bacteria in Re'ation to Plant Diseases," Vol. III, p. 267.

Write a description of the disease, drawn (of course) from your own observations on either sunflower, tomato, potato, or tobacco, or all four. If you have time, make a special study of the dwarfing effects of the parasite. To what poison is this

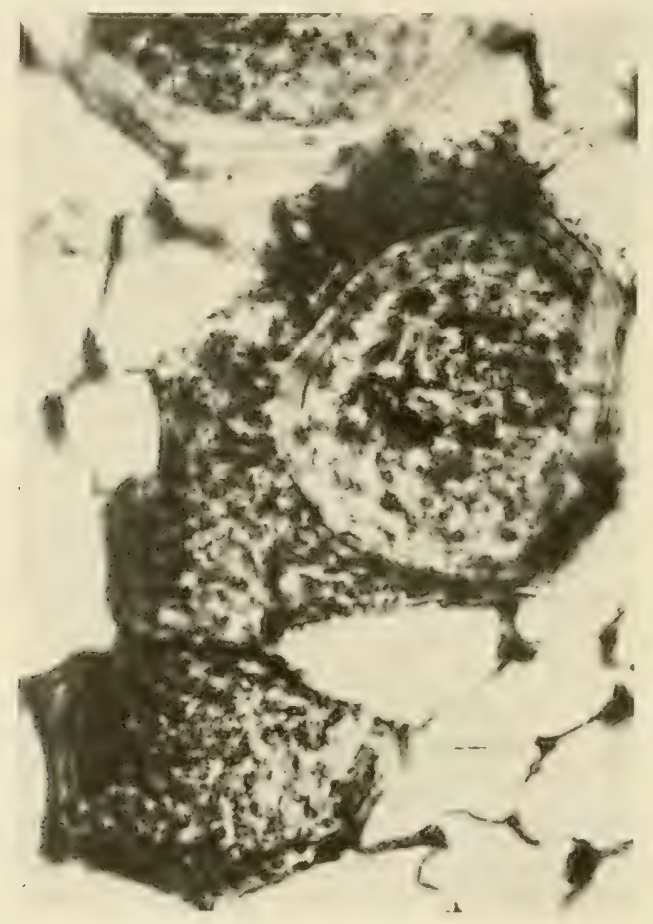

FIG. 138.-Cross-section of a potato stem in the vaseular region showing vessels occupied by Bacterium solanacearum and the beginnings of a bacterial cavity. Plant inoculated on a leaflet, May 27, 1895, and collected June 17. Stem sound externally. Block $113 . \times 800$.

due? Can you produce it with extracts of the bacteria: $a$ by injection, $b$ by watering the soil?

Histology.- Section, stain and study leaves and stems for action of the organism on the tissues. Make good permanent preparations. Are vessels occupied first? Are cavities formed in the bundles? Have you found the organism in the phloem? Study invasion of the pith, of the bark. Draw what you see. 
How are the cavities produced? On the root-infected plants (tomatoes, Daturas, Tropaeolum, castor oil-plants), trace the bacteria from vessels in the broken roots into the stem and up the latter into the leaves. Are the unbroken roots sound? Also in stem-punctured plants follow the upward and downward movement of the bacteria. How far in advance of the brown stain can you trace the bacteria? Can you judge from the relative abundance of the bacteria in the vessels of the stem (above and below the point of inoculation) whether the infec-

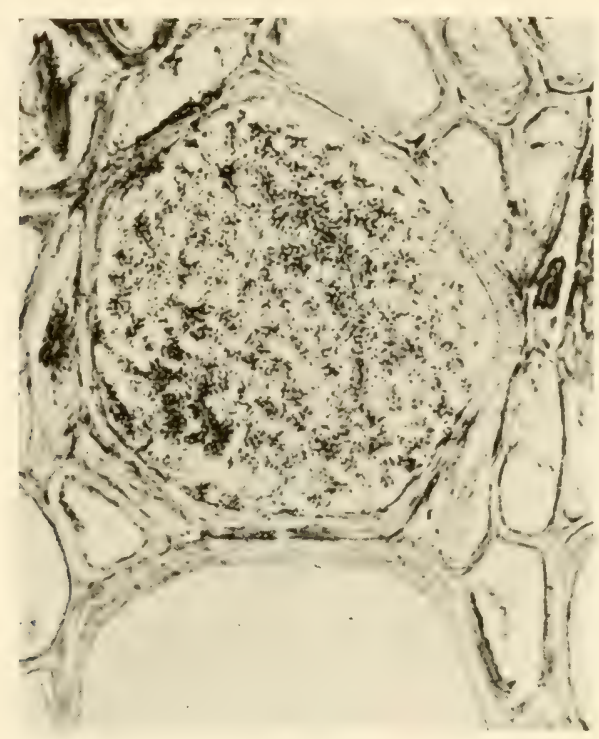

FIG. 139.-Empty and full (bacterially oceluded) vessel in a potato plant. From same series of inoculations as Fig. 138 .

tion is moving up or down the stem? Can you trace the bacteria along the vessels of the rhizome into the developing potato tuber? Is the starch in the tuber destroyed by the bacteria? Is it removed by the plant? Can you find any evidence of an attempt to "cork out" the parasite? Study early stages of cavity formation, appearance of tyloses, and other effects of the organism on the tissues.

Have you observed any bacterial motility in the plant? To see this you must ordinarily take parts only recently oceupied. 
Does the organism come freely to the surface of the attacked plants (Contrast with No. V or XII)? Does it freely attack the root-anlage (Contrast again with No. V)? Stomatal infection is easily obtained and studied on leaves of the Tropaeolum. Check Tropaeolums in the same pot are frequently attacked after some weeks. Consult Figs. 136 to 142.

Variability.--How long does an attacked plant live? Have you seen indications of immunity on the part of inoculated plants? of recovery? Do you think rapid growth or great juiciness favors the progress of the disease? What results

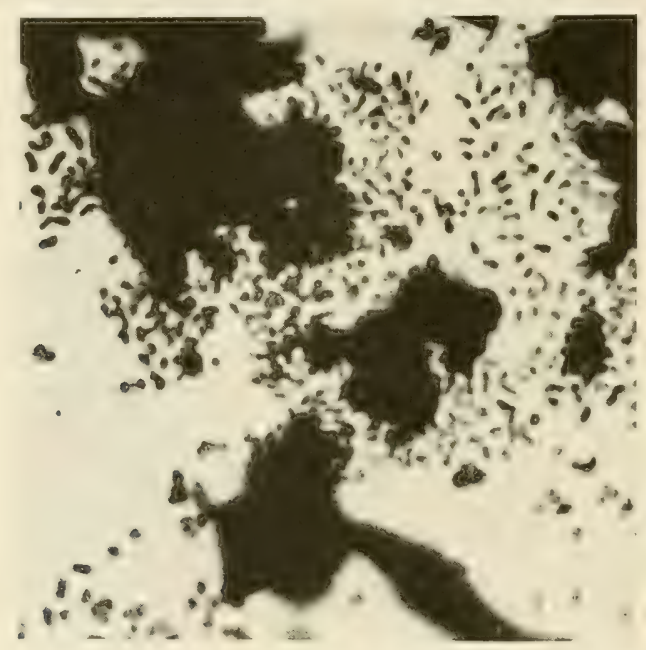

FIG. 140.-A detail from same series as Figs. 138, 139, showing the individual bacteria. $\times 1000$ circa.

did you obtain from your trials on young vs. old plants? Can you increase susceptibility by overwatering or decrease it by liming the soil? or by the liberal use of potash and phosphates? What do you conclude with reference to the effects of temperature? Does the optimum temperature for the plant coincide with that of the micro-organism? Have you found any non-susceptible varieties? A good non-susceptible tobacco would just now be worth its weight in gold! Why is the disease common in our southern states and unknown or hard to find in our Northern States? Can you determine its presence in states north of 
Virginia and Texas? Specifically: is it in California, Maine, Wisconsin, Michigan, Ohio, Kentucky or New York? Does it occur in Canada? If not in these places, why not?

Transmission.- Have you seen any indication leading you to think that insects spread this disease? In 1896 I obtained very successful infections on potato, using the Colorado potato beetle (Leptinotarsa decemlineata). Many narrow, dark, bacterially infested streaks started in the bitten places and passed

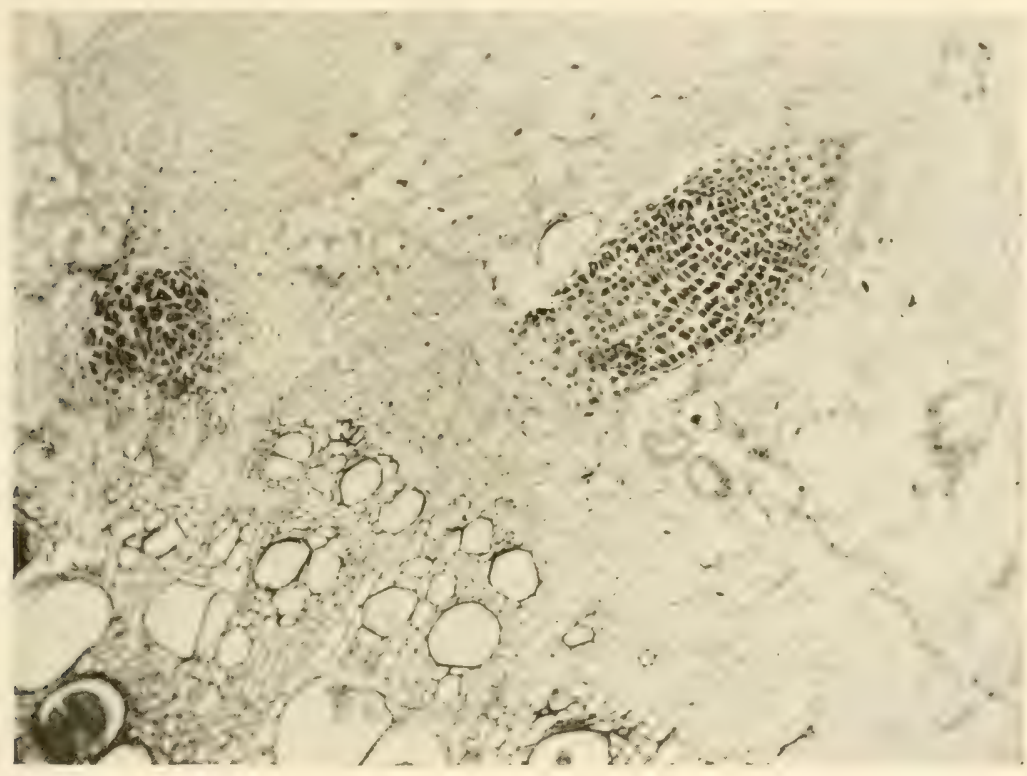

FIG. 141.-Photomicrograph showing origin and structure of two incipient roots in an inoculated diseased tomato stem. Bacterium solanacearum occurs in some of the vessels at the lower left side. What stimulus sets the roots growing?

rapidly down the stems, both stems and tubers being destroyed. If you have opportunity watch infected fields closely and if you obtain clues make some experiments. Hunger in Java incriminated several insects and also thought Phytophthora nicotiana paved the way for this parasite. Are plants on wet soils more liable to it? Do the roots of the infected plants usually bear nematode galls? Are plants on limestone soils free from it?

Of course, one susceptible crop should not closely follow 
another. There should be a long rotation on infected lands, using non-susceptible species-clovers (?), grasses, etc.

In this connection it is very important to know whether any of our common forage crops are susceptible and also whether many of our American weeds are subject to this disease, and might act as hold-over hosts. Honing found susceptible weeds in Sumatra; Stanford and Wolf have found them in North Carolina. Long ago I found it readily inoculable into Datura stramonium (the jimson-weed). Has anyone found it naturally

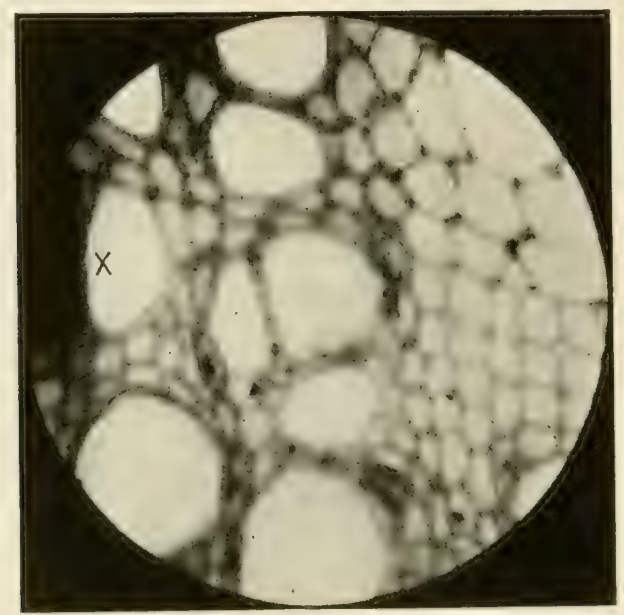

FIG. 142.-Tyloses in vessels of a potato stem attacked by Bacterium solanacearum. At $X$ is a vessel occupied by the bacteria.

on this plant? In this connection read stanford and Wolf's papers. The disease has been reported to me several times from Florida as occurring on "new land."

\section{LITERATURE}

For literature, etc., consult Van Breda de Haan's Wilt of Peanut; Brown Rot of Solanaceae; and Wilt Diseases of Tobacco in "Bacteria in Relation to Plant Diseases," Vol. III, pp. 151153, 174-219, and 220-271, Carnegie Institution of Washington, 1914. Ibid., Vol. I, plates 4, 24, 25, 26, 27, and Fig. 10; and Vol. II, Fig. 1. 
Stanford, E. E. Studies on Resistance of Tomatoes to Bacterial Wilt. N. C. Ag. Exp. Sta. 40th Ann. Rept., 19161917, pp. 92-93.

See also Stanford, E. E. and Wolf, F. A. "Studies on Bacterium solanacearum." Phytopathology, Vol. VII, No. 3, June, 1917, pp. 155-165. 1 Fig.

The first note on this disease was by Prof. T. J. Burrill in 1890. The first paper relating the disease to a definite microorganism was by the writer in 1896: "A Bacterial Disease of the Tomato, Eggplant, and Irish Potato." U. S. Dept. Agric. Bull. No. 12, Div. Veg. Phys. and Path., Washington Govt. Printing Office. Here the name Bacillus solanacearum first appears.

The first paper proving the disease to occur in tobacco was also by the writer: "The Granville Tobacco Wilt." U. S. Dept. Agric., Bu. Pl. Ind., Bull. 141, part II, Washington Gort. Printing Office, 1908.

The last notes are by

Smith and Godfrey, Brown Rot of Solanaceae on Ricinus, Science, N. S., Vol. XLVIII, July 12, 1918, pp. 42-43; and by simith and McCulloch, Bacterium solanacearum in Beans, Science, N. S., Vol. L, Sept. 5, 1919, p. 238. 


\section{BACTERIAL CANKER OF TOMATO}

Type.-This disease (Figs. 143 and 144), which for want of a better name I first called The Grand Rapids disease, after the locality in Michigan from which it was first sent to me and where it occurred seriously over large fields, is an infectious parenchymo-rascular wilt of the tomato (and probably also of the potato), somewhat resembling the brown rot of Solanaceae due to Bacterium solanacearum and often confused with it, but differing in a number of particulars, e.g., it is highly infectious through the above-ground parts; there is less brown stain in the bundles and not so strong a tendency to develop incipient aërial roots (Fig. 145); there is a slow shriveling of the leaflets one after another (Fig. 146) rather than a sudden general wilt of the leaf; the petioles are not reflexed; the meristem is attacked and corroded into cavities, e.g., the heart of the incipient roots (Fig. 147); the phloem is specially susceptible to disorganization (Figs. 148 to 150 ); and there is a strong tendency of the bacteria to come to the surface through fissures on the shriveling leaves, fruits and shoots (Figs. 151 to 154), thus affording an abundant surface slime for the above-ground infection of neighboring plants (through stomata); infection through broken roots has also been observed (Fig. 155). The disease spreads easily from one plant to another often by stomatal infection (Figs. 156 to 158 ) and is very destructive. It is, I believe, primarily a phloem disease. I think also that it is a seed-borne infection. I have seen its yellow slime close under the seeds in the middle of green tomato fruits, both in the rascular bundles of the pericarp and in those of the placenta, and also once in the base of an immature seed, but I have not yet actually traced it into or plated it from the ripened seeds. Whether or not it actually occurs in the interior of seeds capable of germination, the frequent extensive invasion of the outer part of the tomato fruit is certain to bring about a surface contamination of the seeds. It occurs in the Northern United Ntates both under glass and 


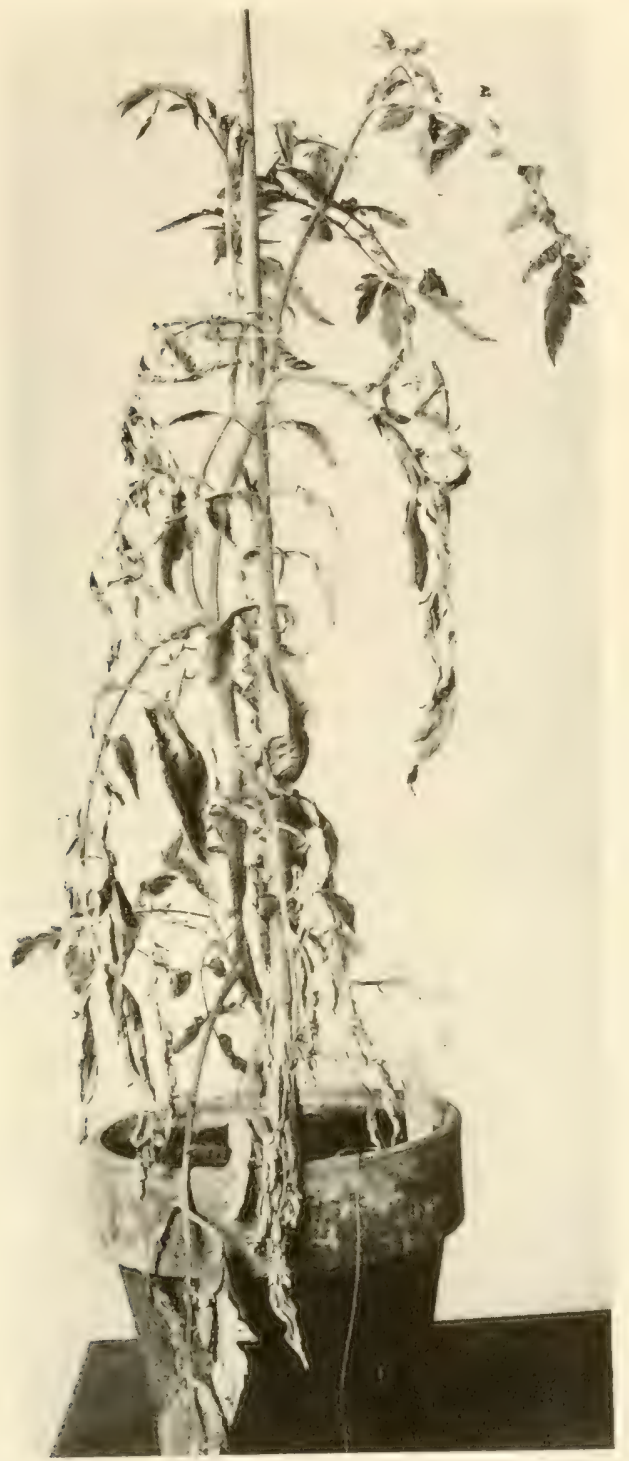

FIG. 143.-Tomato plant inoculated $23 / 2$ months with a pure culture of the non-motile, yellow A planobacter michiganense plated from a New York tomato, showing slow, irregular wilting of the leaflets. Photographed Nov. 25, 1912. This and Fig. 144, made in 1915, may be compared with pure culture inoculations of 1909 shown on plates 12 to 15 "Bacteria in Relation to Plant Diseases," Vol. III. 


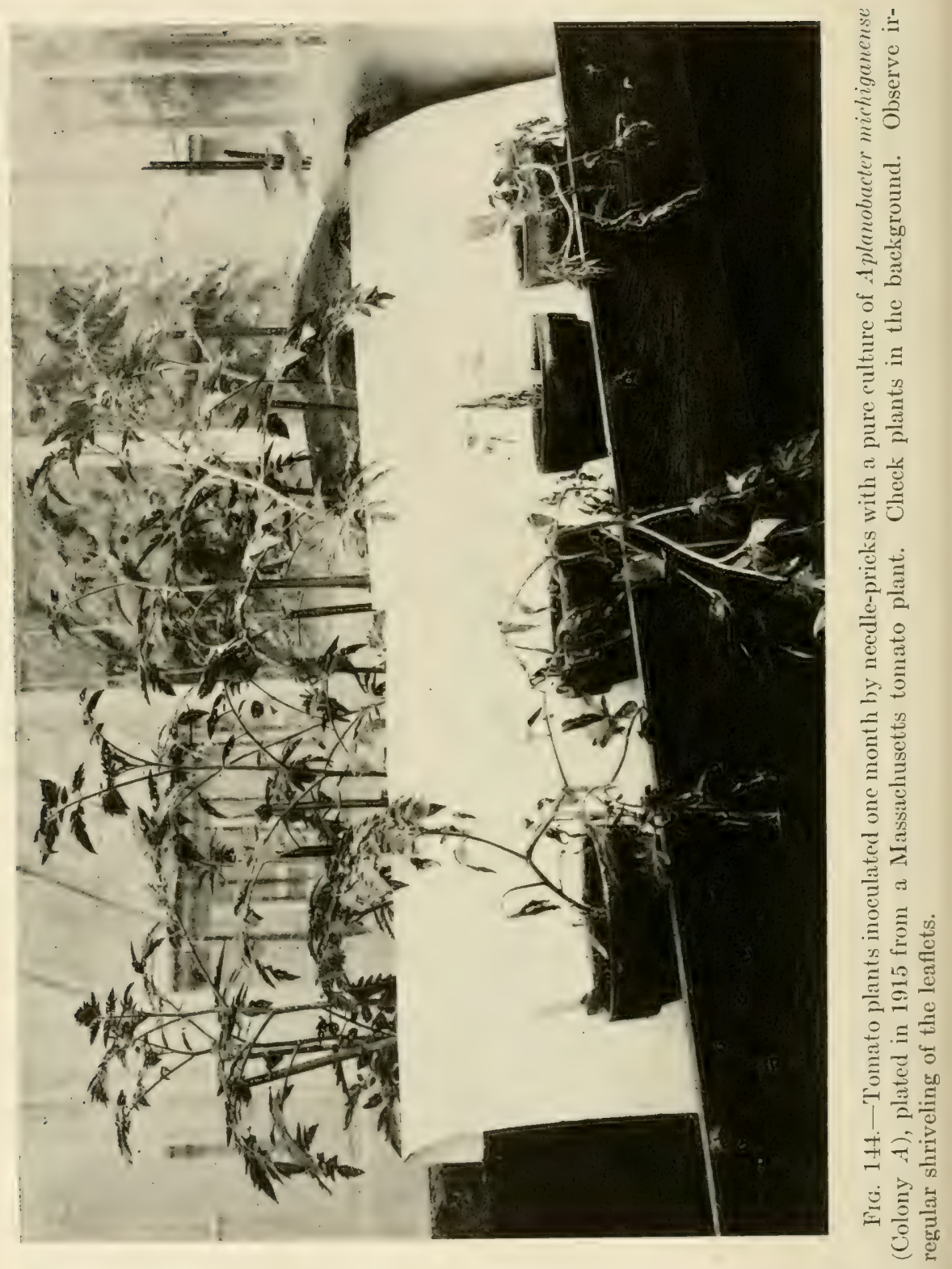


in the field. I have had it from Michigan, Western New York and Eastern Massachusetts. So far it has not been reported from the Southern States, but I believe I had it once from Texas without recognizing it as distinct from the brown rot. It undoubtedly occurs in Europe. It should be looked for in England, France, Belgium, Germany and Italy.

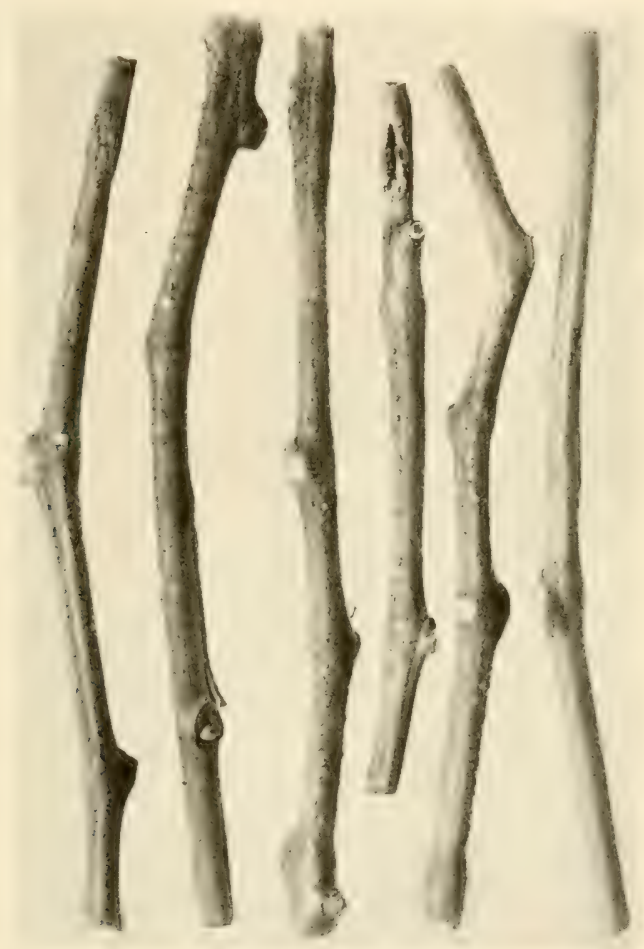

FIG. 145.-Stems of tomato plants inoculated with A planobacter michiganense October 5, 1909, and photographed January 17, 1910, when most of the foliage had shriveled. These show slight tendency to formation of adventitious roots, as compared with those attacked by Bacterium solanacearum. Compare with Fig. 122 inoculated only 12 days.

Cause.-This disease is due to Aplanobacter michiganense EFS. This is a rather short, viscid, yellow, non-motile, nonsporiferous, non-gas-forming, aërobic, very slowly liquefying, non-nitrate-reducing, rod-shaped schizomycete (Fig. 159) forming slowly on beef-peptone agar-poured plates small circular 
colonies which become darker with age but are always yellow (not orange colored). Katherine Bryan has also isolated a form which spreads on agar. It stains by Gram, but is not acidfast. It grows copiously in milk with slow coagulation, forming a thick pellicle and a broad yellow rim. A very little acid seems to be produced, as litmus in milk becomes gray or purplish

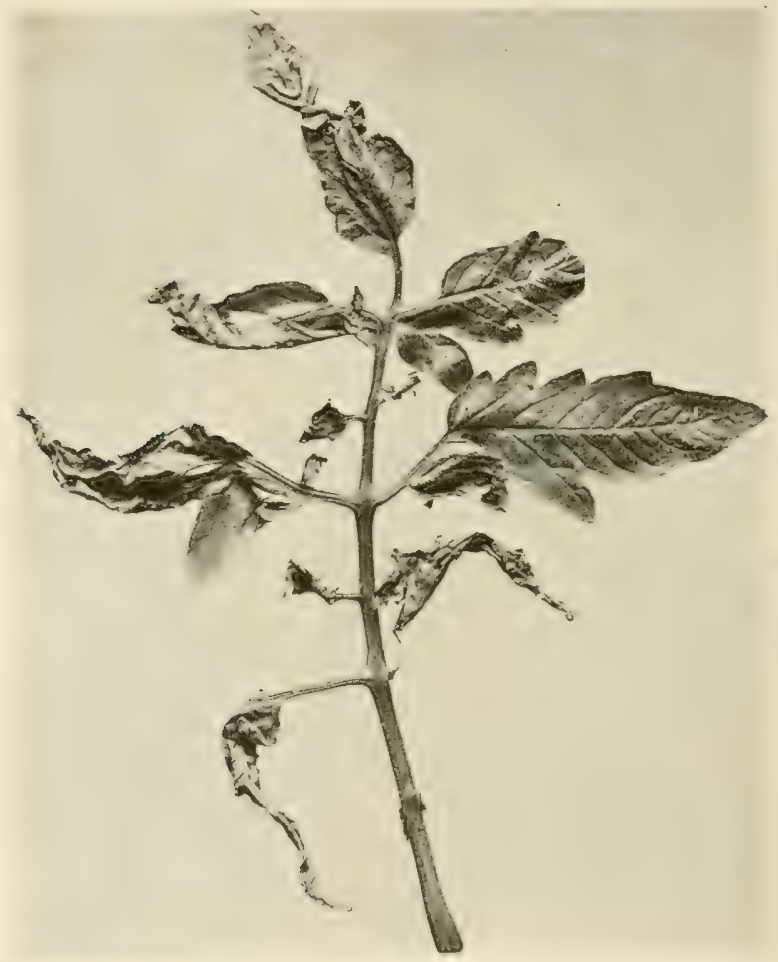

Frg. 146.-Tomato leaf showing irregular wilting of leaflets due to Aplanobacter michiganense. Stem inoculation by Mary Katherine Bryan using a round colony. Photographed May 3, 1917.

red before it is reduced. It grows well on cylinders of steamed potato standing in water, the bacterial layer being pale yellow at first, becoming bright yellow ( $R_{2}$, light cadmium), smooth and inclined to spread. In color, the slime of this organism on potato is not unlike that of Bacterium campestre, but the growth is less prolonged. The substratum out of the water is grayed. Its growth in peptone bouillon, and on gelatin- and agar-poured 
plates is very slow, often so slow as to discourage isolations. It is sensitive to heat, acids, even of beef juice (Fig. 160), and sodium chlorid. It endures drying well. It gradually loses virulence on culture media. Litmus agar containing dextrose is reddened. It does not grow in Cohn's solution or in Uschinsky's solution. The slime is apt to be viscid, both on potato and on agar. It is also viscid in certain sugar solutions. Is it ever viscid in milk?

Spieckermann in Germany has described a potato disease of slow development but considerable importance, due to a slowgrowing, yellow, non-motile schizonycete which I suspect to be this organism, or one closely related to it. This he has named Bacterium sepedonicum ( 1 pl. sepedonicum in my terminology.)

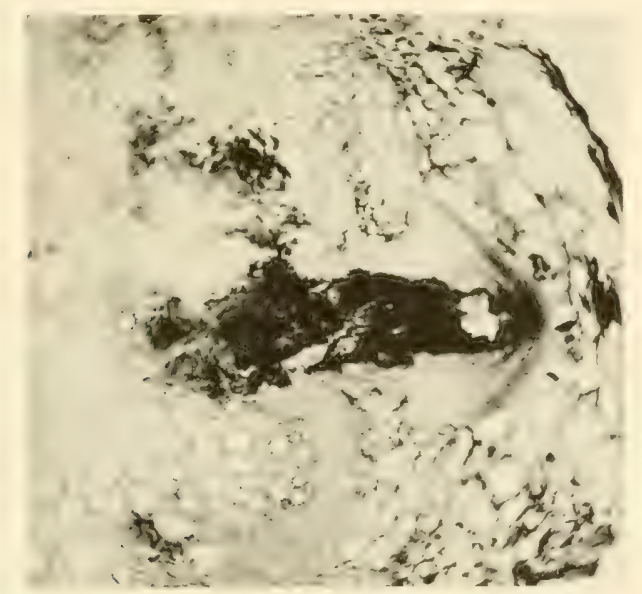

FIG. 147.-Tomato stem in cross-section showing the center of an incipient root honeycombed and destroyed by A planobacter michiganense.

Technic.-Because of the slow development on poured plates, isolations from the plant may be made in deep Petri dishes by parallel streaks on slices of steamed potato, where the last wipings of the needle (there should be 6 or 8 ) should yield single colonies from which poured plates and sub-cultures may be made.

The upper part of stems of young rapidly growing plants may be used for inoculations which may be by needle-pricks from young potato cultures. If the organism is virulent, results will begin to appear in 10 or 15 days, but the inoculated plants should 

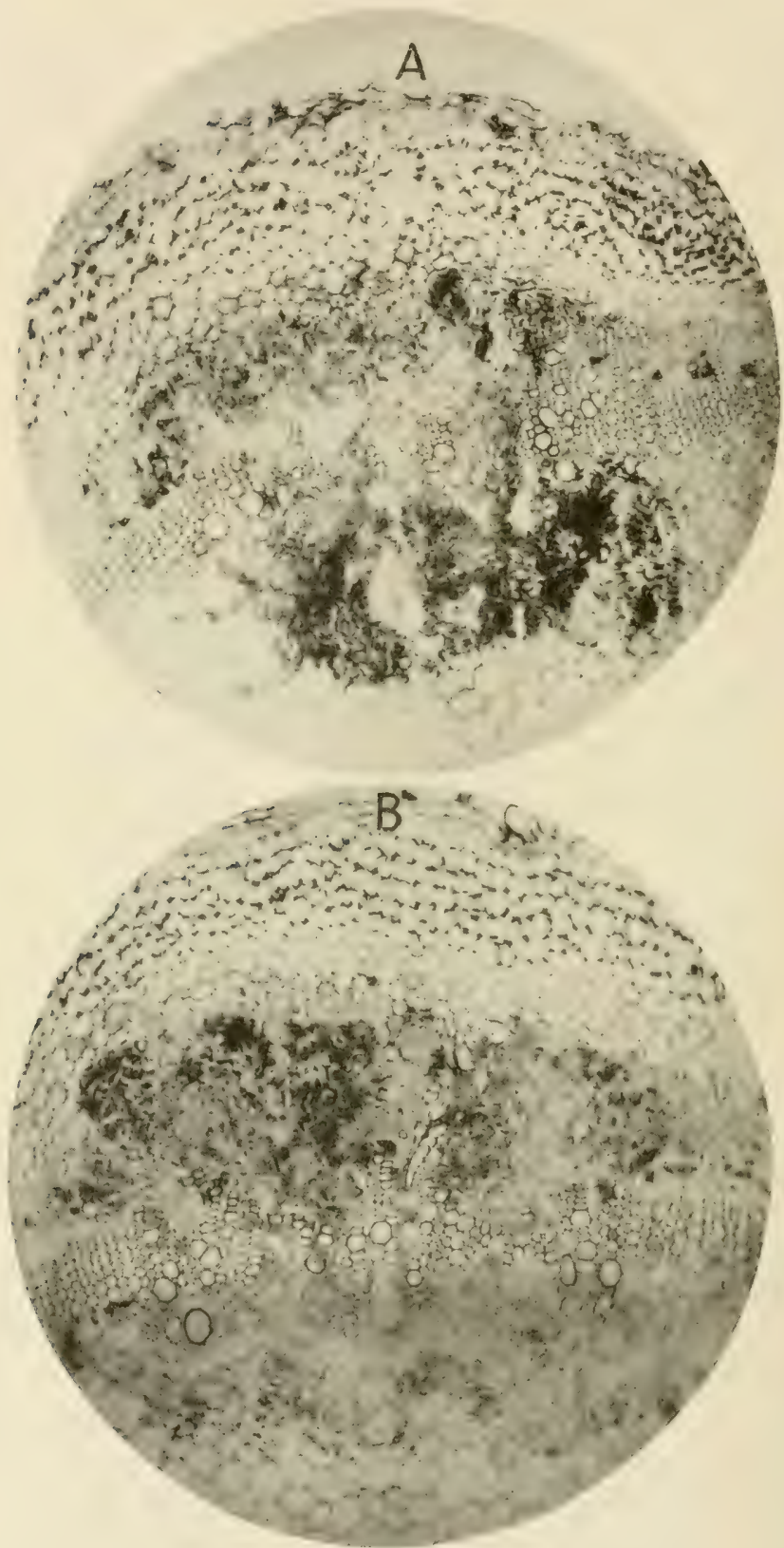

FIG. 148.-A. B. Tomato stem inoculated with Aplanobacter michiganense, showing bacterial cavities to either side of the wood, i.e., cavities originating in the phloem; xylem not much disturbed. A later stage than Fig. 143. The two views are on opposite sides of the same stem and at the same level. 


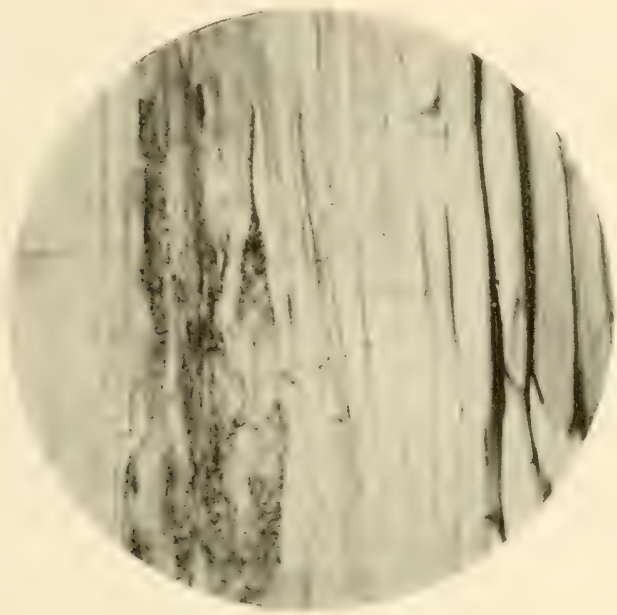

FIG. 149.-Longitudinal section of a tomato stem showing the phloem attacked by A planobacter michiganense and the other tissues free.

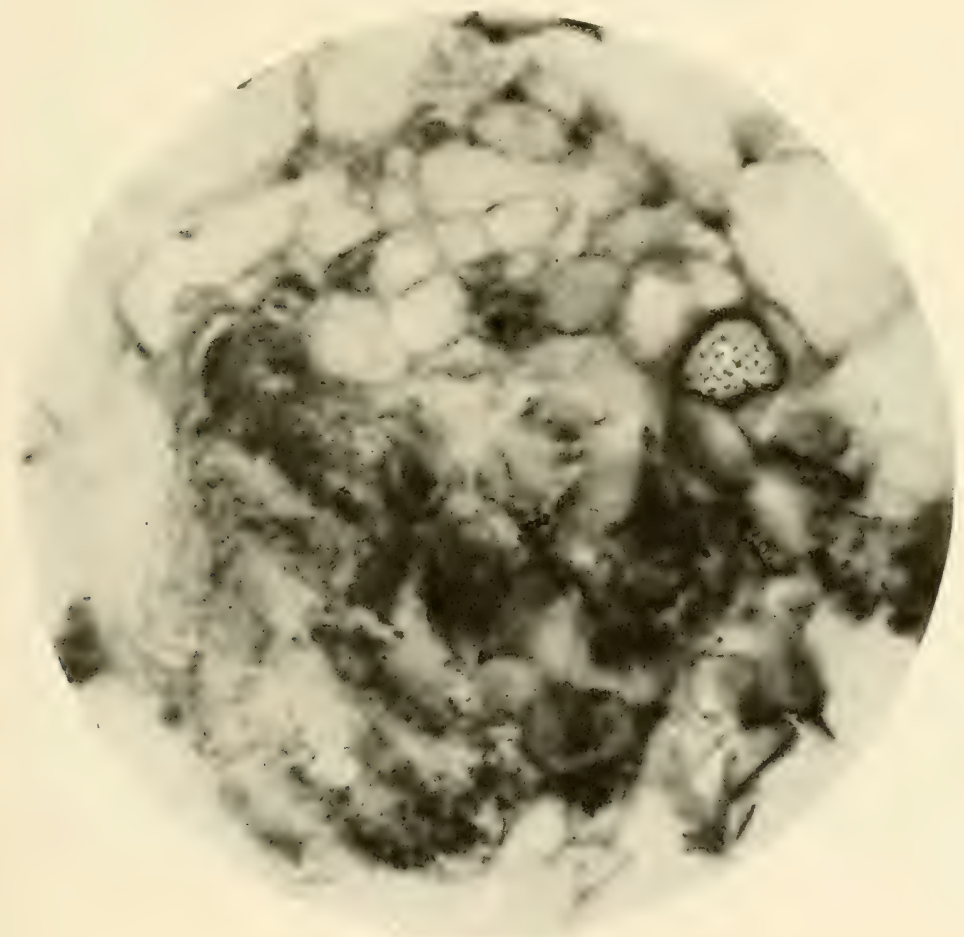

FIG. 150.-Cross-section of a tomato stem showing a small group of sievetubes attacked by Aplanobacter michiganense and the surrounding tissue free Sieve-plates are visible. 


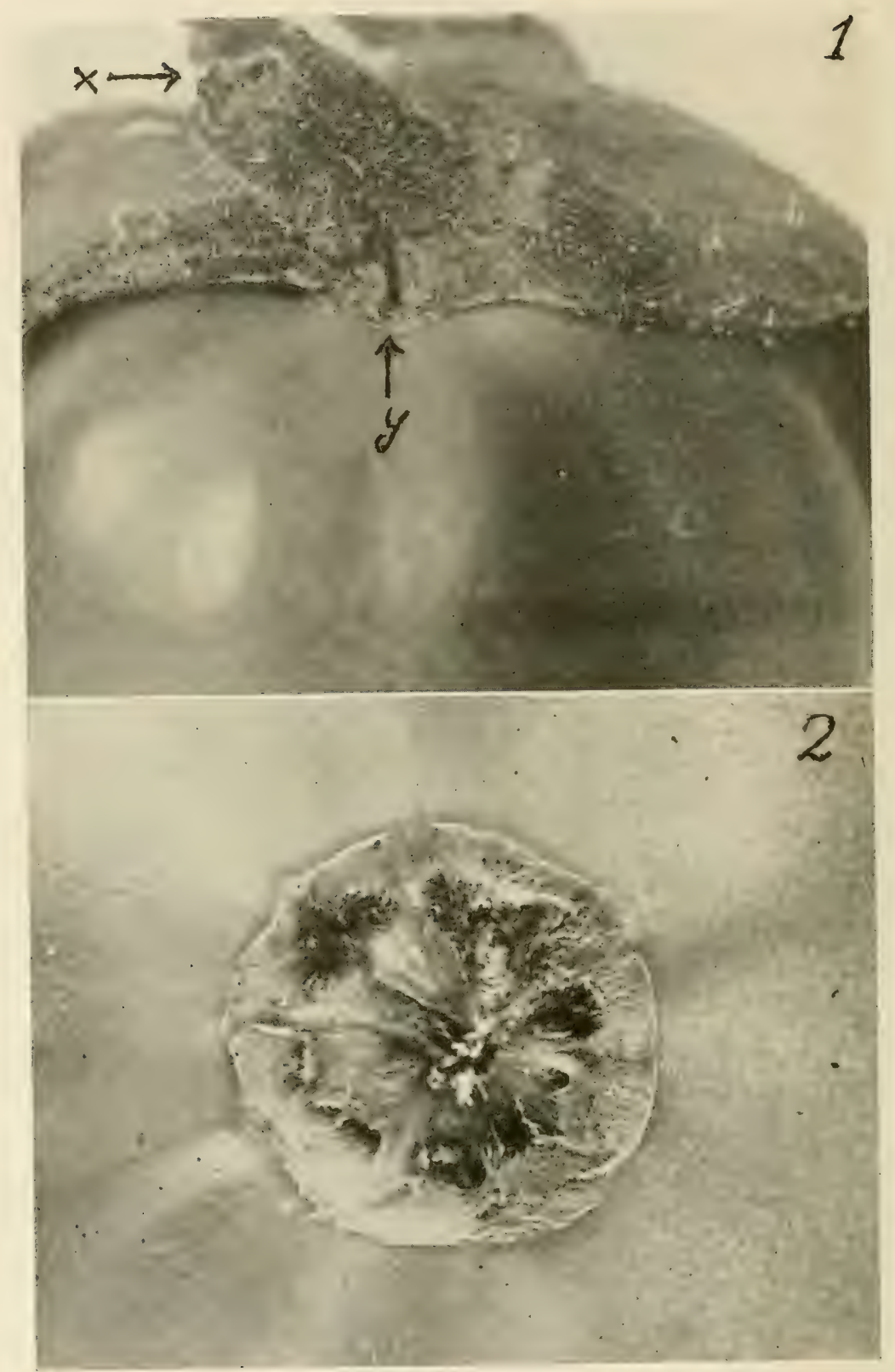

Fig. 151.-(1) Green tomato fruit sound ex́ternally but showing the pedicel (at $x$ ) honeycombed and full of Aplanobacter michiganense. At $y$ also there is a 


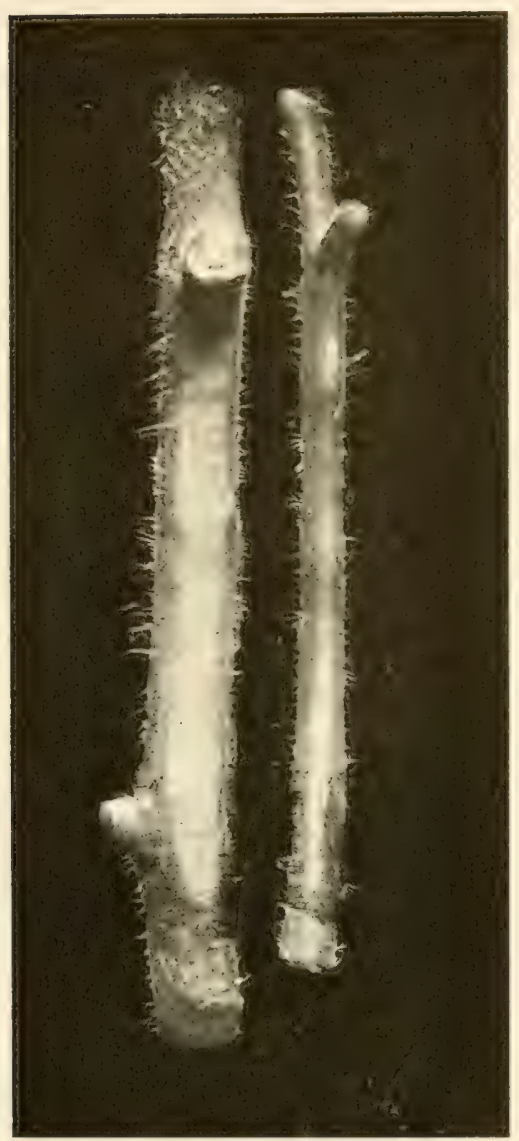

FIG. 152.

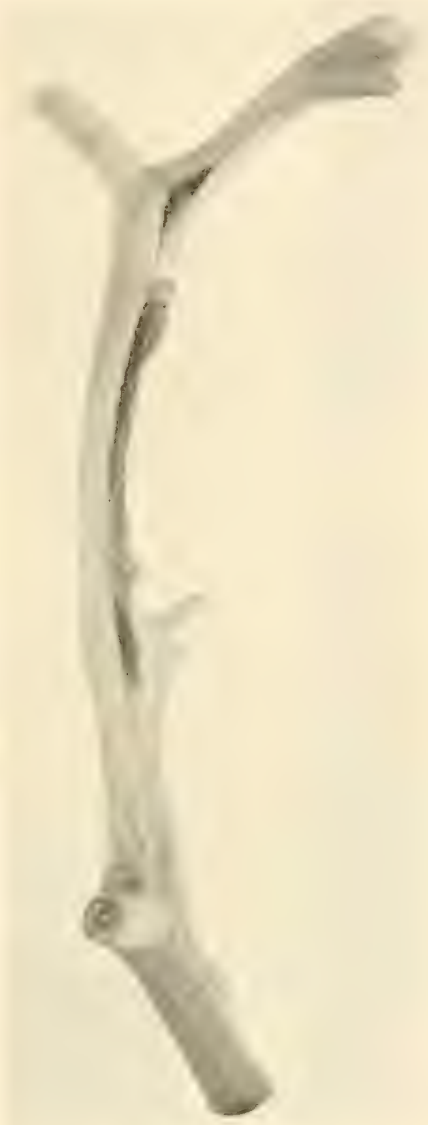

Fig. 153.

Fig. 152.-Tomato stems showing loss of color (whitening) and swelling prior to the formation of longitudinal cankers. Plants inoculated for several weeks below parts here shown, with Aplanobacter michiganense (round colony). Photographed May 3, 1917. Natural size.

Fir. 153.-Typical canker-crack on a tomato stem due to A planobacter michiganense. Plant inoculated on the stem below the part here shown.

natural crack or eanker from which the yellow bacteria are oozing abundantly. $\times 5$.

(2). Another green fruit from which the diseased pedicel has been removed. On the darker parts of the scar are masses of the yellow bacteria which have penetrated into the interior of the fruit which is sound externally. $\times 8$.

Natural infections from a hothouse in Massachusetts. Received in September, 1915. These yielded a long series of pure culture inoculations. 
be kept under observation for three months or more. The spreading colony is the more virulent one.

Agar-plate cultures, especially when

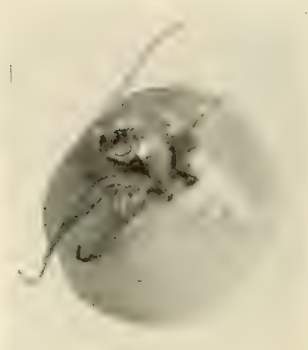

FI G. 154.-Green tomato fruit oozing Aplanolacter michiganenive around the pedicel. The result of a stem inoculation. Photographed from alcoholic material. made directly from the plant, should be kept under observation for at least fifteen days. Colonies are seldom ready for examination earlier than the eighth day. Agar titrating +8 or +10 on Fuller's scale is better for plate cultures than +15 or that which is more acid. In general, inoculations will be more successful if made with sub-cultures from recent isolations rather than with those long in the laboratory. They should be of the same summer, if possible.

\section{Determine}

FOR THE ORGanisur. Morphology.Size in microns, form, aggregation of elements. Examine for motility, stain with flagella stains, search for endospores, stain

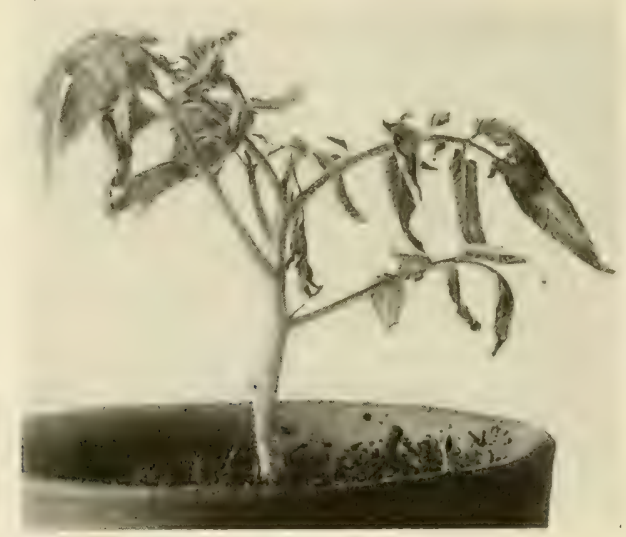

FIG. 155.-Tomato plant infected with a pure eulture of Aplanobacter michiganense through the soil by way of broken roots. Inoculated Nov. 17, 1910. Photographed Dec. 21, 1910. This also shows irregular wilt of leaflets.

viscid cultures for a capsule; try Gram's stain; acid-fast stain. Any evidence of involution forms? 
Cultural Characters.-Growth on thick vs. thin-sown agar and gelatin plates. Behavior in agar and gelatin streaks and stabs. Can you find two types of colony: $a$ round, $b$ spreading? On which agar do you get the best results $(a)+15,(b)+6$, or $(c)$ +0 ? Will the organism grow on -10 agar" - 20 agar? Appearance on steamed potato; behavior in bouillon, and in nitrate bouillon;

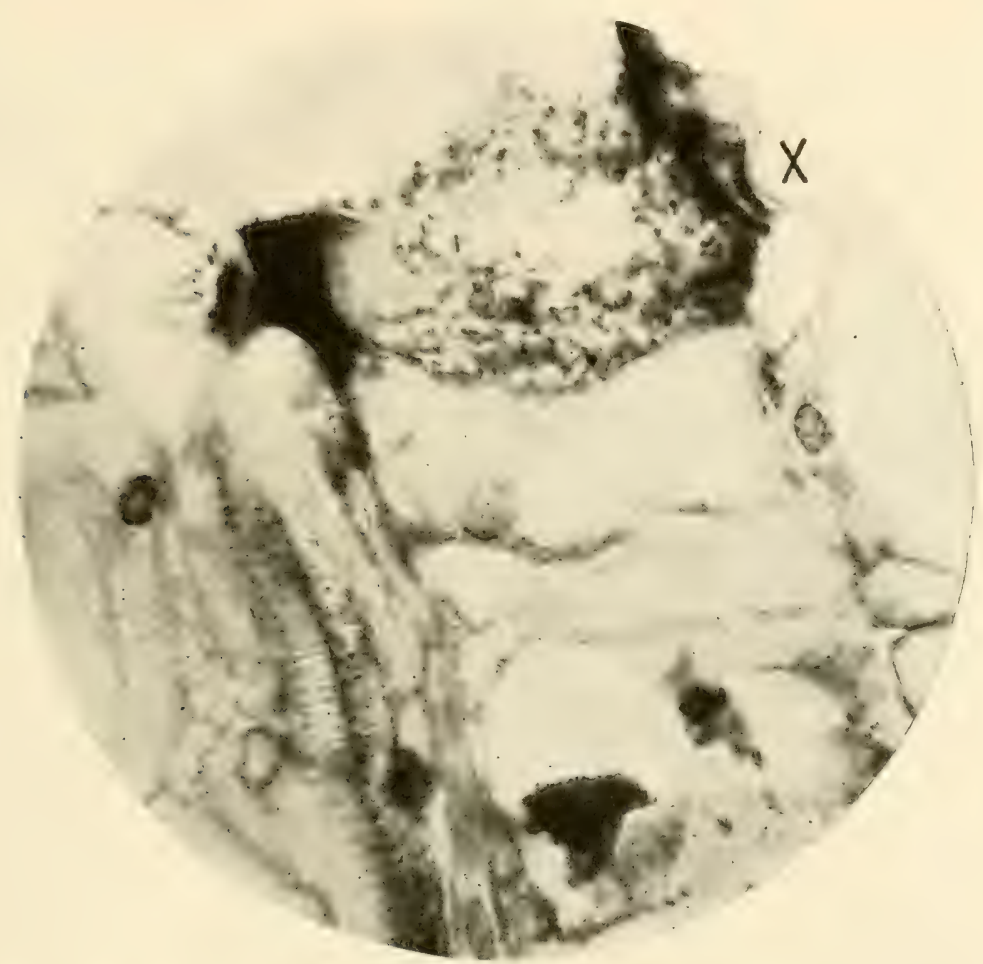

FiG. 156. - Stomatal infection on sprayed tomato leaf due to Aplanobacter michiganense. The stoma is at $X$. Under it the cells are destroyed and the bacteria are abundant in the bundle. Time, 21 days.

behavior in milk and litmus milk; streaks on litmus-lactose agar; grow th in peptone water in fermentation tubes with various sugar's and alcohols. Relative rapidity of growth in diluted tomato and potato juices, as compared with Dunham's solution and peptone bouillon (Titrate each to determine acidity and inoculate sparingly with a $1-\mathrm{mm}$. loop from a fluid culture); behavior in 
various synthetic media; Cohn's solution, U'schinsky's solution, Fermi's solution, Meyer's solution, etc.

Non-nutritional Environment.-This organism offers a number of very interesting problems. Perhaps you can help to settle 'some of them. Can you get any growth in milk, or in bouillon, at $1^{\circ} \mathrm{C}$, or at $37^{\circ} \mathrm{C}$ ? What is the thermal death-point? Determine its toleration for malic, citric, and tartaric acids begin-

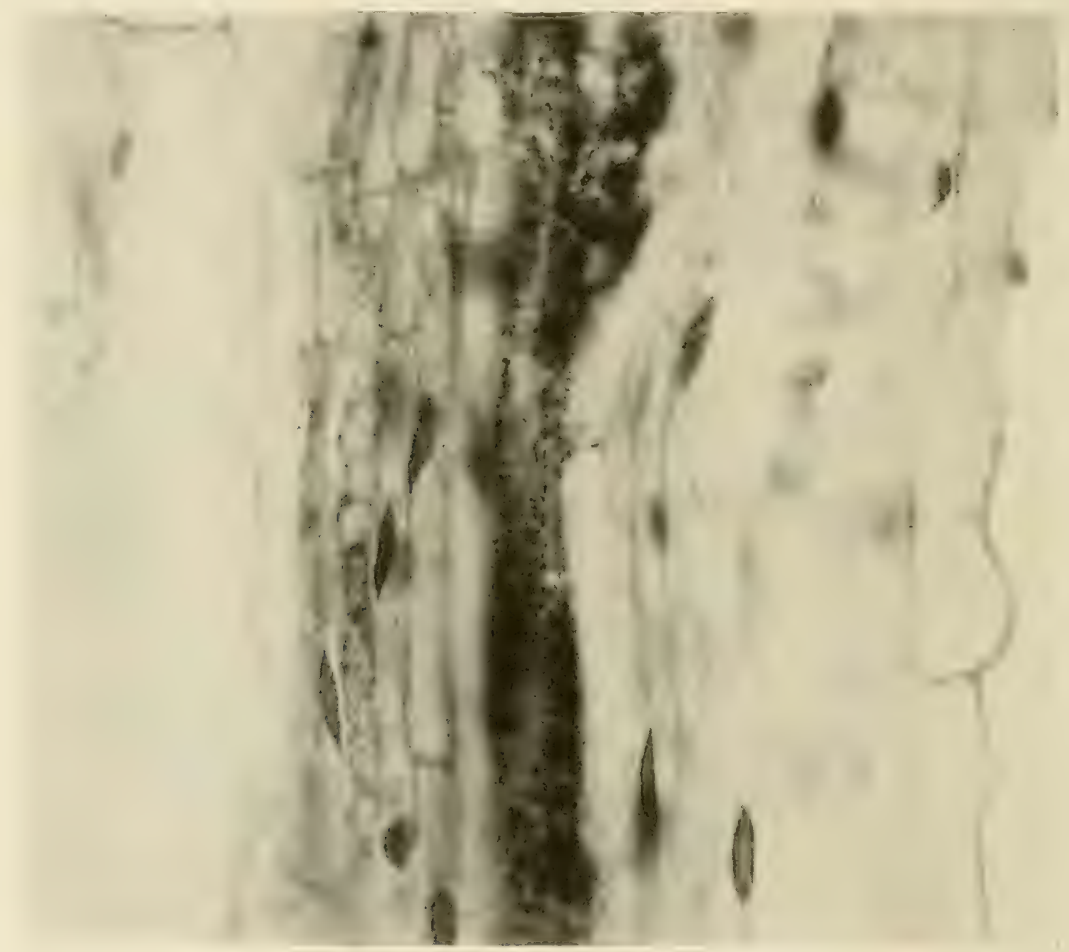

FiG. 157.-Longitudinal section of a tomato leaf showing bundle disorganization due to Aplanobacter michiganense. Stained section from a sprayed leaf. Time, 21 days.

ning with +20 (the acid of the tomato is said to be tartaric); for sodium hydrate beginning with $-20^{\circ}$. My own experiments lead me to think it is rather tolerant of alkali and comparatively sensitive to organic acids. Try salted bouillons-1, 2, 3, 4 , 5 , etc., per cent. Determine if you can the inhibiting substance in the culture-media in which it makessuch a slow growth; 
is it the peptone? or the sarco-lactic acid of the beef juice? Test its growth in diluted steamed tomato juice or potato juice, and in the same with very small quantities of lactic acid added (the first days are the important ones for observation). What are your conclusions? Can you devise an agar medium on which it will grow readily? Determine effect of drying, of insolation, of germicides. What causes loss of virulence? What is the best medium for its retention?

For the disease. Signs.-Period of incubation. Time between appearance of the disease on the inoculated leat and general infection of the plant. What are the most conspicuous external indications of his disease? Why are the leaves not reflexed as in case of No. IV? Note especially the swollen whitish lines followed by corrosion and eracking open of stems, petioles, etc., and the irregular wilting of the leaflets on attacked leaves. Write a description of it.

Histology.-Cut freehand sections of leaves, stems, roots and fruits, and determine: $a$, extent of

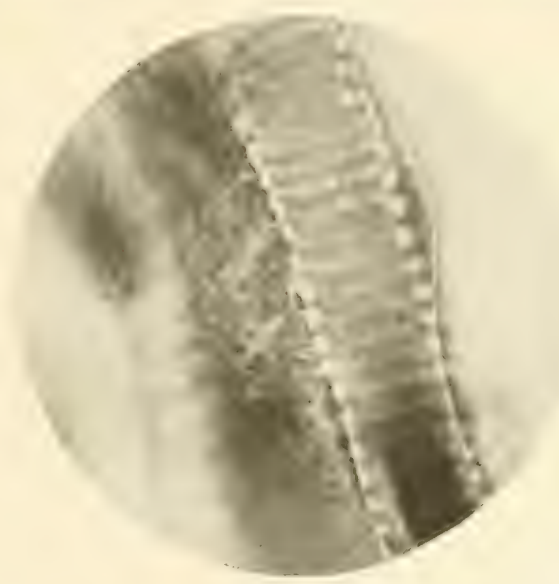

FIG. 158.-Detail showing infection of a small bundle in a tomato leaf sprayed with A planobacter michiganense. Time, 21 days.

movement of the bacteria in the plant; $b$, tissues attacked (xylem, phloem, parenchyma); $c$, movement of the bacteria to the surface of the plant: $d$, evidence of bacterial entrance through stomata. Make stamed preparations from paraffin-embedded material, showing the bacteria in these various tissues (stain with Ziehl's carbol fuchsin). How are the cavities formed? Is cellulose destroyed?

Variability.-How long does an attacked plant live? Are young plants more susceptible than half-grown or old plants? Search in the field and hothouse for resistant varieties, and if you see indications of resistance, make experiments. If you 
have time and a place include a rariety test in your inoculations. Determine if the shoots of the potato are susceptible (do not expect rapid infection); look for it in the field upon potatoes: (a) stems; (b) tubers. (Read Spieckermann's papers.)

Transmission.-Determine whether I am right in thinking that the organism freely oozes to the surface of diseased tomato plants, and that infections are

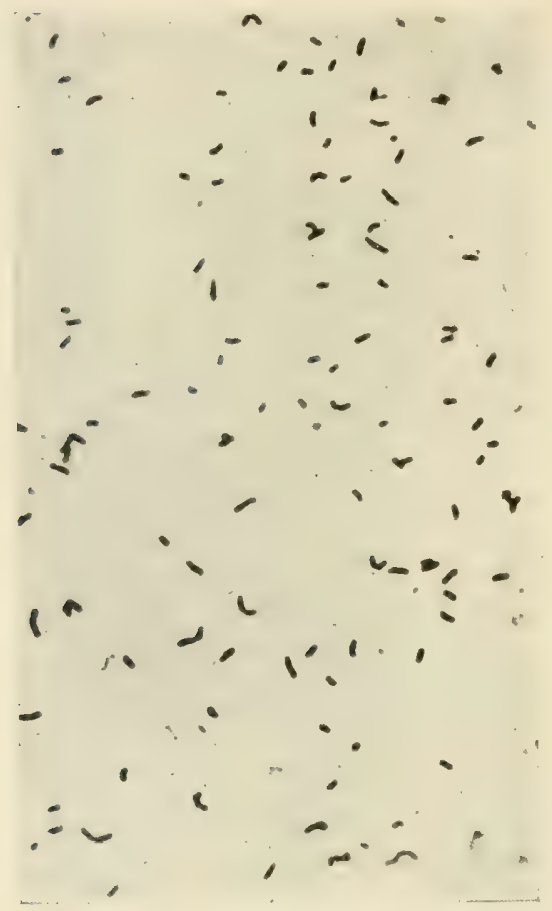

Fig. 159.- -Rods of Aplanobacter michiganense. From an agar culture 2 days old, stained by van Ermengem's silver nitrate method. $\times 1000$. commonly above ground through stomata.

It is very important to know whether it is borne on tomato seeds (I believe it is, since it resists drying and we find it very commonly in the fruits). If so, it may come into the field from the seed bed, as in case of Bacterium campestre (No. II). To establish this conclusively, I have done it only inferentially, would be a fine practical contribution to our knowledge of the disease.

Once in the field, how is the organism carried from plant to plant? Rains excluded, it can scarcely be windborne, do you think? If you have opportunity to study this disease in the field (the writer has not had) you should examine particularly for carriers of infection (insects, etc.), for evidence of under-ground infection, i.e., through the root-system, and for transmission on seeds taken from diseased plants. The disease was so prevalent and destructive at Grand Rapids, Michigan, that seemingly it must have begun early in the life of the plants.

It escaped from my control in one of the Department of 


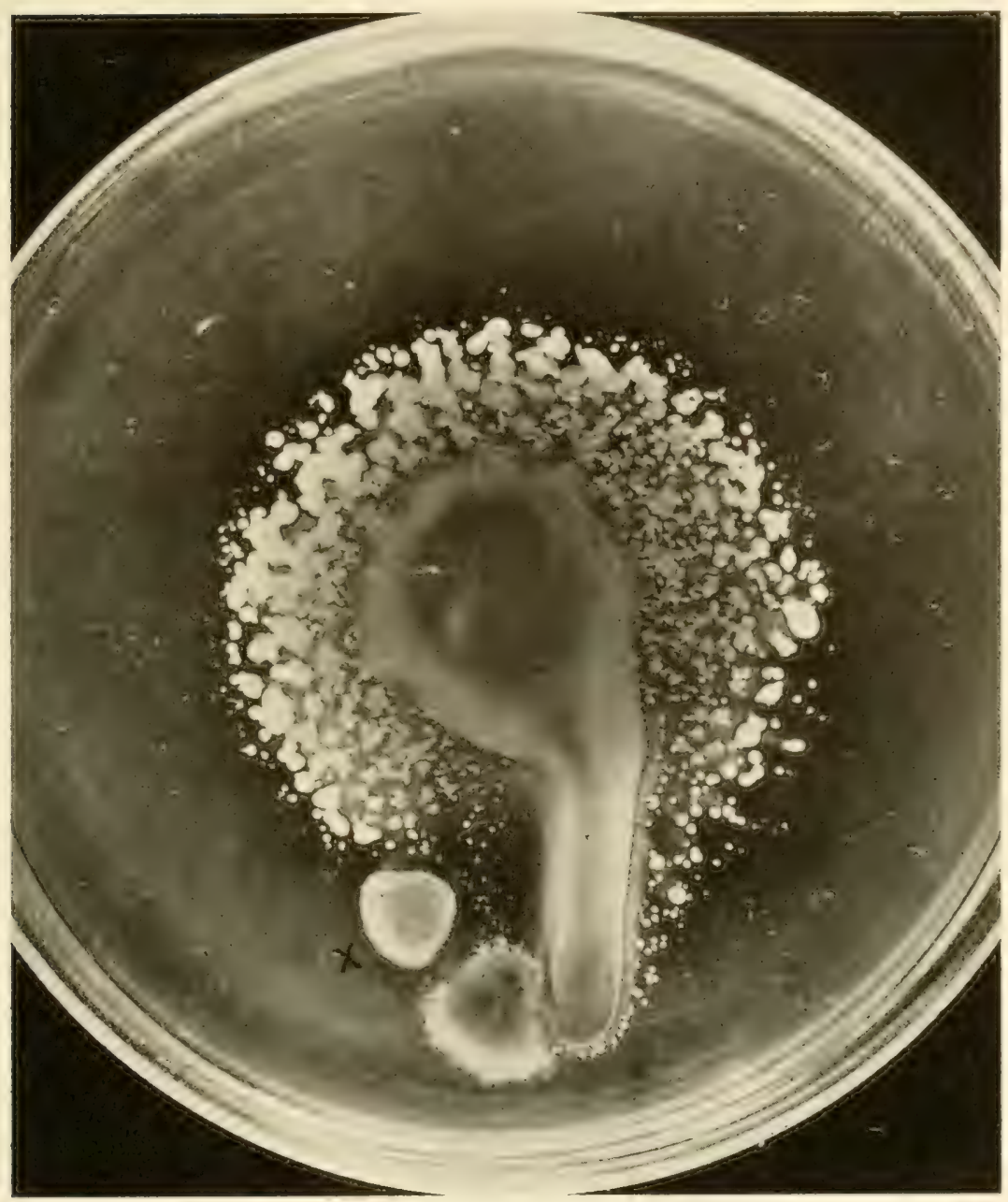

FIG. 160.-A planobacter michiganense: uniformly sown on +15 peptone-beef agar-poured plate, showing growth of colonies inhibited everywhere except in the vicinity of the central white intruding colony which is an alkali-producing schizomycete. At $x$ there is an inhibiting mold colony, probably an acid producer. There was a brown stain in the agar between and around the yellow colonies. The colonies on the inner part of the periphery were fluorescent. Those on the outer one-fourth were not fluorescent. Photographed December 13, 1915. Slightly enlarged. 


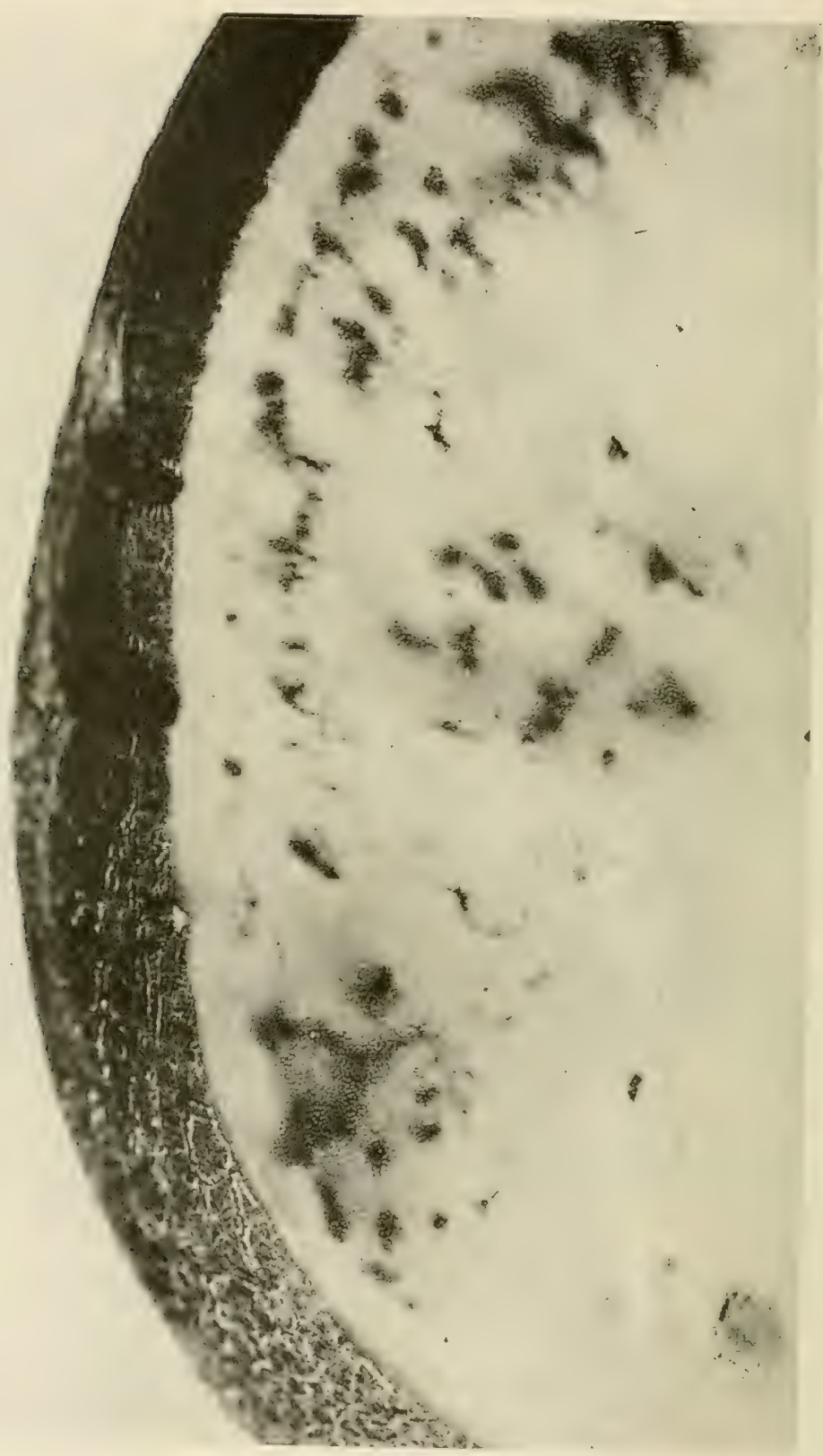

FIG. 161.-The Berkshire, Mass., potato disease (net-necrosis). Slice of tuber photographed by reflected light. February $28,1919 . \times 4$. 
Agriculture hothouses and infected various check tomato plants and also a bed of West Indian plants (Solanum mammosum) said to be resistant to Bacterium solanacearum. This unwelcome infection was attributed to spatterings from the gardener's hose. I first called attention to this method of dissemination in 1914. The experiences of growers in New York and Massachusetts show that it is capable of doing much damage to hothouse tomatoes.

Host Plants. - It is very important to determine whether this parasite has other hosts than the tomato. I believe it occurs also on the potato but the evidence is not yet conclusive.

In the winter of 1918-19 I received potatoes from Berkshire ('o., Mass., said to be fair samples of a great many oceurring in that locality. These tubers were sound externally but the outer one-half inch or more of their flesh was mottled with numerous brown spots, forked lines and streaks (Fig. 161). On studying sections under the microscope, no distinct lesions were observed but foci of bacteria were found in the center of some of the spots. In all the tubers I examined, the stem end of the tuber was always badly diseased, but often the eye-end was free (Fig. 162). When the flesh of the tuber was examined in thin section (1-3 $\mathrm{mm}$.) by transmitted light, the brown spots and streaks were seen to be surrounded by a narrow clear zone indicating disappearance of the starch in the surrounding tissues (Fig. 163) which was confirmed by tests with iodine. Several organisms were cultivated out on potato. Some made a pale whitish slime at first, becoming distinctly yellow, but in other cases pure white cultures were obtained, and in many instances nothing whatever. Inoculation tests on tomato and potato gave nothing definite.

This disease was not discovered by the planters in the field but during the winter in the stored tubers (variety, Green Mountain). This new disease has received the name of "Netnecrosis." By some it has been ascribed to frost injuries, but I cannot think the phenomena as it occurred in Massachusett. in the winter of 1918-1919, and as shown on the accompanying plates, was due to freezing. When the plates were made I believed the disease due, probably, to bacteria, but now I 


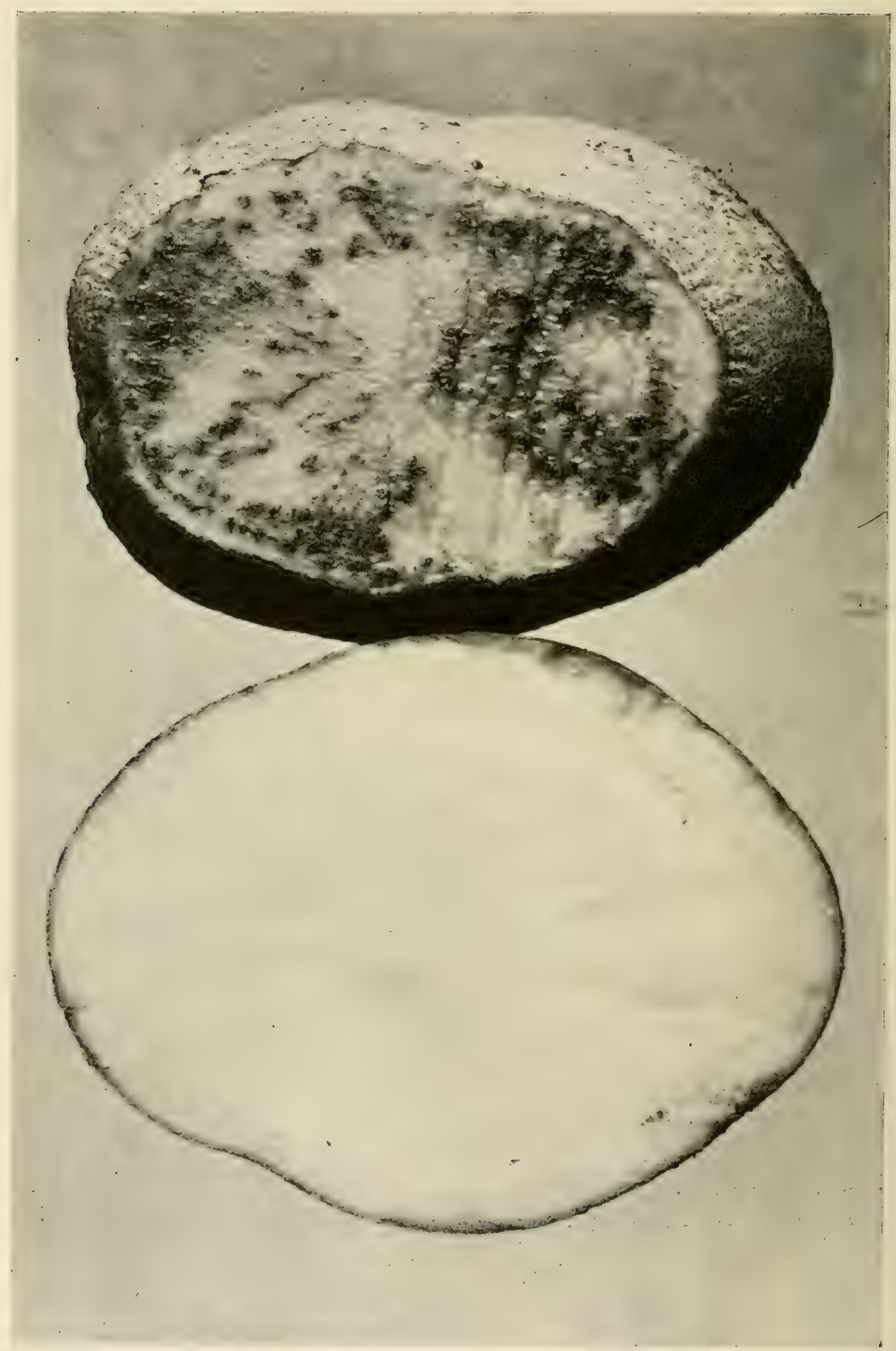

Fig. 162,-Cross-sections of a Green Mountain potato tuber from Erwin E. Maynard, Savoy Center, Berkshire Co., Mass., showing net-necrosis. Stemend diseased; eye-end free. Photographed April 3, 1919. 


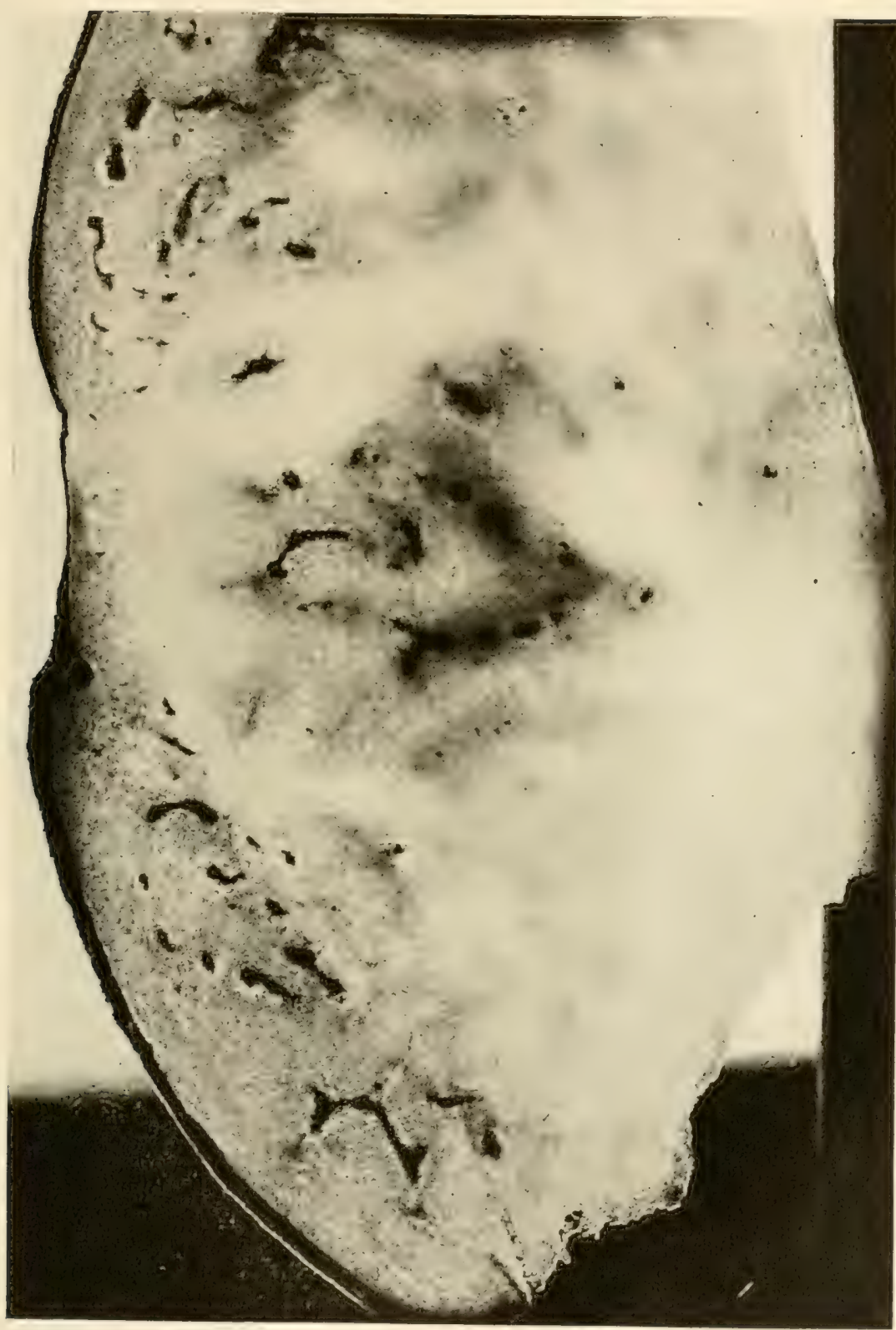

FIG. 163.-Like Fig. 161, but from a thin section photographed by transmitted light to show narrow clear spaces (starch destruction) around the browned vascular bundles. $\times 4$. 
have no definite opinion as to its cause. Possibly it is of fungus origin. The disease appeared again the following year in Berkshire County, according to Mr. Maynard, but less seriously. Such tubers give spindling p'ants. My illustrations should be compared with those of Jones, Miller and Bailey in "Frost Necrosis of Potato Tubers" (Agr. Exp. Sta. of Univ. of Wis. Research Bul. 46, Oct., 1919) which appeared since the above was in type.

\section{LITERATURE}

The first paper definitely relating this tomato disease to a particular organism was by the writer in 1910 , Science, N. S., May 20.

For literature, etc., consult The Grand Rapids Tomato Disease in "Bacteria in Relation to Plant Diseases," vol. III, pp. 161-165. In this connection, read also what is said concerning Spieckermann's potato disease, Ibid., pp. 166-167.

Spieckermann and Kotthoff's full paper on the ring rot of the potato is in Landw. Jahrbücher. Bd. 46, Heft 5, 1914.

See also Paine, Sydney G. and Bewley, W. F. "Comparison of the Stripe Disease with the Grand Rapids Tomato Disease" in Studies in Bacteriosis. IV.- "Stripe" Disease of Tomato. The Annals of Applied Biology, Vol. 6, 1919, Nos. 2 and 3, pp. 200-202. 


\section{JONES' SOFT ROT OF CARROT, ETC.}

Type.-This is a rapid bacterial wet-rot of storage parenchyma (roots, rhizomes, fruits and fleshy stems). It seldom attacks well-developed green parts, nor does it develop vigorously in storage tissues unless they are turgid. It was described in 1901 by Prof. L. R. Jones from carrot roots grown in Vermont, but he obtained it on the fleshy parts of many other plants by pure-culture inoculation, and it is now known to be widespread in nature on a variety of hosts. Probably it occurs all over the world but its geographical distribution remains to be worked out.

We owe most of our knowledge of this disease to Prof. Jones, but others have also studied it critically in recent years, notably, Harding and Morse, and to some extent also the author of this book.

Since the appearance of Jones' first paper the same organism has been isolated from soft rots on other plants by several plant pathologists, who have studied and described it under other names. Furthermore, several other very closely related if not exactly identical soft-rot organisms have been discovered, described and named. M. C. Potter's white rot of turnips is due to this organism, and his paper appeared in 1899 ( $t$ wo years earlier than Jones" paper), but he described as its cause a polar flagellate organism and his name, therefore, cannot be substituted.

The parasitic action of all of these morphologically and culturally similar soft-rot schizomycetes is essentially the same and Harding and Morse believe all of them to be one species but I am not entirely committed to this belief. They enter the plant through wounds and rapidly disintegrate the susceptible parts into a soft, wet pulp (Fig. 164to 166), having first poisoned the tissues by means of their by-products. They advance into the weakened tisues by way of the intercellular spaces and separate 
the cells one from another by dissolving the middle part of the cell-wall, which is of a different. composition from the outer part. The protoplasm of such separated cells is collapsed and dead, but the bacteria are not found inside the cells except in late stages of the disease.

The first indications of disease in a carrot root are the appearance of water-soaked (translucent) places around the infected wounds. These spots are visible in from 18 to 36 hours

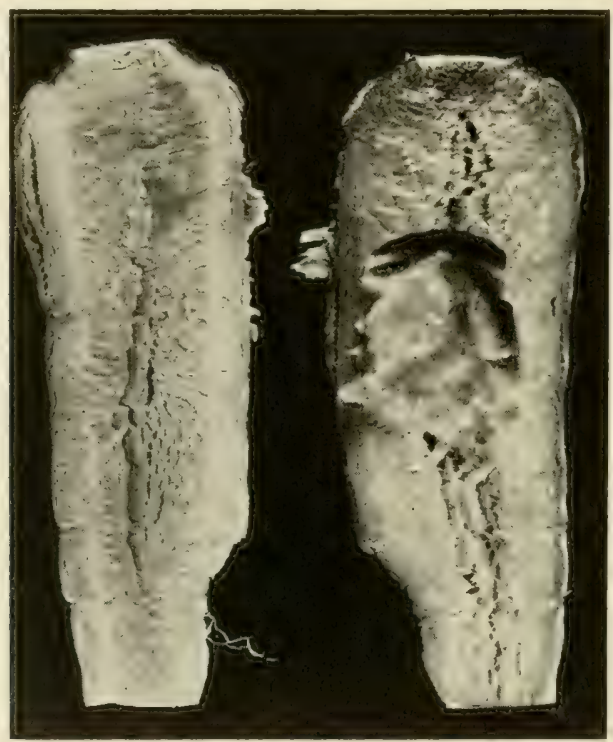

FIG. 164.-Bacillus carotovorus L. R. Jones, streaked for 3 days on raw carrot. Kept on the table at $23^{\circ} \mathrm{C}$. in a large covered dry culture dish. The inoculation was from a rotting raw potato which was inoculated from a gelatin colony. The carrot was first washed, then soaked in 1:1000 mercuric chlorid water, and cut with a cold sterile knife. The left (check) part remained sound.

after inoculation when the roots are held at $20^{\circ}$ to $24^{\circ} \mathrm{C}$. Within two or three days this tissue breaks down, shrivels and exudes drops of a gray fluid swarming with the bacillus. Sometimes a thin, gray bacterial film also covers the surface. When a 2 $\mathrm{mm}$. loop of a bouillon culture is placed on a slice of carrot in a covered Petri dish the water-soaked appearance may sometimes be seen in 6 hours at $20^{\circ}$ to $23^{\circ} \mathrm{C}$. In nature the rot usually 
begins at the crown or at the root-tip. The disease continues in the stored earrots which often decay very rapidly and in large numbers. The core of the carrot rots more rapidly than the outer part of the root, and flabby roots are much less susceptible than turgid ones (Fig. 167). The attacked roots of half-long orange carrots are stained a dark brown, this color commencing within 24 hours; those of the long-orange carrot are not stained or only slowly and slightly stained. Inoculated parsnip roots are

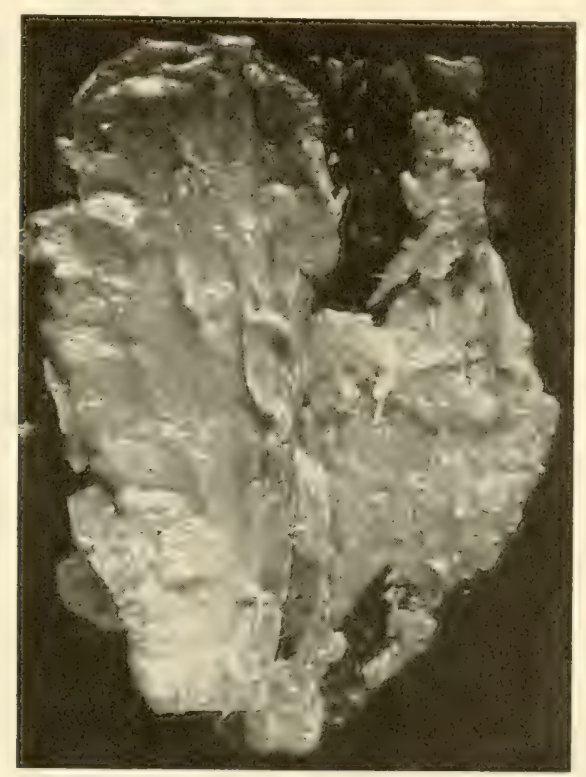

Fig. 165. - Same as inoculated half of Fig. 16t, but after it had been dropped.

Tissue entirely soft rotted except a thin external layer. 1/2 nat. size.

changed to a clay color deepening to cinnamon brown. The spots on green tomato fruits are turned dark. Jones observed no stain in other inoculated rotting plants. Decay of the cruciferous roots was accompanied by an offensive odor. Decaying onions also emitted a bad odor.

The disease has been seen in the United States occurring naturally or has been obtained artificially by pure-culture inoculations on the following plants: carrot, parsnip, celery, 
lettuce, cabbage, cauliflower, turnips, radish, cucumber, muskmelon, potato, tomato and pepper (ripe and green fruitsfaster in the latter), eggplant (ripe fruits), hyacinth (leaf and scape), and onion (bulb and leaf).

Jones' inoculations failed on ripe oranges, bananas, pears and apples; on cauliflower, sweet potato, beet, asparagus; and

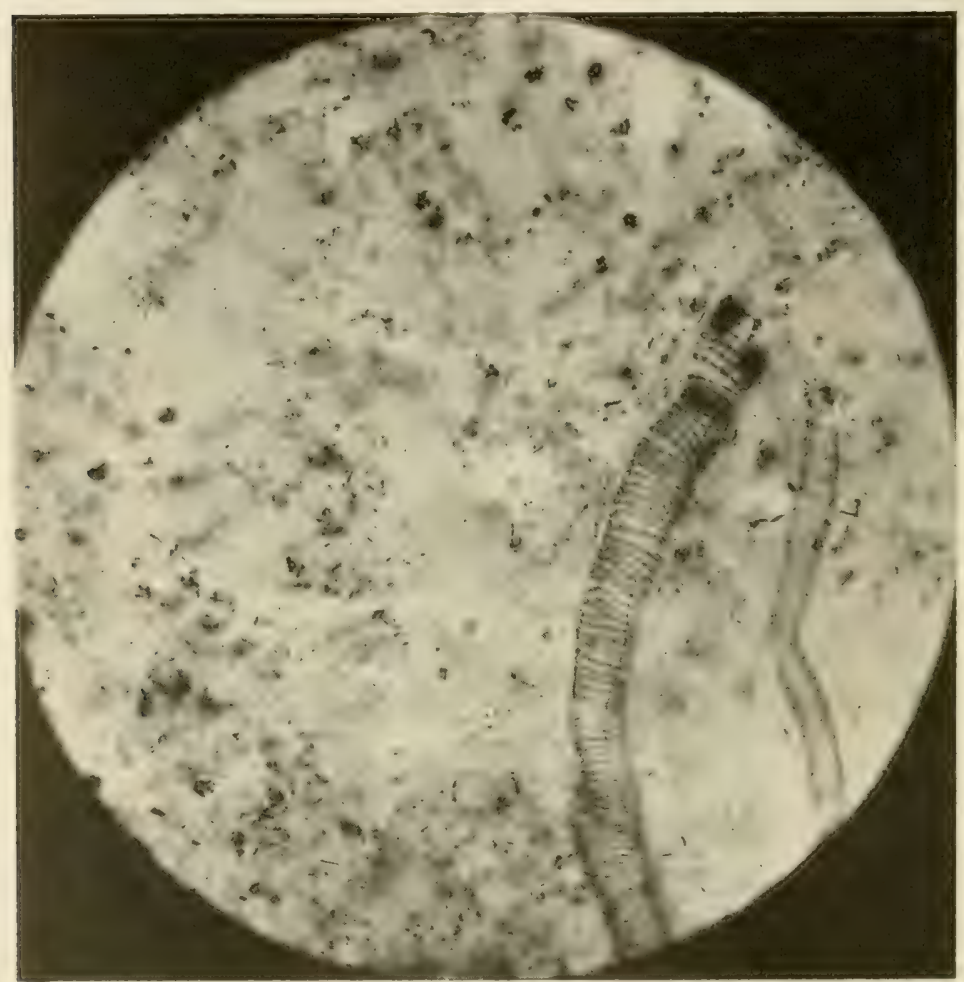

Fig. 166.-Photomicrograph showing separation of cells of carrot due to the action of Bacillus carotovorus. Inoculated from a becf-bouillon culture. Time, 2 days. 1915. Organism $3 a$, in the laboratory several years.

repeatedily on Irish potato tubers (once successful, however). They also failed on young carrot, parsnip and lettuce plants, and on the petioles and stems of the tomato. Most of his early inoculations were made in my laboratory in Washington early in the year (February to April) on roots and fruits from the mar- 
JONES' SOFT ROT OF CARROT, ETC.: TYPE
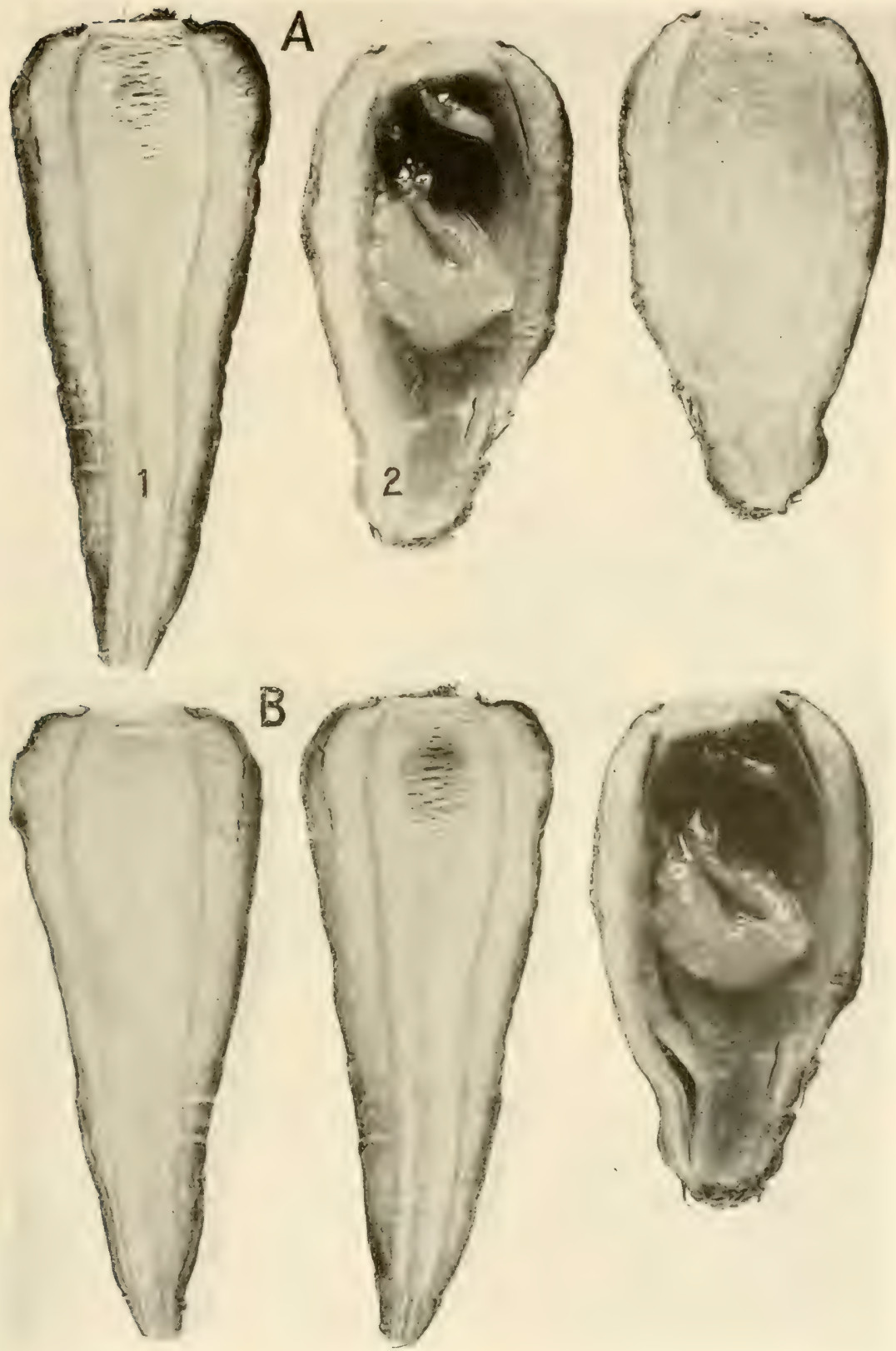

Fig. 167.-A. Shows photograph of two carrots inoculated at the same time. 

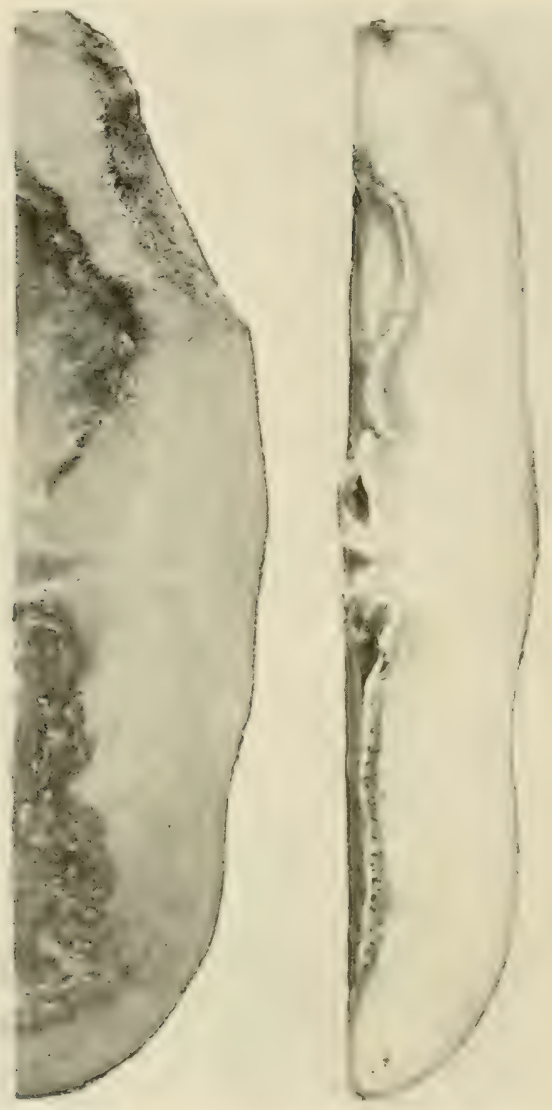

Fig. 168 .

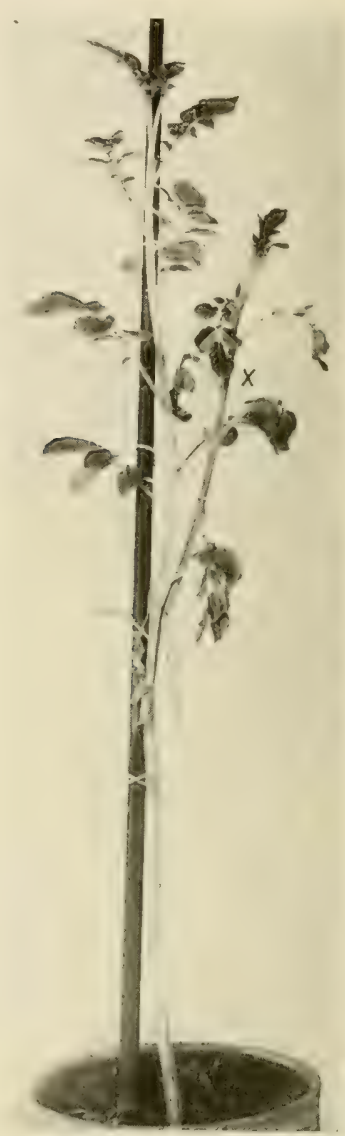

FIG. 169 .

Fig. 168.-Surface and side view of a raw potato tuber (Green Mountain) streaked 4 days, at $23^{\circ} \mathrm{C}$., with Bacillus carotocorus from a gelatin colony $(3 a$, long in my laboratory). The right-hand figure shows the depth to which the rot has penetrated. Photographed Jan. 16, 1916.

Frg. 169.-Potato plant, variety Green Mountain, one shoot of which has been inoculated 7 days with Bacillus carotororus. Inoculated shoot dwarfed and wilting with internal brown streaks. Organism less active than Bacillus phytophthorus. Photographed Feb, 8, 1915.

from same (t-day) bouillon culture of Bacillus carotoiorus. No. 1 was flabby, No. 2 was turgid. Left check omitted. Time, 3 days.

$B$. Same as $A$, but at the end of 6 days at room temperature $\left(25^{\circ} \mathrm{C}\right.$.) in a large culture-dish. The inoculated half of the flabby carrot now shows a slight rot at the top where an unusually large amount of the cloudy bacterial fluid was deposited, i.e, much more than on the badly rotted piece. Experiment of May, 1915. Four days later there was little change. Right check omitted. This was still sound. 
ket. Time of year, absence of turgor, varieties used, or gradual loss of virulence on the part of the organism might make a difference with potato tubers. Or it may be that what is here described as Bacillus carotovorus is a composite of two or more species. His conclusion at that time was that it did not attack the potato.

According to my observations the organism does not lose virulence readily, and the culture I have (which came originally

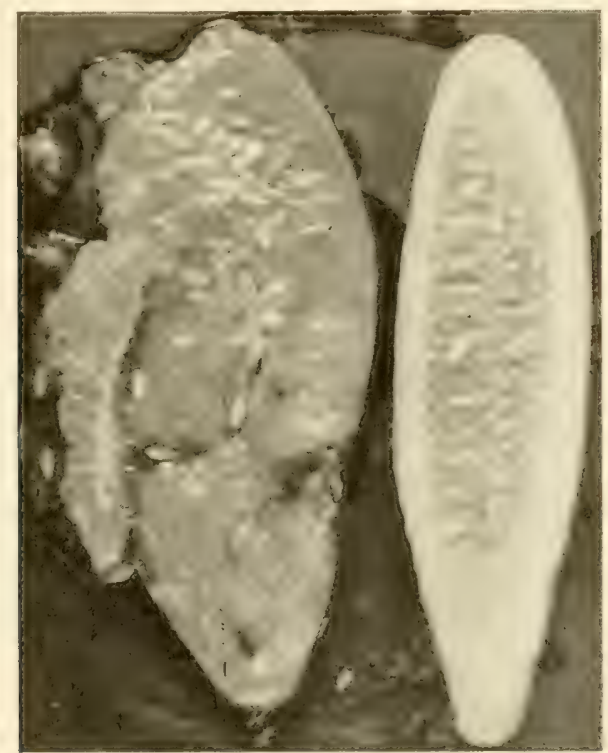

Fia. 170.-Green cucumber inoculated by longitudinal stabs introducing Bacillus carotororus from gelatin colonies. Sliced and photographed January 20,1915 , i.e., after 6 days at $23^{\circ} \mathrm{C}$. Interior soft rotted. Sliced (check) eucumber from the same lot on the right side, entirely sound. 1/2 nat. size.

from Jones, but bas been transferred many times in my laboratory) rots raw potato tuber's readily (Fig. 168) and also attacks the soft green stems of this plant (Fig. 169). Its disintegrating action on many tissues other than those of the carrot, e.g., green cucumber fruits (Fig. 170), is very rapid. I have also obtained with it a calla lily rot resembling Townsend's rot (Figs. 171 to 173) and a rot of young leaves of carrot. 


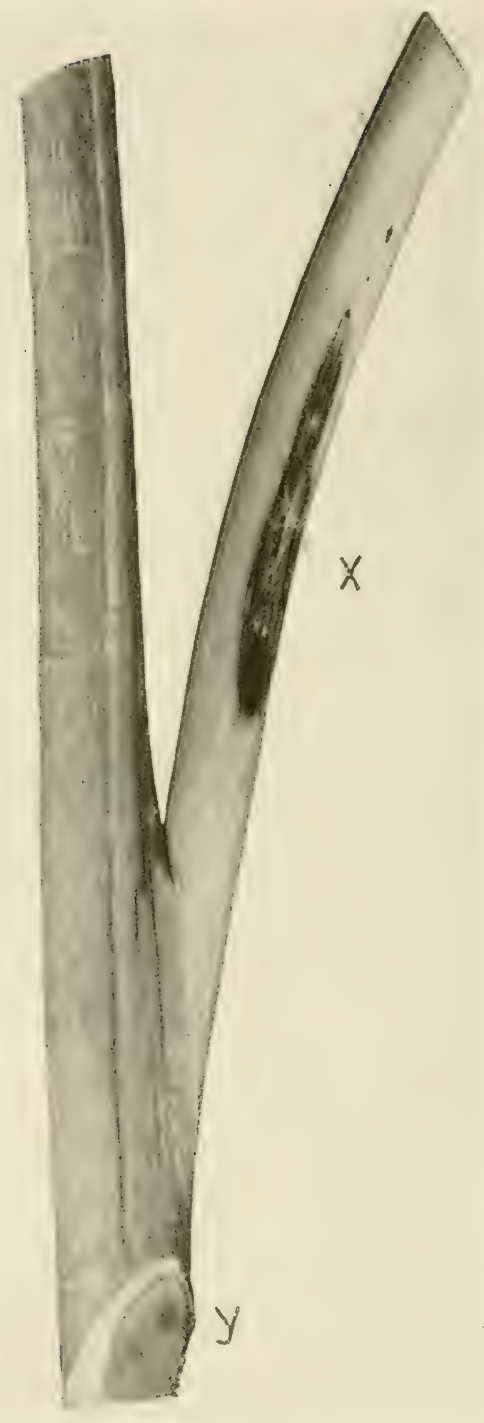

Fig. 171. Calla lily rot due to needle-pricks introducing Bacillus carotororus. Leaf-stalk inoculated 48 hours at $X$. The rot extended internally beyond $Y$. Another leaf-stalk of the same series rotted entirely across and fell over the third day.
In potato tubers a protective layer of cork is often developed under the rotting area (Fig. 174). In the shoots of potato it is not partial to the vascular system but nevertheless may sometimes be found in vessels at a considerable distance above the place of inoculation (Fig. $175)$.

Cause. - The cause of this disease is Bacillus carotovorus L. R. Jones. This is a gray-white, ${ }^{1}$ non-capsulate, non-sporiferous, actively motile ( 2 to 5 flagellate), peritrichiate (Fig. 176), slowly liquefying (gelatin, but not coagulated egg albumen or Löffler's solidified blood serum), nitrate reducing, milk curdling (by an acid), aërobic and facultative anaërobic, gas-forming (with muscle sugar, dextrose, saccharose, lactose and mannit but not with glycerin nor with

1 Wormald says yellow on Soyka's milk rice (.l c.). The quality of whiteness is variable as is that of any other color. I agree with Wormald that it is yellowish in contrast with the pure white of the rice medium, about as yellow as steamed potato cylinders, but I would call these white rather than yellow or more exactly following $R_{2}$ nearly pale cream color, becoming eream color in old cultures. It is a matter of opinion. Very few white organisms are as white as white rice but nothing would be gained by calling all of them chromogens. For preparation of this useful medium see Eyre's Bacteriological Technique. 
potato juice in fermentation tubes, ${ }^{1}$ the gas being 20 per cent $\mathrm{CO}_{2}$ and 80 per cent explosive), heat-sensitive (thermal death-point $51^{\circ} \mathrm{C}$. - even 10 minutes in bouillon at $47^{\circ} \mathrm{C}$. retards growth), dry-air-sensitive (sometimes even to 2 minutes' exposure-Jones), sunlight-sensitive (10 minutes of direct sunlight and 2 hours of diffused sunlight, fatal-Jones), not exceedingly frost-sensitive frozen in +15 peptone beef bouillon, in 1919, 13 per cent survived) short, rod-shaped, catenulate, or filamentous (up to $200 \mu$ or more-Jones) schizomycete

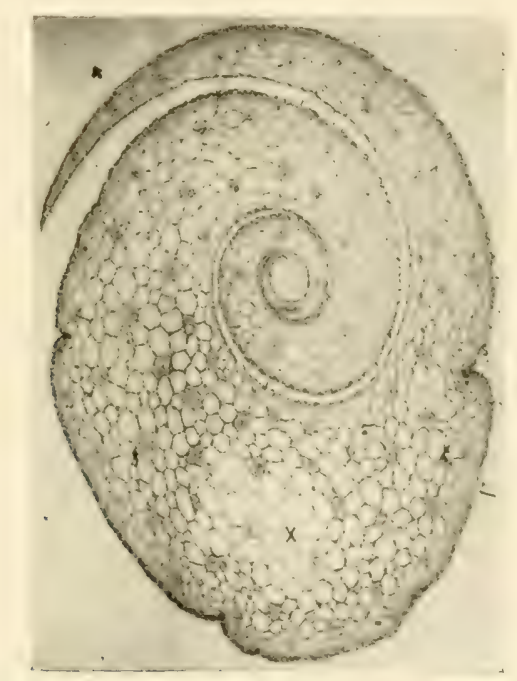

Fig. 172.-Cross-section of Fig. 171 at $Y$, moderately enlarged to show character of the bacterial rot. The tissue of the attacked part $X$ did not hold the stain.

(greatest observed rariation in diameter 0.6 to $0.9 \mu$, usual diameter 0.7 to $0.8 \mu$ ), growing on the surface of agar-poured plates in the form of round, raised, smooth, gray-white, wetshining colonies ( 2 days) having entire well-defined margins and a transient flaky areolation $(\times 10)$ with a slight fluorescence, the buried colonies being globose, oblong or spindleshaped with irregular margins $(\times 125)$, but, if thin sown,

${ }^{2}$ Repeated in 1919 in potato juice in fermentation tubes with contradictory' results, using Jones $3 a$ (branched) and also $3 a$ received from Wisconsin in 1920. The latter sometimes gives a little gas and at othertimes not. 
the surface colonies (Jones $3 a$, stock long in my laboratory) are sometimes more or less irregular in outline and may send out finger-like branched projections (Fig. 177). Fearing that in some transfer the labels of Bacillus aroideae and Bacillus carotovorus might have been interchanged I sent to Wisconsin in 1920 for another culture of $3 a$ and this in agar-poured plates

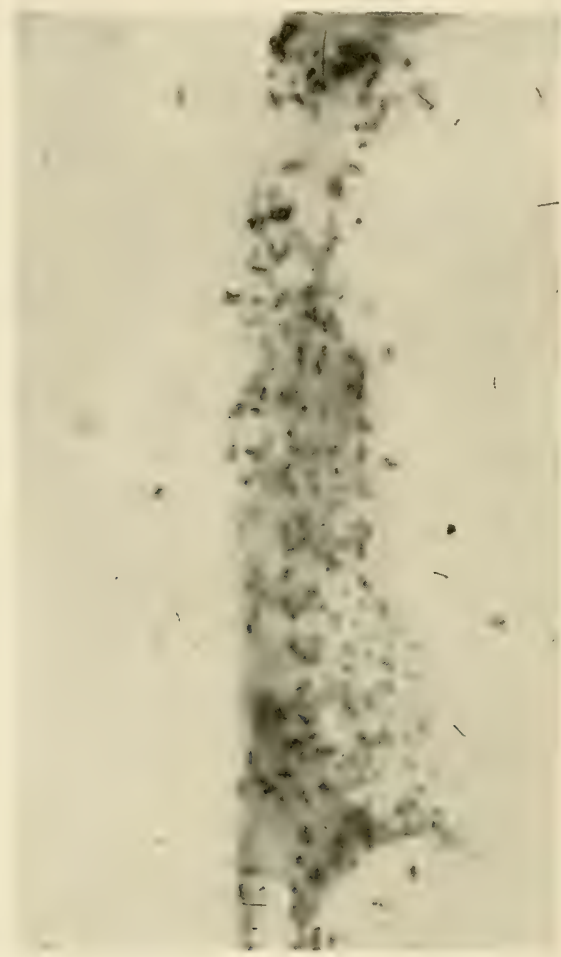

FIG. 173. - Detail from Fig. 172 at X. Much enlarged to show the bacteria disintegrating the swollen cell-wall and confined to the intercellular spaces.

gives round colonies (Fig. 178). The two stocks also differ in amount of gas formed from potato juice (Fig. 179) and in other ways.

On the +10 gelatin-poured plates the margins of the young surface colonies $(\times 125)$ are thickly set with parallel filamentous outgrowths (Figs. 180, 1S1), this fimbriate margin being about $50 \mu$ wide on the second or third day. The buried colonies 


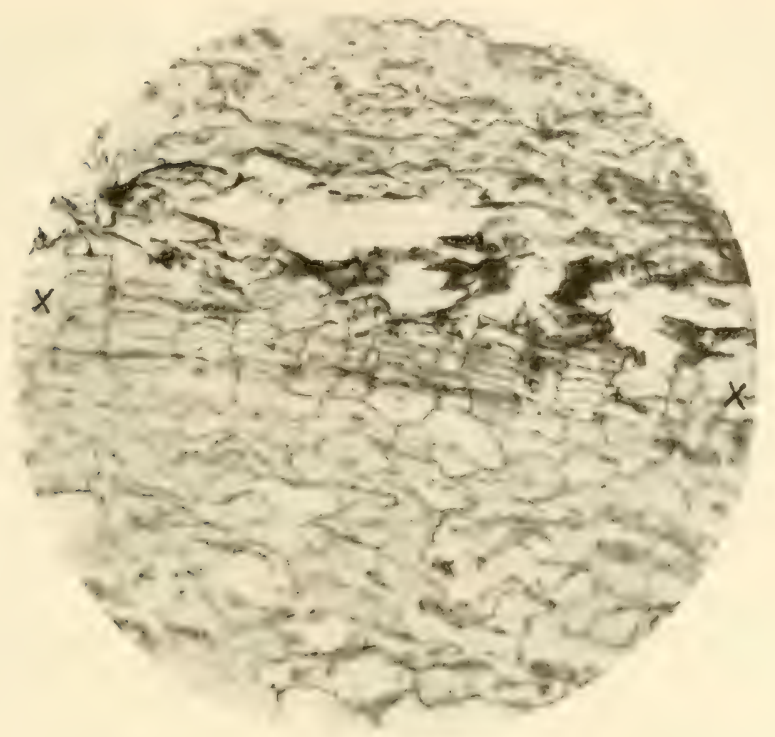

FIG. 174.-Cross-section of a MeComick potato tuber taken 12 days after inoculation, i.e., when the rot had subsided, showing (at $Y-X$ ) the formation of an inhibiting layer of cork under the rotted area. This tuber was streaked with Bacillus carolovorus at the same time as Fin. 16s, and rotted as well at the beginning. The rotted part (at top) is full of stareh grains. From the sound part (below) the starch has been removed to form the cork-layer. Compare with Fig. 136.

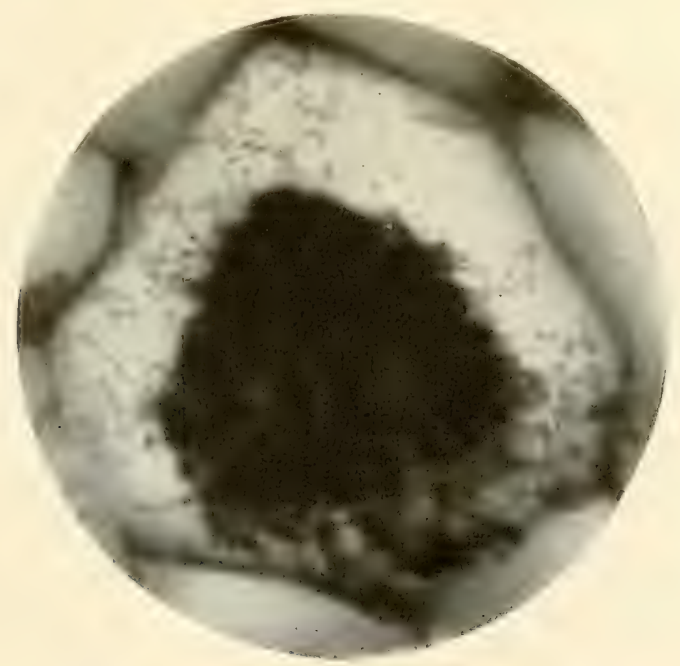

FIG. 175.-Cross-section of at potato stem inoculated with Bacillus carotovorus for comparison with Bacillus phytophthorus. Section far above the point inoculated. Vessel full of bacteria. 
in gelatin plates $(\times 125)$ are irregularly spherical, often more or less clumpy, uniformly granular and with sharp margins which tend to become hazy. Sometimes the buried colonies send out colorless root-like growths (Fig. 182). Stab cultures liquefy first at the surface but eventually throughout (Fig. 183A). There is a fragile imperfect white pellicle and a copious white precipitate, the fluid becoming strongly alkaine.

Peptonized beef bouillon clouds very rapidly, especially when neutral to phenolphthalein (in 6 hours at $30^{\circ} \mathrm{C}$., when inoculated with a $1-\mathrm{mm}$. loop). If undisturbed there is formed a very thin imperfect pellicle which shakes down readily leaving a.scanty interrupted rim, easily washed away. The white

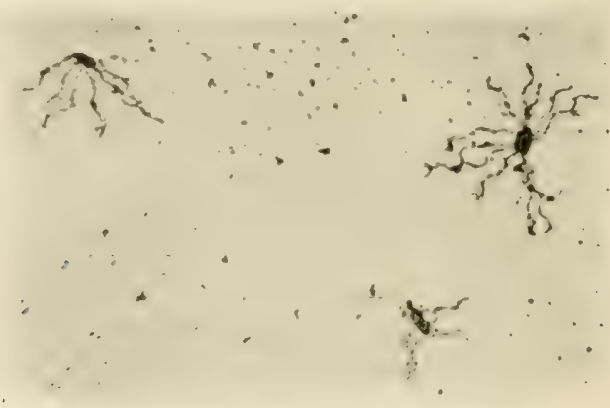

Frg. 176.-Flagellate rods of Bacillus carotovorus. From a 2-day agar streak. Van Ermengem's silver nitrate stain. In the upper right there are two bacterial rods lying together. $\times 1000$.

precipitate is not copious. It $(3 a)$ gives in +15 peptone bouillon a heavier clouding than B. phytophthorus. Growth in Dunham's solution is feeble. Growth in Uschinsky's solution is abundant and long-continued and the fluid remains more or less acid throughout: there is a copious precipitate (15 or 20 times that in bouillon), but only a delicate easily fragmented pellicle. In milk a curd separates about the fourth day. It has the odor of cheese curds and there is little or no peptonization of this curd. Litmus milk is reddened and the litmus is, or may be, subsequently reduced. Other pigments are reduced, such as methylene blue (in Dunham's solution with grape sugar, not without). 


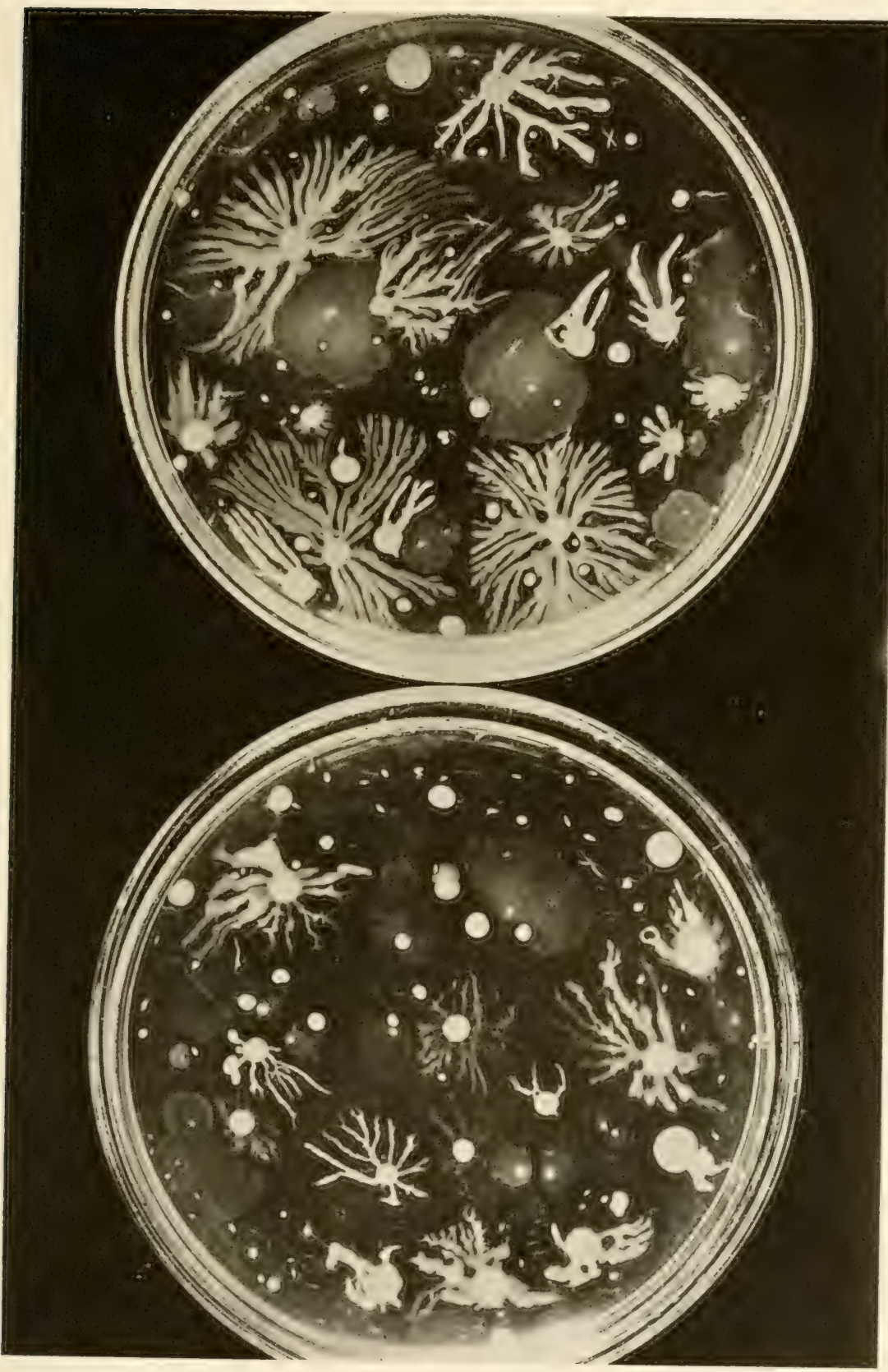

FIG. 177.-Agar poured plates of Bacillus carotororus? (Jones $3 a$ ?) on +15 peptone beef agar at $25^{\circ} \mathrm{C}$. for 10 days. Photographed May 3, 1919. Culture long in my laboratory and frequently transferred along with other soft rot isolations. Possibly confused in some transfer with Bacillus aroideae. This is the culture that was infectious to calla lily, and various other statements in the text respecting $B$. carolovorus are based on this oraanism: 


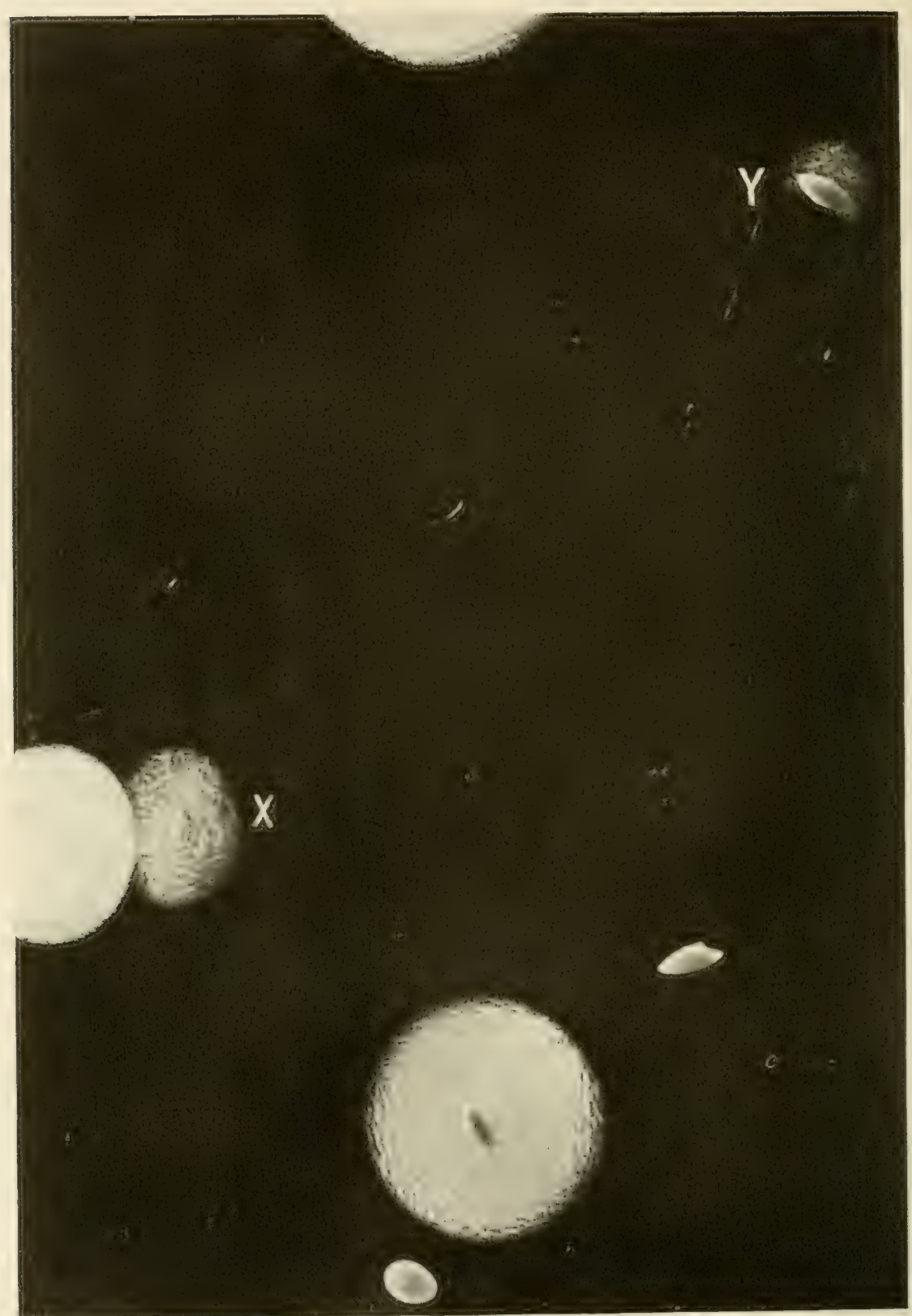

Fig. 178.-Original stock of B. carotororus (Jones' $3 a$, received from him in 1920). Photographed after 3 days at $25^{\circ}$ on +14 beef-pepton agar, showing surface and buried colonies. $Y$ is a buried colony beginning to come to the surface, $X$ is a young thin colony. Photographed, $X 10$ by oblique transmitted light for comparison with Fig. 177. The colonies are smooth on the surface and show internal wavy markings by oblique transmitted light. Still infectious to carrot 
The growth on steamed potato cylinders forms a slightly raised. wet-shining, smooth, cream-white cosering, with a slight. evolution of gas and the conversion of starch into amylodextrin.

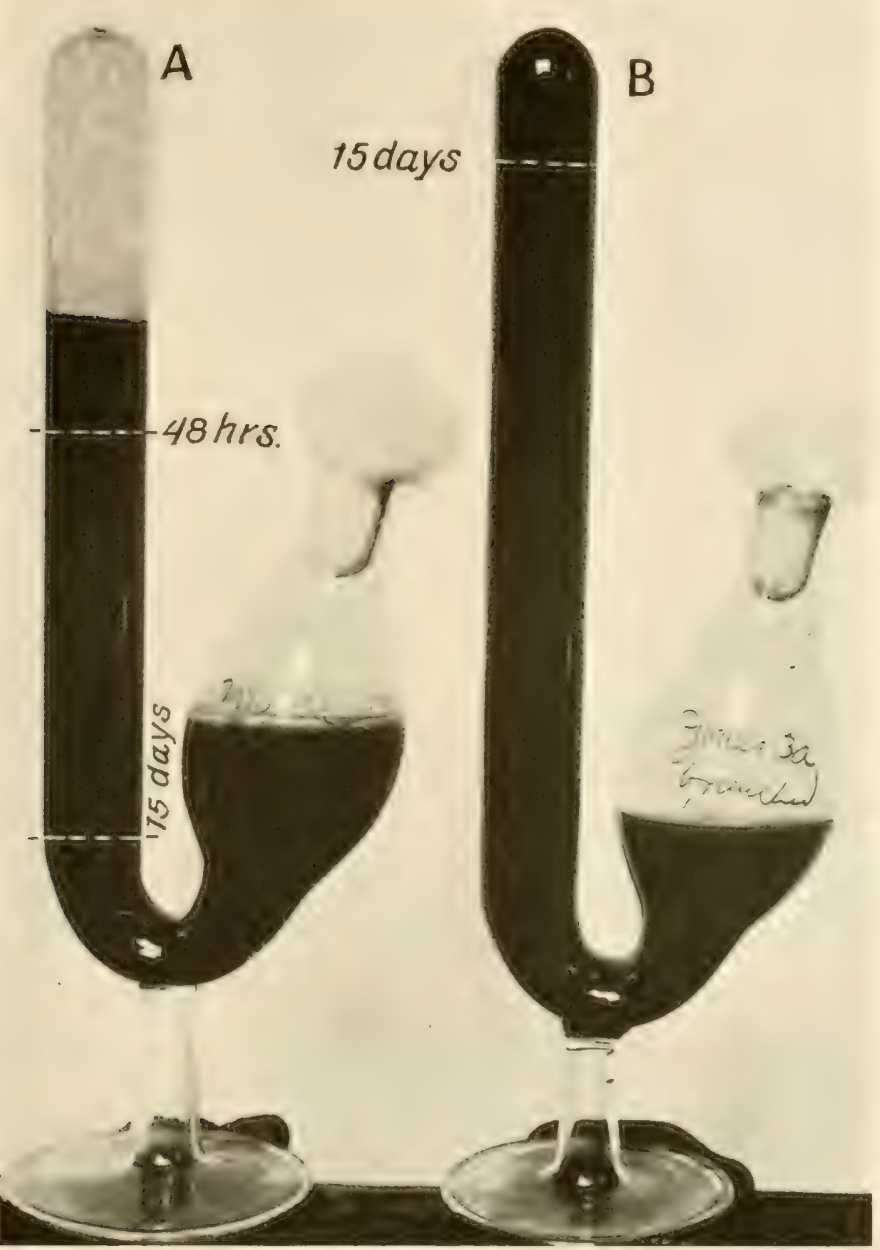

Fig. 179.-Fermentation tubes with potato juice: A. Jones 3 $\beta$ (original Bacillus carotororus) from Wiseonsin in 1919. Gas in 24 hours. The gas in 48 hours and in 15 days is also indicated. $B$. Jones 3 a (long in my laboratory). No gas in 4 days. Amount of gas in 15 days is indicated. Good growth in both tubes. $B$ rots calla lily, $A$ does not. $B$ also rots young carrot tops.

Gas is also formed from steamed carrot cylinders and the graywhite bacterial layer is seldom thick enough to hide the orange 
or yellow color of the substratum. Both these substrata become alkaline as early as the third day and increasingly so later on; both are softened, especially the carrot. which often may be shaken apart in water after a week (Jones) or even in much less time.

The maximum temperature for growth is between $38^{\circ}$ and $39^{\circ} \mathrm{C}$. The optimum temperature for growth is between $25^{\circ}$ and $30^{\circ} \mathrm{C}$. The minimum temperature for growth on steamed vegetables is above $4^{\circ} \mathrm{C}$. Raw regetables have not been reported upon. ${ }^{1}$ No appreciable growth was obtained on any medium at $0.6^{\circ}$ to $1^{\circ} \mathrm{C}$. (20 days) but there was a slight growth on nutrient gelatin at $2^{\circ}$ and at $3^{\circ} \mathrm{C}$.

Growth after 5 days at $12^{\circ} \mathrm{C}$. on steamed vegetables (potato, carrot, turnip, rutabaga) was about one-third that on the same substrata at $20^{\circ}$ to $24^{\circ} \mathrm{C}$.

Except as already noted the cultures were free from strong odors. Not much inciol is produced.

Neutral bouillon gives the best growth, but the organism tolerates sodium hydroxid in bouillon down to below -40 on Fuller's scale and malic acid up to a little beyond +30 . The organism is sensitive to it own acid products. In peptone water containing grape sugar, swollen, racuolate and knobby involution-forms occur.

Tolerates sodium chlorid up to $6+$ per cent but not 7 per cent in +15 peptone beef bouillon. Grows well in +15 bouillon with 5 per cent $\mathrm{NaCl}$.

Jones $3 a$ (culture received from him in 1919-descendant of his original isolation of Bacillus carotovorus) tolerates ethyl alcohol up to 7 per cent in +15 peptone bouillon; grows promptly and well in the presence of 5 per cent. In further experiments it grew readily and formed a heavy pellicle in the presence of 10 per cent ethyl alcohol and made some growth in the presence of 11 per cent, but would not grow in the presence of 12 per cent. See Fig. 184 where the behavior

${ }^{1}$ In October, 1915, growth and rot were obtained by the writer on raw potato and carrot at $5^{\circ} \mathrm{C}$. inoculating $(3 a)$ from a potato culture, but neither at $5^{\circ} \mathrm{C}$. nor at $8^{\circ} \mathrm{C}$, inoculating from bouillon. The first rot from the bouillon inoculations was at $9^{\circ}$ to $11^{\circ} \mathrm{C}$. and that feeble (5 days). 
of six soft-rot organisms is shown in +15 peptore beef bouillon containing ten per cent of squibh's absolute ethyl alcohol viz. $3 a$ recently from Jones (year 1919), 3 a long in my laboratory (the branched $3 a$ of Fig. 177), Potter's organism (No. 79 of Jones laboratory), spiechermann's organism (Xo. Ts of Jomes laboratory), Bacillus phytophthorus (Appel I) and Bacillus apiovorus Wormald.

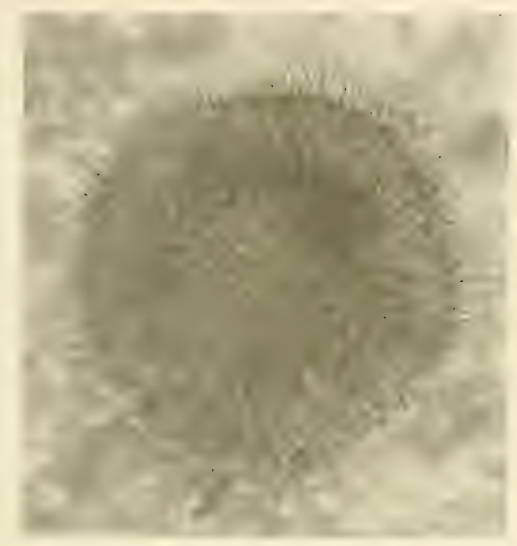

Fig. 1S0.

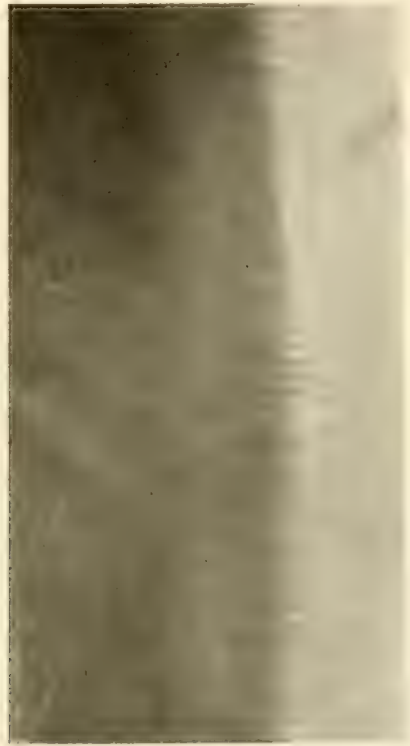

FIf. 181.

Fig. 1S0.-Surface colony of Bacillus carotororus on +10 beef-peptone gelatin after 24 hours at $18^{\circ} \mathrm{C}$, showing marginal fringe. $\times 110$, about. Actual diameter of colony, $0.4 \mathrm{~mm}$,

Fig. 181.-Margin of a surface colony of Bacillus carolovorus after 3 days on gclatin, showing bacterial fringe pushing out into the gelatin. The darker band behind the fringe was liquefied and full of bacteria which exhibited, as a whole. a wearing or swaying motion. Medium magnification.

Note.- Not having myself worked-over all of these soft-rot organisms critically, i.e., through a series of years, the following conclusions on the synonomy are expressed tentatively.

Forms apparently identical with Bacillus carotovorus are Bacillus oleraceat Harrison on cauliflower and Bacillus ommimorus. van Hall on iris. Under the name of Bacillus apiovorus 
Wormald in England has described a schizomycete which attacks celery producing a soft-rot (Figs. 49 and 1.5.) but is not active on potato shoots (Fig. 186). This, he is now inclined to think, is also identical with Bacillus carotovorus, but I am in doubt and shall keep it separate for the present.

Very closely related forms are Bacillus aroideae Townsend (Fig. 187) on calla lily and Bacillus melonis Ciddings on muskmelon. Townend's organism differs in the form of its colonies on agar (they are, however, like those shown in Fig. 177) and in some of its fermenting powers, i.e., acid without gas from dextrose, lactose, saccharose and mannit. Its effect on raw

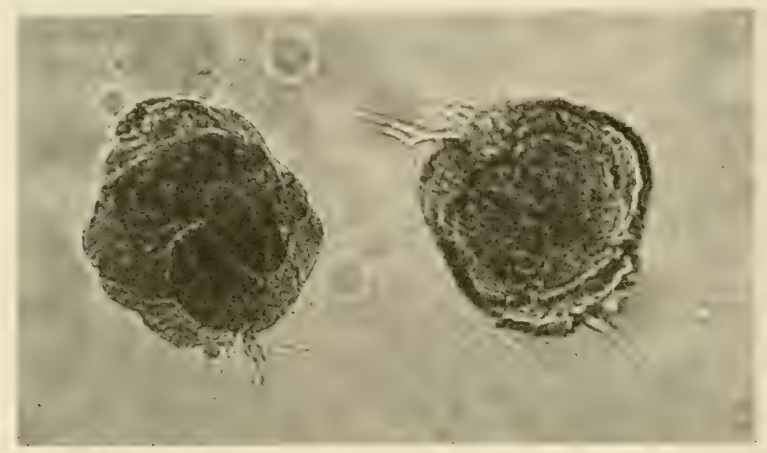

FıG. 182.-Buried colonies of Bacillus carotorom in +10 beef-peptone gelatin plates after 24 hours at $18^{\circ} \mathrm{C}$, showing colorless root-like extensions. The several small dark spots ringed with light are due to irregularities in the gelatin or to dirt on the eyepiece. $\times 135$ cirea.

carrot at the end of $S$ days is shown on Fig. 188. Gidding's organism produces abundant gas from milk (99) per cent. ( $\left.\mathrm{O}_{2}\right)$ in the closed end of fermentation tubes; liquefies blood serum; does not produce gas with dextrose, saccharose, lactose, maltose or mannit, and has a maximum temperature of about $45^{\circ} \mathrm{C}$.

I think Bacillus aroideae and Bacillus melonis are identical. At least an organism isolated by us from rotting calla lily and identified as Bacillus aroideae produces gas in milk (Fig. 189). With his original isolation (now lost) Dr. Townsend made no tests in fermentation tubes containing milk.

I have been inclined to think that Bacillus carotovorus and Bacillus phytophthorus: are not strictly identical, and have kept. 
them separate in this volume, but further comparisons are necessary.

Technic.-It is not difficult to isolate this organism, since rery often it occurs almost unmixed in the decaying tissues. If the advancing margin of the rot is selected and the surface organisms are destroyed by pressing a hot spatula on the part selected (which may be the sound surface near the rot), one may then dig through the burned surface and into the rotted area with little danger of external contamination and the certainty of ob-

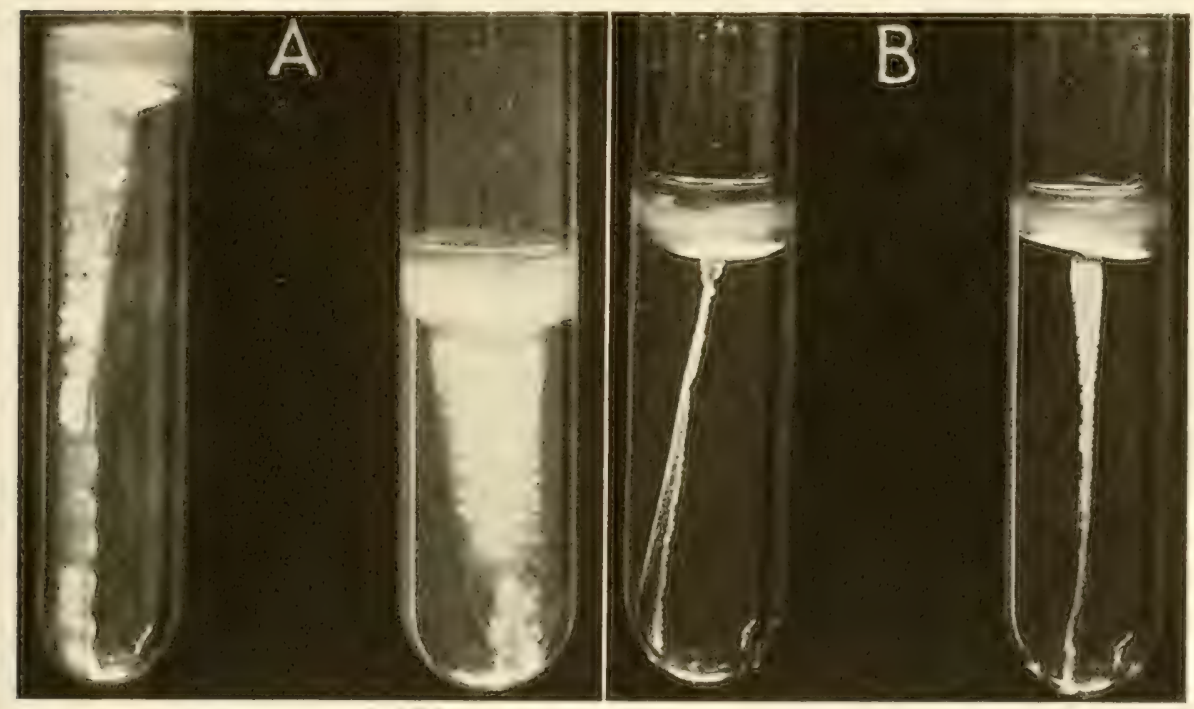

Fig, 183.-A, Bacillus curotoroms L. R. J., and B, Bacillus apiocorus Wormald, in gelatin stabs at the end of 5 day's at $20^{\circ} \mathrm{C}$.

taining on the poured plates almost or quite a pure culture of the parasite. The organism is easily identified by its rapid disintegrating action on raw earrots or turnips and by its cultural peculiarities. As here described it can not be distinguished with certainty from Bacillus phytophthorus (No. VII) by its behavior on, raw potato, nor by its growth in thin-sown gelatin plates, as I formerly supposed (compare Figs. 206 and $212 A$ with $a, b$ of Fig. 205).

For inoculation experiments, roots of various kinds may be selected and also fleshy above-ground parts. The work may 
in

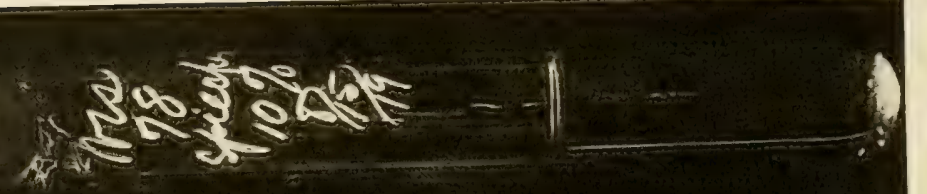

$\frac{1}{3}$

$\exists$

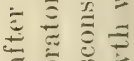

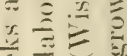

菃

i.

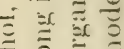

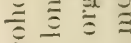

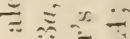

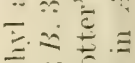

Thy stato

1

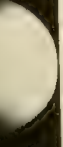

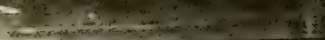

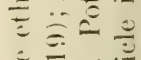

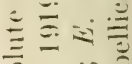

三

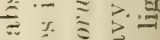

$\% \cong$

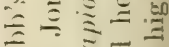

立

$\int_{3} \frac{5}{3} \sec \frac{1}{4}$

\section{I)}

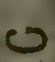
$x^{2} \leq a^{2}+$

$+\frac{1}{-3}$

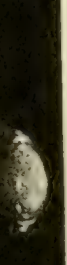

$\infty$

250

13

< 20305 
be done either in the laboratory or in the hothouse. Owing to the rapidity of the rot, it lends itself very well to laboratory experiments, as the various suseeptible organs can be inoculated and the results obtained before the plants begin to shrivel from exposure to unsuitable laboratory conditions. If whole roots are used, such as carrots, radishes and turnips, they may be exposed after inoculation either to the dry air of the room or may be put into deep uncovered jar's. These latter serve better than the open air of the laboratory to hasten the earlier stages of the infection, but are not required to induce it. Full-grown or nearly full-grown roots are better for inoculation than immature ones. Such roots must not be flabby.

As additional materials for inoculation, the student may use green cucumber fruits, which rot quickly, or green tomato fruits. He may also try the white, fleshy, central part of cabbage stumps.

By far the most convenient way, owing to the small space required, is to make the inoculations on thick slices of uncooked roots and fruits placed in deep, covered Petri dishes holding part of the slices in each dish uninoculated for comparison. For preparation of these slices which may be 2 to 3 centimeters thick, see Part II, page 103.

\section{Determine}

For the organisir. Morphology. - Size in microns (especially the diameter of the rods, most of which should measure 0.7 to $0.8 \mu$ ). Absence of endospores (try heat and spore stains). Absence of capsules. Motility on the margin of a hanging drop (examine various cultures, old and young). Number and location of the flagella (Löwit's flagella stain, van Ermengem's stain). Occurrence of chains and filaments (examine second-day bouillon and agar cultures). Measure the longest filaments seen. Determine number of elements in the longest chains. Are the filaments and chains always, or usually, motile? Do pseudo-zoogloeae occur and, if so, in what media and under what conditions"? staining properties (using various basic anilin stains with and without mordants). Does 


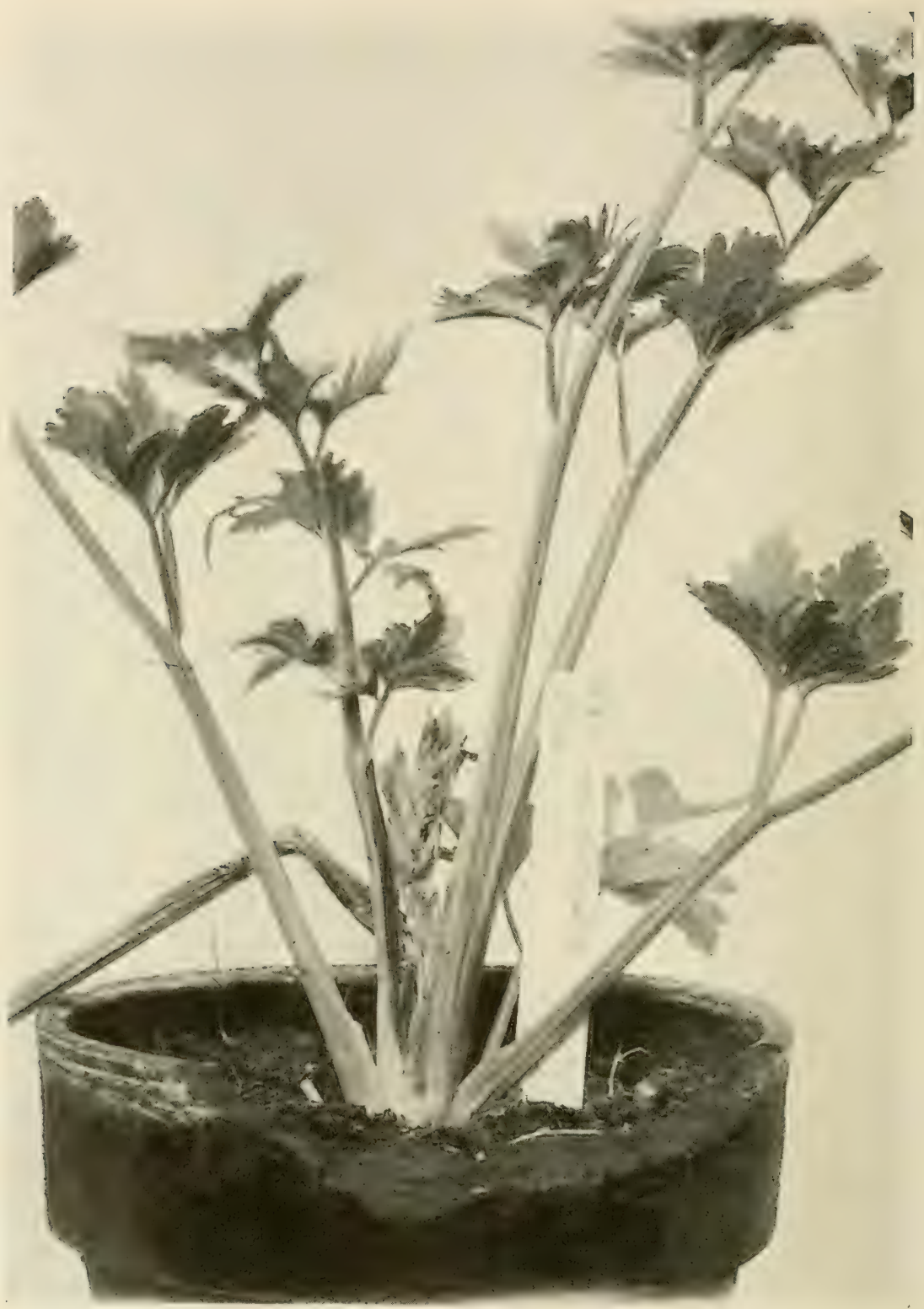

FIG. 185. -A celery plant inoculated by needle-pricks with Wormald's Bacillus apiovorus in the central part. Inoculated May 11, 1915. Photographed May 17. One inoculated leaf-stalk broken over, another diseased and discolored but still erect. 


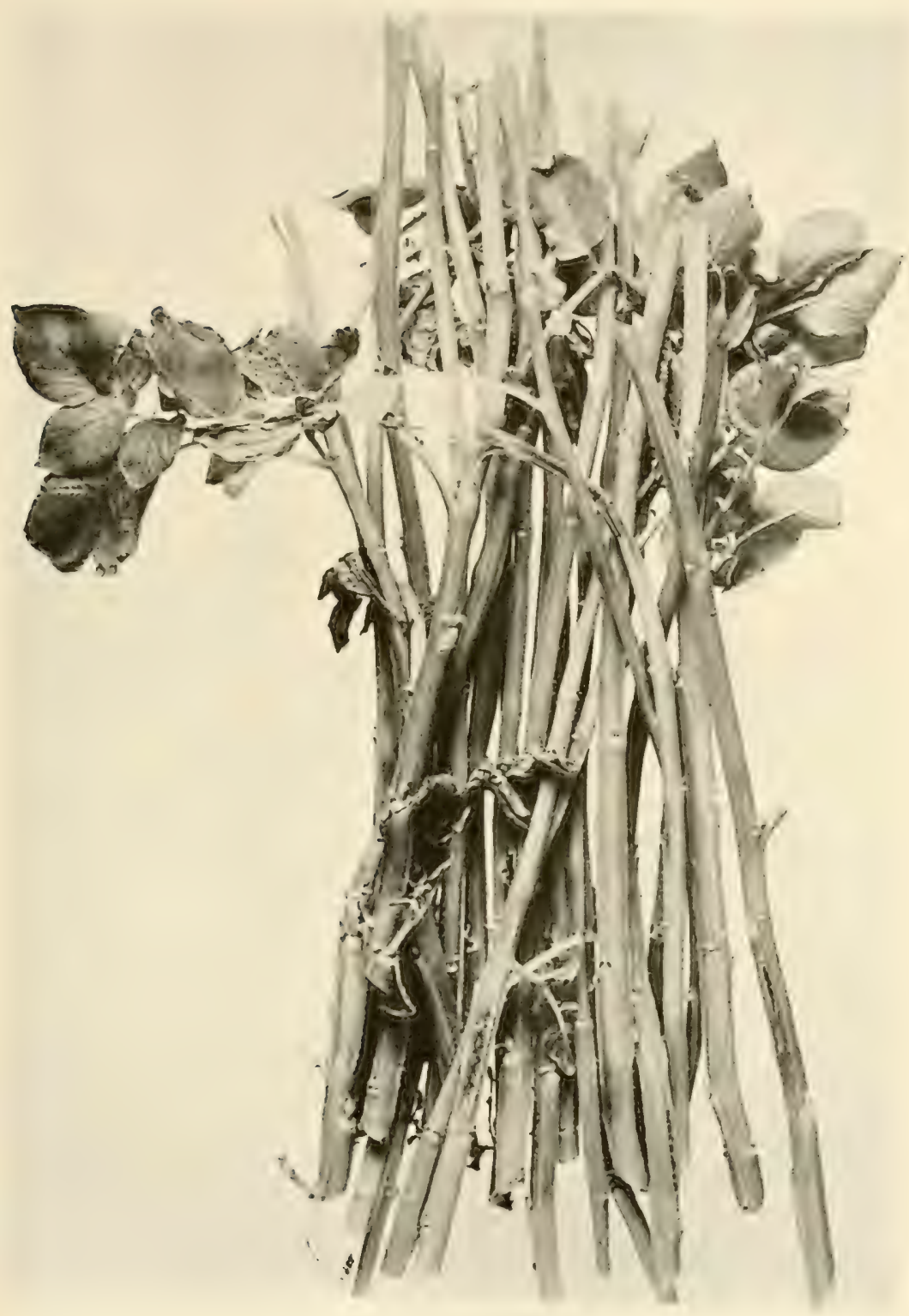

FIG. 186.-Potato shoots inoculated 40 days at base with Bacillus apiovorus Wormald, showing slight effect. Inoculated by needle-pricks March 20, 1915. Photographed April 30. 
the organism stain by Gram? Jones says it does, Harding and Morse say it does not. Examine always with the substage diaphragm wide open. For comment on use of Gram's stain see "Bacteria in Relation to Plant Diseases," Vol. I, page 188. Is it an acid-fast organism: Presence or absence of involution forms (examine 2 -months-old cultures on steamed carrot and read what Jones says on page 314 in his first English paper). Try also much younger cultures in 1 per cent dextrose peptone water. Any Y-shaped or branching forms? Make cultures in bouillon containing 4 to 10 per cent of ethyl alcohol and search for the coccus-like forms which Wormald has described and figured for Bacillus apiororus in "The Celery-rot bacillus." (The Jour. Agr. Science, Vol. VIII, Pt. II, M̌rarch, 1917).

('ultural Characters.- Determine behavior on thin-sown agarpoured plates, also in agar-streak cultures and stab cultures. In thin-sown gelatin-poured plates study (on the first, second and third days) the buried and the fimbriate-margined surface colonies with medium magnifications. Determine rate of liquefaction in gelatin stab cultures; behavior of streak cultures on Loeffler's solidified blood serum, on solidified egg albumen; curdiing effects in milk and litmus milk; growth on steamed potato cylinders and carrot cylinders; hehavior on the surface of raw potatoes in contrast to surface of raw carrots. Do you find any marked difference? Inoculated raw apple and raw turnip will afford another interesting comparison. If there is time, a whole series of raw fruits and vegetables (thick slices in deep Petri (dishes) should be inoculated. Results cannot be compared, of course, unless the temperatures are the same.

Growth in +15 peptone beef bouillon should be compared with that in salted peptone water (Dunham's solution), and in various synthetic media, e.g., Cohn's solution (no growth), L'schinsky's solution (abundant growth), Fermi's solution, ete.

Contrast with $B$. phytophthorus in Soyka's milk-rice. The one culture $(3 a)$ should be yellowish, the other, pinkish.

Behavior in good fermentation tubes in peptone water containing various sugars and alcohols. With which is there clouding in the closed end? With which gas formation? What is the composition of this gas? At least some simple experi- 


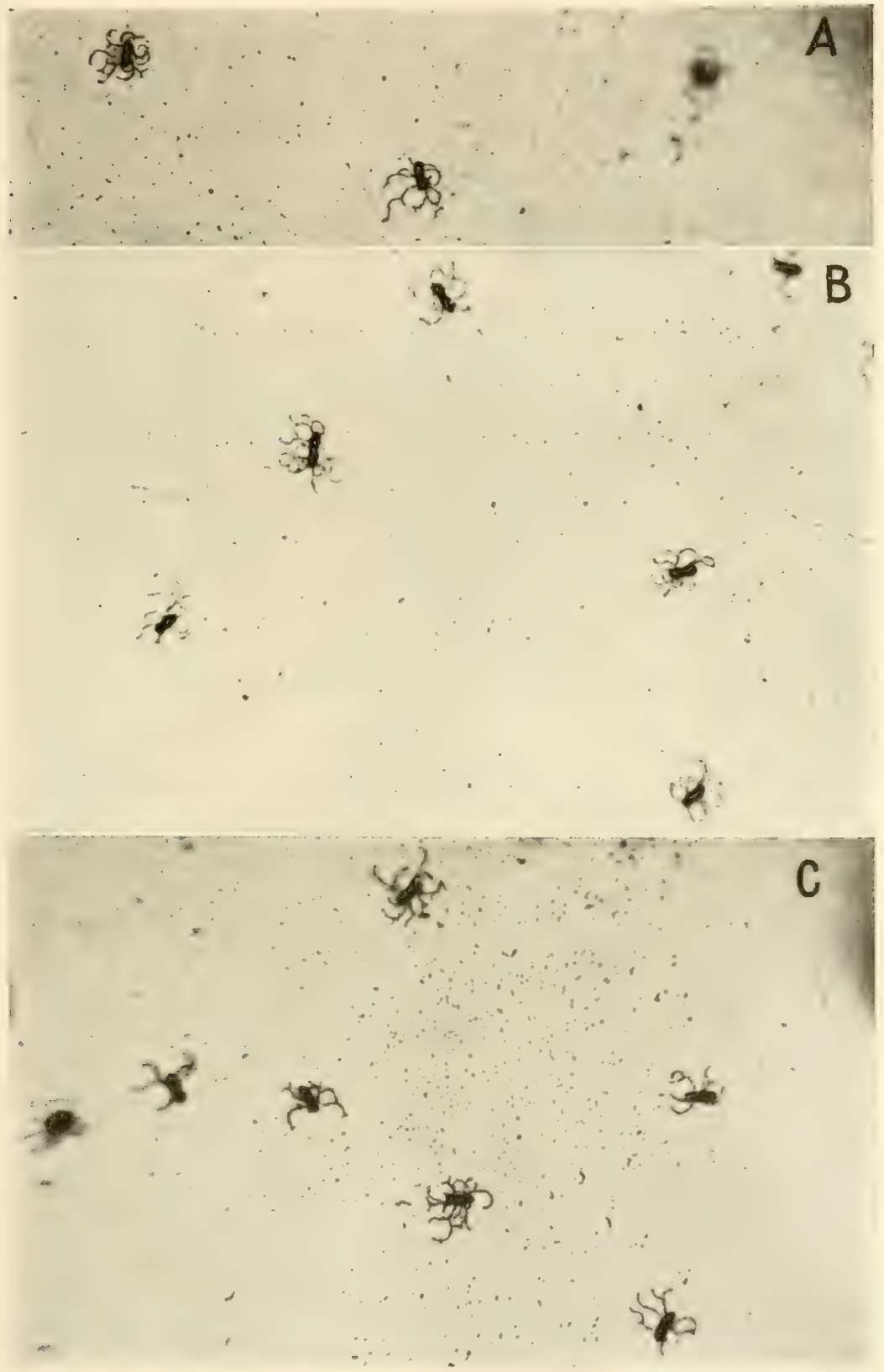

Fig. 187.-Flagella of Bacillus aroideae Townsend. Photographed by the writer March 29, 1915, from three fields on a slide stained by M. Katherine Bryan from a 24-hour agar eulture using van Ermengem's silver nitrate method. Not Townsend's original isolation but one of our own from a diseased calla lily, proved up on calla lily. $\times 1000$. 
ments can be tried, i.e. effect on the gas of shaking, in the presence of a strong solution of sodium hydroxid or potassium hydroxid. Is part of it absorbed? Is the absorbed part, roughly, one-fifth? Do not conclude too hastily. Allow time. Will the remainder

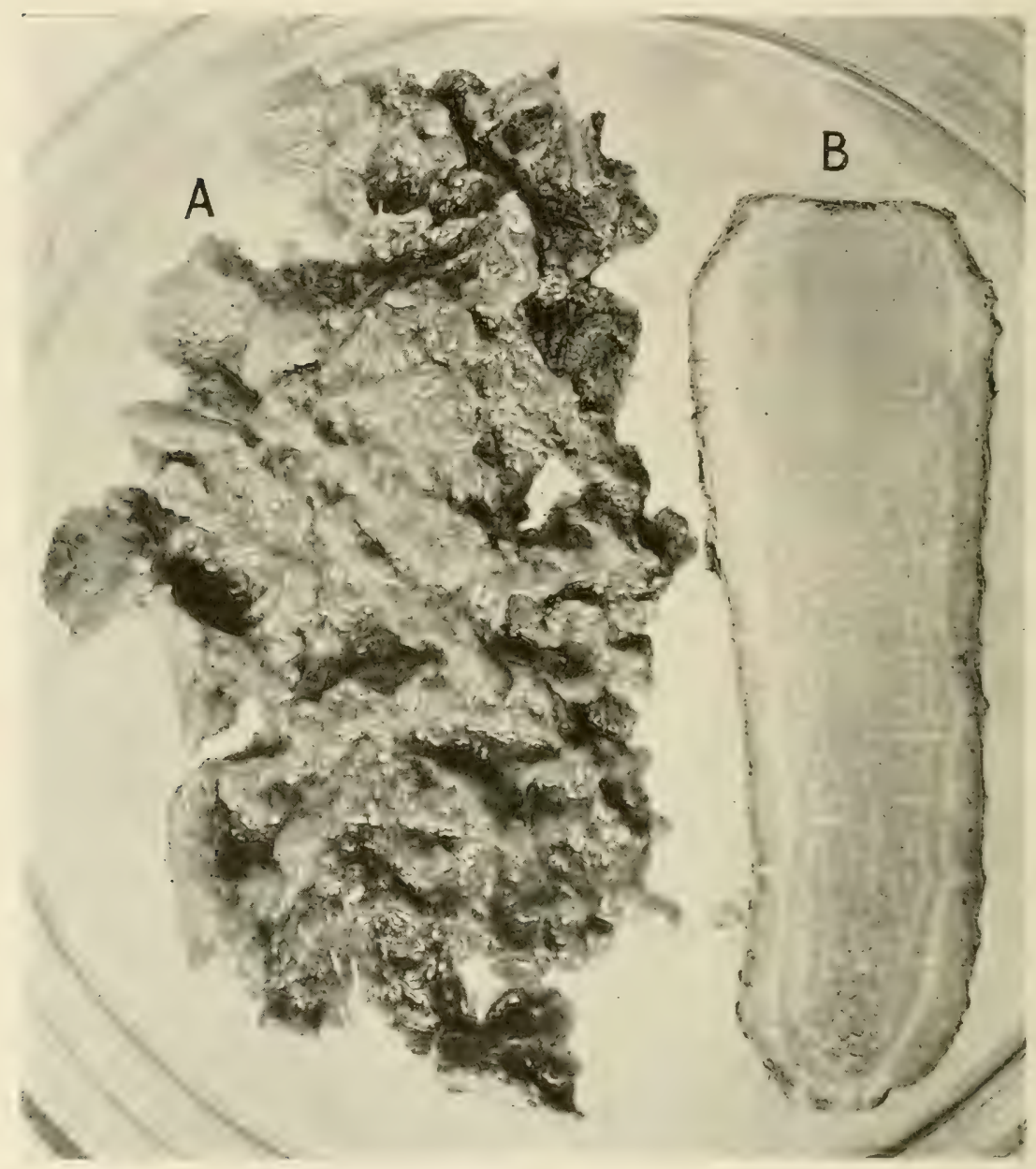

Fig. 188.-A. Effect of Bacillus aroideae Townsend, on raw carrot, B. check one-half. Time, 8 days. The left part was stirred up a little with a glass rod. Inoculated in 1915.

explode when brought into contact with a flame? Is it hydrogen? From what media are acids produced? Can the organism develop acid without gas (try glycerin)? Is more than one 
acid produced". Distill a flask-culture which has become acid and determine whether the steam is acid to neutral litmus paper. Use a large flask with a shallow layer of liquid. C'ollect the steam in water and make tests for nature of the acid. Is it acetic acid or only $\mathrm{CO}_{2}$ ? Boil the residue and determine whether it becomes more acid on concentration. Can you identify the residual acid? Is it lactic acid?

Contrast with $B$. phytophthorus in +15 peptone bouillon with from 5 to 10 per cent of ethyl alcohol added (by means of a sterile pipette) after sterilization.

Study nitrogen nutrition, reduction of nitrates, formation of hydrogen sulphide, ammonia, indol. Production of enzymesstarch-converting, proteolytie, ertolytic, etc. What ispectinase? Try the following experiment: Inoculate the center (surface only) of several agar plates and when the growth has become ${ }^{3} 4$ inch in diameter cut out the agar with a sterile knife in such a way as to remove all of the bacterial growth without touching it and transfer the agar bottom down to slices of raw carrots, turnips, etc. If you have done the work properly there will be no growth of the bacteria on the raw surface and yet it will rot. Why? Demonstrate absence of bacteria in the decaying tissues and describe their appearance under the microscope.

Is the milk curd a normal cheese curd? Is gas ever produced from milk? Try it in the closed end of fermentation tubes. Hold checks.

On what raw media and steamed substrata is the brown pigment produced? What is the nature of this compound? Is it a host reaction or a bacterial excretion?

It is important to isolate the organism from carrots (naturally rotting), from (iidding's melon rot and from Townsend's calla lily rot for comparison. Do so by all means if you have the opportunity, or send the material to some one who will. Much additional work remains to be done on the soft-rot bacteria.

Non-nutritional Environment.-Action of heat, cold, dry air (very sensitive), sunlight (very sensitive), acids, alkalies, germicides. Behavior in racuo, and in neutral gases such as hydrogen, nitrogen, carbon dioxide. 


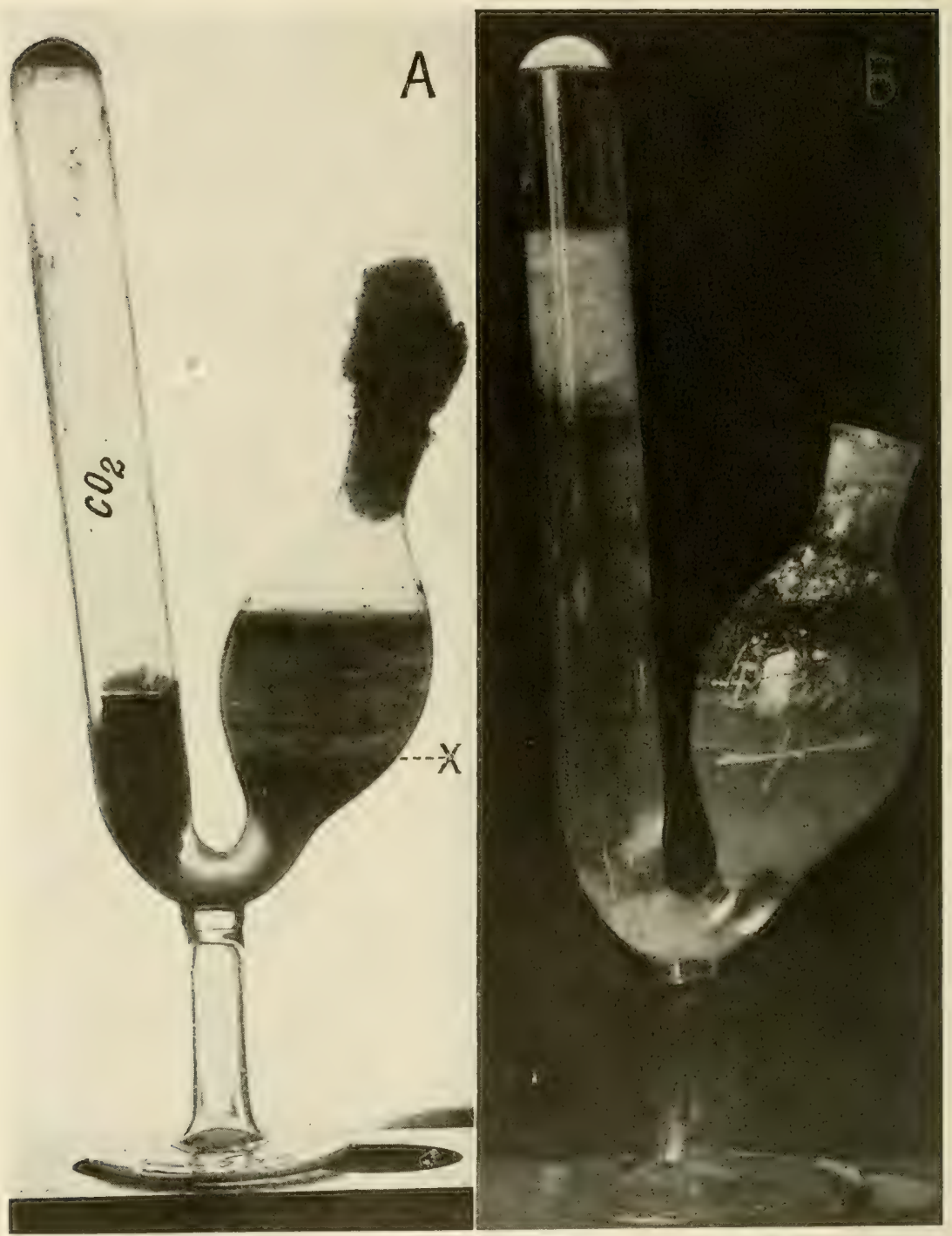

FIG. 189.-A. Fermentation-tube milk culture of Bacillus aroideae. The closed arm is full of gas (all $\mathrm{CO}_{2}$ ) and so is the $U$. From $x$ upward, whey; and downward, curd. Curd also in base of the elosed arm. Inoculated January 15, 1915. Photographed February 10, 1915.

$B$. Same as $A$ but 48 hours later when all the gas has been absorbed by addition of a strong solution of sodium hydroxide. 
Why does 5 per cent grape-sugar retard or inhibit growth? Why does it ear y kill off the cultures grown in media containing it?

For The DISEASE: Signs.-Write a description of the signs of this disease drawn from your own inoculations on carrots and other vegetables. How many hours from inoculation to the first appearance of the soft rot? Study the progress of the rot as related to: (1) copious vs. sparing inocu ation; (2) moist vs. dry air; (3) cool vs. warm air; and (4) flabby vs. turgid tissues. At what cool temperature does the rot cease? Above what temperature does it cease? Compare this organism with No. IV, especially on raw potato, and with No. VII.

- iubmit photographs or good drawings or both. Remember you cannot have too many striking and conclusive illustrations of the various diseases.

Histology.-Fix, embed, section and stain early stages and late stages of the rot on various plants to determine location and action of the organism. Are the cells invaded or is the action of the organism entirely extra-cellular? Do not conclude too hastily. How are the middle lamellae destroyed, i.e., by tearing or by solvent action? What is the composition of this middle part of the cell-wall? Is cellulose destroyed"? How are the bacterial cavities formed? Are the cells killed in advance of the bacterial invasion? Does the water-soaked area surrounding a bacterial nidus stain the same in sections as the sound area just beyond (see Fig. 172 at $x$ )? Under the microscope unstained, does it look the same? What differences in the cellwall? in the cell contents? In the attacked parts just previous to disintegration are the cell-walls swollen? Make good permanent preparations showing various stages of the tissuedisintegration.

Variability.-There appears to be considerable more resistance in some varieties of the attacked species than in others. Is this accidental or inherent? Why are green tomato fruits more subject than ripe ones? Why is the core of the carrot rotted sooner than the outer part? Why are young (seedling) carrots exempt? Are they, really? Why are the green parts of susceptible plants not more generally attacked? Read what 
you can find on this subject and make some experiments. The man who is continually trying out his ideas by means of careful experiments is the one who makes discoveries. Reading alone will not serve; it makes a full man, but not a fruitful one.

Transmission.- Nothing is known respecting special carriers of this disease. One should certainly aroid throwing diseased refuse into manure piles and into streams, and rotation of crops should be practised. Carrots should be dried and sunned as thoroughly as possible before storage, which should be at a low temperature.

\section{LITERATURE}

Read Jones: "Bacillus carotovorus n. sp., die Ursache einer weichen Fäulniss der Möhre." Centralb. f. Bakt., 2 Abt., VII Bd., 1901, pp. 12 and 61; also Jones: "A soft rot of carrot and other regetables, etc." 13th Report, Vermont Experiment. Station, 1901; and Jones, and Harding and Morse: "The bacterial soft rots of certain regetables" (23d Annual Report, Vermont Agricultural Experiment Station, 1910, where other literature is referred to.)

Consult "Bacteria in Pelation to Plant Diseases," Vol. I, Figs. 2, 3, and 88. and some statements in the text; also Ibid., Vol. II, text statements (see index).

Read Apieckermamn's "Beitrag zur Kenntnis der bakteriellen Wundfäulnis der Kulturpflanzen," Landw. Jahrb., 31 Bd., Berlin, 1902, p. 155, and Harrison's "A bacterial rot of the potato caused by Bacillus solanisaprus" Centralb. f. Baht., 2te. Abt., XVI, Bd., 1907, pp. 34, 120, 166, 384.

See also Townsend's paper: "A Soft Rot of the Calla Lily," U. S. Dept. Agr., Bureau of Plant Industry, Bulletin No. 60, 47 pp., 9 pls., 7 text figures, 1904.

And Cidding's paper: "A Bacterial sioft Rot of Muskmelon, Caused by Bacillus melonis n. sp.," Termont Agricultural Experiment Station, Bul. No. 148, pp. 366-416, with 14 text figures, 1910.

The first paper's on this subject and the last one also are by Prof. L. R. Jones. 


\section{THE BACTERIAL BLACK ROT OF THE POTATO}

(Syn. Black leg, Basal Stem-rot and Tuber-rot)

Type.-This is a wide-spread and very destructive soft rot of the potato and some other plants. Vessels are sometimes occupied, but it is a disease of the parenchyma rather than of

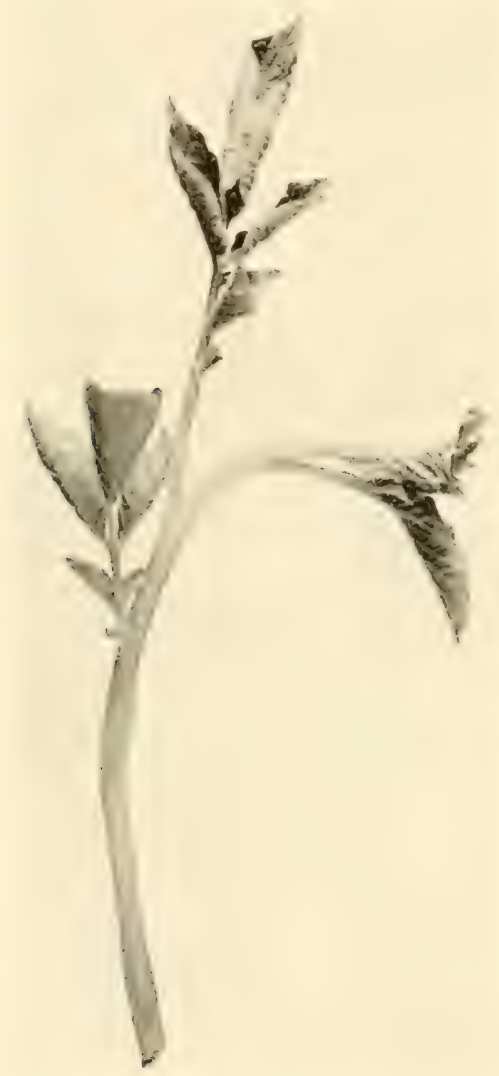

FIG. 190.-Curling of potato leaflets due to Bacillus phytophthoms (Appel I). Spring of 1915. Second set of needle-prick stem inoculations.

the vascular system, being found, according to Dr. Appel, only oceasionally and exceptionally in the resiels of the potato plant. The first above-ground signs of the disease are either sudden 
wilting or a slow yellowing of the lower leaves and a stricter habit of growth in the upper ones, the leaflets of which (Fig. 190) are or may be more or less incurled (upward). If one examines the base of such shoots they will be found to be black-spotted

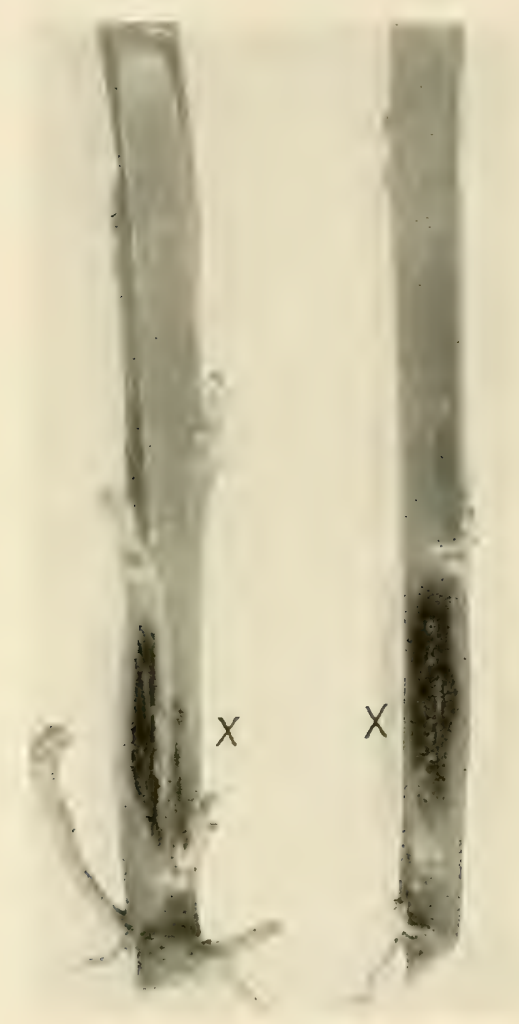

Fig. 191.

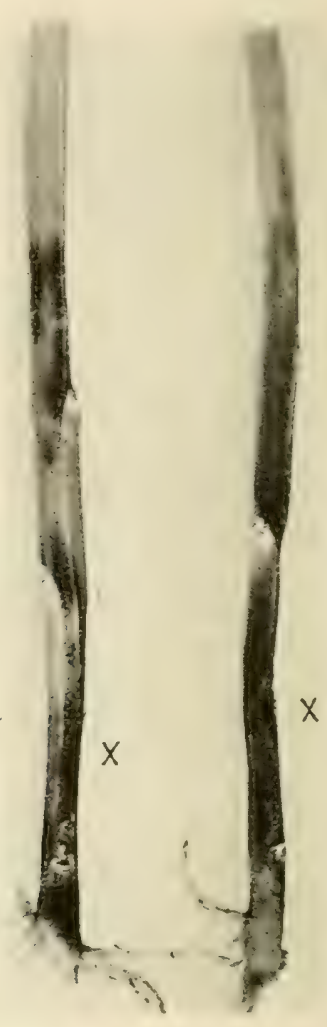

Fig, 192 .

FIG. 191. - Stems of Green Mlountain potato inoculated 48 hours at $\mathbb{A}$ with Bacillus phytophthorus Appel, from a 2-day agar-streak culture. Stems black and rotting in the pricked area. Hothouse experiment of January 23, 1915. Tubers half grown. Organism from Germany. In the laboratory since August, 1906.

FIG. 192. - Same lot of plants as Fig. 191, but 4 days after inoculation (at $X$ ). Stems black and nearly rotted off in the pricked area; bundles infected upward for long distances and with a brown stain coming to the surface.

2nd more or less softened (Figs. 191, 192) at the surface of the earth or just below it, and hence the German name Schuarzbeinigkieit (black leg). (ienerally at first this blackening and ulceration are restricted to the base of the stem but upper parts soon 
wilt, blacken, shrivel, and fall over (Fig. 193), and often the tubers decay. The disease is readily inoculable into the soft upper part of shoots (Fig. 194) and may run out on the petioles in black lines exactly as in case of Bacterium solanacearum (No. IV) or of Bacillus amylovorus (No. XII). It is also readily inoculable into the base of potato shoots when not too old (Figs. $195,196)$ and then progresses in the same way as the natural infections. Old shoots are less susceptible than young ones (Figs. 197, base, and 198) and very often when the basal parts of stems are inoculated they rot across and break over without much downward movement of the bacteria (Fig. 198), the underground parts sending up new dwarfed shoots to take the place of those destroyed (Fig, 199). Prior to shriveling, especially as the season advances, all the green parts of the potato (stems, leaves, flower stalks) may show black spots due to the organism and from these pure cultures of it may often be obtained (Appel). The bacteria neither show any special tendency to multiply in the vascular bundles, although sometimes found there (Fig. 200), nor, in

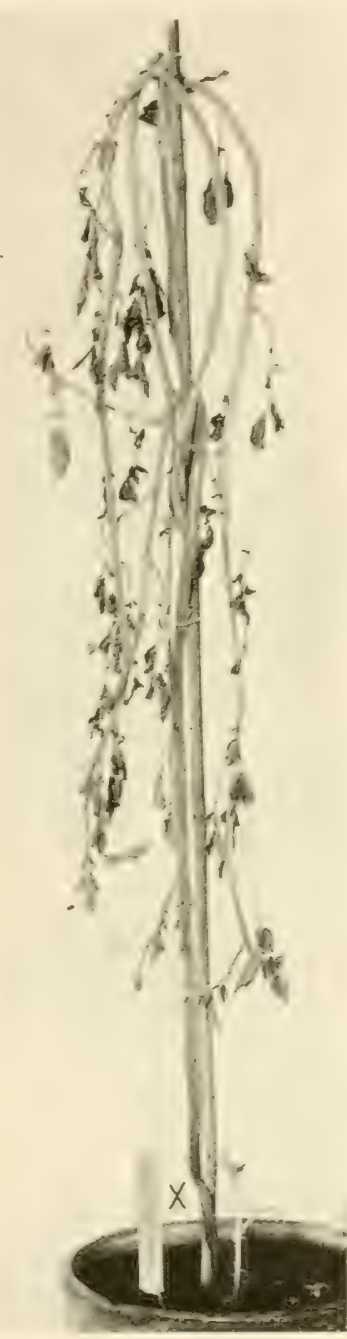

Fi G. 193.-Potato plant inoculated by needle pricks on the base of the shoot (at $\mathrm{X}$ ) and wilted by Bacillus phytophthorus (Appel I). Plant inoculated January 30, 1915 from a 16-day culture on a steamed potato. Photographed on the 7th day, 1,5 natural size. Of 9 shoots on 6 plants all of which were inoculated only one failed to become diseased, and this was one of $t$ from the same tuber (perhaps it was older than the other 3 shoots). The disease progressed much faster upward than downward as shown by the tiny shoot which is still unaffected though coming out of the base of the blackened stem at the earth's surface. Earlier stages of the disease resembled Figs. 191 and 192. 


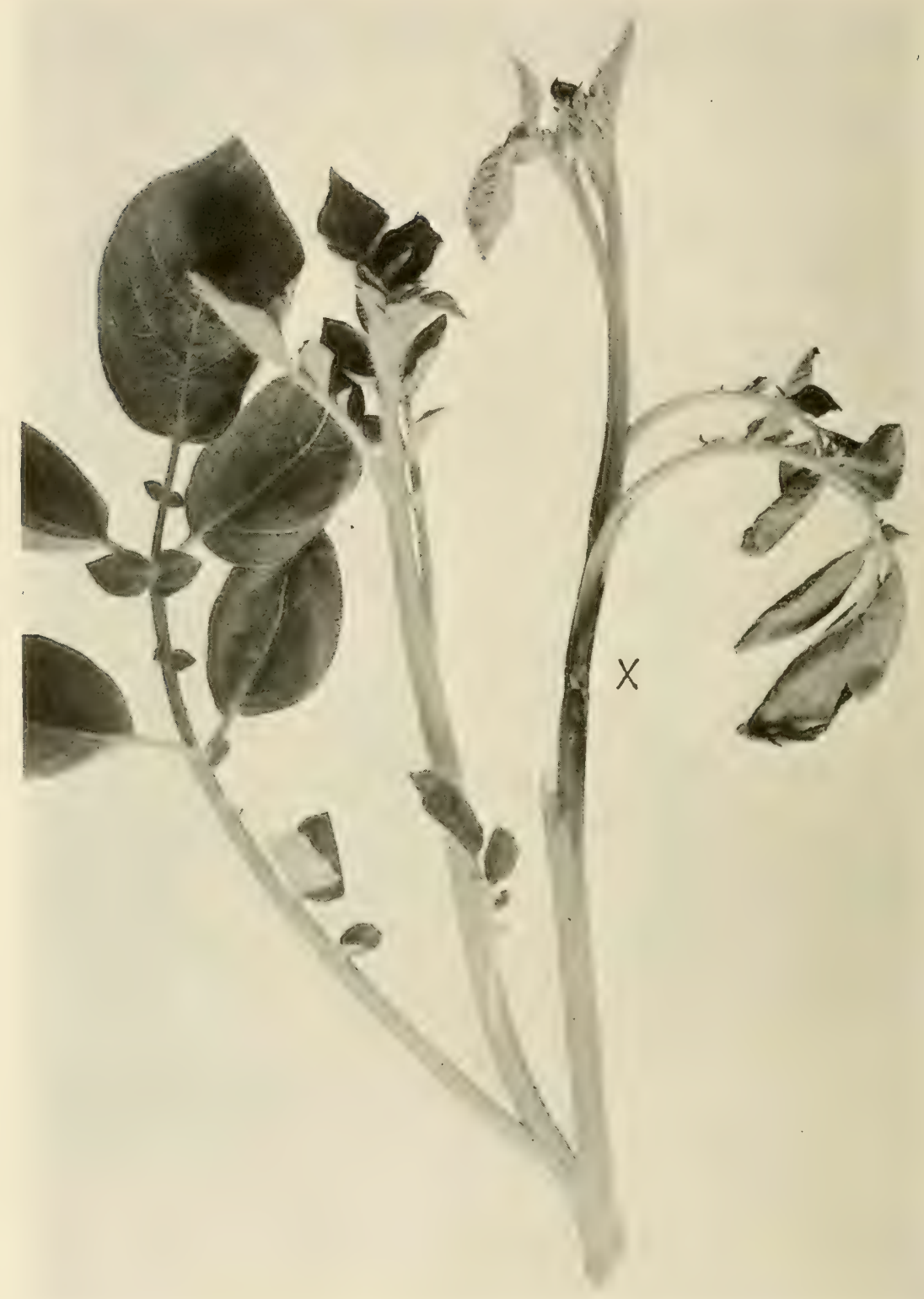

FIG. 194.-Potato shoot from same lot as Fig. 193 (Bacillus phytophthorus) but from another plant and inoculated at the top. Hothouse temperature ranging from $65^{\circ} \mathrm{F}$, to $95^{\circ} \mathrm{F}$. Needle-pricks at $X$, from a 2-day agar-streak culture. Time, 43 hours. German organism (Appel I). 
my top-inoculated plants have I seen any strong tendency of the disease to extend into the tubers such as we see in case of potato shoots inoculated with Bacterium solanacearum. The disease occurs in its worst form during warm moist summers and autumns, but may continue on the tubers through the winter, if the temperature in the store-houses or pits is sufficiently high. In the tubers, the disease does not begin in the vascular ring (contrast with No. IV). In the laboratory raw potato tubers may be rotted very quickly (contrast again with No. IV) by streaking the organism on their cut surface (Fig. 201). Lenticel infections occur on the tubers (Fig. 202). Starch is not destroyed and the infection is chiefly intercellular (Fig. 203).

Dr. Appel's principal studies were made upon the potato but he also isolated his organism from diseased comfrey (Symphytum officinale). He successfully inoculated it into yellow lupins, horse beans (Vicia faba), green tomato fruits, slices of raw carrot, etc.

This disease occurs all over Germany, in Ireland, and in various parts of the United States (Maine, Virginia, South Carolina, Wisconsin). Its distribution is probably co-extensive with the culture of the potato, and I now regard it as one of the most serious diseases of the potato.

Cause. - The basal stem-rot is due to Bacillus phytophthorus Appel (not sufficiently distinguished from Bacillus carotororus Jones, which name is earlier). This is a white, rapid-growing, non-sporiferous, Gram negative, motile, peritrichiate-flagellate (Fig. 204), promptly liquefying, nitrate-reducing, ärobic and facultative anaërobic, acid-forming, gas-forming (but not in the potato), milk-curdling (by formation of an acid), alkalitolerant, sodium chlorid-tolerant, chloroform-tolerant, dryair-sensitive, rod-shaped or filamentous schizomycete, forming quickly on agar-poured plates circular, grayish white or, by transmitted light, slightly bluish white, well-developed colonies; and on very thin-sown gelatin plates characteristic, rapid-growing, big, circular (Figs. 205 and 206), opaque-white, fringed (fimbriate-margined) colonies (Fig. 207), floating in a pit of liquefaction (thick-sown plates liquefy too rapidly for these examinations). The buried colonies in gelatin plates appear as 


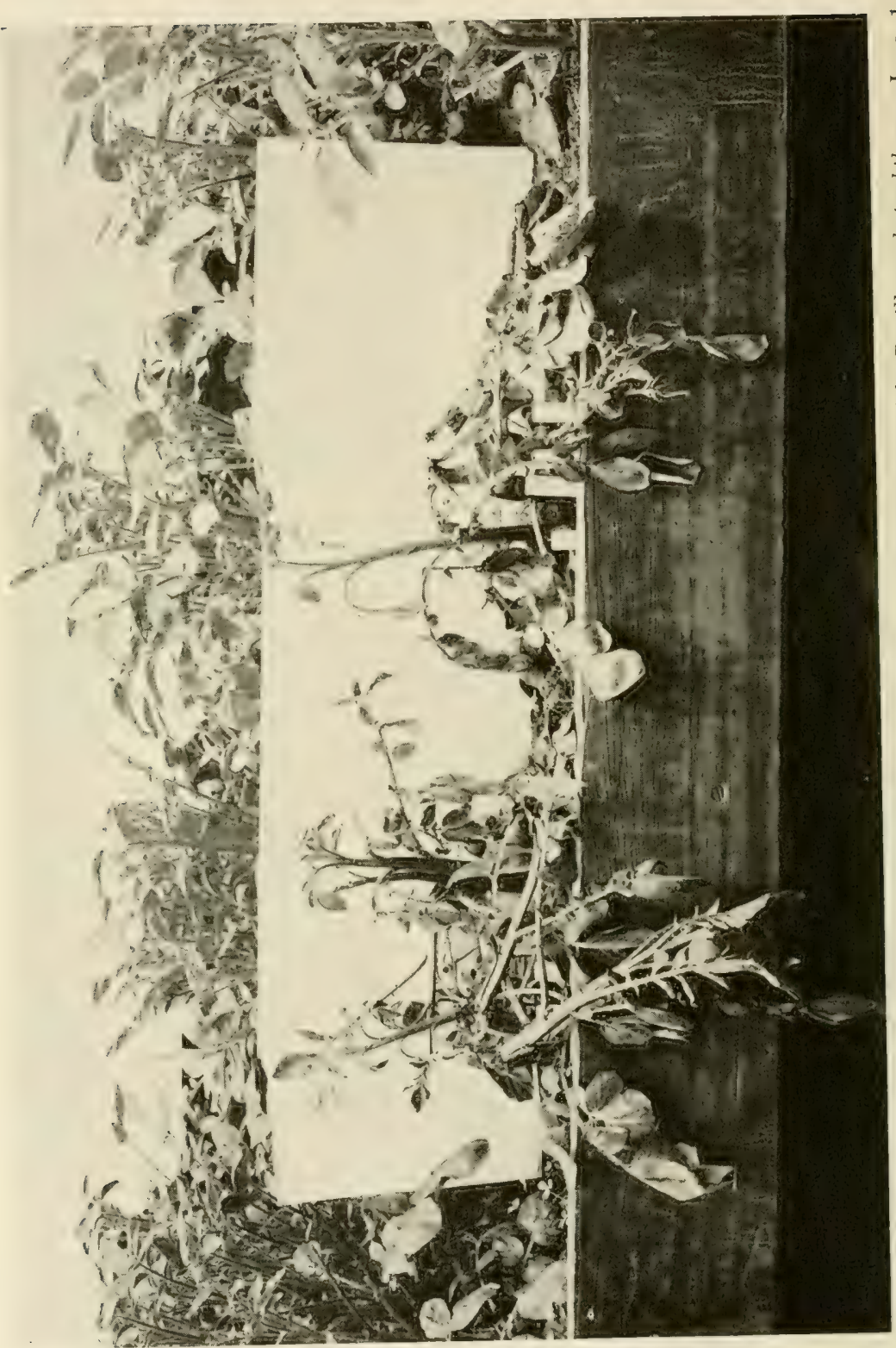

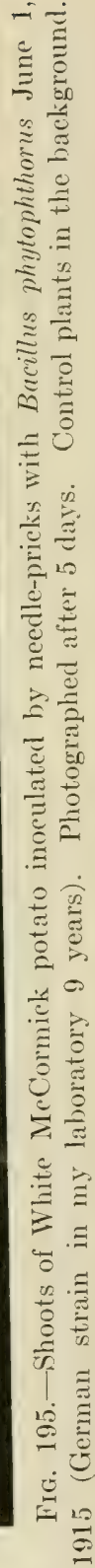




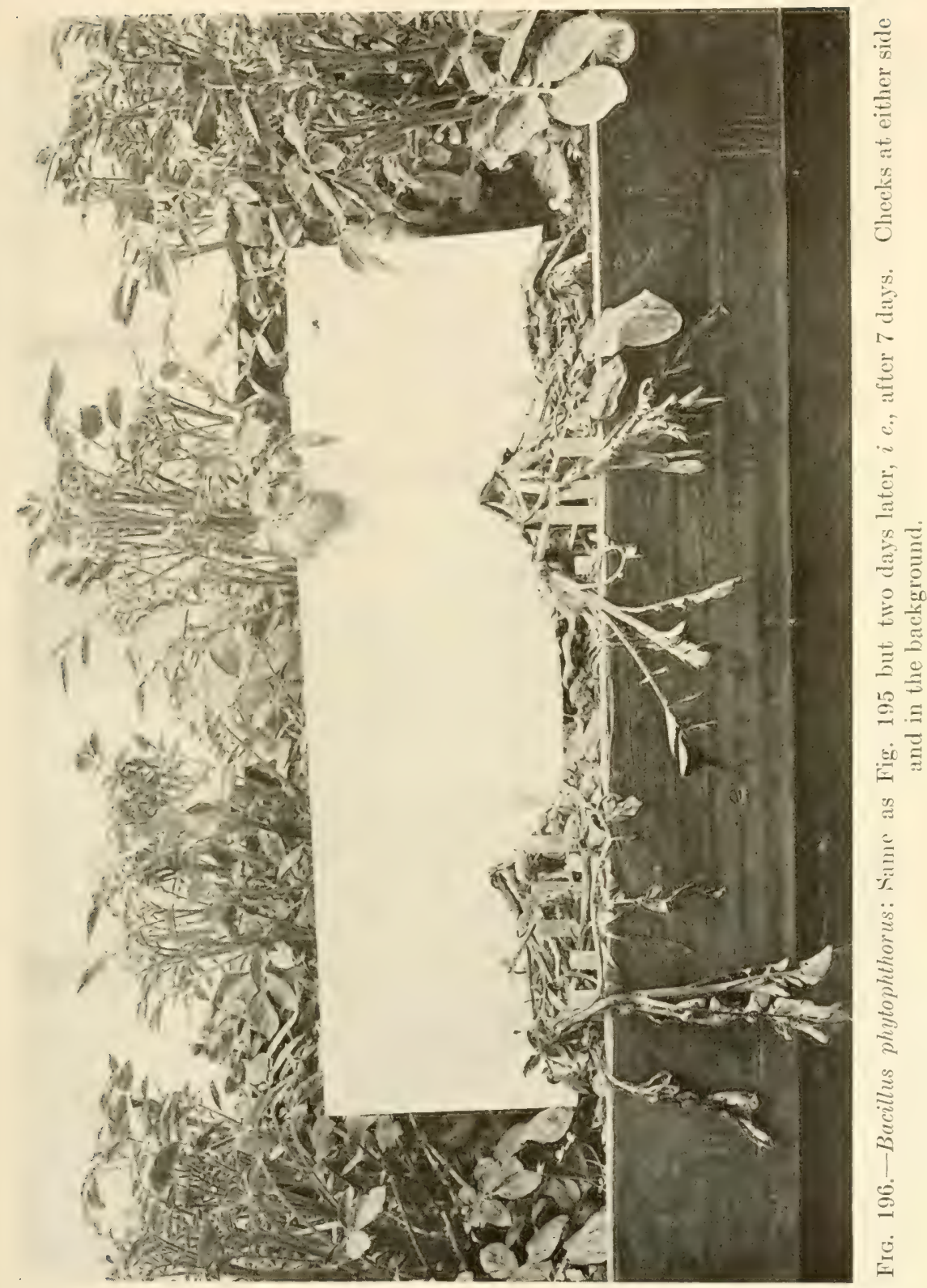


shown in Figs. 208 and 209. The organism is white on most media but on Soyka's milk rice it is pale pinkish cinnamon verging toward vinaceous pink in old cultures $\left(R_{2}\right)$. Streaked on slices of raw potato it grows rapidly and characteristically, forming a white slime surrounded by a dark (black or brown) border in the disintegrating flesh of the potato. The disintegrating potato shoots also are often very black. Bouillon is

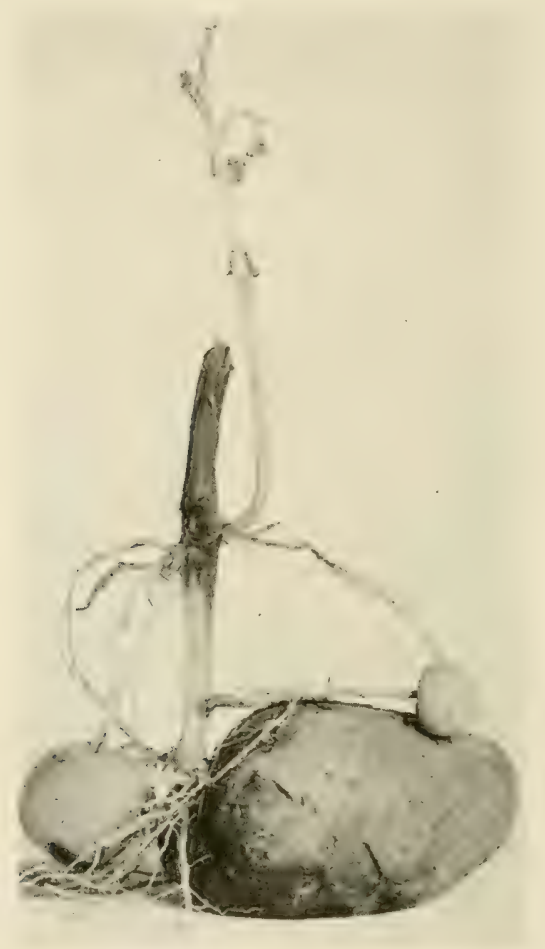

Fig. 197.-Base of Fig. 193, 2 days later. The mother tuber, the young tubers and the woody base of the stem are still sound.

clouded very quickly and gelatin stabs develop a prompt funnel of liquefaction. Potato juice clouds quickly even in the absence of air (closed end of fermentation tubes) but no gas is formed. Ethyl alcohol in peptone bouillon retards or hinders growth (Fig. 210A). The organism does not form indol, and does not grow in Cohn's solution. It produces a nonvolatile acid from dextrose, saccharose, lactose, galactose, and 


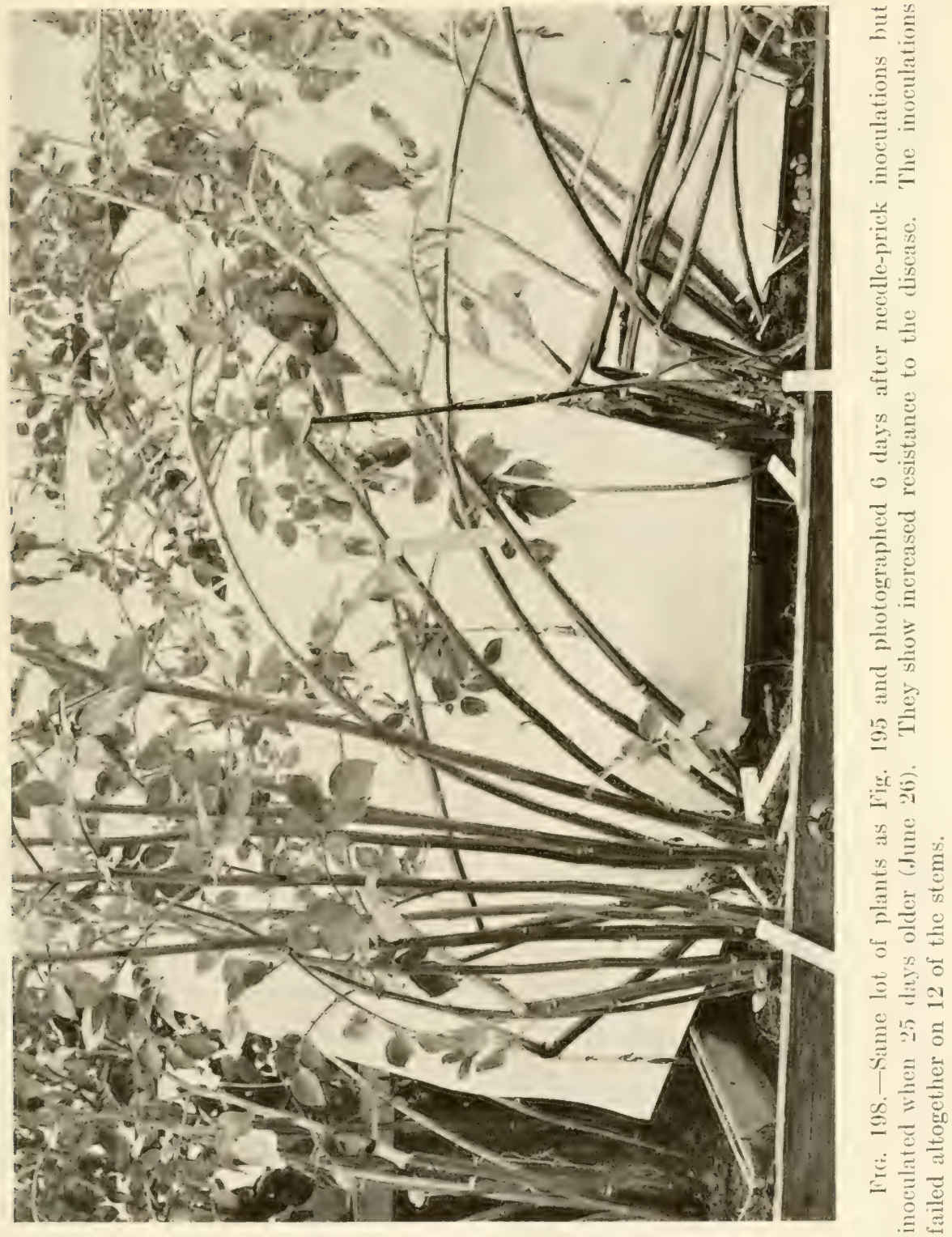




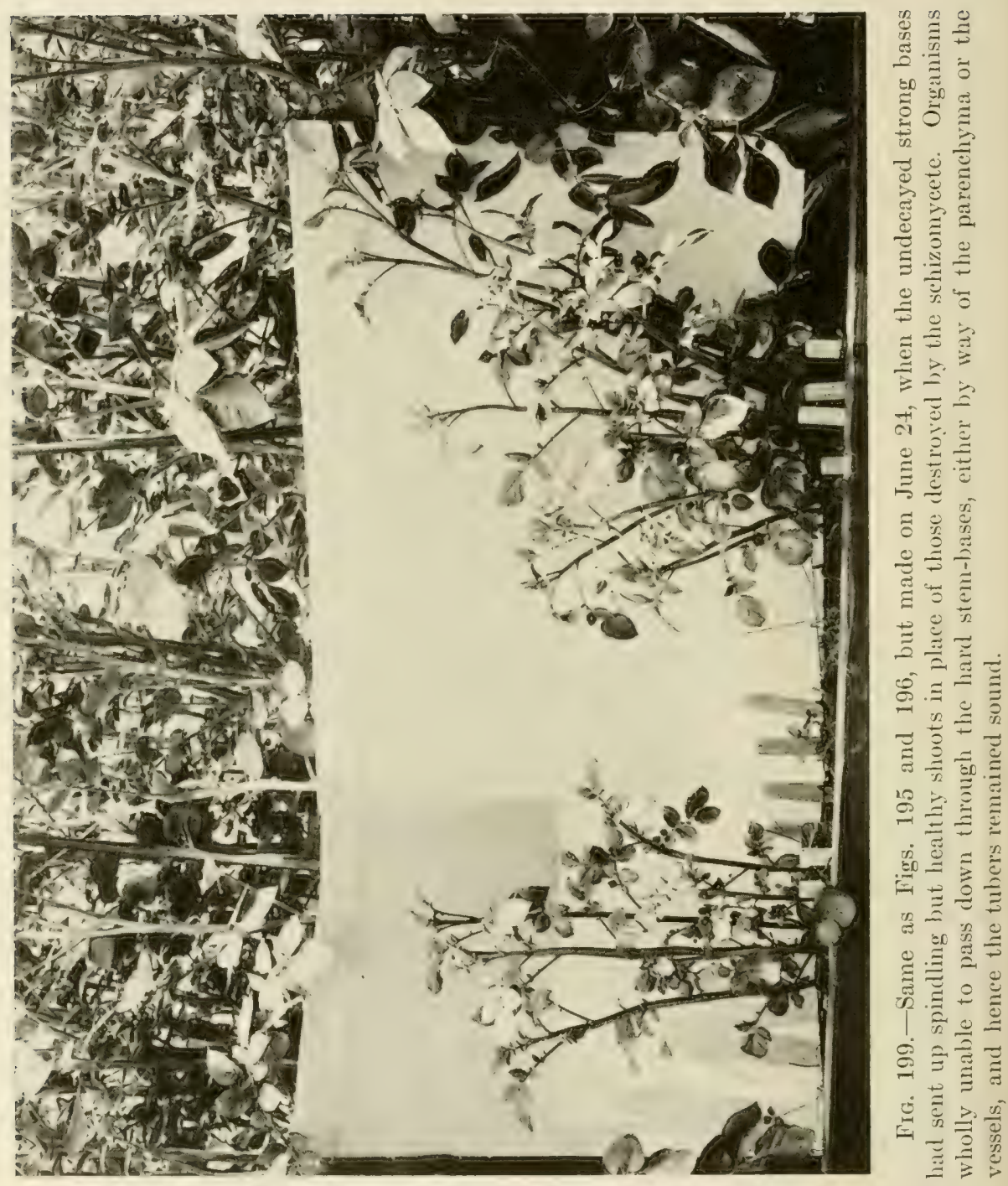


maltose, and small quantities of gas from innosit (muscle sugar), lactose and mannit. A volatile acid also distills off from peptone dextrose cultures (flasks 15 days old). It is a common belief (of German origin) that the organism loses virulence readily, but in nine years, in the strain originally received by me from Dr. Rudolph Aderhold in Berlin, and designated in my laboratory as "Appel I," I have not observed any loss of virulence. The last inoculations made with it by me in June, 1915, on rapidly growing potato shoots by needle pricks, yielded striking

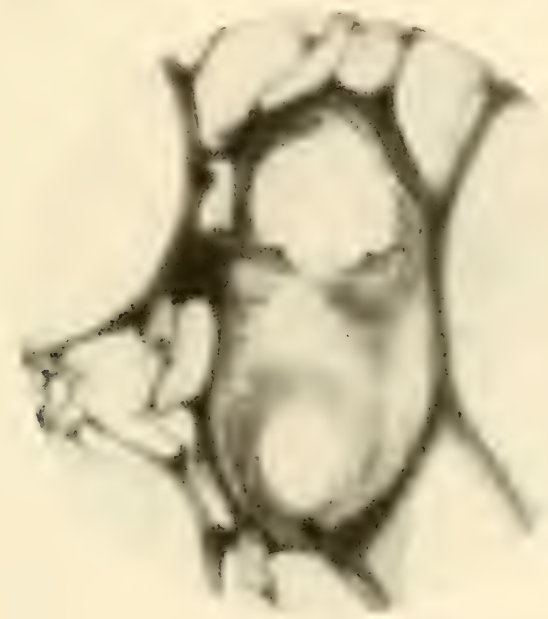

FIG. 200.-Cross-section of potato stem several inches above the inoculated base.

Enlarged to show the bacteria (Bacillus phytophthorus) occupying a vessel.

infections, the tops of the 18 inoculated shoots being entirely destroyed in 5 to 7 days. $^{1}$ A contaminating non-parasitic coceuform is common (Appel). This is, probably, what Dr. A. B. Frank figured, and supposed to be the parasite.

Technic.-Because saprophytes quickly follow parasites in the decaying potato, it is often difficult to isolate the latter, Bacillus phytophthorus being no exception. This sufficiently explains why the causes of such an insistent and annually recurrent phenomenon as the rot of potato tubers remained so long undetermined. Not knowing that the same organism could not. both begin and complete the destruction of the potato tuber,

${ }^{1}$ I tested it again on potato tops in April, 1919 (13th year in my laboratory) with the same striking results. See Fig. 211. It was also infectious in 1920. 
Reinke and Berthold, Kramer, Frank, Wehmer, and, prior to Appel, all the Germans who studied potato rots (mostly by means of the microscope) were led astray by the non-infectious saprophytes (starch-destroyers, gas-producers, endospore-bearing rods, coccus forms, etc.) which soon swarm in the tissues and complete their destruction, but cannot be induced to begin the rot except under very abnormal asphyxiating conditions. Then, of course, almost any refuse-loving organism will grow in the dead tissues, since the potato is a good culture medium for many things. In this connection, read Wehmer's paper in

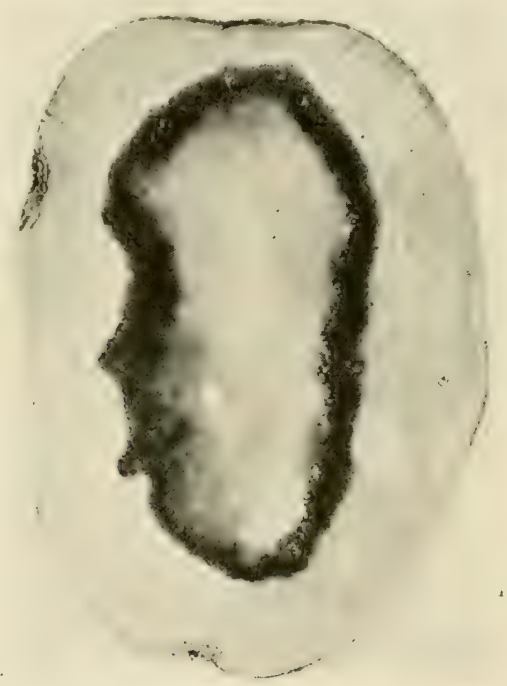

Fig. 201.-Streak culture of Bacillus phytophthorus Appel on raw potato 36 hours at about $23^{\circ} \mathrm{C}$., showing a soft rot bordered by a dark stain. Inoculated from a 48-hour culture on steamed potato. Tuber soaked 30 minutes in 1:1000 mereuric chlorid water before cutting with a sterile knife. The check $1 / 2$ remained sound. Laboratory experiment of 1914. 1/2 nat. size.

Centralblatt $f$. Balteriologie, 2te Abt., IV Bd., 1898, pp. 540' $570,627,694,734,764$ and point out his fallacies.

Appel by his masterly paper (1903) let a flood of light into an obscure situation, because while the writer had proved conclusively 7 years earlier (1896) that a part of the potato rot of the United States was due to a schizomycete, this organism (Bacterium solanacearum) had not been subsequently isolated 
with certainty from European potatoes, and its existence did not account for all of our own potato rots, and particularly for those common in the more northern parts of the United States in which the distribution of Bacterium solancearum remained (and still remains) unknown, although it was isolated by us nearly every year from various species of plants received from our Southern States.

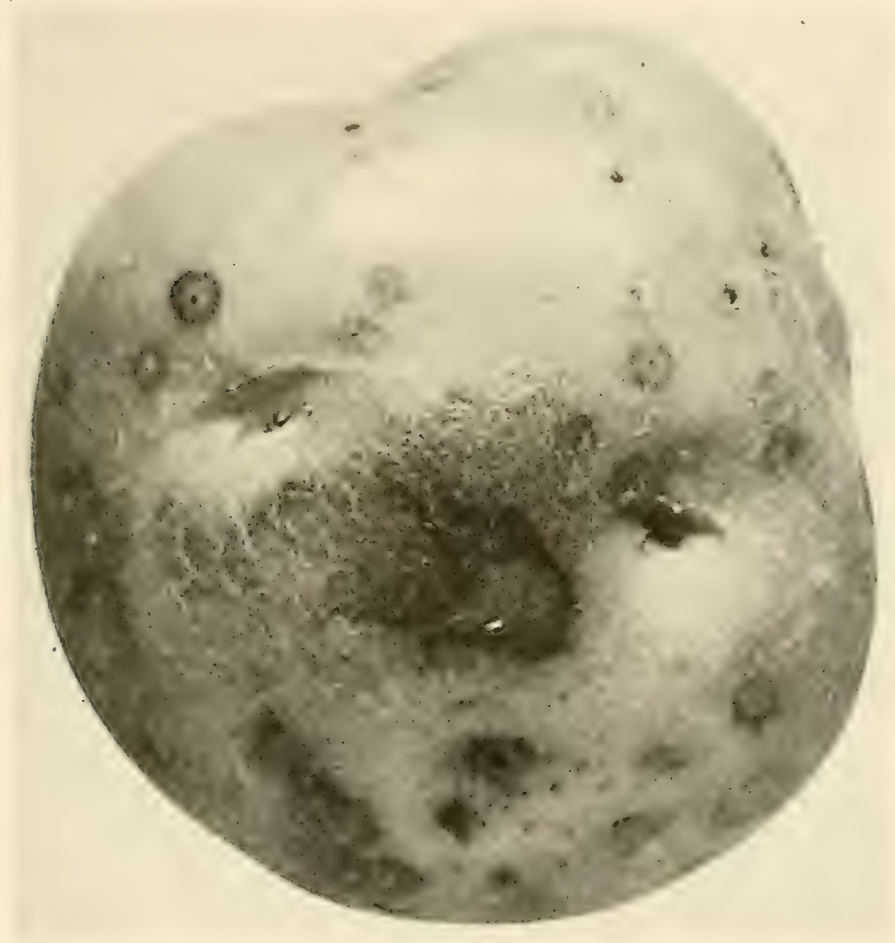

Frg. 202.-Potato tuber showing lenticel infections due to Bacillus melanogenes. At the bottom on the left side and in the center, various infections'have fused. From a plunge inoculation by the writer in 1912 .

Following the appearance of Appel's paper, his organism was found in the United States by the writer and others (Morse, Jones, etc.), and two or three similar organisms were soon described, e.g., Bacillus solanisaprus Harrison. Morse has substituted van Hall's name, Bacillus atrosepticus, for Appel's name but a careful re-reading of van Hall's Dutch paper (May 
$21,1902)$ leaves me in doubt. No one now has transfers from van Hall's original culture, I believe, so as to enable one to clear up the doubtful points and under the circumstances it is best, I think, to retain Appel's name, especially as ran Hall made very few inoculations under natural conditions and as he says of his organism: "On artificial media the parasite loses its virulence very quickly." Moreover, if May 21, 1902, or some

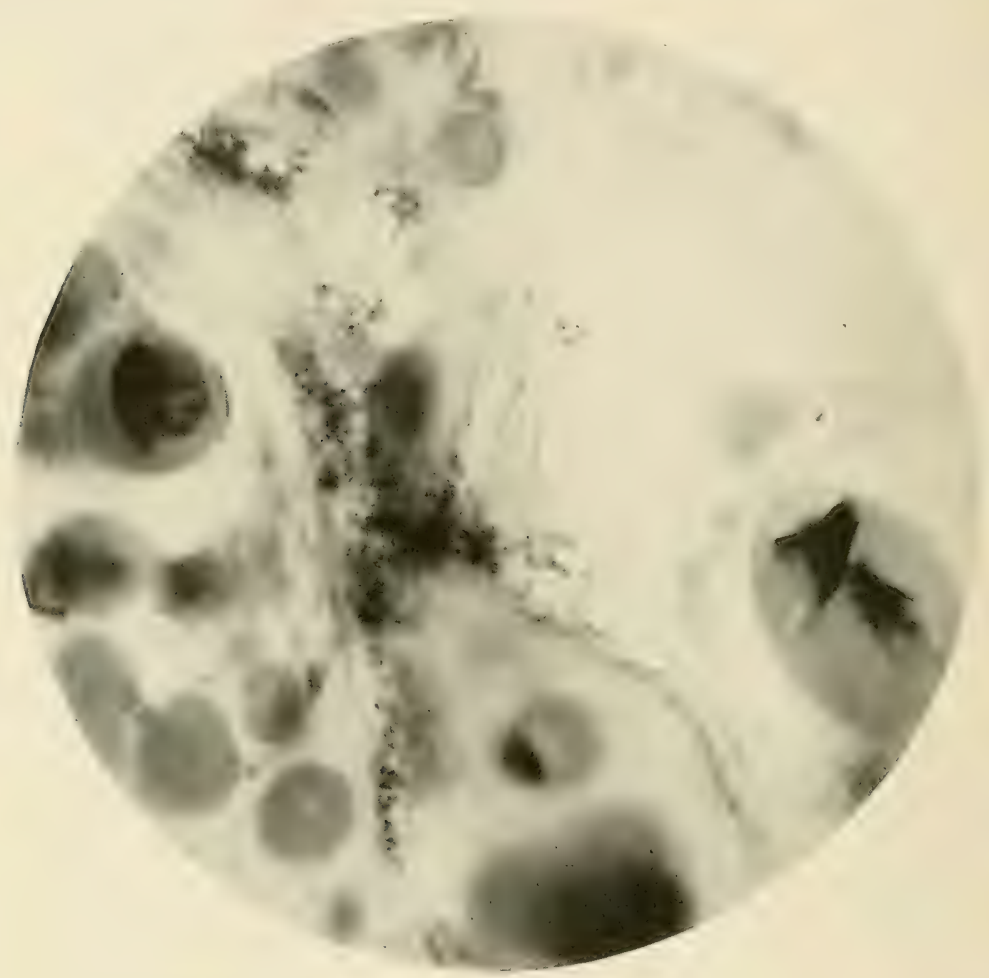

FIG. 203. - Stained section of a potato tuber in the vicinity of an infected lenticel (stage of Fig. 202) showing bacteria dissolving the middle lamella and wedging apart the starch-bearing cells.

later date is the actual date of publication of van Hall's thesis, then Appel's name is at least 2 months earlier than van Hall's name and the latter, even if synonymous, does not have priority.

To isolate this organism, the surface through which it is proposed to enter for cultures should be burned with a hot knife or spatula, or soaked for twenty minutes in 1:1000 mercuric 
chlorid water. By preference the entrance should be through sound tissues close to the advancing margin of the rot, from which scrapings may then be made for the poured plates. One should not be discouraged if the first plates yield only saprophytes, but should try in several other places on the same plant or on other plants.

The organism grows readily and is easily identified by its behavior in Cohn's solution, litmus milk, thin-sown gelatin plates, surface of raw potato, etc. Spore-bearing organisms and coceus forms may be eliminated from consideration on the start, also those schizomycetes that produce gas from potato

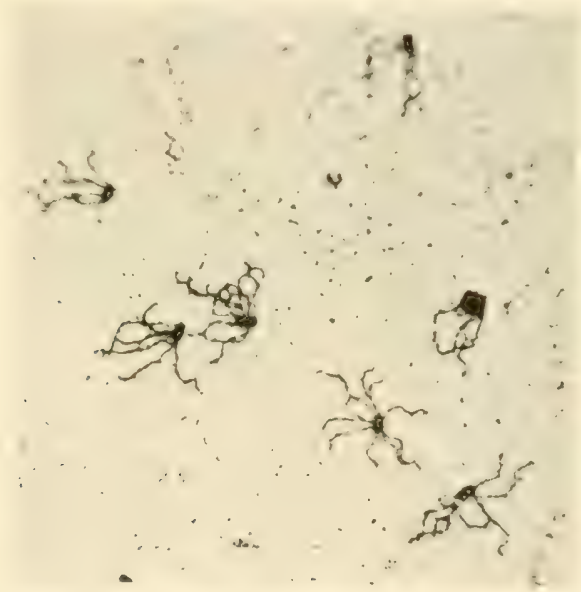

Fig. 204.-Flagellate rods of Bacillus phytophthorus Appel. Stained from a young (2 day) agar culture of Appel I by van Ermengem's silver nitrate method. Photographed March 29, 1915. $\times$ 1000. (Compare with Fig. 176.)

juice in the closed arm of fermentation tubes, and all vile-smelling forms.

For inoculation it is best to select the base of young shoots of the potato in rapid growth, or the soft tops of older plants, using needle-pricks from young cultures on agar, potato or gelatin.

Tubers to be inoculated should be freshly dug (or at least not flabby), sound and flawless, and may be kept either in the open air of the laboratory or in damp air under bell-jars. If many checks are held it is sufficient to wash the surface free from dirt. If none are held, then the part through which the needle 
enters must be soaked in 1:1000 mercuric chlorid water for 40 minutes.

In wet autumns, in moist soil, there is often a wholesale rotting of potato tubers due to the entrance of the parasite through the lenticels and it is a very instructive experiment to demonstrate lenticellate infection in the laboratory. Sorauer was, perhaps, the first person to see bacteria enter the potato tuber in this manner. The writer saw it many years ago (1886) and has obtained on potato tubers in recent years very typical and beautiful infections by way of the lenticels (Fig. 202), using Bacillus melanogenes (which as received by me was a mixture of Bacillus phytophthorus and Bacillus solanisaprus). For this purpose one should select smooth, sound, recently harvested tubers, wash clean and plunge for 30 hours under distilled or autoclared or even non-sterile tap water, to which a young agar-streak culture of this organism has been added. If the variety is susceptible, numerous infections centering in lenticels should appear within a few days, and soon the interior of the tubers should be wholly disintegrated. The sterility of the water used is of no great consequence so long as it does not contain parasites, and so long as the surface of the tuber itself is not sterile, the aim being to set up conditions like those obtaining in ordinary infections in wet earth. Of course, checks to which the parasite has not been added should be held and these will remain sound unless their surface happens to be contaminated with this or some similar parasite, but the tubers must not be asphyxiated.

What proportion of the wholesale rot of potato tubers in the soil in wet autumns is to be ascribed to Bacillus phytophthorus, Bacillus solanisaprus, and similar bacterial parasites, and what to mere saprophytes following asphyxiation cannot be determined until a great many more studies have been made of the flora of rotting potatoes.

\section{Determine}

For the organism: 1. Morphology.-Size in microns, form, aggregation of elements (Do chains or filaments occur? See No. VI), motility on margin of a hanging drop (How long 
does motility persist in cultures?), presence and distribution of flagellæ (use Hugh Williams' stain), absence of endospores (try heating for 10 minutes at $80^{\circ} \mathrm{C}$, and spore stains). Any capsule? Reaction to Gram's stain (examine with the diaphragm wide open). Is the organism acid-fast? Do involution forms occur? Test in dextrose peptone water.

2. Cultural Characters.-Growth on very thin-sown +10 beef-peptone gelatin plates at $20^{\circ} \mathrm{C}$. is very characteristic (If the plate contains only 4 to 6 bacteria, they should grow quickly, forming big circular opaque white colonies ( Fig. 206i) in 3 or 4 days. Compare with No. VI (Fig. 212A.) The rate of

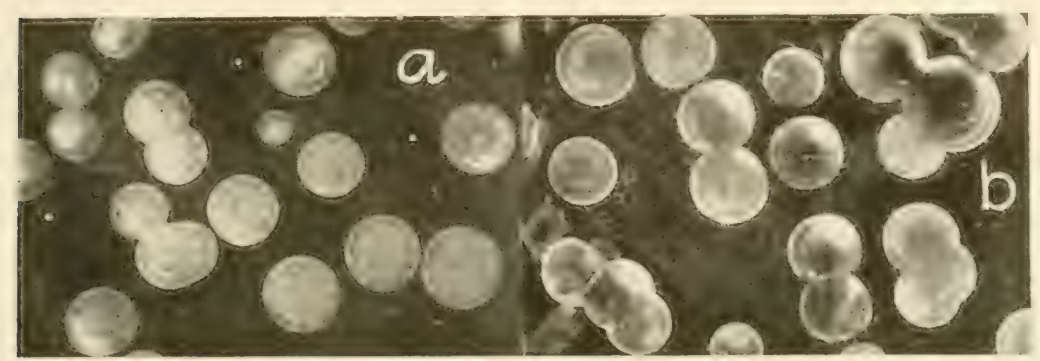

FIG. 205.- - 4 . 48-hour gelatin colonies of Bacillus carotovorus L. R. Jones, grown at same temperature and on same batch of gelatin as $b$. Natural size.

b. Gelatin colonies of Bacillus phytophthorus Appel. Photographed natural size after 48 hours at $18^{\circ} \mathrm{C}$.

liquefaction in gelatin stabs resembles that of Bacillus carotororus. Appearance in agar plates, streaks and stabs. Growth on steamed potato. Behavior on slices of raw potato (select smooth, sound tubers, wash, soak 40 minutes in 1:1000 mercuric chlorid water, slice when dry with a sterile knife, and put into shallow-covered culture dishes or deep Petri dishes). Why does the black stain not appear also in the cultures on the cooked potato? What is tyrosinase? Does it play any part here? Why does the dark stain disappear in later stages of the rot in raw tubers (Fig. 201)? Growth in bouillon, nitrate bouillon, Cohn's solution, Uschinsky's solution, Fermi's solution (Does this medium become yellowish or greenish?). Growth in milk (Is the casein thrown out of solution by an acid or by a lab ferment? What is the odor of the fermented milk? Does this 


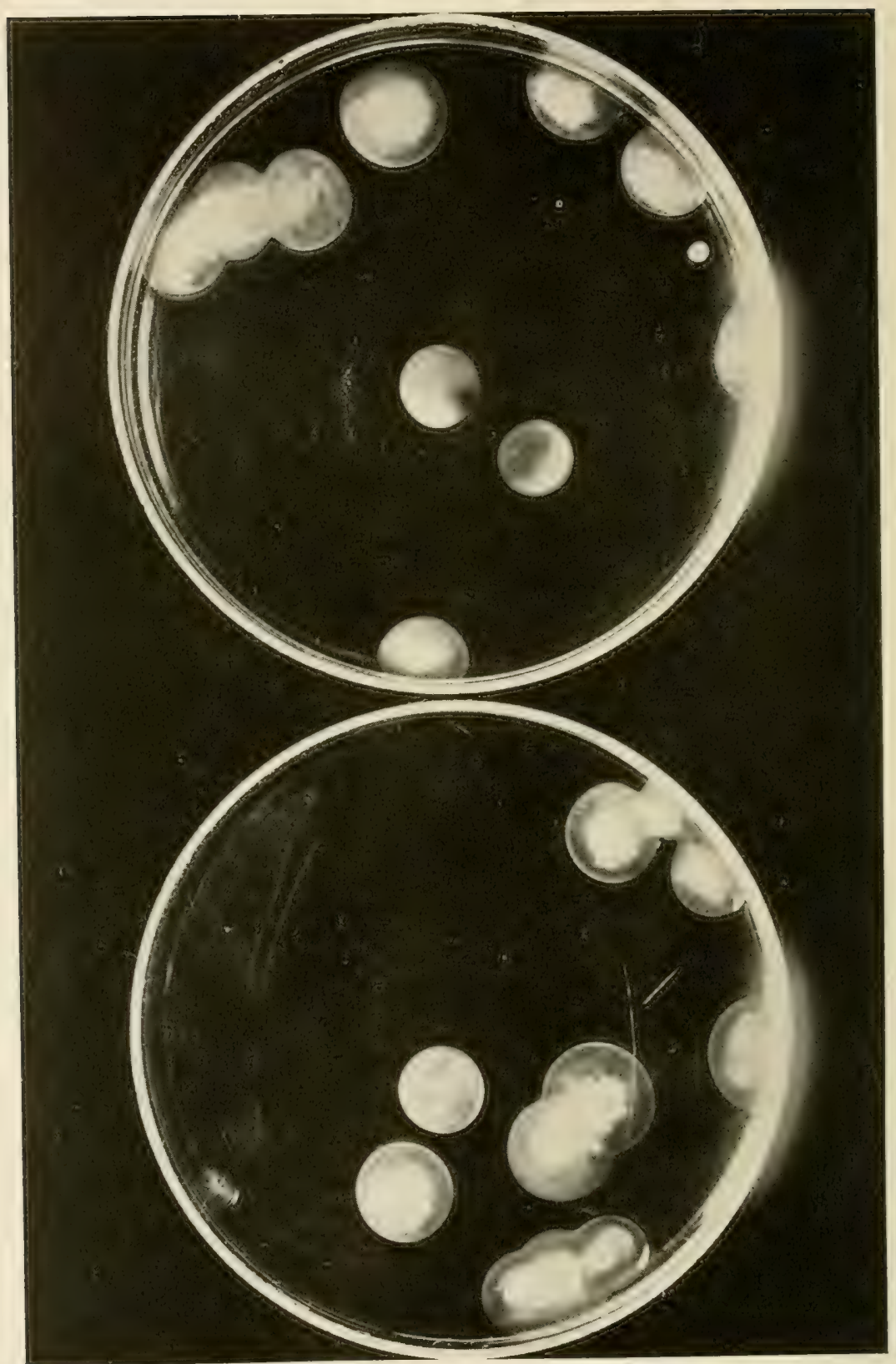

FIG. 206.-Thin-sown +10 beef-peptone gelatin plates of Bacillus phytophthorus isolated from a South Carolina potato in 1917. Colonies exactly like "Appel I" from Germany. 4/5 natural size. 
organism produce a bad odor on any medium?); What is the early and late behavior of this organism in lavender-colored litmus milk (watch closely from the start)? On a proper use of

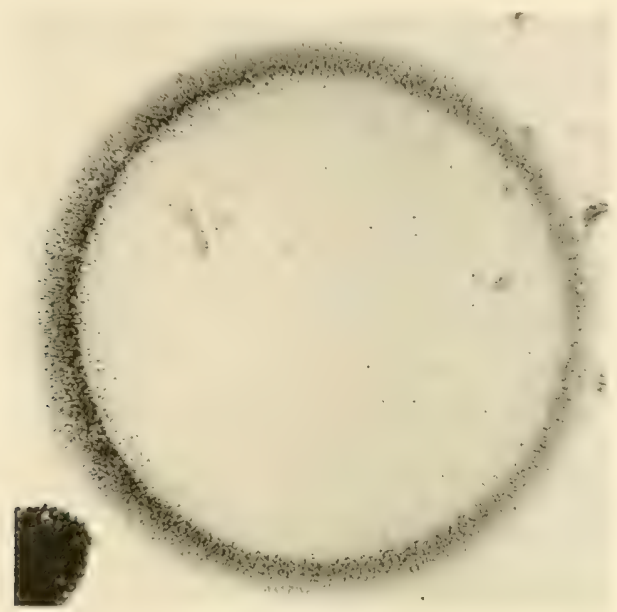

FIG. 207.-Bacillus phytophthorus (Appel I). On +10 beef-peptone gelatin held for 3 days at $16^{\circ} \mathrm{C}$. All but the corona has liquefied. Actual diameter of colony, $1 \mathrm{~mm}$. Margin fringed like Bacillus carotovorus (see Figs. 180, 181). Photographed February 4, 1915. Buried colony below at left. The specks seattered about are due to dust on the eyepiece.

litmus in milk, consult "Bacteria in Relation to I'lant Diseases," Vol. I, pp. 48, 196. Test shake-cultures in beef-peptone agar' (for gas-bubbles which will appear only if muscle sugar is
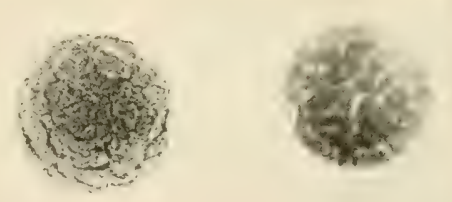

FIG. 208.-Bacillus phyiophthorus (Appel I). Small buried colonies from same gelatin plate as Fig. 207 but enlarged about one-third more. One colony out of focus.

present); try peptone water in fermentation tubes with all the common sugars and alcohols. From which is acid only produced? From which both acid and gas? 
If fermentation tubes are not available, shake-cultures may be made in litmus-peptone agar containing 5 per cent of the carbon compound to be tested (examine early and frequently for gas-bubbles and change of color). Nitudy behavior in potato juice in fermentation tubes. The closed end should cloud. Is any gas formed? I have never seen any. Test suitable cultures for indol, for hydrogen sulphide. What is the nature of the acid, or acids, formed by this organism? Can they be driven off by boiling (test the rapor with neutral litmus paper and ob-

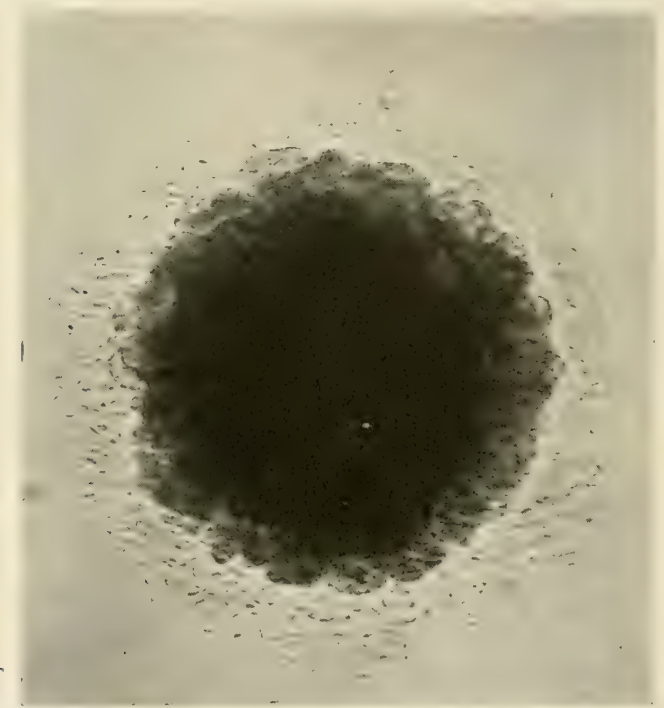

FIG. 209.- Small buried colony of Bacillus phytophthorus (Appel I) after 5 days in gelatin at $16^{\circ} \mathrm{C}$. The fringe looked like individual bacteria but consisted of lenticulate colonies as determined by staining in situ. Colony about 0.4 $\mathrm{mm}$. in diameter. Not all the buried colonies showed this fringe.

serve the litmus reaction of the concentrated fluid)? Is lactic acid produced". Determine toleration of acids. The organism is sensitive to acids (Appel).

3. Non-nutritional Environment.- Effect of heat? of dry air? of sunlight? of freezing (salt and pounded ice)" of salted bouillons (try 5 per cent first)? of chloroform in bouillon? of weak acids? of sodium hydrate (try -40 first)? of germicides?

Can you get any growth on culture-media at $5^{\circ} \mathrm{C}$. or at $40^{\circ} \mathrm{C}$.? Try several sorts, e.g., potato broth, peptone-beef 
BLACK ROT OF POTATO: NON-NUTRITIONAL ENVIRONMENT 273
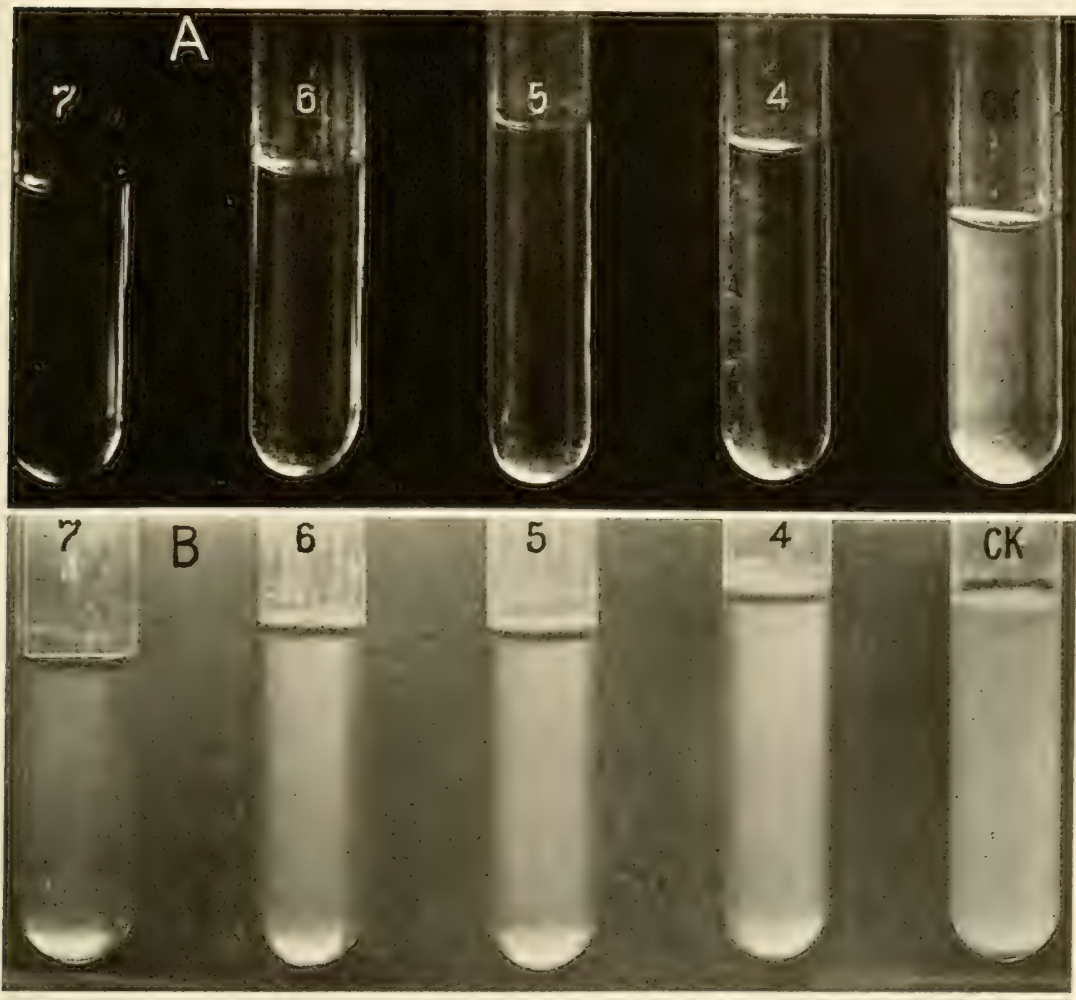

C

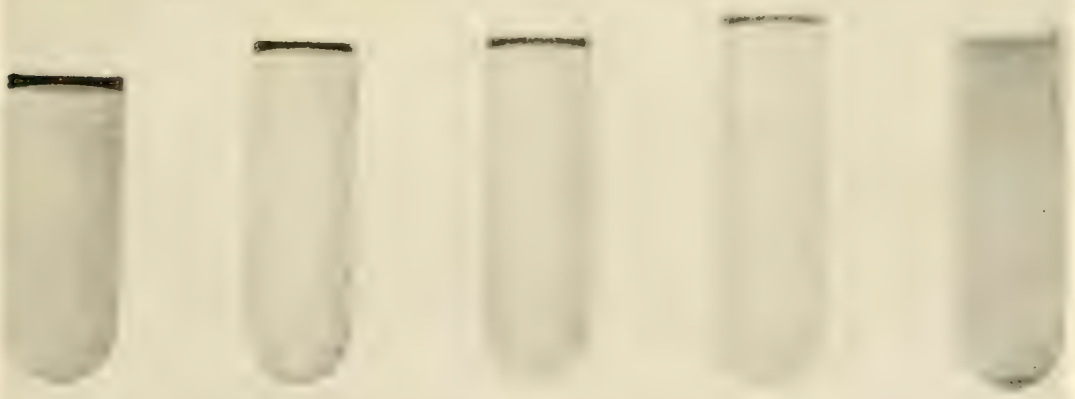

FIG. 210.-A. Bacillus phytophthorus in +15 peptone-beef bouillon with varying per cents of ethyl alcohol ( 4 to 7 per cent). Clouded check tube at the right, time 6 days. The others clear. B. Bacillus carotovorus (old $3 a$ ) ditto. All showing growth. The white at the bottom of the tubes is a reflection, not at precipitate. $C$. Same as $B$, but photographed against a white background. Introduced to show how the camera may deceive. 
bouillon, milk, steamed potato, nutrient agar, etc. Inoculate by needle punctures susceptible tubers (of more than one variety) and place one or more of each sort at the following temperatures: $5^{\circ} \mathrm{C}, 8^{\circ} \mathrm{C}, 20^{\circ} \mathrm{C}, 30^{\circ} \mathrm{C}$. Repeat if you are not satisfied. What do you conclude? Is there any practical application? If you have time, try also dry storage $1 s$. damp storage at different temperatures, inoculating as before.

Select tubers of some variety whose flesh reddens or browns quickly on exposure to the air, pare, grate quickly, squeeze the juice at once through a cheese cloth into a narrow, tall jar, divide into two equal portions, and steam one immediately (to destroy the action of the oxidizing enzyme); allow the other portion to oxidize freely in a shallow dish for 6 hours or more, then steam. The two lots may now be tubed, re-sterilized and comparative inoculations made, using, for each: $a$, one carefully measured 1-mm. loop from a very young fluid culture; $b$, the least quantity that can be withdrawn by dipping the end ( ${ }_{1}{ }_{10}$ centimeter) of a platinum needle into the culture fluid. Watch the early stages of growth critically. What do you conclude?

For the DISEASE: (1) Signs.-What is the period of incubation-on stems of different ages? on tubers? Time between local rot on the base of the inoculated shoots and a general appearance of disease". What changes occur in the foliage" How soon after the above-ground signs do the tubers begin to rot? This is best studied in the open field in summer and autumn. Can the tops be destroyed without causing a rot of the tubers? How do you account for this? Is the brown or black st ain ever absent from the stems when this organism is present? There is a bacterial rot in which the brown stain is absent (Appel). To what is this colorless rot due? Describe the disease. What are the signs on the tomato? Try inoculating green tomato fruits. Is it a common disease of the latter? Can other plants be infected? Try all the plants that are rotted and not rotted by Bacillus carotovorus. Study the flora of many naturally rotting potatoes, especially the advancing margin of the rot, for the presence of this organism.

Histology.-Fection diseased stems and tubers and make permanent mounts. Do the bacteria follow the vessels, or only 


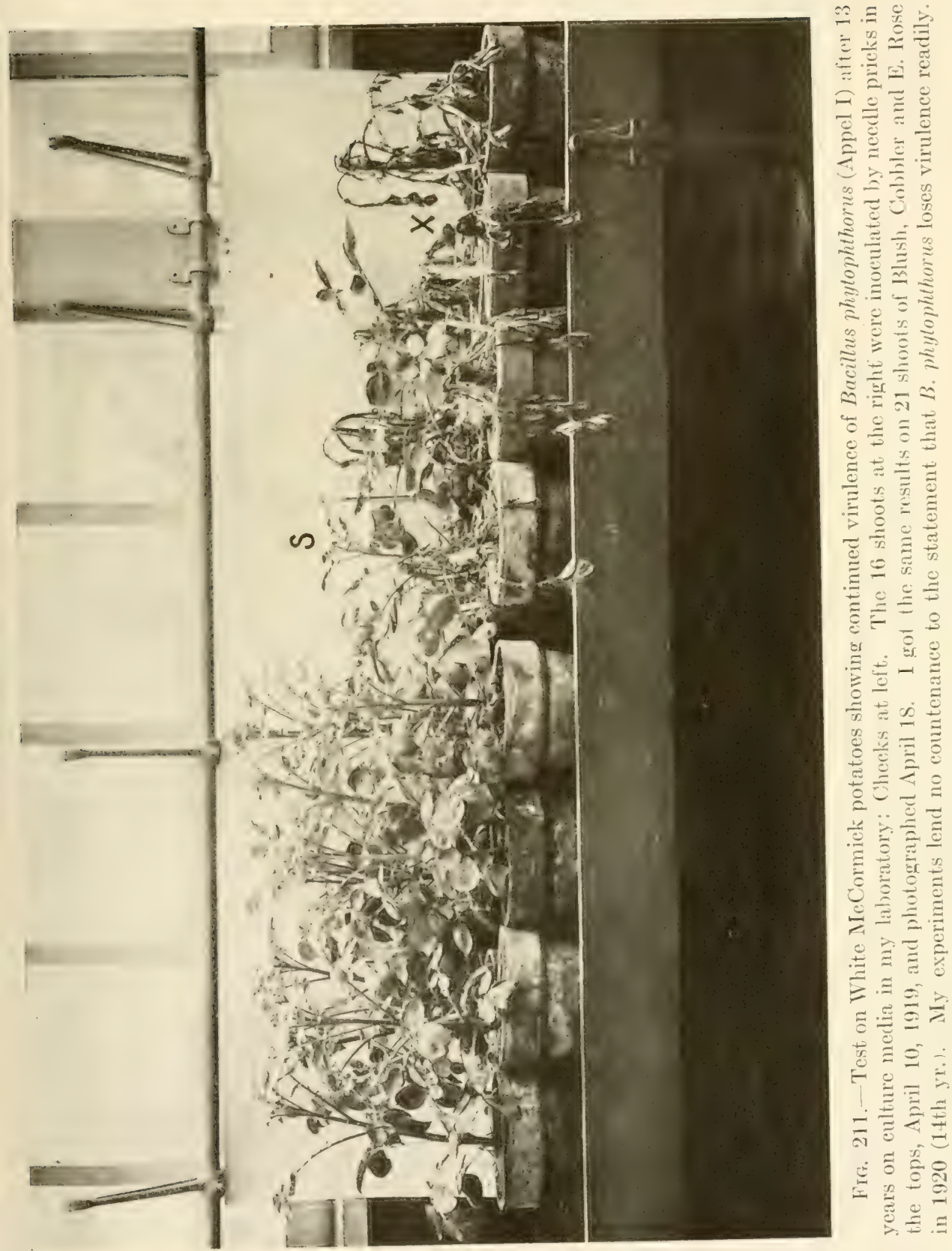




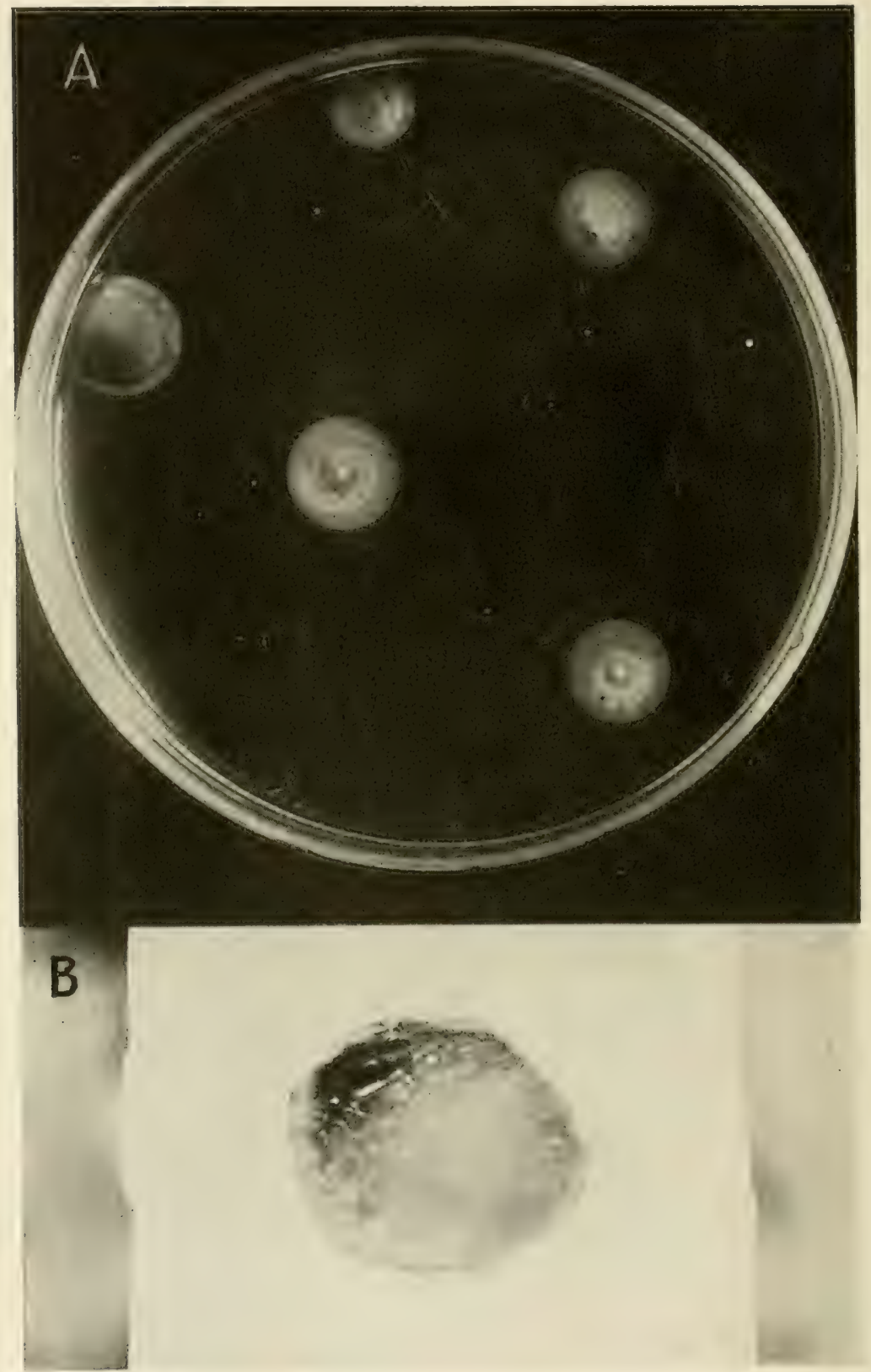

FIG. 212.-A. Thin-sown $(+10)$ peptone-gelatin poured plate of Bacillus carotovorus. Kept for 4 days at $18^{\circ} \mathrm{C}$. Compare with Figs. 205, 206 of Bacillus phytophthorus. 
occupy them incidentally to the general destruction of the parenchyma? (compare with sections of potato plants attacked by Bacterium solanacearum. Situdy the disintegration of the tuber. Are cavities formed? What is the earliest stage of the rot? What becomes of the starch? Of the cell-wall? Is any gas formed out of the tissues of the potato? Compare with Bacillus carotovorus (No. VI). Inoculated, rotting tubers placed at $5^{\circ} \mathrm{C}$. for 10 days offer a good opportunity to study the reduction of bacterial growth and the development of a protective cork barrier (See also No. VI). Cut sections until you have made out the newly formed cork layer clearly. Use some good cork stain if necessary. Make sections through lenticels on the tuber in very early stages of infection to show the bacterial penetration. Cut on the microtome from paraffin-infiltrated material. These sections should be made not much later than the third day, i.e., as soon as a trace of infection is visible on the surface (using a hand lens). A few days later the lenticel infection is much more conspicuous, but then the bacteria have generally passed several millimeters beyond the region of the lenticel. Determine if you can how the bacteria enter the stem, i.e., are the stem infections stomatal, or only by way of wounds? Spray and look for stomatal leaf-infections. Appel left this matter undetermined. I failed in two atiempts.

Variability. - All varieties of potatoes are said to be subject to this disease. Have you been able to find differences, either from your inoculations, or from field observations? Considerable time devoted to such an inquiry might be well spent. It certainly would be if practical results were forthcoming, or eren suggestions toward such results. The Early Rose, Imperator, Maercker, Magnum Bonum, and Wohltmann (sorts commonly grown in Germany) are frequently attacked (Appel). The writer found Daisy, Green Mountain, and Factor quite suscep)rible (see "Bacteria in Relation to Plant |Disease," Vol. II, Plate 11 -facing p. 96). Thite Mc('ormick is also quite susceptible (Figs. 195 and 211). Are potatoes the fleshy part of which

B. Cross-section of stem of Tropacolum majus (nasturtium) attacked by Bacterium solanaccarum, showing brown stain and bacterial ooze. Plant from Baltimore, Md. Photographed July 22, 1914. $\times 8$ circa. 
darkens rapidly on exposure to air more resistant to this disease than those which possess this property to a feeble degree? Are those varieties whose lenticels open freely in wet soil specially subject to this rot? I believe they are.

Transmission.-In two localities Appel saw this disease develop severely in places where potato refuse from rotten pits had been thrown out (for reference to a similar observation on black rot of the cabbage see No. II) and in one of these places the soil was still infectious after 5 years (Appel l.c., p. 387). Appel also found that sound-looking tubers from diseased fields often carried the infectious organism on their surface. Should rotting potatoes be left in the field? Should they be thrown on the dung heap, or fed to stock? What do you conclude respecting selection and treatment of seed tubers? What respecting early digging of the tubers, i.e., before fall rains have set in? What respecting the necessity for dry and cool storage, especially in years when the rot is very prevalent?

The organism is sensitive to dry air and for this reason potatoes should be dry when stored to avoid further rot in pits and cellars.

Mr. Melhus states that he has combated this disease in the field very successfully by persistently pulling out the diseased hills and exposing them to the light and air (oral communication).

My own experiments lead me to believe that well-drained fields should be much less liable to attacks of the tuber rot in autumn than those which become water-logged following heavy rains.

Rot due to Bacillus phytophthorus ceases at $4^{\circ} \mathrm{C}$. and below $8^{\circ} \mathrm{C}$. $\left(46^{\circ} \mathrm{F}\right.$.) it is slow. Potato tubers from fields where this rot has prevailed should therefore be stored at low temperatures and disposed of early.

\section{LITERATURE}

Consult Appel's paper "Untersuchungen uber Schwarzbeinigkeit und die durch Bakterien hervorgerufene Knollenfäule der Kartoffel" in Arbeiten aus der Biol. Abth. f. Land.-u. Forstwirthschaft am Kaiserl. Gesundheitsamte, Band III, Heft 4, 
Berlin, 1903, pp. 364-432. His first paper on this disease is in Ber. d. d. Bot. Ges. XX Bd., Heft 1, 1902.

Read the writer's account of this organism entitled "Bacillus phytophthorus Appel," in Science, N.'., Vol. XXXI, May 13, 1910, pp. 748-751; Morse's paper in Journal of Agricultural Research, Jan. 15, 1917, p. 79; also Morse's earlier paper, Bull. No. 174, Maine Agr. Exp. Nta., Dec. 1909; and Rosenbaum and Ramsey's paper on "Influence of Temperature and Precipitation on the Blackleg of Potato," Journal of Agricultural Research, Vol. XIII, No. 10, Washington, D. C., June 3, 1918, pp. 507-513.

For reference to the paper by Pethybridge and Murphy see the foot note on page 64 .

The name Bacillus phytophthorus was first published by Dr. Appel in 1902, in Ber. d. d. Bot. Ges., XX Band, Heft. 2, pp. 128-129. Noteread Feb. 28 and Heft published March 27. 


\section{THE BEAN BLIGHT}

(Syn. The bacterial bean spot)

Type.-This is a disease of beans common on leaves, stems and pods, and confined principally to the parenchyma although the vessels also are invaded, sometimes for a distance of several inches. It occurs on several species of beans (Phaseolus) and is a serious disease. Whether other related genera are subject remains uncertain. Similar looking bacterial diseases occur

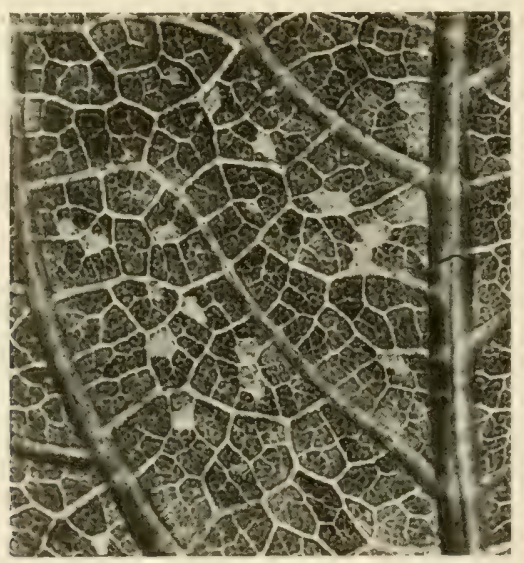

Fig. 213.-Portion of under surface of an immature bean leaflet showing stomatal infections (light spots) due to a pure culture spray inoculation of Bacterium phaseoli isolated from an Idaho bean. 'Time, 3 days. Spots translucent but not yet brown or sunken. Planar enlargement by James F. Brewer, September $26,1914 . \times 8$.

on cowpea (Vigna) and on soy bean (Mucuna), but my crossinoculations to plants of these genera failed (one trial only, but using many plants and virulent cultures sprayed on the foliage). A yellow organism resembling this one on agar and potato was plated from spots on leaves of the soy bean in my laboratory in 1902 from Charleston, South Carolina, and Washington, D. C., and again in 1917 from Norfolk, Virginia. 


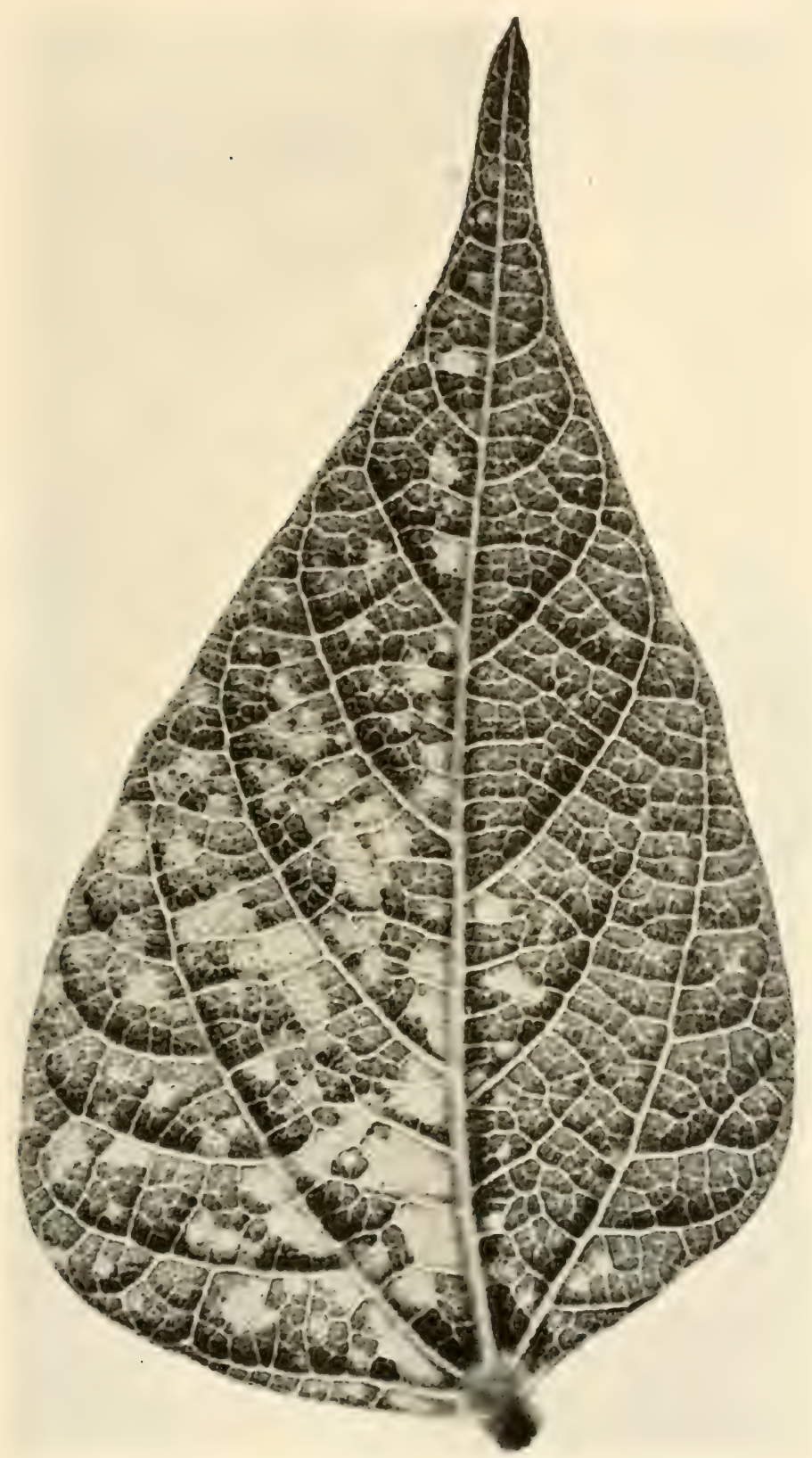

FIG. 214.-Bacterium phaseoli: A pure culture. spray inoculation on a bean leaflet. Time, 3 days. Done by the writer in 1914. 
The disease is first visible on the leaves a few days after infection (Fig. 213) is the form of minute translucent dots which gradually enlarge (Fig. 214) and from being slightly protuberant become sunken and discolored, forming irregular reddish, yellowish or brownish spots ( Fig. 215). Frequently on the yellowing leaves the green of the leaf persists around the spots (Fig. 216). As in cotton leaves attacked by Bacterium malvacearum, there may be distortions of the leaves due to disease of the reins (Fig. 217). This occurs, so far as I have observed, only when infection takes place very early, i.e., when the leaflets are quite small. When older leayes are sprayed with a sus-

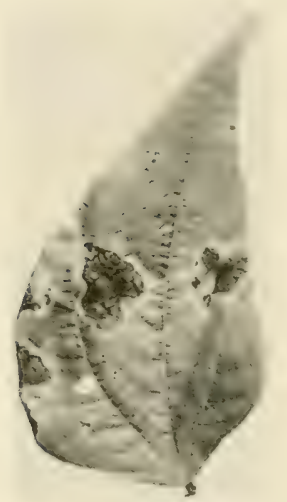

FIG. $215 .-B$ ean leaflet attacked by $B a c-$ terium phaseoli. From a gariten in Trahington, D. C., Junc, 190s. Onehalf natural size. pension of this parasite they become badly spotted but are not then distorted.

On the pods the spots appear the sixth to eighth day as small $(0.2 \mathrm{~mm}$.) circular areas centering in a single stoma and are deeper green than the surrounding tissue (Figs. 218 and 219). These spots enlarge slowly (Fig. 220) being level or slightly protuberant at first, as on the foliage, then sunken and discolored and showing sometimes a reddish border. As the center of the spot shrinks (over the internal cavity), from destruction of the subjacent tissues, bacteria from this cavity (as in the black spot of the plums are forced through the stomata abundantly, especially when the spots are on the pods (Figs. 221 and 222). These extrusions appear in the form of yellowish cirri, if the surface is dry, and of expanded masises or crusts, if the surface is alternately wet and dry.

The bacterial nultiplication in the leares being less abundant than in the pods there is less surface ooze, but almost always there is some. Even in early stages of the leaf-spot, the bacteria in the tissues are very abundant as shown in Figs. 223, 224. The leaf-spots which are circular at first frequently coalesce as they enlarge, forming irregular areas which are often of con- 
siderable size and which usually retain a water-soaked translucent) border.

In severe cases the leaves shrivel and fall off, and the pods become worthless - spotted or dwarfed. If the weather is damp both leaves and pods may also become móldy. If attacked in

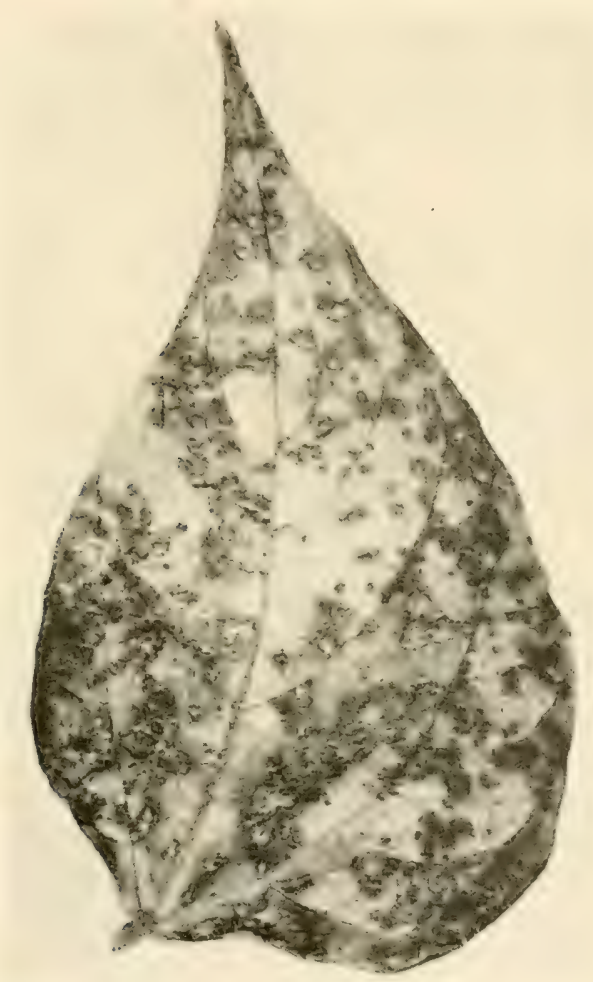

Fig. 216.-First series of inoculations from the Idaho bean (September 23, 1914), showing numerous stomatal leaf-spots due to Bacterizm phaseoli. The leaf was yellow except around the spots, where the leaf-green persisted. Time, 13 days. Temperature of hothouse, $65^{\circ} \mathrm{C}$. to $95^{\circ} \mathrm{C}$. Leaflet about one-third grown when sprayed. Nat. size.

early stages of growth the leaves become curved, twisted and variously distorted by reason of injury to the developing veins (see Nos. IX and XI for similar phenomena). The attacked leaves also exhibit a curious persistence of the leaf green around the spots while it disappears altogether from the rest of the leaf. 
On the fruit, the fleshy portion of the pericarp is the chief seat of the disease (Figs. 225 and 226), but the bacteria also burrow inward and often infect the interior of the pod and the surface of the ripening seeds. The seed itself may also be attacked.

When the infections are through stomata, the first signs of the disease on the pods are minute, green spots, each surrounding a stoma. Although very small in this stage (I have often seen them on my sprayed plants when they were less than onefourth millimeter in diameter), their color difference makes them conspicuous. Do not confuse with stigmonose.

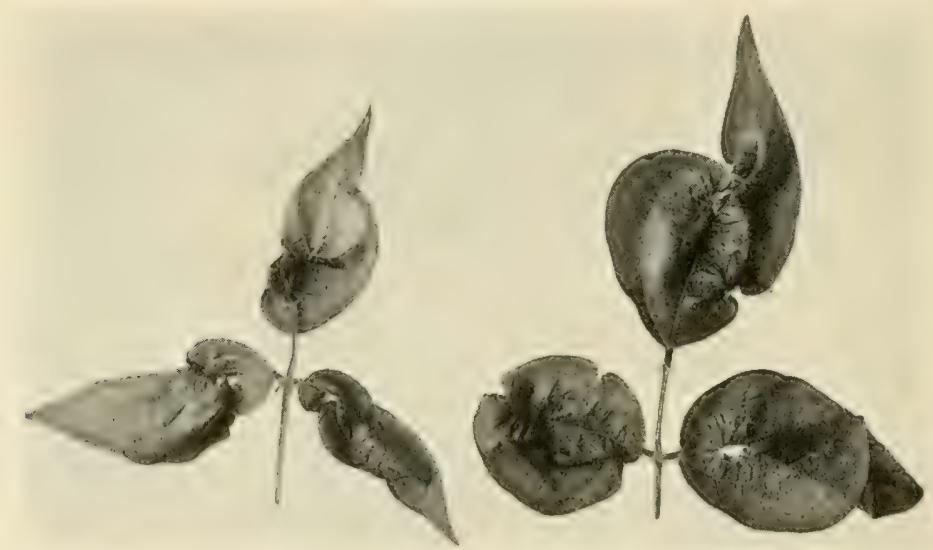

Fig. 217.-Distortion of bean leaves due to Bacterium phaseoli. From the same series of plants as Fig. 216, but the leaves were very smail when sprayed and most of the stomata were not open. Infection confined principally to the veins.

In seasons of exceptional dewfall or rain the entire crop either of bush beans or of lima beans may be destroyed, especially in case of susceptible varieties.

The geographical distribution of this disease is unknown. It occurs in many parts of the United trates, probably in every state in the Union, but little is known concerning its occurrence in other parts of the world. Delacroix once reported it from France, but subsequently decided that his disease was different. I am inclined to think, since seeing his dried material and making sections of it (cultures failed), that his first conclusion is the correct one, and that it does occur in France. I looked for it in 
vain, however, in the Paris markets in 1913. The same year at the International Exposition in Milan in the exhibit of the French Mycological Society I saw a yellow bacterial culture on slant agar, marked "La Graisse," which was, perhaps, Bacterium phaseoli. It was made by Dr. T. A. Cordier of Rheims. The disease has been reported from south Russia by spieshner and from Japan by Arata Ideta who says: "This disease hearily damaged in Ishikari, Hokkaido, in 1903." Reinking has recently reported it from the Philippines (Phytopathology, vol. 9, 1919, p. 131) where it is said to be "common and destructive." Miss Doidge writes me (1919) that it is quite common in South Africa.

Cause.-This disease is due to Bacterium phaseoli EFS. This is a yellow, non-viscid or slightly viscid, motile, polar flagellate (Fig. 227), non-capsulate, non-sporiferous, Grám. negative, liquefying (both gelatin and Löffler's blood serum), aërobic, non-gas-forming, non-nitrate-reducing, starch-destroying, dry-air tolerant, sunlight-sensitive (Fig. 228), frost-sensitive (in bouillon), single, clumping, catenulate, or filamentous schizomycete which grows on agarpoured plates in the form of small

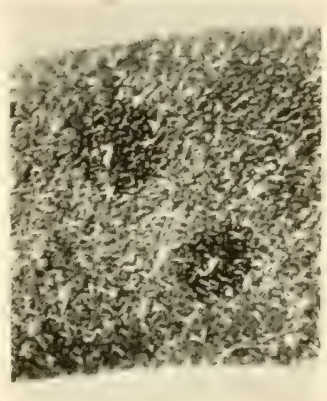

FIG. 218.-Earliest stage of visible bean pod spot. Two infections each central through a single stoma. Plant sprayed Dec. 141914 , and confined for 19 hours in a roomy cage. Photographed Dec. $22 . \times 10$. The organism used was a 72 hour agar-streak culture of the Idaho bean germ after reisolation from a plant successfully inoculated on Sept. 23. circular, or nearly circular, smooth, pale yellow, entire-margined colonies, becoming deeper yellow with age (denser and deeper yellow than those of Bacterium malvacearum) and then often pale ringed. Gelatin and Löffler's solidified blood serum are liquefied rather freely. Milk is curdled by means of a lab ferment, tyrosin being formed. The first eridence of curdling is the appearance of a shallow layer of clear whey above the slowly settling mobile curd. No acid is formed in milk. The organism resists drying. It grows feebly in Cohn's solution and in Uschinsky's solution. The thermal death-point is approximately $50^{\circ} \mathrm{C}$. 


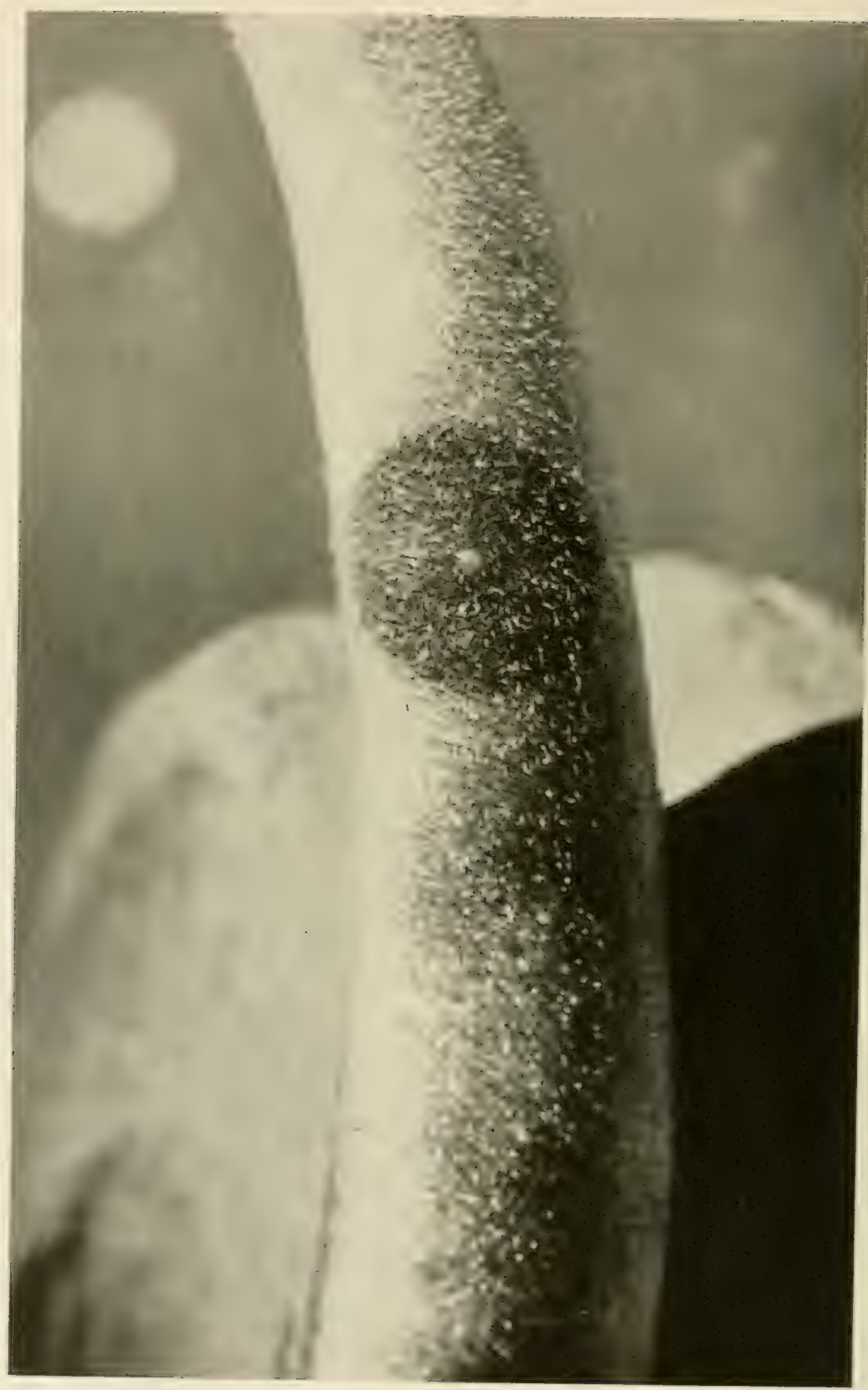

FIG. 219.-Bean blight due to Bacterium phaseoti: Jod sprayed December 14, 1914, with a pure-culture suspension in water. Plants exposed 19 hours in the inoculation cage. This was one of the largest spots on a half-grown pod, most were decidedly smaller. Its regularity indicates a single central stomatal infection. There is a drop of yellowish bacterial ooze in the center of the spot. Variety, Extra Early Refugee. Planar enlargement by James F. Brewer. Photographed December 26, 1914. $\times 6$ circa. 
(recent tests in +15 peptone beef bouillon). The Idaho organism was dead after 5 months on gelatin at $16^{\circ}-20^{\circ} \mathrm{C}$. It is less sensitive to sunlight than Bacterium malvacearum.

On a variety of culture media Bacterium phaseoli is closely like Bacterium campestre (See No. II) but the two organisms are not identical, as shown by the failure of repeated cross-inoculations (cabbage bacterium on beans and bean bacterium on cabbages), but our present means of separating the two forms culturally is insufficient. It is also culturally much like Bacterium citri, but with a virulent strain $I$ failed to obtain any scabs on Citrus decumana (about 60 young seedlings). The student, therefore, who has opportunity might direct his attention to comparative studies of the yellow organisms of this group in the hope of finding additional cultural differences by the use of new media. But in any event, Bacterium phaseoli belongs with Bacterium campestre, Bacterium hyacinthi, Bacterium vascularum, Bacterium pruni, Bacterium malvacearum (No. X), Bacterium citri, and Bacterium translucens in a closely related kinship.

Technic.-Isolations are easy, owing to the abundance and viability of the bacteria. Only such ordinary precautions are necessary as have been described in detail for other diseases in this book, both earlier and later.

Bacterium phaseoli is a good organism to work with because it does not lose virulence readily and plants for inoculation are quickly available at all times of the year. As material for experiment, both lima beans and bush beans may be used. They can be infected from germination almost to maturity, but the

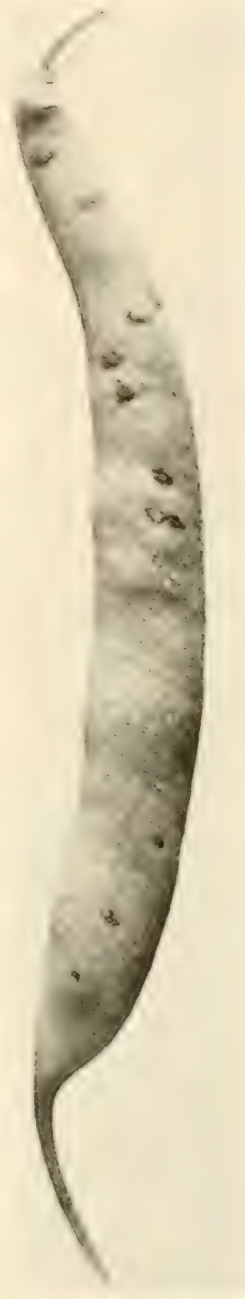

Frg. 220.-Bean pod sprayed with Bactorium phaseoli and kept for 26 hours in an inoculation eage. The organism used was cultivated from the pod shown in Fig. 221. Time, 14 days. 1914. 
various organs are most susceptible during early stages of growth. The beans should be planted 6 or 8 weeks before they are needed and must be shifted occasionally if the pots are small, so that they will continue to develop rapidly. It is best to plant them in 6 -inch pots, shifting to 8 -inch or 10 -inch pots

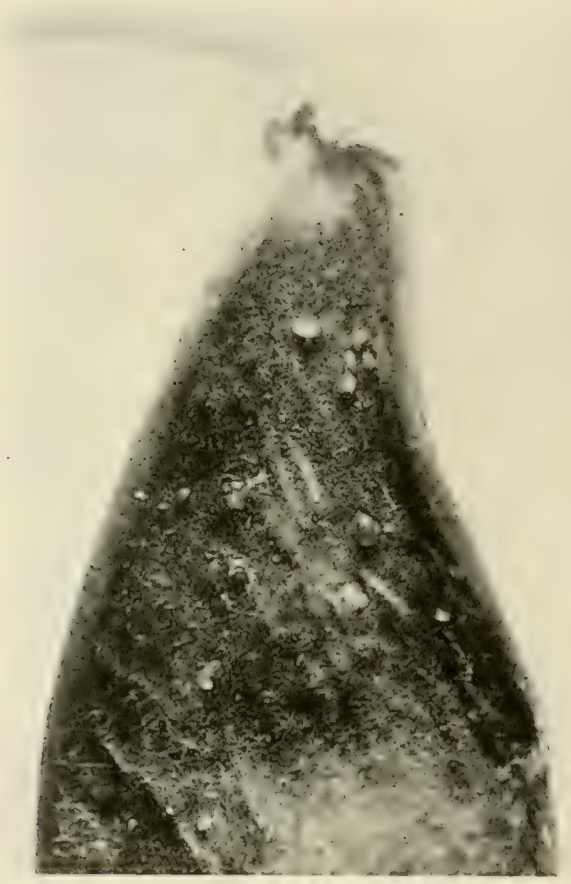

FIG. '221

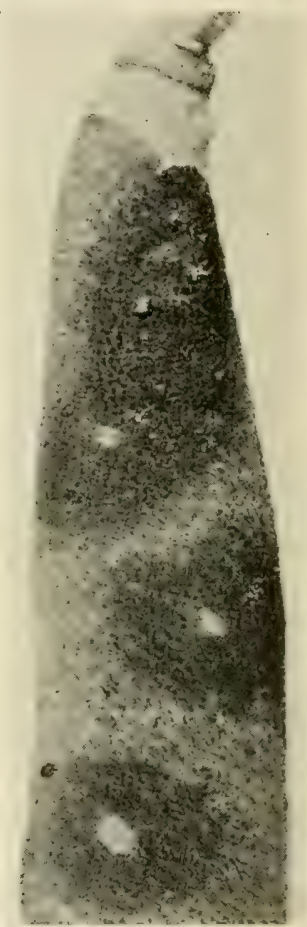

FIG. 222 .

Fig. 221.-Enlarged base of a bean pod showing translucent exudate, due to Bacterium phaseoli. Pod received from Idaho in 1914. The organism isolated from it served for a long series of infections. It is still infectious (1920).

FIG. 222.-Bacterium phaseoli on bean. Same series of stomatal infections as Fig. 220, but later. Spots now large, somewhat depressed and exuding bacteria freely from their center. Time, 19 days.

as they require it. They are very easy to grow and need only ordinary care. There may be 2 to 4 plants in a pot, if plenty of good soil is used.

The inoculations should be both by needle puncture and by spraying since the disease is readily transmitted through the 
stomata. Indeed, it is one of the most convenient diseases for studying stomatal infections.

The needle-pricks should be made on young pods, soft stems, and various parts of the immature leaf petiole, petiolule, reins and parenchyma). For comparison try also needle inoculations in full-grown leaves, stems and fruits.

For the spraying experiments, plants a foot high, bearing mature, immature and undereloped leares, should be selected,

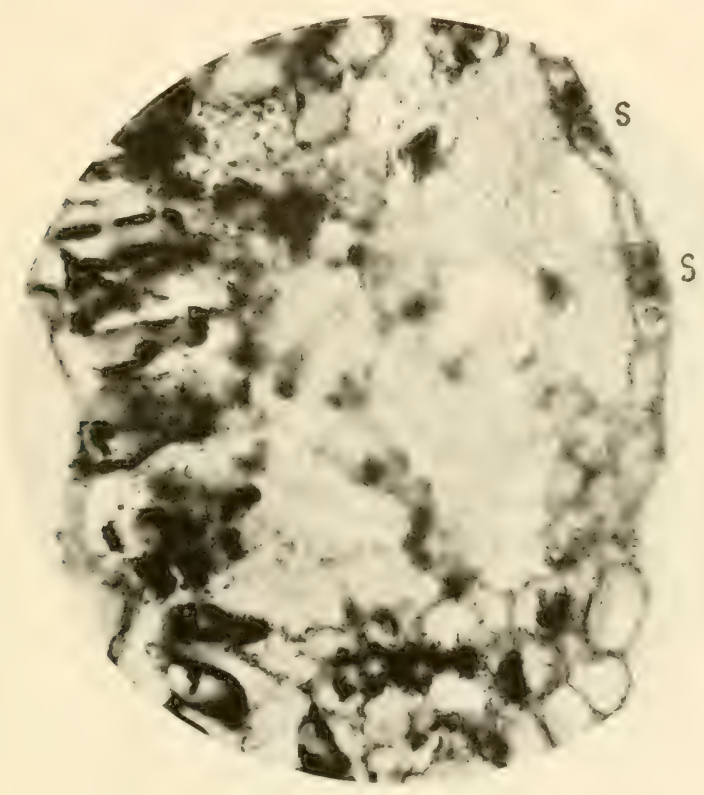

FIG. 223.-Bacterial cavity in a bean leaf 5 days after spraying on a pure culture of Bacterium phaseoli. Tissue not yet collapsed. Stomatal infection through $S, S$.

so as to observe the modifying influence on the disease of age of tissues. The leaves should be free from insects, fungi, and confusing spots of any sort. The plants should be atomized with water holding in suspension bacteria from young (3-day) agarstreak cultures until the surface is covered with small drops of the cloudy fluid. Then the cages should be closed tightly and protected from the light. They should be examined every few hours throughout the daytime to see that the drops have not evaporated. To insure this favorable persistence of moisture 
on the plants it is necessary usually to wet down thoroughly the interior of the cage and the earth under and around it in advance of the inoculations. If moisture does not hold on the leaves they must be sprayed again, and the earth wet down as before. Watch carefully, for if the plants dry off speedily and remain dry your experiment may not succeed. The plants should be left in the cages only as long as necessary to secure numerous infections. The writer does not know the minimum time.

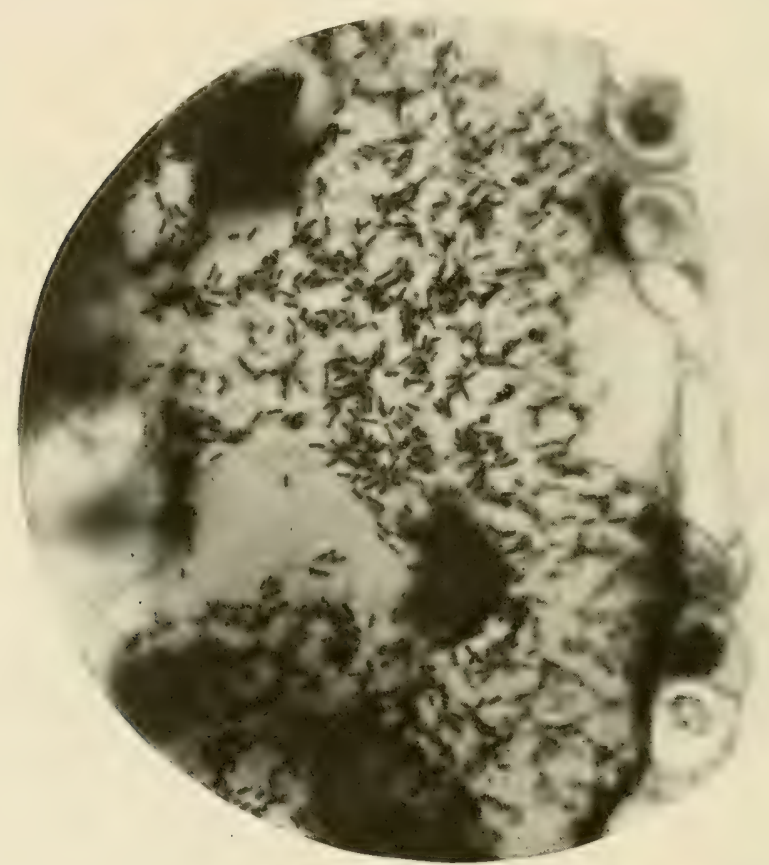

FIG. 224.-Bacterium phaseoli: A detail from Fig. 223, showing the bacteria more distinctly.

Perhaps you can determine it. He has had striking results from 26- and 30-hour exposures, equivalent to a dewy night followed by a misty day. Probably a very considerably shorter period of exposure would suffice. In default of cages, clean barrels or boxes may be turned over the plants, or they may be covered with a tent-cloth or an oilcloth stretched over a frame. Tent-cloths require very frequent wetting.

King of the Garden (lima), Mexican tree bean, Green Flageo- 
let, and Red Valentine are susceptible varieties, also many other's including Early Refugee, reported as resistant.

Infections appear sooner and the disease progresses faster in warm weather than in cool weather. If there are facilities, two sets of spray inoculations may be identical in all respects except as to temperature, i.e., one in a greenhouse at $30^{\circ}$ to $35^{\circ} \mathrm{C}$, , the other in a house at $18^{\circ}$ to $20^{\circ} \mathrm{C}$.

\section{Determine}

For the organisur. Morphology.-Size in microns. Conditions under which chains and filaments occur. Absence of

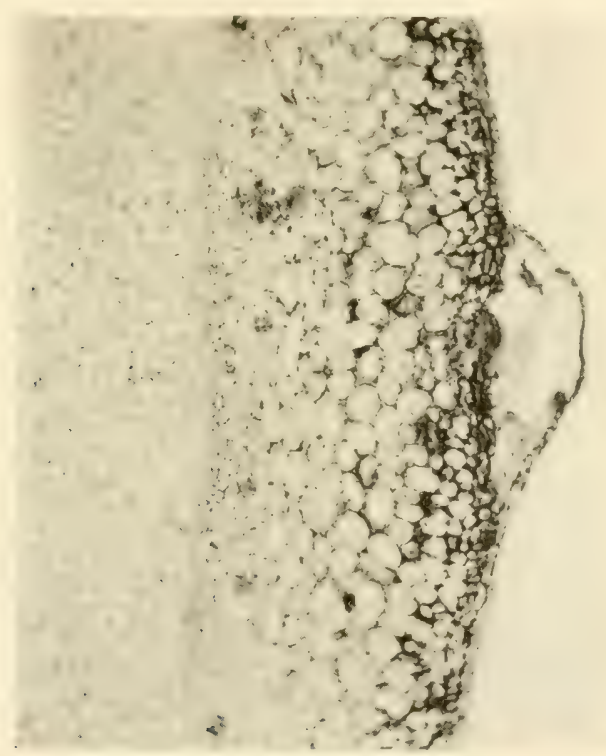

FIG. 225.-Bacterial invasion in outer tissues of a bean pod. Epidermis lifted by bacterial pressure in the stomatal region. Intercellular spaces occupied. A stomatal infection obtained by spraying. Time, 12 days. 1914.

endospores. Number and attachment of flagella. Conditions leading to the formation of clumped masses (pseudozoögloeae). Do involution forms occur? Are the rods ever curved or larger at one end than at the other (see No. II)? Do capsules occur?

Cultural Characters.-Determine appearance of colonies on thin-sown agar plates (figs. 229, 230); behavior in agar stabs and 
streaks; growth on gelatin; in Löffler's solidified blood serum, in Dunham's solution (see fig. 924). Does it cloud Dunham's solution? Study behavior on potato. Hold the potatoes for 6 weeks and then test the substratum for destruction of starch, mashing the cylinders in an abundance of distilled water (50 ce.) to which should then be added 2 ce. of alcohol iodine. Compare with a mashed check cylinder of the steamed potato and

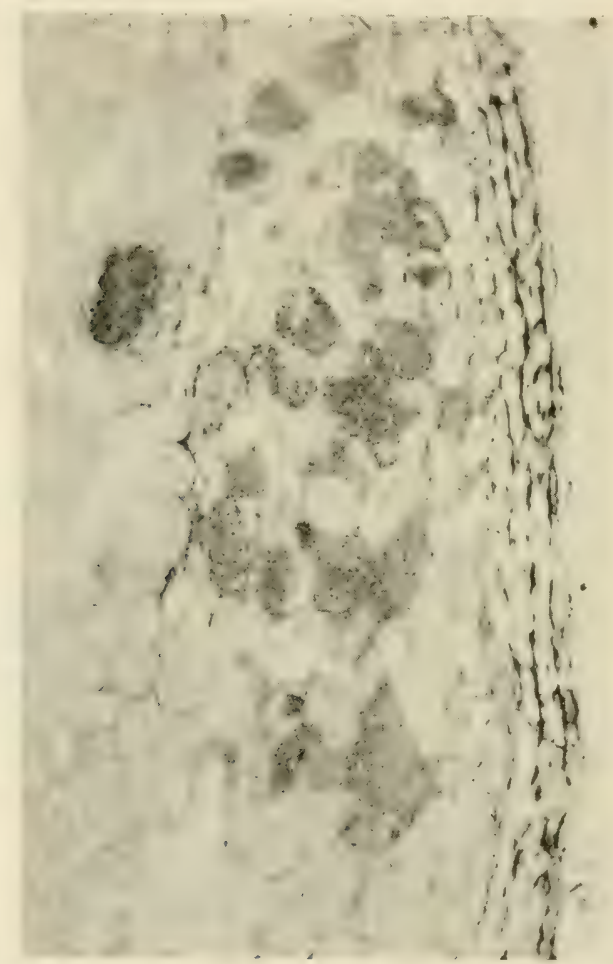

FIG. 226. - Cavities in a bean pod (outer part) due to introducing Bacterium phaseoli by needle-pricks. Inoculated by the writer in 1897 .

with cultures of Nos. II and III. Has the potato lost its firmness? Why? The progressive enzymic destruction of potato starch (change from translucent, lustrous, bluish white to a dead opaque white) may be watched from day to day if streaks are made in test tubes on slant starch jelly. (For its preparation see "Bacteria in Relation to Plant Diseases," Vol. I, pp. 50, 196.) Determine action on milk and litmus milk. After some weeks' 
growth in milk, filter the translucent fluid through coarse sterile paper or sterile cheesecloth and divide it into two equal portions $a$ and $b$ : heat $a$ for 20 minutes in the water-bath at $50^{\circ} \mathrm{C}$. and pour it into a test tube of sterile milk; heat $b$ for 20 minutes at $50^{\circ} \mathrm{C}$. (to kill the bacteria), streak on potato copiously to determine that they have been killed, and pour into another test. tube of sterile milk. Add a small crystal of thymol to each tube by means of sterile forceps. Watch the two closely for the next 48 hours. The milk which received $b$ should curdle in the absence of the living bacteria, that which received a should not curdle. How do you account for the difference? Observe the tubes of inoculated litmus milk carefully from time to time. Is there ever any acid reaction? Do not be deceived by appearance of tubes when held up to the light: all litmus solutions are red by transmitted light. Examine and decide only by reflected light.

Study growth in peptone bouillon; ditto in nitrate bouillon. Are nitrates reduced?

Behavior in Cohn's solution-in Uschinsky's solution.

Growth in peptone water in fermentation tubes with various sugars and alcohols. Compare with Bacterium campestre and with Bacterium malvacearum, testing as many carbon compounds as possible.

Study effect of freezing ( 4 -hour tube cultures in +15 peptone beef bouillon in salt and pounded ice for one hour). In 1919 we tried five isolations with the following per cents of killing: Idaho, original stock, 87; Idaho, G. H., 98; Michigan, 99+; New York, 89; Washington, D.C., 99+; Maryland, 99+. Read Science N. S., vol. XXI, No. 535, March 31, 1905, pp. 481-483.

Is litmus reduced? Is indol formed? Ammonia? Carbon disulphide? Invertase? Catalase? Pour some fresh hydrogen peroxide into an old potato culture and observe the result. What do you conclude as to the nature of the reaction? What other ferments are formed? Nature and solvents of the yellow pigment? Is it a lipochrome?

Non-nutritional Environment.--Reaction to heat, frost, sunlight, dry air, germicides. Behavior on media (use a variety) in non-respirable gases - carbon dioxide, hydrogen, nitrogen. 
For the DISEASE. Signs.-After needle-prick inoculations on young leaves, stems and pods, how long to first appearance of the disease? Rate of progress of the infection.

On sprayed plants how long before faint pale green dots can be detected on the leaves (use hand lens and transmitted light, examining every day)? How many additional days are required for these stomatal infections to become visible to the naked eye by reflected light? How long before they become conspicuous, forming definite, coalescing sunken spots? Have you observed retention of the leaf-green around the bacterial

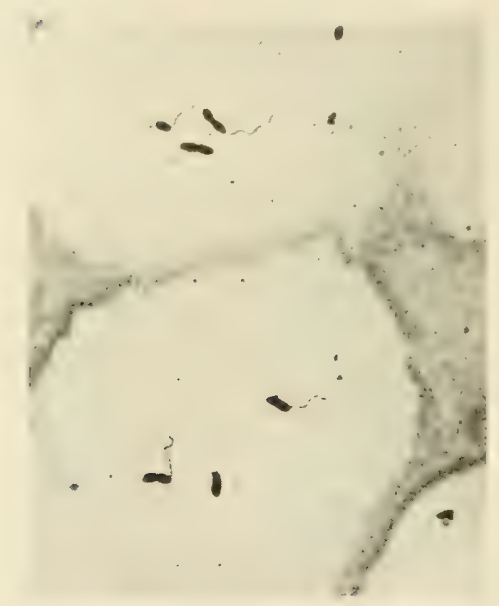

Fig, 227.-Flagellate rods of Bacterium phaseoli. Idaho isolation. Stained by van Ermengem's silver nitrate method. Photomicrograph by the writer. $\times 1000$. spots and discharge of it in other parts of the leaf? How do you account for this?

Make similar observations on sprayed pods as to time of first appearance of spots, rate of progress, etc. Temperature has something to do with this, therefore keep thermometric records.

Describe the disease minutely, including its effect upon the pods and its general effect upon the plant. Are the roots ever diseased? Are the pods dwarfed?

Histology. - Study the manner of entrance of the bacteria into the bean-pod, employing very young spots. Is it always stomatal? Is it generally so? In welldeveloped spots on the pods, determine the manner of extrusion of the bacteria. Is it always stomatal or may it be through rifts in the tissues? (Sometimes the damp chamber may be of assistance in determining this.) Still using the pods, make crosssections (free-hand and on the microtome) of spots in various stages of derelopment to determine what tissues are invaded by the bacteria and how this invasion takes place. Make permanent preparations. Young pods will cut much better than old ones, but tissues of all parts, and of all plants, for that matter, will 
cut better if the air is pumped out of them when they are first put into the acid-alcohol or other fixative.

Do the same things with the leaf spots. Is there any increase in the number of chloroplasts in cells surrounding the leaf spots? To what is the russet or rusty-red phenomenon due? What becomes of the cell-walls? How is the middle lamella disposed of? Ziehl's carbol fuchsin is a good stain.

Is the tissue killed in advance of bacterial occupation? What are your reasons for thinking so?

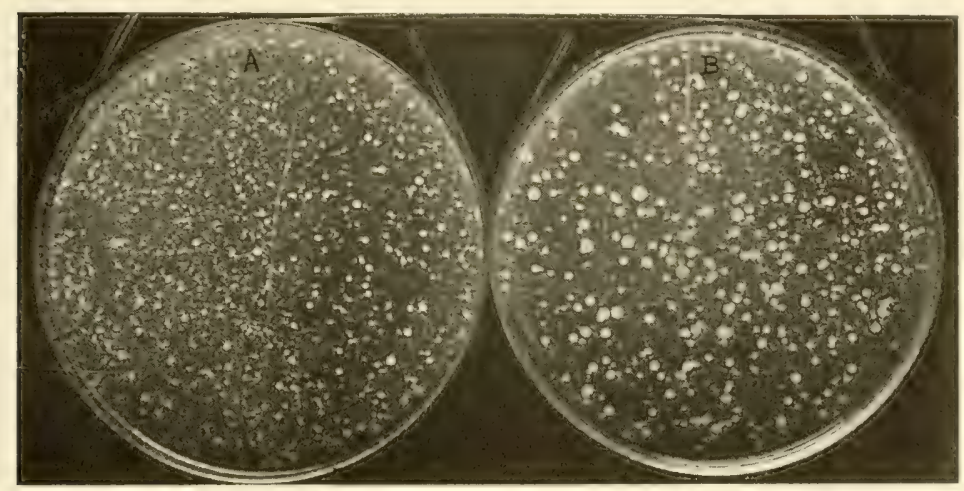

FIG. 228.-Agar-poured plates of Bacterium phaseoli (Idaho isolation). Inner one-half of each exposed to bright sunlight on ice: $a, 2$ minutes; $b, 5$ minutes, and then incubated for 6 days. Much less sensitive than Bacterium malvacearum. Compare with Fig. 249. Photographed June 16, 1915. 1/2 nat. size.

Does the organism frequently penetrate the seed coats?

On stem-inoculated plants how far can you trace the bacteria in the vascular bundles? Is the phloem attacked?

Variability. - Under field conditions different varieties of beans show marked differences in susceptibility. If the student has opportunity he should study variability in the field and garden, being always on the lookout for resistant varieties and hardy individuals in susceptible varieties. Make careful (and legible) pen notes of what you have seen.

Transmission.-We know nothing concerning living carriers of the organism but, owing to the free oozing of the bacteria to the surface, any bird or insect might act as a carrier from diseased to healthy surfaces, as in case of fire-blight of apple 
and pear (No. XII), the only subsequent agent necessary being rain or dew. That a considerably greater number of hours of continuous moisture (than under experimental, freshculture, hothouse conditions) is necessary to insure infection under natural field conditions, is shown, I think, by Halsted's observation that in a New Jersey bean field nine-tenths of the infections were on the west side of the pods, i.e., on that side

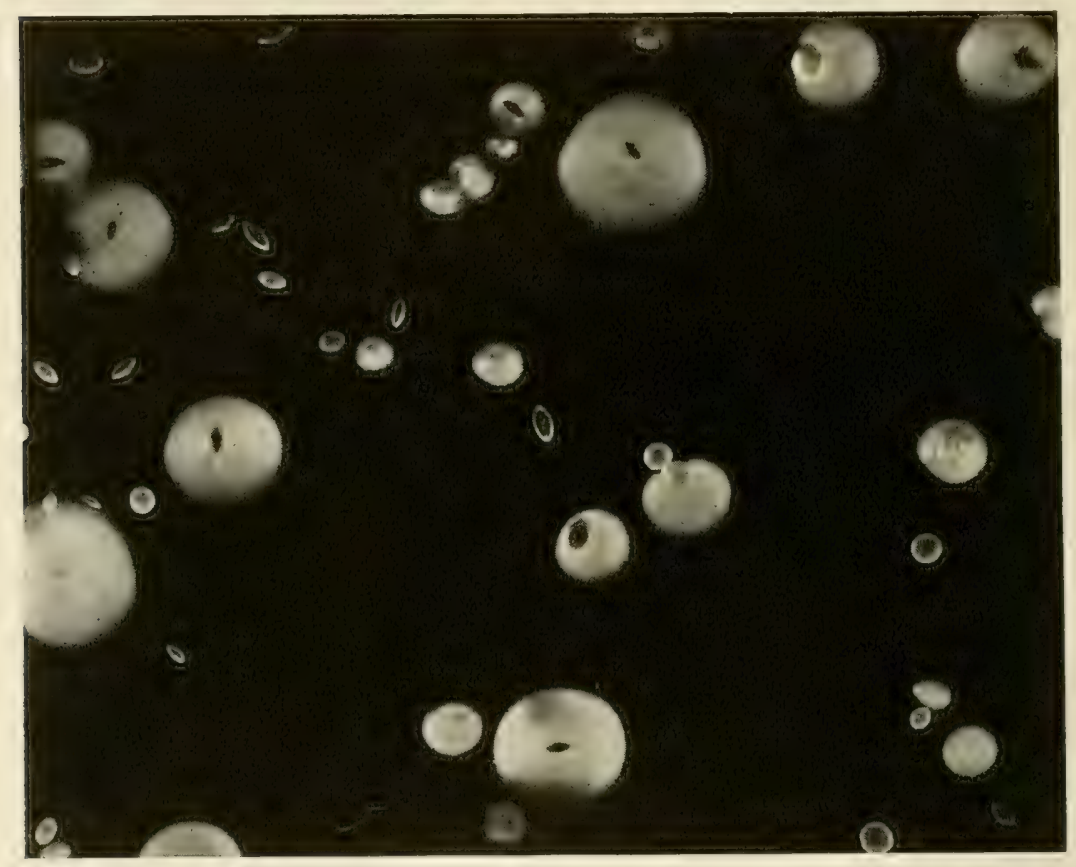

Frg. 229.-Bacterium phaseoli: Buried and surface colonies on an agar poured plate. Idaho isolation. Plate poured August 24, 1914. Photographed August 28. $\times 10$. Oblique lighting.

likely to remain damp longest because shaded from the morning sun. (In this connection read comment on black spot of the plum in "Bacteria in Relation to Plant Diseases," Vol. II, p. 62). Can you verify Dr. Halsted's observations? Do you think that what he saw could have been due to driving rains from the west? In that case the infection should sometimes occur most abundantly on the east side of the pods. Watch for this.

Barlow proved by transfers to culture media that Bacterium 
phaseoli can live over winter on naturally infected seeds (kept both in the pods and in sterile test tubes) and also determined that such seeds were not injured beyond the power to germinate and grow, but does not state that he traced the disease on into the seedlings derived from such seeds.

It has not yet been proved experimentally that this disease is commonly carried on the seed, unless we may assume that Edgerton has done so, but such I believe to be the case (read what is said under Nos. II and III, and respecting Rathay's Disease of Orchard Grass in "Bacteria in Relation to Plant Diseases," Vol. III, p. 160, and make all the observations and experiments you can). My reasons for this belief in addition to Barlow's statement, and Edgerton's, are the facts drawn from my own observations that the bean bacterium is not very sensitive to dry air, and that it may pass entirely through the walls of the pericarp and infect the seeds without destroying them, i.e., as they are approaching maturity. Such seeds, which are usually more or less distorted, should be saved in large numbers in sterile tubes and tested from time to time through the autumn, winter, and spring, to determine: (1) whether Bacterium phaseoli can be cultivated from many of them; and (2) especially whether seedlings grown from such seeds (in autoclaved soil and watered with boiled water) do commonly become infected.

Here is a definite, interesting, practical problem, easy of solution-given a bean field containing an abundance of the disease and a student with some aptitude for research. Five hundred or a thousand diseased bean pods would not be too many to save for such an experiment. A little preliminary observation will determine what pods should be selected, i.e., how badly diseased they must be externally to warrant belief that the pericarp has been perforated. Bean cotyledons are often distorted and bear rusty spots when they emerge from the soil. Is any part of this phenomenon the disease in question, or is it all due to fungous infection?

If Barlow's conclusions can be generalized, as seems probable, we shall have a very simple and practical way of dealing with this disease. 


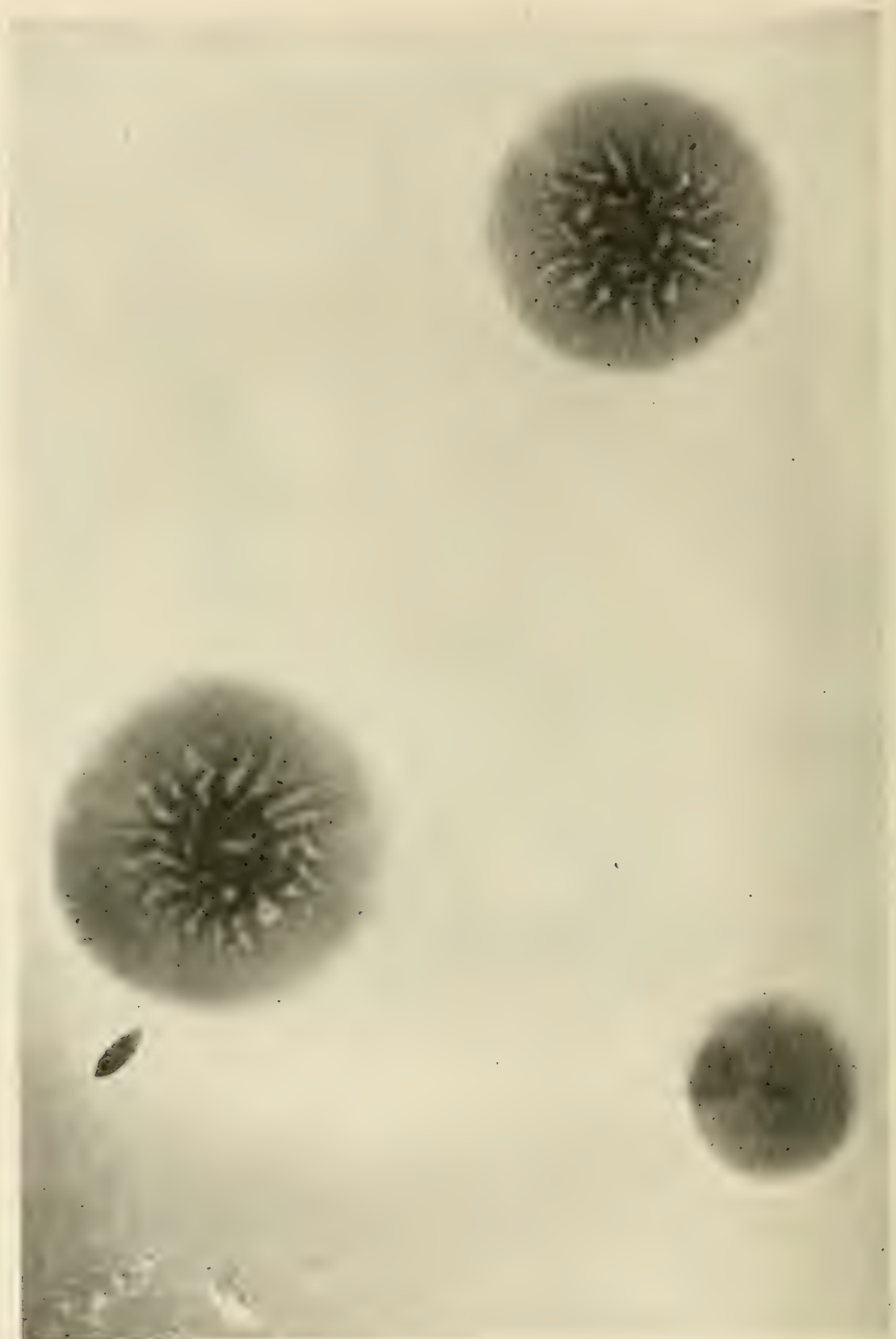

Fra. 230.-Buried and surface colonies of Bacterium phaseoil (Idaho isolation) in a thin-sown +15 peptone-beef-agar poured plate. The smooth, wet-shining, rellow, surface colonies show internal markings by direct transmitted light. Plate poured April 11, 1919. Photographed April 18. $\times 10$. Temperature $25^{\circ} \mathrm{C}$. 
If the organism is generally carried on the seed, then seed treatments are in order, and these should be made anyway, until it is known that they are of no avail. In this connection see Part I, page 69.

Another important subject for field study is the discovery or production of good resistant varieties. The subject is very hopeful if the right persons take hold of it.

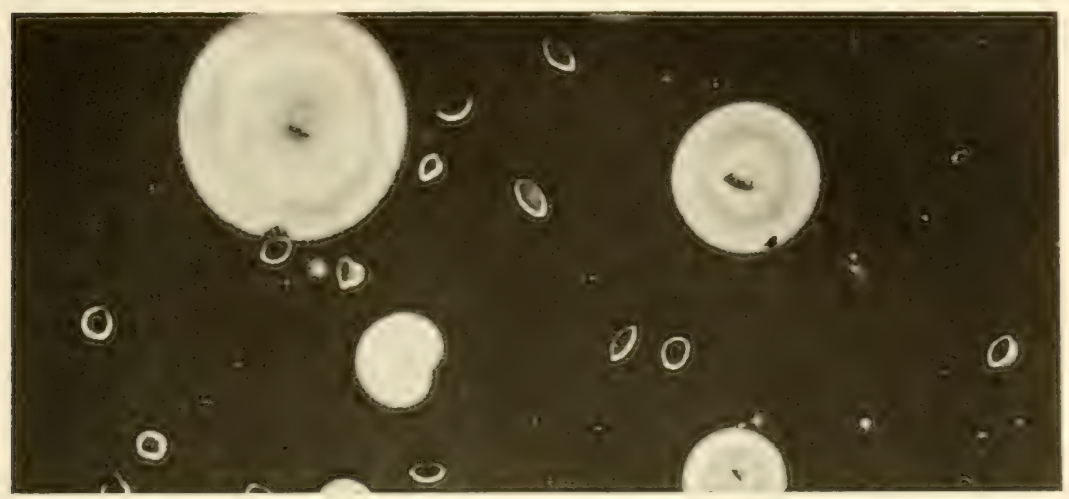

FIG. 230*.-Agar plate of Bact. phaseoli showing a common form of colony referred to in the text. Organism isolated by Florence Hedges in 1917 from a Maryland benn pod and used many times for successful inoculations. Plate poured May 22, 1920, and photographed June $4 . \times 5$.

\section{LITERATURE}

BeAch: Bull. 48, N. S., N. Y. Agr. Exp. Sta. (Geneva) 1892.

Sirith: Proc. Am. Assoc. Adv. Sci., Vol. XLVI, 1897, pp. 288290. Species here named Bacillus phaseoli.

Sмrтtн: Bull. 28, Div. Veg. Phys. and Path. U. S. Dept. of Agric., 1901.

Halsted: Bull. 151, N. J. Agr. Exp. Sta., 1901.

Barlow: Bull. 136, Ontario Agr. Exp. Sta., 1904.

SAckett: Bull. 138, Colorado Agr. Exp. Sta., 1909.

Edgertox and Morelaxd: The bean blight and preservation and treatment of bean seed. La. Agr. Expt. Sta. Bull. 139, Baton Rouge, La. 1913.

RAPP: Aged bean seed, a control for bacterial blight of beans. Science, n. s., Vol. L, Dec. 19, 1919, p. 568.

See also "Bacteria in Relation to Plant Diseases," Vol. I, Fig. 62; Vol. II, Fig. 15 and pl. 17 (Fig. 3). 


\section{McCULLOCH'S CAULIFLOWER SPOT}

Type.--This is a disease of cauliflower and cabbage, characterized by a copious stomatal blotching, spotting or specking of the green leaves, both on the reins and in the parenchyma. When the midrib and the reins are attacked early and seriously, the leaves become variously puckered and distorted (see also Nos. VIII and XI). Seen by reflected light, the spots are at first water-soaked, then brownish to purplish gray, but by transmitted light they appear thin and almost colorless in the center, with a dark border. The spots on cabbage are darker than those on the cauliflower. The individual spots, which occur in great numbers, are usually small (mere points to areas 1 to 3 millimeters in diameter, seldom larger), and are circular when quite small but soon become more or less irregularly angled, owing to limiting veins. By coalescence, elongated, irregular, and much larger spots occur, making the leaves look ragged. The badly spotted leaves also turn yellow and fall off ( 3 to 5 weeks after infection).

The disease was not observed naturally infecting the bleached flowering parts of the cauliflower in the Virginia material, nor was it obtained by spraying such parts, except sparingly on some of the larger flowerstalks, but later was obtained on cauliflower heads from Florida and produced on the cauliflower heads in one of our hothouses by pure culture inoculations. Probably the stomata do not function as readily on the bleached parts as on the green parts and consequently are less likely to be entered by the bacteria.

All of the infections, so far as observed, are stomatal, each small round spot having a single stoma in its center, below which is a bacterial porket. By spraying water-suspensions of young agar-streak cultures upon caulifforer plants and cabbage plants, numerous infections were obtained (Fig. 231) but mostly on the under surface of the leaves. When the infectious spray was confined to the upper surface of the leaves very few spots 300 

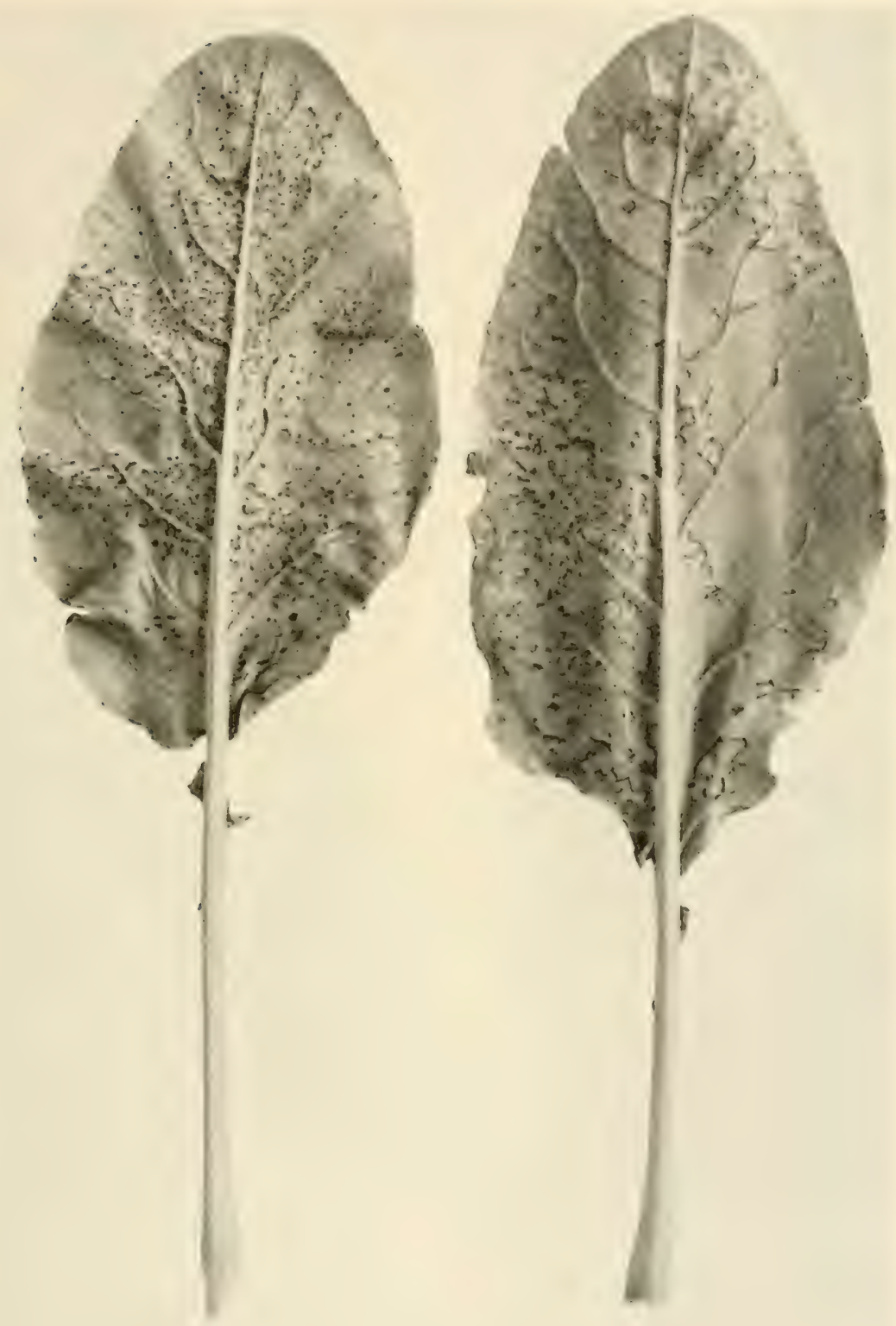

FIG. 231.-Cauliflower leaves attacked and spotted by, Bacterium maculicolum, McCulloch's cauliflower parasite. A pure-culture inoculation. Time, 13 days (May 19 to June 2, 1909). The infections are stomatal. 
were obtained. Time of day might make a difference. The old and the very young leaves appear to be partially or wholly immune (see observations under Nos. VIII and X).

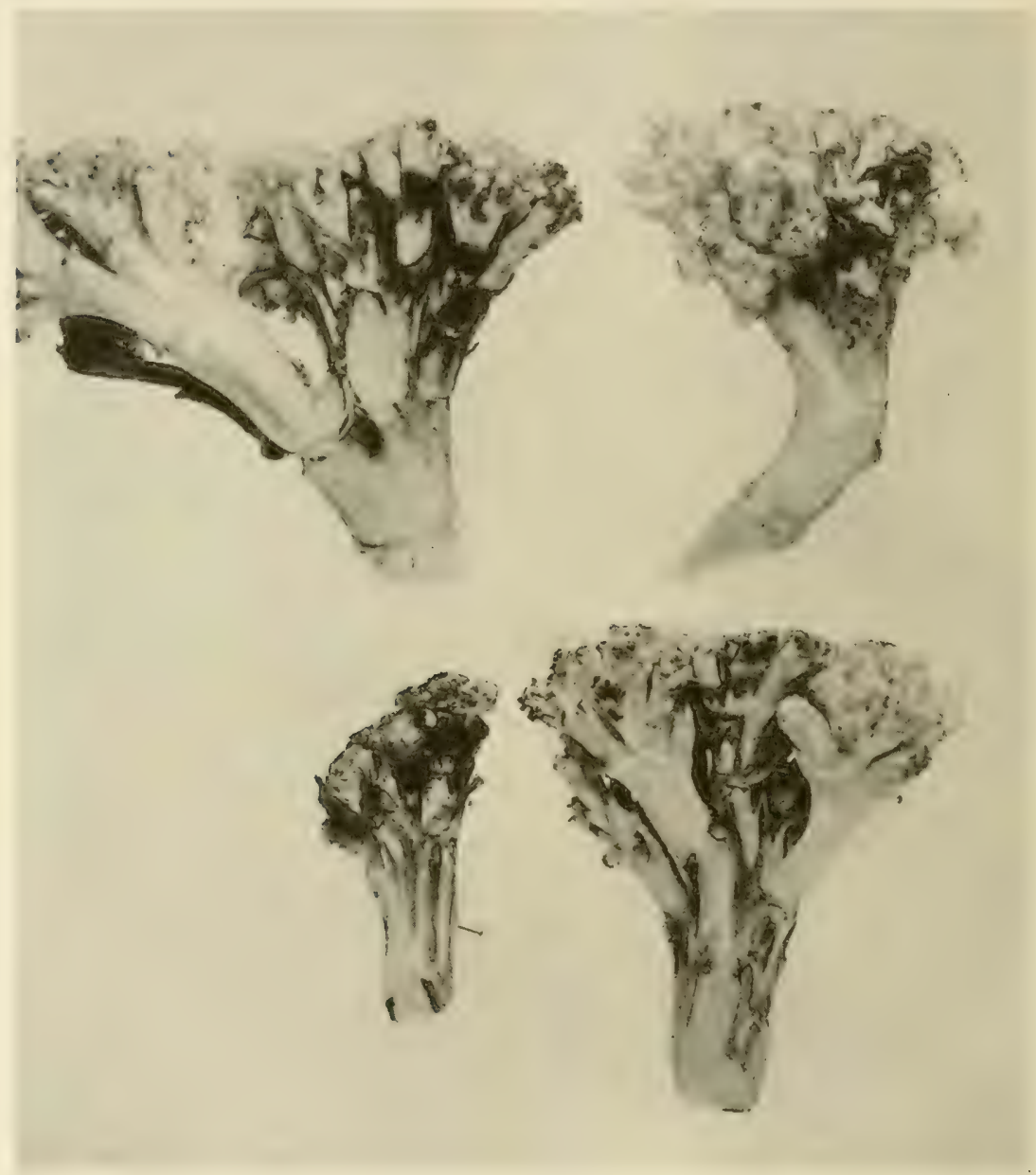

Fig. 232.- Spotted cauliflower head from Sanford, Florida, April 3, 1916. Gray to black discoloration of the epidermis and deeper tissues of the inflorescence. Plates were poured by Miss McCulloch on April 4 and Bacterium maculicolum was obtained and used for successful inoculations.

The period of incubation is short, numerous spots being risible within 3 to 6 days from the time of spraying, and always beginning, as in the spots on the naturally infected field cauliflowers, in the substomatic chamber. 


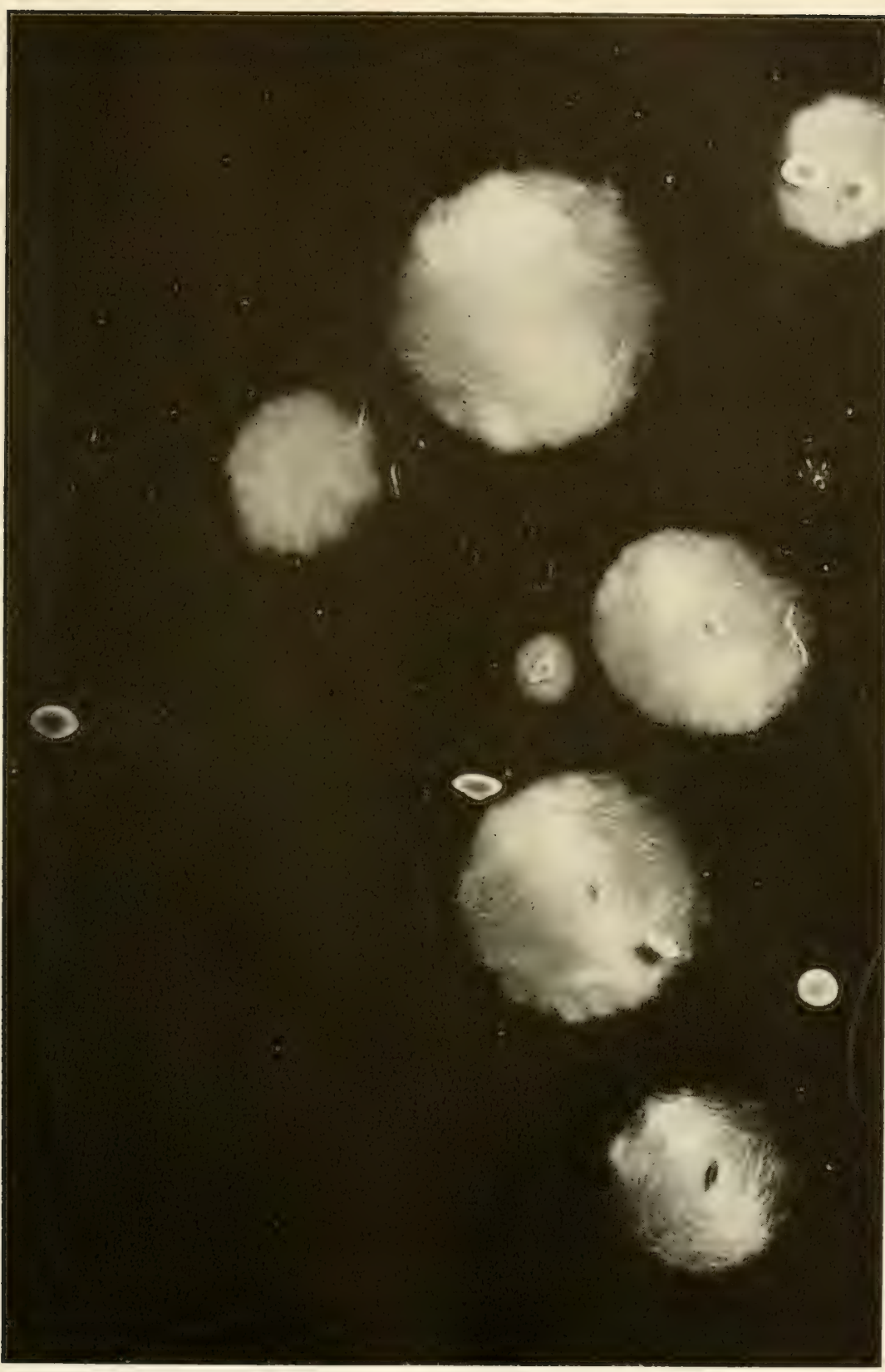

FIG. 233.-Peptone-beef-agar poured plate $(+15)$ of Bacterium maculicolum plated April 28, 1916, from spot on a cauliflower leaf which was inoculated April 24 with the Sanford, Florida, organism. Photographed May 2, with oblique transmitted light for internal colony markings, the surface being smooth. $\times 10$. 
Little is known regarding the geographical distribution of this disease. It was first received at the Laboratory of Plant Pathology in Washington on cauliflower leares from Southeastern Virginia in April and May, 1909. Subsequently (1912) something on cauliflower resembling it was received from Palmetto, Florida, and Miss MeCulloch succeeded in isolating an organism that culturally seemed right but no inoculations were made. Later (1916) from cauliflower heads grown at Sanford, Florida (Fig. 232), the organism was plated out (Fig. 233) and with it pure culture inoculations were obtained (Fig. 234). In 1918 it was received from Prof. H. H. Whetzel on cauliflower leaves collected in Ithaca, New York (Fig. 235). At first Prof. Whetzel thought that the disease was only a peculiar form of the black rot (see No. II) but since the leaves were without marginal infection and the petioles were not diseased, and the spots did not yield any yellow organism, he sent the leaves on to me to know what it was. Miss MeCulloch obtained from it her Bacterium maculicolum, with pure cultures of which she secured typical infections on cauliflower in one of our houses, and from such infections again obtained in pure culture typical colonies of the organism (Fig. 236). In April, 1919 we received it from the New Orleans market (courtesy of Lex R. Hessler) on cauliflowers said to have been grown in California.

This disease probably occurs also in Australia, that is, in 1900 I received specimens of cauliflower leaves and cabbage leaves from Prof. D. McAlpine in Melbourne, bacterially spotted with what I now believe to be this disease. His letter states that it is the cause of serious damage.

The conclusion respecting occurrence of the disease in cabbages depends upon artificial inoculations made in Washington in 1909 and 1910.

We owe our knowledge of this disease to the researches of Lucia Mcculloch, carried on in my laboratory during the years 1909, 1910, 1911 and later. No one else appears to have written upon it.

Cause.--The cauliflower leaf-spot is due to Bacterium maculicolum Mc(ulloch. This is a moderately growing, white, motile (even after 4 months in beef bouillon at $0.5^{\circ} \mathrm{C}$. to $1.5^{\circ} \mathrm{C}$.), $1-5$ 


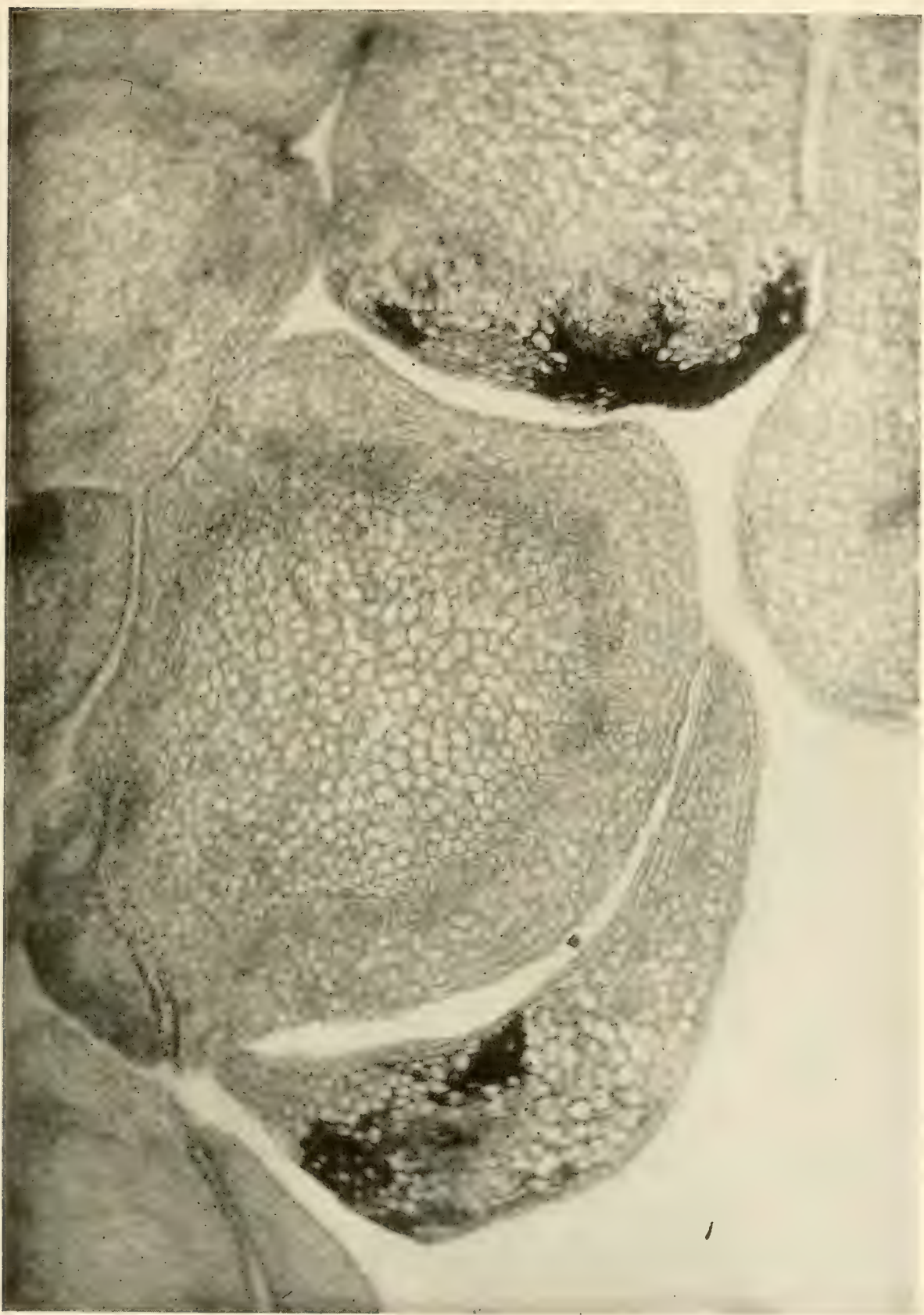

FIG. 234.-Bacterium maculicolum: Cross-section of cauliflower inflorescence (buds) showing depth of black spotting. From a pure-culture inoculation made November 20, 1916, using the Florida organism. Collected and fixed December 7. Slide 1310B5, second section, upper row. Carbol fuchsin stain. $16 \mathrm{~mm} ., 4$ oc. 50 bellows. 
polar flagellate (Fig. 237), non-sporiferous, Gram negative, nonacid-fast, liquefying (gelatin, not Löffler's blood serum), milkclearing (by a lab ferment with formation of tyrosin), non-gasforming and aërobic (in fermentation tubes in peptone water with dextrose, saccharose, lactose, maltose, glycerin or mannit), non-nitrate-reducing, green fluorescent (a pale yellowish-green stain in milk, peptone beef bouillon, peptone beef agar, peptone beef gelatin, Fermi's solution and Uschinsky's solution), alkalitolerant ( $\mathrm{NaOH}$ down to -25 in beef boullon), acid tolerant (in bouillon up to +34 for oxalic acid, and +36 for malic acid and citric acid), sodium chlorid-sensitive (beyond 2 per cent-at 4 per cent in bouillon motility ceases, and at 5 per cent there is scarcely any growth); chloroform-tolerant; grows below $0^{\circ} \mathrm{C}$. but is injured by freezing in bouillon ( 70 to 90 per cent killed) ${ }^{1}$, dry-air sensitive (very), sunlight-sensitive (very), heat-sensitive (very), short rod-shaped, catenulate (on agar and in 4 per cent. $\mathrm{NaCl}$ bouillon) or filamentous schizomycete $(0.8$ to $0.9 \mu$ in diameter), growing on +15 peptone beef agar plates in form of round, smooth, flat, shining, translucent, opalescent, white, entire-margined colonies, becoming 1 to $3 \mathrm{~mm}$. in diameter in 3 or 4 days at $23^{\circ} \mathrm{C}$, at which time or earlier the inner structure is coarsely granular and reticulate under the hand-lens. Later the inner structure becomes finely granular and the reticulations disappear. In thin-sown plates at the end of 7 days the surface colonies are 6 to $8 \mathrm{~mm}$. in diameter, and after 15 days 12 to $15 \mathrm{~mm}$. in diameter. With age the colonies become dull or dirty white, and slightly irregular in shape, with undulate or faintly crinkled margins into which run indistinct radiating lines. The buried colonies are small and lens-shaped.

On +10 nutrient beef-peptone gelatin plates, after 3 days at $17^{\circ}$ to $18^{\circ} \mathrm{C}$., the well-isolated colonies vary from mere points to round growths $2 \mathrm{~mm}$. in diameter. The gelatin is liquefied ${ }_{1}^{1}$ The statement on p. 13 of Bull. No. 225, Bureau of Plant Industry, is erroneous.

Fig. 235.--One of a number of spotted and blotched New York cauliflower leaves received from Prof. H. H. Whetzel in the fall of 1918 . The leaves were yellowish and the spots pale green to black. These gave an organism culturally the same as Bacterium maculicolum McC., and this produced the characteristic lesions when sprayed upon cauliflowers in one of our houses, and from one of these Fig. 236 was obtained. Good infections were also obtained with it in Feb., 1920. 


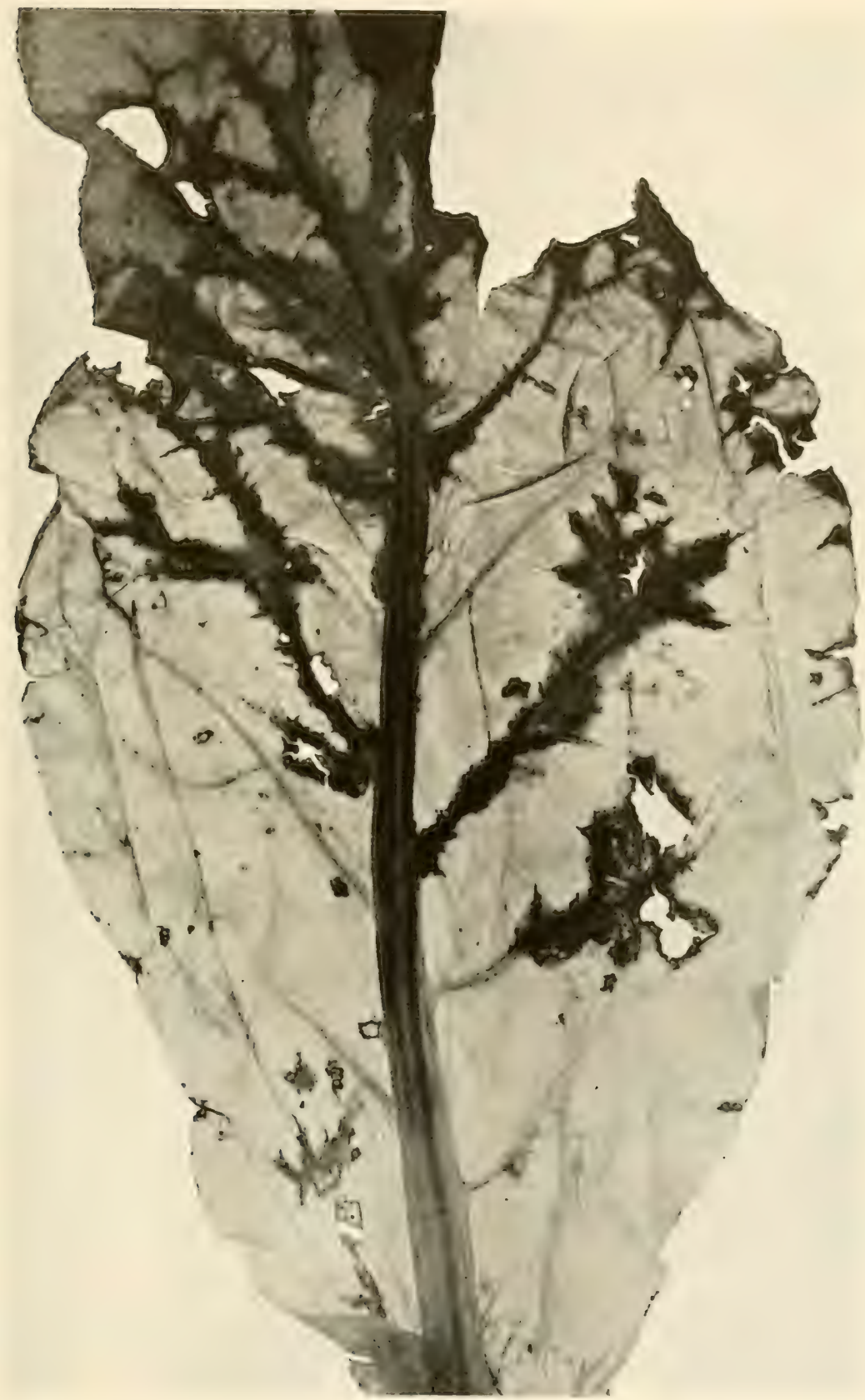

Fici, 2:is. 
in cup-like hollows. The margin of the smaller colonies is entire, that of the larger ones is fimbriate. Thickly sown plates are entirely liquefied in 2 days at $15^{\circ}$ to $16^{\circ} \mathrm{C}$.

Peptonized +15 beef bouillon, if inoculated from young vigorous bouillon cultures, clouds thinly in 6 hours and moderately to heavily in 24 hours at $24^{\circ}$ to $25^{\circ} \mathrm{C}$. The growth is best at the surface, where a fragile white pellicle forms. There is no rim, and no pseudozoögloeae are formed. In two days there are heavy clouds and a flocculent white precipitate which is slimy and finally viscid. The medium becomes slightly greenish and small crystals appear in the sediment.

In acid bouillons, pseudozoögloeae may occur and the rods become very short (spheroidal).

In -17 beef bouillon both filaments and involution forms were seen at the end of 2 weeks.

A fragile white pellicle forms also on Fermi's solution and Uschinsky's solution, and pseudozoögloeae occur in the latter.

In Cohn's solution it grows without green fluorescence, rim, or pellicle, but with the formation of large feathery crystals.

The organism blues litmus milk in well-defined strata from the top downward; no acid is formed, the cultures being dark blue by reflected light even after 6 months.

The color-changes in milk likewise proceed from the top downward in definite layers. In 15 to 20 days the whole tube is yellow with a greenish tinge; it is translucent but without destruction of the fat or separation of whey and curd. In 4 months when evaporated from $10 \mathrm{cc}$. to $5 \mathrm{cc}$. the milk is reddish brown and rather thick.

The organism is a cool-weather parasite. Its optimum temperature is $24^{\circ}$ to $25^{\circ} \mathrm{C}$, its maximum (in bouillon and on agar) is $29^{\circ} \mathrm{C}$, and its minimum below $0^{\circ} \mathrm{C}$. Of 20 bouillon cultures exposed for 10 minutes at $47^{\circ} \mathrm{C}$. none grew; of 12 bouillon cultures exposed for 10 minutes at $46^{\circ} \mathrm{C}$., one clouded after 11 days; exposure of bouillon for 10 minutes at $45^{\circ} \mathrm{C}$. killed the bacteria in some of the tubes (less than one-half) and retarded development in the others 3 to 5 days, i.e., many were killed; finally, exposure in beef bouillon for $3 \frac{1}{2}$ days at $33^{\circ}$ to $36^{\circ} \mathrm{C}$. destroyed the organism, i.e., prevented subsequent clouding at 


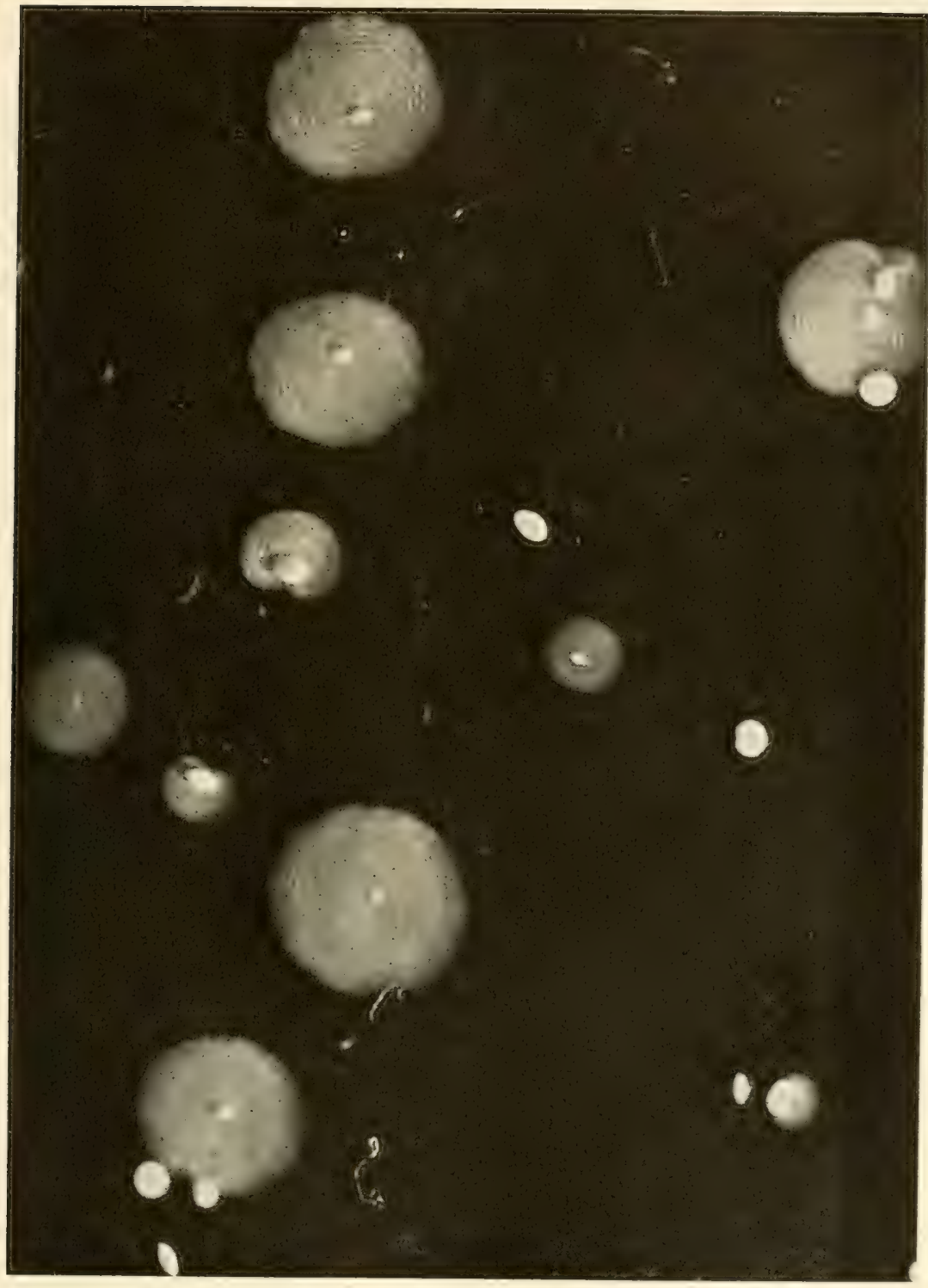

FIG. 236. - Surface and buried colonies of Bacterium maculicolum plated from the New York cauliflower Three buried colonies coming to the surface. Photographed by oblique transmitted light to show internal colony markings. Plate made from a spot on an inoculated plant. $\times 10$. 
optimum temperatures. No growth could be obtained in the plant or on agar or in bouillon at or above $29^{\circ} \mathrm{C}$. $\left(84^{\circ} \mathrm{F}\right.$.).

The organism is rather long-lived on media but loses virulence readily. It stains deeply with carbol fuchsin and by amyl Gram. There is a feeble production of ammonia, indol and hydrogen sulphide. A few cultures in litmus milk showed a slight reduction of the litmus at the bottom.

It is extremely sensitive to dry air and to sunlight. Four minutes exposure to direct sunshine killed all organisms in the insolated half of the thin-sown agar plates, exposed bottom up on ice, although the colonies developed as usual on the covered half of each plate. Taken from young, well-clouded bouillon cultures, and dried in the dark at $22^{\circ}$ to $25^{\circ} \mathrm{C}$. on cover glasses which were then dropped into suitable bouillon, the bacteria were dead on 75 per cent of the covers in 24 hours, on 90 per cent in 48 hours, and on all at the end of 5 days.

Technic.--The organism causing this disease grows readily in +15 agar-poured plates when the temperature is under $29^{\circ} \mathrm{C}$. (not at all at or above this temperature) ${ }^{1}$ and there are no difficulties in the way of isolation, other than surface contaminations, which are held in check, more or less, by short exposures (20 to 30 seconds) in 1:1000 mercuric chlorid water, after which the spots are crushed in bouillon for the poured plates.

${ }^{1}$ I felt so sceptical about $29^{\circ} \mathrm{C}$. as the maximum temperature that in January, 1919, I asked Miss McCulloch to do over for me this part of her work, which she did with the following results:

Tests of Bacterium maculicolum for maximum temperature. Isolations used: (Sanford, Florida, Col. 2 of April, 1916.

A Floral Stalk, Col. 1, December, 1916.

Leaf, Col. 2, December, 1916.

Mid-rib, Col. 6, March, 1917.

B. $\quad$ Ithaca, New York, Col. 3, November, 1918.

(1) $18-25^{\circ} \mathrm{C}$.

Greenhouse, Cols. 10, 11, 13 of January, 1919.

All of the above isolations clouded +15 peptone beef bouillon moderately in 16-18 hours.

(2) $28.5-30^{\circ} \mathrm{C}$. (Incubator heated by electricity and as workmen were changing wires the current was sometimes off.)

"A" strains, which have been in artificial media from two to three years, clouded slightly in 18 hours. 
For the inoculations, growing cabbage and cauliflower plants 6 to 12 inches high may be used. These, preferably, should be made in infection cages, by spraying the under surface of the leaves with water containing suspensions of young agarstreak cultures. If proper conditions are obtained, good infections in large numbers should be available for study by the end of the first week. By "proper conditions" are meant: (1) moist conditions for 48 hours; (2) growing plants; (3) temperatures under $29^{\circ} \mathrm{C} .\left(84^{\circ} \mathrm{F}\right.$.); and (4) use of bacterial cultures which have not lost their virulence or become attenuated by harmful laboratory conditions. Miss MeCulloch several times obtained numerous infections on both cauliflower and cabbage plants by spraying, but none in hot weather and none or few with the descendants of old cultures. It is possible, however, that some of her isolations may represent feeble strains of this parasite.

Under our rather dry hothouse conditions secondary infections were not observed. That is, the infections were limited to the leaves actually sprayed.

\section{Determine}

For the organisur. Morphology.-Size in microns. Absence of endospores (try heat and spore stains). Motility on the margin of a hanging drop. Persistence of motility in old cultures. Number and distribution of flagella (use van Ermengem's or Hugh Williams's method). Conditions

"B" strains were not clouded in 18 hours.

After three days there was faint clouding in "B" strains.

In six days the growth in " $\mathrm{B}$ " strains is less than in room temperature cultures in 18 hours.

(3) $29.5-30.5^{\circ} \mathrm{C}$

"A" strains were slightly clouded in 24 hours.

"B" strains not clouded.

"B" strains not clouded in four days.

(4) $30-31^{\circ} \mathrm{C}$

"A" strains elouded faintly in 24 hours.

"B" strains not elouded in four days. 
under which chains and filaments are formed. Involution forms. Under what conditions do they occur?

Cultural Characters.-Behavior on thin-sown agar-poured plates. Ditto in agar-streak cultures and stab cultures. Character of growths on thin-sown gelatin-poured plates. Ditto in stab cultures and streak cultures on gelatin. Growth in streaks on Löffler's solidified blood serum. Behavior on potato. Growth in milk and litmus milk (examine every day). Growth in synthetic media-Cohn's solution, Fermi's solution, Uschinsky's solution, etc. Action in peptone water on various sugars and alcohols in fermentation tubes. Is any gas produced? Is there ever any clouding of the closed end? Is any acid formed in the open end? Test in appropriate media for production of indol, ammonia, hydrogen sulphid, amylase, lab ferment, proteolytic ferment.

Non-nutritional Environment.-Thermal death-point (begin with $45^{\circ} \mathrm{C}$.). Maximum temperature for growth (try first in +15 peptone beef bouillon at $30^{\circ} \mathrm{C}$.). Optimum temperature for growth (use measured loops into bouillon and examine every three hours). Lowest temperature at which growth occurs (try first at $1^{\circ} \mathrm{C}$. and continue experiment for six weeks). Effect of dry air (using young bouillon cultures first). Effect of insolation (expose on ice to a bright sun for 5 minutes and hold half of each plate covered as a check). Effect of freezing (salt and pounded ice). Behavior in salted bouillons (try 5 per cent first). Behavior in bouillon over chloroform. Toleration of sodium hydroxide in bouillon (begin with -22). Toleration of organic acids in bouillon-tartaric, citric, malic, etc. (begin with +30 ). Action of fungicides.

For the disease. Signs.-Describe early, middle and late stages of the disease and determine how long it takes to produce these conditions on sprayed plants at given temperatures. Make inoculation experiments at the same time in two houses (or places) having temperatures 10 degrees apart: one $20^{\circ}$ to $25^{\circ} \mathrm{C}$, the other at $30^{\circ}$ to $35^{\circ} \mathrm{C}$. Are Miss $\mathrm{Mc}$ Culloch's statements as to impossibility of obtaining growth or infections at or above $29^{\circ} \mathrm{C}$. entirely correct? In that case, 
where does the organism summer over? Can you obtain the disease on the bleached flowering parts?

Histology.-Fix in Carnoy's solution pieces of cauliflower leaves and heads showing small spots, carry them through the paraffin-infiltration procesis, section on the microtome, stain and study. What are your conclusions regarding manner of infec-

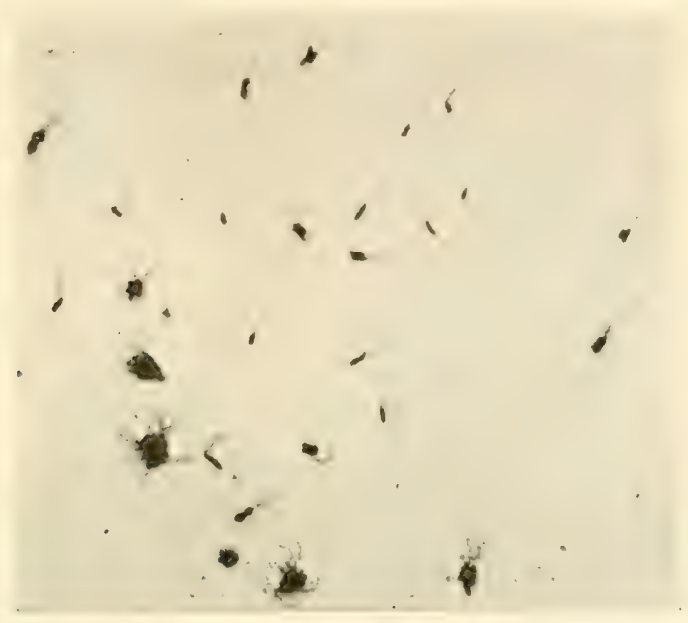

FIg. 237.-Flagella of Bacterium maculicolum. Stained from a 2-day agar streak by van Ermengem's method. $\times 1000$.

tion and process of tissue destruction? Is the disease ever vascular? Is cellulose destroyed?

Variability.-Nothing is known.

Transmission.-Nothing is known

\section{LITERATURE}

Read McCulloch: "A Spot Disease of Cauliflower." Bulletin 225, Bureau of Plant Industry. Washington, D. C., Govervment Printing Office, 1911. The organism is described and named in this paper. 


\section{THE ANGULAR LEAF-SPOT OF COTTON}

Type.-This disease is a common leaf-spot, twig-blight and boll-rot of cotton, comparable with the bean blight due to Bacterium phaseoli. (No. VIII), the walnut blight due to Bacterium juglandis, and in some ways also with the mulberry blight due to Bacterium mori (No. XI).

Following Atkinson, the leaf-disease is commonly known as the angular leaf-spot. The stem-blight is known as "blackarm" or "gummosis," and the capsule spot as "boll-rot." These, however, are only different manifestations of one disease.

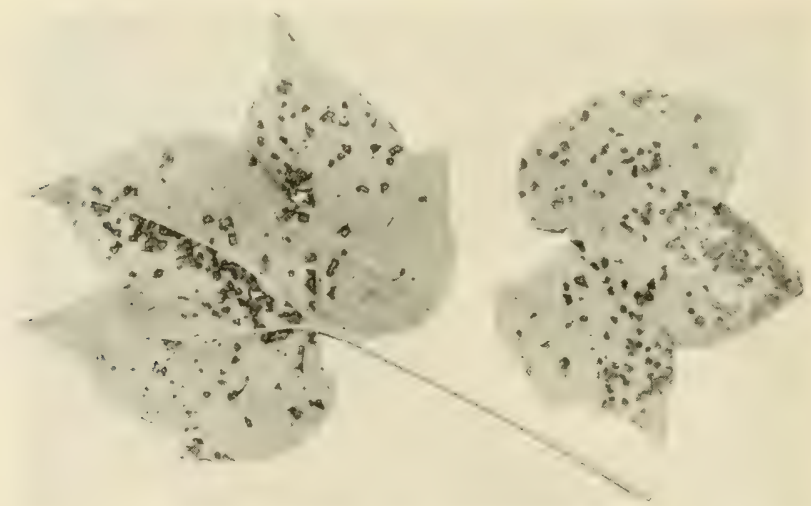

Fig. 238.-Cotton leaves from Monetta, South Carolina, showing Atkinson's angular leaf spot, due to Bacterium malvacearum. Photographed in $1903.1 / 2$ nat. size.

The spots on the leaves were first described in 1891-92 by Geo. F. Atkinson who examined them under the microscope and detected bacteria in them. He isolated a micro-organism and made inoculations, but these were unsuccessful.

Stedman ascribed the boll-rot to his green-fluorescent Bacillus gossypina, but on insufficient evidence.

The writer was the first to reproduce the disease on leaves and bolls of healthy cotton plants (1900-1905) with the true parasite isolated from capsule-spots and leaf-spots. He was 
THE ANGULAR LEAF-SPOT OF COTTON: TYPE

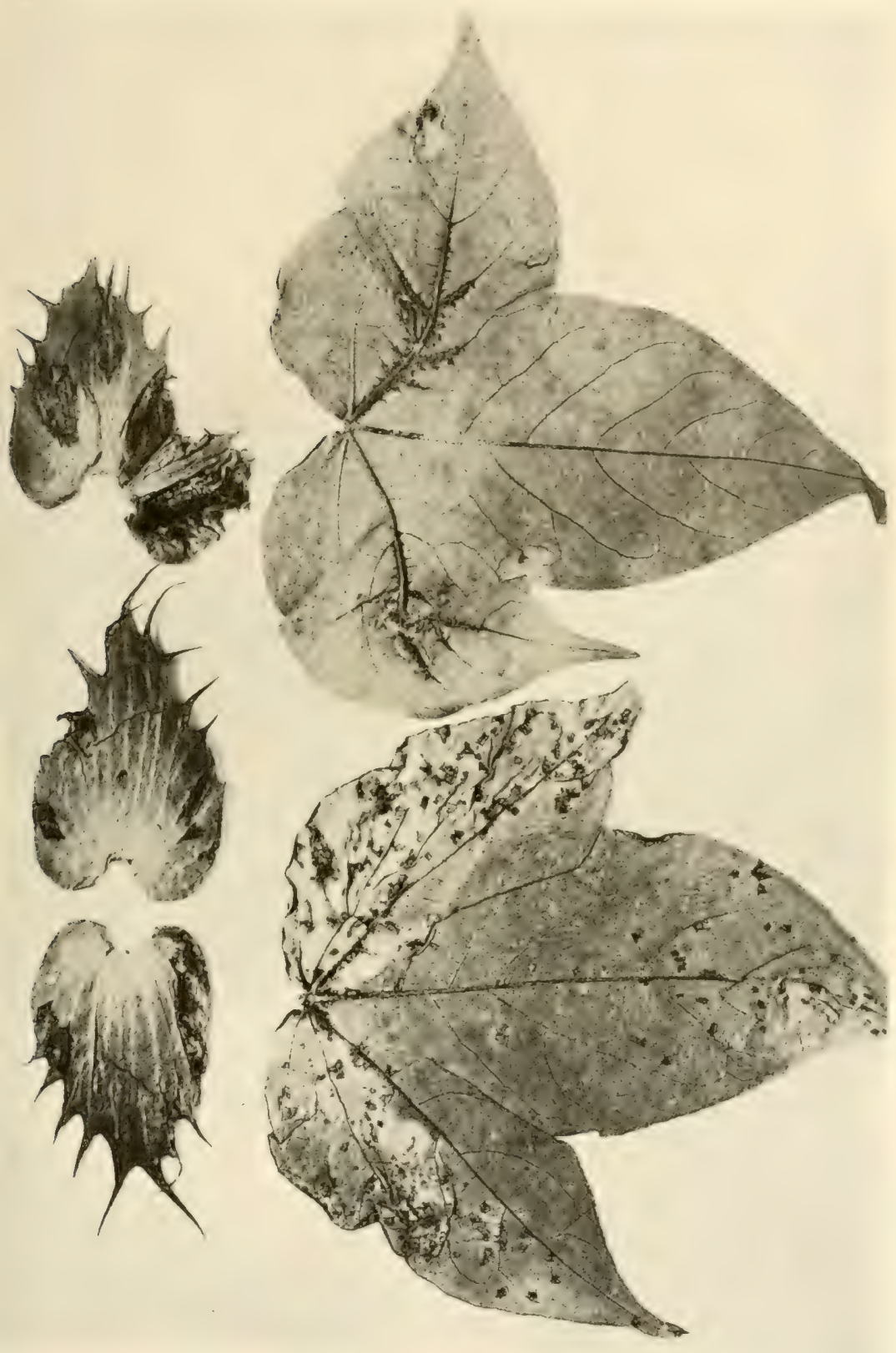

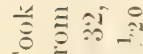

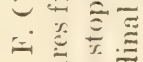

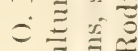

-

$\approx \Xi$

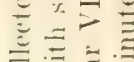

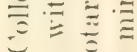

(1)

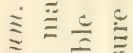

政

气

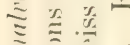

ミ气

ミ的

$\cong \equiv$

¿

$\therefore \equiv$

$\therefore$

$\mp \div \div \equiv$

$\pm \Xi$

\%

芌苛

㱐

‥

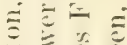

言总总

芹要

三

5

大

苛

三

$\Xi \Xi$

है

范范

跣

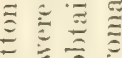

政

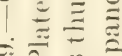

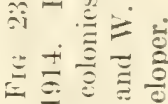

$\exists=$ 
also the one who proved the stem-blight known as black-arm and the angular leaf-spot to be due to the same organism (Washington hothouse inoculations of 1905). The inclusion of blackarm in Mr. Orton's account of the bacterial cotton-blight ("Sea Island Cotton: Its Culture, Improvement and Diseases," U. S. Dept. Agric., Farmers' Bulletin 302, 1907, pp. 41-42) was due to these experiments, some of which he had seen.

The first indications of the disease are minute water-soaked spots. On the half-grown leaves these spots are chiefly between the veins and more or less limited by the latter, the result as

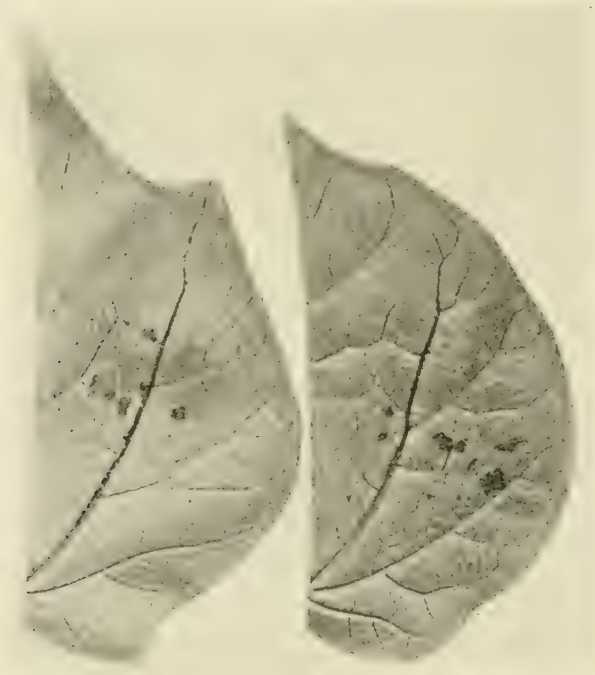

FIG. 240.-Cotton leaves inoculated in spring of 1915, using a pure culture plated from the lower leaf of Fig. 239. Time, 32 days, cool house. Stomatal infection; veins also invaded.

they enlarge being square or variously angled small spots (Fig. 238) which are translucent at first, then brown. These spots by their number and their one-sided enlargement and coalescence may seriously injure the attacked leaves, greatly reducing the amount of assimilating surface and causing them to become yellow and to fall early. The bracts and the veins or ribs of the leaf are also subject (Fig. 239). Contrary to Atkinson's supposition, infection often takes place rery early, i.e., when the 
leaves are quite small, and then the disease is generally confined to the larger veins or ribs of the leaf (Figs. 240 and 241).

The infections are largely stomatal and are easily induced by spraying on water suspensions of pure cultures (Fig. 242). Two to three weeks or more, depending on the temperature, are required for stomatal leaf infections to become plainly visible. Their interior is then as shown in Fig. 243, i.e., the tissues are disintegrating and full of bacteria. The shortest period I have observed for both the vein disease and the parenchyma spot is 12 days. This was in very hot weather in July, 1915, using as source of infection potato sub-cultures from a "windowed" colony of the Arizona organism, cultivated from the leaf shown in Fig. 244.

On the green bolls which are also attacked (Fig. 245), the water-soaked areas enlarge slowly or rapidly according to the age of the bolls and the weather conditions. If the bolls are small when attacked they drop off, and if large they become first green-spotted, then brown or black-spotted and sunken in the attacked parts, and the lint either fails to develop under the spots or becomes wet, brown-stained and rotten (Fig. 246). The pods may also become one-sided in their development. On the stems, particularly the upper and softer terminal branches. the elongated water-soaked spots end in long sunken black stripes (Fig. 247) and the branch either shrivels and dies or is broken over. The amount of branch infection varies greatly according to the season and the variety. The main stem of young plants is also subject to attack and may be killed. From the older spots, especially on bolls and stems, there is often a yellowish bacterial ooze which dries in the form of yellowishwhite granules, scales or crusts.

This disease is widespread in our Southern States and has been reported also from other parts of the world. I have proved it to occur in Asia (Turkestan) by cultivating my organism out of diseased cotton stems received from Tashkent (Dr. Schröder's cotton gummosis), and with pure cultures of it have reproduced the typical disease in American cotton on both leaves and stems in one of our hothouses (1909). I have also isolated it from stems of Egyptian cotton grown at Zomba in 


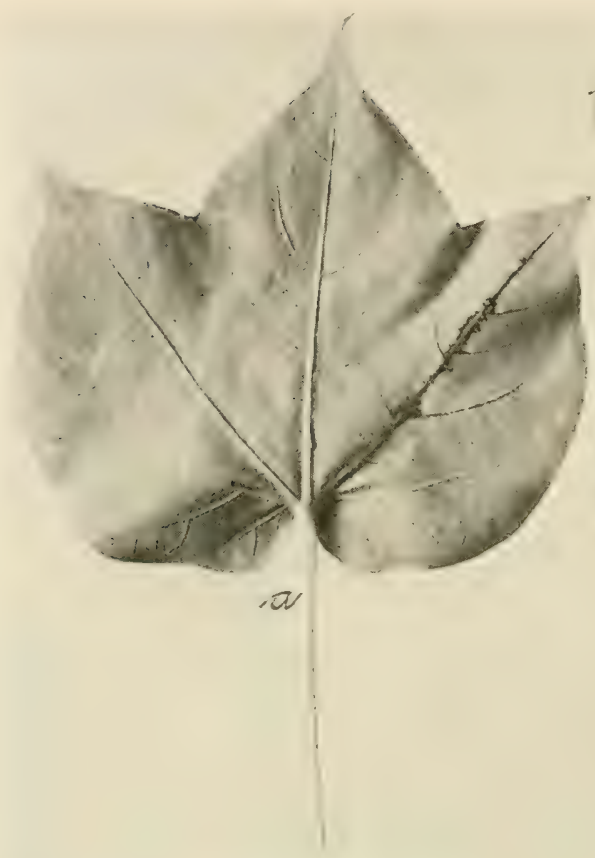

1
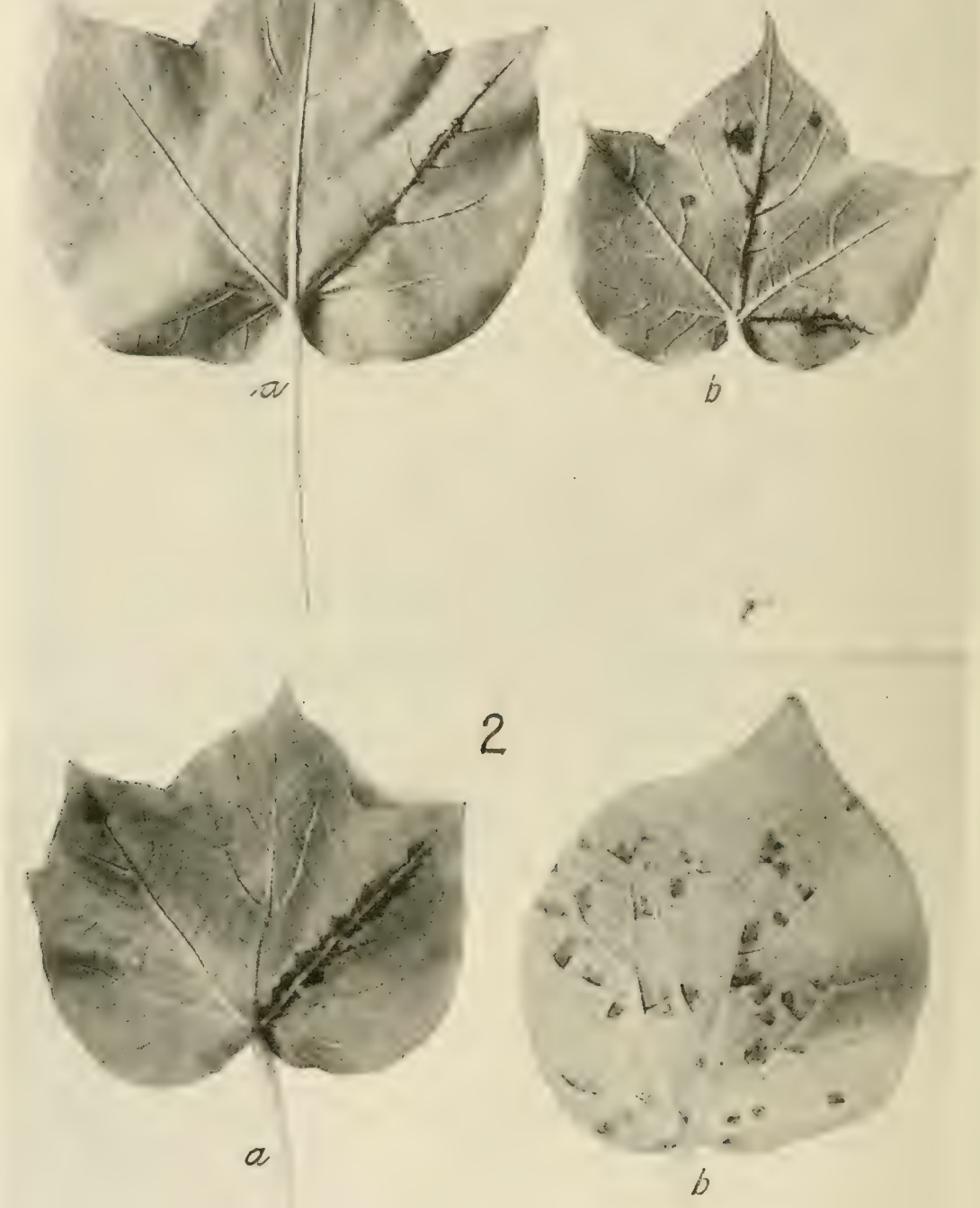

FIG. 241.-Angular leaf-spot of cotton showing varying manner of infection dependent on age. (See next page.) 
East Africa (Nyassaland), and more recently (1915) from cotton grown in Pretoria in S. Africa. In 1915, Bovell and Dash reported it as serious on late cottons in the Barbados. In 1918 Reinking reported it from the Philippines. Miss Doidge writes me (1919) that she has observed it to be quite common in. South Africa. O. F. Cook saw it in China in 1919. Probably the disease occurs in all the cotton-growing regions of the world.

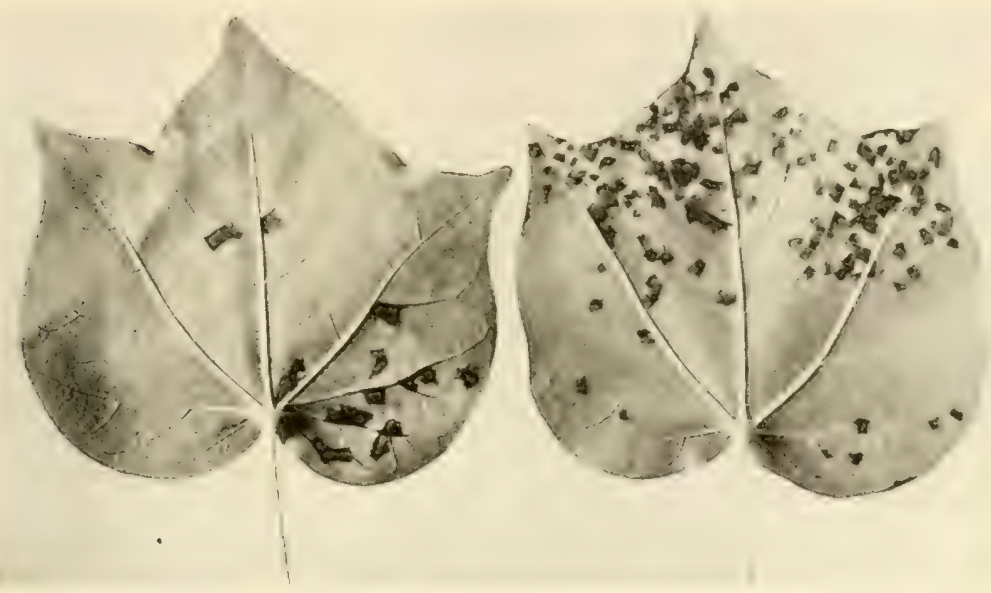

FIG. 242.- Inoculated cotton leaves shorving angular spots due to stomatal infection by Bacterium malvacearum. Bacterial suspension sprayed on. Spots in second stage, i.e., beginning to shrivel and brown. Time, 6 weeks. Photographed April 28, 1915. 1,2 nat. size.

The extent of damage done by it is unknown. It is worse in some localities and some seasons than in others. I regard it as a serious disease.

If any considerable part of the "shedding" of the young bolls is due to it, especially in seasons when shedding is phe-

1. Result of inoculating cotton leaves when very young. Stomata not then open on the parenchyma and attack of Bacterium malvacearum confined chiefly to the veins: $a$, bacteria rubbed by hand on under-surface of right lobe; $b$, bacteria sprayed on. Photographed April 28, 1915. Time: $a, 4$ weeks; $b, 6$ weeks.

2. a, Hand-rubbed (March 25) with Bacterium malsacearum on the undersurface of the right lobe when very small and infection confined to the vicinity of veins; $b$, sprayed when older (March 17), i.e., when about half-grown and disease confined to the parenchyma. Photographed May 1, 1915. 


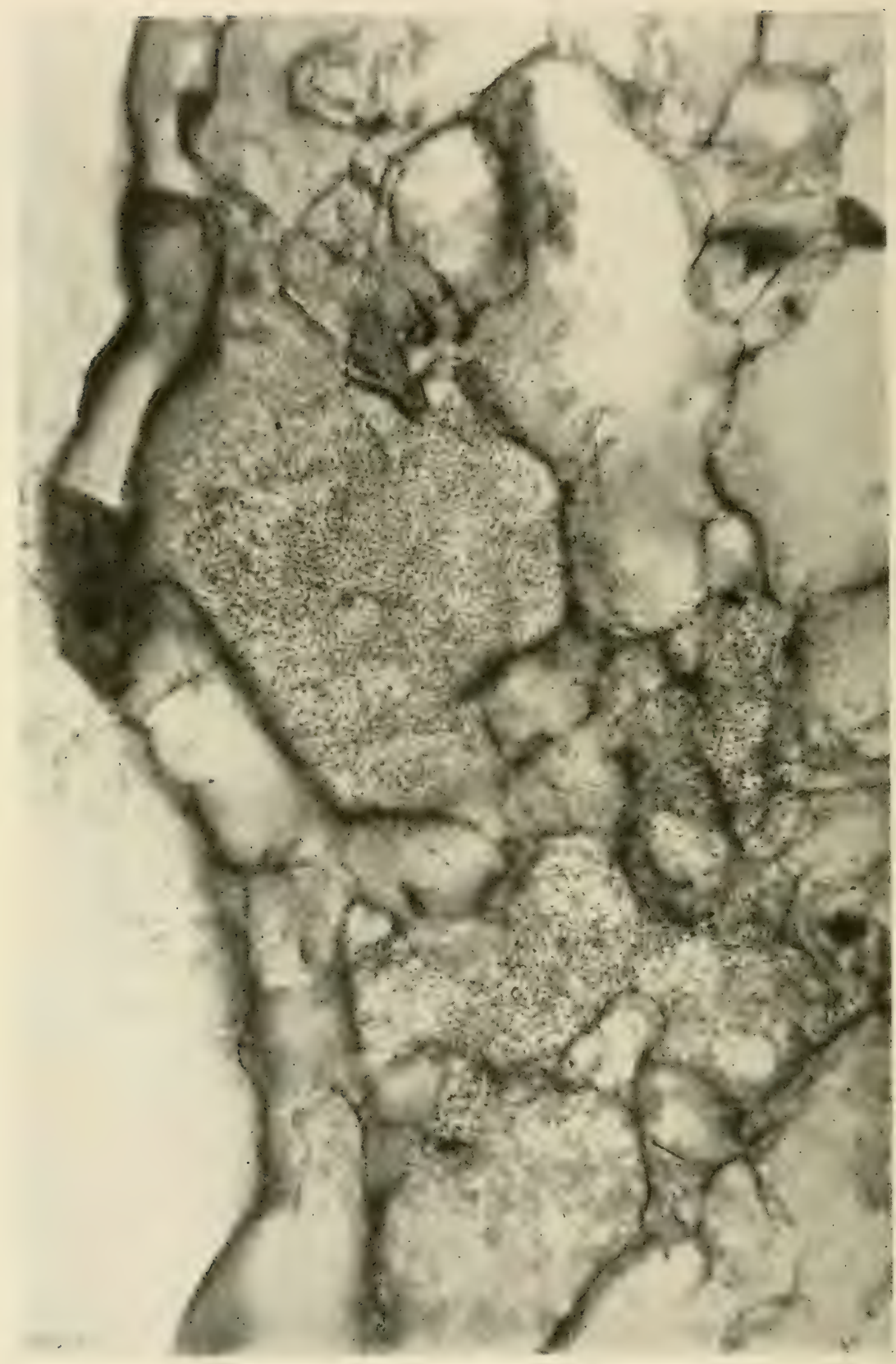

FIG. 243.-Cross-section of a cotton leaf inoculated with Bacterium malvacearum by spraying (uncovered in a hothouse) March 17, 1915. Collected 
nomenally large and interferes with the making of a crop, as now seems probable; and especially, if this schizomycete generally paves the way for the entrance of the destructive boll fungus, Glomerella gossypii (Colletotricum gossypii Southworth), as MIr. Orton believes or did believe at one time, then indeed it is a very serious enemy of cotton growing. This much is certain,

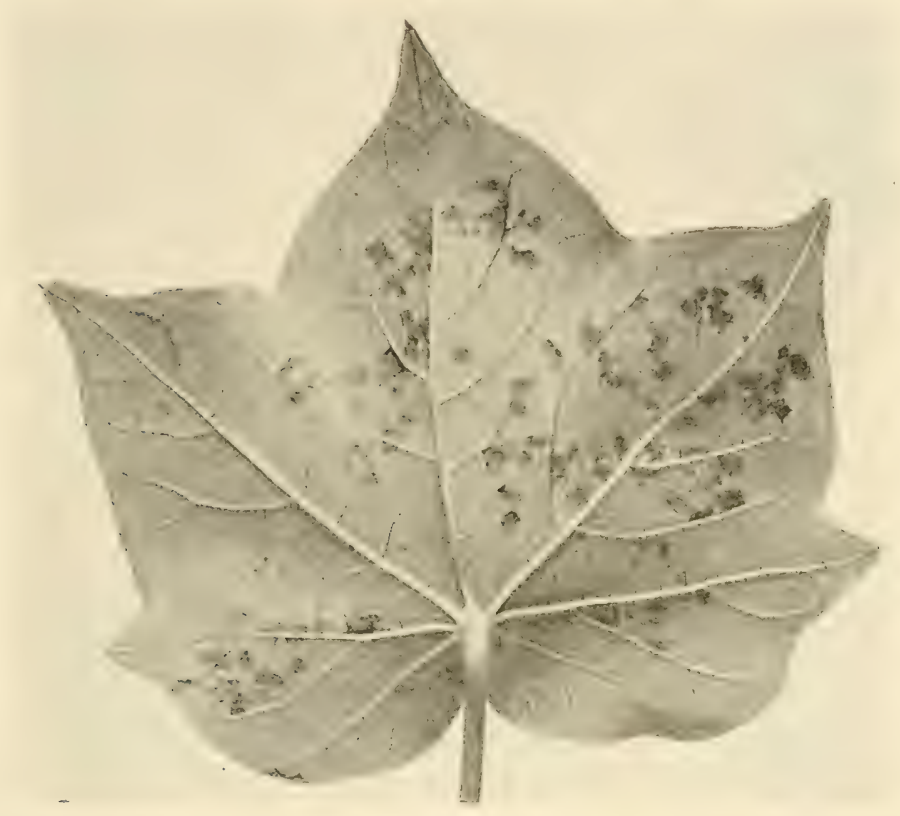

Frg. 244.-Cotton leaf inoculated May 4, 1915, from a windowed colony. Photographed June 26, 1915. Time, 53 days.

the anthracnose fungus and the schizomycete often occur together on the bolls in such a way as to indicate that the first invasion was bacterial. Further studies are necessary. Weather conditions have much to to with the prevalence of the disease.

- Cause.- This disease is due to Bacterium malnacearum EFs. This organism is a yellow, Gram-negative, non-acid-fast

and fixed in Carnoy's fluid, April 5. Sectioned from paraffin. Amyl-Gram stain. Stomatal region pushed up. $\times 1000$. From a photomicrograph by the writer. 
(5-day potato cultures stained 10 minutes in Ziehl's carbol fuchsin, then washed 1 minute in 70 per cent alcohol containing 3 per cent hydrochloric acid), non-sporiferous, motile, polar flagellate (Fig. 248), feebly liquefying (gelatin and Löffler's solidified blood serum), milk-curdling (by a lab ferment), non-nitrate-reducing, starch-destroying, sunlight-sensitive (Fig. 249), dry-air sensitive, frost-sensitive in +15 bouillon (Fig. 250), rod-shaped or short catenulate (2 to 4 or more elements) schizomycete, growing on the surface of +15 agar-poured plates in the form of round, thin, flat, smooth, wet-shining, very pale yellow colonies which become a deeper color with age but are still only pale yellow, i.e., distinctly paler than those of Bacterium phaseoli, never deep yellow or orange colored. Well-grown

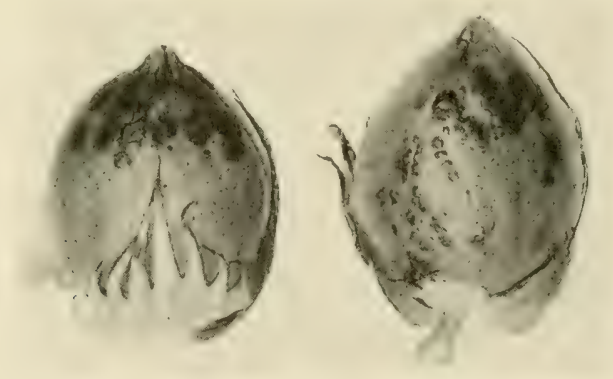

FiG. 245.-Green cotton bolls attacked by Bacterium malvacearum. Accidental, hothouse infection. Washington, 1904.

colonies on thin-sown plates measure 1 to 5 millimeters or more in diameter. Early in their growth on +15 agar (second or third day) the colonies are more or less radiate-mottled and this is a good character for separating the parasite from yellow cotton saprophytes which often accompany it or follow it (Fig. 251). The margin is thin and regular except in old colonies.

10 spots - pedicel also involved; (2) another boll-photographed end on, showing 20 or more coalescing spots some of which involve the whole thickness of the pericarp, as shown in Fig. 3 at $X$; (3) same boll as (2) but a side view with the pericarp split open to show the beginnings of the brown stain in the lint-base of the pericarp also involved; (4) same as (3) but showing the opposite side of the bolllint at top stained brown. Inoculations of July 7, 1915, made with a "windowed" colony of the Arizona organism. The cotton Colletotrichum was not present in the hothouse. Photographed by James F. Brewer. (See next page.) 

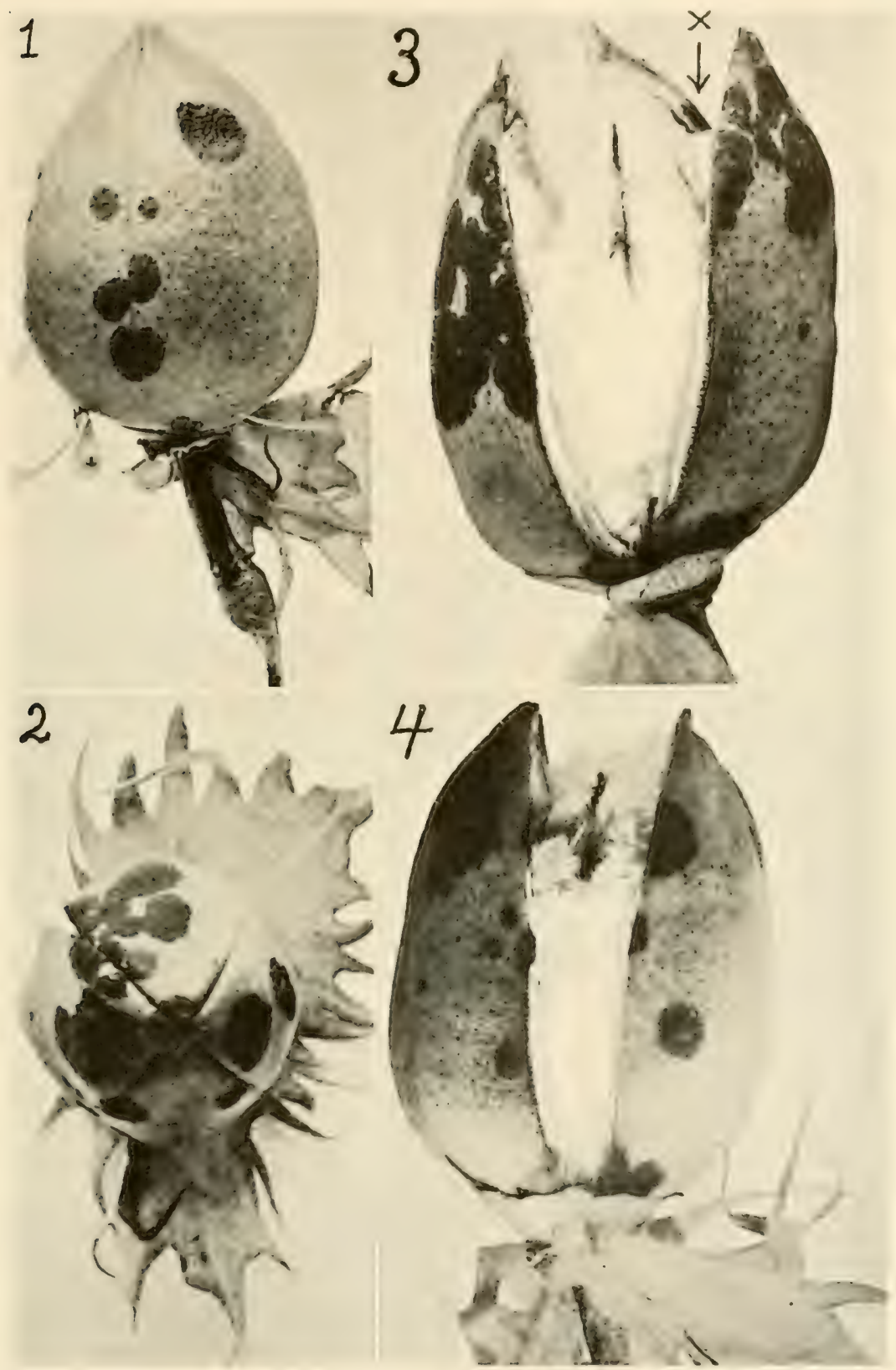

Fig. 246.-Pure-culture inoculations of cotton with Bacterium malvacearum showing later stages of boll-spot than Fig. 255: (1) side view of a boll showing 
Often there is a paler zone at the edge of the colony (Figs. 252 and, especially, the colony in the upper left corner of Fig. 253) or there may be concentric zones as in Bacterium phaseoli. Occasionally the mottling of surface colonies on agar is so conspicuous as to suggest an intruder (Fig. 254), but inoculations with subcultures from such a colony produced thousands of typical spots on cotton leaves (Fig. 244) and also infected the bolls typically

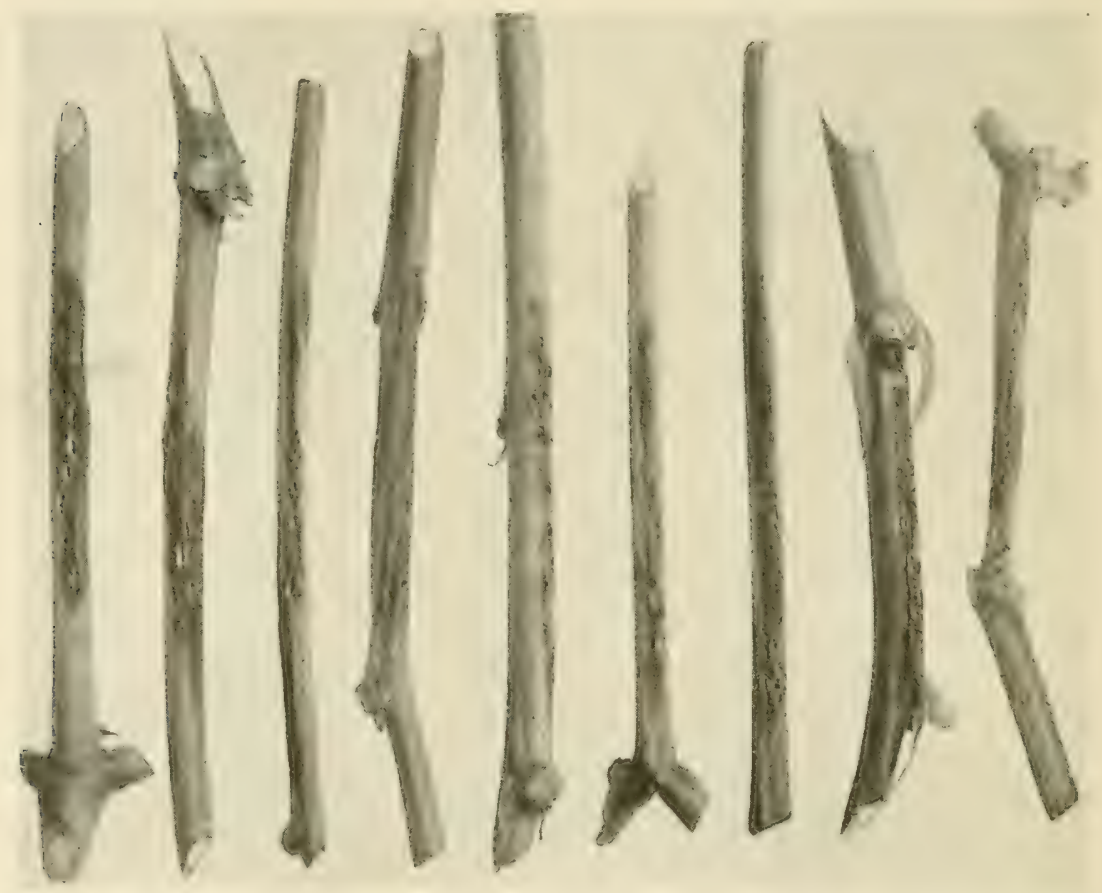

FIG. 247.- - Rather woody cotton stems attacked by Bacterium malvacearum as the result of needle prick inoculations (Nos. 103-111). Sept. 19, 1905. Photographed Oct. 1, 1905 but with insufficient contrast. The "black arm" of the planters.

(Fig. 255). Moreover, after a few days, such strikingly mottled colonies fill up their thin places, as may be seen by comparing Figs. 253 and 256. To these curious forms which suggest rose-rvindows we have given the name "windowed" colonies.

The colonies in +10 peptone beef gelatin plates are also characteristic. They are yellow and circular. A feeble pit of liquefaction is produced and the colony sends into the depths 
of the softened gelatin (Arizona organism) numerous spatulate finger-like projections (Fig. 257). Gelatin stab cultures are liquefied very slowly. In tube cultures 83 days old, one-half to two-thirds only of the gelatin was liquefied. There was no decided rim or pellicle, but a copious yellow precipitate, the fluid gelatin remaining clear and unstained. In another year (1915) tubes of +10 peptone beef gelatin inoculated with the Arizona organism by needle stabs were only one-fourth liquefied after 30 days at $16^{\circ}$ to $19^{\circ} \mathrm{C}$. although there was a prompt and

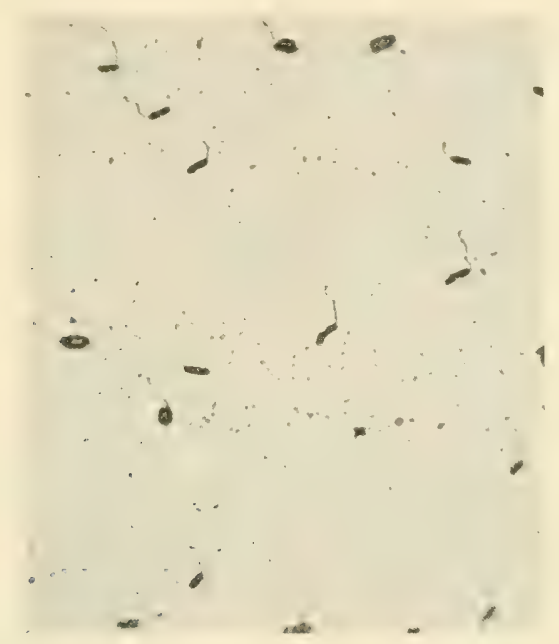

FIG. 248.-Flagellate rods of Bacterium malvacearum cultivated from an angular leaf spot. Arizona cotton. Stained by van Ermengem's silver method. $\times 1000$.

good growth. At the end of 60 days (same temperature) less than one-half the gelatin was liquefied.

On Löffler's solidified blood serum, there is a copious growth (paler yellow than that of Bacterium phaseoli) with slow liquefaction. At end of 15 days in tubes containing Bacterium phaseoli all the substratum had changed color (darkened) and most of it had liquefied; whereas in tubes containing Bacterium malvacearum there was very little change in color (the bulk white) and not one-twentieth part had liquefied. At the end of 30 days the difference in color and amount of liquefaction was 
still marked. Experiment repeated in 1919 with the same distinct differences (Fig. 258).

On steamed potato cylinders standing in water there is at first a thin, pale yellow, wet-shining growth, which soon becomes copious and entirely fills the fluid, making it solid. The color

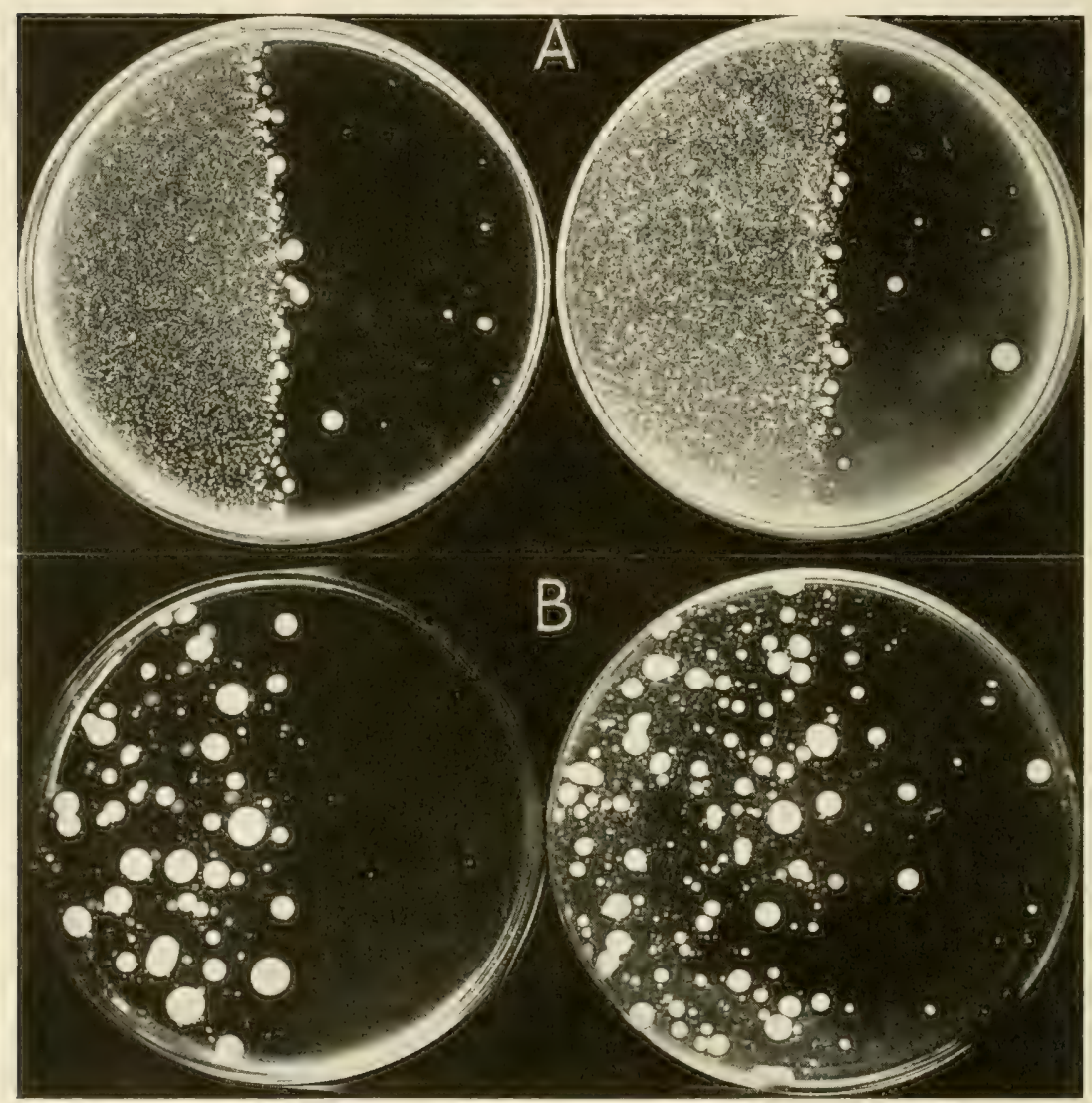

FIG. 249.-Agar-poured plates of Bacterium malvacearum showing appearance 5 days after exposure (on ice) of the right half to bright sunlight for 2 minutes: A. Bacteria isolated from Turkestan cotton in $1909 ; B$. Bacteria isolated from Arizona cotton in 1914.

is then Naples yellow to wax-yellow $\left(\mathrm{R}_{1}\right)$, becoming brownish with age. The potato grays more or less, and the starch is consumed (see No. II and No. VIII). Experiment repeated in 1915 using the Arizona organism with the same result. The 
growth was copious, smooth, glistening and the color after a month was mostly between Ridgway's light cadmium and his empire yellow $\left(R_{2}\right)$, the dark stain ranging from his orange citrine in the slime to his mouse gray in the potato, and all but an insignificant residue of the starch was consumed.

In peptone-beef bouillon there is a moderate and persistent clouding, the best growth at first in unshaken tubes being at the top. There is a pale yellow rim and a moderate maize yellow precipitate. There are some pseudozoögloeae.

It grows moderately in Uschinsky's solution with a pale rim and considerable flocculence. It grows feebly or not at all in Cohn's solution.

The thermal death-point lies between $50^{\circ}$ and $51^{\circ} \mathrm{C}$. but is never $50^{\circ} \mathrm{C}$. (tests of 1919 in +15 peptone beef bouillon). The maximum temperature lies between $36^{\circ}$ and $38^{\circ} \mathrm{C}^{\circ}$. - -repeated in 1919 it grew at $35^{\circ}$ and not at $37^{\circ}$ and after 14 days at $37^{\circ}$ the tubes did not cloud at room temperature ( 6 days). It grows slowly at $10^{\circ} \mathrm{C}$. There was no growth in +15 peptone-beef bouillon in 6 weeks at $8^{\circ} \mathrm{C}$. Repeated in 1919 faint clouding after 10 days at $8.5^{\circ}$ to $10.5^{\circ} \mathrm{C}$; t the tubes at $6^{\circ}$ to $8^{\circ} \mathrm{C}$. remained clear for 21 days (as long as tested).

Tubes of plain milk inoculated in 1919 gave after 43 days the result shown in Fig. 259. At this time there were no tyrosin crystals. The whey, sterilized at $54^{\circ} \mathrm{C}$, or kept in the thermostat at $38-44^{\circ} \mathrm{C}$., caused prompt precipitation of the curd when added to sterile milk and subsequent transfers from these tubes to suitable media showed them to be free from bacteria.

In litmus milk the litmus is blued and the casein is thrown down slowly. The litmus may be reduced, but is not reddened, so that the existence of a lab ferment is inferred. The precipitated curd is not promptly digested but subsequently most of it disappears (2 months), and tyrosin crystals not visible at first (30 to 40 days) are then abundant (Fig. 260). Compare with No. II (Fig. 93).

This organism is extremely sensitive to light, even 2-minute exposures (on ice) being enough to clear the sunlit one-half of thickly sown agar-poured plates, and even 1-minute exposures 


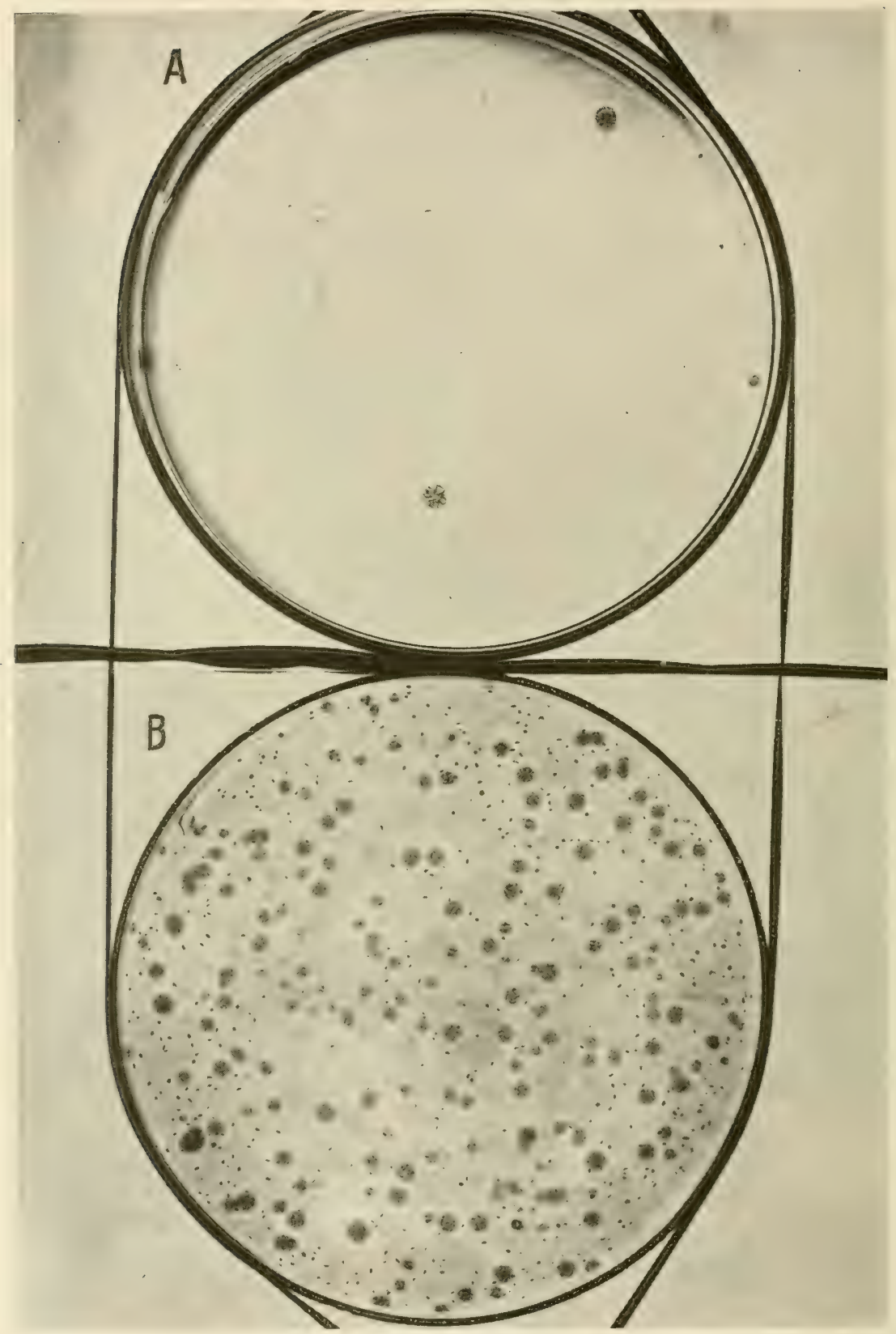

Fig. 250.-Agar putured plates showing effect of freezing on Bacterium malvacearum: Arizona organism. B. Check plate. A. Same quantity of the culture, sowed after freezing for 1 hour in +15 peptone-beef bouillon. 
destroyed the greater number (Turkestan organism; Arizona organism). Contrast with No. VIII.

In various ways this organism resembles Bacterium campestre, Bacterium phaseoli and Bacterium citri but I did not succeed in cross-inoculating it to cabbages, to beans or to oranges. Fur-

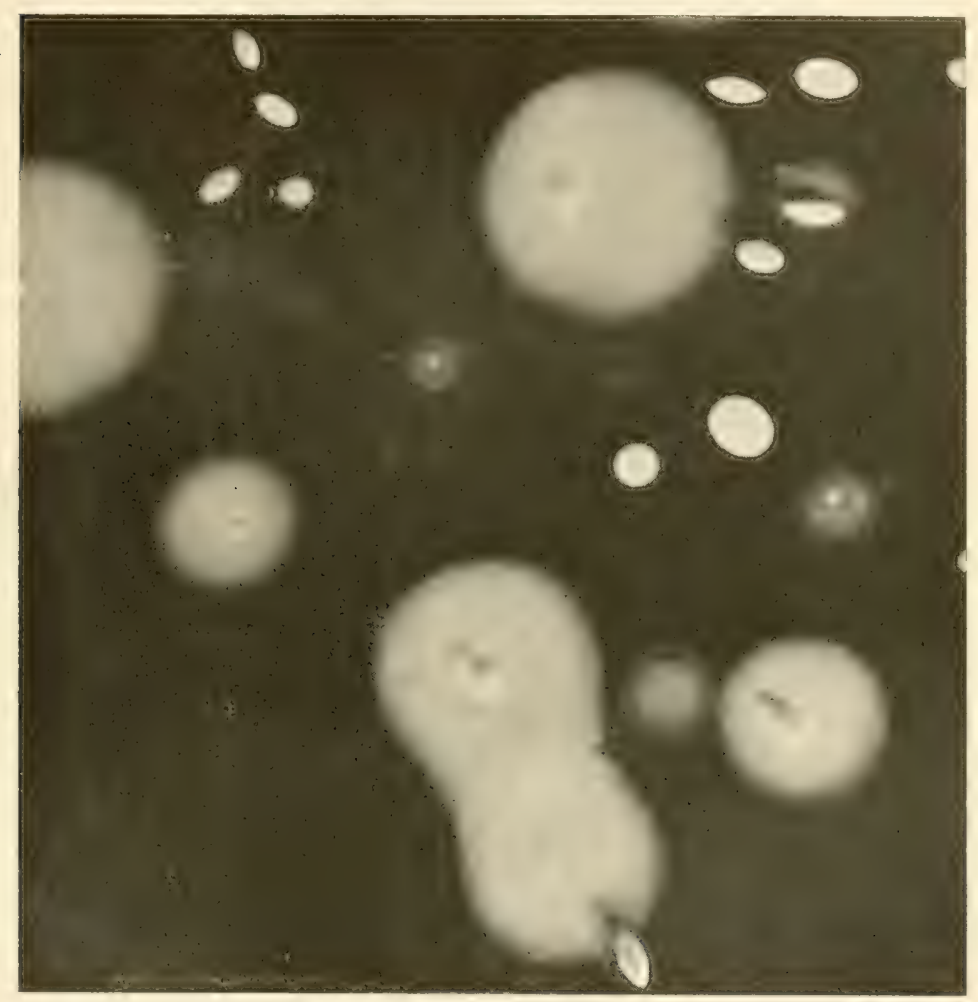

Fig. 251.-Part of an agar-poured plate of Bacterium malvacearum enlarged to show fugitive motcling of the surface colonies. From one of the leaf spots shown in Fig. 240. Time, third day. Temperature $23^{\circ} \mathrm{C}$. Plating of March 20, 1915. $\times 14$.

ther comparisons should be made not only with Bacterium campestre, Bacterium citri, and Bacterium phaseoli, but also with Bacterium pruni, Bacterium juglandis, and Bacterium translucens, all of which are closely related. Indeed, some of these names are perhaps synonyms, but this can be settled only by many crossinoculations and much further study. 
Technic.-Sometimes there are difficulties in the way of isolating this organism, owing to the occurrence on the cotton plant of yellow saprophytes which somewhat resemble it. These are often found in the spots or on the surface and are perplexing

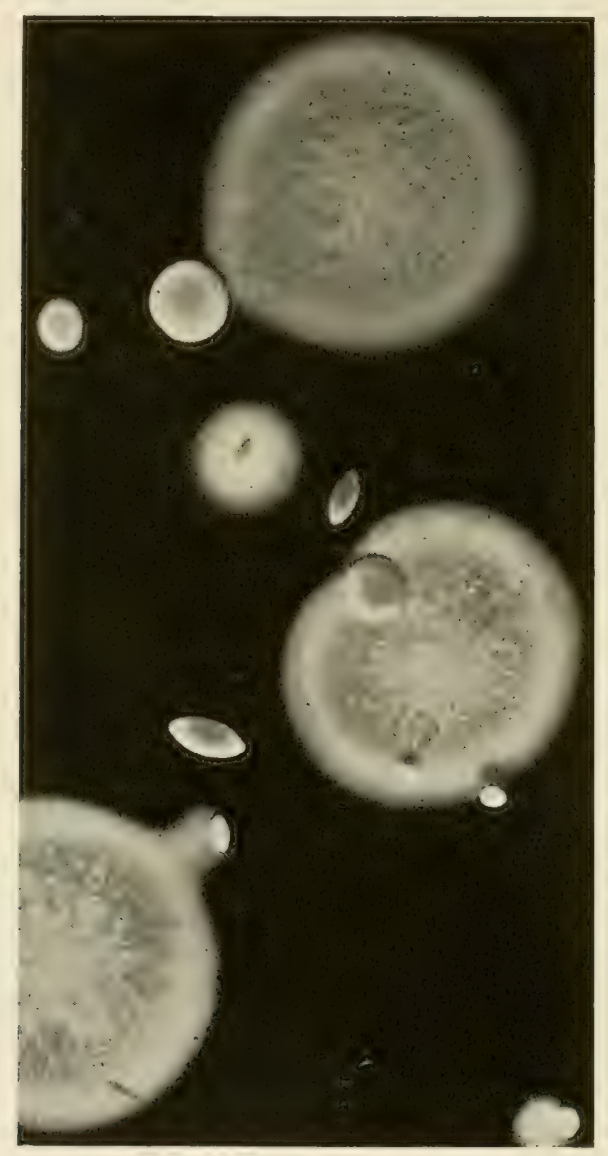

FIG, 252.-Bacterium malvacearum: part of an agar-poured plate, enlarged to show fugitive mottling of the surface colonies. From one of the leaf spots shown in Fig. 240. Time, third day. Temperature $23^{\circ} \mathrm{C}$. Plating of March $22,1915 . \times 14$.

on the agar-poured plates. For this reason great care should be taken to make the isolations from clean leaves, stems and bolls in early stages of the disease, selecting typical-looking spots which have not yet passed beyond the translucent watery- 
looking stage of the disease. Do any of the accompanying saprophytes favor the growth of the parasite?

Only yellow colonies should be considered. Moreover all rellow ones that have a wrinkled surface, all that reduce nitrates. redden litmus milk or fail to throw down the casein must be rejected on the start. Potato cylinders also should be used as a means of separation, all orange-colored and slow-growing, nonstarch-consuming organisms being rejected. On agar-poured plates besides the white colonies and wrinkled yellow ones, circular pale yellow colonies of two or more types may appear. Those having a smooth surface and a mottled interior, i.e., light and dark aggregations, are likely to be the right organism, especially if they give a copious pale yellow growth on potato and precipitate casein from litmus milk without development of an acid. Those pale yellow surface colonies having from the beginning (2d day, $3 \mathrm{~d}$ day) a uniform inner structure and yielding a scanty creamy growth on the potato cylinders should be rejected. Fortunately, young rapidly growing cotton plants are quite susceptible and sub-cultures from the rarious colonies may be tested out quickly, by means of stem and leaf inoculations, care being taken, if the sprayed plants have been shut up over-long in cages, that suffocation spots are not mistaken for bacterial spots, since the former may occur. Sections (Fig. 261) will quickly show whether or not the spots contain bacteria in numbers.

Cotton for the inoculations should be planted in a warm hothouse six weeks to two months before it is needed. Many varieties are subject to the disease. I have had good success with inoculations on Rivers, sunflower, Durango and ('olumbia. The disease is readily induced on young rapidly growing stems and bolls by delicate needle punctures introducing the parasite, and sereral times I have produced it on leaves simply by gently rubbing my infected fingers over their undersurface (Fig. 241aa). Generally, however, for the leaf infections, the spraying of water suspensions of young agar-streak cultures upon plants shut up 48 hours in spraying cages will prove most satisfactory. Cages are not necessary, however. I have not seen the leaf spots due to stomatal infections appear earlier than toward the end of the 
second week. As in many other diseases (see No. V), once a few plants are infected, the gardener's hose is a ready means of distribution to others (Fig. 255), just as a driving rain (Faulwetter) is in the open field.

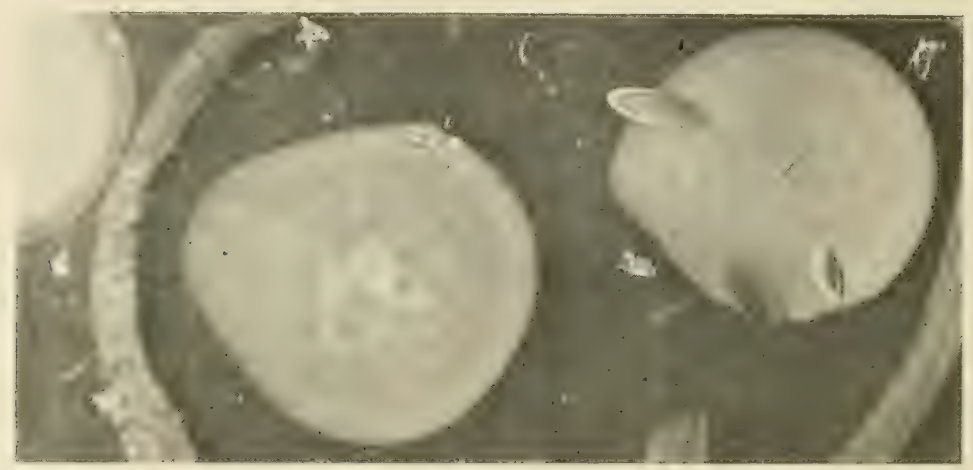

FIG. 253.-Photograph of three surface colonies of Bacterium malvacearum, the middle and right of which were windorved conspicuously on the fourth day (see Fig. 256). These colonies also show the pale rim. Several buried colonies are also visible. $\times 7$. The lines are pencil marks on the bottom of the plate indicating to the photographer the colonies to be photographed.

Before trying isolations from leaf-spots we always plunge the leaf momentarily into 1:1000 mercuric chlorid water to

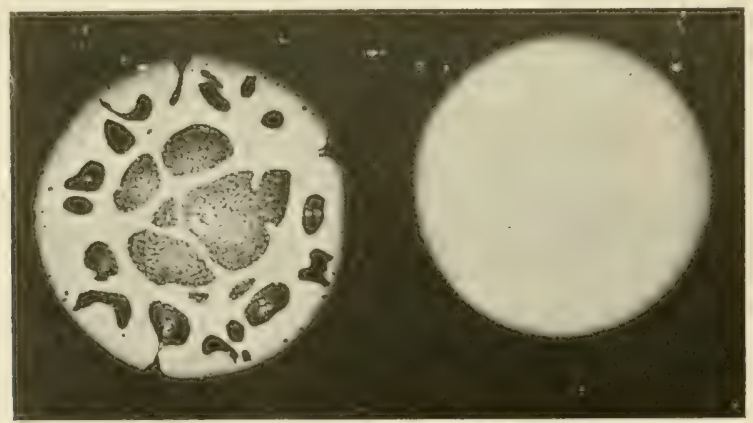

Fig. 254.-Bacterium malvacearum. Agar-poured plate of March 22, 1915. Photographed March 25. Typical transient mottling. From the Arizona cotton. $\times 14$.

discourage surface organisms, but the exposure should never be for more than 20 to 60 seconds. The piece may then be thrown into sterile water and rinsed (always briefly, lest the poison 
be removed and the surface bacteria restored to a growing condition), then the spot is crushed thoroughly in bouillon and, after a half-hour's delay with more or less shaking to diffuse the bacteria, the plates may be poured.

\section{Determine}

For the organism. Morphology.-Size in microns, form (stain with Ziehl's carbol fuchsin or amyl (Gram), aggregation of elements, motility (margin of a hanging drop), number and

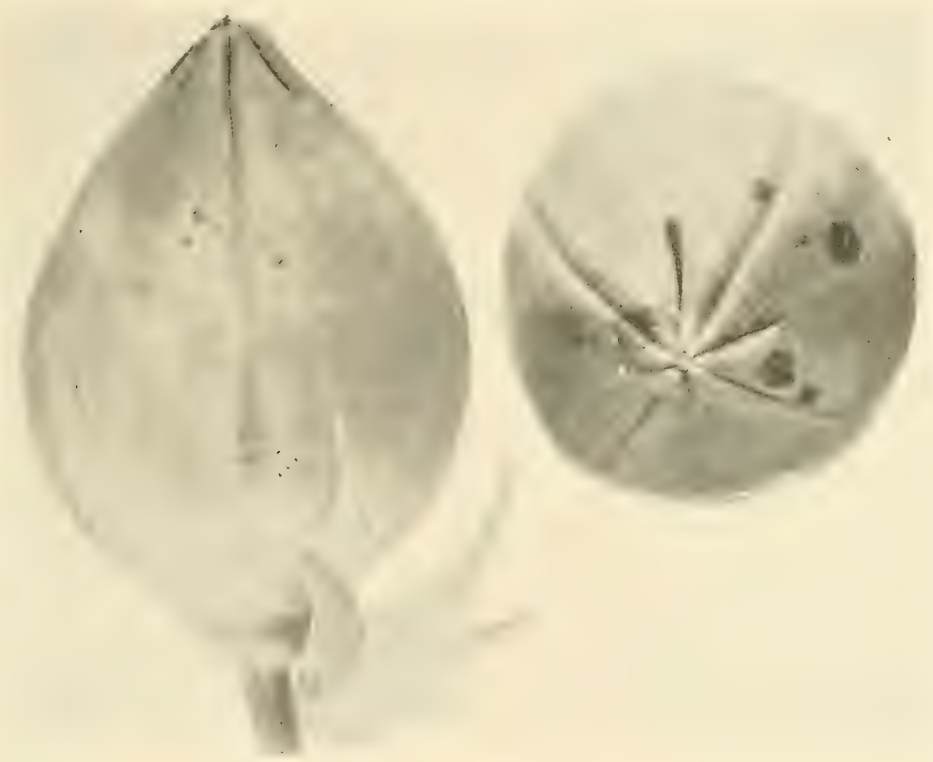

FIg. 255.-Accidental inoculation of Bacterium malvacearum on cotton bolls by spraying, July 7, 1915. Photographed August 2. These are secondary infections by means of the gardener's hose and are approximately 2 and 3 weeks old.

location of flagella (van Ermengem's silver-nitrate stain), absence of endospores (heat, stains), presence or absence of capsule (Ribbert's capsule stain), occurrence of involution forms, reaction to Gram's stain, acid-fast stain.

Cultural Characters.-On nutrient agar, on gelatin $(+10)$, on Löffler's solidified blood serum, on steamed potato, in 


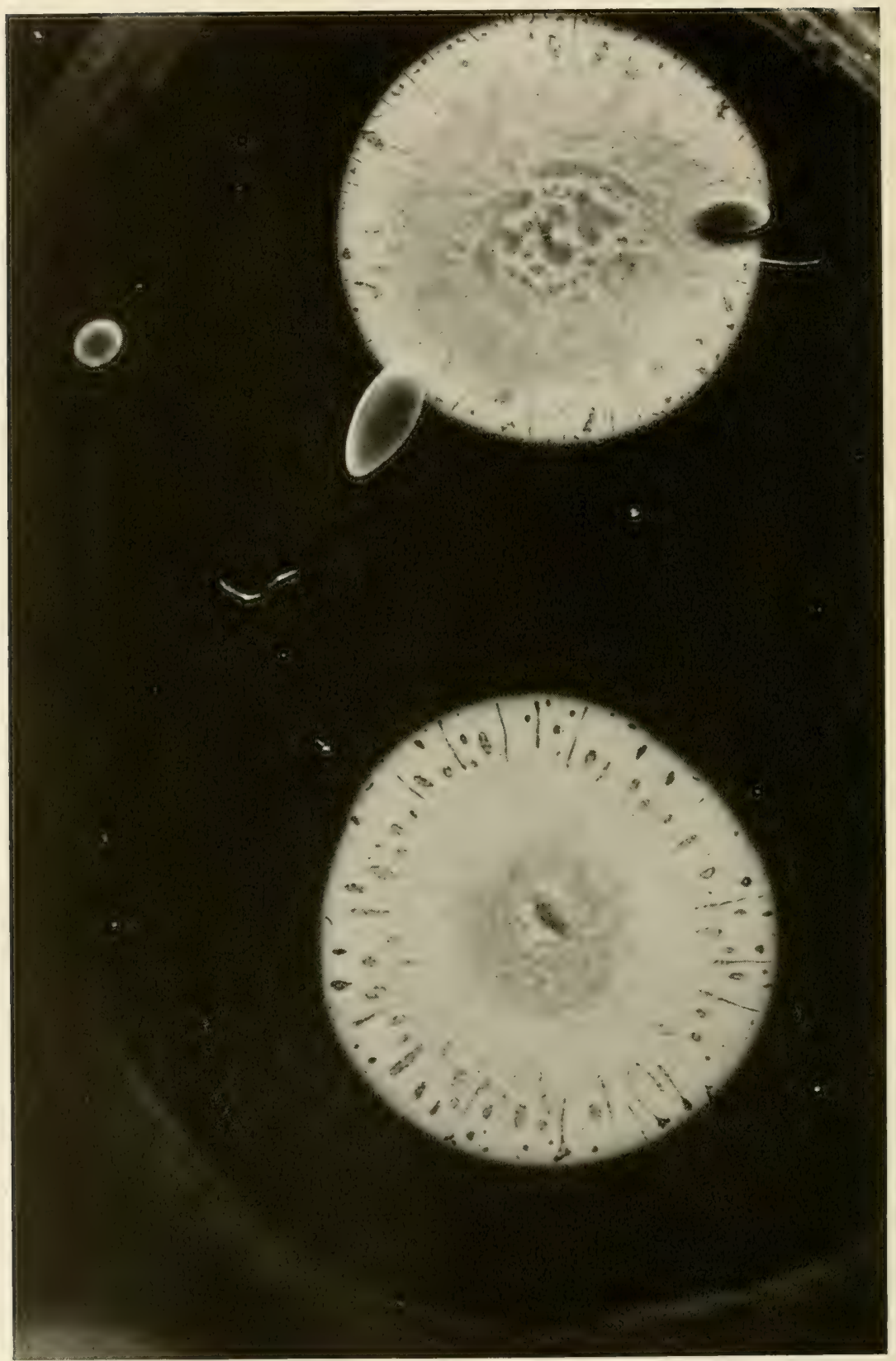

FIG. 256.-Buried and surface (rose-windowed) colonies of Bacterium malvacearum on an agar-poured plate. Photographed March 24, $1915 . \times 14$. For appearance of these colonies two days later see Fig. 253. 
peptone bouillon, nitrate bouillon, Cohn's solution, Tschinsky's solution, Fermi's solution, litmus milk, peptone water in fermentation tubes with various pure sugars and alcohols. Compare with No. II and No. VIII.

Non-nutritional Environment.-What is the optimum temperature for growth? the maximum? the minimum? Can you get any growth at $1^{\circ} \mathrm{C}$. or at $37^{\circ} \mathrm{C}$.? Compare critically with No. VIII. Effect of sunlight (try first a 2-minute exposure on a bright day)? Effect of dry air (use 2-day peptone-bouillon cultures spread on thin sterile cover-glasses - begin at 6 hours;

Fig. 257.-Spatulate, finger-like out-growths of a gelatin colony of Bacterium malvacearum.

thereafter drop some of the infected covers into suitable bouillon every 6 hours - Keep covers in a dark place). Effect of freezing? of weak acids? of sodium hydrate? of chloroform in bouillon? Maximum toleration of sodium chlorid in bouillon? Length of time organism will remain alive inside of leaf-spots, or bollspots? or in cotton stems? It is a very considerable period.

For the disease. Signs.-How soon does the disease appear on the inoculated (sprayed or smeared) leaves? How soon on punctured bolls or stems? How soon do the spots change from translucent to brown? Are leaves or bolls commonly thrown off as a result of infection? Inoculate very young 
bolls and watch. Determine the effect of the disease on young seedlings, inoculating cotyledons and hypocotyl by means of needle pricks. Describe the disease, but not out of this book.

Histology.--Embed, section and stain young leaf-spots, 18th day and earlier. Can you find distinct evidence of stoma-

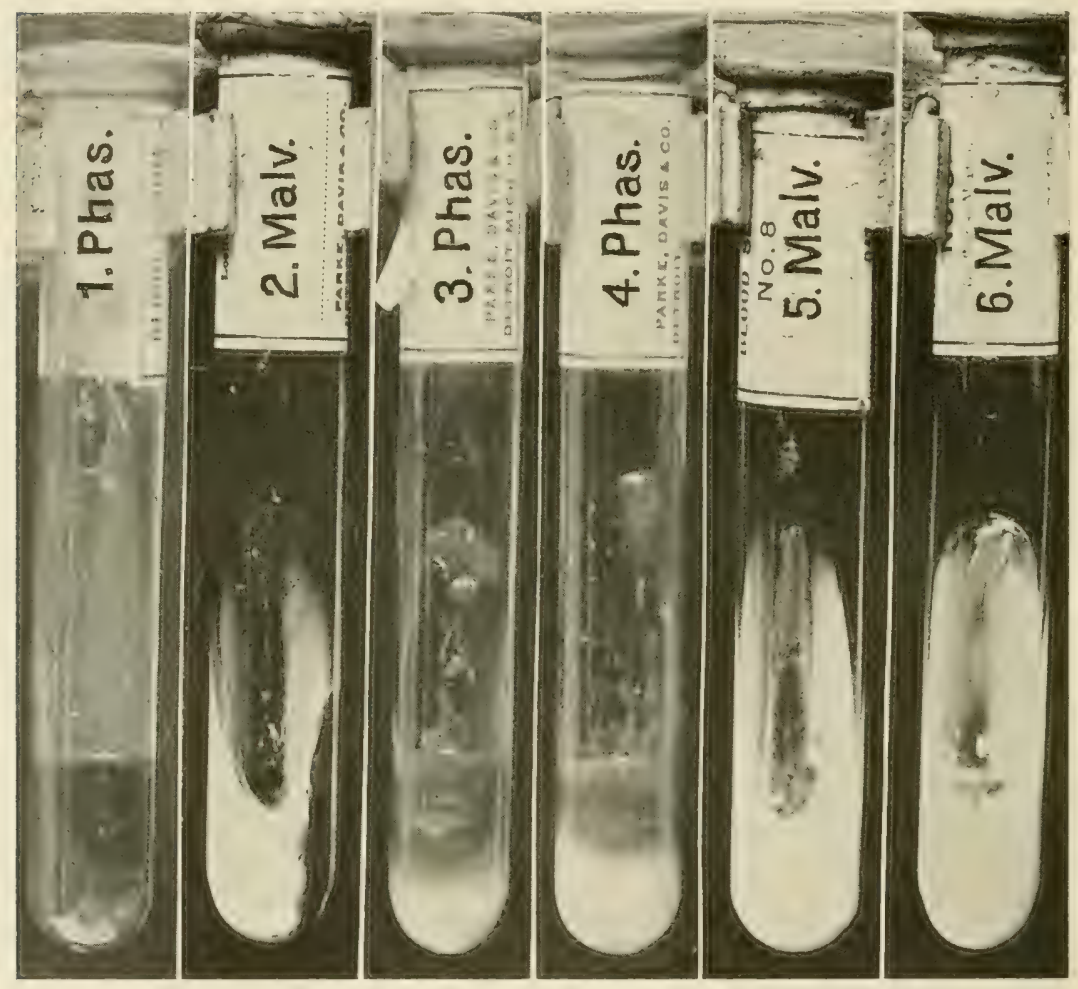

Frg, 258.-Tubes of Löffler's solidified blood serum inoculated from bouillon with Bacterium malvacearum (Arizona organism) and with Bacterium phaseoli (Idaho organism) for comparison; Nos. 1 and 2 streaked April 12; 3 to 6 streaked April 21. Photographed May 3, 1919. No. 1, liquefied; Nos. 3 and 4, partly liquefied; Nos. 2, 5 and 6 not liquefied. No. 2 is drying out on right side.

tal infection? Stain with earbol fuchsin or amyl Gram. In the same way study early stages of the disease on stems and bolls. Does a brown stain accompany this disease?

Variability.-Does this disease ever kill the plant? Ever render it unprofitable? Attack some varieties to the exclusion of others? Appear to be much worse some seasons 
than others? Is it worse on lowlands than on uplands? Is it modified in any way by methods of culture? Are fungi associated with it? Try mixed infections. Study the effect of the disease on seedlings in the hothouse and in the field.

Transmission.- This disease is probably transmitted on the seed, but we have as yet no experimental proof of this. Can you help to clear up the situation? Once established in the field, is it ever spread except by the wind during rain storms?

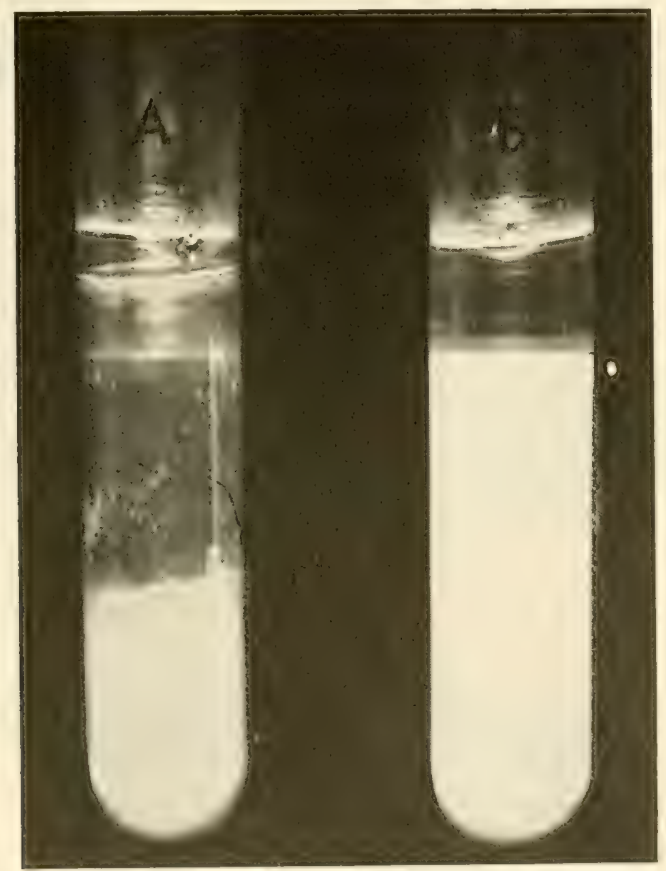

FIG. 259.-A. Bacterium malvacearum. Col. 4 (Arizona isolation), after 43 days in milk at $25^{\circ} \mathrm{C}$. Casein precipitated by a lab ferment. $B$. Check tube. Milk dried out about one-fourth.

Read Faulwetter's paper and look for wind-driven paths of infection. Kellerman reports similar paths of citrus canker.

Does the disease occur on weeds, or on any other cultivated plants? Try inoculations on okra, abutilon and hollyhock by spraying. 


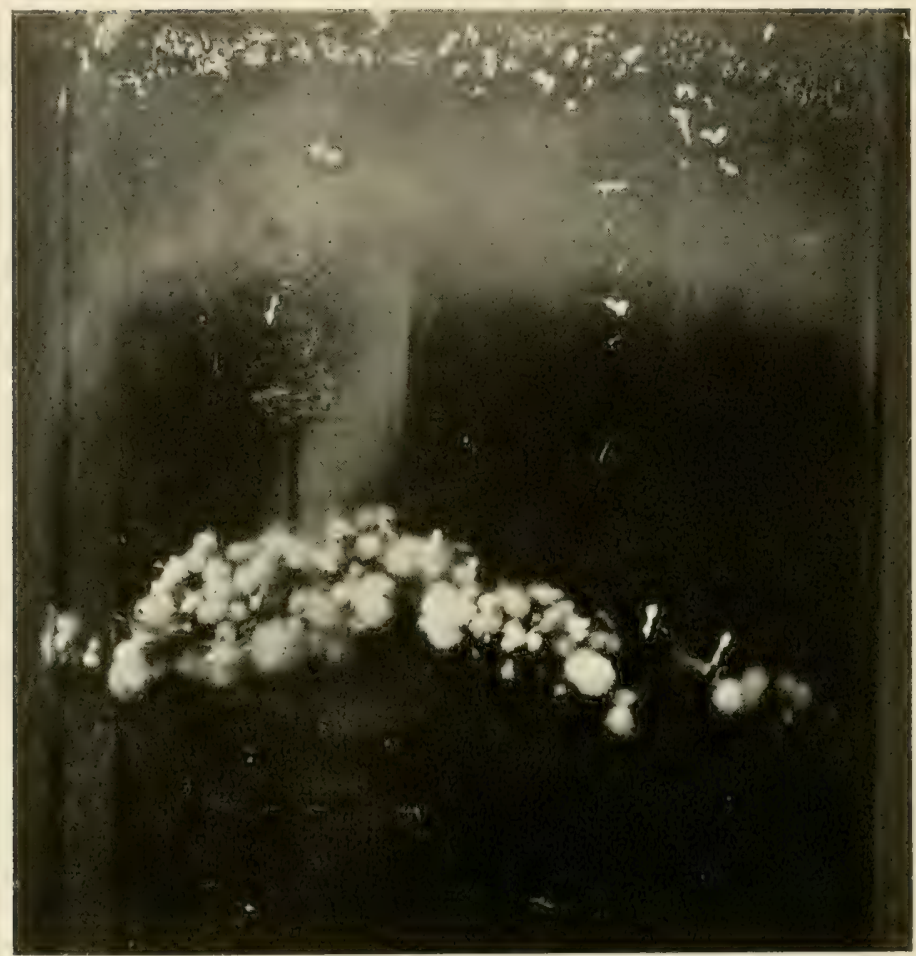

Frg. 260.-Tyrosin crystals from an old litmus-milk culture of Bacterium malvacearum. Arizona cotton, culture of March 20, 1915. Compare with Fig. 93. Photographed June $3 . \times 5$.

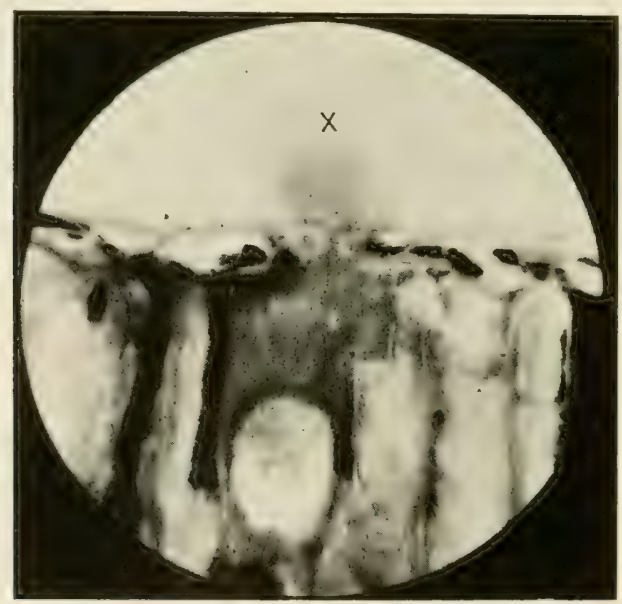

Fig. 261. - Section through an early stage of an angular spot on a cotton leaf, showing the bacteria (at $X$ ) extruding through a stoma in the upper epidermis. Dillon, S. C., 1900. 


\section{LITERATURE}

The writer named the organism Pseudomonas malvacearum in 1901 (Bull. 28, Div. Veg. Phys, and Path., U. S. Dept. of Agriculture, p. 153) but this is the first time he has carefully described it. (This chapter was written in 1915 previous to the appearance of Faulwetter's papers, which see.) There are references to the disease in various Experiment Station publications.

Read especially "The Rots of the Cotton Boll" by C. W. Edgerton (La. Agr. Exp. Sta. Bull. No. 137, Baton Rouge, Dec., 1912 ) and "Dissemination of Angular Leaf Spot of Cotton," by R. C. Faulwetter (Jour. Agr. Research, March 19, 1917, pp. 457-475); also by the same author "Physiology of Bacterium malvacearum Smith" (27 Ann. Report, S. C. Exp. Sta., 1917).

Consult also "Bacteria in Relation to Plant Diseases," Vol. I (1905), Figs. 80 and 118, and Vol. II (1911), Fig. 18 and statements in text (See Index). 


\section{THE MULBERRY BLIGHT}

Type.-This is a blight in many respects resembling fire blight of the pear (No. XII) but slower in its action and with a correspondingly greater tendency to spotting and distortion of the leaves (Figs. 262, 263), in which it resembles the walnut blight, and the leaf-spot of beans (No. VIII). Dark, sunken, longitudinal stripes preceded and bordered by a translucent area also appear on the young shoots. These sunken spots often show a whitish or yellowish bacterial ooze, drying glossy. If the surface is dry this ooze often exudes from the lenticels in the form of cirri (Fig. 264). In such young shoots both wood and bark are invaded by the bacteria, and the end of the disease is either shriveling and death of the shoots (Figs. 265 to 267), or a curved one-sided growth. As in pear blight, we have to do, primarily, with a bark disease (Figs. 268, 269). The disease usually begins in the shoots of the season (Fig. 270), but the blight frequently extends beyond these, especially into shoots of the previous year. On the older parts the disease occurs in the form of cankerous patches. As in fire-blight of the pear, the tendency of the bacteria to ooze to the surface is strong.

On the leaves there are numerous coalescing and slowly enlarging spots which are water-soaked in appearance at first, then brown or black, the surrounding tissues becoming yellow. The bacteria occupy the intercellular spaces and form cavities (Figs. 271, 272B). On the midrib and veins dark sunken spots appear, similar to those on the shoots. Leaves attacked early in their development become variously distorted (see also No. VIII).

So far as known, mulberry trees are seldom or never killed 
outright by this disease (except sometimes nursery stock), but the trees often become ragged, stunted, and unprofitable. As in fire-blight on the apple, the crown of the tree may be spotted all over with conspicuous dead twigs bearing brown leaves.

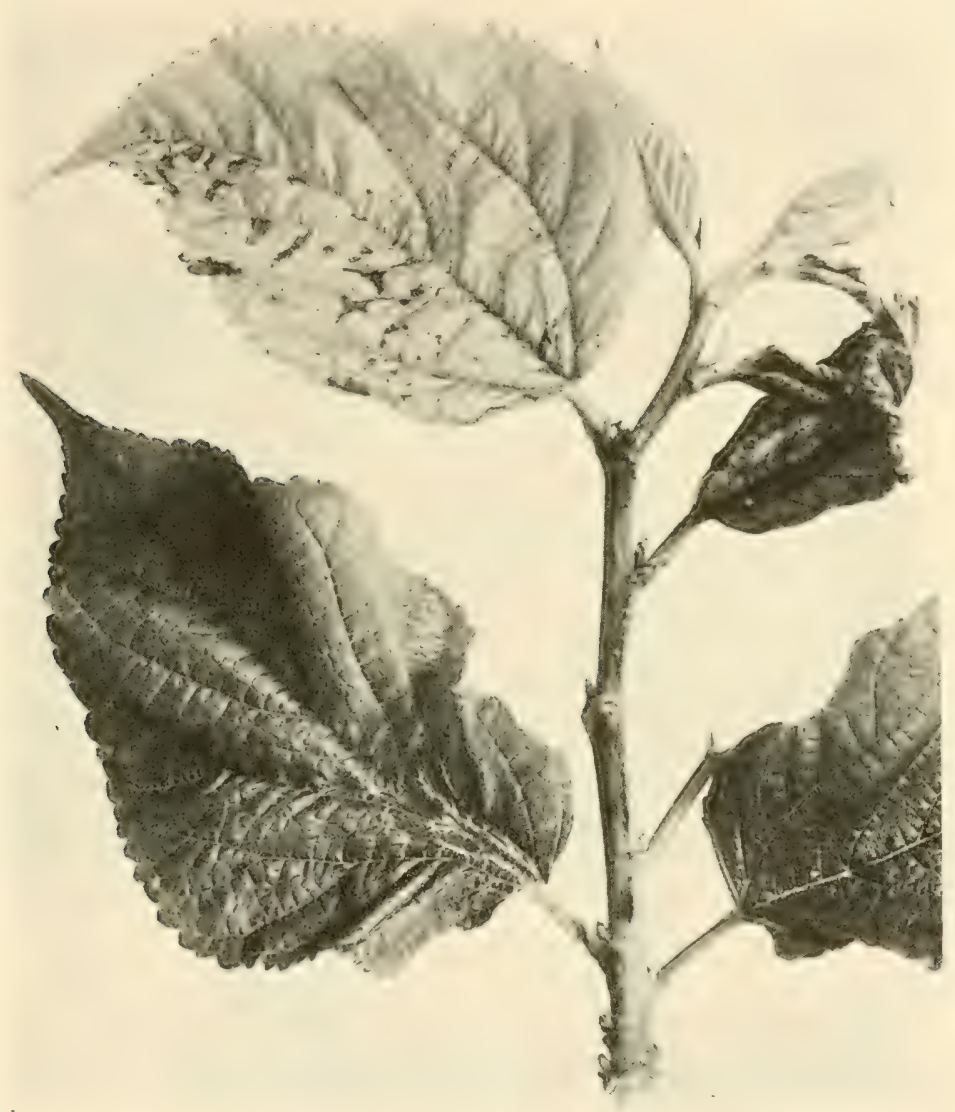

FIG. 262.-A mulberry shoot 9 days after inoculation with Bacterium mori. Shows dark sunken places on the stem (where pricked); younger leaves shriveling; older leaves spotted and distorted. Dept. of Agric. hothouse, Jan. 13, 1909.

The disease prevails on various kinds of mulberry, including the Russian. It cannot be produced by inoculating with the pear-blight organism.

Its exact geographical distribution is not known. It occurs in various parts of the United States (East, South, and West), 
and $I$ have seen it in France. It is very common also in South Africa (Miss Ethel M. Doidge). Prof. Gentaro Yamada, who has seen Arnaud's experiments in Paris, tells me that the disease is common on the mulberry in Japan. It probably occurs also in Italy, Russia, and Australia. The doubt about Italy, where for a long time the same or a similar disease has been known, is one concerning exact identity. Several Italian pathologists have studied the Italian disease but I am inclined to doubt the value of their bacteriological findings; at any rate they have ascribed the disease to Bacillus cubonianus Macchiatti,

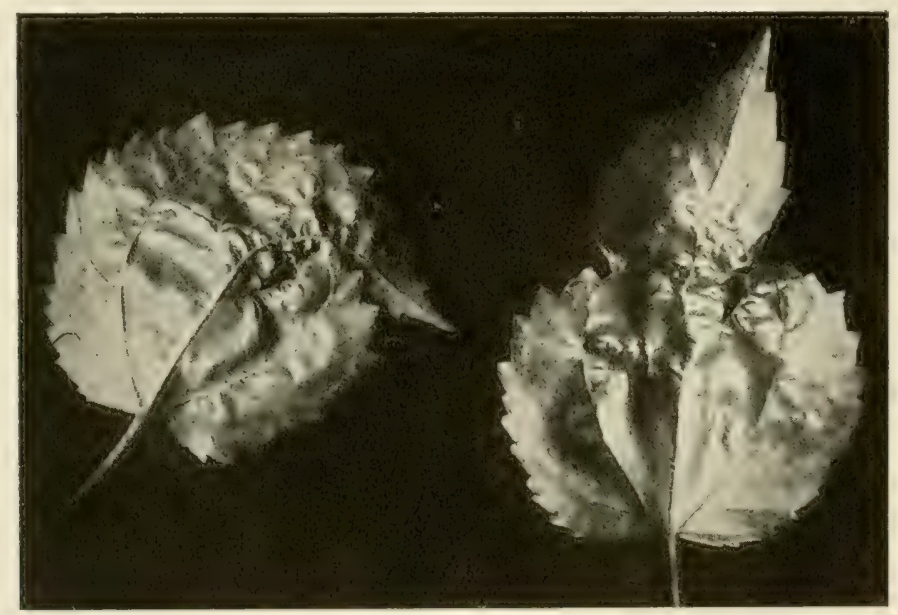

FIG. 263.-Distortion of South African mulberry leaves due to Bacterium mori. After Ethel M. Doidge.

a liquefying, yellow schizomycete. Yellow bacteria are very common on mulberry trees and are often present in the diseased areas, but are not the cause of the disease now under consideration.

Cause.-This disease is due to Bacterium mori Boyer and Lambert emend. EFS.

Here some introductory remarks are necessary on the problem of what to do with an old name when it has been given without a proper characterization. This problem is of ten a difficult one. Always, if possible, I think the first name should be retained by the pathologist. It cannot be, however, especially 
in the absence of successful inoculations, if the author has tied it to definite characters incompatible with parasitism, and the organism in question is definitely parasitic. But sometimes, as in this instance, contradictory statements are made. In such cases I think we may retain the name and reject the contradictions pro-

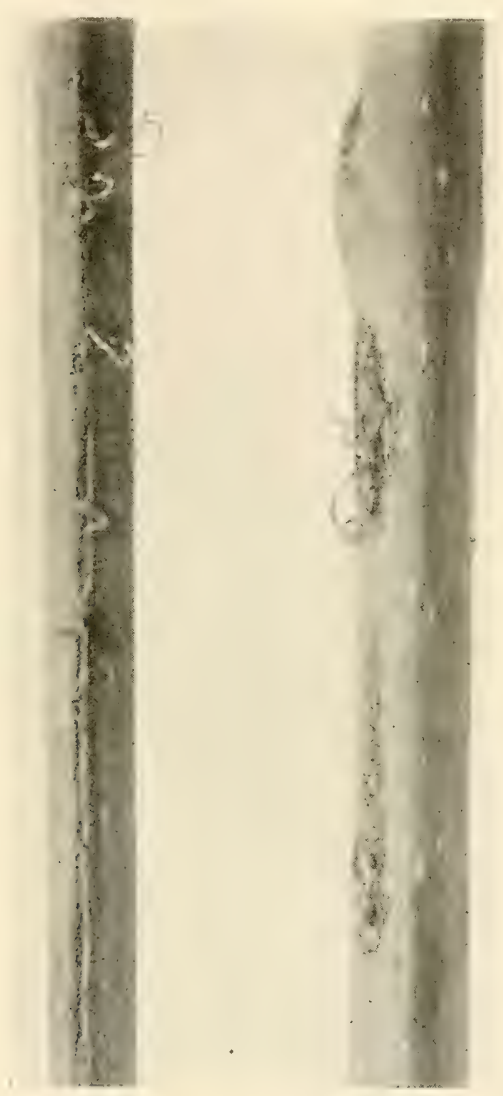

FIG. 264.-Diseased stems of mulberry showing extrusion of bacterial cirri (Bacterium mori) through lenticels. Inoculated January 4, 1909. Photographed January 11.

vided there is a definite history of pathogenicity connected with it. For these reasons I discard Bacterium oleae Archangeli for which there is no history of pathogenicity and no proper characterization (see No. XIII), and retain Bacterium mori Boyer and Lambert where there is a correct account of the 
disease and a definite history of successful inoculations but a very imperfect description of the parasite, one statement in which is erroneous.

Petri gives Bacterium mori B. and L. and Bacillus cubonianus Nacchiatti as synonyms of Ascobacterium luteum Babes. The latter may be, since it is described as yellow, capsulate and liquefying (sporiferous, however, according to Macchiatti) but the former cannot be since Boyer and Lambert obtained with it a disease due to a white organism. The mulberry blight of the Tnited States, of France, and of South Africa, is identical and is due to a non-liquefying white schizomycete, as proved inde-

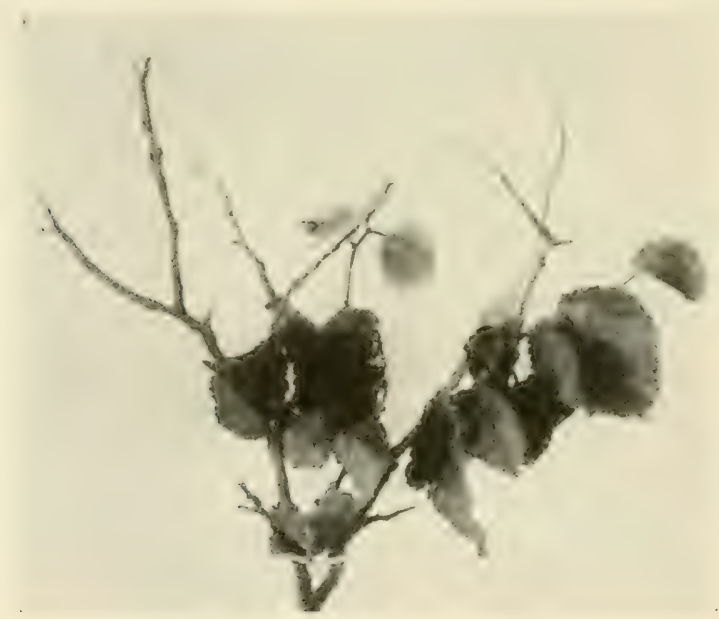

Frg. 265. - South African mulberry twigs killed by Bacterium mori. After Ethel M. Doidge.

pendently in the United States by simith, Rorer, and O'Gara, in France by Arnaud and by Smith, and in South Africa by Ethel M. Doidge. My observations of the signs and lesions of the disease made both in the United states and in France correspond closely to Boyer and Lambert's description of their disease. They state that with the parasite taken from blighting stems of the mulberry they produced the characteristic disease on the parenchyma and in the veins of the leaf, but their description of this parasite is limited to the bare statement that " Isolated and cultivated on the surface of artificial solid media, 
Bacterium mori gives hemispherical colonies which from hyalinewhite [correct statement] pass over into yellow [incorrect statement as a whole, although on some media, e.g., Löffler' solidified blood serum, it is somewhat yellowish]." They promised a farther report but made none. We may assume that they had mixed cultures on the start or soon after, viz., the parasite and

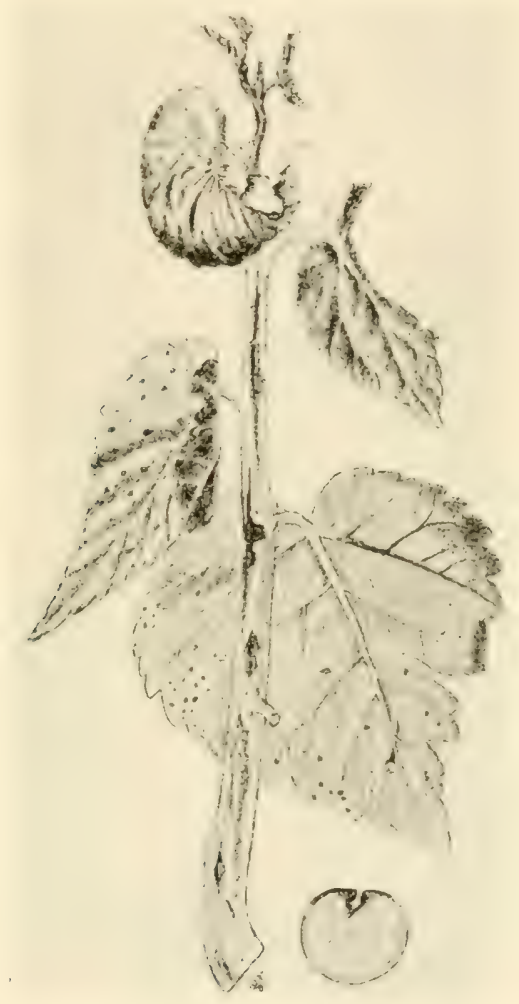

FIG. 266.-Branch of Morus nigra (black mulberry) attacked by Bacterium mori. Collected at Montpellier, France, in July, 1913. Section of axis at right. After Arnaud and Secrétain.

some yellow saprophyte, and that no further report was made because having turned their attention to the wrong organism they could not get any more infections and became confused. Non-parasitic yellow organisms are so common in the mulberry lesions that following Macchiatti's misleading statements it 
would be very easy to make this mistake in the early stages of the investigation. I made it myself.

Macchiatti's name Bacillus cubonianus, is earlier by one year than Boyer and Lambert s name, but unfortunately he made no inoculations and ascribed to his organism characters definitely excluding it from any rôle in the causation of the mulberry disease here described, i.e., formation of endospores, presence of a capsule, yellow color on media, liquefaction of gelatin, etc. His name, therefore. may be reserved for consideration in connection with the Italian disease, in case there should be one different from the French disease. Aceording to Macchiatti the behavior

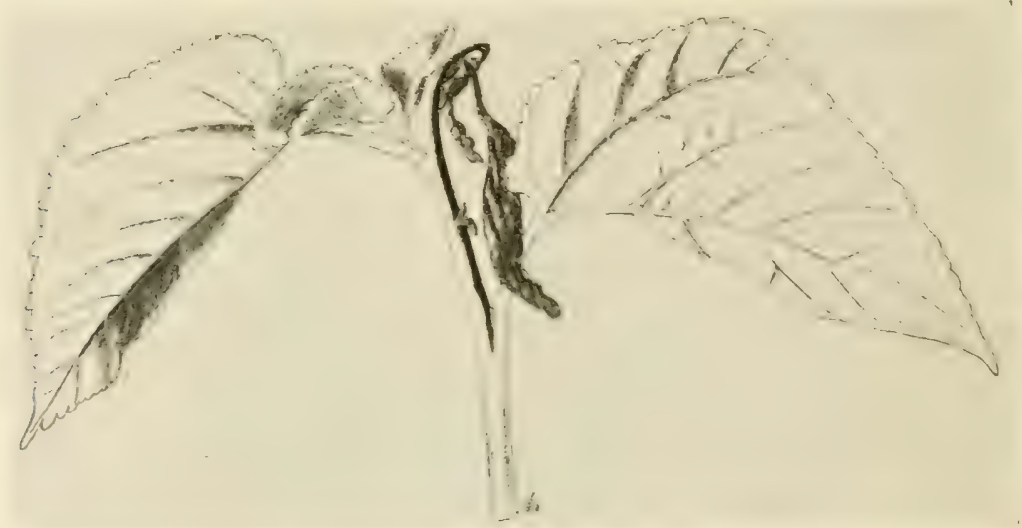

Fig. 267.-Branch of Morus alba (white mulberry) attacked by Bacterium mori. September, 1913. After Arnaud and Secrétain.

of his Bacillus cubonianus is very typical on potato where from the beginning there is a rapid growth with the formation of large. slightly raised, sinuous-margined colonies having a yellow color. which becomes ever more intense with age.

Boyer and Lambert's Bacterium mori is therefore the earliest arailable name for the cause of this disease. We must either accept that or devise some entirely new name. It is almost a nomen mudum, but not quite, since it was isolated from diseased (blighting) mulberries and has a definite if inconsiderable history of pathogenicity attached to it, as the result of successful inoculations. In my first paper (1910), therefore. I felt entirely free to retain their name and to attach to it a description drawn from 
the American species, believing the French organism could not be different from our own. In this belief I was entirely right, as subsequent observations and experiments have proved $1913 \%$

With these introductory comments we may proceed to a statement of the characters of Bacterium mori B. and L., drawn entirely from studies made in my laboratory, using cultures derived both from American and French sources.

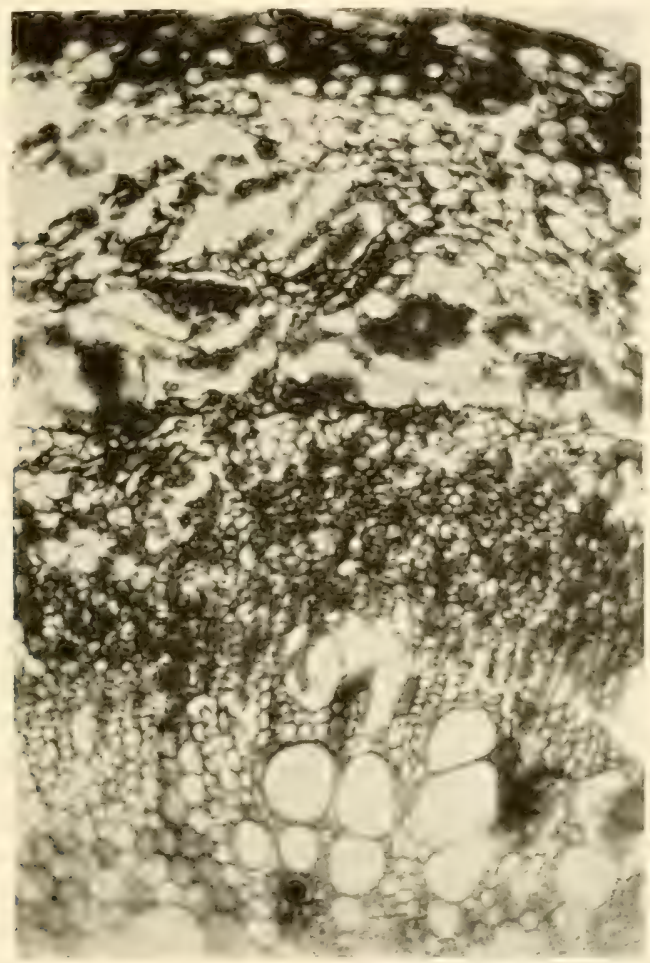

FrG. 268.-Cross-section of young stem of mulberry showing the inner cortex honevcombed by carities due to Bacterium miori. A natural infection from Arkansas. 1908. Medium magnification.

Bacterium mori B. and L. emend. EFS., is a white, non-riscid or slightly riscid (potato', slow-growing, non-sporiferous, noncapsulate, actively motile (1-7 polar flagella, usually 1-4), (iram-negative, non-gas-forming. strongly aërobic, non-liquefying (gelatin and Löfller's solidified blood serum), non-nitratereducing, acid-sensitive (C'ohn's solution), sunlight-sensitive, 
heat-sensitive, chloroform-tolerant in +15 peptone beef bouillon (grows unrestrictedly), dry air-tolerant (30 to 50 day's or more), sodium chlorid-tolerant (to 6 or 7 per cent in +15 peptone beef bouillon) non-coagulating (milk), casein translucing (milk is cleared as by No. IV), rod-shaped, paired, clumped or catenulate schizonycete, forming on the surface of +15 nutrient agar-poured plates slow-growing, translucent, white, circular, smooth, flat colonies, entire at first but becoming undulatemargined after some days, and haring for a time, like many other colonies, a reticulate or striate internal structure.

Growth on young agar-streaks moderate, white, odorless, translucent, spreading, flat, dull to shining, smooth, becoming finely granular; medium not stained. Contrast with No. IV.

Colonies on +10 beef-bouillon peptone gelatin slow-growing, white, flat, circular to irregular with lobate erose margins (compare with XIII). Growth in gelatin stabs filiform, best at top; no stain, no liquefaction.

Growth on Löffler's solidified blood serum, scanty to moderate, yellowish white. No liquefaction-not even after many days.

Growth on steamed potato moderate, spreading, flat, glistening, smooth, white to dirty-white (medium grayed, never blackened), action on the starch slight.

Growth in +15 peptonized beef broth always best at the top where a pellicle develops which fragments easily on shaking and sinks, forming a flocculent, turbid, odorless fluid (clear after 3 months).

Milk is not coagulated but becomes translucent (by some change in the casein); it is then strongly alkaline and not riscid. After 3 months and considerable evaporation the fluid is gelatinous and somewhat brownish (near saccardo's ochroleucous). Purple litmus milk becomes blue; there is never any acid reaction (compare with No. IV).

In Cohn's solution no growth or only a very slight growth (contrast with No. XIII).

In Uschinsky's solution a copious growth and a heavy fragile pellicle, sinking readily. Fluid bluish-fluorescent (5th to 10th day), not riscid. Repeated in 1919: uniformly well clouded 
on 4th day; best growth in top on 6th day when it was bluishfluorescent; many pseudozoögloeae; no distinct pellicle; after 6 weeks, greenish-fluorescent, very copious white precipitate and still hearily clourled (contrast with XIII); organism motile; no filaments observed.

In peptone water in fermentation tubes no clouding of the closed end with dextrose, saccharose, lactose, maltose, glycerin or mannit. Contrast with No. I.

Indol production is absent or feeble. Compare with No. VI.
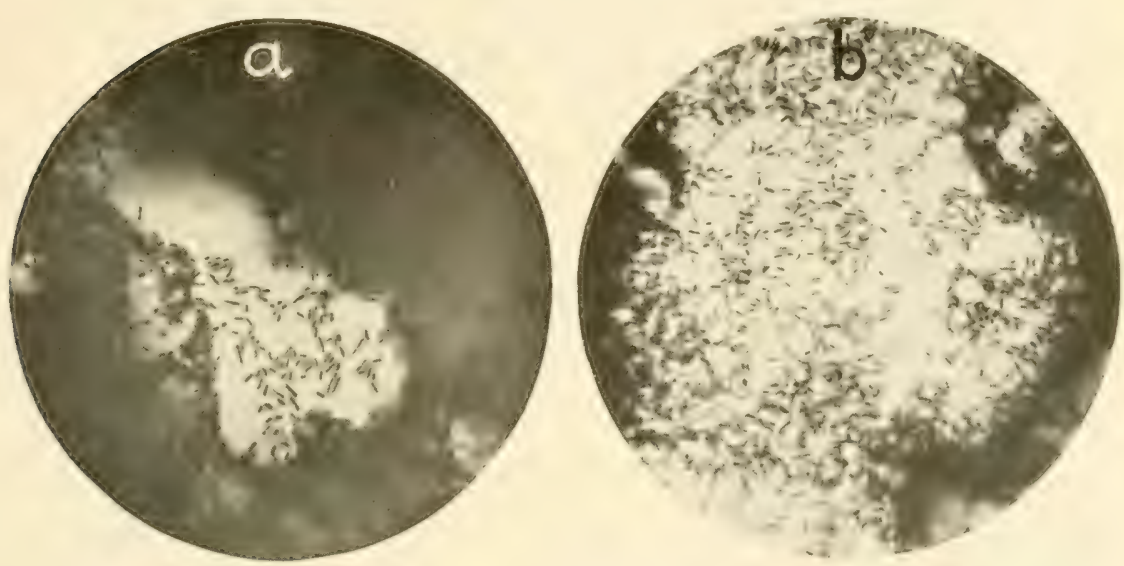

FiG. 269.-Bacteria of mulberry blight: $a$. Bacterial cavity in bark of the roung mulberry shoot shown in Fig. 268; most of the bacteria were washed away in making the preparation. Remnants of tissue on the periphery. Over-stained. $\times 1000$.

b. Center of small cavity in bark of a mulberry shoot inoculated on grouncls of the U. S. Department of Agriculture in 1910. $\times 800$ circa.

Grows from $1^{\circ} \mathrm{C}$. to $35^{\circ} \mathrm{C}$. but remains alive in bouillon for only a short time at the latter temperature. Thermal deathpoint about $51.5^{\circ} \mathrm{C}$.

Grew twice in +15 peptone bouillon containing 7 per cent sodium chlorid but would not tolerate 9 per cent. (Compare with No. VI and contrast with No. I.)

Pseudozoögloeae and involution forms occur.

On thin-sown agar plates all bacteria on the exposed side were killed by 36 minutes exposure to sunlight, bottom up on ice; 26 minutes killed nearly all. 


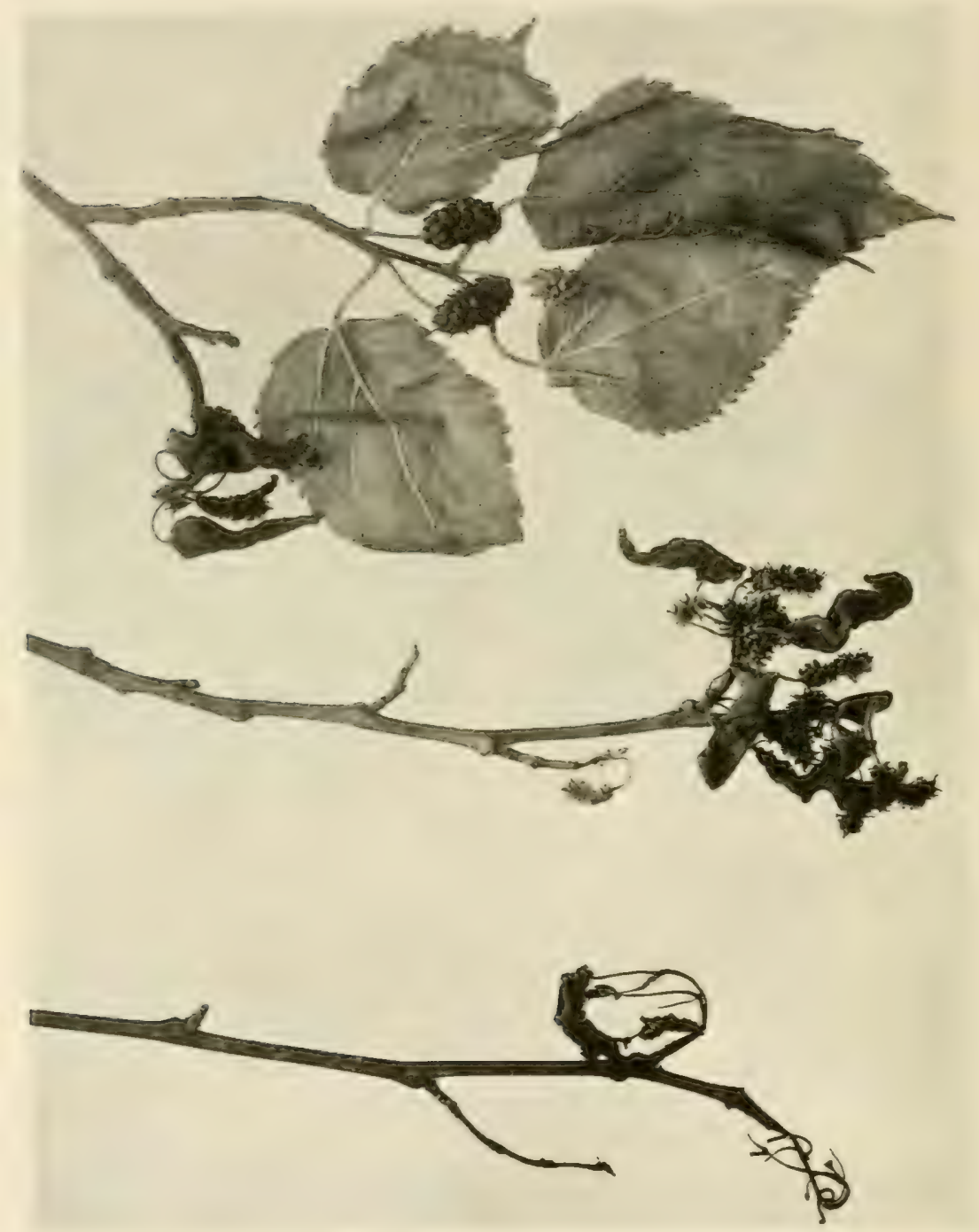

F16. 270.-Leaves and shoots of mulberry attacked by Bacterium mori. From Georgia. May, 1905. 1/2 nat. size. 
Bacterium mori does not lose virulence readily. Cultures of the Georgia organism Berchmans I and II carried along on culture media in my laboratory for 12 years (1908-1920) were still infectious. Contrast with Nos. IV and XIV.

Technic.-At first the writer isolated the wrong organism, owing to misplaced confidence in European statements respecting its color. All the rarious types of yellow colonies appearing on the agar-poured plates were subcultured and inoculated into growing mulberry shoots, but to no purpose. The yellow bacteria would not produce the disease. In this way a whole summer was wasted. The following year, howerer, no difficuity was experienced in plating out an actively pathogenic white schizomycete.

For the isolations the student should select, from stem or leaf, clean parts recently diseased and swarming with the bacteria as determined by a microscopic examination. The surface of the part selected should be flamed lightly. if stem: or plunged for a minute or two into 1:1000 mercuric chlorid water, if part of a leaf, and then rinsed lightly in sterile mater long soaking in water removes this poison and may resuscitate the surface bacteria which one desires to kill or to keep dormant for a day or two; on the contrary a little of the surface poison carried over into the bouillon dnes no harms. If it is a leaf-spot. the piece may now be thrown into a tube of bouillon and crushed with a sterile glass rod. If stem, the diseased part should be scraped out with a cold sterile instrument and thrown into bouillon. In either case the tissue should be allowed to soak for an hour before the dilutions are made and the plates poured. Plates should be sowm both from the original tube and from the dilutions, seeding some hearily and other: lightly. All yellow colonies appearing on the plates should be rejected unless it is desired to study also the saprophytic followers of the parasite. For this reason it is best to keep the agar-poured plates under observation several days before making transfers, since the yellow colonies are frequently quite pale at first and if picked off when small or from plates sown too thickly might be mistaken for white colonies.

For inoculation, select young growing leares and shoots, 


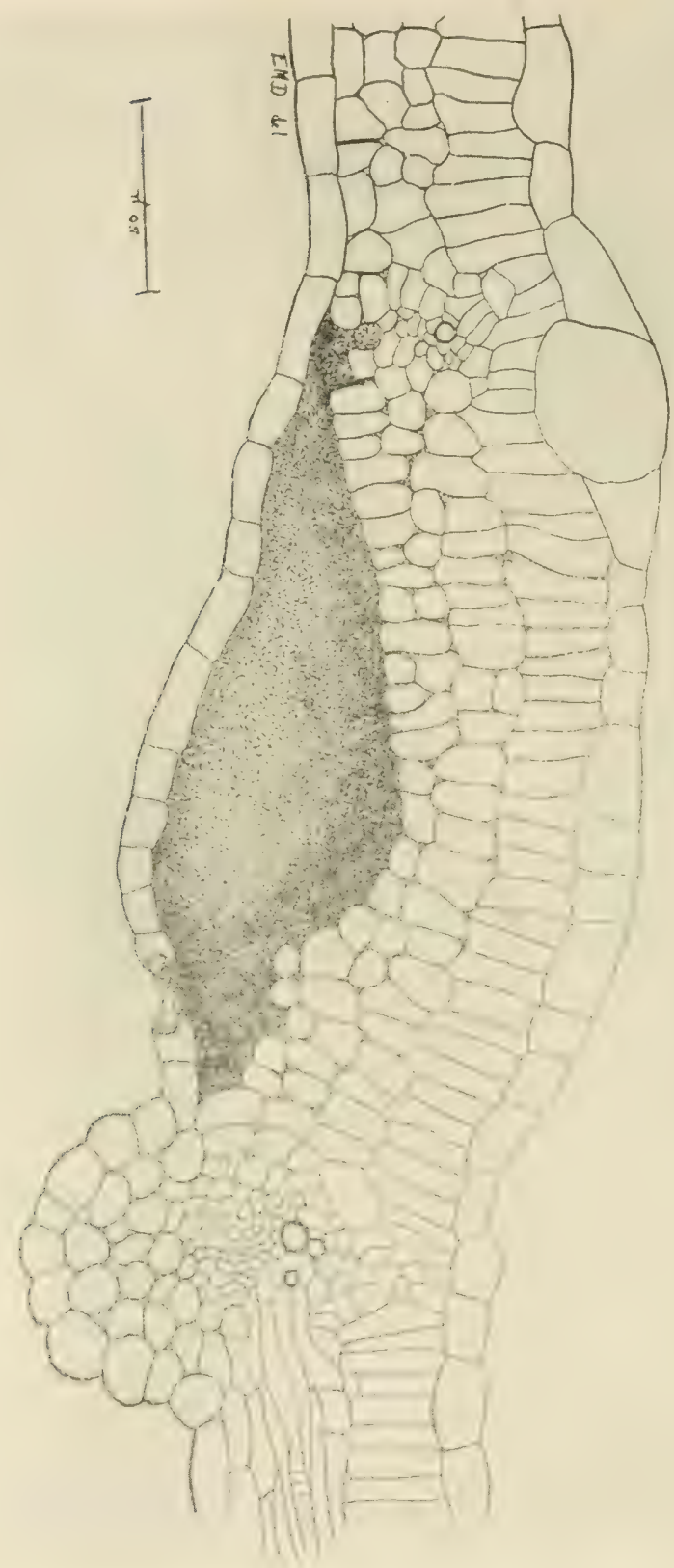

Frg. 271.-South African mulberry blight due to Bacterium mori: section through a water-soaked spot on a leaf of the common mulberry which was fixed 5 days after inoculation, showing lower epidermis lifted, a large bacterial cavity and penetration of the intercellular spaces of the mesophyll. After Ethel $\boldsymbol{M}$. Doidge. 

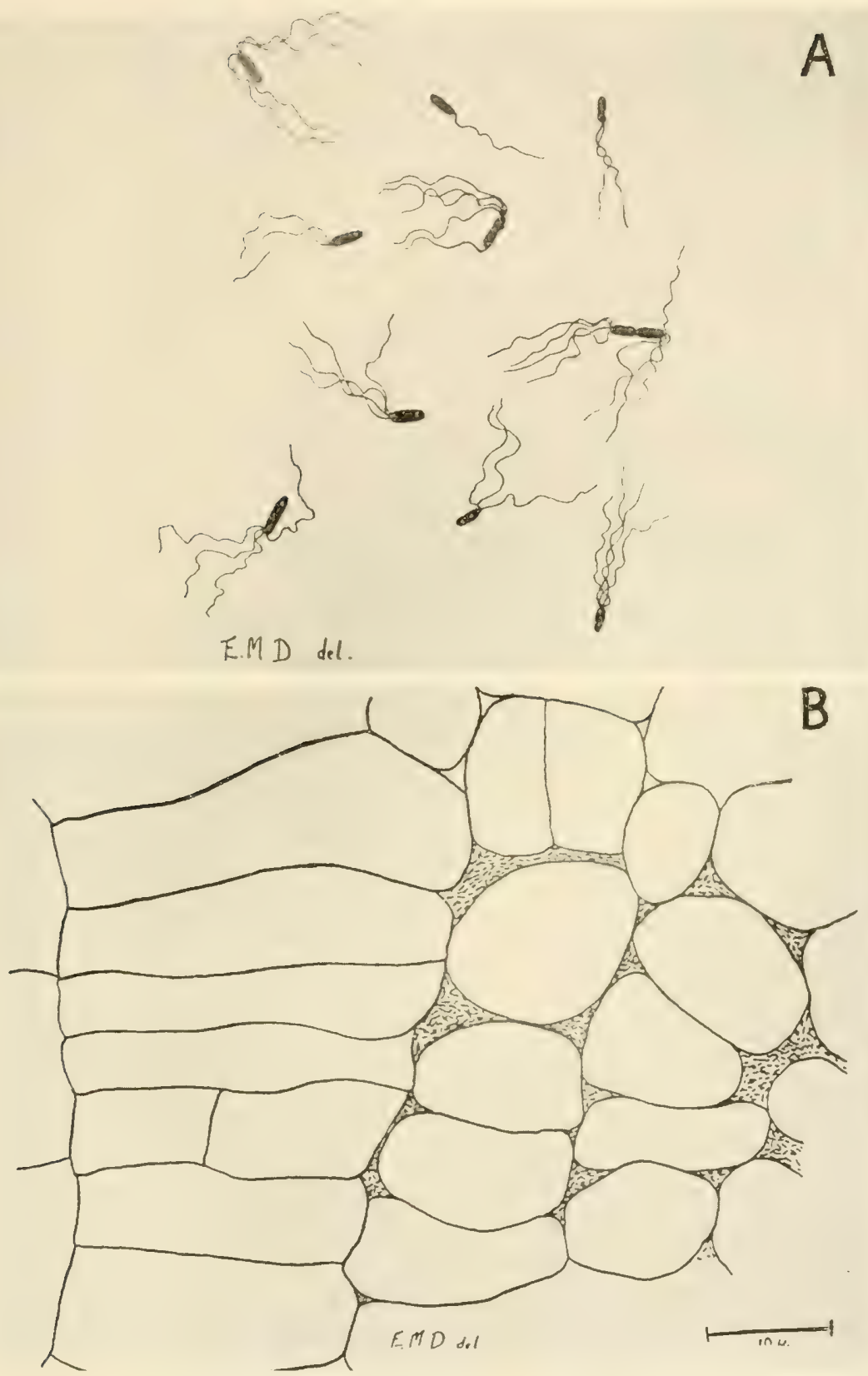

FIG, 272.-A. Flagellate rods of Bacterium mori. $\times 1500$. B. A detail of the mesophyll from Fig. 271. Both after Ethel M. Doidge. 
pricking each several times with a delicate needle infected from young potato or agar-streak cultures. Leaves should be inoculated in the midrib or main veins as well as in the parenchyma.

Small trees suitable for inoculation may be obtained from nurserymen and planted in the autumn for late spring inoculations out of door, or in the hothouse for inoculations in late winter and early spring, whenever shoots are pushing.

\section{Determine}

For the organisur. Morphology. - Size in microns (diameter is more important than length, but that also should be recorded, examining both young and old cultures on various media). Conditions under which chains are formed. Ditto pseudozoögloeae. Ditto involution forms (use peptonized beef broth with 6 per cent sodium chlorid). Motility (on margin of a hanging drop). Number and attachment of flagella (use Pitfield's stain). Ethel M. Doidge in South Africa, finds 1 to 4 polar flagella (Fig. 272A). In my first studies of the Georgia organism I saw only 1 to 2 polar flagella, but slides stained for me in 1915 by Mary Katherine Bryan, using the French organism and ran Ermengem's silver-nitrate stain, show 1 to 7 polar flagella on backgrounds very free from detritus or artefact lines (Fig. 273). Absence of endospores (heat, spore stains), existence or non-existence of a capsule (Ribbert's dahlia stain). Reaction to various other stains including Gram's stain, and acid-fast stain.

Cultural Characters.-Appearance in poured plates of +15 pept one beef agar (Figs. 274, 275), streaks and stabs. Ditto +10 beef peptone gelatin. Growth on Löffler's solidified blood serum (the streak should be flat, white, smooth and glistening). Is there any liquefaction of gelatin or solidified blood serum?

Behavior on potato cylinders. Test, when grow th has ceased, for destruction of starch.

Appearance in +15 peptonized beef bouillon. Action, if any, on potassium nitrate in peptonized beef bouillon. Behavior in milk and litmus milk (watch very carefully the early stages for absence of coagulation and acidity and the late stages for 
clearing, keeping uninoculated tubes for comparison; after 10 weeks examine under the microscope for general appearance, comparing with one of the check tubes). Growth in Cohn's solution (there should be none or very little). Growth in Uschinsky's solution (which should be copious).

Behavior in fermentation tubes in peptone water (Why not in beef bouillon?) containing various sugars and alcohols (which, of course, must be pure). Any growth in the closed end? Any acids formed in the open end?

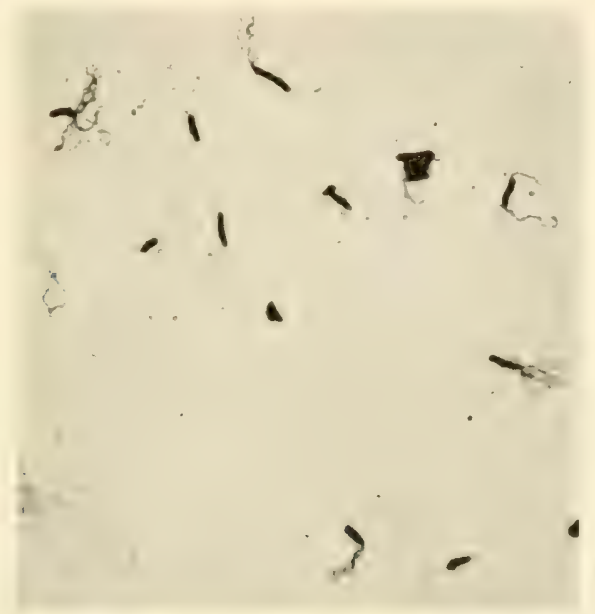

FIG. 273.-Flagellate rods of Bacterium mori. Stained by van Ermengem's method from a 2-day agar streak. James Birch Rorer's isolation. $\times 1000$.

Determine production of indol using Bacillus coli for comparison and testing at end of 10 days and 20 days (heat the tubes in a water bath at $80^{\circ} \mathrm{C}$. for five minutes, if necessary).

Non-nutritional Environment.-Minimum temperature for growth (try first at $2^{\circ} \mathrm{C}$.)? Maximum temperature (try first at $34^{\circ} \mathrm{C}$.)? Can you obtain any growth at $1^{\circ} \mathrm{C}$. or at $37^{\circ} \mathrm{C}$.? Optimum temperature (try first in peptone bouillon at $27^{\circ}, 30^{\circ}$, and $33^{\circ} \mathrm{C}$., inoculating copiously from bouillon and examining every 3 hours)? Is the organism sensitive to dry air (to have all the bacteria freely exposed, use young bouillon cultures)? Effect of sunlight (expose on ice for 10, 20, 30, and 40 minutes in thin-sown agar-poured plates, preferably after a storm, i.e., 
when the sky is free from clouds, dust or haze, keeping one-half of the plate covered).

Effect of sodium chlorid in +15 peptonized beef bouillon (begin with 5 per cent and increase to 10 per cent, comparing on the one hand with Bacillus carotovorus and Bacillus coli and on the other with Nos. I and V).

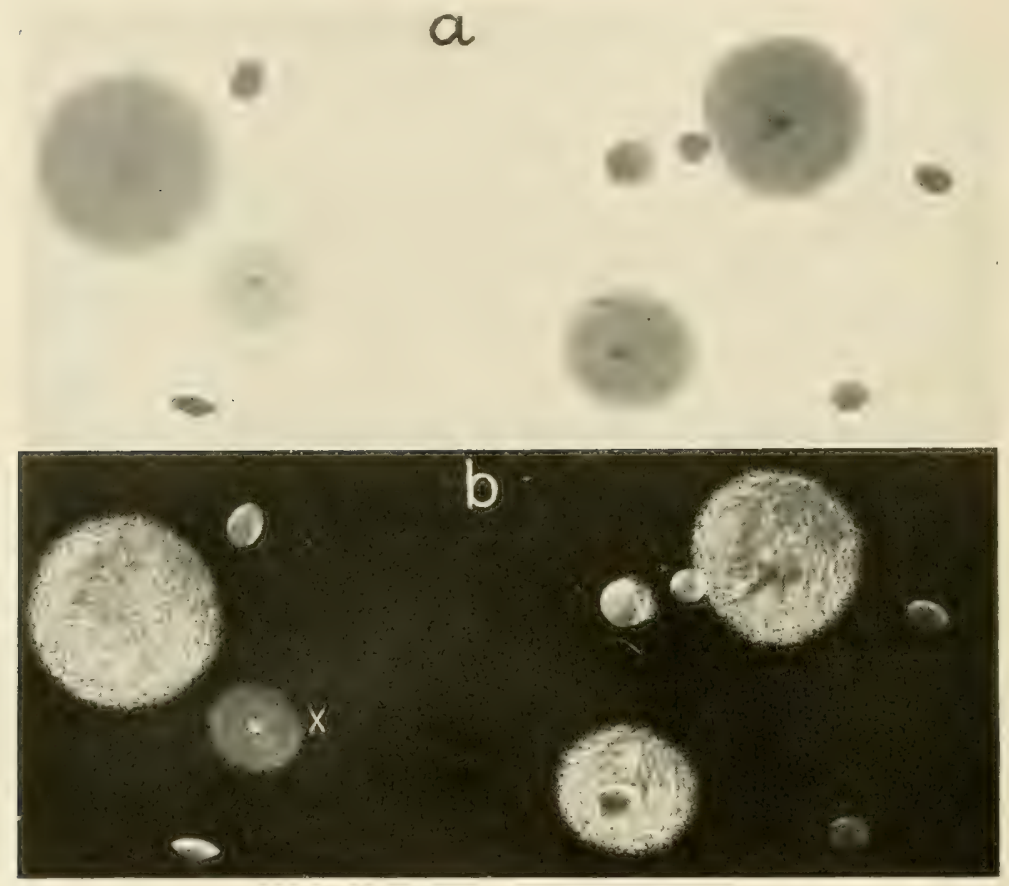

FIG. 274.- Surface and buried colonies of Bacterium mori on agar poured plates. $a$. Photographed by direct transmitted light. $b$. The same by oblique transmitted light, showing the internal markings. These colonies are smooth on the surface and glistening white by reflected light but pale brownish by direet transmitted light. $X$ is a thin colony on the bottom of the plate. Time, 5 days. Photographed February 10, 1919. $\times 10$.

Growth in test tubes of unshaken bouillon over chloroform (Compare with No. II).

Nothing is known respecting the action of germicides. Can't you make some tests?

For the DISEASE. Signs.-Period of incubation in young stems and leaves. Time from appearance of water-soaked 
spots to the blackening of leaves and shoots. How far down the stems in advance of external signs can you trace an internal stain? In what tissues? Effect of the bacteria on the tree as a whole.

Describe the disease. Make photographs or drawings.

Histology.-Cut, freehand, various cross-sections and longitudinal sections of affected stems, and examine at once in water. Fix, embed, section and stain suitable pieces of stem and leaf in early stages of the disease to show the bacterial invasion. Make permanent preparations. Study ooze of the bacteria through lenticels; section young stems some inches below external signs of the blight for presence of tyloses in the affected

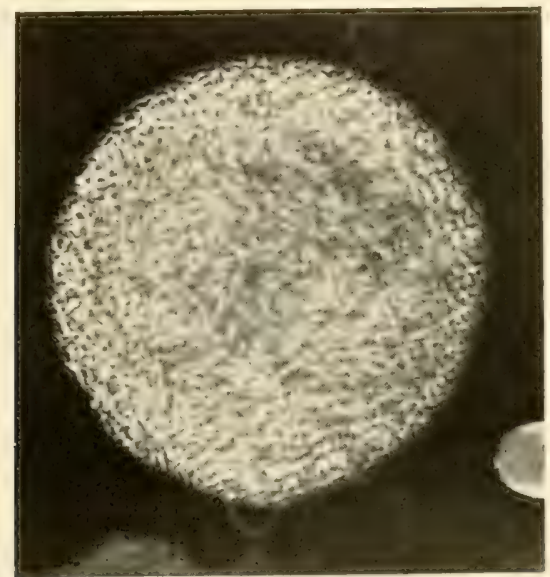

Frg. 275.-Agar surface colony of Bacterium mori showing internal markings when viewed by transmitted oblique light. Colony smooth on the surface, $\times 23$.

vessels. Can you find any in normal shoots of this age? Compare with tomato and potato stems attacked by No. IV or VI, which also show tyloses. What substances cause their production (see Figs. 357, 358 and 350 for tyloses induced by purely chemical means)? How many inches can you trace the bacteria downward in the vascular system below the lowermost external indications of the disease? Can the tyloses be traced farther than the bacteria? What stem-tissues are specially involved? For answer to this question examine both the soft terminal part 
of blighting shoots and the harder basal part. Is the pith involved? Are the medullary rays occupied? Where are the bacteria located outside of vessels, i.e., within cells or between them? In the leaves do the bacteria make special use of the vessels? Is the parenchymatic tissue killed in advance of its occupation? Parts long diseased are hard to embed on account of entrance of air; you will, therefore, collect unshriveled soft stems and leaves, and fix without delay, using the air pump.

Variability.--Little is known.

Transmission.-Nothing is known respecting carriers of the bacteria or the natural methods of infection. The organism enters readily through wounds and probably also through stomata and lenticels. Settle the latter by experiments, if you have the opportunity. As in fire-blight of the pear, the copious ooze of bacteria to the surface of the blighting leaves and shoots affords abundant material for infecting other parts of the same tree and for transmission to neighboring trees, and it is advisable, therefore, to remove all blighting branches promptly.

\section{LITERA'TURE}

For earlier notes by the writer read: Science, N. S., Vol. XXXI, Nay, 1910, p. 792 ; and Phytopathology, Vol.4, 1914, p. 34.

For Macchiatti's paper consult Malpighia, Anno. V. Fasc. VII-XII, Genoa, 1892, pp. 299-303.

For Boyer and Lambert's paper consult Comptes Rendus hebd. des Sé de. l'Acad. des Sci., Paris. Tome CXVII, Aug. 21, 1893 ; pp. 342-343.

Read Doidge's paper "The south African Mulberry Blight" (The Annals of Applied Biology, July, 1915, p. 113).

See also "Etudes sur les maladies du Murier en 1913" by G. Arnaud and C $h$. Secrétain, Annales du Service des Épiphyties. Tome II, Memoires et Rapports, Ministère de L' Agriculture, Paris. Librairie Lhomme, 1915, pp. 233-249, 11 text figs. Consult also "Bacteria in Relation to Plant Diseases," Vol. II, 1911, Figs. 3 and 30. 


\section{FIRE-BLIGHT OF APPLE, PEAR, QUINCE, ETC.}

(Called also pear blight, apple blight, quince blight, etc.)

Type.-Fire-blight, so called since the time of $\mathrm{Wm}$. Coxe (1817), is a time-limited. rapid, parenchymatic decay, chiefly of the pear, the apple, quince, and other pome fruits ( Figs. 276, 277. 278). From stone fruits it was first described in 1902 by L. R. Jones who found it on the cultivated plum (Prunus sps.). It was also found independently on the plum by Merton B. Waite. It has been seen on the loquat (Eriobotrya), and on the cherry. It occurs also on certain wild genera, e.g., ('rataegus, Amelanchier, Heteromeles (Waite). O'Gara has reported it from the apricot in the Northwest. Heald also has reported finding it on the apricot in Texas. In 1915 the writer cross-inoculated it to apricot readily. He also saw it escape naturally from inoculated pears to a neighboring apricot (Fig. 279) and with the organism plated from a dying apricot twig produced typical blight on pear shoots. Munn has recently reported it as inoculable into the blossoms of the strawberry (Phytopathology, vol. 8, p. 33). Can you find it occurring naturally on the strawberry? Search in the vicinity of blighting pear and apple orchards.

It begins by destroying the blossoms, green fruits, and young shoots, including young leaves which are specially favorable places for its development (Fig. 280), but it passes quickly downward, chiefly by way of the bark parenchyma, into the inner bark of the larger branches and of the trunk, which often are girdled and killed. It gets its common name from the conspicuous black or brown appearance of the blighted branches, the dead persistent leaves of which look as if scorched ( Fig. 278). The blackening of the leares is a host reaction and occurs in the absence of the bacteria, but the bacteria often attack leaves as well as stems, passing from the stem through the petiole into the leaf blade (Figs. 280, 281). As the fruits ripen and as the inner (living) bark of the shoots becomes firm, in late summer or 
early autumn, the blight ceases to spread, and the organism, in a majority of cases, dies out of the blighted (killed) trunk and limbs, but in a variable per cent of cases the bacteria persist in certain patches, forming what Mr. Waite, who discovered it, has termed "hold-over blight," and Prof. Whetzel "cankers." From these spots (Figs. 282 and 283), which ooze living and

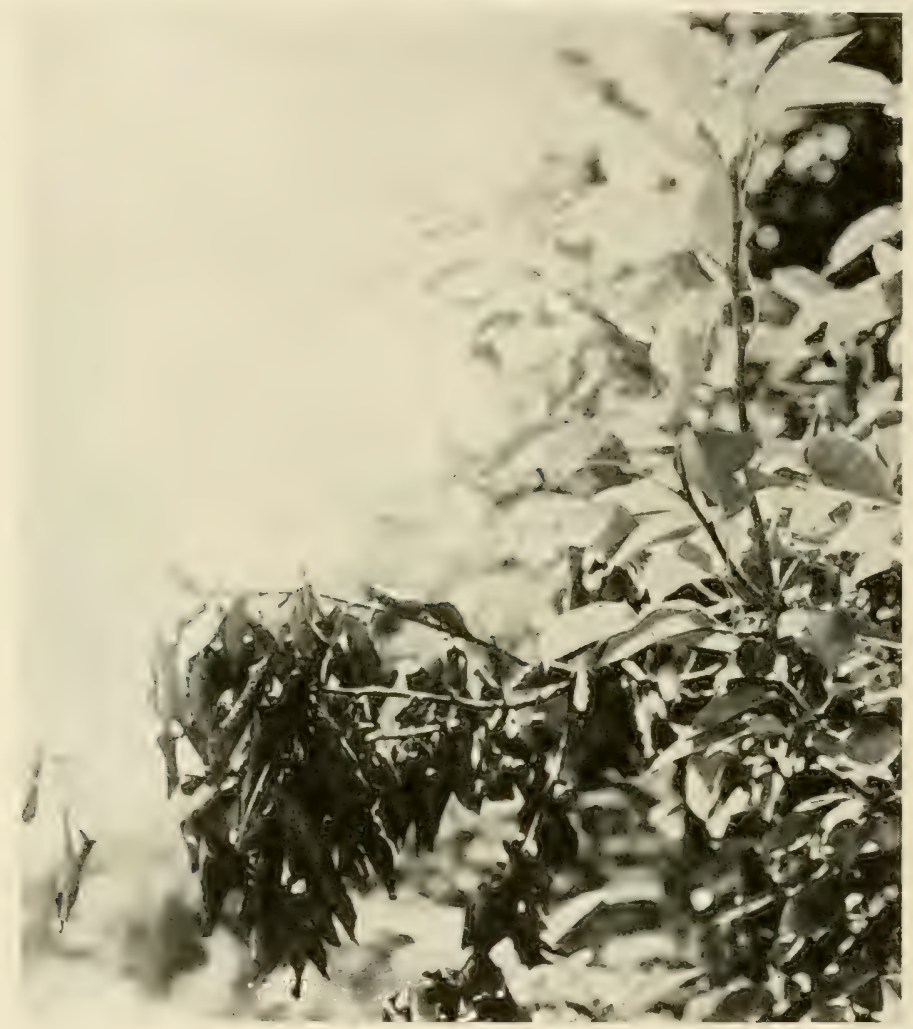

FIG. 276.-Fire-blight on a pear tree. Healthy and blighted branches, seen close. Maryland, July 1, 191t.

virulent bacteria, especially during the increased sap-flow of the spring, and which are risited by bees and other pollen-gathering and nectar-sipping insects, the exudate being sweetish, according to O'Gara, the bacteria are carried to the blossoms of neighboring trees and a new outbreak is started, the organism, brought by these insects, growing first in the nectar of the flowers or in 


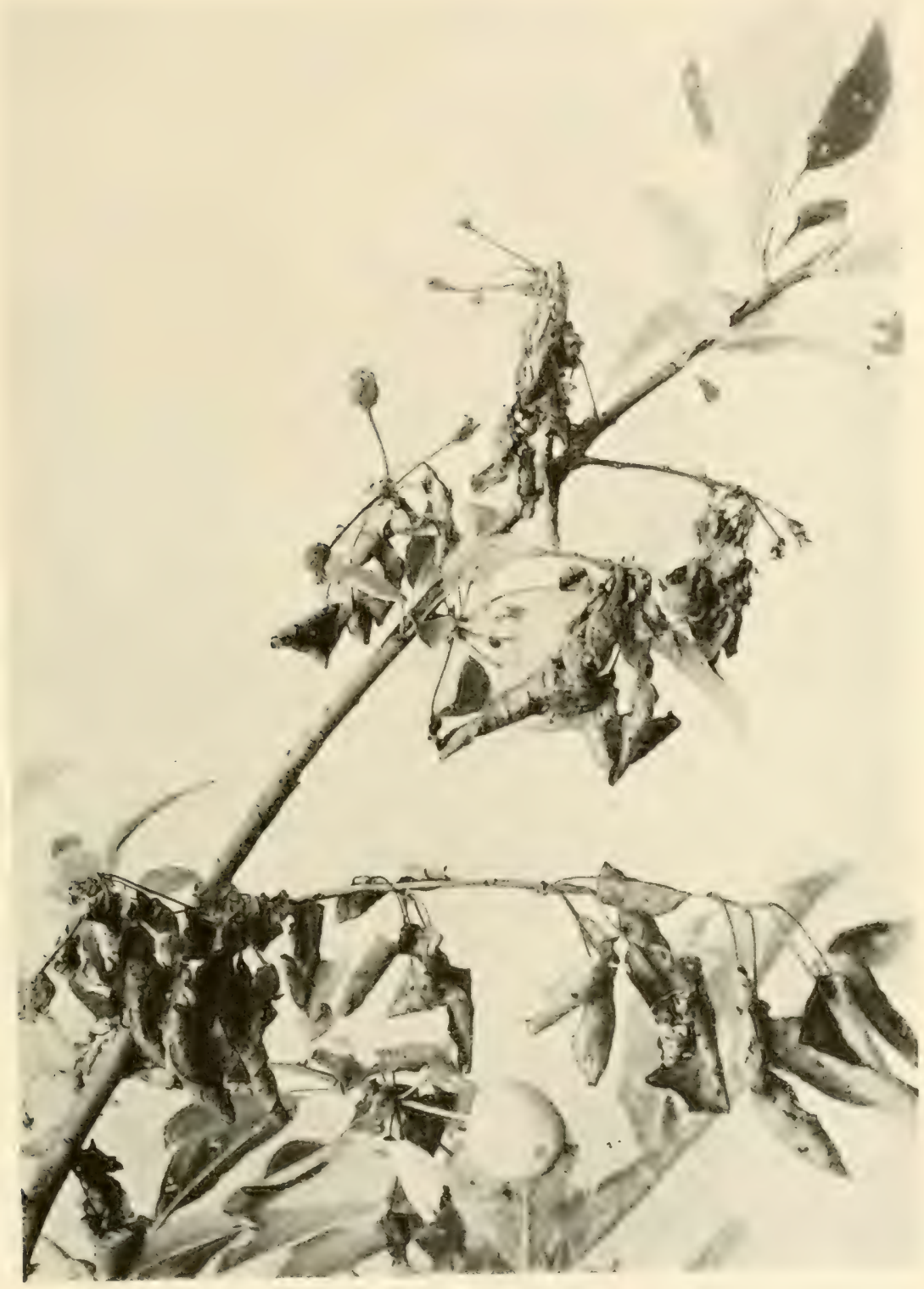

Fig. 277.-Branch of an apple tree showing blighted flowers, fruits and shoots due to Bacillus amylovorus. Time of year may be judged from the size of the green apple below. Season of 1914 . 


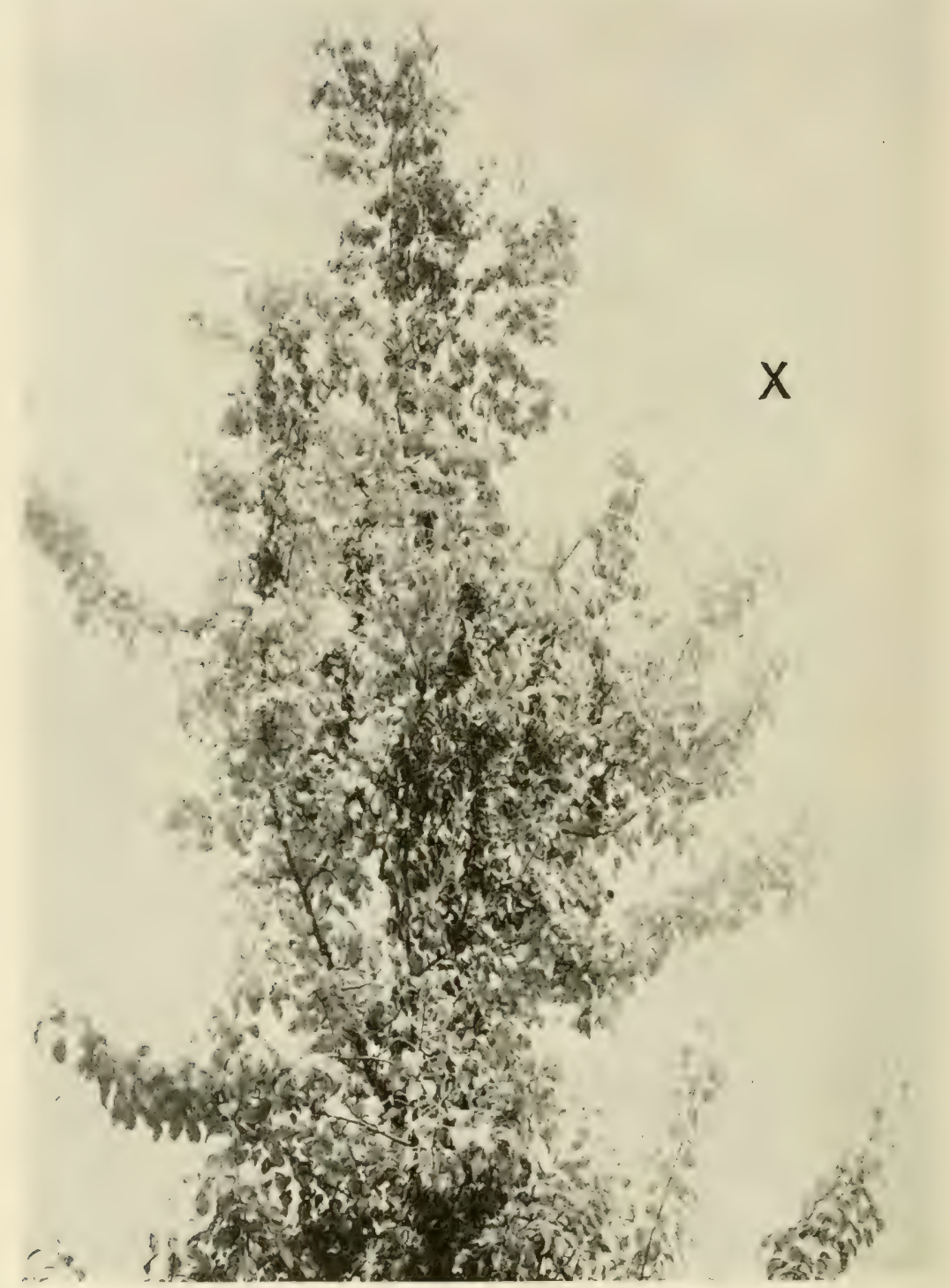

FIG. 278.-A pear tree showing limbs recently blighted by Bacillus amylovorus (from hold-over blight) and at $X$ the old blight, i.e., that of the previous season. Washington, D. C., 1914. 
bitten or punctured shoots. Sackett believes that we have greatly underestimated the number of cases of hold-over blight, especially on the smaller limbs and twigs, since in a total of 8.3 blighted pear twigs, examined by him in the winter and spring of 1910 and 1911 in Colorado, 25 per cent contained living blight bacteria. These cultures were taken at the border line joining sound and blighted tissues. On the contrary, working

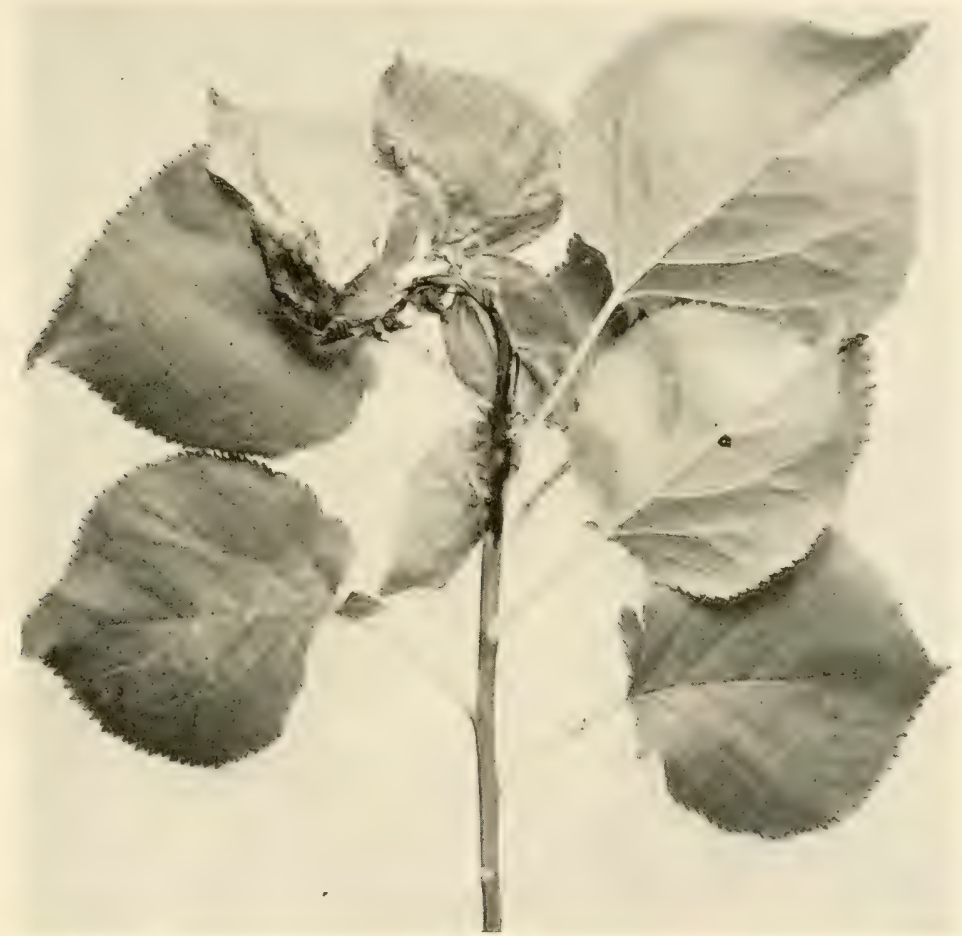

Fig. 279.--Fire-blight on apricot. A natural infection from an inoculated pear tree in one of our hothouses. Photographed June 7, 1915.

in Pennsylyania on pruned branches allowed to lie on the earth, Fulton found that the bacteria were dead in nine-tenths of them at the end of a week (35 branches tested). More tests should be made in various localities. Here is a good opportunity for useful experiments

Secondary infections are very common during the growing season, owing to the abundant and fluid nature of the bacterial 


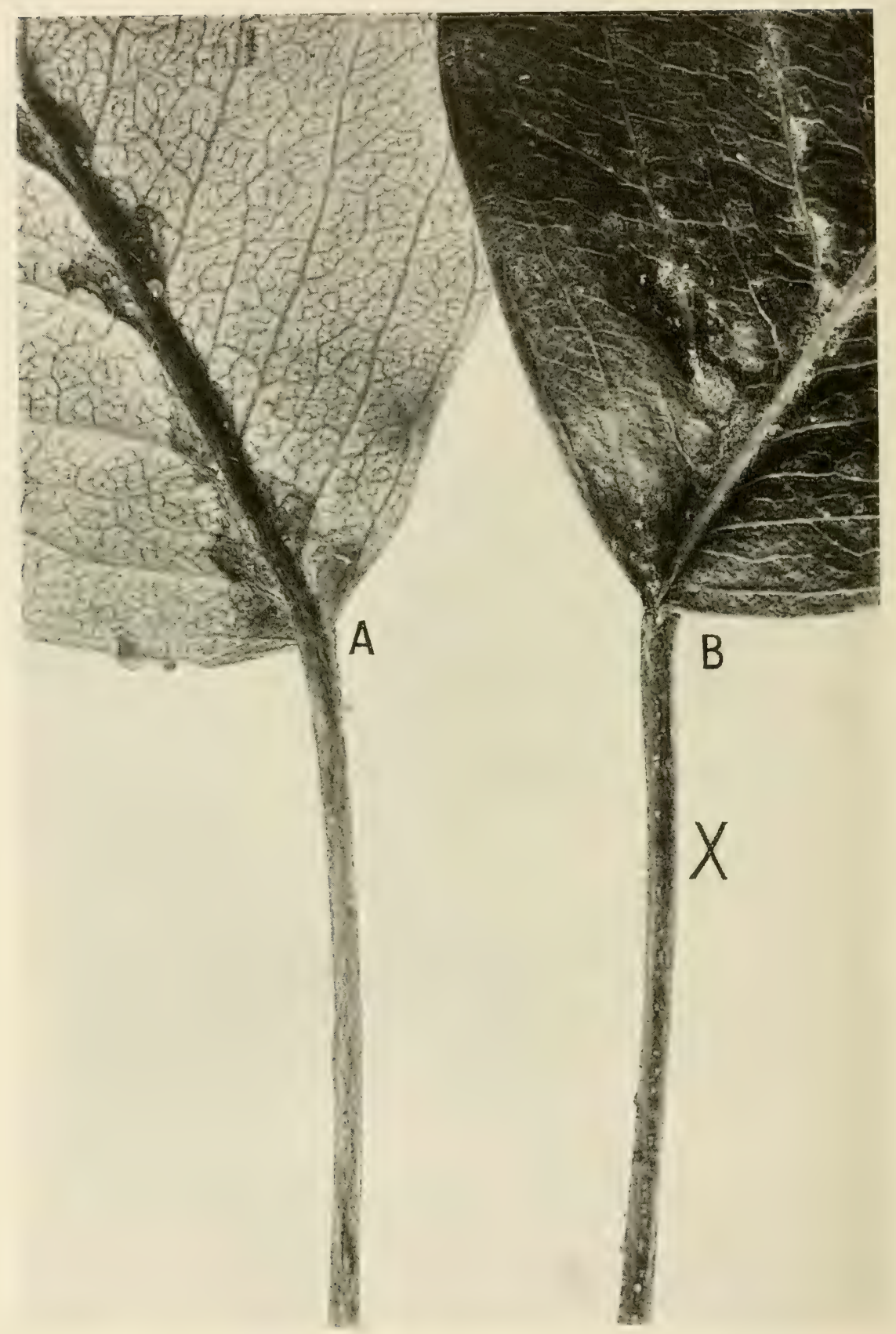

FIG. 250. 
slime which oozes through natural openings (stomata and lenticels) to the surface of stems, fruits (Fig. 284) and leaves (Fig. 285) in great abundance, where it is visited by insects, and from which is also drips readily to other parts of the tree

In the shoots it is primarily a bark disease (Figs. 286, 287). It disintegrates the green fruits by multiplying in the intercellular spaces and dissolving the middle lamellae (Fig. 2SS) and is enormously abundant in such fruits.

In cultures I have not observed rapid loss of virulence. A strain carried along on media in my laboratory for 7 years (1908-1915) blighted pear shoots readily, even of a so-called "blight-proof" sort, when inoculated by needle pricks in June, 1915. Another strain on media 5 years was infectious in 1920.

Fire-blight occurs destructively every year in some part of the Lnited states (Fig. 289), and in certain years (as in 1914 and 1915) sweeps over the whole country. It has been known for a hundred and forty years in the eastern United States where it was probably first present on wild shrubs, but its distribution in other parts of the world remains uncertain. It has, however, been reported from Italy. I have been told also that it now occurs in northern Japan on pear and apple, especially on the Red Astrachan (Cientaro Yamada). In Cornwall, England, I saw what looked at a little distance like fire-blight on apple twigs, but on going into the orchard I found that the twigs had been smothered by lichens.

The disease can be controlled by prompt, intelligent and severe pruning (Fig. 290). This is the only remedy known. To avoid spreading the disease by means of the pruning tools they must be disinfected after the removal of each infected limb. The cut surface should also be disinfected (see Part I, page 71). O'Gara recommends 1:1000 mercuric chloride in water applied

Fig. 280.-Blight on pear leaves due to Bacillus amylovorus. Introducerd to show how petioles and midribs often blight in advance of the leaf-blade. In these leaves both petioles were blackened on their surface (except at $X$ ) and were exuding bacterial droplets from numerous stomata, but enough fluid was still passing through their vascular bundles to keep the leaf-blades green and turgid except an extremely small portion of the base of $B$, and a much larger but still relatively small area along the midrib of $A$. The invasion came from the bark of the shoot, which was blighted. 


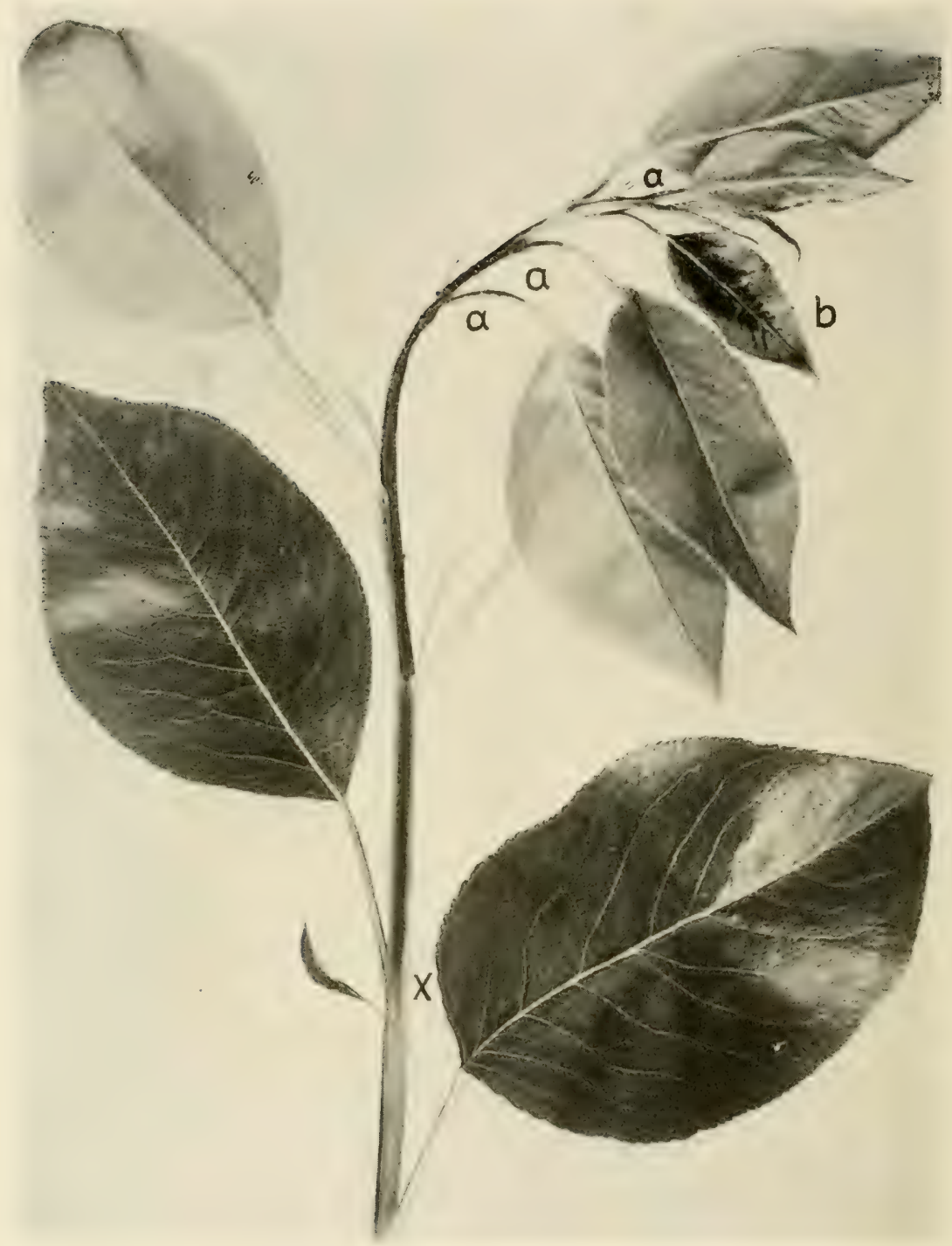

FIG. 281.-Growing shoot of Clapp's Favorite pear inoculated 5 days with a pure culture of Bacillus amylovorus plated from an apple twig. Bark blighted and exuding drops of bacterial slime. Blight running out on petioles $(a, a, a)$ and on leaf-blade $(b)$. Terminal leaves still green and turgid but in another 24 to 48 hours they would have become brown and shriveled. Lowest visible blight at $X$. Internally the bacteria were traced under the microscope 3 inches farther down the stem. May, 1915. The blue-black stripe of blighted bark and the pale green of the normal part of the shoot photographed exactly alike, both with Hammer's double-coated orthochromatic plates and with W. and W. panchromatic plates. The eye-contrast was finally obtained on the latter plate by using a green color screen. 
by means of a sponge. It is most easily applied on trees that have been trained to a vase shape (Fig. 290). Those trees trained to pyramidal form with a single central stem (Fig. 27s) are often killed by the first attack of fire-blight.

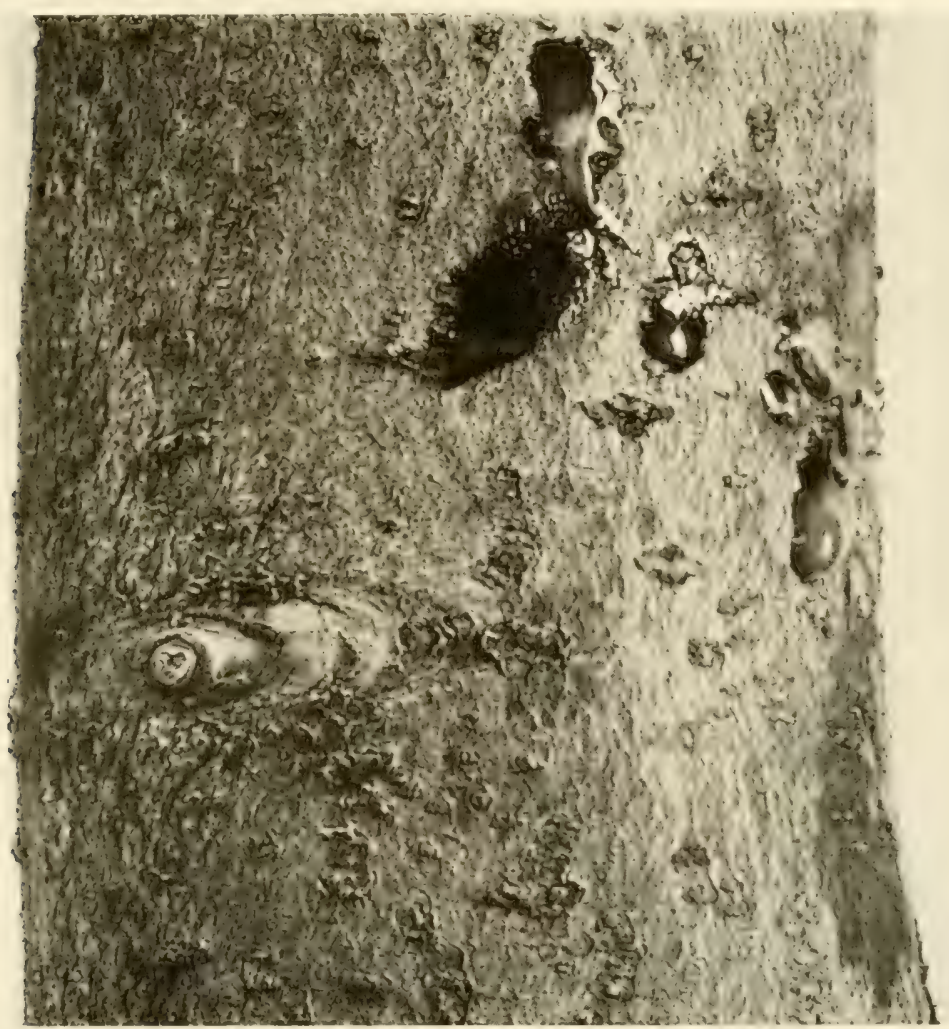

Fig. 282.-Fire-blight canker on apple (Waite's hold-over blight). Spring condition-bacteria exuding and likely to be visited by bees and other pollengathering and nectar-sipping insects. Bark discolored on the right side. After Whetzel.

Cause.- Pear blight or fire-blight is due to Bacillus amylovorus (Burrill) Trevisan. The original name, Micrococcus amylororus, was given to it by Prof. Burrill, under the assumption that it destroys starch but such is not the case. It is a white, motile, peritrichiate-flagellate (Fig. 291), non-sporiferous, non-odorous, non-acid-fast, (iram negative, non-nitrate-reduc- 


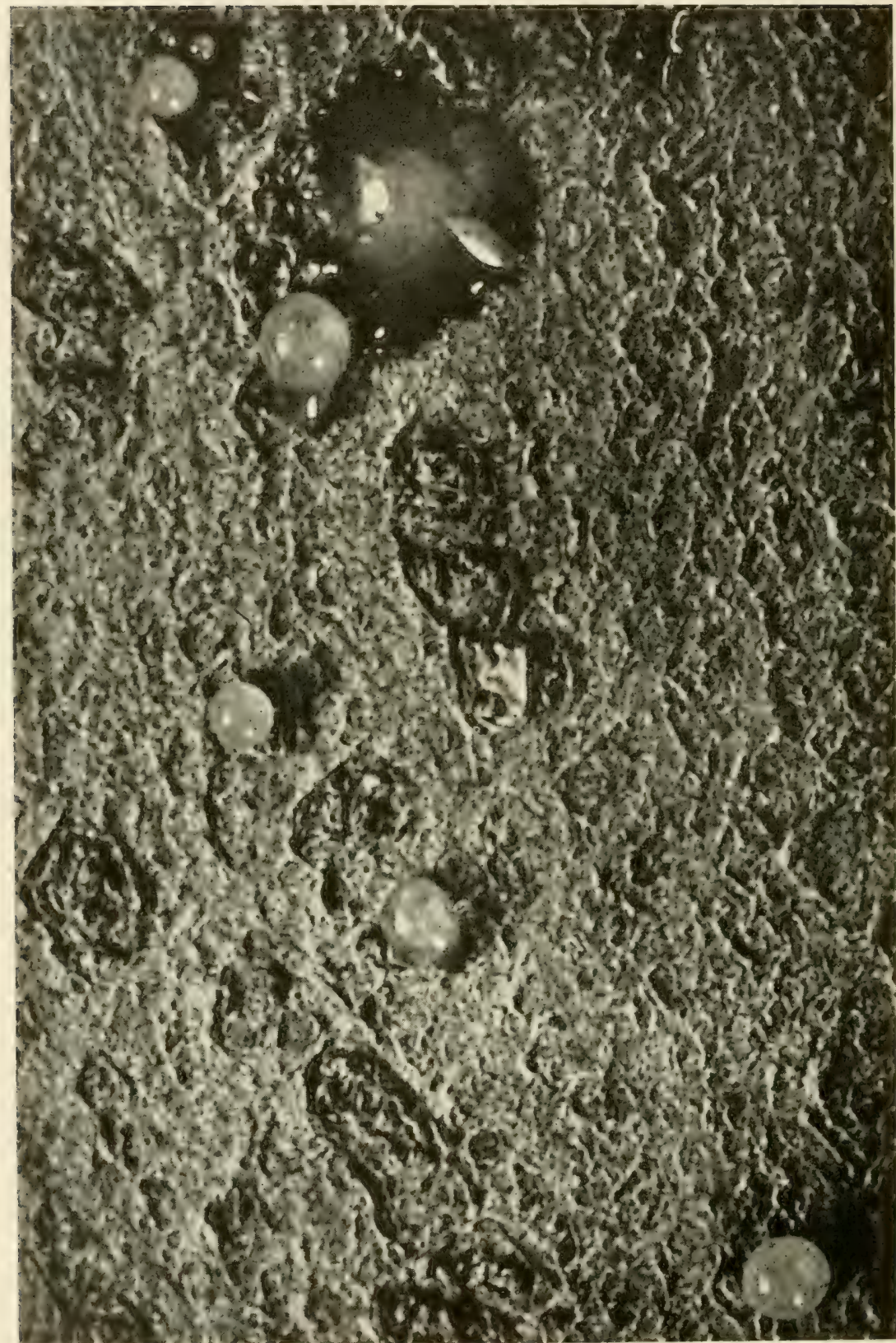

FIG. 283.-Bark of an apple tree in spring showing Bacillus amylovorus oozing to the surface from a patch of "hold-over" blight. Enlarged 6 times from a photographic print furnished by Prof. H. H. Whetzel. Planar by James F. Brewer. 
ing, rather slowly liquefying (gelatin, not Löffler's solidified blood serum), more or less viscid (often quite slimy from pear and apple fruits), butyrous on agar and potato (D. H. Jones) aërobic and facultative anaërobic (with grape-sugar, fruit-sugar, cane-sugar, or malt-sugar), non-gas-forming, sodium

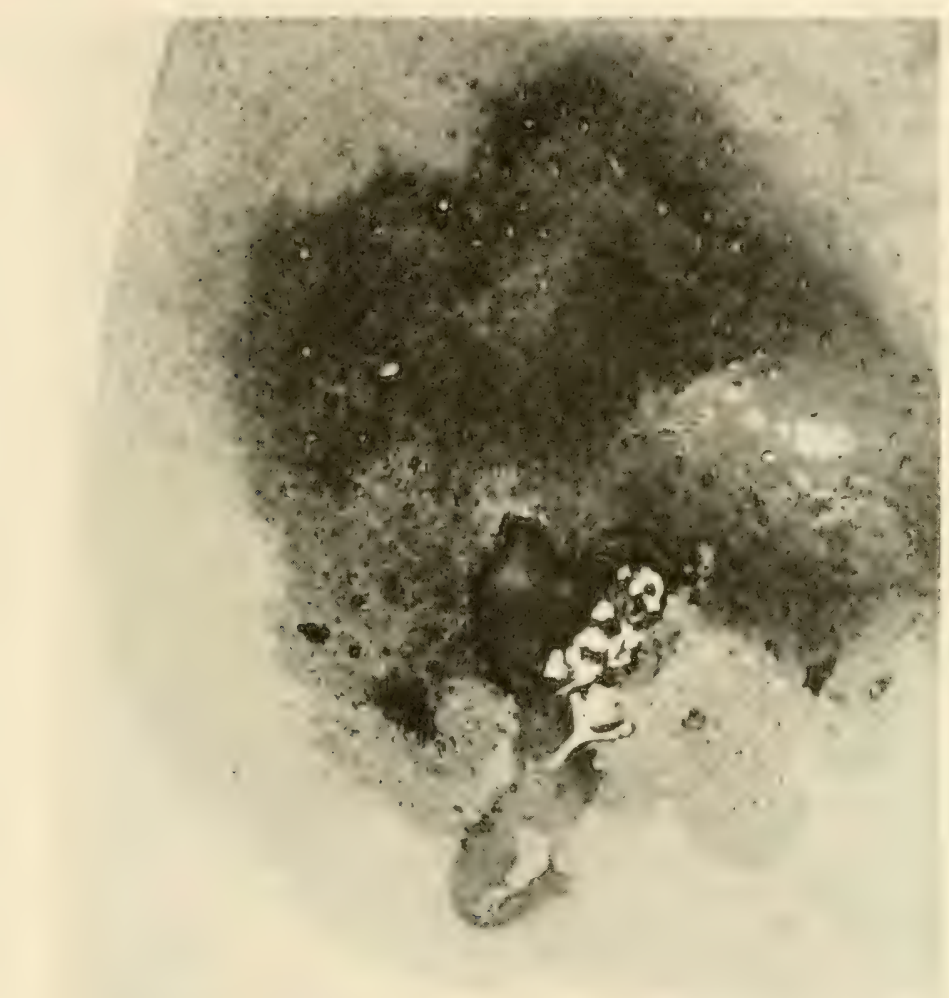

FIG. 284.-Green pear fruit (Duchess) rotted by Bacillus amylovorus. Result of a pure-culture inoculation. Ooze of bacteria through stomata can be seen in many places above the central area. Below is a larger amount of bacterial ooze from cracks in the vicinity of the needle-wounds.

chlorid-tolerant, sunlight-sensitive, dry-air-sensitive, rod-shaped schizomycete, growing on the surface of agar-poured plates in the form of circular, small, entire-margined, more or less opalescent white colonies, and in the depths as smaller, sometimes ringed, fringed or hazy-margined colonies (our pathogenic 


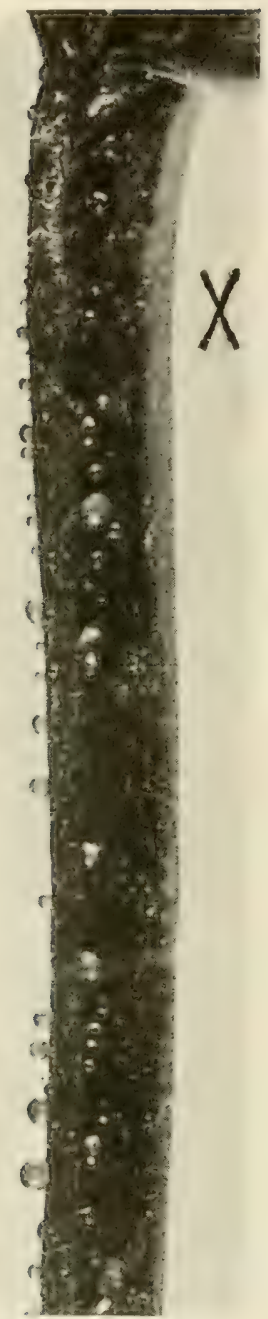

FIG. 285.-Blighting pear petiole. A detail from Fig. 280 at $X$, showing more distinctly the stomatal bacterial exudate $(B a-$ cillus a mylovorus) from the blackened petiole. On the right side at $X$ the tissue is still green and turgid. cultures of 1905 - not those of 1915 ; although both were from apple). On thin-sown +15 peptone-beef agar plates, held at $20^{\circ} \mathrm{C}$. the homogeneous wet-shining surface colonies may reach a diameter of 5 or $6 \mathrm{~mm}$. by the end of the sixth day (Fig. 292). Their appearance when viewed by reflected and oblique transmitted light is shown, on Fig. 293. In tubes of nutrient agar there is a good growth the whole length of the stab. On gelatin plates the colonies are circular and inclined to pile up rather than to spread widely. In some gelatins a rather prompt pit of liquefaction appears around the colony (Fig. 294). The color of inoculated milk remains unchanged but after some days a soft curd settles, and later this is more or less completely digested (Fig. 295A). If a lab ferment is produced it must be very sensitive to heat $\left(15\right.$ minutes at $57^{\circ} \mathrm{C}$.). It does not redden litmus milk, but precipitates the casein usually within a few days (4 or 5). There is often a partial reduction of the litmus, the medium being bluer than the check at the top, paler blue at the bottom (in the curd) and wholly reduced in the middle, i.e., changed to a pale brownish white. It grows rapidly in bouillon especially if cane-sugar is added. In beef bouillon or potato broth there is not only a prompt and heavy clouding with presence of pseudozoögloeae (turbidity) but if undisturbed a slight granular pellicle forms. Clouds potato juice in closed end of fermentation tubes without gas. Indol reaction scanty or negative. Tolerant of small quantities of malic acid and citric acid but not of lactic acid. I now doubt if malic acid actually 
stimulates growth, as Waite supposed. Test. Unneutralized acids of gelatin inhibit growth. Tests may be made. Growth is best when the gelatin is made neutral or nearly neutral to phenolphthalein by use of sodium hydrate. Acids are formed from various sugars. In Uschinsky's solution no growth, or slow growth, unless peptone is added: growth copious, not viscid (D. H. Jones). In Cohn's solution no growth or slight (Repeated in 1915 with the same result). The optimum temperature is $30^{\circ} \mathrm{C}$. Growth at $3^{\circ} \mathrm{C}$. is very slow (D. H. Jones), and there is no growth at $0.5^{\circ} \mathrm{C}$. Exposure in

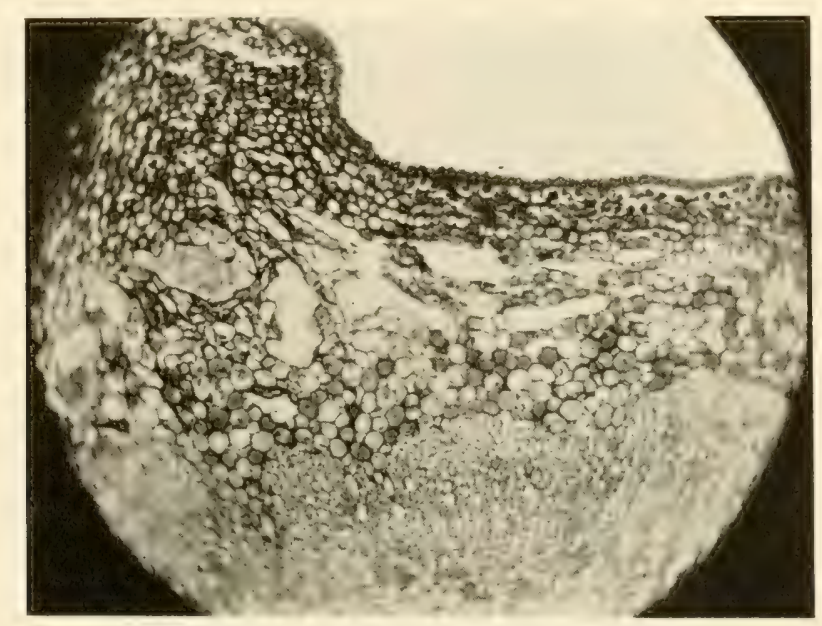

FIG. 286.-Cross-section of a young pear shoot showing cavities in the bark due to Bacillus amylovorus. The bacteria diffuse out of such cavities very readily on staining. Inoculated by the writer in May, 1915.

beef broth at $43^{\circ} \mathrm{C}$. for 10 minutes retards growth and at $43.7^{\circ} \mathrm{C}$. kills (L. R. Jones). The thermal death point in bouillon lies between $45^{\circ}$ and $50^{\circ} \mathrm{C}$. (D. H. Jones). In liquids all are killed by ten minutes' exposure to $55^{\circ} \mathrm{C}$. (O'Gara). In a recent inoculation (Oct., 1919) using our 1915 isolation from apple, the organism clouded at $43^{\circ} \mathrm{C}$. (but with retardation) and finally at $44^{\circ} \mathrm{C}$. One also of the four tubes exposed at $45^{\circ} \mathrm{C}$. clouded (after 6 days) but none at $48^{\circ} \mathrm{C}$. (15 days), when exposed for 10 minutes in the water bath in +15 peptone beef bouillon. The checks grew promptly and the six uninoculated tubes re- 
mained sterile. In a repetition of the experiment there was no clouding either at $45^{\circ}$ or $46^{\circ} \mathrm{C}$. As a rule it lives long on culture media. Drying on cover glasses up to 5 days has no appreciable effect (L. R. Jones, D. H. Jones): Tolerates $\mathrm{HCl}$ in bouillon $(+4)$ up to +16 and $\mathrm{NaOH}$ down to -6 (D. H. Jones). Optimum reaction for growth +0 (D. H. Jones). It resists freezing fairly well. In tests made in 1919,15 per cent survived. It is identified readily by its behavior under bell jars, when streaked,

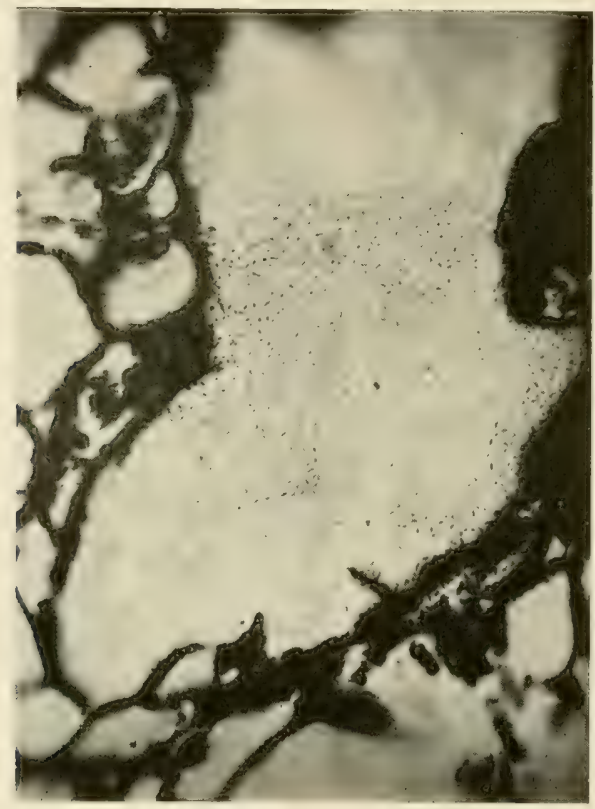

FIG. 287.-Pear blight: A detail from one of the cavities shown in Fig. 286.

on raw green pears, which should rot; and on ripe ones, which should not rot (Waite's method). This test may be made also in late winter or early spring (in advance of the growing season) on vigorous shoots of the pear by bringing them into a warm room and standing the lower parts in a jar of water until they have begun. to sprout (Waite's method, verified by Katherine Golden). Then with a sharp knife remove the tops making a slant stroke, on which should be rubbed the organism to be tested. If it is a virulent strain of Bacillus amylovorus, the 
shoots will soon begin to show the blight. To keep the cut surface from drying out, the jar of water should be covered with a tall bell jar; it should also be protected from direct sunshine. The shoots should be of sensitive varieties, e.g., Clapp's Favorite or Flemish Beauty, and the organism must be virulent.

The following unsupported or wholly erroneous statements respecting the pear blight organism have gained more or less

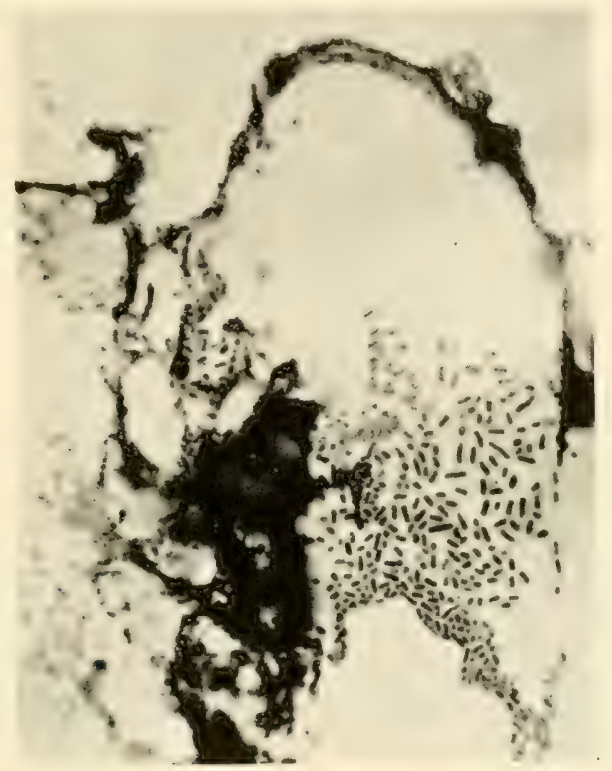

FIG. 288. - Section from a disintegrating pear fruit (like Fig. 284), showing Bacillus amylovorus between and in the cells. Photomicrograph by the writer. $\times 1000$.

currency, viz., that it is a Micrococcus, that it is non-flagellate (the flagella are hard to stain), that it is a rapid destroyer of starch, that it produces gas and more specifically carbon dioxide or hydrogen, that it produces butyric acid, that it will not grow on agar, that it does not liquefy gelatin, that it is yellowish, that it is red or reddish, that it cannot be found swarming in the leaves, that it causes a disease of peach trees and of Lombardy poplar trees, that it commonly passes the winter in dead limbs or in the earth, that it cannot be cross-inoculated from apple to pear and quince or vice versa, that it never enters the 
plant in the absence of wounds. Many other misconceptions exist among horticulturists and the uninformed multitude, e.g., that the disease is due to "thunder and lightning" or to "frozen sap," but the above include about all that the writer has observed in the writings of scientific men.

Technic.-Knowing the biological peculiarities of the pearblight organism, isolation is not difficult if one attempts it only from freshly blighted fruits or shoots and makes his transfers only from the advancing margin of the diseased parts, using the methods described under No. I. Then usually the poured plates are pure cultures. Isolation from older blight is more difficult, and often it is impossible owing to the prompt death of the organism in the blighted dry tissues. The commonest invaders on the plates are non-parasitic yellow colonies and sometimes only these appear.

For inoculation purposes, immature pear and apple fruits are very convenient since they are everywhere available in May and June. They may be inoculated by needle stabs or other wounds at any stage of growth preceding that internal change which takes place when they have reached full size and begin to approach maturity - fruits one-fourth or one-half grown are very suitable. They may be inoculated either on the tree, which is the more natural way, or under bell jars, especially if they are sliced. In the former case they must be protected from insect visitation by covering with a double fold of mosquito netting or with surgeon's gauze.

For inoculations on shoots, it is convenient to have half a hundred small pear trees in pots, some of which must be growing freely. Others which are growing feebly should, however, be inoculated for contrast.

Slow-growing and rapid-growing shoots on various kinds of pear trees in the open may also be inoculated (the best time is May -June) but they should be covered with netting to keep off insects and thus avoid the spread of the disease.

In the same way if the blossoms of pear, apple or quince are inoculated, which may be either by means of an atomizer, a platinum needle, or a pipette drawn to a fine point, the clusters must be covered, unless it is desired to study the transfer of the 


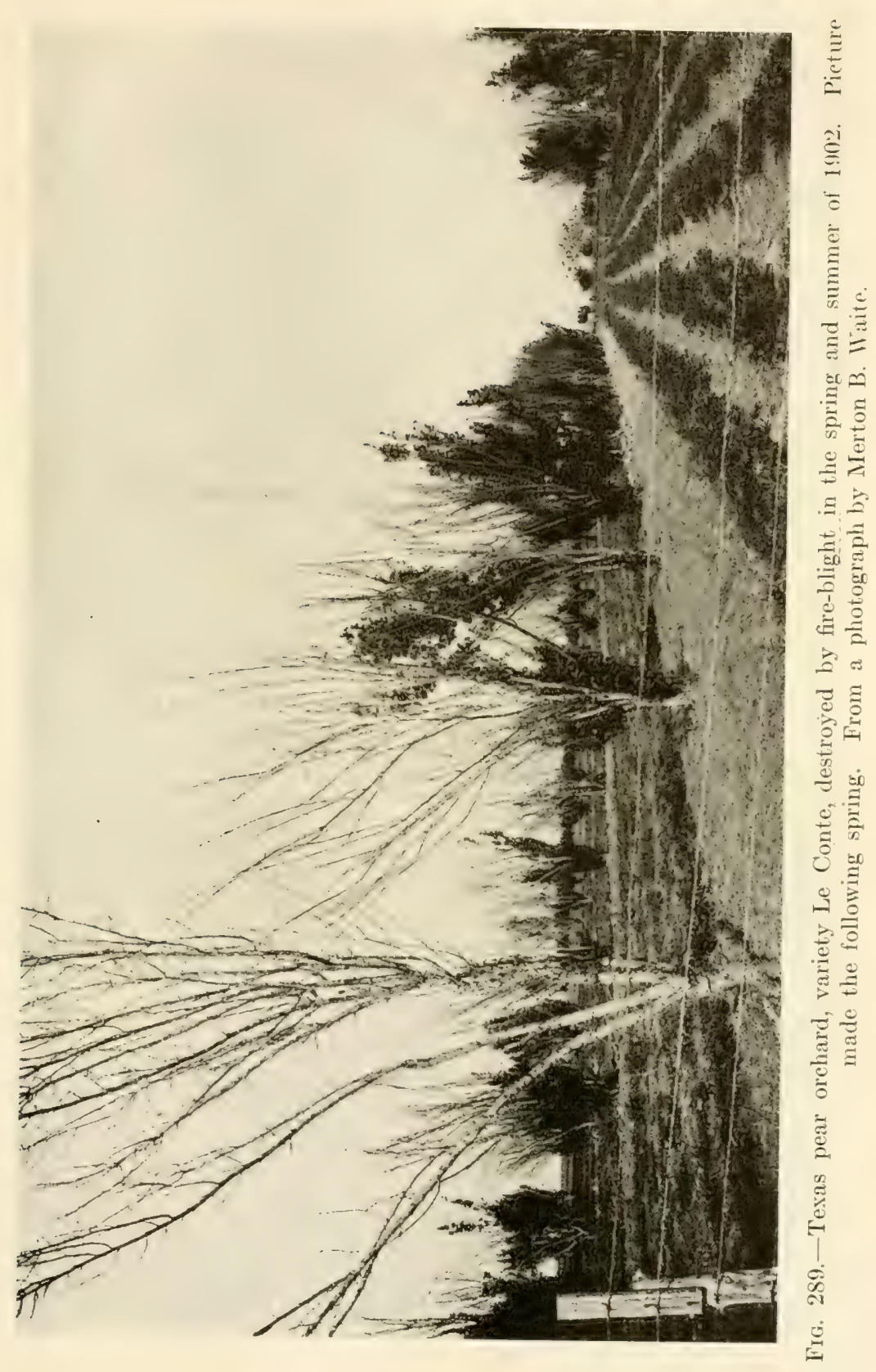




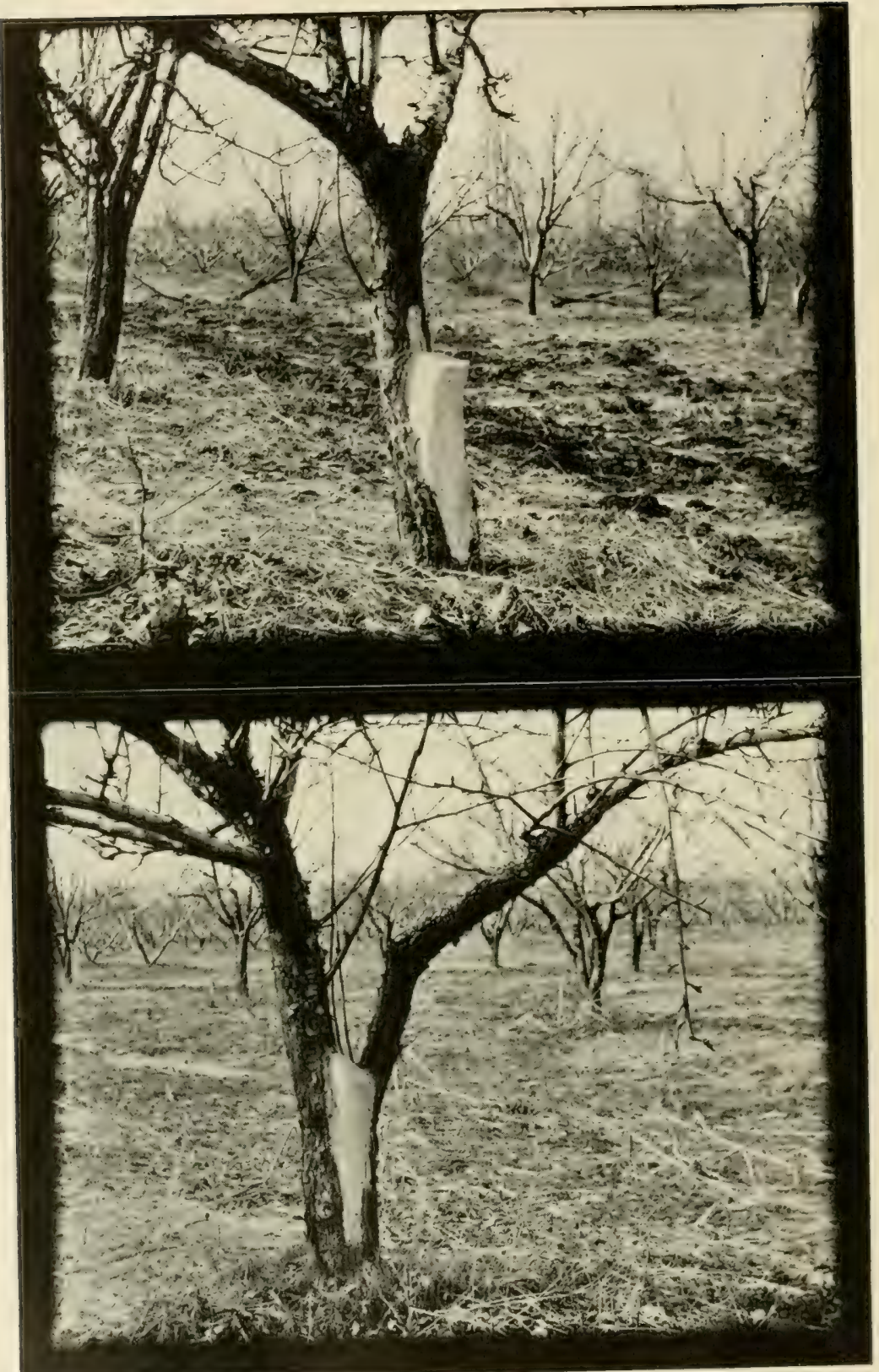

FIG. 290.-Photographs from a Maryland pear orchard showing result of proper eradication of pear blight. Views made in March, 1912. Blighted limbs removed 6 years earlier. From photographs by Merton B. Waite. 
disease by insects. Avoid wounding the flowers in making the inoculations.

For varietal contrast, Seckel, Duchess, Douglas, Winter Nelis or Kieffer (which blight slowly) may be compared with Bartlett, Howell, Flemish Beauty or Clapp's Favorite (which blight rapidly). There is also a so-called "blight-proof" pear derived from the Chinese Sand pear, which is not blight-proof

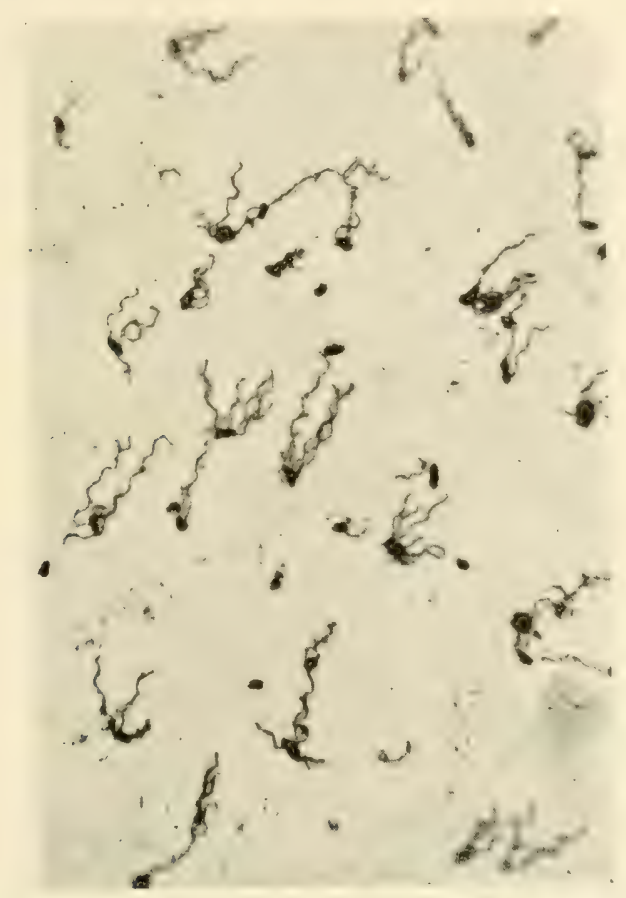

FIG. 291.-Flagellate rods of Bacillus amylovorus. Stained by van Ermengem's silver nitrate method. Isolation of 1908 from apple. $\times 1000$.

An isolation of 1915 from apple stained by Miss Bryan also showed peritrichiate flagella of the same type.

(Fig. 296), and which may be tested. No entirely resistant sorts are known to the writer but recently Reimer has discovered several. These are stocks of Pyrus ussuriensis and other Asian sorts (collected in China by Frank N. Meyer and by F. C. Reimer). These are now being tested on a large scale in the open field in several localities in the West by Reimer, and in the East by the United States Department of Agriculture. O'Gara 
states that stocks of Kieffer and Winter Nelis on the Pacific Coast are quite resistant, the blight on sensitive varieties often stopping at the point of union when these stocks have been used.

Out of season the only means of obtaining material suitable for inoculation is by the use of a forcing house, by use of young

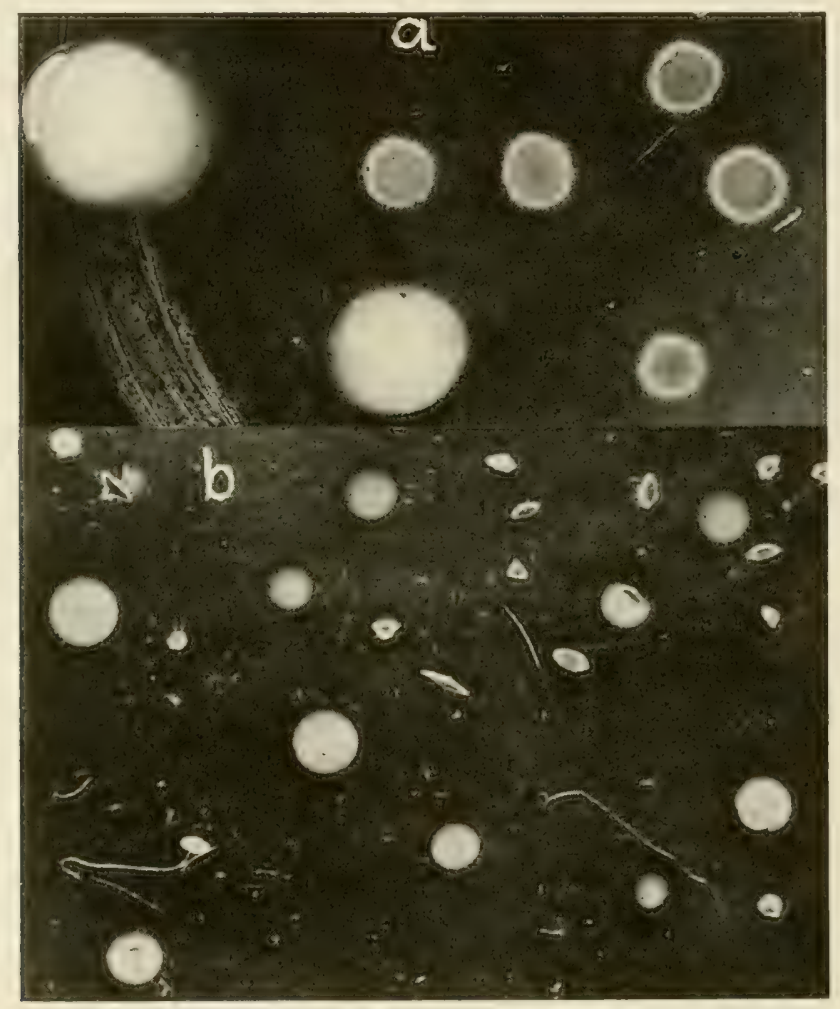

FIG. 292.- Surface and buried colonies of Bacillus amylovorus from agar poured plates. (a) The buried colonies have vague, fuzzy margins. $\times 7$. Age, 4 days. Plated from an apple, in 1905. It was with descendants of this isolation that Dr. Rudolph Aderhold, of Berlin, obtained his infections. From the unlike appearance of the buried and surface colonies he thought at first, so he told me, that I had sent him a contaminated culture. (b) Plated from an apple limb in 1915. Buried colonies not fuzzy but also infectious (see Figs. 281, 296).

seedlings, or on cut shoots by the simple means described under Type, which, however, sometimes fails.

As material for inoculation, streaks on agar or potato may be used, or bouillon or potato-broth cultures. 
FIRE-BLIGHT OF APPLE PEAR, ETC.: TECHNIC 379

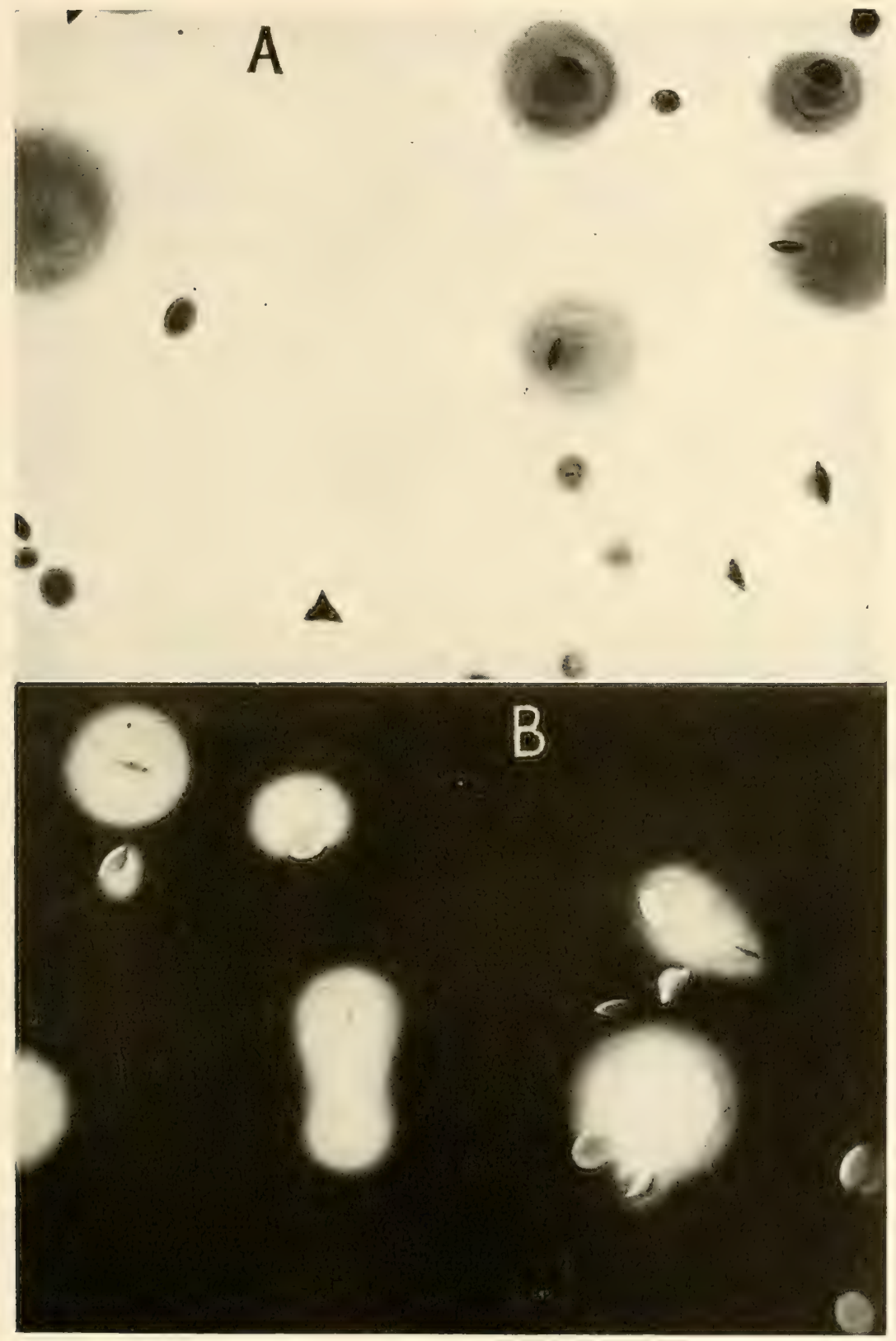

FIG. 293.-A. Surface and buried colonies of Bacillus amylovorus (isolated from apple) on a +14 beef-peptone agar plate. Photographed February 5, 1919 , by direct transmitted light. $\times 10$.

B. From the same plate but photographed by oblique transmitted light. $\times 10$. 


\section{Determine}

For the oRganism. Morphology.-Size in microns (when growing rapidly in media the rods are often several microns long - 3 to 6 or more), form, aggregation of elements, i.e., chains, filaments, pseudozoögloeae, etc., motility (on margin of hanging drop), absence of endospores, presence and distribution of flagella (use I. A. Moore's modification of Löffler's flagella stain, or van Ermengem's stain). Try Gram's stain; acid-fast stain; Capsule stains. Do involution forms occur?

Cultural Characters.-Appearance of colonies on thin-sown agar plates (Figs. 292, 293) and on gelatin plates; in stabs and streaks on agar, ditto on gelatin; behavior in peptone bouillon, in potato broth; try also malated and sugared broths. Growth in nitrate bouillon, Cohn's solution, Uschinsky's solution, milk, litmus milk. Is a lab ferment produced in milk? Beharior in peptone water in fermentation tubes with rarious sugars, alcohols, and acids. Try it also in fermentation tubes with potato broth and other plant juices, e.g., apple or pear broth. Is there any clouding in the closed end? Test milk in fermentation tubes. Can you get the results shown in Fig. 295? Determine the nitrogen nutrition of this organism.

Non-nutritional Environment.-Maximum temperature for growth; minimum? Thermal death-point? Effect of sunlight; of dry air (killed quickly), of freezing (salt and pounded ice), of salted bouillons, of chloroform in bouillon, of acids, of alkali, of germicides. Read Reimer's papers and experiment with rarious germicides.

For the disease. Signs.-Period of incubation (examine morning and night each day); signs in flowers (especially in early stages of the disease-first 72 hours); in shoots (observe that the bark of the shoot may be entirely blackened on the surface from the bacterial action and yet for a time the terminal leaves may remain green and turgid. Why?); on leaves: $a$, direct effect, i.e., dark lines running out along the petiole, midrib or side veins, due to bacterial infection from the shoot; $b$, indirect effect-black specking, flagging, reddening or browning, due to stem injuries farther down. Note the persistence of the 
leaves. Learn the appearance of "hold-over blight." Usually on smooth trunks such patches may be detected readily by the practised eye in the absence of the exudate since their color is somewhat different from that of the normal bark-redder, browner. Under rough bark detection is more difficult and a gouge should be used. Is the dark color of the blighted leaves and shoots a bacterial stain or a host reaction? Kill leafy pear shoots in various ways and see what results follow in the leaves. To what extent are the roots attacked? Write a description of the disease.

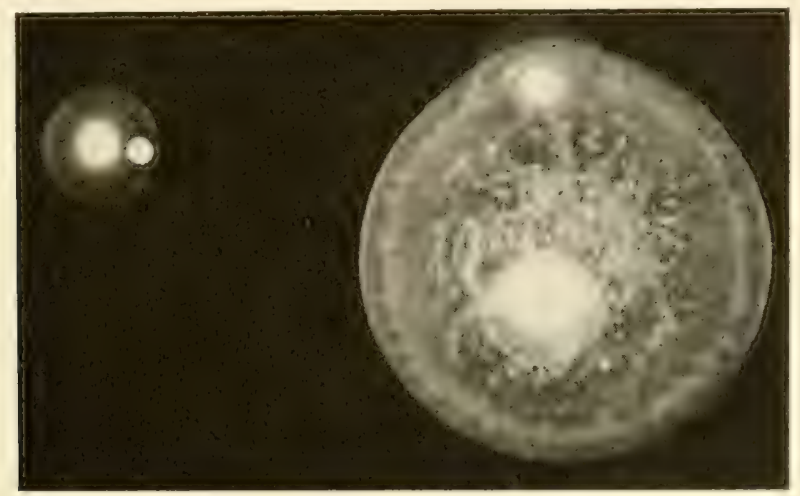

FIG. 294. - Buried and surface colonies of Bacillus amylovons after 3 days at $21^{\circ} \mathrm{C}$. on +10 peptone beef gelatin. The bulk of the surface colony is floating in the middle of a pit of liquefaction. Isolated from apple in 1915. Photographed by the writer. $\times 7$.

Histology.-How many centimeters in advance of visible blight can the bacteria be traced down the blighting shoot? What does this teach you relative to pruning for removal of the disease? Is the organism motile in the tissues? Is the wood attacked or only the bark? To determine this, examine in various places from the soft extremity of the blighted shoot downward. Any differences (compare with No. XI)? O Gara, who has had much experience, states that the bacteria may occur in the rich sap wood of the Bartlett, Howell, and other pears and in that of the Spitzenberg apple. According to Reimer this apple in no longer planted in south Oregon because of its great susceptibility to blight. When the bark only is 
involved which suffers most. phloem or cortical parenchyma? Is the cambium also attacked? What is the color of the nner bark in patches of "hold-over" blight? What tissues are honeycombed with bacterial cavities:" When the organism

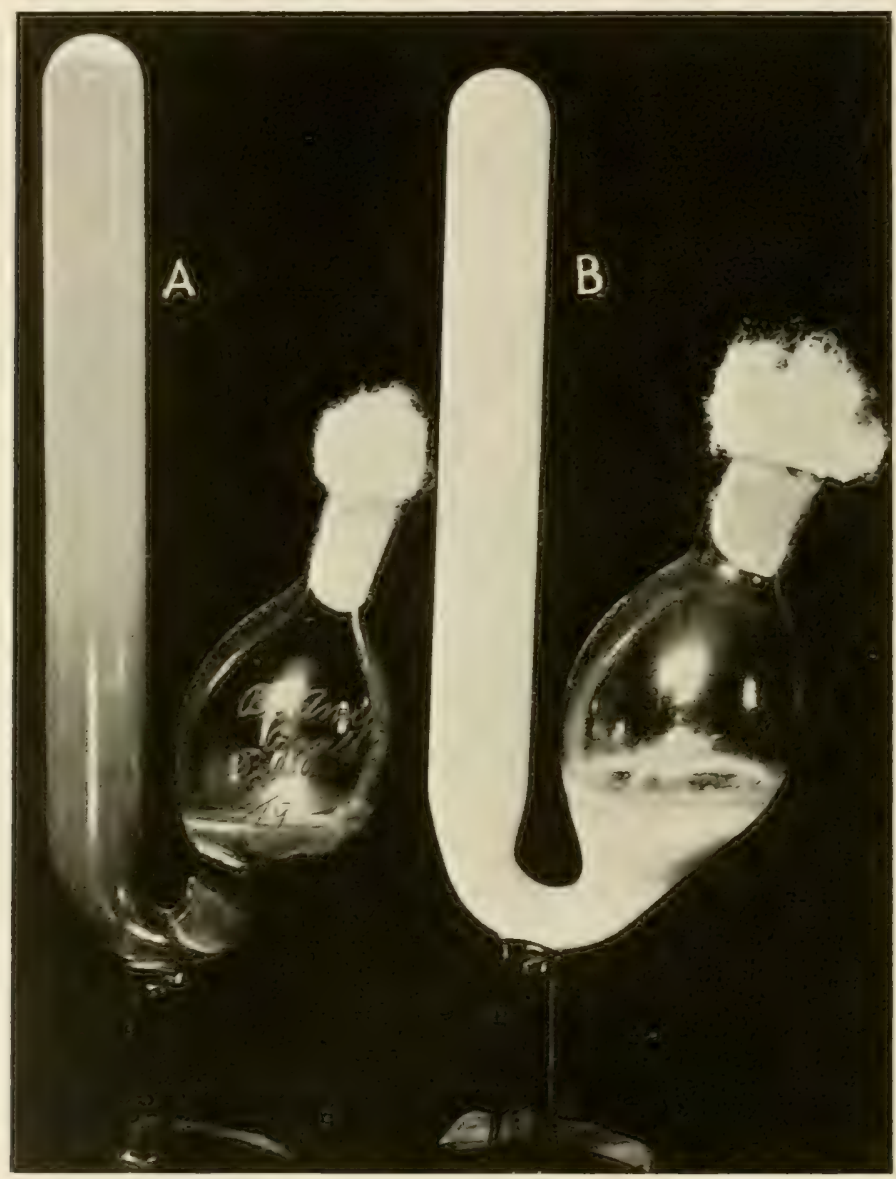

FIG. 295.-A. Fermentation tube of milk containing Bacillus amylowoms. ( i)l. 1, isolation of 1915 from apple. Inoculated August 18, 1919. Photographed sept. 27. Milk cleared and curd digested in closed end. B. Chech tube.

runs out into leaves what petiolar tissues does it invade? In petioles I have observed it wedging apart cells of the bark parenchyma and also forming cavities in the xylem part of the rascular tissues. 
If possible, embed and section on the microtome early stuges of blossom blight. Can you make out: $a$, multiplication of bacteria in the nectary; $b$, invasion of the ovary and pedicel? Is there any choice in the tissues invaded? Study also blighting shoots and fruits. The bacterial slime is often abundant enough to drip from the hands when such fruits are handled after cutting. Is the organism always intercellular or does it sometimes also enter the cells? There is a difference of opinion on this point. Do not decide too hastily. Is the cell-wall destroyed"? What becomes of it? Does the organism commonly come to the surface on attacked stems"? on fruits? Make permanent stained preparations showing relation of the organism to the rarious tissues. Contrast with No. I.

Tariabitity.-How long does an attacked shoot live? Using a susceptible rariety, study effect on rapidity of blight of: a, rapid ws. slow growth, which may be correlated with time of year (MayJune $v$ s. August-September); $b$, amount of rainfall or water given; $c$, moderate $r s$. high temperatures; $d$, light $i s$. heary inoculations, $e$, kind of cultiration and manuring. Rich soils and alkali soils are said to faror the derelopment of the disease (O'Gara).

If you have opportunity to study blighting orchards look for varietal differences. Some commonly cultirated pears are nearly immune, e.g., the Douglas, a seedling of the Kieffer (V. B. Stewart); others are very susceptible. The same is true of apples. Make inoculations on resistant and susceptible rarieties and record the results.

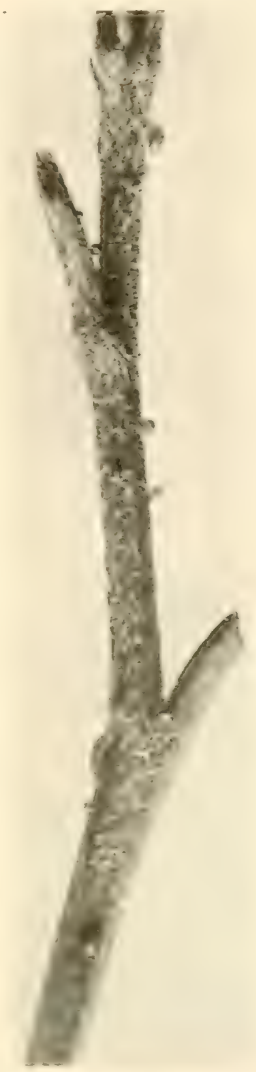

Fic. 2066.- Shoot of "Blight-proof" pear hybrid between the Chinese sand pear and some common pear). Inoculated 5 davs with a pure culture of Bacillus amylororus plated in 1915 from a blighted apple branch. Bark blighted (browned) and heads of bacterial slime oozing from the interior through stomata. May. 1915. This variety blighted rather freely as the result of needle prich inoculations. 
Whatever you do, make full and legible notes.

Transmission.-On account of its large dependence on animals (chiefly on insects) for distribution, this is one of our most interesting diseases. It is quite easy for any student who has the organism and a blossoming apple or pear tree to start blossom-infection and demonstrate transmission of the disease by bees. This was discovered by Waite. According to O'Gara the disease may be transmitted by at least 50 kinds of insects visiting pear flowers.

The disease is common, however, on nursery stock not in blossom, and here bees and flies are probably not the common agents of transmission. Sometimes birds carry the germs on their bills (sap-suckers) or on their claws, which often break and scratch twigs. O'Gara believes that the disease may be introduced sometimes through growth cracks (see No. XIII). D. H. Jones has shown that aphides by their punctures may transmit the bacteria, especially on apple trees. Some beetles also are carriers: Scolytus (D. H. Jones); and some bugs other than aphides: Lygus (V. B. Stewart). More recently (1915), A. C. Burrill also has proved the disease to be transmitted by aphicles (A.avenae), and by an apple leaf-hopper (Empoasca mali). The disease may also be spread by means of pruning tools. Waite saw a nursery block of 10,000 Bartlett trees destroyed by pear blight which was transmitted in the Spring on pruning tools. There was some "hold-over" blight in the nursery and when the tops of the trees were cut down to the dormant inoculated buds the tools were contaminated and the blight was distributed to nearly every tree. In the West, on the apple, it has been found to enter through wounds made by crown galls (O'Gara). It may also enter and blight trunks through soft water-sprouts which for this reason should not be allowed to grow around the base of the tree. According to O'Gara 80 per cent of the initial fire-blight infections in California and South Oregon were through water-sprouts and low fruit-spurs. Heald, in Washington State, has found the disease entering the plant (apple and pear) commonly through the leaves as if by waterpore or stomatal infection (1915). Do apple and pear leaves have water pores? Section a leaf-tooth and see. V. B. Stew- 
art (1915) showed that it may enter through wounds made by hailstones (compare with No. XIII and XIV).

The disease is probably carried sometimes on nursery stock, but not often, I think, owing to the fact that it dies out rather quickly in the dead shoots. Probably this fact also accounts for its not having been introduced into other parts of the world, if we may assume, as seems probable, that the eastern United States is the original home of the disease, and that it has not occurred until recently in any other pear or apple-growing region of the world. Was it introduced into Japan from the United States?

\section{Eradication of the Disease}

Complete freedom from fire-blight may never be hoped for, any more than from any other widespread and highly infectious disease, but there are certain palliatives which if properly applied will reduce its destructiveness to insignificant proportions. These fall into two main categories: (1) tree surgery; (2) resistant varieties, or rather immune stocks for sensitive varieties, since the latter include all our fine sorts of pears and apples, the discarding of which is not to be thought of.

It has been demonstrated conclusively by Waite and others that the spring blight is distributed principally by bees and ot her insects which obtain the infection from onzing patches of "holdover" blight. In the control of this disease it is, therefore, of prime importance to search the trunks, limbs and roots in late autumn or winter and remove all blighted spots. Such removal is equally important if the blight is wind-distributed, as maintained by Stevens and his associates (Science N.S., Vol. XLVIII, pp. 449-450). If this is done thoroughly over a wide area there will be very little spring-blight.

If the eradication of the canker, or hold-over blight, has been neglected the next best thing is to cut out the spring-and summerblight thoroughly as fast as it appears, including the neglected cankers, disinfecting the tools from limb to limb and tree to tree, since if you neglect this you will inevitably distribute the bacteria by means of your saw, gouge, knife and p uning shears. Both tools and tree-wounds should be disinfected. Mercuric 
chlorid, otherwise known as corrosive sublimate or bichlorid of mercury, is generally recommended for this purpose. It is made up in the proportion of one ounce of the poison to one thousand ounces of distilled water, clean rain water or boiled well water. This may be applied as O'Gara recommends by a sponge attached to the wrist or to the buttonhole by means of a string about 2 feet long. The effectiveness of this germicide is destroyed by contact with a metal container. It must be kept, therefore, in glass bottles or wooden pails, never in tin pails. Tools may also be dipped into 5 per cent carbolic acid water or into 1 part of formalin diluted with 9 parts of water. The hands must be kept out of both substances. For notes on Reimer's newer germicides for fire-blight, consult Part I, page 71.

Eventually in this country the pear blight problem, which is a very serious one, will be solved by discarding altogether the susceptible French seedling stocks (Pyrus communis) on which most of our valuable sorts are now worked, and substituting resistant stocks. The most hopeful substitutes are certain East Asianspecies, notably Pyrus ussuriensis, $P$. ovoidea, $P$. calleryana, and $P$. variolosa. All of these species are very resistant to Bacillus amylovorus, and the main question now appears to be which are the most resistant, and which will prove most satisfactory in other respects, i.e., grow equally with the graft, giving to it a firm union and a long life. For details the reader is referred to F. C. Reimer's very interesting paper "Blight Resistance in Pear Trees and Pear Stocks" (1916 Ann. Rept. Pacific Coast Assoc. of Nurserymen. Also a separate pp. 1-8). More recently (July :3, 1919) Mr. Reimer, who is superintendent of the Fouthern. Oregon Branch station of the Oregon Agricultural College Experiment station. (Post Office Talent. Oregon), has written me as follows:

"In my pamphlet I made the following statement regarding Pyrus ussuriensis: 'This species appears to be immune to pear blight, at least under the conditions in Southern Oregon.'

"This statement was based on inoculation work performed with only a very limited number of wild forms of this species. Since that statement was published we have collected at this Station a very large number of types of this species and have repeatedly inoculated them with the pear blight organism. The results based on four seasons' work may be summed up as follows so far as Southern Oregon is concerned: 
"1. Pyrus ussuriensis is more resistant to pear blight than any other known species of Pyrus. 2. Many forms of Pyrus ussuriensis have so far proved immune to pear blight, failing to blight, even in the tips of the young, tender, vigorous shoots, when inoculated. 3. Some forms of Pyrus ussuriensis blight only in the young tender shoots when inoculated, the blight usually killing such shoots back only from one to ten inches, and very rarely as much as fifteen inches, in case of extremely vigorous trees. In such cases the disease is usually confined to the current season's growth, although very rarely and in the most extreme cases it slightly enters the previous season's wood. The disease in these forms has always been confined to that portion of the branch less than one-half inch in diameter, and very seldom has progressed into wood more than one-fourth inch in diameter.

"These results were obtained in a region where pear blight is extremely virulent, on very fertile, irrigated and thoroughly cultivated soil, which produces a very vigorous growth, and where every effort has been made to induce the trees to hlight. Up to the present time no natural infections have ever been found on the young trees of Pyrus ussuriensis."

\section{LITERATURE}

For literature, consult various writings of Burrill, Arthur, Waite, Whetzel, L. R. Jones, D. H. Jones (Bull. 176, Ont. Ag. Col.), Stewart (V. B.), Sackett, Bachmann, Fulton, Heald, O'Gara, Merrill, Reimer, Stevens, etc.

See also "Bacteria in Relation to Plant Diseases," Vol. I (1905), plates 28-31, and Fig. 61. For various brief notes on the organism see also the index to Ibid., Vols. I, II, III.

The student should learn early how to use literature and should be a wide and eager reader not only of all the newer things but also of old books and papers. Search out all the pear-blight papers from the above hints and make a respectable, chronological bibliography.

Aderhold's note is in Aderhold and Ruhland's paper on "Die Bakterienbrand der Kirschbäume," Arb. a. d. Kaiserl. Bio. Anstalt f. Land. u. Forstw., V Bd., 6 Heft, pp. 334-336.

Reimer's paper "A new disinfectant for pear blight" is in Monthly Bulletin of the [California] State Commision of Horticulture, Vol. VII, No. 10, Sacramento, Oct., 1918, pp. 562-565.

P. J. O'Gara's paper "Pear Blight and Its Control upon the Pacific Coast" was published in the Medford Mail Tribune, Medford, Oregon, 1910, and a separate was issued, 8 vo., pp. 1-34.

A pear grower's observations on the disease as it occurred in New Jersey in the first years of the 19th century may be found in Wm. Coxe's book. Who was Coxe? 
The name Micrococcus amylovorus was published by Prof. Burrill in. 1882. W. amylivorus is a typographical error of 1883.

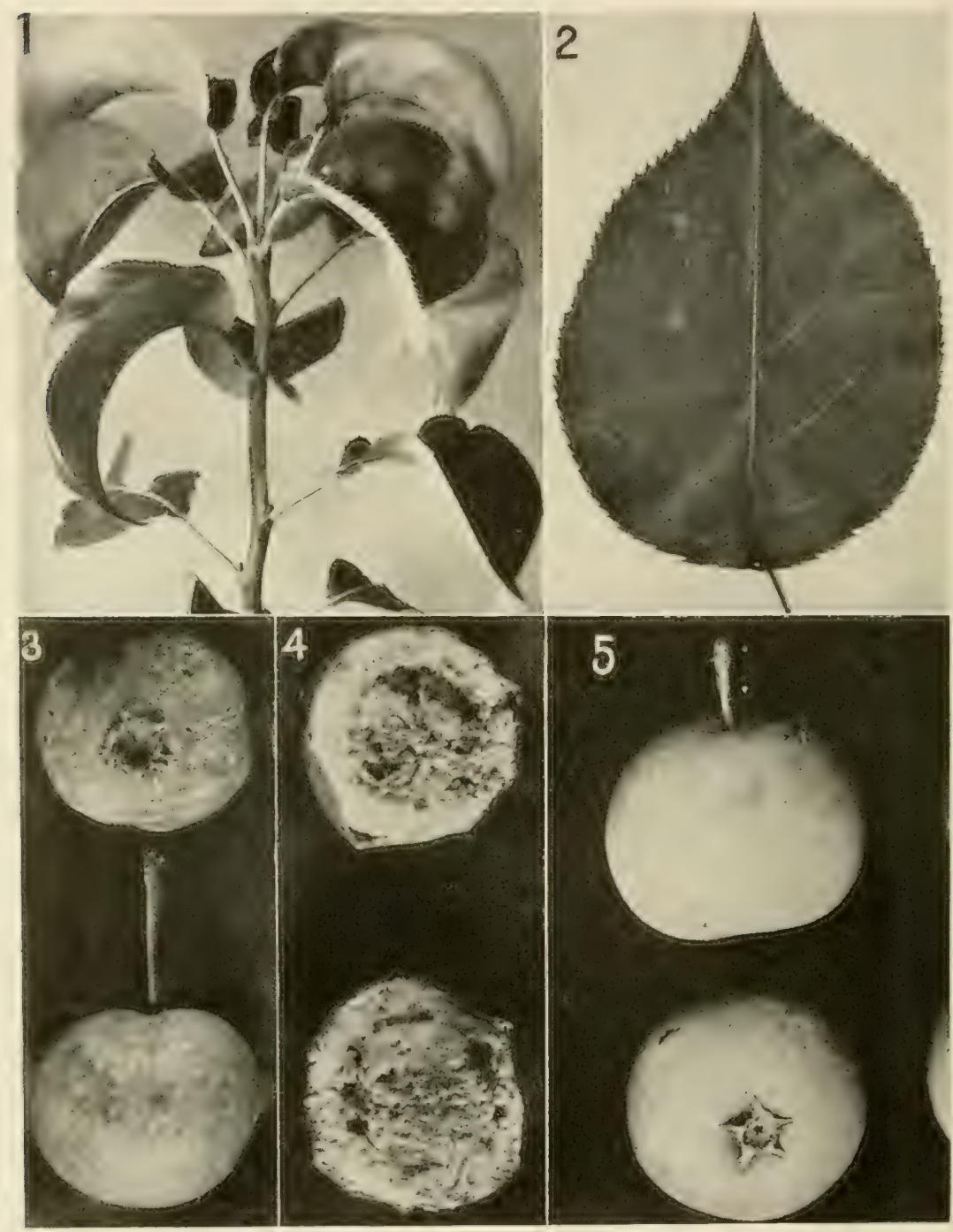

FIG. 296*.-Illustrations of Pyrus ussuriensis Maxim. Resistant to fire-blight.

1. Rosetted terminal growth at close of season. 2. Leaf showing bristled serratures ( $3 / 4$ nat. size). 3. Fruit, showing reflexed persistent calyx lobes $(4 / 5$ nat. size). 4. Ripe fruit eut open, showing easy separation of core. 5. A cultivated variety, called Man Yuan Hsiang, (about 2/3 nat. size). All from photographs by F. C. Reimer. 


\title{
XIII. THE OLIVE TUBERCLE
}

\author{
(Syn. Olive knot)
}

Type.-This disease is a conspicuous overgrowth. It occurs on wild and cultivated olives, forming large or small, irregular, spongy or cheesy knots or excrescences (Figs. 297, 298) which decay rather quickly. Attacked limbs are dwarfed or killed, and oceasionally the whole plant is destroyed, particularly if small and on irrigated land, but more often the trees are only stunted and rendered unfruitful. New outgrowths often occur around the old dead knots, and also similar growths at a distance from them. Roots, trunk, branches, and leaves, are subject. Often when a terminal shoot is attacked it ceases to grow, even if it had been very vigorous (Figs. 299, 300), and the branch is continued by one or more of the lower side shoots, the terminal shoot dying. Once attacked a tree seldom or never recovers, that is, the disease persists from year to year, and invades new shoots and lower parts of the old (Fig. 301).

No tumor-strand occurs and the secondary tumors have the structure of the tissue in which they are lodged, i.e., the disease is a granuloma. The bacteria are abundant and easily visible, being lodged first between the cells and eventually in intercellular, irregularly branched carities, around which the tissue often has a water-soaked or brownish appearance (Figs. 302, 303). During rainy weather the bacteria ooze readily to the surface of the tumor in great numbers (Horne) whence they are washed to other parts of the same tree and carried probably to other trees, entering through wounds to form other tumors. Deep tumors may also arise at a distance from the first tumor and these are due to bacteria which have migrated from the primary tumor by way of the spiral vessels of the inner wood which in such cases are browned, more or less disorganized, and occupied by the gray-white slime of the bacteria (Figs. $304 X, 305$ ). The knot contains or may contain both wood and bark, the vessels 


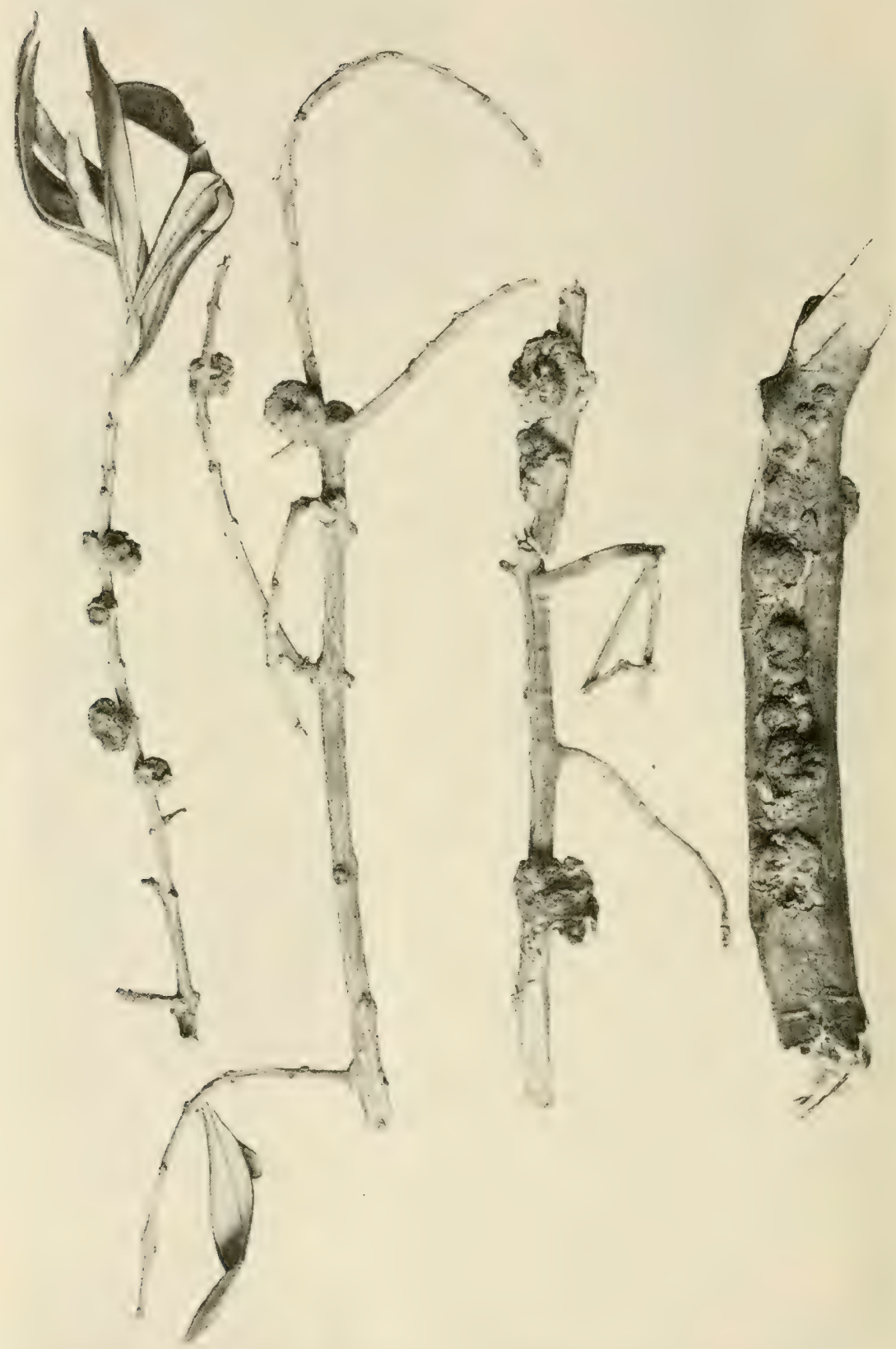

FIG. 297.-Olive branches from Genoa, Italy, bearing tumors due to Bacterium samastanoi. Collected for the writer by P. J. O'Gara in 1905. 
being greatly distorted and reduced in number while the parenchyma is in excess as in crown gall. Often a large part of the tumor, as in Fig. 306, is composed of bark, and then the tumor is of a soft "cheesy" character. The structure of a young tumor developing on the under surface of a leaf is shown in Fig. 307.

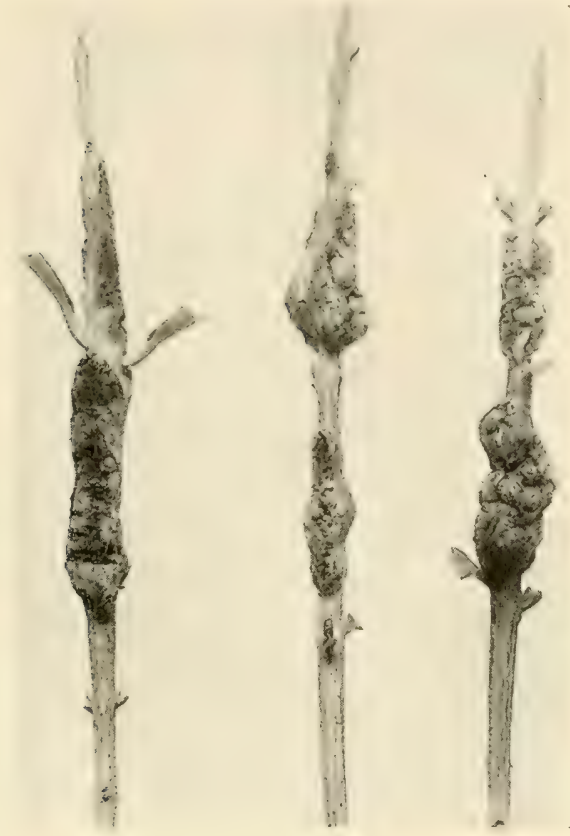

FIG. 298.

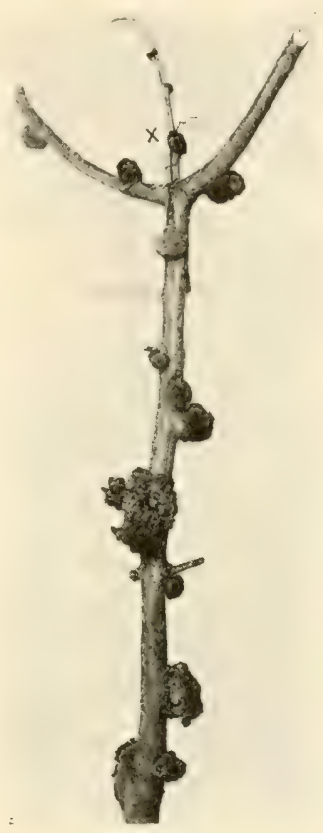

FIG. 299.

FIG, 298.-Pure-culture inoculations of Bacterium savastanoi in olive shoots in 1903. Left-hand shoot Gentile, others Nevadillo Blaneo. Time, 57 days. The organism used was plated from a California olive knot. 1/2 nat. size.

FIG. 299.-Pure-culture inoculation of Bacterium savastanoi made in 1910 , on an olive shoot at $X$, which became dwarfed and died. The lower tumors are later surface infections derived from bacteria that oozed from $X$. Photographed in 1912.25 nat. size.

This disease has been known since the time of Theophrastus (Savastano) and occurs in all olive-growing regions around the Mediterranean, and also in California, Argentina (HaumannMerck) and other parts of the world.

This same disease, or a very similar one, occurs on the European ash (Fraxinus excelsior) in France, Germany, Austria 


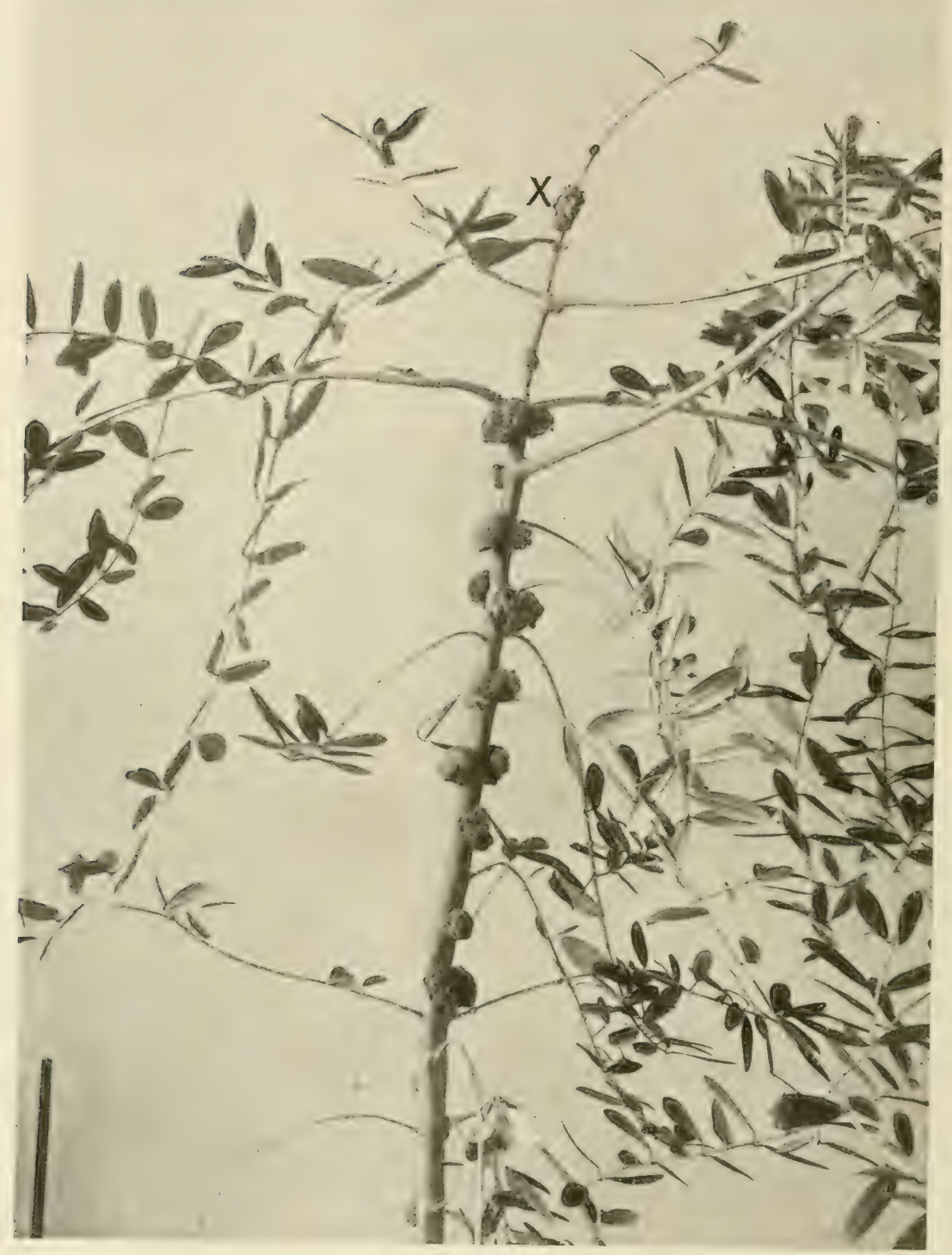

FIG. 300.-Olive tree from one of the Department of Agriculture pathological hothouses showing result of an inoculation of Bacterium savastanoi (at $X$ ). Terminal shoot stunted and many secondary infections, due to slight (natural) wounds and the free use of the gardener's hose. The artificial inoculation was made November 1, 1910, and most of the lower tumors developed the following year. Photographed January 31, 1912. 
and Italy. Noack in Germany described this ash disease in 1893 and attributed it to bacteria, solely on the basis of his microscopic examinations. Subsequently Tuillemin claimed it to be

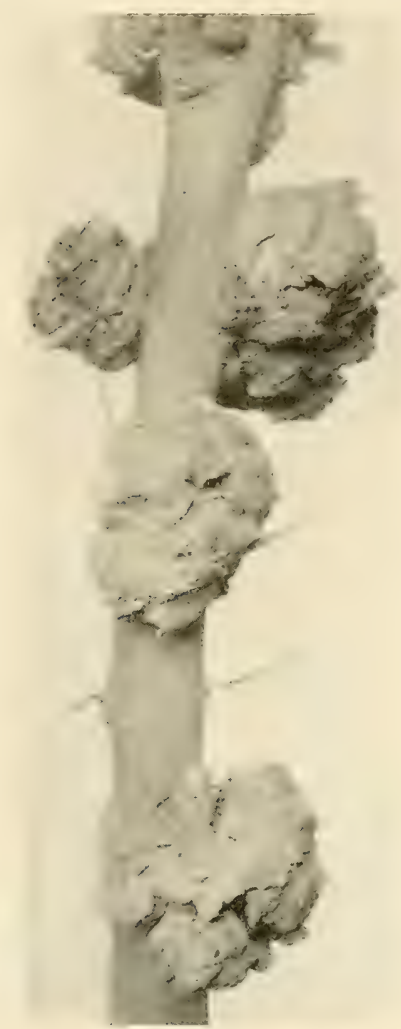

FIG. 301. the same as the olive tubercle without, however, giving his reasons. The writer first saw the ash disease in the vicinity of Vienna in 1913. It persists from year to year on the trunk and limbs, attacking chiefly the bark, making rough cankerous thickened patches as large as one's hand or larger, but also stimulating the growth of the wood so that the cankered part of the trunk or branch may be twice the diameter of the

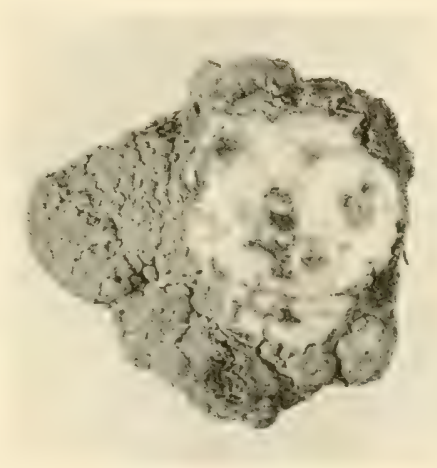

FIG. 302 .

Fig. 301.-Olive tubercle. A detail from Fig. 300, showing secondary surface infections. The primary inoculation was in 1910 with a pure culture isolated from material collected by Florence Hedges at Portofino, Italy, in 1910. Photographed December 5, 1912, department of Agriculture hot-house. Tubercles 6 to 12 months old. One-half natural size.

FIG. 302.-Cross-section of a young, cheesy olive tubercle (pure-culture inoculation), showing small brown bacterial areas with water-soaked borders.

normal parts above and below it. The micro-organism present in these ash cankers has been studied critically in my laboratory by Nellie A. Brown and myself and is scarcely distinguishable from the olive-tubercle organism morphologically and culturally 
in a variety of media and yet is not absolutely identical. With it we have produced typical small cankers on American and European species of ash, especially on the European Fraxinus excelsior, but no tumors on the olive although repeated inoculations were made on young olive shoots both in 1914 and 1915. The ash organism, therefore, should be regarded probably as a variety of Bacterium sarastanoi rather than as identical with the olive organism, or as a distinct species, but further studies and comparisons should be made.

The oleander in Europe and in some parts of the United States is also subject to a bacterial overgrowth on leaves and shoots, which by various observers has been thought to be due to the same organism as the olive tubercle, but my observations and inoculation experiments lead me to think it is not due to the olive-tubercle organism. This is also Petri's opinion.

Cause.-In 1886 Archangeli described the olive tubercle, giving the name Bacterium oleae to something observed in it but without what we should now consider to be a proper description, i.e., it was named from the microscope, without cultures or proofs of its infectiousness by inoculation, and with the statement that it probably had nothing to do with the disease, which was ascribed by him to other causes. Savastano's inoculation experiments (1887-1889), repeated and confirmed by Cavara, first proved the olive tubercle to be due to bacteria, but neither one of these men described the organism sufficiently. Savastano called his cultures Bacillus oleae-tuberculosis, but, following Trevisan, systematic writers generally have spoken of Bacillus oleae (Arch.) Trevisan as the cause of the olive tubercle. Subsequently Schiff-Georgini isolated and described very carefully a non-infectious, white, spore-bearing, peritrichiate, filamentous, potato bacillus from the olive-tubercle, called it Bacillus oleae (Arch.) Trev., and claimed to have obtained tubercles repeatedly by inoculating it into olive shoots (1905). On the contrary, Berlese (1905) considered a yellow organism isolated by him to be Bacillus oleae (Arch.) Trev., and the cause of one type of olive tubercle. Several saprophytes occur commonly in olive tubercles, one of which at least is yellow, i.e., that seen by Berlese. Savastano must also have had a yellow organism in some 
of his cultures, since he describes the olive-tubercle organism as yellow media, which it is not. According to Petri this yellow, capsulate, peritrichiate, liquefying bacillus (which he calls Ascobacterium luteum Babes) splits olive oil, forming freely a fatty acid, and is more tolerant of acids and of meat extract than the olive-tubercle organism.

There being nowhere in literature any proper description of the olive-tubercle organism and in certain quarters much scepticism as to the bacterial origin of the growth (vide Robert Hartig's Lehrbuch, 1900, p. 211, and Alfred Fischer's Vorles-

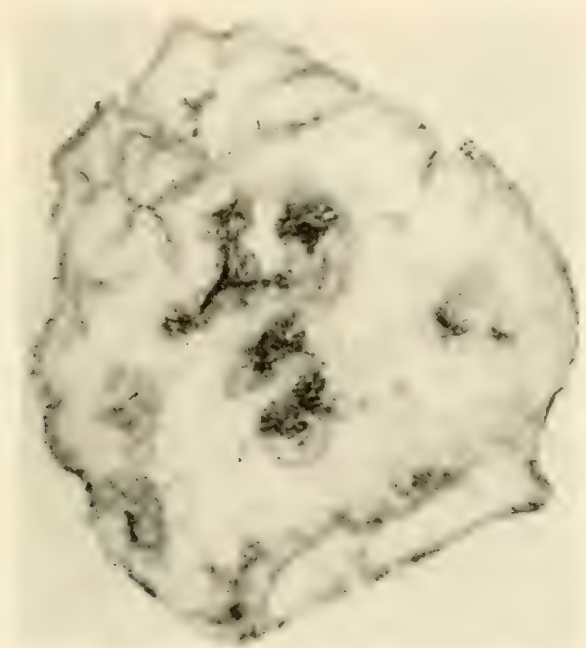

Fig. 303.- Same series as Fig. 302, but further enlarged to show irregular bacterial fissures with water-soaked borders.

ungen, 2 Aufl., 1903, p. 277), the writer undertook (in 1903) to examine the whole question experimentally. For this purpose olive tubercles were obtained from Genoa, Italy, and from California, and cultures and inoculations in parallel series were instituted, he results being: (1) repeated demonstration of the pathogenicity of a particular organism; (2) the non-pathogenicity of all the others, including the common yellow species of bacillus and Schiff-Georgini's white species which was obtained from Kràl of Prague who had received it from Kornauth of Vienna to whom it was given by schiff-Creorgini; and (3) a description 
of the parasite, which, on account of the reigning confusion respecting the nature of Bacillus oleae (Arch.) Trevisan, was given a new name Bacterium savastanoi, in honor of Luigi Siarastano (Fig. 308), who first proved the olive tubercle to be a bacterial disease. With these introductory remarks we may proceed to a description of the organism.

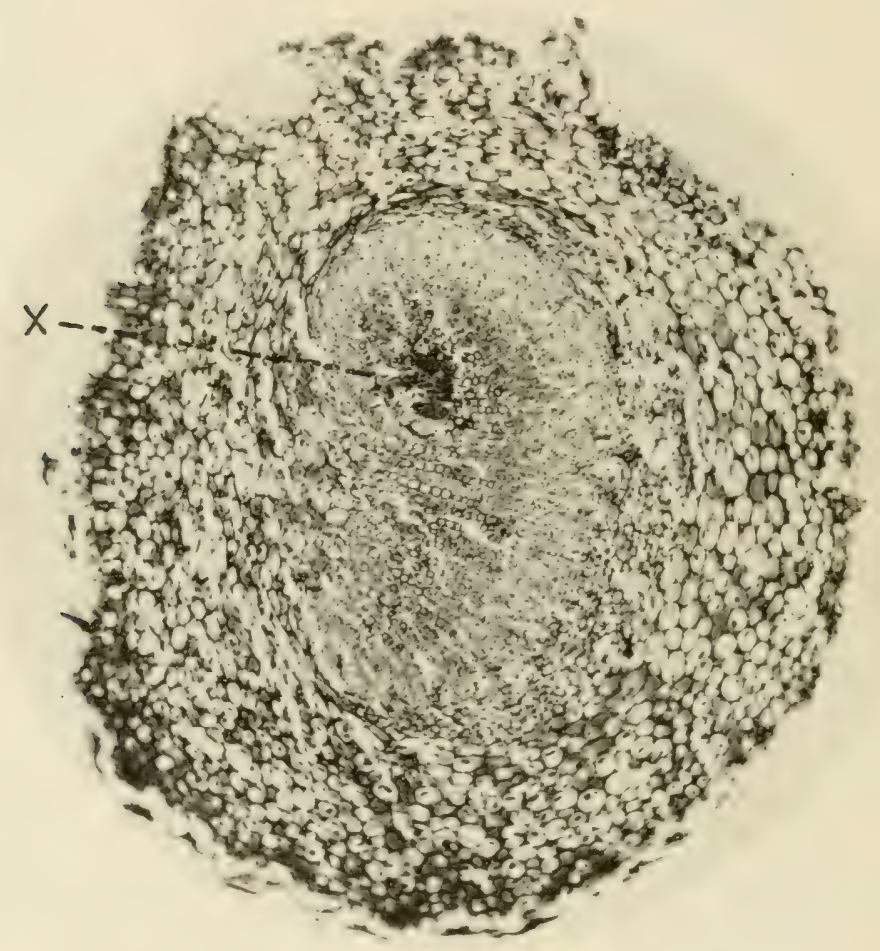

FIG. 304.-Cross-section of an olive petiole showing the brown channel of bacterial infection at $X$. Cut between a primary stem-tubercle (due to needlepricks introducing Bacterium savastanoi) and a deep (unruptured) secondary tubercle on the leaf. See next figure.

The olive tubercle is due to Bacterium savastanoi EFS. This is a slow-growing, white, non-sporiferous, motile, 1 to 4 polar-flagellate (Fig. 309), aërobic, non-liquefying Igelatin and Löffler's solidified blood serum), non-gas-forming (see Petri's statement), non-nitrate-reducing, sunlight-sensitive, heatsensitive, acid-forming (with grape sugar and galactose), 
non-milk-curdling, chloroform-tolerant, sodium chlorid-sensitive, acid-sensitive (but not to the acid of Cohn's solution), alkali-sensitive, slightly viscid (7th day on agar, 3rd day on steamed potato), rod-shaped, or occasionally short filamentous or catemulate (up to $10 \mu$ or $15 \mu$, rarely $40 \mu$ ) schizomycete. forming on the surface of +15 peptone-beef agar poured-plates slow-

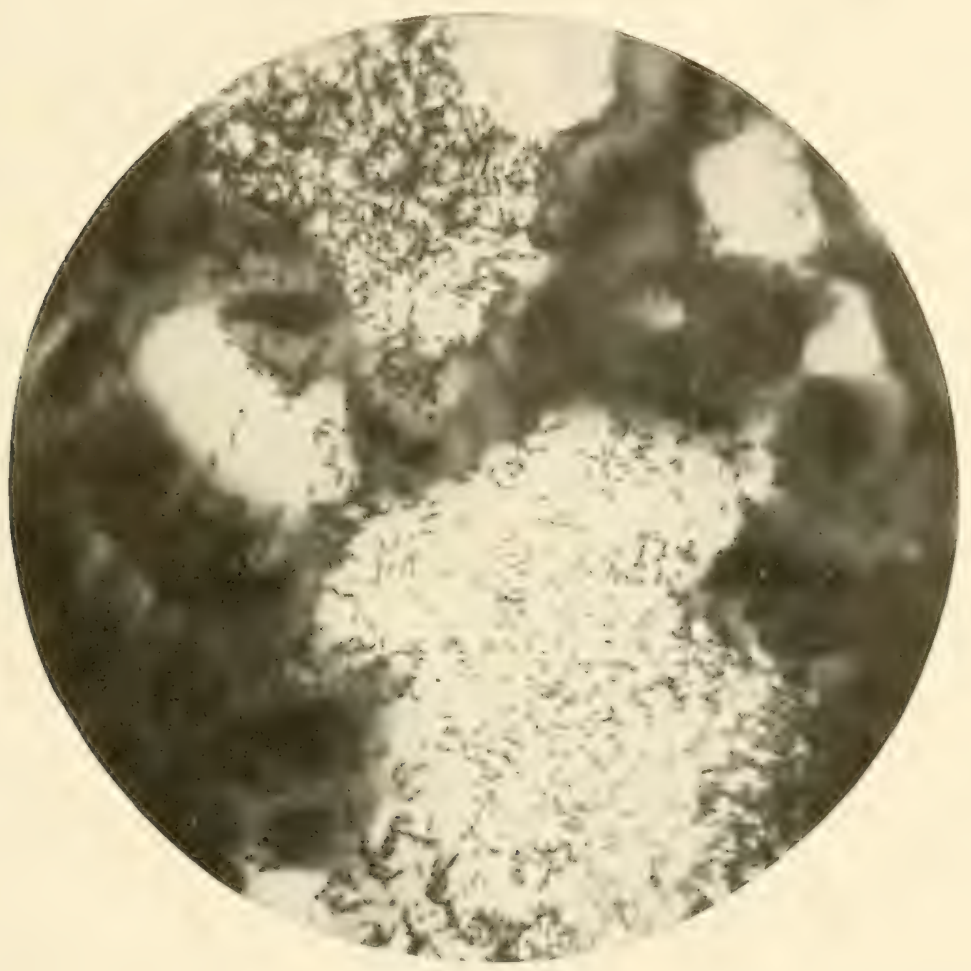

FIG. 305. - A detail from Fig. $30 t$ in the channel of infection, showing the bacteria. Tissues slightly out of focus. $\times 1000$.

growing colonies, translucent at first then pure white, which on thin-sown plates at $22^{\circ}-23^{\circ} \mathrm{C}$. may be 1.5 to $3 \mathrm{~mm}$. in diameter at the end of the third day 2 to $5 \mathrm{~mm}$. at the end of the 7th day) and are circular, flat, smooth, glistening, and entire, or nearly so (Fig. 310), the internal structure under the microscope being amorphous or fine granular; the buried colonies are quite small and often biconvex. Young and perfectly smooth surface colonies may also show for a short time a 
reticulate or fish-scale inner structure, or an opaque white center with a translucent margin. On gelatin the marginal growth of surface colonies or streaks is unlike that of the body of the colony, being undulate-erose, frilled, lobed or incised (Figs. 311 and 312). With 1 per cent dextrose added to the gelatin the colonies are frequently ring-marked (Fig. 313 ). In +15 bouillon there is a thin clouding but no rim, pellicle or floceulence during the first 4 days; later there is or may be a thin pellicle. In neutral bouillon no rim or pellicle was observed. In undisturbed tubes of 2 per cent Witte's peptone water after 5 or 6 days there is a white pellicle which falls as a whole on gentle

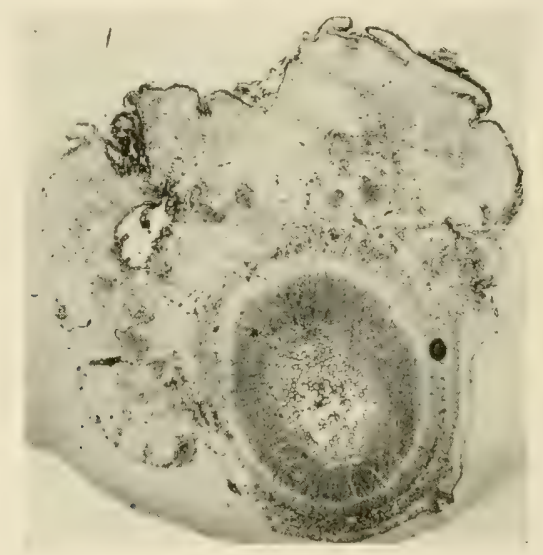

Fig. 306.-Cross-section of an olive twig at the level of a small tubercle. The open place is a bacterial cavity. Tumor composed chiefly of bark parenchyma, the pith and wood cylinder being undisturbed. Result of a pure-culture inoculation using Bacterium savastanoi. Photographed in 1904.

shaking. On steamed potato there is often a soluble brownish stain (tawny or tawny-white). This stain also occurs in some other media, i.e., water containing peptone and dextrose. Potato starch is acted upon a little, the iodine reaction being purple while that in the checks is blue. According to Petri, potato starch is converted into amylodextrine and maltose. The growth, except as influenced by the above-mentioned brownish stain, is white on all media. Milk is gradually rendered translucent (Compare with Nos. IV and XI). Lavender or lilac-colored litmus milk becomes blue. No acid is ever 
formed in litmus milk either with or without cream, nor is the casein of milk precipitated. The organism has only a very slight action on olive oil (Petri, Smith and Brown). Canesugar is inverted (Petri, Smith and Brown) There is only a slight indol reaction. The organism stains readily with Ziehl's carbol fuchsin, but not by Gram. It is not acid-fast. It grows readily and for a long time in Cohn's solution (very often in the form of long rods, sometimes in chains) without fluorescence (Petri says with it) and with the formation of numerous crystals of ammonium magnesium phosphate. These crystals

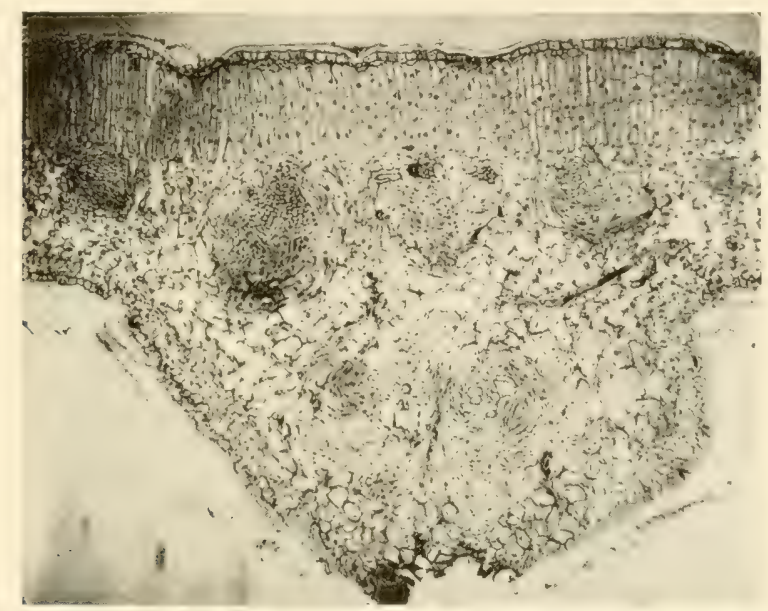

FIg. 307.- Section through an olive leaf showing structure of a young tubercle developing from the lower surface. Result of a needle-prick inoculation. Palisade tissue undisturbed.

become conspicuous in the thin pellicle if the tubes or flasks are left undisturbed for a few days. In Cohn's solution with 1 per cent dextrose, rods in clumped masses occur. In Uschinsky's solution the bacteria are motile and elongated. Repeated in 1919: thinly clouded on 4th day; best growth in top $1 / 2 \mathrm{~cm}$.; on 8 th day a thin white pellicle, no fluorescence, very thinly clouded; motile, short filaments were present; after 6 weeks still clouded, not fluorescent. The organism grows from $1^{\circ} \mathrm{C}$. or below, to $35^{\circ} \mathrm{C}$, or a little above. It will not grow in bouillon at $38.5^{\circ} \mathrm{C}$. and is always killed in +15 peptone-beef bouillon by 10 minutes exposure in the water-bath at 
$50^{\circ} \mathrm{C}$. (10-cc. portions in thin test tubes $17 \mathrm{~mm}$. in diameter inoculated from young peptone bouillon cultures). Repeated twice in 1920 with same result, following exactly Petri's methods. The checks grew promptly. The 20 heated tubes remained clear (20 days). However, $50^{\circ} \mathrm{C}$. is not the thermal death-point. That is still lower, i.e., between $43^{\circ} \mathrm{C}$. and $46^{\circ} \mathrm{C}$. (Miss Brown); over $45^{\circ} \mathrm{C}$. (Miss Elliot). It grows very slowly below $5^{\circ} \mathrm{C}$. (Petri).

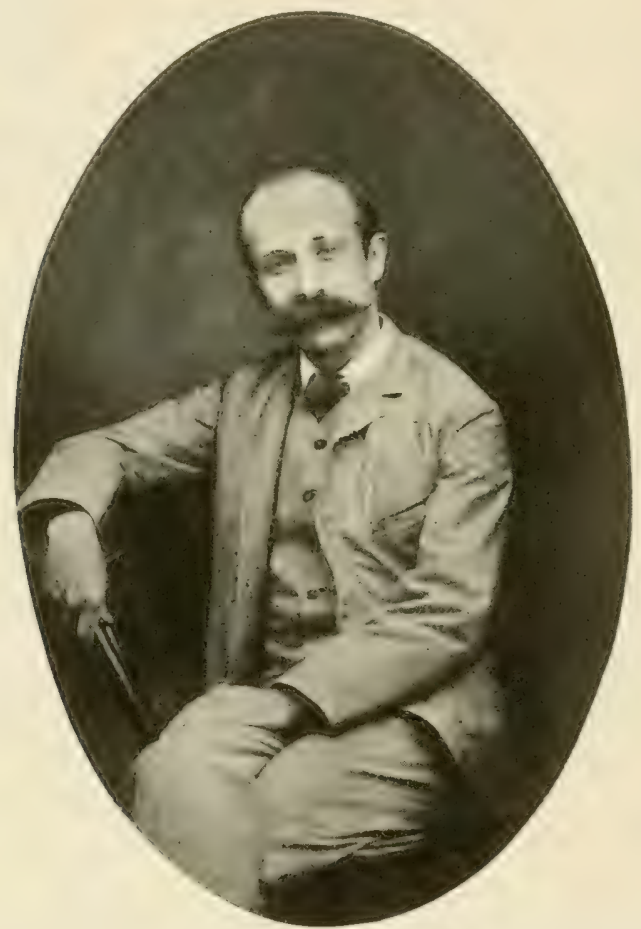

FIG. 308.-Prof. Luigi Savastano. (Photograph made in Naples at the time he was studying olive tubercle.)

A non-volatile acid is promptly formed from dextrose and galactose and this acid appears to be unfarorable to further growth. Saccharose is, on the contrary, very favorable to growth and less acid reaction is visible when it is used in litmus agar. Air is necessary for the production of acid from dextrose and galactose, i.e., there is no growth or production of this acid in the closed end of such fermentation tubes as yield it in the open end. Lactose or maltose added to litmus agar does not 
increase growth, and an alkaline reaction develops the same as on plain litmus agar (even in 30 days there is no acid reaction). Experiment repeated in 1915 with the same result. Litmusmannit-agar first blues then becomes slowly purple, or red, like the litmus-dextrose or litmus-galactose agar. Litmusglycerin agar remains neutral or nearly so for a week or more,

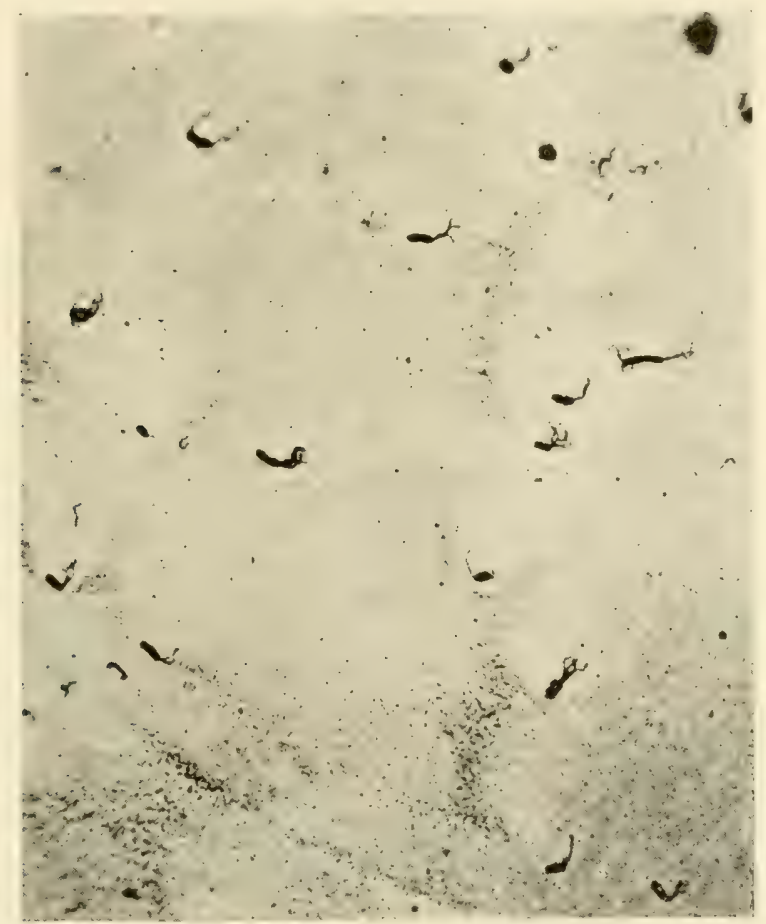

FIG. 309.-Flagellate rods of Bacterium savastanoi EFS, stained by van Ermen gem's silver nitrate method. $\times 1000$.

and then becomes slowly purple, but never red: repeated in 1915 with a good growth of the organism and the same result (tubes under observation 67 days).

Merck's peptone from flesh retards growth (Petri); prevents all growth (Smith and Brown). Liebig's meat extract retards growth (Petri). Beef bouillon is less farorable to grow th than Witte's peptone in water with saccharose (Petri). A little gas is produced in the closed end of fermentation tubes in Uschin- 


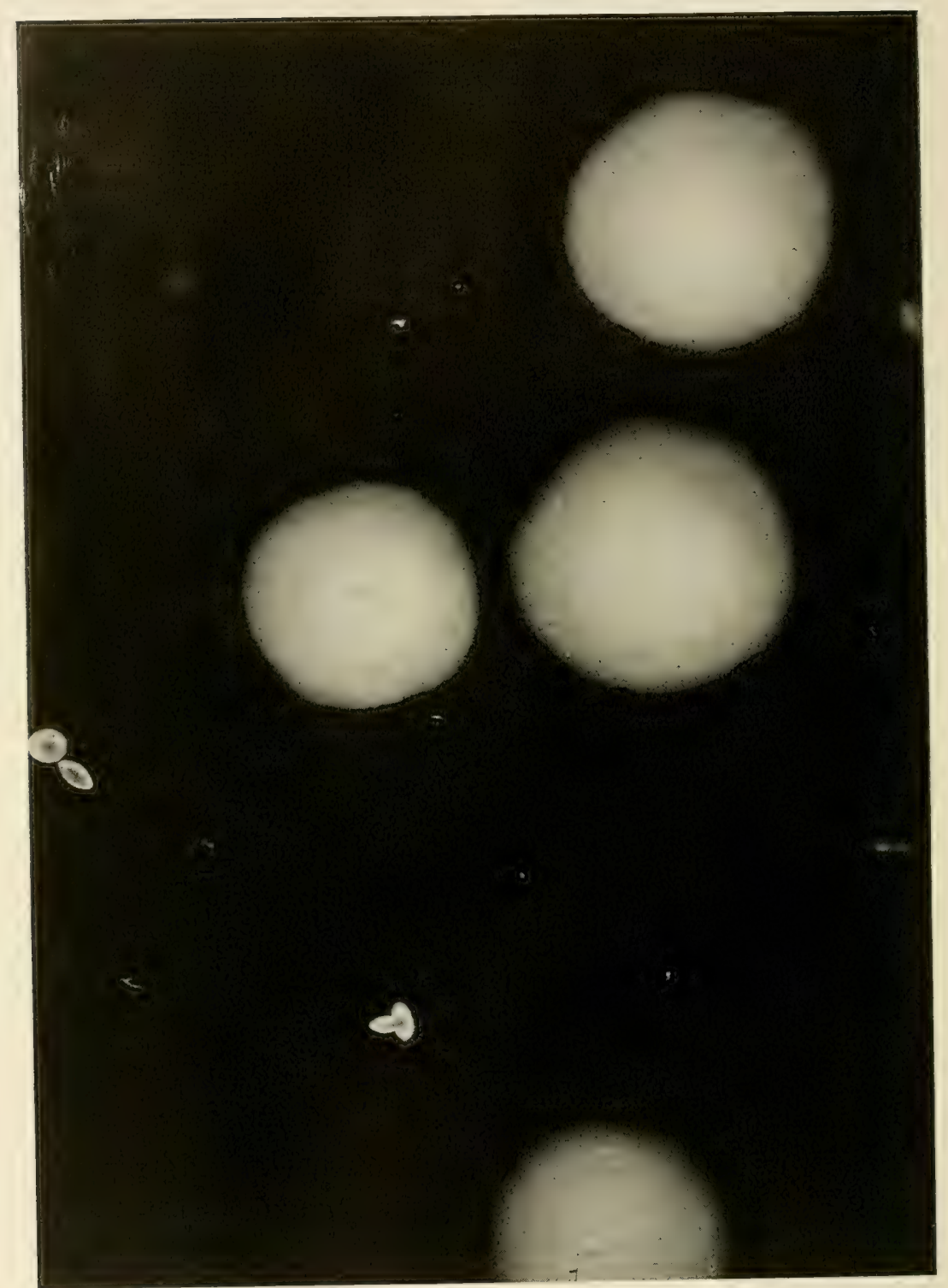

FIG. 310.-Surface and buried colonies of Bacterium savastano $i$ on +15 beefpeptone agar at end of six days at about $23^{\circ} \mathrm{C}$. Photographed March 8, 1915. $\times 10$. The slightly irregular outlines are characteristic. ، 
sky's solution containing 3 per cent xylose and the fluid becomes acid (Petri). We could not get this result with our xylose. Growth in Winogradsky's solution (nitrogen-free medium) with 3 per cent glucose, arabinose or xylose, is good, but in the same with 3 per cent saccharose, lactose or mannit, is scarcely appreciable (Petri). We could not verify these statements. A culture 20 days old in Dunham's solution, when tested for indol, gave a reddish color (Petri). Not much indol is produced (Smith, Petri). Confirmed by Miss Brown in 1915. Slow-growing, white colonies appeared on 1 per cent grape-sugar or canesugar agar (1.5 per cent agar) reinforced with a neutralized decoction of young olive shoots, the tannin compounds inter-

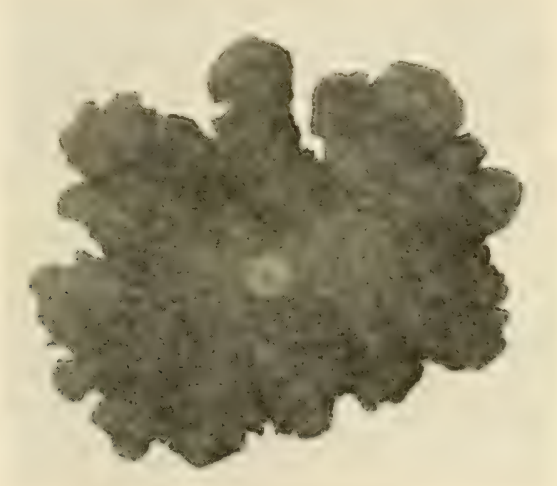

Fig. 311.-Bacterium savastanoi. Surface colony on +10 beef-peptone gelatin 37 days at $16^{\circ} \mathrm{C}$. Photographed in $1908 . \times 5$.

fering with development (Petri). No growth for us. It is viscid on cooked potato (Petri). The most rapid and abundant growth was in Cohn's solution plus 1 per cent anhydrous dextrose, in which there was an abundant white precipitate with formation of a thick pellicle and after about 20 days a pale greenish color (pea-green) in the upper part of the fluid (Petri). Correct, except that we could not verify the greenish color with the Portofino olive organism ( 80 days), but did so with the Vienna ash organism (28 days and later). Neutral bean agar is said to be a good medium for long-continued growth, especially when a trace of sodium phosphate or potassium 
phosphate has been added (Petri). Petri probably used the acid phosphate. Very likely there are several strains of this organism, all pathogenic, but somewhat different culturally (see No. XIV).

The organism according to my observations does not lose virulence quickly on media. It is killed by 30 minutes exposure to sunlight in thin-sown agar plates exposed bottom up on ice (Fig. 314). Repeated in 1915, exposing for a shorter time, when colonies appeared on the insolated half of the plates exposed for 5 minutes, but none on those exposed for 10 minutes (at $15^{\circ} \mathrm{C}$.).

Technic.- The parasite being abundant and active in cavities in the olive tubercle, its isolation offers no special difficulty provided young undecayed parts are selected. The surface should be scraped and then flamed or soaked 60 seconds to 5 minutes, depending on size of the piece, in 1:1000 mercuric chlorid water. The piece selected should be crushed thoroughly in bouillon, the bacteria being allowed to diffuse for an hour or more before plates are poured, which should be both from the tube containing the mashings and from two dilutions of the same. Success in the first series of plates often depends on the care with which the dilutions are made, not only in this instance but in many others. Various contingencies must be provided for, always, especially the two opposite possibilities: $a$, great abundance of viable bacteria in the part selected, which would make thick sowings undesirable, or, $b$, the opposite, which would make thick sowings absolutely necessary.

In making inoculations select rapidly growing soft shoots and introduce the bacteria by pricking the shoots several times with a delicate needle two inches below the growing-point, being careful not to crush or tear the tender bark. Such shoots should be selected as will continue to grow for a month or two. For comparison inoculate some slow-growing shoots. Leaves may be inoculated in the midrib, and in the parenchyma; they should be less than half grown, but comparisons may be instituted by inoculating full grown ones.

Young streak cultures on slant agar or on potato cylinders may be used for the inoculations.

The writer made one unsuccessful attempt to inoculate 


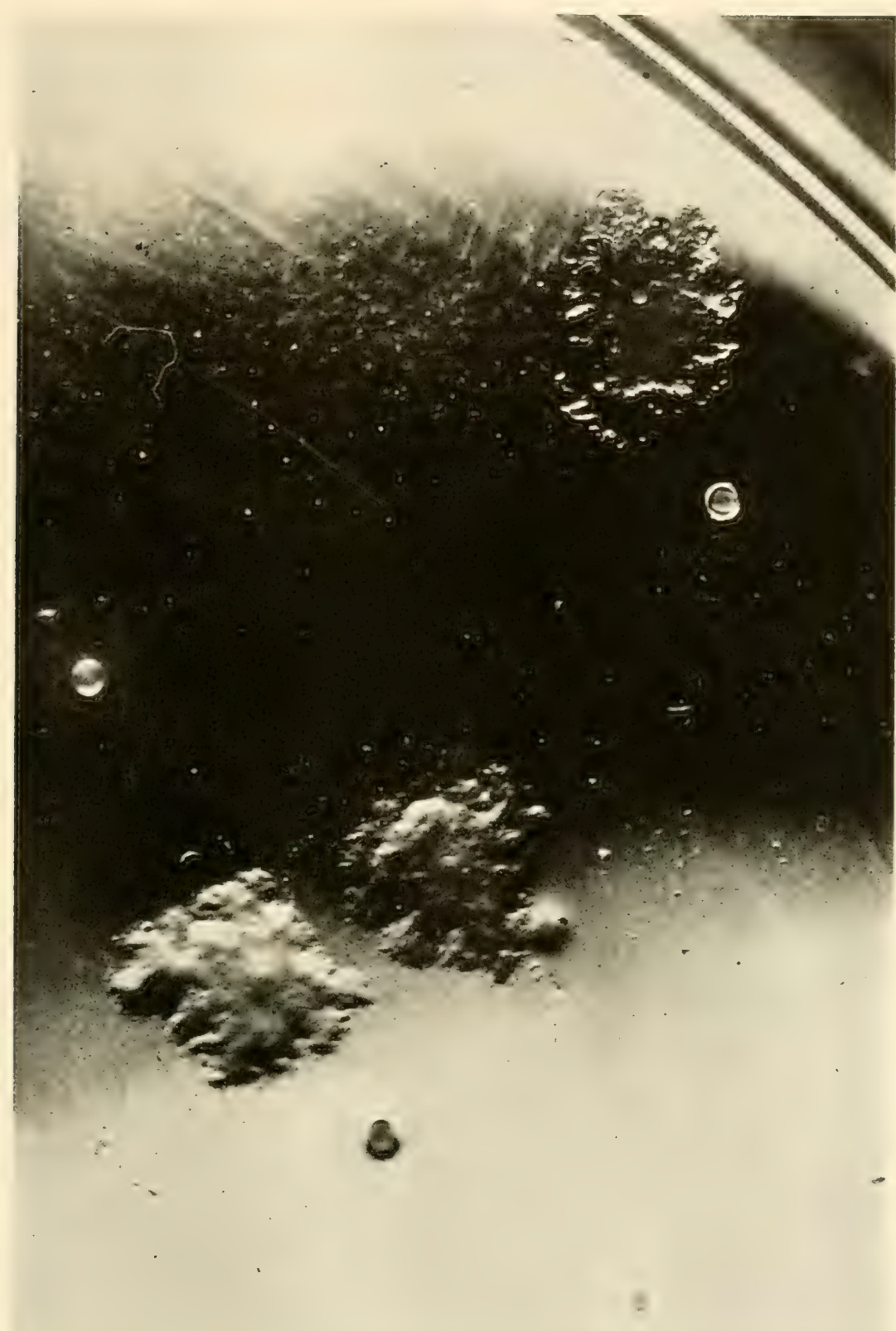

FIG. 312.-Characteristic surface and buried colonies of Bacterium savastanoi on +10 beef-peptone gelatin poured November 26,1910 , kept at about $20^{\circ} \mathrm{C}$., and photographed December $7 . \times 8$ circa. 
through stomata, i.e., by spraying young actively growing shoots under a bell jar. This should be tried repeatedly (in moist air). Is there any special reason why stomatal infections would be more than ordinarily difficult? Cut sections of the olive leaf and study the stomata. Often, perhaps always, the disease begins as a wound infection.

Olives may be propagated from cuttings, but in most instances it will be more convenient to buy the few plants needed from some nurseryman who makes a business of growing them. They should be young plants, and in the extreme southern part of the United States, and similar climates, they may be grown out of doors, but in most parts of the temperate zones they require a warm house: They should be planted in good carth, but do not require large space. I grow them preferably in a deep bed, but if more convenient they may be in small tubs or large pots. Many varieties are subject to the disease.

If cuttings are made they should be from side branches (terminal 5 inches), not in new growth. These are bedded (lower two-thirds) in sand and watered sparingly, the lower leaves being cut away close and the upper ones trimmed back one-half to two-thirds. Several months are required to root the cuttings and they cannot be used the same year.

\section{Determine}

For the organism. Morphology.-Size in microns, using young cultures on various media. Search for chains, filaments and pseudozoögloeae. For elongated forms examine young cultures in bouillon, Cohn's solution, Uschinsky's solution (contrast with Bacterium mori), peptone water with 1 per cent grape sugar, with 2 per cent glycerin, etc. Are capsules formed? Petri says they are not. Try viscid potato cultures. Search for spores. What are your reasons for thinking none are formed? Examine for motility on the margin of a hanging drop, using old and young cultures. Stain for flagella, determining the number and point of attachment. Select your own stain. Is the organism acid-fast? Does it stain by Gram? Are there any involution forms:" Petri has figured interesting 
club-shaped and branched bacterial forms found in gastric diverticula of the larvae of the olive fly (Dacus oleae), and calls them Bacterium savastanoi.

Cultural Characters. - Study and describe the behavior of this organism on thin-sown agar plates; in agar stabs and streaks. Look for ring-formed colonies in peptone gelatin plates contain-

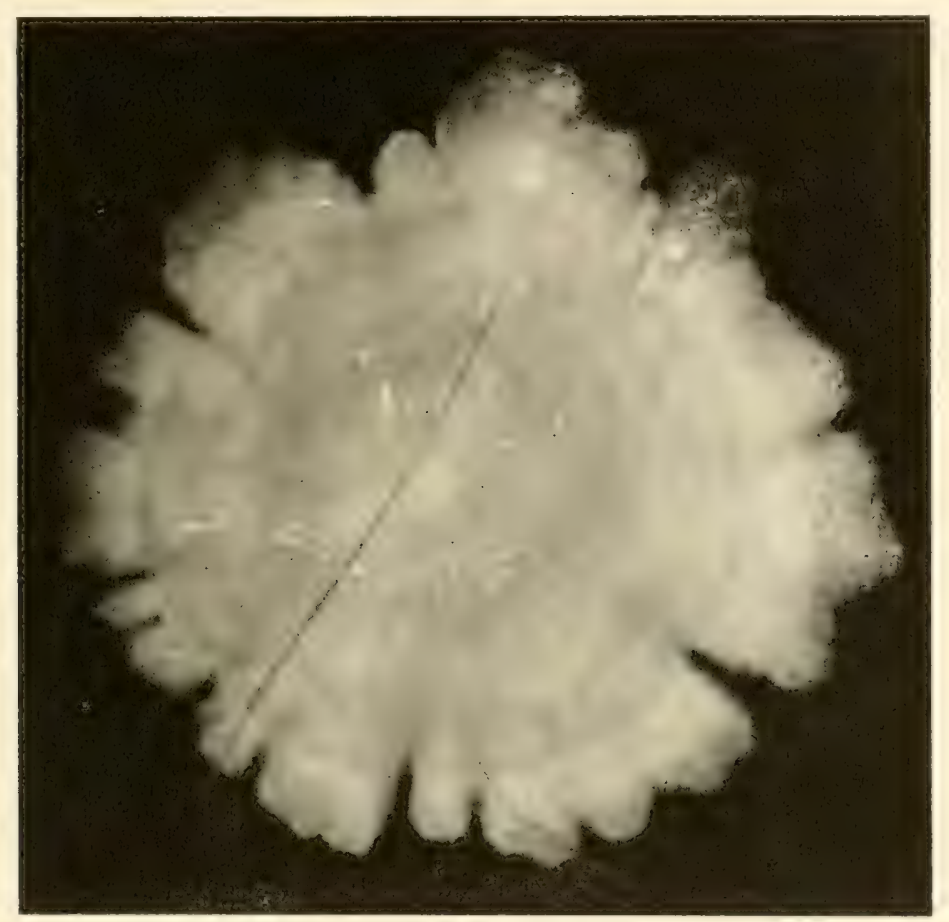

FIG. 313.- Surface colony of Bacterium savastanoi on +10 peptone-beef gelatin containing 1 per cent grape sugar. Time, several weeks; temperature $18^{\circ} \mathrm{C}$. Photographed to show lobes; and the ringed appearance, first mentioned by Petri. $\times 7$.

ing 1 per cent dextrose (Petri). Make very thin-sown +10 beef-peptone-gelatin plates, keep at $20^{\circ}$ to $22^{\circ} \mathrm{C}$. and draw the peculiar marginal frill. Observe the same marginal behavior on gelatin streaks. Savastano likened this growth on gelatin to a leaf. Study development of the pellicle in tubes of peptone water. Observe the formation of crystals in Cohn's solution, e.g., in an undisturbed small flask. Collect them in quantity 
from flask cultures, wash free from organic matters and test them qualitatively for the presence of magnesium, phosphorus and ammonia.

Describe its behavior in bouillon, and nitrate bouillon. Test 10-day and 20-day-old peptone water or peptone-bouillon cultures for indol, using Bacillus coli for comparison. Study its behavior on potato and other cooked regetables and make a note of any striking appearance not here recorded. Do the potato cultures yield a brownish stain? Are they viscid?

Determine behavior of organism in peptone water in fermentation tubes with various sugars and alcohols (these fluids should

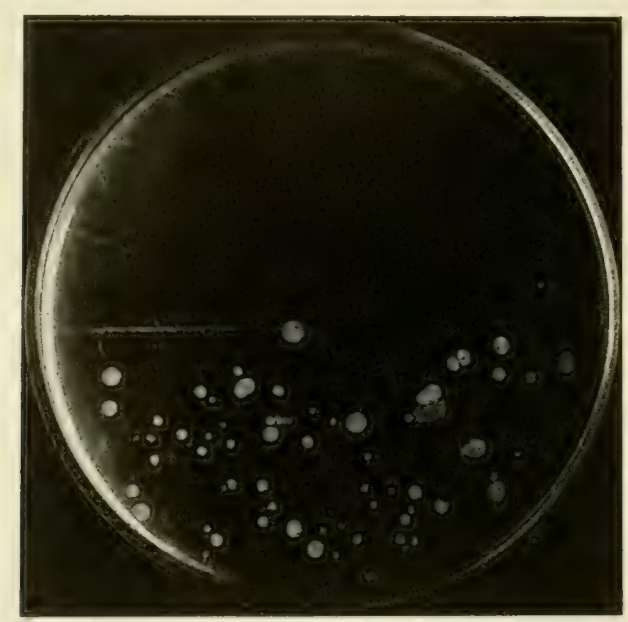

FIG. 314.-Agar-poured plate of Bacterium savastanoi insolated 30 minutes in April, 1908, and photographed 5 days later. The colony-side was covered as far as the line with folds of black paper.

be titrated and corrected to +15 on Fuller's scale). After a week, pipette out the cloudy fluid from the open end of the tubes containing dextrose and titrate with phenolphthalein and $\mathrm{N} / 20$ sodium hydrate; then remove the clear fluid from the closed end and titrate as before. Any difference? Try comparative streaks on peptone litmus agar, having previously added to some tubes 5 per cent cane-sugar and to others 5 per cent dextrose. Any difference in color-reaction or in volume of growth? What is the acid formed from grape sugar? 
Non-nutritional Environment.-Determine sensitiveness of the organism to Liebig's meat extract, to concentrated beef juice (titrate), to Merck's peptone from flesh, to heat, to freezing, to sunlight, to dry air, to sodium chlorid (try 2 per cent first), to sodium hydrate, and to various acids (citric, malic, tartaric, etc.). Also test effect of various fungicides. What is the optimum temperature for growth? With us it has grown better at $20^{\circ} \mathrm{C}$. than at $30^{\circ} \mathrm{C}$. or above. According to Petri, its optimum temperature is about $20^{\circ} \mathrm{C}$. Are your experiments in conformity with this conclusion? Can you obtain growth on or in any medium at $0^{\circ} \mathrm{C}$. ? Carry on the experiment for several weeks and watch your ice thermostat very carefully. Can you get it to grow at $37^{\circ} \mathrm{C}$.? What is the thermal death-point? (See Petri's observation.)

For the disease. Signs.-After inoculation, how long before incipient tubercles are visible on leaves and shoots? Examine about every third day. (In my own experiments these growths were seldom clearly visible, as such, earlier than the end of the second week and the tubercles continued to grow for several months.) Describe the gross appearance of the young tubercles; of the old ones; of the effect of the disease on roots, trunk, branches and leaves. Are the tubercles always fissured? Do they contain an unusual amount of tannin, or peroxidase?

Histology. - With a razor or very sharp knife cut slices freehand of young soft galls ( 1 to $2 \mathrm{~cm}$. in diameter) and examine under the hand lens. Draw some of them enlarged a few diameters. Examine also at once in water under high powers of the microscope in thin, freehand sections. Can you make out the bacteria? Can you see them flood out of the tissues? Contrast with No. XIV. Fix in Carnoy's fluid, embed in paraffin, and cut in various directions to learn the distribution of the bacterial cavities and the reaction of the tissues. To what is the watersoaked appearance due? Are the bacteria lodged between the cells or in their interior? What tissues are chiefly involved in the overgrowth? Is there action of the organism at a distance? If you have studied crown gall, compare sections of the two tumors, and of stems cut between primary and secondary tumors. Some of our thin sections have been stained with Ziehl's carbol 
fuchsin. This stain gives sharp pictures of the bacteria but is apt to overstain portions of the sections. Try amyl Gram, which is very good. Can you devise a better single stain, or a good double stain?

Watch young leaves situated immediately above developing stem tumors and if internal secondary growths occur along the midrib, cut cross-sections of the petiole and of the stem below it for presence of the channel of infection leading from the primary tumor. If you find it well-developed (as in Fig. 304), i.e., as a tiny brown spot, cut also longitudinal sections involving its path and make permanent stained preparations. Draw some of the bacteria seen in it, together with the surrounding parts.

Is the tubercle corked over? Is there commonly a secondary fungous infestation? What other bacteria have you been able to cultivate from natural tubercles? Can you isolate SchiffGeorgini's spore-bearing bacillus (Consult Centralb. f. Bakt. 2 Abt., XV Bd., 1905, p. 198, and U. S. Dept. of Agric., B. P. Ind. Bull. 131, Pt. IV, p. 38)? Berlese's yellow species?

Variability.-All choice cultivated varieties of olives are subject to this disease, and the securing of a profitable resistant sort is a work for the future. In Italy the Maremmano and Leccino are rather resistant (Ferraris, 1915). In California Nevadillo blanco and Manzanillo are more subject to this disease than the Mission olive. The greatest variability thus far observed in this country has been that due to varying degrees of cultivation and water-supply. As in pear blight, those infected orchards that are well tilled and abundantly irrigated or liable to heavy rainfall are most subject to this disease. Frequent light rains are also favorable to the spread of the disease, per contra dry situations and bright sunshine are unfavorable to it.

Transmission.- It is generally believed in Italy that wounds due to hail-stones faror the entrance of this organism, and also those made at harrest-time by the peasants, who thresh the tall straggling trees with poles to dislodge the olives. Observation shows that the tubercles often originate in scars where leaves or branches have been torn off. The reason for these various wound-infections was unknown until Horne, Parker and Daines 
in California showed that under the action of rain the tubercles ooze bacteria freely to their surface from whence they are washed to other parts of the tree. They conclude that: "The infected trees must be covered during the rainy weather of winter with an almost continuous coating of the specific bacteria." Probably birds and insects also help to spread the disease, but exact experiments, so far as I know, are wanting. Petri in Italy has shown, however, if not absolutely at least with a fair degree of conclusiveness, that the olive fly, Dacus oleae, carries this organism along with the yellow bacillus (Ascobacterium luteum Babes) in its salivary gland and intestinal diverticula as a regular (symbiotic) occupant (vide Centralb. f. Bakt. 2 Abt., XXVI Bd., p. 357, and more especially "Ricerche sopra i batteri intestinali della Mosea olearia," Memorie d. r. staz. di patologia vegetale, Roma, 1909, from which also I have taken various accredited citations under Cultural Characters, etc.). The second organism mentioned is the yellow saprophyte so often found in the olive tubercle. Also as in pear blight, it is likely that the disease is sometimes spread by pruning instruments, and certainly it must be brought into the orchard frequently from the nursery. In California during the dry summer season no new infections occur but with the coming on of winter rains and of spring rains infections are numerous. Horne and his colleagues believe that infections take place without insect wounds, by growth of the bacteria in bark crevices from which they penetrate the deeper tissues especially over places subject to tension from rapid internal growth, and that varieties with a smooth bark and an open habit of growth like the Mission olive are, for these reasons, freer from the disease than those having a rough bark and a more compact habit of growth.

LITERATURE

Read: (1) Smith, Erwin F., "The Olive Tubercle," Science, N.S., Vol. XIX, p. 416, March 11, 1904; (2) Do. "Some Observations on the Biology of the Olive-Tubercle Organism," Centralblatt für Bakteriologie, etc., 2 Abt., XV Bd., 1905, p. 198; (3) Do. "Recent Studies of the Olive-Tubercle Organism," Bull. 131, pt. IV, Bureau of Plant Industry, U. S. Dept. Agri- 
culture, Washington, Govt. Printing Office, 1908; (4) Horne, Parker, and Daines, "The Method of Spreading of the OliveKnot Disease," Phytopathology, Vol. II, June, 1912, p. 101; and (5) Horne, W. T., "The Olive Knot," Monthly Bulletin, State Commission of Horticulture, Sacramento, California, August, 1912, p. 592.

Consult also "Bacteria in Relation to Plant Diseases," Vol. I, 1905, Figs. 38 and 57, and Plate 2 ; and Vol. II, Plates 6 and 9, and Fig. 23. Other recent literature is mentioned in Bulletin 131 (above reference number 3), where the name Bacterium savastanoi was first used.

The book by T. Ferraris is "I Parassiti vegetale delle piante coltivate od utile," Hoepli, Milano, 1915. 


\section{THE CROWN GALL}

\section{(Syn. Plant Cancer)}

Type.-This also is an overgrowth, but of a different kind from the preceding. Crown gall is a disease of wide geographical distribution, occurring on a great variety of cultivated plants (Figs. 315 to 319 ) and on some wild ones, e.g., the chestnut. It is primarily a disease of the parenchyma but it is unlike any of the diseases hitherto described in that the cells of the at-

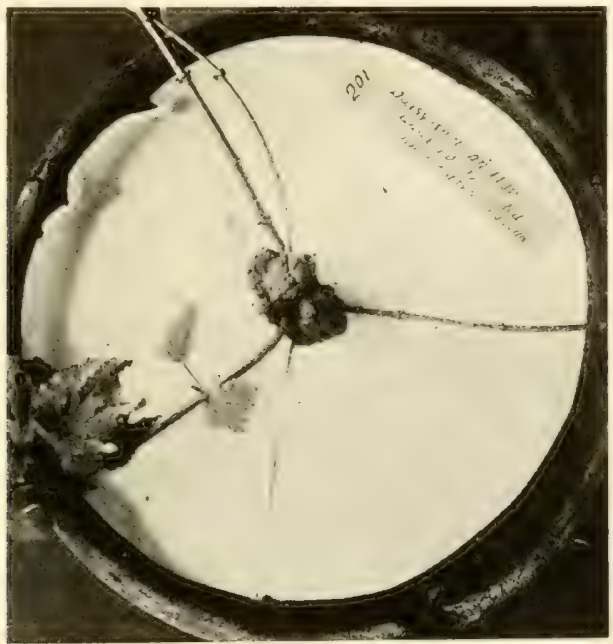

FIG. 315.-Crown gall on hop. Paris daisy strain. A pure-culture inoculation. Time, about 3 months. April, 1907. 1/3 nat. size.

tacked parts are not disintegrated and killed, but on the contrary are induced to multiply, the result being an imperfectly vascularized, covered or naked, irregular, soft or hard overgrowth, or tumor, composed in part at least of masses of rapidly dividing, round or spindle-shaped cells of reduced size, forming a hyperplasia, which on some plants under favorable conditions may be larger than the root or shoot that bears it (Fig. 320) but then 
frequently decays readily, especially on soft plants like the sugar beet and the willow (Figs. 321, 322). The nature of the very large hard tumors on oak trees common in the United States is still undetermined. The largest crown-gall I have ever seen weighed 96 pounds; this was received in 1919 by Dr. B. T. Galloway and is now in. our collections. It was found on the stem

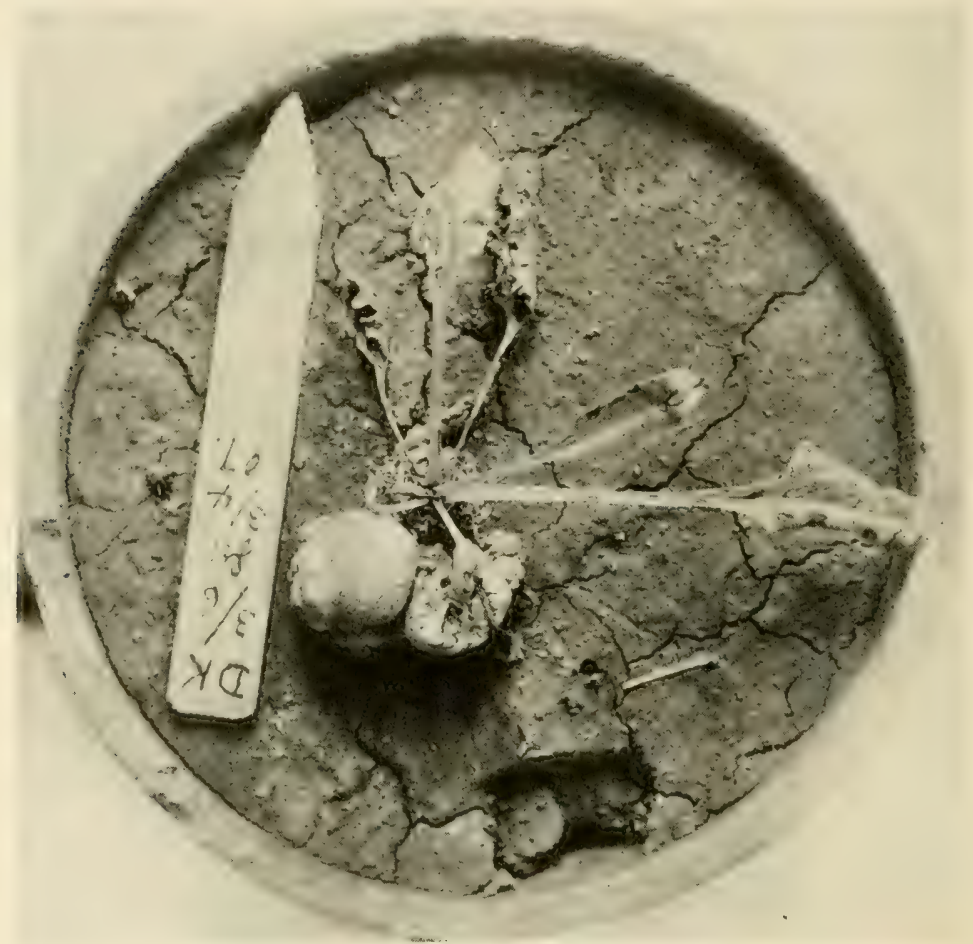

FIG. 316.-Dwarfing effect of erown gall on sugar-beet. Pure-culture inoculation. The organism used was plated from a gall on Paris daisy. Tumor larger than the root. Time, 37 days. Inoculated June 3, 1907. 1/2 nat. size.

of a wild fig on an island in the Florida everglades 40 miles southwest of Miami (Florida State Park). Dr. I. B. Pole

$1 / 2$ nat. size. A serious disease of roses. (3) On apple limb. Above-ground tumors-one growing out of pruned end. From an apple tree in North Carolina. 1911. $3 / 4$ nat. size. Often the entire tree is attacked in this manner. (4) On a pear seedling grafted by Hedgcock with fragments of a rose-gall in the summer of 1907. Photographed December 23, 1907. 3/4 nat. size. See next page. 


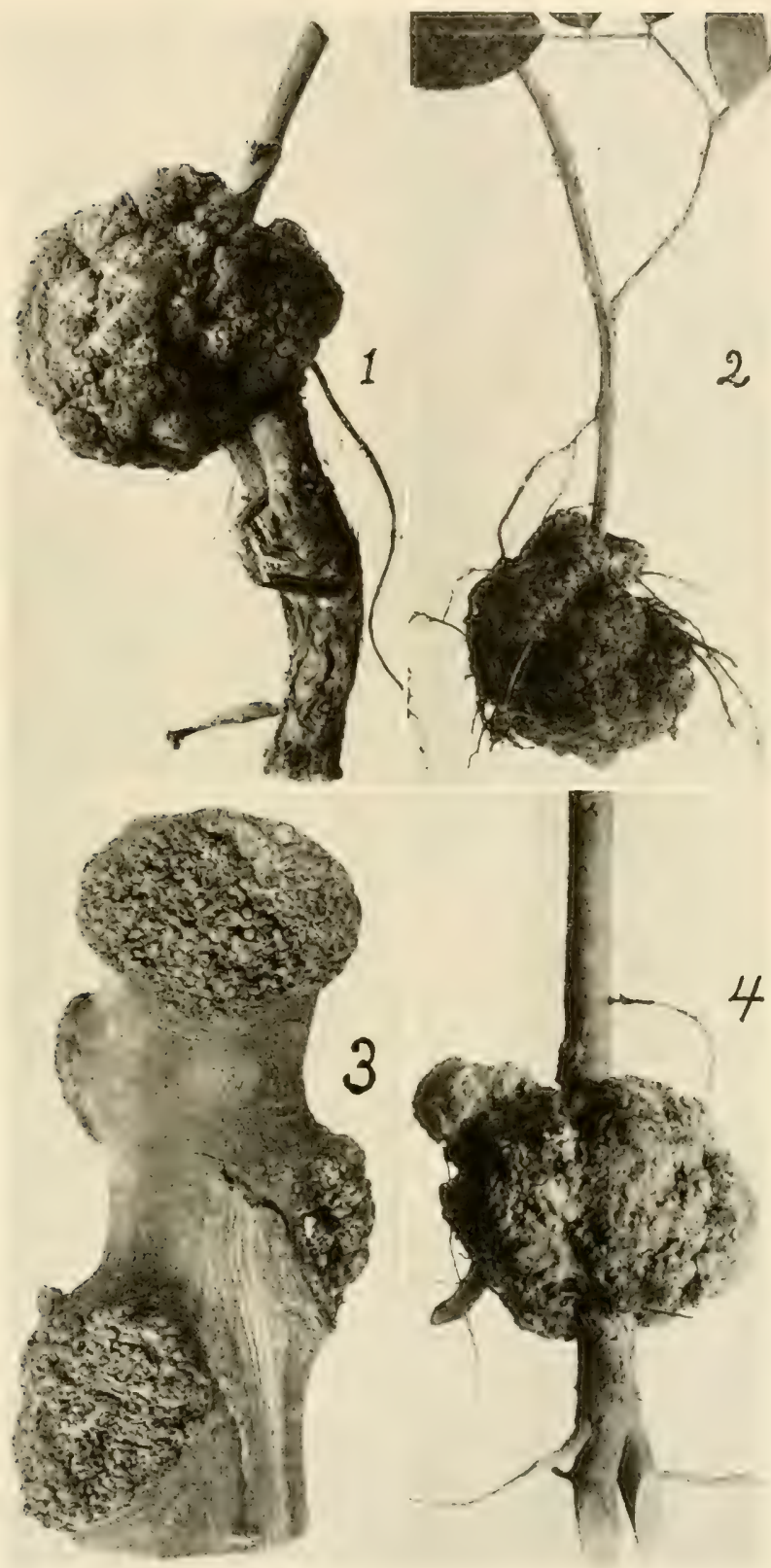

Fig. 317.-Crown galls due to Bacterium tumefaciens: (1) On hop. Natural infection from Washington State. 1908. 1/2 nat. size. Stem dwarfed above the tumor. (2) On rose. Natural infection from a New Jersey rose house, 1909, 


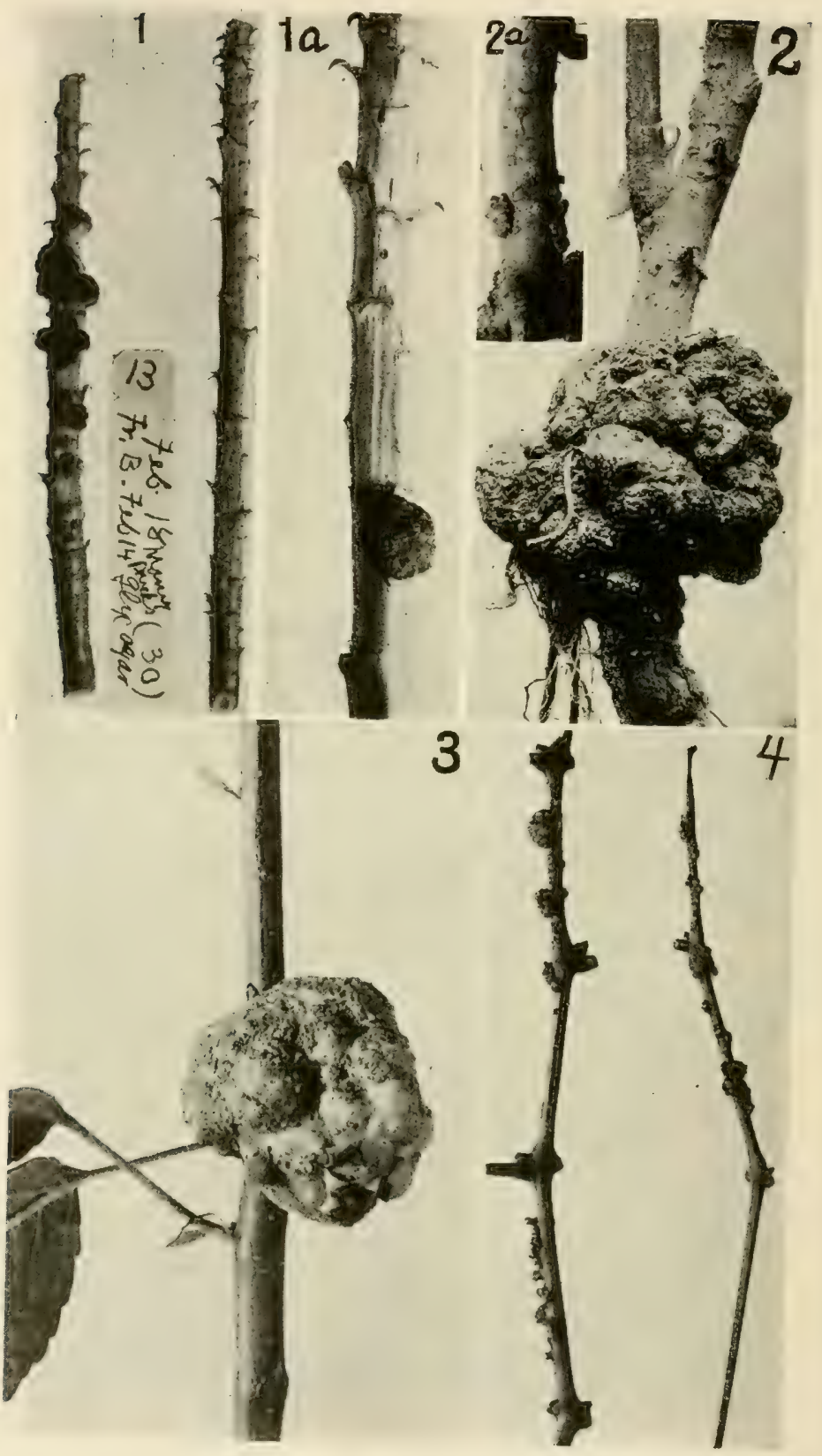

FIG. 318.-Pure culture inoculations of erown gall: (1) On yellow Paris daisy. Check stem at right. Time, one month. February, 1907. The upper softer 
Evans, of Pretoria, has reported still larger ones from the willow in south Africa (20 inches long with a circumference of 4 feet, 7 inches).

This disease is of a peculiar type: (1) in that the growth is extra-physiological and injurious to the rest of the plant, slowly dwarfing or killing it; (2) in that secondary tumors occur as growths from tumor-strands which are bedded deep in the normal tissues (Figs. 319, subs. 5, 6, and 323 to 325 ) and derived by growth (cell-division), in the form of a continuous chain of cells, from the primary tumor; and, finally, (3) in that the secondary tumor's reproduce the structure of the tissues in which the primary tumor has developed even when they appear in other organs, thus if the primary growth is in the stem and the secondary is in a leaf, the attacked part of the leaf will be converted into a pseudo-stem (Figs. 326 and 327, sub. 4). As bone is often out of place in malignant animal tumors, so lignin may be out of place in crown gall (Fig. 328).

The largest tumors are developed out of the cambium, but small ones may be produced by very shallow punctures into the bark parenchyma and these become rascularized (Fig. 329). I have not always been able to produce galls by inoculations into the pith. Much depends on its age. The growth of the tumor may stimulate multiplication of the surrounding uninoculated tissues. For evidence of this, see the lower part of Figure 329 (under $\mathrm{X}$ ) where large bark-parenchyma cells are subdividing, and (Fig. 319, subs. 5 and 6) where the wood is greatly thickened on the side of the stem bearing the tumor strand.

Attacked branches are frequently killed (Figs. 330 and 319, sub. 3), but seldom is the whole plant killed, at least not for a long time, if it is of any size when attacked. Attacked plants are generally more or less stunted in their growth, especially if

part of the shoot has developed the larger tumors. (1a) On yellow Paris daisy, showing tumor due to a single infected needle prick. Sterile pricks above. (2) On peach. Time, 5 months, nearly. The organism used was plated from a gall on the peach. 1908. (2a) On peach. Time, 18 days. (3) On apple. Inoculation from peach, made high up on the stem by needle pricks. 1908. $3 / 8$ natural size. Time, 5 months. Stem above is dwarfed. (4) On European grape. With bacteria plated from crown gall on poplar. Time, 44 days. 1910. A serious disease on raisin grapes (Muscats) in California. 


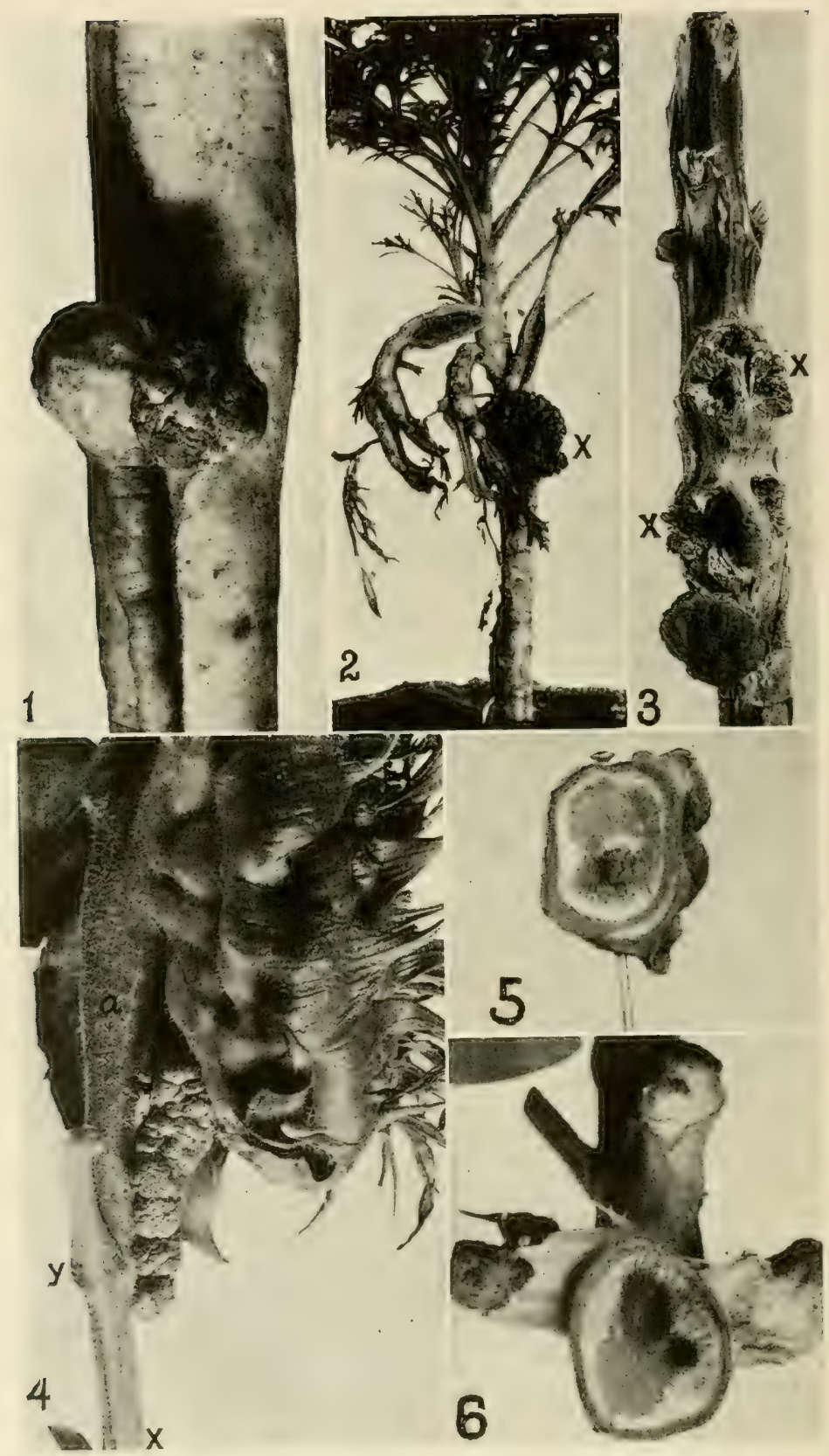

Frg. 319.-Pure culture inoculations of Bacterium tumefaciens: (1) On Japanese radish. The organism used was plated from a radish. 1912. 1/2 nat. size. 
the tumor is centrally located and then the plant may be killed outright, but this is much less frequently the case than with animals attacked by cancers, the anatomy and physiology of the plant being specially unlike that of animals in that there is no central digestive, nervous, or circulatory system subject to attack, with a disastrous reaction upon the whole organism. The nearest analogy to this is the growing point of centrally growing soft plants like young sugar-beets. If the needle is set in so that this is interfered with, as the big tumor develops, death occurs within a few weeks. See Jour. Cancer Research, Vol. I, No. 2, Pl. VII $a$ - All of the inoculated plants there shown died a few weeks later. I have obtained the same results on tobacco.

The organism causing this tumor occurs only inside of certain of the proliferating cells. When the cell divides, the organism is carried over into the daughter cells, in at least a part of which it multiplies. It occurs in the cell in comparatively small numbers and, owing to the granular nature of the protoplasm cannot be made out satisfactorily even with high powers of the microscope. By means of gold chlorid impregnation followed by formic acid we obtained a deep blue-black stain in certain rod-shaped bodies in the tumor cells (Figs. 331, 332) and for a time these were interpreted as the intra-cellular bacteria, but I now regard them as mitochondria.

In 1916 the writer discovered crown galls bearing leafy shoots and subsequently produced many by needle-puncture inocula-

(2) On Paris daisy. 1911. Time, 73 days. Primary tumor at $X$ on stem, secondary tumors in 3 leaves. These were connected with the stem-tumor by tumor-strands lying deep in the wood. $1 / 2$ nat. size. (3) On Paris daisy. The original tumors $(X, X)$ have decayed and a new tumor has grown out below. Stem dead. Time, 10 months, nearly. 2/3 nat. size. (4) Sunflower. Inoculated in the disk when young (August 14, 1915) with isolation from the hop (4-day agar-streak). A tumor-strand passed through the pith rupturing to the surface below in two places-that shown and as a small tumor in axil of $Y . \quad 1 / 2$ nat. size. (5) On Paris daisy. Cross-section of stem showing a primary tumor below and a large green tumor-strand with thickening of wood on that side. The strand was under strong pressure and protruded when the stem was cut. $\times 2$. (6) On Paris daisy. Inoculation made on stem below cut here shown. Observe one-sided thickening of wood, and three tumor-strands which passed to as many leaves, two fusing. The leaves, which bore secondary tumors, were cut away some weeks earlier and from the stubs new tumors have grown out. Time, March, 1911. 


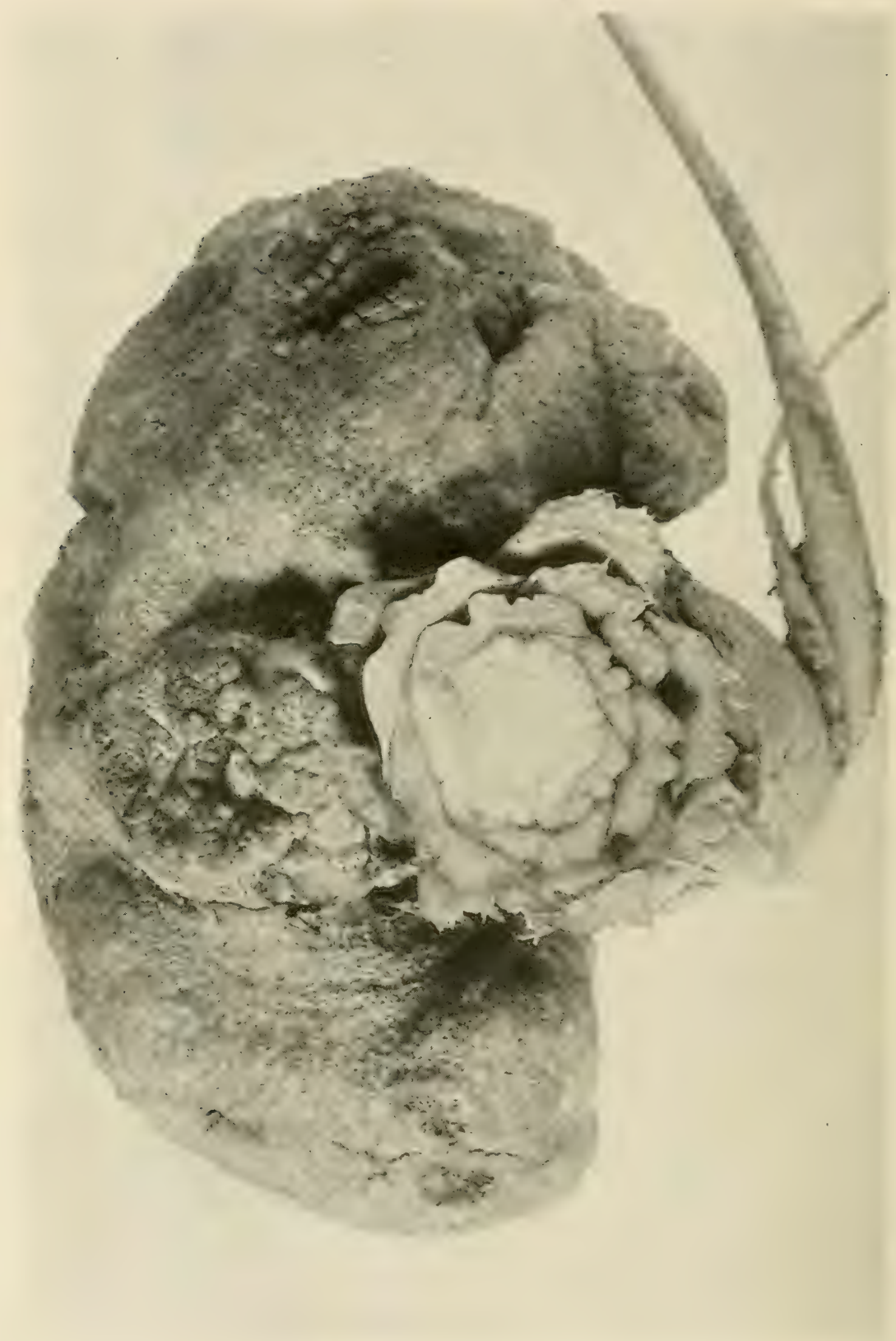

FIG. 320.-Crown gall on sugar-beet due to Bacterium tumefaciens. A pureculture inoculation of 1913. The organism used was plated from a hop tumor. 
tion on stems and leaves of tobacco, Pelargonium and other plants.

Earlier than this by some years, Miss Brown and myself had demonstrated that crown galls may bear roots (hairy root of apple, etc.) but I did not then perceive the full meaning and trend of this discovery, viz., that because the type of a crown gall depends on the kind of tissues inoculated it should be just as easy to produce tumors bearing leafy shoots or flower buds as roots. This had to be stumbled upon to be seen, like many another perfectly obvious thing. Its discovery, however, it seems to me, adds very considerably to our knowledge of the nature of crown gall and throws a flood of light also on the origin of animal teratomas.

The subject of teratomas is so interesting that I have included a number of our more striking results (Figs. 333 to 344 and 347 , 348).

The common name "crown gall" serves to recall the fact that the galls are found very often on the trunks of various fruit trees at the surface of the earth, i.e., on the part known to gardeners as the "crown" of the plant. They may occur, however, on any part of the root or shoot, being very common above ground on the branches of the daisy, grape, quince, apple, rose, willow and poplar. They are also common on the roots of a variety of plants but must not be confused with root galls due to nematodes.

This disease is common in many localities in North America, Europe, South Africa (Fig. 322), and other parts of the world, and is coming to be recognized in the United States as a more serious disease than it was formerly supposed to be.

Cause.-Crown gall is due to Bacterium tumefaciens Smith and Townsend. This is a small, white, motile, polar flagellate (Fig. 349), non-sporiferous, Gram negative, non-acid fast, nonliquef ying, non-nitrate-reducing, aërobic, non-gas-forming, nonstarch-destroying, dry-air-sensitive, sunlight-sensitive, chloro-

The inoculation was by needle pricks from a 1-day agar-streak culture. Leaves cut away to get a clearer view. Actual size (longest way) of the tumor a little more than 5 inches. Time, 3 months. Tumor larger than the root and still sound, i.e., free from necrosis. 


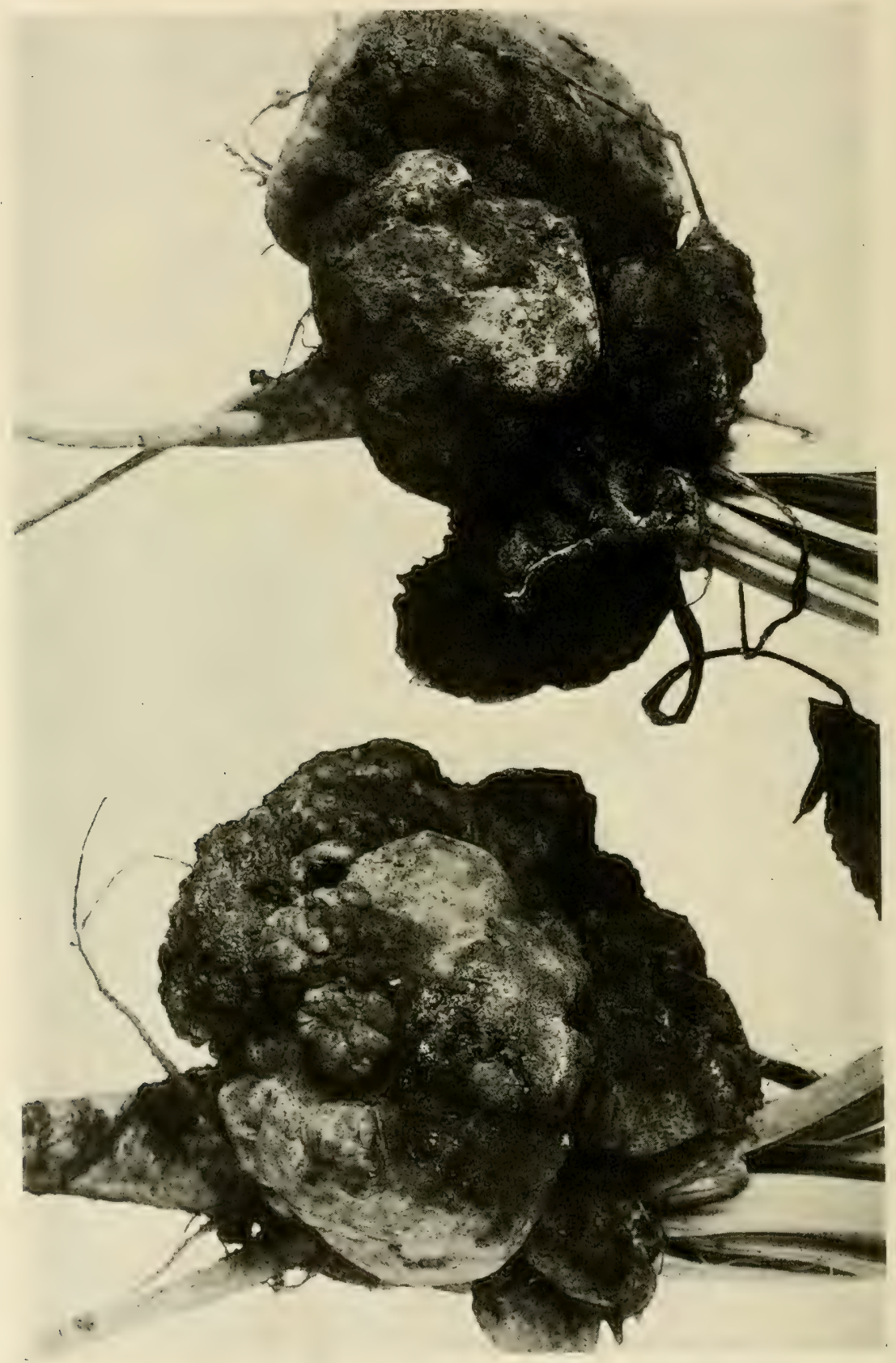

FIG. 321.-Crown gall on sugar-beets due to Bacterium tumefaciens. Pureculture, needle-prick inoculations, using organism isolated from a tumor on hop. Time, 104 days. Necrosis has begun. Tumors larger than the roots. Actual diameter about 4 inches. 


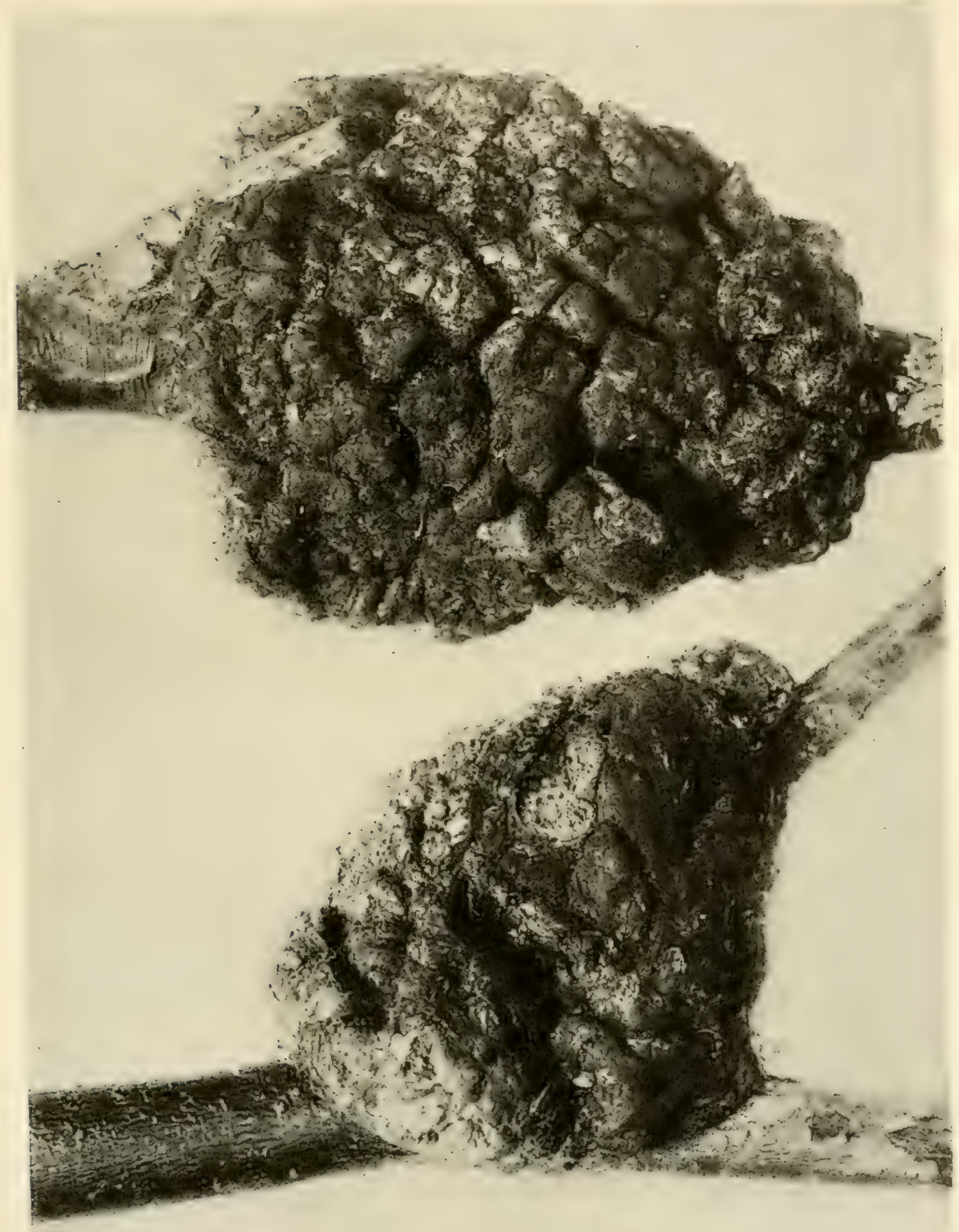

Fig. 322,-Crown galls on willow due to Bacterium tumefaciens. Natural infections from South Africa received in 1911. Frequently these willow galls are a foot or more in diameter, and at a distance the attacked trees look as if large birds were roosting in them. $2 / 3$ nat. size. 


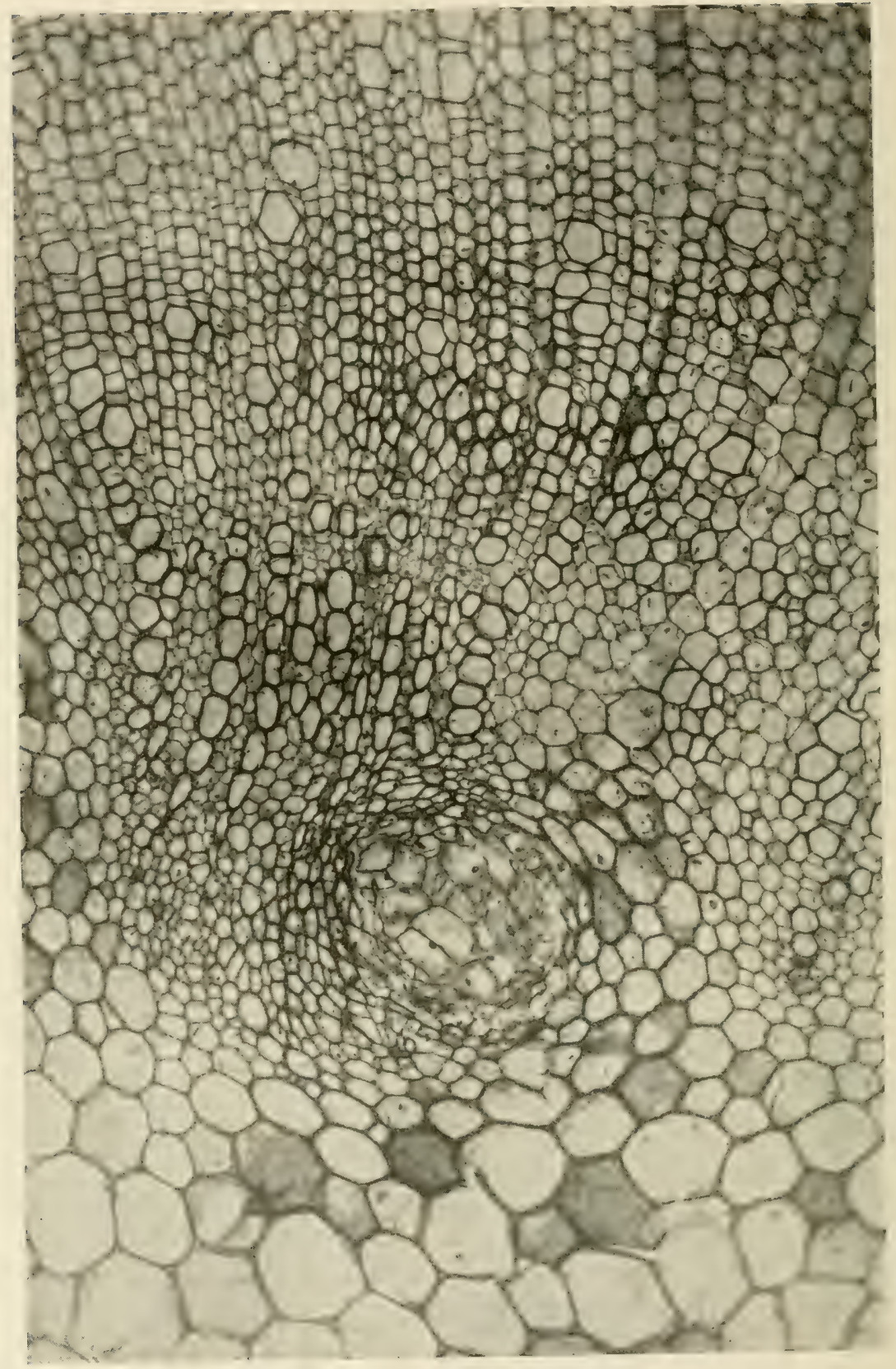

Fig. 323.-Tumor-strand of crown gall in Paris daisy. The result of a pureculture inoculation. Cross-section of stem between a primary stem-tumor (caused by needle pricks introducing Bacterium tumefaciens) and a secondary tumor in a leaf. It shows a tumor-strand in the inner wood and beyond it normal_wood (above) and normal pith (below). 


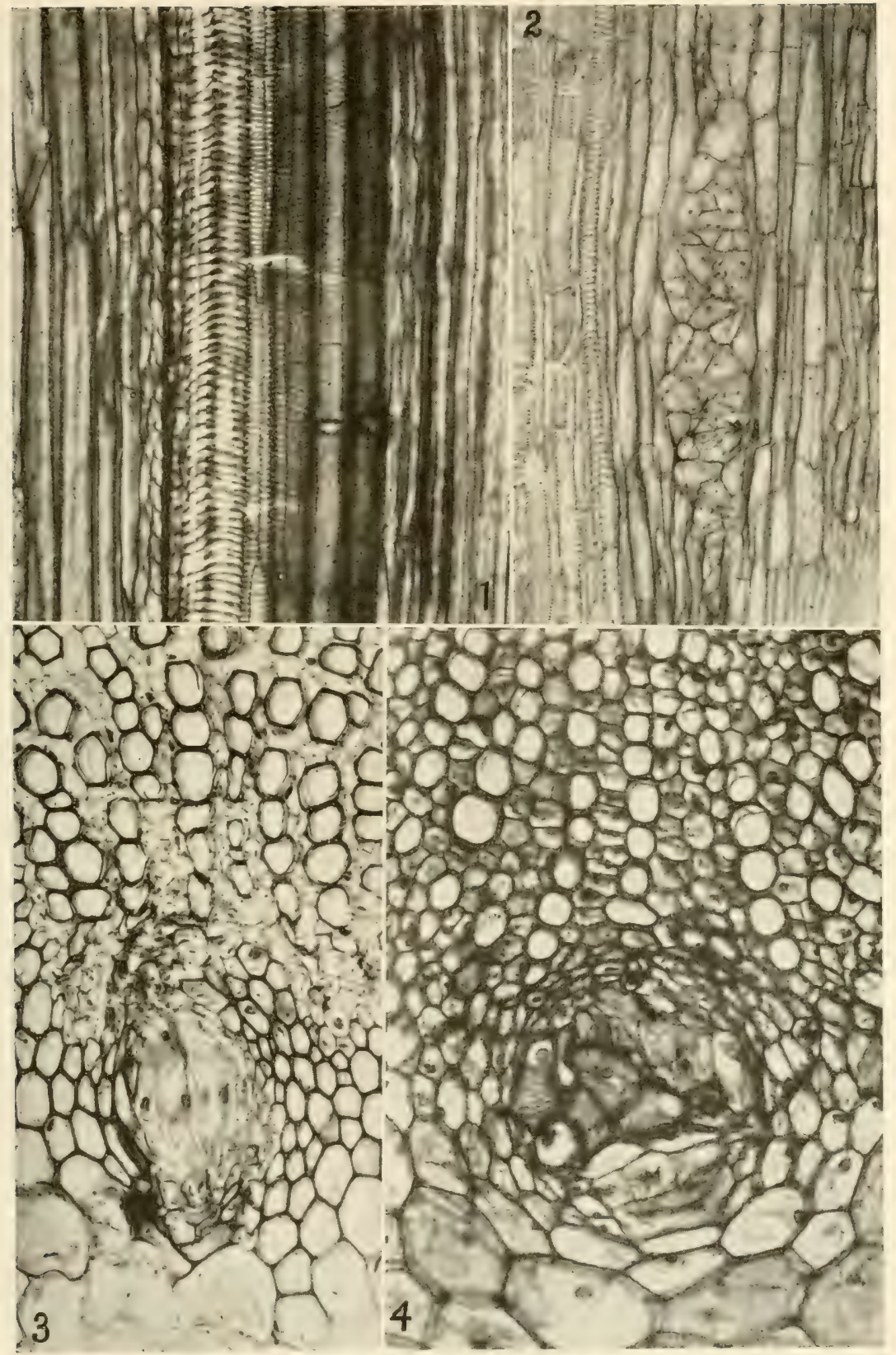

FIs, 324.-Showing crown gall on Paris daisy, results of pure-culture inoculations: (1) Radial longitudinal section through normal bundle of petiole for com- 
form-tolerant, sodium chlorid-tolerant (up to 3.5 per cent), lab-producing, acid-forming (with certain sugars) rod-shaped schizomycete, which grows on agar-poured plates in the form of small circular, somewhat raised, wet-shining, translucent colonies. Streaked on agar from agar the growth is smooth and shining, but when streaked on agar from peptone bouillon the various strains (daisy, hop, etc.) usually give a thin, wrinkled and dull surface. On gelatin plates the surface colonies are circular, small, dense, white and non-liquefying. In +15 peptone bouillon after some days there is more or less pellicle and a whitish rim of stringing, gelatinous threads; earlier ( 48 hours) the bouillon contains numerous delicate suspended filaments which are best seen with oblique light and on shaking. In old undisturbed bouillon cultures there is a rather firm whitish pellicle and very little clouding of the fluid. There is a white transient growth on steamed potato with some graying of the substratum. Growth in Uschinsky's solution is scanty; in Cohn's solution, scanty or absent. In milk the casein is thrown out of solution but only after several days. Litmus milk is blued (never reddened) and the litmus is frequently reduced. The living organism takes up Congo Red from culture media containing it and in this way may be distinguished from the root-nodule organism of legumes (Karl Kellerman). Verified in 1919. Indol production, scanty. There is an invertase, and a lab ferment. Some ammonia and hydrogen sulphide are produced. It grows from $0^{\circ} \mathrm{C}$. to $\pm 37^{\circ} \mathrm{C}$. The optimum temperature for growth lies between $25^{\circ}$ and $30^{\circ} \mathrm{C}$. The thermal deathpoint (10 minutes exposure in the water-bath in test tubes in +15 peptone beef bouillon) is approximately $51^{\circ} \mathrm{C}$. It shows slight toleration for organic acids (malic, citric, acetic) and still

parison with 2. Spiral vessels at the left, pitted vessels at the right. (2) Longitudinal section through a petiole showing tumor-strand in a bundle. Spiral vessels at the left, pitted vessels at the right. (3) Cross-section of stem between primary and secondary tumors, showing large-celled tumor-strand with big nuclei. Pith below, inner wood above. Tumor-cells wedging apart the spiral vessels. (4) Cross-section of a stem between tumors. Pith below, wood above; in the center is a tumor-strand developing tracheids out of certain of its cells. They contain nuclei and are still immature. The vessels above are the normal spiral vessels of the inner wood. 


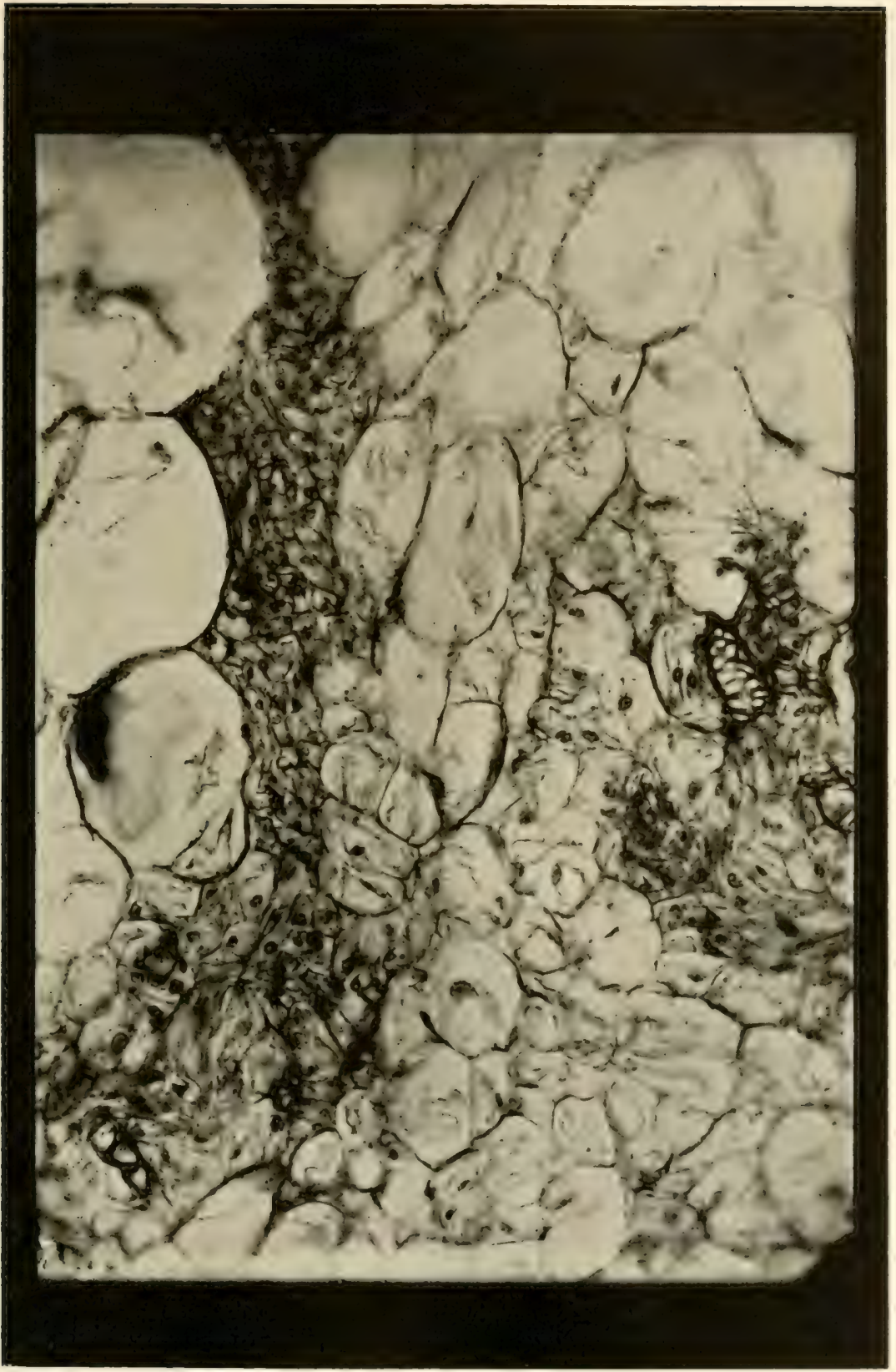

FIG. 325.-Crown-gall tumor-strand in coarse-celled cortical parenchyma of a Pelargonium teratoma. Diffuse tumor tissue with tracheids at the right and lower left. From a pure-culture inoculation. Slide stained by Lucia McCulloch. Photomicrographed by the writer. 
less for sodium hydrate. There is more growth in +15 than in -15 peptone bouillon. The optimum acidity for this organism in beef bouillon appears to lie between +12 and +24 on Fuller's scale (1.2 to 2.4 per cent of $\mathrm{N} / 1$ acid).

The bacterium is sensitive to germicides and slowly loses virulence on culture media. It passes over easily (under action of cold, sodium chlorid, or acids) into club-shaped, Y-shaped,

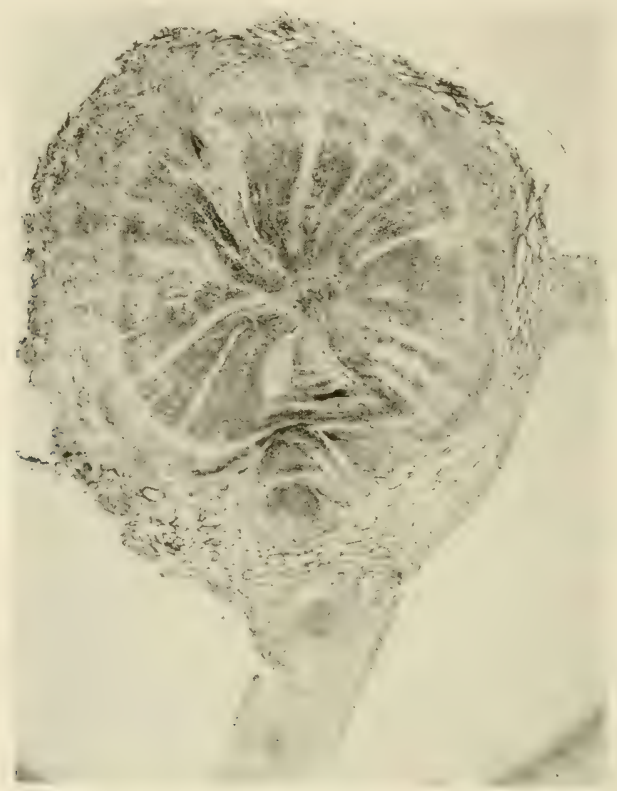

FIg. 326.-Crown gall on Paris daisy. Cross-section of a secondary tumor in a petiole, the result of a pure-culture inoculation on the stem. This has ruptured to the surface at the top and left side with destruction of the normal tissues. In its center is a tumor-strand connecting it back to the primary tumor. It shows crudely the structure of a stem (wood, cambium, phloem). In the lower part of the tumor are vessels running at right angles to the longer axis of the stem.

and variously branched involution forms (Fig. 350) which often are dying or dead, i.e., will not grow on agar-poured plates, or come up slowly. These moribund involution forms occur not only in culture media but are common in the tumor, and to them must be attributed not only our former difficulty in isolating the organism, but also the failure of others to isolate it. To keep the organism alive on ordinary culture media, store the cultures 


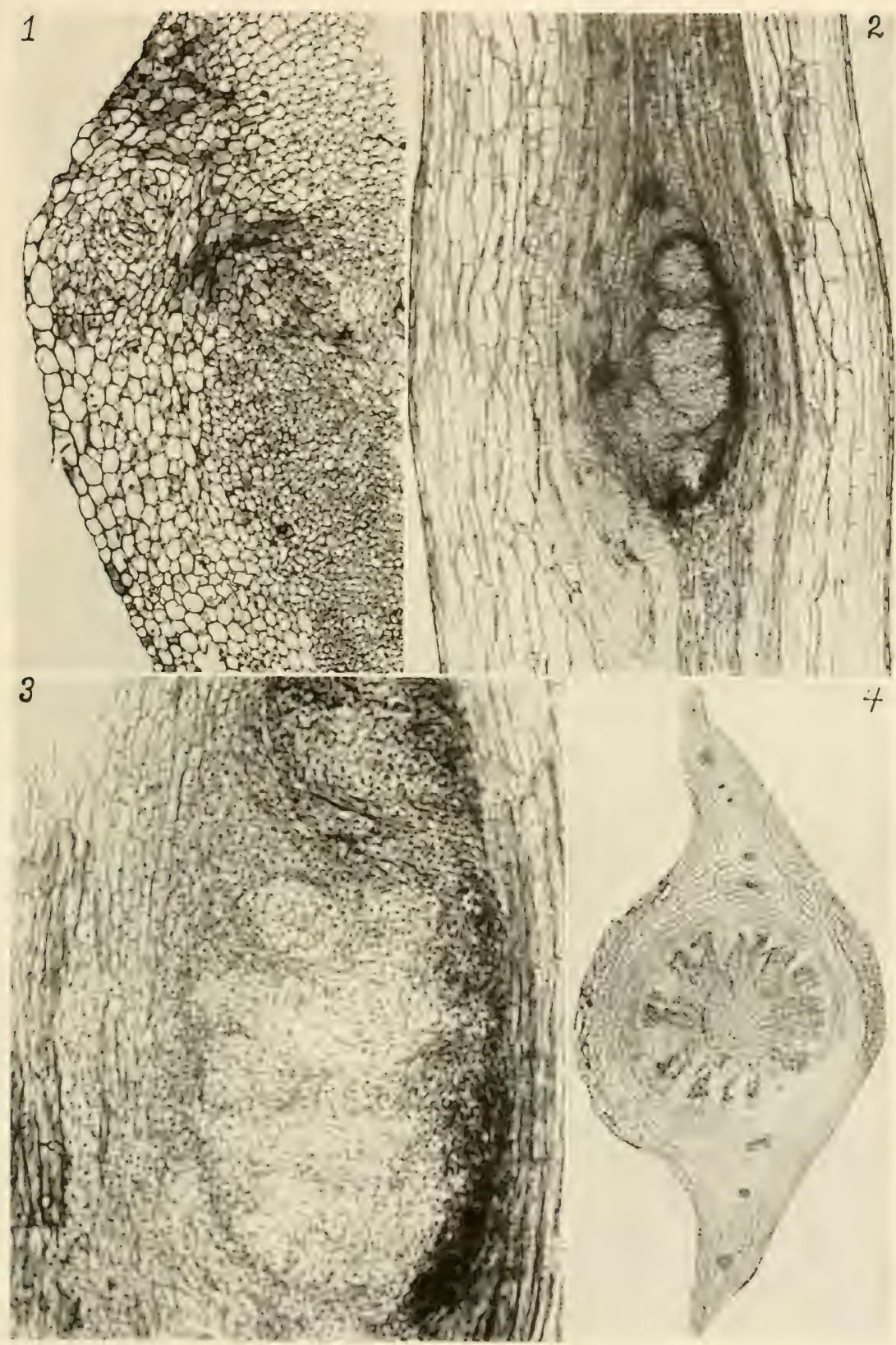

Fig. 327.-Early stages of crown gall in Paris daisy due to Bacterium tumefaciens. (1) Stem 10 davs after inoculation by needle-pricks. Tumor just 
in a cool box and make frequent transfers (once every 3 weeks). It lives longer in milk and bouillon than in agar.

Bacterium tumefaciens is cross-inoculable on a great variety of plants, e.g., using strains cultivated from the daisy and hop we have produced galls on more than 40 kinds of plants belong-

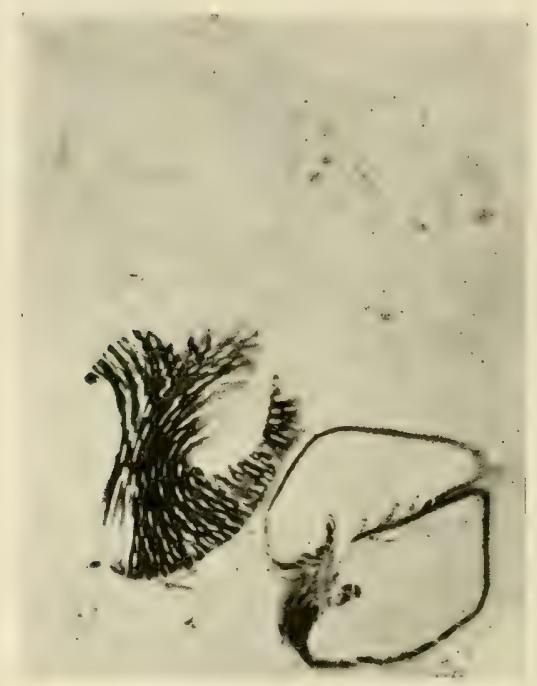

FIG. 328.-Crown gall on Paris daisy. Result of a pure-culture inoculation. Section of a tumor showing lignin deposited out of place, i.e., on the walls of three cells of the large-celled petiole parenchyma (Cortex). Stained with methyl green and acid fuchsin.

ing to 18 families, as follows: daisy ( $2 \mathrm{sp}$.) tomato, potato, tobacco (3 sps.), oleander, cabbage, cauliflower, turnip, radish, beet, carrot, grape, clover, peach, almond, raspberry, apple, pear, carnation, hop, Coleus, Citrus, Impatiens (2 sps.), Opuntia, Persea

beginning; epidermis pushed up. (2) Longitudinal section through a young unruptured secondary tumor in a petiole. Normal tissue under pressure at either side and bulging. Result of a pure-culture inoculation. (3) A part of 2 enlarged. The round spots are nuclei in the cells of the tumor. The bacteria are invisible. (4) Cross-section of a petiole showing the central leaf-trace converted into a secondary tumor which has not yet ruptured: tumor-strand in the center, beyond which is a whorl of wood-wedges not well lignified (the lignified parts are stained dark), beyond these cambium and then phloem. Beyond the tumor is the large-celled leaf parenchyma, which is compressed and bulging. Result of a pure-culture inoculation on the stem. Normal leaf-traces above and below. 


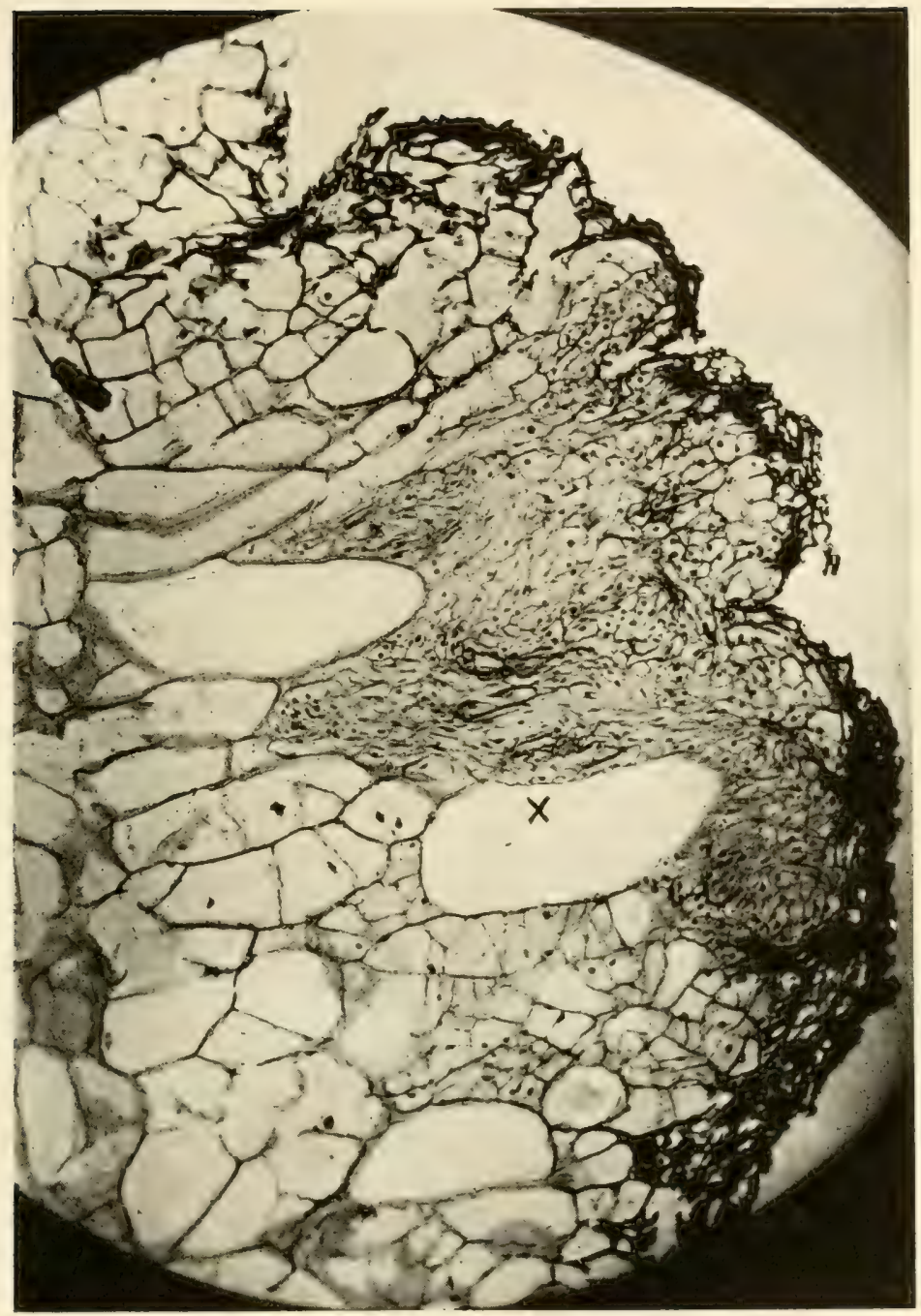

Fig. 329.-Crown gall confined to the bark parenchyma of a Paris daisy stem but containing tracheids (above $X$ ), induced by needle inoculations $1 / 3 \mathrm{~mm}$. deep. Under and at the left of $X$ there is action at a distance, i.e., large cells like $X$ are dividing as if by a stimulus received from the neighboring hyperplasia. The same phenomenon has been observed in crown gall on tobaceo. (Consult Jour. Cancer Research, Vol. I, No. 2, Plate I, Fig. 3, and Plate XXIII, Fig. 78.) 
(with difficulty), Juglans, poplar, Pterocarya, Allemanda, mango, stock, Ricinus, cassara, Fuchsia, Reseda, Salvia, Pisum, Calendula, Helianthus, etc.

Technic.-The writer and his associates experienced great difficulty in first isolating this organism from crown galls but now that the obstacles are known they are easy to c vercome and any one with ordinary technical ability can demonstrate the

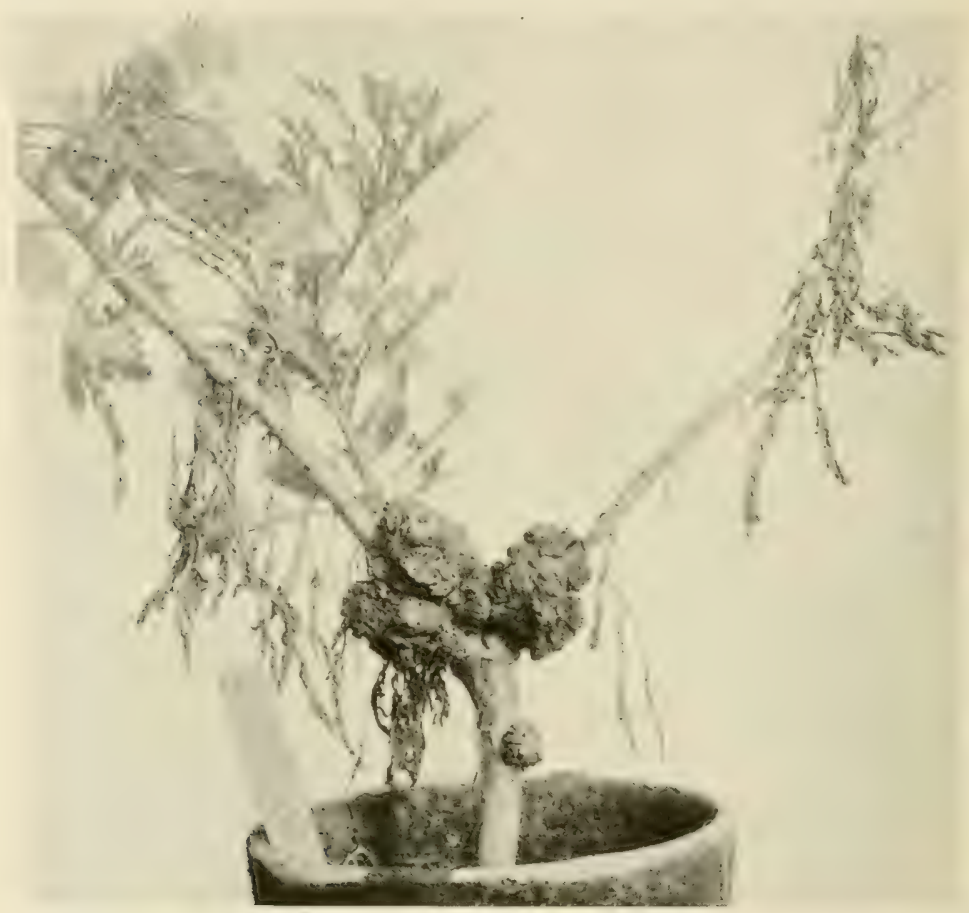

FIG. 330.-Crown gall on white Paris daisy (Chrysanthemum frutescens). Plant inoculated December 13, 1906, with a pure culture of Bacterium tumefaciens (plated from a tumor on the daisy) and photographed 7 months later. One branch killed. 1/4 natural size, circa.

occurrence of the parasite in sound galls by the poured-plate method, with exception of certain problematic galls occurring on the sugar beet. The organism is best isolated from young and rapidly growing tumors, from which it may sometimes be had in practically pure culture. Old galls are apt to be filled with white and rariously colored non-parasitic schizomycetes, especially with yellow and white ones, and may contain mites, nematodes, yeasts, myxomycetes, and various fungi. 
Owing to the fact that the parasitic organism occurs in the tissues in comparatively small numbers (very small numbers as compared with tissues subject to any of the diseases previously mentioned), and further to the fact that a large proportion of such as do occur are in a dormant condition, considerable quantities of the tumor should be taken for the cultures, and on a portion at least of the plates the inoculations should be very

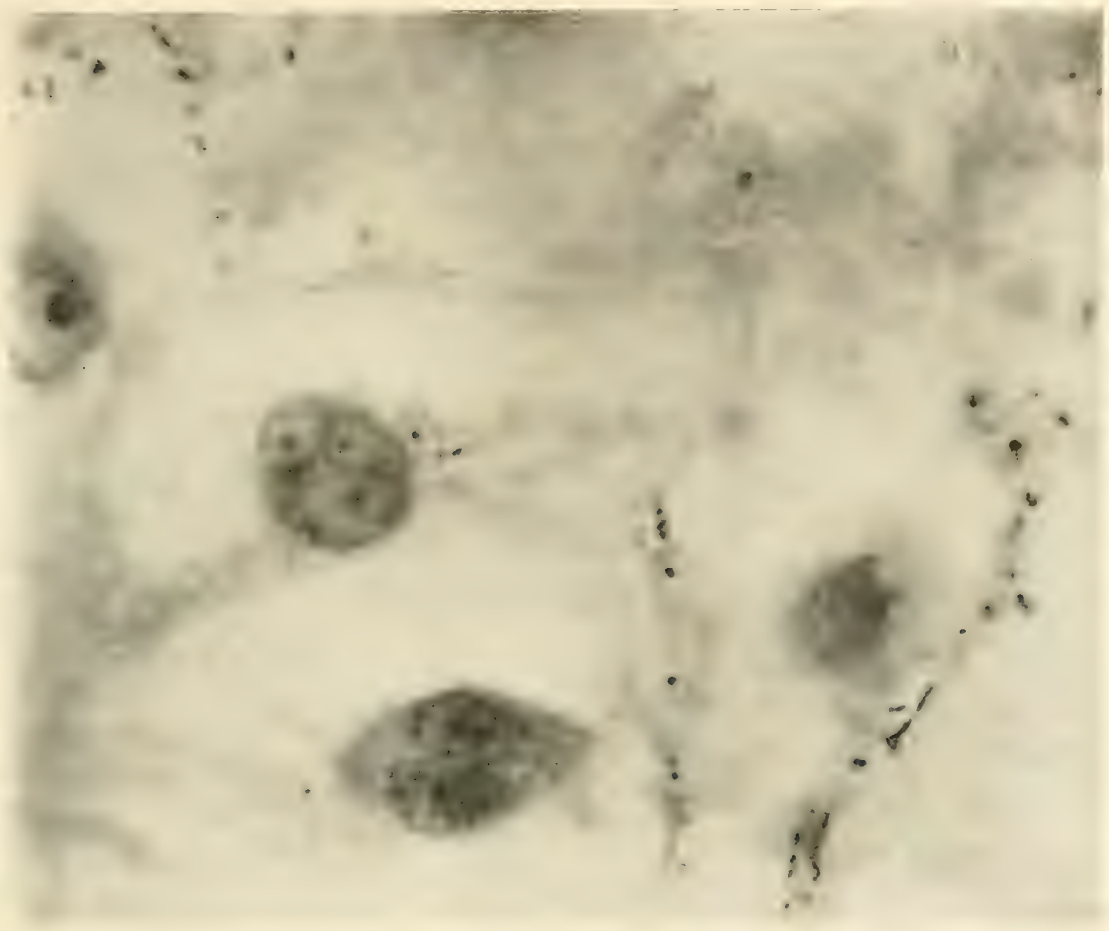

FIG. 331.-Crown gall on Paris daisy showing rod-shaped, mitochondrial (?) bodies photographed in place within the cells. Thin section of a portion of ten tumor cells after treatment with gold chlorid and formic acid and counterstaining with eosin for the nuelei. $\times 1000$.

heavy ( 6 to 8 three-millimeter loops); moreover, the plates should not be discarded until the end of the third week. Those colonies which come up on the poured plates from the th to the Sth day or later are more likely to be the organism sought than those which appear during the first three days. The plates may be kept at $20^{\circ}$ to $30^{\circ} \mathrm{C}$. 
A very good procedure is to flame lightly and pare away the exterior of the tumor with sterile knives, then remove some of the sound-looking interior, plunge for 3 seconds into mercuric chlorid water $(1: 1000)$, then wash for about the same time in distilled water, and crush it thoroughly in a little sterile water or bouillon, using a cold sterile knife-blade on the bottom of a sterile Petri dish (or if great care is taken it may be done

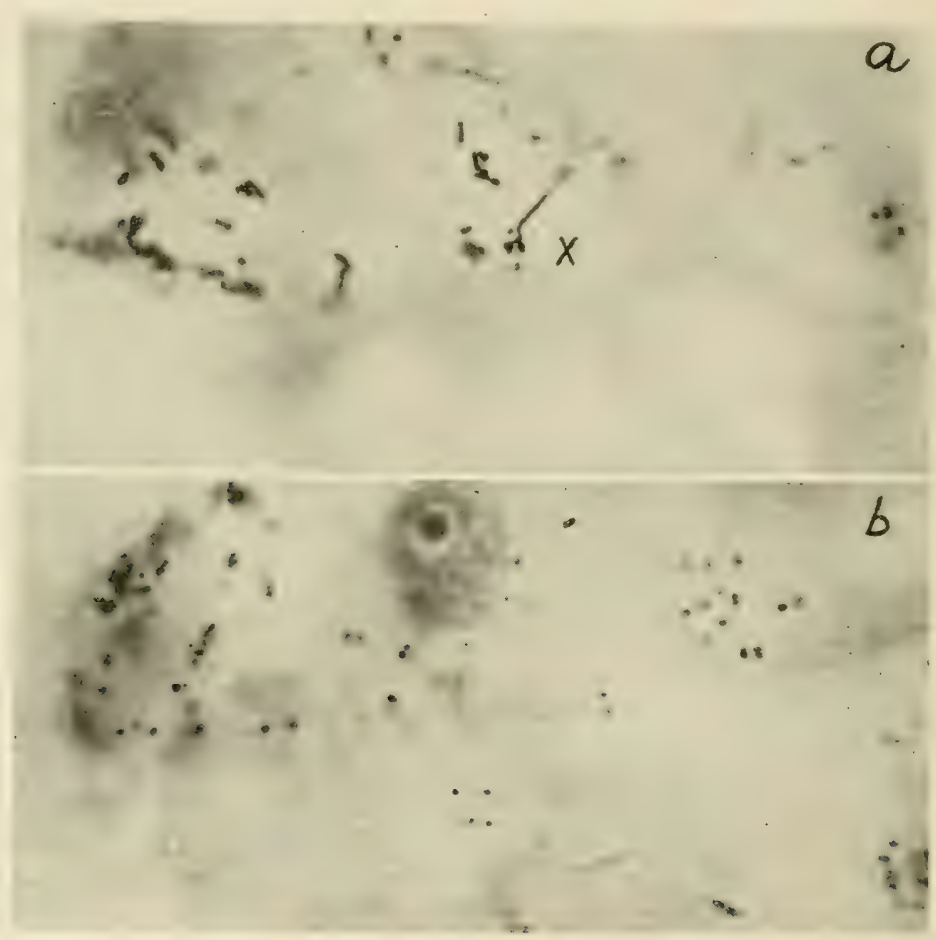

FIG. 332.-Thin sections of crown gall of the daisy. Tissues stained by means of gold chlorid. Nuclei out of focus are visible in each photograph, and at $X$ there is a Y-shaped rod.

inside a thick-walled tube in bouillon), using considerable force. The cloudy fluid in the dish should now be pipetted and the mashings scraped and poured into a tube of peptone water, beef bouillon, or autoclaved water, and allowed to stand for

has ruptured through to the surface. Stem inoculated by needle-pricks in two leaf axils using Bacterium tumefaciens plated from a tumor on hop. Inoculated September 29, 1916. Photographed November 24, 1916. Nat. size. (See next page.) 


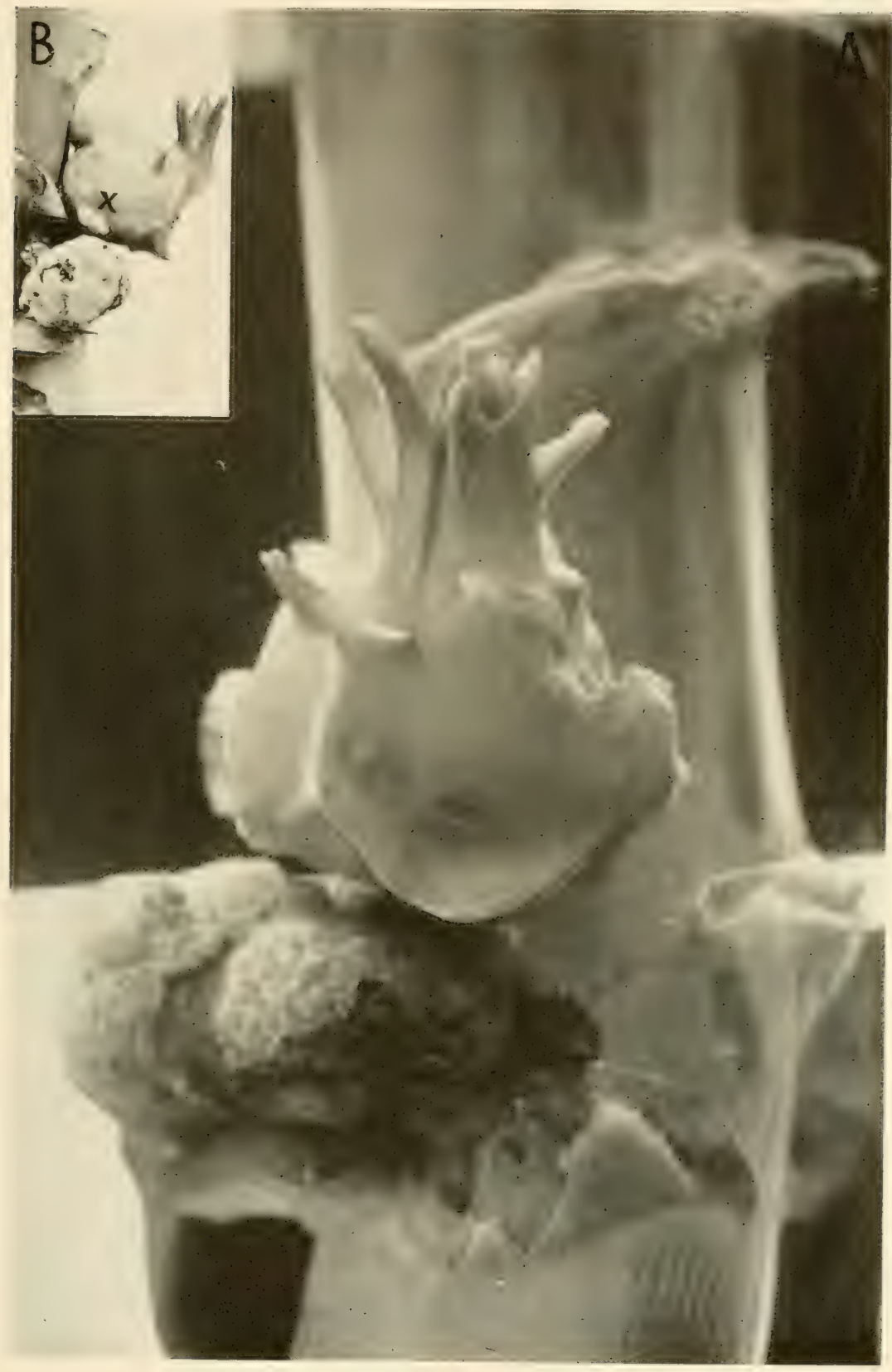

FIG. 333.-A. Inoculated crown-gall teratoma on cauliflower. The pale shoot above the naked tumor has a tumefied sareomatous interior. $\times 5$ circa.

$B$. Same as $A$, but a side view. At $X$ the sarcomatous tissue in the shoot 


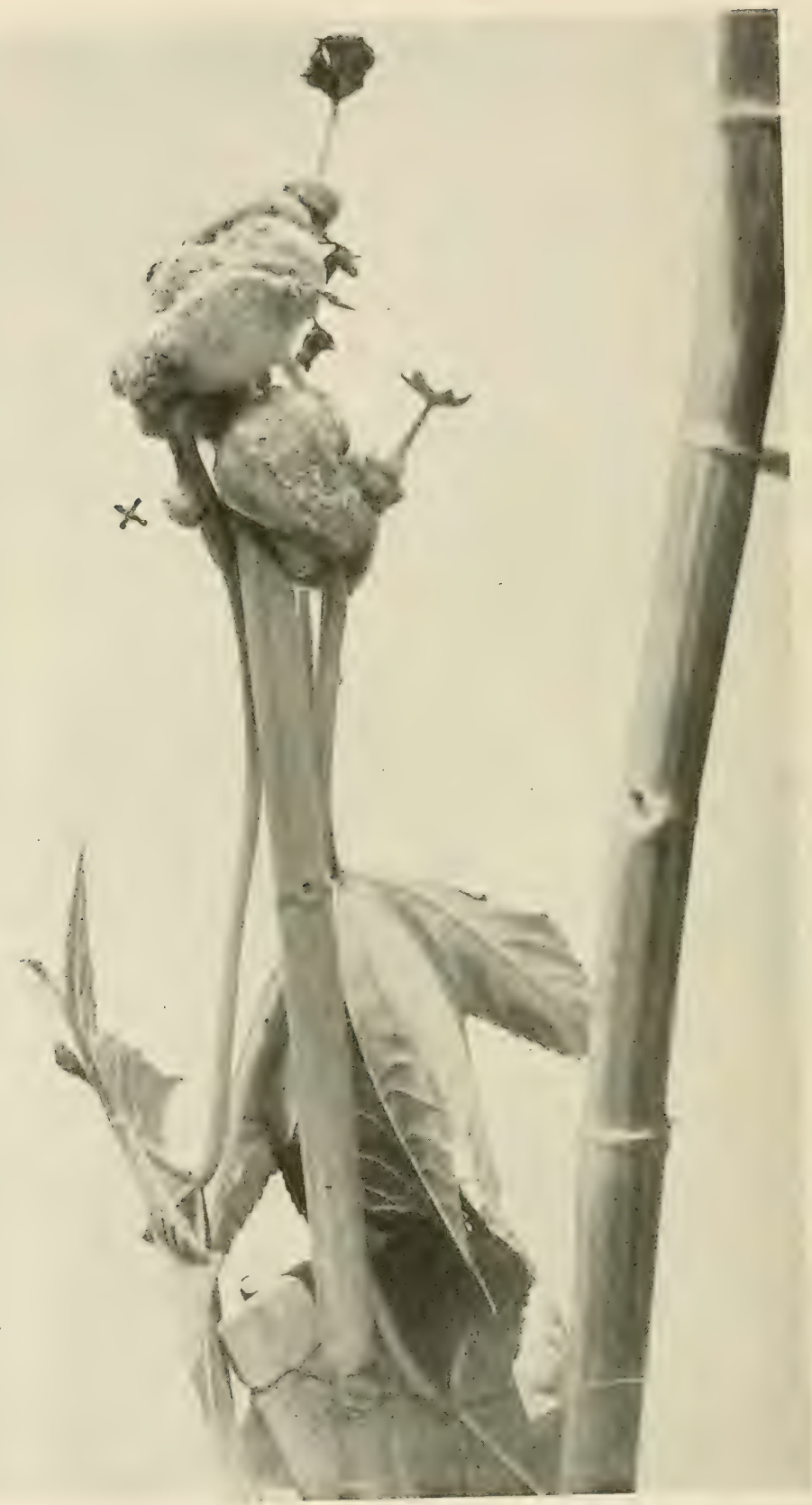

Fig. 334.-Crown-gall teratoma on Ricinus communis (castor oil plant). Inoculated with hop strain of Bacterium tumefaciens in two places by needlepricks March 25, 1916. Photographed April 29, 1916. $6_{7}$ nat. size. Leaves reflexed and dying. Secondary tumors on petiole at $X$. The tumor-bearing plant was of the same age and size as the check when it was inoculated. 


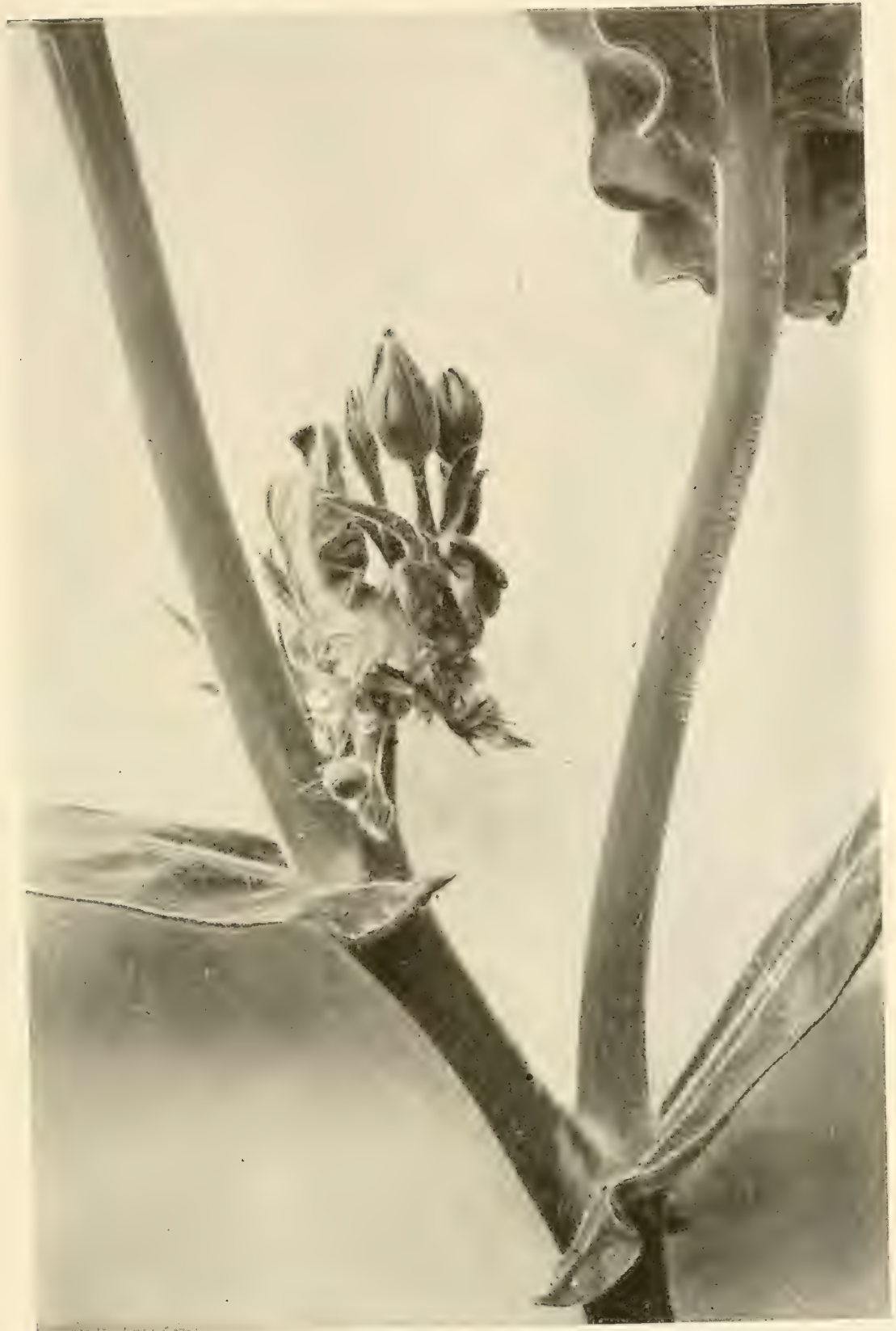

FiG. 335.-Crown gall on common tobacco, bearing leaves and flower-buds. Leaves twisted, fasciated and tumefied at their base. Inoculated by the writer 
some hours to diffuse. Then make the plates, pouring some directly from the tube containing the mashings and others from dilutions of it (several drops of the cloudy fluid into the second tube of bouillon, and after it has stood for an hour, with some shaking, ${ }^{1} 2$ ce. from this tube into a third tube of bouillon). Rarely does one obtain colonies on plates poured from the dilutions when first made. Moreover, if your material is scanty you will of course save not only the remains of the tumor but also your original tube and the dilutions made therefrom, and pour another series of plates next day, but if there is a green stain or if gas is forming in the tube containing the mashings, then pour only from the dilutions. For these poured plates use +15 peptone-beef agar.

On the poured plates all yellowish, orange, greenish, or pinkish colonies, all branching white colonies, and all circular white colonies, if opaque, are negligible. Only those colonies that come up slowly, that remain for a considerable time small, circular, raised and glistening-translucent (watery) need be considered (Figs. 351, 352). Even following this advice some of the colonies selected for the sub-cultures (which may be on agar or potato or in bouillon) may not prove to be infectious, therefore it is advised to experiment with quite a number of colonies, and to examine them by transmitted light, rejecting all that show a narrow clear zone about the colonies even if they look right by reflected light.

For inoculation purposes the student has choice of many kinds of plants since many are susceptible. For class work the young and rapidly growing roots of turnips or sugar-beets, the soft shoots of tomatoes, Pelargoniums, castor oil plants, or Paris daisies, and the crowns of young peach, almond, or poplar are recommended. Shoots and crowns of the hop or the European grape, if growing satisfactorily, may also be used;

July 7,1916 , on the cut surface of the middle of an internode of the main axis near the top of the plant just before blossoming time, by needle pricks, using a pure culture of the hop strain of Bacterium tumefaciens, which had been passed through sunflower. Photographed August 4, 1916. Natural size. There were 11 flower-buds on this date but a day or two later they began to fall off without opening. The big side branches developed after the inoculation. 


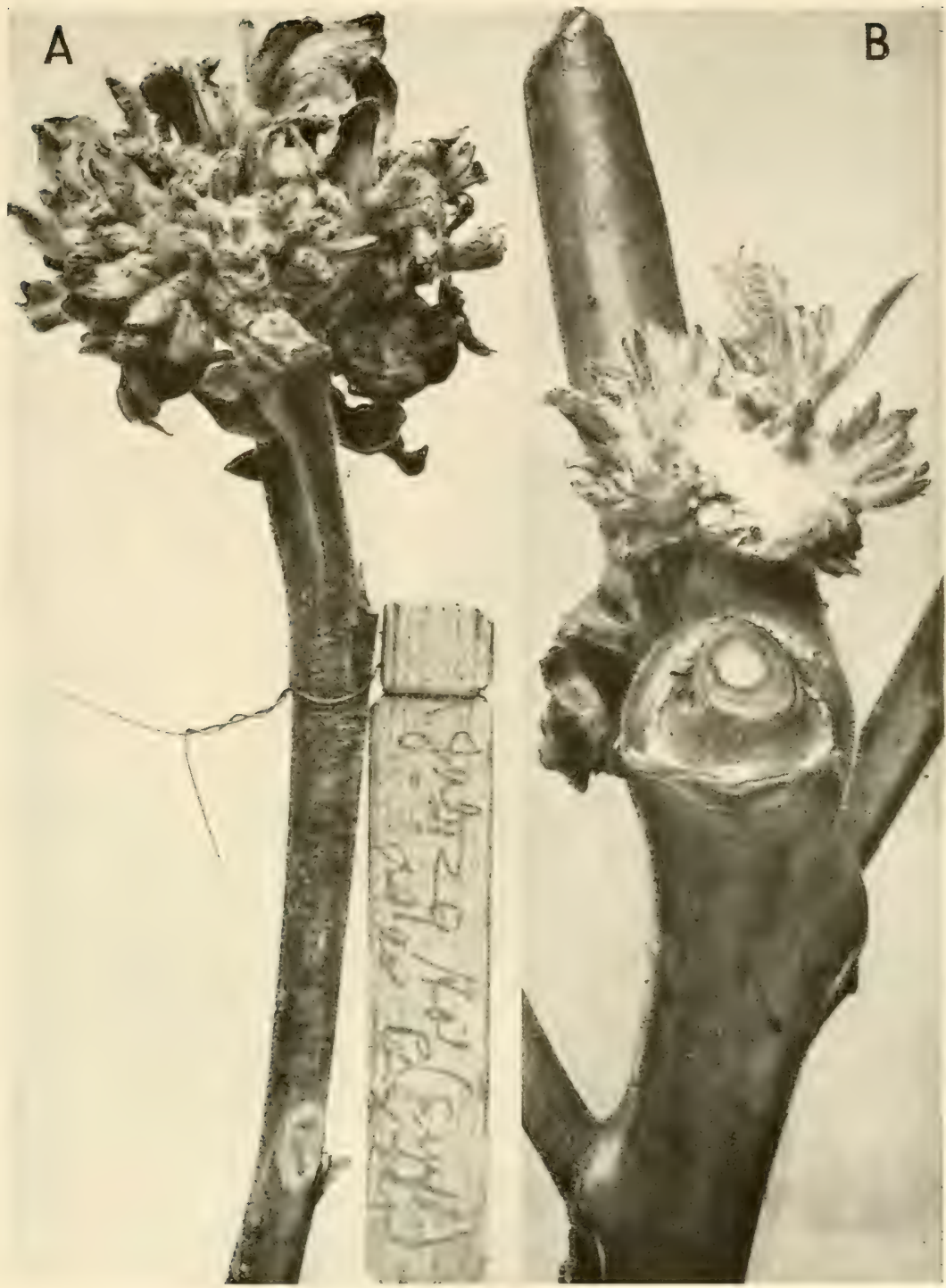

FIG. 336.-Crown galls on tobacco. A. Teratoma containing perhaps 100 leafy shoots. Inoculated July 29, 1916, by needle pricks on the cut end of the stem (middle of an internode) introducing the hop strain of Bacterium tumefaciens from a 48-hour agar culture. Photographed September 1, 1916. 3/4 natural size.

$B$. Like $A$ but inoculated March 1, 1918 (from hop through sunflower) on a cut internode of the main axis. The white part of the tumor was very smooth, free from chloroplasts and covered by an epidermis, i.e., the malignant part lay deeper. Twelve of 13 inoculated internodes contracted the disease. Photographed May 8, 1918, natural size, nearly. 


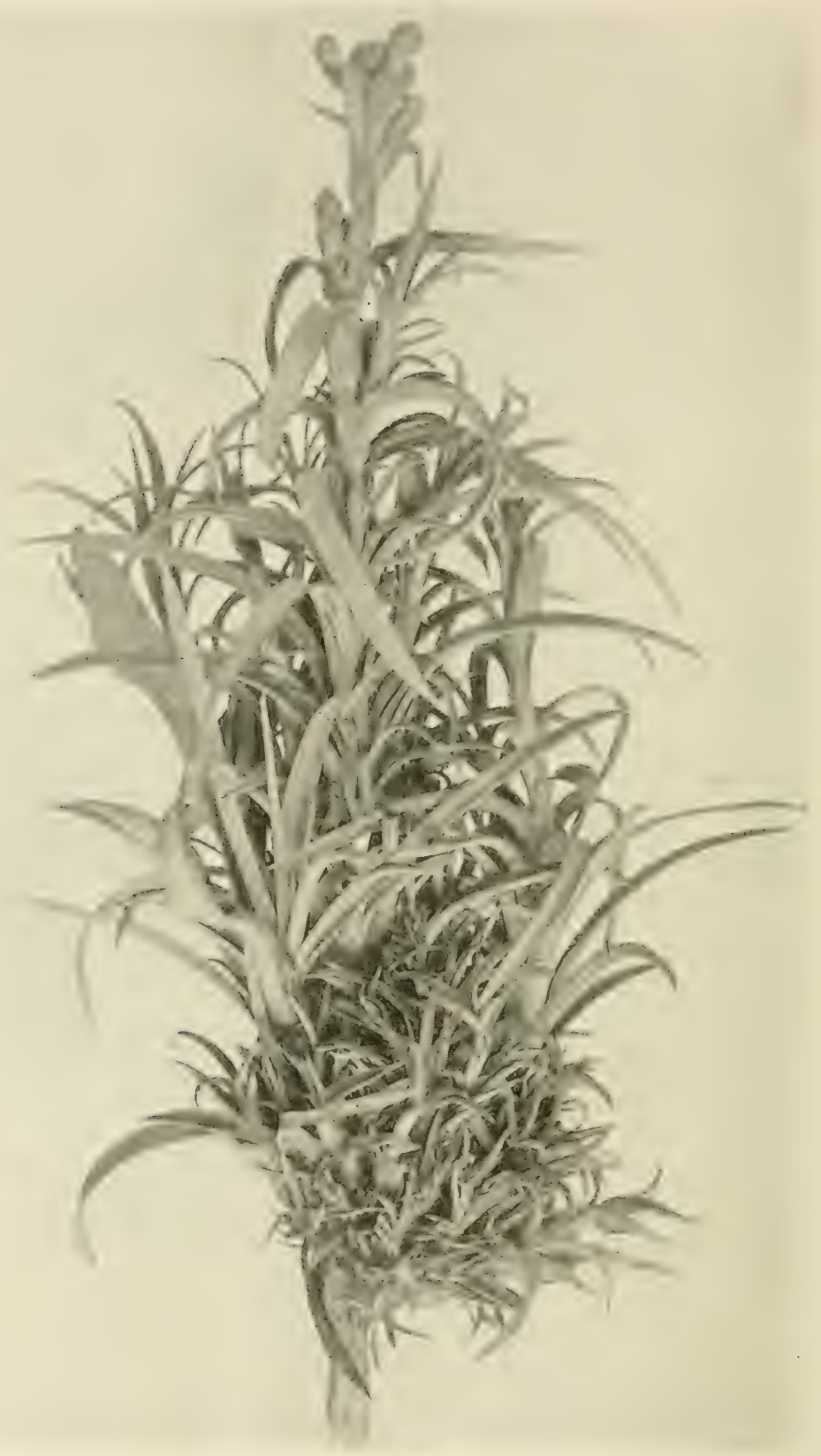

FIG. 337 
FIG. 337.-Crown-gall witch broom on the cultivated carnation due to Bacterium tumefaciens (a natural infection). There was no marked tumefaction at the base of the shoots but, as the sections showed twisted tissues, plates were poured and white colonies were obtained. Six of these were sub-cultured and tested by the writer on Ricinus and tobacco. Colonies 1, 3, 4, 5 and 6 failed to produce any growths, but colony 2 gave sarcomatous tumors on both plants and also on carnation. Photographed November 11, 1916, 6/7 nat. size. 


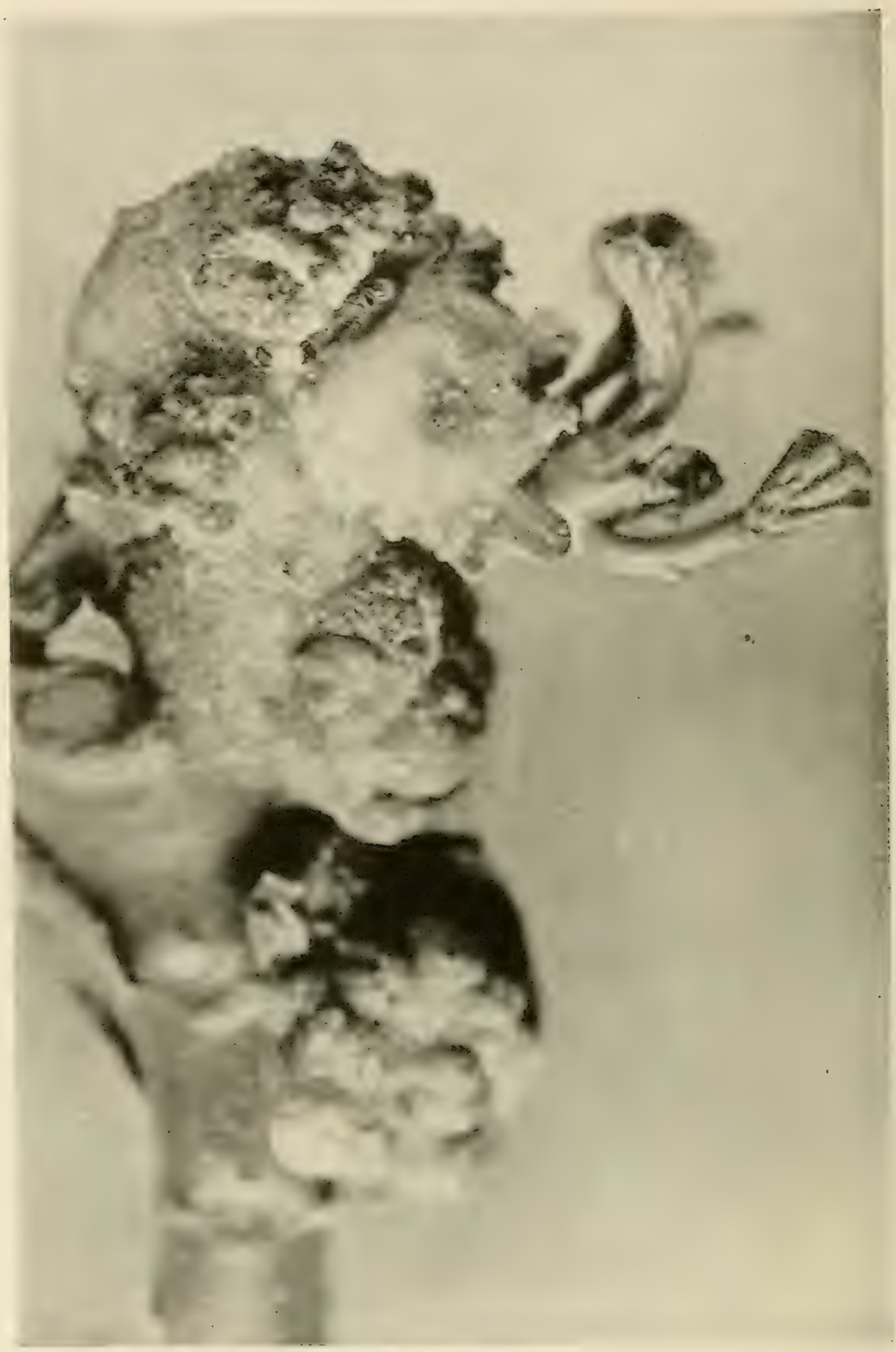

FIG. 338.-Crown-gall teratoma on Pelargonium. From a pure-culture inoculation of Bacterium tumefaciens made by the writer. Photographed January 11, 1916. $\times 4$. Time 12 weeks. 


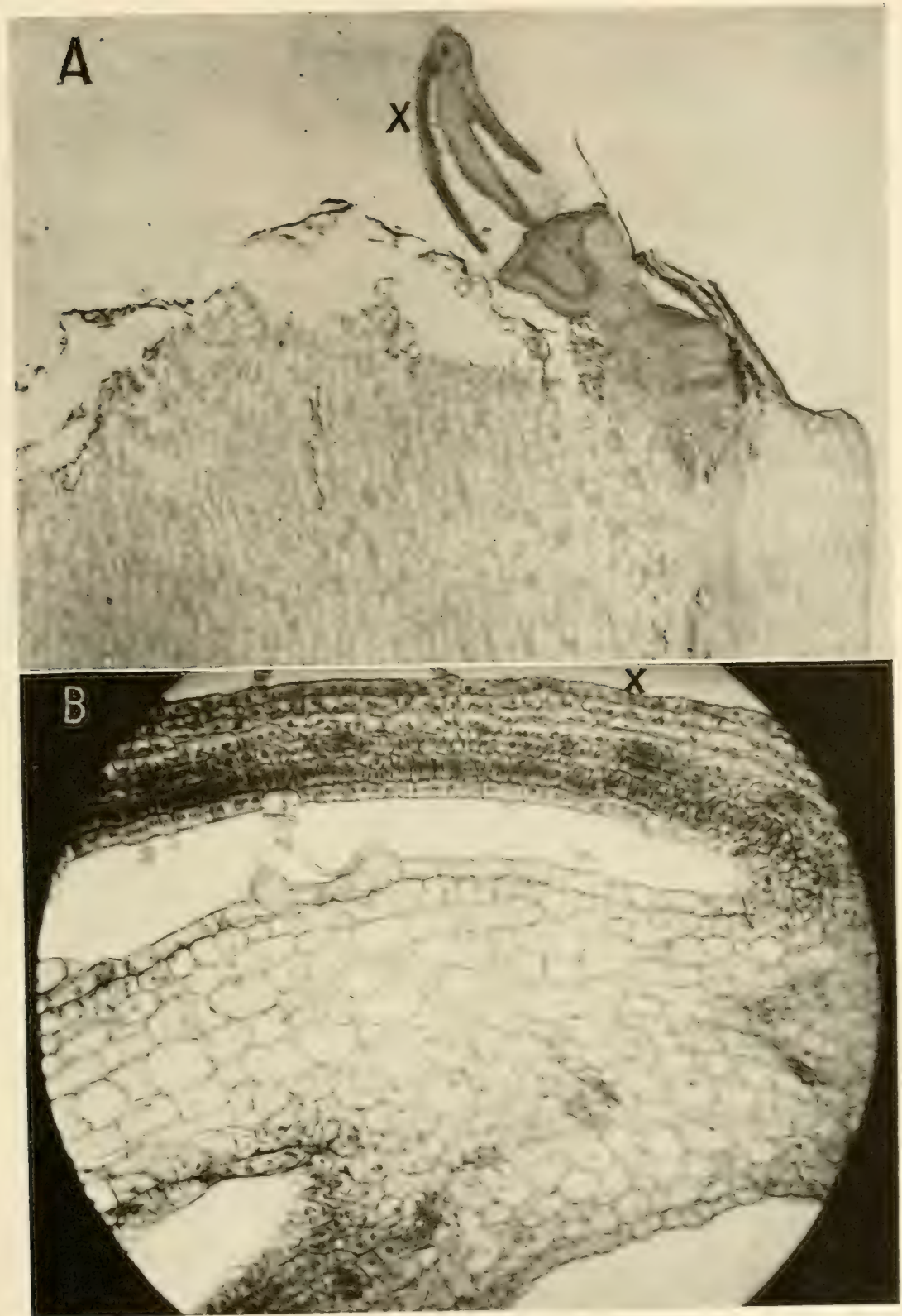

FIG. 339.-A. Section of crown gall on tobacco due to Bacterium tumefaciens. Teratoma developing on the cut end of an inoculated internode. Tumor below and a dwarfed shoot above developing out of it.

$B$. Tissue of leaf from $A$ (at $X$ ) showing the palisade tissue reversed, i.e., facing away from the sky. 


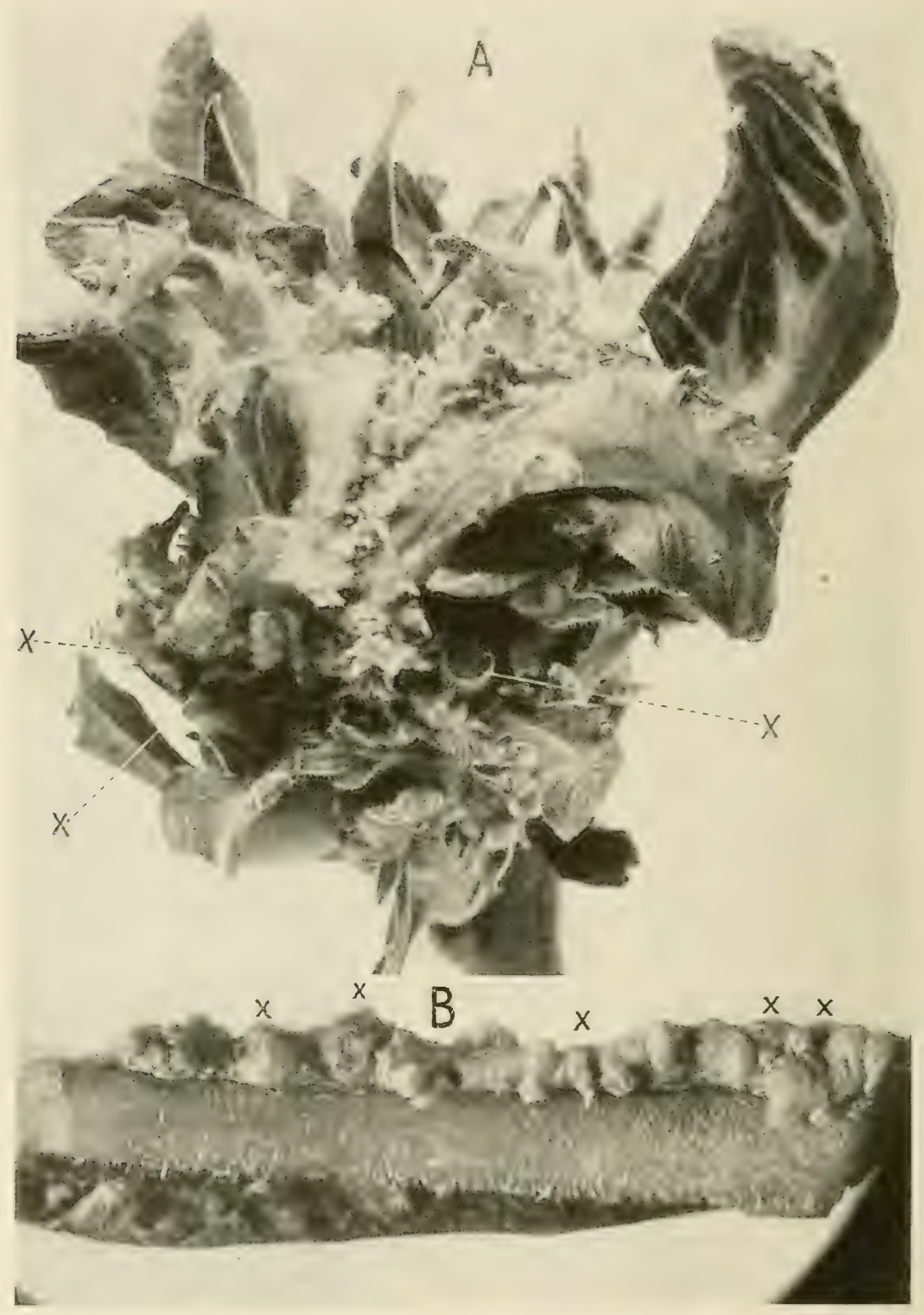

FIG. 340 . 
Fig. 340.-A. Crown-gall teratoma produced by needle pricks on cut internode of Nicotiana tabacum using hop strain of Bacterium tumefaciens passed through sunflower in 1915. Photograph shows fused tumefied leaves, and sprouts growing out of all parts of them. At $X, X, X$, shoots 3 and 4 inches long were cut away. Inoculated March 1, 1918, with 14-day agar-streak culture. Photographed May 8, 1918. Natural size.

$B$. Same phenomena as in $A$, but on a petiole of Nicotiana sylvestris. Hop, colony 1 , check on flask $N$. Inoculated January 16, 1917. Photographed March $2,1917 . \times 2$. There is a continuous tumor on the margin of the petiole with leafy sprouts in five places $(X-X)$. 
Fig. 341.-A crown-gall teratoma on common tobacco showing an abnormal organ, shoot (?), leaf (?). Probably a stem, because its vascular system comes off the normal vascular eylinder and is itself an irregular cylinder. This growth is a blunt, cylindrical, curved, horn-like, white body, pale greenish at the swollen base and bearing 20 abortive green or greenish leafy organs (shoots), most of which are borne on longitudinal seams as if on rudiments of decurrent leaf wings. Possibly it is a modified leaf as it does not arise in any leaf axil. The largest and greenest of the leafy outgrowths are 3 at $X$ along a seam which extends to the top of the horn. Stem inoculated in the leaf axils November 26, 1916, with sub-culture of colony 2 (Bacterium tumefaciens) from carnation witeh broom (see Fig. 337). Photographed January 24, 1917. $\times 4$. 


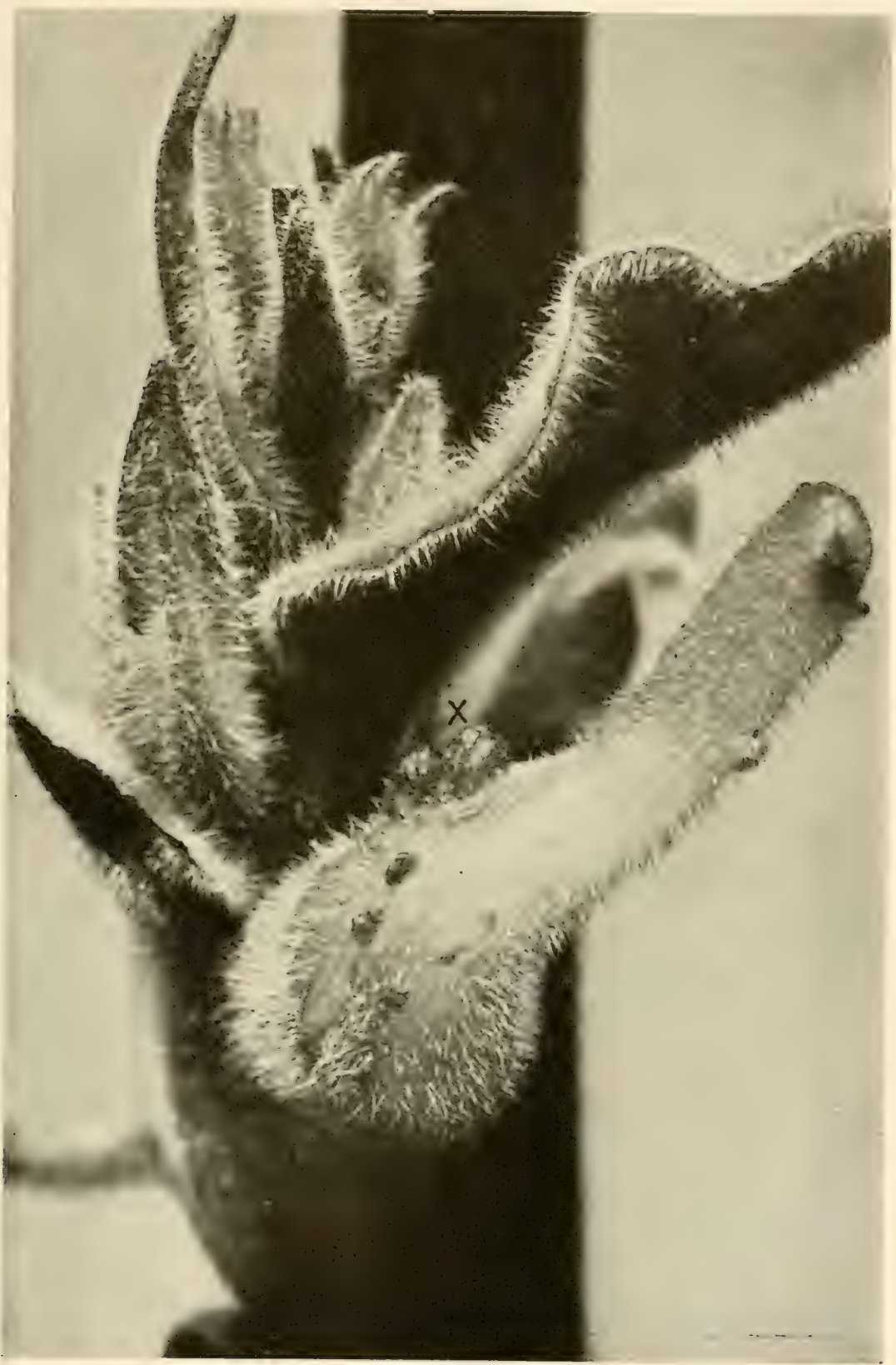

FI(i. 341. 


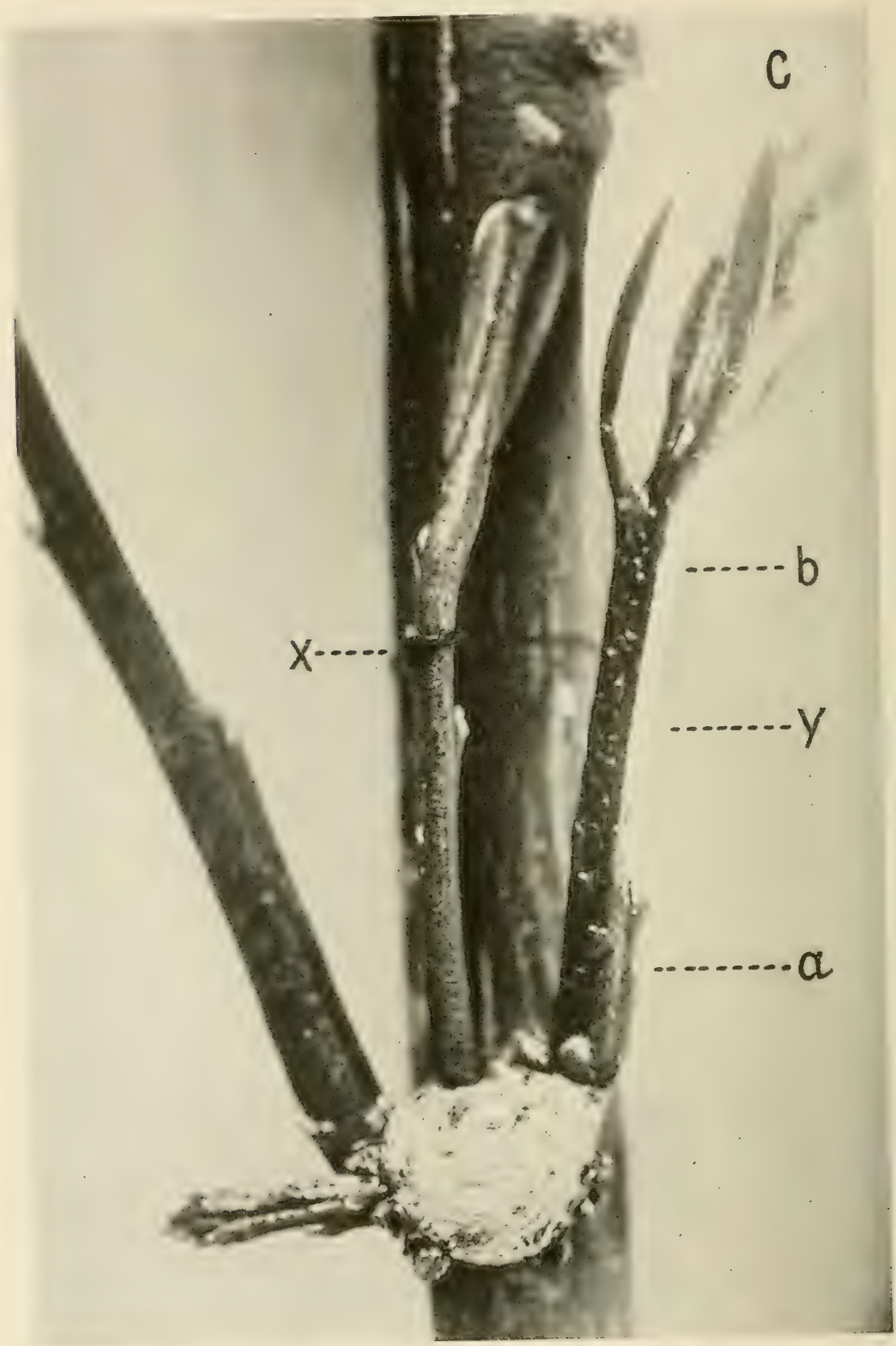

FIG. 342. 
likewise, soft shoots of young tobaceo or the undeveloped disks of the sunflower. For study of the leafy tumors (teratomas), inoculations may be made in the leaf axils or on the cut internodes of various plants. The writer has used chiefly tobaccos and the common hothouse Pelargonium. In the same way, for tumors containing roots, the tops of Impatiens balsamina (the common garden balsam) may be inoculated. For study of the tumor-strand and secondary tumors, the young rapidly growing shoots of the Paris daisy (Chrysanthemum frutescens) are best, and the inoculations should be made toward the top of succulent stems which should continue to grow vigorously for at least 2 months. The needle should be thrust into the stems immediately under the leaves. Peklo in Bohemia $(1915$, l. c.) obtained very good tumor-strands in the stem of the sunflower by inoculating into the young flower disk, and the writer has verified his statements. Hop does not infect daisy,

The result of the inoculations will be successful and interesting in proportion to the virulence of the organism and the activity of the plant. Well nourished rapid-growing plants yield much larger tumors than slow-growing ones. To demonstrate killing effects of the gall use young sugar beets or young Nicotiana sylvestris, inoculating in the center of the crown.

Cuttings of the Paris daisy, if made in the hothouse in September, should give plants suitable for inoculation in November and December. The slips should be end branches

Fig. 342.-Crown-gall teratoma on orange due to Bacterium tumefaciens. Stem inoculated January 14, 1916. This is my No. 48 (hop strain through sunflower, colony 1). It was made by needle pricks in the region of a dormant bud, but nothing in the way of a tumor developed either in 1916 or 1917. I looked at it many times. Other inoculated orange buds developed slight tumors bearing supernumerary buds and then died. 'The small firm dark green shoot marked $X$ is an outgrowth of the stem. This appeared in 1917 but with no evidence of any tumor at its base. Three other shoots and about 12 buds developed from the tumor itself and all of them were soft and light green. This young, rapidly growing tumor appeared within 3 or 4 weeks of the time the photograph was made. The tumor is interesting as having remained dormant for two years and then begun to grow rapidly as an embryoma. The rough white part of the tumor is the naked sarcoma. Photographed March 2, 1918. $\times 3$. Sections of leaf $C$ and of shoot $y$ between $a$ and $b$ were cut and examined for a tumor-strand but none was found. 


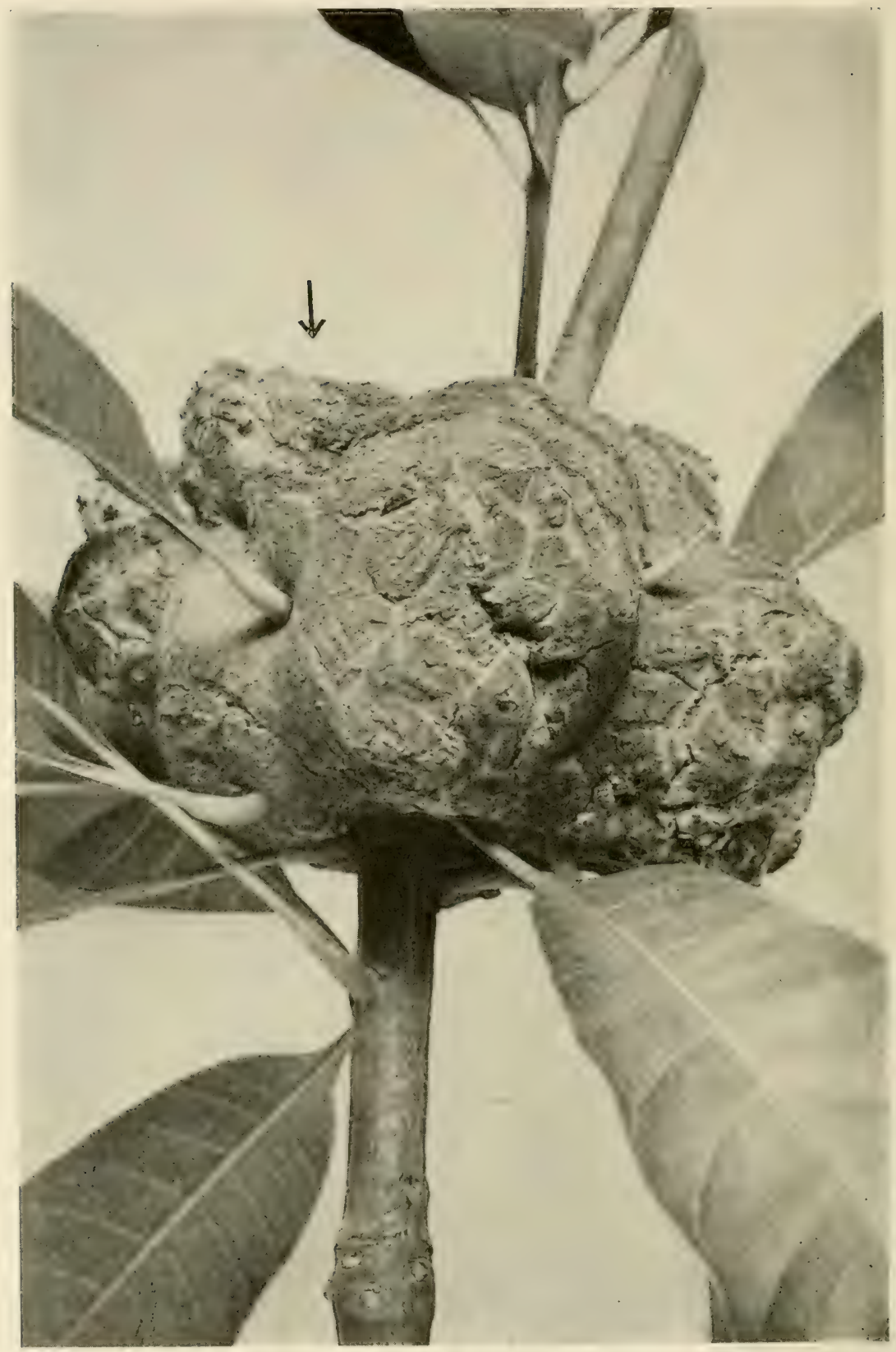

FIG. 343. 
not in flower-bud or in blossom. They should be set into shallow boxes in sand in close rows, and the foliage trimmed up considerably. Here they should remain for about 3 weeks, i.e., until a callus has formed and roots begin to push. Bottom heat is not necessary, as they root readily. They should then be put into good soil in thumb pots and transferred from time to time (rather frequently) to larger pots so as to keep them growing rapidly. There should be no check whatever in their growth else they will bloom prematurely. Pelargonium slips should be treated in the same way. Peaches and almonds should be planted in similar boxes of sand after carefully cracking and removing the shell, without injury to the kernel. Hardshell almonds as they come upon our markets are more likely to germinate than the bleached thin-shell almonds. T'wo or three months must be allowed for growth. Ricinus, tomatoes, tobaceo, sunflowers, sugar-beets, and turnips should be grown from seed. Allow at least 2 months. Cuttings of willows and poplars may be rooted in the spring for use in houses the following winter or spring.

\section{Determine}

For the organisu. Morphology.-In various media, size in microns; form; aggregation of elements, i.e., chains, filaments, pseudozoöglœex; motility, presence and distribution of flagella (use Pitfield's stain); absence of endospores; capsule stain; Gram's stain; acid-fast stain; character of the involution forms.

Cuitural Characters.-Size and appearance of colonies on thin-sown agar and gelatin plates; stabs and streaks on agar; ditto on gelatin; behavior in peptone bouillon (watch early

FIG. 343.-Hard crown-gall embryoma, on mango (Mangifera indica). Terminal bud inoculated by the writer January 19, 1916, by needle pricks using the hop strain of Bacterium tumefaciens (sunflower Colony 1). This tumor contains 6 distinct centers of embryonic growth. For one of the larger ones (under the arrow) see Fig. 344A. Surface brown except the embryonic parts which were green. The leaves surrounded by the tumor, and appearing to grow out of it, are stem leaves. Time, 20 months (nearly). Photographed by James F. Brewer, September 11, 1917. 3/4 nat. size. Actual size of the tumor $6 \frac{1}{4}$ by 41,2 by 4 inches. 

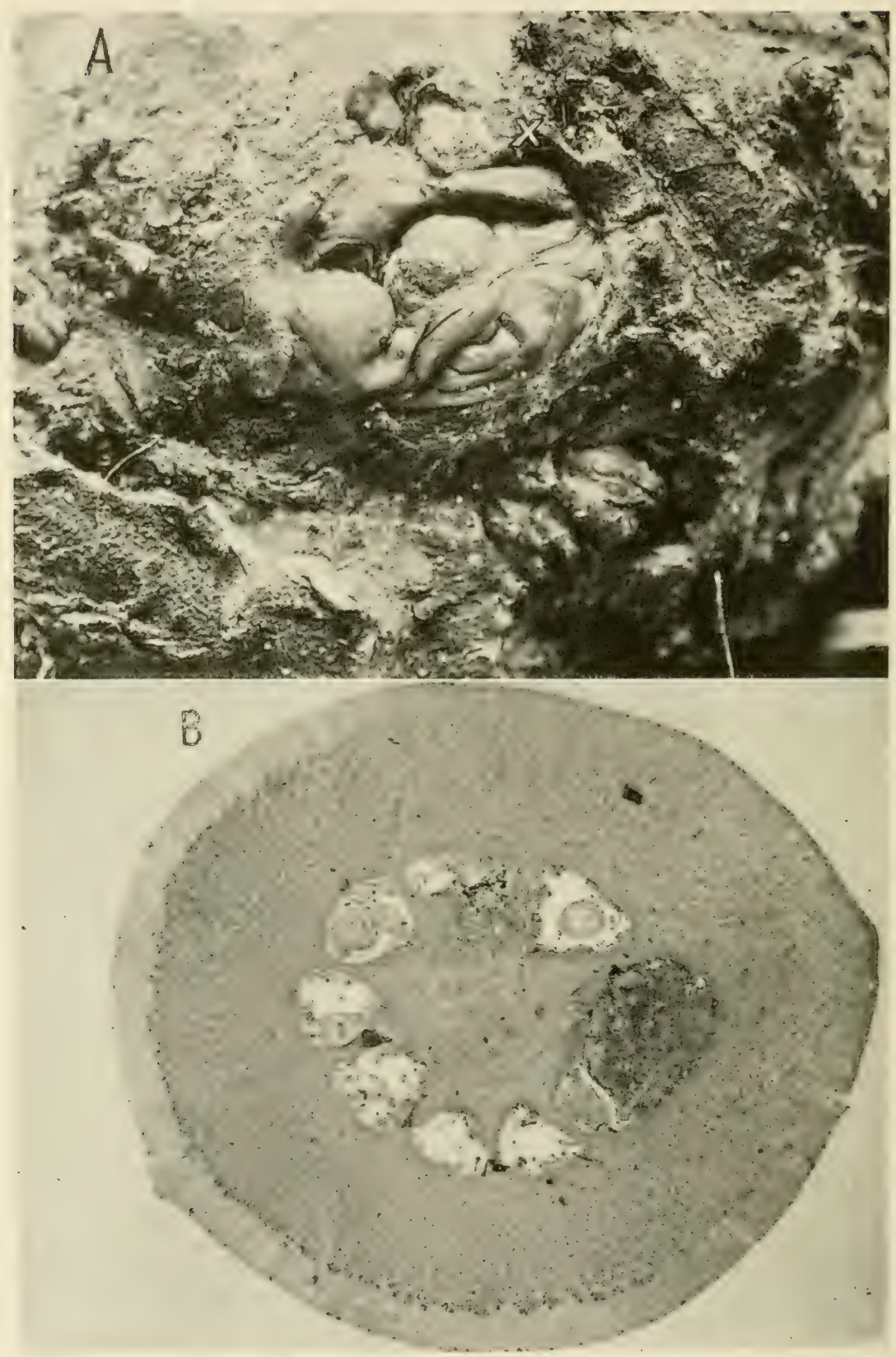

FIG. 344 . 
Fig. 344.-A. Slow-growing crown-gall embryoma on mango. In the center (under $X$ ) a folded (twisted) green bud. Notice also a bud at the extreme left, one in the right upper corner, one below it, and one in the center under the main growth. These five I have counted as one of the six centers of embryonic growth. See Fig. 343. This embryonic portion was under observation many weeks but it developed no shoots. $\times 4.5$.

$B$. Cross-section of a very young orange fruit showing crown-gall tumors in the placental region. Bacterium tumefaciens (hop through sunflower) was inoculated February 1, 1916, by needle pricks into the very young ovary. Two locules are infected, the others are normal. No shoots developed. Orange VI, fixed March 10, 1916. Slide 1198A6, stained with acid fuchsin and methyl green. The tumor tissue stains red. Actual diameter of the section (short way) $1 / 2$ inch. Photographed with $75 \mathrm{~mm}$. planar. 


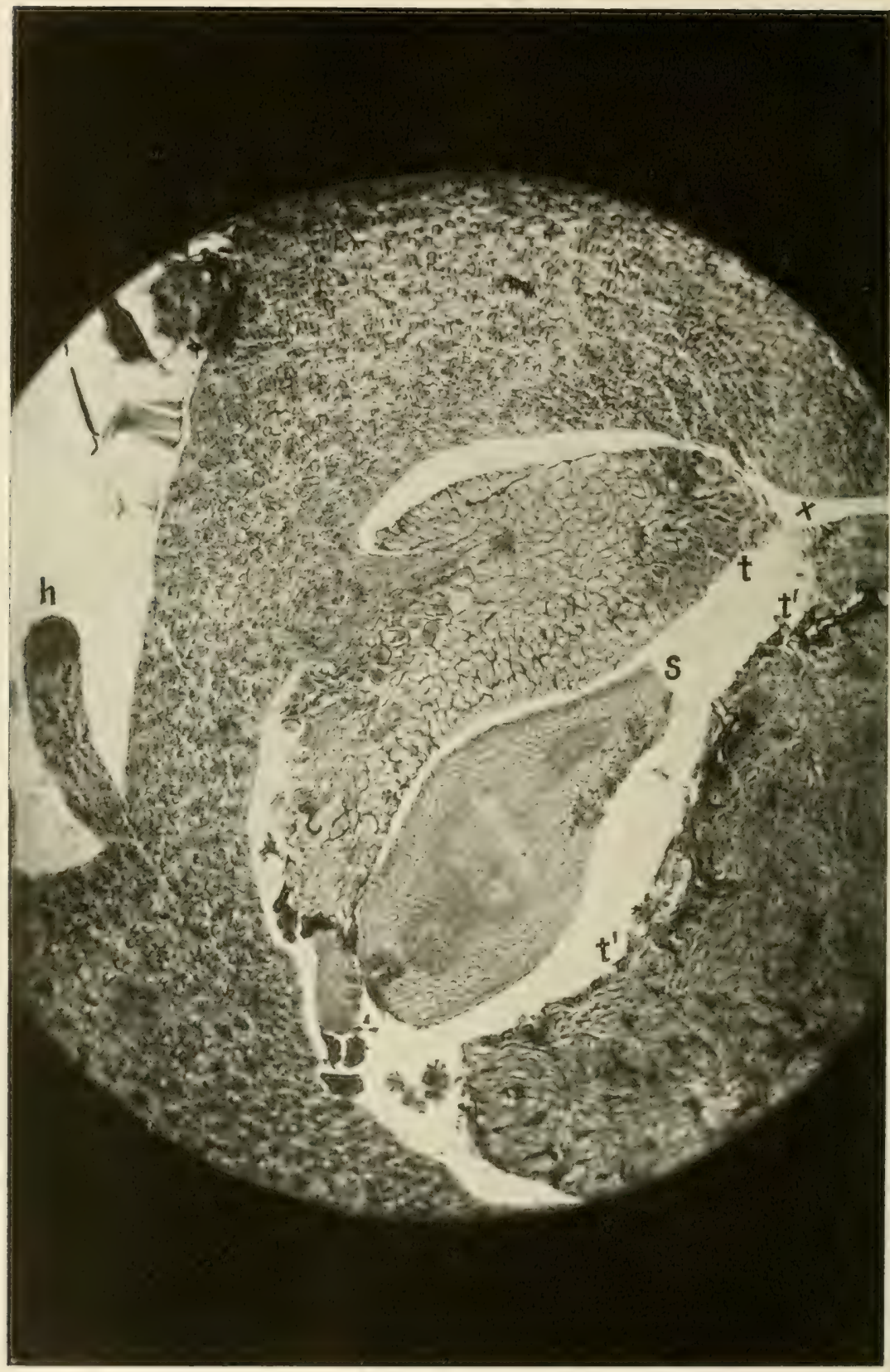

FIG. 345.-Detail of Fig. $344 B$ in tumor region. Tree locule at left; infected locule at right; $s$, young seed the pedicel of which, here torn away, arises from the wall at $x$, a few sections above this one; $t, t^{\prime}$, tumor tissue filling the locule. Between $t, t^{\prime}$ and $x$ on other sections the tumor tissue is continuous. It appears to have developed from the left side of the loculus out of an appendage like $h$. 


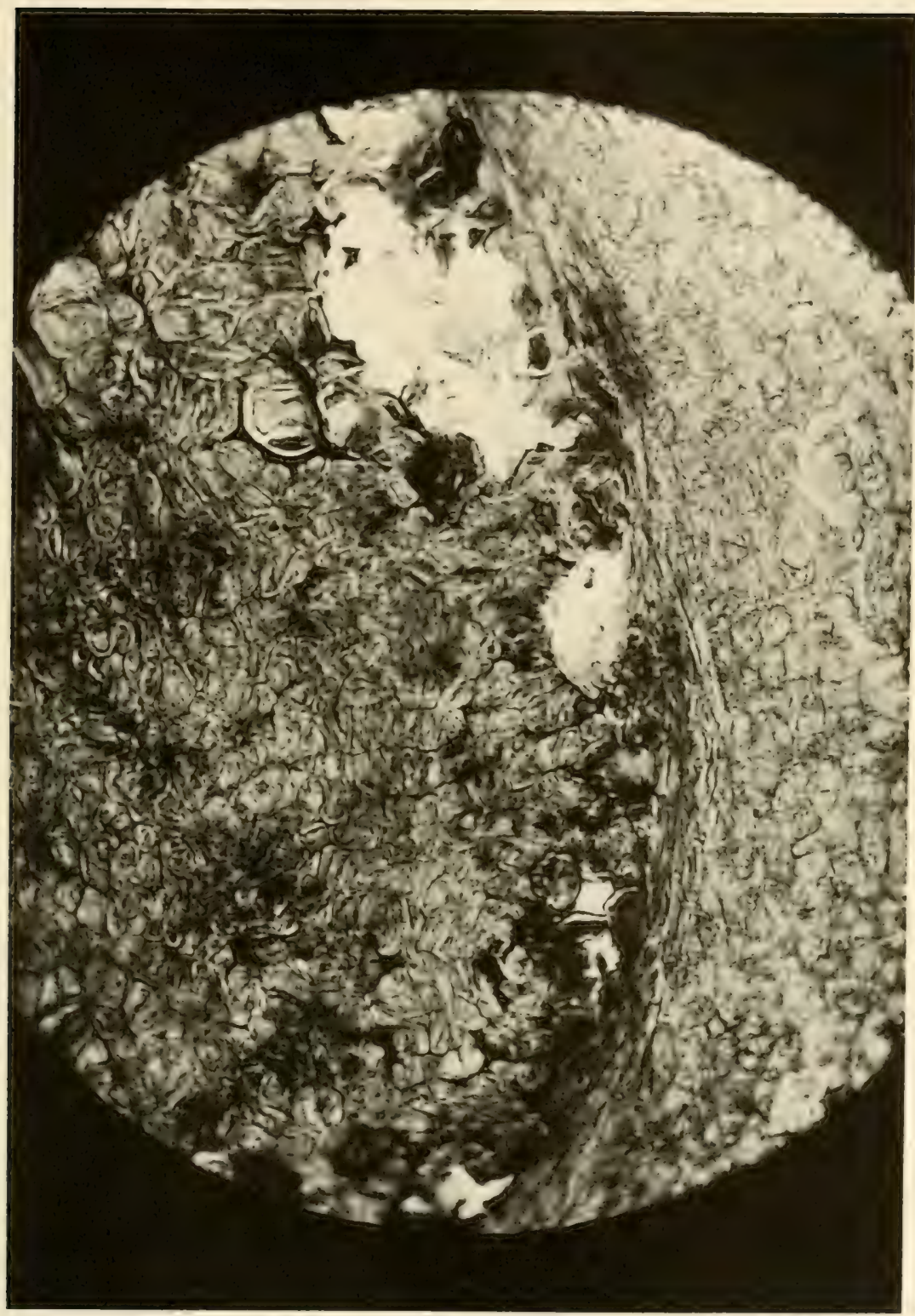

FIG. 346.-Same as Fig. 345 but from the right side of the locule and further enlarged. Normal septum at right. The rest is deep-staining tumor-tissue. Slide 1198A6; acid fuchsin stain. There are tracheids in the middle of this tumor to the left of the part here shown. Observe also the disorderly arrangement of the tumor cells: 


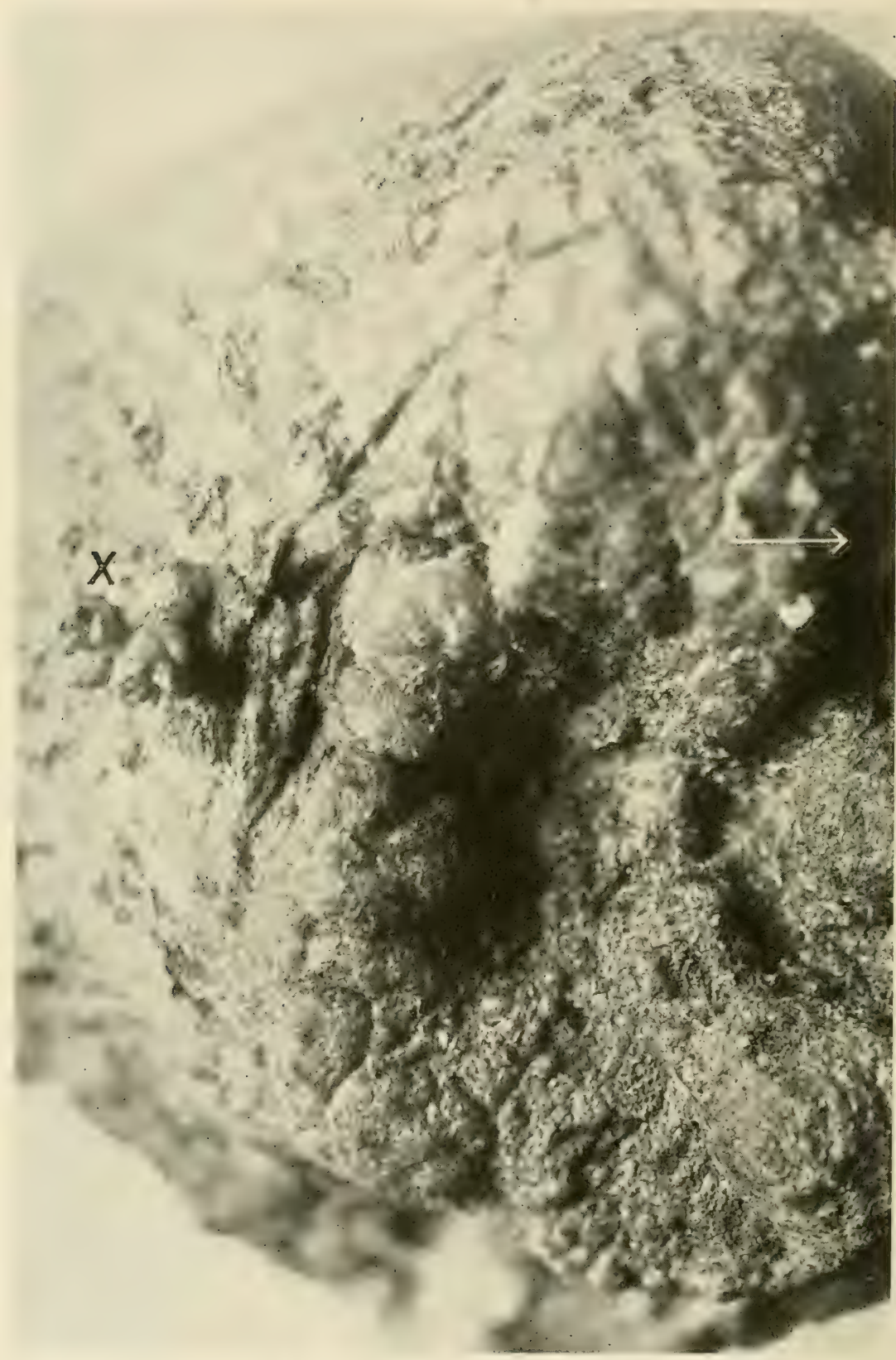

FIG. 347.-Crown-gall teratoma on sugar-beet. Plant inoculated by Nellie A. Brown, January 26, 1918, using a sub-culture of Bacterium tumefaciens plated from a rose gall. The main axis of the beet is a long way off in the direction of the arrow. All here visible is tumor. Growing out of the rough tumor tissue at $X$ is a small, bright-green, branched, fleshy (tumefied) shoot. Photographed April 25, 1918. $\times 6$. 
stages as well as later ones); growth in nitrate bouillon; Cohn's solution; Uschinsky's solution; milk, litmus milk; behavior in peptone water in fermentation tubes with various sugars and alcohols. Is there any clouding in the closed end? Try also various plant juices in fermentation tubes. What acids are produced? Test for formic and acetic. Use flasks of river water with 1 per cent peptone, 1 per cent dextrose and a little calcium carbonate. Examine at the end of 2 weeks, 6 weeks and 3 months. According to the chemists, aldehyd, alcohol and acetone are also produced. Determine its nitrogen nutrition.

Non-nutritional Environment.-Maximum, minimum and optimum temperatures for growth. Thermal death-point in peptone bouillon (10 minutes exposure). Effect of sunlight, of dry air, of freezing, of salted bouillon, of chloroform in bouillon, of acids, of alkali, of germicides. Determine conditions under which the involution forms are produced. Add various dilute organic acids ( 1 part acid to 9 parts water) in small quantity $(5,10,15$ and 20 drops to each 10 ce.) to 24-hour agar and bouillon cultures (holding check tubes), and compare for changes in structure of the organism, i.e., appearance of involution forms (Y-bodies) after 24, 48, 72, etc., hours. Pour plates the $3 \mathrm{~d}$, 5th and 10 th days, from both checks and treated tubes, using carefully measured quantities of the fluids. Any reduction in number of organisms in the acidified tubes? Any retardation in development of colonies on plates poured from such tubes?

Oxidases (?) and peroxidases are said to be much more abundant in the galled tissue than in the normal tissue. Can you verify these statements? (See Bull. 213, p. 173.) Does this fact have any pathological significance? Is the formation by the micro-organism of acids and alkalies of pathological significance? (Consult Jour. of Agr. Research, Jan. 29, 1917.)

How many distinct strains are there of the crown-gall organism? I do not call every isolation of an organism a strain, but only such as possess distinct morphological, cultural, pathogenic or other characteristics. The two strains I am most familiar with are the Paris daisy strain and the Hop strain, but there are others. Jensen in Denmark isolated a strain from the Paris daisy which is unlike our strain in its serological reaction, 


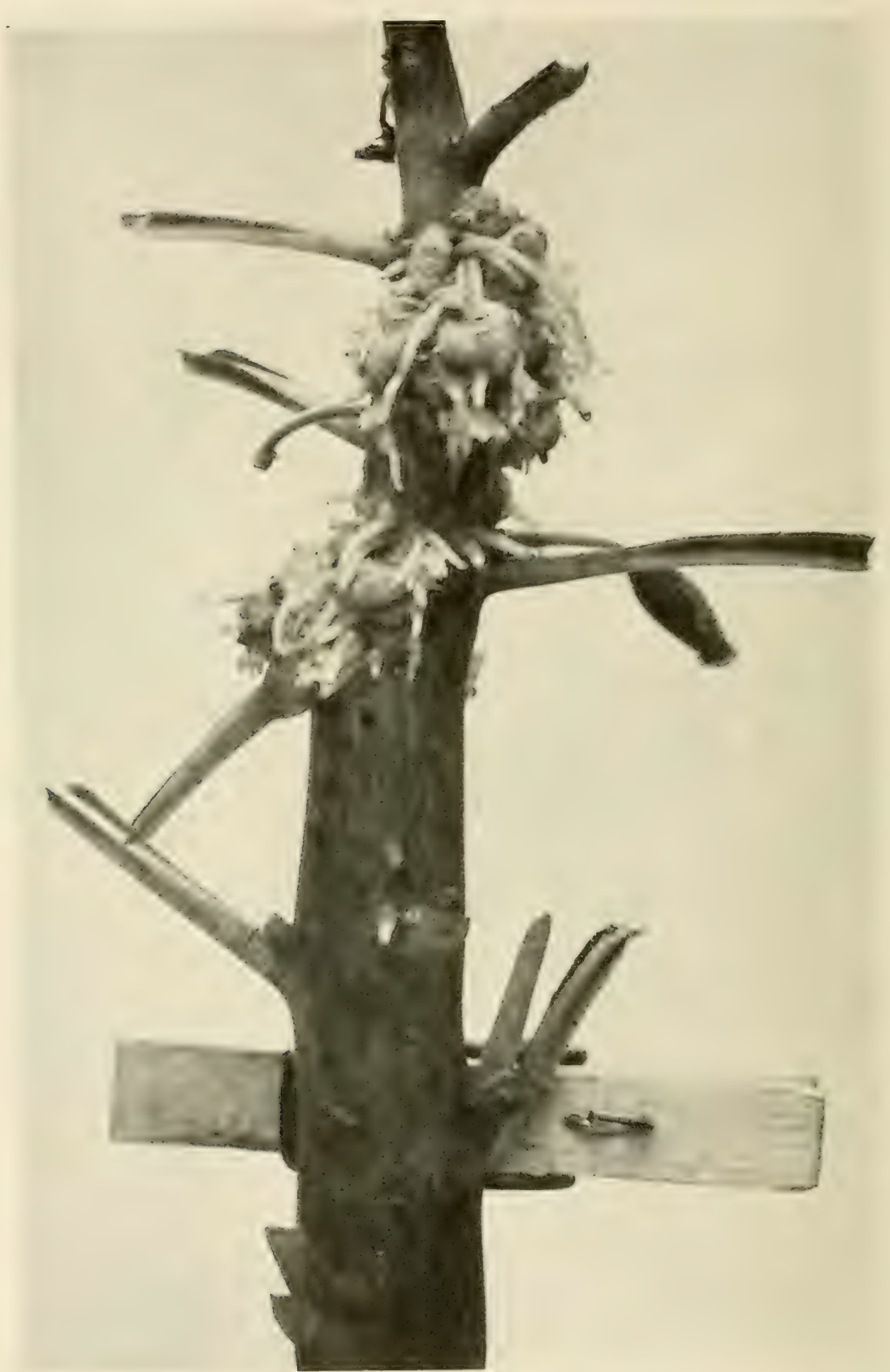


that is, the serum of animals inoculated with it will clump its cultures but will not clump the cultures of the American daisy strain, and vice versa.

For the Disease. Signs.-Period of incubation for primary tumor (I have observed well-developed small galls on the peach 18 days after needle puncture (Fig. 318), on the almond in 10 days; and beginnings on the daisy in 5 days. Under favorable conditions the beginning of galls on sugarbeets may also be seen as early as the $4 \mathrm{th}$ or 5 th day.

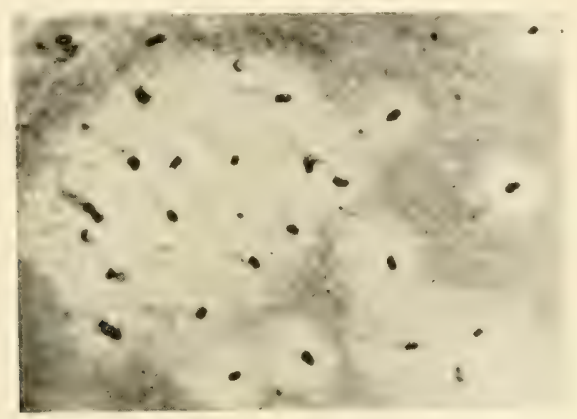

FIG. 349.-Flagellate rods of Bacterium tumefaciens (hop strain) stained by van Ermengem's silver nitrate method. Photomicrographed by the writer. $\times 1000$.

Time required for the development of secondary tumors in leaves of the daisy? The shortest time I have observed is 10 days from the time of stem-inoculation and commencement of the primary stem-tumor. Ordinarily, it is longer. For production of secondary tumors inoculate into leaf-traces immediately under the petiole in rapidly growing Paris daisy shoots.

Is the tumor or tumor-strand (which is sometimes visible to the naked eye) green or greenish? How do you account for this? Is it ever brown or brownish? Is it under pressure?

FIG. 348. - Top of Impatiens balsamina (the common garden balsam) showing "hairy-root" due to inoculation on July 26, 1916, with the hop strain of Bacterium tumefaciens. The stem was needle-pricked in the leaf axils. There was much red stain in the tumors and in the roots. (red flowered variety) although the leaves and stems of this plant elsewhere were pale green. There was no red stain in tumors on the stems of white flowered balsams inoculated at the same time. Photographed August 22, 1916. Nat. size. 
Is it really a growth from the primary tumor, in the sense of a pushing in between tissues or only a change in more and more distant cells owing to the propagation of a chemical stimulus? sometimes it would seem to be the one and sometimes the other. If the cells of the tumor do not change position, how do you account for the tissue distortions? Can you find the tumor strand in fruit trees? Can you cultivate the parasite from the tumor-strand? From the secondary tumors?

What causes the browning of the cut surface of the tumors?

Describe the appearance of the tumors. What effect, if any, do they have on the rest of the plant. Grow sugar beets or

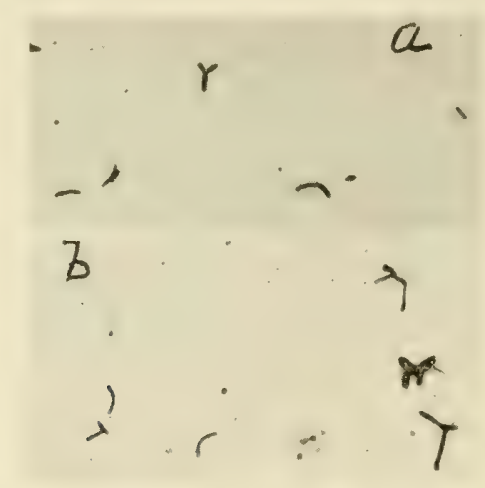

FIG. 350.-Y-shaped bodies of Bacterium tumefaciens from a young, pure culture treated with acetic acid. Colony 2, resistant daisy, 4 days on agar, then exposed 2 days to 10 drops of acetic acid water ( $1 \mathrm{cc}$. acid, 9 cc. water). Smeared and stained with Carbol fuchsin, March, 1915.

tobacco (I used Nicotiana sylvestris) and inoculate the center of the big rosette of leaves rather early and observe the results. Is there ever stimulating action at a distance from the tumor? Observe in some of the photographs thickening of the wood on the tumor side of the stem. How do you account for it? Examine the plant for stunting, curvatures, changes in color of leaves, death of parts, etc. Does the location of the gall make any difference?

Histology. - What is the structure of the earliest visible tumors (10 or 15 days from date of needle-pricks) as compared with structure of the tissue inoculated? How do you account 


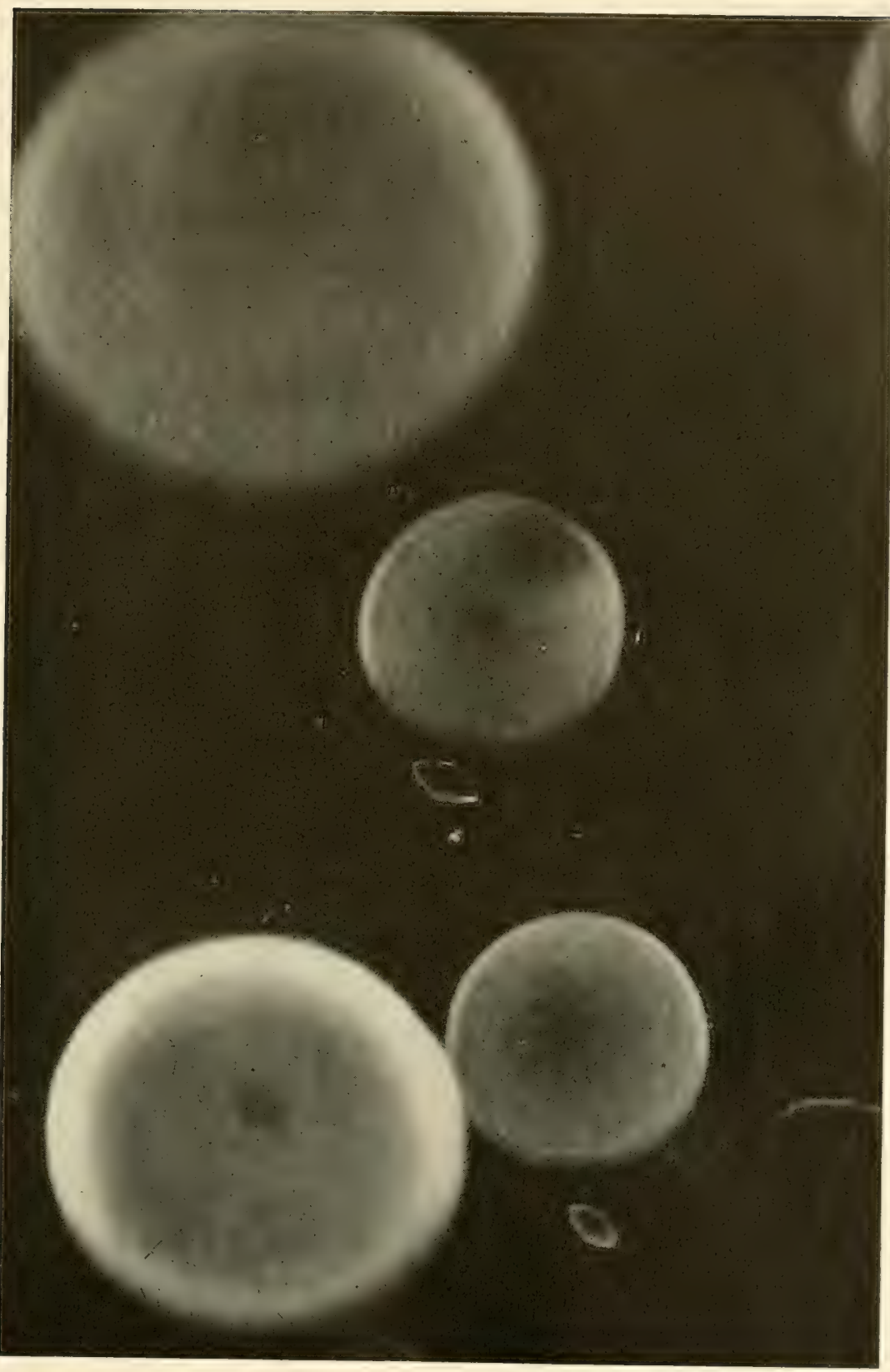

FIG. 351.- Surface and buried colonies of Bacterium tumefaciens (Rose P) on +15 beef-peptone agar. Poured January 26. Colonies up January 31. Photographed February 1, 1917. × 9 circa 


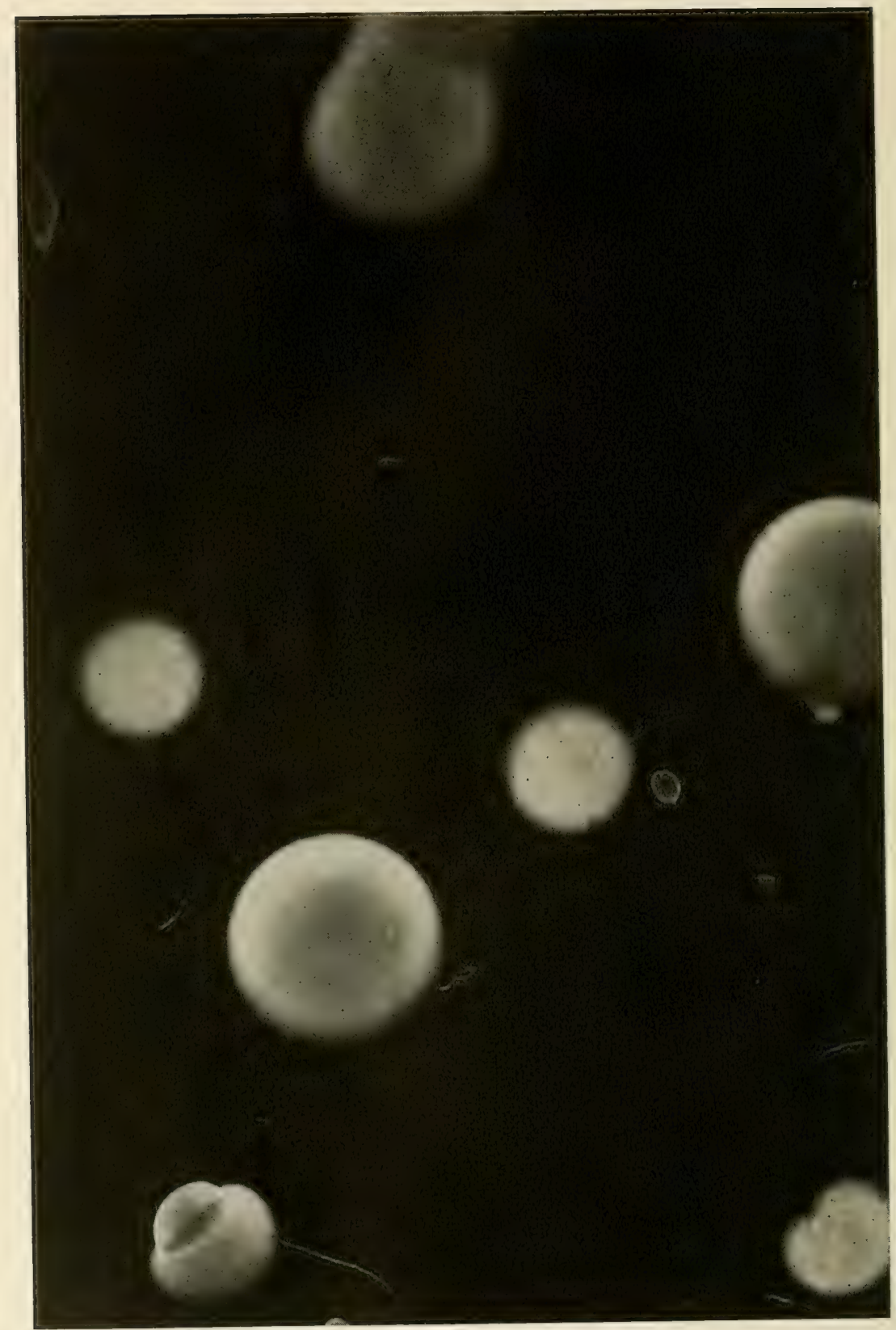

FIG. 352. 
for the small size of the cells? (Young actively growing tobacco stems or daisy stems may be used for this purpose, making shallow pricks.) How many centimeters from the primary tumor to the remotest secondary tumor (using daisy)? On the sunflower shown on Fig. 319, sub. 4, it was 7 inches and on another it was 8 inches (time 5 to 6 weeks) but, of course, meanwhile, there was stretching of the stem. Can you demonstrate the tumor-strand? Can you demonstrate the pseudo-stem structure in any of the secondary tumors occurring in leaves of the daisy, the primary tumor being on the stem? Is there any real difference between the structure of the secondary tumors in leaves and those produced on leaves by direct inoculation? Peklo states that he obtained root structure (secondary thickenings) in tumors on flower stalks of the sugar beet by direct inoculation. Is the browned surface of the tumor composed of cork? What is the character of the vascularization of the tumor? Compare the number and direction of the vascular bundles with those of the normal stem and leaf in daisy-in the torus of the sunflower. How do you account for the distortions? For the difference in number of vessels in the two tissues? Does the tumor contain spiral vessels as well as tracheids? Are these abundant or rare? Normal to it or accidental? In cucumber leaves which contain spiral vessels and no tracheids I obtained crown galls containing tracheids and free from spirals. Are cambium and phloem normal constituents of the tumor? Can you demonstrate sieve tubes in it? Can you produce tumors without wounding the cambium, Are they rascularized? In such tumors (Fig. 329) how do you account for the tracheids? Are sieve tubes also present? Is there any tendency in these tumors toward the production of primitive and undifferentiated tissues - structures that occur in early stages of growth, or in

Fig. 352.-Surface and buried colonies of Bacterium tumefaciens (hop strain) from Flask $P$ ) on +15 beef-peptone agar at end of 4 days at $25^{\circ} \mathrm{C}$. Two buried colonies coming to the surface. The surface colonies are smooth and translucent glistening. Photographed January $13,1917 . \times 14$. In agar-poured plates made from old stock cultures the surface colonies of the hop strain are sometimes very unlike those shown on this plate, i.e., they may have a contoured surface and a sinuate margin with a radiate mottled internal structure, yet are infectious. 


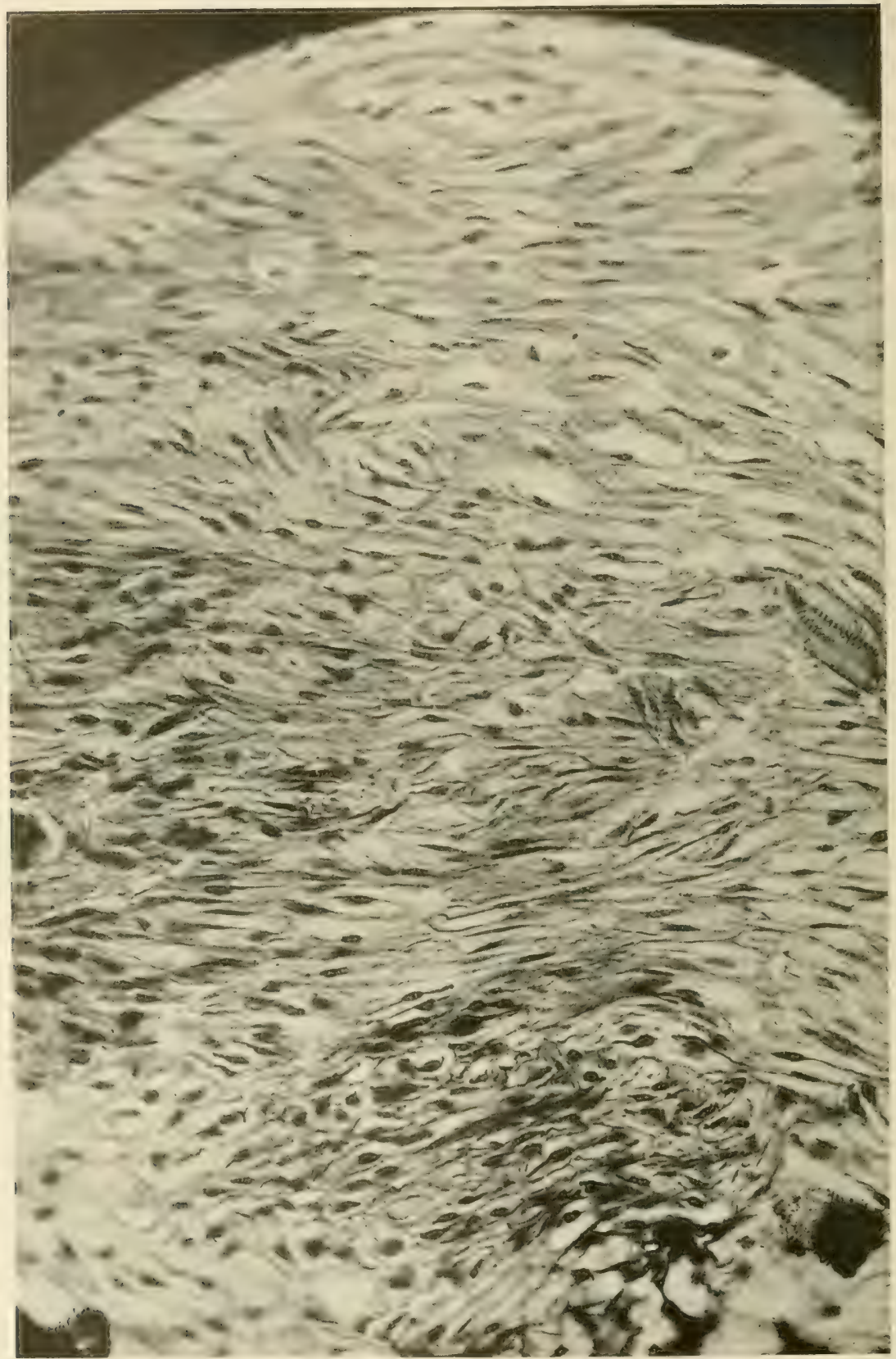

FIG: 353. - Section of crown gall in Paris daisy showing spindle-shaped tumorcells. Tracheids at the right. Slide cut and stained by Lucia MeCulloch. Photomicrographed by the writer. Medium magnification. 


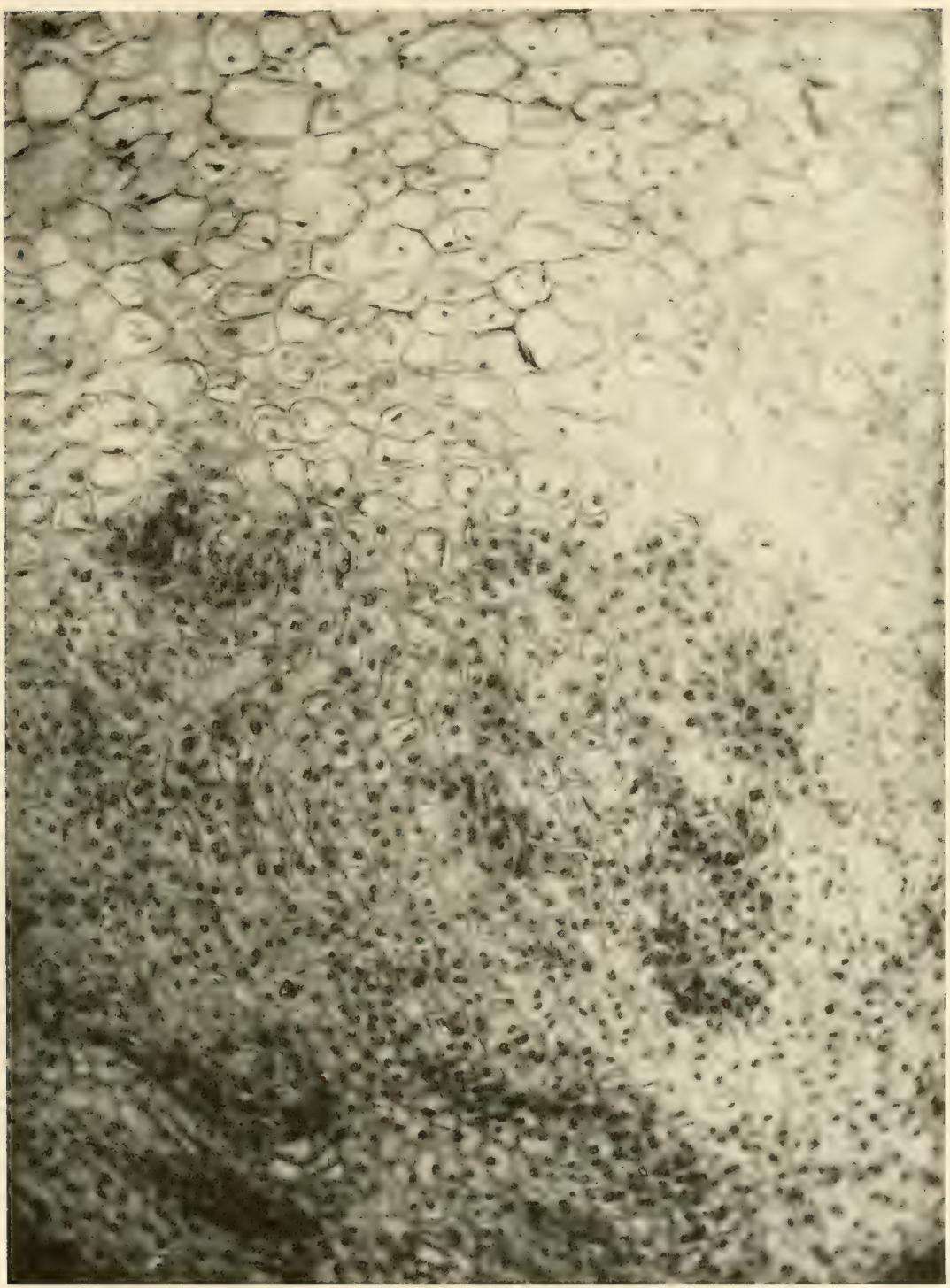

FIG. 354.-Crown gall on Paris daisy: Photographed from another part of same tumor as Fig. 353. Non-malignant part of the tumor at the top. The middle and lower part is composed of large-nucleate round cells which are in very rapid division. The black dots are the deep-staining nuclei. 
related plants? See Figs. 353, 354, 415, 416, 417, 418, and Bulletin 255, Pl. LVI (for the wide medullary ray) for what I mean. Toward the production of giant cells? What is a giant cell? How does the structure of the teratoid crown gall differ from that of the non-teratoid gall? On tobacco internodes the writer obtained tumors bearing leafy shoots not only from the cambium but also from the protoxylem and from the bark. How do crown galls differ in structure from fungus galls? From insect galls? From nematode galls? How do you account for these differences? For structure of the tumor and tumor-strand, cut cross-sections, and longitudinal sections of leaves and stems (between tumors and through them) from fixed material embedded in paraffin. Stain 6 to 24 hours in a 2 per cent aqueous solution of methyl green, and after rinsing in water gently so as not to wash off the sections, counterstain 5 to 15 minutes in a 2 per cent aqueous solution of acid fuchsin (not basic fuchsin). Then pass very rapidly through graded alcohols into absolute alcohol, xylol and Canada balsam. The right amount of staining should be judged under the microscope as it is proceeding. Do not overwash the sections.

Such sections may also be stained in various basic aniline dyes to demonstrate absence of the bacteria in the vessels and intercellular spaces, but the student will hardly be able to demonstrate the bacteria in the tissues, i.e., inside the cells, by means of aniline dyes, unless he should have better success than the writer and his assistants have had. They may be demonstrated by allowing them to diffuse out of the cut tissues in bacteria-free water on slides free from bacteria, i.e., clean flamed slides, which should then be dried and stained with Ziehl's carbol fuchsin, which should also be free from bacteria. Both rods and Y's can be demonstrated in this way. They should be studied under the 2-mm. oil immersion objective, using a No. 8 or No. 12 ocular.

Certain bodies which at one time I identified as bacteria are best demonstrated in the tissues by cutting small slices $(2 \mathrm{~mm}$. thick) from young and tender galls and throwing them for 24 hours into 5 or $10 \mathrm{cc}$. volumes of a 5 per cent aqueous solution 


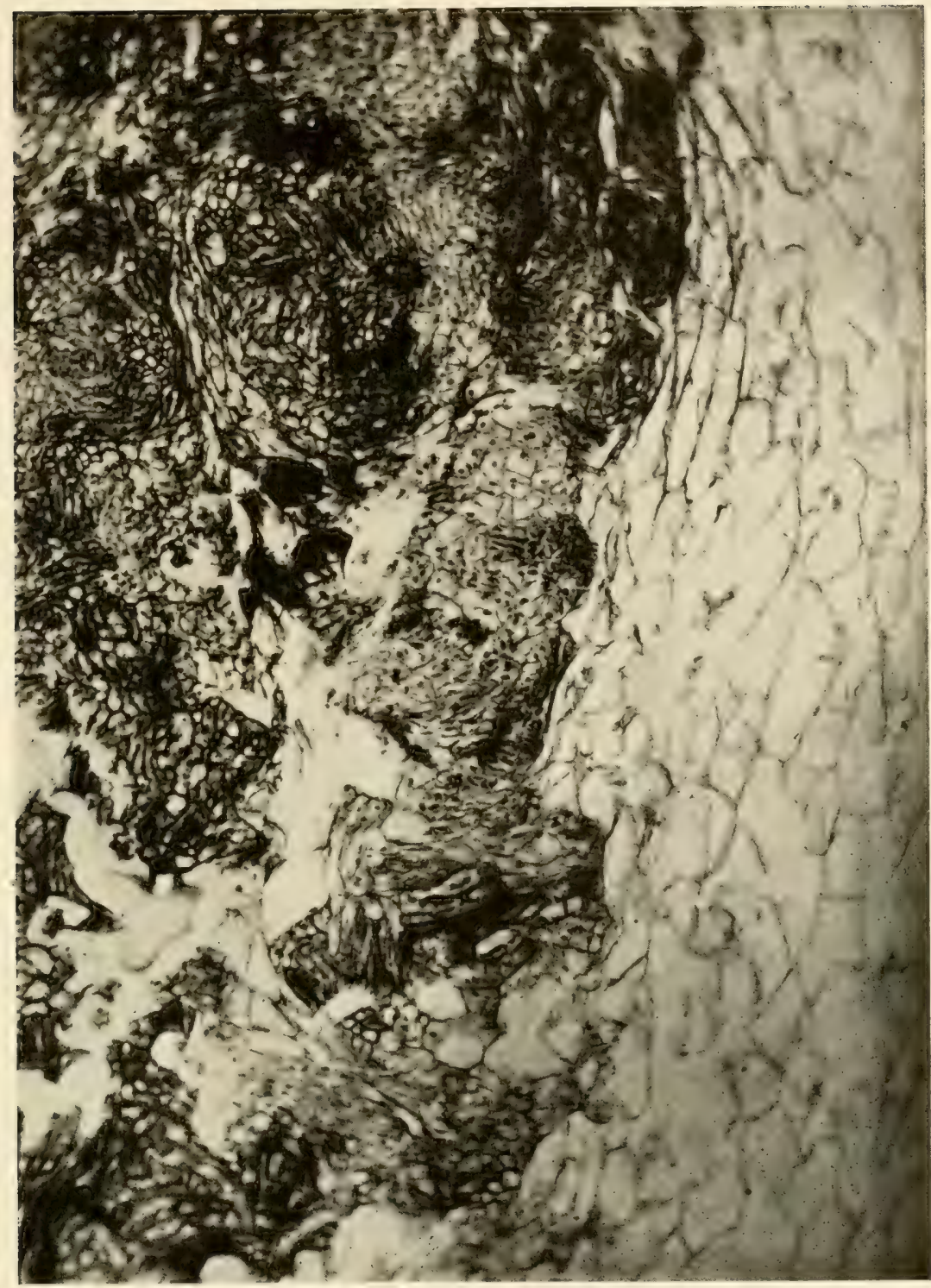

FIG. 355.-Advancing margin of crown-gall tumor in the soft white pith of a sunflower disk Tumor hard grayish green and exceedingly vascular because derived from the very vascular torus (seed-receptacle). The white parts at the left are surrounded and compressed pith cells. Slide stained with acid fuchsin and counterstained with methyl green. Pith white, vessels (tracheids) blue, tumor tissue red. Consult also Jour. Cancer Research Vol. I, No. 2, Plate XIII, Fig. 52. 
of gold chlorid. They are then washed 3 minutes in water and placed for another 24 hours (in the dark) in a 0.25 per cent aqueous solution of formic acid. After this they are washed in water, passed through graded alcohols into xylol and embedded in paraffin in the usual way. Is there not at least a strong probability that these rod-shaped bodies stained by the gold chlorid and supposed to be the bacteria are only normal constituents of the plant cell (mitochondria)? What are mitochondria? (Read a paper by the Lewises in Journal of Anatomy, Vol. 17, 1915, p. 339.) Have you observed any bacteria in the intercellular spaces of sound galls? Study the fauna and flora of old galls. Can you find Toumey's organism?

Have you observed any excess of chloroplasts in the tumor or in the tumor-strand (daisy)? Any bleaching of tumors or shoots from tumors? Any floral pigment in tumors? Try Pelargoniums, inoculating the tops of growing plants which are nearly ready to develop red blossom buds. Try also red balsams, inoculating before the flower buds develop. Any starch? Any excess of sugar or of enzymes? Consult Figs. 353 to 356 for structure of the hyperplasial tumor tissue. Fig. 353 shows spindle-celled tumor tissue and Fig. 354 shows round-celled tumor tissue from the same gall. Fig. 355 shows both the crushing and invasive effect of a tumor which is excessively. vascular, because arising from a very vascular organ - the torus of the sunflower. In Fig. 356 which is from Ricinus the glandular epidermis is also involved. When a tumor is deep seated should the pushed-up and thickened cortex, the cells of which are normally oriented, be reckoned as a part of the tumor? If so, why any more than pushed up skin and muscle?

Variability.-We have found in various isolations from crowngall of the Paris daisy marked differences in virulence (ability to produce galls), and from certain natural tumors on the sugarbeet (supposed to be crown gall) none of the many typical looking colonies on the agar-poured plates were infectious (we tried perhaps a hundred). From other similar looking natural beet tumors we obtained a very few infectious colonies, but these produced only slow-growing small tumors (Bull. 213, 
plate 36). Further studies must be made. In this connection read what Jensen says in his Danish paper (1.c.).

Also two extremely virulent isolations, cultivated for several years in my laboratory, gradually decreased in virulence and finally lost all power to produce galls. Moreover, differences have been observed in the vigor of growth and harmfulness of galls occurring naturally on various fruit trees. The subject, therefore, is not only one of special interest to the pathologist but also one of much complexity and considerable discouragement to the nurseryman and tree inspector.

Query: May a gall of little harm to one plant infect a soil injuriously for another plant?

Should galled apple trees be planted on land that might later receive peaches, raspberries or grapes? Many such queries must be left to the future. The subject is one which invites careful and long-continued experimentation on the part of various experiment stations and boards of inspection.

Query: Can you produce the disease on olives? On alligator pears? On onions or on garlics? On daisy with the hop organism?

Transmission.-Everything we know about crown gall points to wounds as the usual, if not the only way of infection. Nothing is known respecting insect carriers. In some cases it would seem that the "heeling-in" of sound nursery stock in soil containing the organism has served to infect the youngtrees (O'Gara). How is the disease spread above ground on the limbs of trees?

Everything points to nurserymen as the world-wide distributors of this disease. Many of their soils are so badly infected that good stock cannot be grown in them. Mr. Waite has shown me young apple trees, in numbers, badly galled on the graft and almost or quite free in the stock, so that we could come to no other conclusion than that the disease was introduced into the nursery on the grafts. I have seen badly diseased pear stock that was shipped into the country from France, and badly diseased peach trees that were shipped into California from the eastern Lnited States, and badly diseased gooseberries that were shipped from Iowa to the Atlantic Coast, and badly diseased roses that were shipped from Ohio to Florida. These are only 


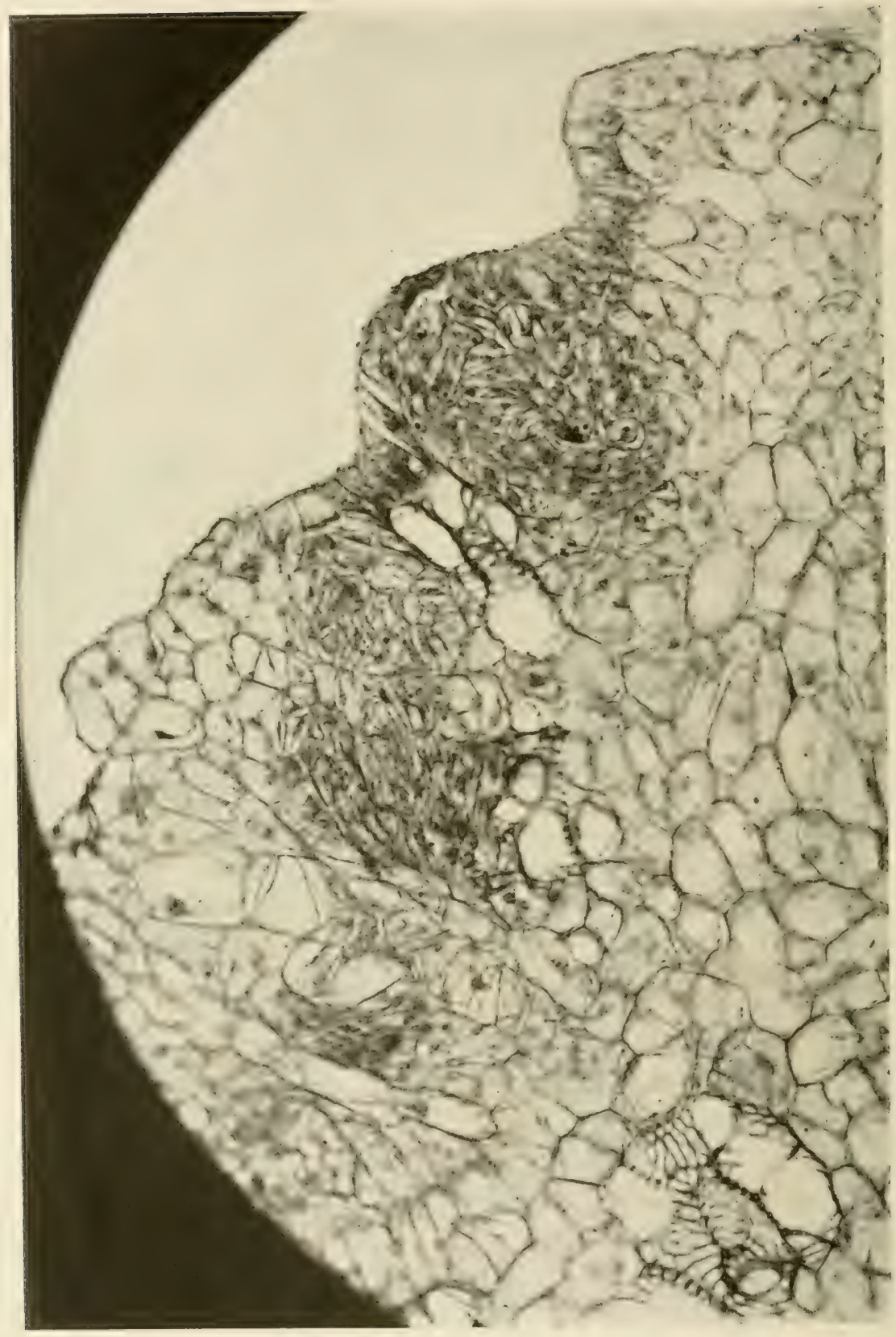

Fig. 356-Gland-inoculation of Bacterium tumefaciens on Ricinus at end of 27 days. The needle penetrated more than one layer of cells but the glandular epidermis appears to be involved and is dividing. Slide 1188. 
a few out of many instances of such transfers that have come to my attention in recent years.

\section{LITERATURE}

Read Bulletins 213 and 255, Bureau of Plant Industry, U. S. Dept. of Agriculture (to be had from Superintendent of Documents, Government Printing Office, Washington, D. C., price 40 cents and 50 cents respectively). See also "Bacteria in Relation to Plant Diseases," Vol. II, Figs. 24, 26, 28, 29, and Plates $5 a, 5 b, 7,8$, and 10; Phytopathology, Vol. I, pp. 7-11; and Brooklyn Botanic Garden Memoirs I, 1918, p. 448.

For suggested relations to cancer see also seven summaries by the writer: (1) "Le Cancer est-il une maladie du règne régétale?" in Proceedings of the 1er ('ongrès International de Pathologie Comparée, held in Paris in October, 1912 (Tome II); (2) "Cancer in Plants" in Proceedings of the 17th International Congress of Medicine held in London, August, 1913 (volume devoted to Section III, General Pathology and Pathological Anatomy); (3) "Studies on the Crown Gall of Plants: Its relation to Human Cancer" (The Journal of Cancer Research, April, 1916); (4) "Further Evidence that Crown Gall of Plants is Cancer" (Science, N. S., June 23, 1916); (5) "Mechanism of Tumor Growth in Crown Gall" (Jour. Agr. Res., Jan. 29, 1917); (6) "Mechanism of Overgrowth in Plants" (Proc. Am. Phil. Soc., vol. 56, 1917); (7) "Embryomas in Plants: Produced by Bacterial Inoculations" (The Johns Hopliins Hospital Bulletin, Sept., 1917).

Read C. O. Jensen, "Undersógelser vedrórende nogle svulstlignende Dannelser hos Planter." [Investigations concerning some tumor-resembling growths in plants.] Kgl. Veterinaer-og Landbohójstioles Aarsskrift, Copenhagen, 1918. Serum laboratory No. LIV. This paper embodies ten years' study of crown gall from the animal (cancer) pathologist's standpoint.

Read "Crown Gall Injury in the Orchard" by Dean B. Swingle and H. E. Morris, Bull. 121, Agr. Exp. Sta., Bozeman, Mont., Jan., 1918, pp. 124 to 139, with 6 text figures. Their experimental work deals with the effect (injurious) of crown gall on apple trees and covers a period of 8 years. 
Read also Peklo, "Ueber die Smith'schen Rübentumoren.", Zeitschrift fur Zuckerindustrie in Böhmen. Jahrg. XXXIX, 5 Heft, pp. 204-219, Feb., 1915. Deals with both Bacterium tumefaciens and Bacterium beticolum, using cultures sent by the writer to Kràl in Prague.

The crown-gall organism was named Bacterium tumefaciens by Smith and Townsend in Science, n. s., Vol. xxv, April 26, 1907, pp. 671-673. 


\section{PART IV}

\section{MISCELLANEOUS}

\section{NOTES ON SOME ADDITIONAL DISEASES}

The foregoing methods apply to the investigation of all bacterial diseases of plants and in case material is not at hand for the study of those diseases treated of in Part III, some of the following bacterial diseases may be available and in the hands of a good teacher will prove equally serviceable. In passing, I might say that I have abundant alcoholic material of several of the foregoing diseases which I shall be glad to give out in small quantity for the preparation of microtome sections for class use and that whenever I can do so I shall also be glad to furnish teachers of pathology with pure cultures of the various plant pathogenic schizonycetes considered in Part III of this book, but cannot promise to furnish photographs, stained slides or lantern slides, nor any of the organisms mentioned below.

1. Mango Leaf-, Stem- and Fruit-spot-Bacillus mangiferae Doidge.

2. Black Spot and Canker of Plum, Peach, etc-Bact. pruni EFS.

3. Stripe Disease of Broom corn and Sorghum-Bact. andropogoni EFS.

4. Jones, Johnson and Reddy's Bacterial Blight of BarleyBact. translucens, J., J. and R.

5. Bacterial Disease of Banana-Bacillus musae J. B. Rorer.

6. Lilac Blight-Bact. syringae (Van Hall) EFS.

7. Wakker's Disease of Hyacinths-Bact. hyacinthi Wakker.

8. Cobb's Disease of Sugar Cane-Bact. vascularum Cobb.

9. Rathay's Disease of Orchard Grass-Aplanobacter rathayi EFS.

10. O'Gara's Disease of Western Wheat Grass-A pl.agropyri O'Gara.

11. Woods' Disease of Carnations-Bact. woodsii EFS.

12. Walnut Blight-Bact. juglandis (Pierce) EFS. 
13. Coconut Bud Rot-Some form of Bacillus coli, according to John R. Johnston.

14. Larkspur Blight-Bacillus delphinii EFS.

15. Alfalfa Stem and Leaf Blight-Bact. medicaginis (Sackett) EFS.

16. Stem Blight of Field and Garden Peas-Bact. pisi (Sackett) EFS.

17. Citrus Canker-Bact. citri (Hasse) Jehle.

18. Lettuce Blight-Bact. aptatum Nellie A. Brown.

19. Metcalf's Soft Rot of Sugar Beet-A planobacter teutlium (Metcalf) EFS.

20. Tubercle of Sugar Beet-Bact. beticolum Smith, Brown and Townsend.

21. Leaf Spot of Begonia.

22. Leaf Spot of Pelargonium-Bact. erodii Lewis.

23. Aderhold and Ruhland's German Cherry BlightBacillus spongiosus Aderh. and Ruhl.

24. Barss' Cherry Blight of Washington and Oregon (which is probably the same as No. 23).

25. Angular Leaf Spot of Cucumber-Bact. lachrymans Smith \& Bryan.

26. Spieckermann's ring rot of Potato. Aplanobacter sepedonicum (Spk.) EFS.

27. Black Chaff of Wheat-Bacterium translucens var. undulosum Smith, Jones \& Reddy.

25. Halo Blight of Oats-Bact.coronafaciens ('harlotte Elliott.

29. Leaf Spot of Soy Bean-Bact. glycineum F. C. Coerper.

30. Velvet Bean Leaf Spot-Bact. stizolobii (Wolf) EFS.

31. Celery Blight-Bacillus apiovorus Wormald.

32. Basal glume rot of wheat-Bacterium atrofaciens Lucia McCulloch.

33. Basket willow disease-Bacillus harai Hori \& Miyake.

34. Tobacco Wildfire-Bacterium tobacum Wolf and Foster.

\section{SUGGESTION OF SUBJECTS FOR SPECIAL STUDY}

LARGER PROBLEMS

1. The natural immunity of plants.

2. Acquired immunity in plants. Effect of hybridization. Search for resistant species and varieties. 
3. Carbon and nitrogen nutrition of the soft-rot organisms. Species relations. Toleration of acids and alkalies.

4. Carbon and nitrogen nutrition of the yellow Bacterium (Pseudomonas) group. Species relations.

5. Field studies of soil relations of Bacterium solanacearum, especially to lime, phosphates and potash.

6. Climatic studies of Bacterium solanacearum. Determination of its northern and western extension in the United States.

7. Geographical distribution of Bacterium solanacearum in Europe and in South America. Ditto Africa and Asia.

8. Exact determination of the causes of the bacterial potato rots of Australia and New Zealand - of France and Italy.

9. Comparative studies of the white organisms Bacillus tracheiphilus, Bacillus amylororus. Bacterium andropogoni, Bacterium woodsii, and Bacterium mori.

10. Does Bacterium andropogoni attack maize as well as broom corn and sorghum?

11. Comparison of the above with Bacillus coli, Bacillus typhosus, and other related animal pathogenes.

12. Comparison of the soft-rot bacteria with $B$. lactis, $B$. coli, etc., in all their varieties.

13. Comparative study of the green fluorescent pathogenic species.

14. Studies of sub-species of various pathogenes. There are a good many.

15. Critical study of the chemistry of all the tumor-producing-species, Bact. tumefaciens in its varieties, Bact. savastanoi, Bact. beticolum, etc., determinations to be made from young, middle-aged and old flask-cultures in various media.

16. Determination of all acids produced by plant pathogens.

17. Hydrogen-ion content of media as related to growth of plant pathogenic species. Conversion of Fuller's scale and Clark's scale to $\mathrm{PH}$.

18. Adaptation of the newer culture media used by animal pathologists to plant bacteriology.

19. New differential media for separating closely related forms, such as the rarious soft-rot organisms and the members of the yellow Bacterium (Pseudomonas) group. 
20. Comparative studies of Aplanobacter species.

21. Old world distribution of Stewart's disease of maize.

22. Methods of distribution of parasitic species on seeds, rhizomes, tubers, corms and bulbs. Responsibility of the seedsman.

23. Distribution of bacterial parasites on nursery stock. Responsibility of the nurserymen and dealer.

24. Insect and other animal distributors of diseases and their control. "Bacillus carriers" among insects. Man's responsibility.

25. The flora of rotting potato tubers - in the advancing margin of the rot and in remoter parts.

26. The saprophytic flora following each parasitic disease.

27. Occurrence of black chaff of wheat in Europe, Asia and South Africa.

28. Occurrence of bacterial barley blight in Europe and Asia.

29. Occurrence of Elliott's oat blights in Europe and Asia.

30. Symbiotic diseases: Ardisias, Pavettas, etc.

31. Favoring organisms-bacterial, fungus, protozoan.

32. Antagonistic soil organisms.

33. Cause of tobacco mosaic and other mosaic diseases.

34. Nature of the sugar-cane disease in Brazil.

35. Nature of the sugar-cane disease in Argentina.

36. Nature of the East Indian cane-disease known as Sereh.

37. Nature of the serious Porto Rican stripe-disease of sugar cane. This occurs also in Java and Hawaii. One should plant sound cane and avoid rattoon crops. Insects spread it.

38. Nature of the destructive sugar cane disease of Fiji. (H. L. Lyons, Hawaiian Planters Record, Vol. III, July, 1910, p. 200 and F. Muir, Ibid., p. 186). This causes tumors in stems and leaves.

39. Nature of the bark disease of rubber (Petch: Physiol. and Diseases of Hevea brasiliensis, London, 1911, Pl. IX).

40. Nature of Janse's disease of Erythrina trees in Java.

41. Cultural characters of the bacterial organism causing tumors on the Aleppo pine and on other European pines.

42. Cause of peach yellows. Is it a leptome disease?

43. Cause of peach rosette and of pecan rosette. Are they mosaic diseases? Are they denitrification diseases?

44. Cause and control of bud-rot of the coconut.

45. Correlation of tobacco leaf spots. How many are there? 
46. Bacterial diseases of cultivated orchids. How many?

47. Bacterial diseases of ferns; 48. of Algae; 49. of fleshy fungi. 50. Do plants harbor animal pathogens?

51 . Is loss of virulence in cultures ever due to the death of an invisible symbiont? If not, why do some organisms lose virulence quickly and others retain it for many years?

\section{SMALLER PROBLEMS}

I have suggested many such problems in the preceding pages and others will occur at once to teachers and students.

\section{PRODUCTION OF TUMORS IN THE ABSENCE OF PARASITES}

On susceptible species of plants, in the absence of parasites, overgrowths of suitable tisules can be brought about in at least five ways: (1) by introduction of irritating foreign substances, that is by certain poisons, administered in stimulating rather than in killing amounts; (2) by slight freezing; (3) by mechanical irritation, that is by woundings; (4) by over-watering in a confined atmosphere; (5) by semi-asphyxiation with vaseline, etc.

My attention was first drawn to this subject in 1909 as the result of observations on the formation of cell-ingrowths (tyloses) in the ressels of plants, especially of those attacked by bacteria. and, second, by experiments in 1916 with crown-gall products.

In the vessels of mulberry shoots attacked by Bacterium mori, in various plants attacked by Bact. solanacearum and in old parasitized stems of ('ucurbita, Citrullus and Vitis, tyloses are very common but their cause has remained in doubt. They occur also in many other plants but I am speaking only of those in which I have studied them. To me everything goes to show that they are the host-reaction to by-products of invading organisms which may not be, necessarily, active parasites. I have produced them by pure-culture inoculations with Bact. mori in young shoots of the mulberry where they never occur nat urally. (see "Bacteria in Relation to Plant Diseases," Tol. II, Fig. 30) and also with Bact. solanacearum in very young shoots of the potato (Fig. 142). Here it is certainly not the bacteria per se that act as the stimulus but their soluble products, since the tyloses may occur at some distance from the advancing growth 
of the bacteria. This is also suggested by the fact that vesselingrowths in great numbers may be produced in the absence of parasites, by purely chemical means. The most striking exhibition of tyloses I have ever seen, a veritable pseudo-parenchyma, was obtained in 1914-1915 by Caroline Rumbold in the vessels of chestnut wood, by injecting a 1/500 g.m. solution of lithium carbonate (Fig. 357 to 359). Here the effect was quite local both in time and place and there were other surprising phenomena, viz., the appearance in the bark of

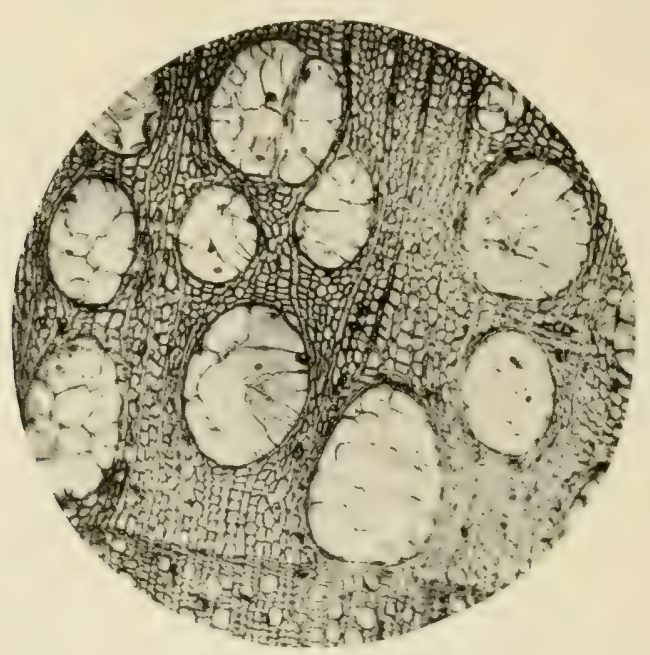

FIG. 357.-Cross-section of chestnut wood, spring of 1914, showing large vessels filled with tyloses. Cut in 1915. Below is unaffected autumn wood of 1913. From Caroline Rumbold's chestnut bark injections of spring of 1914 using 1500 g.m. $\mathrm{Li}_{2} \mathrm{CO}_{3}$. Photograph by the writer November, 1916. $16 \mathrm{~mm} ., 4$ oc.. bellows at 35 . Reduced $1 / 3$.

numerous well-developed islands of wood, causing it to bulge out (Figs. 360, sub. 6 to 362) while in the normal situation in 1915 much less than the usual amount of wood was produced (Fig. 360 at 3). We may suppose the stimulus to have been either the alkali, an excess of carbon dioxide liberated from it, or both acting together. The same curious phenomenon-enormous thickening of the bark (from $1 \mathrm{~cm}$. to 5 or $10 \mathrm{~cm}$.) with formation in it of numerous islands of wood-occurs in the brown bast disease of rubber trees (Hevea brasiliensis) in the DutchiEast 


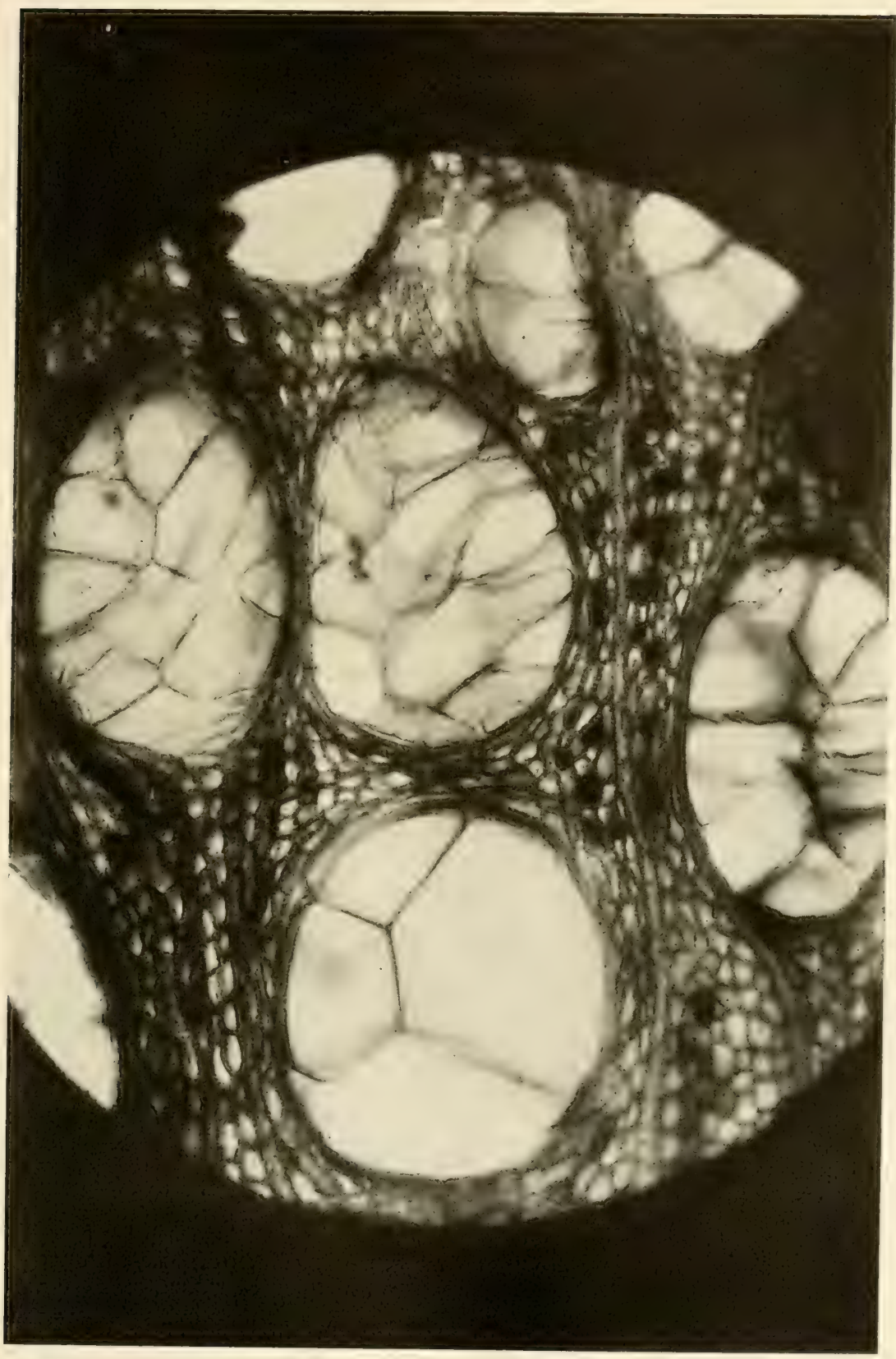

FIG. 358.-Chestnut wood of the year 1914 in cross-section, showing tyloses in the pitted vessels. Bark injected by Caroline Rumbold in the Spring of 1914, with $1 / 500$ g.m. $\mathrm{Li}_{2} \mathrm{CO}_{3}$, cut and stained by her in 1915. Photomicrograph by the writer November, 1916. $8 \mathrm{~mm}$. Zeiss apoc. obj., No. 4, comp. ocular and bellows at 35 on small upright stand. (See Fig. 55.) 


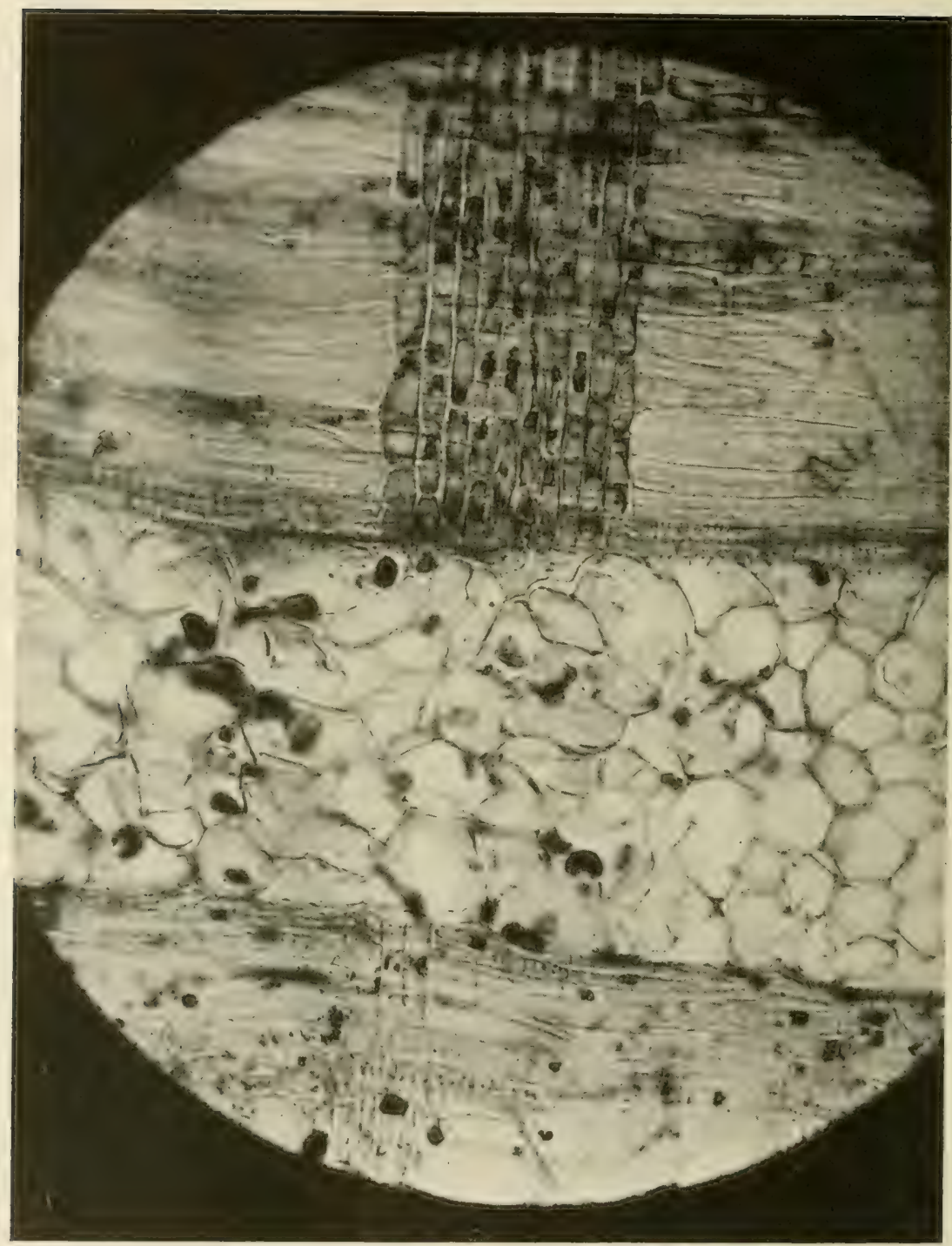

FIG. 359.- Same as Fig. 358, but from a longitudinal section which passes through the middle of a big vessel which is full of the proliferated cells. Wood at either side, also portion of a medullary ray. Photomicrograph by the writer. Same magnification as Fig. 358. Auerbach's stain (C.R.1914, 6). 
Indies, and here the phenomenon is probably due to the alkaline by-products of some undiscovered parasite. I also know from my crown-gall inoculations that a true cambium developed in the bast of tobacco plants may give rise to tumor tissue and to shoots ("Embryomas in Plants," l. c.) and from these results it would seem as though wood and bast respectively must be developed from cambium in a slightly alkaline medium and in

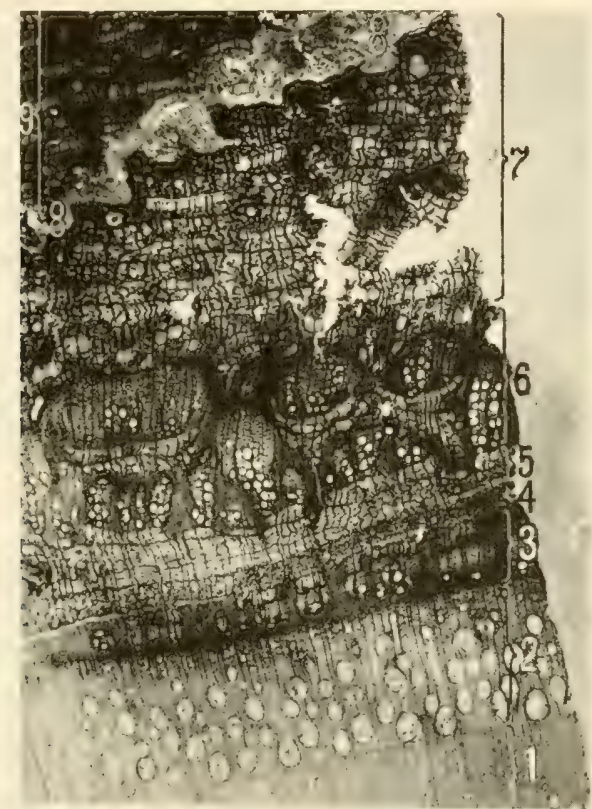

FIG. 360.-Chestnut bark injection of 1914 by Caroline Rumbold showing in cross-section islands of xylem in the phloem: (1) 1913 wood (free from tyloses); (2) 1914 wood (full of tyloses); (3) 1915 wood (free from tyloses); (4) cambium; (5) phloem; (6) islands of wood in the phloem; (7) more phloem; (8) cork: (9) injected (killed) area, $1 / 500$ g.m. $\mathrm{Li}_{2} \mathrm{CO}_{3}$ being the substance used. Photographed by the writer from a section made and stained by Dr. Rumbold.

a slightly acid medium and that to reverse the ordinary process it is only necessary to change the reaction. If this should prove true it would help perhaps to explain certain curious phenomena of wood and bast distribution observed in the stems of lianas and sometimes in other plants (See Jour. Agr. Res., Vol. VI, No. 4, Plates XX and XXI). By injecting a solution of sodium bicarbonate into cabbage stems I obtained hard woody cylinders 


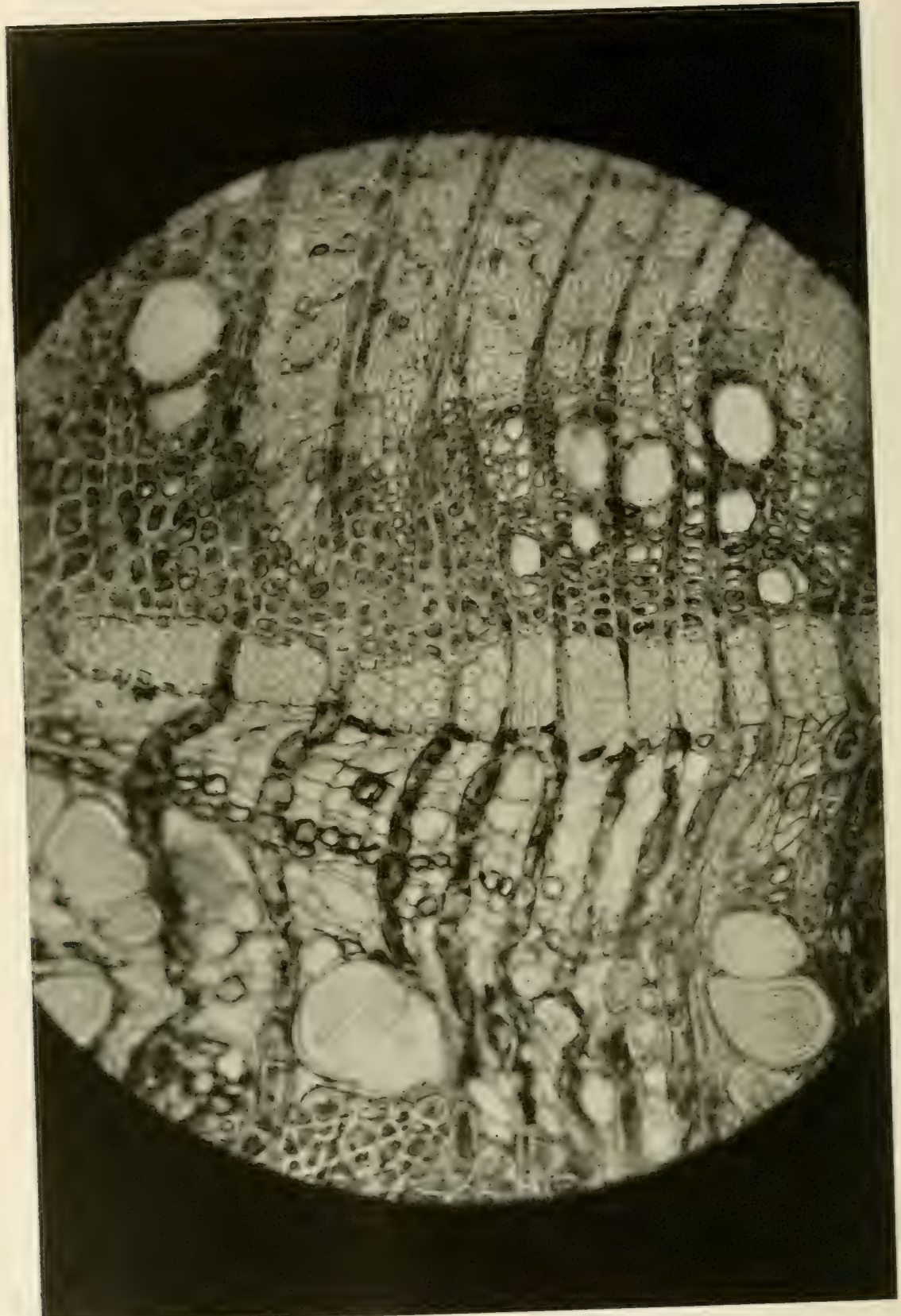

the inner one-half of an island of wood which iereluped in chestnut bark following an injection of $1500 \mathrm{~g} . \mathrm{m}$. of lithium 
in the pith (Fig. 363) but no islands of wood in the bark. The experiment, howerer, should be repeated expecially on plants with a thicker and firmer bark. In most if not all of my attempted bark inoculations the fluid ruptured to the surface and escaped.

As in tyloses, so in crown gall we are forced to conclude that it is not the mere presence of the bacteria in the tissues that leads to the overgrowth, but rather the stimulus of certain products of their metabolism. Theoretical considerations led me to ask the chemists of the Department of Agriculture to make analyses of flask cultures of Bact. tumejaciens and on the basis of their finding: I experimented with rarious plants subject to crown gall, using dilutions (fluids, vapors of irritating substances said to be present in the cultures. With these I obtained many striking small overgrowth: hyperplasias-) and little or no evidence of wounding. Such responses were obtained with ammonia (Figs. 364. 365), acetic acid Figs. 366 to 372). aldehyd (Fig. 373), and formic acid (Figs. 37t to 377 )-all said to be crown-gall products. All these tumors are chlorophyll free, even when arising in tissues full of leaf-green.

Many years ago Hermann ron Schrenk showed that intumescences could be obtained on cauliflower by the use of copper salts, and I have seen them on amaryllis sprayed with Bordeaux mixture, but of course, our interest in artificial hypertrophies and hyperplasias centers chiefly around the question of their production with substances which are the by-products of parasites. In my first cases, as already stated. I did not detect any killing when vapors or large fluid dilutions were used. but with Mac(arty's finding: in mind (Mayo Laboratories' ${ }^{1}$ ), that in very early stages of breast cancers he was able always to detect a trace of cell-injury preceding the development of the malignant cells. I repeated some of my experiments. studying

¿For list of Dr. MacCarty's suggestive papers on cancer see references at end of the second one I have cited under "Literature."

carbonate by Caroline Rumbold. (See her paper in Jour. Am. Phil. Soc.) The wood occupies the upper one-half of the field and is bedded against the outer face of a row of hard bast fibers, the original location of the cambium from which it developed. Photographed by the writer from one of Dr. Rumbold's sections. 


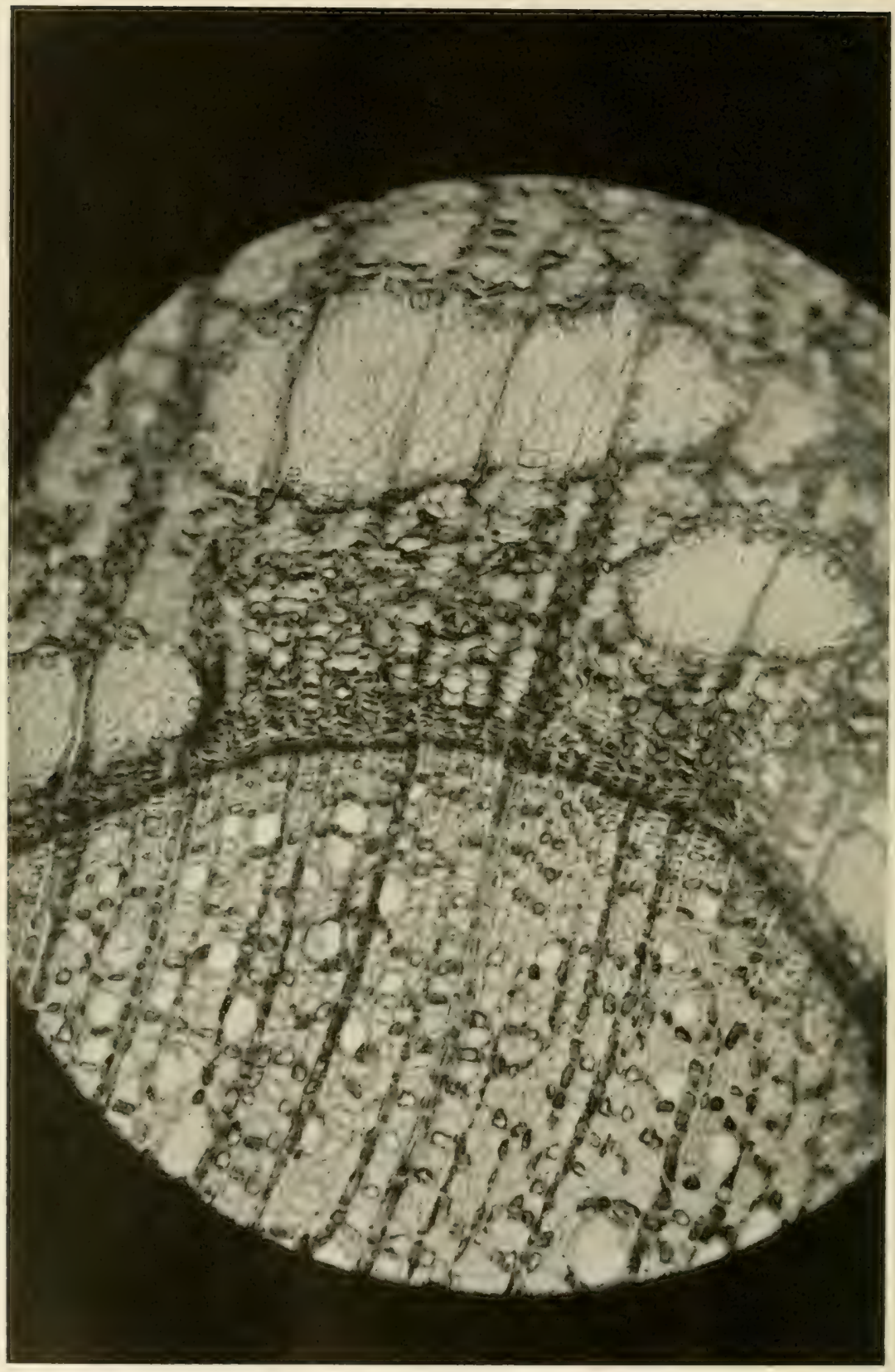

Fig. 362.-Outer part of same wood-island in bast as Fig. 361. The dark eurved line in the middle is the cambium, the dark parallel lines below it are 
earlier (2-to 3-day) stages of the tumor (levelopment (hyperplasias on cauliflower leaves resulting from acetic acid sprays) and always found, judging by differences in staining, indications of at least a few killed cells under the stoma through which the acid penetrated (Fig. 378).

In 1918, Harvey, of the U. S. Department of Agriculture, showed that cabbage leares, exposed to $-3^{\circ} \mathrm{C}$., freeze at first

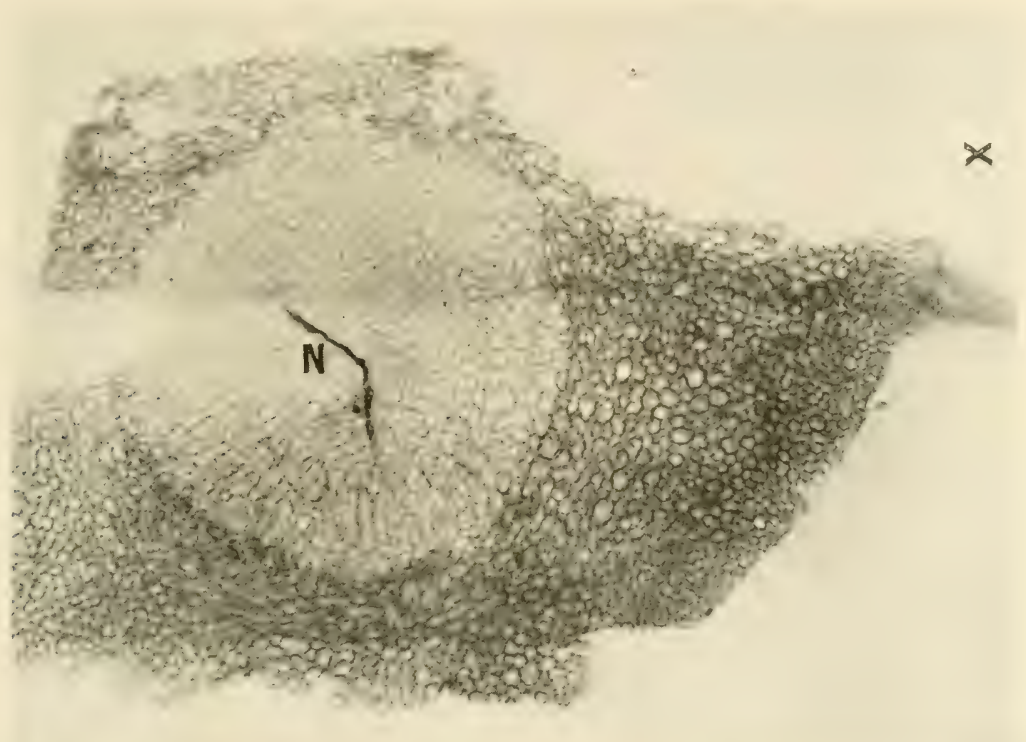

Fig. 363.-Cabbage pith showing a hard woody cylinder which developed after injecting a solution of sodium bicarbonate. Needle track at $N$. Under $X$ a little of the normal wood cylinder.

irregularly in small spots and if the freezing be interrupted at the right moment, say at the end of $1 / 2$ hour, and the plants returned to proper conditions, overgrowths (Fig. 379), which judging from his sections, may be either hypertrophies or hyperplasias, develop from such chilled or frozen spots (Fig. 380) These frozen spots are visible at once because there is extrusion

rylem medullary rays. The white islands in the upper part of the figure are groups of hard bast fibers in cross-section. Photographed by the writer from one of Miss Rumbold's slides. 


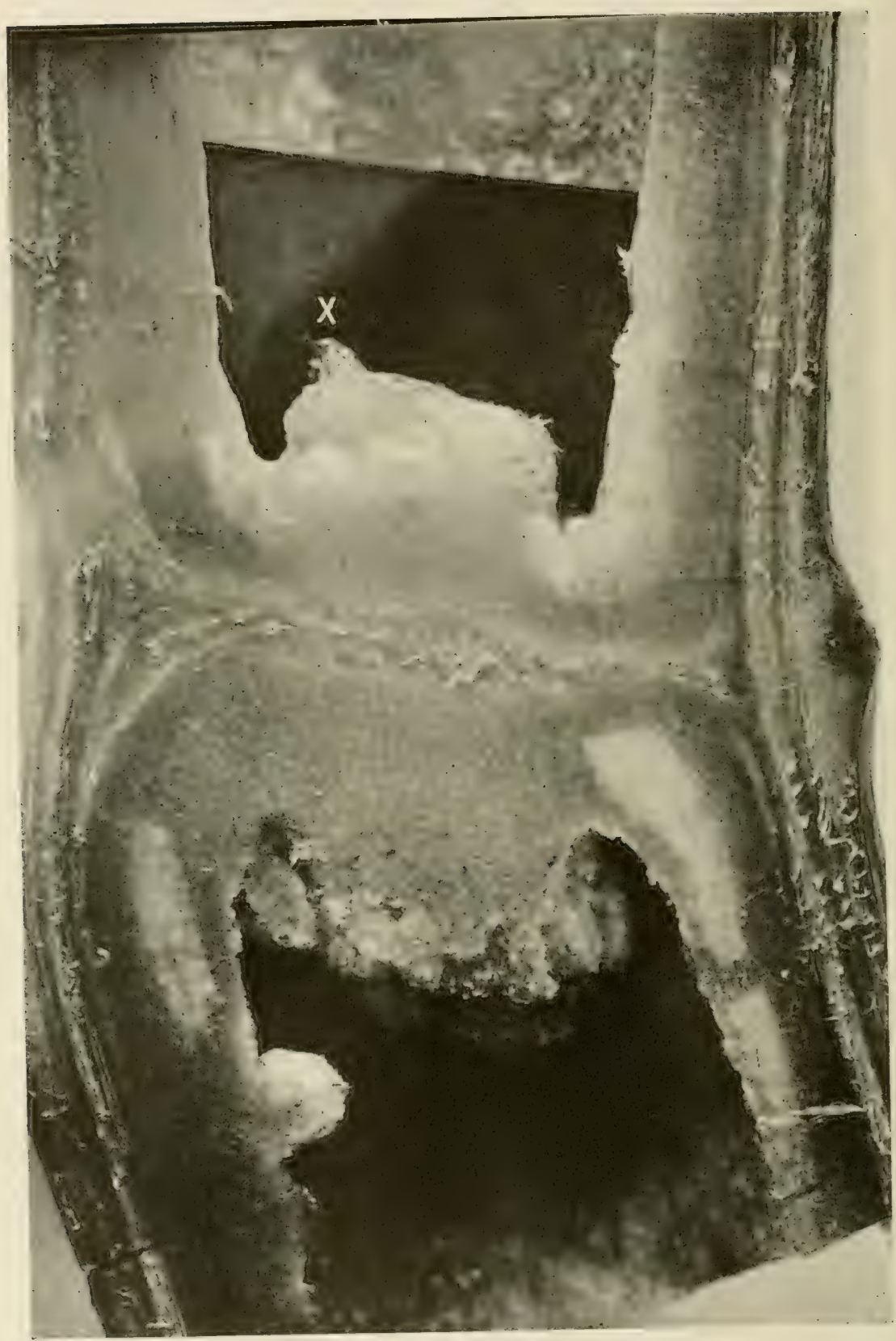

FIG. 364.-Ricinus stem in longitudinal section showing tumors produced by exposure to the vapors from $0.2 \mathrm{cc}$. of a 20 per cent solution of monobasic ammonium phosphate held in a small serum tube resting on the next septum below. The unopened internode above shows its base also tumefied. 


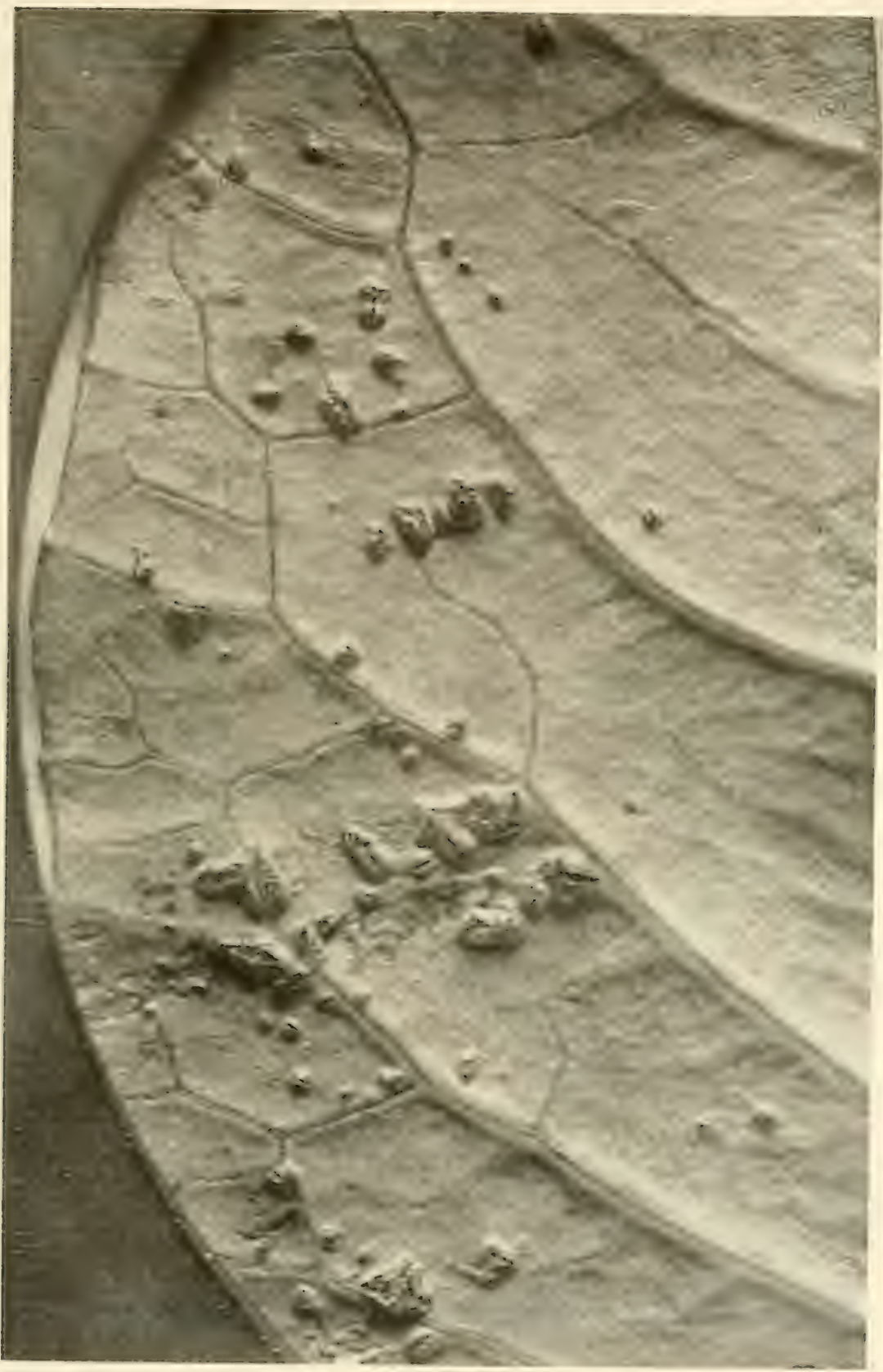

FIG. 365.-Small tumors on under-surface of a cauliflower leaf produced by vapor of ammonia water. Exposed for 15 minutes in 10 cubic feet of air space to $0.5 \mathrm{cc}$. of $0.90 \mathrm{sp}$. gr. water of ammonia. Photographed after 9 days. $\times 4$. 


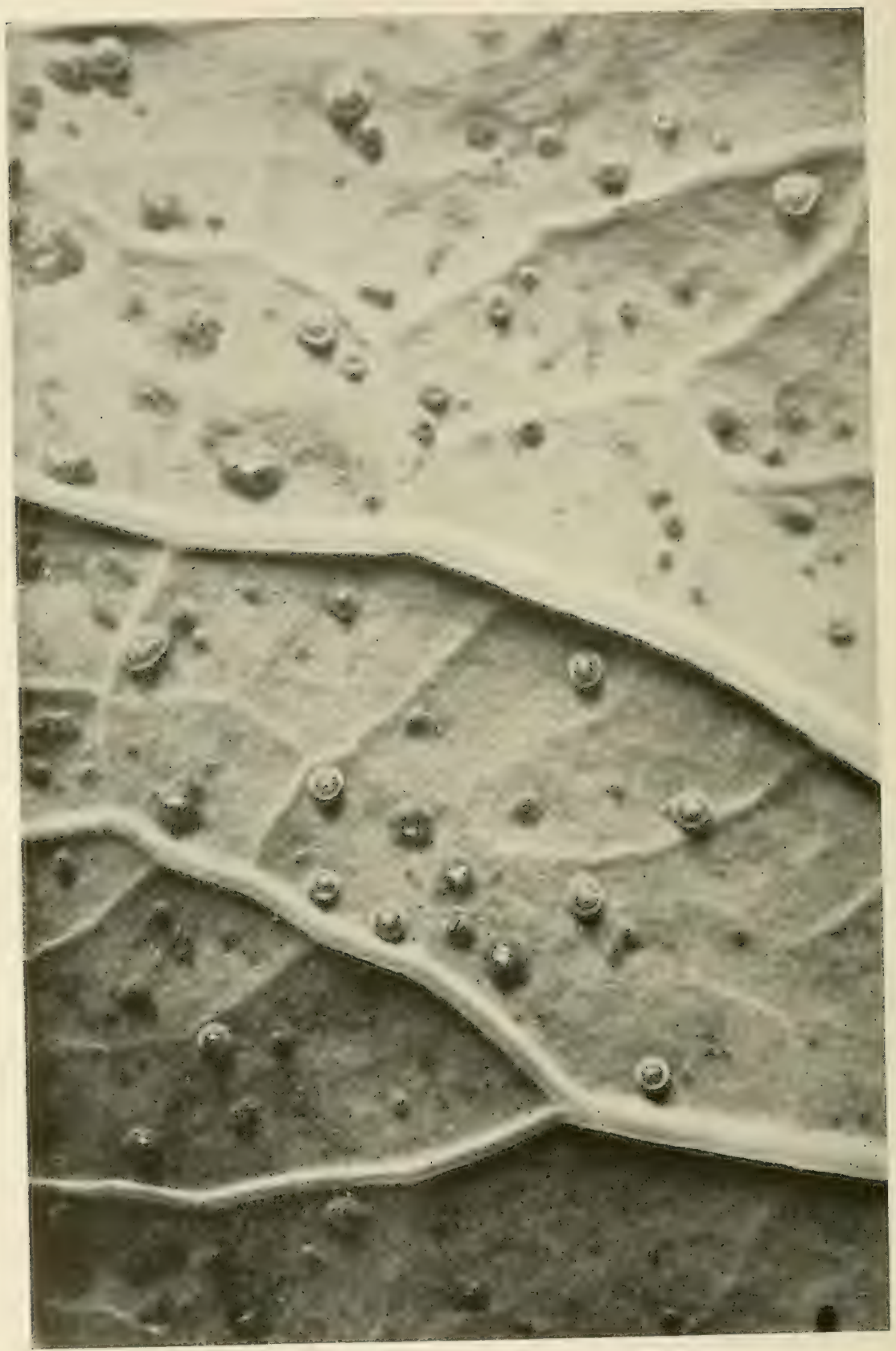

FIG. 366.-Under-surface of a cauliflower leaf showing small tumors produced by exposure for $1 / 2$ hour to vapors of heated Carnoy solution (acetic acid + ethyl alcohol) in 10 cubic feet of air space (temperature $20^{\circ} \mathrm{C}$.). Exposure begun September 21, 1916. Photographed September 28, 1916. $\times 10$. 
of water from the injured cells and this leads to a change in color, but this color difference soon disappear's and the leares appear to be normal until the growth has advanced to the second or third day. As I have recorded elsewhere ("Mechanism of Tumor Growth in Crown gall"), the same transient spotting precedes the development of tumors on cauliflower leaves exposed to dilute vapors of ammonia (Fig. 381) and is undoubtedly to be explained in the same way, as due to loss of water from injured cells into the surrounding intercellular spaces.

Earlier in the same year (1918) Wolf showed that intumescences may be produced on cabbage leaves by means of a sandblast and ascribes int umescences occurring naturally on cabbage plants in the field to sand driven by the wind. In this he is unquestionably right. They may also be produced on cauliflower leaves in the hothouse by sandpapering the leaves, and on bean plants by various woundings. All of Wolf's figures are hypertrophies (Fig. 382).

Some years ago (1892-93) George F. Atkinson experimented with the oedema of the tomato, which is an intumescence (Fig. 383 ) and reached the conclusion that on susceptible varieties (Fig. 384) oedema may be induced by insufficient light and bad ventilation coupled with too much water in the soil, and a soil temperature too near that of the air, leading to the accumulation of acids in the plant and to weak cell-walls, easily stretched as water is imbibed. He says: "When there is an abundance of water in the plant these acids draw large quantities into the cells, causing the cells to swell, resulting many times in oedema." . . . "Ordinarily there is no increase in the number of cells." He claims to have produced oedema by forcing an excess of water into the plants, but his experiments were few, in a place where oedema was naturally very prevalent, and they should be repeated. If he made any experiments to determine increased acidity they are not mentioned.

Sorauer, who, following earlier writers, gave the name of intumescences to these wart-like growths which occur at times on plants of many species, thought they were "caused by an excess of water during a period of low assimilation." In another place he speaks of these formations as due to "an 


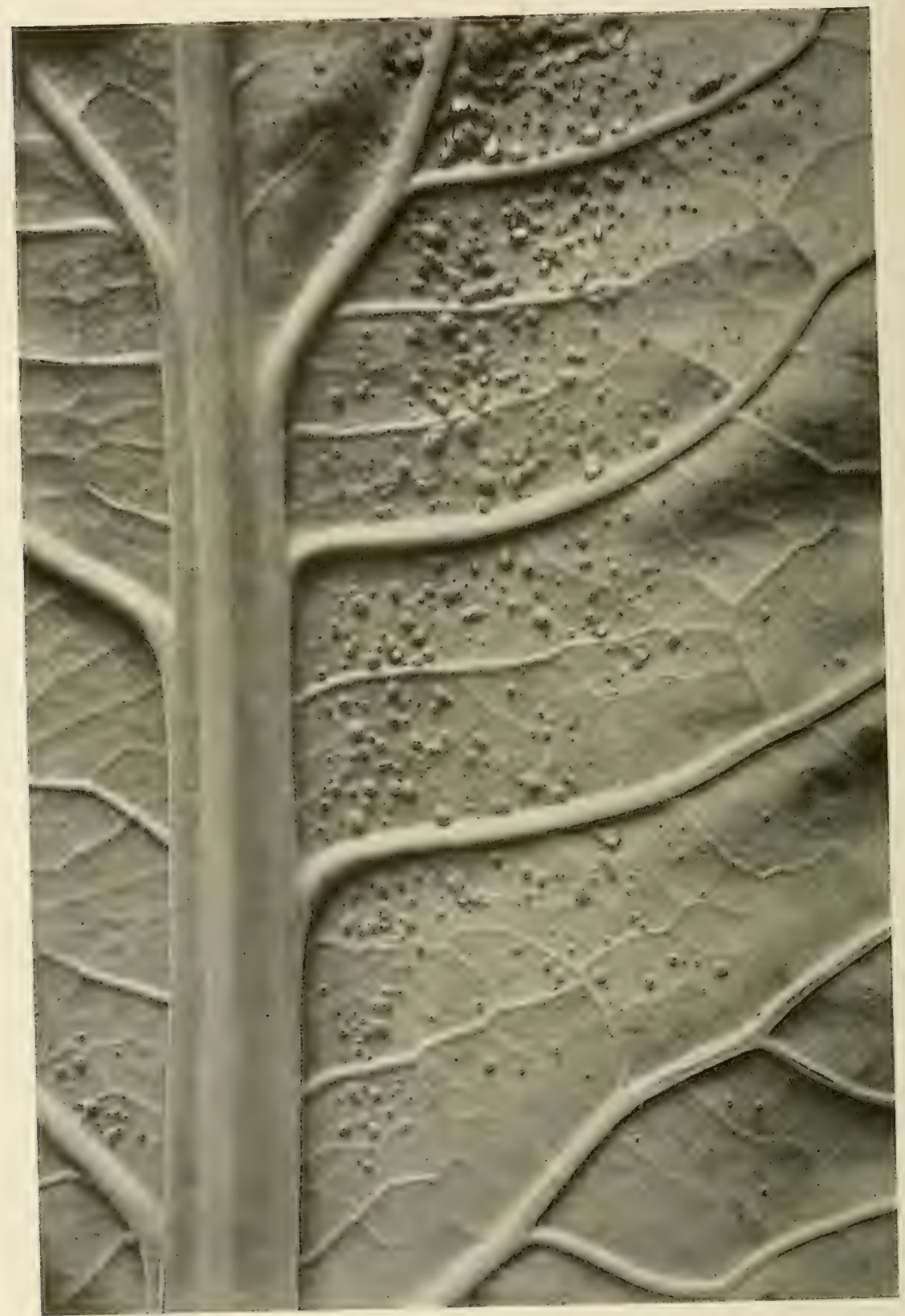

FiG. 367-Under-surface of a cauliflower leaf 4 days after spraying with acetic acid in water $(1 / 100)$. Photographed August 5, 1918. $\times 4$. 
abnormal elevation of temperature and excessive water supply," combined with weak illumination. With this view Atkinson agrees. In the last edition of his book Sorauer

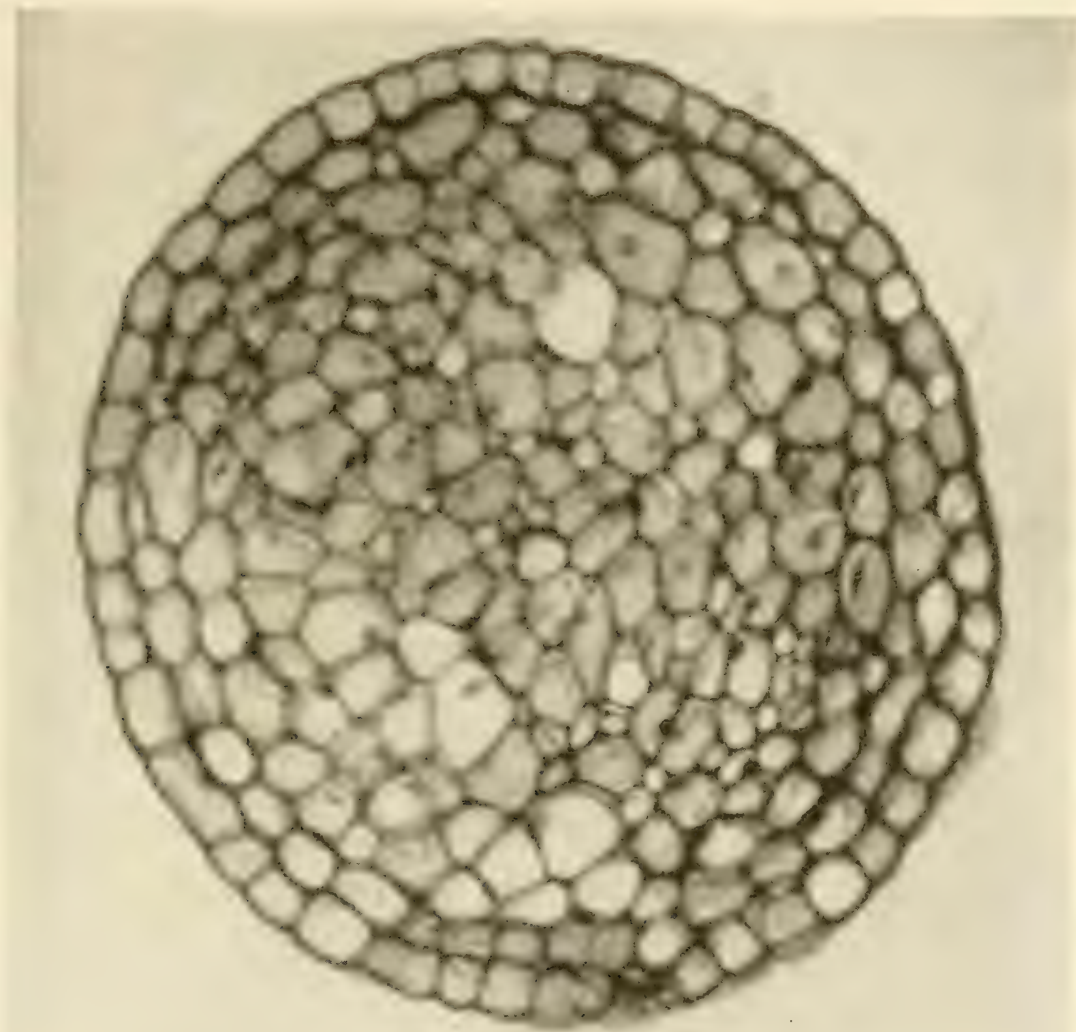

FIG. 368.-Cross-section, well above the leaf surface, of acetic acid tumor on cauliflower leaf 7 days after exposure. Surface covered by an epidermis. Block 1289. Fixed September 28, 1916. The exposure was for 1/2 hour in 10 cu. $\mathrm{ft}$. of air space to rapor from $10 \mathrm{cc}$. of Carnoy's fluid on a warm bath (about $65^{\circ} \mathrm{C}$.). $8 \mathrm{~mm}$. obj., 4 oc., bellows at 50, and enlarged $1 / 4$ by engraver. Photomicrograph by the writer.

places intumescences under diseases due to "excessive moisture of the air."

Other observers regard strong light as favorable and specifically on grape leaves (Viala and Pacottet, l.c.) "excess of light in 


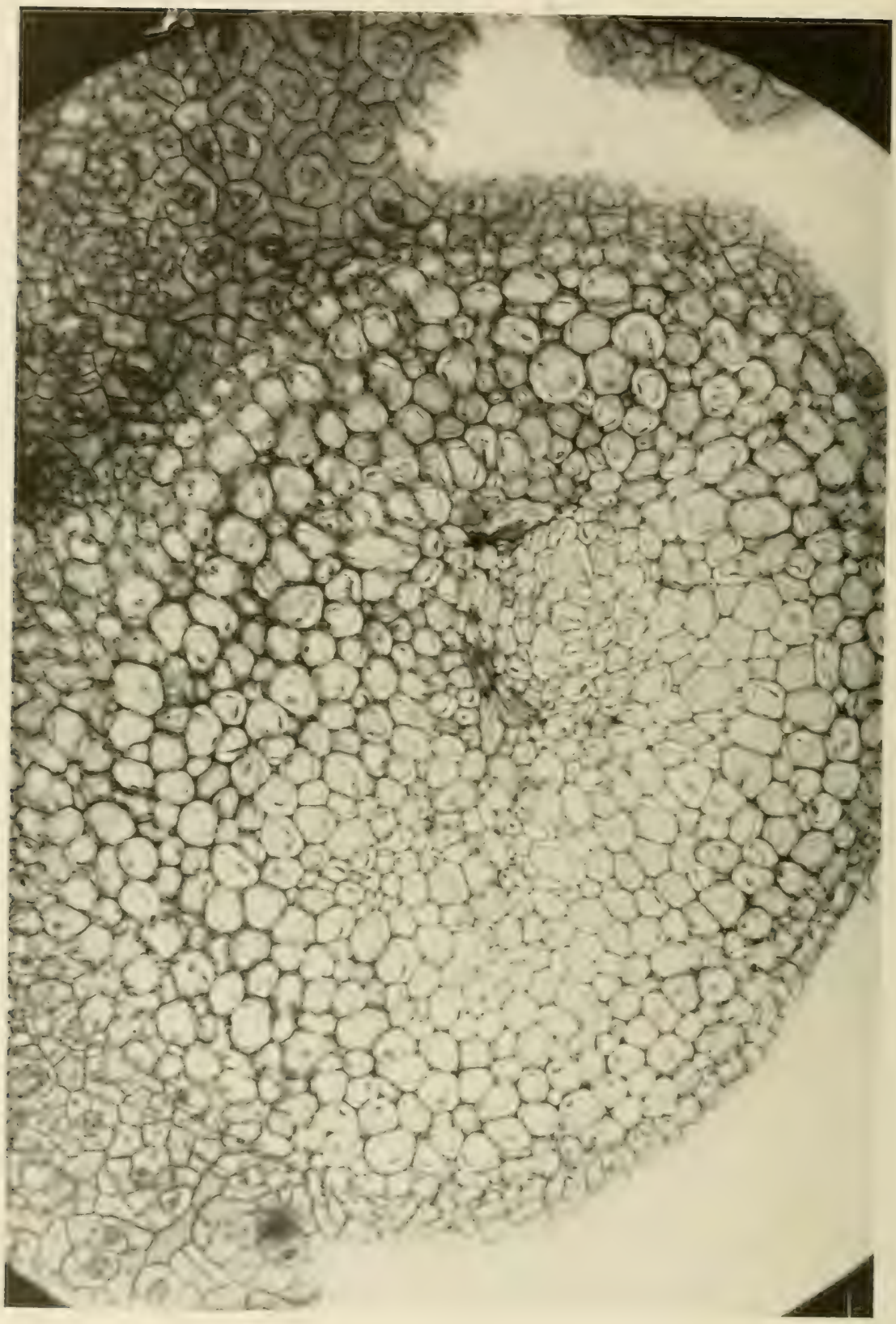

FIG. 369.-Cross-section of acetic acid cauliflower tumor at level of leaf surface (stomata of normal leaf surface abore and belom). 1/100 acetic acid water sprayed April 10, 1917. Fixed in Carnoy, April 17. Slide 1336B2. tumor $C$. 


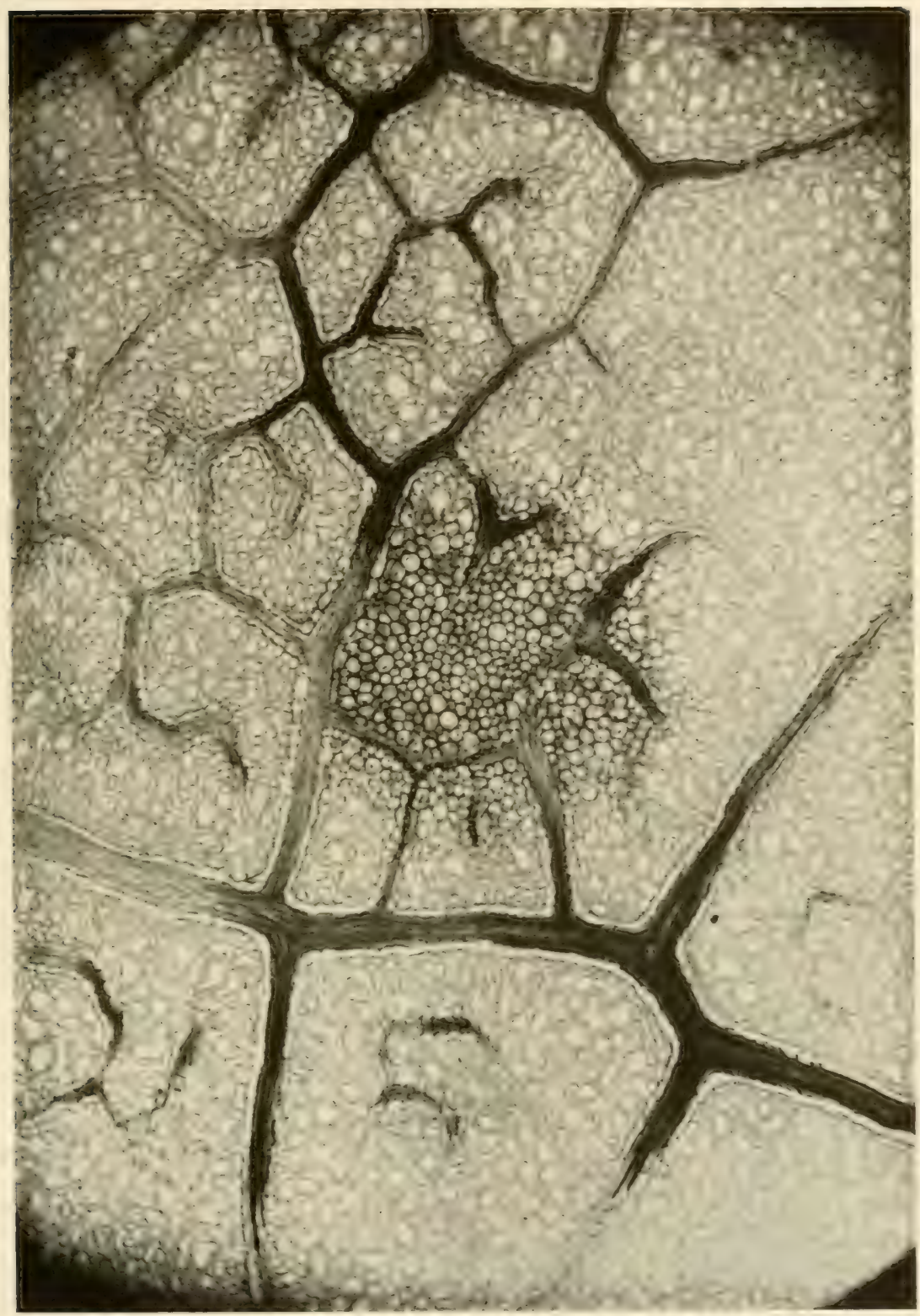

Fig. 370.-Same series as Fig. 369, but tumor $D$ and from the middle level of the leaf. In the center compact tumor tissue, surrounded by normal vessels and loose mesophyll of leaf. Slide 1336D3. Top rom, 2d section from left. $8 \mathrm{~mm}$. obj., 4 oc., bellows at 45 . Photomicrograph by the writer. 


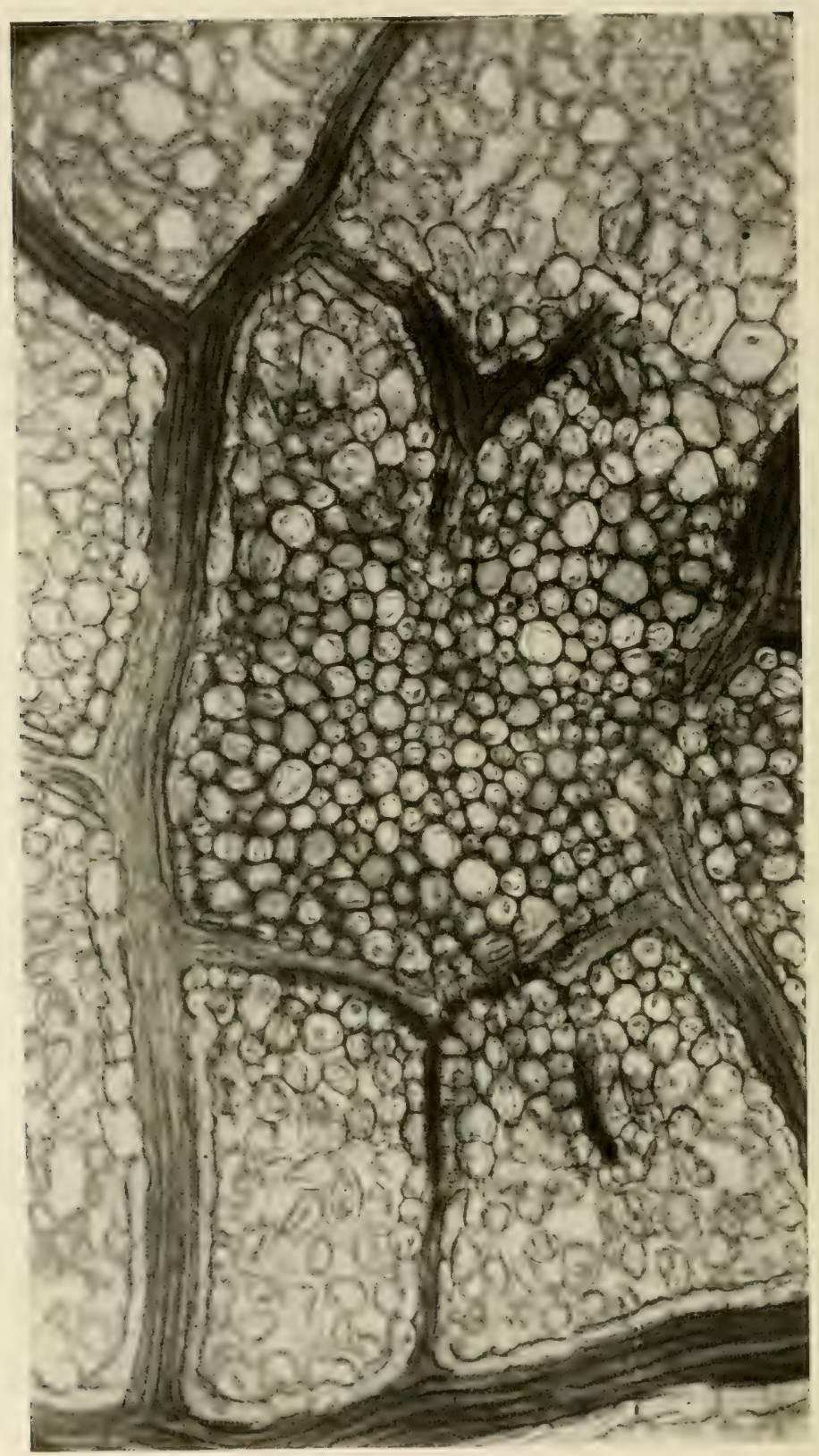

Fig. 371.-Middle part of Fig. 370 further enlarged. Normal mesophyll cells with large intercellular spaces, above, below and at the left. Tumor tissue very compact, like normal embryonic tissue. Photomicrograph by the writer. 
MISCELLANEOUS: TUMORS IN ABSENCE OF PARASITES 495

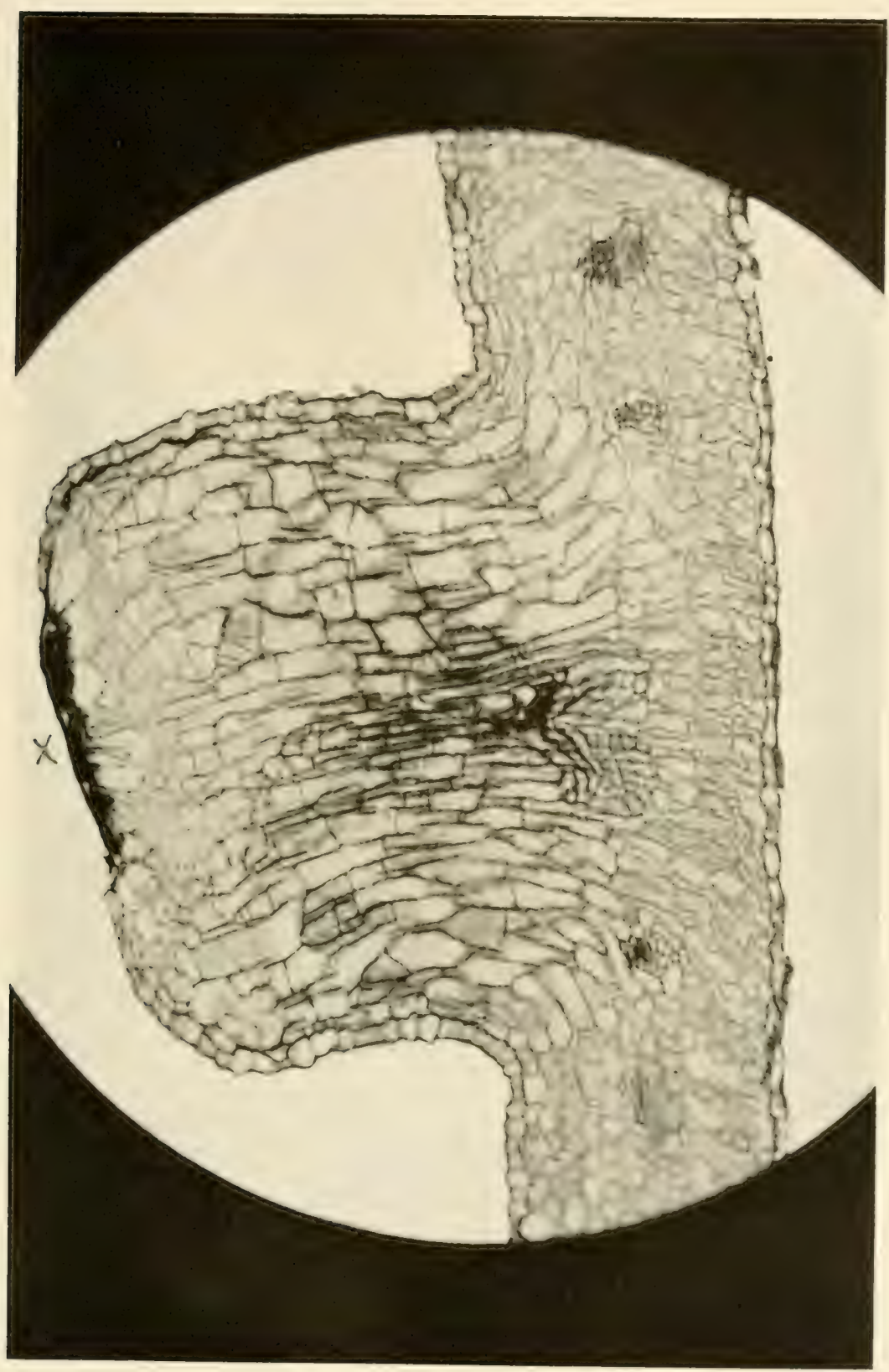

FIG. 372.-Longitudinal section of acetic acid tumor on cauliflower leaf. Tissue dead at $X$. Time, 7 days. $8 \mathrm{~mm}$., 4 oc., bellows at 35 . 
a humid atmosphere." They say, "It is only during periods of the most brilliant illumination and directly under the glass of the houses, that the intumescences form in quantity. They do not occur in the same greenhouse on leares which are in a diffuse light, or in the shade."

In commenting on this statement Dr. Hermann ron Schrenk says, "Observations made in the greenhouse of the Missouri Botanical Garden during the present season [1904] on grape vines which were covered with these intumescences, fully bear out the observations made by Viala and Pacottet. The intumescences were formed only on the leaves immediately under the glass, while all the leares in the shade were free from them."

Judging from my own observations and experiments, made on the potato, neither "insufficient light" nor "brilliant illumination" has anything to do with the formation of intumescences, at least with those which are hyperplasias. Also they may appear in the absence of any excess of moisture and when the ventilation is good.

Not satisfied with the explanation of intumescences above given I made experiments of my own. After some thinking as to how best to begin, it appeared to me that I might imitate defective greenhouse conditions on a small scale by enclosing vegetation in sealed glass tubes. For this purpose I took unshriveled, carefully washed, sound potato tubers of several varieties, soaked them for 30 minutes in 1:1000 mercuric chlorid water to discourage surface organisms, pared away the poisoned surface with sterile knives and cut the remainder into rectangular blocks. These blocks were then dropped with sterile forceps into sterile cotton-plugged test tubes about an inch in diameter and containing at the bottom a wad of cotton, wet with 1 to $3 \mathrm{cc}$. of distilled water. The cotton plugs were then shoved down a half inch and the top filled with melted sealing wax. In these tubes I obtained the results detailed below.

In 1910, the Russian botanist, P. Wisniewski, called attention to the production of intumescences on stems by obstruction of the lenticels with vaselin. Five years later (1915) the German, 

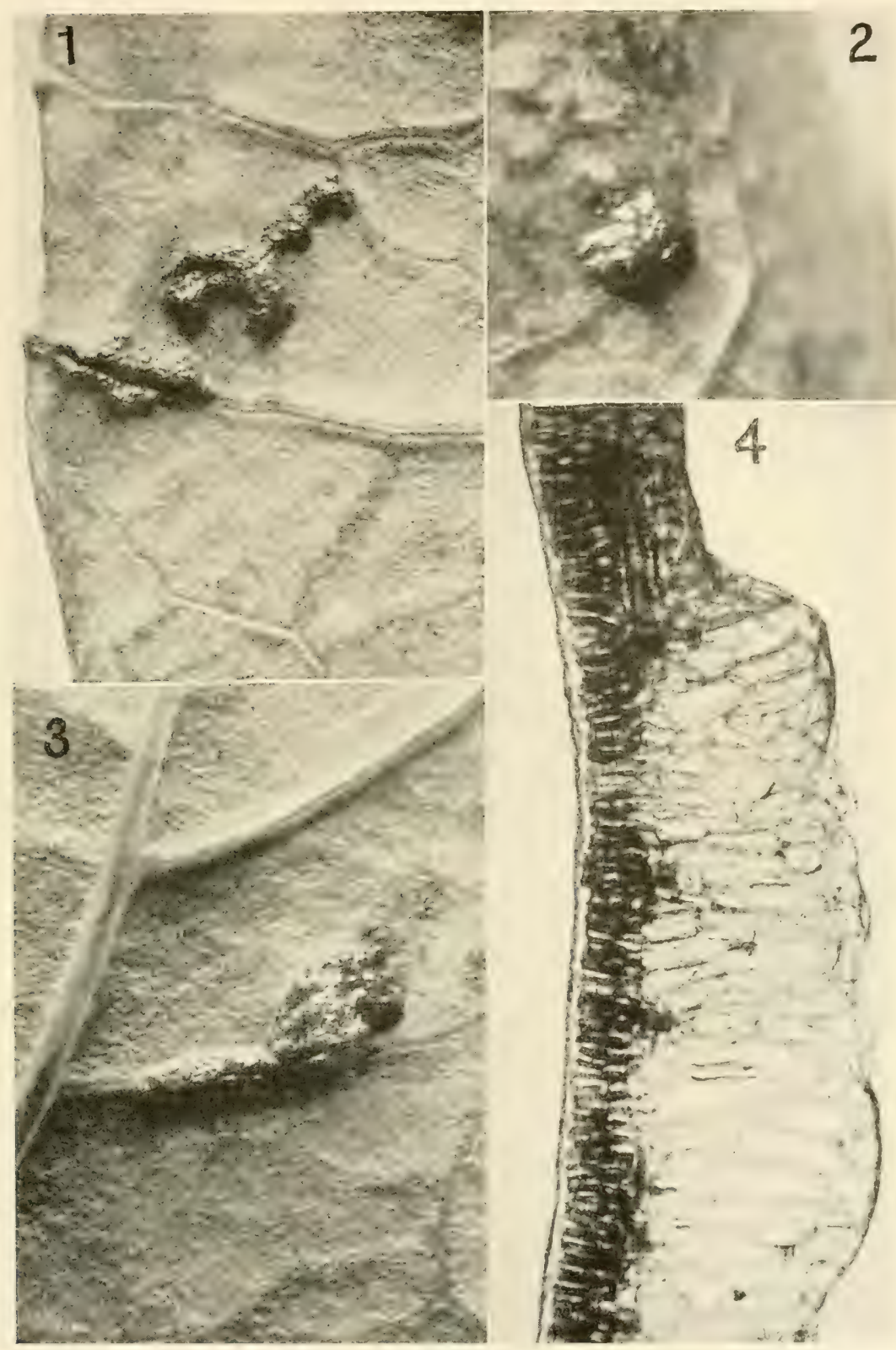

FIG. 373.-(1), (2) and (3). Small tumors on under surface of cauliflower leaves produced by formaldehyde (gas), exposure of February 21, 1917. Time, 6 and 7 days. $\times 5$.

(4) Cross-section, showing nature of the overgrowth. The dark green palisade tissue is only slightly involved. At top, normal thickness of leaf tissue. From an unstained free-hand section. $16 \mathrm{~mm}, 4 \mathrm{oc}$, bellows at 35 . 


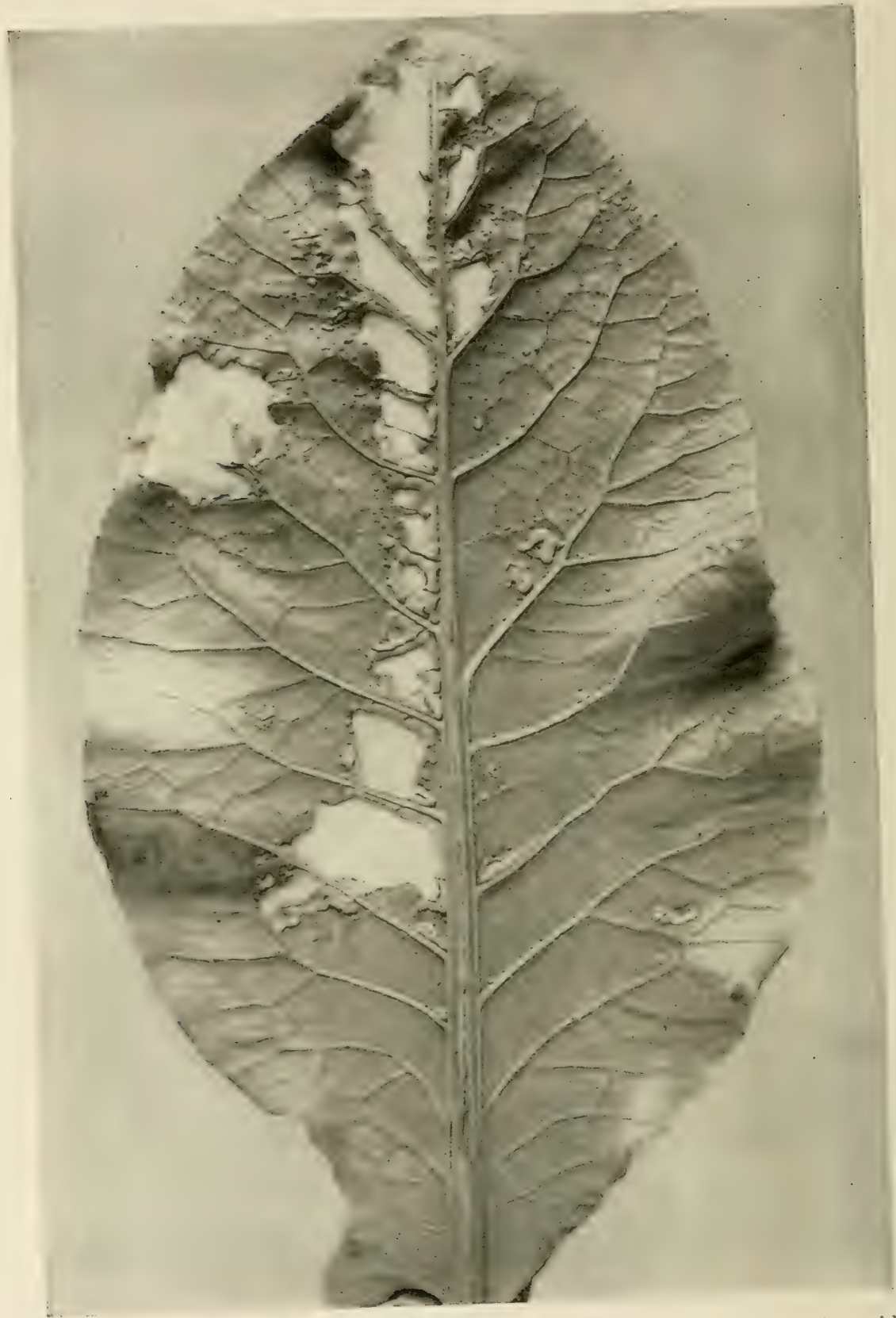

Fig. 374-Under-surface of a cauliflower leaf spraved with formic acid water $\left(1_{100}\right)$ on March 24, 1917. Photographed March 31. Natural size. Shows small tumors and"white (killed) areas. See pl. 5.5 J. Ag. Res. Jan. 29, 1917. 


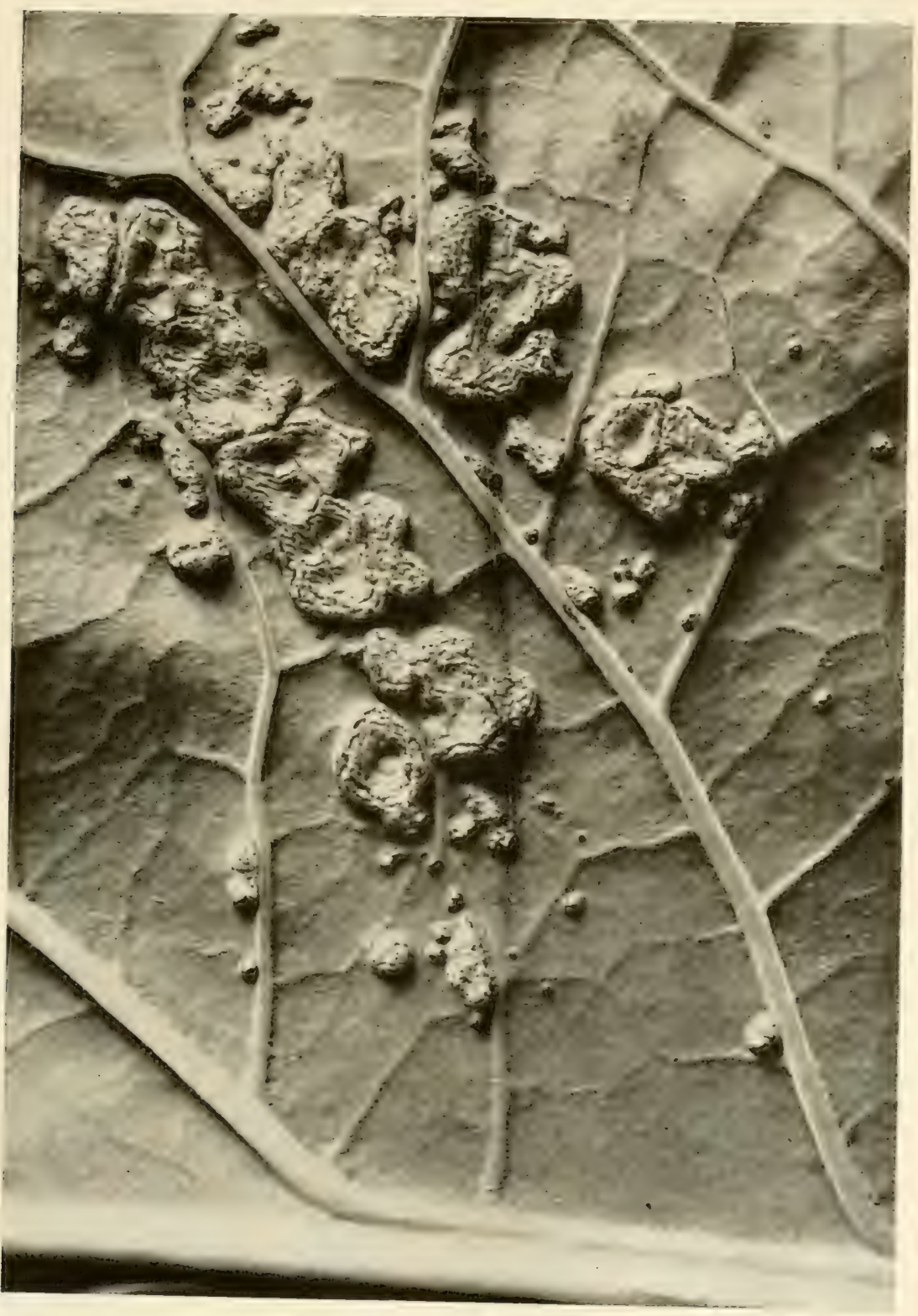

FIG. 375.--Under-surface of a cauliflower leaf in same series as Fig. 374, showing tumors due to formic acid ( $1 \mathrm{pt}$. to $100 \mathrm{pts}$. of water). Second sprayed plant. Time, 7 days. $\times 4$, nearly. 

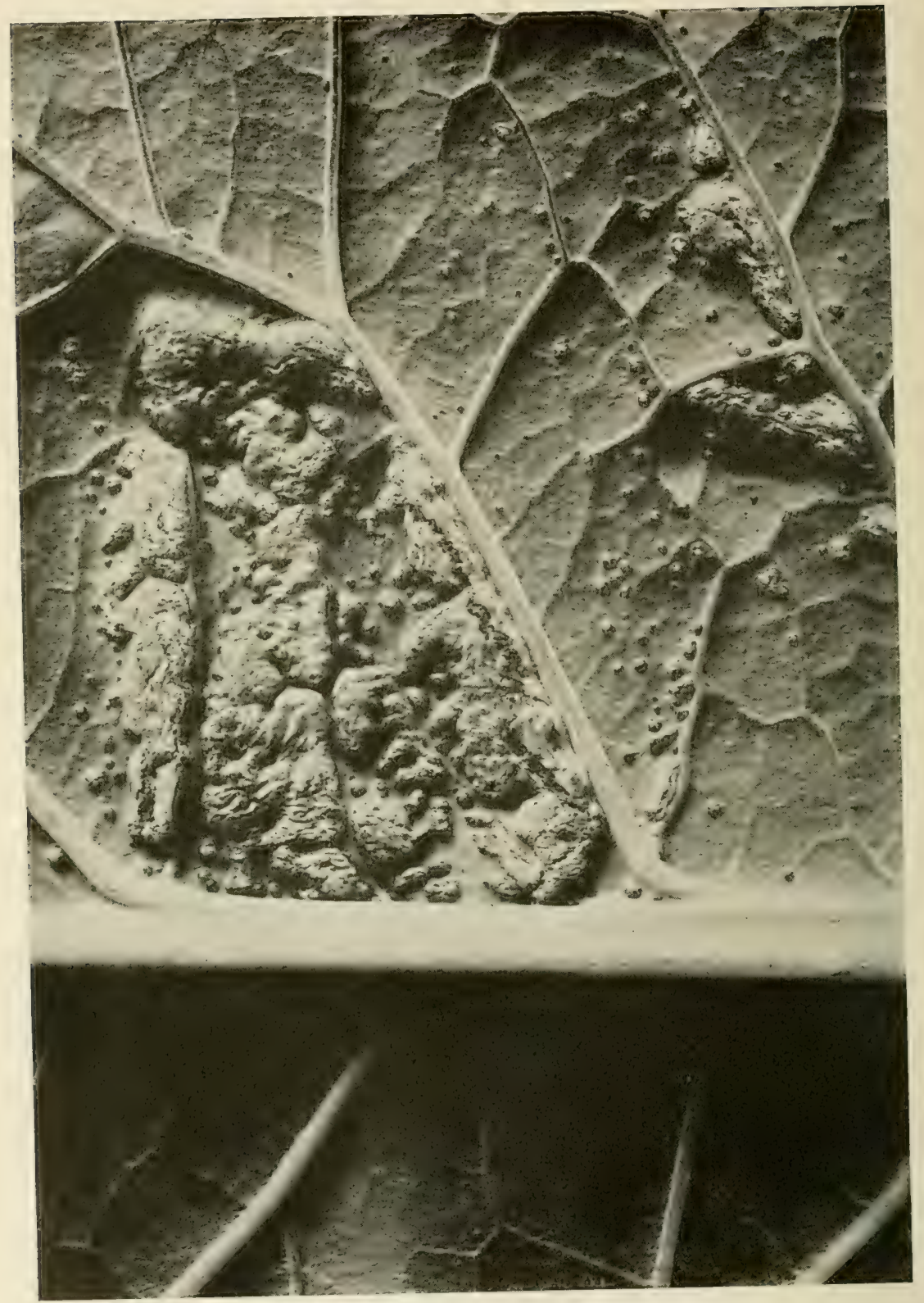

FIG. 376.-Under-surface of cauliflower leaf showing overgrowths due to formic acid water $(1 / 300)$. Leaf sprayed March 24, 1917. Tumors not so welldeveloped as on plants sprayed with $1 / 100$ formic acid water, i.e., not raised so high. The very small round tumors are undoubtedly due to entrance of the acid in a minimum quantity through a single stoma. Photographed March 31, 1917. $\times 4$, nearly. 
MISCELLANEOUS: TUMORS IN ABSENCE OF PARASITES 501

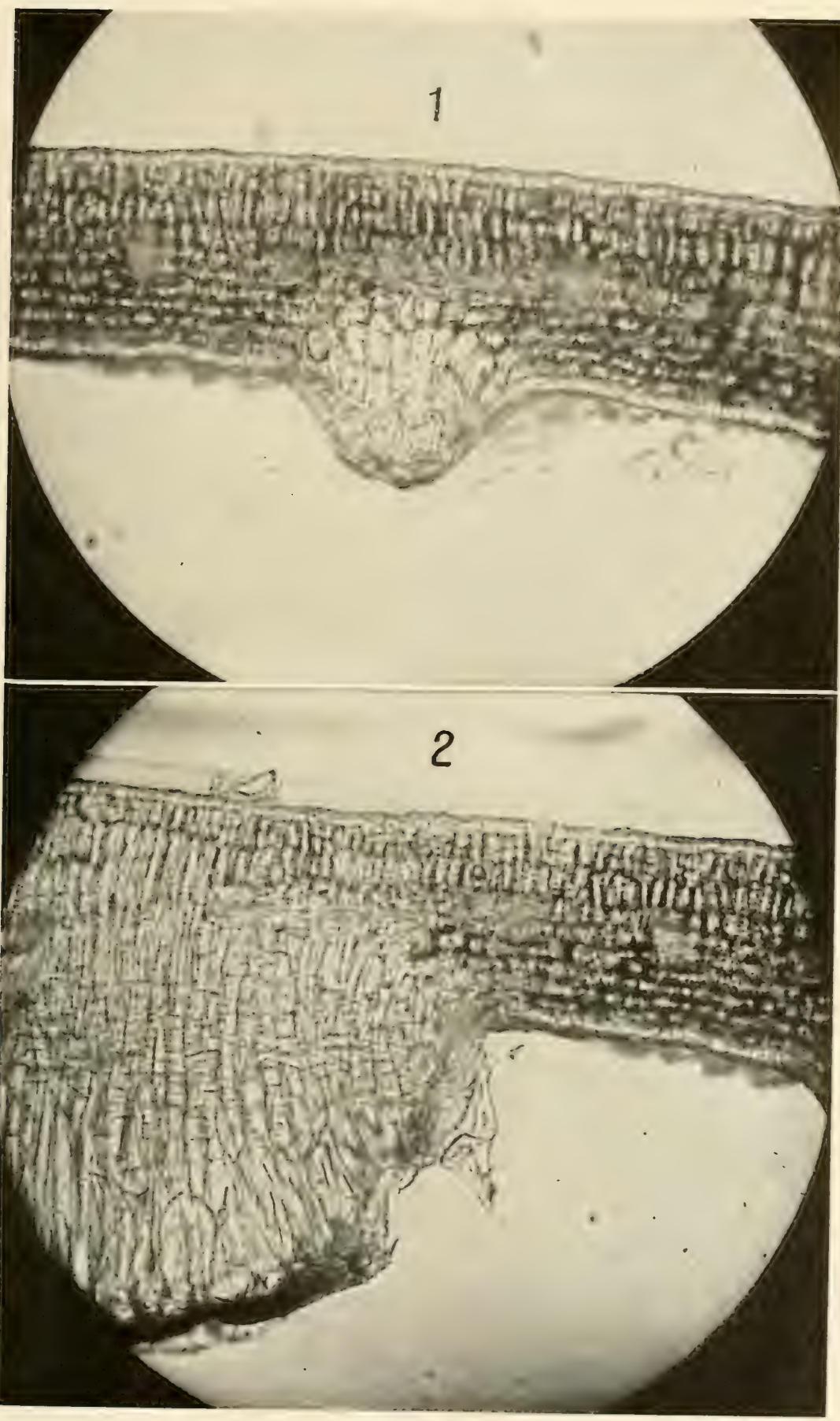

III: :3\%. 
E. Schilling, published on the same subject, having repeated and expanded Wisniewski's experiments with similar results. The writer has also experimented on a number of plants, fig, mulberry, olive, begonia, ginkgo, etc. (Figs. 385A, 386) using Squibb's petrolatum. As soon as the lenticels are obstructed, gas interchange, i.e., inflow of air and outflow of carbon dioxide and vapor of water, ceases, or at least is greatly restricted, and following this (in susceptible species, but not in ginkgo) the cells under the lenticels at once begin to divide and a considerable cushion of cells (hyperplasia) may develop (Figs. $385 B$, and 387 to 389 ).

Earlier than this it was known that the lenticels of potato tubers frequently proliferate in very moist earth (Sorauer), and also that the cut surface of potato tubers may proliferate. Fig. 390 shows proliferations that appeared on a pared sterile block of raw potato sealed into a test tube some months earlier by Mr. Shapovalov, who gave it to me thinking it might be crown gall. His experiments were for another purpose and these growths occurred in one of his check tubes. We could find no organisms in the tissues, either with the microscope or by means of agar-poured plates. Their internal structure (Fig. 391 ) is a twisted vascular hyperplasia not unlike crown gall. I tried to duplicate this in an atmosphere of nitrogen but only succeeded in asphyxiating the tissues. It would, I believe, be easy to get it with sensitive tubers and exactly the right reduction of air space or of oxygen. Possibly it is an abortive effort on the part of the flesh of the potato to reproduce the whole plant.

since the preceding paragraph was written I have repeated the experiments (spring of 1919) with pared blocks of raw potatoes sealed into a moist, confined air-space and have verified my prediction, as may be seen from Fig. 392. The blocks, which were some of those already referred to as in cotton-

FIG, 377.--Structure of small and large tumor on cauliflower leaf sprayed with 1100 formic acid water. From unstained water mounts: (1) Weaker stimulus (stomata less open). (2) Edge of a large outgrowth. The whole tumor is about four times the length of the part here shown. Both $\times 130$ circa $(8 \mathrm{~mm}$., $4 \mathrm{oc}$, and bellows at 35). 

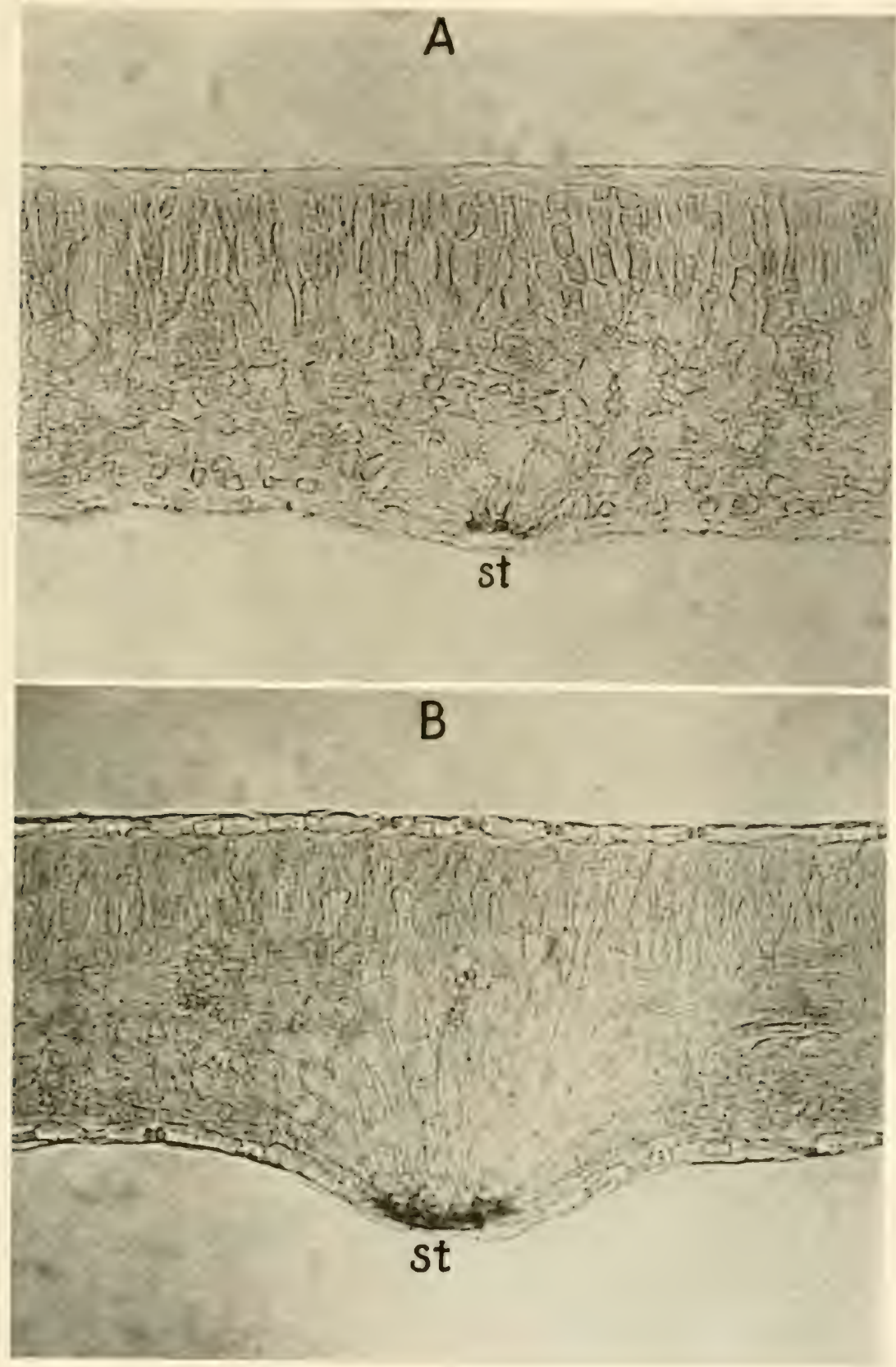

FIG. 378.-A. Cauliflower leaf showing slight sub-stomatal injury preceding acetic acid tumors. Time, 48 hours. Slide 1416, No. 23. Acid fuchsin stain. $\times 1$ 1.11.

$B$. Same as $A$ but after 6 days. Here a minimum of acid entered judging from small size of tumor. Slide 1420, No. 1. Acid fuchsin stain. 


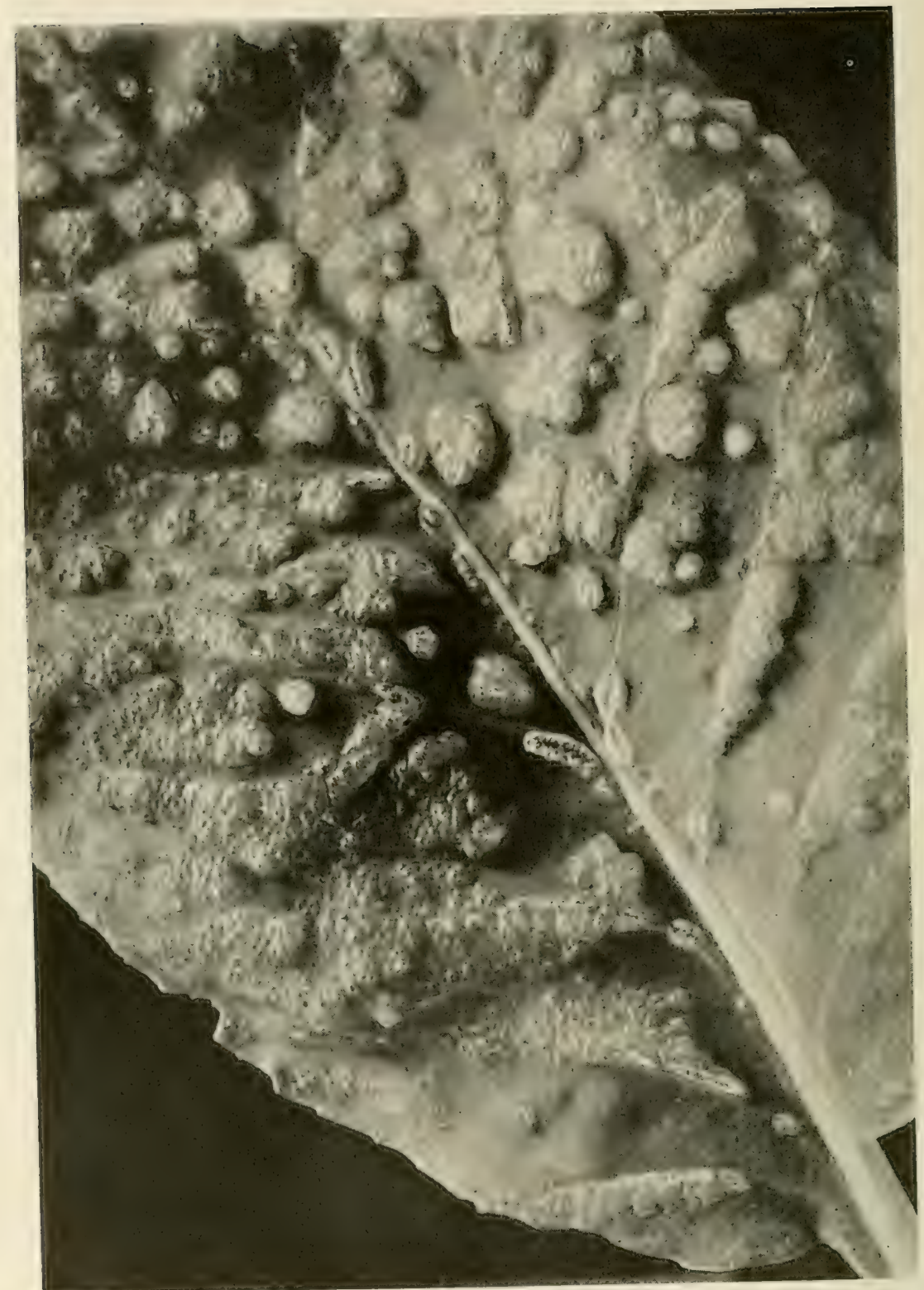

Fig. 379-Cabbage leaf showing tumors which followed a slight freezing. Leaf thawed in air. Time, about 7 days. $\times 2$ circa. (After Harvey.) 


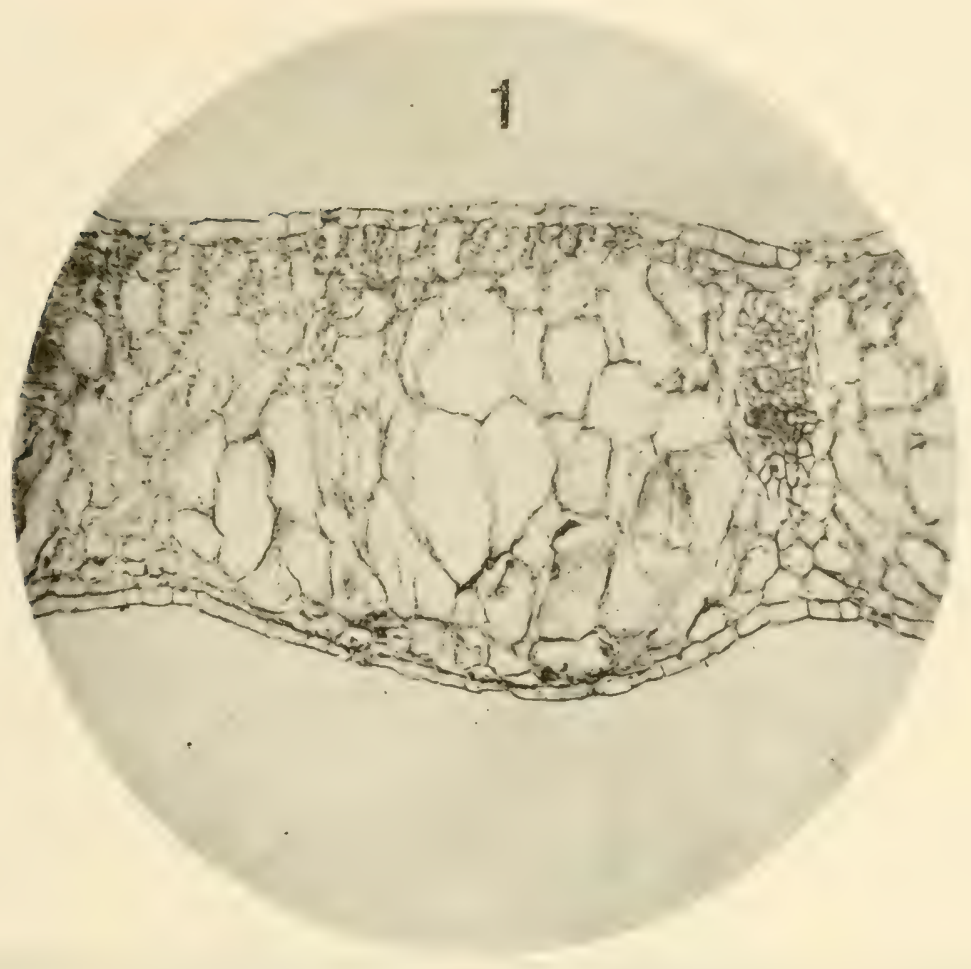

2

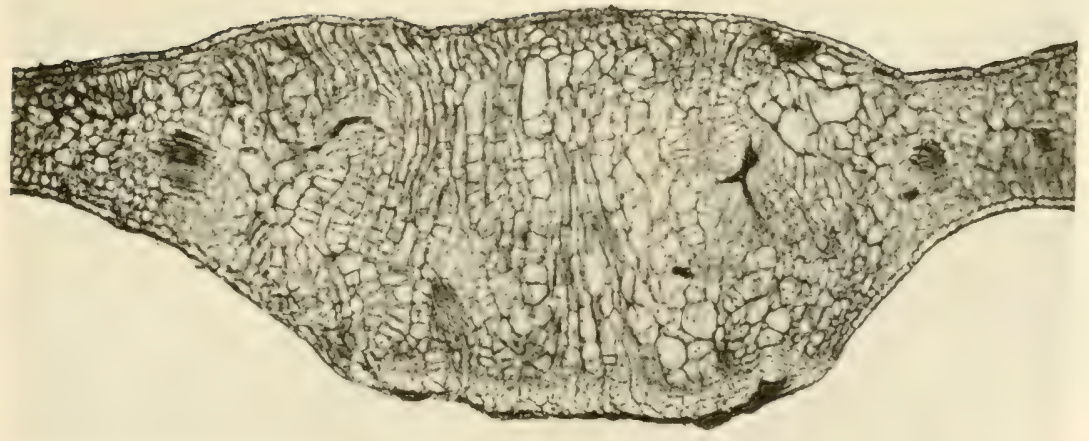

FIG. 380.-Varying structure (hypertrophy and hyperplasia) of frost tumors on cabbage leaves. (After Harvey.) 
plugged test tubes sealed in with sealing wax and resting on wet cotton, developed glistening ridges or hummocks of rounded cells and long hair-like cells (callous tissue) freely, especially in the cambium region of the tubers, also occasionally sprouts, and over most of their surface in course of a few weeks a welldefined cork-layer under which small hyperplasial tumors developed, pushing up the cork and frequently cracking it open;

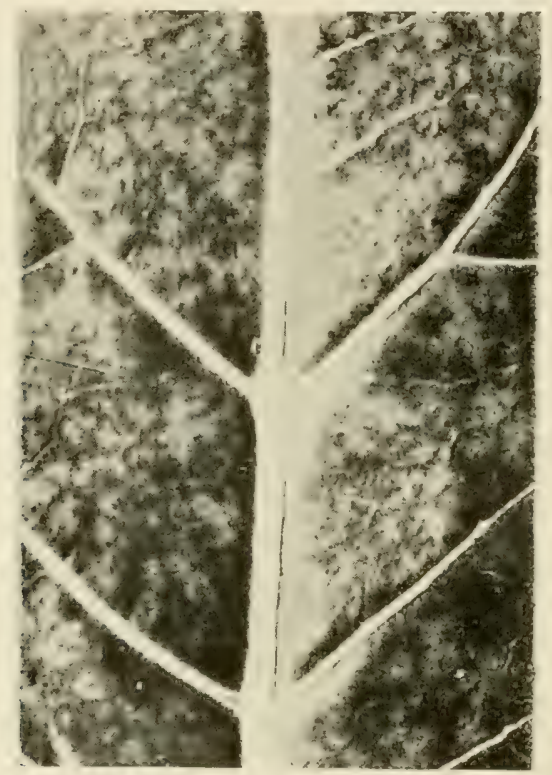

Fig. 381. - Cauliflower leaf three-fourths hour after exposure to vapor from $0.5 \mathrm{cc}$. strong ammonia water $(0.90 \mathrm{sp}$. gr. $)$ in $10 \mathrm{cu}$. $\mathrm{ft}$. of air space to show fugitive mottling.

sometimes also abortive buds developed from these tumors or in their vicinity (Figs. 393, 394).

The sealed tube experiments were continued for several months and many small tumors were obtained (Figs. 395 to 399). The nutrient substances in these small blocks of potato flesh are soon exhausted and the tumors cease to grow, but, if one could feed them, it would seem as if growth should continue for a considerable period, and that some of the tumors would become large.

When the pared blocks of potato in the sealed tubes de- 

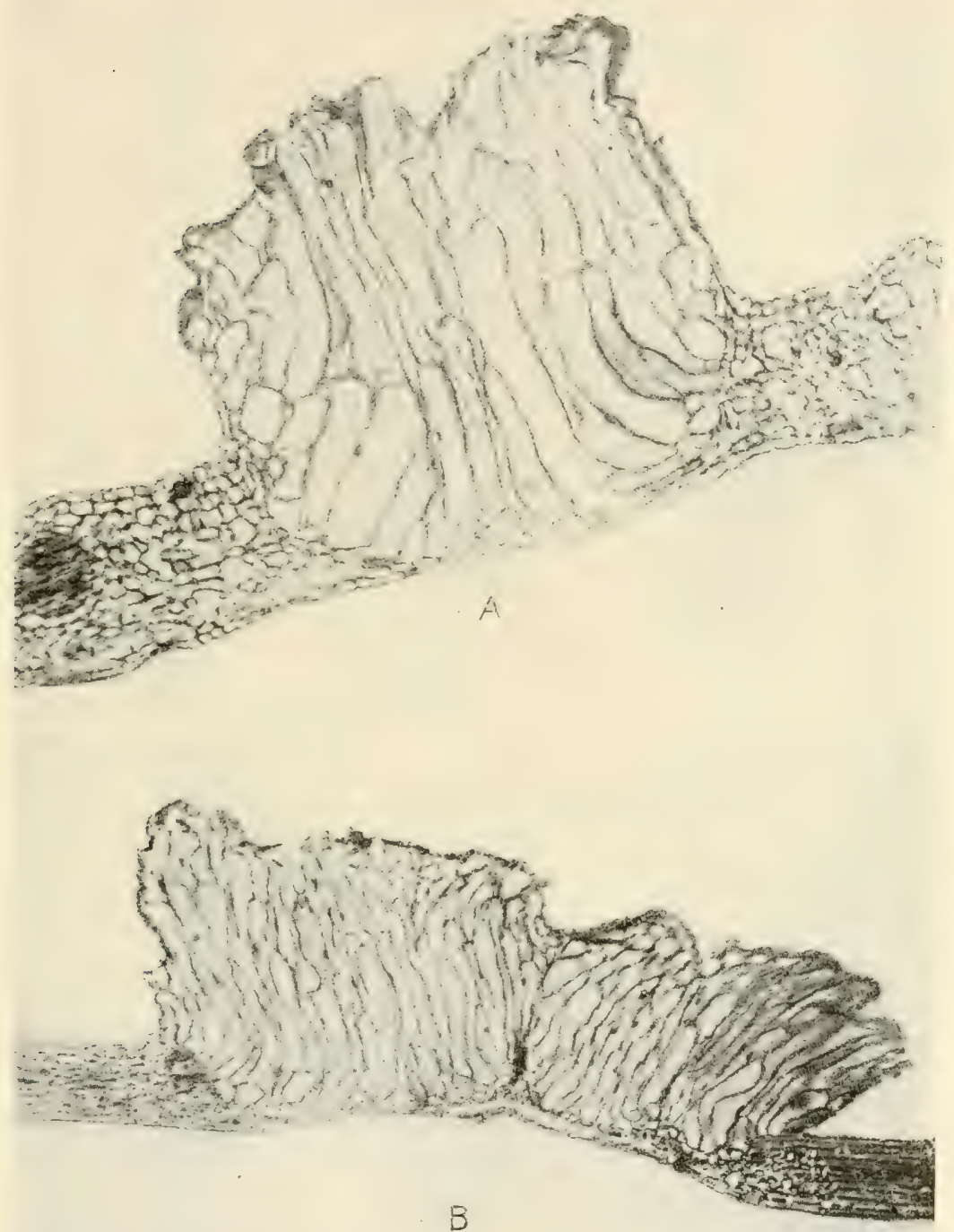

FIG. 382.-From Wolf's paper showing structure of intumescences (hypertrophies) produced on cabbage leaves by means of a sand blast. 
veloped shoots, the latter regularly produced, under stomata, which were always wide open, small intumescences (hyperplasias) in large number's both on the stems and on the leares (Figs. 400 to 404). These intumescences were more abundant or rather more conspicuous at $28^{\circ}$ to $35^{\circ} \mathrm{C}$. (Fig. 405)

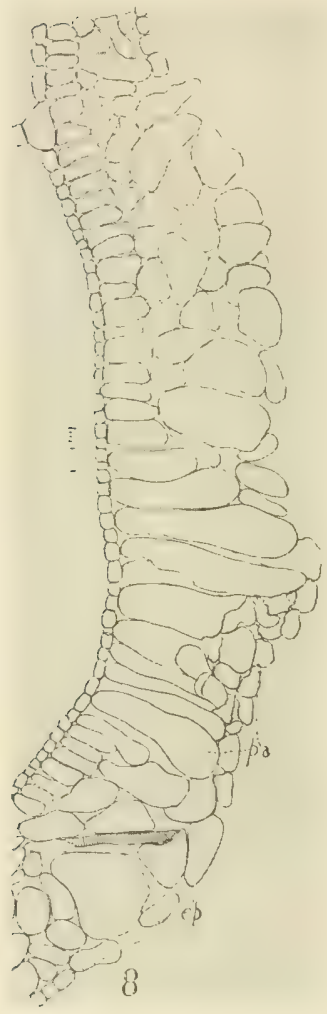

FI G. 383 . - Crosssection of a Vermont tomato leaf showing marked natural odema. Upper surface at left. A few of the palisade cells unchanged. (After Atkinson.) than at $23^{\circ}$. to $25^{\circ} \mathrm{C}$, but they occurred also at the latter temperature (Figs.406), although on some parts of the shoots at this temperature a microscopic examination was necessary to determine their presence (Fig. 407). The former were in bright light, and the latter in the dark or rather in very feeble diffused light, packed away in quinine cans. The other conditions were the same, viz., a wet base (the block stood on very wet cotton or in water), saturated air, diminishing oxygen and increasing carbon dioxide. I am inclined to think, in this case, therefore, that the intumescences were due to excessive absorption of water, coupled with acid stimuli liberated by a disturbed transpiration, due to a saturated or nearly saturated atmosphere. Of course, with temperatures near the optimum for growth (as would be the case in the top of a hothouse in bright light) there would be a more conspicuous development of such intumescences than at lower temperatures in which growth is much slower and in the latter it might require examination with the microscope to demonstrate the beginnings of intumescences. On the pared sterile blocks of potato one of the most striking of these tumors, which was narrowly pediceled and covered with membrane, developed as a teratoma (Fig. 408).

In these various examples it will be observed that the cells exhibit all grades of development from simple hypertrophy (Figs. 
MISCELLANEOUS: TUMORS IN ABSENCE OF PARASITES 509

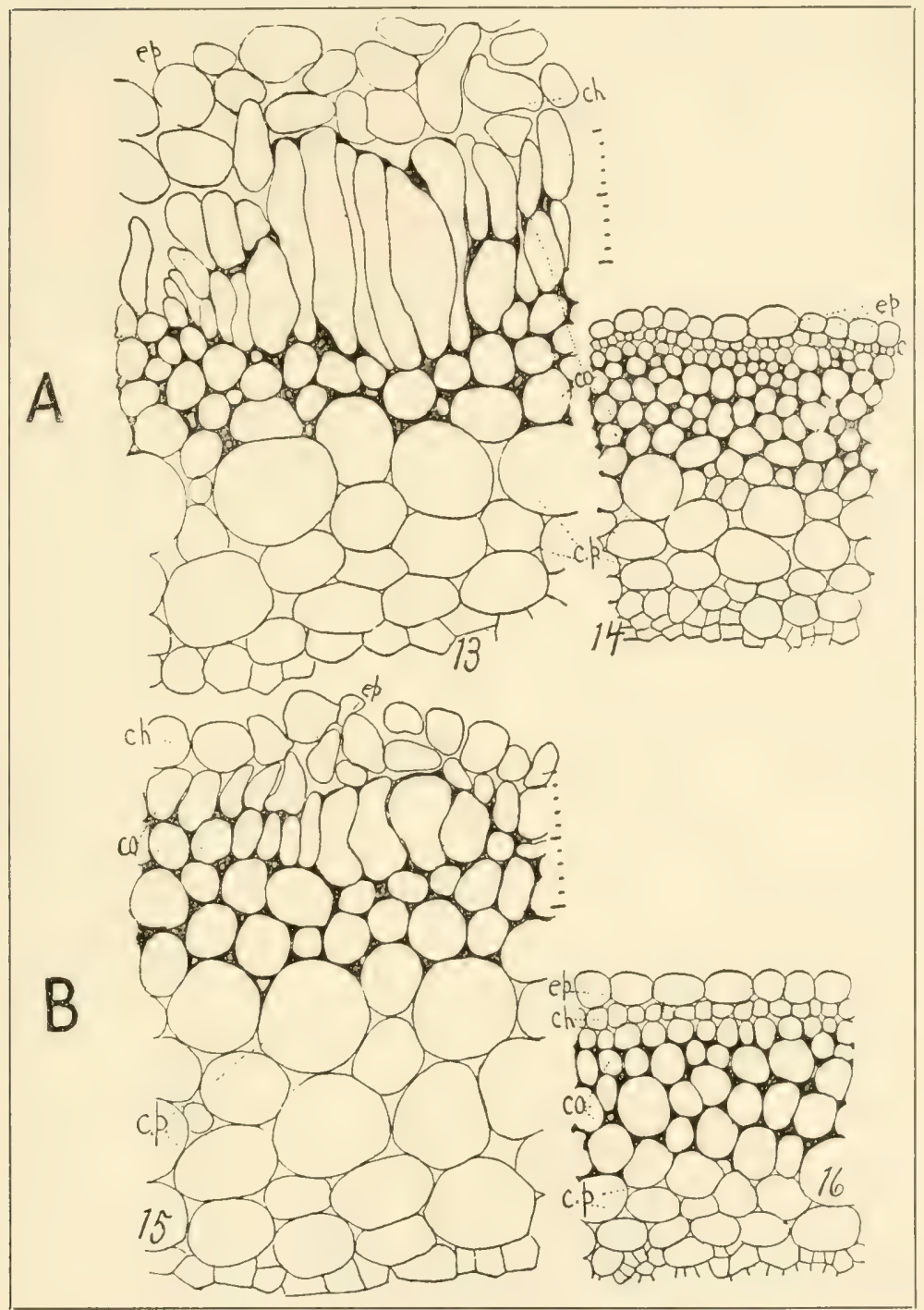

FIG. 384.-Cross-section of intumescences on tomato produced, it is said, by forcing water into the stems: $A$. Variety No, 18. Normal tissue at the right. B. Variety Lorillard. Normal tissue at the right. (After George F. Atkinson.) 
380 , sub. 1, and 382 to 384 ) to marked hyperplasia (Figs. 368 to 372 and 377 ). They have one element, however, in common and in this they differ from all overgrowths due to active parasites, that is, corresponding to the fleeting nature of the stimulus, their growth is usually of short duration, whereas tumors due to parasites, because supplied with a continuous stimulating exudate from the foreign organism, may continue their development indefinitely. The physico-chemical stimuli are, however, I beliere, much the same in all cases where genuine hyperplasias occur. To these let us now turn our attention.

\section{SPECULATIONS ON THE CHEMICAL AND PHYSICAL STIMULI UNDERLYING TUMOR-FORMATION}

Classed according to the number and size of their component elements, tumors are of three kinds: (1) simple hypertrophies (cell enlargements); (2) hyperplasias (cell multiplications); and (3) mixtures of the two, that is hyperplasias containing giantcells. The size and shape of the cells forming the hypertrophy or the hyperplasia differ from tumor to tumor even in the same tissue, thus in animals we have round-celled, oat-celled and spindle-celled, large-celled and small-celled connective tissue tumors (sarcomas). The nature of tumors varies also, of course, greatly according to the nature of the tissue in which they originate, since the cells of each organ have a histology and an inheritance of their own. For this reason, connective tissue yields one type of tumor, glandular tissue another type, vascular tissue a third type and so on.

An enormous amount of data has been accumulated on tumor differences, that is on the gross and minute anatomy of tumors, especially of human and animal tumors, because this has been the easiest method of approach, but it is not the most interesting side of the problem. That lies in quite another field, viz., in the field of hypothesis and experiment dealing with their etiology.

All overgrowths, without reference to whether they are due to parasites or have developed independently of them, appear to me to be singularly alike in their chemical and physical origin and physiological requirements, their diverse appearances being 
attributable to slight variations in the direction or force of the stimuli and to the diverse cell-inheritances, each and every tissue responding according to its own specific nature. All tumors begin, so far as we know, in injured places ${ }^{1}$ and, fundamentally, I believe all may be regarded as excessive and continually modified wound-repair reactions.

In this chapter I shall deal with the secondary causes of tumors and shall endeavor to present my ideas as briefly as may be, premising that they are based on experiments and that where they pass beyond experiment into the field of hypothesis, no one need be led astray, if he keeps my title in mind. The best of any iconoclastic writing in science is not so much the new facts it has to offer as the changed outlook it gives, which new perspective often leads to renewed important experiments and to general discussion by many workers. I may claim to have contributed, at least, this much toward the elucidation of the complex and important problems involved in the origin of tumors.

I may state at the outset that my conception of tumor formation involves a loss of water and a change of chemical reaction in the cells which are to become tumor cells. This change which is toward cell-sap concentration and increased acidity must occur, I believe, to give the necessary stimulus to tumor formation. The stimulus may be long-continued or fleeting and may be brought about, as we shall see, in various ways. I will develop the subject as I proceed, and only add here at the beginning two other hypothetical postulates, first, that hyperplasias appear to me to represent a reponse of cells to oxygen-hunger or semi-asphyxiation, and, second, that the type of cell-response in the tumor, that is, whether a simple cell-enlargement with mitotic or amitotic nuclear multiplication (a giant-celi), or a full karyokinetic nuclear division with a corresponding hyperplasia, appears to depend on whether the partial protoplasmic cell-paralysis involves both nucleus and hyaloplasm, or is confined to the latter, leaving the nucleus free to divide by

${ }^{1}$ Of 850 breast cancers studied by MacCarty in the Mayo Laboratories every one showed evidences of having been preceded by inflammatory injuries (chronic mastitis). 


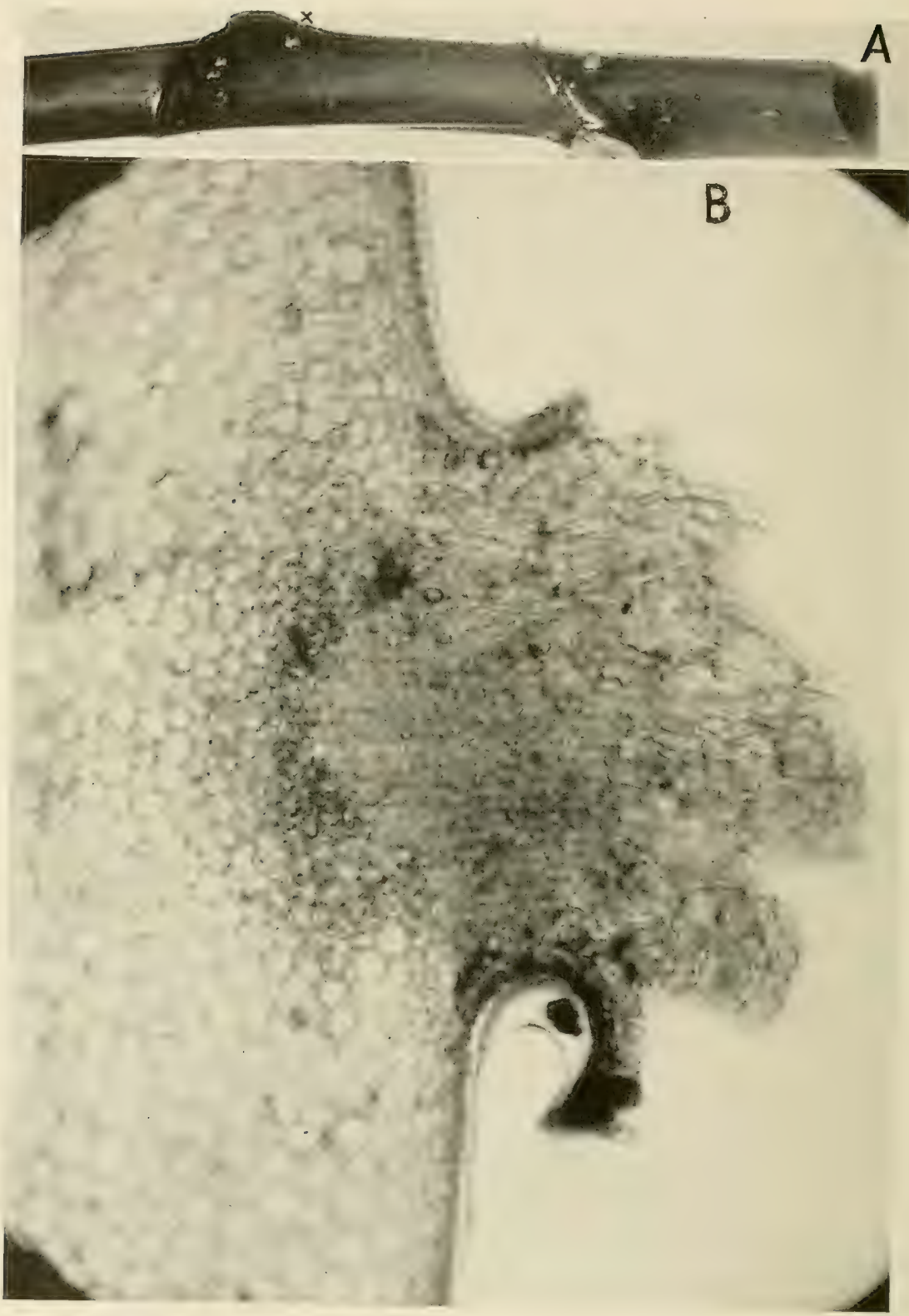

FIG. 385.-A. Under-surface of a young green branch of the common ornamental rubber tree (Ficus elastica) showing outgrowths from lenticels 8 days after painting it with Squibb's petrolatum. On the 5th day the treatment was repeated. Nat. size, nearly. For section at $X$ see $B$.

$B$. Proliferation (hyperplasia) of semi-asphyxiated lenticel of Ficus elastica. 
mitosis and to form cell-walls. The extent of the cell-enlargement will then depend on the amount of water imbibed and that in turn will depend on the acidity of the cell sap and on the corresponding extent to which the physiological control of imbibition, exerted by the hyaloplasm, is upset. But cell division will be rapid if the paralysis involves only the hyaloplasm.

Let us take the simplest case first, that of hyperplasias developed under obturated lenticels (Figs. 385 to 389). Here we may suppose that some air still enters and that some vapor of water and gas still escapes, but the gas-exchange is demonstrably reduced to a very small fraction of what it was, that is, vapor of water and carbon dioxid cannot now escape through these openings as before, and air cannot now enter freely. In other words, there is a stasis in the tissues under these openings, less entrance of air and less movement of aërated water, with more or less oxygen-hunger and with increase in cell-acidity (due to products of incomplete oxidation); also, owing to rootabsorption, with increase of turgor presicure and, corresponding to these changes, a hyperplasia develops. Subjected to these conditions, many plants derelop small tumor's under the lenticels. The character of the hyperplasia, whether few-celled or many-celled, slow-growing or active, will depend on the nature of the tissues, and on the extent to which the lenticels are closed and the gas-exchange is interfered with. If there is less and less gas-exchange, the acid condition and the oxygen-hunger will be proportionately increased and the hyperplasia will be very small-celled and active. If there is still considerable ertrance of air and exit of aërated water and of gas either through imperfect closure of the lenticels or directly through the surface of the stem, the hyperplasia will be large-celled and slow-growing, and this seems to correspond to the facts observed.

Every growing cell is in constant need of oxygen-must have it at once or die. This is absorbed, it is now believed, through its whole periphery, either directly from the air or indirectly out of the aërated fluid which bathes its surface. If the

Painted with petrolatum March 18, 1918. Photographed from a free-hand, unstained section in water, March 26. Upper part of proliferation torn away in making the section. $16 \mathrm{~mm} ., 4$ oc., bellows at 45 . 

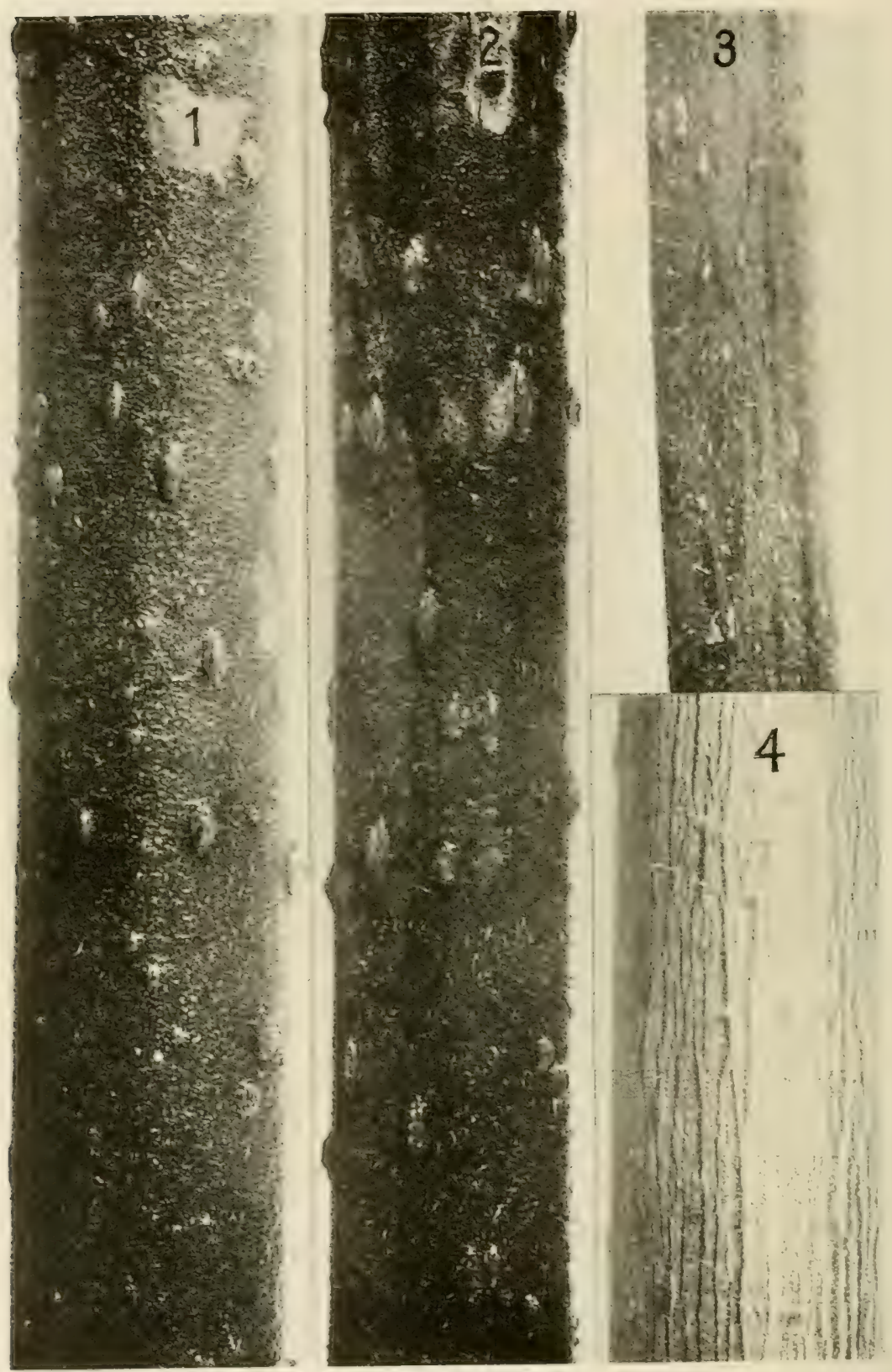

FIG. 3S6. - Foung vigorous shoot of Morus alba showing lenticel proliferations due to closure of the lenticels by Squibb's petrolatum: (1) and (2). Two treated portions-2 was taken a foot above 1 . (Time 13 days; 2 d treatment on 11 th day but not necessary.; Exposure begun March 5, 1918. Cut and photographed, March 18. $\times 5$. (3) Untreated part, above 2. (4) Untreated part, below 1. 
volume of oxygen offered to such a cell (I am not here thinking of anaërobes) is reduced by the abstraction either of water or of air, it is plain that the only way the cell has of compensating for this reduction of an absolutely necessary substance is by cell-division, that is by increasing the area of its oxygen-absorbing surface, or to put it in other words, by increased respiration through the development of a hyperplasia. ${ }^{1}$ If the amount of oxygen offered to the tissues is much below the amount required, then the hyperplasia will be fine-celled and active, if it is only a little below the needs of the tissues, the hyperplasia will be coarse-celled and slow-growing. All the evidence we have, enzymic and other, points to increased respiration in tumors of all kinds, and their feeble vascularization and correspondingly slow and uncontrolled circulation leads to just the stasis necessary to produce more or less oxygen-hunger. I do not mean that there is complete absence of oxygen because in ordinary plants and animals that would mean prompt asphyxiation and death of tissues. Asphyxiation also occurs often in tumors but it is an end term that need not concern us here. What I mean is just sufficient reduction of the normal supply of oxygen to bring about cell-division for compensatory purposes, i.e., to afford a larger oxygen absorbing surface.

Two factors, at least, may be supposed to enter into this semi-asphyxiation hyperplasia under obturated lenticels: (1) oxygen-hunger, the cells being no longer bathed freely by air or by aërated water in movement toward the lenticel; (2) increased acidity of the cell- ap (from incomplete combustion of carbon compounds, leading to more or less paralysis of the protoplasmic membrane (the hyaloplasm which governs intake and outflow) with correspondingly increased cell-permeability, allowing water to escape, and water, sugar and other food-stuffs to be brought back into the cells in increased quantities from

${ }^{1}$ The reason the bacterial cell accomplishes work out of all proportion to its size is just this, that its oxygen absorbing surface is enormously greater in proportion to volume of protoplasm than that of any other known organism. The surface of the rods in a cubic centimeter of bacterial slime, such as we frequently obtain in a test tube on our solid media and observe in the plant, represents an oxygen absorbing area equal to the surface of an ox. Indeed, we might say that the smallest hacteria are almost all surface. 


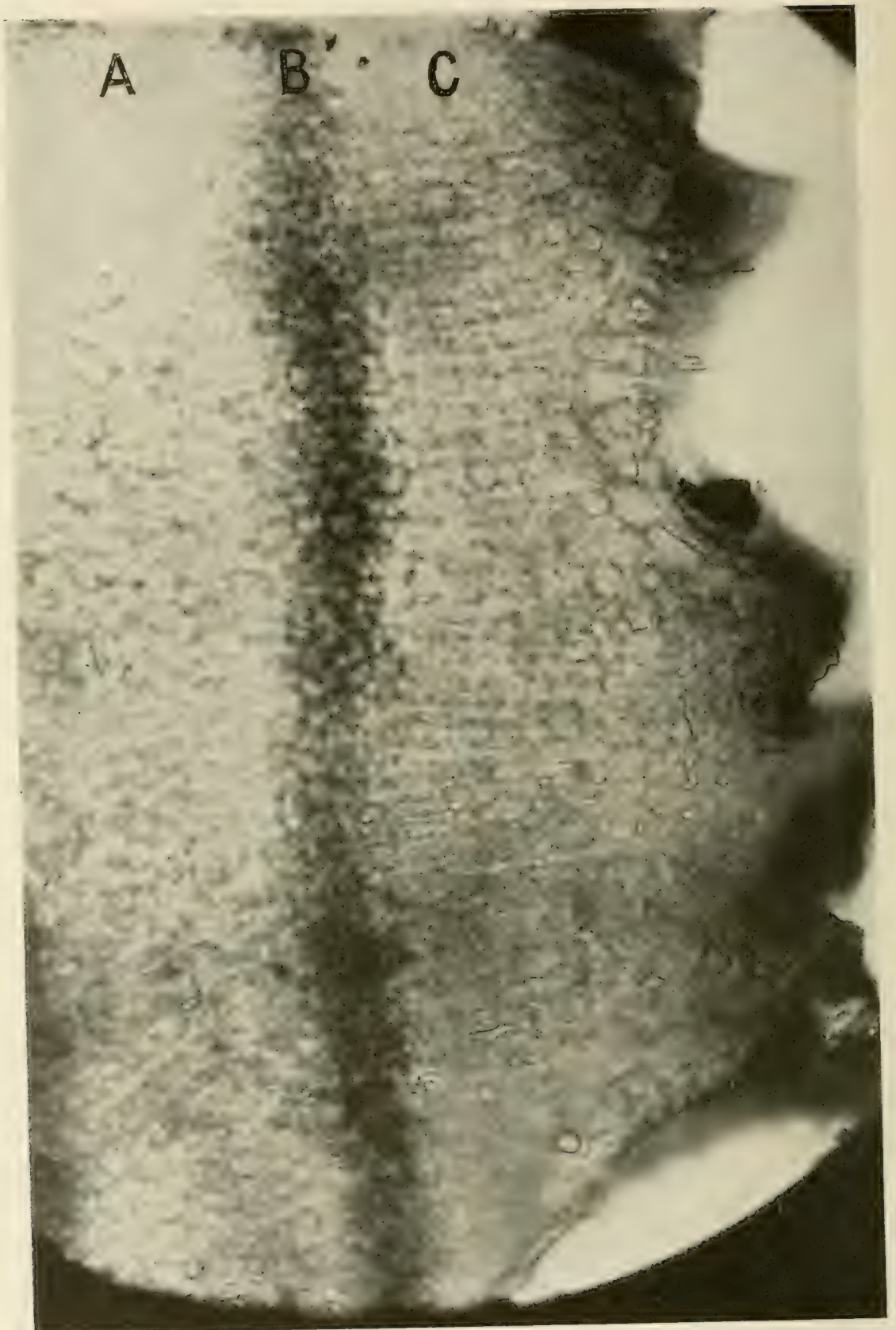

Frg, 387.-Cross-section of one of the mulberry tumors shown in Fig. 386. It is a hyperplasia: $A$, normal part; $B$, chlorophyll band; $C$, lenticel proliferation. Photographed from an unstained section mounted in water. $16 \mathrm{~mm}$. obj., 4 oc. and bellows at 45 . 

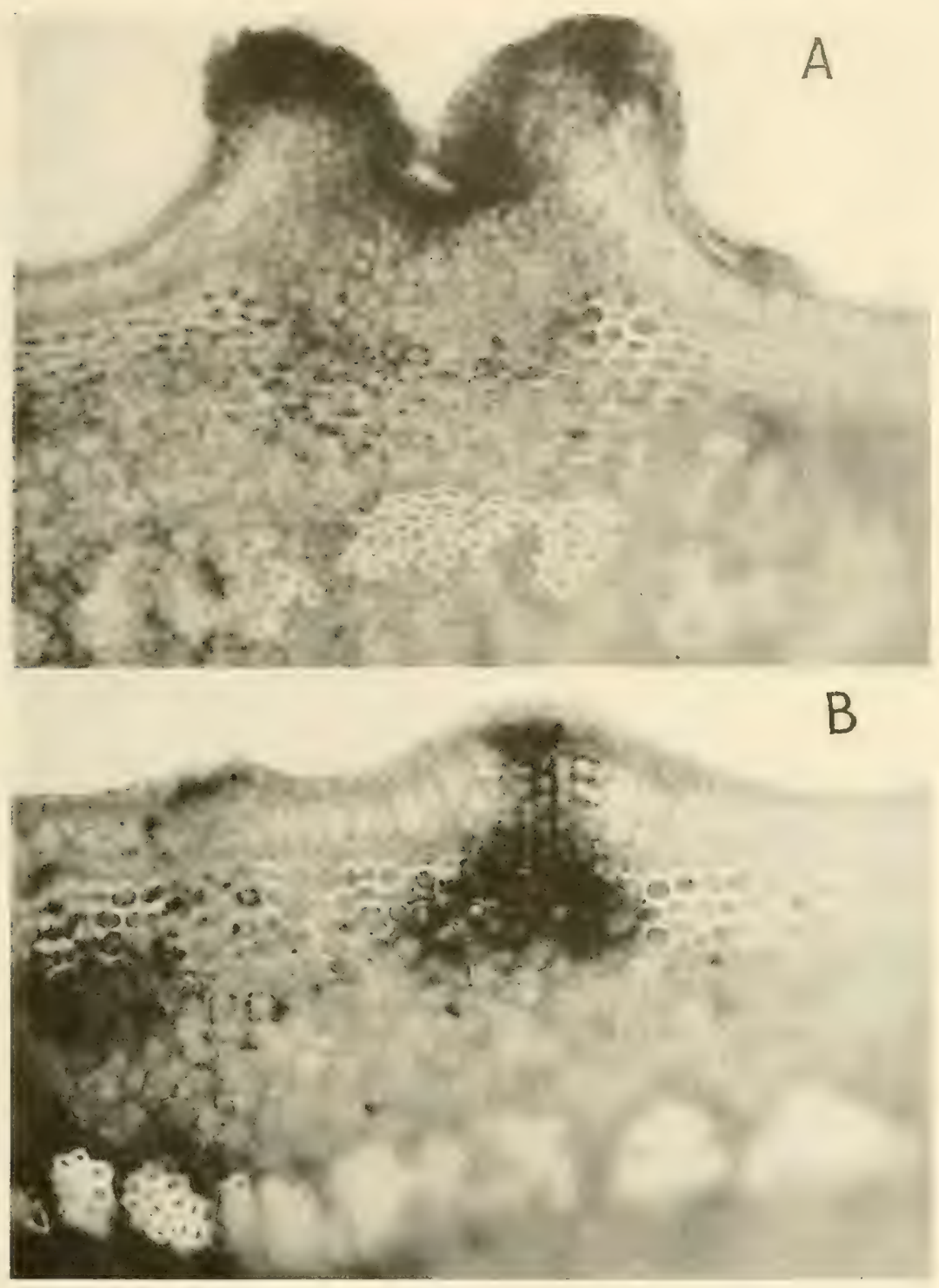

FIG. 388.-A. Hyperplasia in a lenticel on a young olive shoot due to treatment (March 4, and several times after that) with petrolatum. Response rather slow. From an unstained free-hand section. Photographed Narch 28, 1918. $8 \mathrm{~mm}$. obj., 4 oc., bellows at $45 . \quad B$. Cross-section showing a normal lenticel. Olive shoot of same age as $A$. The dark color under the lenticel is due to chlorophyll. 


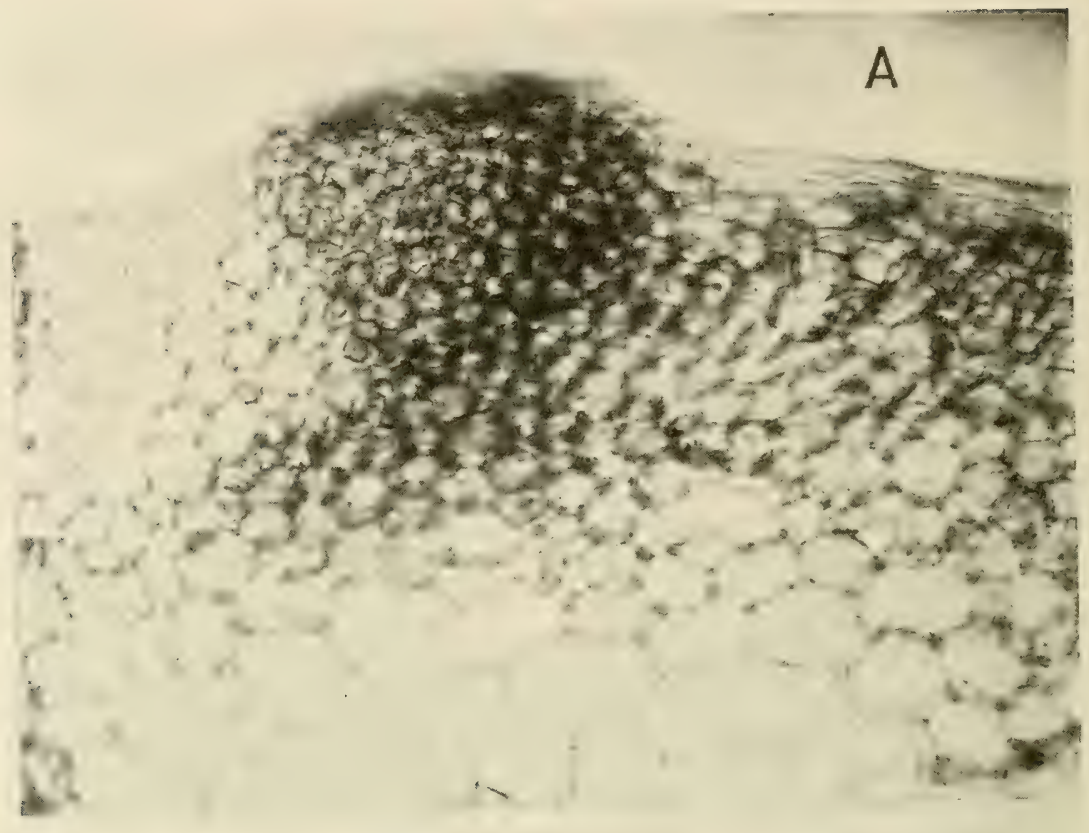

B

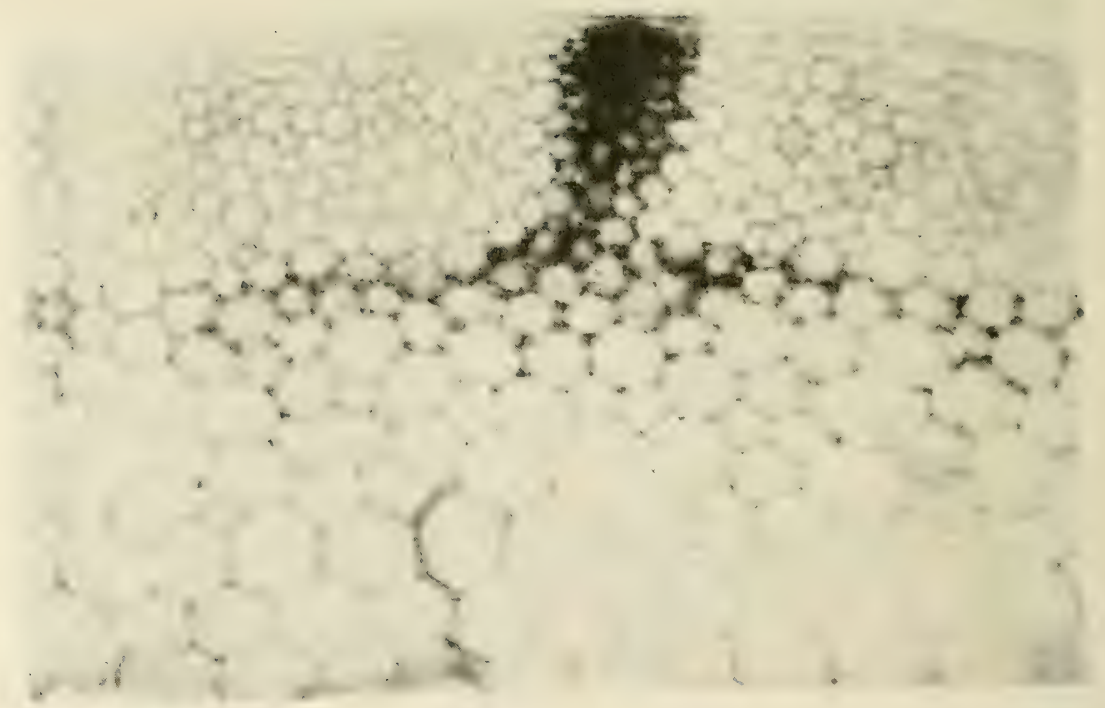

Fig. 389.-Experimental intumescence on a silver spotted begonia (Begonia corallina lucema):

A. Cross-section of internode of a young shoot, six days after painting with 
the surrounding tissues to compensate for the substances removed by growth as the tumors develop, and especially as they rupture to the surface and are not protected against irregular loss of water. Possibly there may be a third factor involved, viz., excessive turgor, due to the pressure of too much absorbed water.

That there is an excessive movement of food-stuffs centering in all active tumors is shown not only by the rapid growth of such tumors, but also by chemical and microscopic analyses, by the overgrowth of neighboring tissues not actually involved in the tumor itself but affected by it (see Fig. 319 , subs. 5 and 6 ), and, finally, by the starvation of remoter normal tissues.

What proportion the air dissolved in the circulating fluids of the plant bears to the direct intake of air through the lenticels or the stomata in furnishing oxygen to the cells cannot be stated. It is conceivable that in many cases the first or indirect source would furnish more oxygen to many cells, especially in very young organs, the stomata on which are usually closed and the intercellular passages $n$ which are undeveloped, while in other cases the second or direct source would be most drawn upon. C'ertainly all the water that enter's the transpiring plant through its root-system (in the aggregate, an enormous amount), as well as all the fluid that circulates in animals, is well aërated and bathes all the normal living tissues continuously, but there is not much active circulation in tumors, and consequently their cells will receive less oxygen from this source than normal cells.

The hyperplasias produced from the flesh of raw potatoes in sealed tubes and those developed under stomata on young shoot: in such sealed tubes, I would explain in the same way. As factors in the production of hyperplasias under the stomata, I believe we may eliminate both the decreasing external oxygen and the increasing external carbon dioxid in the sealed tubes,

Squibb s petrolatum. The cells of the lenticel have multiplied and pushed up the epidermis but have not yet ruptured it. Photographed March 11, 1918, from a water mount of an unstained free-hand section. $16 \mathrm{~mm}$. obj., 4 oc., bellows at 52. For well developed intumescences see Fig. 394*.

$B$. Same as $A$, hut passing through a normal lenticel. From a free-hand unstained section in a water mount. The dark color is due to chlorophyll. Photographed March 11, 1918. $16 \mathrm{~mm}$. obj., 4 oc., bellows at 52 (small upright stand). 

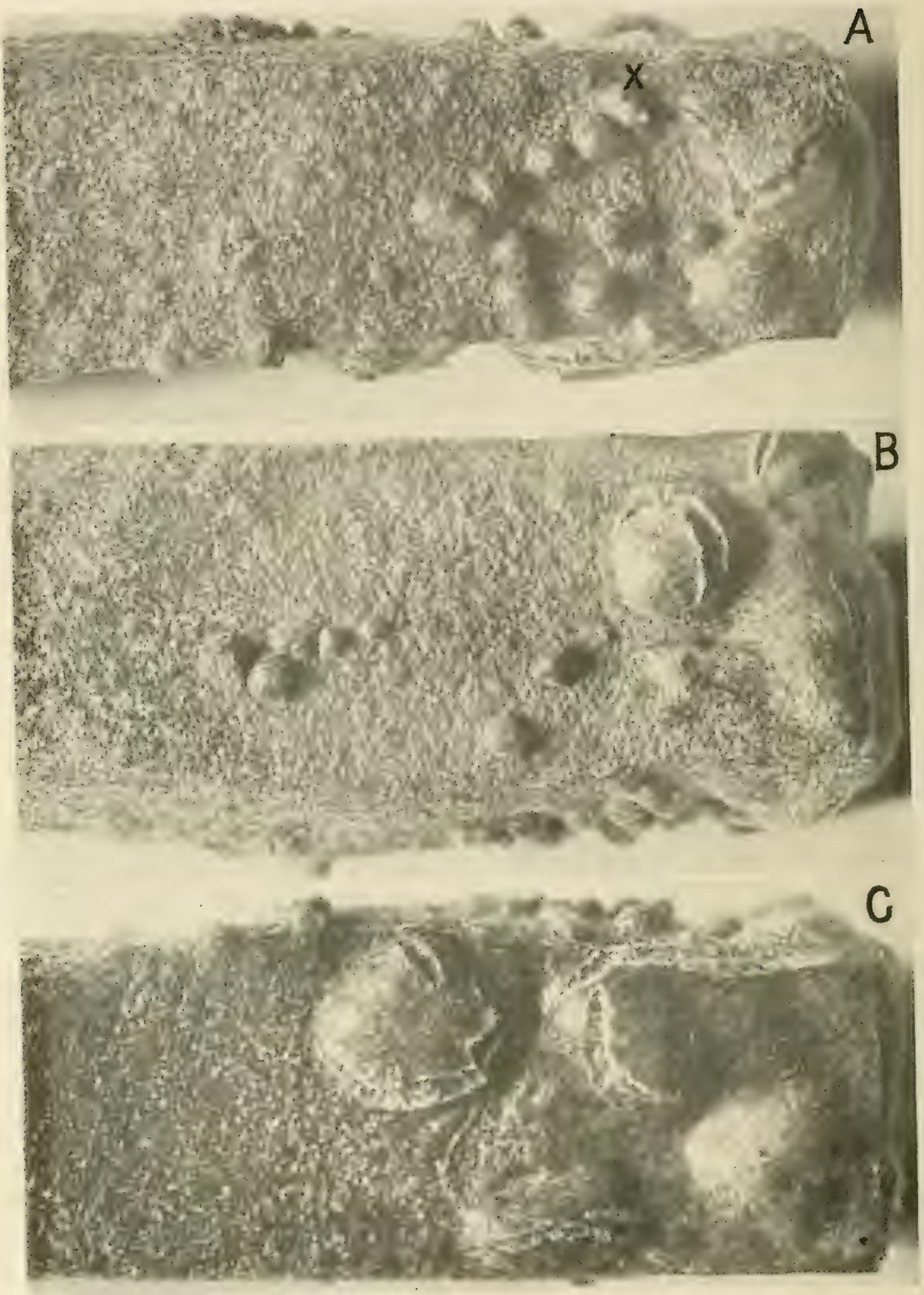

FIG. 390.-Photographs showing small tumors developing under the cut surface (cork-layer) of a raw potato which was sealed into a very limited air space: $(A)$ Frent view; $(B)$ upper surface of $A ;(C)$ lower surface of $A$. The cork-layer is ruptured in places. Block enclosed in a test tube May 2, 1917, and sealed in with sealing wax. At $X$ one of the tumors has developed a bud. Photo. Sept. 25, 1917 


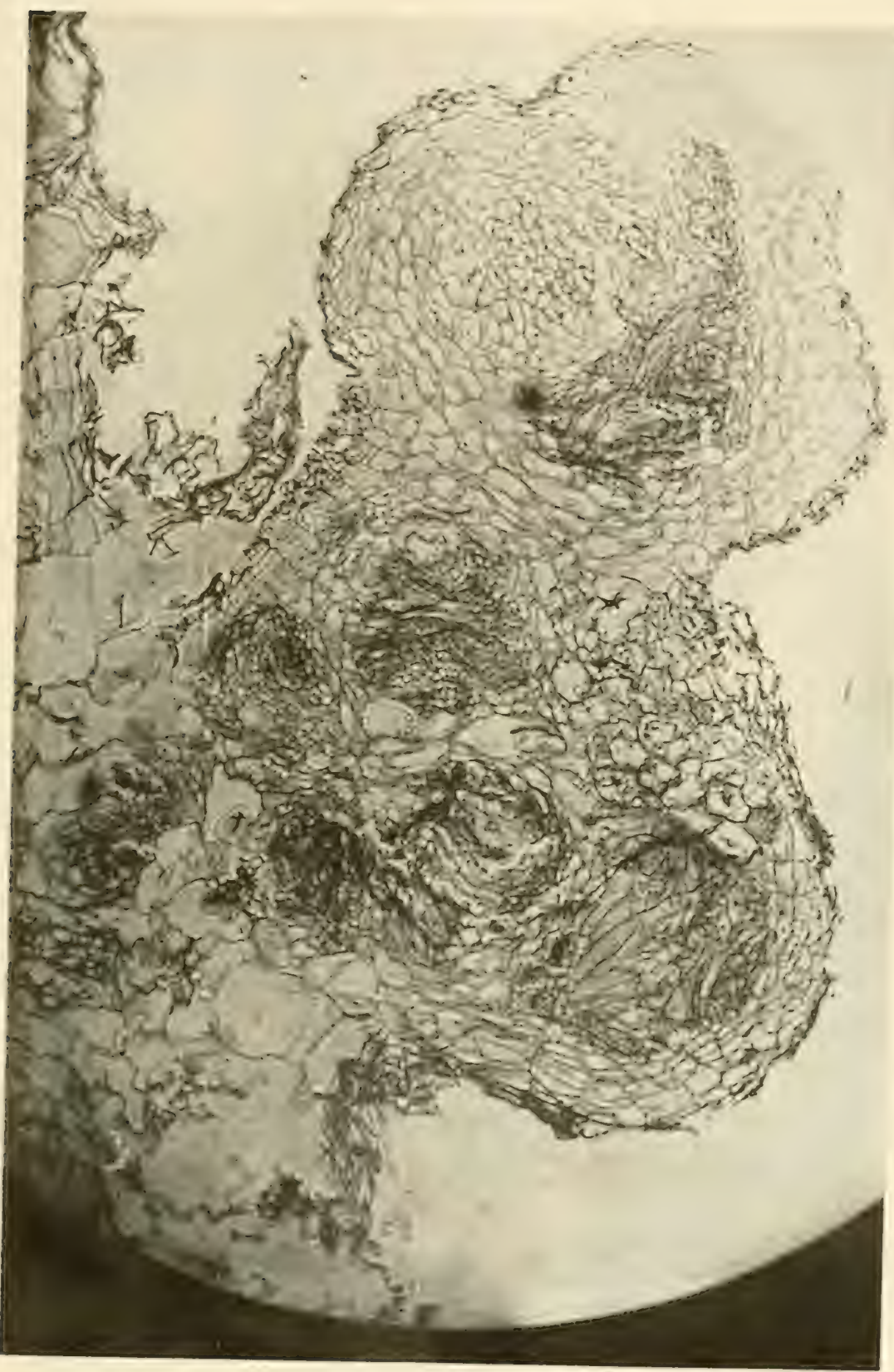

Fig 391. - Section of the outgrowth $X$ on cut flesh of Fig. $390 A$, showing distorted vascular structure of the tumor. At left, below, a few normal cells. At left, above, some cells of the newly formed cork layer. 


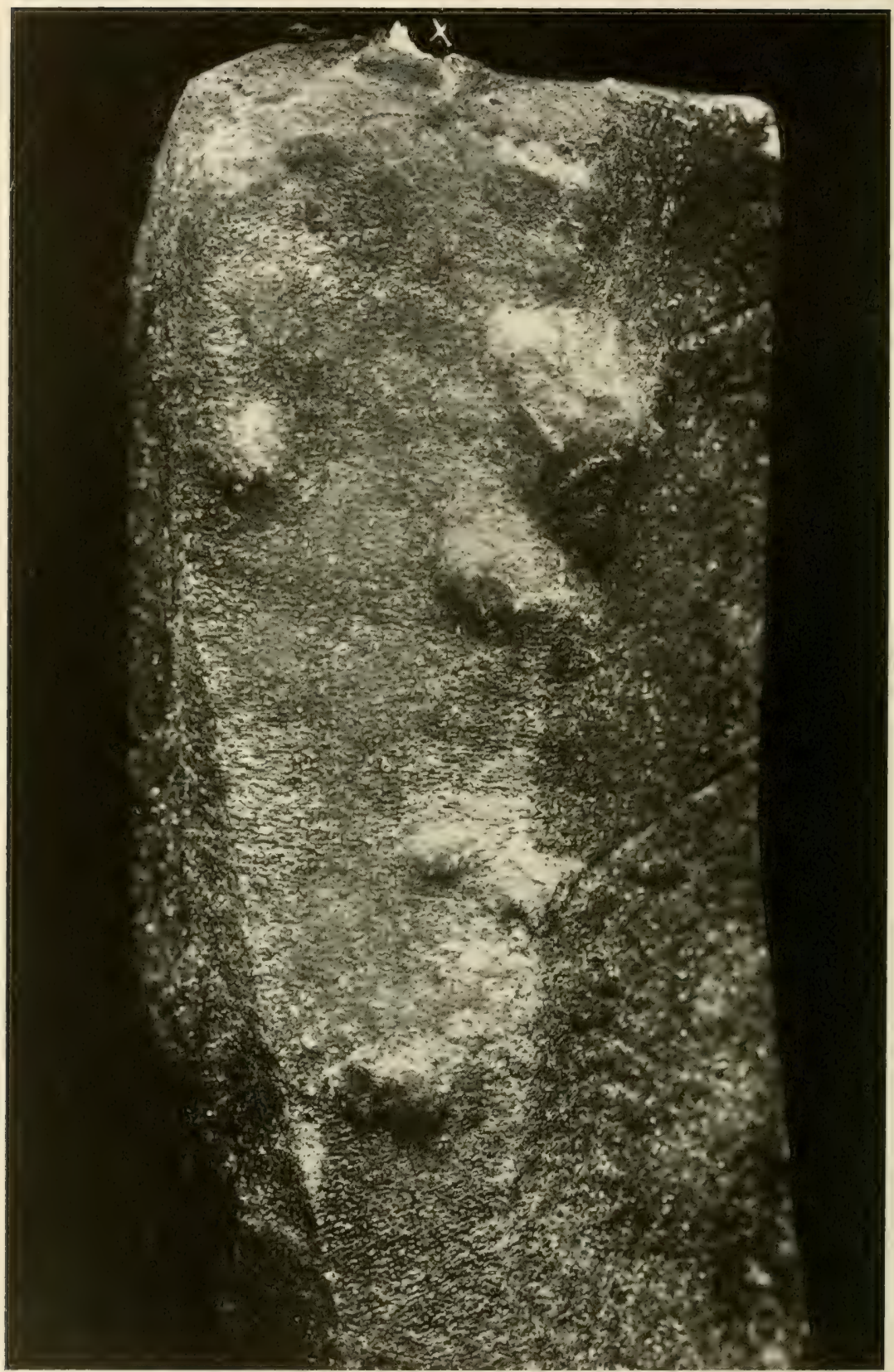

FIG. 392.-Block of raw potato showing experimental production of small tumors like the accidental ones of Fig. 390. The pared sterile potato flesh, resting in wet cotton, was sealed into a test tube February 7, 1919, kept in the dark at room temperature, $22^{\circ}$ to $25^{\circ} \mathrm{C}$., and photographed April $17 . \times 5$. Small shoots were torn away at $X$, which was the bottom of the block berlded in the wet cotton. 


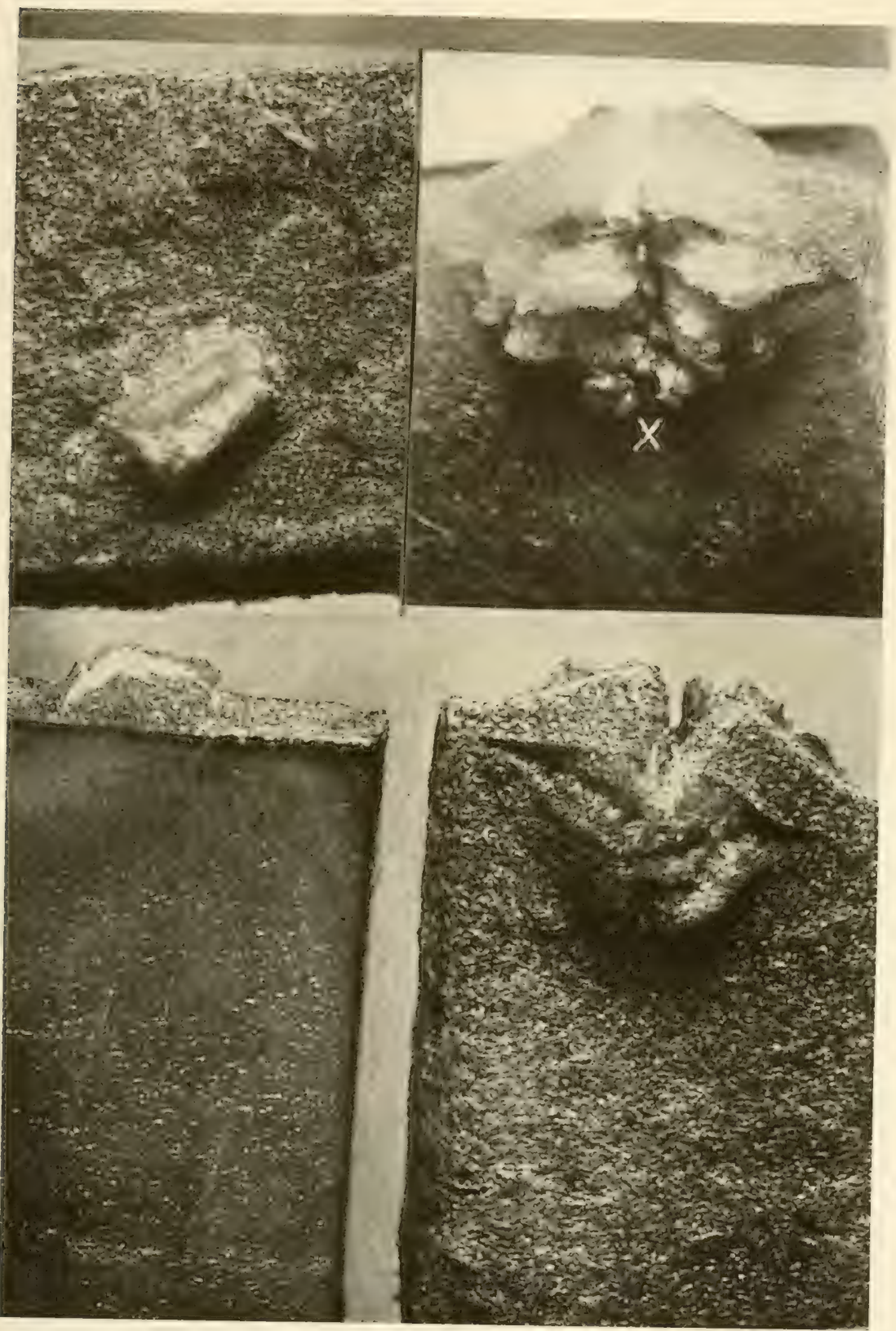

FIG. 393.-Top and bottom (right side) of a pared block of sterile raw potato sealed into a test tube on wet cotton February 18, 1919, and kept in dull light at room temperatures $\left(22^{\circ}\right.$ to $25^{\circ} \mathrm{C}$.). The photos show top snd side views of the two tumors, both of which have ruptured the cork layer that covered them. At $X$, shoots are pushing. The lower left, block freshly pared to show the thickness of the cork-layer. Photographed March $22 . \times 5$. 


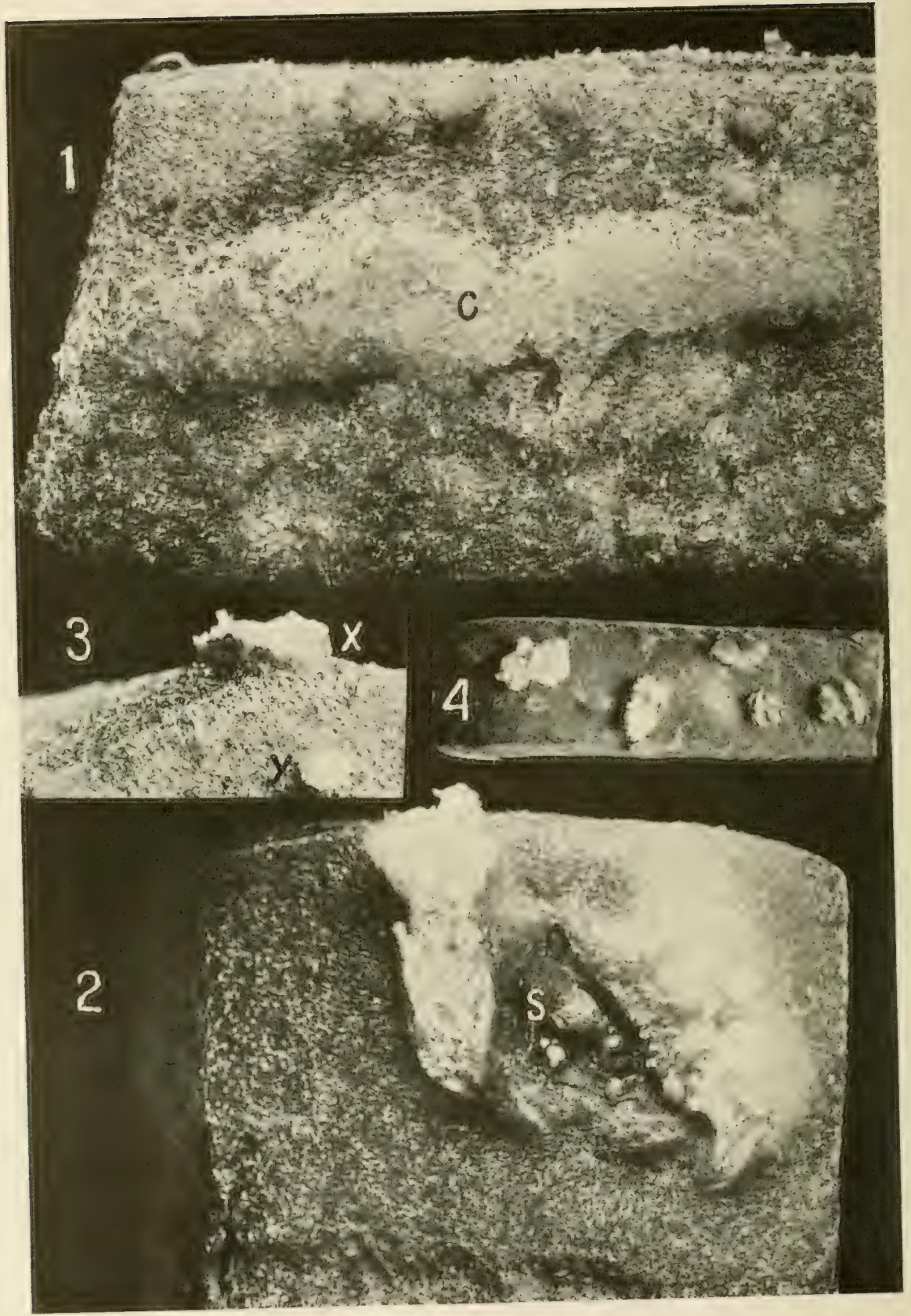

FIG. 394.-1, 2. Blocks of sterile raw potato sealed into test tubes on wet cotton February 18, 1919 , kept in the dark at temperatures of $23^{\circ}-25^{\circ} \mathrm{C}$., and 


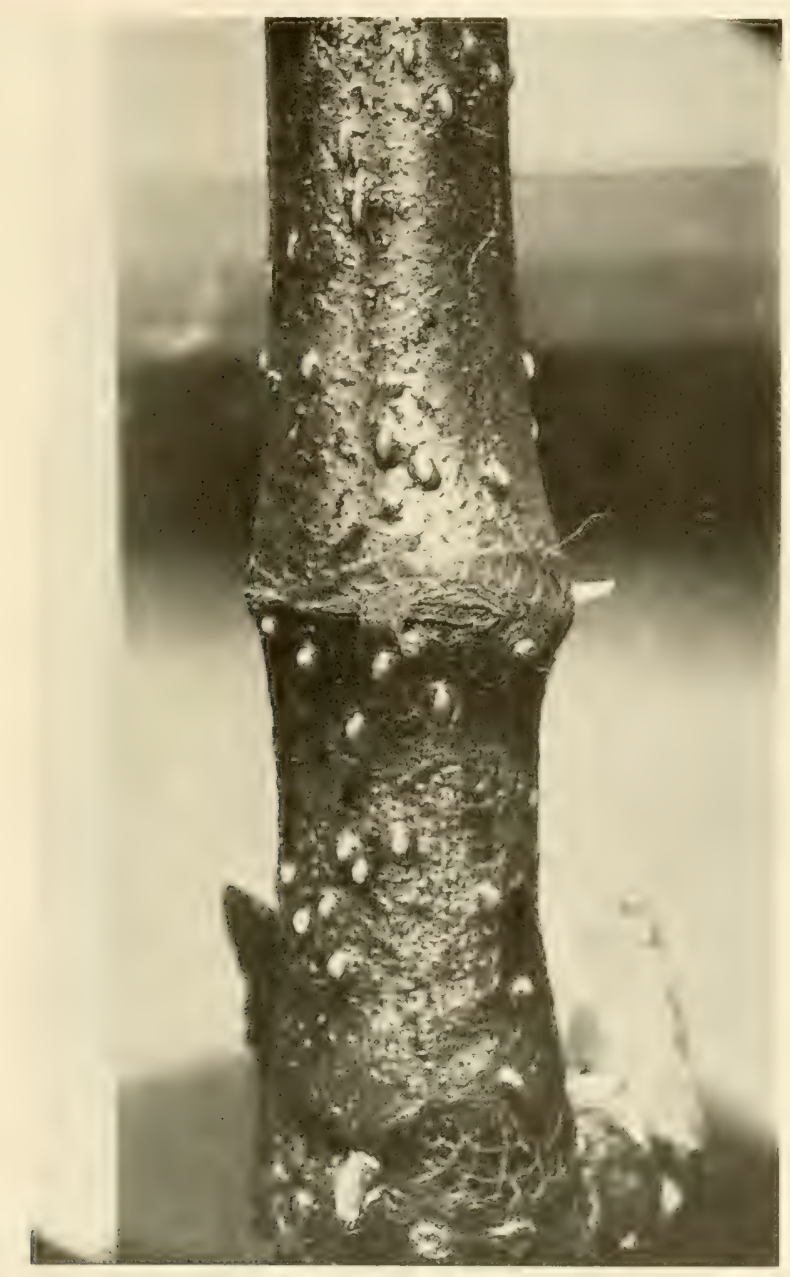

FIG. 394*.-Well developed intumescenees which formed under lenticels on a silver spotted begonia that was painted with Squibb's petrolatum April 19 and 22, 1920. Photo. May 20. $\times 2$.

photographed March 24, $\times 5:(1 C)$ A ridge of callous tissue from the cambium region, also small nodules. (2) At $S$ stunted shoots pushing from a cambium, and at either side hyperplasias rupturing through the cork. (3) Small tumor at $X$ bursting through the cork, at $Y$ a naked small nodule. (4) Same as $1-3$ but sealed in February 8, 1919, unpared and photographed March 29. Small hyperplasias rupturing through the original tough cork layer. 


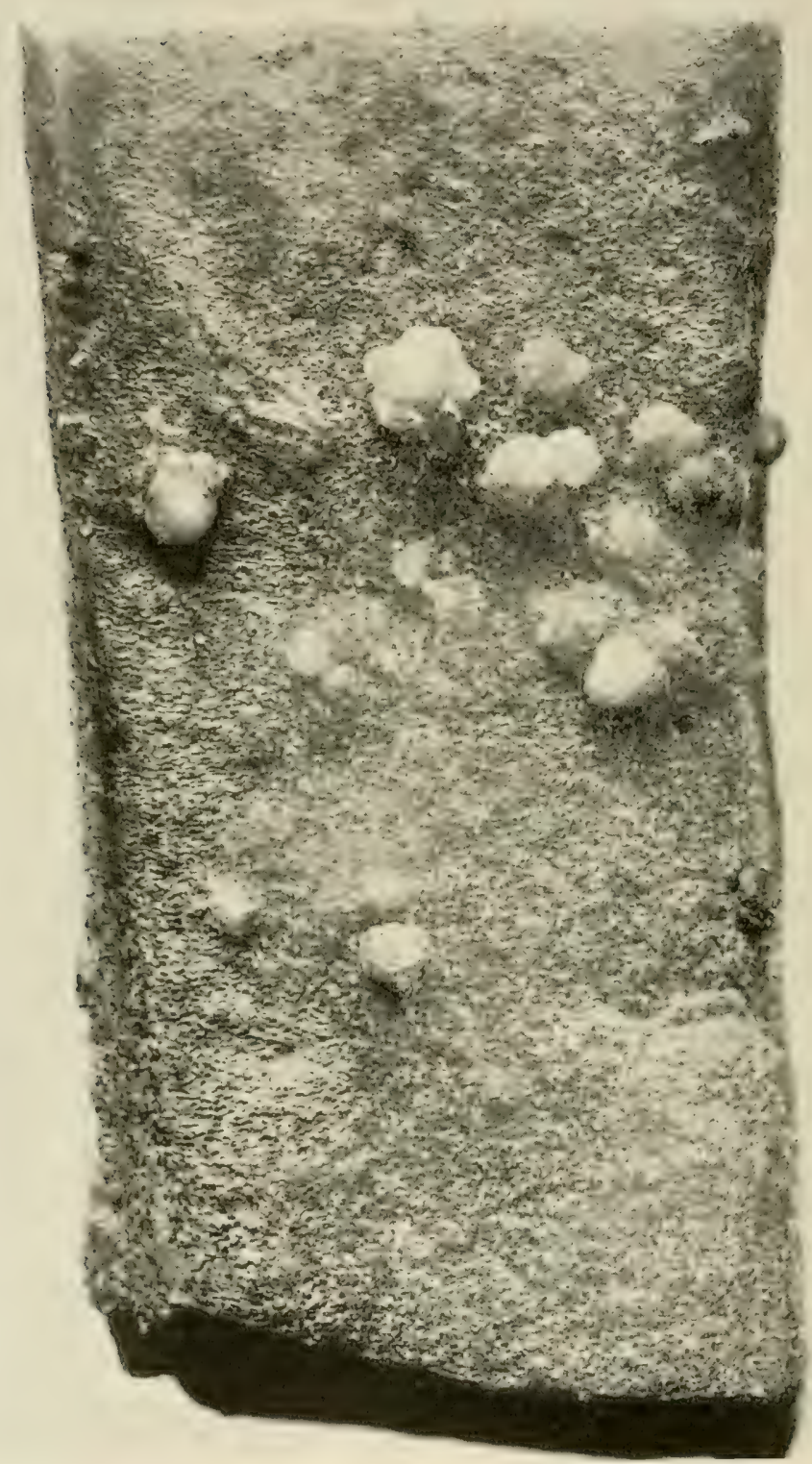

FIG. 395.-Pared, sterile block of an Early Rose potato tuber sealed into a test tube on wet cotton March 22, 1919, showing development of small tumors. Tube kept in the lahoratory in dull light at $23^{\circ}$ to $25^{\circ} \mathrm{C}$. In these sealed tubes there was a saturated atmosphere and, owing to continued respiration of the tuber, reduction of oxygen and increase of carbon dioxide with probably some anaërobic respiration leading to the production of alcohol and acids. Photographed June $14,1919 . \times 5$. 


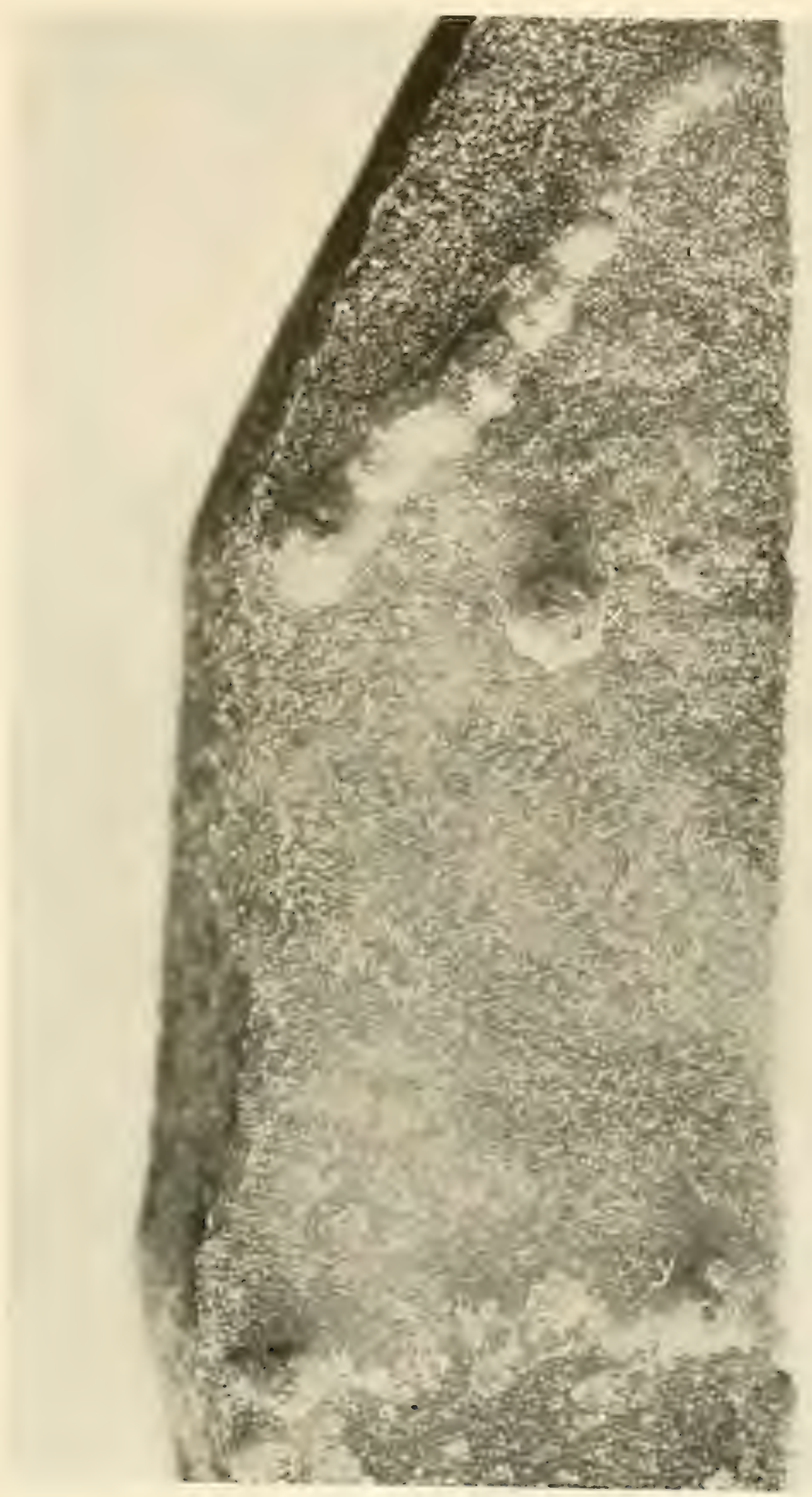

FIG. 396.-From the same series as Fig. 395. A pared, sterile block of Early Rose potato showing development of small tumors from the cut surface. Most are broad based but $X$ was narrowly pedicelled. Those at the top and the lower left are from the region of the cambium; $X$ and $Y$ are from deeper tissues. Photographed June 14, $1919 . \times 5$. 


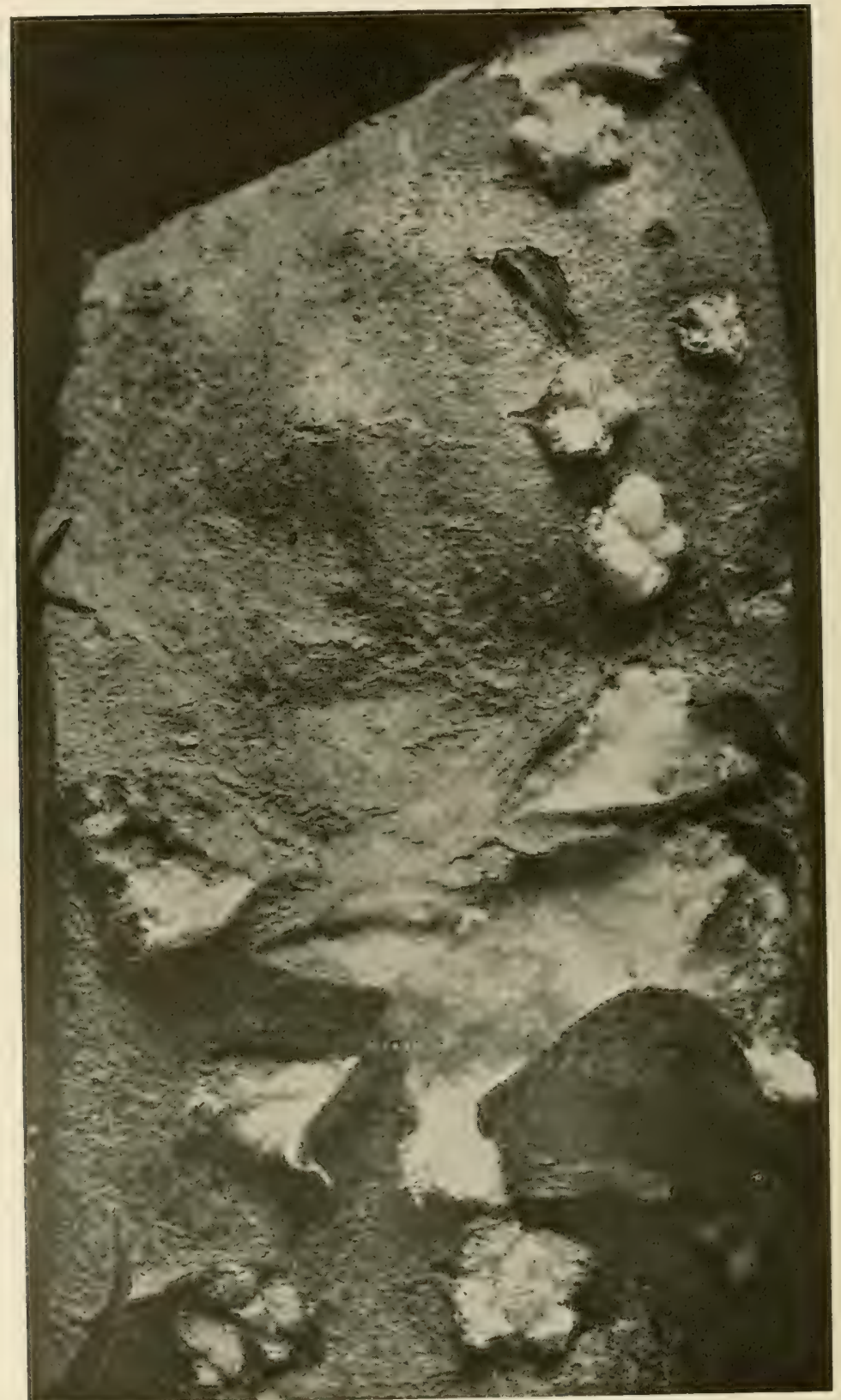

FIG. 397.-Portion of an Irish Cobbler potato sealed into a test tube on wet cotton April 26, 1919. It shows numerous unruptured and ruptured intumescences, the latter bursting through the surface of the tuber (original strong cork layer). Flesh more acid than normal potato flesh, i.e., +35 on Fuller's Scale. Photographed May 14, 1919 . $\times 4$ circa. 


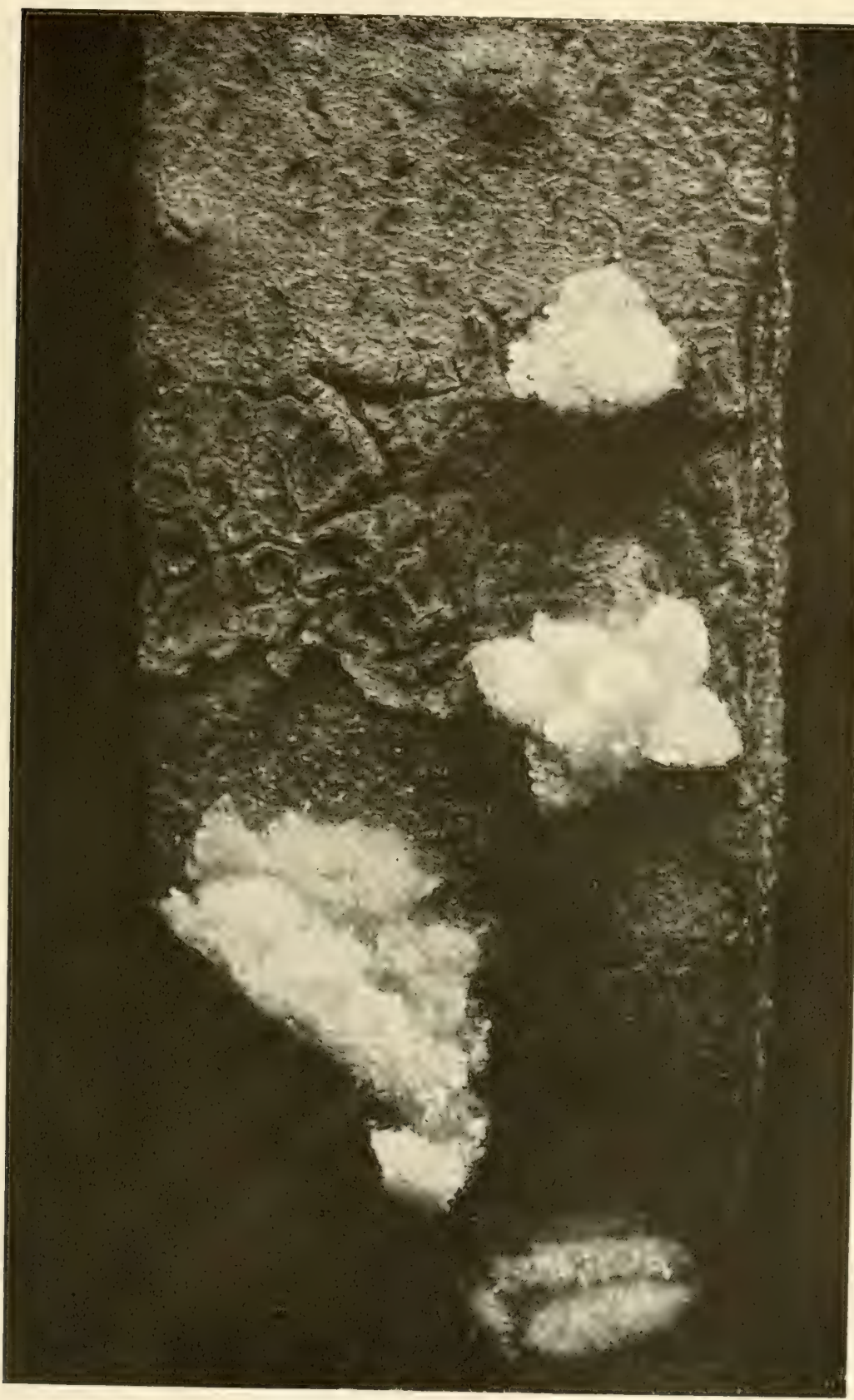

FIG. 398.-From same series as Fig. 397, showing ruptured and unruptured hyperplasias produced in 18 days under the skin of a potato tuber expose 1 to dull light on wet cotton in a confined air space at $25^{\circ} \mathrm{C}$. Block sealed into the test tube April 26, 1919. Photographed May 14. $\times 5$. Acidity of whole flesh +35 . 


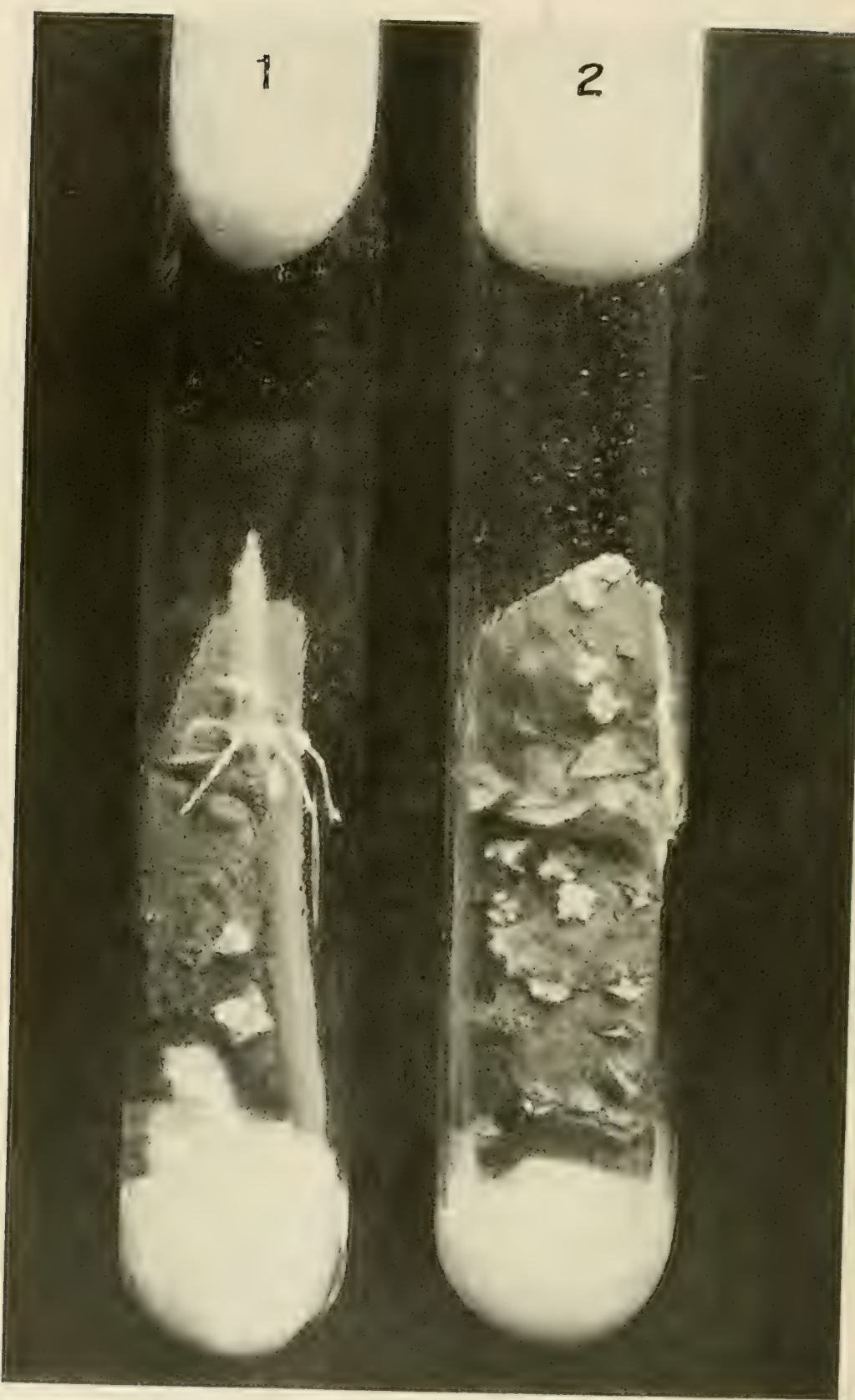

FIG. 399.-General view of sterile potato blocks shown in detail in Figs. 397 and 398. Above the cotton plugs were plugs of sealing wax. Condensed vapor of water is visible on the walls. For details of the two shoots see Fig. 403. 
because, as we have seen, intumescences often occur in hothouses where there can be no question of diminished oxygen (I mean, of course, that external to the plant) or of increased external carbon dioxid. The active factors in the production of these tumors must then be diminished internal oxygen and increased acidity of the tissues (as shown by titrations), both due to the saturation of the ambient air which prevents transpiration (which normally by continual movement of absorbed water continually bathes the tissues in an aërated fluid) and to waterlogging of the tissues, which prevents the entrance by way of the stomata of sufficient external air for the needs of respiration. There is certainly saturation of the atmosphere in my sealed tubes as there may be in defective greenhouses and at the same time there must be consumption of the oxygen by respiration and increased absorption of water by the lower parts of the plant (roots in hothouse plants and living cells at the base of the raw potato blocks in my sealed tubes). This absorbed water, carrying its dissolved air, is passed on to the shoots rather in excess tending to internal saturation and turgor pressure, but moving more and more slowly owing to the interrupted transpiration. The tissues, especially under the stomata toward which all these various streams of water are moving, will then be very full of a sluggish current from which the insufficient oxygen is quickly removed, and hyperplasia must then set in as a compensatory measure, or otherw se there will be asphyxiation of the tissues. As a matter of fact, a little later, suffocation did occur in all the roots and shoots dereloped in my sealed tubes (Figs. 402, 404, 406, 40S D, E) but the death of parts, as I have said, is a subsequent matter, an end term, which does not concern us here. The reason the hyperplasia sets in only under the stomata or lenticels is because here are the youngest most sensitive cells.

After the above was written I discovered that intumescences could be produced on potato shoots in two other ways: (1) by bacterial destruction of the tops while the roots continue to function, and (2) by reducing the intake of water.

On April 10, 1919, I made inoculations on potato plants with Bacillus phytophthorus for another purpose (Fig. 211) and 


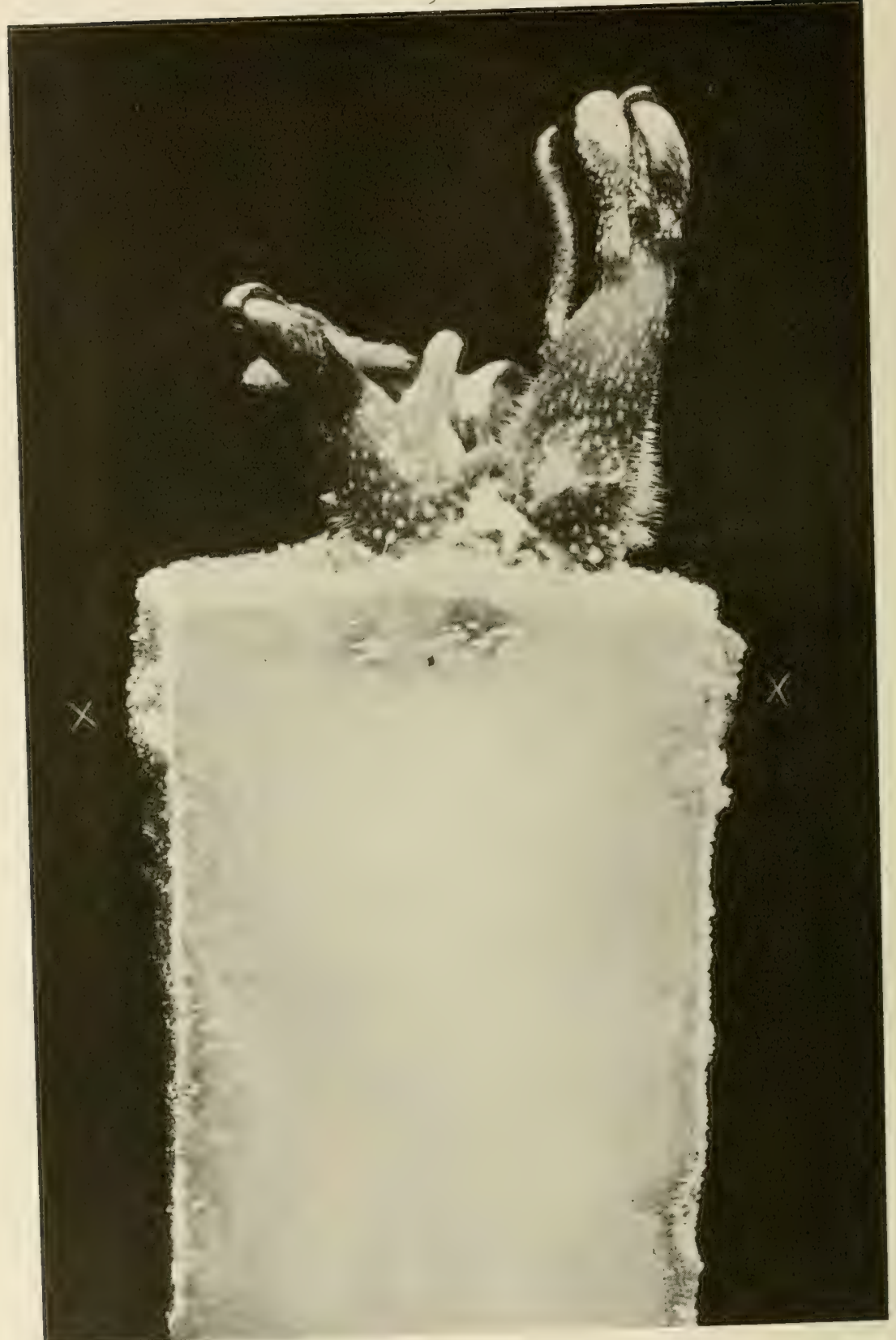

Fig. 400.- Small hyperplasias developing in potato shoots in water-saturated air in hright light at hothouse temperatures $\left(28^{\circ}-35^{\circ} \mathrm{C}\right.$.). The shoots are from pared sterile potato flesh sealed into a test tube on wet cotton, March 28, 1919. At $X X$, callous tissue. Photographed April $10 . \times 5$. 


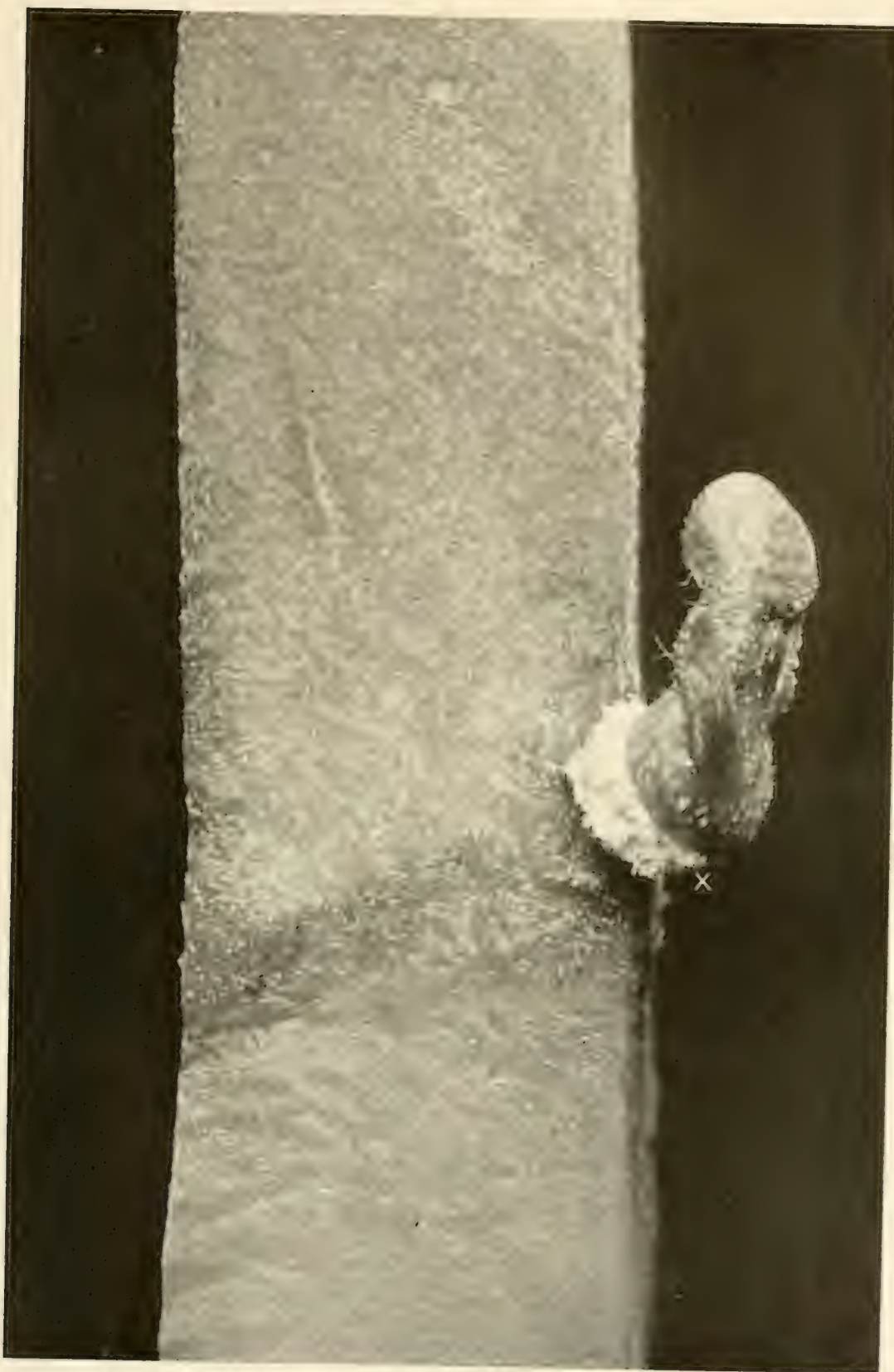

FIG. 401.-Block of pared sterile potato flesh exposed to same light, temperature and atmosphere as Fig. 400 and in all respects like it, except that the lower hyperplasias have fused and ruptured encircling the entire base of the shoot. Photographed April 10. $\times 5$. 


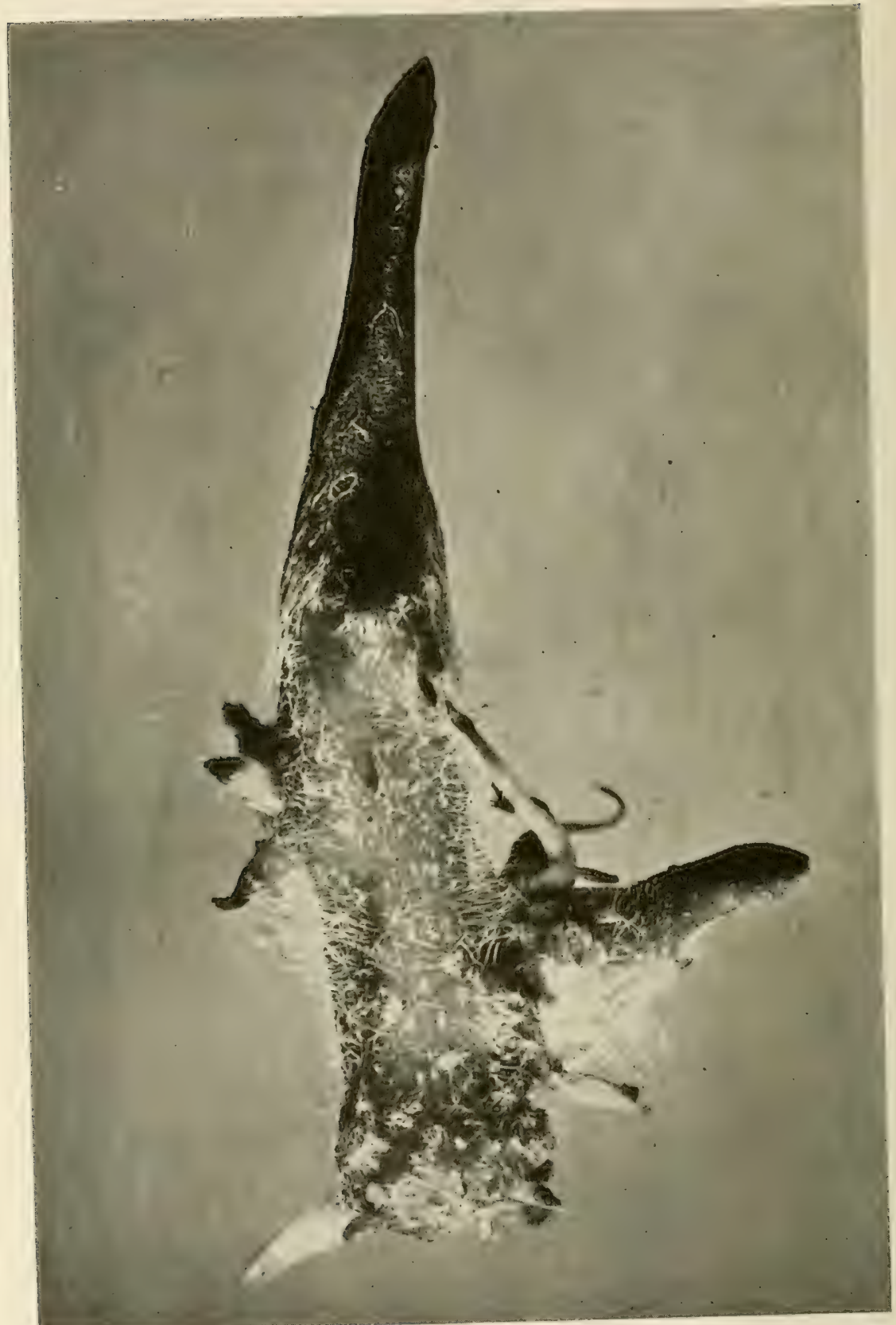

FIG. 402.- Shoot of White McCormick potato from a pared sterile block cut from a potato tuber and sealed into a test tube on wet cotton, February 18, 1919 , and held in very dull light at $23^{\circ}$ to $25^{\circ} \mathrm{C}$. Base and middle covered with intumescences, ruptured and umuptured. Shoots and roots dying of asphyxiation. Photographed March $22 . \times 5$. 
MISCELLANEOUS: STIMULI UNDERLYING TUMOR-FORMATION 535

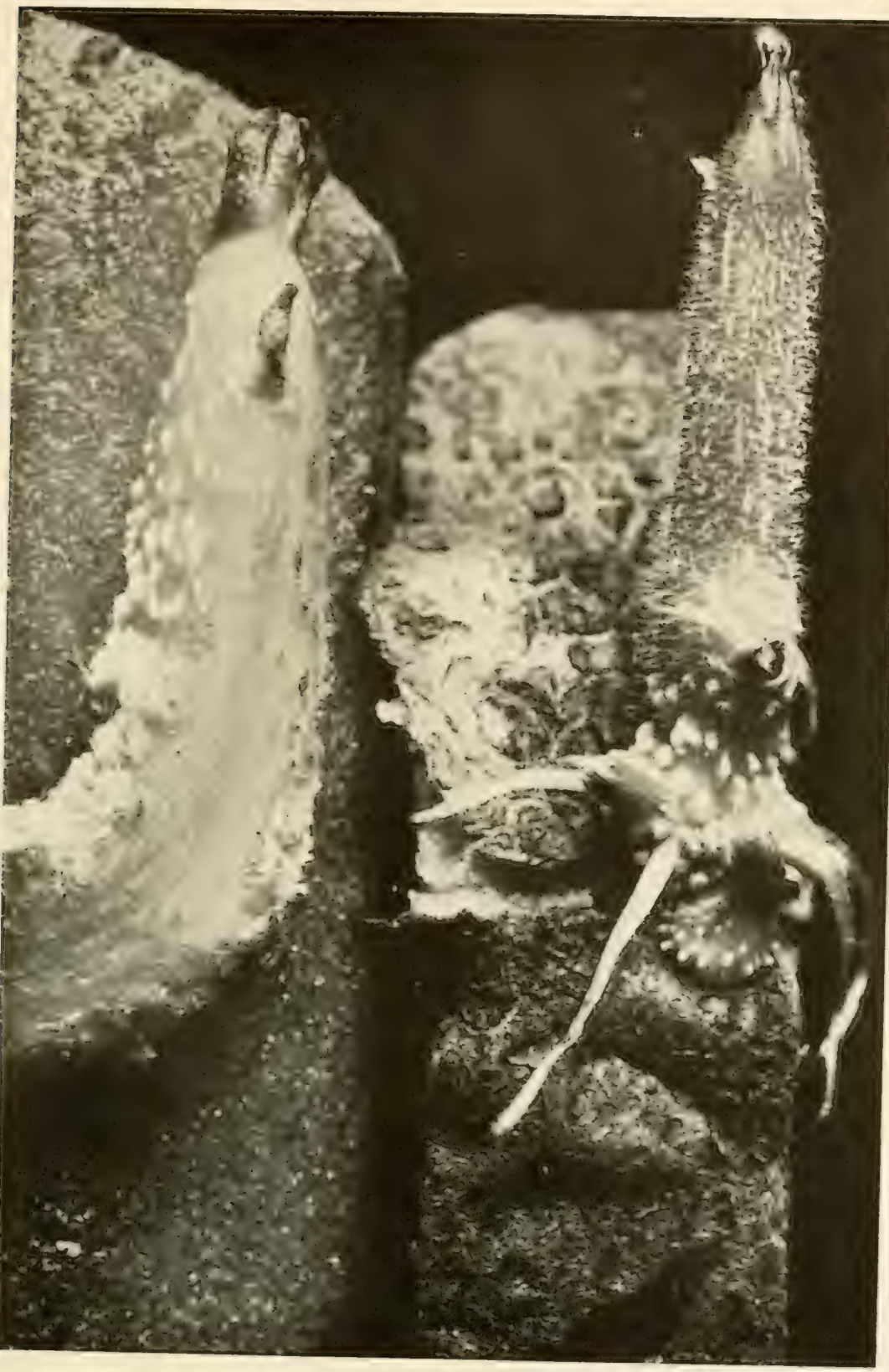

FIG. 403.- Ruptured and unruptured hyperplasias on stunted shoots of potato grown in dull light at $25^{\circ} \mathrm{C}$., in the sealed tubes shown on Fig. 399. Time, 18 days. The right-hand block also shows two unruptured hyperplasias below the shoot and a rupturing one at the left. Theses are pushing shrough the rery resistant cork surface of the tuber. Photographed May 14, 1919. $\times 5$. 


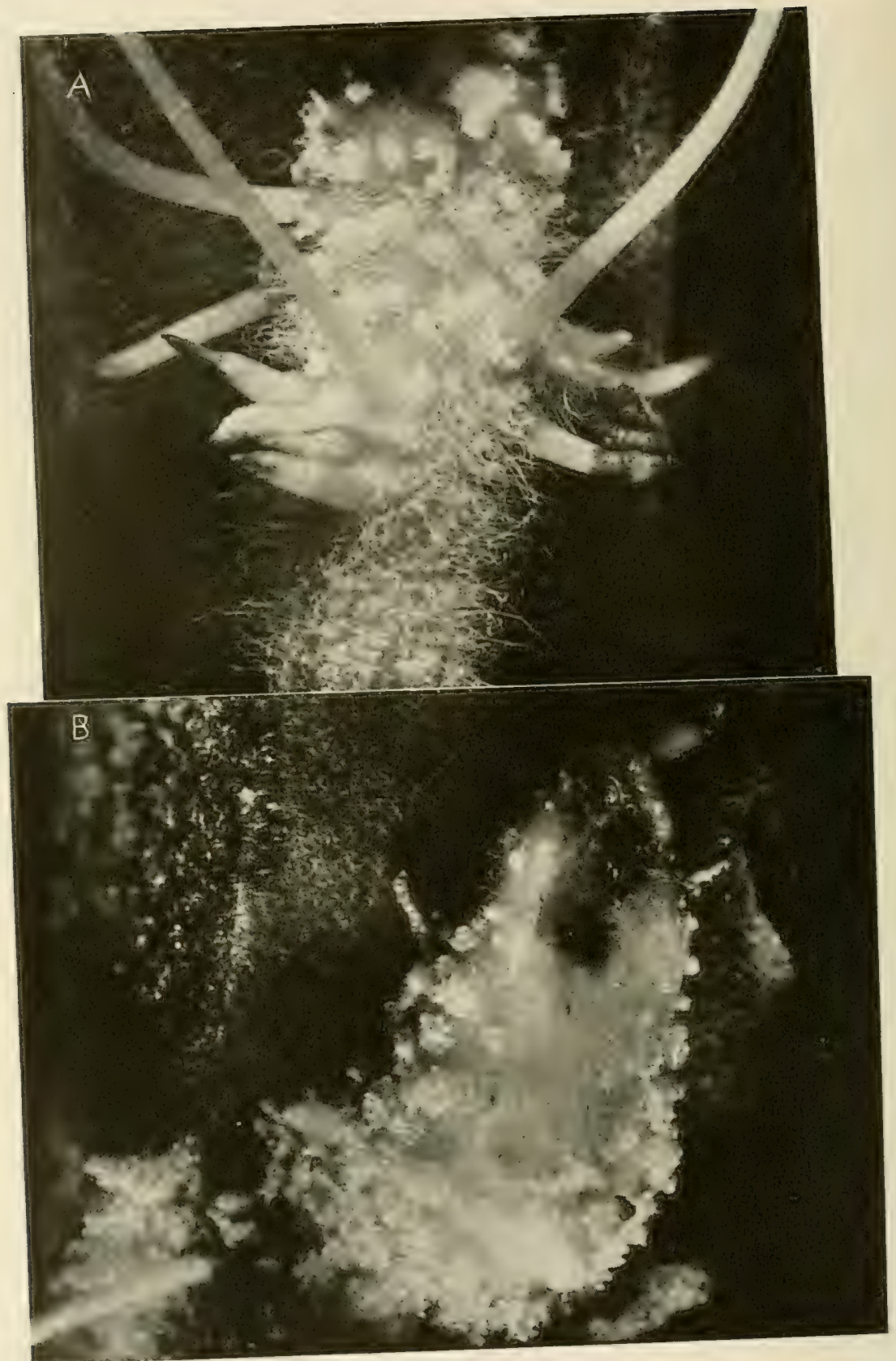

FIG. 404.-A. Same series as Fig. 403. Roots beginning to die from asphyxiation. Shoot covered with widely ruptured hyperplasias. Acidity of shoot +55 
discovered that intumescences in great numbers ( Figs. 409, 410) appeared on the base of some of the shoots both above ground and below, and not only on the older main axis but also on small compensatory side shoots which began to develop as soon as the tops were destroyed. On a critical examination (9 days after inoculation and 5 or 6 days after the tops were killed) these intumescences were found on 14 of the 16 inoculated shoots (13 pots) and there were none whatever on the 17 control shoots (13 pots). The two shoots which did not show any intumescences were those least injured by the inoculation and which had

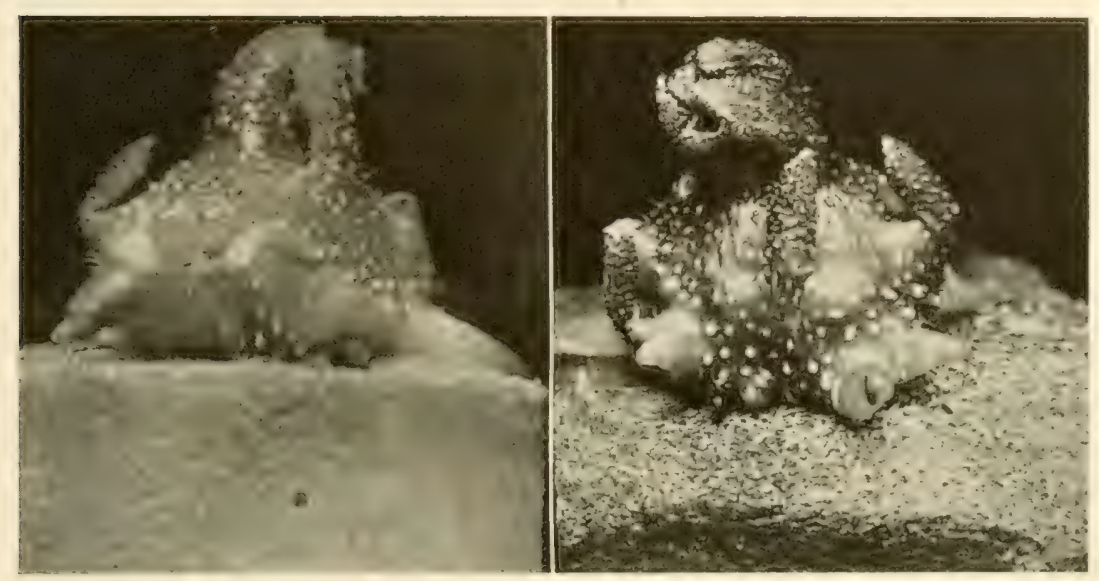

FIG. 405.-Intumescences (hyperplasias) on a stunted tumefied potato shoot grown from a pared sterile block of potato flesh in a stagnant saturated atmosphere for 10 days in bright light at $28^{\circ}-35^{\circ} \mathrm{C}$. Tube sealed March 28 . Front and back view. Photographed April 7, 1919.

retained a considerable number of actively transpiring leaves. One of the 14 plants bearing intumescences was specially interesting in that it bore an uninoculated and uninjured sideshoot arising from the main stem at the surface of the earth. This shoot, full of green leaves and transpiring freely, bore no intumescences whaterer at this time, whereas the green base of the main axis, killed to within 2 or 3 inches of the ground by the

on Fuller's scale, that is, excessive. Tissues full of starch and oxydizing enzymes.

$\times 5$. The acidity of normal potato juice is about +20 .

$B$. Same series as Fig. 403, but intumescences more widely ruptured and tip of the shoot asphyxiated. Photographed May 14, 1919。 $\times 5$. 

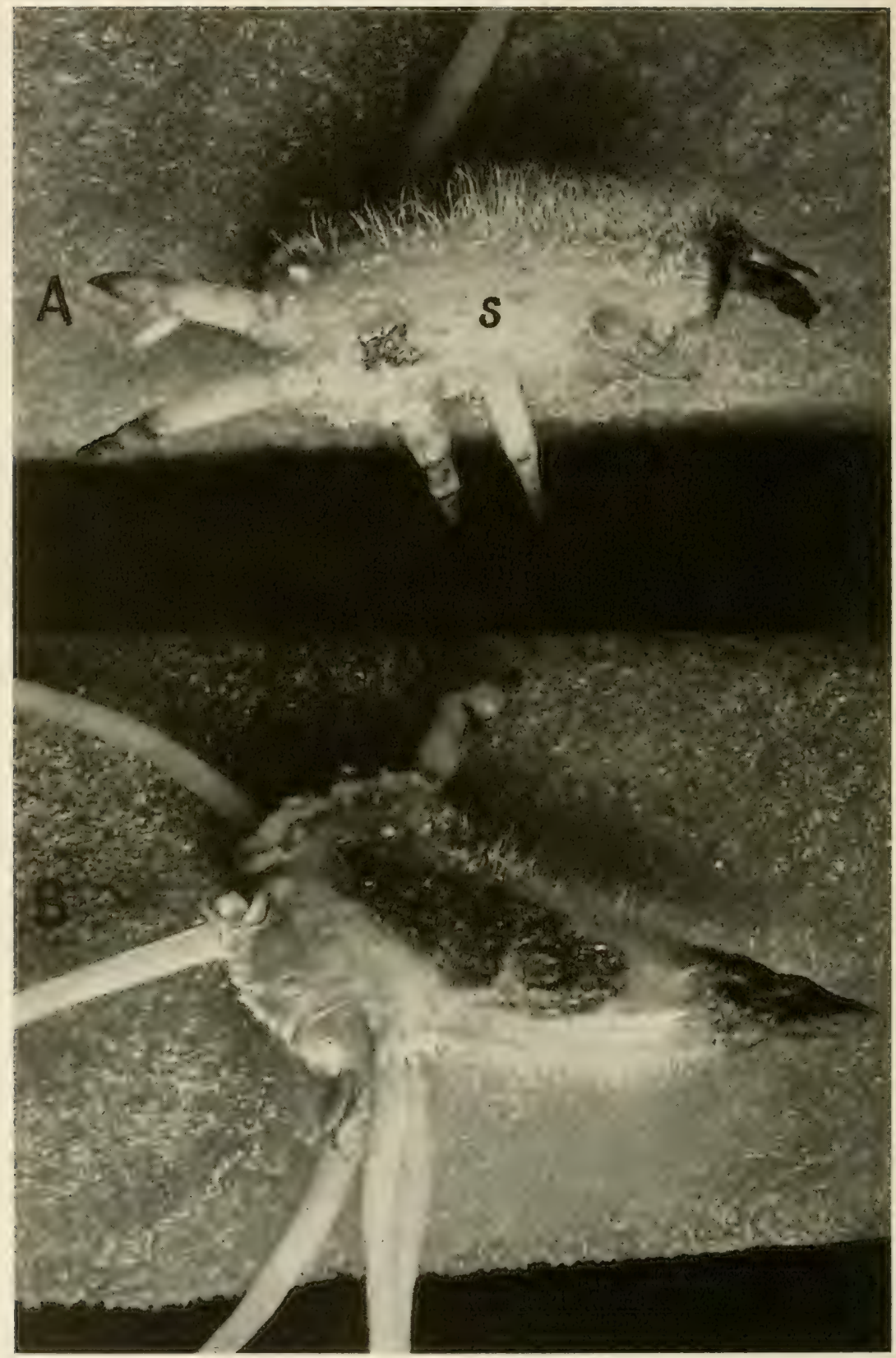

Fig. 406.--Pared sterile blocks of Early Ohio potato from sealed tubes of March 25, 1919. The swollen shoots are covered with hyperplasial intumescences 
inoculation and thus suddenly deprived of all its freely transpiring foliage, was covered with intumescences, even close to the base of the branch. Some days later the branch also developed intumescences especially on its base. All the intumescences on these plants were hyperplasias and they were in all stages of development, from those requiring a microscope for their detection to those well-rounded out and those cracked open. Also in all the cases which I examined the stomata over them were wide open as if in need of air or burdened with excess of water. These plants were in 8-inch pots and stood on a central bed in a large, well-ventilated hothouse cool enough to be suitable for cauliflowers and they did

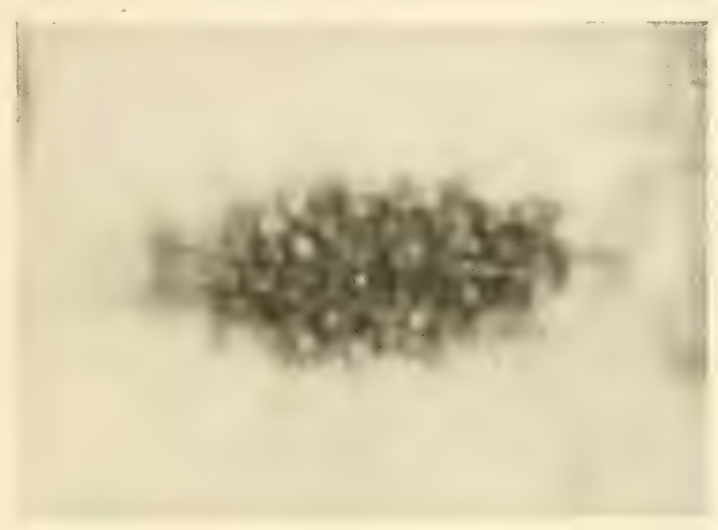

FIG. 407.-Hyperplasia under a stoma in the middle of a potato shoot. From $s$ of Fig. 406 not receive an excess of bright light because they were 15 feet from the glass roof and were shaded from the afternoon sun by a tall banana house. The possible effect of the bacillus, which is an acid producer, was tested by cutting off the top of a part of the 17 check shoots whereupon their stubs also developed intumescences but more slowly and much less conspicuously. In this instance, therefore, neither high temperature, nor bright light, nor feeble light, nor a saturated atmosphere had anything to do with the production

ruptured and unruptured, and each is beginning to die from asphyxiation, as are also the root-tips. Each block stood on wet cotton, and the tubes were kept in the dark at $23^{\circ}-25^{\circ} \mathrm{C}$. The parts of the shoots which did not show the hyperplasias to the naked eye, as at $s$, did so under the microscope and they were always under stomata (see Fig. 407). Photographed April 14, 1919. $\times 5$. 


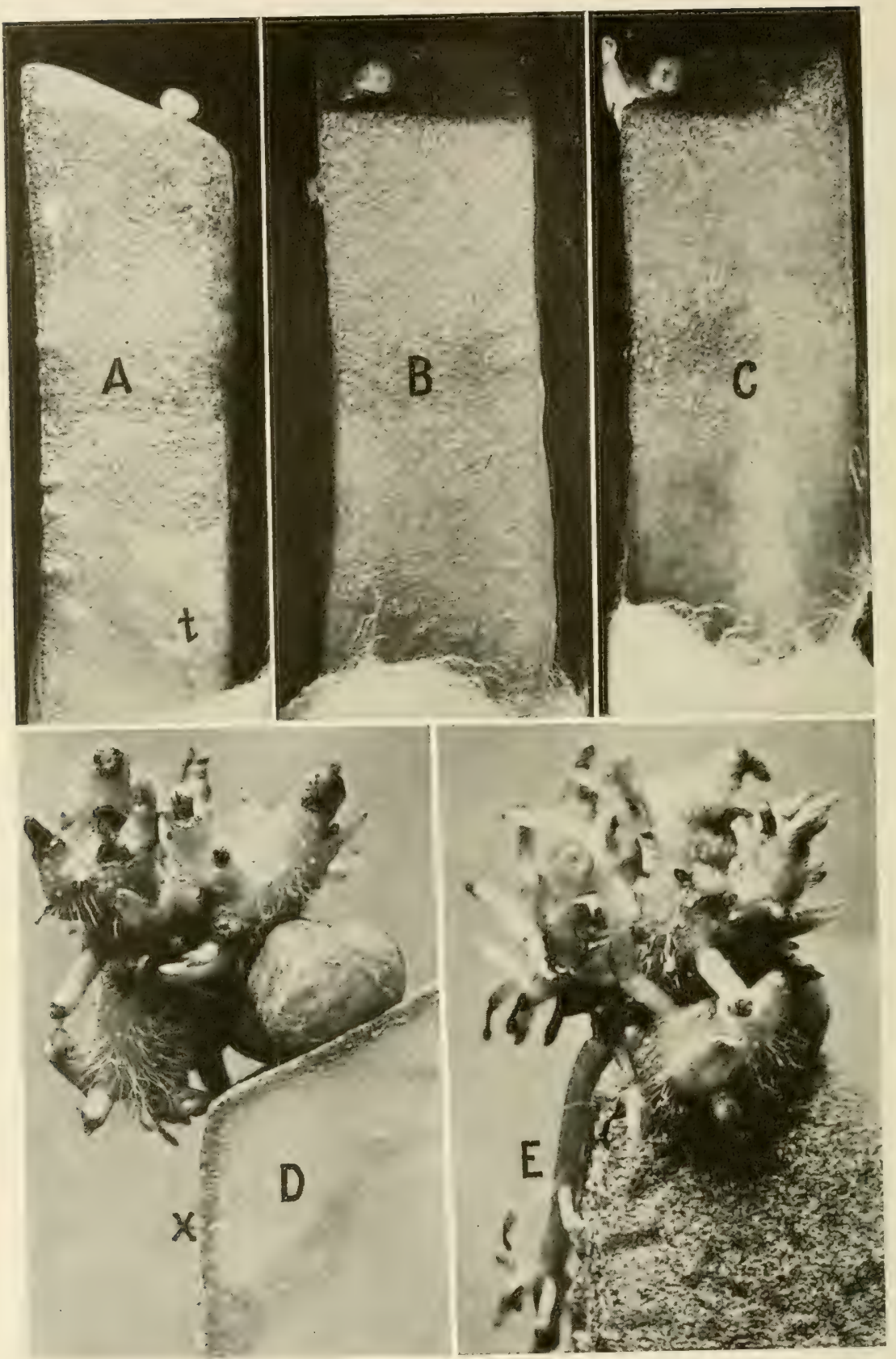

FrG 408-Tumor which developed on a pared sterile block of raw potato (Irish Cobbler) resting on wet cotton in a tube, sealed Feb. 13, 1919: 
of the intumescences, but only a diminished oxygen supply due to stasis of the water current and presumably an increased acidity of the tissues due to this fact, probably in part also to presence of acid by-products of the parasite; and this is illuminating as to the origin of other hyperplasias.

Finally, intumescences occurred freely under stomata on swollen stunted leaflesis shoots ( Fig. 411 ) developing in . I pril from dry potato tubers kept on my laboratory table at $25^{\circ} \mathrm{C}$, part in open deep glass jars exposed to a north light and the remainder. of another variety, enclosed in covered paper boxes. Here again, neither high temperature, nor bright light, nor feeble light, nor at saturated atmosphere, nor in this case exeessive water supply had anything to do with their production. In these shoots we know that there was a defective transpiration apparatus and we may assume that there was a sluggish, feebly aërated water-current, and consequently that there was more or less oxygen-hunger. These swollen shoots were rather hard and were gorged with starch (Fig. 412), showing that there was in them, as there is of ten in crown galls, a great excess of sugar beyond that needed for growth. This was also made evident by tests with Fehling's solution which showed reducing sugars to be scanty in the flesh of the mother tubers, but to be very abundant in the shoots

A. Pediceled, white-shining, smooth tumor covered by an epidermis. It arises from the cambium. Photo. March $22 . \times 2$, nearly. On May 2 there were also several small tumors at $t$.

$B$. The membrane has ruptured widely across the middle of the tumor from internal pressure and a tiny shoot has started from its base in the vicinity of the pedicel. Photo. March 31.

C. Further development of the shoot. The tip of the shoot is green, the roots are white and the remainder is pink. The tumor is yellowish white. The sealed tube has been, all of the time, in the dark at $23^{\circ}-25^{\circ} \mathrm{C}$. The beginnings of intumescences are visible on the pink and green parts of the shoot. Photo. April 9, 1919.

$D, E$. Front and back view of Fig. $C$, three weeks later. Asphyxiation has begun. The intumescences are now distinct. Under $D$ there is a freshly cut surface; at $X$, the newly formed cork-layer is visible. Photo. May $2,1919 . \quad \times 5$. The tissues were not tested for acidity, but the juice of similar intumescent shoots from other sealed tubes in this series was strongly acid ( +75 on Fuller's scale) and full of stareh. The normal acidity of potato tubers is \pm 20 . 


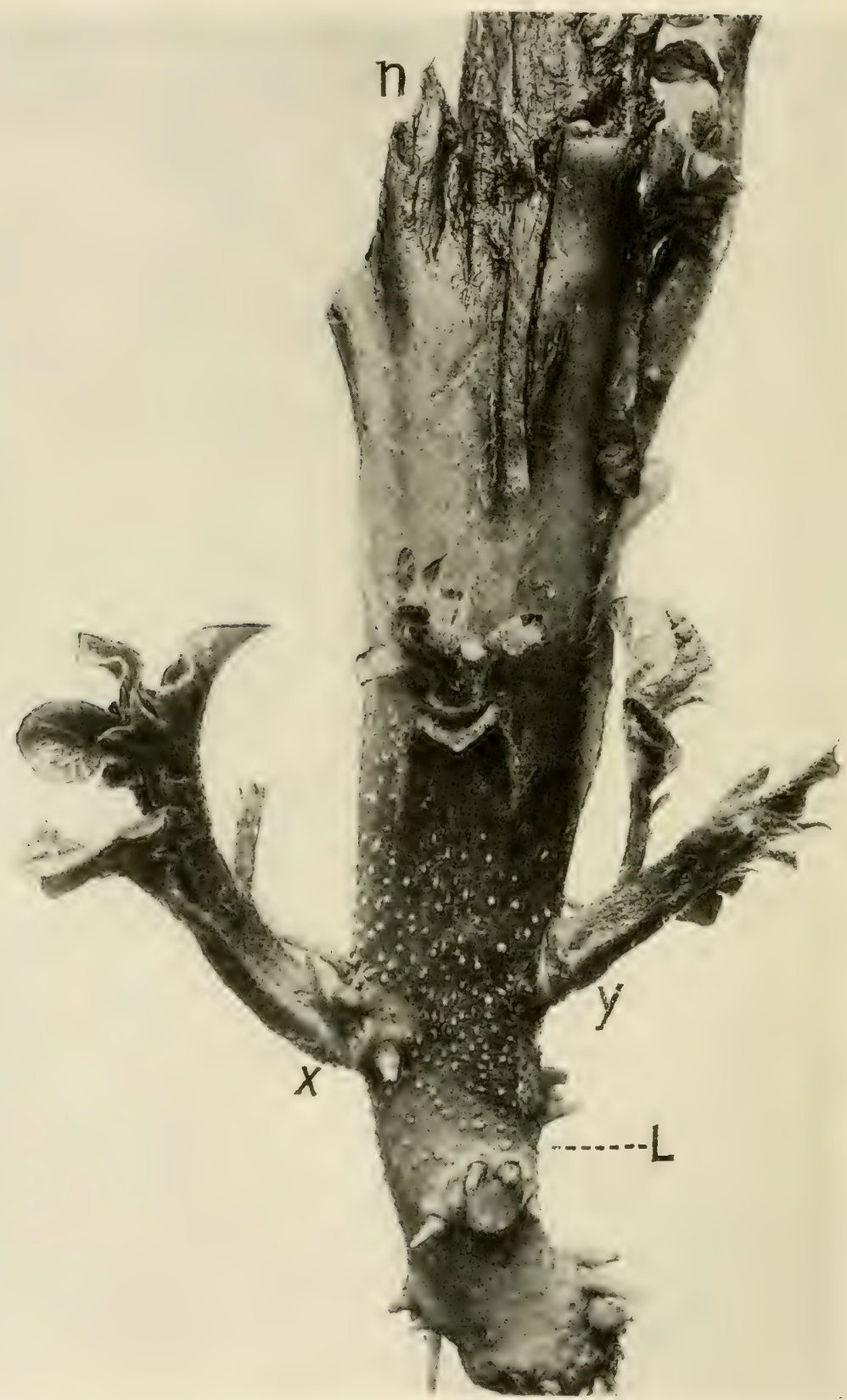

Fig. 409.-Intumescences (hyperplasias) on the base of a potato shoot full of water and in active growth, the whole top of which was suddenly killed by 
(ten times as plentiful as in the tubers). The shoots also contained an excess of oxidizing enzymes and a great excess of organic acids -2 to 3 times as much acid as the flesh of the mother tubers. ${ }^{1}$ The shoots had, therefore, every requisite for normal growth except a sufficient water-supply. This lack of water prevented elongation and the development of the respiring and transpiring organs, and the hyperplasias were brought on as the result of the increasing acidity and oxygenhunger of the tissues. The stomata over these hyperplasias were always wide open (Fig. 413), and here this condition could not have been due to excessive water-supply, but must have been due rather to oxygen-hunger or to purely physical tensions.

We may now consider another and quite different type of overgrowth, viz., that found on the roots of a great variety of plants. I refer to the tumor due to Heterodera radicicola (the common gall-producing eel-worm), which tumor is a destructive disease on many cultivated plants. Here the larval forms of the parasite live, from the beginning, wholly buried in the roottissues. Is soon as the worm is hatched it begins to feed on the surrounding cells, and immediately there is a tumor response on the part of the infested plant. This response, however, is quite unlike that under the obturated lenticels. The tumors are irregular, soft and large, and composed chiefly of a few cells enormously hypertrophied, each cell containing from a halfdozen to twenty or more nuclei (sometimes several hundred), which either have divided amitotically or have not pushed ordinary nuclear division as far as to the formation of cell-walls. These giant-cells appear in the earliest stages of the tumor, soon after the eel-worms have hatched; and always, in thin sections of the very young tumors, one may find the young worms sur-

'The tests were made as follows: weighed quantities (35 grams) of (1) the mixed shoots and of (2) the mixed flesh of the tubers were wrapped in surgeon's gauze and crushed in the same manner in a mortar, extracted 10 minutes in 100 ce. of distilled water at $80^{\circ} \mathrm{C}$., filtered, and immediately titrated.

Bacillus phytophthorus, down to $N$. Intumescences also at $X$ and $Y$ on the young side shoots. Level of soil-surface at $L$. White McCormick potato inoculated in the top of the shoot April 10 and foliage destroyed as early as April 13 or 14 (see $X$, Fig. 211). Photographed April 18. $\times 2$. 


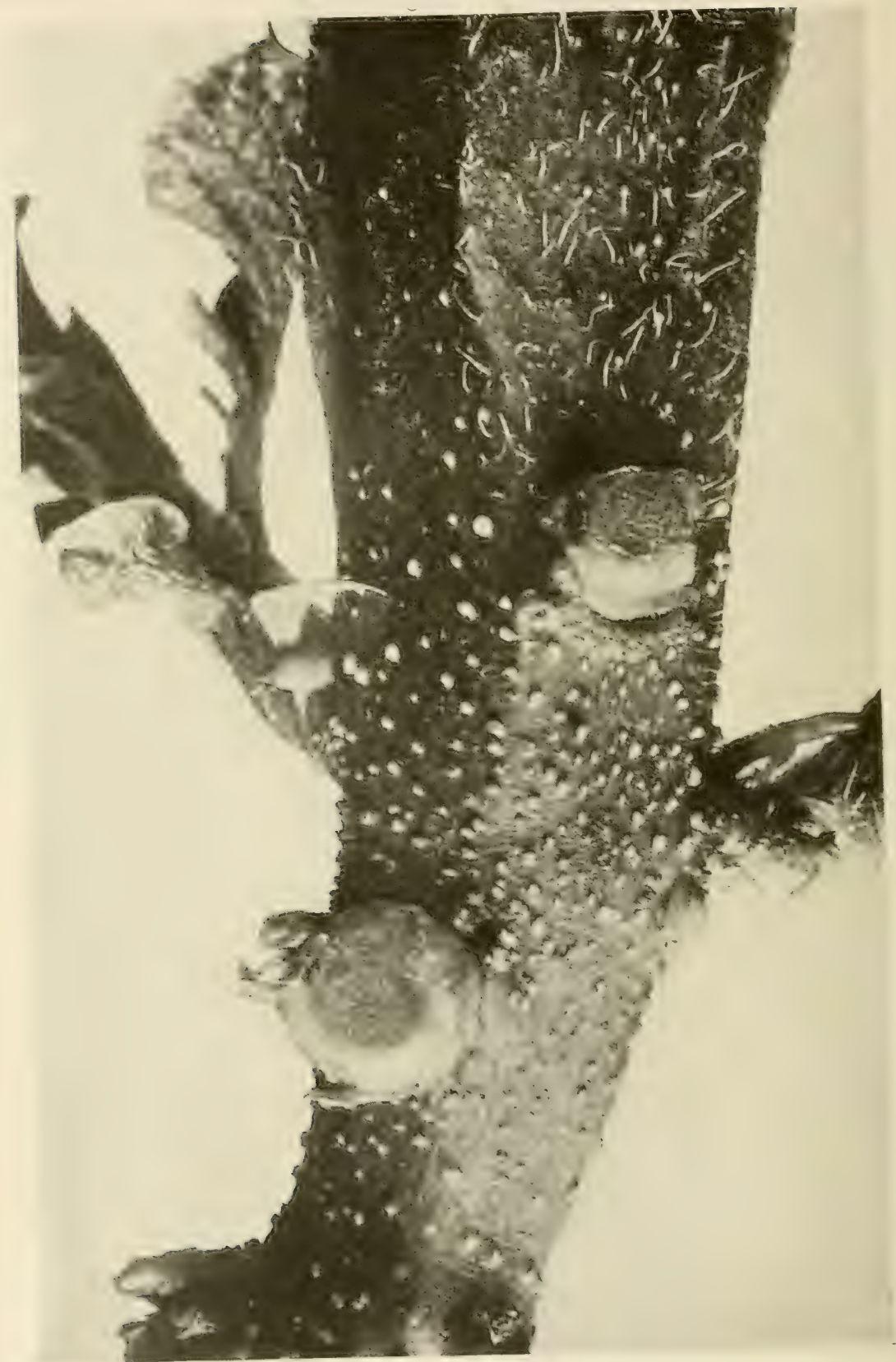

F1G. 410.-Other side of the stem shown in Fig. 409 showing ruptured and nuruptured intumescences (hyperpiasias? following destruction of the top hy Bacillus phytophthorus. Photographed April 1s. $\times 5$. This is an exaggeration of a common phenomenon. 
rounded by and closely appressed to the big cells (Fig. 414) but I have not actually seen their sucking organ inserted into them. I have seen these large multinucleate cells in very carly stages of gall-development where the worms had been present only a few days, but always already the head of the young worm is in close contact with the cell-membrane where by means of its mouth-parts it is able to feed. From this it might be thought that the stimulus to growth must reside exclusively in the saliva or other excretion from the mouth-parts of the feeding worm, and so long as we had no counter observations this explanation, which is not yet altogether excluded, appeared to be reasonable and sufficient. But there is in Florida on orange-roots, as Cobb has shown, a free-living parasitic nematode, closely related to Heterodera radicicola, which also sends its mouth-parts into many root-cells, but no tumors result, and the explanation I have to offer for this marked difference in response is not that the orange cannot respond by overgrowths like other plants, since it generally responds quickly to crown-gall inoculations but that, the greater part of the bodr of the orange-root nematode being outside of the plant, the anal excretions are voided into the earth and do not reach the tissues, whereas in the Heterodera radicicola the anal excretions are voided into the tumor and are, I believe, the chief cause of its development. The cells nearest to the worm receive the greatest volume of stimulus and in these cells not only is the protoplasmic membrane paralyzed so that it allows a great influx of water and foodstuffs into the cell, but the karyokinetic mechanism of the nucleus is also partially paralyzed so that the cell cannot divide and the result is not only a repeated mitotic division of the nucleus within the cell (I have seen 30 nuclei in a cell and Nĕmec has seen more than 500 in cells of Titis gongylodes) but also at times amitotic division with an enormous growth and stretching of the cell-wall until the soll often becomes several hundred times its normal size, gorged with water and foodstuffs which serve the worms for nutriment. Later there may be nuclear fusions, all the nuclei merging into one or several mulberry-like conglomerate masses (Nĕmec). These cells are totally unlike any normal cells of the plant and so large that, in thin slices of the gall examined superficially, it. 


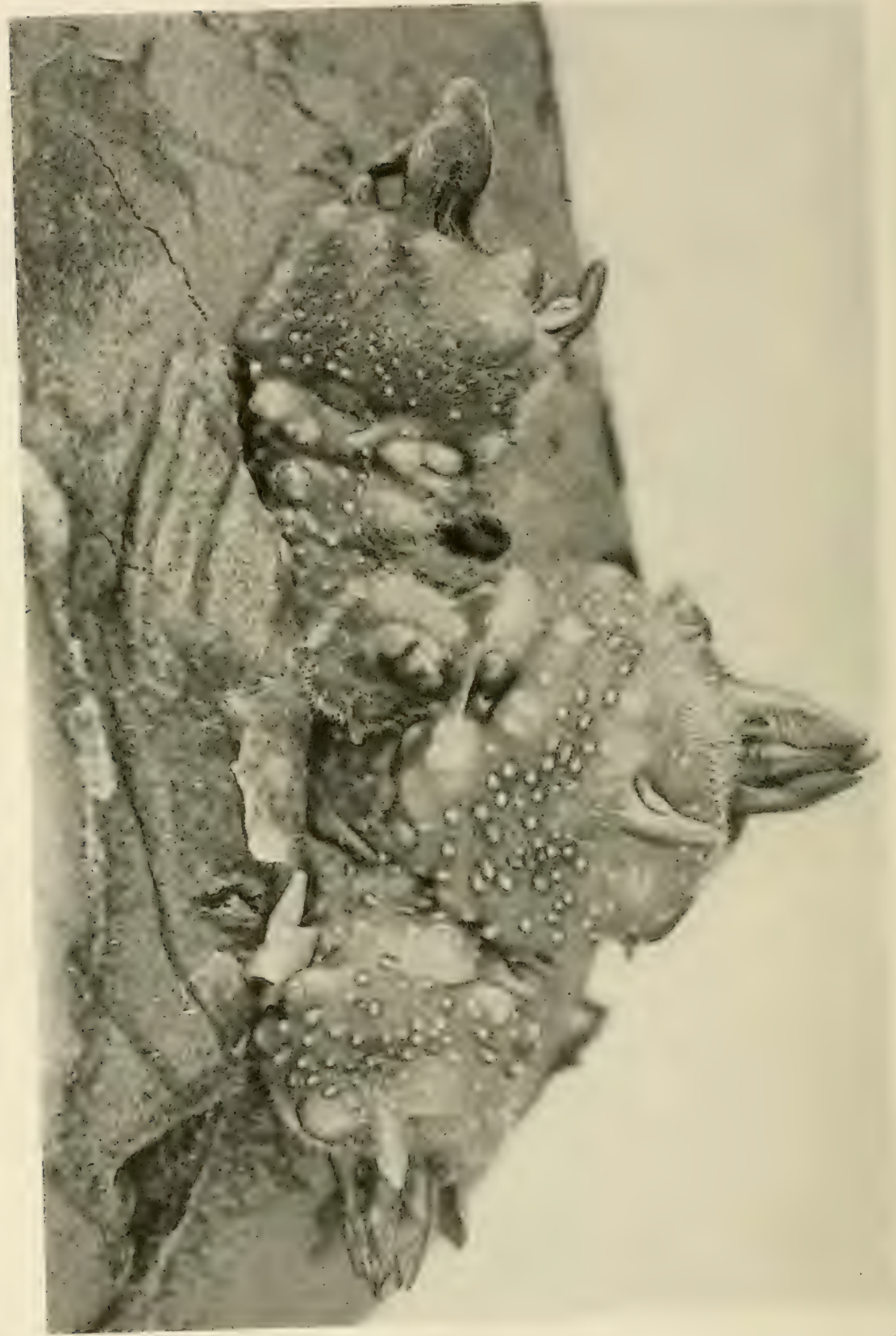

FiG. 411.- Hyperplasias on tumefied potato shoots germinating on a table without soil or water. Diffused north light, temperature $25^{\circ} \mathrm{C}$. Shoots full fo starch, sugar, acids and oxydizing enzymes. The intumescences were under wide open stomata (See Fig. 413.) 


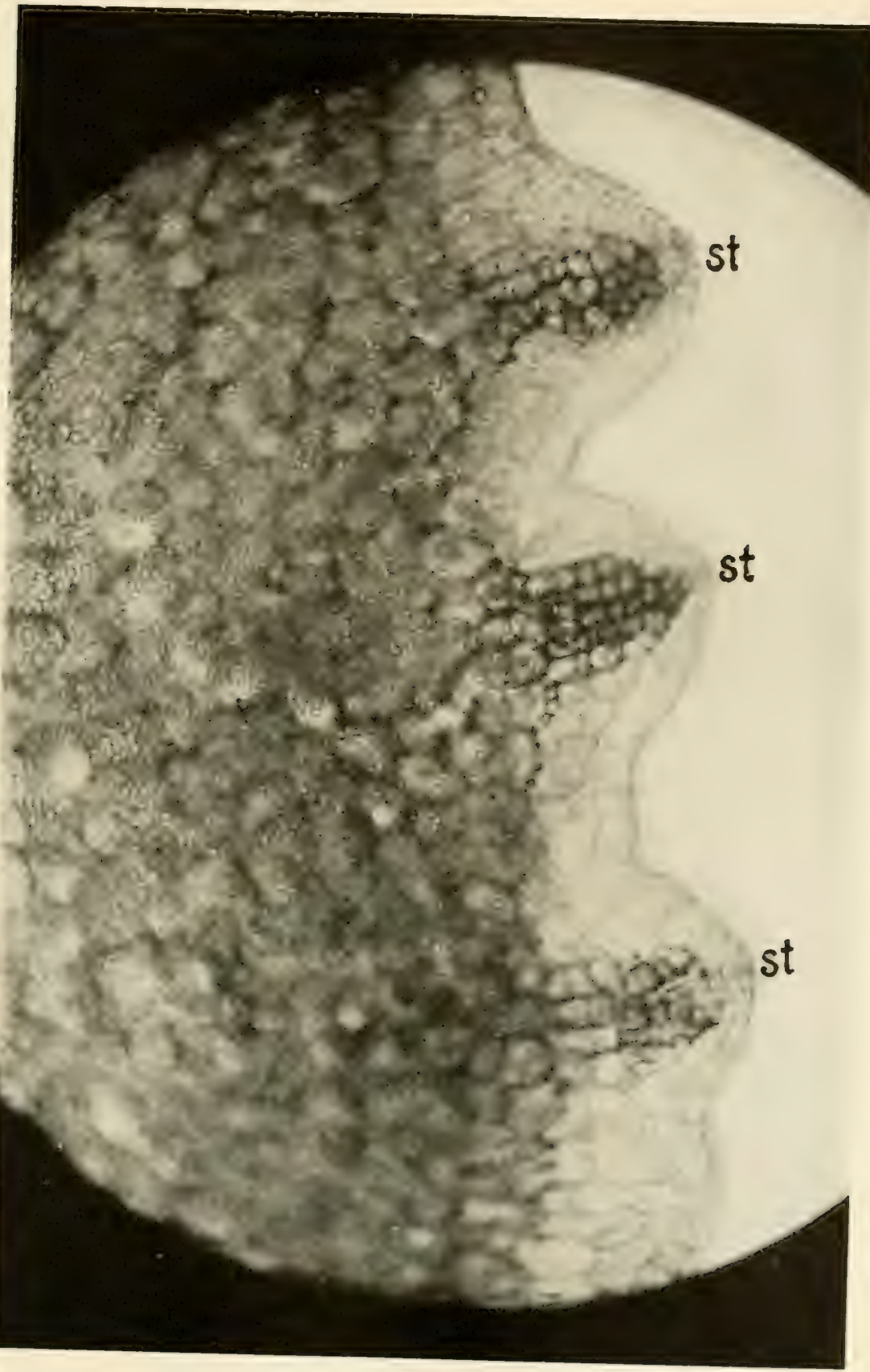

Fig. 412.-Vertical section through the hyperplasial region shown on Fig. 111. St, stomata. Cortex full of starch grains. The pith was also full. Photomicrograph by the writer from a free-hand section mounted in water. $16 \mathrm{~mm}$. obj., 4 oc., bellows at 35 . 

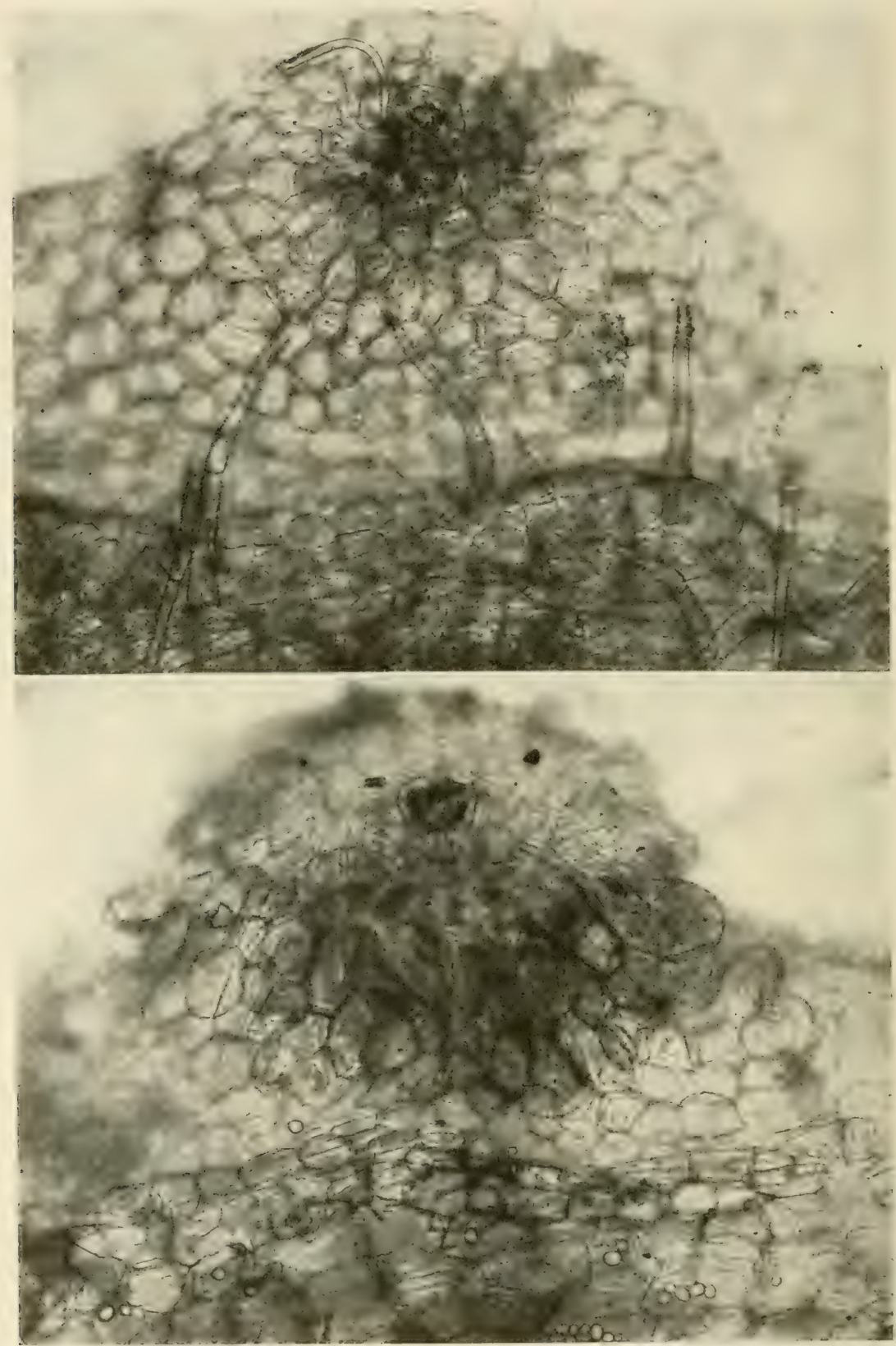

FIG. 413.- Surface view of two intumescences on a potato shoot (Fig. 411) showing over each a central wide open stoma. Photomicrographed by the writer at 5:00 P.M. from unstained water mounts. 
seems as if they must be cross-sections of the worm rather than of the host-plant. They have, however, been studied critically by Nĕmec and I have been able to confirm many of his findings. What the worms excrete into the tissues we do not know, but undoubtedly, judging from the excretions of higher animals, their waste products must include both acids and alkalies. Possibly the giant-cells are due solely to acid mouth secretions. There is no reason why the different parts of the tumor might not be due to different secretions, e.g., the general hyperplasia to the anal excretions and the very peculiar giant-cells to the mouth excretions. We shall come again. to this subject of acids and alkalies in connection with overgrowths, when we discuss ammonia tumors, acetic acid tumors, crown galls, etc.

If my hypothesis is correct, farther away from the feeding eel-worm larvæ the excreted poisons should be more dilute and less active, and as the karyokinetic mechanism of the nucleus appears to be more resistant to paralysis than the protoplasmic membrane of the cell, since in many tumors of plants and animals it is not at all interfered with, and by this I mean that in many tumors there are no giant-cells, we should expect to find hyperplasia also in remoter parts of the nematode gall and also in its earliest stages, and this is just what we do fird (Fig. 414). Also in club-root, due to Plasmodiophora brassicae, as may be seen from Kunkel's photomicrographs, we find similar phenomena. Moreover, in a variety of other galls, such as those due to various gall flies (Figs. 415 to 424 ) there is a curious likeness to what occurs in the nematode galls, that is, close to the feeding organism where the excreted, poisons are most concentrated, there is a stretching of the cells to form the so-called "nutritive layer," which layer is rich in sugar, starch, oil and albumen, while farther away from the larval chamber, where the diffusing excretions would be weaker, there is always a fine-celled overgrowth, also stuffed with foods-starch, sugar, etc., arranged in such a manner as to be clearly related to the stationary larval carity or cavities, a hyperplasia not developing irregularly, as in tumors due to eel-worms, fungi or bacteria, organisms able to move about and thus to change the direction and movement of the stimulus, but always quite regular in its 


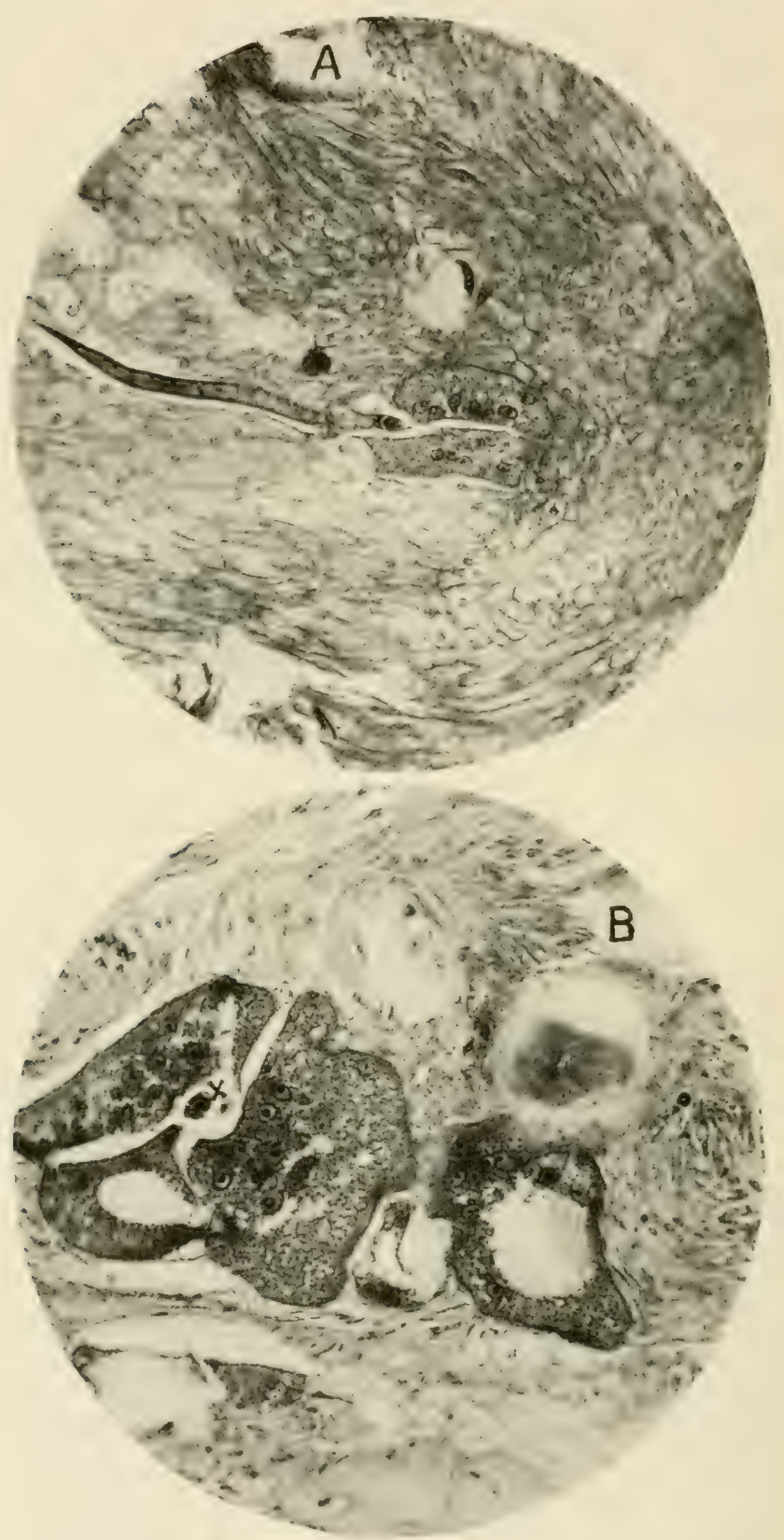

FIG. 414.-A. Early stage of a nematode gall on a sugar beet root. In the center the young worm is in place and near its head are two giant cells. Farther away is the ordinary hyperplasial tissue of the gall. $B$. Same as $A$ but from 
development and relation to the larval cavity, so much so as to have caused great wonder among cecidologists. In these galls. the enlarged cells of the inner laver ( Fig. $419 \mathrm{Hy}$ ) often contain more than one nucleus (Fig. 424), i.e., the mechanism of celldivision is more or less upset.

It is worth while here to mention another type of plant tumor in which cell-hypertrophy is a marked characteristic but in which the nucleus takes even less part than in the preceding. I refer to the root-nodules of legumes and, for the sake of a second example, again to the club-root of cruciferous plants, the one due to a bacterium, the other to a myxomycete. Here the parasite is wholly inside the cells, not outside sending into it feeding organs, as in case of the eel-worm. In both instances the parasitized cells become enormously distended and filled with the bodie: of the parasite, the dividing cells being the remoter, non-parasitized cells. The nucleus is killed early in the invasion and all the protoplasm of the cell is finally consumed and hence it would seem as if the final enlargement of the parasitized cells must be due to growth of the cell-wall uneontrolled by the protoplasm or to nechanical stretching, and this seems to be confirmed by the fact that remote from these large parasitized cells there is little evidence of hyperplasia, such as we might expect if soluble cell-stimulating poisons were excreted. There is more or less cell-multiplication in each of these tumors, often considerable. but in their end terms, at least, these two types of overgrowth are as far removed as possible from active hyperplasias, and need not long detain us, although at one time much study was put upon the club-root of turnips and cabbages (due to Plasmodiophora brassicae) by various persons who thought they saw in it certain resemblances to animal cancer.

More interesting in every way are hyperplasias produced by purely chemical means, such as I have illustrated in Figs. 364 to 377. We may take for discussion two examples, the acetic acid tumors and the ammonia tumors.

When cauliflower plants are exposed for a short time to vapor

another part of the gall. Cross-section of the young worm at $X$ ) surrounded by multinucleate hy pertrophied cells. Farther away is hyperplasial tissue. Medium magnification. 


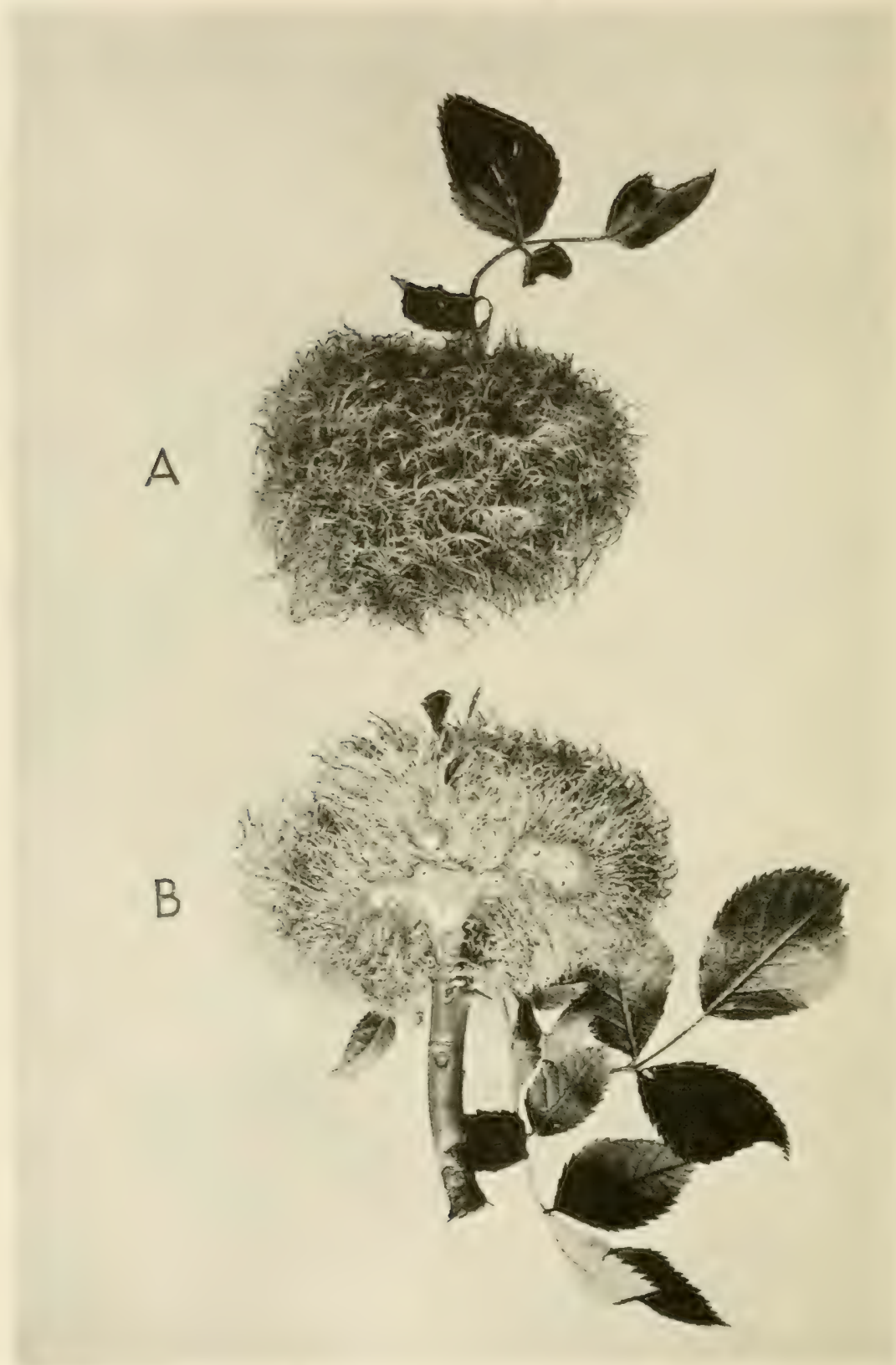

IFG. 415.-A. Polythalamous very leafy gall on sweetbriar (Rosa rubiginosa) due to Rhodites rosae L. B. Vertical section passing through some of the larval chambers. The felted mass consists of finely dissected green leaves of a type totally unlike the normal leaves of the plant. 
of ammonia liberated in small quantity in a closed space, the protoplasmic membranes of many cells of the leaf are paralyzed and water escapes into the intercellular spaces, the evidence of this being a fugitive mottling of the leaf, due to the substitution of water for air in certain of the intercellular spaces. This mottling due to escape of water into the spaces between the cells can be produced in various other ways, e.g., by sulphur dioxid, as O'Gara has shown, by chloroform, or simply by a minimum freezing, as Harvey has shown. Usually within a half hour the mottling of the cauliflower leaves due to slight exposure to vapor of ammonia (Fig. 381), disappears and the plant again appears to be normal, but it is not, since tumors immediately begin to develop in the least mottled areas and within a few days are plainly visible on the surface of the leaf (Fig. 365). Depending apparently on the amount of the stimulus, or cell-paralysis, these tumors are either hypertrophies or hyperplasias, just as they are in frozen spots on the same plant and in the insect, nematode, and myxomycete galls already referred to. This, at least, is the way I would interpret it. If the karyokinetic mechanism of the cell is paralyzed the hyaloplasm is certain to be more so and in the end there will be an inflow of water with stretching of the cell (hypertrophy); if on the contrary, only the protoplasmic membrane is disturbed, with the returning influx of water and foods the cell will divide repeatedly and a hyperplasia will result. The irregular spotting of the leares and correspondingly irregular development of tumors depends clearly on the varying degree to which stomata are open at the time of the exposure, since the alkalin vapor enters the leaf through these minute openings. In leaves with the stomata wide open there is always a considerable killing effect, similar to that shown in Fig. 374, whereas in young leaves with the stomata closed or nearly closed only a stimulating minimum of the poison enters and tumors result. ${ }^{1}$

${ }_{1}^{1}$ To determine quickly the extent to which stomata are open in various areas on the upper and under surface of young and old leaves at different times of day, the surface may be painted with petrolatum, the irregular penetration of which corresponds exactly to the irregular killing effects of excess of ammonia and of acids. The writer stumbled on this method indepondently but apparently it was first used by Emmy Stein (Ber. d.d. bot. Ges., 30 Bd. 1912, p. 66). 


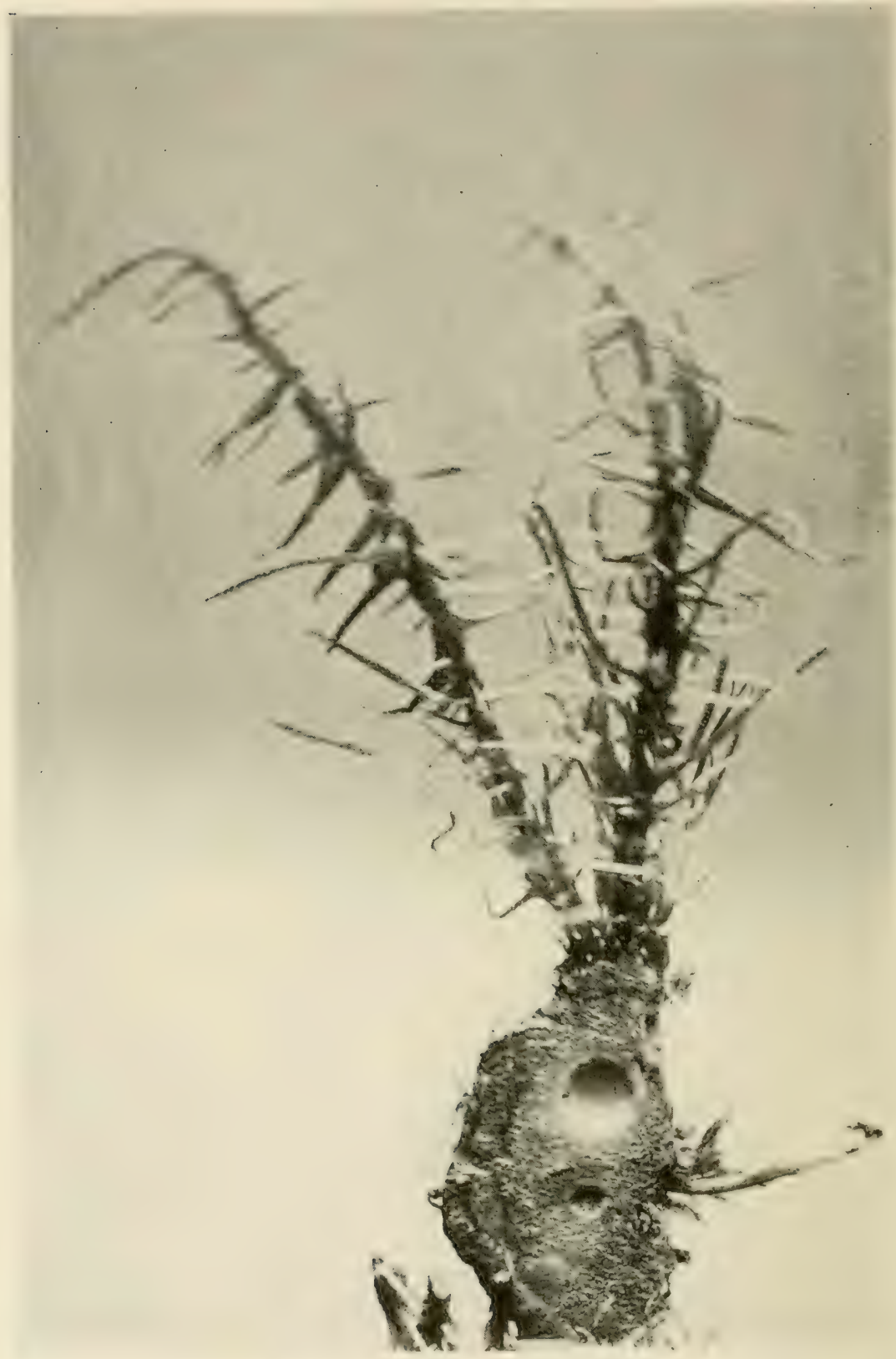

Fig. 416.-Enlarged view of some of the gall chambers of Fig. $415 B$ together with a few of the abnormal leaves. The nearest approach I have seen to such leaves is on the calyx but the dissected calyx-leaves are very glandular while these are not. Possibly there are leaves of this sort on the seedling or on the ancestors of this rose. 
The further discussion of the cell response may be left until we have considered other cases.

If cauliflower plants are exposed to vapor of alcohol carrying acetic acid, or are sprayed lightly with acetic acid water (1 part of acid to 100 or more parts of water) tumors begin to form at once in many parts of the leaf, if it is not too old. Here again the entrance of the stimulating substance is through the stomata and as a result we may assume, for the present at least, that always there is a temporary partial paralysis of the protoplasmic membrane, that there is initial loss of water, that cell-acidity is increased, that the mechanism of respiration and transpiration is disturbed, that consequently, cell-division is forced, with consumption of sugars, amino acids and proteids, and that subsequently there is a compensatory movement of water and food-stuffs into the area from surrounding tissues, the result being the rapid development of a hyperplasia. This, however, grows only for a week or two, just as in case of the ammonia tumors, because there has been no repetition of the initial small stimulus such as is continually taking place in crown gall and in other tumors due to parasites. If it were possible to repeat the stimulus at frequent intervals, undoubtedly large tumors would result.

Although I have studied sections of a good many acetic acid tumors I have not seen any evidence of hypertrophy except in the earliest stages in cells nearest to the stoma and likely to have received the greatest volume of the acid. Always the remoter growth is a hyperplasia, as in the examples shown (Figs. 368 to 372 ). I have followed the sections in series, from the level of the leaf surface down to the bottom of tumors, and immediately under them in the depths of the leaf, without finding any evidence of killed cells in the deeper parts, but always, it seems to me, there is at least some slight evidence of injury at the surface of the tumor in its middle part close under the epidermis (Fig. 378). The initial growth of the tumor is not from the epidermis itself but from cells immediately below it. Tumors are more apt to begin in the lower parts of the leaf than in the upper parts, possibly because the stomata on the lower surface are more apt to be open and are also more 


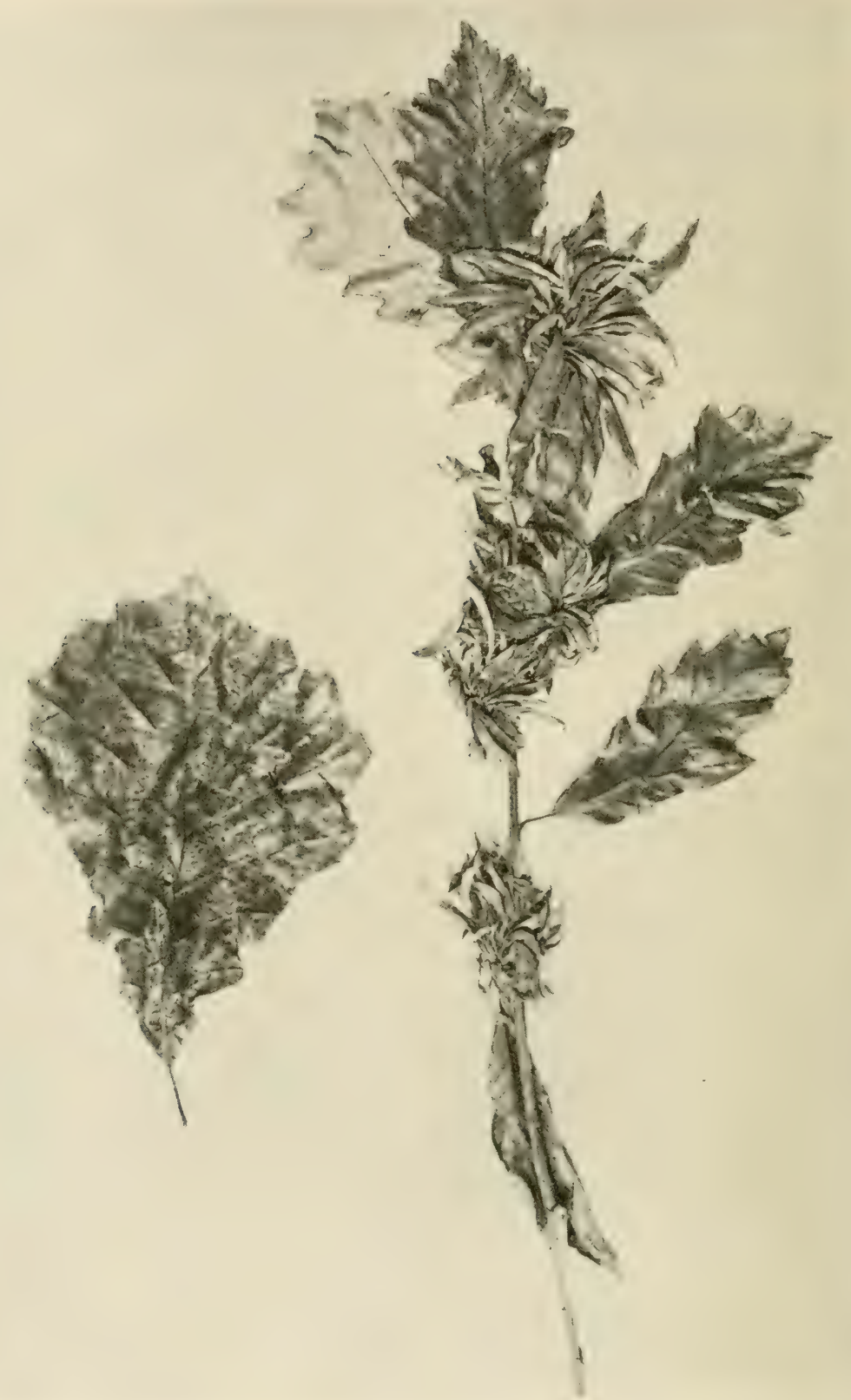

FIG. 417.-Monothalamous galls due (?) to Andricus topiarius Ashmead, on a Washington, D. C., oak, said to be Quereus prinus, showing tufts of linear leaves resembling the leaves of the willow oak $(Q$. phellos). Probably what is known in the older literature as Cynips frondosa. These tufts grow from the tissue immediately below the gall. 

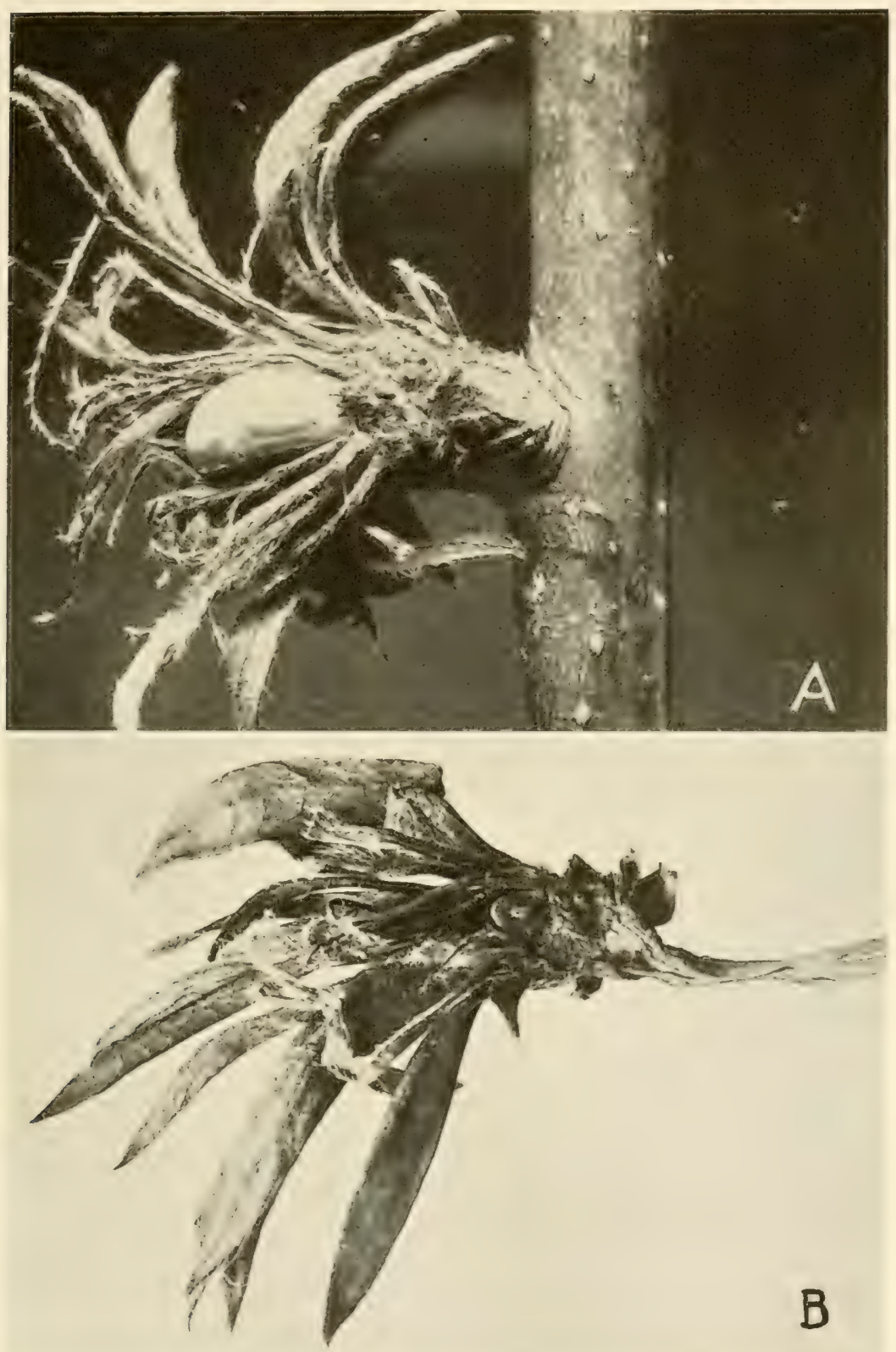

FIG. 418. - A. Like Fig. 417 but with many of the linear leaves removed so as to show the smooth white gall which seems to occupy the place of a bud. $B$. Vertical section of a similar gall showing a single larva in place. Planar enlargements. 
numerous. Sometimes after a few days the whole thickness of the leaf is involved, at other times the tumor is confined chiefly or exclusively to the loose mesophyll, the palisade tissue remaining normal or nearly normal. Always there is a striking contrast between the surrounding normal, spongy, chlorophyllbearing mesophyll tissue, in which the intercellular spaces occupy roughly about one-third to one-fourth of the whole leaf-space, and the tumor, in which the cells are free from chloroplasts and very compactly arranged, much as in embryonic tissues. Rudimentary vascular bundles are developed in these tumors but their development does not proceed very far because after about two weeks the tumors begin to lose water rapidly and shrivel.

Acetic acid, formic acid, ammonia and aldehyd are all capable of causing tumor development and are the substances I have experimented with most because these are said to be products of the crown-gall organism and are probably common products of a variety of tumor-producing parasites, and for this reason are much more interesting than non-vegetable and nonanimal products, like copper sulphate, mercuric chlorid, etc., with many of which small overgrowths may be produced, probably in the same way, that is by partial paralysis of the hyaloplasm and nucleus of the cell, leading to loss of water, concentration of cell-sap, increased acidity, oxygen-hunger, nuclear division and return movement of water and food-stuffs, the stimulation resulting in a hyperplasia or a hypertrophy according to the extent of the paralysis of the protoplasm.

Let us now turn to higher types of tumors, those which are complex in structure and have a self-centered growth. In crown gall, as in olive tubercle and sugar-beet tubercle, large overgrowths are produced by the bacteria. It will be sufficient here to consider the first named tumor, since it is more highly developed and more like animal cancer than either of the others.

What then is the intimate nature of the shock leading to tumor formation in crown gall, or in other words, what is its secondary etiology? It is, I believe, first of all, following growth of the bacteria and the extrusion of their by-products into the tissues, an increased acidity in the parasitized cells and prob- 


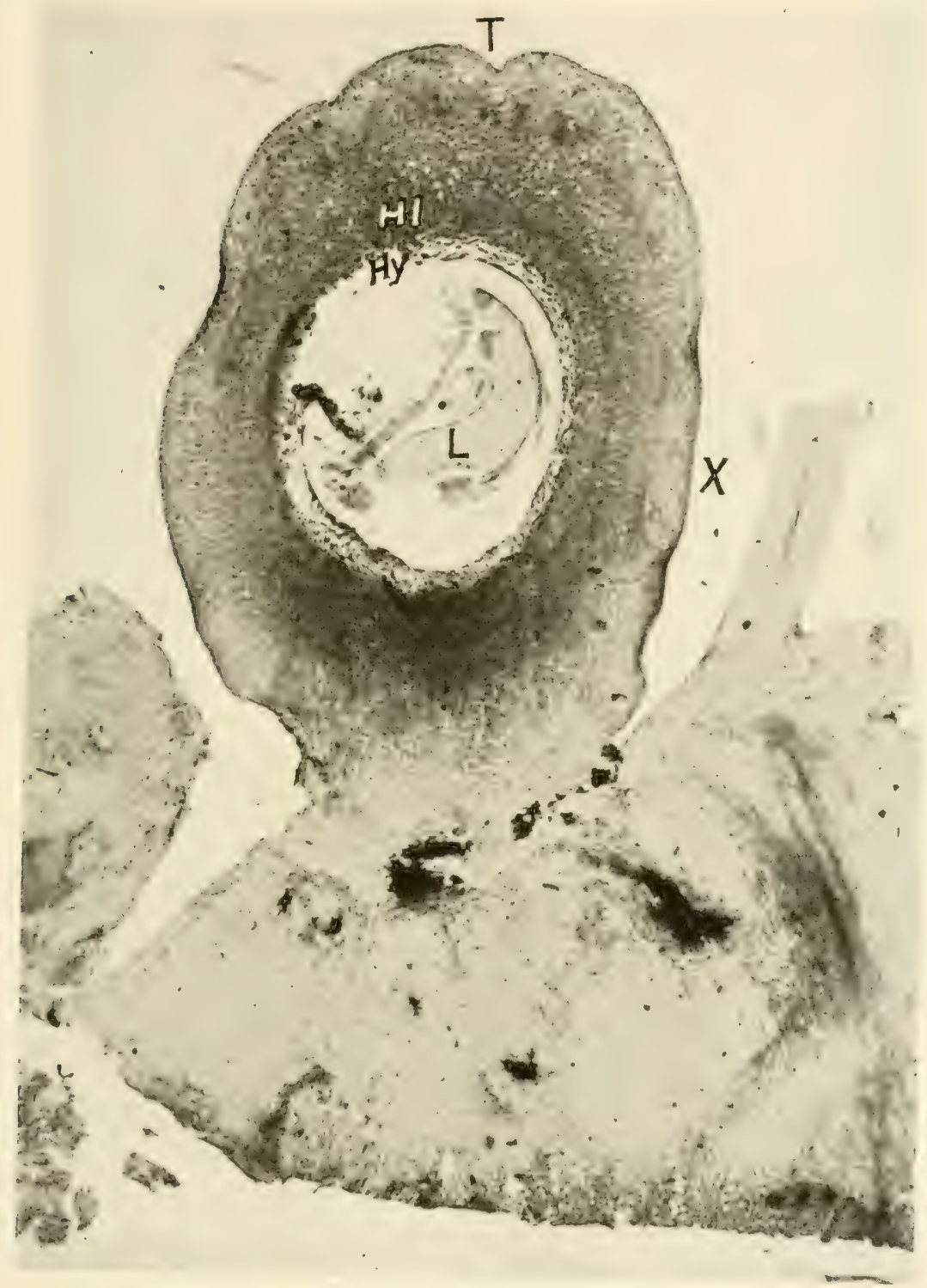

FIg. 419.-Vertical section through an oak gall like the ones shown in Fig. 418, together with tissue under it: $L$, larva. Hy, hypertrophied layer; $\mathrm{Hl}$, hyperplasial iayer. Planar enlargement. $\times 25$. 


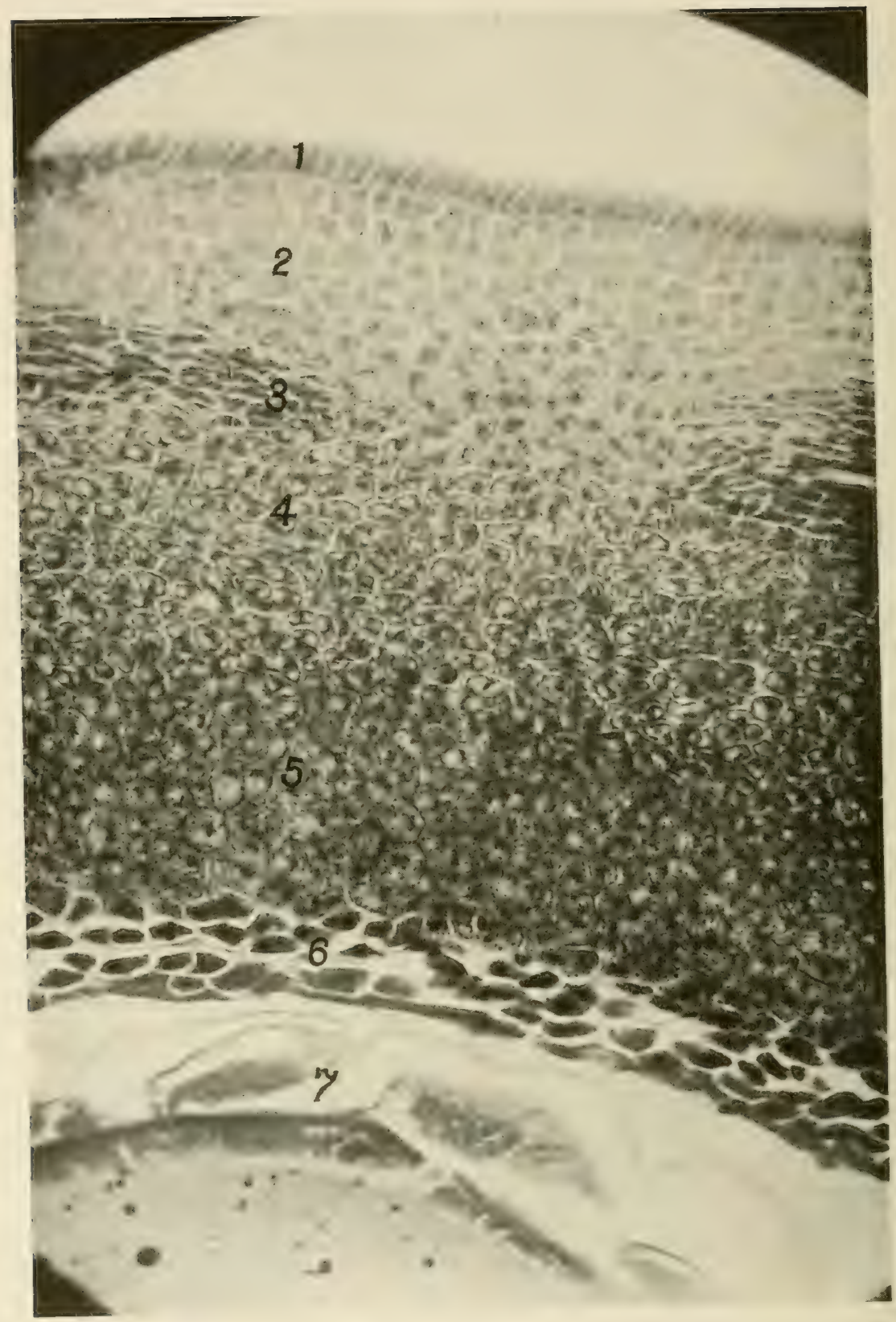

FIG. 420.-Section of Fig. 419 at $X$, further enlarged: (1) epidermis; (2) subepidermal tissue not much stimulated; (3) vascular tissue; (4) hyperplasial tissue coarser than 5; (5) hyperplasial tissue full of starch, sugar, etc.; (6) the 
ably also in some of their neighbors, or, to express it in another way, it is the liberation of an excess of hydrogen-ions in such cells. This leads to a whole train of phenomena whereby a

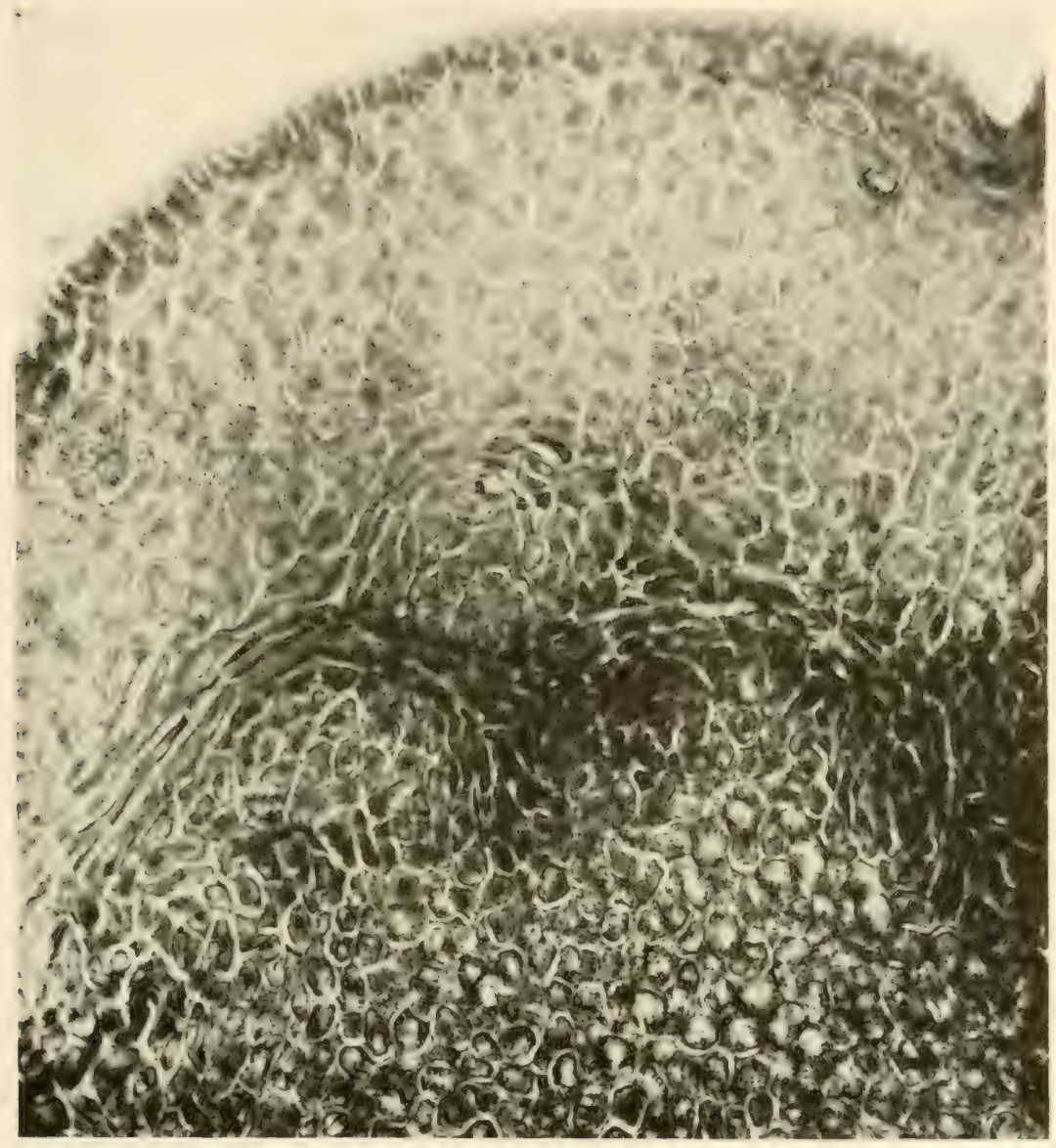

FIG. 421.- Section of outer one-half of Fig. 419 at $T$. Vascular tissue in center. Outer portion of the stimulated (hyperplasial) layer at bottom. This also contains starch but not as much as the inner portion.

normal cell (young enough to respond) becomes a tumor-cell, and is consequently more or less emancipated from physiological hypertrophied layer directly in contact with the feeding insect; (7) section of the larva. Section cut and stained by Lucia McCulloch. Photomicrograph by the writer. Medium magnification, $8 \mathrm{~mm}$. apochr. obj., 4 oc., bellows at $401 / 2$. 'The inner layers have taken most of the acid fuchsin stain. 


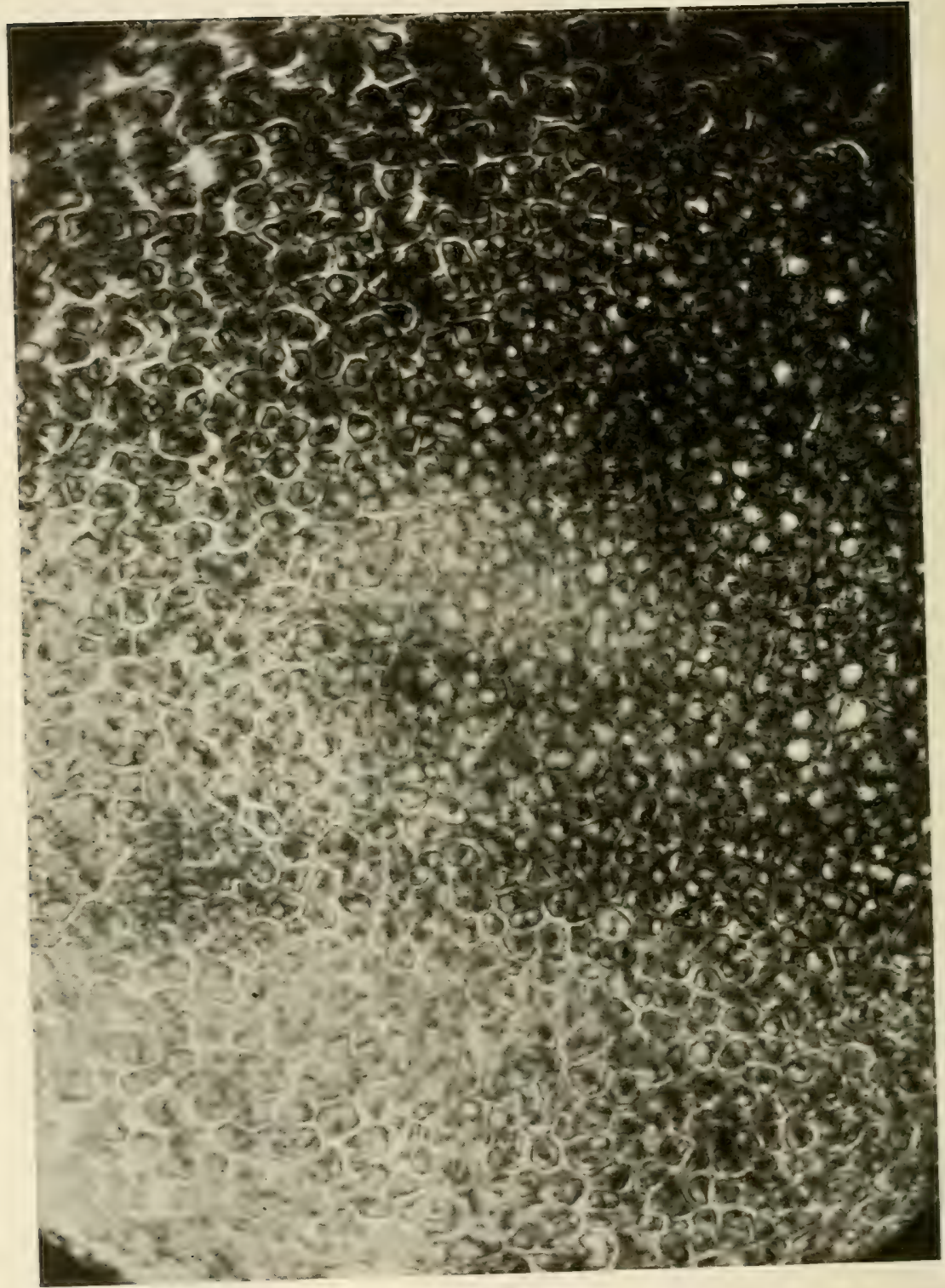

a. The antral portion of the figure passes through the inner part of the hyperplasial i:1 1 r. the top and bottom through its larger-celled outer part. 
control. Later the tumor as a whole might show increased alkalinity, since the organism eausing it also produces ammonia, and changes in the tumor tending toward decay are always on the increase. Some of the steps in this process remain to be worked out experimentally but we may suppose that they exist and occur in about the following order: (1) increased acidity ( $\mathrm{H}$-ionization) due to bacterial excretions; (2) paralysis of the protoplasmic membrane leading to increased cell permeability; (3) lows of water from the parasitized cells; (4) concentration of cell sap ; (5) formation of cell precipitates; (6) disturbance of transpiration; (7) disturbance of respiration; (8) increase of peroxidases and increase of respiration due to (9) repeated karyokinetic celldivision during which food-stuffs are consumed; (10) compensatory return flow of water and food-stuffs into the tumor faroring continued rapid growth, which is also favored in later stages by continued superficial loss of water.

A number of more or less well established facts, some of which I have already mentioned, point to these conclusions. For instance, we know that in flasks of tap-water containing peptone and grape sugar the crown-gall organism produces ammonia, aldehyd, acetic acid, and formic acid, and there is every reason to suppose that if it can produce these substances in a flask it can do so in the plant, and that these are the substances which cause the development of the hyperplasia, since I have shown that each one of these substances is capable of producing small hyperplasias when raporized or sprayed upon susceptible plants. Sugar is abundant in crown galls, often so abundant that it cannot all be used in growth and consequently a portion of it is re-converted into starch and deposited in the tissues, much as glycogen for the same reason, is stored in animal cancers. Sugar is very abundant in acid potato shoots giving rise to intumescences (p. 541). It is also abundant in the frost tumors (Harvey). Peroxidases are abundant in crown galls and also in the frost tumors. There is, undoubtedly, accelerated respiration in all tumors but who can say whether it is a cause or a consequence of the abnormal growth? I have indicated how I think it occurs, namely as a response to oxygen- 


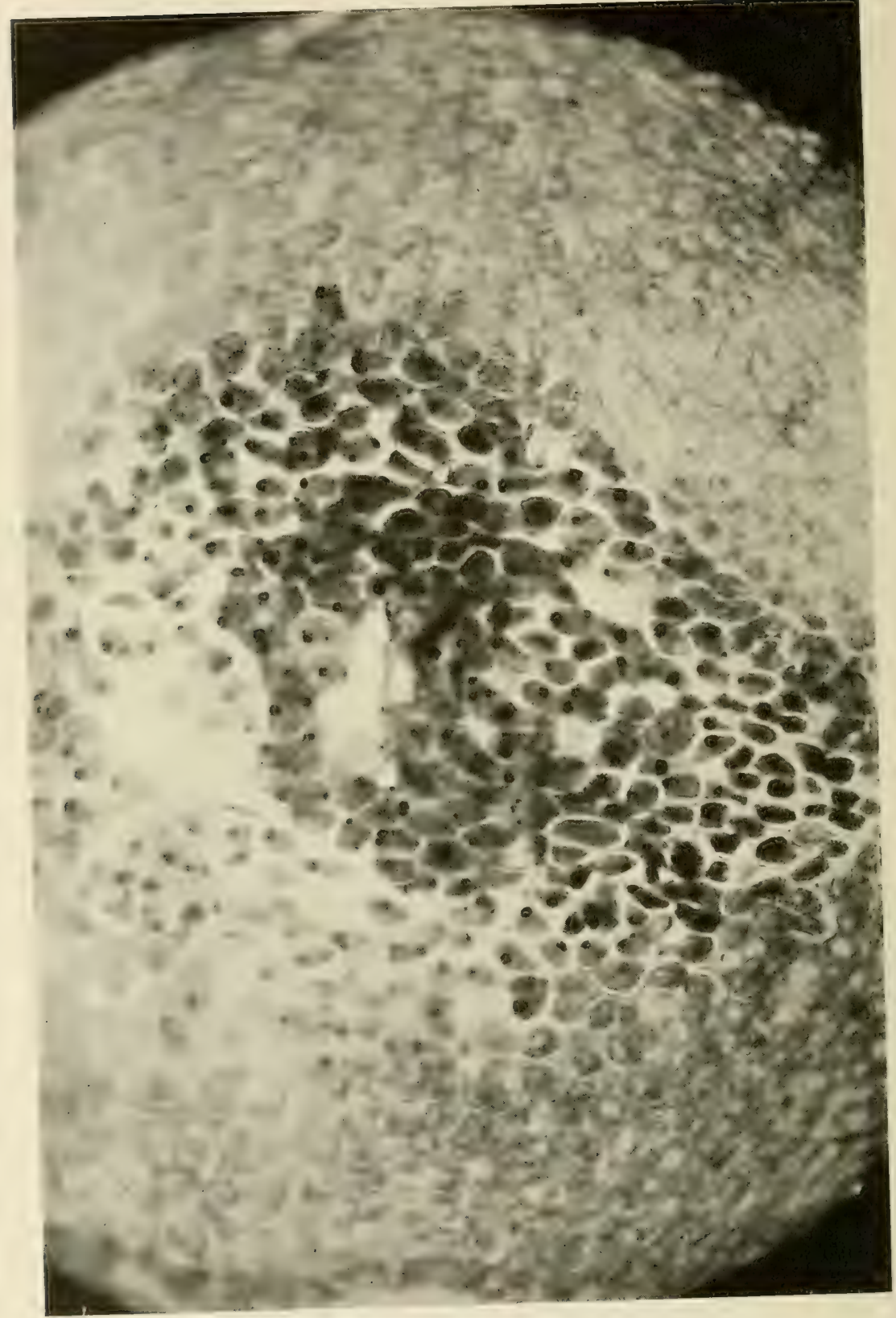

Fig. 423.-Tangential section of the oak gall passing in the middle part through the hypertrophied inner layer. The cells contain large nuclei (often several) and take a deep red stain with acid fuchsin. Hyperplasial (food storage) layer at either side. 
MISCELLANEOUS: STIMULI UNDERLYING TUMOR-FORMATION 565

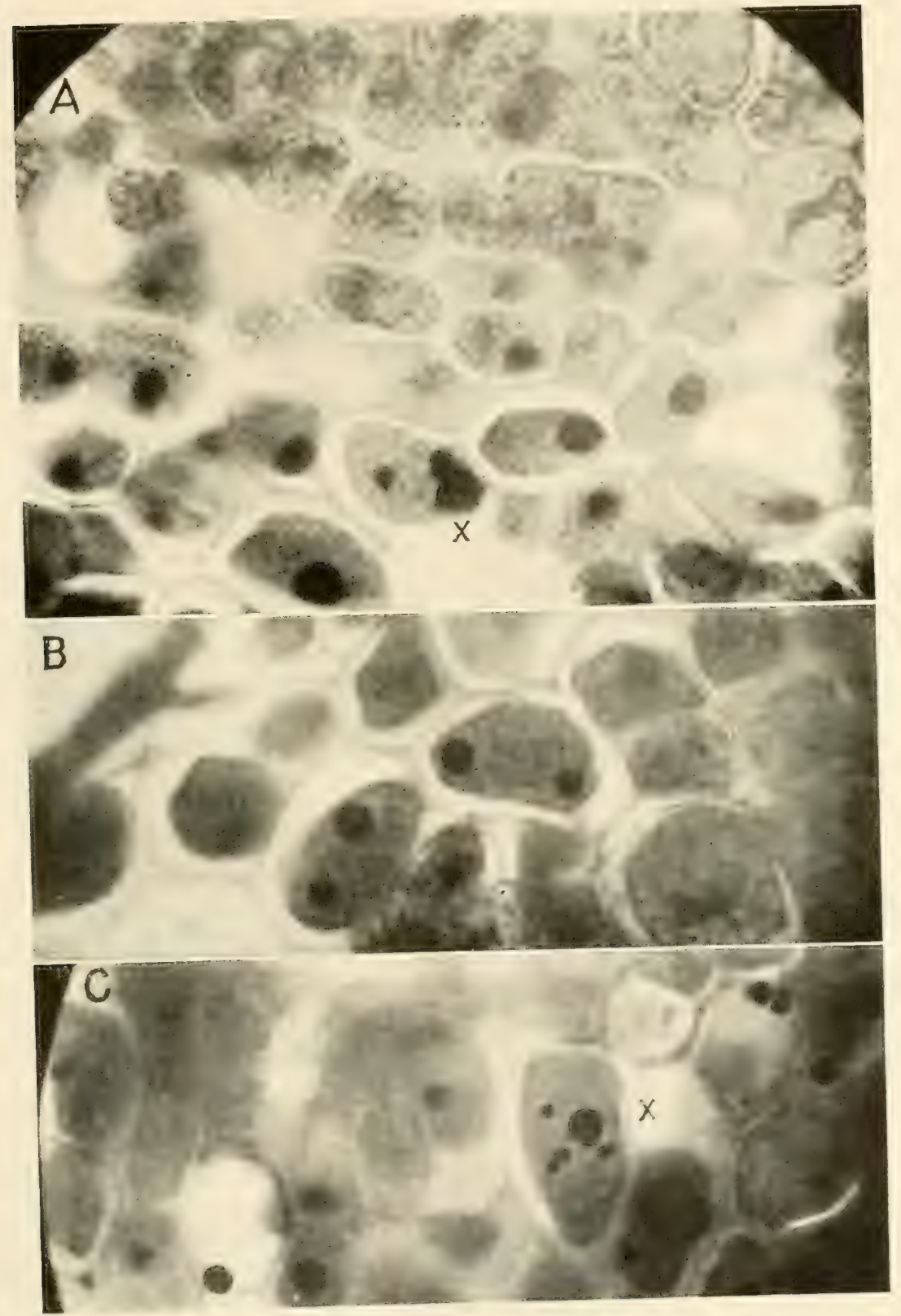

FIG. 424.-A, B, C. Portions of the inner (hypertrophied) layer of the oak gall highly magnified to show binucleate and multinucleate cells. In $A$ at $x$ there is a nuclear fusion. In $C$ at $x$ the nuclear substance is in seven pieces. $2 \mathrm{~mm}$, apochromatic oil im. obj., No. 4 oc, bellows at about 40 . $\times 850$. (?) 
hunger, which may result, as I have shown, from various causes, parasitic and non-parasitic.

Thus, whether brought about by direct abstraction of water. as through wounds; or by dry conditions, as in the potatoes on my table; by semi-asphyxiation, as under obturated lenticels; by growth of wet tissues in a minimum of very moist air, as in my sealed tubes; by direct addition of ammonia, formaldehyd. or acids from without, as through stomata: or finally, by the introduction into the cells of an alkali and acid-forming tumor parasite, the end result is the same, viz., the formation of a tumor, the type of which (hypertrophy or hyperplasia) depends. I think, on the extent of the cell-stimulus, or cell-paralysis; and the extent of the growth on whether the stimulus is selflimited or is due to a continually multiplying parasite.

Recently light has been thrown on some of these problems by Dr. R. B. Harrey, of the L. S. Department of Agriculture. In experiments on the hardening of plants by cold he has shown that when cabbages are exposed to $-3{ }^{\circ} \mathrm{C}$. for about 30 minutes their leaves freeze in spots and intumescences afterward develop from these spots. Such frozen spots extrude water into the intercellular spaces, as shown by the eranescent spotting, and judging from his experiments on egg-white plus phenolphthalein and on leaves of Coleus, using their cell-sap as an indicator, freezing increases the acidity, or hydrogen-ion content, of such cells. This leads to an increased cell-permeability and to the presence in the tissues of an excess of sugar and an excess of peroxidase, all of which favor growth.

In experiments made with red cabbages I could not get the same result that Dr. Harvey obtained with Coleus. The frozen leaves showed no change in color. Because all of the red pigment is in the surface cells, the leaves were then ground, mixed with a measured rolume of distilled water and frozen for three hours, but again there was no change in color. All of the check tubes but one were kept at room temperature and did not change in color. One check tube was exposed for the same length of time (three hours) in warm water $\left(60^{\circ}-62^{\circ} \mathrm{C}\right.$.) and this one reddened decidedly. On freezing the fluid in this tube changed color plainly but it became bluer not redder. 
There must be also defective respiration and loss of water leading to concentration of cell-sap and increased acidity in Wolf's wounded cabbages and my wounded cauliflower's already referred to as developing intumescences.

It is possible also that the tumor-producing action of ammonia is not very unlike that of the acids I have mentioned. It is likely that it would combine at once on entering the living cell with some one of the acids always present and act as an acid salt. The organic acids most likely to be present in plants attacked by crown gall are malic acid and citric acid, and the ammonia salts of these acids act in the cell. I believe, like acids. It is true they both give an alkaline reaction with Congo red or methyl orange but these are indicators which, so to speak, ignore the acid part, being interested only in the ammonia of the salt. If we use phenolphthalein as indicator they both give a strongly acid reaction, but here, again, the indicator may be said to ignore the other partner in the combination, being interested only in the organic acid. None of these indicators can, I think, be depended upon for the purpose required. Litmus is a much better indicator for this purpose because it is a plant product and both ammonium malate and ammonium citrate, so far as tested, react acid to neutral litmus paper. What is still more to the point, they both react acid to the hot water extract of the anthocyan from red cabbage. which is the same species of plant as the cauliflower on which I have produced the ammonia tumors. Up to this time I have not been able to find out what organic acids occur in cabbages and cauliflowers, but malic acid is of almost universal distribution in plants and citric acid is common. so that it is probably one of these two. But even if the ammonia acts on the cell directly as an alkali there will be afterward, according to my ideas, an increase in acidity due to loss of water through the disturbed hyaloplasm, and in any erent there will be disturbed respiration.

In the production then of these weak acids and alkalies out of place or in excess in certain tissues we have, it would seem, the key to the whole tumor situation. Given a multiplying and feeble parasite, that is, one able to produce these substances in stimulating (membrane paralyzing) amounts and at the same 
time destitute of any killing excretions, so that it shall be able to live on good terms with the host-cell, and you have my conception of a tumor-parasite, and in the chain of phenomena set up by its presence (H-ionization, disturbed respiration, etc.) the origin of all tumors which have the power of self-centered continuous growth.

This physico-chemical hypothesis, which does not always require the presence of a parasite in animals any more than in plants, since we may suppose that there are in animals slowgrowing benign tumors quite like the non-parasitic growths under stomata and lenticels, serves also to explain the development of fetal fragments in tumors and the formation of teratomas in the absence of tumors, thus uniting and correlating all types of abnormal growth. I have shown for crown gall that when the tumor develops under or in a dormant bud, as for example in the axil of a leaf, it always contains embryo-fragments and may be full of perishable leafy shoots (Figs. 333, 334, 338, 342). I have shown, furthermore, that preformed dormant buds are not necessary for the production of these embryomas, but that they occur whenever the crown gall organism is inoculated into a cambium, that is into a tissue containing totipotent or pluripotent cells (Figs. 335, 336, 339. 340), that a cambium which normally produces only bark-cells may under the crown-gall stimulus produce also totipotent cells, and that the nature of these embryonic inclusions, i.e., the kind of organs included in the tumor, such as roots, leaves, stems, flower-buds, depends on the location of the tumor or, in other words, on the type of mother cells reached and stimulated.

Recently, I have discovered how to cause dormant totipotent cells to develop in the absence of tumor cells. This also I believe I have accomplished by increased acidity due to the abstraction of water (and along with it oxygen) from very young tissues. For this purpose I used buds of the proliferous hothouse plant, Begonia phyllomaniaca. On this plant, which is probably a hybrid, and which is rery sensitively balanced to loss of water, it is possible to produce a veritable forest of shoots on leaves and on internodes by wounding the roots and also directly in the lips of wounds if these wounds are made in very young tissues, 
such as the immature red leares just emerging from their stipule sheathes. See Chapter V.

What relation, if any, these discoveries, especially those relating to crown gall, may have to the question of the etiology of animal tumors must be left for the oncologists to determine. My own views, expressed repeatedly during the last ten years, are that they have a profound relation, and Jensen of Copenhagen and Borrel of Paris, as well as several cancer specialists in the United States, are of the same opinion. The moment one has established that there is a cancer in plants due to an obscure wound-parasite it becomes illogical and unthinkable that cancers in men and animals are of non-parasitic origin. Why should Nature have two such diverse ways of reaching the same end? The differences between plants and animals are not sufficiently fundamental to lead us to expect it. Both are equally subject to parasitic diseases. Both are alike in a hundred ways, as Claude Bernard first showed, and as I have elsewhere pointed out (Science, l.c.). Moreover, no one has formulated a workable non-parasitic hypothesis. In plants, we see that it is easy to produce short-lived tumors by means of a single short exposure to dilute acids and alkalies, but for the production of a continuously growing malignant tumor something more appears to me to be necessary, to wit: a feeble commensual parasite of a special type, an organism that shall continuously furnish acid or alkaline substances to the cells in stimulating small quantities, but is not able to destroy the cells. This we have for plants in the crown-gall bacterium. Whether the cells thus originated may then continue to grow in the absence of the parasite, as Jensen believes, is a subject for further consideration.

That no one has yet isolated a micro-organism from animal cancers which will reproduce them when inoculated, does not weigh heavily with me for several reasons. I recall the history of syphilis, of tuberculosis, of hog-cholera, and of a dozen other animal diseases, and I am no longer in awe of the animal pathologist. It may be he is as wrong about cancer as he was about syphilis prior to Schaudinn, or tuberculosis prior to Villemin and Koch. First, the difficulties in the way of isolation may not have been overcome. Parasites are often sensitive to slight 
differences in culture media, growing well in one medium and refusing to grow in another. See, for example, p. 401 dealing with the olive tubercle. Here the organism causing the tumor grows in an agar made with one peptone and refuses to grow in that made with another peptone, or grows in the presence of the latter only with much retardation. See also Fig. 160 (p. 217). Many such cases are known to me, as they are to every working bacteriologist. Second, the organism may have been isolated and neglected for some more common form. How often the wrong organism has been selected and studied, and by good men too, sometimes for years, in case of other diseases both of plants and animals! Nothing is more natural than to select for study that which appears to be common and constant on the poured plates and yet it may be the wrong thing. Third, cancer, at least in the narrower meaning of the word, is a dyscrasia of which the tumor is simply the end term and we may not hope to reproduce it in animals by the inoculation of an organism until the living substratum has become suited to it, that is until we have reproduced the beginning and middle terms of the dyscrasia. These may depend on inherited tendencies (Slye); or on a long-standing vicious physiological disturbance, a malnutrition, for example; or on the long-continued action of some feeble secondary parasite, a streptococcus, for example. Possibly the cancer parasite itself is a streptococcus. Certain streptococci have many of the necessary characters of such a parasite, viz., low visibility in tissues, feeble parasitism and vitality, sensitiveness to slight changes in culture media so that they will not grow, ${ }^{1}$ ability to produce acids, ability to destroy blood, ability to induce vegetations, etc. My assumption is that the carcinoma parasite, if there is one, can act only in an organism which has gradually become adapted to it, i.e., only in an abnormal body. The normal animal body is amply protected against all weak parasites by its leucocytes which might be expected to pick up and destroy any injected bacterium of as feeble a nature as a cancer parasite must be supposed to be, i.e., one incapable of destroying the cells. For this reason plants,

${ }_{1}^{1}$ The writer was perhaps the first person to observe (1906) that the streptococcus of endocarditis (S. viridans) is sensitive to sodium chlorid, and will not grow in bouillon or nutrient agar made neutral to phenolphthalein by sodium hydroxid. 
which have no leucocytic apparatus, are easier to work with than animals and undoubtedly their tumors will continue to yield to careful study many facts which must throw interesting side-lights on animal tumors, and the time is not far removed when they will be studied in many laboratories for this purpose.

Neither does it seem to me a valid objection to the above argument that cancers of rats and mice in which no parasite has been found are easily inoculable, grow rapidly, and soon destroy the host animal. Here the case is quite different from that of a naked bacterium. The cancer graft carries into the body of the mouse or rat a compact mass of cells, hundreds of thousands of them, functioning as a unit. If the graft heals on, the cancer cannot fail to continue its malignant growth. If, however, it were possible to divide this mass of cells into its component elements we should then have a suspension of cancer-cells comparable to a bacterial culture. The cancerous mass would then have lost not only its unity but its strength, and undoubtedly the body would then react to it very differently, that is to say, just as it often does to a few cancer cells that have drifted away from the main body of the tumor and are surrounded by lencocytes and destroyed in a thrombus, or just as it does to an injected bacterial suspension of a feeble parasite, a cancer parasite let us assume, each separate foreign cell being surrounded and overwhelmed by the leucocytes. If we could devise a satisfactory method of overcoming the resistance of the normal body in our experimental animals, a resistance due to leucocytes and anti-bodies, we should then have the pre-cancerous stage, about which we have heard so much in recent years, and in reality know so little, and it would probably be easy to produce tumors in some of them, even with crown-gall bacteria.

How the oncologist approaches the problem of the etiology of tumors will depend very largely upon his training. In looking toward the solution of the cancer problem, not much is to be hoped from such pathologists as have only a descriptive knowledge of tumors but much from some of the younger biologists, especially those who are well trained in bio-physics and bio- 
chemistry. for these are the sister sciences which, when joined to physiology and pathology, may be counted upon to solve the problem of the cause of malignant human and animal tumors. The time is ripe and I believe the solution of the problem is rery near. The elimination of the disease, however, will be much more difficult.

\section{- LITERATURE}

1886. Sorauer, Paul. Handbuch der Pflanzenkrankheiten. 2te neubearbeitete Auflage. Erster Theil. Blattauftreibung (Intumescentia) pp. 222-227. Berlin, Paul Parey. 1886.

1889. Atkinson, Geo. F. Nematode Root-galls. Science Contributions from the Agricultural Experiment Station, Alabama Polytechnic Institute, Auburn, Ala., December, 1859, Vol. I, No. 1, Bulletin No. 9, New Series, pp. 177-226, 6 Plates.

1893. Athinson, George F. Edema of the Tomato. Cornell Univ. Agric. Exp. Sta., Bulletin 53, May, 1893.

1893. Atkinson, G. F. Edema of Apples Trees. New Fork (Cornell) Agricultural Experiment station, Bulletin 61, December, 1893. Published by the Univ., Ithaca, N. Y., pp. 299-302, Figs. 1 and 2.

1898. Tubeuf, C. von (see p. 631).

1904. Viala, P. and Pacottet, P. Sur les Verrues des feuilles de la Vigne. Comptes Rendus des Séances de l'Académie des Sciences. Tome 13S, Janvier, 1904, pp. 161-163.

1905. Von Schrenk, Hermann. Intumescences Formed as a Result of Chemical stimulation. Missouri Botanical Garden, 16th Ann. Rpt. St. Louis, Mo., 1905, pp. 125-148. 7 Plates.

1909. Sorauer, PAUl. Handbuch der Pflanzenkrankheiten. Dritte, vollständig neubearbeitete Auflage, Erster Band. Dienichtparasitären Krankheiten. Fünftes Kapitel. U'bermässige Luftfeuchtigkeit, pp. 435-449. Berlin, Paul Parey, 1909.

1910. Moldiard, Marin. Sur quelques caractères histologiques des C'écidies. Produites par l'Heterodera radicicola Cireff. Revue générale de Botanique. Tome 12, Paris, 1900, pp. $157-165,1 \mathrm{Pl}$.

1910. NĚnec, Prof. Dr. B. Das Problem der Befruchtungs- 
rorgänge und andere zytologische Fragen. Chapter VI. Vielkernige Riesenzellen in Heterodera-Gallen, pp. 151-173, 18 text Figs. Berlin, 1910. Gebrüder Borntraeger.

1910. Wissiewski, P. Uber Induktion ron Lenticellenwucherungen bei Ficus. Bulletin International de l'Académie des Sciences de Cracovie. Série B: Sciences Naturelles. No. 5B. May, 1910, pp. 359-367. 2 Plates, including 11 Figs., 9 of which are photomicrographs.

1914. Совв, …. Citrus-root Nematode. In Jour. Agr. Research, Vol. 2, No. 3, pp. 217-230, 13 Figs.

1915. MacCarty, Wir. Carpenter. Facts versus Speculation in the Professional Conception of Cancer. Texas State Joumal of Medicine, July, 1915.

1915. Schilling, E. Über hypertrophische und hyperplastische Gerrebeswucherungen an Sprossachsen rerursacht durch Paraffine. In Jahrb. Wiss. Bot. [Pringsheim], Bd. 55, Heft. 2, pp. 177-25s, 43 Figs.

1916. Surth, Erwix F. Further Evidence that Crown gall of Plants is Cancer. Science, N. S., Vol. XLIII, No. 1121, pp. S71-889. June 23, 1916.

1916. Rumbold, Caroline. Pathological Anatomy of the Injected Trunks of Chestnut Trees. In Proc. Amer. Phil. Soc., Tol. 55, No. 6, pp. 485-493, Pl. 15-18.

1916. Slye, MAUd. The Inheritability of Spontaneous Tumors of specific Organs and of specific Typesin Mice. studies in the incidence and inheritability of spontaneous tumors in mice. Fifth Report. .The Journal of Cancer Research. Vol. I, No. 4, October, 1916, pp. 479-502.

1916. Slye, Maud. The Inheritability of Spontaneous Tumors of the Liver in Mice. Studies in the incidence and inheritability of spontaneous tumors in mice. Serenth Report. The Journal of Cancer Research, Vol. I, No. 4, October, 1916, pp. 503-522.

1917. Slye, Maud. The Inheritance Beharior of Infections Common to Mice. Studies in the incidence and inheritability of spontaneous tumors in mice. Ninth Report. The Journal of Cancer Research. Vol. II, No. 2, April, 1917, pp. 213-238.

1917. Sмiтh, Erwix F. Mechanism of Tumor Growth in 
Crown gall. Journal of Agricultural Research, Vol. VIII, No. 5, January 29, 1917, pp. 165-186.

1917. Sмith, Erwin F. Embryomas in Plants. (Produced by Bacterial Inoculations.) Johns Hopkins Hospital Bulletin. Vol. XXVIII, No. 319, September, 1917, pp. 277-294. 115 Figures on 14 Plates and 1 text Fig. Also a repaged separate.

1918. Wolf, F. A. Intumescences, with a Note on Mechanical Injury as a Cause of their Development. Journal of Agricultural Research, Vol. XIII, No. 4, April 22, 1918, pp. 253-259.

1918. MacCarty, Wm. C. Cancer's Place in General Biology. The American Naturalist, Vol. LII, Nos. 620-621, August-September, 1918, pp. 395-408. 7 Figs. in text.

1918. Kunkel, L. O. Tissue Invasion by Plasmodiophora Brassicae. Jour. Agr. Research, Vol. XIV, No. 12, Sept. 16, 1918, pp. 543-572. 20 Plates.

1918. Harvey, R. B. Hardening Process in Plants and Developments from Frost Injury. Journal of Agricultural Research, Vol. XV, No. 2, October 14, 1918, pp. 83-111.

(See also Literature references under Crown. gall, Part III.)

\section{ON THE PRODUCTION OF TERATOSIS IN THE ABSENCE OF TUMORS AND OF PARASITES}

For several years I have been experimenting on the cause of excessive proliferation in plants, using for this purpose Begonia phyllomaniaca (Fig. 425), and have obtained results of general interest which may be expressed as follows, premising that the plant is one that has been in cultiration for a long time, is of doubtful origin and has been known since it was first described by von Martius (in 1852) to throw adventive shoots irregularly from its stems and leaves (Figs. 426, 427). It is figured and described in Curtis' Botanical Magazine (Vol. XVII, pl. 5254), in von Martius' "Flora Brasiliensis" (Vol. IV, Part I, p. 386, Pls. 99, 100), and in various other places. Von Martius says the plant was received at the Royal Botanic Garden in Munich from a garden in Hamburg about the year 1848, without name and as of Brazilian origin, but he points out that it belongs to a group of begonias which do not occur 
in Brazil. He says it grows frequently in Mexico and Central America and thinks De Candolle may be right in supposing it to be of Guatemalan origin.

Bateson believes the plant to be a hybrid because it is perfectly sterile, because he has seen phyllomania in sixteen hybrids resembling this plant, which he obtained by crosing Begonia heracleifolia with Begonia polyantha, and because Duchartre reported phyllomania in hybrids which Nodot obtained by crossing Begonia incarnata and Begonia lucida. Bateson thinks the phyllomania camnot be ascribed to the sterility of the plant because he knows another begonia called Wilhelma "which is exactly B. phyllomaniaca and equally sterile, though it has no trace of phyllomania." He says: "We would give much to know the genet ic properties of Begonia phyllomaniaca." Goebel thinks the plant was probably obtained by crossing $B$. manicata with $B$. incarnata. His plant showed a rhythmic production of the phenomena, the shoots appearing only in the winter season, but this, I am inclined to think, was only because his gardner repotted the plant in the autumn rather than in the spring.

The main facts I have discovered are briefly as follows:

1. The initial impetus to phyllomania on a given leaf or internode is not determined by the amount of photosinthetic or other material in the organ, nor is the phyllomania a low-growth or winter state of the plant, as believed by Goebel, but is conditioned on a definite shock. Whether the phenomenon appears in the summer or in the winter depends on when the shock is administered. The phyllomania may be produced at any time of year.

2. Following such a shock, however, the number of shoots which develop or remain abortive appears to depend on the foodsupply.

3. Leaves and internodes are susceptible to shock only during a brief period of meristematic growth. Then they have passed much beyond this period they are no longer susceptible.

4. The tissues are most susceptible after they have passed out of their most primitive condition, but are still embryonic. 


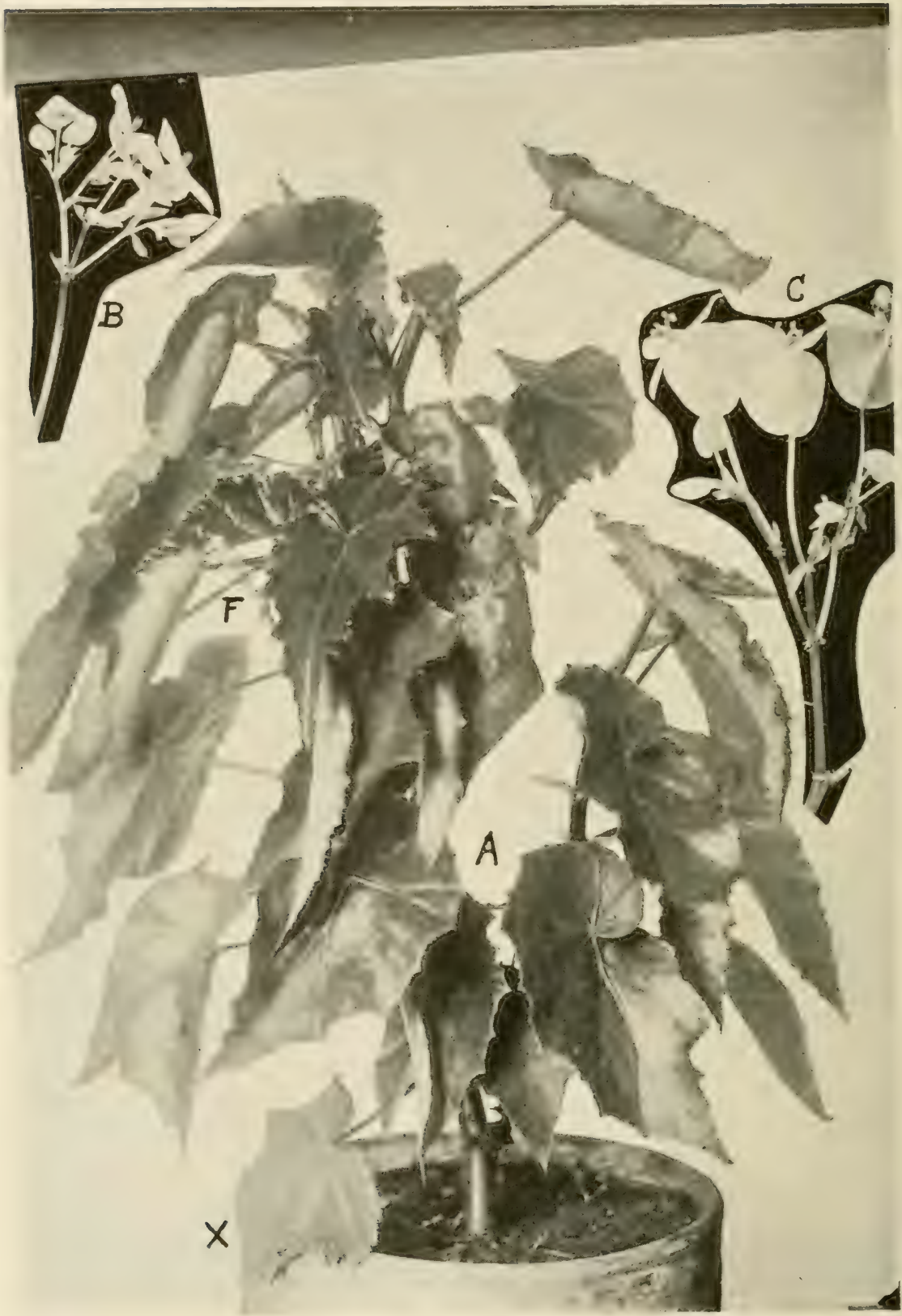

FIG. 425.-A. Begonia phyllomaniaca (top removed). Flowers at $F$. The only leaf showing many shoots is $X ; 1 / 25$ of the total leaf surface here shown yielded $6 / 7$ of the total number of shoots. Photographed April 13, 1918. About 1/4 natural size. $B, C$. Cluster of flowers, natural size, the larger are pistillate. $B$ belongs on the base of $C$. 


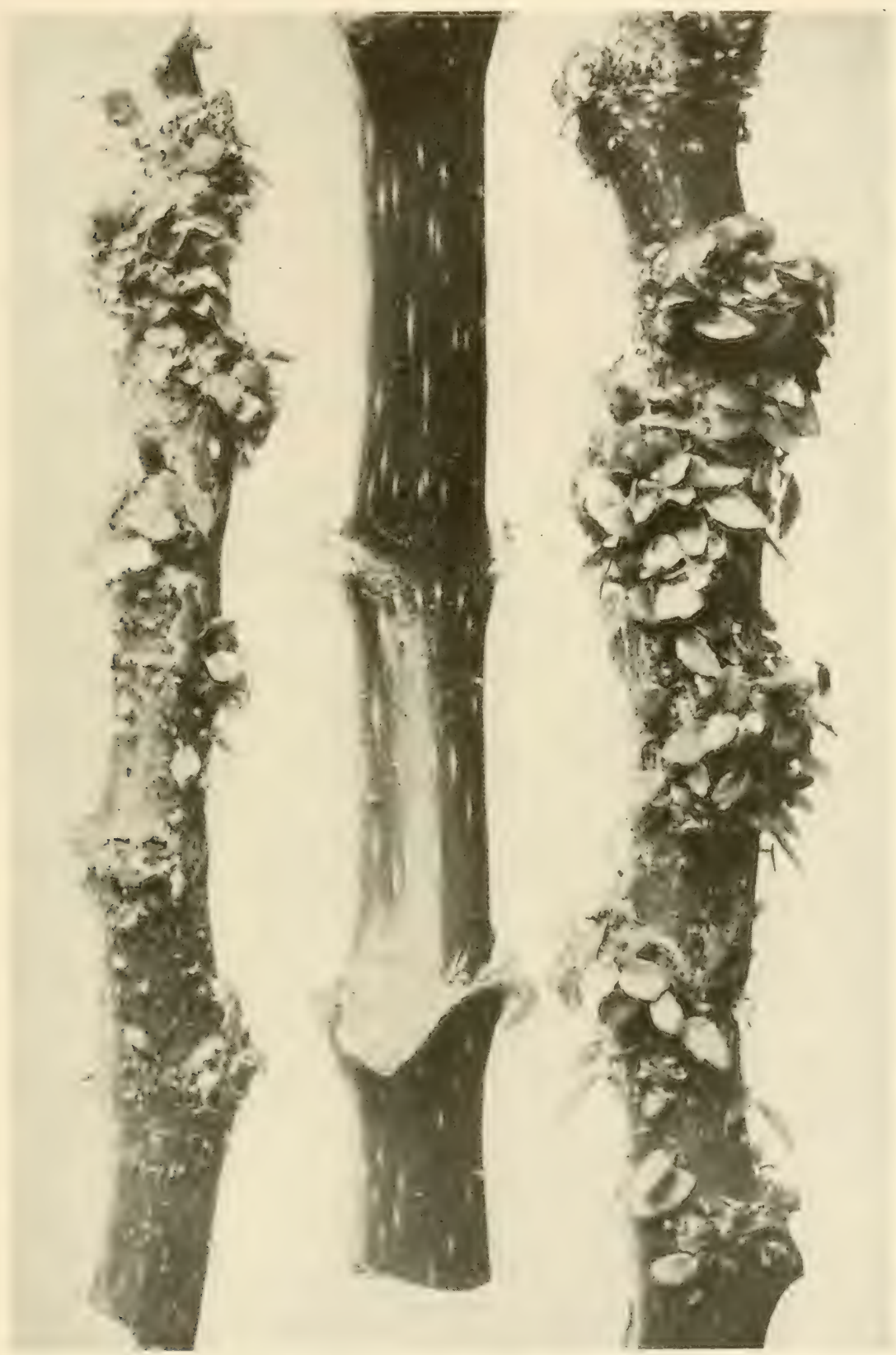

FIG. 426.-Main axis from three plants of Begonia phyllomaniaca. Right and left old prolierous shoots, center a young main axis nearly free from proliferations. The left stem bore 425 shoots, the right stem 591. The longitudinal white stripes are lenticels. Photographed March 27, 1918. $\times 11 \% 2$. 


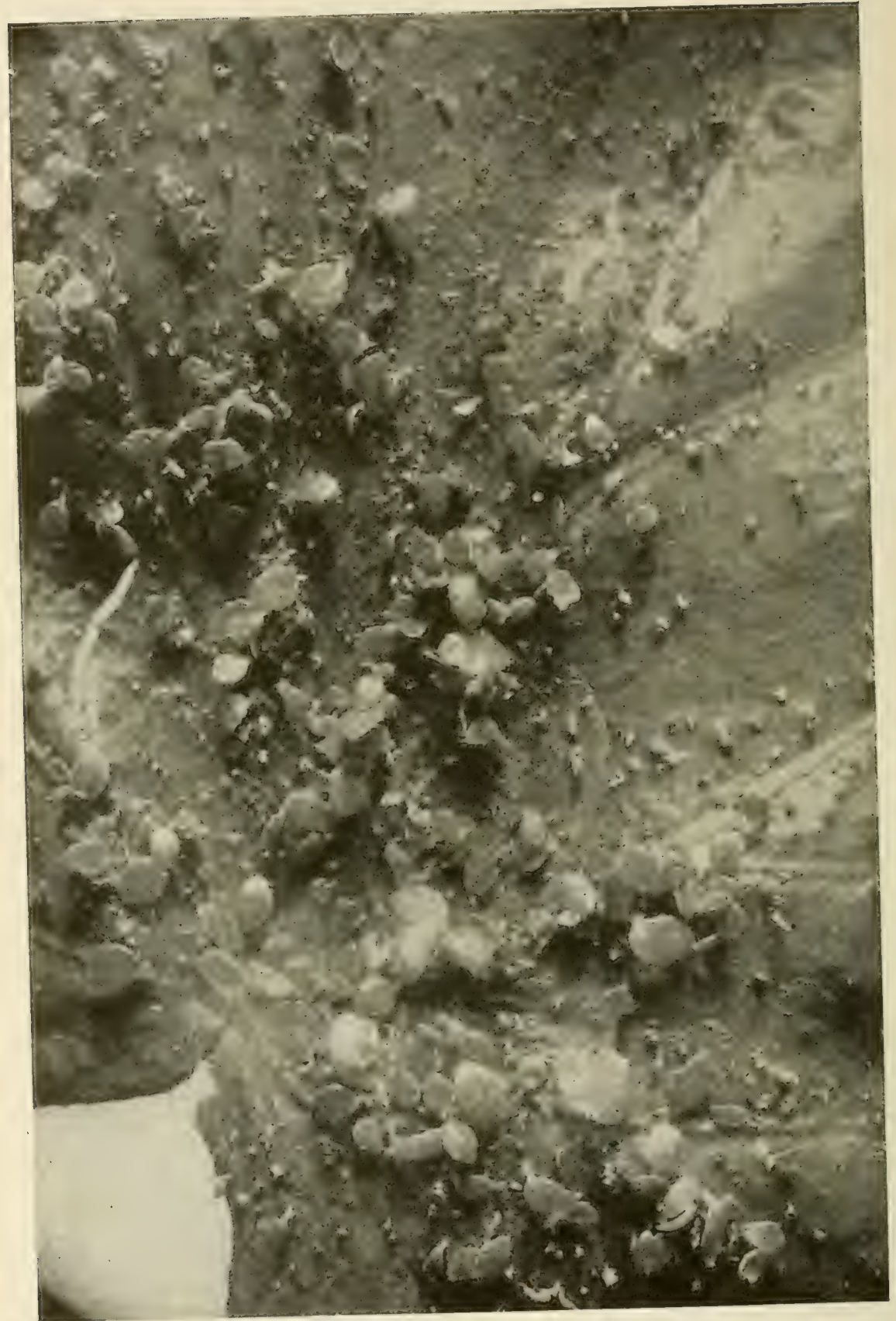

Fig. 427.-Center of blade of a dwarfed leaf, showing proliferations not 
Either way from this stage the degree of susceptibility usually falls rapidly.

5. Internodes are most susceptible to shock when they are about ${ }^{1}{ }_{16}$ to ${ }^{1} \mathrm{~s}$ inch long, and leares when the folded 2-stipulecovered blades are about 1/4 to 1/2 inch long, but responses can be obtained from considerably larger leaves (blades $1^{1}$.2 inches long, or more). The closely wrapped terminal bud (Fig. 428.1) usually contains three plainly visible young leares, each separately stipule-wrapped. The outermost is usually about 3/8 inch long (Fig. 428B, enlarged) including the petiole. The one next above it is usually about ${ }^{3} 16$ inch long, while the third is a mere red speck about ${ }_{1} 16$ inch long. Above these three young leaves are several undifferentiated colorless rudiments.

6. I can now produce the response (teratosis) on a given leaf or internode at will. That is to say, in the summer of 1918 I made experiments, predicted the results, and two months later saw my predictions fulfilled to the letter, not once or twice, or on a single plant, but in at least 150 places on 34 different plants.

7. The response to the shock is in the form of great numbers of adventitious embryo plants covering the surface of the leaves and other shocked parts (Figs. 429, 430). Tery often the number of sporadic plants growing out of a shocked leaf-blade has been as many as 500 or 600 and occasionally they have appeared in much greater numbers (2500 to 4000 ) the leaves above and below (Figs. 430, 433, 440, 446) being free or nearly free from shoots. The petioles, likewise, respond freely, sometimes bearing as many as 500 of these tiny plants (Figs. $429 x$, $4364 x, 438,439 B, 443,445 y)$. Also on single internodes remote from leaf axils I have obtained from 200 to 2000 such diminutive plants, the internodes above and below the shocked ones being free or nearly free (see Figs. 429, 432, 434, 436, 437, $439 A, 444,445,449$ sub. 3 , and Table II).

8. Most of these crowded shoots perish after some weeks, but a considerable number of them live for months, growing

restricted to the main veins. Contrast with Figs. 441, 442 and 443. There are no shoots on the lower surface. Photographed January 14, 1918. $\times 4$. It was appearances like this and those in Fig. 426 which led me to make these experiments. 


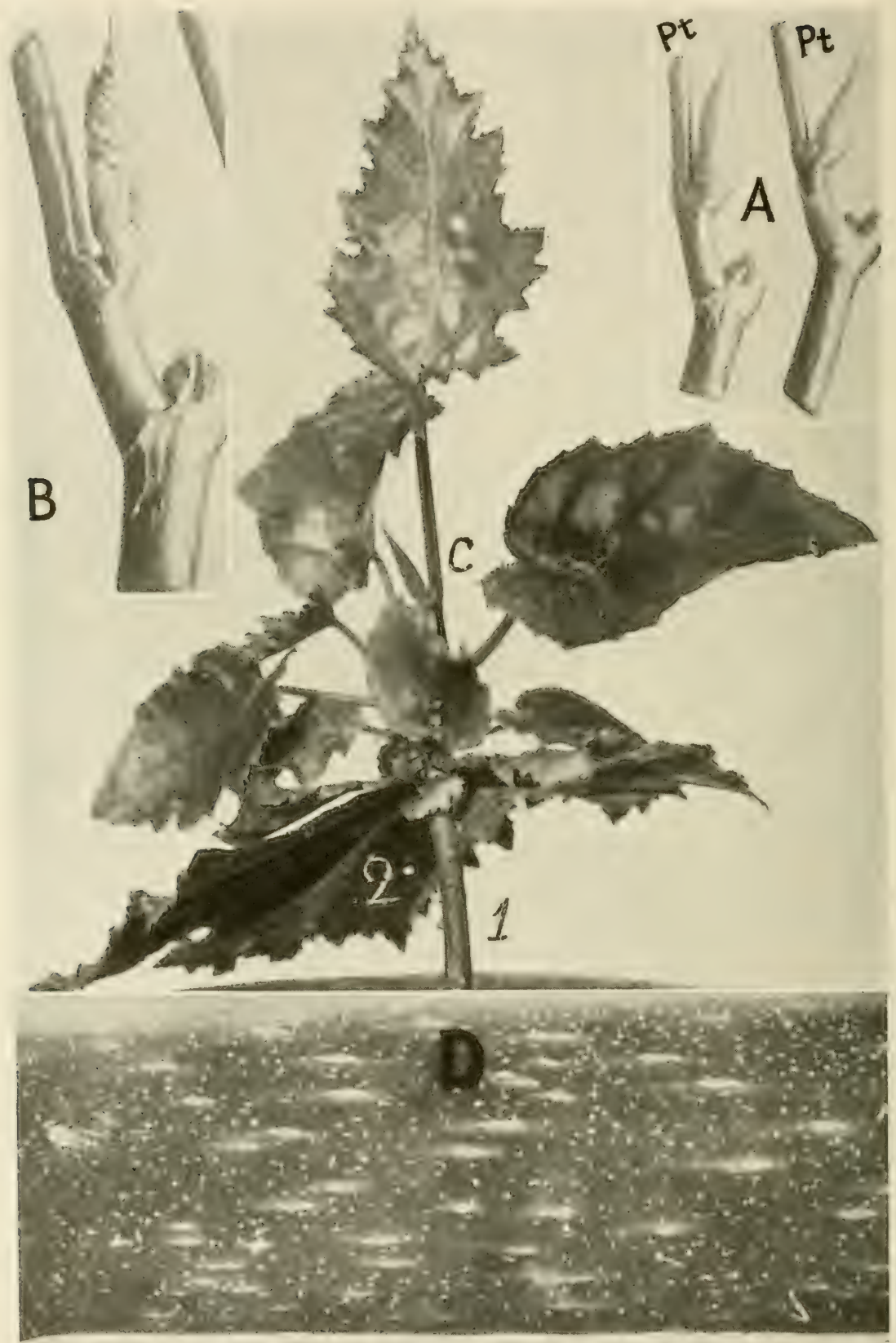

Fig. 428.-A. Terminal buds of Begonia phyllomaniaca. pt, base of upper leaf. Each young leaf is separately stipule-wrapped. It was the leaves and inter- 
slowly and developing several small, green leaves, which may be of the ordinary shape or may be rariously malformed or grown together. They do not separate naturally from the parent plant to root freely, like bulblets, neither are they to be regarded as branches, except in so far as they subsequently become connected with the vascular system of the mother plant, but under very exceptionally favorable conditions, as is well known, such adventive shoots can be grown into large plants, i.e., when separated artificially from the parent plant, rooted with great care in sand, and potted in good soil. Unlike Bryophyllum no roots develop from these proliferations as long as they remain attached to the plant, nor do they root freely in sand. In other words, the shoots are of no use to the plant and their development cannot be explained teleologically.

9. The extent of their development on the plant depends very largely on the nutrition of the particular organ from which they have sprung. If the leaf, for example, remains small they are correspondingly dwarfed, many being scarcely more than slightly raised green places (pimples) on the surface of the leaf. They are better developed on large, well-nourished, actively growing leaves and on such leaves a few shoots, especially those over midribs where the water supply is most abundant, may develop several leaves with blades an inch or more in length. I have grown one such laminar shoot (Fig. 428C) into a plant 12 inches high, all its nourishment coming through the rooted petiole of the mother leaf, the blade of which soon perished. It is, however, a crooked stunted plant.

10. In earliest stages of development these proliferous shoots are very superficial. Enlike the normal axillary buds they have

nodes in similar buds which specially responded to the root-stimulus, as described in the text and as shown on the following plates. Nat. size.

$B$. Same as $A$ but with the outermost 2 stipules removed to show the larger of the three folded leaves. $\times 2$.

$C$. Plant which developed from an adventive shoot on a leaf blade.

Rooted petiole. (2) Blade of the mother leaf which soon shriveled. Photographed July 15, 1918.

D. Portion of upper main axis of No. 1, first series, enlarged to show the lenticels (spindle-shaped white markings) and the glands (numerous white specks) from the base of which most of the adventive shoots arise. $\times 4$. 


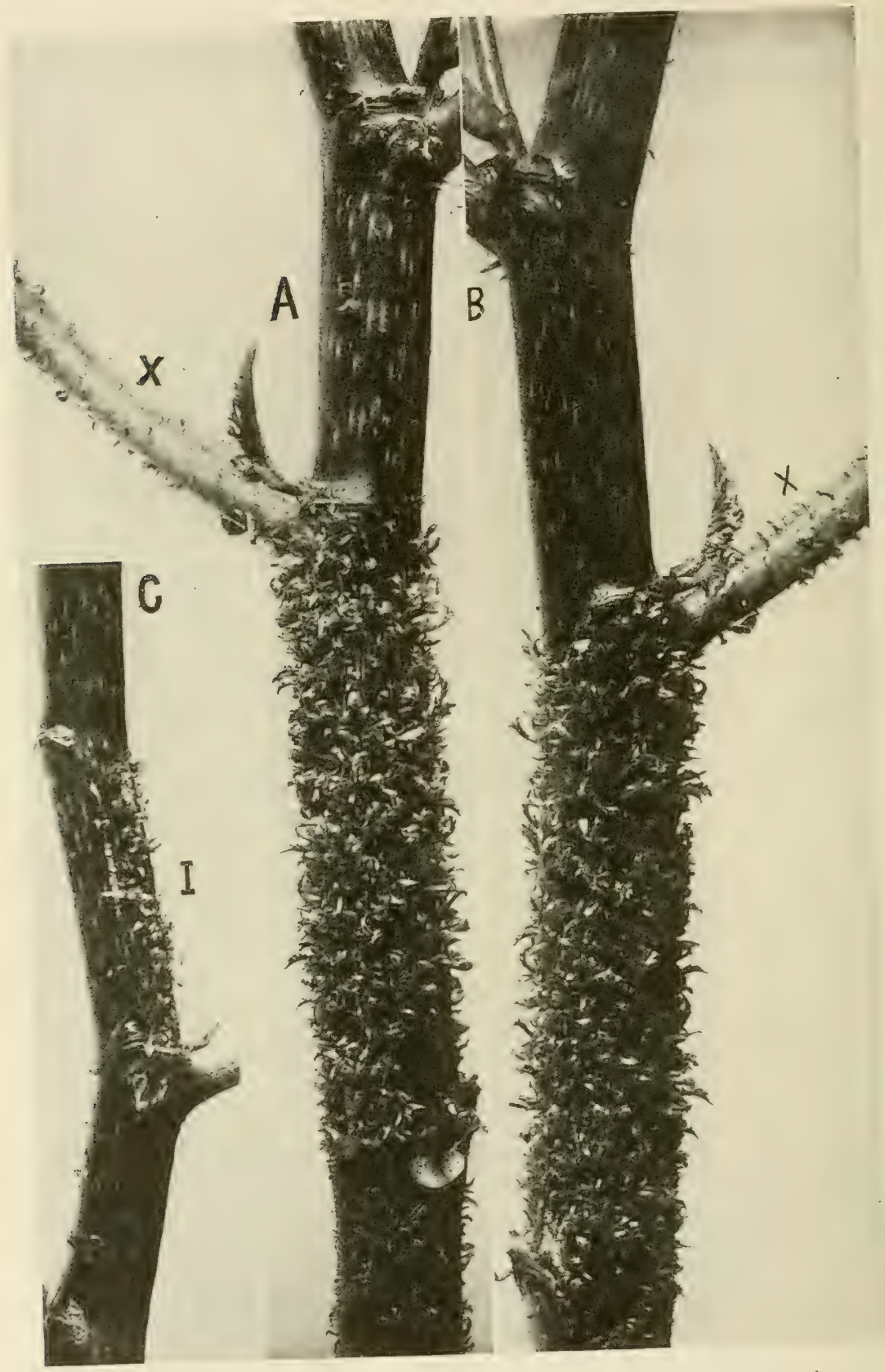

FIG 429-A. Main axis of No. 1, first series, showing proliferous internode and petiole $(X)$ : 
no comnection with the ordinary vascular system of the plant (Fig. $451 \mathrm{~A}$ leaf, $B$ stem), but are independent growths (parasitical implants, so to speak) developing either from scattered hairs or from various other places in the epidermis, especially glands which abundantly dot the surface of the young stems and the very young leaves (Figs. $428 D$ and $452 X, Y$ ). In this stage they are separated from the vascular cylinder of the stem (Fig. $451 B$ ) and leaf (Figs. $451 . A$ and 453 ) by a thick layer of colorless, coarse-celled hypoderm. These embryo plants, or new organisms, as they must be considered, develop a rascular system of their own, but those that perish (the vast majority) never succeed in connecting this with the normal rascular system of the parent plant. Those shoots that persist are the ones that have formed a junction with the xylem-phloem of the mother plant.

11. My experiments show that the surface of this plant, at least above-ground and in early stages of its growth, has, rather uniformly distributed in it, thousands of germinal or totipotent cells, most of which ordinarily remain dormant but which can be shocked into development, if the shock is applied early enough, that is, while the tissues are still very young. These shoots are not the development of preformed buds. They are not branches, but independent organisms.

12. Not only are such insignificant organs as the scattered petiolar hairs and the base of stem-glands and leaf-glands, at already stated, able to grow out into whole plants, but these are the parts most likely to give rise to the proliferation. Indeed, I suspect that the trichomes and glands are the only part of the epidermis able to develop these shoots but have not made enough examinations to be able to pronounce definitely. Judging from my experiments, there is germinal tissue at the base of every acicular hair and of every botryose gland. Often several shoots arise from a single trichome base or its vicinity, but the trichome itself also may give rise to a shoot (Figs. 436C,

B. Back side of $A$.

C. A branch of No. 1, first series, with shocked internode at I. There is a narrow strip of cork in the middle of $I$.

These proliferating parts were embryonic, stipule-wrapped tissues on July 24. Photographed October 8, 1918. × 145 . 


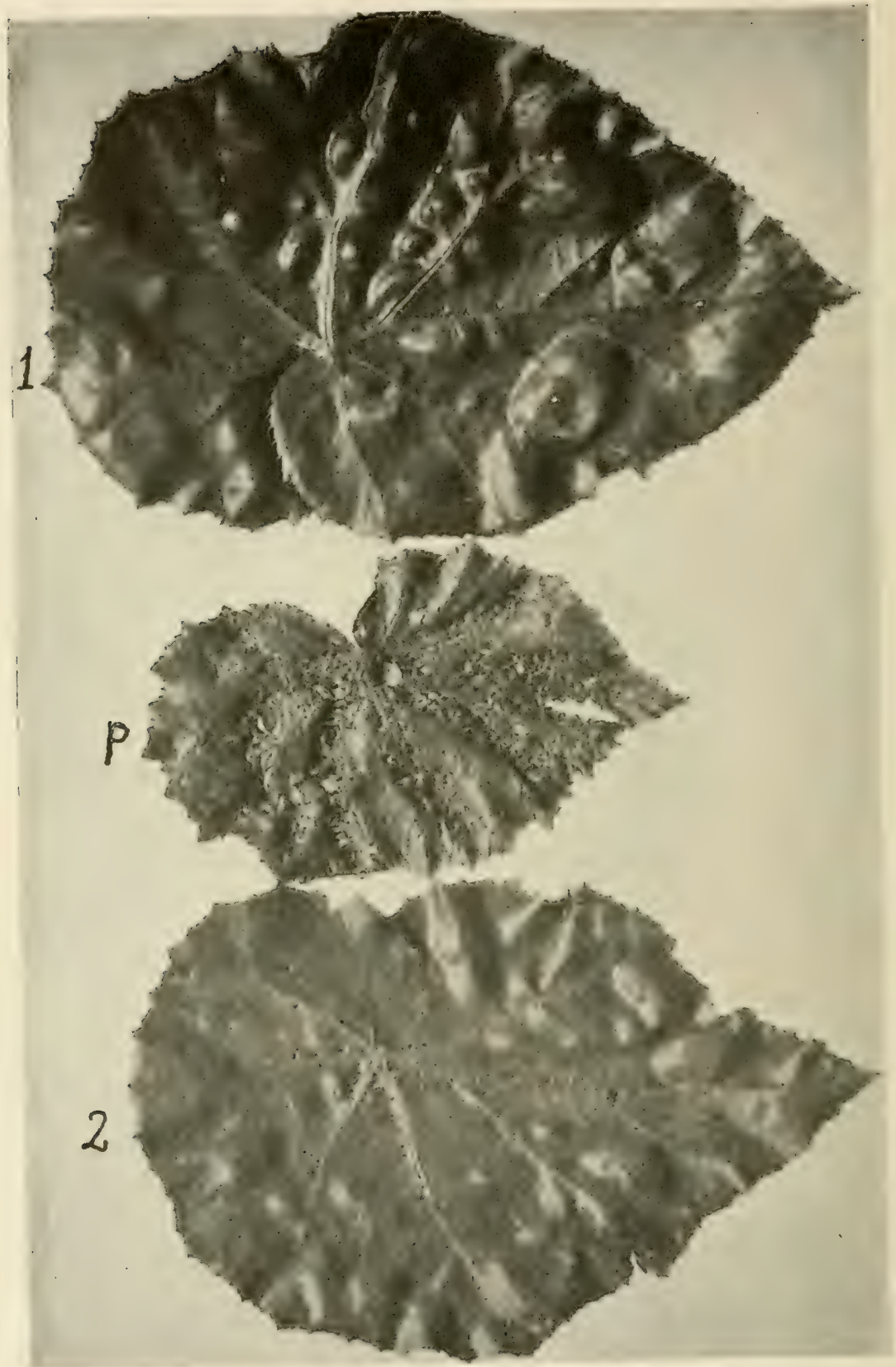

FIG. 430.-From the main axis of No. 1, first series. Very proliferous, shocked, dwarfed leaf $(P)$ and the next two leaves above it (nearly smooth). The order of the leaves above $P$ is stated on the cut. Photographed October 8, 1918. Reduced. The actual length of the very proliferous blade was $\mathbf{5}$ inches. 


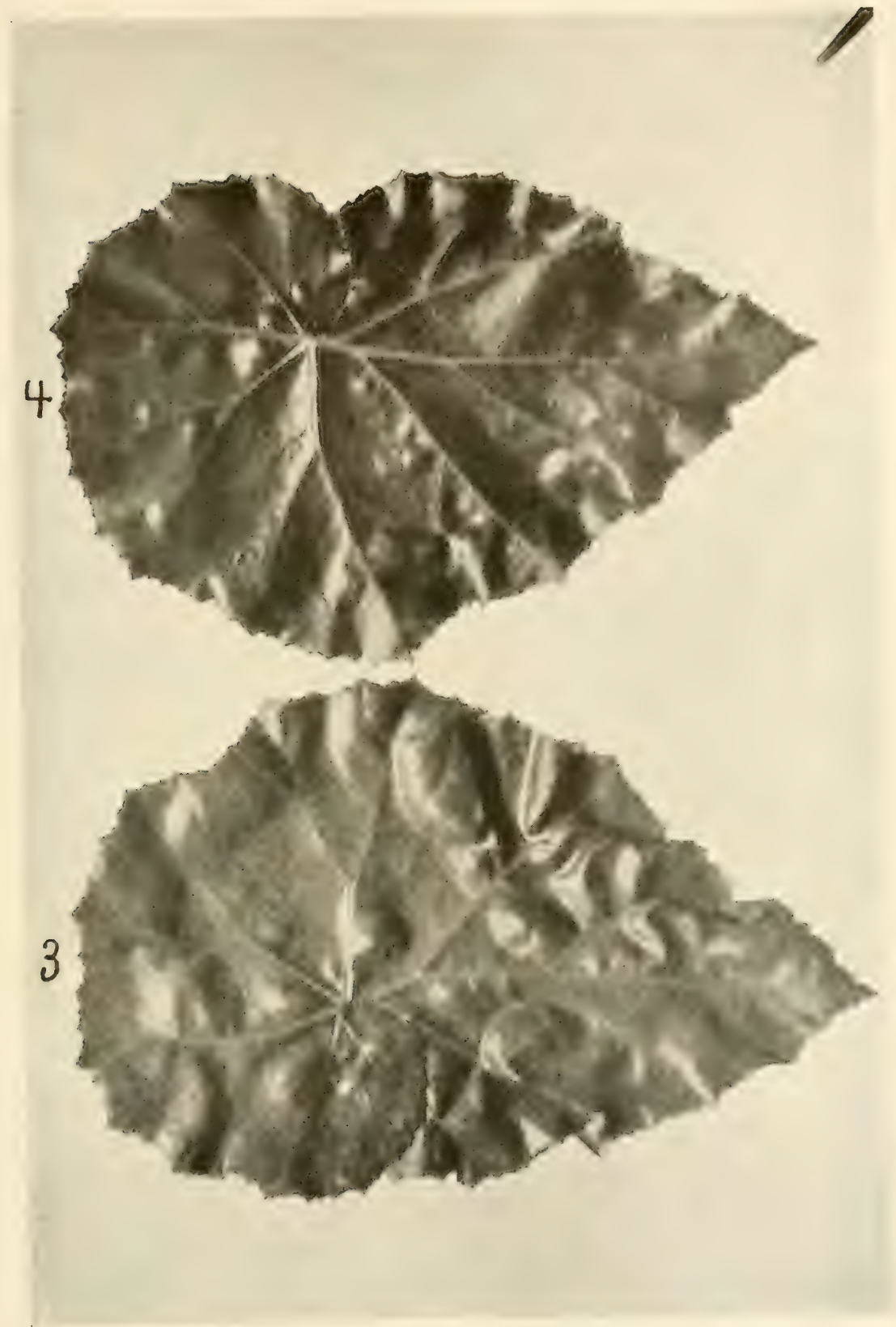

Fig. 431.--Smooth leaves, 3 and 4, above the proliferous leaf, $P$, of Fig. 430. 


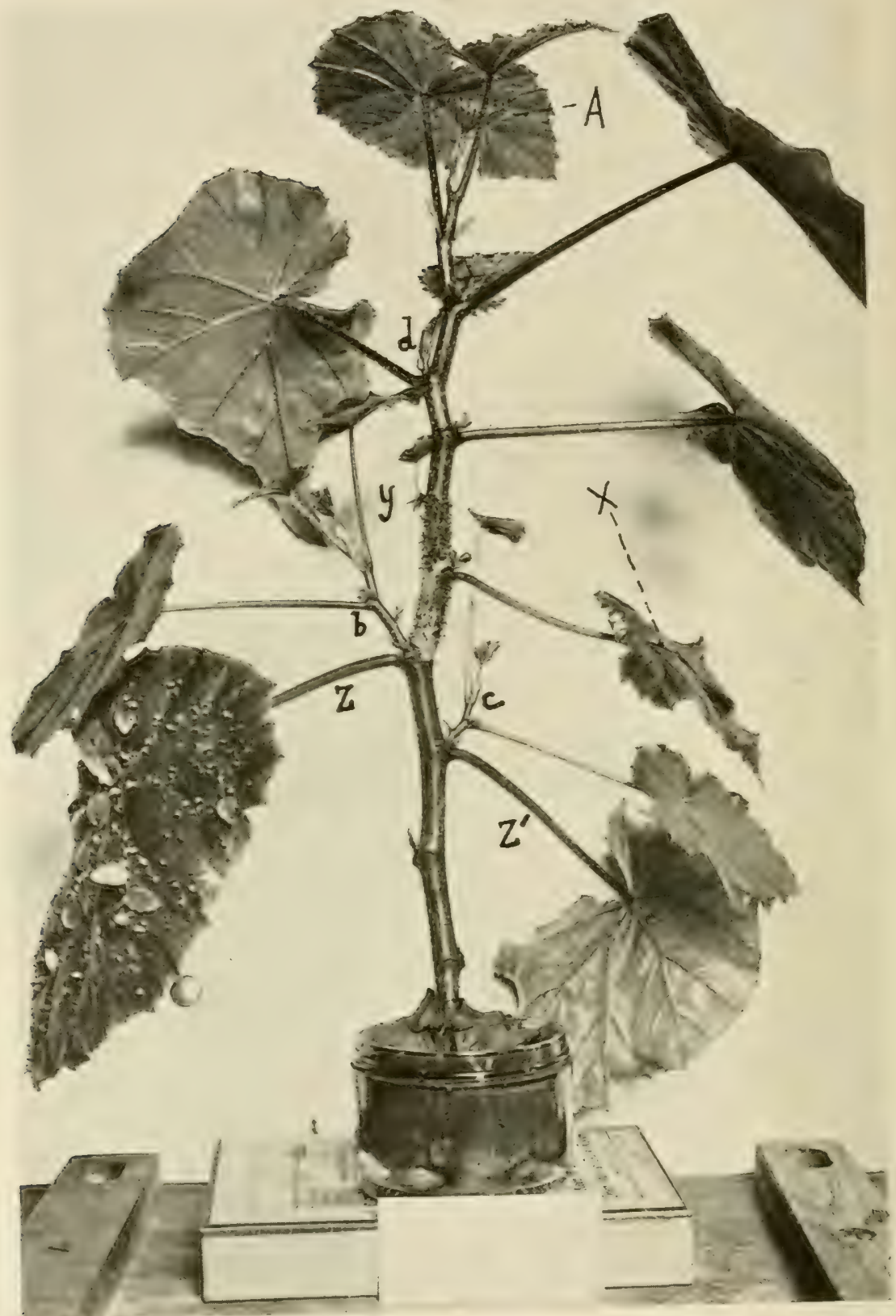

FIG. 432.-No. 6, first series, branch arising underground. $X$, dwarfed proliferous leaf; $Y$, scar of fallen leaf (probably also dwarfed and proliferous); 
$440 B, 449,450)$. Apparently, on the internodes the shoots are not restricted to the vicinity of the glands, but this may be more apparent than real, since the glands disappear early. The very young normal tissues of this begonia are red, the wound-repair tissue also is red. The epidermis of developed organs is green but those parts of the leaf giving rise to the acicular hairs are red, as if still embryonic.

13. I was led to study this curious plant, which is smooth rather than conspicuously hairy or sealy (Fig. 425), thinking it might throw some light on the origin of teratomas in animals and hoping that I might be able to discover some law underlying its peculiar and apparently lawless beharior. I had one plant at first, from which by cuttings I have propagated many. For a long time this plant, which was left undist urbed, behaved much like any other begonia plant. It refused to throw new adventive shoots, although it bore some old ones, and I was much discouraged, but by persistently experimenting with it I have succeeded in making it do wonders. The hist ory of my plant, as far an I have been able to trace it, is that it was propagated from a plant descended from one which was received at the Washington Botanic Garden more than 18 years ago. The present superintendent does not know its origin but as Mr. smith, the former superintendent, was a Kew man. I suspect it to have come from the Kew Gardens where B. phyllomaniaca has been grown for a long time.

14. In good soil, exposed to medium hothouse temperatures and not over-watered, ${ }^{1}$ the plant grows freely and is healthy. There is, however, little substance to it. By this I mean that it has a large watery pith, a thick soft cortex and only a thin woody cylinder, the amount of water in it being excessive as compared with most plants of its size and age. For example,

${ }^{1}$ If watered abundantly the plant in our houses is frequently attacked by a fungus (Fusarium sp.) and rots off at the surface of the earth.

$Z$, a well developed proliferous leaf $b, c, d$, branches of recent origin. The corky proliferous internodes are between $Y$ and $Z$. Their back was free from cork and entirely proliferous (Fig. 434, Sub. 2). $Z$ was the small top leaf of July 25, corresponding to leaf $A$ in this photograph. For upper face of $Z^{1}$ see Fig. 433. Photographed October 11, 191s. About 1/4 nat. size. 


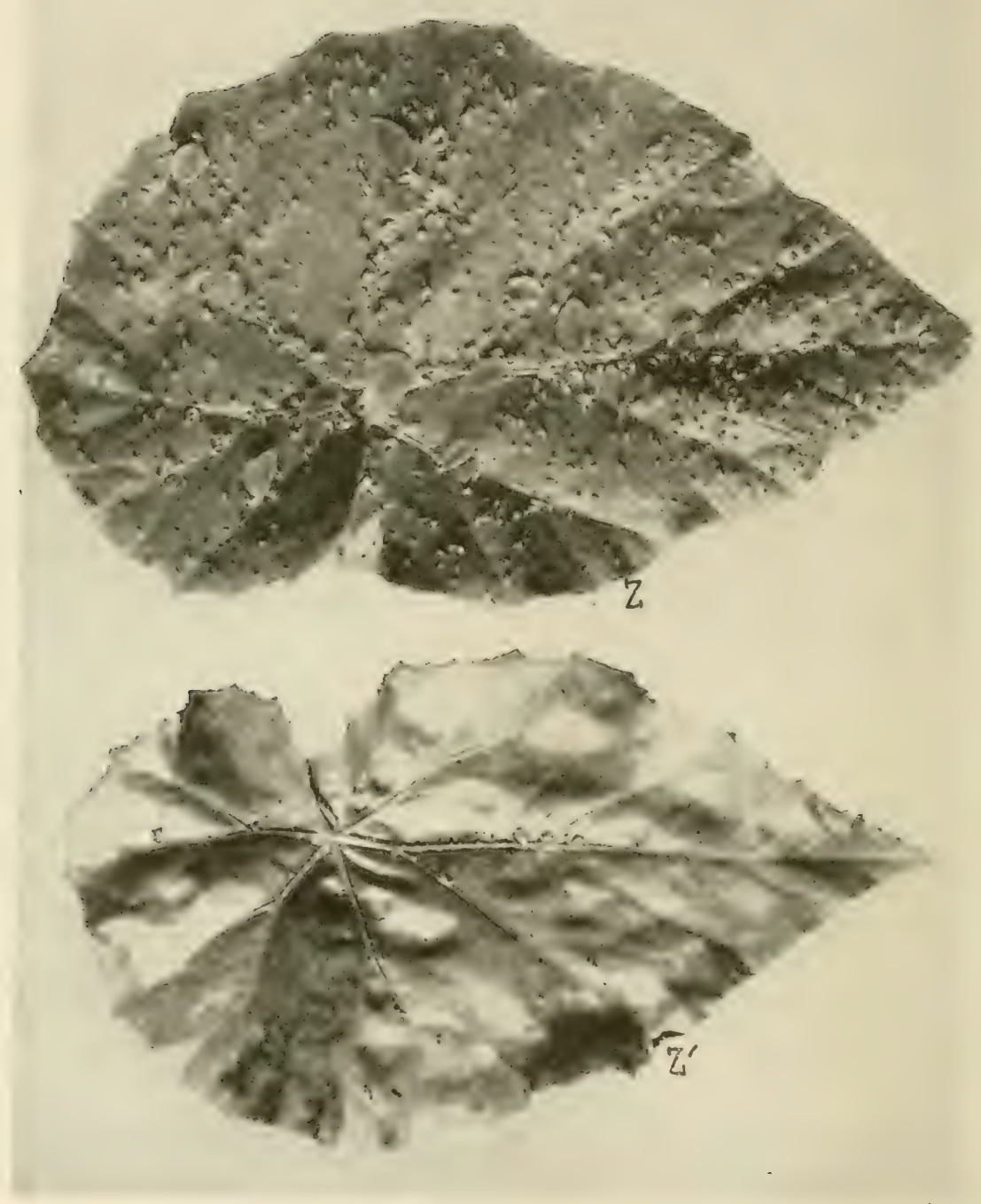

FIG. 433.-No. 6, first series. Upper face of leaves $Z$ and $Z^{1}$ of Fig. 432. $Z$ shocked on July 25. $Z^{1}$ was too old at that time to respond freely. Notice regular distribution of shoots in $Z$ and compare with midrib distribution on Figs. $438,441,442,443$. Notice also that the largest leaves are over the main watersupply, i.e., over the midribs. About is natural size. 


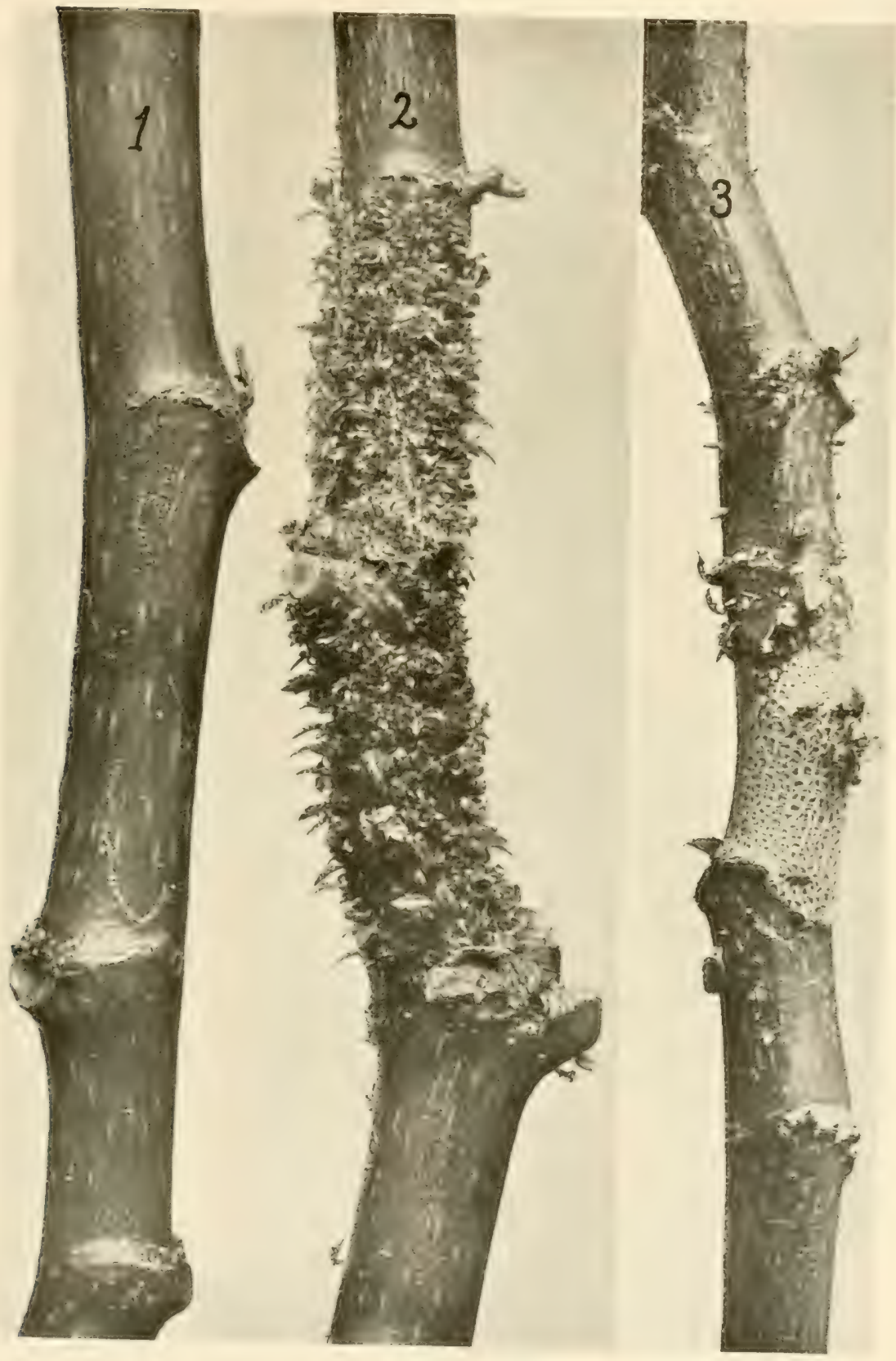

FIG. 434.-(1) Lower and (2) middle internodes of a shoot of Begonia phyllomaniaca (No. 6, 1st series). The middle internodes were induced to proliferate 
the above-ground parts of a plant ten months old, 3 feet tall and weighing 399 grams, yielded only 28 grams, or 7 per cent, of water-free substance, most of which, of course, was the woody part. My attention was first called to its watery nature by its marked shriveling when put into alcohol, by its prompt disintegration in boiling water containing acidified copper acetate (I could not make a coppered "specimen" of it), and by its extensive watery hypoderm. It is not known just where begonias belong in the natural system, but their general appearance and behavior would seem to indicate that they are primitive plants or at least hark back easily to prinitive conditions. They are said to be shade-loving plants, but the only one I have seen wild grows on rocks in a tropical sun, and all I have examined under the microscope seem to me to show a xerophytic structure. Probably some grow in one place and some in another.

15. I should now state the kind of shocks that cause the plant to throw adventive shoots in great numbers. I use the expression "in great numbers" advisedly because the plant is so sensitive that it is always throwing more or less adventive shoots, especially around the stipule-scars, and I am not speaking of its normal beharior but of an abnormal, local and very excessive proliferation, as may be seen from my plates.

I first experimented with stem- and leaf-woundings. These are effective, but only if made at the proper time, that is, on young tissues. My first experiments made on 1, to 12 grown leaves and internodes failed, probably because such tissues are too mature. Later, I got many striking results by wounding very immature leaves. My best results were on leaves the blades of which were still red and not over an inch long (the blades of mature green leares on well-grown plants are 7 to 10 inches long). Here, from the margins of needle-pricks and small knife-wounds, where a red callus develops, I obtained dozens and scores of adrentitious buds, so many, in fact, that often they were counted with difficulty (see Fig. 447 , where only the larger

by root injury when these internodes were very small, i.e., wrapped in the bud, and the proliferation is ascribed to stimulation due to loss of water.

3. A branch of No. 1, 1st series, where the proliferation was largely restricted by cork-formation which developed in the stimulated internode. 


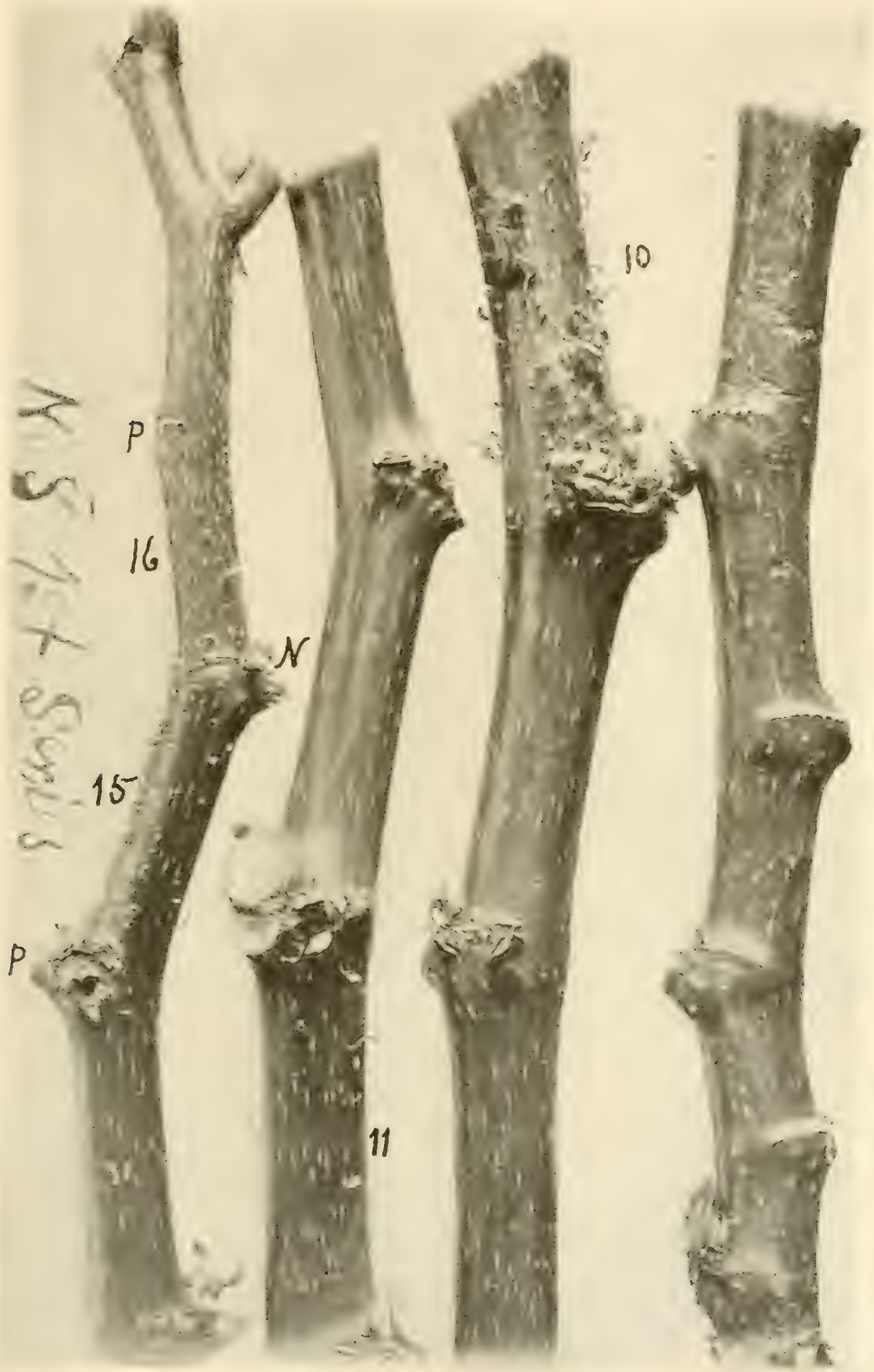

FIG. 435.-No. 8, first series. Main axis. The proliferous internodes are 15 and 16 and these were embryonic and stipule-wrapped on July 25. An old stimulus (due to the May repotting) is shown at 10 and 11 , where all but a few of the shoots have shriveled and fallen, especially on 11 . The leaves $p, p$, were proliferous. The leaf $N$ was not proliferous. Most of the shoots were on the left side of internodes 15, 16. Photographed October 21,1918. 


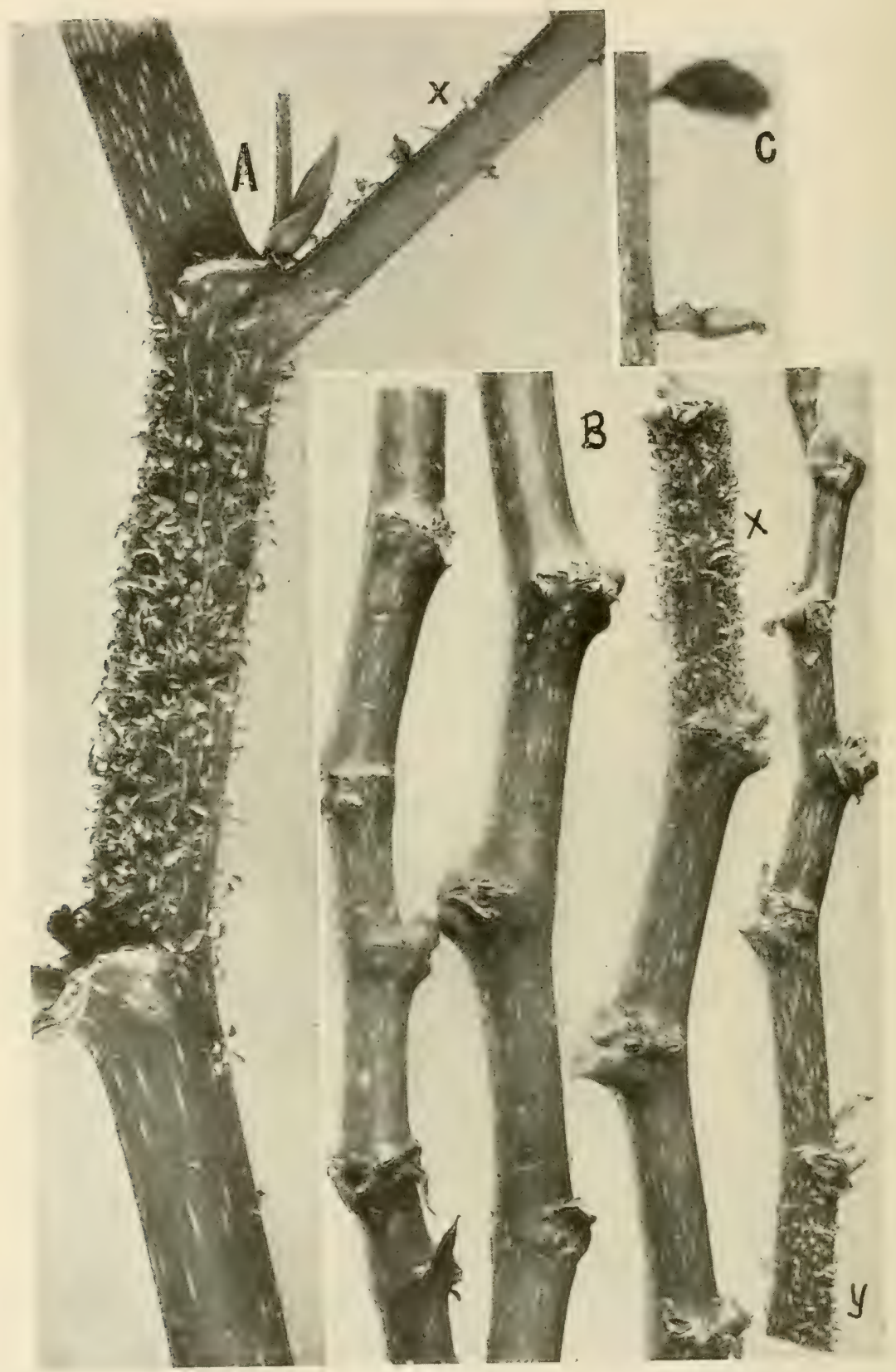

Fig. 436-A. No. 8, first series, third branch, showing proliferous and nonproliferous internodes. The proliferous internode and leaf above it $(x)$ were stipule-wrapped on July 25. Photographed October 14, 1918. $\times 1 \frac{4}{5}$. 
ones are visible), while the vast mass of the leaf remained free or nearly free from such buds. On some leaves, as may be seen from Table I, the lips of the wounds bore many times more shoots than the rest of the blade, e.g., on the leaf from branch $I_{2}, 1_{40}$ of the surface (the wounded part) bore 183 shoots while the remaining 3940 bore only 8 shoots; on the leaf from branch $I I I_{1}, 1 / 19$ of the surface bore 141 shoots while the remainder bore only 5 shoots; on the leaf from branch $V_{2}, 1 / 43$ of the surface bore 58 shoots, the remainder only 3 shoots. The number of shoots from wounds is strictly conditioned on the nutrition. Generally each wounded leaf received enough food to enable a portion at least of the adventive shoots to develop, but occasionally not (see Fig. $448 B_{2}$ and the footnote to Table I).

16. This local response, however, did not explain the origin of extra-axillary buds in the absence of visible wounds and I was especially puzzled by the fact that often one or two internodes or leaves on a plant would bear hundreds of these adventitious buds (Figs. 426, 427) while all the others were free or nearly free from them (Fig. 425, exclusive of $x$.)

17. Believing the response must be due to excessive loss of water I next tried the drying of cuttings for a short time before planting them. In this way, frequently, I obtained more or less striking results at the top of the plant, i.e., in the parts which were embryonic at the time of making the cuttings, especially if the cuttings were allowed to dry for a day or two before planting. but this method did not give as uniform results as the following, especially when the drying period was short.

18. In the spring of 1918 I discovered that the striking response referred to under 16 was due to root-injury sustained at the time of repotting. The results of my preliminary observations were so convincing that I had no doubt as to the correctness of my conclusions, i.e., that the very copious restricted or regional response was due to root-injury acting on young tisisues.

B. No. 9, first series. Entire main axis (leaves removed). The two proliferous internodes, at $X, Y$, were embryonic and stipule-wrapped on July 25. For the opposite side of a part of $X$ in more detail see Fig. 439A. Photographed October 10, 1918. Reduced.

$C$. Shoot arising from a hair on a petiole. The trichome top is shoved over to the left and its base is much thickened. $\times 10$. 


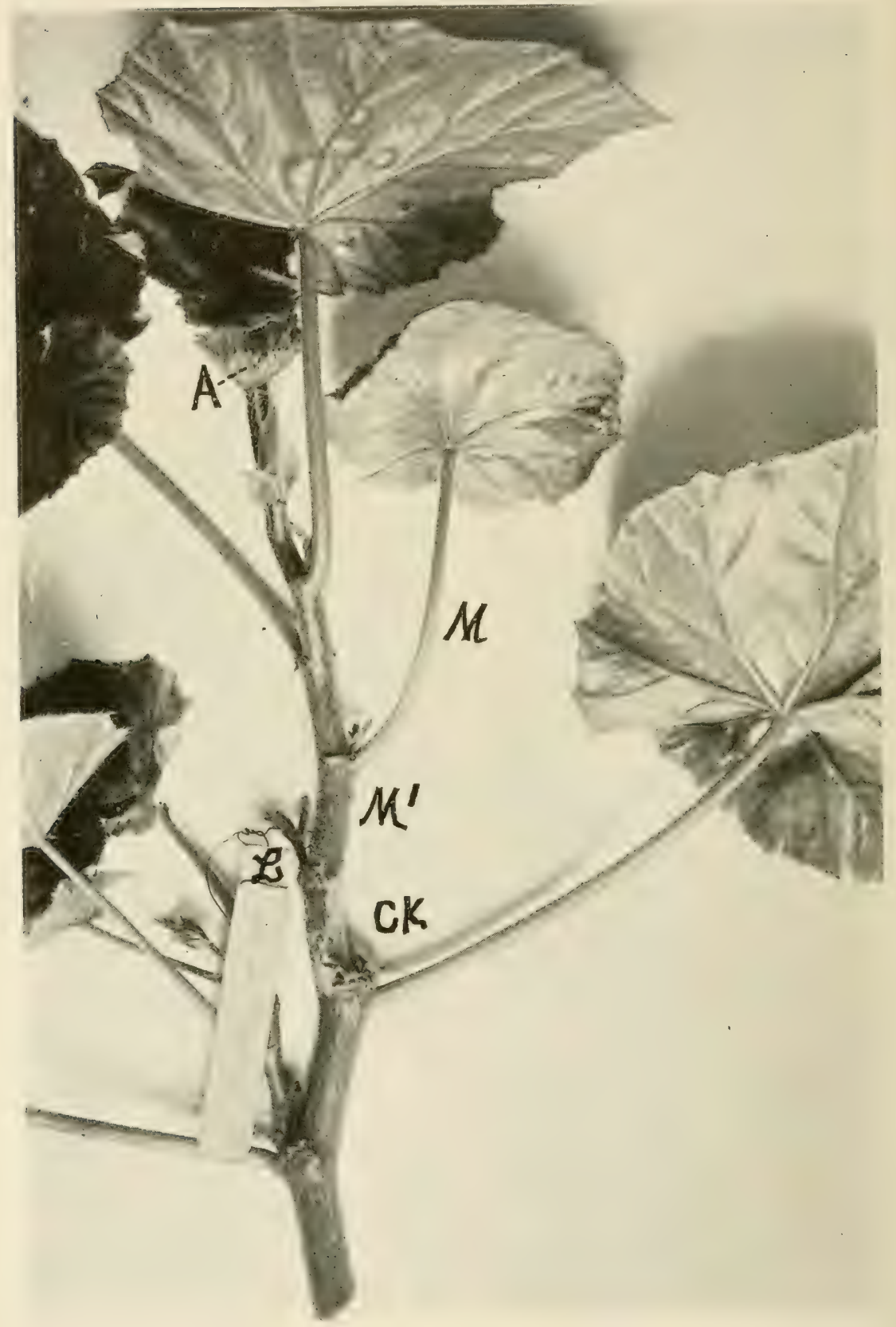

Fig. 437.-No. 3, second series, main axis. The leaf $L$, which has fallen, $v$ as the topmost small leaf on July 12 corresponding to Leaf $A$ in the photograph 
In other words, the organs then full grown and proliferous were embryonic some weeks earlier at the time of repotting when the shock was assumed to have occurred. I reached this conclusion by knowing about how much growth a given plant was able to make in 6 or 8 weeks and counting back in this way from its tip several internodes I would come always to the leaves and internodes showing the excessive proliferation of shoots, which leaver and internodes must have been quite small at the time of the repotting. This, of course, while a legitimate inference, did not. throw any light on the exact size of the leaf or internode (stage of development, wrapped or unwrapped) when the shock occurred and, other than inferentially, did not prove the phyllomania to be due to loss of water, nor did it answer the question: Can you get it again, or is it seasonal and outside of experimental influence?

19. In July, 1918, therefore, I measured and made records of the stage of development of each leaf and shoot on 18 wellgrown plants before they were repotted, the final records being made in the afternoon of July 23 and the plants repotted the next forenoon at which time many of the superficial roots were cut away. These were plants 10 to 20 inches high (most 13 to 18 inches) with many fine leaves. They were grown from dried cuttings set out March 28, 1918. Every one of them responcied to the shock more or less, and most of them (all but one dwarf plant) strikingly (see Figs. 429, 430, 432, 434, 435, 436, 439.4, and first part of Table II). The dwarf referred to was branched six times at or near the surface of the earth when examined in October and showed no phyllomania on its internodes, but when reexamined six weeks later adventive buds in small numbers and large corky patches were developing from the proper internodes on four of the six shoots.

20. In a second experiment I used 16 larger plants standing on the same bench. These were plants grown from dried cuttings planted December 26, 1917. These 16 plants were

Leaf $M$ (dwarfed) and the internodes $M_{I}$ and $C K$ were embryonic and stipulewrapped on July 23. Cork has formed at $C K$. Both $M$ and $M_{1}$ are full of shoots and also $C K$ where it is not covered with cork. $L$ undoubtedly was also proliferous. Photographed September 30, 1918. Much reduced. 


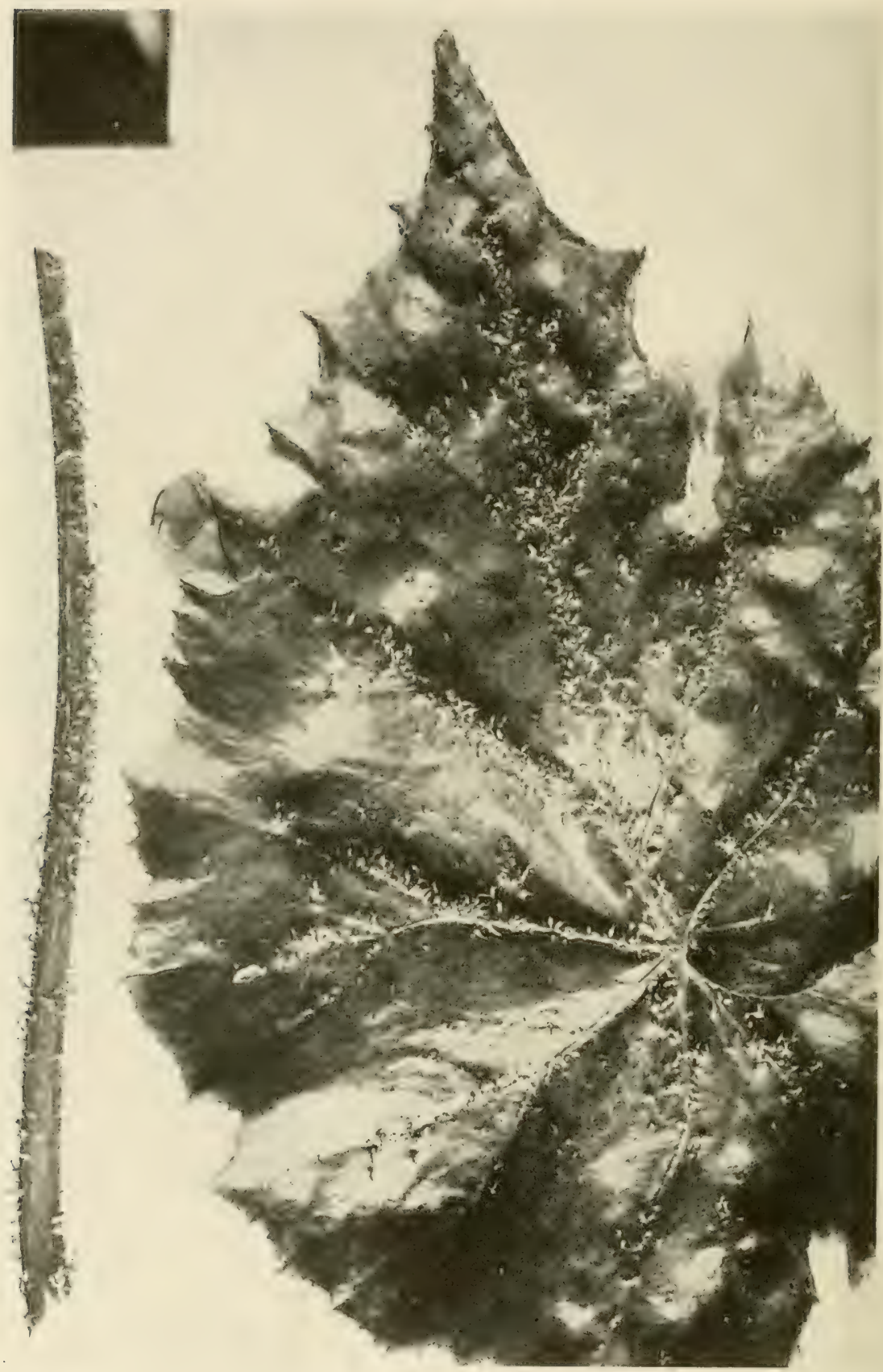

FIG. 438.-No. 9, second series, main axis. Upper face of leaf $M$ which was 
repotted July 25, many with root-woundings. Each one responded to the shock and most of them (all but two) very strikingly (see Figs. 437, 438, 439B, 440, 443, 444 and second part of Table II). It was, in fact, the response of these plants to the original drying of the cuttings in December, 1917, and to April and May pottings which had given me a clue to the cause of the proliferation. Unfortunately for completeness sake, it did not occur to me to make Table II until I had examined and thrown away a number of the plants without counting their many proliferations.

21. In another experiment (Series III, begun after the conclusion of Series I and II because the results were so astonishing that I wished additional confirmation) I made use of 29 plants. The principal dates are as follows:

July 12, 1918, cuttings made and left on the bench in dry air for three days.

July 15. Cuttings bedded in sand to root and watered sparingly.

August 6. , Plants set into 4-inch pots.

September -. Plants set into 6-inch pots.

November 12. Plants shifted to 8 -inch pots where they remained undisturbed until the close of the experiment.

March 15, 1919. Experiment closed and plants used for other purposes.

Results: The history of these plants, in which the proliferations also occurred in the summer and autumn, not in the winter or spring, is as startling as that of Series I and II. During the first four months, in which the plants were subject to repeated loss of water, from the initial drying and from the root-disturbances due to three pottings, each one of these 29 plants proliferated enormously on a great many leaves and internodes (Fig. 445). In fact, most of the leaves and internodes, exclusive of those which were large when the cuttings were made, proliferated and many of them bore hundreds of shoots. On the

an embryonic, stipule-wrapped leaf on July 24. Proliferous petiole at left. Most of the 1760 shoots are from the petiole and the vicinity of the midribs. The leaves above and below this leaf were comparatively free from shoots. Photographed September 27, 1918. About $3 / 4$ nat. size. 


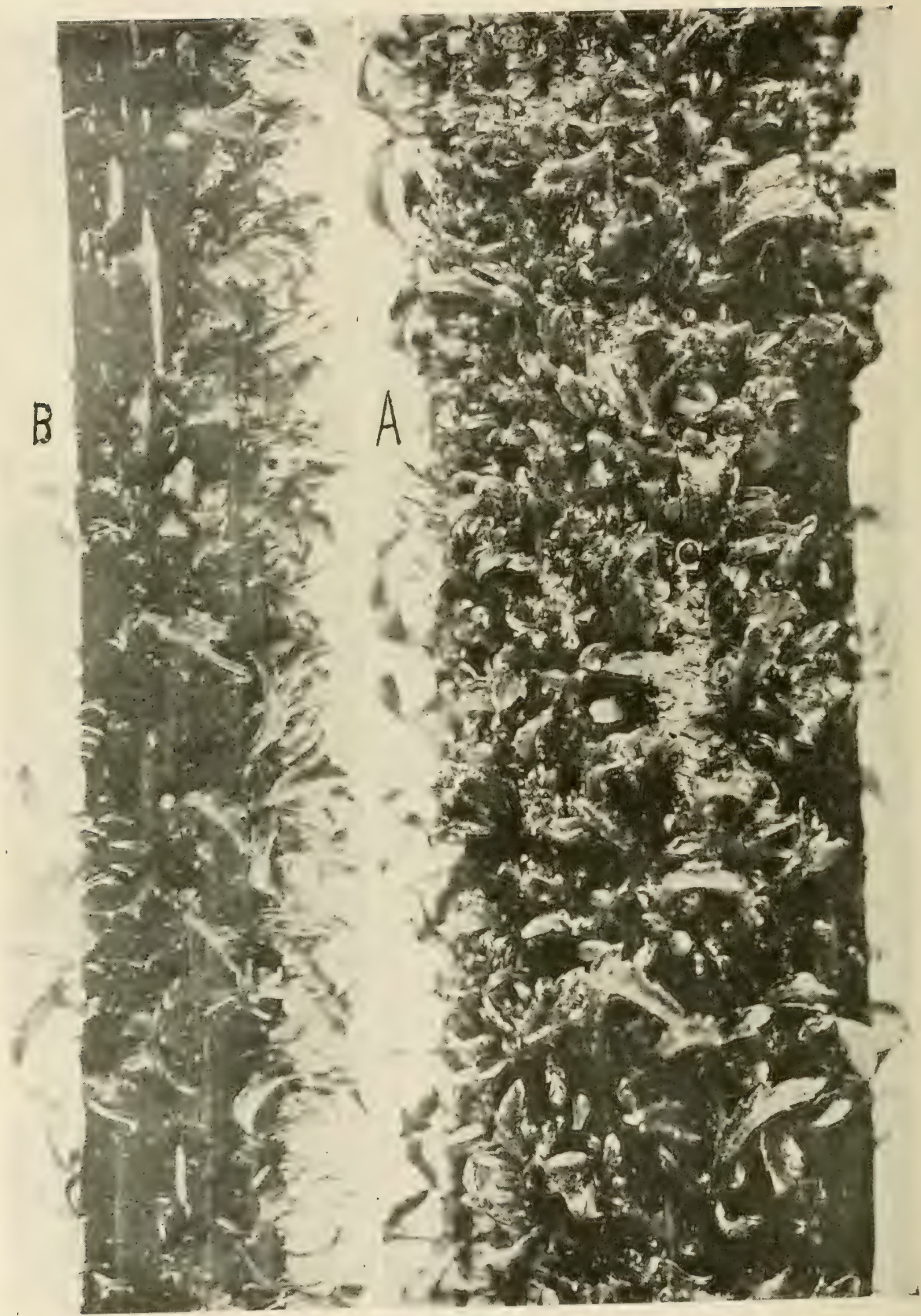

FIG. 439.-A. No. 9, first series. Middle part of lower proliferous internode (back of $X$ in Fig. $436 B$ ). In the center at $C$ a small corky area. Photographed October 10, 1918. $\times 4$. 
first of December it did not seem as if the plants would ever produce smooth leaves, but during the second four months, in which the plants remained undisturbed and were watered sparingly but regularly and sufficiently, they proliferated either not at all or scarcely at all, producing several hundred smooth leaves and internodes, so that on March 15 each one of the 29 plants closely resembled the plant shown on Fig. 425.

When finally examined on March 15 nearly all of the lower very proliferous leaves had fallen (see Table III) but there were still a large number of proliferations visible on the lower internodes, that is adventitious growths on the lower 5 to 9 inches of the stem, corresponding to the stimuli of July 12-15, August 6, September - and Norember 12, but all of the upper 15 or 20 inches of the plant was so nearly free from adventive shoots that one would say entirely free until he examined closely, when a few shoots were found here and there on the leaves and internodes, but in no case dozens or hundreds, as during the first period. Great numbers of the leaves were particularly fine and smooth. In other words, undisturbed, the plants ceased to proliferate, except around the stipule scars which are places more subject, it would seem, to loss of water than other parts and which always proliferate except on the youngest nodes, upper 4 to 6 inches of the stem (Fig. $445 \mathrm{St}$ ) where the stipules are still living. The above statements hardly express the full difference, because at the close of the experiment (March 15) there were more than 800 smooth leares, whereas on the first of December there was not a single one.

22. It now remains to consider the nature of this shock, since merely to say that wounding causes it, or that it is the plant's response to a wound, does not satisfy, and especially not, because the place of response, as we have seen, may be very far away from the place of wounding, i.e., as far as from the roots to the top of the plant. I have only a hypothesis to offer, but it is confirmed by the experiments, fits in very well

B. No. 9, second series, main axis. A small portion of the proliferous petiole of Leaf $I$ (Fig. 438) enlarged. Nearly every trichome has developed a shoot. $\times 4$. 
with some other facts, already detailed in the preceding chapters, and may help to throw light on the mechanism of the response, and also, perhaps, on the origin of animal teratomas and of certain cancerous phenomena.

23. First, let us try to conceive what takes place in the plant when it is suddenly deprived of a part of its roots by cutting or breaking, while others cease to function, owing to loosening of the previously compact earth. One thing at least happens with certainty, there is a sudden marked diminution of the very considerable water-supply necessary for the well being of the plant. The plant is transpiring more or less freely over a broad leaf surface (several square feet) and suddenly it is deprived of its water-supply. This, I believe, is the shock which starts the dormant totipotent cells into development. It is impossible that the plant should wholly cease to transpire. Since it must breathe to live, water will escape from its stomata and lenticels, and it seems likely that the thin-walled, immature and delicate tissues of the terminal buds will be just the ones from which proportionately most water will be abstracted to meet this unusual demand and which will be most shocked by the loss they sustain. That the plants lose water in excess is demonstrable by the balances. Other phenomena also occur but these are secondary results, e.g., there is sometimes slight wilting especially in cuttings, growth above-ground ceases for a short time and the elaborated food that would have been used for further extension of normal shoots is sent downward to make new roots. The aëration of the interior must also be less perfect than it was since the absorbed water always carries dissolved air. Less oxygen, therefore, will reach the tissues, and, theoretically, they should become more acid than normal. ${ }^{1}$

\footnotetext{
${ }^{1}$ Subsequently I tested the terminal buds of 42 plants of Series VI with the following results:

A. I. 21 tops (bearing $4-5$ leaves) cut from the plants and dried 48 hours at $28^{\circ}-30^{\circ} \mathrm{C}$. on a laboratory table (July $12-14,1919$ ) in diffuse light:

1. Fresh weight, 740.25 grams.

2. Loss of weight in 48 hours, 191.50 grams.

3. Juice of the 21 buds crushed at end of the 48 hours, extracted 10 minutes in hot water $\left(90^{\circ} \mathrm{C}\right.$., falling to $35^{\circ} \mathrm{C}$.), squeezed dry in a hand screw-press and filtered:
} 
There can be no reasonable doubt, therefore, that the tissues which afterward proliferate not only lose water, but become more acid.

In a week or two all the root-injury has been repaired and the plant takes on a new and vigorous growth and apparently no harm has resulted. This new growth is, of course, from the terminal buds which were shocked and the leaves and internodes of which will exhibit copious proliferation when they develop. As growth continues and the shoot elongates we soon come to leaves and internodes formed after the date of the shock and these will be free or nearly free from adventive shoots, like the lower older tissues which were mature or semi-mature at the time of the root-injury. Thus we may have on a large plant

Acidity +158 (Fuller's scale). The readings of the 3 titrations were 159,157 and 158 .

II. 21 fresh terminal buds brought in, crushed, extracted, squeezed and filtered as above:

Acidity +126 (three titrations, each of which gave the same reading).

This experiment was repeated some days later (July 22-23) with the following results:

B. I. 9 tops (bearing 4 and 5 leaves each) cut away and left on a table for 24 hours:

1. Fresh weight, 288 grams.

2. Loss of weight in 24 hours, 44.5 grams.

3. Juice of the 9 buds including uppermost small undeveloped red leaf extracted from crushed tissues 10 minutes in hot water $\left(90^{\circ} \mathrm{C}\right.$., falling to $35^{\circ} \mathrm{C}$.), squeezed dry in a hand press and filtered:

Acidity $+\mathbf{1 8 0}$ (Fuller's scale). No reducing sugar present. It is a faintly clouded pink liquid.

II. Juice of 9 fresh buds treated in the same way:

Acidity +168 . No reducing sugar. The pink liquid is decidedly cloudy and contains at least 10 times as much starch as $I$.

C. I. In December, 1919, 24 rather slender shoots from side branches, each bearing several leaves, were eut away, weighed and left in a heap in an open wooden box on the hothouse bench fur three days, the first two of which were cloudy and wet:

1. Fresh weight 242.25 grams.

2. Loss of weight in 72 hours 59.75 grams.

3. The 24 terminal buds were then removed, weighed, crushed ( $7 \mathrm{~min}$.), extracted 8 minutes in 50 c.c distilled water at $90^{\circ} \mathrm{C}$. falling to $35^{\circ} \mathrm{C}$., squeezed dry in a hand press, filtered and titrated. The fluid was a cloudy pink which a drop or two of the alkali changed to colorless:

Acidity +195 (Fuller's scale).

II. Juice of 24 fresh buds treated in the same way:

Acidity +190 . 


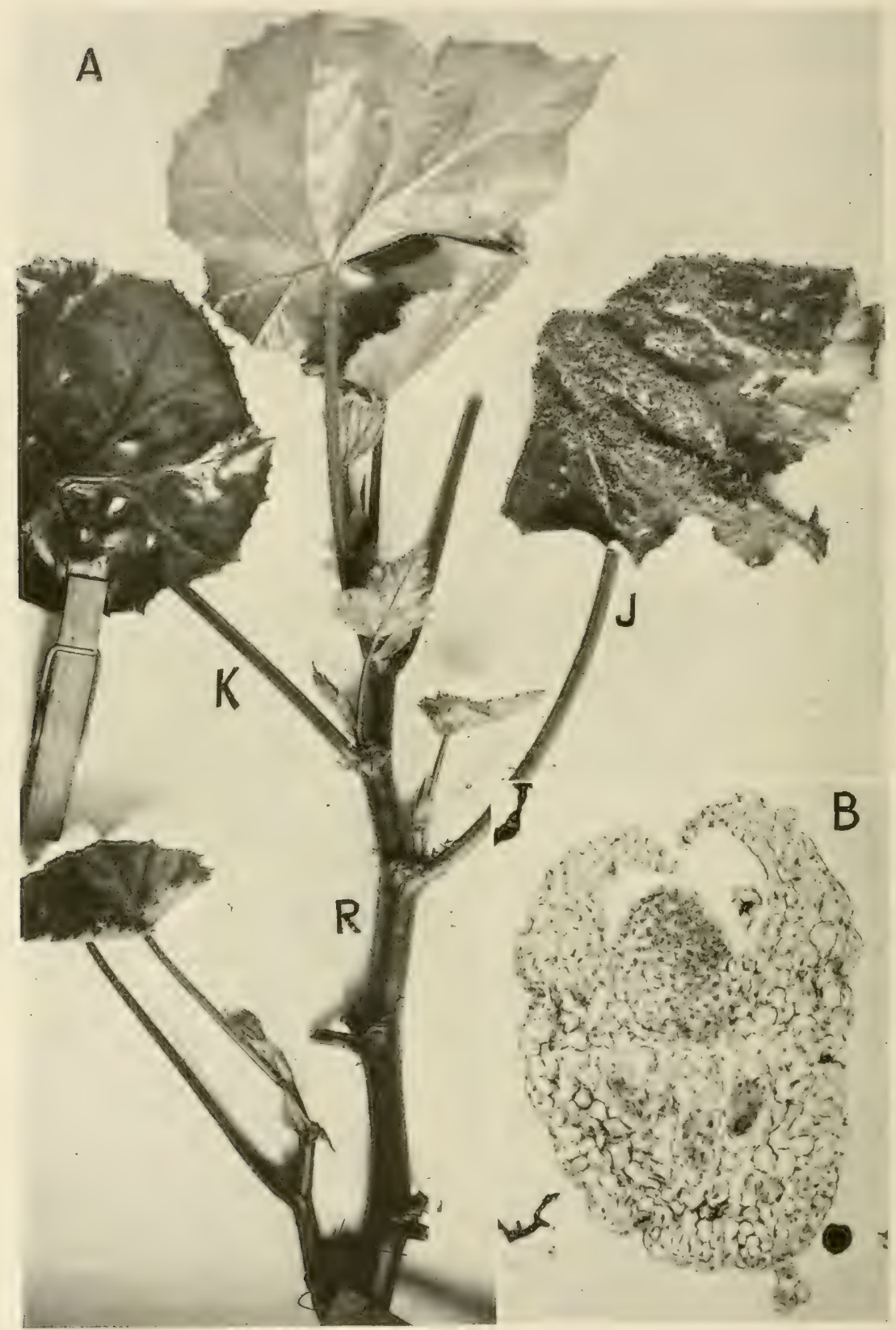

FIG. 440.-A. No. 10, second series, main axis. Leaf $J$ not dwarfed but enormously proliferous and twisted, 4000 shoots present, nearly all on upper surface. 
a series of proliferous leaves and internodes, corresponding to a series of pottings or water-interruptions, separated from each other by leaves and internodes free or nearly free from such shoots.

24. The normal upward movement of water from roots to shoots being thus interrupted, the water movement will now be from inner parts of the stem toward the surface and especially toward the leares, and undoubtedly some leaves will transpire more than others, making at times an unequal drain upon the young tissues which will be manifested later by the development of an unequal number of adventive shoots. There will be also, as I have said, an abstraction of food which must move downward to repair the roots. That there is often a real shortage of food in the plant at this time is shown by the frequent stunting of the shocked and proliferous leaves. Often, when full grown, although by no means alway, the shocked leaf is plainly smaller than the leaves below it or the ones above it (Figs. 430P, 432X, $437 \mathrm{M})$. Occasionally it is not $1 / 3$ or $1 / 5$ the size of the next leaf below it or the next leaf above it; although it is generally full of adventive shoots, or pimply with their rudiments. But on the other hand, a very profound phyllomania may occur (many hundreds of shoots developing) on big leaves (Figs. 432z, $\left.440 j, 446_{4}\right)$ which exhibit no evidences of starvation. I take the starvation and the shock, therefore, to be two distinct things. The shock, in other words, I believe to be of short duration, like that due to the particles of acetic acid water or other substances which start the growth of intumescences on cauliflower leaves, like the crown-gall stimulus which determines the growth of adventive shoots in tumors on internodes of various plants, or like Bataillon's needle prick which starts the unfertilized frog's egg into growth, ${ }^{1}$ while the starvation, if there is any, extends

${ }^{2}$ Comptes Rendus des sé. de l'Acad. des Sci., Paris. 1910, Tome 150, page 966. Confirmed by Jacques Loeb. Proc. Nat. Acad. of Sciences, vol. 2, 1916, p. 313.

Contrast $J$ with $K$ the next leaf above it which is nearly free from shoots. Axis proliferous at $R$ especially on the back side, but very much less so than the leaf $J$, or than other internodes shown on these plates. For center of the twisted proliferous leaf blade (not shown here) see next plate. Photographed October 1 , 1918. About 1/2 natural size.

B. Cross-section of a petiole-trichome showing the origin of a shoot. $\times 80$ circa. 


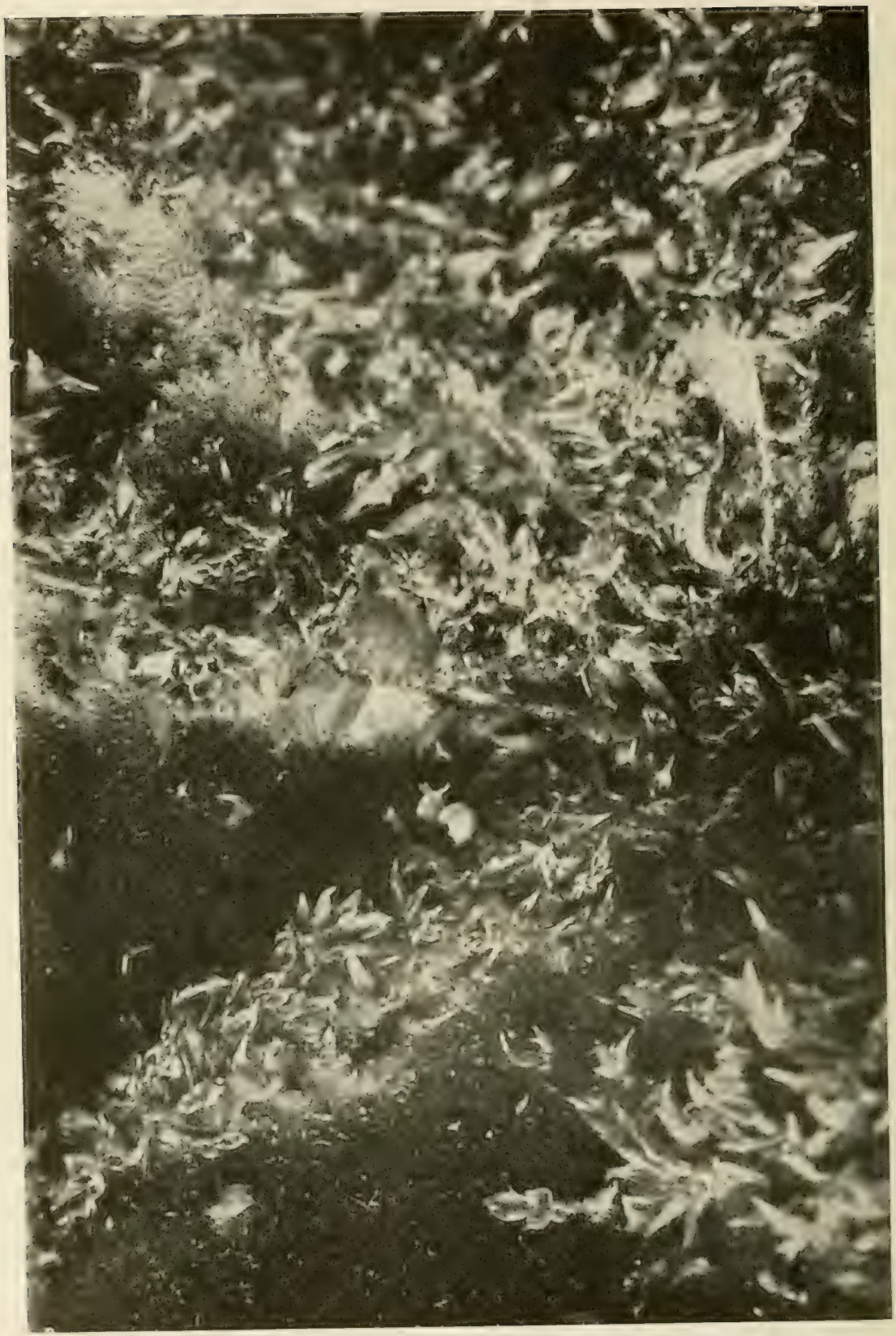

Fig. 441-Central part (upper face) of leaf $J$, of Fig. 440. Proliferation chiefly from the midribs. Photographed October 1, 1918. Part out of focus because not all in one plane. $\times 5$, nearly. 


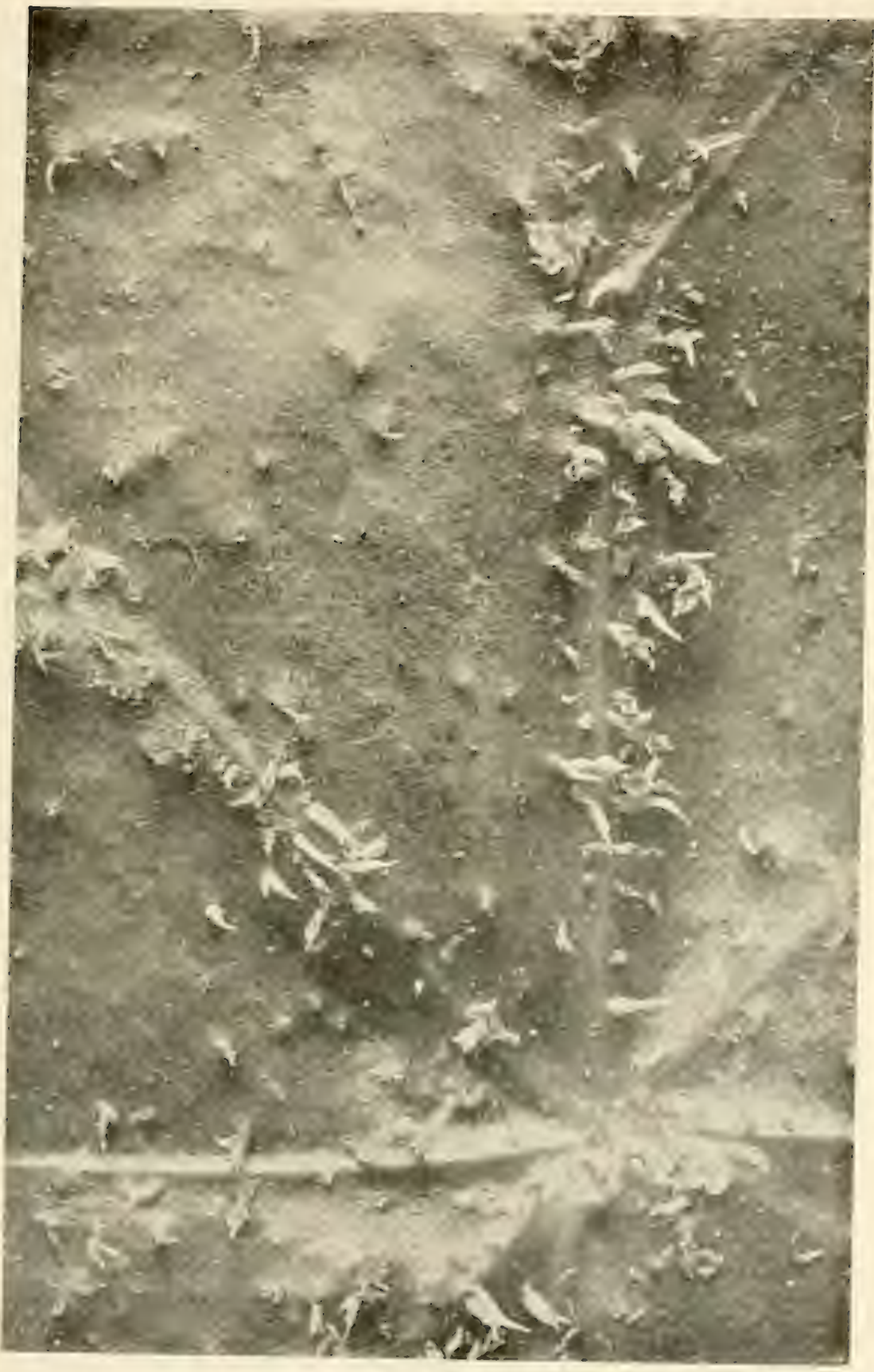

FIG. 412.-No. 10, second series, middle leaf of a branch from the axil of leaf $G$. Most shoots are near the main source of food and water supply, i.e., are in the vicinity of the midribs. Photographed October $1,1918 . \times 4$ circa. 


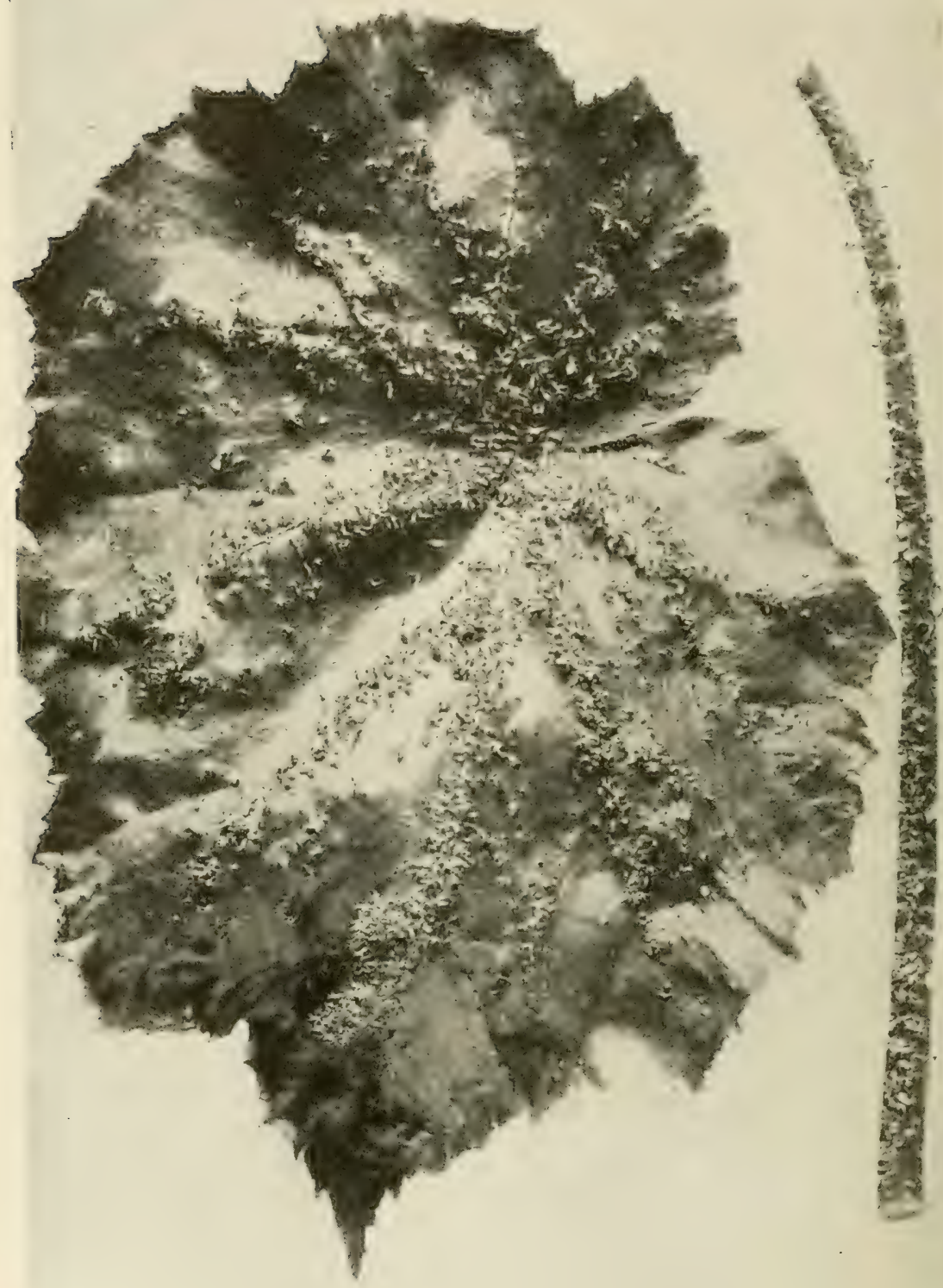

FIG. 443.-No. 15, second series, main axis. Upper face of leaf $L$, which was embryonic and stipule-w rapped on July 24. On the blade there are 1700 embryo shoots, mostly upon of near the main ribs; on the petiole, 420 shoots. Photographed October 7,1918 . About $3 / 4$ natural size. 
over a considerable period, one long enough to produce a dwarfing from which the leaf cannot recover. Such leaves look sickly and may fall early. Oceasionally, when they are greatly dwarfed, although extremely pimply, they bear very few shoots, as if the latter could not develop for want of food.

The prolification, I think, can hardly be brought about by starvation which we know may throw dwarfed plants of various kinds into premature or excessive blossoming, since it is common observation that in a great variety of woody plants in full and vigorous foliage there is enough food present in the roots and shoots to make an entire new set of leaves in case the leaves have been destroyed wholesale by caterpillars or by frost, but hardly ever enough for a third set of leaves. Moreover, this begonia may be kept in a small pot for a very long time without starving it into phyllomania. There would appear, therefore, to be an abundance of food in these broad-leaved vigorous plants so that totipotent cells in the embryonic epidermis need not behave as if in the last stages of starvation, even granting that they would proliferate, if starved.

25. That there is excessive loss of water from the shocked leaves and internodes would seem also to be indicated conclusively by the fact that very frequently corky patches are developed on such organs, especially on the internodes (Figs. $432,434_{3}, 437,449_{3}$, and Table III), often entirely surrounding them, while cork is present nowhere else on the plant either above or below. This, I interpret, as a more or less futile effort on the part of the organ to protect itself from loss of water.

In this connection Series VI is also very interesting. This experiment deals with 59 plants. It was begun on March 5, 1919, and the principal dates are as follows:

March 5. Cuttings made and left to dry on the hothouse bench.

March 7. Cuttings bedded in sand.

May 7. Rooted cuttings transplanted to 4 inch pots.

June 2. Transplanted to 8 inch pots.

The plants grew splendidly and were mostly unbranched and about 15 to 16 inches high on July 12 to 23 when the tops were 

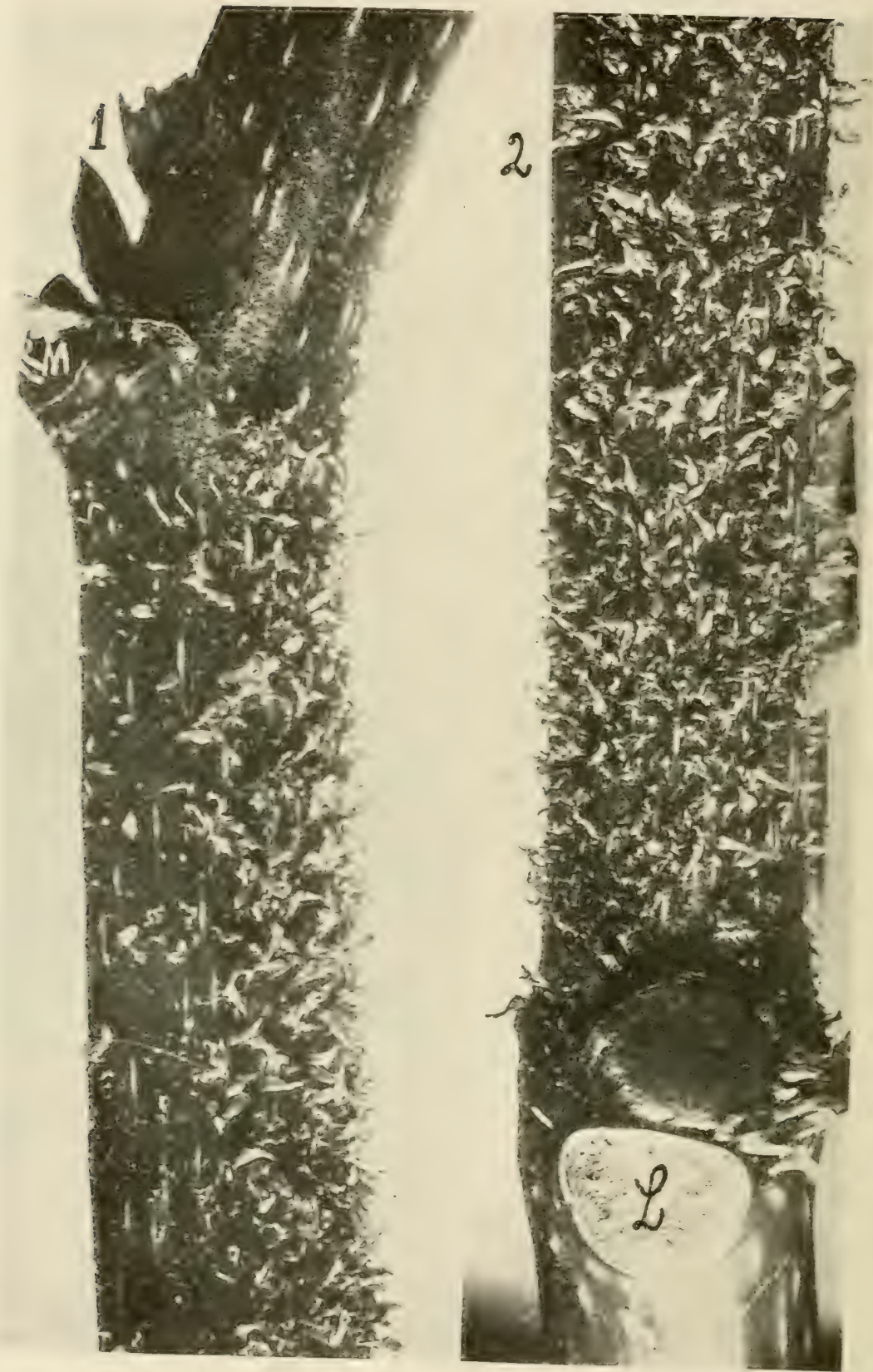

FIG. 444.-(1) No. 18, second series, main axis. Upper part of proliferous internode. Shoots mostly on the right side. Leaf it Upper part of proliferous 2. Same os the above but low par. $\times 4$. left to show the cut away. Photographed September 28 , Leaf $L$ and its branch 
cut away (upper 4 to 5 leaves) mostly for the titration experiments described on page 600 .

Result in November: Dormant buds just under these tops have now pushed stunted small shoots 12 to 4 inches and these are covered with cork, some almost entirely, others partially, and where not very corky they have also pushed adventive shoots. The leaves are small (stunted) and many of them have fallen. These small upper side shoots most of which were undeveloped, but some of which were an inch or so in length when the top was removed, are the only corky parts of the plants, and each of the 59 plants (all of which were cut back) shows this cork phenomenon to a rery striking degree. Some of the plants also show cork-formation on the main axis immediately under the cut (the upper inch or so of the stub). These are the stems which were softest at the time the tops were remored, and which lost most water, as shown by their contracted and flattened shape. It is a striking confirmation of my idea that loss of water induces cork formation and the adventive shoots.

26. Why loss of water should shock dormant cells into growth I have undertaken to discuss in the preceding chapters. It seems to me likely that the initial stimulus to all spring growth of land plants may be conditioned on gradual winter losies of water through stems and twigs. This would be more rapid in mild winters than in cold ones. When the removal of water from the dormant buds has reached a certain point then they will begin to grow. Etherized plants also push their shoots earlier than normal plants and in this case also we may suppose that there is excessive loss of water from cells of the buds through the temporarily paralyzed protoplasmic membranes. Te should distinguish. I believe, between the initial shock or stimulus, the cause of the first cell-division of a dormant totipotent cell, and the subsequent growth, which latter depends on renewed foodsupply, water-supply, proper temperature, etc. and will proceed as a matter of course, once the initial dormancy has been overcome.

27. The prolification usually is most pronounced on the upper surface of leaves and petioles, that is, it is negatively geotropic. but sometimes it occurs, although less freely: on their under- 


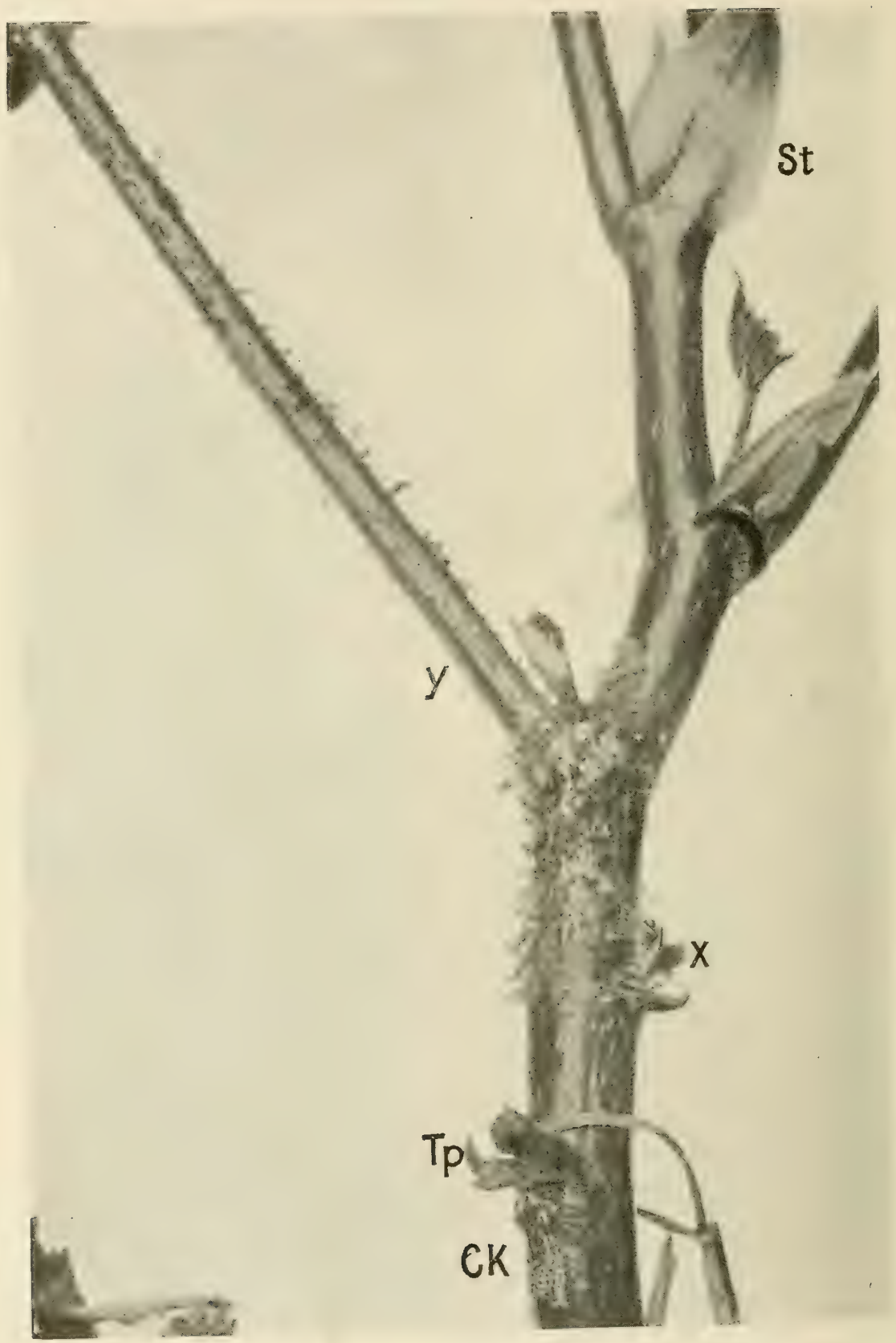

FIG. 445.-Plant No. 1, third series (dried cuttings) at the end of three months. Leaves $T p$ and $X$ have fallen. $T p$ was the small top leaf when the cutting was made; $X$ and $Y$ were stipule-folded rudiments. Cork at $C k$. Stipules at $S t$; $Y$ was a dwarfed leaf. Axis smooth above and below the stimulated part. Photographed October $15,1918 . \times 2$, nearly. 


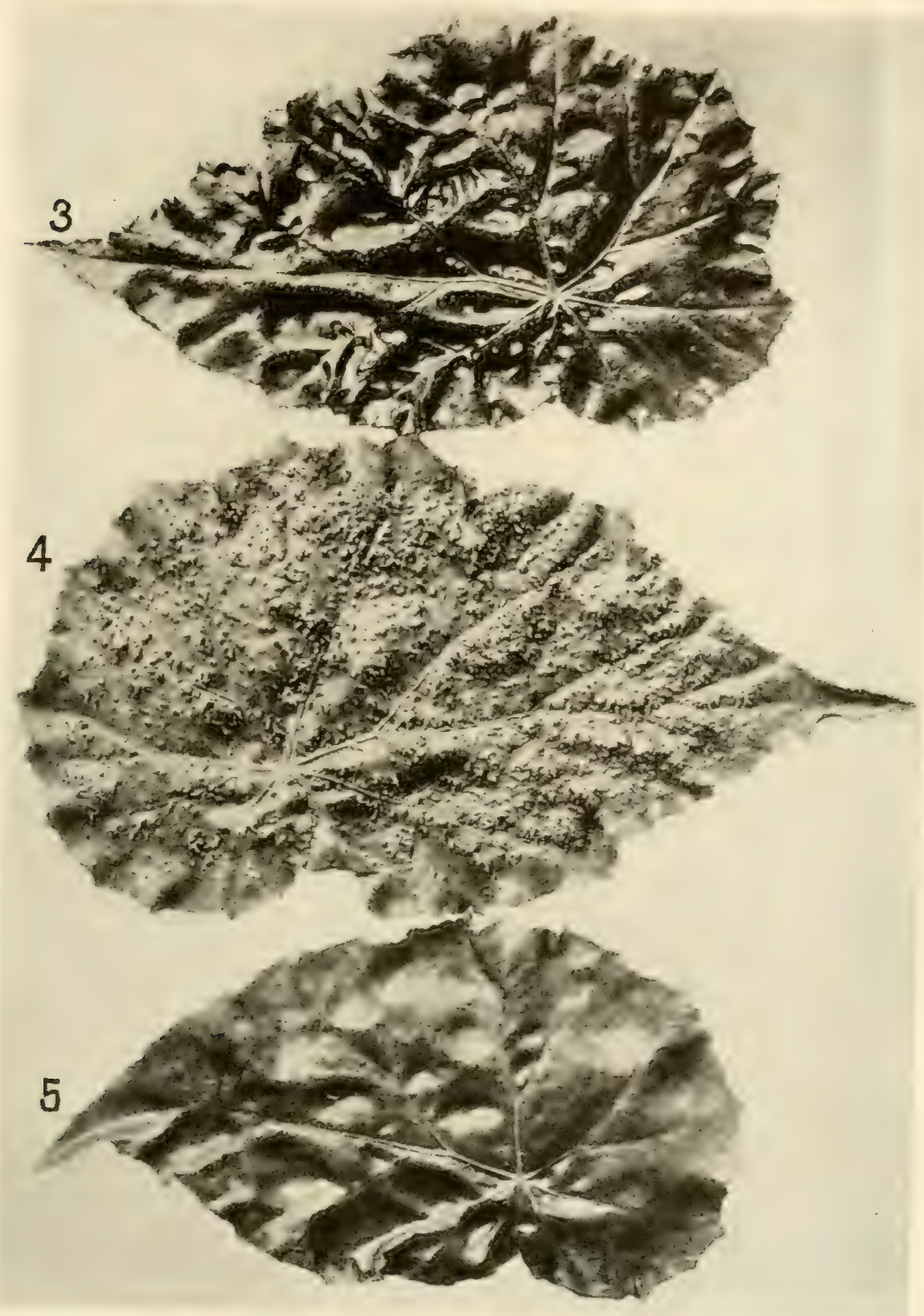

FIG. 446.-Plant No. 1, sixth series of dried cuttings. Made March 15, 1919. Transferred from sand bed to a 4 -inch pot May 7 . Repotted in an 8-inch pot, June 2. Photographerl June 28, 1919. Proliferous leaf (No. t) not dwarfed. Its blade was $93{ }_{4}$ inches long. Leaf 5 was tull grown. Leaf 3 was not full grown. Leaf 1 at the top, just under the hud was quite small and Leaf 2 had a hlade about 3,2 inches long. None of these leares were proliferous on their under surface. No. 5 bore 85 shoots, No. 4 bore 2500 shoots, and No. 3 bore 116 shoots. 
surface (Figs. 438, petiole, and $448 \mathrm{~A}$, blade). Very frequently the proliferation is abundant only over the main ribs of the leafblade or in their vicinity (Figs. 438, $441,4+2,443$ ) but not always (Figs. $427,433 Z$, and $446_{4}$.). Sometimes it is restricted to the apex of the shocked leaf. This apical development I have observed 5 or 6 times. On the internodes it may be strikingly one-sided (Figs. 429C, 435, 436 B, 44t ), quite uniformly distributed (Fig. 429A, B), or more on the upper or lower end, the latter depending apparently on the condition of the neighboring internode, i.e., on whether it is proliferous. Thus, frequently, I found one internode proliferous throughout, but only the apex of the next below it, or only the base of the one next above it (see Table II). When the phyllomania is one-sided, involving two internodes, the leaf midway on the free side of the stem is itself free (Fig. $435 \mathrm{~N}$ ), while the leaf next below it and the one next above it (those on the proliferous side of the internodes) are both proliferous. This I explain, as already suggested, by supposing more water to have been drawn from one side of the stem than from the other. On the nodes, the chief seat of proliferation is around the stipule-scars, which would seem to be places where the plant is least well protected.

28. In addition to being stunted, the shocked leaf-blade may be variously twisted and distorted (Fig. 440j), owing to excessive proliferation from its main ribs, the tissues being crowded downward, since most of the shoots are from the upper surface and they must have room to grow. In this way the ribs may become abnormally thick, corky and cracked open in many places, quite as if parasitized.

29. The adventive leaves in this begonia are not mirror images of the parent but quite normal in orientation (except positively geotropic on under surfaces) and, except for fusions, only abnormal in number, size, shape and vitality, because they are crowded and starved. I have seen one case in which that part of the dorsal surface of a leaf-blade directly over the petiole was fused its whole length to the dorsal surface of another blade, the petioles also being fused, but the blade-wings free (Fig. $448 C)$; other fusions are common.

The abnormalities (Fig. 452) observed on these adventitious 

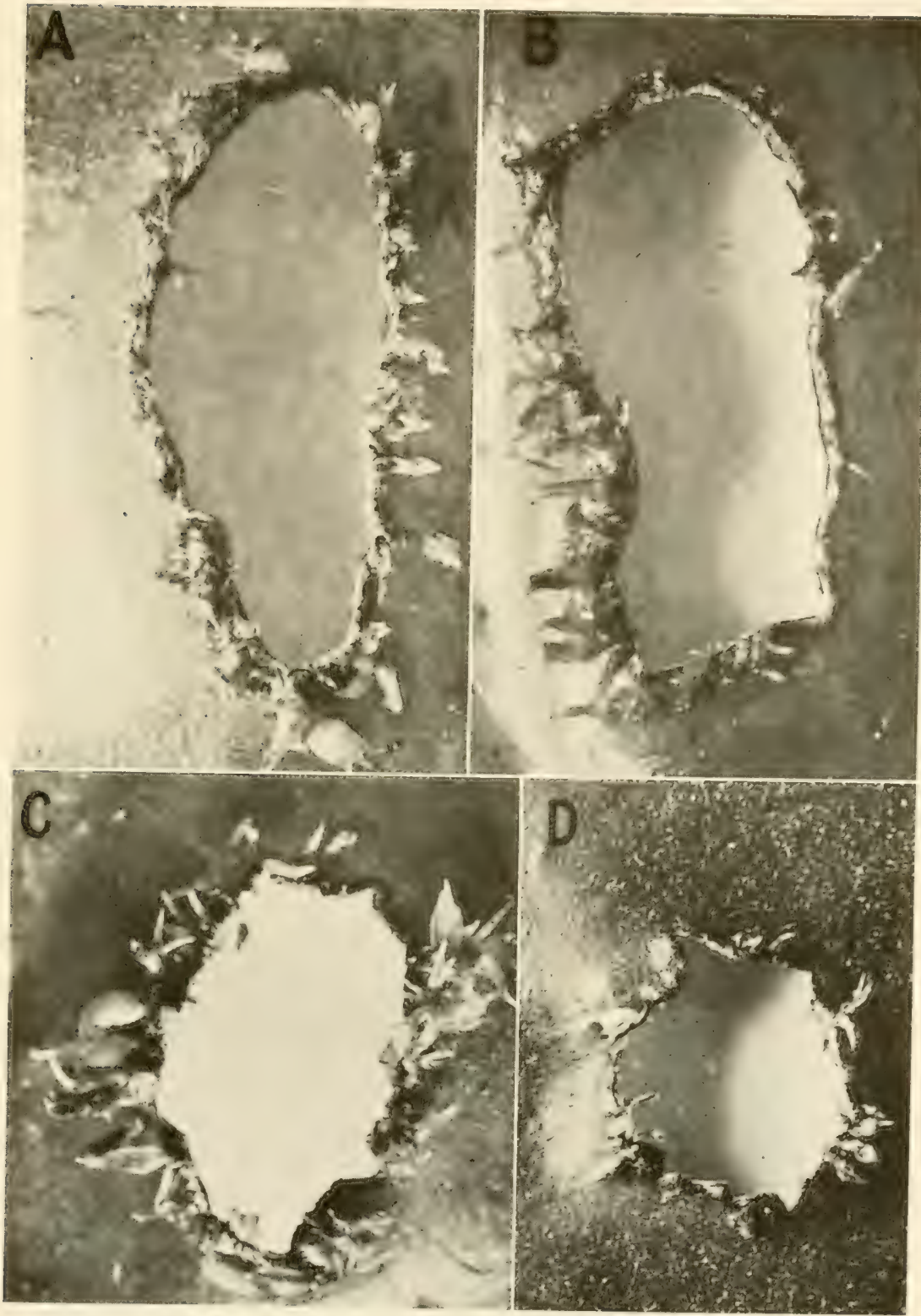

FIG. 447.-A, B. Plant III (Table I). Upper surface of a leaf-blade showing numerous proliferations from the thickened red border of small knife wounds made March 30, 1918, when the leaf-blade was quite young (less than 1 inch long). Most of the shoots are too small to be seen distinctly. The surrounding tissue is quite free from shoots. Photographed May 1, 1918. $\times 5$.

$C, D$. Upper surface of a leaf-blade showing proliferations from margin of holes bored with a hot needle on May 14, when the leaf-blade was 11 , inches long. Photographed July 13, 1918. $\times 5$. 


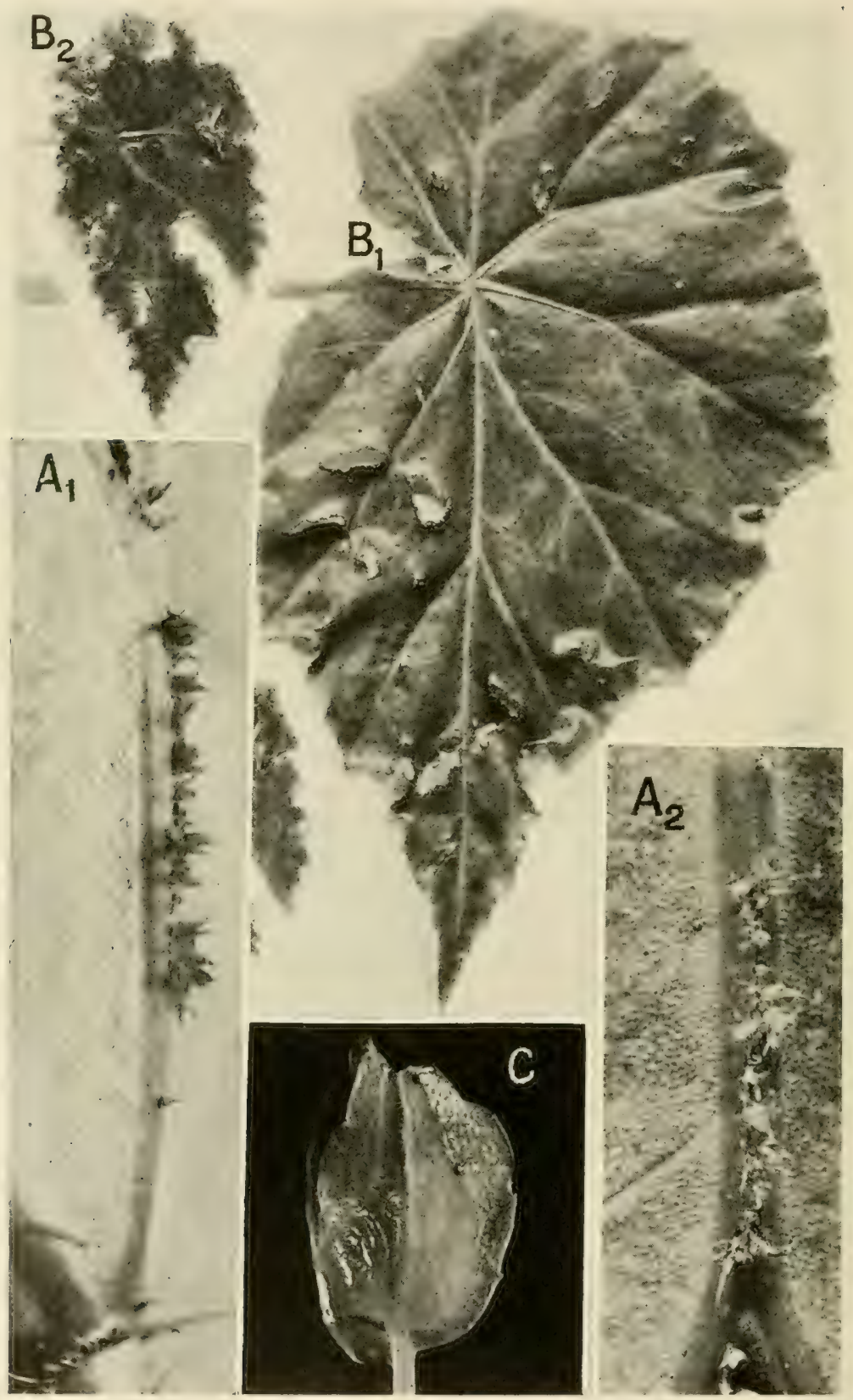

FIG. 448.-A. Leaf showing origin of shoots from the margin of a slit wound on under surface of a midrib: $A_{1}$, side view; $A_{2}$, vertical view. The red leaf-blade 
shoots relate to: (1) dwarfing or disappearance of parts, (2) distortion or enlargement of parts, (3) duplication or fusion of parts. For example, we may have petiole absent, petiole very short, petiole twice the length of the blade, petioles fused; blades widened and cleft at apex (variously 2-lobed), sinus at base closed (Tropaeolum leaf), blades spatulate (petunia leaf), blades destitute of serratures or serratures reduced to mere undulations, blades deeply incised (grape leaf), blades with basal lobes widened so as to be triangular in outline (ivy leaf), blades abnormally short and broad, blades abnormally long and narrow (olive leaf), tissue mostly wanting on one side, whole blade abortive, basal obliquity absent, two blades partly fused, i.e., petiole fusion continued into the blade.

30. The shock is something which either causes the derelopment of totipotent cells, out of young peripheral unipotent or pluripotent cells (the cambium of the plant is not involved) or else causes great numbers of totipotent cells, already present in the epidermis chiefly in its appendages (hairs and glands) but dormant, to be shocked into division, after which, that is, when the plant has acquired a new root-system and general growth has recommenced, they continue to grow until they appear above the surface as young plants bedded in the issues of the mother plant.

31. That the plant requires only a moderate amount of water for its well-being is well-known to gardeners. This is indicated structurally both by its elaborate sub-epidermal storage system (hypoderm) and by its paucity of transpiring organs. On the green stems there are no stomata, so far as I have been able to see, but only a few lenticels, and on the leaves there are fewer stomata than one would expect from their abun-

was folded and only $3 / 4$ inch long when slit. Leaf wounded Mareh $30\left(\mathbf{I}_{1}\right.$ of Table I). Photographed April 25. $\times 5$.

$B_{1}, B_{2}$. Effect of dwarfing on production of shoots from the edges of wounds. Leaves from $I V_{1}$ and $I V_{2}$ (Table I). Leaves wounded March 30 when quite small. The large leaf developed 283 shoots of which 241 were in the vicinity of the wounds. The small dwarfed leaf developed only 8 shoots, all from the edges of the wounds. Photographed May 3, 1918. 5/7 natural size.

C. Two leaves grown together along middle part of dorsum. Adventitious shoot from a leaf-blade. $\times 5$. 

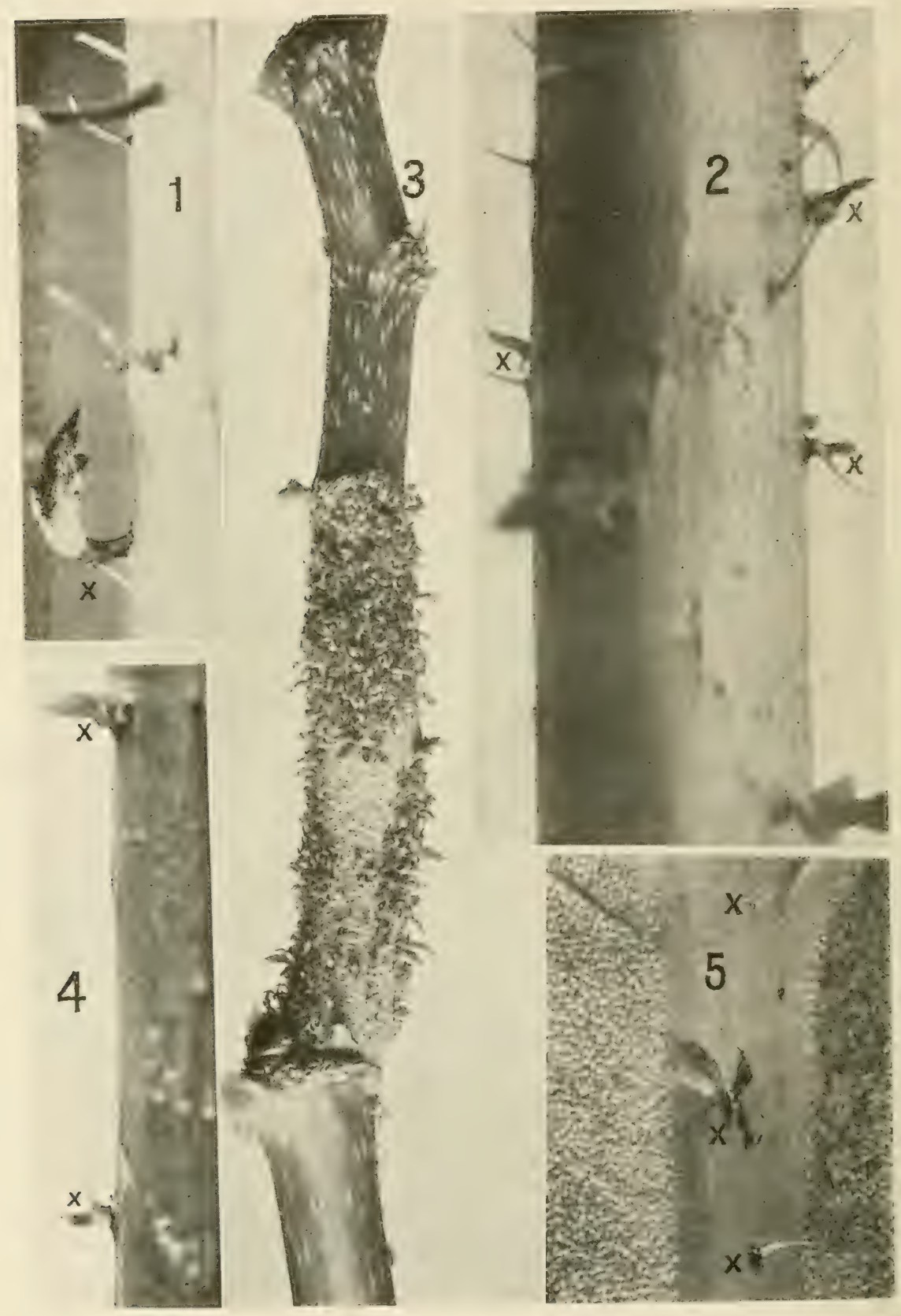

FIG. 449.-1, 2, and 4. Petioles developing shoots from trichomes at $x, x$. $\times 8$ circa. (5) Under surface of leaf showing rib trichomes developing shoots at $x, x$. (3) No. 6, first series, a detail from Fig. 432; much cork on the lower of the two stimulated internodes. 


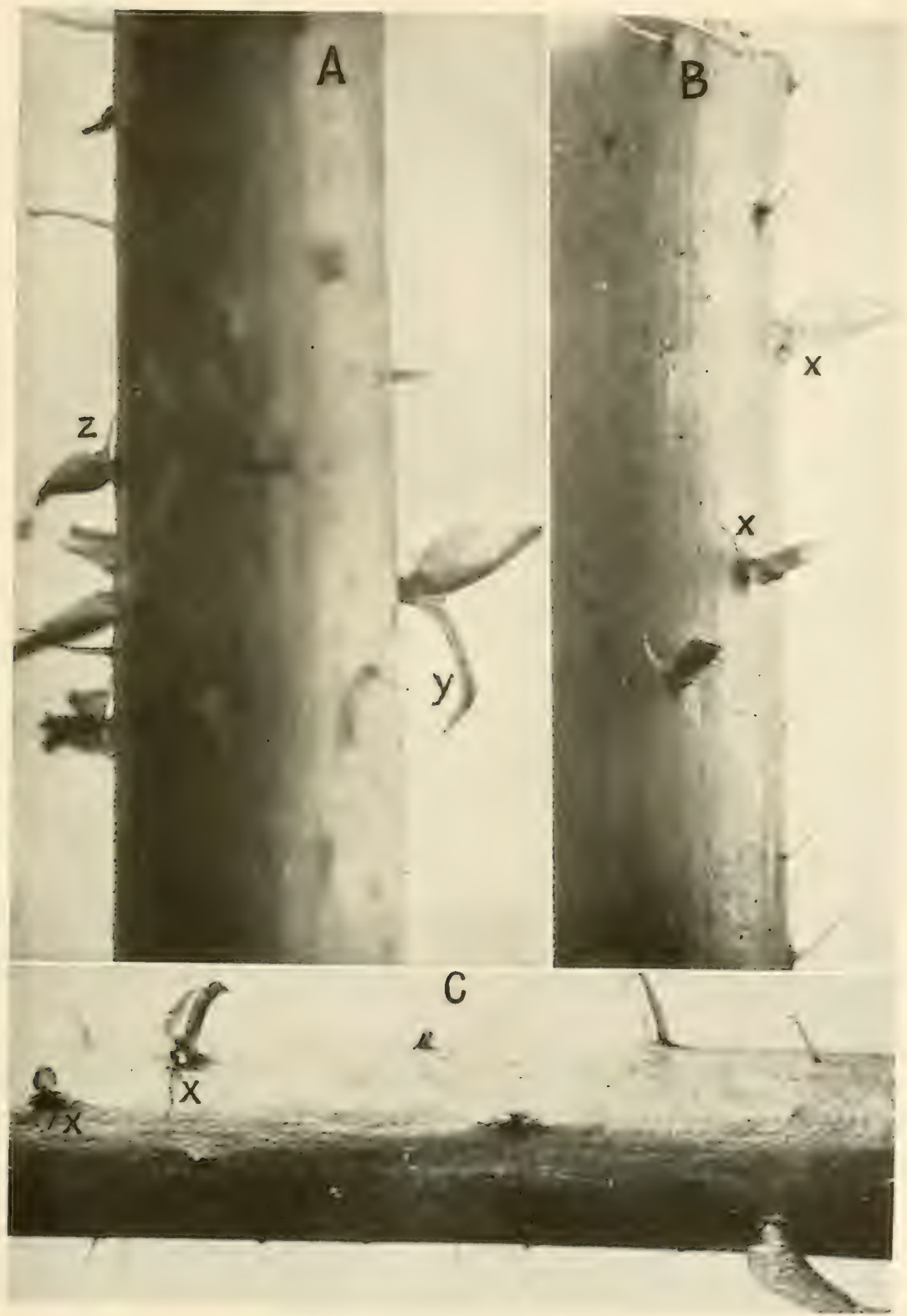

FIG. 450.-A, B, C. Three petioles showing origin of shoots from trichomes. At $x, x$, the trichome has begun to shrivel; at $y$ it has thickened throughout; at $z$ it has not. Normal trichomes scattered about. $\times 7$. 


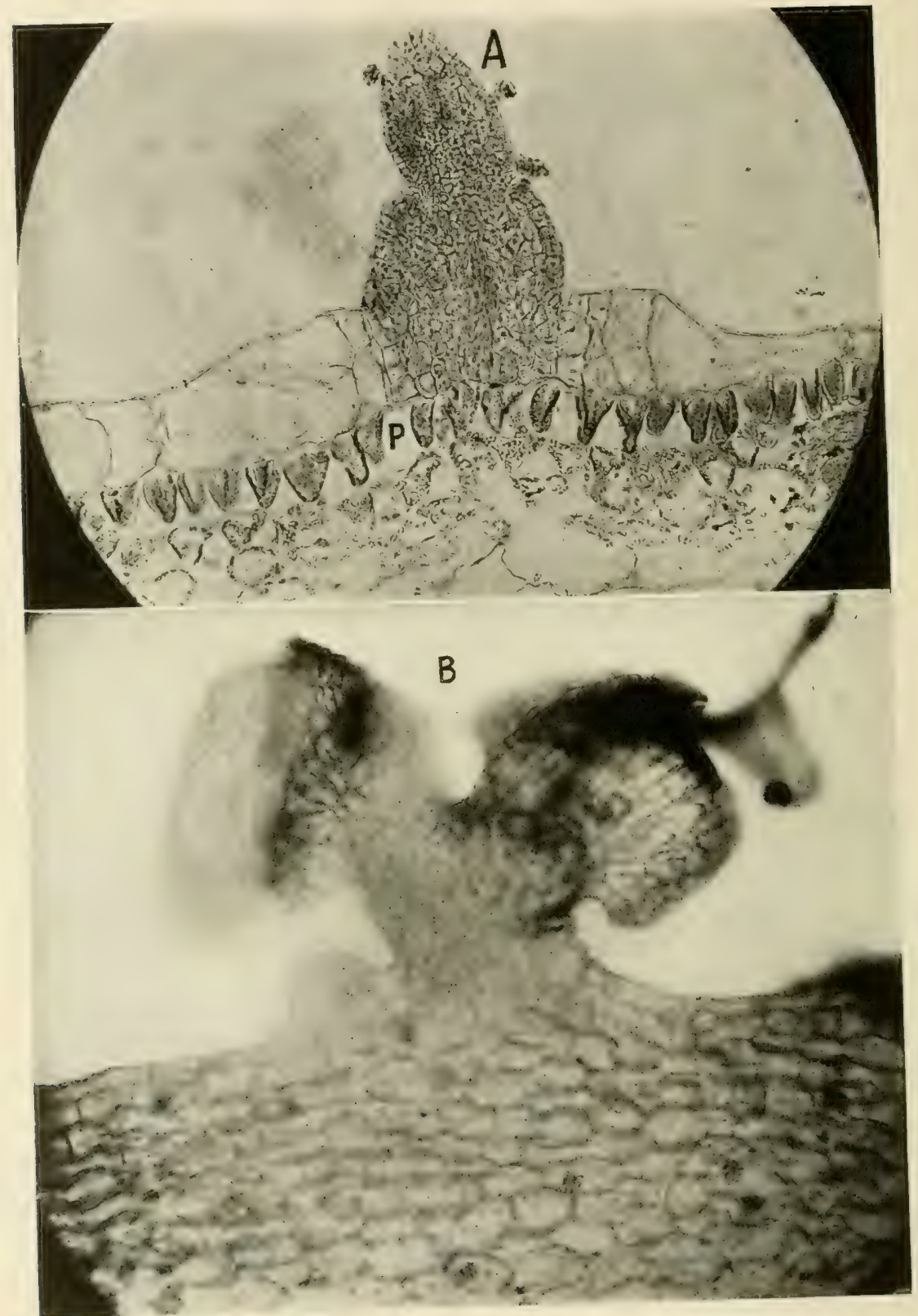

FIG. 451.-A. Cross-section of a leaf from No. 18, second series, showing superficial origin of a shoot. It arises from the colorless tissue (epidermis) above the palisade tissue $(p)$ which is unbroken. As such a shoot grows it displaces $P$ 
dance on other green plants. On the upper surface of the leaves I have not found any stomata and on the lower surface the average is only about 20 per square millimeter, but in this respect it is not different from a half dozen other begonias I have examined.

32. When new phenomena appear our first thought is to inquire whether there are any old and well-known phenomena which can be linked up with the new appearances and thus serve to explain them and also whether there are any other unsolved problems on which they themselves will serve to throw light. In this case one naturally thinks of root-pruning or bruising, sometimes used to throw sterile fruit trees into bearing; of the development of young plants from the leaf margins of Bryophyllum calycinum, which also occurs, so far as I have observed, only when the water-supply is interfered with, i.e., when the leaves are severed or partly severed from the stem or when water is withheld from the roots, or is drawn away from lower leaves to more active upper leaves, but here, while the stimulus appears to be the same, we have to do not with pathological or semipathological phenomena, or with regeneration, as I understand the term, but only with the growth of preformed dormant buds located in unusual places but otherwise normal; of prolepsis and prolification in peach trees attacked by peach yellows and peach rosette, where I have satisfied myself that there is premature death of a great many feeding roots, so that loss of water might exceed the intake, although the cause of this root-injury remains to be determined; of regeneration in general in plants and animals where the response is directly from the wounded surface or the cells in its vicinity, as it is in this begonia when young leaves are wounded; of crown-gall embryomas, where the shock which causes the development of roots and shoots in the tumors is comnected with the presence in the tissues of the products of Bacterium tumefaciens and the growth of the tumors in the vicinity of totipotent cells, which are also set growing; of intu-

and occupies deeper parts of the leaf. From a stained serial section. For a much earlier stage see Fig. 453 at $X . \times 55$ circa.

$B$. Cross-section of an internode showing superficial origin of the proliferous shoot. The phloem-xylem is a long distance below the part here shown and no vessels extended into it. Section photographed unstained in water. $\times 75$ circa. 

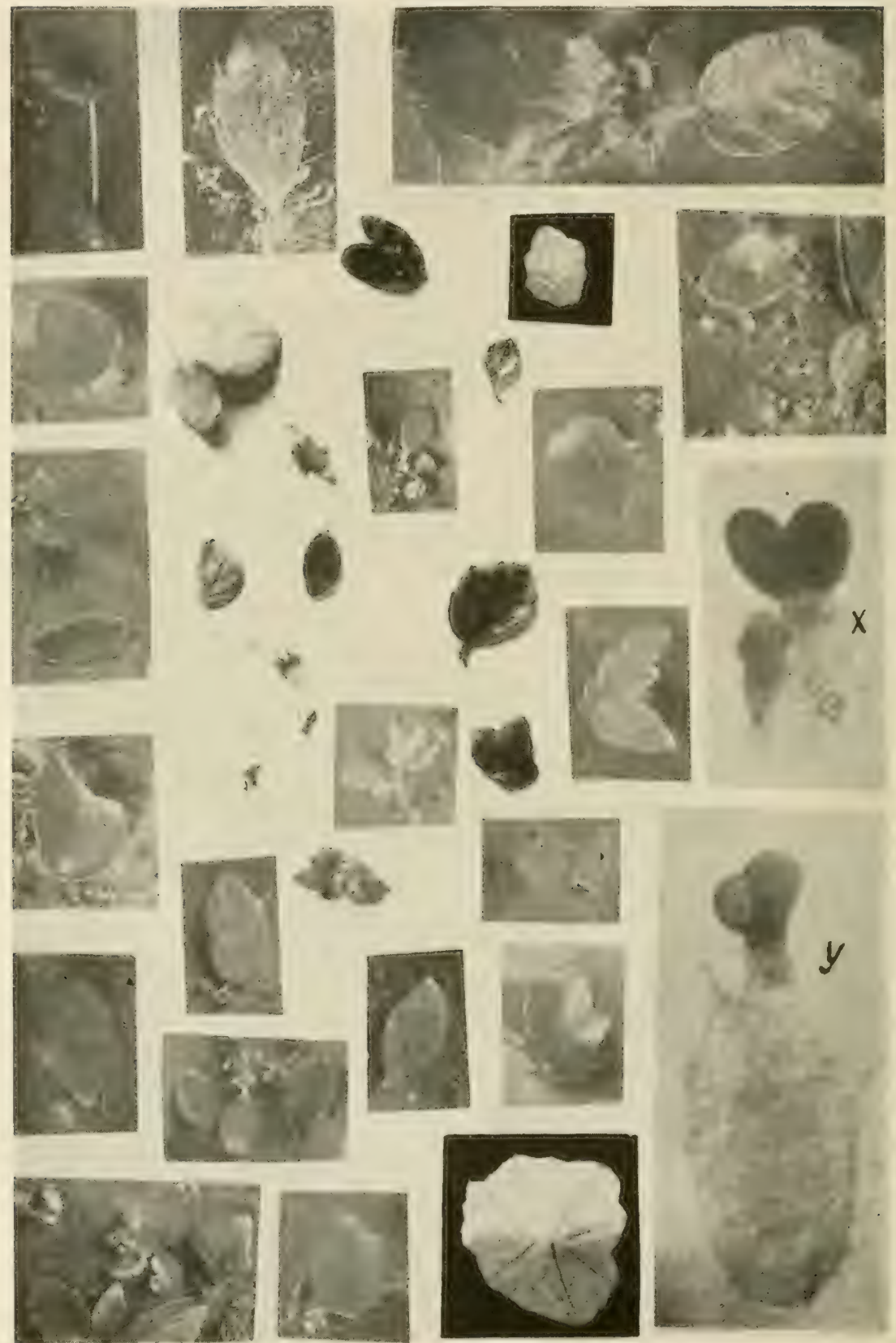

FIG. 452.-Leaves from adventive shoots showing fusions and other abnormalities referred to in the text. At $x, y$, are stem glands (enlarged) giving rise to shoots at their base. 


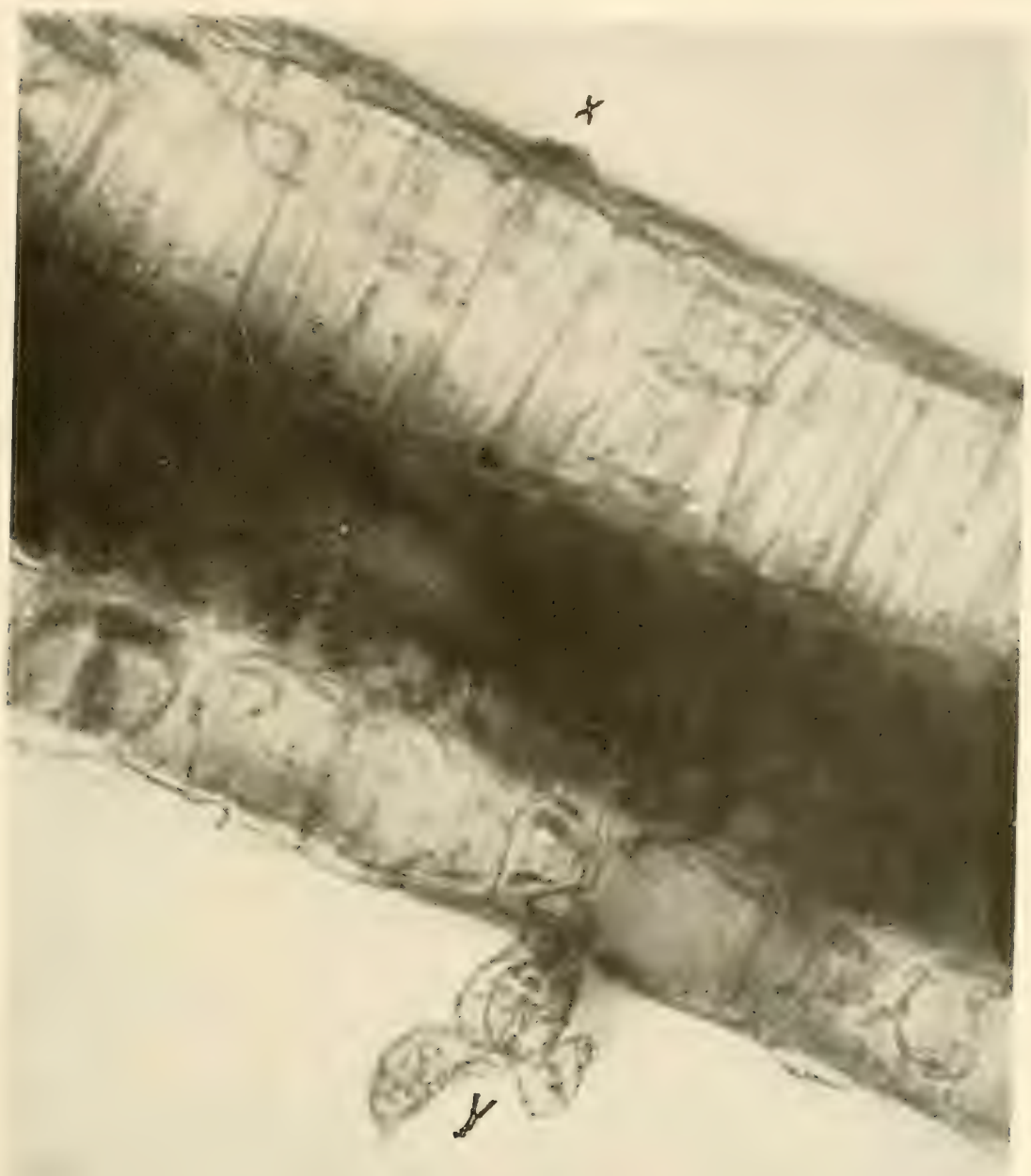

FIG. 453.-Cross-section of a leaf of Begonia phyllomaniaca showing early stages of adventive shoots at $x$ and $y$. The dark central band is the oniy part of the leaf producing chlorophyll. From series $V$ at end of three weeks. Photographed in water from a thick free-hand section. $8 \mathrm{~mm} ., 4$ oc., bellows at 35 . 
mescences due to chemical and mechanical injury or to frost where clearly there is always some initial loss of water and in some instances, at least, increase of acidity; and finally, of teratomas in animals where nothing is known as to cause but where the consensus of expert opinion appears to be that the totipotent or pluripotent cell or cells giving rise to the fetal fragments dates from embryonic time, and in case of the atypical forms although "out of place," would have continued dormant but for the shock of the developing cancer.

33. In this connection one thinks also of the various processes used by gardeners to hasten the pushing of dormant buds.

In 1885 Dr. Hermann Müller-Thurgau showed conclusively that potato tubers of varieties which ordinarily do not sprout until spring can be made to germinate in autumn or early winter by exposing them on ice for a number of weeks. If they are then removed and placed under conditions suitable for growth the dormant buds immediately begin to grow. He showed that potato tubers placed under these conditions change a portion of their starch into sugar and he beliered that this increase of sugar is the cause of the germination. He mentioned incidentally that there is also an increase of acid but lays no stress on this increase which, howerer, I believe to be the actual cause. His chilled potatoes which had become sweet were twice as acid as the unchilled ones (3.14 pro mille reckoned as malic acid. as against 1.74).

In 1900 Dr. W. Johannsen, the Danish physiologist, experimenting at first with sulphuric ether discovered that a great variety of plants which ordinarily do not push their winter buds until spring can be induced to push them in late autumn or early winter by etherizing the plants or by chloroforming them. Lilacs, for example, by this method can be brought into blossom at Christmas time and willows can be induced to push their catkins in autumn within a week or ten days of the time they have been anesthetized. This method of procedure, worked out in detail by Johannsen for a variety of plants, proved so dependable and profitable that it is now used by florists the world over. The dose, temperature and time for lilacs is as follows: 30 to 40 grams of ether per hectolitre of air space 
(about $33_{2}^{1}$ cubic feet), a temperature of $9^{\circ}$ to $20^{\circ} \mathrm{C}$. and generally an exposure of 48 hours. When chloroform is used the time and temperature may be the same but the dose is reduced to 6 to 9 grams per hectolitre. The soil must be fairly dry otherwise much ether will be absorbed and the results disappointing. Ether vapor being hearier than air and explo-ive in the presence of fire, it must be liberated in the top of the airchamber and the work must be done out of door or in a room where there is no fire. Johannsen states that he derived much benefit from a perusal of Müller-Thurgau's writings and from the earlier work of the great French physiologist, Claude Bernard.

In 1909 Dr. Hans Molisch of Vienna published a very interesting paper showing that the same results obtained with ether and chloroform can be obtained simply by dipping the tops of the plants into warm water $\left(30^{\circ}\right.$ to $40^{\circ} \mathrm{C}$.) for a short period (6 to 12 hours). They are then set on the greenhouse bench under suitable conditions and bloom prematurely just as if they had been etherized. This method hestates had been used for a considerable time by Russian gardeners but Molisch was the first to make exact experiments and to bring it to the attention of the scientific world.

Neither Müller-Thurgau, Johannsen nor Molisch have offered satisfactory explanations for the results obtained. MüllerThurgau's explanation that the hasty pushing of the buds is due to the presence of sugar in the tissues cannot be held to be a proper explanation since, as Johannsen points out, plants in a dormant state sometimes contain sugar in quantity, for example, garlic bulbs, and there is also always a considerable quantity of sugar circulating during the summer season in a variety of deciduous plants while their winter buds are forming and yet these buds do not ordinarily push. Preceding Johannsen's work Dr. Raphael Dubois, professor of physiology in Lyons, France, published a paper (1891) on the action of chloroform in which he claims that the anesthetic acts by dehydration. I was unaware of the existence of Dubois' paper until Norember, 1919, when I read for the first time Johannsen's paper, although I had already arrived theoretically at the same conclusion, as may be seen from the preceding pages which were then in type. 
Johannsen makes light of the work of Dubois, as does also Overton. Johannsen objects that the figure which Dubois shows (that of an Echeveria exposed to chloroform and exuding drops of water from all of its leaves) is the figure of a dead plant, and this may well be, but clearly there must be all stages in the exudation of cell-water from its mere beginnings in the live plant to its end, when not only the intercellular spaces and the sub-stomatal chambers are filled with the exuded sap, but also a sufficient quantity has exuded to appear on the surface in the form of tiny drops and to have exhausted the cells beyond recovery. In fact, Overton admits that there is loss of water from nareotized muscle and that Dubois is not wholly wrong. Recently I have observed all stages of dehydration in chloroformed cabbages. If the anesthetization is moderate there is only a spotting of the leaves (innumerable tiny spots, water-soaked or darker green by reflected light and translucent by transmitted light) without surface exudate. If the chloroforming is continued longer, the change of color orerspreads the whole leaf, and, if it is an undeveloped leaf with small intercellular spaces, there is an exudate of clear fluid from hundreds of stomata mostly to the under surface of the leaf, but, if it is an older leaf, the large amount of intereallular space is sufficient to accommodate the exuded water and it seldom appears on the surface. What becomes of such leaves depends on how far the dehydration is pushed. If the experiment is stopped before the exudate or spotting appear's the leaves recover, if pushed until exudate appears on their surface I have not seen them recover.

Temporary loss of function on the part of the protoplasmic cell membrane whether brought about by chilling, by hot water, by anesthetics, by acids, or by alkalies would lead, I believe, to the same set of phenomena; viz., loss of water, disturbed respiration, more or less oxygen-hunger, and compensatory cell-division with movement of water, sugar and other foods back into the growing point. Once the dormancy is overcome buds will continue to grow if placed under growing conditions. I believe, therefore, that we have in these common forcing methods added evidence that the phyllomania in this begonia must be due to 
the shock produced by excessive loss of water acting on dormant totipotent cells.

34. I am inclined to think there is nothing in Weissmann's theory making a sharp distinction between somatic and germinal cells. I believe that cells in many young undifferentiated parts are totipotent and that what finally becomes of them, that is whether they avail themselves of their totipotency, or not, depends on circumstances. Under ordinary conditions we know how they behave (that is, physiologically) but under extraordinary conditions they may behave quite differently, that is may attempt to reproduce the whole organism. In this begonia, totipotent cells are distributed in great numbers over its superficial, actively growing parts. They occur, I believe, similarly if not so abundantly in the epidermis of other plants and in the skins of animals, but in most cases require a much stronger shock to set them growing, that is, a tumor, or a parasitic stimulus of some sort. That pluripotent cells should occur in the skin of a man, let us say, seems a very strange thing, yet man has inherited his skin and all the rest of his anatomy from the lower animals, some of which, for aught we know, may have germinal cells as widely distributed and as sensitive to shock as they are in this curious begonia. No one knows, for instance, what effect a shock of some sort, such as a severe blood-letting or a drastic purgation of the mother, might have on a fetus in the way of starting dermoid cysts or other monstrous growths. The subject is one calculated to provoke thought and lead to further experiments. The effects of root-injury on this plant seem to me very suggestive as to the origin of Sereh of sugar-cane, of rosette diseases, of orange wilt, of peach yellows, and of the somewhat similar East Indian spike disease of sandalwood. It has also various other interesting bearings.

35. That this begonia is more subject to shocks leading to phyllomania than other plants may be conceived to be due to its watery nature and especially to its inheritance of very sensitive and easily permeable cell-membranes. That it is alone in the world, in such behavior, I do not for a moment believe. 
TABLE I

Showing result of Wounding undeveloped leaf Blades of Begonia phyllomaniaca. Knife wounds made March 30, 1918. Examinations made AFTER A MONTH

\begin{tabular}{|c|c|c|c|c|c|c|c|c|c|}
\hline \multirow[b]{3}{*}{$\begin{array}{l}\text { Plants and } \\
\text { branches } \\
\text { of plants }\end{array}$} & \multicolumn{2}{|c|}{$\begin{array}{l}69 \text { unwounded } v s \text {. } \\
13 \text { wounded leaves }\end{array}$} & \multicolumn{7}{|c|}{ Contrasts on wounded leaves } \\
\hline & \multirow[b]{2}{*}{$\begin{array}{c}\text { Average } \\
\text { number of } \\
\text { shoots per } \\
\text { sq. in. on } \\
\text { unwounded } \\
\text { leaf blades. } \\
\text { Total } \\
\text { surface, } \\
784 \text { sq. in. }\end{array}$} & \multirow[b]{2}{*}{\begin{tabular}{|l|} 
Average \\
number of \\
shoots per \\
sq. in. on \\
wounded \\
leaf blades
\end{tabular}} & \multicolumn{3}{|c|}{ Wounded parts } & \multicolumn{4}{|c|}{ Unwounded parts } \\
\hline & & & $\begin{array}{l}\text { Fraction } \\
\text { of sur- } \\
\text { face oc- } \\
\text { cupied } \\
\text { by } \\
\text { wounds }\end{array}$ & $\begin{array}{c}\text { Total } \\
\text { number } \\
\text { of } \\
\text { shoots } \\
\text { (com- } \\
\text { pare } \\
\text { with } \\
\text { last col- } \\
\text { umn) }\end{array}$ & $\begin{array}{l}\text { Shoots } \\
\text { per each } \\
1 / 8 \text { sq. in. } \\
\text { of } \\
\text { wounded } \\
\text { surface }\end{array}$ & $\begin{array}{c}\text { Shoots } \\
\text { per } \\
\text { each } \\
1,8 \text { sq. } \\
\text { in. }\end{array}$ & $\begin{array}{l}\text { Total } \\
\text { sur- } \\
\text { face }\end{array}$ & $\begin{array}{l}\text { Total } \\
\text { shoots }\end{array}$ & $\begin{array}{l}\text { Average } \\
\text { number of } \\
\text { shoots on } \\
\text { any equal } \\
\text { fraction } \\
\text { (For comp. } \\
\text { with col- } \\
\text { umns } 4 \\
\text { and 5) }\end{array}$ \\
\hline $\mathbf{I}_{1} \ldots \ldots \ldots$ & 2.0 & 17.3 & $1 / 12$ & 215 & . & $\ldots$ & $11 / 12$ & 46 & 4.0 \\
\hline $\mathbf{I}_{2} \ldots \ldots \ldots$ & $0.6^{1}$ & 19.0 & $1 / 40$ & 183 & 61 & 0.07 & $39 / 40$ & S & 0.2 \\
\hline II $_{1}$ lower leaf & $\ldots$ & 9.8 & $1 / 54$ & 71 & 32 & & $53 / 54$ & 86 & 1. 6 \\
\hline $\mathrm{II}_{1}$ upper leaf & 1.0 & 11.6 & $1 / 45$ & 117 & 43 & 0.125 & $44 / 45$ & 57 & 1.3 \\
\hline $\mathrm{II}_{2} \ldots \ldots \ldots$ & 1.6 & 20.6 & $1 / 11$ & 238 & 24 & 0.5 & 1011 & 51 & 5.0 \\
\hline $\operatorname{III}_{1} \ldots \ldots \ldots$ & 2.0 & 21.0 & $1 / 19$ & 141 & 47 & 0.09 & $18 / 19$ & 5 & 0.3 \\
\hline $\mathrm{III}_{2} \ldots \ldots \ldots$ & 1.5 & 19.0 & $1 / 22$ & 246 & 49 & 0.2 & $21 / 22$ & 24 & 1.1 \\
\hline $\mathrm{II}_{3} \ldots \ldots \ldots$ & 0.5 & 36.0 & $1 / 21$ & 267 & 89 & 0.18 & $20 / 21$ & 11 & 0.55 \\
\hline $\begin{array}{l}I V_{1} \ldots \ldots \ldots \\
I V_{2} \text { (dwarf }\end{array}$ & 1.15 & 15.0 & $1 / 29$ & 241 & 48 & 0.3 & $28 / 29$ & 42 & 1.5 \\
\hline shoot)..... & 0.0 & 0.27 & $1 / 6$ & 8 & 3 & 0.0 & $7 / 8$ & 0 & 0.0 \\
\hline$V_{1}$ lower leaf. & 1.3 & 6.7 & $1 / 69$ & 46 & 31 & 0.4 & $68 / 69$ & 41 & 0.6 \\
\hline$V_{1}$ upper leaf. & $\ldots$ & 14.0 & $1 / 16$ & 145 & 24 & 0.24 & $15 / 16$ & 22 & 1.5 \\
\hline$V_{2} \ldots \ldots \ldots$ & 0.33 & 8.0 & $1 / 43$ & 58 & 39 & 0.04 & $43 / 4$ & 3 & 0.07 \\
\hline $\begin{array}{l}\text { Av. } 5 \text { plants } \\
\text { (11 branches) }\end{array}$ & 1.2 & 15.2 & $\ldots$ & 152 & . & & $\ldots \ldots \mid$ & . & 1.4 \\
\hline
\end{tabular}

${ }_{1}$ There was also a leaf $\cdot\left(I_{3}\right)$ which received eleven wounds, but the total wounded surface was not recorded. This was on a dwarfed shoot from the axil of the branch $\mathbf{I}_{2}$ and there were no shoots either from the wounded or unwounded parts. 
TABLE II

Showing NuMber of SHoots oN INTERNodes stimdLATEd JULY 24-25, 1918, AND ON UNSTIMULATED INTERNODES IMMEDIATELY ABOVE AND BELOW THE SAME. Counts Made in September-October, 1918

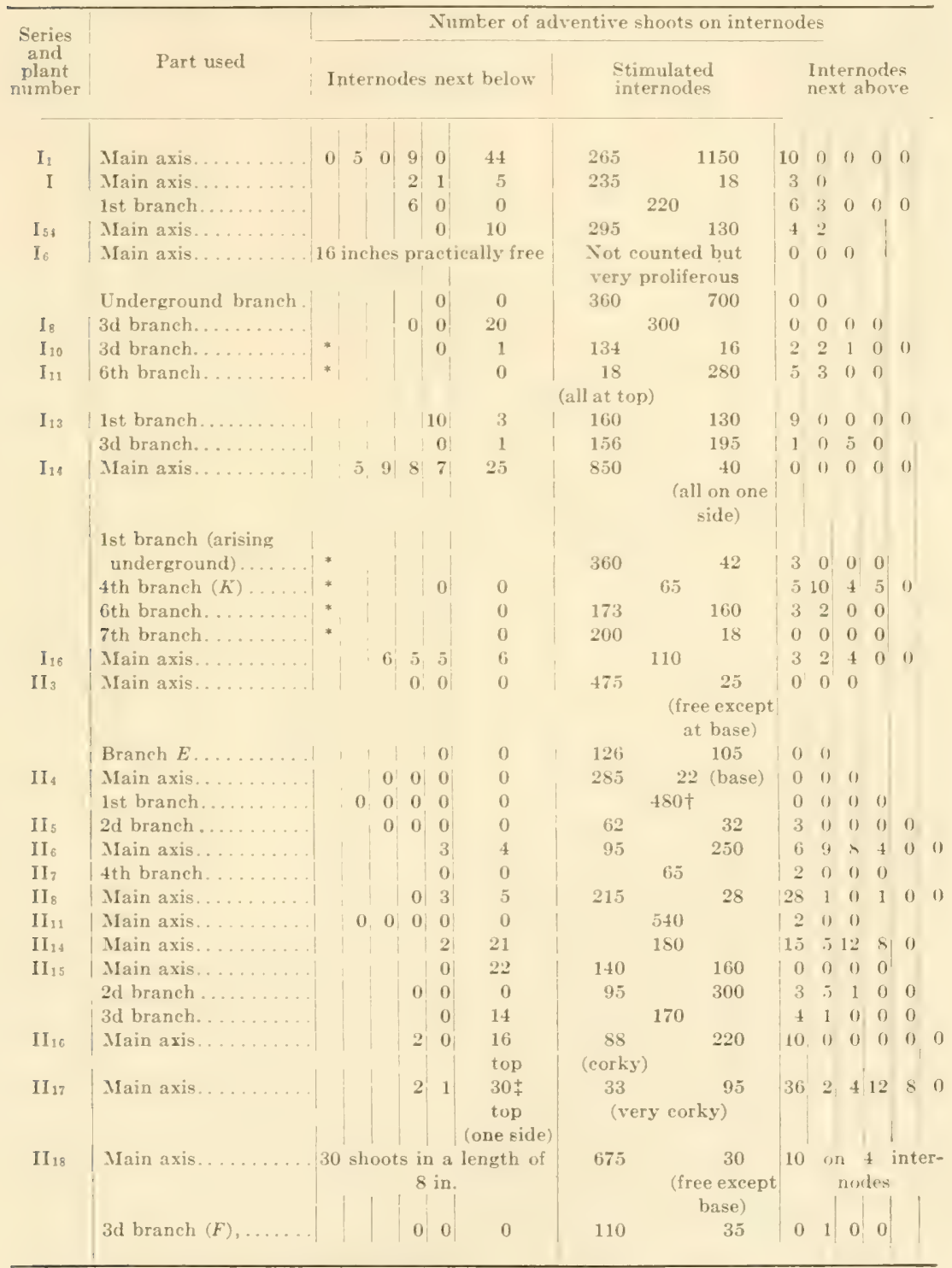

* No internodes below first recorded one

+ When but a single number is given there was only one proliferous internode.

$\ddagger$ In cases like this the shock undoubtedly influenced more than two internodes. 


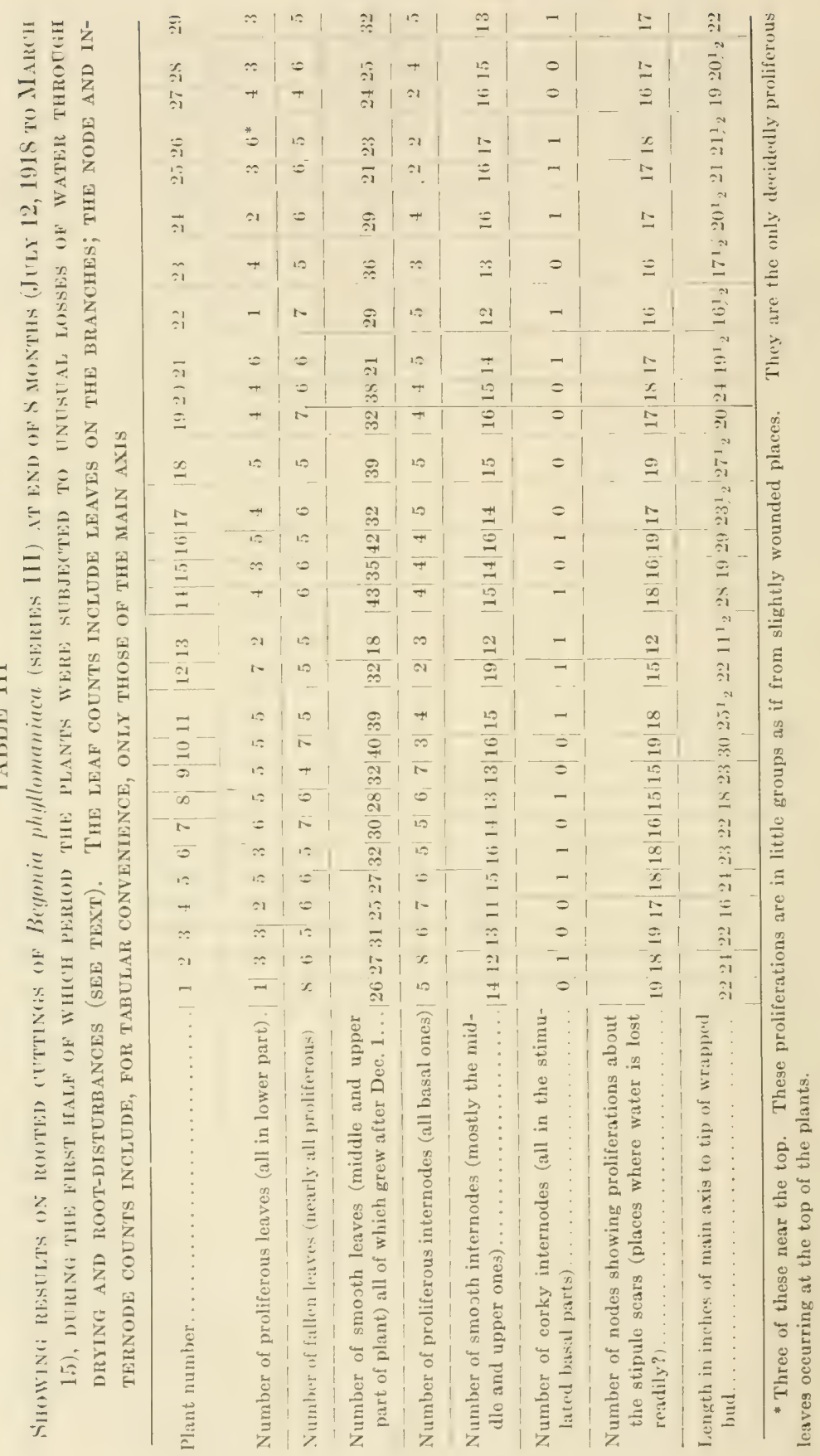




\section{BEGONIA LITERATURE}

1852. Begonia phyllomaniaca Martius. Hooker's Journal of Botany, Vol. IV, pp. 206-207.

1853. De Martius, C. F. Ph. Begonia phyllomaniaca in "Delectus Seminum in Horto R. Bot. Monacensi" Anno 1852 Collectorum. Annales des Sciences Naturelles. 3 Série, 19, 1853, p. 366.

1854. Von Martius. Flora Brasiliensis, Vol. IV, Pars I, pp. 386-387. Plates XCIX and C.

1854. Kцотzsch, Hrv. Begonia phyllomaniaca in "Begoniaceen-Gattungen und Arten," Abhandlungen der Königlichen Akad. der Wiscenschaften zu Berlin, 18int, p. 129.

1863. Verlot, J. B. Begonia. Bulletin de la Société Botanique de France. Tome X, p. 474 .

Eight lines from a letter in which he states that hairs on the leaves of a begonia (sp. called $B$. geranioides) are changed into buds which render the leaves in some sort viviparous. The letter and specimen were sent to M. de Schoenefeld who exhibited them at a meeting of the Société Botanique de France.

1863. Prilleux, Ed. Observations sur une feuille gemmipare de Begonia. Bulletin de la Société Botanique de France, Tome X, pp. 492-494.

At a following meeting of the Société Botanique Prillieux discussed Verlot's discovery and fogged the whole subject, denying that the shoots were the outgrowth of hairs.

1875. Caruel, T. Nota su di una trasformazione di peli in gemme. (Begonia phyllomaniaca.) Nuova Giornale Botanico Italiana, Vol. 7, pp. 292-294, Pisa, 1875.

Note on plants seen at the Kew Gardens in London. His observations confirm Verlot's statements that hairs are converted into buds.

1880. Hansen, Adolph. Vergleichende Untersuchungen über Adventivbildungen bei den Pflanzen. Abhandlungen Herausgegeben von der Senckenbergischen Naturforschenden Gesellschaft. Vol. XII. Frankfurt, pp. 147-154.

1887. Duchartre, P. Sur un Begonia phyllomane. Bulletin Société Botanique de France. Tome XXXIV, Paris, 1887, pp. 182-184.

Forty plants raised by Nodot from seeds showed phyllomania on their stems. 
One of these was studied by Duchartre, who says, "How are these little supplementary leaves produced? I have had neither the time nor the material necessary for seeking their first origin. . . . Each one of these growths constitutes in reality a leafy branch"

As a simple hypothesis he thought they originated from the epidermis.

1894. Warburg, O. Begonia phyllomaniaca. Die natürlichen Pflanzenfamilien. Engler und Prantl. Teil III, Abt. 6 and $6^{a}$.p. 124. Leipzig.

1908. Goebel, K. Einleitung in die Experimentelle Morphologie der Pflanzen. Naturwissenschaft und Technik in Lehre und Forschung eine Sammlung von Lehr- und Handbüchern. [Begonia phyllomaniaca on pp. 153-155.]

1913. Bateson, William. Problems of Genetics. [Begonia phyllomaniaca on pp. 50-53.] Yale University Press.

1917. Smith, Erwin F.- Embryomas in Plants (Produced by Bacterial Inoculations). The Johns Hopkins Hospital Bulletin, Vol. XXVIII, September, 1917. Also a repaged separate. Foot note on page 279.

1919. Sмith, ERwin F. The Cause of Proliferation in Begonia phyllomaniaca. Proc. Nat. Acad. Sciences, Vol. V, February, 1919, pp. 36-37.

LITERATURE ON EFFECT OF COLD, HEAT AND ANESTHETICS

1885. Müller-Thurgau, Hermann. Beitrag zur Erklärung der Ruheperioden der Pflanzen. Landw. Jahrbücher. XIV Bd. Berlin. Paul Parey, 1885, pp. 851-907.

1891. Dubois, Raphael. Mécanisme de L'Action des Anesthésiques. Revue Générale des Sciences Pures et Appliquées. Tome 2, Paris, Sept. 15, 1891, pp. 561-567. 2 text Figs.

1900. Johannsen, W. Mein Aetherverfahren in der Praxis. Die Gartenwelt, 5. Jahrg., 1900-1901, p. 265.

1901. Overton, E. Studien über die Narkose zugleich ein Beitrag zur allgemeinen Pharmakologie, pp. 195. Jena. Verlag von Gustave Fischer, 1901. (Dr. E. Overton, Privatdocent der Biologie und Assistent der Botanik an der Universität Zürich.)

1904. Johannsen, W. Frühtreibversuche mit Sträuchern nach erfolgter Aetherisierung oder C'hloroformierung. Sitzgsber. der "Flora," 1902-1903. Dresden 1904, pp. 71-83. 
1906. Johannsen, W. Das Aetherverfahren beim Frühtreiben, mit besonderer Berücksichtigung der Fliedertreiberei. 2 Aufl., pp. 65. Jena. Gustav Fischer, 1906.

1909. Molisch, Hans. Das Warmbad als Mittel zum Treiben der Pflanzen. Jena. Verlag von Gustar Fischer. 1909, pp. IV, 38. Mit 12 Figuren im Text.

\section{ADDITIONAL LITERATURE ON INTUMESCENCES}

(See page 572)

1898. Tubeuf, C. von. Uber Lenticellen-Wucherungen (Aërenchym) an Holzewächsen. Forstlich-naturwissenschaftliche Zeitschrift, VII Jahrgang, 12 Heft, December, 1898, pp. 405414, 7 Figs.

This very interesting paper, which was read with fear and trembling, came to my knowledge too late to be mentioned in the body of the text (page 477 et seq.), r.e., not until the corrected proofs had been returned to the printer. It anticipates by twenty years some of $\mathrm{my}$ findings but not all. The author raises the question of reduced transpiration as a possible cause of the tumors and decides against it because he also obtained them in his closed vessels when projecting leaves were on the plant and transpiration was in progress, but if the fluid transpired possessed a limited oxygen-content as it must in closed tubes, the peripheral stem tissues would still receive insufficient oxygen; and they might even, if the water transpired by the leaves, had sufficient oxygen, i.e., was ground water, since the moist air in contact with the lenticels in the closed chambers would soon become deficient in oxygen. Concerning increased acidity of such tissues it does not appear to have occurred to Dr. Tubeuf to make any inquiries.

Von Tubeuf states that the proliferation may be so extreme as to be pathological and that it is not due to an excess of water in the tissues. He cites Goebel to the effect that it arises in consequence of an undetermined irritation and Schenk that "it is not very probable that simple contact of the epidermis with the water, as such, is a factor, it is much rather to be supposed that lack of oxygen in the inner tissues, the plasma of the phellogen cells, leads to the production of the aërenchym."

Dr. Tubeuf's experiments were made with stems and roots of small treeselms, etc.

1913. Wehmer, C. Ubergang älterer Vegetationem von Aspergillus fumigatus in "Riesenzellen" unter Wirkung angehäufter säure. Berichte der Deutschen Botanischen Gesellschaft, Vol. XXXI, No. 5, 1913-1914, pp. 257-274, 7 text figures.

Wehmer obtained great numbers of giant cells in cultures of Aspergillus and Penicillium, using ammonium sulphate. He attributes these giant cells to the action of free acid ions on the spores of the fungus. 
1919. Taylor, William Randolph. On the production of new cell formations in plants. Contributions from the Botanical Laboratory of the Univ. of Pennsylvania, Vol. IV, No. 2, pp. 271-299, 8 pls.

1920. Rumbold, Caroline. The injection of chemicals into chestnut trees. American Journal of Botany, Vol. VII, No. 1, Jan., pp. 1-20, 7 text figures.

1920. Rumbold, Caroline. Causes for the production of pathological xylem in the injected trunks of chestnut trees. Phytopathology, Vol. X, No. 1, Jan., pp. 23-33, 2 pls.

1920. Harvey, R. B. Relation of Catalase, Oxidase, and $\mathrm{H}^{+}$Concentration to the Formation of Overgrowths. Am. Journal of Botany, May, 1920, pp. 211-221. 


\section{PART T}

\section{GENERAL OBSERVATIONS}

How to make the most of one's education, how to achieve the largest success, must ever be a matter of immediate concern to the student who has to win his own way. With such persons in view, and I am speaking to no others in these pages, I will here set down some observations that have grown out of my own experience. If occasionally they prove useful and help to smooth ways which are often hard in the beginning, I shall feel well repaid. I have expressed my individuality very decidedly on a variety of subjects in the following pages but I could not do otherwise. If anyone thinks these observations smack too much of "Thus spake Zarathustra" he has the remedy in his own hands. We are often compelled to listen to an individual when we are bored, but never to a book. "Si ce livre me fasche, i'en prens un aultre."

\section{ON SUBSIDIARY STUDIES}

I have spoken farther along about the need of modern languages and may say a word here about the despised Latin and Greek. As cultural studies, there can be no doubt of their value. The student of Latin and Greek is generally a more discriminating student and forceful writer of his own language than other men and this is a sufficient reason for their study. In the case of the naturalist there are other reasons: (1) the terminology of science is derived from these languages, and (2) all the oldest scientific writings and some of the modern ones are in Latin and Greek, and these, in some instances at least, must be read. Finally, Latin is the mother of all the great Romance languages, whose literatures will be to you a source of profit and delight for many other reasons than the purely pathological one. My advice to the pathologist therefore would be: study both Latin and Greek, or at least Latin, and get as much out of it as you can. 
Of the sciences, the higher mathematics would seem to be of least use to the experimental pathologist, and yet I may be wrong in this judgment. Certainly the end of all experimenting is to be able to express one's data in plots and curves, but biology is a very complex subject, too complex apparently for any mathematician to understand, and biologists, for the most part, are very far from being able to express themselves after the manner of mathematicians, however desirable it might be. Their language and ours are unlike almost to mutual exclusion. If, then, you are only an arerage biologist do not spend several years on the higher mathematics, because in the end you will be only an indifferent mathematician, a plodder and a grubber like the rest of us, not a member of the great race. When, as a student, I lamented to Harrington, the astronomer, my lack of proficiency in the higher mathematics, he said: "Tou have not cut as much underbrush in this direction, that is all." But I am sure the defect lies deeper, viz., in a type of mind, and one very common among biologists. The case is quite different, however, if your liking for mathematics is second only to your love of biology. Then you may study it as long as you feel inclined. You will be a kind of a white blackbird among your fellow biologists but this need not disturb you, since you will be able to do some things which they cannot do.

Of sciences which are closer to the pathologist I may mention experimental physics (especially those branches of it dealing with heat, electricity, hydrostatics, surface tension, viscosity, etc.) and chemistry, of which he cannot have too much. Bio-chemistry in particular will be of service to him at every turn. He cannot do without it unless he can arrange to work jointly with some chemist and even then he should not be content simply to look over the fence. The type of chemistry the pathologist should cultivate is that which deals with organic compounds wuch as his parasites produce or attack, and the problems connected with which he will have to face. I mean the chemistry of starches, sugars, celluloses, pectoses, tannins, acids, aldehyds, amino acids, glucosides, enzymes, ethers, esters, and the like. The pathology of the future lies right in the midst of these things and more and more the pathologist must be a chemist if he would succeed in a large way. 
The student should also know something of meteorology and of surface geology and soil physics. He must have some knowledge of zoology and especially of entomology, both because insects act as carriers of disease and because he must know how to keep his experimental plants free from all sorts of depredators. He should certainly know all the common insect pests, and the broad general conditions under which all animal life develops and functions. To know these things will give him a much broader and firmer grasp of his own problems.

In botany, the pathologist may be trusted to acquire as he goes along a knowledge of the morphology and structure of plants because all his life he will be making sections of various organs on a variety of plants, but plant physiology he should study thoroughly from the beginning, for how can one know the meaning of a disease if he does not know the functions and behavior of a normal plant! He should also understand gardening, that is the proper care and cultivation of plants in the open and under glass, and to this end he should affiliate with competent gardeners.

There is only one other group of studies I would touch upon. Human and animal pathology and modern medicine, with its stimulating outlook, are close neighbors, and the plant pathologist will be wise to make friends with the well-trained physician and the animal pathologist and to keep in touch as much as he can with the progress of these sister sciences.

There is a large program laid out, I hear it said. So be it, but if you are not lazy nor wasteful of your time, but hew to the line through a series of years you can accomplish it all and much more, and must, because what I have mentioned is only subsidiary to the main task.

\section{ON SEEING THINGS}

The successful student of nature, and especially the successful scientific man, must not belong to that type against whom it was said of old "Having eyes they see not!" In him "that inner eye which," according to the poet, "is the bliss of solitude" must be forever open to the faintest impressions from the 
natural world, if he would fathom its meaning. Seeing is not enough but it is the first step, the beginning of all the others. How to see with the eyes of a Darwin, a Pasteur, or an Asa Gray, that is the question! Poets are said to be born, not made, and inheritance must also play no inconsiderable part in the lives of all great men of science. Yet another saying has it that genius counts only for one-tenth while hard work is nine-tenths of every man's success. These are extreme statements and the truth lies somewhere between the two. Both environment and heredity are important. Certain it is, however, given some basis of good material to work upon, that patience and perseverance will do much to cultivate and sharpen the seeing eye. This must be so, otherwise the amateur would be as efficient as the highly trained man and we know that this is not the case in any field of endearor. As every teacher knows, it is hopeless to try to make students out of many persons because "It isn't in them," as the saying goes. They carry an insurmountable inheritance of dullness. On the contrary, long pondering on a subject with oft-repeated observations of the physical phenomena involved gradually enables the right sort of a person to see definite principles quickly and clearly in that which was at first only a maze of obscurity and uncertainty. The plainest things are often the hardest to see because all our seeing and all our thinking runs, or is apt to run, in stereotyped channels and the older we grow the greater the danger. Strive, then, to keep an open mind and to enlarge your horizon as you grow old.

But the first inertia is the most difficult to overcomec'est le premier pas qui coûte. The new and strange are always hard to comprehend and interpret. For this reason the first foreign language, especially if it is Latin or some other much inflected tongue, is I believe, always hardest for English-speaking persons. A Chinese student once told me that Latin was easy for him (because inflected, I presume) but English "very hard." For the same reason first impressions of a strange country are always most vivid but generally rery inaccurate, witness many books. Every one has heard the story of Agassiz's student to whom a fish was given that he might point out its most conspicuous feature. The bilateral symmetry of the fish was 
what the master had in mind, but this was the rery last thing the student thought of. ${ }^{1}$ Why?

Learn then to see, and to think upon what you have seen! And look again and again lest you should miss something.

By seeing I mean not loose general observations such as would enable you to distinguish a man from a tree (Smile, if you will, but this is the common way of seeing. I have exaggerated it only a litfle) but patient, long-continued discriminating observation. In this way, gradually, all the hidden details of an object become visible. When they are clear enough to be drawn or to be reflected upon as separate entities then only can you be said to know them. By thinking I mean prolonged logical reflection leading to clarity of view, not mere hap-hazard dreaming.

"Learning without thought is labor lost; thought without learning is perilous."

\section{ON EXPERIMENTATION}

Observations and reflections, however extensive and profound, are not sufficient guides in pathology. These might serve to make a statesman or a philosopher but not a scientist. Things observed are to be questioned-and this questioning is done by means of well-planned experiments. These experiments lead necessarily to many new observations and often to a materially changed point of view, so that the imperfect framework of a discovery, which may have been nine-tenths insight at first, is gradually filled in and worked over experimentally until it becomes a substantial and lasting structure. In pathology, as in all subjects dealing with phenomena, experimental tests of the validity of one's ideas are necessary at every step and the term "scientist" is a misnomer when applied to any one who does not try his hypotheses in the reducing fire of experiment. The world is full of shouting theorists who have never made an experiment in all their lives, certainly not one worthy of the name, and yet they are asking all men to follow them. This is why most politics, economics, socialism, spiritualism, psychic research, psychology, philosophy and

1. Doubtless, Louis Agassiz (1807-1873) tried this on many students, but Dr. IV. J. Beal is the one who told it to me. 
theology are such hogs and quicksands of the human intellect. They have not been, and from their very nature, in many cases, (annot be subjected to rigid experiment, and, therefore, have not arrived at, and in many cases, never can arrive at certainty. They belong on another plane, that of possibilities or probabilities and some are not even possibilities.

- The best advice I can give the young pathologist is this: If you would go far, experiment continually. Try out all of your theories and other men's theories by experiment. Let no day pass without something done to verify the correctness of the various ideas you have formed from your observations. In this way you will be able to discard many specious but erroneous assumptions, and will be continually adding to your sum of exact information.

The reason many men are only hewers of wood and drawers of water is because they are content with simple observations and reflections, of ten very superficial ones, and st op short of experiment which would show them where the truth lies. They may lack the seeing eye and the inquiring mind, may have "hook worm," be simply lazy, or perhaps only untaught. In too many children the eager questioning spirit is repressed by a hard and uns.mpathetic environment. such persons are conspicuously weak in memory, and in a knowledge of the past. Consequently they are the natural and easy prey of the walking delegate, the political demagogue and the yellow journalist.

\section{ON BEGINNING WORK THOUGHTLESSLY}

The best advice I can give the ambitious student is this: As far as posible, think out carefully in advance all the main ramifications of your experiments. This is not easy, even for the adranced worker, and surely you will have overlooked something. however thoughtful you may be, but by such preliminary cogitation you will escape many pitfalls, and come at once into the only proper way of research. "But I cannot afford the time," I hear someone say. Well, time wisely spent in the beginning of an undertaking is often time saved in the end. The shrewd commander takes into account all posible contingen- 
cies, as nearly as may be, and thereby wins a battle or a campaign. The commander who cannot afford the time, or who lacks the foresight and the acumen. is beaten and discraced. You have your choice. But what profit a student thinks he will derive from a blundering course of experimentation ending in some dead end or no thoroughfare, I cannot imagine. Your results, you may be sure, will not be commensurate with your labors. "Palma non sine pulvere." Yes, but Seneca is careful to add "per viam rectam." You may flounder through the mud and dust desperately, but if you are on the wrong road all of your energy will not save you.

Literature is full of examples of this sort of bungling, espe('ially Theses. which once printed have to be read but which really have no raison d'être, since often they do not add materially either to human knowledge or to the reputation of the writers. Sit down, therefore, with your problem and think it over seriously in all its various aspects before you attempt a stroke of work. The more thought you put upon it in adrance the more likely you will be to obtain convineing results when you actually begin to experiment. Here I camnot resist telling an old story. An Irishman invented a cumbrous cover to keep water out of a gig in case of sudden rains while on the road. which cover, he said. was to be stored away underneath the gig in clear weather. "But there is no room for it underneath." said a critic. As this was only too evident. Pat was nonplused for a moment and then replied, "Well, you can leave it at home." This is like many a human cogitation! Tried out it does not work!

I am not attacking any one. Some of my own experiments have been of this sort, but fewer I trust in recent years than earlier. Now I always spend more time, often rery much more, thinking orer my proposed experiments, than I do in the performance of them. And generally speaking. I know in adrance. harring some unforeseen contingency. just how they are coming out. If they fail, I begin to search shamefacedly for that something which I have overlooked. and sometimes it turns out. when discorered, to be as plain as the nose on a man : face, or as the bilateral symmetry of the fish. 


\section{ON INTERPRETATION OF PHENOMENA}

First of all, you are to remember that very often things are not what they seem! Two sets of phenomena may resemble each other superficially but be of quite unlike origin. Herein lies many a pitfall for the unwary. Probably most blunders in science result from failure to distinguish between similarity and identity, between resemblances that are fundamental and must depend on community of origin, and those that are only superficial and consequently must have diverse origins. The student, and the older worker as well, should be on his guard continuously against the fallacy of mistaken identity. The difference between a careful worker and one who is sometimes careless, or habitually so, lies in just this, that the latter sees the superficial similarity and is content with an inference, while the former probes the inference, demonstrates its non-ralidity, and saves his reputation.

Laziness, or inhibitions due to overwork, lie at the bottom of most such blunders. I think, but sometimes orer-confidence. Usually it is quite easy to show that a given result corresponds exactly to another or differs from it in various particulars, if enrironmental conditions are duplicated, and if cultures are made and sections are cut and studied, but all this takes time and painstaking care, which some persons are loth to give. It also involves good judgment and good training. Especially must you demonstrate, if you have made inoculations and obtained results: (1) that the resulting lesions are identical with those occurring naturally on the plant; and (2) that the organism in the lesions is identical with the one isolated from the natural disease and used for the inoculations. Not to do these two thing: thoroughly well is to leave your whole paper a tissue of uncertainties.

"Verify everything!" is the best advice I can offer. Then you will have no after regrets. Nearly every productive scientific man, however, has some regrets of this sort.

ON REPETITION OF EXPERIMENTS-OTHER PEOPLE'S, ONE'S OWN

There is a mistaken notion abroad that if someone has worked on a subject and published a book or paper, that settles 
it, and no one else need consider the problem farther. especially if that someone is a person of reputation. No supposition could be wider of the mark! Some reputations are founded on a rock, others are mere bubbles. Moreover, nature hides from us very securely her secret things, and the chances of going astray in their interpretation are many. The young scientific man, filled with his intellectual pride and knowing rery little really, either about the complexities of nature or the history of science, which for the most part is the story of one long series of blunderings (toward the light, however, not into deeper darkness), is apt to judge the mistakes of his fellows and of older men har-hly: the experienced honest man, on the contrary, knows that to err is human and judge all hones work leniently. since he know that eren the best work is certain to contain some erroneous observations, or some errors of interpretation.

Remember this, therefore, as a fundamental doctrine in science: Nothing is too sacred to investigate, and nothing can be regarded as indubitably established until various careful observers and experimenters have arrived independently at the same conclusion. Copy this out and stick it up where you can see it every day! If the second man over a subject finds the first man correct in all escontial observations and interpretations, the more creclit to the former. The second man will, nerertheless, usually be able to extend the first man's observations somewhat and should leave the field clearer than he found it and in any event his observations will be useful, as confirmation. Unfortunately, often, as the history of science shows, the second man over a subject is only a bumptious fool, and, when he has finished, the subject is covered with a cloud of uncertainty, until some third man, of greater ability, goes once more methodically over the entire field, blows away the dust, and again sets matters in their true light. If you repeat a man's experiments, try to be at least as painstaking and circumspect as he was, unless you wish to be intellectually pilloried for the contempt of oneoming generations. Never think it a waste of time or a work of supererogation to repeat the experiments of another person. Do not call it "duplication of work." It is not that, because no two individuals ever bring to a problem just the same sort of train- 
ing or outlook, and consequently, very often, one man finds what many others have missed. To exactly "duplicate" another man's work you would need to have exactly the other man's type of mind. Only by the labors of many minds has modern science come to stand where it does, as the only trustworthy interpretation of the world.

so much, about the repetition of other people s experiments! It is still more important to repeat your own experiments. Most mistakes in science result from neglect of this simple and fundamental precaution. If this practice were universal there would not be so many papers published, it is true, but those which did see the light would be much more worth reading, and would redound far more to the credit of the author and of the publisher. New species would not then be made from different shoots of the same root nor from different branches of the same tree. Remember: Rushing into print with some half-finished article may give you an ephemeral success, but not any lasting one! "Though the mills of Ciod grind slowly, yet they grind exceeding small." and the clarified and final judgment of the world on any human performance is apt to be rery near its true worth, certainly not in excess of it. Be careful then of what you publish. Repeat your experiments again and again, and only conclude that you have the truth when they adrance each time to a definite result like clock-work. Then, rightly, you may be full of that joy of discorery than which there are few keener delights, and may publish as speedily as possible with the full assurance that confirmation and due credit will not fail to appear.

I now endeavor to repeat all my own experiments several times over and in the end I have a rounded-out and better riew than one series only could possibly give me. Incidentally, I usually succeed in eliminating some errors or half-truths, which appertained to the first experiment.

I consider this subject so important that the whole chapter ought really to be printed in capitals!

Pasteur's two golden rules are worth remembering: $N^{\prime} a$ rancez rien qui ne puisse être prouté d'une façon simple et décisive, and in the presence of failure, Refaisons les mêmes experiences, l'essentiel est de ne pas quitter le sujet. 
ON PUBLICATION

The object of publication is to let other persons know what we have discovered. We cannot reach everyone, nor is that the aim, but we should be able to reach those cultivating the same field. The choice of a place for publication is, therefore, not unimportant. Generally we should choose some journal deroted to our specialty or, at least, concerned with kindred topics. some publication in which one would naturally look for papers on plant pathology. Journals are better than Transactions because they are issued more regularly and frequently, and are read more widely. Among journals select that recognized as a leading journal. If you print in a Transactions or in a Report be careful to select one that is published on time, not a year or two after going to press. Remember: printing is not publication, but distribution by sale or otherwise is. By no means bury your contribution in a newspaper or other ephemeral sheet, nor publish it in a journal, or Transactions, that seldom prints pathologieal papers, lest it should be overlooked and perish still-born! Do not print it in the middle of some other man's paper, nor in the middle of one of your own papers devoted to some other subject. I am referring to actual cases! Print your paper, don't send it out mimeographed. Yet such copies are better than none. Finally, always secure and distribute several hundred separates, so that no one will have an excuse for neglecting it. In this distribution include all the leading journals and workers both at home and abroad. This is the more essential, in many cases, because certain journals have only a limited circulation outside of their own country, whereas science is international. Pathological problems also are international. I approve of patriotism, but that sort which has no international outlook is a narrow and vicious kind, fit only for barbarians.

\section{ON CLEARNESS IN PRESENTATION}

Having selected a place for publication, the serious question arises how best to present the subject matter. This is comparatively easy only when the subject is a simple one and the contri- 
bution is but a note. It is grave if the subject is complex, and the writing extensive. Moreover, I have observed that the difficulty increases in proportion to the ignorance of the writer. Many a big book could have been boiled down to a few chapters, and in some cases to a few sentences, or to nothing at all, had its author been possessed of clear ideas. As a means of compression, learn to think. This is too much to expect of every one, but not too much to insist upon for the man of science. Whatever is worth doing at all is worth doing well. Clarity is the soul of truth, and especially in science there should be an idea behind every expresion, and this idea should be stated as clearly as language permits. To read the dictionary is usually considered in the light of a joke, but I doubt if any student could do better, and that, too, through a long series of years. If he does not continually thumb grammar and dictionary, and persistently read the best author's, he will seldom acquire a luminous and persuasive style, than which, exclusive of a single-minded devotion to the truth, nothing is more to be desired. There are various ways of saying things, but only one best way. Nevertheless, to read the contributions of many scientific men one would suppose they must think any method of expression sufficient, even the most clumsy and ambiguous. Yet such is not the case. In spite of this motley array of bad writers, it is best that subject and predicate should agree, that one should aroid split infinitives and especially that each statement should be susceptible of but one interpretation!

Every paragraph and every sentence in your paper should receive eareful and repeated consideration, first, as to whether it tells the exact truth; second, as to whether it is absolutely clear, i.e., will convey the same meaning to all as to yourself (try it on your friends, if they will submit to it); third, as to whether it is complete, or requires various additions or qualificationsscience is an eternal qualification; fourth, as to whether the sentences in it are entirely logical and move convincingly toward your final conclusions. These things can be determined only by repeated readings and much pondering. It helps greatly, when one has finished a paper, judging from my own experience, to turn back and re-write the whole of it. During this laborious 
and more or less irksome process, many new ideas occur to me, and better ways of stating ideas already expressed. It helps alio. I find, to put aside the completed paper and come back to it months later, as to a new subject, or to one by another author. Occasionally there is a person who can write a thing as it should be the first time trying, but I have known only one or two such persons. Generally, easy writing is hard reading. Darwin sometimes recast his paragraphs a dozen times, and most of us may expect to reach a good style, if at all, only by dint of much labor and repeated re-writing. Yet who can doubt that it is an end worth all it may cost?

You publish to convince your readers and advance your own branch of science, and incidentally to enhance your own reputation. Look to it, then, that your writings are not only permeated with a love of the truth, but are forceful and limpid as a mountain stream. To this end, avoid technical terms when common words will serve, even if you must do so at the expense of some conciseness. Nothing is more discouraging to the general reader than a book or paper bristling with a newly invented terminology, or full of mathematical formulae.

\section{ON COMPLETENESS OF PRESENTATION}

If you wait for absolute completeness, you will never publish anything but be always following up some one of the many side paths ranifying entrancingly in every direction from the great central subject under consideration.

Nature is boundless and our own working lives are very short. There must, then, be some compromises. The investigation must be broken off somewhere. The question is, where? This is solved, partly, but not altogether satisfactorily, by not undertaking very complex problems. All I can say is-Do each piece of work as thoroughly as time permits, but publish, otherwise, especially on the assumption that you have something really worth publishing, your generation is more or less defrauded.

Granted that you intend full publication, how complete the first paper should be, whether it should include all, or only 
a synopsis, or only some particular features of what is to follow, is a matter depending on various contingencies. If you have time, and are not likely to be forestalled, put it all into one complete and convincing paper, and illustrate it as thoroughly as possible. If, on the other hand, various other workers are in the field and you have reason to believe that their eyes are quite as sharp as your own, then it is important that you should get your discoveries into print as quickly as possible, if you are to receive due credit. You may then publish only a preliminary note, stating clearly what you have found and referring your readers to your later full paper for details and supporting proofs. Be sure of your facts, however, if you do this, since it is much better to let the credit of a discovery go to another than to rush into print only to discover later that you are wrong in places where you might have been right by taking a little more time for verification. In this connection it is well to recall the remark of the great zoologist of Johns Hopkins University, the late William Keith Brooks, when some one, alluding to an unpublished research of his, asked him if he did not fear anticipation. "I long since ceased to be troubled by such thoughts, for if another should publish on this or any other subject before I do, his work would probably be better or worse than mine. If it was better, I should be glad to be saved the mortification of having published poorer work; if worse, it would only afford additional material for my paper."

This, I should say, is better advice for a mature worker with a well-established reputation than for a young man with his reputation to make, and yet it is worth the young man's pondering.

By complete presentation I do not mean extensive and tedious presentation. Far from it! Many scientific papers, especially in Germany, are spun out to great length simply, it would seem, to increase the size of the honorarium. By all means avoid such doings. I shall deal more at length with this in the next section.

ON BREVITY OF STATEMENT-WHEN BREVITY IS NOT DESIRABLE

A good rule is never to use two pages for a subject that can be compressed by a little thinking into one. The generality 
of men use more words to express an idea than are actually necessary, if the best words had been chosen. study the meaning of words, their shades of meaning, and re-write a subject twenty times, if necessary, to state it cogently and with brevity. Remember: nearly everybody will read a brief statement on an interesting subject, while only the most phlegmatic and determined will hold themselves to a long-winded one. You will more than treble the number of your readers by halving your paper! Moreover, for the necessity of those who can't spend even the minimum of time necessary to read a short paper, and for the convenience of everybody, especially of the foreigner, it is your solemn duty to sum up the substance of your contribution in a series of brief conclusions which everyone will read, and which, if well put, may induce many to turn back and read your whole paper. No little thing vexes me more than to take up a paper two hundred pages long, let us say, often in a foreign language, and find no summary. I dip into it here and there trying to find what it is all about, without actually reading it word for word, and if I cannot do this the chances are that I throw it aside. Other people beside an author have some rights! Once I might have read it verbatim, but I have read too many such without profit, and now I am wary. It may be nearly all ambrosia, but how is one to know if its author has not respected it enough to provide a summary of its contents, as an appetizer"?

Study then with all your might how to be brief, how to say much in little, and do not use a word more than is requisite! Yet at the same time, use all the space that is necessary to follow your subject into all its various ramifications, and to present each and every feature of it clearly. Brevity is never desirable when it leads to obscurity. Often, especially in abstracts of papers read at scientific meetings, a few words more, especially if well chosen ones, would have converted a glittering generality which tells nothing, nothing exactly and usefully, and therefore is worth nothing, into a helpful note. There is a great opportunity for reform in this particular. Either journals should publish no abstracts whatever, or else exact, useful ones. Not every one can make a good abstract, in fact, very few can; and in general you should consult original papers rather than abstracts 
if you would be well-served and master of your subject. Often it is some slight side remark of an author. sure to be missed by the reviewer, that will prove suggestive to you and fruitful.

Another prevalent sin is neglect to provide long papers and books with a table of contents and with a suitable inder. It is ton murh for any author to expect the reader to make an index to his book, unless he is a rery guileless individual. My omn opinion is that such authors are lazy, rather than unsophisticated. Any way, they deserve to be put into a pillory because sometimes unfortunately it is necesary to use their books, and to read much in order to get a little. Publishers are also to blame for accepting and printing unindexed works. That a second volume with a general index is contemplated is no proper excuse for neglesting tw index the first rolume, becaute the serond Tolume may be long delayed or never published. I rerall -everal such cases. Ebermayer's "Physiologische Chemie der Pflan$z e n$ " is a capital example. A second flagrant example is "Les Maladies microbiennes des animaux" by Nocard and Leclainche (2 Vols.. Paris, Masson et Cie., 1903).

\section{ON THE ETHICS OF RESEARCH}

The scientific man is under the same moral obligations as the rest of the world! He cannot plead "art for art's sake" and run amuck, but like the common man must be held to strict account. If he does disreputable things he must expect to suffer the consequences, and he will, whether he expects it or not! The scientific man, of all men, ought to be the most upright, truthful and truthloving, because his whole life is spent in a search for the truth. If he cannot be trusted, who may be" If he has not high ideals, where shall we look for them?" "Buy" the truth and sell it not." should be his watchword. To him the truth should be a breastplate and a frontlet, a javelin and a strong tower. He should sacrifice to it and love and worship it above all thing-! Therefore. when the -reientifire nun depurtfrom just ways the scandal is peculiarly great. For this reason

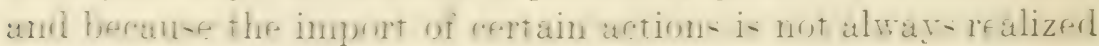
at the time, especially by the younger workers, it is worth while 
to consider for a few moments the ethics of our conduct as related to other scientific men, past, present and future.

Credit to Earlier Workers. - From at -ingle person. dicupery seldom cones full-fledged. like Minerrat from the hrain of Jove! Usually there are dim beginnings to which rarious men have contributed, and all of these, so far as they are real experimental contributions. should be cited by the man who is last to bublish. that the historic development may be plain. Indeed. it is imperative that he should do so if he would aroid one or other of two inferences: (1) ignorance; (2) dishonesty. I will admit that to the uninitiated it makes an author seem more important, if no previous literature is cited in his book or bulletin or paper. since then he may be supposed to have done it all by himself. and this probably has been the incentive to some flagrant cases of omission, but a moment's reflection will show anyone that such a procedure is a very short-sighted one, particularly if the man desires the re-pect of his fellow-workers and of intelligent lavmen. who also soon learn the true state of the case.

Begin your work, therefore, with a firm determination to be honest, and before you have gone very deep into any subject seareh wut the literature of it and prepare a menger biblingraphy. Do this in a workmanlike manner, citing in full-author, title. place of puhlieat ion. Year. rolume and puce and nathe it chronological not alphabetical. A chronological bibliography shows the derelopment of a subject at a glance and this is what the student desires to know. or should desire to know. since this is the historical method. Your readers will thank you earnestly for full citation, and, on the other hand, will curse you, if you carelessly refer them to places where the article is not to be found. or where it can be found only after prolonged search, generally in time that can be ill-spared for it. Many a day have I wasted trying to run down - horenly hiblingranhical reference and hence I write with some feeling. Every author owes certain things to his readers and this is one of them. It is so easy for you to fix a citation right when you have the rolume and page before your eyes and so difficult for another to verify it when he has only some bungling assininity as his guide.

You must know the literature of your subject. whaterer else 
you neglect and must cite it, and as a rule you should see, as I have said, the original papers. To this end, learn several foreign languages and have accurate translations made of such important papers as you cannot read in the original.

Finally, you must not minimize the work of the earlier author to magnify your own work. This is a common and mean sin. Such meanness of soul is its own reward, but always there is further punishment in store, since by no shift can such a person aroid the moral judgments of his own generation and of posterity. When a man has made use of an earlier author without citation it would seem that the work is his own, but often he has copied not only the discoveries but also the peculiar mistakes of the first writer and thus his dishonesty is revealed and punished.

Treatment of Contemporaries.-There is much honest rivalry in science and to this there can be no objection whatever. No one has any right to build a tight board fence around any locality or any problem and claim it as his peculiar preserves. Such a claim is highly absurd. Nature is free, or should be, for all, and the more outspoken the criticism and frequent the rivalry, the more rapidly will science adrance. Nothing throws such a wet blanket over the advancement of science as the suppression of free speech and the domination of a few wouldbe masters. Feel perfectly free, therefore, to take up any problem that interests you, unless you know that some one else has it already well in hand, in which case courtesy would seem to dictate the choice of another subject. The mere fact, however, that others have begun to work on it need not deter you, if you are not beholden to them for any of your ideas, and know that their researches are as yet only in the dough, and this is peculiarly true if the disease is wide-spread and economically important.

The things which you must not do are these: You have no right to begin a research, or to finish one, building it on the unpublished ideas of another man which he has imparted to you in confidence, or which you have obtained in some illicit way. It may be you have overheard a conversation, or have seen by accident some of the other man's experiments, or have received information from a friend who has heard the news or seen the 
experiments. By use of this knowledge you may be able to fructify your own sterile ideas and forestall him, but you have no moral right to do so. You cannot use these ideas without lowering yourself in your own estimation and in that of your fellows, for stealing, like murder, will out! You cannot conceal it, try as you may!

Be something first, then do something! Be willing to stand upright and to build on your own foundations.

Don't listen to conversations not meant for you, don't go about poking and prying, don't ask leading questions, and if anyone seems about to volunteer information as to his own work, ask him not to tell you. Thereby you may aroid charges of supplanting another, and much bitterness, because it often happens that other workers tell you the very things you already know, and have known perhaps for years, and yet if you then publish them as your own, the other man will be pretty certain to think that you are indebted to him and that you have not dealt with him justly. Judging from my own case, every experienced worker has hundreds of unpublished facts not of much value by themselves, perhaps, but kept in store waiting the discovery of other facts necessary to weld them into a vital whole. I give opinions freely where I can, and spend an aggregate of much time in the service of others, but to every one who comes to me for advice and wishes to tell me just what he has done, I now say, if he is working in my own field: "Don't tell me! Keep it to yourself until you have published it; then I shall be glad to read it."

You also owe to your fellow worker certain minor amenities. One of these is courtesy, another is generosity. If you discover scientific material of value to him, and which you do not intend to use, it is your duty to send it to him. Also, if you run across out-of-the-way papers on his subjects, he will be grateful to you for a reference and the kindness costs you but little. Finally, do not bother him with unnecessary questions, or ask for his unpublished data, or for his cultures until he has published on them, or for information it may take him days to prepare for you. Young men are often very inconsiderate in such matters, particularly if they are also very ignorant. I have had a re- 
quest within the year for references to all of the literature of plant pathology. Such requests, coming now and then, elicit only a smile, but dozens of them get to be a bore.

What We Owe to the Future.-Our duty to posterity requires us to pass on the torch of learning, trimmed and burning brightly. The little we are able to do individually brightens or obscures the pathway of science just to the extent that we are honest or dishonest, penetrating or dull. Our duty to the future is to do things thoroughly, to state things clearly, to point out weak places in our own work as freely as in that of others; and to cover up and obscure defective spots, for our own immediate profit. or reputation, under no circumstances whatever. If you have made a mistake, the manly way is to own it. Shame should not deter you, for every one makes mistakes, even the most famous and the most circumspect: Darwin made them, Pasteur made them. The only man who never makes any mistakes is the one who never makes any discoveries.

Ideals.-You are to remember that you are consecrated to the truth. If that prevails and you have helped to make it prevail, what matters it if you are first in the race, or last? In Milton's noble words, "They also serve who only stand and wait!" Nevertheless, the workman is worthy of his hire, and the great public is too little cognizant of this fact when that workman is a scientific man and not the director of a corporation. Science and the scientific man have not yet come to their own. The life of the common man in modern times has been ameliorated in a thousand ways by the labors of scientific men but he seldom thinks of this, and the Croesus never! It is a part of our duty to demand justice and fair play and to organize to get it if necessary.

Cultivate good judgment, be not easily discouraged, confess ignorance, aim high, be diligent! What Montaigne said about learning in general, applies with peculiar force to science- $L a$ science, pour bien faire, il ne faut pas seulement la loger chez soi, il la faut épouser. In his fascinating chapter "On books," Iontaigne also has the following words of wisdom which are well worth taking to heart: La science et la verité peuvent loger chez nous sans iugement; et le iugement y peult aussi estre sans 
elles: voire la recognoissance de l'ignorance est l'un des plus beaux et plus seurs tesmoignages de iugement que ie treuve.

Perhaps I can best close this section with the mottoes of my own laboratory which are from far away and long ago, but which I love all the more for these reasons, since in my philosophy of life all men are brothers and all times helpful. We can never escape from the great Past if we would, and we ought not to wish to do so, because to it and to the great men of other races than our own we owe many things - reverence being one.

"Ve are the fruit of Time and owe all to the immeasurable Past." Emerson.

I love them also because they teach at the same time uprightness and humility, independence and co-operation. The first is from Egypt and the second from China:

\section{Be not of your learning vain. \\ Treat the simple and the wise \\ With like honor. Open lies \\ Art's great gate for all, and they \\ Who have entered by that way \\ Know how still before them flies \\ The perfection they would gain.}

$$
\text { Precepts of Ptah-Hotep. }
$$

(33 eenturies B.C.)

Sayings of Confucius

(500 B.C.)

The way of heaven and earth may be completely diselosed in one sentencethey are without any doubleness.

To be fond of learning is to be near to knowledge.

The essence of knowledge is, having it, to apply it; not having it, to confess your ignorance.

There were four things the Master taught: Letters, ethics, devotion of soul and truthfulness.

The Doctrine of the Mean.

The Confucian Analects

There are many equally wise and suggestive aphorisms in the Confucian books. Here is one:

Hwuy gives me no assistance. There is nothing that I say ir which he does not delight.

And here is another:

Yuen Jang was squatting on his heels, and so waited the approach of the Master, who said to him, "In youth not humble as befits a junior; in manhood 
doing nothing worthy of being handed down; and living on to old age: This is to be a pest." With this he hit him on the shank with his staff.

Look for the "L. Y. T." edition, English-Chinese, published at Hongkong in 1898. Buy it, if you can find it, and live with it.

\section{ON KEEPING ONE'S OWN COUNSEL}

The scientific man's discoveries are his stock in trade. On them depends his reputation, and on that, very often depends his ability to obtain a livelihood and to care for those dependent upon him. The pecuniary compensation he receives is small, often despicable, if we consider the initial ability required and the long years of training requisite to perfect it into a productive career, and, especially, if we compare it with the great and alluring rewards held out to the young man by professional and business opportunity. Among a multitude of dollar chasers, who usually despise him, the scientific man deliberately chooses to remain poor for love of his science. His discoveries are his sole riches! He has no regrets and does not ask for sympathy but would like justice, and a livelihood! Any course of action, therefore, either on his own part, or on the part of directors or boards of control of institutions, which tends to rob him of the results of his labor strikes him in a peculiarly vital manner. If his discoveries are stolen or are frittered away to others by premature publicity, he is robbed of all that which makes his professional life worth while. Money he has not, and reputation is taken away from him. There is very little appreciation of this fact on the part of non-scientific men, but it is a fact, nevertheless, and one which must be taken into account by all who have to deal with men of science. Their ideals and their psychology must be understood and should receive courteous consideration from all in authority over them if they are to work without endless friction and deep humiliation. Most of all, the safety of his unpublished researches must be considered by the scientific man himself since he is beset on all sides, first, by marauding fellow workers who being unable to get results themselves are always on the lookout for what crumbs they may be able to pick and steal from others; second, by the so-called 
practical man who is generally clamoring to have his own selfish needs satisfied without much consideration for the research worker. He thinks it enough if the scientific man's salary is paid quarterly, yet there are more important obligations than parment of salary. The number of scientific men who deliberately steal from their fellows is few, I should hope, yet a half dozen glaring instances of this sort of iniquity have come to my knowledge in recent years and lead me to believe that his disreputable kind must be always wandering about. The scientific man must, therefore, protect himself as best he can not only from this class but from that much larger class who have some ideas of their own, which, however, require the stimulus of another's speech to render them fertile, and who seldom trace their incentive to its real source, or give any thought to it. We are all more or less of this sort, and while protecting our own discoveries should also aroid receiving what properly belongs to another.

These remarks lead naturally to the following piece of advice, riz., when you are with men working independently in the same field or with their friends-keep your own counsel. 'You may talk freely with them on apparatus, technic, the last novel, or any subject on which you are not working, but never a word on what you have discovered, or are now doing! It is time enough for them to know when you publish to the world what you have discovered. Conversely, a delicate sense of propriety should lead you to avoid trying to discover what the other man has done, or is doing. In other words: Don't talk shop with visitors. Any other course is suicidal. Nor should visitors be allowed to wander freely about experimental houses, laboratories, or grounds since an inoculated plant or animal may speak plainer than a man on a house-top. Cases are known where even the reading of a paper in adrance of its publication has given another man opportunity to lay fraudulent claim to priority of discovery, with resulting loss, recrimination and bitterness. For this reason papers detailing important discoveries should not be read before societies until they are actually in type and ready to appear. It is not a good plan even to tell what you contemplate doing. Do it, rather than expatiate on it, and when it is done then quickly make it available to every one. 
Pasteur set an admirable example in this respect, as in many others. He had no confidants. No one outside of his own laboratory, and often not even his assistants, knew what he really thought about a problem until the time was ripe for the announcement of his perfected discovery. No one suffers from such a course because discoveries published in an incomplete form, mixed with various erroneous assumptions incident to the early stages of a research, are seldom very useful. It is better to hold back the report until everything is verified and then so to publish it that the man who has actually made the discoveries shall receive the credit which he deserves, and by it be stimulated to make additional discoveries. It is all the more striking and memorable if these discoveries come like a flash out of a clear sky!

This brings us to the obverse side of the shield, which will be considered in the next section.

\section{ON TEAM WORK}

Nothing in the foregoing chapter militates in any way against the association of scientific men and women in small groups for the casier solution of difficult problems. Many complex problems can be attacked successfully only in this coöperative way, and this has come to be very clearly understood in modern times and is now, I think, rather overdone, there being a disposition in some quarters to consider scientific men as only so many cogs in a mechanism to be run exclusively by a nonscientific director or business man, in the interests of a bleareyed and jealous god called "Efficiency." The highest efficiency, however, obtains when the non-scientific man does the least meddling. "The accomplished scholar is not an utensil."

Such team-problems involve mathematies, chemistry, physical chemistry, physics, and various phases of biology and no one person can be supposed to possess the requisite training in all of these sciences, but several congenial persons by joining forces may succeed unitedly where each would fail separately. I have used the word "congenial" intentionally, for inharmonious natures do not mix any better than oil and water. Not every person is adapted to team work. Indeed, some persons are so suspicious of every one that they are shut into a very little world 
of their own and seldom accomplish much. These are at just the other extreme from those expansive persons whose loquacity is their worst enemy. There is, however, a happy middle ground where justice and mutual esteem prevail.

Usually in team work there must be a leader, if the various separate researches are to be properly coördinated, and always there must be frequent conferences and a mutual good understanding. This generally involves proximity. It is of little use, ordinarily, in my judgment, to undertake long-distance coöperations in biological research. Either money is wasted by lack of careful planning and constant supervision, or one party gets the lion's share of credit by publishing in adrance of and without the consent of the other party or, finally, one does most of the work or makes most of the discoveries and yet must share equally with the shirker, or with the dull one. Such coöperations are always a loss to one of the contracting parties, and frequently also, from neglect on the part of one of the coöperators, a loss to science. Said a well known experiment station director to me some years ago: "If I have discovered any good thing I am going to keep it to myself; if you have discovered any good thing, and wish to share it, I shall be very glad to 'coöperate." I also heard another station director say in public, frankly and without shame, that he wished to get all of the ciorermment money he could for expenditure in his own state, but that he cared nothing for researches outside of it. This, I believe, is the kind of coöperation many people have in mind, but it is not the sort that makes for the advancement of science, or that which I have in mind. In true team work each party does his share honestly and efficiently and the credit belongs equally to all. Nevertheless, the most brilliant and far-reaching discoveries are usually the product of a single mind.

The field applications of research, on the contrary, afford many opportunities for useful coöperations in plant pathology.

\section{ON SHARING CREDITS}

This is a delicate subject and views differ, especially the views of younger and older workers. What I shall have to say belongs logically under two heads. 
Teachers vs. Pupils. - A thousand interesting problems occur to every live teacher, but, with his hands tied by a multiplicity of duties connected with the imparting of knowledge, he must carry on his own researches in the odds and ends of his time, and largely by setting various students at work on these problems. They are so many instruments of inquiry, rather dull and defective tools in many cases, it must be admitted, but better than none. The teacher cannot be blamed, therefore, if he uses his students in this way. They are but beginners. They cannot do researches alone, and even with much guidance they generally manage to plunge into every alluring pitfall, every bog that in the least resembles solid ground. If the teacher is competent and faithful they receive from him far more in the way of stimulus and training than the value of what they return to him either in money or in research. Each student discorers something, let us say, but only the labors of many students in various years, plus the insight and the additional labors of the professor enable him finally to present a finished piece of work. Manifestly, the completed work belongs to the teacher who has been the brains of it from the beginning. Certainly it does not belong to the individual students, many of whom, perhaps, are now specializing in quite other fields or have abandoned science altogether, having gotten from it the training desired. In exceptional cases where the student has developed marked aptitude for a research, has devoted an unusual amount of time to it, and has made independent discoveries, the teacher should, I think, share with the student in the finished product, and generally I believe he is willing to do so. Students are often rather conceited and not always just to faithful teachers. It is good to try to put one's self mentally into the teacher's place. It is also good to remember St. Paul's advice- "Let no man think more highly of himself than he ought!"' Modesty is commendable in all, and especially in intellectual babes and sucklings. These remarks apply in large measure also to graduate work exclusive perhaps of "doctor's theses," of which in my judgment there are altogether too many published.

Chiefs vs. Subordinates. - In early stages of association the case is the same between chiefs and assistants. Later when 
the apprenticeship has been fully served, proper training acquired, and ability for independent research developed, there should be a just sharing of credits. Any other course leads to injustice and bitterness, is not creditable to the chief, and should not be endured by the subordinates. Here again, however, the subject calls for an exhibition of mutual forbearance and courtesy. In the end, the aim of all wise and honest chiefs should be to see their assistants set up as independent workershonest, capable and productive. It is enough glory for him that he has trained them! All this on the supposition that they have developed marked ability for independent research. The time required for this development varies greatly, and some never acquire it. The latter must be content to serve always in subordinate places, and all should defer a good deal to the judgment of their chief, premising always that he is an honest man of broad views and sound judgment.

ON ATTENDING MEETINGS AND KEEPING UP MEMBERSHIP IN SOCIETIES, AND ON BEING GENERALLY PUBLIC-SPIRITED AND HELPFUL IN SCIENCE

A man's success in life, granted some inborn ability and a proper training, depends very largely on the friends he makes, both the number and kind. If he is a reserved and shy individual, he is apt to get on slowly. He may be an excellent man but nobody finds out his good qualities. Likewise, if he is penurious, he stands very much in the way of his own advancement because then naturally he will think he cannot afford to purchase and distribute separates of his own papers, to buy books and to subscribe for scientific journals through which he would become well informed, or to belong to societies and attend meetings where he would meet many interesting men and might make friendships of lasting service to him. A clear outlook is essential. Remember the proverb: "Nothing ventured nothing won!" If you plan a career in science you cannot do better than to join scientific societies and attend scientific meetings regularly, even at cost of considerable inconvenience and self-denial. You should also visit other laboratories, and strive in every way to keep abreast 
of the rapidly moving current of modern scientific life. It is a duty that you owe not only to yourself, but also to your fellowworkers, since no one lives wholly to himself! Science has many enemies, and being your chosen goddess deserves your unqualified and generous support. Her worshippers are a small band and often they are too individualistic for their own best interests. In union only is there strength. If you are not public-spirited and helpful, you fall naturally into the ranks of the mean and selfish, and will deserve the fate you may be quite sure the gods have in store for you. It may even now be upon you without your knowing it.

On the contrary, if you are public-spirited, friendly and generous, lending a hand wherever you can, working along patiently and thoroughly, biding your time and not disturbed by selfish elbowing or band-wagon tactics on the part of your fellows, your opportunity will surely come, and a hundred hands will be reached out to help you where you expected none at all. The scientific public is quick to welcome all worthy comer', only it must be certain that they are really worthy, and if you keep yourself away from your fellows, how can anyone know what stuff is in you?

Be, then, ambitious for a worthy place and be willing to work hard for it, sixteen hours a day if need be, in spurts, but also remember that you must let people know who you are and what you are doing.

The counter of this advice is-Do not crowd in where you are not invited, do not elbow and push for the best places, but rather strive to be so courteous and to make yourself so thoroughly master of your subject that people will invite you. Honors in science are welcome if they come unsought, but, always, if you lobby for them, they will be less pleasant than you anticipated, and will lower you in your own estimation and in that of others.

\section{ON REST AND RECREATION}

By good food, pure air and temperate habits seek to put your body into tone, like some perfect musical instrument. Then the joy of living will overflow, expressing itself in ener- 
getic good work. Juvenal's mens sana in corpore sano is the ideal! Especially be very careful of your eyes since they are your most precious instrument of research and avenue of information. Very often, unknown to the student and the man of science, bad headaches result from slight eye-strain. For this reason consult good oculists frequently and, in general, avoid reading in bed, on a moving train, in fading daylight, or by a dim or flickering artificial light. ['se your eyes interchangeably at the microscope and rest them frequently if the instrument tires. Properly used, the microscope ought to strengthen the eyesight, or at least ought not to harm it.

Finally, remember that much use dulls a delicate instrument, especially the brain, while frequent rest and recreation tone up the mind to keener insight. Years ago a well-known man of science told me that two of his most interesting discoveries were made on days when he had decided to do nothing and had gone out to lie under the trees. The late Nir William Osler said to me: "I work tremendously hard nine months in the year, but the other three I play." Change of scene often means renewed life and energy and even change of subject helps somewhat. Many scientific men are rather narrow in their outlook on life and would be greatly improved not only socially but in every other way, by getting at frequent intervalsentirely away from their narrowing specialty, through the cultiration of literature, music, art, nature in her more general aspects, and the amenities of social life. 



\section{INDEX}

ACETIC acid tumors, 483,555

figures illustrating, 488, 490, 491 $492,493,494,495,555$

hypertrophy only in early stages, of, 555

origin of cells of, 555

substomatal injury preceding, 503

Acids, found in fruits, table of, 13

increase of, in tumor-forming tissues, 531,543

Adventitious buds, 50, 419, 574-630

Agar used for culture media, 105

Air in tissues, how removed, 295

Aleoholic material, care of, 120

Aldehyd, tumors formed on plants by, 483

Alfalfa

figures illustrating, 497

bacterial disease of, 55,474

white spot (physiological disease), 55

Amenities of research, 651

Ammonia, tumors formed on plants by, 483,553

figures illustrating, 486,487

loss of water precedes formation of, 489

theoretical action of, 567

Angular leaf-spot

of cotton. (See under Cotton) 55,314

of cucumber. (See Bacterium lachrymans),

Animal and human pathology, useful to plant pathologists, 635

Ants, control of, 109, 114

Aplanobacter, morphology of, 35, 132

Aplanobacter agropyri O'Gara, 47, 473

Aplanobacter michiganense EFS, 202

behavior on various media, 206

cause of bacterial eanker of tomato, 202
Aplanobacter michiganense EFS, characters of, 205

geographical distribution of, 205

in both field and hothouse, 202

infectious nature of, 219

isolation difficult, 206, 207

literature, 222

meristematic tissues attacked, 207

method of obtaining pure cultures, 207

phloem infected by, 202, 208, 209

resemblance on cooked potato to

Bacterium campestre, 206

seed-infection, 202, 216

sensitiveness to acids, 211,217

stomatal infections, 202

Aplanobacter rathayi EFS, 473

distortions in infected plants, 49

resistance to sunlight and drying, 36

Aplanobacter sepedonicum (Spk.) EFS, 207,474

Aplanobacter Stewarti (EFS) MeC., (See also Stewart's disease of maize.)

characteristics of, 160

colonies of, 172,173

color changes in infected corn plants, 49,162

cultural characteristics, 161

deseription of, 161

host plants, 167

inoculation methods, 165

literature, 176

morphology of, 161

most susceptible age of host, 8

resistance to drying, 36

seed-borne, 161, 174, 176

technic for obtaining pure cultures of, 163

temperature relations, 161

varieties of maize sensitive to, 167 
Aplanobacter stewarti, virulence persistent, 161

Aplanobacter teutlium (Metcalf) EFS, 474

Apparatus for

hothouse and inoculation experiments, 86

isolation and care of cultures, 80

photographic room, 89

preparation and study of sections, 81 preparation of eulture media, 77

Appel's potato-rot (See Bacillus phytophthorus)

discovered in Germany, 64

Apple, fire-blight of (See Bacillus amylovorus) (See also under Fireblight), 359

Ardisia, experiments with, 44, 45

figures illustrating, 41,42

mutualism in, 41, 42

Arthur (J. C.), 2

Ascobacterium luteum Babes, 344, 395 , 411

Ash tumor, 391

Australia, bacterial diseases found in, 52

Autoclaves, for sterilizing soil and pots; 86

in use in pathological laboratory, 78

Bacritus amylovorus (Burrill) Trevisan. (Cause of fire-blight of apple, pear, quince, etc.), 359

acids from sugars, 371

anä̈robic (facultative), 369

appearance of infected trees, 359 , 360

blossom-infection, 360,374

cankers on pear and apple trees caused by, 360

colonies of, $378,379,381$

control measures, 377,385

deseription of, 367,374

economic importance of disease due to, 365

erroneous statements respecting, 373

factors favoring spread of, 13,360 , 365

flagella, 367,377
Bacillus amylovorus, germicides, 71 , 365,386

growth on or in,

agar plates, 370

beef bouillon, 370

Cohn's solution, 371

gelatin plates, 370

milk, 370,382

potato broth, 370

Uschinsky's solution, 371

hold-over blight due to, 360

host plants, 359

in bark, 359,365

inoculation experiments, 374

in sap wood, 381

liquefying, 369

literature, 387

losses in United States due to, 54, 5.)

method of isolating pure cultures of, 374

methods of control, $71,365,377$, 385

most susceptible age of host, 8

non-gas forming, 370

non-nitrate reducing, 367

ooze from hold-over blight, 360,367 . 368

ooze from summer blight, 369,370 , 383

optimum temperature for growth, 371

plants susceptible to, 359

pruning to eheck, 367,376

resistant varieties, 377,385

ripe tissues immune, 372

secondary infections of, 363

susceptible varieties, 377

thermal death point, 371

transmission by insects, 360, 384 use of cyanide for disinfection, 71

use of formalin for disinfection, 71 use of mercuric chlorid for disin-

fection, 365,386

virulence persists, 365

winters over in trees, 360

yellow saprophytes may accompany, 374 
Bacillus apiovorus Wormald, 67, 239, $241,244,245,246,474$

Bacillus aroideae Townsend, 240, 247, 248

behavior in milk, 250

Bacillus atrosepticus Van Hall, 265, 266

Bacillus carotovorus L. R. Jones, (See also soft rot of carrot), 223

acids produced by, 230, 238

attacks young green shoots of carrot, 237

behavior in various media, 230,237

behavior in the tissues, 223,224

cause of soft rot of carrot, 223

colonies of,

on agar, 232,236

on gelatin, $239,240,269,276$

color on media, 230

compared with other soft rot organisms, 239, 240

disintegration of cell-wall, 232

dwarfing of plants infected with, 49,228

flagella of, 234

gas formed, 230, 237, 240

gelatin liquefied, 234

grape sugar, harmful to, 251

host plants, 223, 225, 226, 229

inoculation experiments, 241

involution forms, 238

literature, 252

means of gaining entrance to the plant, 223

method of isolating from the tissues, 241

milk curdled, 234

milk-rice, 246

nitrates reduced, 230

range of cultural characters in doubt, 232-241

resemblance to other organisms, $223,229,240$

sensitiveness to drying, 36, 147, 231

sensitiveness to sunlight, 36, 231

swelling of cell-wall, 251

technical description, 230

temperature relations, 231, 238

tolerates sodium chlorid, 238

type of disease caused by, 223

virulence not lost readily, 229
Bacillus carriers, 33

Bacillus coli Esch., 54, 355, 356, 408, 474

Bacillus cubonianus Macch.; 342, 344, 346

Bacillus delphini EFS, 474

Bacillus gossypina Stedman, 314

Bacillus harai Hori and Miyake, 53, 474

Bacillus mangifera Doidge, 473

figures illustrating, 3,9

most susceptible age of host for, 8

Bacillus melanogenes Pethybr. and Murphy, 265, 268

Bacillus melonis Giddings, 240

Bacillus musae Rorer, 473 figure illustrating effect of, 11 type of infection, 10

Bacillus oleae (Arch.) Trev., 394, 396

Bacillus oleae-tuberculosis Savastano, 394

Bacillus oleraceae Harrison, 239

Bacillus omnivorus Van Hall, 239

Bacillus phytophthorus Appel (See also Bacterial black rot of potato), 253

acid and gas forming, 257, 260, 263

alcohol, effect of, 260

appearance of tissues infected with, 255

behavior in various media, 257, 260

cause of potato black rot, 257

colonies of, $269,270,271,272$

distortion of infected potato plants, 49

dry air sensitive, 257,278

flagella of, 267

gelatin liquefied, 257

inoculation experiments, 267

inosite, gas from, 263

lactose, gas from, 263

life in soil, 34

literature, 278

mannit, gas from, 263

method of isolating pure culture of,

263,266

milk curdling, 257

milk-rice, 246, 260

nitrate reducing, 257

non-growth in Cohn's solution, 260

non-parasitic coccus accompany-

ing, 263 
Bacillus phytophthorus Appel, raw potato, growth on, 264, 267

ready means of identification, 267 related organisms, 265,268

technical description, 257, 260, 263 type of disease, 253

virulence of, long continued, 34,35 , $258,263,275$

Bacillus solanisaprus Harrison, 265, 268

Bacillus spongiosus Aderh. and Ruhl., 474

Bacillus tracheiphilus EFS. (See also Cucurbit wilt), 132

anaërobic (facultative), 135

cause of cucurbit-wilt, 132

coccus follower of, 138

colony, internal markings of, 136

colony, surface appearanee of, .138

cultural characters, 135

dwarfing of plants infected with, 49

figures illustrating, 136, 138, 140,

143,144

flagella of, 136

geographical distribution, 132

host plants, 137

insect carriers of, $30,134,135,144$

isolation of, 135

literature, 145

sensitiveness to acids, 135

sensitiveness to drying, $36,135,147$

sensitiveness to sunlight, 36,135

staining of, 117

technic of inoculation, 137

type of disease, 132

viscidity, 136

Bacteria in plants

action on middle lamella of cellwalls, 46

animals inoculations with, 36,459

cultural characters of, 35,36

gas production of, positive, 36,230 ,

257

gas production of, negative, 135 ,

$147,161,182,205,306,347,369$,

396,421

intracellular, 46

many diseases due to, 1,4

morphology of, 35

most, extra-cellular, 46

pigments of, 35
Bacteria, production of toxins by, 46 small size of, 75

staining of, from cultures, 118

staining of in tissues, 116

Bacterial black rot of potato, 253

Bacterial canker of tomato. (See Aplanobacter michiganense), 202

a phloem disease, 202, 209

figures illustrating, 203, 204, 205, $206,210,211,212$

histology, figures illustrating, $207,208,209,213,214,215$

Bacterial cell, why able to do so much work, 515

Bacterial diseases of plants

changes of susceptibility to, 9

cryptogams, occurrence in, 4

discovery of, 1

distortion of host plant as a result of, 49

distribution of, among flowering plants, 4

dwarfing of host as a result of, 49 early workers on, 1

fungous diseases following, 34 geographic distribution of, 51 immature tissues and, 8

in Australia, 52

in China, 53

in Denmark, 62

in Dutch East Indies, 52

in France, 66

in Germany, 64

in Great Britain, 64

in Holland, 62

in India, 54

in Italy, 66

in Japan, 53

in New Zealand, 55

in the Philippines, 54

in Portugal, 66

in Russia, 66

in Sandwich Islands, 64

in South Africa, 54, 55

in South America, 54

in Spain, 66

in Tasmania, 55 \}

in United States and Canada, 54

in West Indies, 52 
Bacterial diseases of plants, incubation period of, 17

lateney of, 8, 17

list of plant families attacked by, 4

list of plant genera attacked by, 7

losses due to, $51,52,53,54,61$, $62,64,66$

matured tissues attacked by, 9 methods of control, 68

new type of, 48

number of, 1,4

one followed by another, 34

parenchymatic vs. vascular, 10

period of greatest susceptibility to, 8

reaction of host plant to, $48-51$ scepticism as to occurrence of, 1 slow early progress in study of, 1 subject forty years old, 1

what governs infection, 12 when first discovered, 1

Bacterium, morphology, 132

Bacterium andropogoni EFS, 473, 475 method of infection, 16

Bacterium aptatum Brown and Jamieson, 474

green fluorescent species, 36

Bacterium atrofaciens McCulloch, 474 cause of basal glume rot of wheat, 55

figures illustrating, 57,58

Bacterium beticolum Smith, Brown and Townsend, 472, 474

cause of tuberculosis of beet, 50

Bacterium campestre (Pam.) EFS. (See also Black rot of crucifers), 145 colonies, figures illustrating, 150, 151

cultural characteristics, 147,153

drying resistance to, 36,147

growth on agar, 147

flagella of, $147,150,152$

host plants, 146

in Holland and Denmark, 62

inoculation by insects, 148

inoculation experiments, 149

isolation of, from diseased plant, 149
Bacterium campestre, literature, 159

method of infection, 16

method of inoculation, 150

morphology, 147

non-infectious to beans, 287

resistant varieties of plants, 149

retention of virulence, 148

seed-borne, 36, 159

type of infection, 16, 145

Bacterium citri (Hasse) Jehle, 59, 60, $61,62,66,287,329,474$

Bacterium coronafaciens Elliott, cause of halo blight in oats, 474

Bacterium delphinii, factors favoring infection, 13

Bacterium glycineum Coerper, cause of blight of soy bean, 474

Bacterium hyacinthi Wakker, 17, 62, 473

Bacterium juglandis (Pierce) EFS, 55, 329,473

Bacterium lachrymans Smith and Bryan, 474

cause of angular leaf-spot of cucumber, 36

factors favoring infection, 13

figures illustrating, 14, 15, 37, 38, 39,40

prevalence of, 69

Bacterium leguminosarum (Frank)EFS, action of, on plant tissue, 46

a polar flagellate organism, 46

marked viscidity of cultures, 139

Bacterium maculicolum McCulloch.

(See also Cauliflower, spot of), 300

aërobe, 306

appearance of cauliflower infected with, 300

attacks cabbage also, 300

behavior in various media, 306-310

cause of cauliflower spot, 304

colonies of, 303, 309

dry air sensitive, 310,316

flagella of, 313

green fluorescence, 306

heat sensitive, 310,316

inoculation experiments, 31]

lab ferment, 306 
Bacterium maculicolum, liquefying, Bacterium malvacearum, method of 308

literature, 313

method of obtaining pure cultures of, 310

motility, 304

sodium chloride sensitive, 306

strata in milk and litmus milk, 308

sunlight sensitive, 310,316

technical description of, 304-310

temperature relations, 308

type of disease caused by, 300

tyrosin, 306

virulence soon lost, 310

Bacterium malvacearum EFS. (See

also Angular leaf-spot of cotton), 314

beans, non-infectious to, 329

cabbages, non-infectious to, 329

citrus, non-infectious to, 329

colonies, 329, 330, 322, 334

comparison with other yellow organisms, 329

contrast with Bact. phaseoli, 322, 325

description of, $321,322,324,325$, 326. 327

flagella, 325

gardener's hose spreads organism, 332

gelatine plate colonies, 324,335

geographical distribution, 317,319

growth on or in

agar plates, 322

beef peptone bouillon, 327

blood serum, 325,336

litmus milk, 327

milk, 327,337

potato, 326

Uschinsky's solution, 327

history of disease caused by, 314

infections due to wind driven rain, 322,337

inoculation experiments, 331

lab ferment, 322

literature, 339

maximum temperature for growth, 327

means of distinguishing, 331

method of infection. 16, 337

making pure cultures, 330

non-growth at low temperatures, 327

resistant in tissues, 335

sensitive to drying, 36

sensitive to freezing, 328

sensitive to sunlight, $36,326,327$

stomatal infections, 317

thermal death point, 327

type of infection, 317

tyrosin, 327, 338

windowed colonies, 324

yellow saprophytes with, 330

zoned colonies, 324

Bacterium marginale Nellie A. Brown, cause of lettuce spot, 36

Bacterium medacaginis (Sackett) EFS, 474

Bacterium mori Boyer and Lambert emend. EFS. (Cause of mulberry blight), 340

acid sensitive, 347

appearance of plants infected with, 340

chloroform tolerant, 348

cirri of, 340

colonies, 356,357

description of, $347-351$

flagella, 353, 354, 355

geographical distribution, 341

growth on or in

agar streaks, 348

beef bouillon, 348

blood serum, 348

Cohn's solution, $34 \mathrm{~S}$

litmus milk, 348

milk, clearing of, 348

peptone water, 349

potato, 348

Uschinsky's solution, fluorescent, 348

history of disease, $342-347$

inoculation experiments, 351

involution forms, 349

loss of virulence in media slow, 351

literature, 358

method of isolation of pure cultures, 3.51

nomenclature, $342-347$ 
Bacterium mori, non-liquefying, 348 non-nitrate reducing, 347 pseudozoögloeæ formed, 349 thermal death point, 349 sensitive to sunlight, 349 sodium chlorid tolerant, 349 tyloses due to, 477 yellow saprophytes with, 342

Bacterium phaseoli EFS. (See also Bean blight.)

appearance of tissues inoculated with, 282

bean varieties resistant to, 289 , $290,291,292$

behavior in milk eultures, 293 cause of bean blight, 280, 285 colonies of, 296,298

contrasted with Bact, malvacearum, 285, 287

description of, 285287

distortions due to, 282, 284

factors favoring infection, 13, 289

flagella, 285, 294

freezing, effect of, 293

geographical distribution, 284

growth in bean plant, 282, $28 t$

growth in various media, 285, 287

inoculation experiments, 288

lab ferment, 285

liquefying, 285

literature, 299

method of obtaining pure cultures, 287

non-infectious to cabbage, 287

non-infectious to citrus, 287

resemblance to other yellow species of Bacterium, 287

resists drying, 285

starch destroyed by, 292

sunlight, effect of, 295

temperature relations, 285,287 , 294

treatment of plants inoculated with, 290

virulence persists, 287

winters over on seeds, 296, 297

zoned colonies, 285, 324

Bacterium oleae Arehangeli, 343, 394

Bacterium pisi (Sackett) EFS, 474

Bacterium pruni EFS, 287, 329
Bacterium pruni, cause of black spot and canker of plum and peach, 13,473

method of infection, 16

most susceptible age of host, 8,10

Bacterium savastanoi EFS. (See also

Olive tubercle)

acids formed, 400, 401

aërobic, 400

appearance of infected olive trees, 389

appearance of tissues infected with, 391

chloroform tolerant, 397

colonies of, 402,403,405, 407. 408

cultural characters of, 396

dwarfing of infected olive shoots, 49,392

Hagella, 396, 401

formation of crystals in Cohn's solution, 407

growth on or in

agar plates, 397

beef bouillon, 401

Cohn's solution, 403

Dunham's solution, 403

gelatin plates, 398

litmus milk (blued), 398

milk cleared, 398

potato, 398

Uschinsky's solution, 401

Winogradsky's solution, 403

history of nomenclature, 394

inoculation experiments, 404

literature, 411

loss of virulence on media not rapid, 404

maximum temperature for growth, 399

Merck's peptone harmful to, 401

method of infection, 15, 389

method of isolating from diseased

tissues, 404

methods of staining, 399

non-liquefying, 396

non-nitrate reducing, 396

plants susceptible to, 394

thermal death point of, 400

transmission of, 21,410 
Bacterium savastanoi, undulate-erose colonies on gelatin, $398,403,405$ varieties of olive resistant to, 410 Bacterium solanacearum EFS, 177.

See also Brown rot of Solanaceae. aërobism, 186

appearance of the disease, 178

bipolar staining, 186

colonies, figures illustrating, 190, 191

cultural characteristics, 182

dark stain on steamed potato, 186 distortions of infected planis, 49 , 179

duration of virulence, 34

dwarfing of infected plants, 48, 49, 184. 189

flagella of, 192

fluid colonies, 191

geographical distribution, 182

growth on or in

agar, 186

gelatin, 186

non-growth in Cohn's solution, 186

host plants, 177

inoculation technic of, 188

insects may distribute, 199

isolation of, from diseased plants, 188

literature, 200

loss of virulence on media, 186

loss of virulence in soils, 195

method of infection in Sumatra, 21

morphology, 182

most susceptible age of host, $\mathrm{s}$

motility, how best observed, 197

nematodes and, 181

on beans, 178

on egg plant, 177

on potato, $177,178,180$

on Ricinus, 184

on sunflower, 185

on tobacco, 180,181

on tomato, 178

opalescent colonies of, 182

plants for inoculation experiments, 189

pure cultures, method for obtaining, 188
Bacterium solanacearum, recovery of plant from infection with, 18 reduces nitrates, 186 renders milk alkaline, 186 roots, entrance through broken, 181

rotation of crops advised, 200 sensitive to drying, 36,186 soil organism harmful to, 195 stain in tissues due to, 180,183 stock cultures, care of, 188 tyloses due to, 477 two strains of, 188 type of disease eaused by, 177 virulence lost quickly, 186 weeds subject to, 178,200 well-water infected by, 21 var. asiaticum EFS, 188

Bacterium syringae (Van Hall) Güssow, 35,473

cause of lilac blight, 35

Bacterium translucens Jones, Johnson and Reddy, 36, 329, 473

Bacterium translucens var. undulosum Smith, Jones and Reddy, 474 colonies of, 20, 26, 27, 28, 29, 31, 32

destroyed by formalin, 70 effect on wheat kernels, 56 resistance to drying, 36 resistance to sunlight, 36 signs of, on wheat heads, 22, 23, 24

variable severity of, 51

Bacterium tumefaciens Smith and Townsend, 413 . (See also Crown gall.)

acid-forming, 426

action on plant tissue (hyperplasial), 46

animal inoculations with, 36

appearance of tissues infected with, 413

cause of a disease in man, not established, 36

chemical products of metabolism of, $457,483,558$

colonies of, $438,461,462$

Congo red absorbed by, 426

cultural characters, 421 
Bacterium tumefaciens, flagella, 459 geographical distribution of, 413 growth on or in

agar, 426

bouillon, filaments and stringing threads in, 426

Cohn's solution. 426

gelatin plates, 426

litmus milk (blued), 426

milk, casein slowly separated, 426

potato, 426

Uschinsky's solution, 426

host plants, 430

how distinguished from saprophytes in media, 438

inoculation experiments, 438, 449

involution forms, 428,460

isolation from diseased tissues, $432,433,438$

lab forming, 426

literature, 471

may live in soils, 35

mitochondria (?) confused with, 419

non-liquefying, 421

non-nitrate reducing, 421

non-starch destroying, 421

occurs in tumor in small numbers, 433

plate cultures directly from tumor often develop slowly, 433

saprophytes accompanying, 432

sensitive to acids and alkalies, 426

sensitive to germicides, 428

serological reactions, 457

several strains of, 457

staining of, 466,468

temperature relations, 426

transmitted by nursery stock, 469

type of tumors produced by, 413

virulence lost slowly, 428,469

virulence of colonies from tumors variable, 468

Bacterium vaseularum Cobb, 473

dwarfing and distortion of sugar cane infected with, 49

how avoided in New South Wales, 73

Bacterium viridilividum Nellie $A$.

Brown, cause of lettuce spot, 36
Bacterium woodsii EFS, 16, 473 method of infection, 16

Balances, 78

Banana, bacterial disease of, 473 figure illustrating, 11

Panama disease, 52

rot of, in Philippines, 54

in Sandwich Islands, 64

Bark tumors in rubber trees (Hevea), 478

Barley, bacterial blight of, 55, 473

Basal glume rot of wheat, 55. (See Bacterium atrofaciens.)

Basal stem rot and tuber rot of potato, 253. (See Bacillus phytophthorus and black rot of potato.)

Basket willow, bacterial disease of, 53 , 474

Bean, bacterial spot of. (See Bean, blight of.)

Bean-blight, 280. (See also Bacterium phaseoli.)

appearance of disease, 282

bacterial crusts and cirri in, 282

care of inoculated plants, 290

causal organism oozing from tissues, 282

chiefly parenchymatic, 280

chlorophyll may persist around leaf spots, 282, 283

color changes in diseased plants, 282 control of, 299

description of causal organism, 285

discolorations in, 282

distortions due to, 282, 283

dwarfings due to, 283

etiology, 285

figures illustrating, 280-288

first signs of the disease, 282

geographical distribution, $54,55,284$. 285

Halsted's observation, 296

histology, figures illustrating, 289, 290, 291, 292

host plants, 280

inoculation experiments, 288

isolation of causal organism, 287

late stages of the disease, 282,283

literature, 299

pathogen seed-borne, 297 
Bean-blight, resemblance to other yellow organisms, 287

rust-red margins of spots, 288 seeds infected, 284, 297 selection of material for sections, 294 stomatal infection, 284, 285, 289 stomatal ooze in, 282 susceptible varieties of beans, 290 , 291

temperature relations, 291

time required to infect, 290

troublesome nature of, 55,285

type of disease, 280

Bees, agents in transmission of plant diseases, 25, 30

Beetles, agents in transmission of plant diseases, 30

Begonia, bacterial leaf spot of, 474

Begonia hybrids and phyllomania, 575

Begonia phyllomaniaca, 568, 571-628 a hybrid, 575

amount of water needed by, 615

buds from trichomes, 616,617

comparison with Bryophyllum calycinum, 619

dwarfing of proliferous leaves, 594 embryonic tissue red, 587

experiments with, 574-631

formation of adventive shoots, 575 nearly free from, when undisturbed, 599

history of, 574,575

leaf distortions in, 620

lenticels in, 615

literature on, 629

origin of plants experimented with, 587

phyllomania in, cause of, 575,593

figures illustrating, $586,588,591$, 594,602

proliferations at stipule sears, 599 scarcity of stomata in, 615,619

sensitive to shock, 625

shoots from internodes, 577,582 . $589,592,598,608$

shoots from leaf blades, 578, 584, $604,605,611$

shoots from petioles, $596,598,606$, 610

shoots from wounds, 613,614
Begonia phyllomaniaca, sub-epidermal storage system, 615

watery nature of, 587

Bibliographies, preparation of, 648

Biochemistry, subsidiary study in pathology, 633

Black arm, 314. (See Bacterium malvacearum.)

Black chaff of wheat. (See also Bacterium translucens var. undulosum.)

distributed on seed, 20, 56

introduced (?) from Russia, 66 germicidal treatment of, 69-71 prevalent in Central United States, 55

Black-leg of potato, 253. (See Black rot of potato.)

Black rot of erucifers, 145. (See also Bacterium campestre.)

brown or black veination of leaves, 146,148

cause of, 147

chlorophyll, increase of, in, 157

destructive nature of, 148

dissemination by insects, 148

dissemination by refuse from cabbage houses, 156

dissemination by seed, 148

dissemination from a seed bed, 159

etiology of, 147

figures illustrating, 145, 146, 147, 148,149

geographical distribution. 147 histology, figures illustrating, $154,155,156,158$

host plants, 145

introduced into United States

from North Europe, 159

literature, 159

means of prevention, 159

resistant varieties, 149

slugs as carriers of, 159

stain of vaseular bundles in, 146

type of infection, 145

variability of, 157

water-pore infections common in, $146,147,148$ 
Black rot of potato, 253. (See also Bacillus phytophthorus.)

appearance, 255

base of stem specially subject to, 254,255

black stain conspicuous in, 254 , 260

cause of, 257

contrasted with Bacterium solanacearum, 257

control of, 278

figures illustrating, $253,254,255$, $256,258,259,260,261,262$ 264,275

geographical distribution, 257 histology, figures illustriting, 263,266

host plants, 257

inoculation experiments, 267

leaf-curl in, 263

lenticel infection, 265

literature, 278

method of isolation, 263

non-starch consuming, 264, 266 non-vascular disease, 253, 255

resemblance to other potato diseases, 265

resistant varieties, 277

stomatal infections doubtful, 277

temperature relations, 274,278

transmis-ion, 278

type of disease, 253

varieties subject to, 277

virulence long persistent in organism causing, 263

weather relations, 257

Blood serum, use as culture medium, 10.5

Blossom-blight, 16, 359-361

Blue prints, bleaching of, 128

Boll-rot of cotton, 314. (See Bacterium malvacearum.)

Bordeaux mixture, 74, 114

Braun (Harry), method of control of seed-borne organisms, 71, 72

Brevity, advantage of, in scientific papers, 647

when not desirable, 647

Bromide prints, bleaching baths for, 128 43
Brooks (Wm. K.), citation from, 646

Broom corn, leaf-stripe of. (See Bacterium andropogoni), 473

Brown rot of Solanaceae, 177. (See also Bacterium solanacearum.)

distribution of, 182

figures illustrating, 177, 178, 179, 180, 181, 182, 184, 185, 186, $187,189,276$

histology, figures illustrating, $193,194,196,199,200$

in East Indies, 54

in United States, 55

widespread on many hosts, 177

Brusone, rice disease common in Italy, 66

Bryophyllum, what sets leaf-buds growing, 619

Bud-rot of coconut, 9, 52, 54, 474

Buds, on tomato leaves, 50 on crown galls, 419, 437, 439, 442, 452,456 ,

Burrill ( $\mathrm{T}$. J.), discovers cause of pear blight, 1

CabBAGE, black rot of, 145. (See Black rot of eruciferous plants.)

in Holland, Denmark and United States, 62

tumors due to freezing, 485

tumors due to sand-blast, 489

Cabbage pith, woody cylinder in, 485

Cabbage spot disease, 300 . (See cauliflower spot.)

Calla lily rot, resemblance to soft rot of carrot, 229,230

Cameras, for general purposes, 90, 92, 93

Crandall model, 91

for use in making photomicrographs, 94

Canada, bacterial diseases found in, 54

Cancer

in plants, 413. (See Crown gall.)

literature cited, 573

of rats, 571

parasite (?) suspected cause of, 570 plant tumors suggestive of, 51, 417, $419,421,471,558,569$ 
Cancer, pre-cancerous stage, 483, 511, 571

theory as to cause of, 569

Cane diseases

Australian, 52

East Indian, 52

Fiji, 52

Porto Rican, 476

South American, 54

Canker of peach and plum, 13, 473

Cankers on plants as a result of bacterial infection, 50, 202

Capsule spot of cotton, 314. (See Bacterium malvacearum.)

Carbol fuchsin, 117

Card catalogues, use of, 130

Carnations, leaf spot of, 473. (See

Bacterium woodsii.) new type of infection found in, 48

Carnoy, fixative, formula of, 115

Carrot, soft rot of, 223. (See Bacillus carotovorus.)

Catalogues, 139

Cauliflower,

black rot of, 145. (See black rot of crucifers.

Harrison's soft rot of, 239

McCulloch's spot of, 300 . (See also

Bacterium maculicolum.)

appearance of diseased tissues, 300

cause of disease, 304

cool weather disease, 308

description of pathogen, 304, 306,308

figures illustrating, 301, 302, 307

geographical distribution, 304

histology, figure illustrating, 305

history of the disease, 304

immunity of very young and

very old leaves, 302

incubation period short, 302

inoculation experiments, 311

literature, 313

method of isolating causal organism, 310

period of incubation, 302

stomatal infections in, 300, 301

type of infection, 300

tumors due to chemicals, 551
Cauliflower, tumors formed by sandpapering, 489

Cavara (Fridiano), 2

Cell-division, caused by lack of oxygen, 515

Cell-paralysis and cell-stimulus in tumor formation, 566

Celery, blight of, 474

rot,.common in England and United States, 64

figures illustrating, 67,244

losses from, 51

soft rot of, 240

Cellulose, doubtful action of pathogenic bacteria on, 46

Centrifuges, use in Pathological Laboratory, 78

Chemical cell-stimulation, in chestnut wood, 478

Chemicals, necessity for purity of, 107

Chemicals produced by crown gall, 483

Chemical stimulus resulting in tumor formation, 510

Chemistry, need of, in pathology, 634

Cherry, Barss' blight of, in Washington and Oregon, 474

Cherry, German blight of, 474

Chestnut, tyloses in wood of, 478

China, bacterial diseases in, 53

Citrus canker, 61, 474

appropriations by Congress to control, 61

distribution of, 52,62

figures illustrating, 59, 60, 61, 62

in Australia, 52

in Japan, 53

in India, 54

in Phillippines, 54

inspections in Florida for, 62

Cladosporium citri Massee, 62, 65

Clean hands, importance of, 108

Clear ideas, 644

Clearness, necessity of, in scientific writing. 643

Coconut, bud-rot of, 474

figure illustrating, 9

in Philippines, 54

in South America, 54

in West Indies, 52

Coleus, freezing experiments with, 566 
Colletotrichum gossypii Southworth, 321

Colonies, planar enlargements with oblique light, 111

Color changes in plants, due to bacterial infection, 49

Color-chart used, 132

Competing saprophytes, 74

Confueius, sayings of, $637,653,656$

Control, methods of, 68

Coöperation, a necessity in modern research, 656

Copper sulphate treatments, 69

Cork-formation, as a result of bacterial infection, 50, 233

Corrosive sublimate treatments, 69 , $159,176,386$

Cotton, angular leaf-spot of, 314. (See also Bacterium malvacearum.)

black arm and boll rot, other forms of, 314

description of causal organism, 321

distortion of leaves due to, 282

early stages of the disease, 316

economical importance, 321

figures illustrating, $314,315,316$, $318,319,321,322,323,324$, $3: 33$

geographical distribution, 54, 55, 317,319

histology, figures illustrating, 320,338

history of disease, 314

infection may be early, 316

inoculation experiments, 331

late stages of the disease, 317

literature, 339

method of isolating the organism, 330

method of transmission, 337

prevalent in China, 319

prevalent in South Africa, 54, 317,319

prevalent in Turkestan, 317

spot disease versus vein disease, 316,317

stomatal infections in, 317

type of disease, 314

Crandall camera for field work, 91
Crown gall, 413. (See also Bacterium tumefaciens.)

a hyperplasia, 413

animal inoculations with organism causing, 36

bearing leafy shoots, 419

cells not killed by the parasite, 413

chlorophyll in tumor strand, 459

conversion of adjacent normal cells into tumor cells, 431

erushing effect of tumor cells, 468 description of causal organism, 421

disorientation of cells in, 455,460 , 467,470

dwarfing of infected plants, 49

$414,415,417,436$

early stages, 459

effect on host plant, 417

embryomas, illustrations of, 435 ,

$436,437,439,440,442,443,444$,

$447,448,452,456,458$

etiology, 421

figures illustrating, $413,414,415$, $416,418,420,422,423,432$, 450

flower buds from, 437

found in France and Italy, 66

found in South Africa, 54

geographical distribution, 413,421

growth, extra physiological, 417

growth from cambium, 417

growth from cortical parenchyma, 417

growth stimulus extending beyond the tumor cells, 460, 468

hairy root, 421

histology, figures illustrating, 428, $429,430,431,433,434,443,454$, $455,464,465,467,470$

host plants, 430

inoculation experiments, 438, 449, 451

invasive tumor cells, 460, 468

killing effects, 449

lignin on bark parenchyma cells, 430

literature, 471

method of control in rose houses, 73

method of infection in South Africa, 15 
Crown gall, method of isolating organism, 432-438

non-infectious colonies from, 468

nurserymen common distributors of, 469

olive resistant to, 469

on chestnut, 413

onion resistant to, 469

on oak (undetermined), 414

on rasin grapes in California, 417

on wild fig, enormous size of, 414

on willow in Africa, 417

parasite intracellular, 419

parasite, how carried in the tissues, 419

parasite, occurs in small numbers. 433

Peklo's studies, 463

peroxidases in, 457,563

phenomena suggesting cancer, 51, 558, 569

prolonged incubation period in an orange tree, 17,448

respiration accelerated in, 563

roots from, 421,458

secondary etiology of, 558

secondary tumors from primary

tumor with structure of latter, 417

secondary tumors, time required for development, 459

shoots from, 419, 439, 440, 442, 444

stages in development of, 563

staining diseased tissues, 466

starch stored in, 563

stem-structure of secondary tumors in leaves, 428, 429

strains (several) of organism causing, 457

sugar abundant in, 563

tracheids in, from stem-, leaf- and

fruit-parenchyma, 431, 455, 463 transmission of, 460

tumor strand, figures illustrating, $418,424,425,427$

tumor strands in sunflower, 449

type of disease, 413

when excessively vascular, 468

where found on the plant, 421
Crown gall, wound disease. 469

young tissues produce largest tumors, 417,449

Cruciferous plants, black rot of, 145 , (See Black rot of erueifers.)

Cryptogams, bacterial diseases of, 4

Cucumber, angular leaf spot of. (See

Bacterium lachrymans Smith and

Bryan.)

Cucumber wilt, 132. (See also Bacillus tracheiphilus.)

carried by striped beetles, 30

etiology, 132

geographical distribution, 132

literature, 145

type of disease, 132

winter occurrence of, 132

Cucurbit wilt

controlled by destruction of insects, 74

figures illustrating, 133, 134, 135

histology of, figures illustrating, $141,142,143$

Cultures of bacteria, care of, 80,109

isolation of, 80

staining of, 118

study of, 110

tools for isolation of, 80

transfer chambers for making, 80

Culture media,

agar, 105

blood serum, 105

bouillon, 105

gelatin, 105

milk, 104

peptone water, 106

preparation of, 77,100

pure sugars for, 107

raw vegetables, 103

steamed vegetables, 101

synthetic, 106

uses of, 99

vegetable juices, 103

Cuttings, disease transmitted by, 73

Cyanide of mercury for pear blight, 71

Dacus oleae (Rossi) Meigen, 407, 411

Dark room, for photography, 95

Denmark, bacterial diseases found in, 62 
Developer,

for ordinary photographs, 95, 122

for use in making photomicrographs, 95,125

Diabrotica vittata Fabr., agent in transmission of eucumber wilt, 30

Bacillus tracheiphilus winters over in, 33

Distortions, as a result of bacterial infection, 49

Drainage, importance of, 74

Drawings, essentials of good, 129 preparation of, 126-129

Dry plates recommended, 95, 121

Dubois $(\mathrm{R})$, experiments in chloroforming plants, 624

Duplication of work, no danger of, 641

Dutch East Indies, bacterial diseases found in, 52

Dwarfing, as a result of bacterial infection, 48,49

EFfect of cold, heat, anesthetics, literature, 630

Emerson, wisdom of, 653

Entomology, subsidiary study in plant pathology, 634

Eel worm, galls due to, 543

Environment, effect of changes of, on parasite, 12

Enzymes, excess of in diseased potato shoots, 543

Erythrina, root disease of, 52

Ether, as a stimulus to dormant buds, 609,622

Ethics of research, $6 \pm 8$

Experimental method, importance of, 638

Experiments necessity for repetition of, $637,638,640,642$

Eyepieces, Zeiss, 85

Eyestrain, 661

Field corn, attacked by Stewart's disease, 160

Filing systems, 131

Filters

Berkefeld, 79

Chamberland, 79
Fire, use of, in isolating bacteria from tissues, 107

Fire-blight of apple, pear, quince, etc. (See also Bacillus amylovorus), 359

a bark disease, 359,365

a blossom-blight, 359

appearance of diseased tissues, 359

bacterial ooze in. 365

Burrill's studies of, 1, 367

control of, $365,367,385$

description of causal organism, $367-372$

disintegrating action, 365

early stages of disease, 359

economic importance of, 55 , 365

etiology, 367

figures illustrating, 360,361 , $362,363,364,366,367,368$, $369,370,375,383$

following crown gall, 384

geographical distribution, 365 germicidal treatment, 71,386 hailstone infection. 385

listology, figures illustrating, $371,372,373$

history of the disease, 359,360

hold-over blight or winter stage, 360

home in United States, 385

host plants, 359

inoculation experiments, $3 \overline{7} 4$

insects transmit, $360,384,385$

isolation of causal organism, 374

late stages of the disease, 360

literature, 387

means of detecting hold-over

blight, 381

nectarial disease, 360

on wild shrubs in United

States, 359

orchard destroyed by, 375

parenchymatic disease, 359

pruning for prevention, right sort of, 367,376

wrong type of, 362,367

Reimer's studies of, 386 
Fire-blight, resistant varieties of pears, $377,383,386,387$

Sackett's studies of, 363 secondary infections, 363 soils favoring development of, 383 susceptible varieties of plants, 377

transmission by aphids, 384 transmission by bees, 384 transmission by birds, 384 transmission by pruning tools, 384

type of disease, 359

varieties of pears immune to, 386,387

Waite's studies of, 25, 359, 360, 372

waterpore infections, suspected, 384

water sprouts favor, 384

Fire-heated soil, 73

Fish, tumors in, 36

Fixative, Carnoy, 115

Flagella, staining of, 118

Flemming's triple stain, 117

Flowers, infection through, 16

Forcing plants, by ether, by cold, and

by warm bath method, 622,623

Formaldehyd, method of use for control of plant diseases, 69

Formalin treatments, 69, 71, 73

Formic acid, tumors formed on plants by, 483

figures illustrating, 498, 499, 500, 501

France, bacterial diseases in, 66

Fraxinus excelsior, tumors on, 391, 394

Freezing, tumors due to, 485 figures illustrating, 504, 505

Fundamental doctrine of science, 640

Fungi followed by bacteria, 34

Fungus infested soils, 114

Fusarium cubense EFS, cause of the Panama banana disease, 52, 54

Fusarium sp., following crown gall, 34

Gatl formation, theory of, 549

Gas production, by bacteria, 36. (See also Bacteria in plants.)
Gelatine, used for culture media, 105

Generic names, how used in this book, 132

Germany, bacterial diseases in, 64

Germicidal sprays, 74

Germicides, use of, in isolating bacteria from tissues, 107

Giant cells, 543, 545, 550, 565

Glassware, in common use in plant pathology, 77

Glomerella gossypii (Southw.) Edgerton, 321

Gram's stain and variants, 117

Grand Rapids disease of tomato, 202. (See Aplanobacter michiganense.)

Grape, crown gall on, 417 intumescences on leaves of, 496

Grass, western wheat-, disease of, 47 , 473

Great Britain, bacterial diseases in, 64

Gummosis of cotton, 314. (See Bacterium malvacearum.)

HaIL stones, infection through wounds due to, $15,385,410$

Half-tones, preparation of, 122

Hand lens, Zeiss, 86

Herbarium specimens, care of, 119

Heterodera radicicola Greef, cause of galls, 543

Hevea brasiliensis Muell., brown bast disease of, $52,476,478$

Holland, bacterial diseases found in, 62

Honing, on transmission of tobacco infection by well water, 21

Hot air treatment of seed, 69

Houser cabbage, disease resistant, 149

Hutchinson (C. D.), disease of wheat in Punjab, 47

Hyacinths, Wakker's disease of, 473 yellow disease of, in Holland, 62

Hyaloplasm, paralysis of, and tumor formation, 553

Hybridization as a means for control of plant diseases, 75

Hyperplasias in plants, chemicals a cause of, $483,551,563$

formed non-parasitically on potato, 502

freezing a cause, 485 
Hyperplasias in plants, gall flies a cause, 552,560

increased acidity a cause, 515,531 , 541

myxomycetes a cause, 549

nematodes a cause, 543

primarily due to physical-chemical stimuli, 558, 563, 568

result of bacterial infection, 51, 413

semi-asphyxiation a cause, 496, $502,511,513,519,541$

wounding a cause, 489

Hypertrophy, caused by physicalchemical stimulus, 508

ICE boxes, use in culture work, 110

Ice thermostat, 110

Altmann's, 81

Ideals of research workers, 651

Illustrations, preparation of

blue prints, 128

drawings, 126-129

engravings, 127

paintings, 129

photographs, 120

photomicrographs, 123

Imbibition, seed treatment by use of, preceding germicides, 71

Immunity, aequired, 19

Indexes, necessity for, 648

India, bacterial diseases in, 54

Incubation, period of, 16,17

Infection,

birds, transmit, 25

cages for, 111

carried on seeds, 20,202, 297, 337

chemiotaxis and, 16

distortion of host as a result of, 49

due to wind-driven water, 21

dung heap and, 21

dwarfing of host as a result of, 49

external factors governing, 13

formation of overgrowths as a result of, 50

insects and, 25, 30, 74

internal factors governing, 12

rain or dew and, 21

recovery from, $17-19$

spread by molluscs, 33

spread by nematodes, 33
Infection, through broken roots, $\mathbf{1 5}, \mathbf{1 6}$, 181,212

through hail storms, 15, 385, 410

through natural openings, 16, 21, 146 ,

$160,181,202,282-284,300,317$, 358,360

well water and, 21

Inoculated plants, care of, 113

Inoculation

by use of insects, 112

by soil, 111

cages, 111

methods of, 111

syringes, 111

time and place for, 112

Insects, agents in transmission of plant diseases, 25, 30, 74, 159, 384

Intumescences

Atkinson on, 489

due to acid stimuli, 508

figures illustrating, 512, 514, 516, 517, 518

formed by lenticel obstruction, 496

formed in absence of parasites, 477510

formed on potato in sealed tubes, 506

Harvey on, 485

literature, 572

Sorauer's work on, 489, 491

Tubeuf on, 631

Viala and Pacottet on, 1491

Von Schrenk on, 483

Wisniewski on, 496

Wolf on, 489

Iris, soft rot of, 239

Islands of wood in bark, 478

figures illustrating, $481,482,484$

Isolation of bacteria, technic of, 80,107

Italy, bacterial diseases in, 66

$J_{\text {APAN, }}$ bacterial diseases in, 53

Johannsen: etherization of dormant buds, 622

Jones' soft rot of carrot, etc., 223. (See

Bacillus carotovorus.)

disease corked out in potato, 253

disintegration of tissues, 226 , 229,238

dwarfing due to, 228 
Jones' soft rot of earrot, figures illustrating, 224, 225, 227, 228, 229,230

geographical distribution, 223 histology, figures illustrating, $226,231,232,233$

host reaction, 230

one species or several as cause of, 223,229

on many hosts, 223,225

prevention, 252

swift action, 224, 229

turgid tissues most susceptible, 225,227

wound parasite, 223

Journals for publication, 643

Juvenal, wisdom of, 661

KALE, black rot of, 145. (See Black rot of crucifers.)

Knee-shaped bendings, 49

Knot of olive, 389. (See Olive tubercle.)

Kohlrabi, black rot of, 145. (See Black rot of crucifers.)

LARKSPUR, blight of, 474

Leaf-spots, 8, 74, 280, 300, 314

Latin and Greek, need of in pathology, 632

Legumes, root-nodules of, $46,139,551$

Lenses, for photographs, 91 planar, 92, 126

Lenticels, tumors formed in, 513

figures illustrating, 512, 514, 516, $517,518,525$

Lettuce, blight of, 474

Lettuce diseases, methods for control of, 74

Lichens, apple twigs smothered by, 365

Light filters, for use in photography, 94

Lilac, blight of, 62, 473. (See also Bacterium syrings.)

Lime-sulphur spray, 74

Longfellow, citation from, 642

Losses due to bacteria, 51,54

Marze, Stewart's disease of, 160. (See also Aplanobacter stewarti.)

Maladie d'Oleran, bacterial nature of, 66
Mango, bacterial disease, (See also Bacillus mangiferae.)

figures illustrating, 39

in South Africa, 54

Mango leaf-, stem-, and fruit-spot, 473

Manihot, disease of, found in South America, 54

Manure-heap, keep diseased rubbish out of, 74

Massachusetts potato disease, 219. (See also net-necrosis.)

Mathematics, as a subsidiary subject in pathology, 634

McCulloch's cauliflower spot, 300 . (See also Cauliflower.)

Media for cultures

agar, 105

blood serum, 105

gelatin, 105, 106

milk, 104

peptone water, 106

preparation of culture media, 100

Soyka's, 230

steamed vegetables, 101

synthetic, 106

uses, 99

vegetable juices, 103

Medicine, knowledge of, useful to plant pathologists, 635

Mercuric chloride treatments, 69, 159, 176,386

Metabolism, products of bacterial, cause overgrowths, 483

Methods of control, 68

Methods of research, 76

Meyer (Frank N.), discovers tobacco wilt in China, 53

resistant pear trees collected by, 377

Micrococcus amylovorus Burrill, 367, 388

Microscopes,

eyepieces for, 85

objectives for, 85

Zeiss, 84

Microscopic preparations, how preserved, 120

Microtomes,

Minot precision, 83

Minot Rotary, 83 
Mierotomes, Reinhold-Giltay, \$2 Spencer rotary, 83

Milton, eitation from, 652

Modern languages, need of, in patho$\log y, 633,650$

Modern science, value of, 642

Molisch, Hans, forcing dormant buds with warm water, 623

Molluses, diseases transmitted by, 33

Montaigne, wisdom of, 633,652

Mottling of leaves due to loss of water, 506,553

Mulberry blight, 340 . (See also Bacterium mori).

appearance of diseased plant, 340 dead twigs due to, 341

description of pathogen, 347

distortion of leaves, 340,342

early stages of disease, 340

figures illustrating, $341,342,343$, $344,345,346,350$

geographical distribution, 341,342

histology, figures illustrating, 347, $349,352,353$

history of disease, 343

inoculation experiments, 351, 254

late stages of disease, 340

literature, 358

method of isolating causal organism, 351

resemblance to pear blight, 340

susceptible varieties of mulberry, 341

tyloses in, 357,477

type of disease, 340

Müller-Thurgau, potato experiments, 622

Museum specimens, 120

Mushrooms, bacterial rot of, 66

Mustard, black rot of, 145. (See black rot of crucifers.)

Nectaries, infection through, 16

Negatives,

filing of, 131

labeling of, 131

Nematode galls, 543, 550

Nematodes, as agents in transmission of diseases, 33,181
Nematodes in soils, treatment of, 73 , 114

Němec, studies of nematode tumors, 545,549

Net-necrosis of potato, 218-221

Nigrosin, use of, in staining, 117

Nitrate reducing organisms, 147,182 , 230,257

Non-nitrate redueing organisms, 135, $161,205,285,306,347,367,396,421$

Nucleus, division of, in tumor formation, 545

Nurserymen, responsible for disease, 19 , 20

OAK, frondose gall on, 556, 557, 559, $560,561,562,564,565$

Oats, halo-blight of, 55, 474

Objectives, Zeiss, 85

Observation and reflection, insufficiency of, 637

Oedema of tomato, 489

figures illustrating, 508, 509

O'Gara (P. J.), disease of western wheat grass, 47,473

on fire blight, $365,371,381,384,386$

Oleander tubercle, 33,394

Olive knot. (See olive tubercle.)

Olive tubercle, 389. (See also Bacterium savastanoi.)

appearance of diseased tissues, 389 bacterial ooze abundant, 389

cavities formed in tissues, 389

channel of secondary infection, 396

etiology, 394

figures illustrating, $390,391,392$, 393,395

geographical distribution, 66, 391

German views, concerning, 395

granulomatous nature of, 389

histology, figures illustrating, 396, $397,398,399$

history of the disease, 391

in what fields and climates most abundant, 410

literature, 411

method for control of, $74,410,411$

method of isolating causal organism, 404 
Olive tubercle, nomenclature of organism causing, 394

no tumor strands in, 359

structure of, 389

type of disease, 389

wild olives subject to, 389

wound infection, 389

Opium poppy, bacterial disease of, 54

Orchard grass, new type of infection found in, 48

Rathay's disease of, 473

Osler (Sir Wm.), wisdom of, 661

Oven, for sterilizing glassware, 78

Overgrowths, as a result of bacterial infection, 50

how otherwise produced, 477

Oxygen and the bacterial cell, 515

and the tumor-cell, 511, 531, 541

Paintings, for illustration, 129

Panama disease of banana, 52

Panchromatic plates, use of, in photomicrographic work, 95

Paraffin oven, 83

Parasites, sensitive to environment, 12 action on tissues, 46

dry air sensitive, $135,195,231$ $257,306,322,372,421$

dry air resistant, 147, 161, 207, 285,348

effect of freezing on, 285,306 , 322,372

effect of moisture, 13

effect of shade, 13

effect of sunlight, 156, 231, 285, $306,322,349,369,404,421$

effect of winds, 13

extracellular versus intracellular, 46

killing temperatures, 135, 139, $155,214,231,272,285,308$, $327,348,371,399,426$

soon followed by saprophytes, 34 summer temperatures, stimulating effect of, 13

summer temperatures repressive effect of, 310

Parasitism versus symbiosis, 41

Pasteur, wisdom of, 642, 656
Pavetta nodules, figures illustrating, 42 , $43,44,45$

Pea, stem blight of, 474

Peach, black spot of, 473. (See Bacterium pruni.)

Pear blight, 359. (See also fire-blight and Bacillus amylovorus.)

discovery of bacterial origin of, 1 economic importance of, 54 enormous losses due to, in United States, 55

how spread, 68

in stone fruits also, 69,359

methods of control, 68,385

occurs now in Japan, 365

Pelargonium, leaf-spot, 474

Peptone water, use as culture media, 106

Peroxidase in tumors, 563

Pethybridge and Murphy, potato rot of, 64

Phenolphthalein, how used in titrations, 106,132

Philippines, bacterial diseases found in, 54

Photographs, preparation of, 120

Photography,

cameras, 90

lenses, 91

room for, 89,96

value of, 121

washing devices, 95

Photomicrographs, camera for use in making of, 94

developer for, 125

fixing bath, 125

light filters, use of, in making, 94

preparation of, 123

time of exposure for, 124

Phyllomania in Begonia, 574-630

abnormalities observed in, 615

causes distortions, 612

comparison with effect of anæsthetics on dormant buds, 622

comparison with effect of cold, 622

comparison with effect of heat, 623

due to shock, 575

epidermal nature of, 583

from glands and trichomes, 583

from wounds, 590 
Phyllomania in Begonia, not a winter state, 575

proliferations not mirror images, 612

nutrition and, 581

root-injury causes, 593

stage of greatest susceptibility, 579

theory concerning, 600-607, 609

top pruning causes, 609

Physics, a subsidiary study in patho$\operatorname{logy}, 633$

Phytophthora infestans(Mont.)de Bary, bacteria follow, 34

Pierce (N. B.), control of walnut blight, 74

Piricularia on rice, 66

Planar lenses, 92, 126

Plant cancer, 413. (See crown gall.) suggested relation of, to animal cancer, 569, 571

Plant parasites, general morphology and cultural characters, 35

Plant, physiology, importance of, to pathologists, 634

Plasmodiophora brassicae Woronin, 549 , 551

Plates, lumière, 126

Plum, black spot of, 473. (See Bacterium pruni.)

Poppy, bacterial disease of, 54

Portugal, bacterial diseases in, 66

Potato,

Appel's rot of, 253

basal stem rot of, 253. (See also

Bacillus phytophthorus.)

black leg of, 253. (See black rot and Bacillus phytophthorus.)

black rot of, 253

brown rot of, 177

intumescent shoots,

excessive acidity of, $528,536,543$

excessive sugar content of, 541 , 563

figures illustrating, 532, 533, 534, $535,536,537,538,539,540$, $542,544,546-548$

lenticel proliferation in, 502

net-necrosis of, 219

rots,

found in Australia, 52
Potato, rots found in England, 64 found in France and Italy, 66 found in Germany, 64

found in United States and Canada, 54

general discussion of, 263-266

great looses due to, $54,64,66$

Spieckermann's ring rot of, 207,474

Printing papers, 122

Proliferation, in Begonia, 574-630

abundant over mid-ribs, 596, 604, $605,606,612$

arising from epidermal hairs, 583, 616,617

arising from epidermis, 583,618 , 621

arising from internodes, 577

a teratosis, 579

caused by a definite shock, 575

caused by loss of water, 593

caused by wounding, $590,593,613$, 614

changes in plant leading to, 600

comparison with similar phenomena in other plants, 581,619

corking over of stimulated tissues, $586,589,594,607,609,616$

development of adventive shoots away from the mother plant, 580,581

distortion resulting from, 612

experimentally produced on internodes, 582, 586, 589, 592, 598, 608,601

extent of development of, 581

from totipotent cells, 583

general on leaf-blade, 578

increase of acidity as a cause of, 601

literature on, 629

nature of shock necessary to produce, 599

produced at will, 579

season of year it may be produced, 575

shocked leaves not stunted, 584, 594,612

shocked leaves stunted, 602, 611

table of number of shoots on stimulated internodes, 627 
Proliferation, in Begonia, table of results of wounding leaf blades, 626

Pre-soak seed treatment, 71

Prophylaxis, 68

Protea, leaf spot of, 66

Pseudomonas tritici Hutchinson, cause of wheat disease in India, 48

Ptah-Hotep, precepts of, 653

Publications, brevity desirable in, 646 clearness essential, 644 good summary essential, 647 place of publication important, 643

Pyrus ussuriensis Maxim., resistant to pear blight, $377,386,387,388$

RAND (F. V.), experiments with bacterial wilt of eucumbers, 30

Rape, black rot of, 145. (See black rot of crucifers.)

Rathay's disease of orchard grass, 62, 473

Razors, for microtome use, 83

Recovery from disease, 17-19

Red cabbage, freezing experiment with, 566

Reimer's resistant pear stocks, 386,387

Reimer's treatment of pear blight, 71

Research, ethics of, 648

Resistance, to disease, in plants, 16,75

Rice disease, nature of, in 1taly, 66

Ring rot of potato, 474

Root-nodules, of legumes, 46,551

Roots, infection through, 15, 16, 188, 212

from crown gall, 421,458

Rose galls, how avoided, 73

Rotation, as a method of control in plant diseases, 74

Rubber, brown bast disease of, 52,476

Russia, bacterial diseases in, 66

Saint Paul's advice, 658

Salamanders, inoculations of, 36

Sand-blast, hypertrophies due to, 489, 507

Sandwich Islands, bacterial diseases in, 64

Savastano (Luigi), 2, 400

Scientific man's stock in trade, 654

Sections, free-hand, 114
Sections, fugitive stains, 117

microtome, cutting and care of, 115 fixing tissues for, 115

keeping record of, 115

staining of bacteria in, 116

filing of, 120

preparation of, 81,114

stains recommended for, 117

straightener for, 83

technic of making, 115

Seed-beds and disease, 73, 159

Seeds, treatment of, 69,71

Seedsmen, responsibility for spread of disease, 19,20

Seneca, wisdom of, 639

Sereh of cane, 52,476

Sharing credits, 657

Shriveled seeds and disease, 56, 69

Similarity and identity, fallacy of, 640

Soft rot of carrot, 223. (See also Bacillus carotovorus.)

appearance of diseased tissues, 224

description of causal organism, 230

etiology possibly confused, 229 , $230,232,235$

figures illustrating, 224, 225, 227, $228,229,230$

geographical distribution, 223

histology, 226, 231, 232, 233

inoculation experiments, 241

literature, 252

method of isolating causal organism, 241

other host plants, 225

resemblance to calla lily rot, 229 resemblance to other soft rots, 223,239

type of disease, 223

Soil,

and infection, 21, 34

method of sterilizing, 86

Solanaceate, brown rot of, 177. (See also Bacterium solanacearum.) appearance of disease, $17 \mathrm{~s}$ cause of disease, 182 dwarfing due to, $181,184,189$ figures illustrating, $177,178,179$, $180,181,182,183,185,186,187$ 
Solanaceae, brown rot of, geographical distribution, 182

histology, figures illustrating, $193,194,196,197,198,199$. 200

history, 177

host plants numerous, 177

inoculation by needle pricks, 188

literature, 200

method of isolating pathogen, 188

plants and cultures for artificial inoculation, 189

type of disease, 177

Sorghum, leaf-stripe of, (See also Bacterium andropogoni.)

South Africa, bacterial diseases found in, $5 t$

South America, bacterial diseases found in. 54

Soy bean, leaf spot of, 474

Spain, bacterial diseases in, 66

Specimens, care of, 119

Spieckermann's disease of potato, 64 , 207,474

Spraying for control of disease, $7 t$

Staining,

bacteria, 116,118

flagella, 118

jars for, 84

methods, 116

Stains,

Carbol fuchsin, 117

Flemming's triple, 117

Gram's, 117

Grübler's, 84

methylviolet, 117

nigrosin, 117

special, 119

Starch,

removal by the plant from vicinity of the diseased tissues, 50, 233

storage of, in diseased tissues, 50,541 , 547,563

Stasis of eirculation and tumors, 541

Statesman and philosopher versus man of science, 636

Steamers, used in sterilizing culture media, 78

Steam-drag, 74
Steam-heated soil, 73, 114

Stereotyped thinking, 636

Sterile coöperations, 657

Sterilization

by fire, 107

by germicides, 107

of leaf surfaces, 351

importance of still air, 108

importance of clean hands, 108

Stewart's disease, 160 . (See also Aplanobacter stewarti.)

appearance of, on sweet corn, 160 cause, 161

cultural characteristics of pathogen, 161

dwarfing, 170

etiology of, 161

field corn also attacked by, 160

figures illustrating, $160,162,163$,

$164,170,171,174$

first signs, 170

geographical distribution, 161

histology, figures illustrating, 165 ,

$166,167,168,169,174,175$

host plants, 167

how disseminated, 176

inoculation experiments, 165

literature, 176

means of prevention, 176

morphology of pathogen, 161

seed-borne, 161

type of disease, 160

white male inflorescence, 162

yellow ooze from cut stems, 163

yellow pockets in tissues, 164,171

Still air, importance of, in making iso-

lations, 108

Stomata, infection through, 16. (See also Infection through natural openings.)

test for condition of, 553

wide open over intumescences, 543,548

Streptococcu- viridans Schottmüller, 570

Stripe-disease of broom corn and sorghum, 473

Style, how acquired, 644,645

Subjects, suitable for special study, 474 , $475,476,477$ 
Success, how attained, 659

Sugar beet,

crown gall on, 414, 420, 422

leaf spot, 474

Metcalf's soft rot, 474

tubercle of, $50,472,474$

Sugar cane,

bacterial disease of, in South America, 54

Cobb's disease of, 52,473 period of incubation in, 17

Fiji disease, 476

Sereh, 52,476

stripe disease (mosaic), 476

Sugar in tumors, 563

Summaries, importance of, 648

Supernumerary organs, 50

Susceptibility, period of greatest, 8

Swedes, rot of, 66

Sweet brier, frondose gall on, 552, 554

Sweet corn, Stewart's disease of, 160 .

(See Stewart's disease.)

Symbiosis, 41

Syringes, 111

TEAM work, necessary in research, 656

Temperature, arrangements for controlling, for culture work, 81

Teratosis, production of in Begonia, 574-630

Teratoma, on potato, 508,540

Text-books recommended for study, 76

Thermo-regulators, Roux, 81, 109

Thermostats, 109

Rohrbeck, 81

Tyloses in plants, 357,477

figures illustrating, 200, 478, 479, 480

Titration, apparatus for, 80

Titration of media, how practiced in my laboratory, 132

Tobacco,

bacterial disease of, in South Africa, 54

brown rot of, 177. (See also Bacterium solanacearum.)

disease of, in Sumatra and Java, economic importance of, 52

leaf-spots of, 54,476

wilt, in China, 53
Tobaceo wilt, in Cuba and Porto Rico, 182

in Japan, 53

in Southern United States, 55

Tomato,

bacterial canker of, 202. (See also

Aplanobacter michiganense.)

appearance of the disease, 202

cause of the disease, 205

figures illustrating, 203, 204, 205,

$206,210,211,212$

geographical distribution, 205

histology, figures illustrating, $207,208,209,213,214,215$

infectious nature of, 202,216

isolation of causal organism, 207

literature, 222

parasitic organism probably seed-borne, 202

resemblance to a disease of potatoes in Germany, 207

resemblance to brown rot, 202

restricted growth of pathogen in certain media, 206, 207, 217

signs of the disease, 202

staining of tissues, 202

stomatal infection common, 202

technical description of pathogen, 205

tissues attacked, 202

transmission of disease, 202

type of disease, 202

brown rot of, 177. (See Bacterium solanacearum.)

oedema of, 489, 508, 509

wilt, found in South Africa, 54

Topics suitable for special study, 474 , $475,476,477$

Toxins, production of, by bacteria, 46

Transfer chambers for making cultures, 80

Transmission of disease, agents, 19-34

by aphides, 159,384

by bees, $25,30,360,384$

by beetles, $30,134,135,199$

by bugs, 384

by birds, 25,384

by bulbs, 20

by diseased refuse, 159,278

by dung-heap, 21 
Transmission of disease, by flies, 384, 411 by gardener's hose, 219,332

by grafts, 20, 469

by hail, 410

by lepidotera larvæ, 159

by molluses, 25,33

by nematodes, 33,181

by nursery stock, $62,385,469$

by pruning tools, 73,384

by seeds, $20,56,58,148,159$, $161,216,297$

by seedsman, $20,159,174$

by snails, 33

by soil, 21, 195, 469

by tubers, 278

by well-water, dew, or rain, 21 , 411

methods of control, 68

wind driven rain, 21,337

worms, 25, 410, 411, 469

Trap crops, 74

Tubercles and tumors in plants as a result of bacterial infection, 50, 389, 413

Tubeuf on intumescences, 631

Tumors, etiology of, more important than structure, 510

excessive movement of foodstuffs to vicinity of, 519,541

formed by bacteria, $50,389,413,558$

structure of, $51,424,425,427$, $428,429,430,431,454,455$, $464,465,467,470$

formed by ehemicals, 483,551

structure of, $491,492,493,494$, $495,497,501,503$

formed by freezing, 485 structure of, 505

formed by increase of acidity, 513, 531,543

formed by loss of water, 513

formed by nematodes, 543

structure of, 550

formed by oxygen-hunger, 513,531

formed by sand blast, 489

structure of, 507

formed by semi-asphyxiation, 496,515

formed by wounding, 489

formed in absence of parasites, 477509
Tumors, formed in sealed tubes, 502 figures illustrating, 520, 521, $522,523,524,526,527,528$, $529,530,540$

formed not by strong light, 496,539 formed on potato shoots in sealed tubes

figures illustrating, 532, $533,534,535,536,537$, $538,539,540$

formed on potato shoots in the open, $542,544,546,547,548$

general discussion of origin of, 510572

giant cells in, $543,545,550,565$

higher type of, 413,558

hyperplasial, non-parasitic, on potato, 506

in begonia, 502

in fig, 502

in leaves of grape, 491, 496

in mulberry, 502

literature, 572, 631

many classes of, 510

physical-chemical stimuli underlying, 510-572

secondary eauses, 511,566

stasis in tissues originating, 513,531 , 541

theory of cause, $511,555,566,568$

Turnips, black rot of, 145 . (See black rot of crucifers.)

Tyloses, origin of, 477

Uniten States, bacterial diseases found in, 54

\section{VACUUM pumps, 80}

Varieties resistant to disease, 75,135 , $149,295,377,383,386,387,410$, 411

Sensitive to disease, $167,277,290$, $291,377,410$

Vascular diseases, 132, 145, 160, 177 tissue invasion in, 10, 141, 166, 196

Velox printing paper, 122

Vine diseases in France and Italy, 66

Virulence, loss of, 19 symbionts and, 477 
Von Faber (F. C.), on Pavetta nodules, 45

Von Schrenk (H.), on intumescences, 483

Waite (M. B.), discovers transmission of pear blight by bees, 25 finds "hold over" blight, 360 photograph, 2

Wakker (J. H.), 2

Walnut blight, 473

in Chili, 55

in New Zealand, 55

in South Africa, 55

in Tasmania, 55

in United States, 55

Water-color drawings, 129

Water pores, infection through, 16, 21

Water pores, figures illustrating, 146, 147

Water, varying requirements of parasites for, 13

varying requirements of plants for, 113
Wehmer (C.), on potato rots, 264

West Indies, bacterial diseases found in, 52

Wheat, basal glume rot, $57,58,474$

black chaff of, $19,20,22,23,24,26$, $27,28,29,31,32,56,70,474$

White spot of alfalfa (physiological), 61

Willow,

disease of Japan, 53,474

disease of South Africa, 423

Wilt disease

of cucurbitaceæ in United States, 55,132

of potato and tomato in Africa, 54

of tobacco in United States, $\mathbf{5 5}$

Witch-broom, on pine, result of bacterial infection, 50

Woods' disease of carnation, 473

Wordsworth, citation from, 634

Worms, cause of tumors or galls, 543

YELLOW disease of hyacinths, 62

Zoologr, subsidiary study in plant pathology, 634 





LIBRARY OF CONGRESS IIII 